




\section{Allgemeine Biologie.}

Zweite Auflage des Lehrbuchs

„Die Zelle und die Gewebe“

\section{Oscar Hertwig}

Direktor d. anatomisch-biologischen Instituts der Universität Berlin.

Mit 371 Abbildungen im Text.

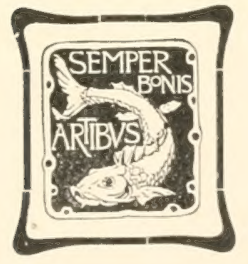

Verlag von Gustav Fischer in Jena.

1906. 
Alle Rechte vorbehalten. 
SEINEM FREUNDE UND KOLLEGEN

W. WALDEYER. 



\section{Vorwort zur zweiten Auflage.}

Nachdem schon eine Reihe von Jahren der erste Band vom Lehrbuch: „Die Zelle und die Gewebe“ vergriffen war, habe ich jetzt Zeit zur Veranstaltung einer zweiten Ausgabe gefunden. Dieselbe hat sehr eingreifende Veränderungen erfahren. Die beiden Bände der ersten Auflage waren in einem Zwischenraum von sechs Jahren erschienen, was manche Ungleichmäßigkeiten in der Darstellung mit sich gebracht hat. Diese mußten entfernt, und die zwei zu verschiedenen Zeiten entstandenen Hauptteile zu einem mehr einheitlichen und zweckmäßiger gegliederten Ganzen zusammengearbeitet werden. Auch war den zahlreichen, in 12 Jahren gemachten Fortschritten auf dem Gebiet der Morphologie und Physiologie der Zelle in gebührender Weise gerecht zu werden; ich erinnere nur an die Vertiefung des Reduktionsproblems, an die Synapsis, an die Merogonie, an die künstliche Parthenogenese, an die Keimplasmarelation, an die Lehren der physiologischen Chemie von den Agglutininen, Hämolysinen, Präzipitinen, den sogenannten biologischen Reaktionen, und an die Experimente über Vererbung erworbener Eigenschaften.

So muBten in der zweiten Auflage viele neue Tatsachen und Lehren aufgenommen, ganze Abschnitte vollständig umgearbeitet, namentlich im zweiten Teile eine Umgruppierung und andere Disposition vieler Kapitel vorgenommen werden. Man wird daher die verbessernde Hand fast auf jeder Seite wahrnehmen, so daß in der zweiten Auflage ein wessentlich verändertes Buch vorliegt. Auch äußerlich kommt dies darin zum Ausdruck, daß die beiden Bände der ersten Auflage jetzt zu einem Band zusammengefaßt sind und die Anzahl der Textfiguren von 257 auf 371 gestiegen ist.

Ich fand es zweckmäßig, der zweiten Auflage des Lehrbuchs zugleich auch einen neuen Titel zu geben und es "Allgemeine Biologie" zu nennen. Als „Allgemeine Biologie“ bezeichne ich die Wissenschaft, welche von zusammenfassenden Gesichtspunkten aus die Morphologie und Physiologie der Zelle und die großen, hiermit zusammenhängenden Fragen des Lebens: den elementaren Aufbau und die Grundeigenschaften der lebenden Substanz, die Probleme der Zeugung, der Vererbung, der Entwicklung, des Wesens der Spezies oder der naturhistorischen Art usw. behandelt.

Daf in der Darstellung und Auswahl des Stoffes noch viele Lücken bestehen, und dab der Inhalt einer allgemeinen Biologie, wie er mir vorschwebt, noch in sehr ungleichmäBiger Weise behandelt worden ist und noch mancher wichtigen Kapitel entbehrt, die hierher gehörten und zur Vervollständigung und Abrundung der Lehre vom Leben hätten aufge- 
nommen werden müssen, bin ich mir wohl bewußt, doch ich mußte mir, und dies mag zur Entschuldigung dienen, eine Beschränkung in der Auswahl und Verarbeitung des so außerordentlich umfangreichen, überwältigenden Lehrmaterials auferlegen, wenn anders sich das Erscheinen der zweiten Auflage nicht noch um Jahre verzögern sollte.

Grunewald b. Berlin, Oktober 1905.

\title{
Vorwort zur ersten Auflage des ersten Teiles.
}

\author{
Jedes lebende Wesen muß als ein Mikrokosmus \\ betrachtet werden, als ein kleines Universum, das aus \\ einer Menge sich selhst fortpflanzender Organismen \\ gebildet wird, welehe unbegreiflich klein und so zahl- \\ reich sind, als die Steme am Himmel."
}

Darwin. Das Variieren der Tiere und Pflanzen.

Wer die zahlreichen Lehrbücher der Histologie überblickt, wird finden, daß in ihnen viele Fragen, die in der wissenschaftlichen Forschung sich eines lebhaften Interesses erfreuen, kaum berührt werden, und daf manche Wissensgebiete, die mit der Histologie auf das engste zusammenhängen, von der lehrbuchmäßigen Darstellung mehr oder minder ausgeschlossen sind. Der Leser erfährt, wie die Zelle und die aus ihr hervorgehenden Gewebe unter dem Mikroskop je nach den verschiedenen Präparationsmethoden aussehein, aber er erfährt sehr wenig von den Lebenseigenschaften der Zelle, von den wunderbaren Kräften. welche in dem kleinen Zellorganismus schlummern und sich dem Forscher in so mannigfacher Weise bald an diesem, bald an jenem Untersuchungsobjekt in den Phänomenen der Protoplasmabewegung, der Reizbarkeit, des Stoffwechsels und der Zeugung offenbaren. Wer sich in dieser Richtung augenblicklich eine dem Stand der Wissenschaft entsprechende Vorstellung von dem Wesen des Zellorganismus verschaffen will, mub die Fachliteratur studieren.

Die Ursache hierfür ist leicht zu entdecken; sie ist hauptsächlich in der Trennung eines früher einheitlichen Lehrfaches in die Fächer der menschlichen Anatomie und Physiologie zu suchen. Die Scheidung der Lehrgebiete hat sich bis auf die Zelle ausgedehnt, nur ist sie hier, wie mir scheint, weniger angebracht. Denn die Trennung, welche für das Studium des menschlichen Körpers in vieler Hinsicht ein Fördernis und eine Notwendigkeit ist trotz mancher Nachteile, die sie naturgemäß auch mit sich bringt, ist für das Studium der Zelle nicht durchführbar und hat in Wirklichkeit nur dazu geführt, daß neben der Anatomie die Physiologie der Zelle, zwar nicht als Wissenschaft, aber doch als Lehrgegenstand, stiefmütterlich behandelt worden ist, und daß Vieles von dem Besten, was Forscherfleiß zutage gefördert hat, nicht in entsprechender Weise durch die Lehre weiter fruchtbar gemacht wird.

Mit dem vorliegenden Buch habe ich das gewohnte Geleise verlassen, und um dies äuferlich auch, anzuzeigen, zu dem Haupttitel, ,die Zelle und die Gewebe," noch den zweiten Titel „Grundzüge der allgemeinen Anatomie und Physiologie" hinzugefügt.

Wie von meinem Lehrbuch der Entwicklungsgeschichte, kann ich auch von dieser Arbeit sagen, daß sie in enger Fühlung mit meiner 
akademischen Lehrtïtigkeit entstanden ist. Der Inhalt des jetzt erscheinenden ersten Buches, in welchem ich ein zusammenfassendes liild von dem Bau und dem Leben der Zelle zu entwerfen versuche, hat zum groben Teil auch den Gegenstand für zwei öftentliche Vorlesungen ahgegeben. welche ich seit vier Jahren an der lierliner Universität unter dem 'Titel: „dic Zelle und ihr Leben" und .Theorie der 'Leugung und Vererbung gehalten habe.

Zu dem Antrieb, die oft mündlich von mir vorgetragenen Anschanungen anch im Druck einem weiteren Leserkreis mitzuteilen, gesellte sich als zweiter Antrieh noch der Wunseh. zugleich eine zusammenfassende

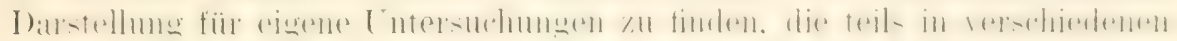
Zeitschiften zerstrent, teils in den mit meinem Bruder gemeinsam herausgegebenen sechs Heften. .zur Morphologie und Physiologie der Zelle ${ }^{\circ}$. erschienen sind.

Endlich habe ich noch ein drittes Noment hervorzuheben, welches mich bei der Abfassung geleitet hat. Die Grundzüge der .allgemeinen

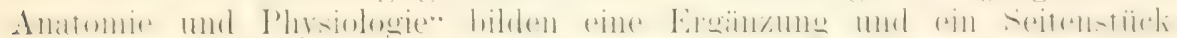

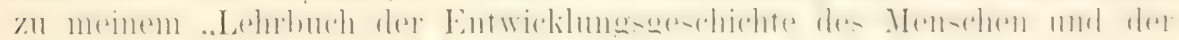
Wirheltiere:. In demselben habe ich die Gesetze darzustellen versucht. welche die tierische Formbildung beherrschen. die Gesetze. nach denen sich das Zellmaterial, welches durch fortgesetzte 'Teilung aus der befruch-

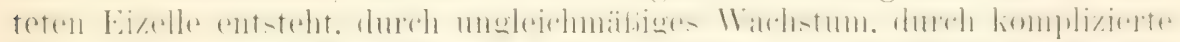

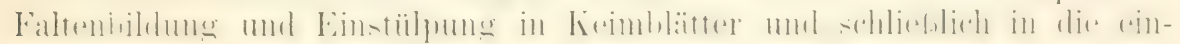
zelnen Organe sondert.

Tehen der Massenverteilung und Anordnung des Zellmateriales oder neben (ler morphologischen Differenzierung spielt sich num aber im Entwicklungsleben noch eine zweite Reihe von Prozessen ab, welche man als die histologische Differenzierung zusammenfassen hann.

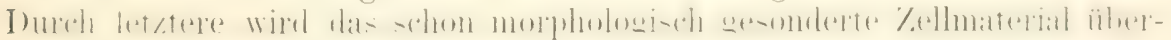
haupt erst in den Stand gesetzt, die verschiedenen Arbeitsleistungen zu rerrichten, in welche sich der Lebensprozeh des fertig entwickelten Gesamtorganismus zerlegen läbt.

In ..Lehrbuch der Entwicklungsgeschichte" konnte anf die zweite,

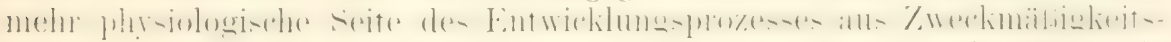
gründen nicht näher eingegangen werden. Insofern bildet die Anatomie und Physiologie der Zelle und der Gewebe, wie ich oben sagte, eine notwendige Ergänzung und ein Seitenstïck zu ihm. Dies wird dem Leser schon in dem ersten hier vorliegenden t'eil des Lehrbuchs, welcher allein die Zelle zum Gegenstand hat, bemerkbar werden. Denn nicht nur findet sich im VII. (jetzt XI.) Kapitel eine ausführliche Darstellung der Anatomie und Physiologie der Zeugung, welche in letzter Instanz, wie des Nähreren ausgeführt ist. „ein reines Zellenphänomen“" ist; sondern es handelt auch noch am Schlusse das XI. (jetzt XIII.) Kapitel, betitelt ..die Zelle als Anlage eines Organismus". ausführlich ron den älteren und neneren Vererbungstheorien.

Toch mehr aber wird der zweite 'Teil des Buches. wehcher die Lehre ron den Geweben unfast und etwa den gleichen Unfang wie der erste Teil erreichen wird, eine Erginzung zur ..Entwicklungsueschichte" bilden. Denn es wird in ihm neben (ler bescheibung der (iewehe ein hesonderes

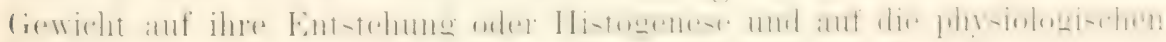
Ursachen der Gewebebildung gelegt werden: damit wird auch die zweite

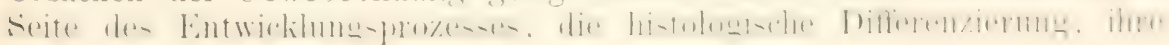
Darstellung finden. 
Wissenschaftliche Gesichtspunkte sind es in erster Linie gewesen, welche mich bei der Darstellung, die ich, so weit es möglich ist, zu einer

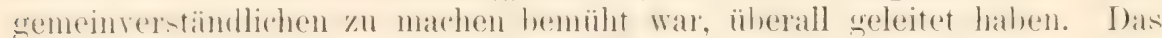
wenigstens nach besten Kräften angestrebte Ziel war mir, den wissen-

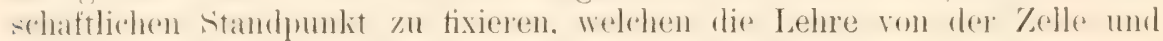
den Geweben augenblicklich einnimmt.

Für wichtigere Theorien habe ich ein Bild ron ihrem historischen Entwicklungsing zu entwerfen versucht: in shwebenden streitfragen habe ich oft die verschiedenen Meinmong amander gegenïhergestellt. Wenn in der I)arstellung, wiewohl naturgemibi., meine Auffassung ron der \%elle in den Vordergrund tritt, und wemn ich dabei hier und dort von den Ansichten mal Dentmen hervorragender mol von mir hochgeschätater Forscher ahweiche, so glaube ich ihnen das fieständnis zu schulden, dali ich darum weder die ron mir hevorzugte Auftassung fïr die unherlingt richtige halte. noch viel weniger aber von entwegengesetzten Auffassungen gering denlie. Demm der fiegensatz der Meinumen ist zum Leben unl zur Entwillinng der Wissenschaft notwendig; und wie ich in verschiedenen historischen Exkursen habe durchblicken lasien. schreitet gerate in Widersuruch der Meinmgen und Beohachtungen die Wissen-chaft am raschesten und erfolgreichsten vorwärts. Wie in unserer Natur begründlet ist, sind fast alle lieohachtungen und die aus ihnen gezorenen schlïse einseitig und sind daher fortwährend einer Korrektur bedürftig. Wie sehr aber mub dies der Fall sein bei dem (iegenstand vorliegender Lntersuchung, hei der Zelle. welche sellst ein wunderhar lomplizierter Organismus ist. .ein lileines

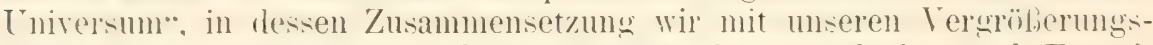
shïsern. mit chemisch-physikalischen L'ntersuchungsmethorlen und Experimenten nur mühsam einzudringen vermögen.

Berlin, Oktober 1892.

\title{
Oscar Hertwig.
}

\section{Vorwort zur ersten Auflage des zweiten Teiles.}

\author{
La science ne consiste pas en faits, mais tans \\ les conséquences, que l'on en tire. \\ Claude Bernard.
}

Dem im Jahre 1893 erschienenen ersten Teil meiner allgemeinen Anatomie und Physiologie hahe ich den zweiten Teil nicht so bahl, als ur-prünglich healsichtigt war. folgen lassen kömnen, wie ich hotte. nicht zum Sidharlen des vorliegenden Buches. Demn die fünf Jahre, dic seitrlem vertiossen sind, zeichnen sich gerade durch fruchthringende Forschungen und Disku-sionen äher (irundfragen der allgemeinen Anatomie und P'hrsiologie und manentlich ïher solche aus. welche einen wesentlichen Inhalt dieses Buches ausmachen.

Der Umstand, daß ich selbst in die Diskussion mit verwickelt wurle, ist die eigentliche Irsache der angetretenen Panse gewesen. Ich habe sie benutzen müs-en, mm mich in meinen ..Zeit- nnd streitfragen der Kiologie* 
mit weit verbreiteten Ansichten anseinander zu setzen, mit welchen nach

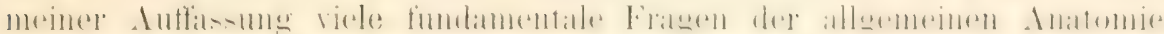
und Phrsiologie nicht in Einklang zu bringen sind.

In der Schrift: "Präformation oder Epigenese! Crundzüge einer

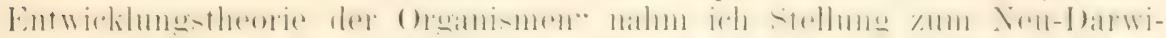
nismus, wie man häufig die Richtung bezeichmet. welche WEISMAÑ in

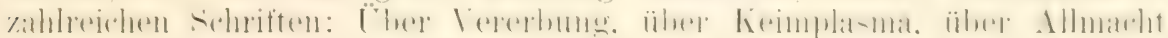
der Naturitichtung, über Germanialselelition ete., vertritt. In der zweiten

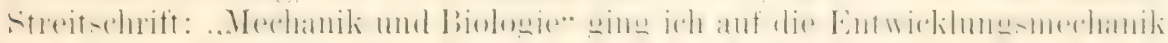

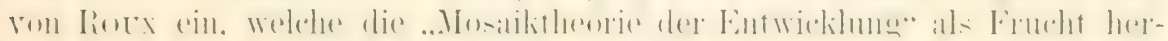
vorgebracht hat.

So gehören jene beiden Schriften mit zu den Vorarbeiten für den zweiten 'Teil des Lehrbuchs. Mit seiner Verötfentlichung glaube ich das Programm erfült zu haben. welches ich 189:3 im Volwort zur ..Zelle*

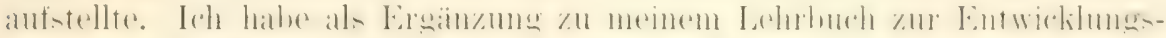
geschichte jetzt auch die physiologische Seite des Entwicklungs-

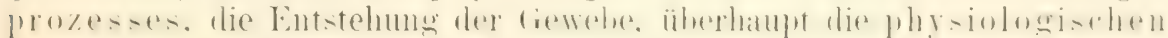
Ursachen der Gewebe- und Organbildung nach den verschiedensten Richtungen erörtert.

Wer den Inhalt der einundzwanzig Kapitel übersieht, wird finden,

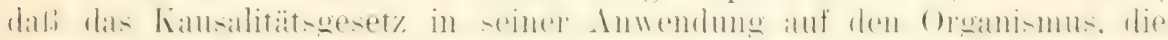

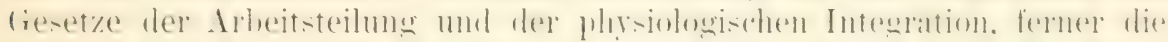

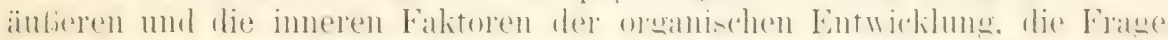
endlich nach der Vererbung neu erworbener Eigenschaften und das biogenetische Grumdgesetz eingehend besprochen werden. Hierbei war es

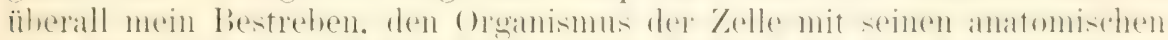

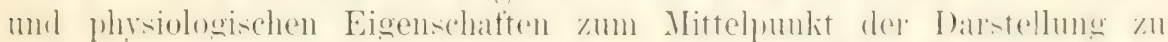
machen und in ihm die Grundlage zum wissenschaftlichen Aushau einer

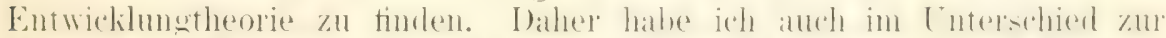

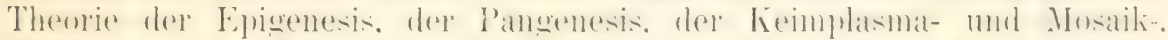

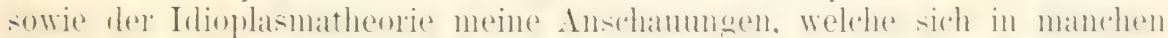
Zügen von denen anderer Forscher unterscheiden, als die 'Theorie der

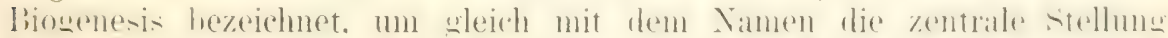

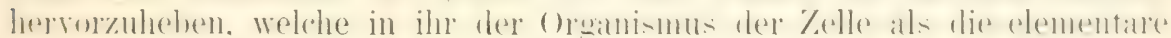
Lebenseinheit der organischen Schöpfing einnimmt.

Eine grobe Fülle von Tatsachen, welche in den Zeitschriften der

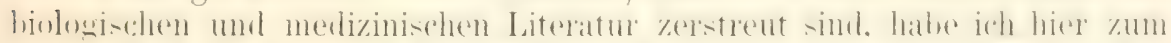

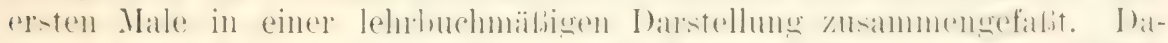

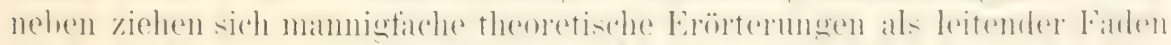

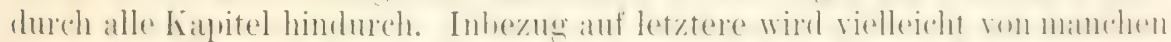

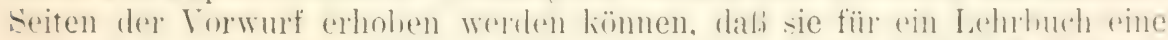

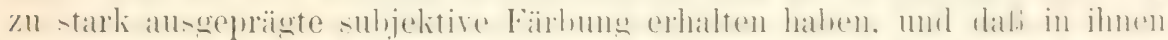

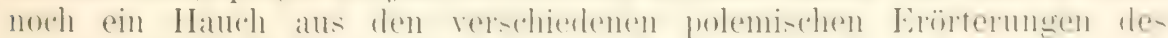
letzten Jahrzehnts hindurchzieht.

Auch ich fühle dies. wemn ich als möglichst objektiver Kritilier mich

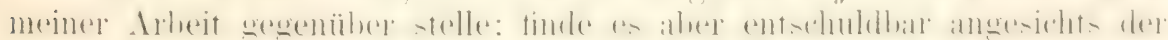
zurzeit herrschenden Gegensätze, welche ihrer Natur nach nicht zu überbrüclien sind, und in anbetracht des Umstandes, dab es sich um Fragen

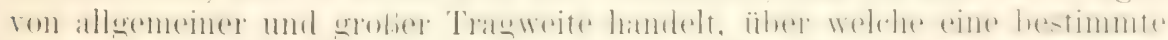

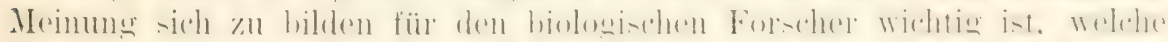

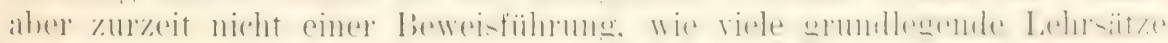
der Physik und Chemie, zugänglich sind. Auch glaube ich, dab den Vor-

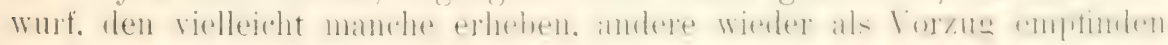




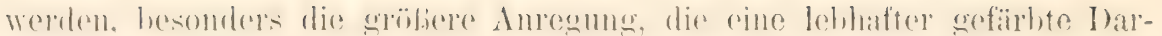
stellung zur Beschäftigung mit den vorliegenden Problemen gibt.

Jedenfalls aber wirl. wie ich hoffe. auch der Ieser. welcher den oben besprochenen Tadel erhoben hat, auf der andern Seite anerkennen, daß ich bei allen theoretischen Erörterungen das durch Beobachtung und Experiment erelieferte Tatsarhemmaterial als Auswang mod cirmullage hemutzt habe, daß ich auf Grund desselben mir in allen Fragen einen eigenen Standpunkt zu bilden bemüht war, und daß ich zum ersten Male Grundfragen der allgemeinen Anatomie und Physiologie, widetige beohachtungen mon Experinente. welche in andern I,ehrbüchern gewöhnlich keinen Platz finden. zum diegenstand einer zusammenhängenden. in sich gerdho-senen,

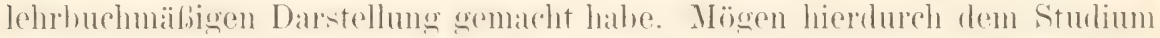
(ler allgemeinen Anatomie und Physiologie, welche viele zu kräftiger Entfaltung bereite Keime in sich trägt, Freunde und erfolgreiche Mitarbeiter gewonnen werden.

Berlin, im März 1898.

Oscar Hertwig. 


\section{Inhalt.}

\section{Erster II atutteil. \\ Die Zelle als selbständiger Organismus.}

Erstes Kapitel. Geschichtliche Einleitung Die (ieschichte der /sellentheorie

Die feschichte der Protoplasmatheorie

Literatur zu Kapitel I

\% weites Kitpitel. Die chemisch-physikalischen und morphologischen Eigenschaften der \%elle

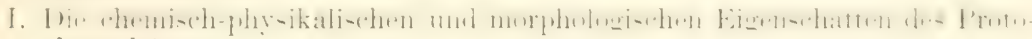
plasmakörpers

a) Begrifi des Protoplasmas und seine Berechtigung

b) Charakteristik des I'rotoplasmas in physikalischer, chemischer und morphologischer Bezichung

c) Protoplasmastruktur

Drittes Kapitel. II. Dic chemisch-physikalischen und morphologischen Eigenschaften des Zellkerns (Nucleus)

a) Form, Gröbe und \%ahl der Kerne

b) Die Kernsubstanzen

c) Die Kernstruktur. Beispiele für die verschiedene Beschaffenheit clerselben

III. Ciibt es kernlose Elementarorganismen

IV. Die Zentralkörperchen (Centrosomen) der Zelle

$\checkmark$. Hvpothesen iiber die Elementarstruktur der Zelle

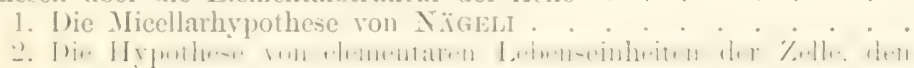
Bioblasten

Literatur zu Kapitel II und III

Piertes Lapitel. Die Lebenseigenschaften der Kelle

1. Stoffweehsel und formative lätigkeit .

Alleremeine Charakteristik

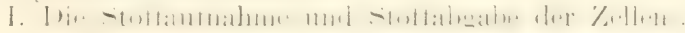

1. Die Anfmahme und Abgabe gasfömmiger Stoffe

2. Die Autnahme und Abgabe flüssiger stoffe .

3. Die Aufnahme fester Kïrper

II. Die Stoffumsetzung und die formative Tätigkeit der Zelle .

1. Die Chemie des Stoffumsatzes.

2. Kur Morphologrie des Stoffumsatzes. Die formative Tätignkeit der '/elle.

a) Die inneren Plasmaprodukte

b) Die äulBeren Plasmaqrodukte.

Literatur zu Kapitel $1 V^{\gamma}$

Fünftes Kapitel. Die Lebenscigenschaften der Kelle

II. Die Jewegungserscheinungen.

1. Die P'rotoplasmabewegung

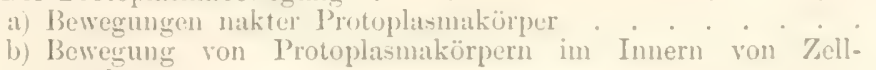
membranen

c) Erklärungsversuche der Protoplasmabewegung . 
2. Die GeiBel- and Flimmerbewegung . . . . . . . . . . 11 \%

a) Zellen mit Geißeln . . . . . . . . . 11s

b) Zellen mit vielen Flimmern . . . . . . . . . . 1:1

3. Die kontraktilen Vakuolen oder Behälter einzelliger Organismen 12f;

4. Verïnderung des Zellkörpers durch passive Bewegung . . . . 12̌s

Literatur zu Kapitel V. . . . . . . . . . . . . . . . . . 129

Sechstes Kapitel. Die Lebenseigenschaften der Kelle . . . . . . . . . 1:31

III a. Das Wesen der Reizerscheinungen . . . . . . . . . . . . . 131

Das Kausalitätsgesetz in seiner Anwendung auf den Organismus . . 1.92

Verschiedene Formen der Kansalität . . . . . . . . . . . . . 1333

Die Bedeutung der vielen Úrsachen . . . . . . . . . . . 13:

Unterschiede zwischen Maschinenwesen und 'Organismus, zwischen

Mechanischem und Organischem . . . . . . . . . . 111

Litcratur zu Kapitel VI. . . . . . . . . . . . . 113

Siebentes Kapitel. Die Lebenseigenschaften der Kelle . . . . . . . . 144

$11 \mathrm{l}$ b. Untersuchung der einzelnen Reizarten . . . . . . . . . . . . . 144

1. Thermische Reize . . . . . . . . . . . . . . . . 144

2. Lichtreize . . . . . . . . . . . . . . . . 149

3. Elektrische Reize . . . . . . . . . . . . . . 15t

Erscheinungen des Galvanotropismus . . . . . . . . . 1.j)

4. Mechanische Reize . . . . . . . . . . 15s

5. Chemische Reize. . . . . . . . . . . . . . . . . . 159

a) Erste Gruppe ron Versuchen.

C'hemische Einwirkmugen, die ron allen siden den Zellkörper treffen

b) Ziweite Gruppe von Versuchen.

Chemische Einwirkungen, die in einer bestimmten Richtung den Zellkörper treffen

1. Gase

2. Flïssigkeiten

\section{Literatur zu Kapitel VII}

Achtes Kapitel. Die Lebenseigenschaften der Zelle. . . . . . . . . 16!?

IV. Die Fortpflanzung der Zelle auf dem Wege der Teilung. . . . . . . 1fi!

Geschichte der Zellentstehung . . . . . . . . . . . 1693

ler Prozels der Kernteilung und seine rerschiedenen Arten . . . 171

1. Die Kernsegmentierung. Mitose. Karyokinese. . . . . . . 171

a) Zellteilung bei Salamandra maculata . . . . . . . . 1:3

Pro-Phase. Vorbereitung des Kerns zur Teilung. . . . . $17: 3$

Metaphase der Teilung . . . . . . . . . . 17.5

Anaphase der Teilung . . . . . . . . . . . 176

Telophase der Teilung . . . . . . . . . . . 17i

b) Teilung der Eizellen von Ascaris megalocephala . . . . . 1is

c) Teilung der Eier von Echinodermen . . . . . . . . 18if

d) Teilung pflanzlicher Zellen. . . . . . . . . 185

c) Beispiele von karyokinetischen Teilungsfiguren bei einzelligen Organismen . . . . . . . . 18\%

f) Historische Bemerkungen, strittige Fragen und eigentümliche Sonderfälle der Kernsegmentierung. . . . . . . . 191

Chromatindiminution . . . . . . . 199

g) Allgemeine Probleme der Kernsegmentierung . . . . . 201

1. Das proportionale Kernwachstum . . . . . . . . ำ1

2. Das Zahlengesetz der Chromosomen . . . . . .

3. Die Theorie der Chromosomenindividualitait . . . . . .

4. Die Bedeutung der ganzen Karyokinese . . . . . 201s

2. Die Kernzerschnürung (direkte Kernvermehrung, Fragmentierung,

Amituse) . . . . . . . . . 20.99

3. Endogene Kernvermehrung oder Vielkernbildung $:-213$

Becinflussung der Kernteilung durch äußere Faktoren. Abnorme Kern-

teilungsfiguren. Kerndegenerationen. . . . . . . . . . . . 214

Literatur zu Kapitel VIII . . . . . . . . . . . . . . . . . . . . . . .

Neuntes Kapitel. Die Lebenseigenschaften der Kelle . . . . . . . . . ...5

Verschiedene Arten der Zellvermehrung und experimentelle Abänderung

de- Terlaufs der Zellteilung. . . . . . . . . .

1. Allgemeine Regeln. . . . . . . . . . . . . . 225 
2. Ühersicht der Arten der Zellteilung .

I i. Die äquale T'eilung .

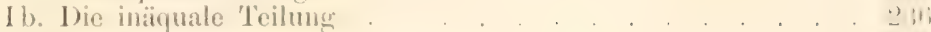

I c. Die Knospung. . . . . . . . . .

II. Partielle T'eilung . . . . . . . . . . . . . .

III. Die Vielzellbildung . . . . . . . . . . . . . .

3. Experimentelle Abänderung der 'kellteilung . . . . . . . . ㅡ:

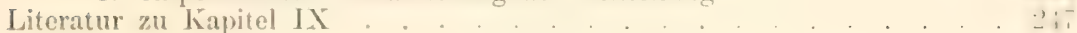

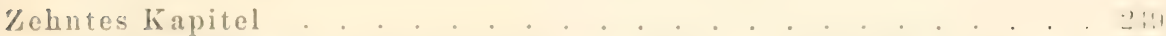

I. Wechselwirkungen zwischen P'rotoplasma, Kern und \%ellprodukt . . . 2:?

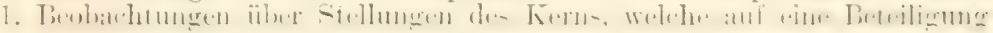
bei formativen und nutritiven prozessen hinweisen

2. Experimente, aus denen sich auf eine Wechselwirkung zwischen Kern und Protoplasma schließen lälit

II. Die Kermplasmarelation

III. Das Problem von der Lrzeugung der Kelle

Literatur zu Kapitel X.

Elftes Kapitel. Die Erscheinungen und das Wesen der Befruchtung

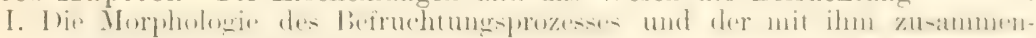
hängenden Ei- und Samenreife

1. Die Befruchtung und Reifung der Geschlechtszellen im Tierreich . .

A. Die Befruchtung des Eies . . . . . . . . . . . . . …

a) Echinorlermeneier . . . . . . . . . . . . . .

b) Ascaris megalocephala . . . . . . . . . . . . . . . .

B. Der Reifeprozel ron Ei- und Samenzelle . . . . . . . . .

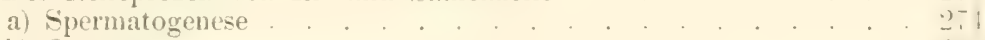

b) Oogenese . . . . . . . . . . . 2.4.

c) Theoretische Betrachtungen . . . . . . . . . . . . . 22-1

C. Übersicht über Modifikationen der Reife- und Befruchtungserscheinungen im Tierreich und strittige Fragen

I. Das Reduktionsproblem

a) Die cumitotische Reifungsteilung

b) Die pseudomitotische Reifeteilung .

II. Beobachtungen, betreffend das weitere Schicksal des beim Befruchtungsakt vereinten väterlichen und mütterlichen Chromatins des Keimkerns

a) Die Autonomie des väterlichen und mütterlichen Chromatins

b) Die Synapsis

2. Die Befruchtung der Phanerogamen

3. Die Befruchtung der Infusorien

4. Die rerschiedene Form der Geschlechtszellen. Die Iquivalenz der beim Keugungsakt beteiligten Stoffe und die Begriffe ,männliche und weibliche Geschlecht-zellen"

5. Die Ur- und Grundformen der geschechtlichen Zeugung und das erste Hervortreten von Geschlechtsdifferenzen

Literatur zu Kapitel XI

Zwölftes Kapitel

II. Die Physiologie des Befruchtungsprozesses

\section{$-2-2$}

a) Die normale Parthenogenese . . . . . . . . . . . . 321

b) Die Merogonie . . . . . . . . . . . . . . . 325

c) Künstliche oder experimentelle Parthenogenese . . . . . . . 326

d) Die Apogamie . . . . . . . . . . . . . . . . . .

‥ Die sexmelle Affinität . . . . . . . . . . . . . 32!

a) Die sexuelle $\Delta$ ffinität $\mathrm{m}$ allgemeinen . . . . . . . . 330

b) Die sexuelle Affinitat im einzelnen und ihre verschiedenen $\mathrm{Ab}$ stufungen

(a) Die Selbstbefruchtung

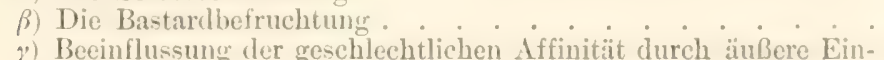
uriffe

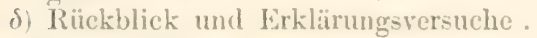

Literatur zu Kapitel XII 
Oreizehutes Kapitel Die "zelle als Anlage eimes Organismus .

I. Geschichte der älteren Entwicklungstheorien _. . . 3,i)

II. Nenere Keugungs- und Entwicklungstheorien . . . . . . . . . . . . 3.1.)

III. Der Kern als Träger der crblichen Anlagen . . . . . . . . . . . 3.)

1. Die Äquivalenz der männlichen und der weiblichen Erbmasse . . . : :.).

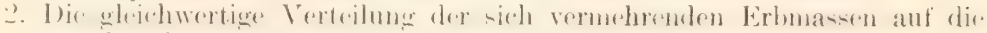
aus dem befruchteten Li hervorgehenden Vellen

3. Die Verhütung der Summierung der Erbmassen

4. Die Isotropie des Protoplasmas

IV. Die Entfaltung der Anlacen.

Literatur zu Kapitel XIII

\section{Zweiter Haupteil.}

\section{Die Zelle im Verband mit anderen Zellen.}

Vierzehntes Kapitel. Dic Individualitätsstufen im Organismenreich

I. Die organischen Individuen erster Ordnung

II. Die organischen Individuen zweiter Ordnung

1. \%ellkolonien

2 Durch innigen \%ellverband entstandene mehrzellige ( )rganismon (Personen

a) Srmeytien oder Kellfusionen

b) Der zellige Verband

III. Die organischen Individuen dritter Ordnung

1. Stöcke von mehr locker verbundenen Personen

2. Stöcke von fester verbundenen und zugłeich verschieden differenzierten Personen

Literatur zu Kapitel XIV

Fiinfzehntes Kapitel. Artgleiche, symbiontische, parasitäre Zellvereinigung.

I. Artgleiche Vereinigung

Die Lehre von der vegetativen Affinität

II. Die symbiontische Vereinigung (Srmbiose)

III. Die parasitische Vereinigung

Literatur zu Kapitel XV

Sechszehntes Kapitel. Mittel und Wege des Verkehrs der Zellen im Organismus

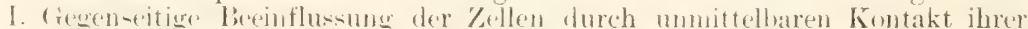
Oberflächen

II. Verbindungen der einzelnen Zellen durch Protoplasmafäden (Interzellularbrückent

1. Histologische Befunde .

2. Die physiologische Bedeutumg

Reizleitung und Stofftransport durch Protoplasmaverbindungen

III. Verbindungen der Zellen durch Nervenfibrillen

IV. Verkehr der Zellen durch die im Organismus zirkulierenden Säfte Literatur zu Kapitel XVI

Siebzehntes Kapitel. Die Theorie der Biogenesis

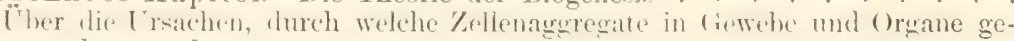
sondert werden

1. Erstes Gesetz. Die Wichtigkeit konstanter Verhälnisse für die Ausbildung besonderer Funktionen und Strukturen an den Zellen. (Spezifische Energie)

2. Zweites Gesetz. Die Wichtiokeit der Wechselwirkung mit anderen Zellen für die Ausbildung besonderer funktion und Struktur in einer Zelle. (Gesetz (ler physiologischen Arbeitsteilung')

a) Die Arbeitsteilung in der menschlichen Gesellschaft als Vergleichsobjekt

b) Die Arbeitsteilung im Zellenaggregat

$\therefore$ Drittes Gesetz. Entsprechend dem Grad ihrer Differenzierung wird die einzelne Zelle zu einem unselbständigen und abhängigen Teil einer iibergeordneten Lebenseinheit. (Giesetz der phrsiologischen Integration) Über die doppelte Stellung der Zelle als Elementarorganismus und als determinierter und integrierter Teil eines übergeordneten, höheren Organismus 
Achtzehntes Kapitel. Die Lehre von der Spezifizitit der Zellen, ibren Metamorphosen und ihren versehiedenen /uständen

a) Die Lehre von der Spezifizitït der Gewebszellen

b) Verschiedene /ustände und Modifikationen der artgleichen /celle Hypertrophic, Atrophic, Metaplasie, Hyperplasie, Nekrose.

A. Erste Grimple. Der veränderte '/ustand der Gewebe äuBert sich nur in der Beschalfenheit der P'rotoplasmaprodukte

1. Die Hypertiophie der Gewebe

2 . Die Itrophic der Gewebe

3. Funktionswechsel. Metamorphose und Metaplasie der Giewebe a) Die physiologische Gewebsmetamorphose . . . . . . . . 11:

b) Die pathologische Gewebsmetamorphose

B. Kweite Gruppe. Der verinderte Kustand der Gewebe iulbert sich außer in der Beschaffenheit der Protoplasmaprodukte auch in der Beschaffenheit vou Protoplasma und Kern

1. Wucheratrophie

5. Hyperplasie

6. Degeneration und Tod der Kelle (Nekrose)

Literatur zu Kapitel XVIII

Seunzehntes Kapitel. Besprechung der Keimplasmatheorie von WEIsMxy Literatur zu Kapitel XIX

Kwanzigstes Kapitel. Die Theorie der Biogenesis

I. Die äußeren Faktoren der organischen Entwicklung

1. Die schwerkraft

2. Die Zentrifucalkraft

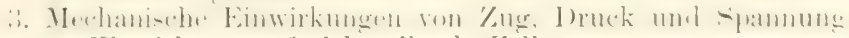

a) Einwirkung auf sich teilende Zellen

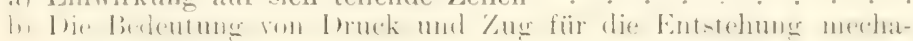
nischer (iewebe

a) Die mechanischen Eimrichtungen bei Pflanzen .

B) Die mechanischen Eimrichtungen bei Tieren

Literatur zu Kanitel XX.

Einnudzwanzigstes Kapitel. Die äußeren Faktoren der organischen knt-

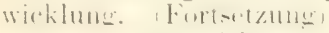

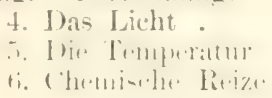

a) Beeinflussung bei Pflanzen

b) Beeinflussung bei Tieren

7. Reize zusammengesetzter Art

8. Organische Reize, die in Einwirkungen zweier Organismen aufeinander bestehen .

a) Pfropfung und Transplantation P'fropflyybride

b) Wechselwirkungen "wischen Embryo und Mutterorganismus

e) Organismen als Ursachen von Gallen und krankhaften Geschwiilsten Literatur zu Kapitel XXI

/Weiundzwanzigstes Kapitel. Die Theorie der Biogenesis.

II. Die inneren Faktoren der organischen Entwicklung

A. Dic Korrelationen der Zellen während der Anfangstadien des Entwicklungsprozesses

Literatur zu Kapitel XXII

Dreiundzwanzigstes Kapitel. Die inueren Faktoren der organischen Entwicklung. (Fortsetzung.)

B. Die Korrelationen der Organe und Gewebe auf späteren Stadien der Entwichlung und im ausgebildeten Organismus

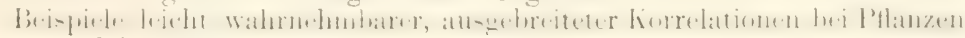
und bei Tieren

Einteilung der Korrelationen in einzelne Gruppen

1. Chemische Korrelationen.

a) Chemisch-physikalischer Prozeß der Sanerstoffaufinhmo und Kohlensäureabgabe

b) Harnbildung. Niere.

(.) 1)i. 1..1n l. 
2. Mechanische Korrelationen Mechanomorphosen)

a) Mechanomorphosen aktiv beweglicher Organe und Gewebe . 535

b) Mechanomorphosen passiv beweater Organe und Gewebe . .;:;

Literatur zu Kapitel XXIII.

Vierundzwanzigstes Kapitel. Die inneren Faktoren der organischen Entwicklung. (Fortsetzung.)

3. Die Erscheinungen der Regeneration

4. Die Erscheinumgen der Heteromorphose

Literatur zu Kapitel XXIV

Fünfundzwanzigstes Kapitel. Die im Organismus der Zelle enthaltenen Faktoren des Entwicklungsprozesses . . . . . . . . . . .

I. Die in den Spezialeigenschaften von Ei- und Samenzelle gegebenen besonderen und mehr untergeordneten Faktoren des Entwicklungsprozesses

II. Ei und samenfalen als gleichwertige Träger der Arteigenshatten. Das Idioplasma als innerer Faktor des Entwicklungsprozesses. . . . . . .

a) Erste Periode in der Eientwicklung . . . . . . . . . iti

b) Zweite Periode in der Eientwicklung. . . . . . . . . .

c) Die dritte Periode in der Eientwicklung . . . . . . . . . . . Jfit

Literatur zu Kapitel XXY . . . . . . . . . . . Jffit

Sechsundzwanzigstes Kapitel. Hypothesen über die Eigenschaften des Idioplasmas als des Trägers der Arteigenschaften. Das Problem der Vererbung. . . . . . . . . . . . . .

I. Vererbung ererbter Eigenschaften. Die Kontinuität der Generationen .

Siebenundzwanzigstes Kapitel. Das Problem der Vererbung. (Fortsetzung.)

II. Vererbung neuerworbener Eigenschaften.

III. Weitere Folgerungen Literatur zu Kapitel XXVI und XXVII

Achtundzwanzigstes Kapitel. Ergänzende Betrachtungen . . . . . . IIP

I. Die Biogenesistheorie und das biogenetische Grundgesetz. . . . . . . .92

I1. Das Prinzip der Progression in der Entwicklung . . . . . . . . 5.? Literatur zu Kapitel XXVIII

Neunundzwanzigstes Kapitel. Erklärung der Unterschiede pHlanzlicher und tierischer Form durch die Theorie der Biogenesis

I. Die Formbildung bei den Pflanzen

II. Die Formbildung bei den Tieren

Die Gesetze der tierischen Formbildung.

1. Ungleiches Wachstum einer Epithelmembran.

2. Auscheriden von Zellen und Zellaggregaten aus dem eprithelialen Verband

3. Verschiedenartige Differenzierung der Zellen infolge von Arbeitsteilung Literatur zu Kapitel XXIX

Dreißigstes Kapitel. Historische Bemerkungen über die Stellung der Biogenesistheorie zu andern Entwicklungstheorien

I. Die Theorie der direkten Bewirkung. Der Lamarckismus

II. Die Lehre von der Übertragung erworbener Eigenschaften auf den Keim. (l) Te Terloungstheorit-)

Einunddreißigstes Kapitel. (Fortsetzung.)

III. Die Kontinuität im Entwicklungsprozeß .

A. Die durch Beobachtung festgestellten Tatsachen.

I) Hypothen äher die Kontinutatit in Entwicklungerered? Erste Gruppe .

1. Die provisorische Hypothese der Pangenesis ron DARWIX.

2. Galtons Theorie vom Stirp

3. Herbert Spexcers Hypothese von den physiologischen Einheiten

4. Die Idioplasmatheorie ron NigeLI Zweite Gruppe

'Zusammenfassung der Hauptgesichtspunkte der Theorie der Biogenesis Literatur zu Kapitel XXX und XXXI. 


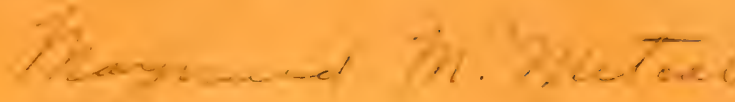 \\ intone ifiof \\ Allgemeine Biologie.}

Zweite Auflage des Lehrbuchs

„Die Zelle und die Gewebe“"

\section{Oscar Hertwig}

Direktor d. anatomisch-biologischen Instituts der L'niversität Berlin.

Mit 371 Abbildungen im Text.

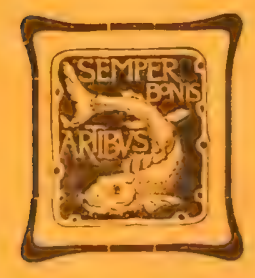

Verlag von Gustav Fischer in Jena.

1906. 
Die Entwidkelung der Biologie im 19. Jahrbundert. Vortrag gehalten

lung dentscher Naturforscher zu Aachen am 17. September 1900 von Dr. Osear Hertwig, Prof. der Anatomie und Direktor des II. anatomischen Instituts an der Universitït in Berlin. J900. Preis: 1 Mark.

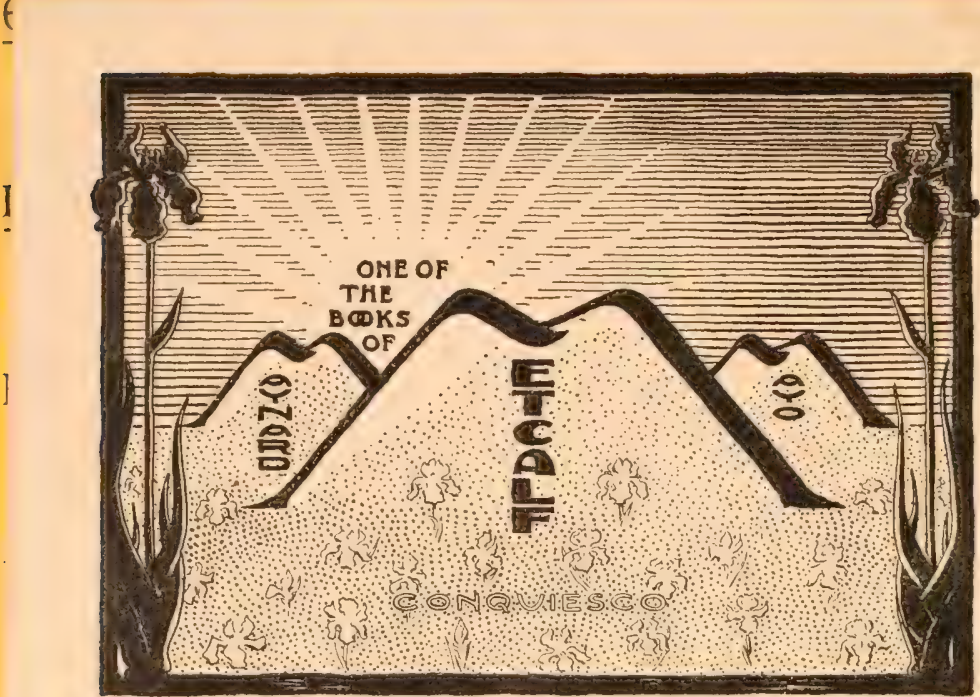

)re.

isen). ii. rlin.

ial. It11:mite 8949.

Ini-

sitït gilst ituts

Prof. Dr. F. Keibel, Freiburg i. Br., Privatdozent Dr. Rud. Krause, Berlin, Prof. Dr. Wilh. Krause, Berlin, Prof. Dr. v. Kupffer, München, Prof. Dr. Maurer, Jena, Prof. Dr. Mollier, München, Privatdozent Dr. Peter, Würzburg, Dr. H. Poll, Berlin, Prof. Dr. Rückert, München, Prof. Dr. Schauinsland, Bremen, Prof. Dr. Strahl, Giessen, Prof. Dr. IV aldeyer, Berlin, Prof. Dr. Ziehen, Berlin. Hernusgegeben vou Dr. Osear Hertwig, o. ö. Professor, Direktor des anatonisch-biologischen Instituts in Berlin. Vollständig in etwa 25 Lieferungen zu je 4 Mark 50 Pf., welche in rascher Folge erscheinen sollen. Bisher erschien Lieferung 1-24.

Die Glemente der Entwidklungslebre des Menschen und der Zirbel-

tiere. Anleitung and Repetitorium für Studierende und Aerzte. Von Oscar der Universität Berlin. $Z /$ weite $A$ uf $l$ age. Mit 373 Textabbildungen. Preis: 8 Mark, geb. 9 Mark.

Cebrbuch der Zoologie. Von Dr. Richard Hertwig, o. ö. Prof. der Zoologie Si ben vergleichende Anatomie an der Universitat Munchen. Piebente ungeabeitete A uflage. Mit 581 Abbildungen im Text. 1905. Preis: brosch. 11 Mark 50 Pf., geb. 13 Mark 50 Pf.

MLorphologie und Biologie der Zelle. Von Dr. Alexander Gurwitsch,

Mit 239 Abbildungen in Text. Preis: 9 Mark, geb. 10 Mark.

Anatomischer Anzeiger, XXV, Nr. 16/17 rom 27. September 1904:

Wenn auch für die "Anfänger" bestimmt, wird das Buch auch erfahrenen Histologen und über diese Krreise hinaus von Interesse und Nutzen sein. Die Ausstattung ist in gewohnter W Weise musterhaft, der Preis außerordentlich niedrig. 
ERSTER HAUP'T'PEIL.

Die Zelle als selbständiger Organismus. 



\section{ERSTES KAPITEI.}

\section{Geschichtliche Einleitung.}

'Tiere und Pflanzen, so verschiedenartig in ihrer äuferen Erscheinung.

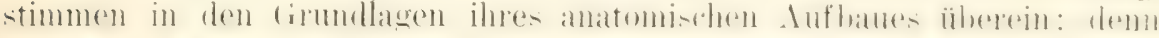

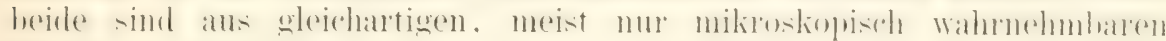
Elementareinheiten zusammengesetzt. Man bezeichnet die letzteren einer jetzt verlassenen, älteren Theorie zuliebe als Zellen. sowie die Lehre, daf Tiere und Pflanzen in äbereinstimmender Weise ans solchen kileinsten Teilchen bestehen. als die Zellentheorie.

In der Zellentheorie erblickt man mit Recht eines der wichtigsten

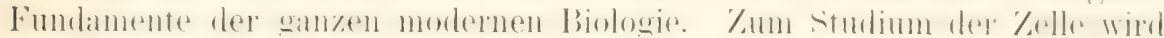

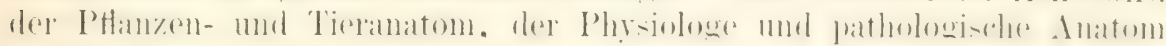
auf Schritt und Tritt hingeleitet. wenn er tiefer in das Wesen der normalen und der krankhaften Lebensprozesse eindringen will. Denn die Zellen, in welche der Anatom die ptlanzlichen und tierischen Organismen zerlegt, sind die Träger der Lebensfunktionen: sie sind, wie VIRchow sich ausgedrickt hat, die Lebenseinheiten.

Yon diesem Gesichtspunkt aus betrachtet, erscheint der Gesamtlebensprozeb eines zusammengesetzten Organismus nichts anderes zu sein als das höehst verwickelte Resultat der einzelnen Lebensprozesse seiner zahl-

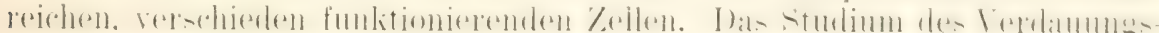
prozesses, der Muskel- und Nerrentätigkeit führt bei tieferem Eindringen

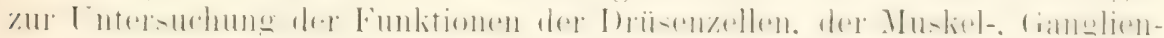
und Sinneszellen. Und wie die Physiologie ihre Findamente in der Zellentheorie gefunden hat, so hat sich anch die Johre von den Krankiciten in eine Zellularpathologie umgewandelt.

In vieler beziehung steht somit die Lehre von der Zelle im Mittelpunk der biologischen Forschung der Gegenwart. Sic bildet in jeder Beziehung den vornehmsten Gegenstand der allgemeinen Anatomie, wie man früher, oder der Histologie, wie man jetzt gewöhnlich die Lehre von den Mischungs- und Formbestandteilen der Organismen zu benemen pflegt.

Die Vorstellung und der Begriff. den man in der Wissenschaft mit dem Wort ..Zelle" verbindet, hat sich im Laufe von ti(), Jahren sehr wesentlich geändert. Die Geschichte der verschichenen Auffassmngen oder die Geschichte der Zellentheorie ist von hohem Interesse. Nichts ist geeigneter als ein kurzer Abrib derselben. um den Anfänger in den V'or- 
-tellumbsheris, den man jetzt mit dem Worte Zelle verhindet, einzuführen. Auch möchte der Hinweis auf die Geschichte der Zellentheorie noch in anderer Richtums nuitzen. Indem wir die angenblicklich herrschende lorstellung von der' Zelle sich aus älteren, minder vollkommenen Vor-

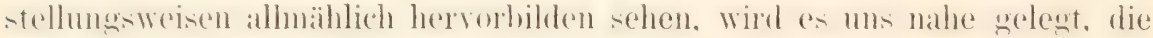
erstere auch nicht als etwas in sich Fertiges zul betrachten; es erscheint vielmehr die Hoftnung berechtigt, daß bessere und verfeinerte Untersuchungsmittel, - wobei man indessen nicht nur von einer Verbesserung der optischen Instrumente alles Heil zu erwarten braucht, - unsere derzeitig gewomnene Erkenntnis noch wesentlich rertiefen mol vielleicht mit ganz neuen Vorstellungsreihen bereichern werden.

\section{Die Geschichte der Zellentheorie.}

Zu der Erkemntuis, dal.j die Organismen ans Zellen zusammengesetzt sind, wurde der erste Anstol, dureh das Studium der P'tlanzen-Anatomie gegeben. Am Ende des 17. Jahrhunderts gewannen der Italiener MaRCellus Malpighi (1674) und del Engländer Grew (1682) den ersten Einhlick in den feineren ban der T'tlanzen; sie entdeckten an ihnen mit schwachen Verglölerungsulisern einmal kleine, kimmerartige, mit festen Wandungen versehene und mit Flüssigkeit erfüllte Rïume, die Zellen. und zweitens noch lange Röhren, die in den meisten Ptlanzenteilen in mamigfarher destalt durch das firundsewehe zichen, und die jetzt je nach ihrer Form als spiralröhen und fiefalie hezeichnet werlen. Eine tiefere Bedeutung gewannen diese Tatsachen aber erst, als am Ende des 18. Jahrhunderts sich eine mehr philosophische Betrachtungsweise der Natur Bahn brach.

Caspar Friedrich WolfF (1764), OKen (1809) u. a. warfen die Frage nach der Entstehung der Pflanzen auf und suchten ihre Gefäße und Röhren von der Zelle als Grundform abzuleiten. Namentlich aber

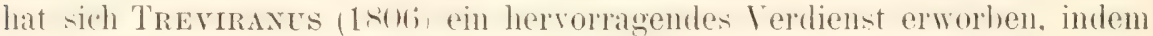
er in seiner 1808 erschienenen Schrift ,Tom inwendigen Bau der Gewähose" an jungen Pthanzenteilen den Vachweis führte, dali die crefälie aus Zellen hervorgehen: er fand, dab, junge Zellen sich in Reihen anordnen und dureh Authösung der (Duerseheidewände zu einer langgestrechten Röhre verschmelzen, eine Entrlechung. welche später durch die Xachuntersuchminen von MoHL (1S:3(1) zum wesicherten Iseritz der Wiscuschaft erhoben wurde.

Nicht minder wichtig für die Wertschätzung der Zelle wurde das Studium der niedersten PHanzen. Man lernte kleine Algen kennen, die zeitlebens entwerler nur eine einzige Zelle darstellen orler einfahe fieihen von Zellen sind, welche sich leicht von einander loslösen können. Endlich führte das Nachdenken über den Stoffiwechsel der PHanzen zu der Eimsirht, dab die \%elle es sej, welhe in der vegetabilischen Ifamshaltung die Sahrumgsitofte anfinmm, verarbeitet und in verinderter Form wieder abgibt. (T'urpin, Raspail.)

So war schon am Anfang unseres Jahrhunderts die Zelle als der morphologische und physiologische Elementarteil der I'Hanze ron verschiedenen Forschern erkannt worden. Besonders klar findet sich diese Anschaumg in dem 1830 herausgegebenen Lehrbuch der Botanik von MrYex in folgendem satze ansge-virochen: ..Die Pflanzenzellen treten 
entweder einzeln auf, so daß eine jede ein eigenes Individum bildet, wie dieses bei Algen und Pilzen der Fall ist, oder sie sind in mehr oder weniger großen Massen zu einer höher organisierten Pflanze vereinigt.

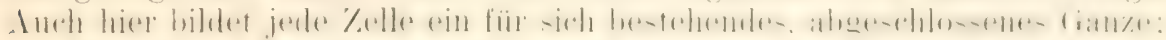
sie ernïht sich selbst, sie bildet sich selhst und verarbeitet den aufgenommenen, rohen Nahrungsstoff zu sehr verschiedenartigen Stoffen und Gebilden." MEYEx bezeichnet daher geradezu die einzelnen Zellen als ..die kleinen PHlinzchen in den gröberen."*

Zu allgemeinerer (ieltung gelangten indessen derartige Ansichten erst vom Jahre $18: 38$ an, in welchem MatTmas ScHLEIDEx, den man so häutig

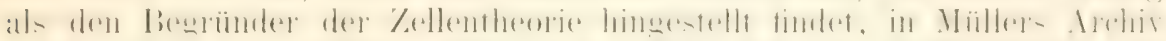

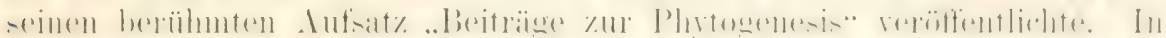
demselben suchte M. Scmlempex die Frage zu lösen, wie die Zelle ent-

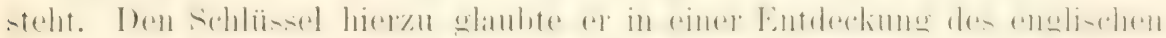
Botanikers RoBERT BRown gefunden zu haben. welcher im Jahre 18:3:; bei seiner Untersuchumg der Orchideen den Kellenkern entdechit hatte.

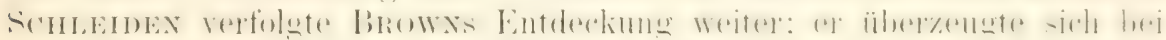
vielen Ptlanzen von dem Vorkommen des Kerns. und da er ihn nament-

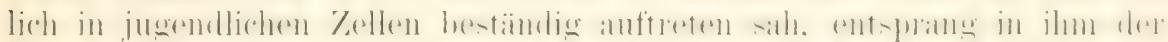
Gerlanke, daf der Kern eine nähere Beziehung zu der so rïitselhaften

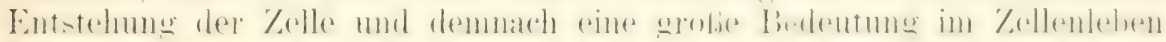
haben mïsse.

Die Art und Weise, wie Schleidex diesen (iedanken auf Grund irT-

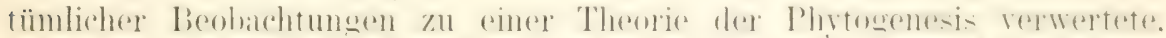

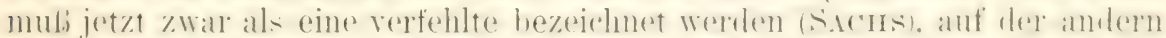

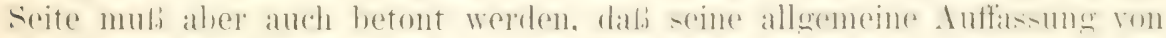

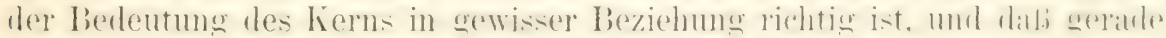
dieser eine Gedanke weit über das engere Gebiet der Botanik hinaus

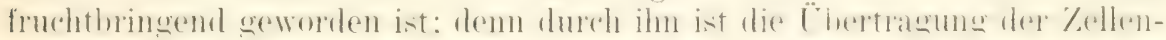
theorie auf die tierischen Gewebe ermöglicht worden. In diesen treten

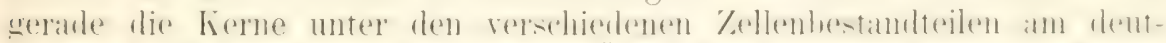

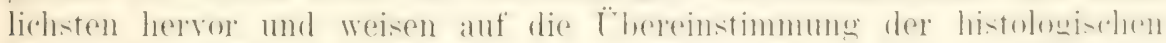

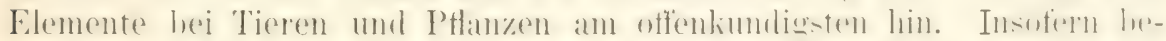

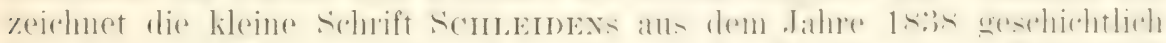

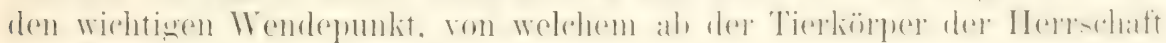
der Zellentheorie unterworfen wurle.

An Versuchen, den Tierkörper als eine Vielheit kleinster Elementar-

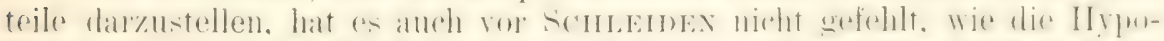

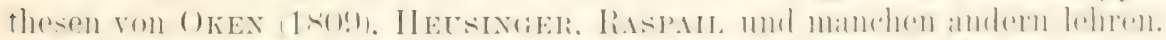

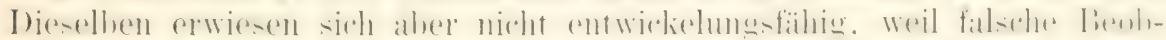
achtungen und verkehrte Dentungen in ihnen das Gute ïberwogen. Erst in den dreißiger Jahren, in denen die optischen Hülfsmittel eine V'er-

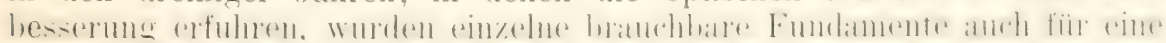
tierische Zellentheorie gelegt. Schon verglichen PURkINJE (1837) und Valextix. Joh. Jüller (18:30)) und Hexle (1837) einzelne Tiergewehe

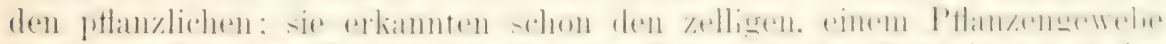

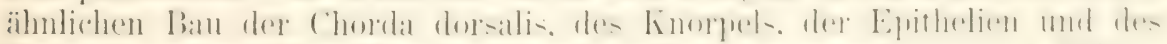

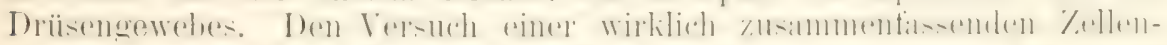

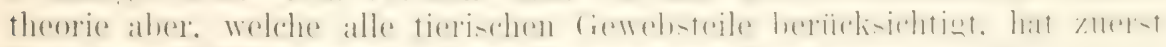

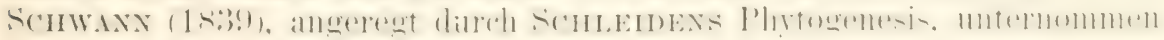
und in genialer Weise durchgeführt.

Im Jahre $18: 38$ erfuhr Scriwaxy in ciner Unterredung mit ScInEIDEx ron der neuen Theorie der Zellenbildung und von der bedentung. 
welche den liernen bei den l'flanzen zukommen sollte. Er erkannte hierin sofort. wie er uns selbst erzaihlt. charaliteristische Momente genug. welche \%u einem Vergleich mit tierischen \%ellen anfforderten. Mit hewundernswertem Fifer stellte er eine umfassente Reihe von Lntersuchungen an,

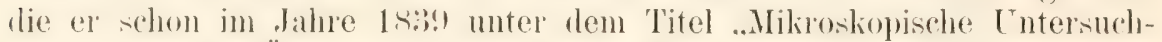
ungen äher die Überenstimmung in der Struktur und dem Wachstum der Tiere und Pflanzen" veröffentlichte. - Dieses Buch ScHwanns ist ein grmullegendes Werk ersten Ranges. durch welches die miliroskopische Anatomie der Tiere trotz der viel schwierigeren Aufgahe anf gleiche stufe mit der Pflanzenanatomie gehoben wurde.

Zu dem raschen und glänzenden Erfolg der Schwansschen Untersuchungen haben wesentlich zwei Momente beigetragen. Erstens hat Schwans zur Erkennung der tierischen Zellen vorzugsweise die Anwesenheit des Kerns benutzt, von dem er hervorhebt, daß er der am meisten charaliteristische und ann wenigsten veränderliche Zellenbestandteil sei. Wie schon angedeutet, liegt hierin das Fördernis, welches ScHwans durch SCHLEDEN empfangen hat. Das zweite nicht minder bedeutsame Moment ist die richtige Methorle, welche ScHwaxn hei der Ausführung und Darstellung seiner Beobachtungen hefolgt hat. Wie die Botanilier dureh das Studium unentwickelter Pflanzenteile z. B. die Röhren aus der (irundform der Zelle abgeleitet hatten, so untersuchte auch er hauptsächlich die Entwicklumgsgeschichte der (iewebe und fand, dab der lieim auf frühesten Stallien aus einer Summe ganz gleichartiger Zellen hesteht: er verfolgte dann weiter die Metamorphosen oder die Cmbildungen, welche die Zellen erleiden. his sie in die fertigen (iewehe des erwachsenen Tieres ühergehen. Er zeigte. wie ein Iruchteil der Zellen die ursprüngliche, kuglige fruntform beibehält, andere eine zylindrische Gestalt annehmen, andere in lange Fasern auswachsen oder zu sternförmigen (iehilden werden. indem sie an verschiedenen Stellen ihrer ()berfläche zahlreiche Ausläufer ausschichen. Er zeigte an den Kunochen, Knorpeln und Zähnen, wie wieder andere Zellen starli verdickte Wandungen bekommen; endlich erklärte er noch eine Reilıe der an meisten abgeänderten (iewebe ans einer Verschmelzung ron Zellengruplen, wohei er auch wieder einen analogen Vorgang bei den Pflanzen, die Entwickelung der Gefäße, im Auge hatte.

Auf diese Weise war durch Schwann ein allgemeines, wenn auch mit vielen Fehlern behaftetes, dafür aber leicht fabliches und auch im (ianzen glückliches Schema geschaffen, nach welchem ein jerler tierische Teil aus Elementarteilen, welche den P'flamenzellen entsprechen. entweder zusammengesetzt oder durch Metamorphose von solehen entstanden ist. Es war ein gutes Fundament gelegt, auf dem sich weiter bauen lief. Im einzelnen litt aber die Vorstellung, welche Schlenden und ScHwann sich vom Wesen des pflanzlichen und tierischen Elementarteils gebildet hatten, an vielen Irrtïmern. wie bald erkannt wurde. Beide Forscher definierten die Zelle als ein kleines Bläschen. das in einer festen Membran einen flüssigen Inhalt umschließt, als ein Kämmerchen, eine cellula im eigentlichen. Sinne des Wortes. Als wichtigsten und als den wesentlichen Teil an dem Bläschen bezeichneten sie die Membran. von der sie annahmen, daß sie durch ihre chemischphysikalischen Figenschaften den Stoffwechsel regeln sollte. Schwaxs crblickte in der Zelle einen organischen Krystall, den er sich durch eine Art ron Krystallisationsprozeb aus einer organischen Mutterlauge (Cytoblastem) bilden lieb. 
Die Vorstellungsreihe, welche wir jetzt mit dem Worte .Zelle: verbinden. ist dank den groben Fortschritten der letzten sechs Jahrzehnte

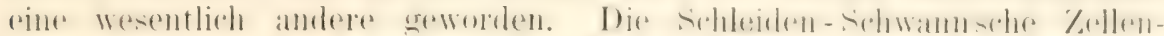

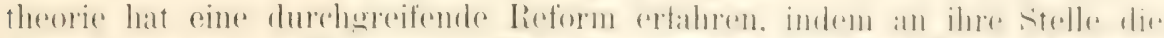

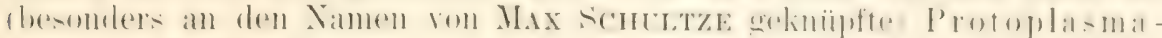
theorie getreten ist.

\section{Die Geschichte der Protoplasmatheorie}

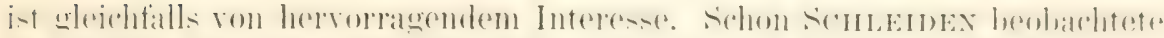

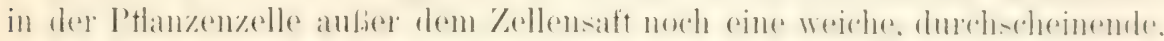
mit kleinen Körnchen versehene Substanz, welche er Pflanzenschleim namnte. MomL (1846) gab ihr im Jahre 1846 den später so bedentmos-

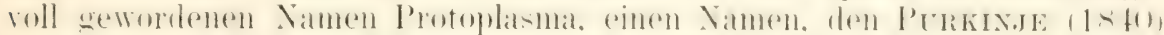

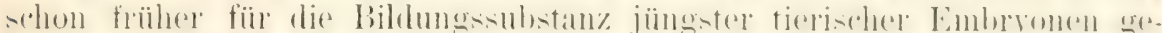
braucht hatte. Auch entwarf er ein genaues Bild von den Lebenserschei-

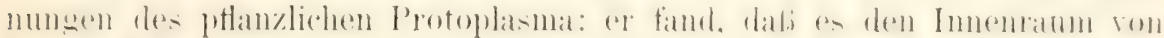

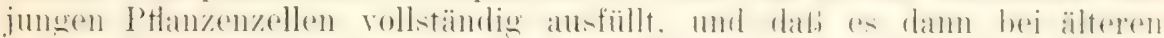
und größeren Zellen in sein Inneres Flüssigkeit aufnimmt. die sich in Blasen oder Vakuolen ansammelt. Endlich stellte Momt fest. daf das Protoplasma, wie ScHLEIDEx auch schon für den Pthanzenschleim an-

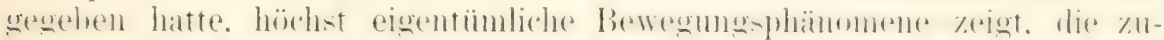
erst von Bonaventura Corti im Jahre 1.7 72 mol voll C. I. Treviranus (1807) entdeckt und als ,kreisende Bewegung des Zellsaftes" beschrieben worden waren.

Hierzu gesellten sich noch andere Beobachtungen. welche den proto-

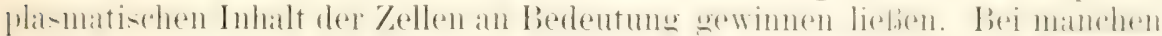
nierlersten Algen zieht sich, wie CoHx und andere fanden. das Protoplasma zur Zeit der Fortpitanzung von der Zellmembran zurieck und bildet einen frei im Zellraum liegenden, ovalen, nackten Körper, die

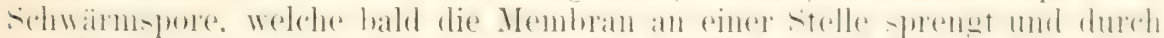
die Öftnumg hindurchschlüpft, um sich im Wasser mit Wimpern wie ein selbständiger Organismus, aber ohne Membran, fortzubewegen.

Desgleichen wurden beim Studium der tierischen Zellen Tatsachen

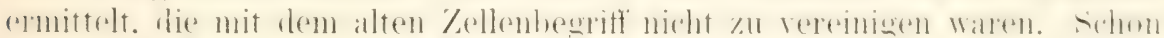
wenige Jahre nach dem Auftreten von ScHWAxy machten verschiedene Forscher [KöLliker (1845). Brschoff (1842) auf viele tierische Zellen anfmerkam. an welchen eine besondere Membran nicht nachzuweisen war, und es erhol) sich infolgedessen ein langer Streit, ob wirklich diese fiebilde membranlos und daher keine Zellen. odler oh es echte Zellen seien. Auch beobachtete man an der schleimigen. mit Körnchen versehenen Grundsubstan\% einzehner tierischer Zellen. wie \%. B. der

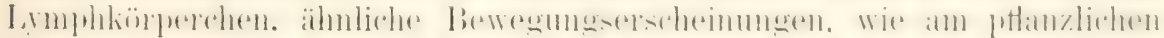
Protoplasma. (Siebold, Kölliker, Remak, Lieberkümx etc.) - Reina (1552. 1555) übertrug daher den von MonL für den Pthanzensehleim ein-

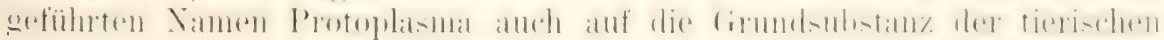
Zellen.

Wichtige Einblicke in die Natur des Protoplasma eröthete endlich

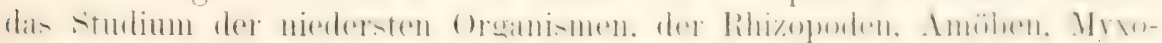

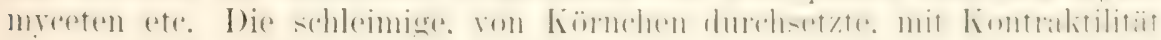
begabte Substanz derselben hatte Durardax Sarkode genamnt. Indem 
MAX ScIIULTZE (1863) und DE lBARY (1859) ilne Lebenserscheinungen auf das genameste studierten. wiesen sie nach, dab das Protoplasma ther Pflanzen und 'Tiere und die Sarkode der niedersten Organismen identische Stoffe sind.

Im Hinblick auf diese 'Tatsachen legten Fol'scher, wie NïGELI. Alexander Braun, Leydig, Kölliker, Cohn, de Bary etc. der Tellenmembran im Verhälnis zu ihrem Inhalt eine nur untergeorhete liedrutume bei; vor allem aber hat MAx Schultze sich das Verdienst erworben, die

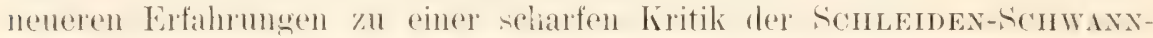
shen \%ellentheorie und zur Begrimdung einer Protoplasmatheorie henutzt zu haben. In 4 kleinen, ausgezeichneten Schriften, welche vom Jahre 1860 an veröftentlicht wurlen, zog er gegen die alten dilanhensiäze, deren man sich zu entledigen habe, zu Felde. Aus der 'Tatsache, daf bei allen Organismen ein bestimmter Stoff vorkommt, welcher sich durch die merkwiurdigen Bewegungsphänomene ansedehnet Protoplasma der Tiere und P'tlanzen, Sarkode der einfachsten (tranismen), ans der Tatsache ferner. dalo das Protoplasma der Pflanzen zwal rewöhnlich ron einer besonderen festen Membran umschlossen ist, in einigen Fällen aber die letztere abstreifen und als nackte Schwärmspore sich im Wasser selbständig forthewegen kann. aus der Tatsache endlich. dab die tierischen Zellen und die einfachsten einzelligen Organismen sehr häutig lieine Menbran hesitzen und dann als nacktes Protoplasma und als nackte Sarkode erscheinen,

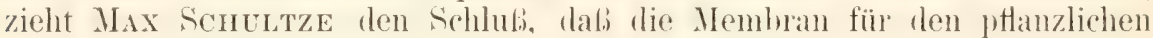
und tierischen Elementarteil etwas Unwesentliches sei. Zwar behält er den durch Schlemen und Schwans in die Anatomie eingebürgerten Namen Zelle bei, definiert dieselbe aber, (1861) als ein mit den Eigenschaften des Lebens begabtes Klümpchen von Protoplasma.

Mit dieser Definition knüpfte Max Schultze — wie der historischen Gerechtigkeit wegen hervorgehoben sei — wieder an die älteren Bestrebungen von PuRKinje (1837-1840) und ARnold (1845) an, welche eine Körnchen- und Klümpchentheorie auszubilden versuchten, aber gegenüber der besser durehwearheiteten und ihrer Zeit mehr angepabten Zellentheorie von ScHwann wenig Erfolg hatten.

Unter einem Klümpchen von Protoplasma stellten sich indessen schon damals Max Schultze und andere Forscher keineswegs etwas so Einfaches vor, wie das Wort auszudrücken scheint. Namentlich der Physiologe BRÜCKE (1861) schloß aus der Kompliziertheit der Lebenseigenschaften, deren Träger das Protoplasma ist, mit Fug und Recht, daß das Protoplasmakiumpehen eine komplizierte struktur. einen .höchst liunstvollen bau" besitzen mïsse, in welchen nur die I'nzulänglichkeit unserer Deobadhtungsmittel keinen hefrierligenden Einblick gestatte. Daher hezeichnete denn schon BRüCKE sehr treffend den Elementarteil der Tiere und Pflanzen, das Protoplasmaklümpchen, als einen Elementarorganismus.

Tei dieser Sachlage ist eigentlich der Name Zelle ein verkehrter. Daß er trotzdem beibehalten worden ist, erklärt sich teils aus gerechter Pietät gegen die rüstigen Streiter, welche, wie BRücke sich ausdrückt, unter dem Banner der Zellentheorie das gesamite Feld der Histologie erobert haben, teils aus dem Umstand, daß die Anschauungen, welche die nene Reform herheigeführt hahen. erst nach und mach ausgebildet wurden mul zu allgemeiner (ieltung zu einer Zeit gelangten, als das Wort Zelle sich schon durch jahrzehntelangen Gebrauch in der Literatur eingebuirgert hatte. 
Seit BrüCKE und Max Scrularze lat sich unsere Kemtnis vom Wesen der zelle noch auferordentich vertieft. Fis sind viele nene Einblicke in die Struktur und die Lebenseigenschaften des Protoplasma gewomnen worden. besonders aber hat das Studium des \%ellenliernes und der Rolle, welche er bei der Vermehrung der 'zelle und hei der geschlechtlichen \% \%

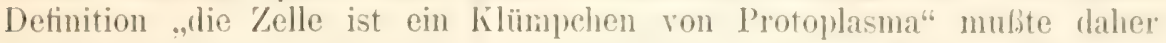
erweitert werden in die Definition: ,1)ie Kelle ist ein Kilümpehen von Protoplasma, das in seinem Innern einen besonders greformten Bestandteil, den Kern (Nucleus), einschlieht."

Auf die Geschichte dieser neueren Errungenselaften wird hie und

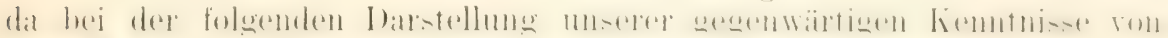
dem Wesen des Elementarorganismus eingegangen werlen.

Das reiche Wissensmaterial, welches eine hundertjährige Forschung ïber die Zelle angesammelt hat, wird sich am besten in folgender Weise systematisch gruppieren lassen:

In einem ersten Abschnitt sollen die chemisch-physikalischen und morphologischen Eigenschaften der Zelle dargestellt werden.

Ein zweiter Abschnitt wirl dam von den Lebenseigenschaften

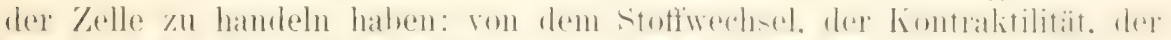

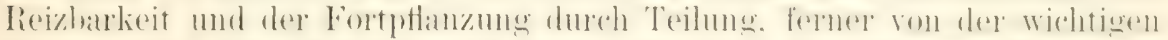

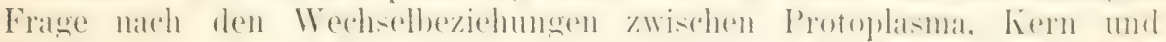
Zellprodulit und ron dem gehemmi-vollen l'roblem der liefruditume.

\section{Literatur I.}

1) Fr. Arnold, Lehrbuch der Physiologie des alenschen. 2. Teil. Ziürich 18+2. Mandbuch der Anatomie des Menschen. I845.

2) de Bary, 1/yxomyceten. Zeitschrift f. wissenschaftl. Lool. I850.

3) Lionel S. Beale, Die Struktur der cinfachen Gezebe des menschlichen Körpers. Übersetzt z'on Carnis. I862.

4) Bischoff, Entwicklungsgeschichte des Kinnincheneies, I8 42 .

5) R. Brown, Observations on the organs and mode of ficundation in Orchideae and Asclepiadeat. Transactions of the Linnean society'. London 1833.

(i) Brücke, Die Elementarorganismen. H'iener Sitzmgsber. Jahrs. 1861. TLIV. 2. Abt.

7) Cohn, Vachträge z. Naturgeschichte des Protococous pluviatilis, lova acta Vol. . KIII. pag. 607-70\%.

S) Bonaventura Corti, Obserazioni microse. sulla Tremella e sulla circolazione del fluido in una pianta acquariola. $177+$

9) Grew, The anatomy of plantes. 1862.

10) Haeckel, Die Radiolarien. 1862.

Derselbe, Stzutien ziber die Honeren. 1870.

11) Henle, Symbolae ad anatomiam zillomum intestinalium. 1837.

12) Oskar Hertwig, Die Geschuchte der Zellentheorie. Dentsche Rumlschau.

13) Huxley, On the cell theory. Monthly Journal. I853.

1.1) Kölliker, Die Lehre zon der tierischen Zelle. Schleiden 2 . Nägeli, Misschschafh. Botanik. Hleft 2. $18+5$.

Derselbe, Handbuch der Gearbelehre des Wensithen.

15) Malpighi, Anatome plantarum. 1674 .

16) Meyen, Prytotomic. Berlin 1830.

17) H. v. Mohl, Ubor die Térmetums der J Panzenzellen durch Teiluns. Dissert. Tï̈bingen 7835 . Flora 1837.

18) Dersclbe, Über die Saftbeacgung in Innern der Zellen. Botanische Zeitung. $18+6$.

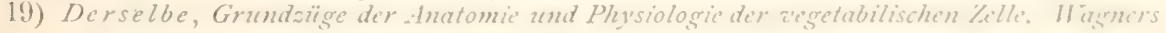
Handiërterbuch der Physiologie. 1851

20) J. Müller, Tergleichende Anatomic der Ifyxinoitin. I835.

21) Oken, Lefurbuch der Noturphilosophie. 1800. 
22) Purkinje, Bericht Z̈ber die lersammlung deutscher Vaturforseher und Ärzte in Prag im September 1837 . Pras 1838. pag. I74-175.

2:3) Dersebe, Ubersicht der Arbeiten und Veränderungen der schlesischen Gesellschaft für vaterländische Inultur im Jahre 1839 . Breslau 1840.

21) Derselbe, Jahrbücher für wissenschaftliche kritik. 1840. Ar. 5. pag. 33-38.

25) Remak, Über extrazelluläre Entstehung tierischer Zellen und wiber Vermehrung derselben durch Teilung. Mïllers Archiv. I852.

26) Derselbe, Untersuchnngen ïber die Entaicklang der Virbclticre. 1855.

27) Sachs, Geschichte der Botanik. 1875.

28) Matthias Schleiden, Beiträge zur Phytogenesis. Müllers Archiv. 1838. Derselbe, Grandzïge der wissenschaftlichen Botanik. 2. Anfl. 1845.

29) Max Schultze, Das Protoplasma der Rlizopoden und der Pflanzenzelle. 1863.

30) Derselbe, Über Mnskelkörperchen und was man eine Zclle au nemnen habe. Archizi fiir Anatomie und Physiologie. 1861 .

31) Th. Schwann, Mikroskopische Untersuchungen ïber die Übereinstimmung in der Struktur und dem Vachstum der Tiere und Pfanzen. 1839.

32) L. C. Treviranus, Iom incendigen Ban der Geteïchse. 1806

33) R. Virchow, Die Zellularpathologie in ihrer Begriüdung anf physiologische und pathologische Gerebelehre. 1858. 2. Auth. 1862.

34) Casp. Friedr. Wolff, Theorie zon der Generation. 1767. 


\section{\%WEITES KAPITEL.}

\section{Die chemisch-physikalischen und morphologischen Eigenschaften der Zelle.}

Mit Recht ist die Zelle auf Grund der Lebenseigenschaften, die an

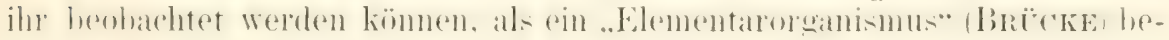
zeichnet worden. Sie ist auch in den Fällen. wo sie mit unseren unvoll-

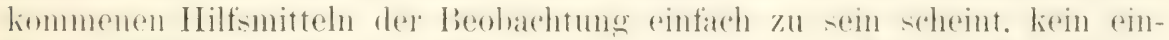

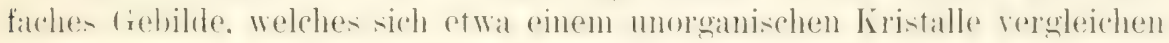
liefe. wie es ron Th. Schwaxy versucht wurde, vielmehr ist sie sellost

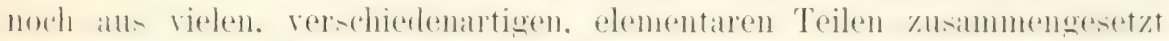
zu denken, aus Teilen, welche einfacher als die Zelle, aber zusammengesetzter als das chemische Molekiül sint. und welche, wie die Organe in einem höheren Organismus beim Lebensprozel, zusammen wirken. Die

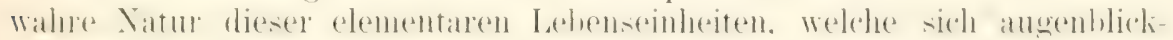

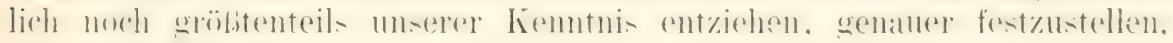

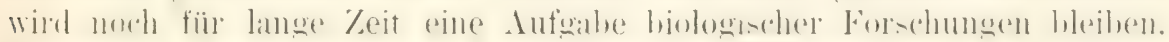

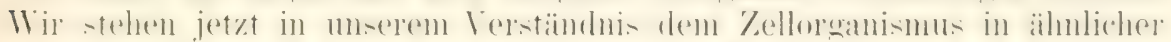

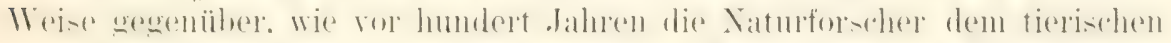

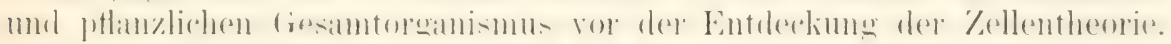

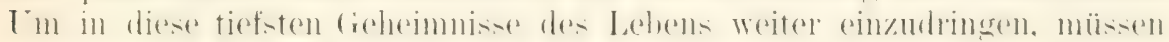
unsere optischen Hilfsmittel, noch mehr aber unsere chemischen Untersuchungsmethoden auf eine höhere Stufe der Vollendung gebracht werden. Es scheint mir zweckmäbig. diese Gedanken gleich hier

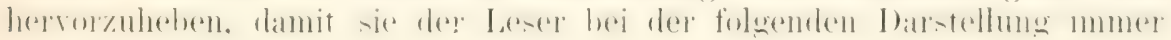
ror dugen hat.

In jeder Zelle ist ausnahmslos ein besonders geformter 'Teil nachzuweisen. welcher in ganzen Organismenreich mit einer groben Gleichförmigkeit auftritt. der Kellkern. Ihm und dem übrigen T'eil der Zelle.

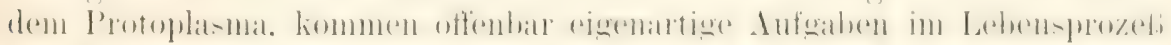
des Elementarorganismus zu. Daher läbt sich die Untersuchung der

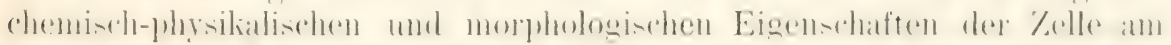

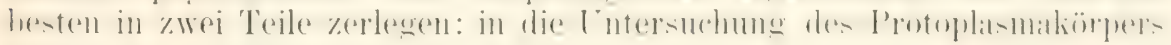
und in die Untersuchung des Zellkerns.

Daran schliefen sich als Anhang noch zwei lileinere Abschnitte an.

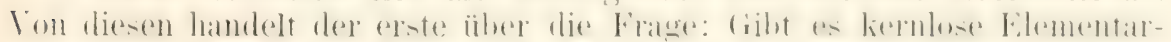

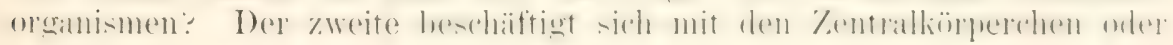




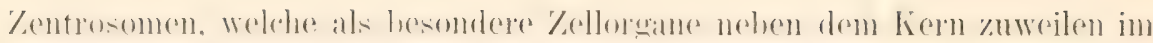
Protoplasma aufgefunden werilen.

\section{Dir rhomisch-physikalischen mud morphologischen Eigen- schaliten des Protoplasmakörpers.}

\section{a) Der Begriff des Protoplasmas und seine Berechtigung.}

Bei Pthanzen und Tieren sehen die Zellen zuweilen nach Form und Inhalt so außerordentlich verschieden aus, daß sie auf den ersten Blick äherhaupt nichts (iemeinsames darzuhioten scheinen. Man vergleiche den Inhalt einer PHanzenzelle am Vegetationskegel mit einer von Stärkekïnern erfüllten zelle der Kartoftellinolle oder eine Embryonalzelle einer lieinscheibe mit einer Fettzelle oder einem mit Dotterplättchen angefüllten Amphibienei. Der unbefangene Beobachter wird nur Unterschiede erblicken. Trotzlem stmmen die genamnten Zellen bei tieferer L'ntersuchung in einem Punkte überein: in dem Besitz einer sehr wichtigen, eigentümlichen Substanz, die dort in gröBerer Masse, hier nur in Spuren vorhanden ist, in keinem Flementaroranismus aber vollstimlig vermibt wirl. Dieselbe läbt in rielen Fällen die Lebenseigenschaften erkennen, von denen später gehandelt wird, die Eigenschaft der Kontraktilität, der Reizbarkeit etc., und da sie außerdem bei jugendlichen Zellen, bei niederen Organismen, bei den Zellen des Vegetationskegels und der Kieimscheibe, allein den Zellkörper - vom Kern natürlich abgesehen - ausmacht, hat man in ihr den hauptsächlichen Träger der Lehensunktionen exblickt. Sie ist das Protoplasma von Max Schultze oder die bildende Substanz forming matter) des englischen Histologen BEALE (I. 1862).

Wenn das Wort "Protoplasma" hier und im folgenden gebraucht wird, so geschieht es in der ursprünglichen Bedeutung, welche ihm MoнL, Max Schultze, Levdig u. a. gegeben haben. In nenerer Zeit ist leider eine Verwirrung in der Terminologie eingerissen. Strasburger (1882), dem sich andere Forscher angeschlossen haben, bezeichnet als Protoplasma den ganzen Inhalt der Zelle, den Kern mit imbegriffen, und unterscheidet in ilım wieder Cytoplasma (das Protoplasma der älteren Autoren) und das Karyoplasma.

Um zu wissen, was Protoplasma ist, wird man am besten dasselbe an solchen Zellen untersuchen, in denen es möglichst frei von anderen Beimischungen und in größerer Nenge auftritt, und am besten an den ()hjekten, an denen sich die Begründer der Protoplasmatheorie ihre Vorstellung von seiner Natur gebildet haben. Solche Objekte sind junge Pthanzenzellen, Amöhen. Rhizopoden, die Lymphkörperchen von Wirbeltieren. Wer hier die charaliteristischen Eigenschaften des Protoplasmas erkamnt hat. wird dassellue auch in solchen Zellkörpern auffinden, in denen es nur in geringer Menge vorhanden ist und durch andere Substanzen mehr oder minder verdeckt wird.

Es ist von Flemming der Vorschlag gemacht worden, den Begriff Protoplasma. mit dem ein unberechtigter liultus getriehen werte, überhaupt sanz fallen zu lassen: denn die Verwendung dieses Wortes sei heutzutane eine so mubestimmte und schrankenlose geworden, dab man sich mit liecht fragen kïmne, ol durch seinen jetzigen (iehrauch wirklich Nutzen und nicht vielmehr Verwirung gestiftet werde. 
Dieser Vorschlag kann weder als ein zweckdienlicher, noch als ein in der Sache berechtigter bezeichnet werden. Denn wenn auch zugegeben werden mag, dab von mancher Seite das Wort in verschiedener Weise gebraucht wird, daß es auch nicht möglich ist, in einem kurzen Satze eine erschöptende Definition des Wortes Protoplasma zu gehen, und daß man in manchen Fällen in Verlegenheit kommt, zu sagen, Welcher 'Teil in einer Zelle Protoplasma ist und weleher nicht. so geht aus alledem die Ent-

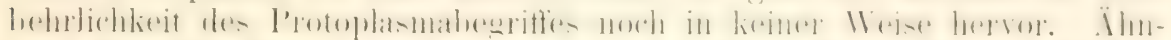

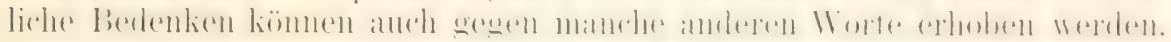
durch welche wir uns über bestimmte Stoffgemenge der Organismen zu rerständigen suchen. Mit dem Wort Nuklein oder Chromatin bezeichnen wir \%. B. einen gewissen Bostandteil des lierns, der für manchen leidlich gut bestimmbar erscheinen wird. Und doch wirk der Mikroskopiker zugeben müssen, daß es im ruhenden kierngerüst nicht möglich ist, genan zu bestimmen. was Linin und was Nuklein ist, oder zu entscheirlen. oh man im einen Fall nicht zu viel, im anderen Fall zu wenig mit gefärbt hat.

Ebensowenig wie das Wort Chromatin, ist das Wort Protoplasma

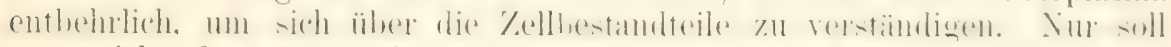
man nicht den Anspruch erheben, daß mit dem Wort Protoplasma ein chemisch scharf definierbarer Körper bezeichnet sei.

Protoplasma ist ein biologischer Begriff (und dasselbe gilt mehr oder minder auch für das Wort Chromatin und so viele andere):

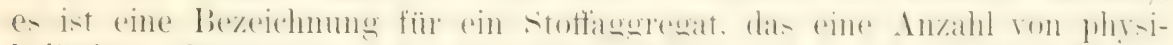

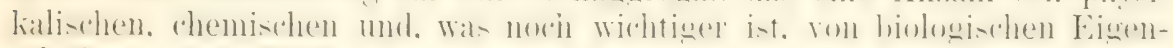

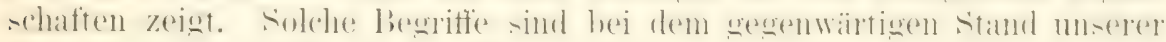
Wissenschaft unentbehrlich. Wer mit der Geschichte der Zelle bekannt

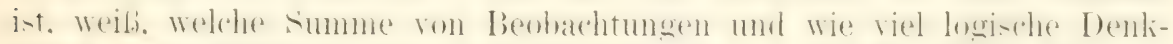

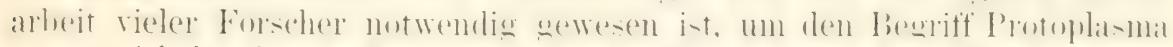

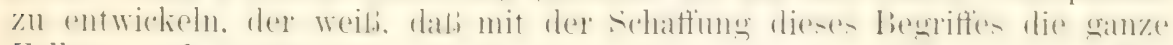
Zellen- und Gewebelehre einen viel tieferen Inhalt gewonnen hat. Wie viele Kämpfe hat es gefordert, his festgestellt wurde, daß an der Zelle

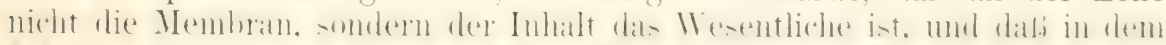

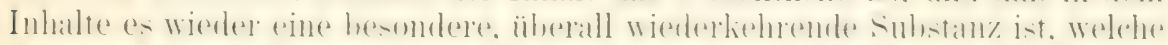

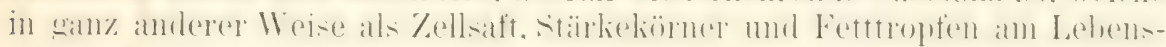
prozeB beteiligt ist.

Das Wort Protoplasma lat daher nicht nur seine historische, sondern

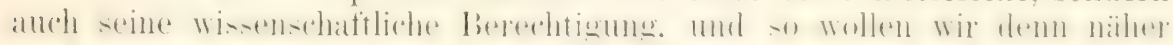
zu bestimmen suchen. was darunter zu verstehen ist.

\section{h) Charakteristik des Protoplasmas in physikalischer, chemischer und morphologischer Beziehung.}

Das Protoplasma einzelliger Organismen. pflanzlicher und tierischer Zellen (Fig. 1 und 2) erscheint als eine zähttüssige. fast immer farblose,

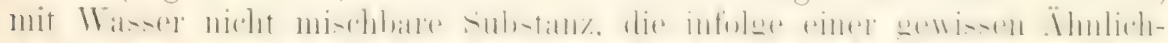

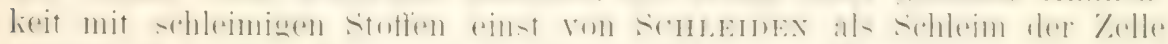
bezeichnet wurde. Es bricht das Licht stïrker als Wasser. so dab selhst

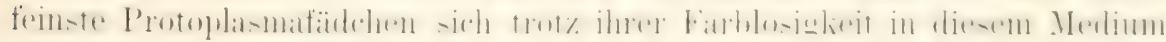
erkennen lassen. Ferner hat es ein etwas größeres spezifisches Gewicht als Wasser, yon einigen Fällen abgesehen, in denen es Luftblasen orler

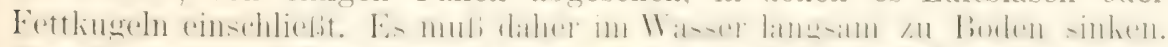

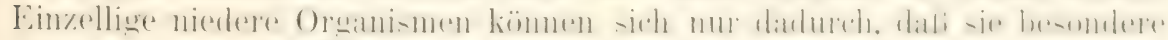

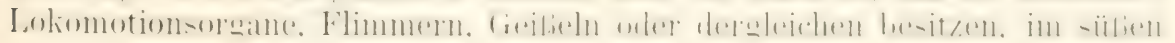


oder salzigen Wasser in der Schwebe erhalten. Der Physiologe J Ensen hat das suezifiche fiewicht des Flimmerinfusors Paramareom anteliat auf etwa 1.25 berechnet.

Nach Untersuchungen von PFeffer hat das Protoplasma einen ziemlich hohen Grad von Konsistenz. Denn wie sich durch Experimente feststellen liedi, zerrisen Protoplasmastränge von Plasmodien des ('homdrionderma difforme erst, nachdem auf sie ein Zug von 120-300 mg auf den Quadratmillimeter ausgeübt worden war.

In keinem Protoplasma fehlen kleinste, nur wie Punkte erscheinende Körnohen, die Mikrosomen, die bald spärlicher, bala reichlicher vorhanden

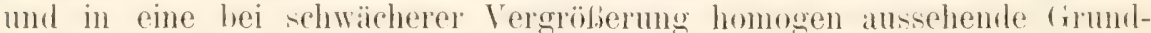
substanz eingebettet sind. Je nach ihrer Menge sieht daher das Protoflasma hald mehr durchscheinend. hyalin, hald etwas dmulker mol hörnig

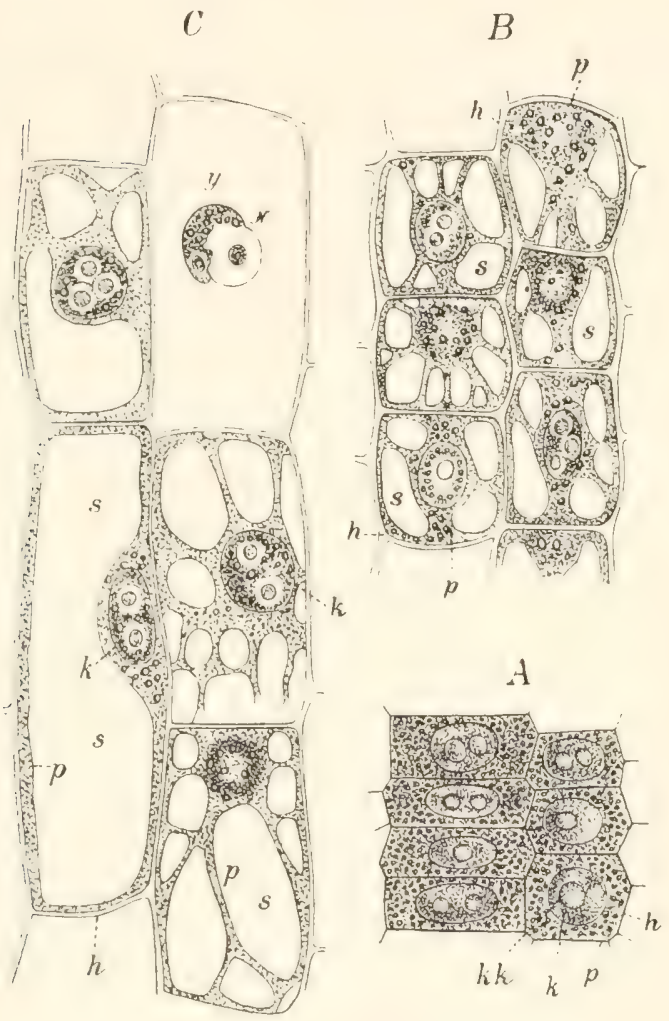

Fig. 1. Parenchymzellen aus der mittleren Schicht der Wurzelrinde von Fritillaria imperialis; Längsschnitte, nacl 550maliger Vermrößerung. Nach SAcHs. A dicht über der II urzelspitze liegende, sehr junge Zellen, noch ohne Zellsaft; $B$ die gleichnamigen Zellen etwa 2 Millimeter über der Wruzelspitze, der Zellsaft s hildet im Protoplasma $p$ einzelne 'Tropfen, zwischen denen Protoplasmawände liegen; $C$ die gleichnamigen Zellen etwa $7-8$ Millimeter über der Wurzelspitze; die beiden Zellen rechts inten sind ron der Vorderfliche resehen, die grobe Zelle links unten im optischen Durchschnitt resehen: die Zelle rechts oben durch den Schnitt geöffnet; der Zellkem läßt mer dem Enfluß des eindringenden Wassers eine eigentiumliche Quellungserscheinung wahrnehmen $(x y) ; k$ Kern; kk Kernkörper; $h$ Membran.

aus. Thre Verteilung im Zellenleib ist selten eine gleichmägige. Gewöhn-

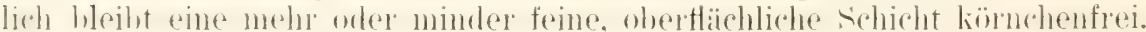
Da dieselbe auferdem noch einen etwas festeren Agoregatzustand als die von ihr eingeschlossene, wasserreichere und körnige Protoplasmamasse darbietet. hat man beide als zwei verschiedene Plasmaarten unterschieden und die eine als Hautplasma oder Hyaloplasma und die andere als Körnerplasma bezeichnet (Fig. $2 \mathrm{ek}$. ch.).

Manche Forscher, wie namentlich Pfeffer, de VRIEs etc. sind geneigt, in der Hautschicht ein besonders differenziertes und mit besonderen Funktionen betrautes Organ des Zellkörpers zu er- 


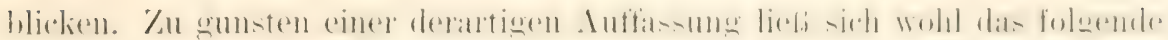
von mir angestellte Experiment verwerten: Reife, in den Eileiter eingetretene und mit einer Gallerthïlle umgebene Eier von Rama temporaria

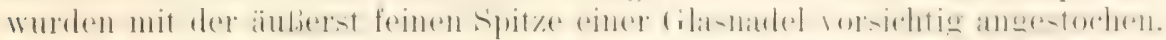

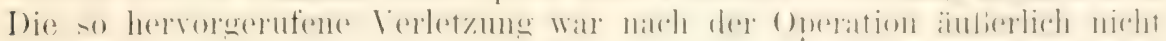
wahrnehmbar. Ein Austritt von Dottersubstan\% war an der Stichstelle nicht zu bemerken. Als aber darauf die Eier befruchtet wmolen. so begann nach einiger Zeit an allen verletzten Eiern Dottersubstanz in ziem-

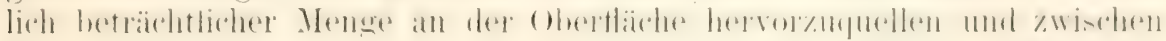
Ei- und Dotterhaut einen mehr oder minder groben Höcker (Extraovat. Roux) zu bilden. Durch den Alit der Befruchtung wurde der Substanz-

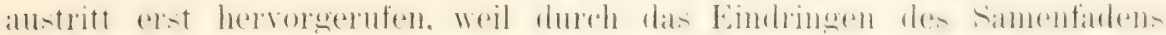

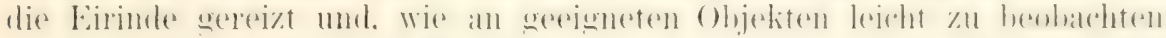
ist, zu einer energischen Kontraktion angeregt wird. Durch den Stich mub mithin in der Hautschicht der Zelle eine Wunde entstanden sein. welche bis zur Befruchtung noch nicht hatte ausheilen kömnen und erst

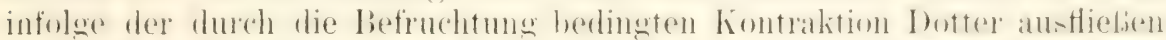

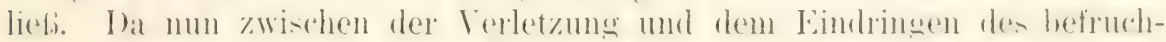
tenden Samenfarlens bei den Froscheiern immer ein längeres, von mir

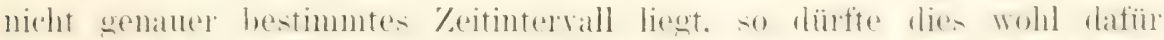

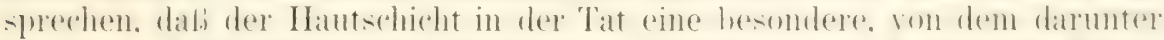

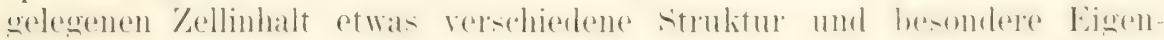
schaften zukommen.

Häufig hat das Protoplasma einen so hohen (iehalt an Imbibitionswasser, daß es Eigenschaften wie eine Flüssigkeit darbietet. Nicht nur zeigt es das später zu besprechende Phänomen der Protoplasmaströmung, sondern wird auch von den Gesetzen beherrscht, welche Plateau und Quracke füir Flïssigkeiten festgestellt haben. Wie die Gesetze der Obertlächenspannung die $\mathrm{Mb}$ lundung eines Flüssiglieitstropfens zur Kiugelform bewirlien, so nehmen auch Protoplasmamassen. welche aus groben P'tanzenzellen, wie Vaucheria, Bryopsis etc., an verletaten Stellen ansgeprebt werilen können. im Wasser alsbald die Form von kingeligen Tropten an.

Auf Grund derartiger Ïhnlichkeiten, welche sich nicht in Abrede stellen lassen. sind manche Forscher, durehdrungen von der Überzeugung, dab alle Lebensvorgänge in letzter Instanz physikalisch, chemisch orler mechanisch erklärbar sein müssen. zul der Ansicht verleitet worken. daßs das

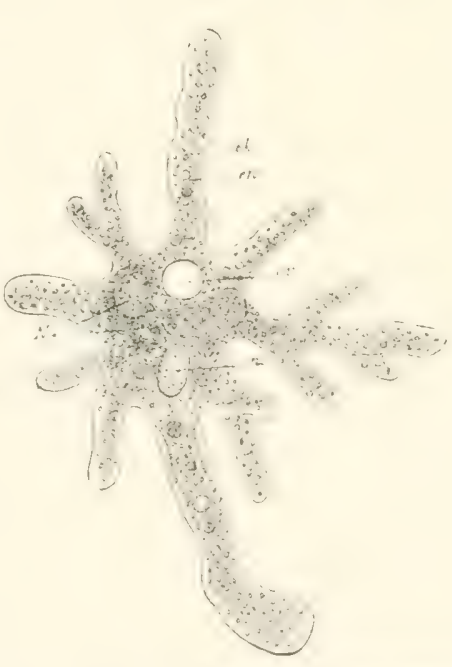

Fig. 2. Amoeba Proteus. Nach Lindo Aus Rich. Hertwig, n. Kerm. 'a'. Kontralitile Vakmole. V. Nalumuersballen. en. Kï̈rnerplasma. ck. Hauptplasma. lebende Protoplasma seiner Natur nach eine Flüssigkeit mol zwar eine Mischung verschiedener flüssiger Substanzen, also eine .Lmulsion" sei.

In seinen Studien über Protoplasmamechanik spricht sich BErTHouD mit Entschiedenheit in diesem Sinne aus. Ihm schliebt sich in jeder

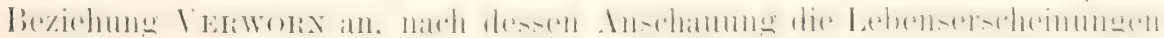
sehr wohl an ein Hüssiges Sulstrat gelinüptt sein können. El erkiärt es als ,eine starke Voreingenommenheit für gewisse unhalthare Theorien, 
wenn man sich der 'Tatsache verschließen wolle, daß das Protoplasma sich physikalisch wie eine Flüssigkeit verhalte".

Er definiert daher auch die Zelle als ein meist mikroskopisch kleines libumplen Hïsiger substan\%, in der vershiedene, teils geformte teils gelöste liestandteile aingelagert sind, und er findet. .. wem man die lebendige sulstan\% mit Hüssigen fiemischen vergleicht, dafi sie sich in ihren

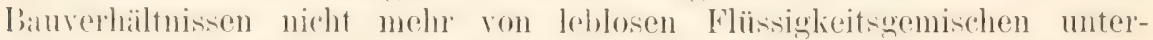
scheidet, wie diese untereinander, ja nicht einmal so sehr, wie diese von einem Kristall".

(iegen derartige und ähnliche Auffasimgen rom Wesen der Zelle muß hier entschieden Stellung genommen werden, da sie ron Girund aus unvereinhar sind mit der Vorstellung rom Elementarorganismus, welcher sich wie ein roter Farlen durch dicses Lehrhuch hindurchzieht und schon gleich auf Seite 11 in einigen Sützen skizziert wurde. Denn wenn auch zugegeben werden muli, dabis das l'rotoplasma unter T'mständen sehr viel Imbihitionswasser aufnehmen und dadureh Eigenschaften wie eine Flüssiglieit erhalten kamn, woraus sich manche Erscheinungen erklären (siehe S. 15). so darf deswegen doch nicht das Protoplasma als eine Flüssigkeit hezeichnet werken. Durch eme solche Definition wird die Erklärung auf etwas ganz. Nebensächliches gelenkt, dagegen von der eigentlichen IIauptsache abgezogen. Denn Hüssig ist im Protoplasma nur das in ihm enthaltene IVasser: die es anfhamenden Eiweibkörper aber und alle ihre unzähligen Derivate, die als die eigentlichen Träger des Lehensprozesses in Frage lommen, befinden sich in einem festen Aggregatzustand und stehen auberdem in näheren und geordneten Beziehungen zueinander, die erst das Wesen des organismus ausmachen. Wen gelöstes Eiweis in der Zelle noch auberdem gefunden wird. so hat es die Berleutung von Nahrungsciweib. welches entweder zu einem integrierenden Bestandteile des Protoplasma erst umgewantelt orler hei tem stoft- und liraftwechsel in ihm in irgend einer Weise aufgebraucht wird.

Wie Nigeri und viele andere Forscher, sind wir der Überzengung. dab die komplizierten Frscheinumen des Lebensprozesies, vor allen Dingen rer Vererbung, nicht aus den Eigenschaften von Flïssigkeiten oder gelïsten Stoffen erklärbar sind. Mit Recht hezeichnet daher Wiesver ..den Tersuch, die Eigentümlichkeiten der lehenden Substanz auf Eigenschaften (ler Flüssigkeiten zurückzuführen, als einen befremulichen."

Eine große Förlerung hat die Lehre rom Protoplasma in der Zukunft von chemischen Untersuchungen zu erwarten. Zur Zeit sind allerdings die Schwierigheiten, welche sich einer rationellen Zellchemie entgegenstellen. Ganz aulierordentliche. Denn. wem schon die ('hemie der Eiweißkörper im Verhältnis zu anderen Gebieten weit zurück ist, so gilt dies in noch höherem Gradle von den Eiweißkörpern der Zelle. Haben wir es doch im Protoplasma nicht mit einer einfachen Proteïnsubstanz, sondern wahrscheinlich mit muzihligen Iodifikationen von solchen zu tun. die in kleinsten Mengen mit einander verbunden sind: zu ihnen treten noch andere Substanzen hinzu, die ans Lmsetzungen von Eiweibkörpern gehildet werlen. und entwerler einer mogressiven oller regressiven Metamorphose angehören kïmnen, in letzterem Falle also Zerfallsprodulite darstellen. Die Schwierigkeit wird im wesentlichen noch darlurch erhöht, dab. jeder lileinste rhemische Fingrift' den Toul der Zelle herheiführt. und gerade das Wesentliche des Protoplasmas, anf welchem der Lehensprozeb heruht. rernichtet. I)al, auf diesem (iehiet mit den gewöhnlichen Methorlen der 
gegenwärtigen Chemie nicht sehr weit zu kommen ist. läbt sich schon jetzt ersehen. Die Zellchemie der Zukunft wird sich daher noch ihre eigenen Methoden ausbilden mïssen. Lin Weg, der schon manches Ergebnis gefördert hat und noch besseres erwarten liibt. bietet sich hier in der farbenanalytischen Methode, wie sie EHRLicr genamt hat. Dieselhe besteht darin, dab man kleinste spezitische Stoffteilchen in der Zelle durch charaliteristische Fürbungen kenntlich und ron anderen unterscheidbar macht. Die zahlreichen Farbstofie. namentlich aber die basischen. sauren und neutralen Anilinfarben gewähren zu weiteren Fortschritten in dieser Richtung die Möglichkeit, namentlich wenn die Färbetechnik sich erst zu einem rationelleren Zweig der Wissenschaft heransearbeitet haben wird.

In dem Protoplasma legt man einen besonderen Wert als den eigentlichen Trägern der Lebensprozesse den Proteinsubstanzen bei, den

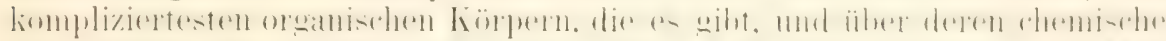

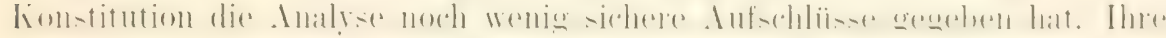
komplizierte Struktur beruht in erster Linie auf den ganz außergewöhn-

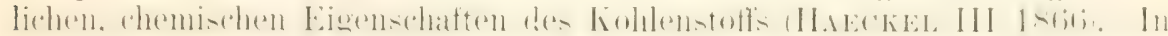
den Proteinsubstanzen haben sich dem Kohlenstoff vier andere Elemente. Wasserstoff, Sauerstoff. Stickstoff und Schwefel, beigesellt. in eimem Verhältnis. welches man durch die Formel $\mathrm{C}^{i-H^{106}} \mathrm{~N}^{15 S O} \mathrm{~S}^{22}$ (Z $11 \mathrm{sammen-}$ setzung eines Eiweibmoleküls) auszudrücken rersucht lat (NïGELI III $188+$ ).

Unter den verschiedenen Arten der Proteinkïrper (Albumine, Globuline, Fibrine, Plastine, Nulieine ete.) scheint für das Protoplasma besonders das Plastin charakteristisch zu sein (REINE III 18ऽ1, ScHWARz III 1887, Zacharias III 185\%); (lasselbe ist im Wassel und 10\% Kochsal\% und $10 \%$ schwefelsaurer Magnesia unlöshich; in verdünnter Essigsäure

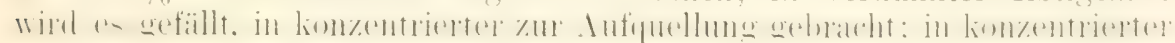
Salzsïure wird es gefailt: es widersteht sowohl der Pepsin- als der 'Trypsinverdaumg. Es fürbt sich wenig oder gar nicht in basischen, dagegen in sauren Anilinfarben (Eosin und S-Fuchsin).

Daneben finden sich in geringerer Menge Globuline und Albumine. die auch in gelöstem Zustand im Zellsaft der Pflanzen vorkommen.

1) as Protoplasma ist sehr reich an IV asser. welches. wie SACHs (III 1882) bemerkt, zu seiner Molekularstruktur in demselben Simme gehört, wie \%. B. das Kristallwasser zur Struktur sehr vieler Liristalle

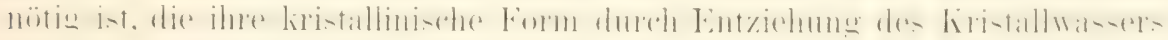
verlieren. An frischen Fuchthörpern von dethalium septicum fand Rerxie (III 1S81) $71,6 \%$ Wasser und $28,4 \%$ bei 100 Grad getrocknete Substanz. $66 \%$ \% Flüssigkeit lief. sich durch Auspressen erhalten.

Im Protoplasma liommen ferner stets eine Anzahl verschiederer Salze vor und bleiben bei der Verbrennung desselben als Asche zuriek.

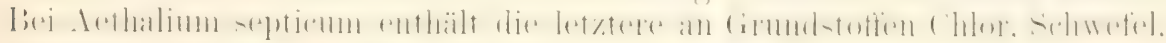
Phosphor, Kalimm. Natrium, Magnesium. Calcium. Eisen.

Lebendes Protoplasma gibt eine deutlich alkalische Reaktion: rotes Lackmuspapier, sowie ein in Braunkohl vorkommenter. von Scuwarz. verwandter, roter Farbstoff wird blau. Es ist dies hei PHanzen auch damn łer Fall, wenn der Zellsaft, wie gewöhnlich, saner reagiert. Die allalische Reaktion rührt nach (len Untersuchungen von Scmwarz (III 1ssi) bei den Ptlanzen ron Alkali her. welehes in dem lebenden Protoplasma an die Proteinkörper gebunden ist. Aethalium septicum entwickelt nach REINKE (III 1.881) in getrocknetem Zustande Ammoniak.

Auberlem lassen sich im Protoplasma stets die verschiedensten St offwechselprodukte nachweisen. welche teils der progressiven. teils der 
regresiven Metamorphose angehören. Sie zeigen im tierischen mol ptlanzlichen \%ellenkërper eine grobe C̈hereinstimmung. Hiep wie dort sind Pepsin. Diastate. Myosin. Sarkin. (ilykogen. Zueker. Inosit. Inextrin. ('holestearin

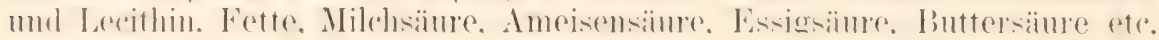
gefunden worlen.

Als licispiel für die quantitative Zusammensetzung einer /elle

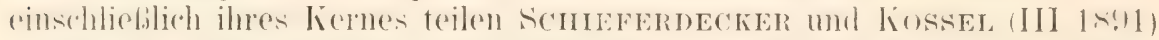

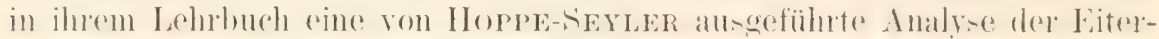

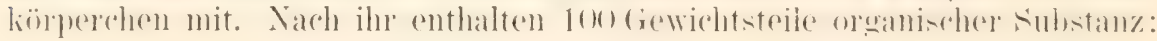

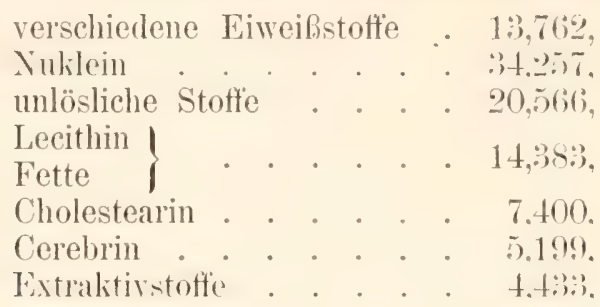

In der Asche fand sich Kalium, Natrium, Eisen, Magnesium, Calcium. Phosphorsäure und Chlor.

Ein anderes, sehr geeignetes Material zur Ausführung chemischer Analysen bieten die Samenfäden des Lachses dar, welche von MiEscher einer Analyse unterworfen worden sind. Da die Köpfe der Samenfäden hauptsächlich aus Kernsubstanz bestehen, ergibt sich ein hoher Prozentsatz von Nuklein. Miescher hat die Lachsmilch in 100 Teilen organischer Stoffe zusammengesetzt gefunden aus:

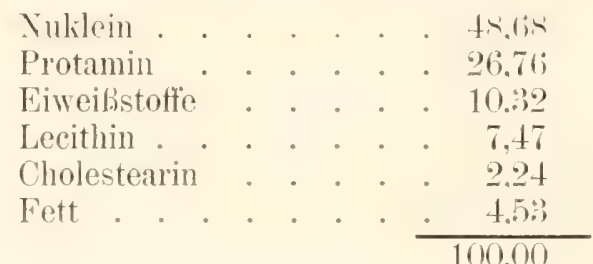

Von manchen Seiten ist die Ansicht ausgesprochen worden, daß die Eiforshume der Lebenssulstanz mud des Lebensprozesses ein chemischphysikalisches Problem sei. Nur scheint auch in diesem Ausspruch eine Verkemmug der eigentlichen Aufgahen. welche die Liologie zu lösen hat. enthalten zu sein. IVir sind weit entfernt, den alten Begriff der Lebenskraft wieder neu auffrischen zu wollen. Wir schliehen vielmehr so: Nehmen wir selbst an. die Wissenschaft der Chemie wäre in einer fernen Zukunft so weit vervollkommnet, daß sie uns genau den Aufbau aller mö̈glichen Eiweilinolekïle und ihrer Derivate durch Analyse nachzuweisen imstande ist, dals sie ferner auch mit ihren Methoden anzugehen vermöchte. welehe Arten von Eiweilimolekiilen mol anderen organisehen stoffen und in welcher Menge sie in der lebenden Zelle enthalten sind, so wïrde nach unserer Ansicht durch diese gewib wunderbaren Leistungen chemischer Fixprimentierkunst und Methodik der eigentliche liern des Lehensprohlems moch mogelost mul die Einsicht in das Wesentliche der lebenden Zelle mul des Protoplasma noch nicht gewonnen sein. Denn die Zelle ist kein "lebendes Eiweis", wie man zuweilen gesagt hat, sie ist nicht einfach ein fiemengel zahlloser Fiweibmolekïle, somdern sie ist ein (Hoanismus. gebildet aus gestzmäbig untereinander verbundenen elementaren Lebensein- 


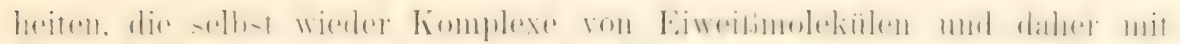

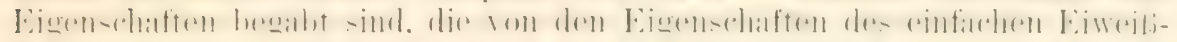
molekïils ebenso verschieden sind, wie die Eigenschaften des letzteren von den Eigenschaften der es aufbanenden Atome. Daher sagte ich in einem Vortrag: .. Wenn es Aufgabe des Chemikers ist, die zahllosen Verbindungen

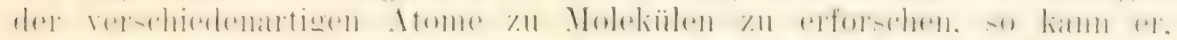

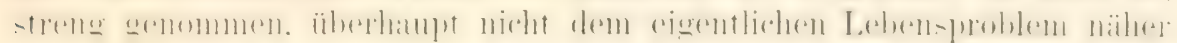
treten. Denn dieses beginnt ja überhaupt erst da, wo seine Untersuchung authört. Über dem Bau des chemischem Molekiils erhebt sich der Bau (ler lebenden Substanz als eine weitere höhere Art von Organisation, erhebt sich der bau der 'Zelle und über diesem erhebt sich wieder der Bau

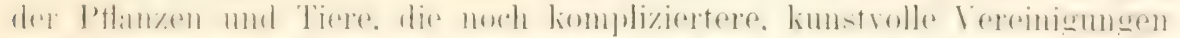

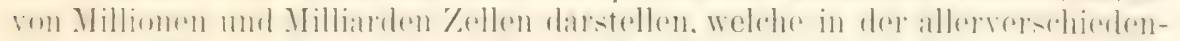
artigsten Weise zusammengeordnet und differenziert sind."

.Was hat in aller Welt chemische Wissenschaft, wie sie jetzt ist, mit

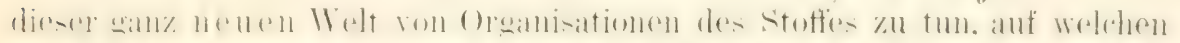

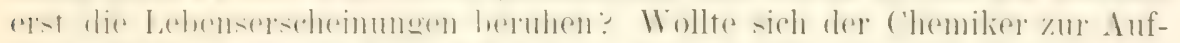

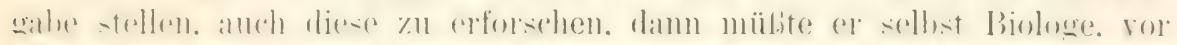
allem Morpholuge: werden damn aher wïrlen atuch seine Arbeitsmethorlen mol biele durchaus andere und viel umfassendere sein."

Wenn die Chemie dereinst auch alle Eiweißkörper durch Synthese

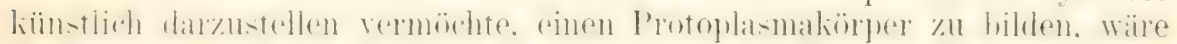

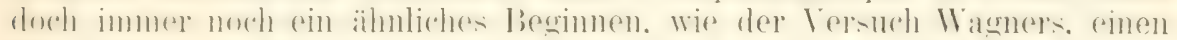
Homunculus in der Phiole auszukristallisieren. Denn nach allen unseren Erfahrungen entstehen Protoplasmakörper auf keinem anderen Wege als durch Fortpflanzung aus vorhandenem Protoplasma; ihre heutige Organisation ist daher das Produkt einer auberordentlich langen historischen Entwicklung.

In den feineren Ban des Protoplasma mit Hilfe des Mikroskops

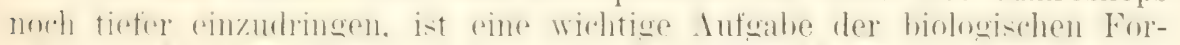
shome. In Virsuchen dazu hat es in dem letzten Jahloehnten anch nicht

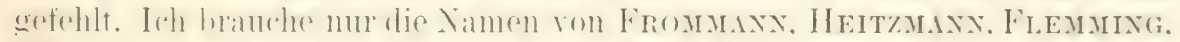

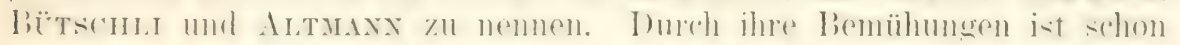
eine besondere, kleine Literatur viber das Krapitel:

\section{,Protoplasmastruktur}

\section{entstanden.}

Die Ergebnisse sind allerdings noch wenig zufrierlenstellende. Auch

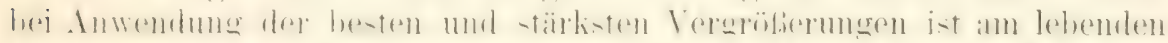

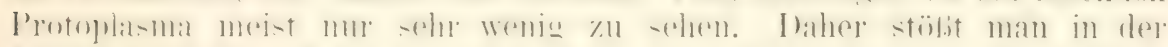

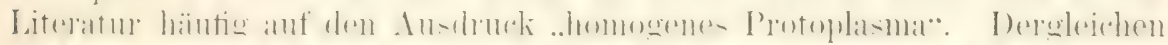

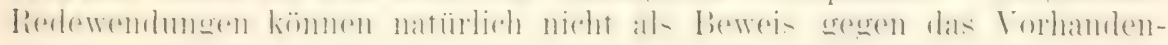
sein einer feineren Struktur verwertet werlen. (la dieselbe sich unserer

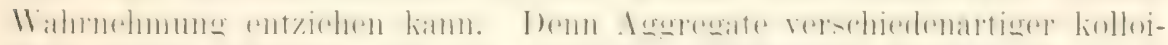

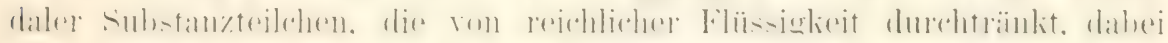
sehr klein, farblos und in ihrem Lichtbrechungsvermögen von einander und rom Imbibitionswasser nicht geniigend verschieden sind. werden uns optisch homogen erscheinen.

Bei dieser Sachlage wird man zwar versuchen müssen. soweit es möglich ist, schon am lebenden Protoplasma etwa vorhandene Strukturen zu erkemmen. aber auch auf die Iilfsmittel nicht verzichten, die passende

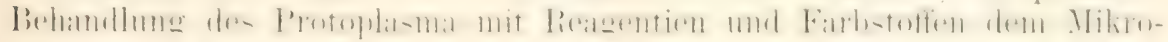
skopiker darhietet. Demn dureh (ierinnumg und Färbung können anch 
kleinste Substanzteilchen in der Zelle auf das schärfste sichthar und zugleich von anderen chemisch verschiedenen Körpern differenziert werden. Allerdings wird man sich hier mehr, als es häutig geschieht, den so er-

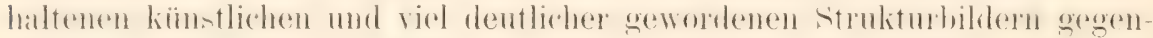
über sehr kritisch zu verhalten haben und wird stets prüfen müssen, ob

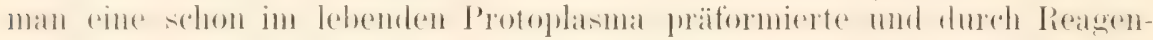
tienwirkung nur erkembar gemachte, oder ob man eine im Leben gar nicht vorhanden gewesene, nur durch die Konservierung hervorgerufene Struktur, ein Artefact. vor sich habe. Die erstere ist von Wert. die letztere belanglos. Die Unterscheidung zwischen beiden ist oft gewils nicht leicht, und sind in der Literatur zuweilen Kunstprodukte als normale Verhältnisse beschrieben worden. Es ist ein Verdienst von A. FIscher in seinem Buch Fixierung, Färbung und Bau des Protoplasma die kritische Sonde angelegt zu haben.

Als Kunstprodukte sind alle festen Gebilde aufzufassen, die durch Ausfillung von Alhuminaten mul abnlichen stoffen entstanden sind. die sich, wie wir wissen, im Imbibitionswasser des Protoplasma und im Kernsaft in Lösung vorfinden. So können Körnchen, Hohlkugeln, Fädchen, Netze und andere Arten von Gerinnseln in der Zelle zum Vorschein kommen, die, wie die Gerinnsel im Kernsaft nicht das geringste mit wirklich präformierten Strukturen zu tum haben. Der Mikroskopiker darf sich auf der einen Seite durch dergleichen Gebilde nicht täuschen lassen, auf der anderen Seite darf er in der. Skepsis aber auch nicht so weit gehen,

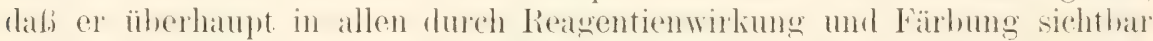
gemachten Strukturen Kumstprodukte vor sich zu haben argwöhnt. Dem-

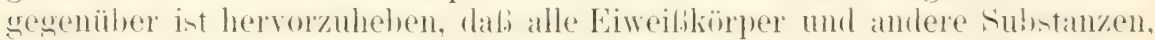
die sich in den lebenden Zellen schon in einem festen Aggregatzustand befinden, hei leagentienhehandlung und Färbung Form nud Tusammenhang in ursprimglicher Woise anch heibehalten werden. ()h, hierhed dieses oder jenes rebilde efwas geschrumpft orler gerpollen orler sonstwie etwas verändert ist, bleibt Nebensache gegenüber dem Umstand, daß wir in eine wirlich vorhandene struktur der lehenden Zelle cinen Einhlick gewonnen haben. In diesem Sinne betrachte ich als wirkliche Strukturteile der Zelle das Kernnetz, die Chromatinkörner, die Nukleolen, Chromosomen, das Centrosom, die Plastiden, Vakuolen, viele fibrilläre Gebilde usw. Nach unserem Ermessen ist FIsCHER in seinen kritischen Untersuchungen, so verdienstlich sie sind, in manchen Beziehungen viel zu weit gegangen und ist zu Zweifeln geführt worden auch in Fällen, wo sie uns nicht angebracht zu sein scheinen. Mein Standpunkt lälit sich kurz dahin zusammenfassen, dab, der Mikroskopiker sich nur zu hüten hat, vor einer Verwechselung der durch Reagentienbehandlung ausgefälten, in der lebenden Zelle aber gelösten Albuminate etc. mit präformierten, in festem Aggregatzustand befindlichen und daher wirklichen Strukturteilen der Zelle. Die Unterscheidung zwischen beiden mag zuweilen nicht leicht sein.

Eine andere Schwierigkeit bei der uns beschäftigenden Frage beruht darauf, daß die bei sehr starken Vergrößerungen sichtbar werdenten Strukturen, namentlich wem der Lichtstrahl durch viele kleine. über einander

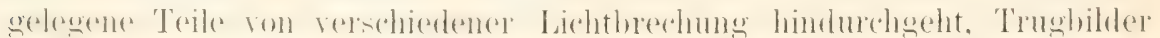

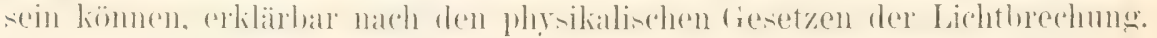
Kein geringerer als AвBE, der beste Kenner des Mikroskops und der Gesetze der Optik, hat davor gewarnt, nicht jedes bei starker Vergrößerung erhaltene Bild als den richtigen Ausdruck einer im untersuchten Gegenstand wirklich vorhandenen Strulitur zu halten. So wäle anch in dieser 
Richtung Vorsicht geboten. Daher kamm es mus nicht wumlemehmen, dab. das Thema der feineren Protoplasmastruktur noch etwas im argen liegt.

In den letzten Dezennien sind über Protoplasmastruktur wenigstens vier Ansichten geäufert worden, welche als Gerïstheorie, als Schaumoler Wabentheorie, als Filartheorie mol als (iramulatheorie charakterisiert werlen kïmnen.

Die Geriettleorie ist von Fromany (III 1875)). Hertzanax (III

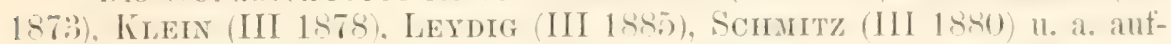
gestellt worden. Nach ihr besteht das Protoplasma aus einem selı feinen Tetzwerk von Fibrillen orler Fïserchen, in dessen Lüicken Flüssigkeit enthalten ist. Es gleicht daher im allgemeinen einem Schwamm: seine Struktur ist. wie man sich kurz anstriekt, eine spongiöse.

Bei einem Überblick ïber diese Literatur wird man finden. daf.) muter der Bezeichmung ,spongiöser bau des Protoplasma* zuweilen ganz heterogene Dinge zusammengeworfen worden sind. 'Teils beziehen sich die lieschreibungen auf gröbere Gerüstwerke, welche durch Einlagerung verschiedenartiger Stofte in das Protoplasma, wie später noch ausführlicher besprochen werden wird, bedingt sind und daher nicht als eine dem Protoplasma als solchem anhaftende Struktur bezeichnet und mit in zusammengeworten werlen dürfen. Dies gilt z. B. für die Beschreibung der Becher\%ellen yon LIST (III 1895). Teils sind zuweilen auch netztörmige Strukturen beschrieben und abgebildet worden, die durch (ierinumg (dureh einen Entmischungsvorgang) hervorgerufen sind und als Kumstprodukte gedentet werlen müssen. Küustliche Gerüststrukturen kann man sich z. B.

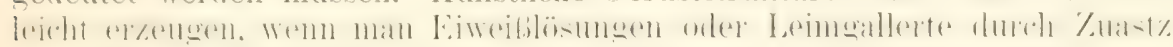
von Chromsäme. Pikrinsäme orler Alkohol zur Gerimmung bringt. So zeichnet HEITZMLAN (II 17 ) in sehr schematischer Weise in die verschie-

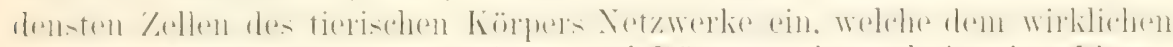

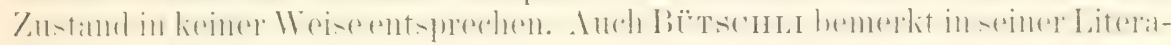
turübersicht (III 18.92 p. 11:3), ..es sei überhaupt häufig recht schwierig zu

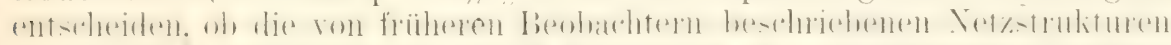

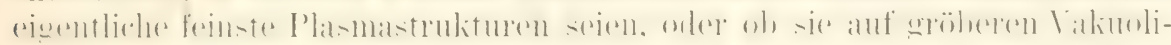
sationen beruhen. Da sich beirle sehr ähnlich sehen, könne man hierïber

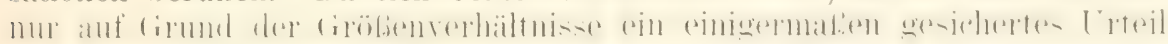
gewinnen." Bütschut fand durchgängig, dab die Maschenweite der eigentlichen Plasmastrukturen kaum 1 u ïberschreitet.

Wenn somit gegen viele Angaben gerechte Zweifel erhoben werden

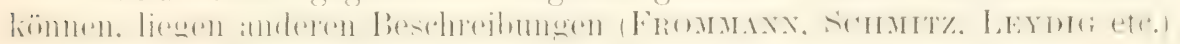
wohl wirklich feinere Surukturen des \%ellkörpers zugrunde.

in der Deutumg der als Netzwerk beschriebenen Bikler nimmt Bütschu einen eigenen, von den genamien Folschern abweichenden Standpunkt ein. welcher ihn zur Aufstellung einer Schanm- orler Wabentheorie des

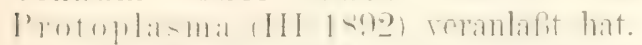

Jurch Vermischung von einge-

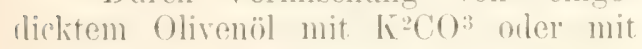
Kochsal\% orler Rohrzucker gelang es ihm, feinste Schïume her\%ustellen. deren (rimul-

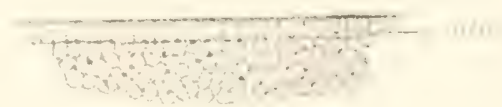

Fig. 3. Optischer Durchschnitt der Randpartie eines aus Olivenöl und Koclisalz hergestellten ölschaumtropfens mit sehr deutlichex und relativ holier Alveolarschicht

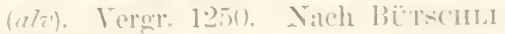
laf. III, Figr. I. masse Öl ist. ras von zahllosen. allseitig ahgeschlossenen und von wässeriger Flüssigkeit erfüllten Rïumehen durehsetzt ist (Fig. :3). Der Durelumesser (ler letzteren bleibt hei selu feinen 
mikirosiopischen schämmen in der liegel unter (1,on) mm. I)ie kleinen Rämmehen. die sich Bienenwahen vergleichen lasien und die verschiedenartigsten Polyeder darstellen kömnen, werden durch feinste, das Licht etwas stälier lorediende (Ollamellen voneinander getrennt. In der Anordnums der Waben muß nach physikalischen Regehn stets die Bedingung erfïllt sein, dafi immer nur drei Lamellen in einer Kante zusammenstoßen. Auf dem optischen Durchschnitt treffen daher in einem Kinotenpunkte immer nur drei Linien zusammen. Waren im öl vor der Schaumbildumg feine liublartikelchen verteilt. so sammeln sich dieselhen in den Knotenpunkten des Wabenwerkes an. An feinen Schäumen läbt sich endlich noch eine ohertlächliche sichicht nachweisen. in welcher die kleinen Wahen in besonders eigentümlicher Weise angeordnet sind in der Weise, daß ihre an die Obertläche stobenden Scheidewände aus Ö senkrecht zu dieser gerichtet und daher anf dem optischen I)urchschnitt parallel zueinander gelagert sind. Büтschi. unterscheidet dieselhe als cine Alveolarsehicht (Fig. 3 ali).

Fig. 4.

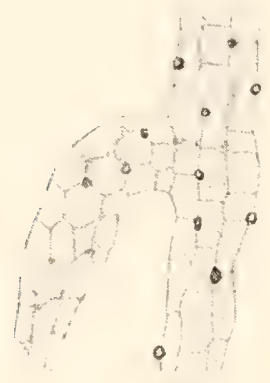

Fig. 4. Zwei lebende Plasmastränge aus den Haarzellen einer Malve. Ltwa 3000 fach vergr. Nach Bütschli Taf. II, Fig. 14.

Fig. 5. Schwimmhautartige Ausbreitung mit sehr deutlicher Struktur aus dem Pseudopodiennetz einer Miliolide. Lebend etwa 3000 fach vergr. Nach Bütschli 'Taf. II, Fig. 5 .
Fig. 5 .

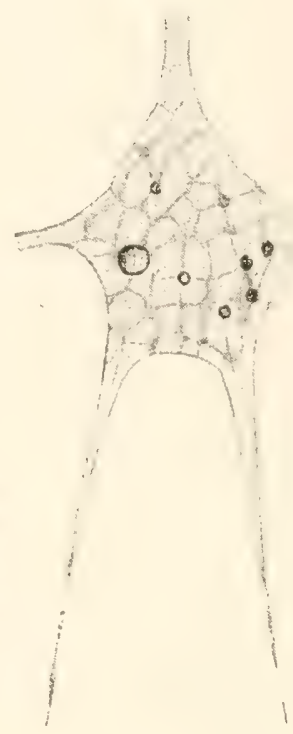

Genau denselben Bau glaubt num Bürschli für das Protoplasma aller ptlanzlichen und tierischen Zellen (Fig. 4 u. 5) auf Grund seiner Cntersuchms lehender und mit Reagentien hehandelter ()hjekte annehmen zu müssen. Den Öllamellen, welche im künstlichen Schaum die Flüssiglieitstriptelen trennen. entspricht ein plasmatisches fierïnt. Auch hier sind in den Knotenpunkten desselben die Körnchen (Mikrosomen) zusammengedrängt. Auch hier ist der Protoplasmakörper nach außen häutig zu einer Alveolarschicht differenziert. Das Bild, welches andere Forscher als Faden- und Netzwerk mit kommunizierenden, die Flüssigkeit bergenden Maschenräumen beschreiben. deutet Bütschli als Waben- und Schaumwerk mit allseitig abgeschlossenen Räumen: er bemerkit aber selbst zu dieser Deutung, daf bei der Kleinheit der in Frage stehenden Strukturen natch dem mikioshopischen bilde allein eine feste Entscheidung darüher, ob 


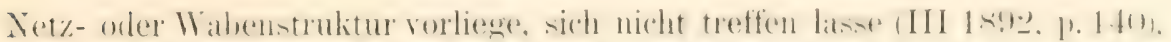

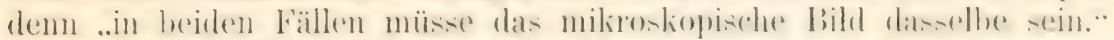

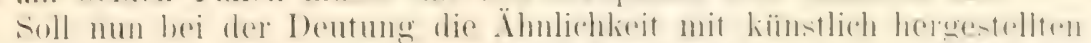

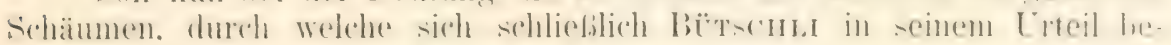
stimmen läßßt, den Ausschlag geben?

Hier möchte ich doch zwei Bedenken geltend machen: erstens das

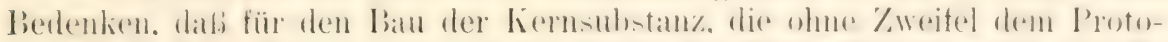

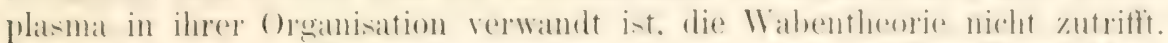

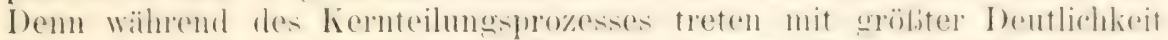

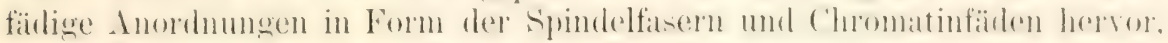
deren Existen\% wohl von niemand in Zweifel gezogen werden kam.

Das zweite Bedenken ist mehr theoretischer Natur:

Öllamellen bestehen aus einer Flüssigkeit, (lie mit Wasser nicht

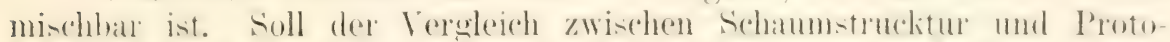
plasmastrubtur anf etwas mehr als einer oberfläehliehen Ïhnlichkeit les-

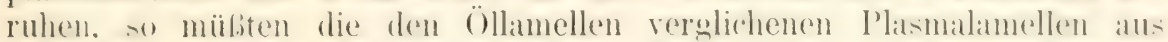

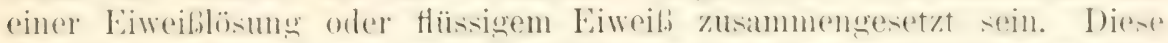

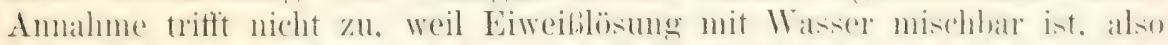
auch mit dem Wabeninhalt sich mischen mülite: Eiweilischïmme müliten mit Luft heresestellt werlen. Cm diese schwierigleit zu umgehen. nimmt

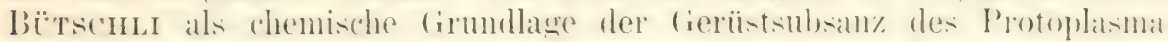
eine flüsigheit an, die ans einer Kombination ron eiweibatigen mol ron

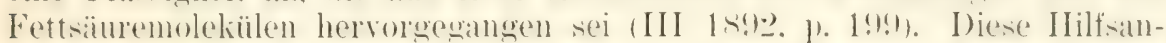
nalme diufte. Wie äherhaupt die Annahme einer flï-igen IBeschaffenheit der lierïstsubstan\%, wenig beifall finden. Denn nach vielen Rirhtungen hin erscheint doch die theoretische forderung eine wohlherechtigte. diali die strukturelemente der Protoplasma, mögen sie num Färlchen cines Xetzes oter Lamellen eines Wabenwerkis oder Körnden oler sonst Was sein. einen festen Ageregatzustand haben. I)as Protoplasma ist kein fiemeng-el zocoler

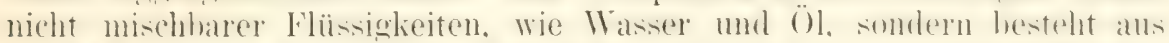
einer Verbindung fester organischer substanzteilehen mit reichlichem Wasicer.

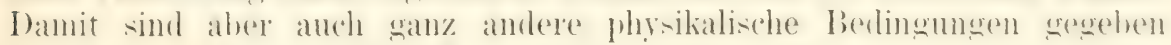
(vergl. den Abschnitt über Molekularstruktur, p. 49).

Die dritte von den oben aufgeführten Lehren oder die Filartheorie ist an den Namen von Flemming (III 1882) geknüpft.

Bei der Untersuchmo vieler Zellen im lebenden Zustand (Ḱnorpel-,

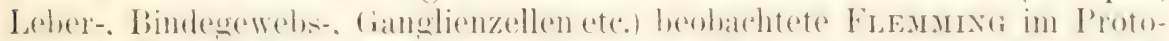

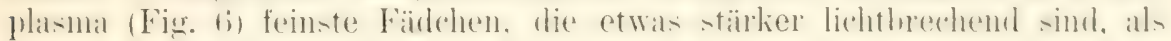
die sie tremnende Zwischensubstanz. In manchen Zellen sind die Fädchen liüzer, in anderen länger: bald sind sie spärlicher, bald reichlicher vorhanden. Ob sie vonemander getrennut sind und durchweg aneinander vorbeilaufen, oder ob sie sich zu einem Netz verbinden. konnte nicht bestimmt entschieden werden: wollte man sie sich aber auch zu einem Netz verbunden denken. so würden die Maschenräume sehr ungleich weit ausfallen.

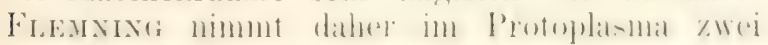

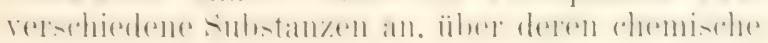
Natur und deren Agregratzustand er sich nicht näher äufert: eine Fädchensubstan\% und eine Z wischensubstanz, oder eine Filar- und Inter-

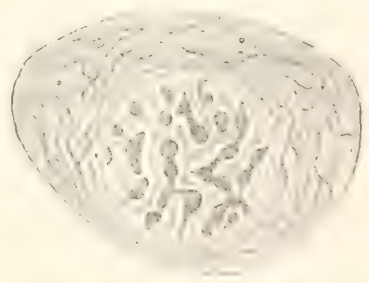

Fin. 6. Lebende Knorpelzelle der Salamandexlarve, stark vergxößert, mit deutlicher Filarsubstanz (Hach FI.JMMI(i). A11 H.LTSCHEK Fin. 2. filarmasse. (Mitom und Paramitom.) Welche lie- 
deutung dieser Struktur zukommt, worïber sich zurzeit noch gar nichts aussagen lälst. mulb der Zukunft anheimgegeben werlen.

In dem Abschnitt, ,Protoplasmastruktur" künnte anch auf die strahlige Anordnumg des Protoplasma, wie sie auf gewissen Stadien der Kernteilumg voriibergehend beobachtet wird, oder auf das streifige Aussehen, welches das Protoplasma sekretorischer Zellen so häufig zeigt, uäher eingegangen werden. Da es sich aber hier $n$ m Strukturen handelt, die durch besondere Verhältnisse verursacht werden, wollen wir erst an späterer Stelle auf sie zuriickkommen.

In einer vierten Richtung endlich bewegen sich wieder die Bestrebungen Altandans (III 1s90), eine feinere Zusammensetzung des Protoplasma nachzuweisen (Granulatheorie). Dieser Forscher hat duch Ausbildung

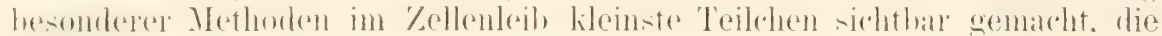
er als Granula bezeichnet. Er konserviert die

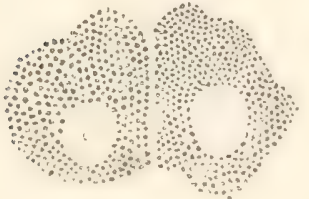

Fig. . . Leberzellen mit Granulis (nach ALTMANx). Aus Terworss Lehrbuch d. allg. Phys. Fig. 7. Organe in einem Gemisch ron $5 \%$ Lösung ron Kaliumbichromat und ron ²\% iger Überosmiumsaime und färbt die ron ihnen angefertigten femen Schnitte mit Säurefuchsin, wobei die Färbung durch alkoholische Pikrinsäurelösung schärfer differenziert wird. In einer farblosen frundsubstanz werden bei diesem Verfahren zahlreiche, kleinste, dunkelrot gefärbte Körnchen sichtbar gemacht, die entweder isoliert bald dichter, bald lockerer nebeneinander liegen odler in Reihen zu Färlen verbunden sind.

Altmann knïpft an seinen Nachweis eine weittragende Hypothese. Er erblickt in den Granula noch kleinere Elementarorganismen, aus denen die Zelle selbst wieder zusammengesetzt ist; er nennt sie die Bioblasten, schreibt ihnen den Bau eines organisierten Kristalls zu und betrachtet sie für gleichwertig den Mikroorganismen. die sich auch als Einzelemente in Haufen zu einer Zoogloea oder der Reihe nach in Fäden anordnen. . Wie in der Zoogloea die einzelnen Individuen durch eine gallertartige Aus-

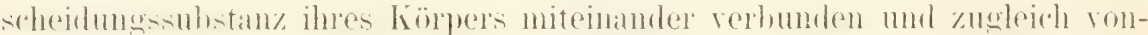
einander getrennt sind, so dürfte dies auch bei den Granulis der Zelle der Fall sein; auch hier werden wir in der Umgebung derselben nicht nur

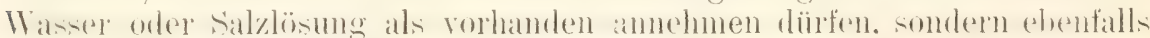

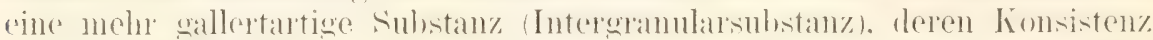
in manchen Fällen bis an den Hüssigen Zustand heranreichen, in andern aber ziemlich derb sein wird. Für den ersten Fall spricht die grofe Beweglichkeit, die manchen Protoplasma eigen ist. Häuft sich die Intergranularsubstanz irgendwo in der Zelle ohne Granula an. so vermag sie hier ein echtes Hyaloplasma zu bilden, welches frei von lebenden Elementen ist, darum auch den Namen eines Protoplasma nicht verdient."

Altudany definiert dader .das Protoplasma als eine Kiolonie von Biob) lasten, deren einzelne Elemente sei es nach Art der Zoogloea, sei es nach Art der (iliederfäden gruppiert und durch eine indifferente Substanz rerbunden sind:" "Der Bioblast ist daher die gesuchte morphologische Einheit aller organisierten Naterie, von welcher alle biologischen Erwägungen in letzter Instanz auszugehen haben." Doch ist der Bioblast der Zelle keines isolierten Lebens fähig. er stirbt mit der Zelle ab. In ihr aber, so nimmt Altudax an, vermehrt er sich nur durch 'Teilung. (Omne granulum e granulo.) 
Gegen die Altmaxsche IJyothese, soweit sie sich anf Dentung beobachteter Verhältnisse bezieht. lassen sich manche finwände erheben. 1. Die kleinsten Miliroorganismen einer Zoogloea sind durch vielfache Übergïnge in der Größe mit gröberen Sprob- und IJefepilzen verbunden. die ihrem bau nach von Zellen nicht zu unterscheiden sind und daher nach Altuax auch liolonien von Bioblasten sein mübten. Auch hat Bürscur bei gröferen Mikroorganismen eine Somderung in liern und Protoplasma und damit die Überemstimmung im lau mit anderen Zellen

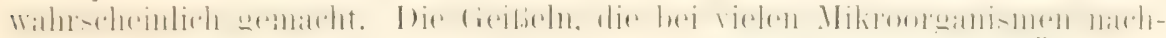
gewiesen sind, müssen auch als Zellorgane gerleutet werlen. 2. Über die Beschaffenheit und Aufgabe der (ranula in der /elle sind wir noch viel zu wenig anfgeklärt, als dab sich nur irgendwie die Schlubfolgerung rechtfertigen liefe, durch welche sie zu den eigentlichen Lebenselementen der Zelle erhoben werden. Durch die Alturaxssehe Hypothese wird der llert. welchen man den Zellsubstanzen bisher znerteilt hat, vollständig umgehehrt. Artanns Intergramularsubstan\%, welehe ihrem physiologischen Wert nach der Gallerte der Zoogloea gleich geschätzt wirl, ist im wesentlichen das Protoplasma der herrschenden Zellentheorie, also die Substanz, welche als die wichtigste Grumellage der Lebensprozesse betrachtet wind; die Granula

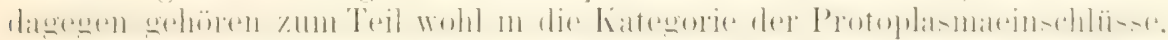
denen man bisher eine minder bedeutungsvolle Rolle znerteilt hat. So bezeichnet Alturaxy in der Pigmentzelle die Melaninkörnchen als die Bioblasten, das sie verbindende Protoplasma als Intergranularsubstan\%. Ebenso kehrt Altuax beim Kern. wie bei der Beschreibung desselben hervorgehoben werden wird, den physiologischen Wert der Substanzen vollständig um, indem seine Granula im Liernsafte enthalten sind, die Intergranularsubstanz aber dem chromatinhaltigen Kernuetz entspricht.

Mit deni Worte Glanula hat nach unserer Auffassung DrTurax Gebilde von sehr verschiedenem morphologischem Wert, die zum Teil in die

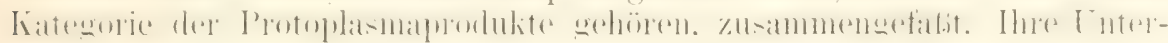
suchung durch nene Methoden zugïnglicher gemacht zu haben, wird das Hauptrerdienst der auf sie bezüglichen Aibeiten von ArTardx bleiben. wïhrend die auf sie gegriundete Bioblastentheorie sich wenig Anhänger erworben haben dïrtte.

Wenn wir jetzt die mitgeteilten 'Theorien auf ihre Berechtigung prifen und aus dem Widerstreit der in ihnen zutage tretenden Ansichten ein Endergebnis zu gewinnen suchen, so scheint es uns zurzeit nicht möglich zu sein, eine universelle Formel für die Protoplasmastruktur autzustellen. Wie auch Kölliker, Fleminga, Wilsox, Hexsegur und andere schon hervorgehohen haben, kann das Protoplasma sowohl fibrilläl, als alveolär. oranulär oder anscheinend homogen sein: auch kam seine Struktur während der Entwicklmo der Zelle sich ändern, wie es WILsox fiur das Ei der Echinodermen verfolgt hat, ferner liann es auf bestimmten Phasen sciner Lebenstïtigkeit bestimmte Strukturen vorübergehend ammehmen. \%. B. ein strahlig fibrilläres Aussehen während der liefruchtung in der Umgebung des eingedrungenen Samentadens sowic im Verlant der haryolinese.

Endich kam das Protoplasma noch ein sehr versehiedenartiges Anssehen dadurch gewinnen, daf.j es Einschlüsse von chemisch differenten Stoften enthailt. Diese kömnen zuweilen in solcher Masse ahgelagelt sein. dab der ganze Zellkörper fast allein aus ihnen zu bestehen scheint. Denlen wir sie uns in rliesem Falle entfernt. so entstehen naturgemiil. in dem /ollkürper zahlreiche größere und kleinere Iü̈chen, zwischen denen die proto- 
plasmatische cirundlage der zelle als ein zuweilen andiorortentlich feinesFach- und Gerïstwerk zutage tritt. Dieses darf nicht, wie schon hervor-

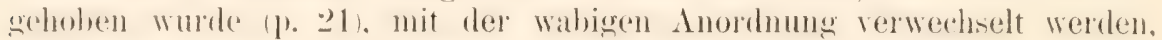
welche als feinere "Protoplasmastruktur" oben besprochen wurkle.

Nach CRATo und WrLson sollen übrigens die gröbere oder pseurloalveoläre und die feinere oder, ,wahre" wabige Struktur yon Bütschur durch alle möglichen Dhstufungen unteremander verhunden sein. so dab nach der Ansicht von WILSON (III 1900, p. 50) kein logischer Grund für eine prinzipielle Unterscheidung zwischen ihnen besteht.

Man hat für die im Protoplasma eingeschlossenen Substanzen die

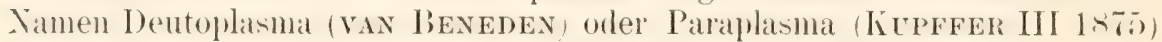
vorgeschlagen. Da man aber mit dem Wort Plasma doch immer die Vorstellung einer Fiweibsubstanz verbindet, die Finschlösse aber auch aur Fett. Kohlenhydraten. Saft und manchem anderen bestehen liönen, diurfte sich der fiehrauch jener heirlen Bezeichnumgen nicht empfehlen. und es ist besser anstatt dessen entweder allgemein von inneren Plasmaprocluten und Zelleinschlïssen oder, je nach ihrer Bedeutung. von Reserve- und Sekretstoffen oder speziell von Dotterplättchen, Fetttropfen, Stärliekïrnern. Pigmentkömchen ete. zu reden. Auf diese ciebilde wird in dem Abschnitt, der ïher den Stoffwechsel der Zelle handelt, noch näher eingegangen werden.

Zwischen dem Protoplasma und den Substanzen, die als Zelleinschlüsne zusimmengefabt werden können. besteht ein ähnlicher Lnterschied, wie zwischen den Stoffen, die die Organe unseres Körpers ansmachen. und den stotten. die erstens als Nahrmg in unseren Körper aufgenommen werden und zweitens in Hüssigem Zustande als Ernährungssaft huch alle Or.gane zirkulieren. Die ersteren. welche rom jeweiligen Ernährungszustand des Körpers weniger abhängig und geringerem Wechsel unterworfen sind, nemt man in der Physiologie Dauerstoffe, die letzteren Verbrauchsstoffe. Dieselbe Tnterscheidung ist auch für die den Zellkörper zusammensetzenden Substanzen anwendbar. Das Protoplasma ist ein Dauerstoff, dagegen die in ihm eingeschlossenen Substanzen seine Verbrauchsstoffe. 
DRITTES KAPITLI.

\section{Die chemisch-physikalischen und morphologischen Eigenschaften des Zellenkerns. (Nucleus).}

Ebenso wichtig wie das Protoplasma ist für das Wesen der Zelle der Zellenkern: (derselbe wurle 18:33 von RoBert Brown (I 18:3:3) in

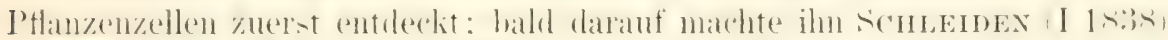

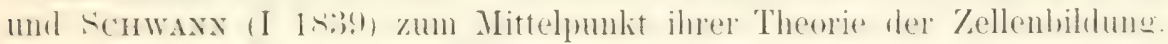
Datm trat das studium des Zellkerns eine Zeit lane in den Hinterermud. als man mit den interessanten Lehenserschemungen des Protoplasma näher bekannt wurde. Erst vom Jahre 1870 an ist auch auf dem Gebiet der Kernlelre eine Entdeckung der anderen gefolgt und hat das zuror rer-

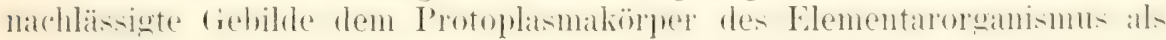
gleichwertig erscheinen lassen.

In der Geschichte des Zellenkerns läBt sich eine gewisse Aualogie mit der Geschichte der Zellentheorie nicht verkennen. Auch den Zellenkern fabte man zuerst als ein Bläschen, ja geradezu als eine kleinere Zelle in der größeren auf. Wie man dann in der Zelle das Protoplasma als die lohenstätige substanz beurteilen lernte. so sah man suater auch heim herm ein. daß die Form des Bläschens etwas Nebensächliches sei. dab die

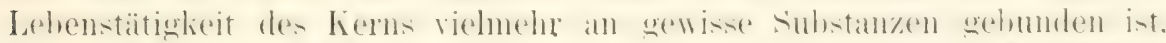

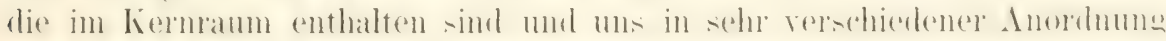
im ruhenden und tätigen Zustand entgegentreten kömnen.

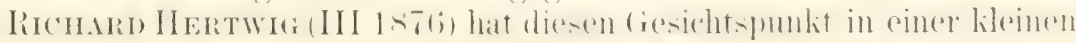

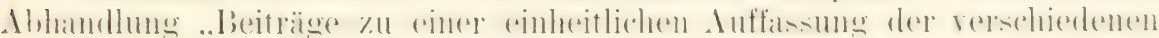
Kernformen"* zuerst klar ausgesprochen in den Worten: .Als den wichtig-

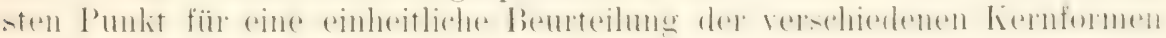
mub ieh gleich am Anfang meiner Betrachtungen hervorheben, dab sich

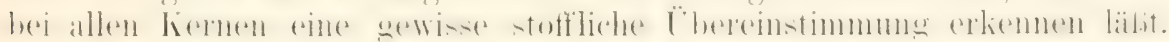
Ob wir nun Zellkerne von 'Tieren. Pflanzen oder Protisten untersuchen mögen. stets finden wir dal. sie mehr oller minder von einer Substanz gebildet werden. welche ich im Anschlub an frühere Autoren als ..Kernsul)stanz: (Nuklein) bezeichnen worde. Ton der Charakteristik dieser Sulustan\% müssen wir ausgehen, ebenso wie derjenige. Welcher das Wesentliche der Zclle schildern will, zunäichst mit der Zellsubstanz oder dem Protophasma beginmen muli." 
Wir definieren daher jetzt den Kerm nicht meh" im Sinne von Scminex und Schwaxy als ein kleines bläschen in der Zelle, sondern als eine rom Protoplasma unterschiedene Masse eigentümlicher Kernsubstanzen. Welche in sehr verschiedenartigen Formzustïnden sowohl im ruhenden, als auch im aktiven Zustand bei der' 'Teilumg auftreten.

Wir betrachten nacheinander die Form. die Größe und die Zahl der Lerne in einer Zelle, alsdann die im Kiern enthaltenen Substanzen und ihre verschiedenartige Inordnungsweise (die Kernstrulitur).

\section{a) Form, Größe und Zahl der Kerne.}

Gewöhnlich erscheint uns der Kern in pflanzlichen und tierischen Zellen als ein mitten in der Zelle gelegener, kugeliger oder ovaler Körper (Fig. 1, 2. 6, 7). Da er häufig reicher an Flüssigkeit ist als ras Protoplasma, läbt er sich von letzterem auch in dem lebenden Objekt als ein heller. matt lionturierter Fleck, als ein Bläschen odler als Vakuole unterscheiden. Das ist aber nicht immer der Fall. An vielen Objekten.

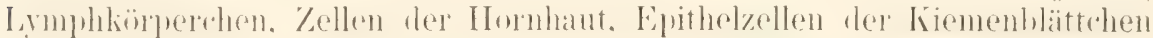
von Salamanderlarven ist der Kern im lebenden Zustand nicht zu beobachten, wird aber sofort beim Absterben der Zelle orler bei Zusatz von destilliertem Wasser oder von verlümnten Säuren infolge eintretender Gerinnung dentlich.

Bei manchen Zellarten und nierleren Organismen bietet uns der Kern sehr abweichende Formen dar. Bald bildet er ein Hufeisen manche Infusorien), bald einen langen, mehr oder minder gewundenen Strang (Vorticellen), bald ist er ein reich verästelter Körjer, der die Zelle nach den rerschierlensten Richtungen durchsetzt (Fig. \& B u. C). Letztere Kiernform

1
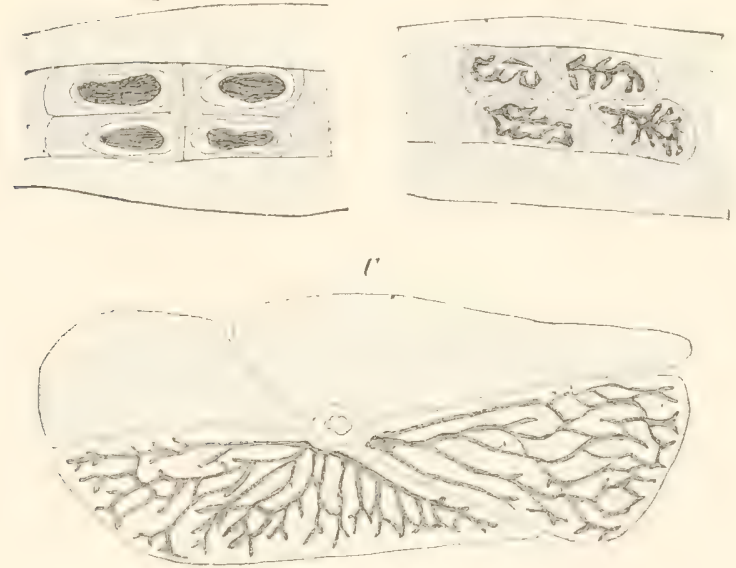

Fig. S. Nach PAul Mayer. Aus horschelt Fig 12. A Ein Stiick vom siebenten Bein einer jungen Phronimella ron $5 \mathrm{~mm}$ Länge. Tergr. 90. B Ein Stïck des sechsten Beines einer erwachsenen Phronimella. Vergröß. 90. C Eine Zellgruppe der Drüse im sechsten Bein ron Phronimella. Nur in zwei Zellen ist der Kern eingezeichnet. Vergr.

kommt namentlich in den großen Drïsenzellen vieler Insekten vor (in den Malpighischen Röhren. Spimn- und Speicheldrüsen ete.), ebenso in Drüsenzellen von Phronima, einer Kirustacee. Als eigentümliche Formen seien auch noch erwälnt: 1. die ringförmigen herne oder die Lochlierne, welche in den Lymphkörperchen an der Oberfläche der Amphibienteher 
und in den Epithelzellen der Harnblase des Frosches heobachtet worden sind und uns später noch eimmal beschätigen werden: "2. die polymorphen Kerne, wie sie besonders in den Riesenzellen des Knochenmarkes sich finden. Polymorph heiben sie, weil sie ein amöhoides Lussehen darbieten und aus Lappen bestehen, die mit Höckern besetzt sind und häufig untereinander nur durch feine Verbindungstiiden zusammenhängen.

Die fröbe, welche ein Kier'n erreicht. steht in ter Regel in einer gewissen Proportion zu der Größe des ihn umhüllenden P'rotoplasmakörpers. Je gröber dieser ist, um so gröber ist der Kern. So funden sich in den

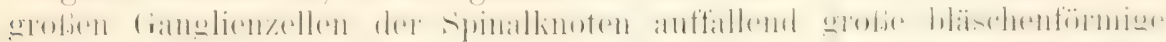
Kerne. Gan\% riesige Dimensionen aber erreichen sie in umeifen Eizellen und zwar in einem ihrer Gröle entsprechenden Mafistabe. Aus uneifen

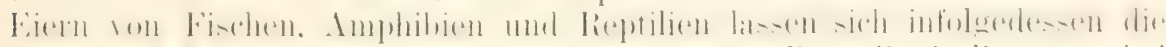

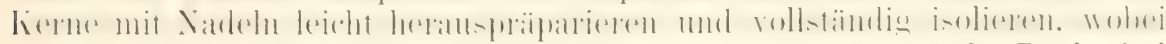
sie mit unbewaffinetem Luge als lileine Punkte erkembar sind. Doch sind Ausnahmen von der Regel hervorzuheben. Dem dieselben Eier, welche

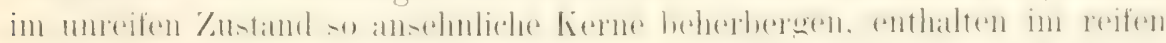
und im befruchteten Zustand einen so winzigen Kern, dab sein Nachweis mit den allergrößten Schwierigkeiten verbunden ist.

Niederste Organismen besitzen, wenn sie von beträchtlicher (rö̈ße sind, häufig einen einzigen groben Kern; derselbe erreicht ganz riesige Dimensionen im limnenbläschen vieler Rarliolarien.

Was die Tahlenverhätnisse endlich betriftt. so ist bei Pflanzen und 'Tieren das Gewöhnliche, dab in jerler Zelle nur ein Kern vorhanden ist. Einzelne Elementarteile machen davon eine Ausnahme. Leberzellen zeigen häufig zwei Kerne: bis 100 herne und mehr sind in den Riesenzellen des Knochenmarks, in den Osteoklasten, in Zellen mancher krankhafter Geschwiilste eingeschlossen. Dureh Vielkernigkeit zeichnen sich, wie ScHмitz entrleckt hat. die Zellen vieler Pilze und mancher nierlerer Pflanzen aus, der Cladophoren (Fig. 9) und Siphoneen (Botrydium, Vaucheria, Caulerpa etc.).

Vielkernig sind zahlreiche niederste Organismen, wie die Myomyceten. viele Mono- und Polythalamien, Radiolarien und Infusorien (Opalina ranarum). Die Kerne sind hier hänfig so klein und in so grober Anzahl im Protoplasma verteilt. dlab ihn Nachweis erst in jüngster Zeit bei Anwendung der vervollkommmeten Furbemethorlen geglückt ist. (Mromycyten.)

lïg. 9. Cladophora glomerata. Eine Zelle des fadens nach einem Chromsäure-Karmin-I'riparat. Tach STrusBURgEr, Bot. Prakticum, I'ig. 121, n \%ellkern. ch Chromatophoren, \& Amylumherde, a Stärkekürnchen. V'ergr. j)f().

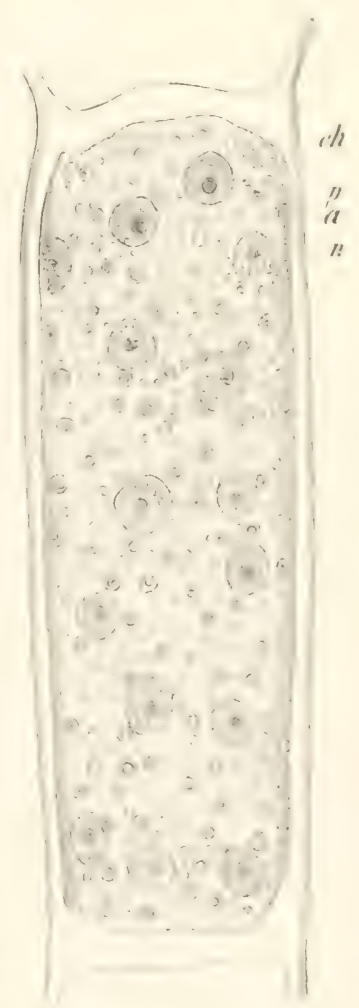

\section{b) Die Kernsubstanzen.}

In stofflicher Hinsicht ist der Zellkern ein ziemlich zusammengesetztes Gebilde. Stets lassen sich in ihm zwei. sehr häufig aber drei bis 


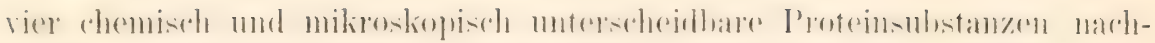
weisen. Die beiden stets wiederkehrenden Substanzen sind: Nuklein forler Chromatin) und Pyrenin; zu ihnen sind meist noch hinzugesellt: Linin, Lernsaft und Amphipyrenin.

Das Nuklein oder Chromatin ist die für den Kern am meisten

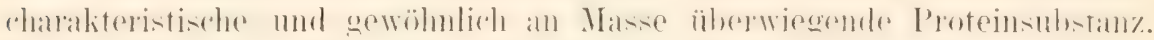
In frischem Zustand ähnlich wie körnchenfreies Protoplasma aussehend, unterscheidet es sich von ihm in sehr prägnanter Weise namentlich durch sein Verhalten bestimmten Farbstoffen gegenüber. Nachdem es durch Reagentien zur Gerinnung gebracht ist, speichert es Farbstofte aus zweck-

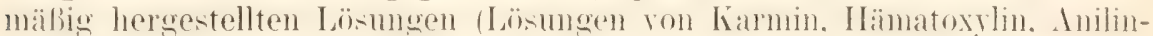
farben) in sich auf. Mehr noch als im rulienden Zustand des Kerns ist dies in den Vorstadien zu seiner Teilung und während der Teilung selbst der Fall. $\mathrm{Ob}$ es sich bei der Färbung um chemische oder um physikalische Vorgänge handelt, ist zurzeit noch nicht festgestellt.

Die hochwichtige Tatsache der Kernfärbung, welche in der Entwicklum@ der histologischen Technik epochemachend ist, hahen HarTar mul (iERLaCH mabhängig von einander entrleckt. HarTag bemerlite schon im

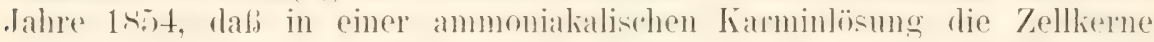
rot tingiert werden. 1858 machte GERLACH, als el für mikroskopische

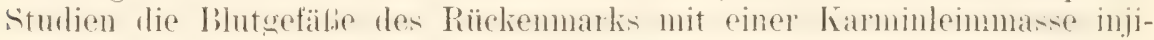
zierte, die Beobachtung, daß der Farbstoff, wie es ja so leicht geschieht, durch die Gefäband in die Tmgehmong diffundiert war und die lierne der nächst gelegenen Zellen rot gefärbt hatte. Auf Grund dieser zufälligen. aber in ihrer Berlentung richtio geschätzten Wahrnehmumg bildete er die

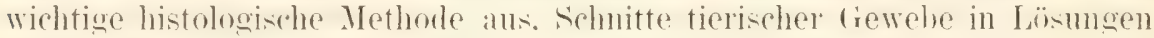
von Ammoniakkarmin zu färben, den Farbstoff abzuspülen und in den

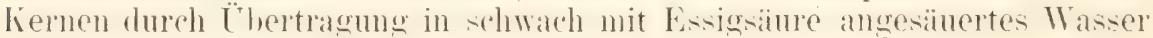
zu fixieren.

Die Kunst des Färbens oder Tingierens ist jetzt-schon soweit ausgebildet worden, daß es leicht gelingt, das Chromatin des Kerns allein durch irgend eine Färomg sharf hervorzuhehen. während der äbrige Inhalt des lierns und der Protoplasmakiorper entweder vollständig farblos hleiben oder nur sehr wenig mitgefärbt sind. Auf diese Weise gelingt es, selbst Chromatinteilchen, die nur die Größe eines Bakteriums etwa besitzen, in relatir grolien Protoplasmakörpern kenntich zu machen, wie zum Beispiel die winzigen lï̈pfe von Samenfürlen oder die Chromosomen der Richtungsspindel mitten im Körper großer Eizellen.

In chemischer Hinsicht zeigt das Chromatin, welches für gewöhnlich mur dem Kern zukommt und im Protoplasma vermilit wird. charaliteristische Reaktionen, die bei der Konservierung der Kernstrukturen im Auge zu behalten sind. (Schwarz III 1887, ZaCharias III 1882-1885). Es quillt in destilliertem Wasser, desgleichen auch in sehr verdïnnten alkalischen Lösungen, sowie in zwei- und mehrprozentigen Lösungen von Kochsalz,

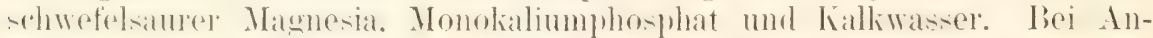
wendung von 10 bis $20 \%$ Lösungen der genannten Salze geht es inter Quellung allmählich ganz in Lösung über. Desgleichen wird es in einem Gemisch von Ferrocyankalium + Essigsäure oder in konzentrierter Salzsïure, oder wemn es der Trypsinverdaumn unterworfen wird, vollständig aufgelöst. In Essigsäure in Konzentrationen von $1-50 \%$ wird es ziemlich unverändert zur Fällung gebracht, wobei es sich durch stärkere Lichtbrechung und eigenartigen Glanz vom Protoplasma mitunter sehr scharf 
abhebt. Das gleiche ist auch der Fall bei /usat\% von $0.1 \%$ iger Salzsinme und nach Einwirkmo von Pepsinsalzsïme. Im Kernramm tritt es uns (Fig. 10) bald in Form isolierter Körnehen ( 1 ), orler als feines Netzwerk (b.C) oder in Fïlen (D) entgegen.

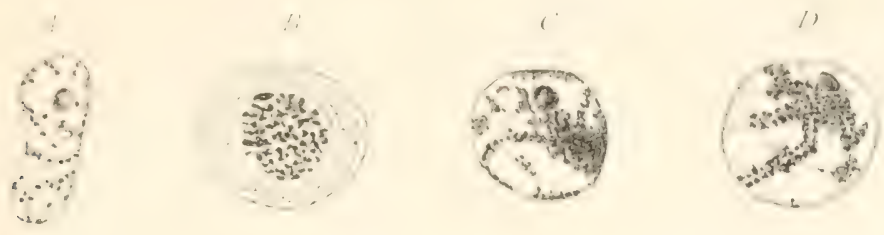

Firs. 10. A luhender hem einer Lrsamenzelle von Ascaris megalocephala bivalens. b Kern einer Samenmutterzelle aus dem Anfang der Wachstumszone von Ascaris megalocephala bivalens. $C$ Ruhender Kern einer Samenmutterzelle aus der Wachstumszone von Ascaris megalocephala bivalens. D Bläschenfömiger Ken einer Samenmutterzelle von Ascaris megalocephala bivalens an Anfang der Teilzone in Vorbereitung zur 'T'eilung.

Das Chromatin hat Mescuer (III 1874) zuerst 1871 aus den Kermen ron Eiterkïrperehen und ans tieri-rehen samenfärlen, in deren höpfen es enthalten ist. $7 u$ isolieren und rein darzustellen versucht. indem er dureh

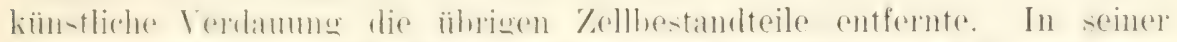

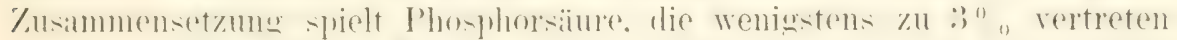

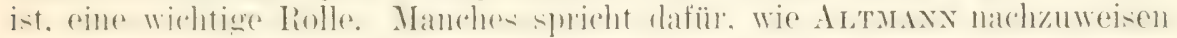
versucht hat, daf das Chromatin des Kerns „eine Vereinigung eines

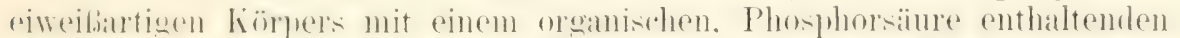

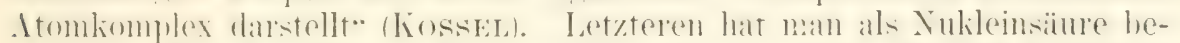

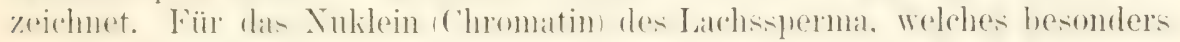
leich an Nukleinsiume ist, hat Mrescher die Formel $\mathrm{C}_{2: 9} \mathrm{H}_{49} \mathrm{~N}_{9} \mathrm{P}_{3} \mathrm{O}_{22}$ berechnet.

..Bei längerer Einwirkung von verdünnten Säuren oder Alkalien, sclbst shom heim Auflewahren im fouchen Zustand werlen die Vukleine

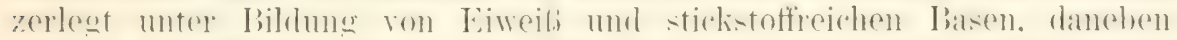

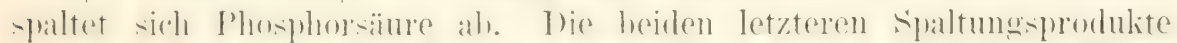

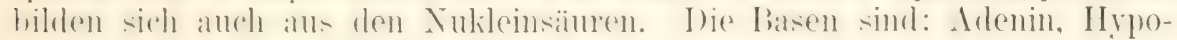
xanthin, Guanin, Xanthin."

In verschiedenen Arten von Zellkernen scheint die Nukleinsäure mit

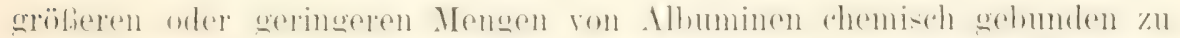
sein. Durch diese Annahme sucht man auch die abweichenden Resultate der Analysen ron Nukleinen, die aus verschiedenem Naterial gewomen wurken. zu erkiären.

Besonders reich an Nukleinsïure erweisen sich die Kerne der mämn-

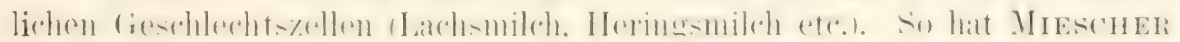
in 100 T'eilen von Spermatozoen des Lachses gefunden:

\begin{tabular}{|c|c|c|c|c|c|c|}
\hline Nukleinsäure & & & & & & 48.68 \\
\hline Protamin & . & . & . & & & 26.76 \\
\hline Eiweißstotie & & & & & • & 10.32 \\
\hline Lecithin. . & & & . & & • & 7.47 \\
\hline Cholestearin & . & & . & • & . & 2.24 \\
\hline Fett. . & . & & . & & & $4.5: 3$ \\
\hline
\end{tabular}


Wahrscheinlich ist hierbei die Nukleinsäure mit Protamin rerbunden und beträgt somit mehr als $75 \%$ der Gesantmenge der Samenfäden.

Das Pyrenin ist eine Proteinsubstanz, welche wohl in keinem liern fehlt. (loch ist seine Rolle für die Lebensprozesse des Kerns noch unklar und viel weniger gut als die des Chromatins erkannt. Es kommt im Kern in der Form kilemer Küugelchen vor, die als echte Nulileolen oder Kernkörperchen (Plasmosomen) beschrieben werden (Fig. 10).

Allen Mitteln, in welchen die Chromatinsubstanzen quellen, destilliertem

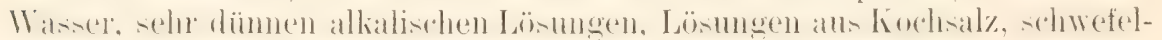

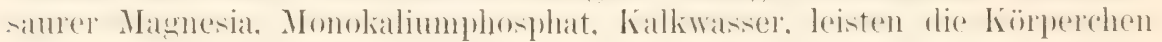
aus Pyrenin Widerstand. Während die aus Chromatin bestehenden Strukturen schwinden, sind in dem Kernraum, der ein homogenes Aussehen gewonnen hat, die aus Pyrenin bestehenden Gebilile oft mit großer Dentlichkeit, stets besser als im lebenden Kern, zu erkennen. Hieraus erklärt es sich, daß bereits den älteren Histologen, Schleidex und Schwaxs. die gewöhnlich die Gewebe nach Zusatz von Wasser untersuchten, die Kernkörperchen wohl bekannt waren.

Ein sehr brauchbares Mittel. um sie sichtbar zu machen, ist die Osmiumsäure. durch welche sie besonders stark lichtbrechend werden. während die Nukleinstrukturen verblassen.

Bei Einwirkung voll $1-50 \%$ Essigsäure verhalten sich Pyrenin und chromatin gerade entuegengesest. Wähend letzteres zur forimmung gehracht wird und einen starken cilanz erhält, quellen die Kernkërper mehr oder minder bedeutend auf und können ganz durchsichtig werden, ohne indessen in Lösung überzugehen; denn beim Auswaschen der Essigsäure werden sie wieder unter Schrumpfungserscheinmngen besser sichtbar.

Hervorzuheben ist ferner in Gegensatz zum Chromatin die Unlöslichkeit des Pyrenin in $20 \%$ Kochsalz, in gesättigten Lösungen von schwefel-

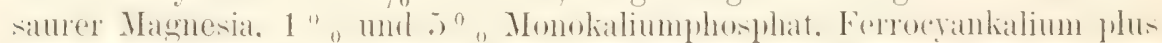

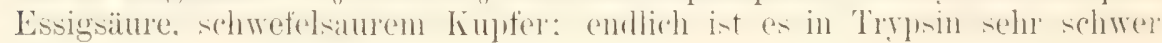
verdaubar.

Auch bei Behandlung mit Farbstoften zeigt sich zwischen Chromatin und Pyrenin ein gewisses gegensïzliches Verhalten. Wie Zacharias bemerkt und ich aus eigener Erfahrung im allgemeinen bestätigen kann. färben sich Chromatinkörper besonders scharf und intensiv in saueren Farb-

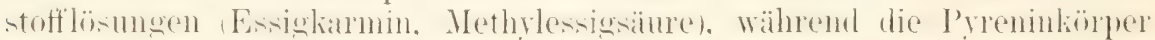
fast farblos bleiben. Umgekehrt tingieren sich letztere besser in ammoniakalischen Farbstofflösungen, wie in Ammoniakkarmin etc.

Manche Farbotoffe baben entwerler zum l'homatin orler zum Prenin eine größere Verwandschaft. Nach dem Vorschlag von EHRLich hat man zweckmäßigerweise die Anilinfarben auf Grund ihrer chemischen Eigenschaften in die beiden Gruppen der basischen und der sauren Farben geteilt. Basisch sind Methylgrün, Bismarckbraun, Methylenblau, sauer S-fuchsin, Eosin, Orange. Zu den basischen Anilinfarben, namentlich zum Methylgrün zeigt das Chromatin eine besondere Affinität, zu den saueren das Pyrenin, sowie überhaupt das Protoplasma. Auch bei Herstellung chemischer Präparate von Nukleinsäure und Albumin kam man bei Färbeversuchen (LILIENFELD) das gegensätzliche Verhalten konstatieren. Daher hat man auch die basischen Anilinfarben als spezifische liernfärbemittel, die saueren als Protoplasmafarbstoffe in der histologischen Technik bezeichnet. In übrigen soll nicht unterlassen werden, hervorzuheben, das zur Erzielung des gewünschten färberischen Resultates die Art der Vorbehandlung des Traptates mit honserviorenden Reagentien ron wesentlider 


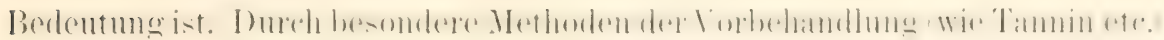
liamu man es zum Beispiel erreichen, dab die Fähbungen von Kern und

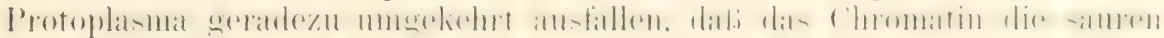

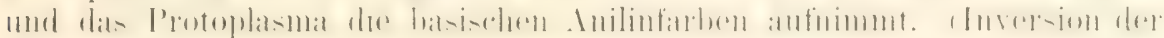
Färbung. RaWtTz.)

Bei gleichzeitiger Anwendung von zwei und mehr larbstoffen von

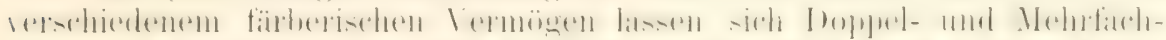

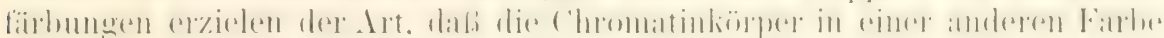
erscheinen, wie Protoplasma und Pyrenin. Hierfïr geeignete Zusammen-

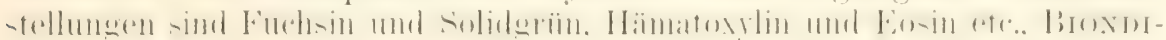
sches Gremisch.

Im Vergleich zum Chromatin und Pyrenin erscheinen von geringerel bedeutung die drei anderen in Kern noch unterscheilharen Substanzen. welche vielleicht äberhaunt nicht stets vorhanden sind. das linin. der liernsaft mol das Amphipyrenin.

As Linin bezeichnet Scrrwarz (III 1sist) den Stoff ron liaden. welche in vielen Fälen in dem Kernram ein Net\%-oder (ierüstwerk bilden. sich nicht in den gewöhnlichen liernfärbungsmitteln tingieren lassen und sich hierdurch. sowie auch in ihren chemischen Reaktionen wesentlich vom Chromatin unterscheiden, das ihnen meist in Form von Kömchen und Brocken aufgelagert ist. (Fig. 10 A und ( C). In mancher Hinsicht ähnelt es dem Plastin des Zellkörpers, welchen Namen ihm dem auch gerarlezu Zacharias gegeben hat.

Der Kernsaft ist bald nur spärlich, bald reichlicher vorhanden; er füllt die Lücken zwischen den aus Chromatin, Linin und Pyrenin bestehenden strukturen aus. Er läbt sich dem Zellsaft vergleichen, der in einem vakuoligen Protoplasma enthalten ist, und spielt wohl dieselbe Rolle für die Emährung der Kernsubstanzen. wie dieser für die Emährung des Protoplasma. Bei Einwirkung wn manchen Reagentien. wie absolutem Alkohol, Chromsämre etc. treten im Kernsaft feinkörnige Nierlerschläge auf. welche als Kunstprodukte nicht mit normalen Strulituren zu verwechseln sint. Es müssen daher in ihm rerschiedenartige Stoffe, darunter vielleicht auch Albuminate, gelöst sein. welehe Kacmaris mit einem wohl enthehrlichen Wort als Paralinin zusammenfabt.

Unter Amphipyrenin endlich versteht Zacharias die Substanz der Membran, durch welehe der Kermaum gegen das Protoplasma. wie dieses durch die Zellhaut nach auben, abgegrenzt ist. Das Vorhandensem einer Kernmembran ist in vielen Fällen ebenso schwer festzustellen. wie der Streit zu entscheiden ist. ob manche Zellen von einer Membran umhüllt sind oder nicht. Am leichtesten ist sie an den groben Keimbläschen vieler Eier, wie z. B. von Amphibien nachzuweisen. wo sie zugleich eine nicht unbeträchtliche Festigkeit besitzt. Infolgedessen gelingt es leicht.

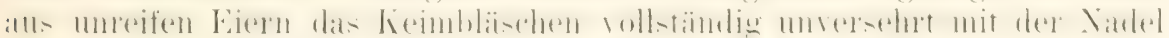
zu isolieren. Man kamn damn mit der Sarlel auch die Kermmembran zerreißen und den von ihr eingeschlossenen Inhalt zum Austlieben und zur

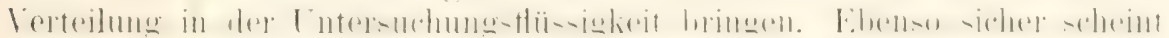
aber in anderen fällen eine eigene liermuembran zu fehlen, so dab Kernsubstanz und Protoplasma ummittelbar anemander grenzen. So worde sie \%. B. von FLemang (III 1882) in den Bhtzellen von Amphibien und ebenso ron mir in den Kernen von Samenmutter\%ellen der Jematoden auf einem hestimmten Stadium (Fig. 10 B) rermibt. 
Wie fuir den Protoplasmakörper, hat Arturass anch fïr den Kern eine Kusammensetzung aus Granula mittelst einer eigenartigen Färbung durch Cyanin nachzuweisen versucht. Fs ist ihm hierduch gelungen, den Saft. welcher die Liicken im Kernnetz ansfüllt. intensiv zu fürben und so Kioner darzustellen. wahrend das Kermetz ungefarbt bleibt und ais Intergramularsubstanz bezeichnet wird. Ammans hat auf diese Weise den negativen Abdruck von der Kemstruktur erhalten, wie sie sich bei Anwendung der gebräuchlichen Kernfarbstoffe durch Färbung des Kernnetzes ausprägt. Indem er die Granula als Hauptbestandteil des Kerns betrachtet. kommt er zu einer entgegengesetzten Auffassung von der jetzt herrschenden Meinung von der Bedeutung der Kernsubstanzen, nach welcher der Kernsaft als minderwertig im Vergleich zu dem Chromatin und Pyrenin erscheint.

(') Die Kernstruktur.

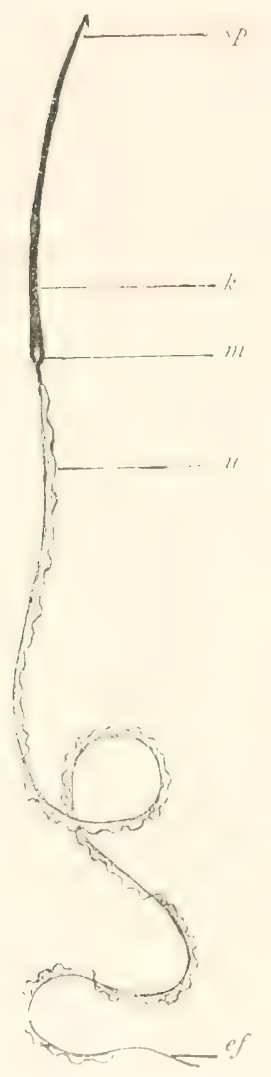

liig. 11. Samen. faden vou Salamandxa maculata. $k$ liopf. $m$ Mittelstiick. of Endfaten. "Spitze. "murulimomste Ilembitin.

\section{Beispiele für die verschiedene Beschaffenheit derselben.}

Die oben aufgeführten Substanzen, von denen wenigstens das Chromatin und Pyrenin niemals fehlen, erscheinen in den Kernen der verschiedensten pflanzlichen und tierischen Zellen unter sehr mannigfachen Formzuständen; namentlich gilt dies von dem Chromatin, das man bald in feinen Körnchen, bald in Fäden, bald in Form größerer Körper, bald als ein Gerỉst. bald als Wabenwerk im Kernraum verbreitet sieht. Dabei kann in verschiedenen Lebensphasen einer Zelle die eine Struktur in die andere übergehen.

Bei einer Definition des Kerns ist daher ron der wechselnden Form ganz abzusehen, und es ist der Schwerpunkt, wie bei der Definition der Zelle in das Protoplasma, so bei dem Kern in die in ihm enthaitene wirksame Substanz zu legen. „Der Kern ist ein rom Protoplasma unterschiedenes und in gewissem Grade abgesondertes Quantum eigentümlicher Kernsubstanzen." Eine Auswahl einiger prägnanter Beispiele von Kermstrukturen wird uns eine Vorstelhug von der hier herrschenden Mannigfaltigkeit geben:

Unstreitig die einfachste Struktur - wenn wir von den später zu erörternden molekularen Verhältnissen absehen - zeigen uns die Kerne der reifen Samenzellen. Wenn die Samenzellen, wie gewöhnlich, eine fadenförmige Gestalt, welche zum Finbohren in die Eizelle am geeignetsten ist, angenommen haben, bilden die Kerne das vorderste Ende des Farlens orler soinen Kopf. Bei Salamandra maculata hat der Kopf die Form eines in eine scharfe Spitze auslaufenden Schwertes (Fig. $11 \%$ ); er besteht alls dichtem ('hromatin. das anch bei stälister Vergrößerung einen homogenen Eindruck macht.

Auch in Samenelementen. welche die Form einer Zelle beibehalten halun. "robeint der liern als ein kombakter, kugeliger chromatinkörper: so hei Ascaris megalocephala (Fig. 12). dessen Samenelemente im unreifen 


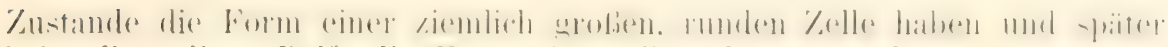
bei vollständiger Reife die Form eines Fingerhutes ammehmen.

Der einfache Zustand. in welehem uns die Kerne der Samenzellen. gewissermaßen nur aus aktiver liernsubstanz zusammengesetzt und frei

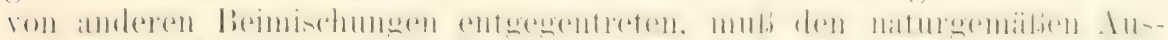

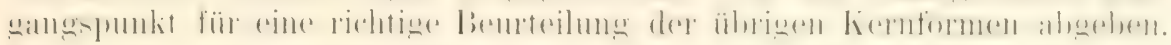
Es lassen sich damn nämlich die verschiedenen Struktulen. die man bei pflanzlichen und tierischen Kernen wahrimmt. hauptsächlich anf das eine Moment zur ückführen. daf die aktive Kernsubstanz eine grobe Neigung hat. Flïssiglieit und in dieser gelöste stoffe in sich autzunehmen und in Lïcken abzuscheiden meist in solchem Maße, dab der ganze liern das Aussehen cines in dem Protoplasma eingeschlossenen Bläschens gewinnt.

Es tritt also bei ihnen im wesentlichen ein ähnlicher Vorgang ein, wie beim Protoplasma, in welehem sich \%ellsaft in Valinolen orler croblen sift-

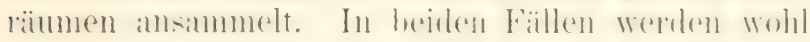
die Vorgänge die gleiche Berleutung haben. Sie werden in Beziehung zum Stoftwechsel der Zelle ame des kornes stehen, indem in der Flïs-igheit Stoffe in Lösung enthalten sind. Welche mit den aktiven Substanzen infolge der gröberen Oberflächen-

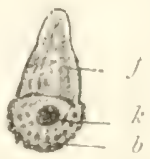

Fig. 12. Samenkörper von Ascaris megalocephala. Xill

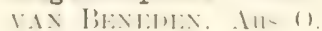
Harituri, lintumm. k Kiern. b Basis des lierels, mit welchem die Inheftume an Ei rrtolgt. ff liettglimzende. Substanz. entwicklung derselben in leichteren Austausch treten.

Der Vorgang del Saftautnahme läbt sich direkt beobachten. wenn nach der Befruchtung der Samenkern in der Eizelle in Funktion tritt. In manchen Fällen beginnt er dann allmählich auf das 10_-20 fache seiner ursprünglichen Gröhe anzuschwellen. und zwar nicht durch Ver-

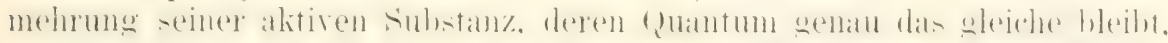

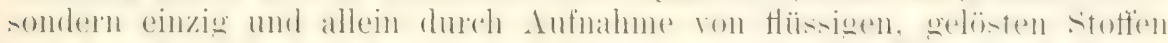

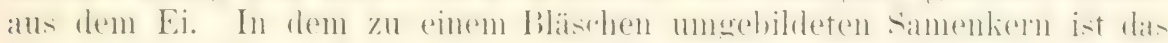
Chromatin in feinen Fädlen zu einem Netz ausgebreitet; ferner sind auch

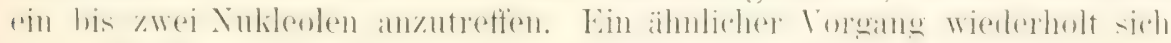
bei jeder Kernteilung während der Rekonstruktion der' Tochterkerne.

Je nachrlem num der Kern eine geringere oder größere Menge von liernsaft aufgenommen hat, ordmen sich seine festen, als Linin und Chromatin chemisch näher charakterisierten Substanzen bald zu einem feineren, bald gröberen Geriistwerk an, von welchem die Fig. 1:-16 Beispiele geben.

Higur 1:) zeigt uns den Kern einer Cilioflagellate. Er besteht in ïhnlicher Weise wie der Hauptkern der Infusorien aits einem seln eng-

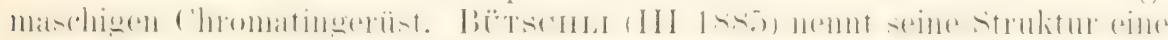
feinwabige; er läbt den liern zusammengesetzt sein aus langgestrecliten. Hrei- bis mehrseitigen Waben, deren sehr feine Scheidewände aus Chromatin bestehen und den nur wenig färbbaren Kernsaft umschliefen. Xach der Oberfläche zu sind die Waben gegen das Protoplasma ebenfalls duch eine feme Schicht abgeschlossen. Während eine besondere Fermmembran fehlt. Die Kanten. in denen die Wabenwinde zusammenstohen. sind sïulenartig verdickt. Je nach der Seite, von der man den Kern erblickt.

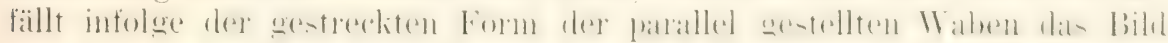
verschieden aus. wie durch Betrachtung der Figuren $13 /$ u. B3 leicht zu verstehen ist. Ein bis zwei Nukleolen sind in den Lücken nachzuweisen. 
Figur 14 stellt das Kerngerüst von einer Bindegewebszelle

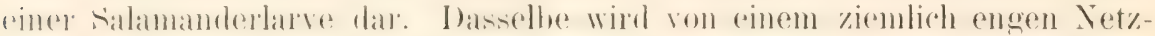

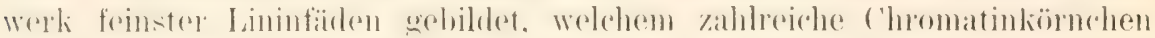
anfogelagert sind. Unter ihnen treten hie und da einige dickere Anschwellungen auf. welche den Farbstotf besonders zäh festhalten; sie ptlegen namentlich an solchen Stellen rorzukommen, wo mehrere Balken zusammenstofien. Es sind dichtere Ansammlungen von Chromatin; sie können den aus Pyrenin gebildeten, wahren Nukleolen in ihrem ÄuBeren sehr ähnlich sehen und sind daher, $11 m$ sie von diesen $7 u$ unterscheiden. yon Fimming als Netzknoten bezeichnet worden.

Die lierne der verschiedenen tierischen Gewebe haben bald ein feineres, bald ein gröberes fieruist. In letzterem Fall kann es zuweilen nur aus wenigen Strängen bestehen, so dafo es , den Namen Gerist oder Netz kaum verdient". Im allgemeinen haben, wie Fuemmsg bemerkt. die lierne junger, embryonaler und wachsender (iewebe dichtere Netze. als solche im gleichen erwachsenen Gewebe.

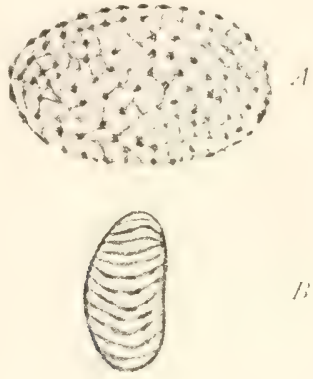

Iig. 1:3.

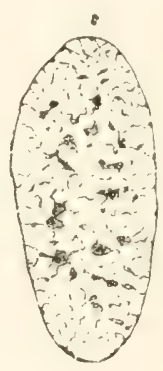

Fig. 14.

Fig. 13. Ein sehr deutlich feinwabiger Kern von Ceratium Tripos. Nach Bïrscher Taf. 26, Fig. 14. It In der Ventralansicht des Ceratiums. I3 In seitlicher Ausicht. Beide Ablildungen geben nur optische Durchschnitte.

I.i. 14. Kern einer Bindegewebszelle des Peritoneums einer Salamanderlarve mit in der Nähe gelegenen Zentralkörperchen. Nach Fifmurxi lig. $t$.

Meistenteils ist das Kerngerüst aus zwei verschiedenen substanzen, aus Linin und aus Chromatin, aufgebaut, von denen bei den gewöhnlichen Kerntinktionen nur das letztere den Farbstoff aufnimnt umb festhät. Leide substanzen sind gewöhnlich so angeordnet. dafi das Chromatin in wriberen mul feineren kïrnehen dem sich nicht färhenden

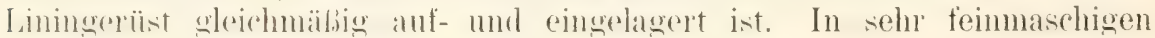
(Geristen. wie Figur 14 ein solches darstellt, kam die Unterscheidung heider Substanzen sehr schwierig, ja sogar ummöglich werden. Leichter gelingt dieselbe bei dem gröberen Netzwerk der Figur 15, welche einen ruhemden \%ellkern aus dem protoplasmatischen Wandbelag des Embryosackes von Fritillaria imperialis wiedergibt. Nach der Be-

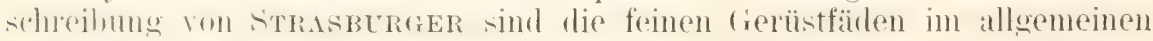
nicht färbbar: sie bestehen also aus Linin. Ihnen sind kleinere und "rräbere sich fiorbente ('hromatinkiomer anfgelagert. In tieriist sieht man außerlem eine Anzahl größerer und kleinerer Nukleolen.

Ton der Existenz eines besonderen Liningerüstes kann man sich sehr leicht durch das Studium der Kerne von Samenmutterzellen des Pferdespulwumes (Fig. 16) ïberzengen. In dem Vorstadium zur 


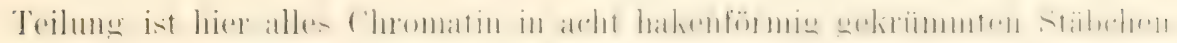
enthalten. die in zwei Bündeln zusammenliegen. Sie werden im Kermaum gewissermalien in der Schwebe erhalten, indem sich farblose lininfäden sowohl zwischen ihnen ausspannen, als anch ron ilmen sich zur líernmembran begeben. Dab. die Fäden lieine dureh lieagentien im liernsafi hervorgerufene (ierimnsel sind, lält sich aus ihrer überaus regehmäbigen Anordnung erschliehen. Ehenso lehrt ihre chemische Realition und in. Verhalten beim Teilungsprozeb, dab sie rom Chromatin und Prenin etwas wesentlich Verschiedenes sind.

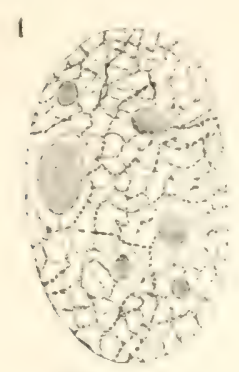

Fi.: $1 . i$.

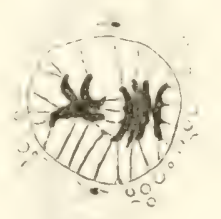

Fie. Ifi

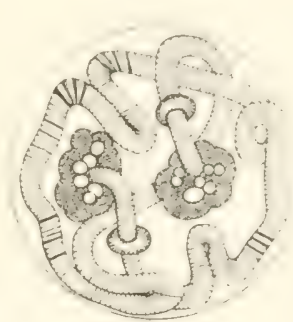

lig. $1^{-}$ I: KiEk,

Fï. 15. Fritillaria imperialis. Ein ruhender Zellkern. Jich stris-

Fig. 16. In Vorbereitung zur Teilung befindlicher Kern von Ascaris megaloc. bivalens mit 8 in 2 Gruppen angeordneten Kernsegmenten und den 2 Centrosomen. Nach HrkTwi(; III. 1890, Taf. II, Wig. Is.

Fig. 17. Struktur des Kerns einer Zelle aus einer Speicheldrüse von Chironomus. Jach BAIBLAx, Zoolog. Anzeiger 1SS1, Fig. ?.

Nicht immer ist übrigens das Chromatin in einem (ieribst ansgebreitet. So ist 2. 13. in den großen. bläschenförmigen Kernen ron Chironomuslarven (Fig. 17). Wie BaLbian (III 1881 gefunden hat, cin einziger dicker Kernfaden eingeschlossen: derselbe ist in verschiedenen

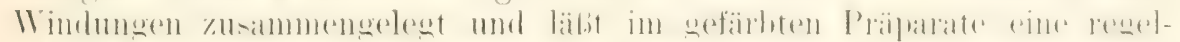

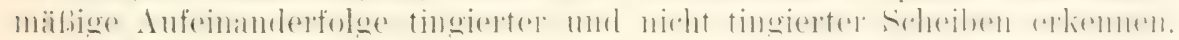
was Strasburger (III 1887) anch von einigen Pthanzen berichtet. Die? beiden Enden des Fadens grenzen an zwei Nukleolen an. Ahulich geartete Kerne mit einem gewundenen Nukleinfaden. Spiremkerne. wie sic

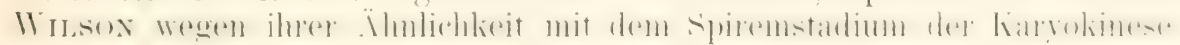
genamnt hat, sind auch noch an einigen anderen Objekten aus dor lilasse der Arthroporlen ron CARxoy. Hexwegur, (iEnuchex beobachtet worden. so 7. B. in den Kernen der Ejpithelzellen einer Dipterenlarve.

In anderen Fällen wieder ist die Hauptmasse des Chromatius zu cinem gröberen, kugeligen hörper konzentriert, der wie ein Vukleolus anssieht. sich aber substanziell von den oben beschriebenen echten Nukleolen (l'asmosomen aus Prrenin) (s. S. 32). unterseheidet. Um Verwechshngen vorzubeugen. enipfiehlt es sich. solehe Gebilde als Chromatinkörver zu bezeichnen. Sie entsprechen den Nucléoles noyax in den sichriften von Carxor und semen Schiilern. Als Beispiel hierfï sei der Kern rou

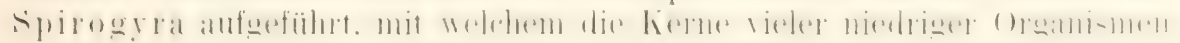
im Bau ïbereinstimmen. Derselbe stellt ein Bläschen dar, das sich rom Protoplasma durch eine feine Membran abgrenzt und ein feines lierngeriist enthält. Da dieses den Farbstoff' hei 'Tinktionen nicht fosthält. 


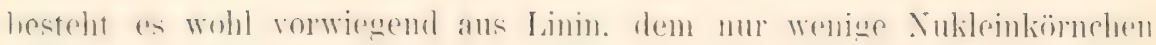
aufgelagert sind. In Geruist liegt ein grofer Chromatinkörper, der zuweilen auch in zwei lileinere zerlegt ist. Daf er hauptsächlich aus Chromatin besteht, geht aus der Art seiner Färbung, vor allen Dingen aber daraus hervor, dab seine Substanz bei der Kernteilmo in Könchen zerfällt und die Kernsegmente liefert. Mit ihm ist noch eine zweite nicht färbbare Substanz verbunden. welche R. HerTwig für Actinosphärium

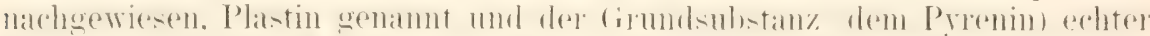

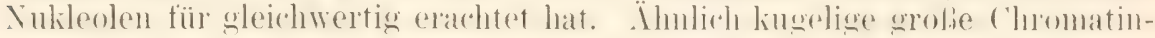
körper. in denen alle färbbare Kernsubstanz konzentriert ist, kommen auch bei mehreren Arten niederer, einzelliger Organismen vor, bei Gregarinen, bei Actinosphärium, Arcella, Flagellaten etc.

Die Struktur des ruhenden Kerns kann im Leben einer Zelle sehr tiefgreifende Veränderungen erfahren. die sich oft in einer streng wesetzmäligen Weise und im Zusammenhang mit hestimmten Phasen der \%ellentätigkeit einzustellen scheinen. Am leichtesten läbt sich diese Tatsache beim Studium der Entwicklung der Geschlechtszellen nachweisen. E. liegt hier ein Gebiet ror, auf welchem bei sorgfaltiger und zielbewubter Durcharbeitung seegneter ()hjekte noch aine reiche Ausbeute wirhtiger Befunde und ein tieferer Einblick in die Funktion der einzelnen liernsubstanzen zu erwarten ist.

Um die Formwandlungen an den Kernen der Samenmutterzellen zı

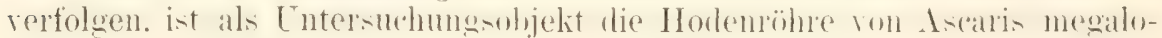
cephala zu empfehlen. Figur $18 A-D$ zeigt uns die Kernstruktur in vier aufeinander folgenden Zeiten. In der Ursamenzelle $A$ enthält der Kiern

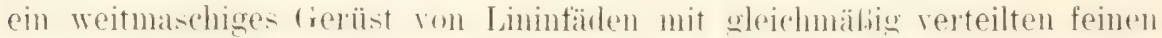
('hromatinkömehen mol rinem ainzigen rumblen Nukleolus. Die jüngsten samenmutterzellen (B) hahen membranlose kerne mit einem diehten chor

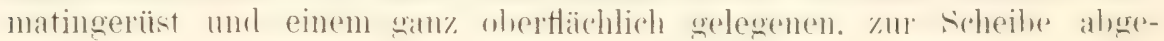

$A$

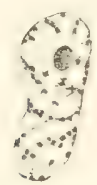

li

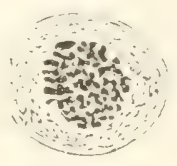

$C$

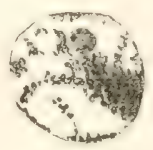

D

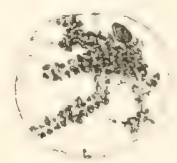

Fig. 18. A Ruhender Kern einer L'wamenzelle ron Ascaris megalocephala hivalen. B kem einer Samenmutterzelle aus dem Anfang der Wachstumszone ron Ascaris megalocephala bivalens. C Ruhender Kern einer Samemmutterzelle aus der Wachstumszone ron Ascaris megalocephala bivalens. D Bläschenförmiger hern einer Samenmutterzelle ron Ascaris megalocephala bivalens an Anfang der Teilzone in Vorbereitung zur. Teilung.

platteten Nukleolus. Bei etwas älteren Zellen $(C)$ ist daraus ein gröberer hläschenfümiger Kern mit deutlich ansgeprägter Menhran hervorgenangen. Im Saftraum spannen sich einzelne Lininfädlen aus. Das Chromatin ist in einem oller zwej aus Fädehen mu lïrnchen zusammengesetzten. unregel-

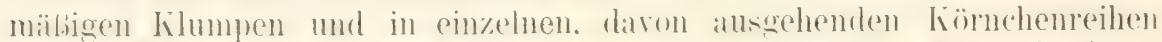
angehäuft. zwi-chen denen ein mehr oder minder lingeliger Nukleolus liegt. Aus diesem Zustand geht dam gerame Zeit vor der T'eilung wieder das

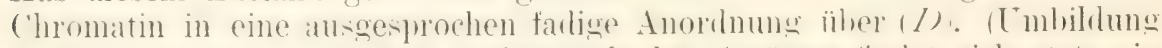
in Chromosomen). In dem Lürelienwerk des lierïstes findet sich stets ein Nukleolus.

Noch mäblere Mannigfaltigkeit hieten die Kieimblischen der Eier sowohl hei rerschiedenen Tieren. als anch hei ein umd demselhen Tier im 


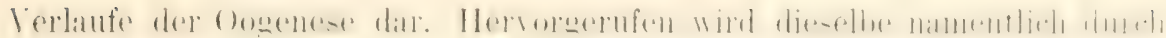
die sehr wechsehnde Form und hahl der Nukleoli, die hier auch den Xancu der Keimflecke oder Maculae germinativae führen. Nur einen oder ein

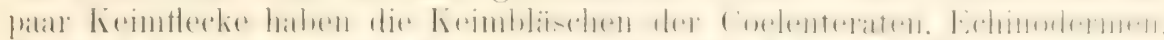

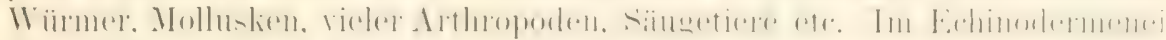
(Fig. 19) \%. B. liegt in einem groben (ieriist ron Lininfïlen nur ein groher gläuzender, kugeliger Kernkörper. Bei sïugetieren mud anderen findet sich neben ihm noch eine geringe Anzahl kleinerer Kü̈gelchen, die gewöhnlich als Nebennukleoli aufgefïhrt werden.

In den liesenkeinhläschen. durch welche sich die groben, dotterreichen Eier der Fische. Amphibien und Reptilien auszeichnen, nimmt die Zahl der lieimflecke während des Wachstums der Zelle auberordentlich zu und kamn sich schlieh-

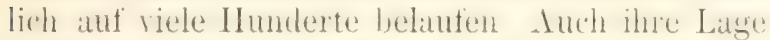
reänlert sich im Lanfe der Entwirlinns. 11 je

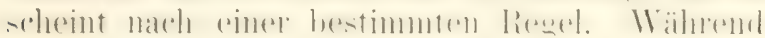
in jüngeren Eiern fast alle lieintlecke an der ()bertlïche des lieimbläshens zu tinten sind und

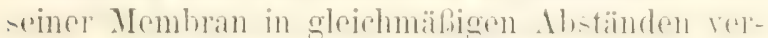
teilt anliegen. wander'n sie später zum grölten 'Teil ins innere und häufen sich hier an einer bestimmten Stelle entweder in einem gröberen Hanfen orler in eincun Ringe an.

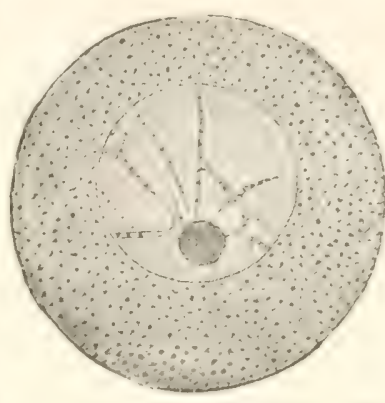

Fiu. 1!). Unreifes Ei aus dem Eierstock eines Echinoderms. Das große Keimbläschen zeigt in einem Netzwerk vou Fäden, dem Kermuetz, einen Keimfleck. 1). 111:1:1"॥, Fintwieklungsgeseh. I"jug. 1

Über den streng gesetzmäbigen Wechsel der Kernstrulitur zu verschiedenen Zeiten der Eientwicklung haben uns Borx. CARxoy. IdEBrux 11. a. bei Amphibien. Kistschenko und RücKent bei Selachiern Mit-

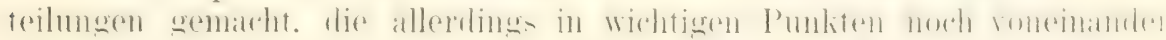
abweichen. Einige Stadien aus der Umwandlung des Keimbläschens eines Tritoneies geben uns die Figuren 20-24. Die kleinsten Keimbläschen

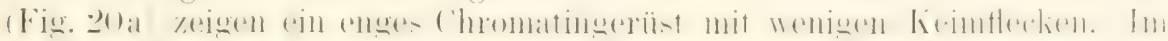
nächsten Stadium (Fig. 20b) sind die Keimflecke an Zahl vermehrt und meistens der Kernmembran dicht angelagert: im Kernsaft sind zahlreiche gewundene Chromatinstränge anzutreffen. Diese werden an etwas ïlteren Fiern (Fig. 21) nach den Angaben yon CARxoy auferelöst. Während sio mach bonx nur undentlich und nicht mehr färbhar werden sollen. Xu die peripher gelegenen und an 'Lahl sehr vermehrten Nukleolen bihlen nach Caryor die einzigen geformten Bestandteile des lieimblïschens. Anf einem späteren Stadium (Fig. 22) ist em 'Teil der noch zahlreicher geworklenen Nukleolen von der Peripherie in das Innere des lieimbläscheneingewandert: anch sind jetzt wierler viele Chromatinstrïnge nachweishar. die aus einem femen. in viele Windungen gelegten Faden bestehen unt

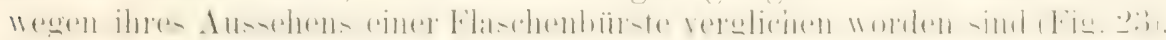
Während Borx eine Identität dieser Stränge (Chromosomenj mit den auf

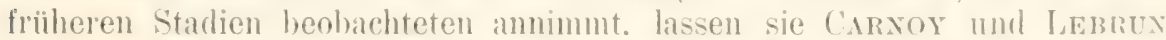
aus dem \%erfall der nach Inmen wandernden Nukleolen nen entstehen. Letztere sind nach Ansicht der belgischen Forscher chromatinhaltig. jil sic sollen alles Chromatin vorübergehend in sich aufnehmen während des

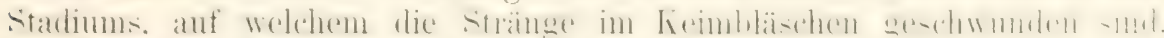

Wemn endlich zur Zeit der Eireife das Keimbläschen nach dem ani-

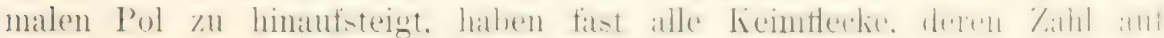




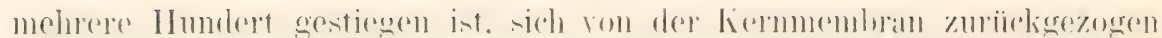
(Fig. 24) und zu einem mehr oder minder zentral gelegenen Haufen vereint. Hier verlieren sie ihre Färbbarkeit. werden von vielen Vakuolen durchsetzi und erfahren einen Umbildungspozeb, der schlieblich zu ihrer völligen Auflösmng führt. Währendlem ist in der Mitte des Haufens die erste Richtungsspindel entstanden mit den Chromosomen, über deren Herkunft BORN anf der einen Seite, CARNOY und LEBRUN anf der anderen wierler verschichene Ansichten vertreten. namentlich in (ler Frage, ob auch Iiestandteile der Nukleolen an ihrer Bildung beteiligt sind.

lï. 2 (1) il.

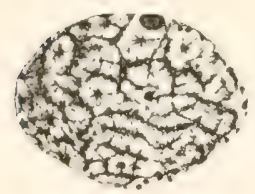

rịg. $2+41$.

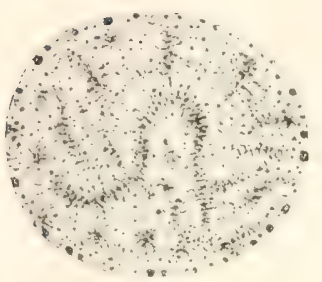

Fin. ㄴ.1.

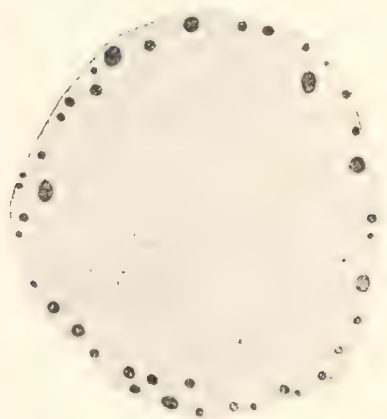

liig. 2:3.

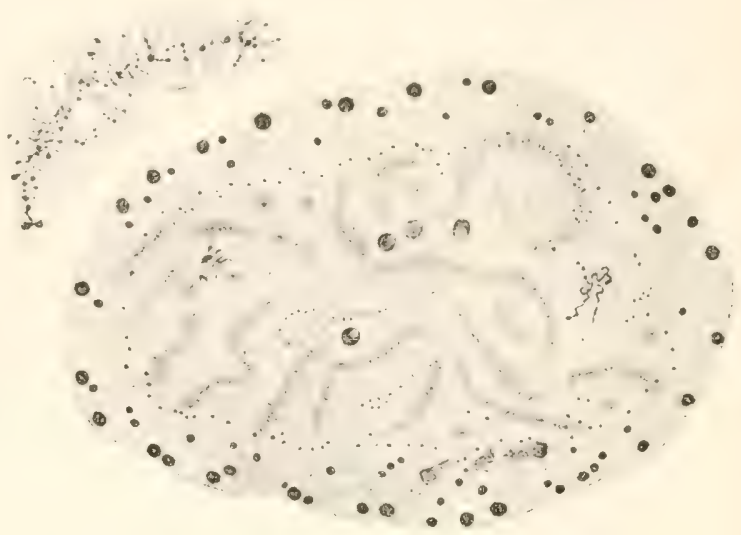

1'ix. ㄴ. 1.

lij!...

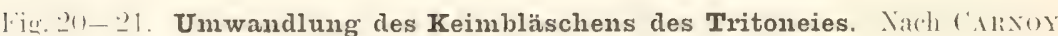
und Lebnux. Fig. 20a Eigröße 0,07 mm; Fig. 201 Eigröße 0,09 mm; liig. 221 Eigröße $0,11 \mathrm{~mm}$. Vergr. 600 .

Fin. Keimblächen eines $0,8 \mathrm{~mm}$ großen Eies. Nukleoli wanderı in das zentrum. Fergr. 180. Nach Carsoy und Lebrux. Ton den jetzt deutlich darstellbaren chromatischen Iäden ist ein Stück, welches einer Flaschenbürste vergleichbar ist, daneben in Fig. 23 stärker vergrößert.

Fin. Keimbläschen eines 1,0 $\mathrm{mm}$ großen Eies. Ansammlung der Nukleoli im Innern des Keimbläschens in einem Haufen. Nach CARsoY u. LABrux.

Eine so kolossale Zahl von Nukleolen wie in den Keimbläschen der Eier einiger 'Tierklassen ist auch - allerdings in sehr vereinzelten Fällen - in den Kernen von Gewebszellen beobachtet worden. Als ein derartiges

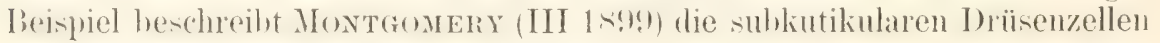
yon Piscicola rapax. Welche hei völliger Entwicklung so grob werlen. dali 
sie schon mit bloben Auge leicht zu sehen sincl. Wie heim Ei die Zunahme der Nukleolen mit der $\Lambda$ usbidelung des Dottermaterials. so scheint sie hier mit der Ansammlung des Sekretes Iland in Hand zu gehen. Denn die jungen, noch nicht mit Sekret gefüllten Drüsenzellen haben einen klemen Kern mit Chromatinnetz und einem einzigen Vukleolus. Esst mit der Sekretbildung und der dadurch allmählich hervorgerufenen riesigen Vergröferung der Zelle steigt die Kahl der Nukleoli. die unregehmäliges Formen annehmen und s- oder v-oder w-förmig werden. bis sie sich schlieblich in dem entsprechend vergröberten liern anf :30)-400 beläuft.

Endlich kommt es. wie in den Keimbläschen. auch zu einer Rückbildung der Nukleolen, die auf einem gewissen Stadium aus dem Inhalt des Kernes in das Protoplasma der Drïsenzelle ausgestolen werden. bis anf einen einzigen. der in dem verkleinerten hern zurïckbleibt. In \%ellinhalt verlieren die ausgetretenen Nukleolen ihre Fibbbarkeit und werilen allmählich anfgelöst.

In ihren chemischen Eigenschaften zeigen die Keimflecke von den echten Nukleolen, die sich in den gewöhnlichen Kernfarbstoften nicht tingieren und aus Pyrenin bestehen, zuweilen Verschiedenheiten. So gibt es Keimflecke. die sehr deutlich aus zwei verschiedenen Substanzen aufgebaut sind. Es ist dies Verhältnis zuerst durch LEYDIG bei lamellibranchiaten Mollusken beobachtet. dann dureh Ftammas (III 1852) an demselben Objekt und von mir (III 1875--187s) noch in anderen Fällen genaner festgestellt worden. Ich lasse hier die lieschreiloung des Tatbestandes, wie sie Flemang gibt, folgen.

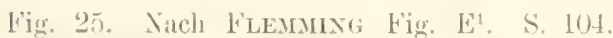
" Kern eines Fierstockeies ron Unio frisch ans der Zelle getreten in Orarialflüssigkeit. \%weiluckeliger Tukleolus. Geringe Teile des herngerïsts sichthar. " Ein solcher Kern nach Zufließen vou Essigsäure 5 $\%$. Gerïststringe sind aufgetreten, der größere blassere Teil des IIauptnulileolus und die Tebennukleolen sind in gleichem Grade gequollen und erblaßt; der kleinere Hauptteil des qrolien Nukleolus ist ebenfalls, aher schwächer geypollen. \& Xukleolus eines Eies ron Tichogonia (Dreissena) polymorpha: der glämzende IIauptteil sitzt als liappe auf dem grölieren blassen. $\beta\left(O_{1}\right.$ tisches Durchschnittshild desselben, schematisch.
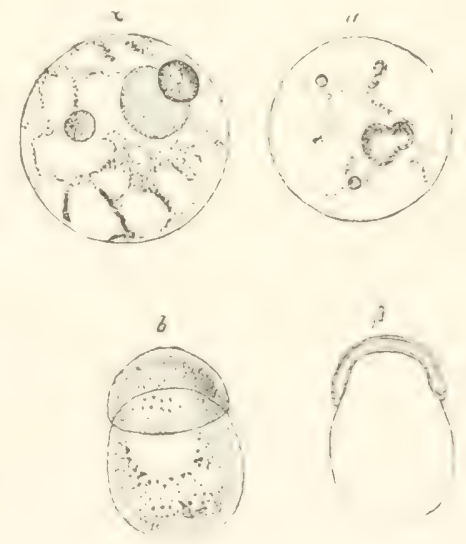

Bei Cyclas cornea und bei Yajaden tindet sich im Keimbläschen ein Hauptunkleolus außer einigen wenigen Nukleolen (Fig. 25). .Der erstere besteht aus zwei difterent beschatfenen T'eilen: einem kleineren. der belentend stärker lichtbrechend mul stärker tingierbar ist, mnd einem gröheren. blasseren und schwächer chromatischen, der in Säure stärker quuillt. Bei Anodonta hängen die beiden 'Teile zusammen. bei Unio sind sie vielfach nur miteinander in beriihrung oder liegen sellst getremnt. Die klemeren Nebennukleolen. die hier in den Ballien des Kerngeriistes lagern. zeigen dieselhe Lichthrechung. (Quellharleit und Tingierharkeit. wie der grobe Teil des Hauptnukleolus. Bei Wasserzusat\% verschwindet dieser Hauptteil und die Tebennukleolen nebst den Gerüststrängen: es

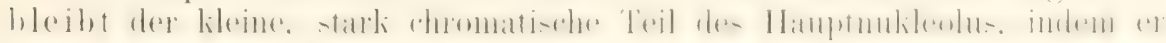
dabei noch verschärft wird und etwas schrmmutt mol eine scharf abge- 
setzte Kontur bekommt. Zusatz von starker Essigsäure (5\% oder mehr) läbt den gröberen. blasseren T'eil des Hauptnukleolus rasch aufquellen und verschwinden, während der kleine, glänzende zwar auch etwas quillt. aber erhalten bleibt." "Bei Anwendung von lierntinktionen färbt sich zwar der starkbrechende 'Teil der Nukleolen hesonders intensiv. aber in erheblichem Grade auch der andere T'eil und die Nebennukleolen." .. Solche Differenzierung der Hauptnukleolen in zwei 'Teile kommt bei Eizellen vieler 'Tiere vor'. Bei Dreissena polvmorpha ist der stark lichtbrechende und chromatische T'eil als Hohlkappe um ten blasseren herumgelagert."

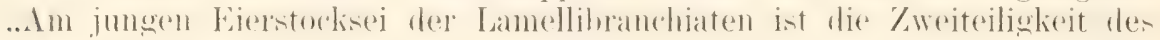
großen Kernkörpers moch nicht zu finden. sie bildet sich erst am reifen Ei helaus."

$$
\text { Fig. }-26 \text {. }
$$
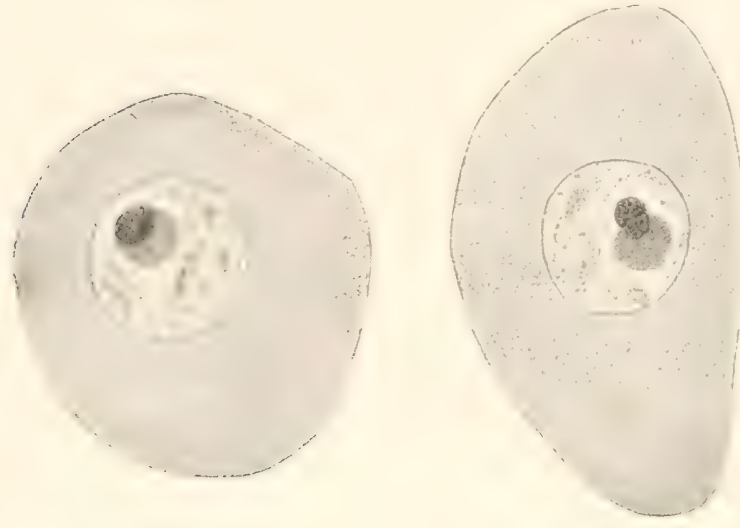

Eine gute Vorstellung von den aus zwei Substanzen zusammengesetzten Keimflecken geben auch die Figuren 26 und 27 , von denen die eine das Eierstocksei von Unio batavus. die andere von Limax maximus darstellt.

Fig. 26. und 2-. Eierstocksei von Unio batavus (Fig. 26) und von Limax maximus (Fig. 27) mit Keimflecken aus zweierlei Substanzen. Nach OBsT aUSKOORGCHELT Und HEIDFR.

Es ist eine offene Frage, die von wenigen Forschern bejaht, von den meisten aber in Abrerle gestellt wird, ob das Chromatin des Kerns mit dem Pyrenin des Kieinflecks bei einzelnen Tierarten zeitweilig rerbunden
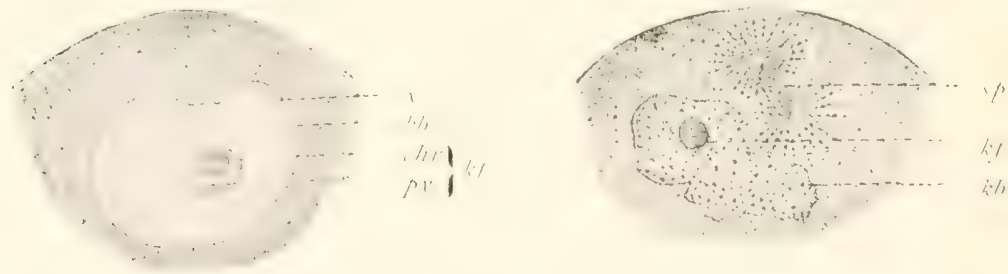

[iig. 2S. Ausschnitte aus Eiern von Asterias glacialis. Nach HFRTWI(i. Sie zeigen die Rïbkbildung des keimblissehens $(k b)$. In lig. 1 begimt dasselbe zu schrumpfen, indem ein l'rotoplasmahöclier $(x)$ mit einer Strahlung in sein Inneres einAringt und die Nembran dasellst auflöst. Der Keimfleck (kf) ist deutlich in zwei Substamzen gesondert, von denen sich die imnere (chr) stärker färbt.

In Fig. Is ist das Keimbläschen $(k b)$ ganz geschrumpft, seine Membran ist anfrelöst. der heimfleck $(\mathrm{k} f)$ nur noch in kleinen Resten vorhanden; in der Gegend des I'rotoplasmahökers mit Strahlung in der Fig. $\perp$ ist eine Kernspindel $(s p)$ in Ausbildung begriffen.

auftritt. Wenn ich von den noch unsicheren, oben erwähnten Angaben CARNOYs mind LEBRUNs absehe, so scheint mir das Keimbläschen ron 
Asterias glac. einen Fall darzubieten, in welchem der Chromatingehalt des lieintlecks kam anzuzweiteln ist. Wie ich sehon rol 30 dihren beobachtet habe. sondert sich die Masse des groben lieimflechis in zwei sul.stanzen (Fig. 29), von denen die eine als ein klemes Kügedchen in eine

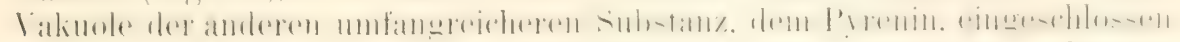
ist. An der Bildung der Richtungsspindel ist der Kimfleck in hervor-

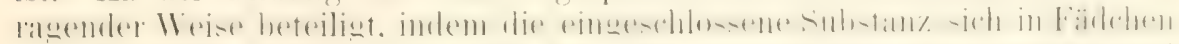

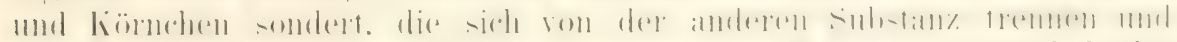
nach dem Ort der Spindelbildumg hinwanderm. Wem so der Inhatt der Vakuole des Keimflecks entleert ist. bleibt ter Rest, das Pyenin, als leere

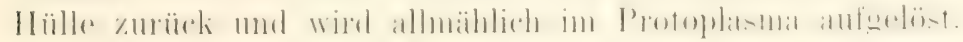

Diese befunde haben in jüngster Zeit durch IIARTAxs eine vollständige bestätigung und eine Ergänzung gefunden. In seiner mit den

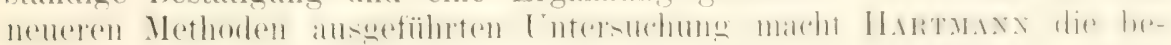
stimmte Angabe, dab bei Asterias glac. am Schlub der Reifeperiode alles Chromatin und Plastin im Nukleolus vereinigt sind, und dala ans seinem

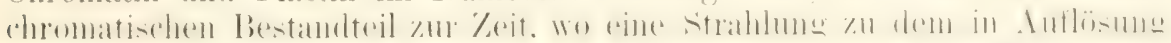

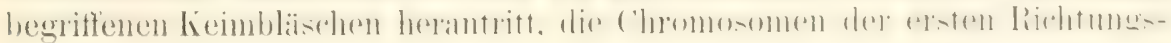
spindel entstehen.

Die Befunde von Asterias wïrden sich somit an die oben erwähnten

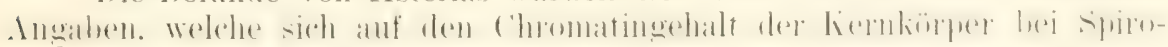
wra, Actinosphärium, (iregarinen ete. beziehen. anreihen lassen. D)al.) iibrigens das Chromatin sich zu einem einzigen kompakten und scheinbar

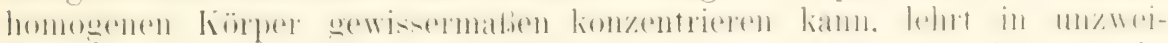
deutiger Weise der Zustand. Welchen es im Samenkörper, \%. B. bei Ascaris. annimmt, bei dem es ja auch in einen nukleolusartigen Körper, in ein liompaktes liugelchen, mimgewandelt ist.

Die Form der Nukleoli ist in den liernen von (iewebszellen und Fiern eine wechselnde: meist sind sie rein kugelig. wemn sie vereinzelt anfreten: wo sie zahlreich vorkommen. kömen sie alle möglichen Formen amnehmen und mit Fortsätzen und Lapplen bedeckt sein. so dab sie einer

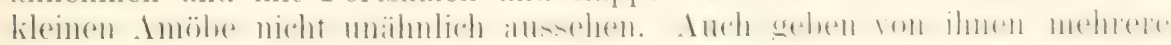

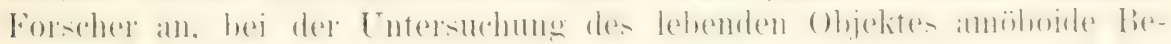
wegungen beobachtet zu haben.

Häufig finden sich in der Substanz der lieimflecke kleine Vakuolen.

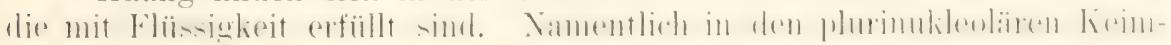
bläschen werten sie einige Zeit vor der Auflösung der Keimflecke so zahlreich. (lab ihre Substanz ein wabiges Ausselien gewimnt. Durch Ter-

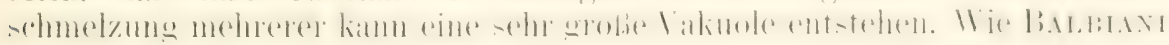
an den Kieimtlecken der Eier von Phalangium opilio beobachtet hat, rïcken die Valinolen zeitweise dicht an die Obertläche heran. entleeren ihren Inhalt durch Platzen und werden wieder durch neugebildete ersetzt.

Von mehreren Forschern wird angegeben, daf Nukleolen und lieinHecke sich durch Teilung vermehren kömmen. Zmanermaxi hält dies so-

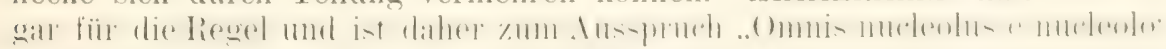
veranlabt worlen. Hiergegen erhebt MonTGovery, der eine gröbere zusammenfassencle Arheit über Nukleolen veröftentlicht hat. wie uns scheint mit Recht. mehrfache Berlenken. Denn anf der einen Seite ist ihre Vermehrung durch Teilung noch in licinem Fall vollkommen cinwandstiei

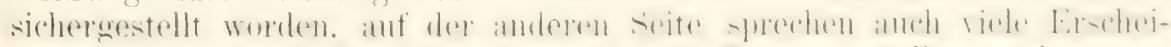

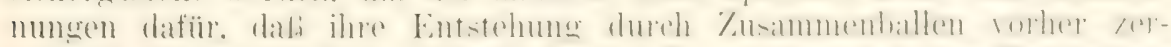

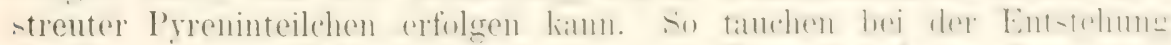

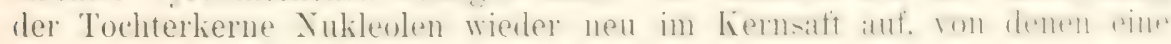


direkte Abstammung von einem Mutternukleolus direkt in Abrede gestellt werden muf. Und ebenso ist es durch nichts erwiesen, dab die Hunderte ron liemtlecken im Keimblïschen der Hisch- und Amphibieneier durch 'Teilung eines ursprüinglich einzigen entstanden sind.

In einigen Fällen ist eine Verschmelzung mehrerer kleiner zu einem einzigen gröberen Nukleolus beobachtet worden. An sichersten ist wohl die Angabe ron E. Zacuarias, der in lebenden, sich teilenden Zellen von Chara in jedem Tochterkern vier Nukleolen beschreibt, die in fünf Stunden zu einem einzigen verschmolzen waren.

Über die Rolle, welche die Nukleoli im Leben des Kerns spielen. läBt sich zurzeit noch nichts Sicheres aussagen. Wir wissen hierüher viel weniger als über die Rolle des Chromatins. Hennegur vergleicht die Nukleolen dem Makionukleus der Infusorien, mit dem sie darin übereinstimmen. dal. sie an Masse im Vergleich zur chromatischen Substanz der Nebenkerne stark zumehmen, und dann zu gewissen Zeiten in Stïcke zerfallen und aufgelöst werden: HAEcker erklärt die Nukleolen für ein ..Stoffwechselprodukt des Kerns, dessen krzengung in einem gewissen $\mathrm{Ab}$ hängigkeitsverhältnis zur Intensität der vegetativen Leistungen von Kern und Zelle steht."

Noch manche andere Ansichten lassen sich bei einer Durchsicht der Iiteratur zusammenstellen: ans ihnen allen resieht man hauptsächlich wohl das eine. daß unsere Kenntnisse in der Nukleolenfrage noch sehr mangelhafte sind, und dab hier ein Gebiet liegt, auf welchem durch planmäbige ausgedehnte, vergleichende Untersuchungen erst eine bessere (xrmullage für weitergehende allgemeine Schlüsse gewomnen werden muß.

\section{Gibt es kernlose Elementarorganismen?}

An die Beschreibung der chemischen und morphologischen Eigenschaften des Kerns läbt sich noch die wichtige Frage kniipfen, ob der Kern ein unentbehrlicher Bestandteil jeder Zelle ist. Gibt es kernlose Elementarorganismen? Noch vor einer Reihe von .Jahren war man mit einer Antwort anf diese Frage nicht verlegen. - Da man infolge cler

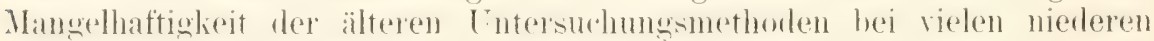
Organismen keine Kerne gefunden hatte, nahm man die Existenz von zwei rerschiedenen Arten von Elementarteilen an, you einfacheren, die nur aus einem Klümpchen von Protoplasma bestehen, und von zusammengesetzten, welche in ihrem Innern noch als besonderes Organ den Kern entwickelt haben. Die ersteren bezeichnet HAEckes (I. 1870. HI. 1866)

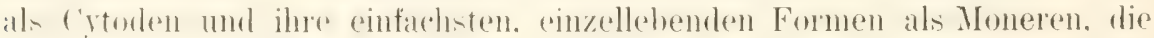
letzteren als Cellulae oder Cyten. Seitdem aber hat sich der Stand der Frage wesentlich verändert.

Dank den verbesserten optischen Hilfsmitteh und den vervollkommneten Färbungsmethorlen ist die Existenz von Organismen ohne Kern sehr in Frage gezogen.

Bei sehr vielen niederen Ptlanzen (Algen, Pilzen) und bei P'rotozoen,

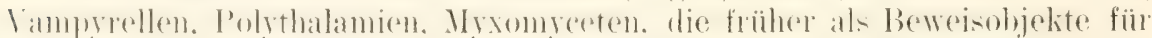
das Fehlen des Kerns gegolten hatten, gelingt es mit leichter Mühe, Kerne nachzuweisen. Xachdem anch bei der reifen Eizelle der Kern gefunden worken ist (HERTwIG III. 1875), kömnen wir sagen, dal. im gesamten 'Tierreich kein Fall von kernlosen Zellen existiert. Man wird mir vielleicht die roten lihuthïnerehen der sïngetiere entegenhalten. Freilich fehlt hei 
ihmen ein liern, es fehlt ihnen aber ehensogut auch das Protoplasma, und es läfit sich mit guten Gründen die Ansicht verfechten. dal.i die Bhutscheiben der Säugetiere nicht den Wert ron Elementarorganismen besitzen. sondern nur die Lmwandlungs- oder Bildungsprodukte ehemals vorhandener Zellen sind.

Eine '/uflucht findet jetzt die Lehre von der liernlosigkeit nur noch bei den Mikroorganismen, bei den bakterien und verwandten formen, bei denen wegen ihrer ablierordentlichen Kkeinheit die Unterscheidung von Protoplasma und hermsubstan\% auf Schwierigkeiten stoblt. Indessen hat

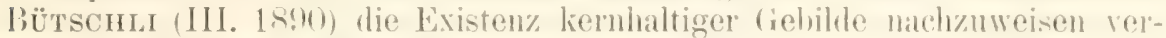
sucht. Als solehe deutet er bei Osvillarien u.a. (Fig. ㅁ․ 1, B) Köruer, welche bei (ler Verdaumng duch Magensaft nicht aufgelöst werden und einzelne in Farbstoff sich intensiy farbende Körnchen (wahrscheinlich Nukleinkörnchen) beherbergen. Dieselben machen den gröberen T'eil des Zellkörpers aus. während Protoplasma nur als diüme Embiülung vorhanden ist. Bütschus Ansichten werden im allgemeinen roll ZACIARIAS (II. 1890) UmL SCHEWIAKOFF (III. 189:3) geteilt. Dieser beobachtete auch im Körper von Achromatium zerstrente, stark fïrbbare Körner, welche er als Chromatin dentet. und für welche die Bezeichnung, ,verteilter oder zerstreuter Kern" (distributed or scattered nucleus Wilson III. 1900) gebraucht worden ist.

IV er diese Angaben nicht als beweisend anerkemmen will, wird zugeben müssen. (lab) die Ammahme, welche die Mikronganismen gan\% orler rorzugsweise aus Kernsubstanz bestehen libst, wenigstens ebenso viel, wenn nicht mehr, fiir sich hat, als die Annahme, sie seien nur
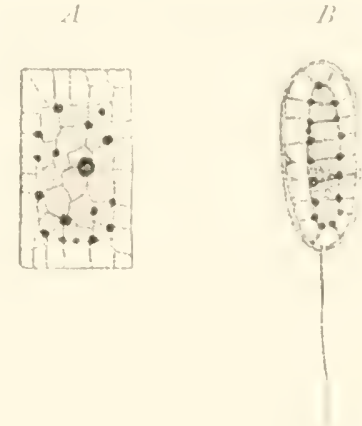

Fig. 29. A Oscillaria. ()ptischer Durchschnitt einer Kelle eines Fadens. Mit .llkolonl getïtet mol in Ifimatoxylin gefairbt. Nach Bürscmu lï.12a. /) Bacterium lineola (CoHx) im

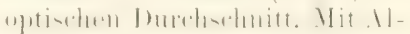
kohol getötetes und in Ilämitoxylin gefärhtoe Exomplar. Nach Bütachli Fig. 3a.

kleinste, einfache Protoplasmaklümpchen. Denn für die erste Ammahme

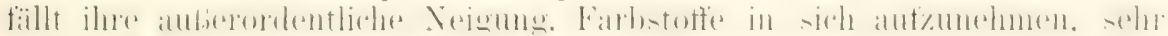
in die Wagschale, sowie der Umstand, dab man bei der chemischen Analyse von Bakterienmassen viel Nuklein erhalten hat.

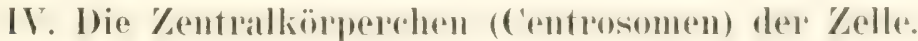

In jüngster Zeit ist neben dem Kern im Protoplasma einiger Zellen ein autierordentlich winziges, aber durch seme Funktion sehr wichtiges Gebilde nachgewiesen worden, das \%entralkörperchen (Centrosoma).

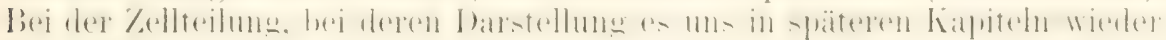
beschäftigen wirl. ist es schon seit längerer Zeit bekannt und spielt hier eine sehr arobe Rolle, da es den Nittelpunlit für eigentümliche Strahlumg-formen

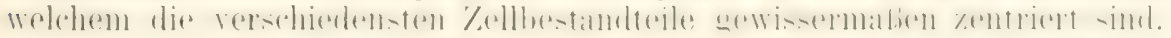

Seine Gröhe lient an der Grenze des eben sichtbaren und bleibt hr̈ufig unter dem Durchmesser kleinster Mikroorganismen zurück. Es richeint stofflich aus derselben Substanz. wie das Mittelstiuck der Samenfïden zu bestehen, zu welchem sich ïbrigens auch beim Befruchtungsprozelj genetische Beziehungen ergeben ( $\therefore$ s släteres liap). Bei (len ge- 
wöhnlichen Kernfärbemethoden nimmt es kemen Farbstoff anf. läßt sich aber bei geeignetem Verfahren. namentich durch saure Anilinfarben. wie sianrefuchsin, Safranin, Orange, besonders aber durch Hemdenuars Hämatoxylin, dessen man sich jetzt zu seinem Nachweis am häugsten be(lient. lebhaft tingieren.

Das Zentralkörperchen ist gewöhnlich noch von einer homogenen Substanz umgeben, die sich vom übrigen Protoplasmakörper bald mehr, bald weniger absetzt und als Zentrosphäre unterschieden werlen kann. '/u gewissen Zeiten, namentlich aber im Verlauf der Zellteilung beginnt sich un das Zentralkörperchen mit seiner Sphäre das Protoplasma in Strahlen anznordnen, so dab unter diesen Umständen seine Lage in der

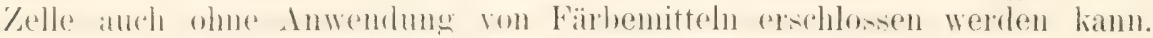
Ist weder Strahlung noch Sphäre vorhanden, so kann das Centrosom mit anderen Kömchen des Zellinhalts leicht verwechselt oder von ihnen viberhaupt nicht unterschieden werden. Sehr häufig ist es, daß in der ruhenden Zelle zwei Centrosomen dicht nebenemander in einer gemeinsamen Sphäre beobachtet werden.

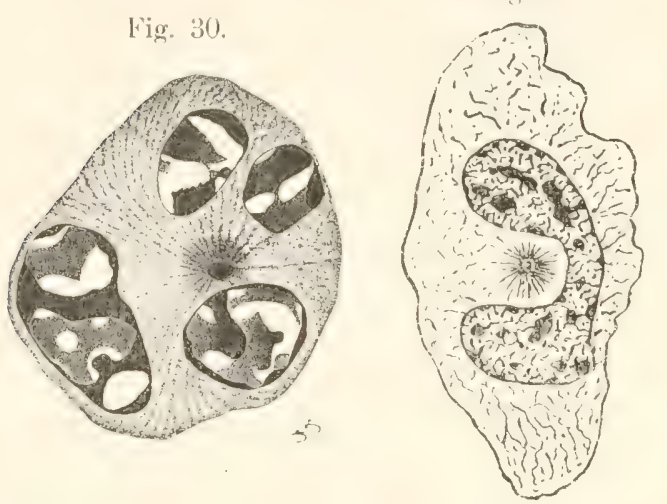

\begin{abstract}
Fig. 30. Ieukocyt von Salamandra mit Centrosom und Sphäre. Vergr. 2500. (Sublimat, Eisenhämatoxylin.) Nach HernexHAIN.
\end{abstract}

Fig. 31. Leukocyt aus dem Peritoneum einer Salamanderlarve. Der Zentralkörper in der strahligen Sphäre ist zur Verdeutlichung des Zinkdrucks von einem hellen Ring umgeben dargestellt, welcher in natura fortzudenken ist. Nach FI.wIIING Fig. 5.

Im Gebrauch des Wortes Centrosom ist in der Literatur eine recht mangenchme V'erwirrung eingerisen, welehe das gegenseitige V'erstänhis arshwert. Boveri, welcher den Vamen zuerst gehildet hat, hezeichnete mit ihm in seinen Ascarisuntersuchungen die Sphäre, das in ihr einge-

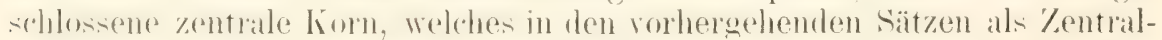
körperchen odler Centrosoma aufgeführt wurde, als sein Zentriol. Als man nm später auch in tierischen Gewebszellen, sowohl während der 'Teilung als auch in der Ruhe kleinste Körnchen durch besondere Firbemethoden als Mittelpunlite von strahlentiguren nachzureisen vermochte. namnte man

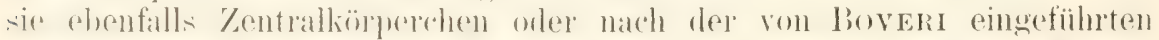

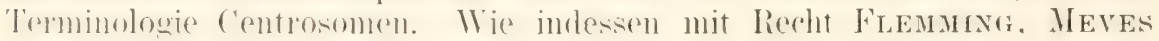
II. a. hervorgehoben haben, entsprechen die letzteren Gebilde nicht den vielmals größeren Centrosomen Boveris im Ascarisei, sondern den in ihmen eingeschlossenen Zentriolen. Man dürfte daher, streng genommen, bei (iewebszellen und ihren 'Teilungsfiguren nur von Zentriolen reden. I'azu wird man sich aber schwer entschliefen, da man sich schon daran gewöhnt hat, das im Mittelpunkt der Strahlungstiguren gelegene Korn Zentral-

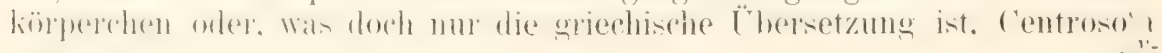
zil nennell.

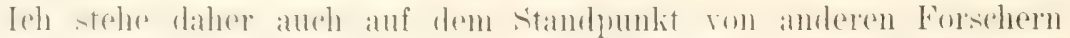
und insbesondere von Wruson, der ihm in die Sätze zusammengefaßt hat: 
.Lastly. we must recognize the justice of the view urgerl by Kostanechi. Griffin. Mead. Lillie. Coe and others. that the term centrosome should be applied to the central granule and not to the sphere surrounding it (medullary zone), despite the fact, that historically the word was first applied by Boveri to the letter structure: 'The obvious interpretation is that the central gramule is the only structure that shonld be called a centrosome, the surrounding sphere being a part of the aster. or rather of the attraction sphere." Nur in diesem Sime werden wir in folgenden ron Centrosomen (d. h. Zentralkörperchen). Centrosphären und Kentrenstrahlumg (Aster) oder strahliger Anordnung des Protoplasma reden.

Wenn wir yon der Zellteilung und dem Befruchtungsprozeb absehen. ïher welche spätere Abschuitte handeln, so ist das Kentralkörperchen

Fig. 32 .

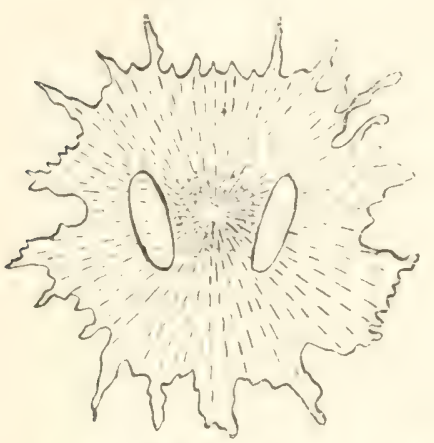

Fig. 33.

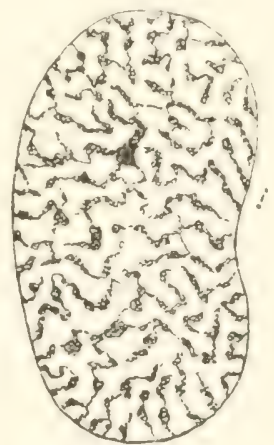

lïig. 34

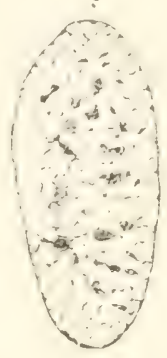

Fiig. :i. . Pigmentzelle des Hechts mit 2 Kermen und 1 Zentralkörperchen in einer Strahlensphäre. Nach SoLcisr.

FiL. :i... Kern einer Endothelzelle des Peritoneums einer Salamander-

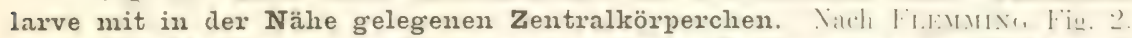

Fin. 2t. Kern einer Bindegewebszelle des Peritoneums einer Salamander-

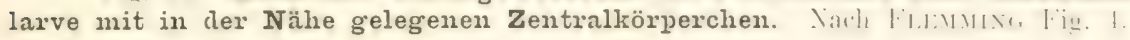

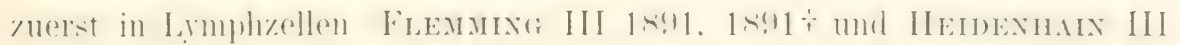
1892). in Pigmentzellen des Hechts (SolgEr III 1891), in sehr Hachen

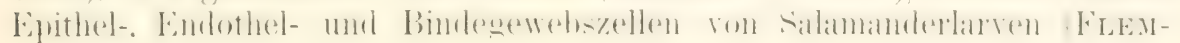
arisg) aufgefunden worden.

In Lymphzellen kommt meist nur ein einziges Zentralkörperchen vor (Fig. 30) und ist dies außer der Fübung noch dadurch kenntlich

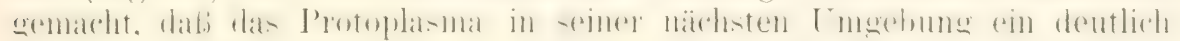
strahliges Gefüge zeigt und die später uns noch öfters beschäftigende

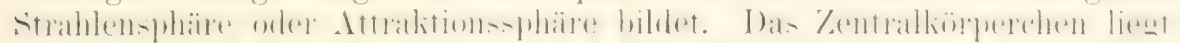
zuweilen in einer Einbuchtung des Kerns (Fig. 31) oder, wenn dieser in

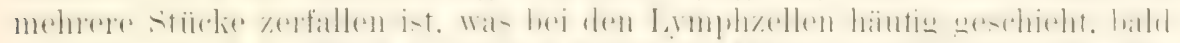

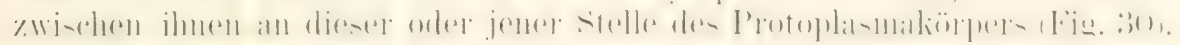

Lei Pigmentzellen (Fig. 32) hat Solger (III 1891) nur die Centrosphäre als eine helle Stelle zwischen den strahlig angeorlneten f'igment-

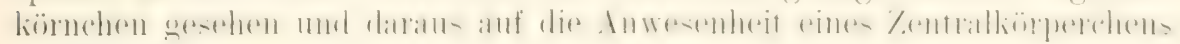
geschlossen.

In den Epithelien der Lunge, in Endothel- und Bindegewebszellen des Bauchfells von Salamanderlarven (Fig. 33 und 34) find Fuemung fast stets anstatt eines einzigen zwei dicht zusammengelegene Zentral-

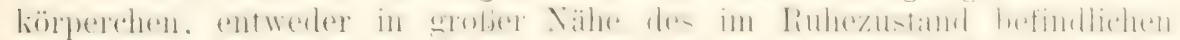

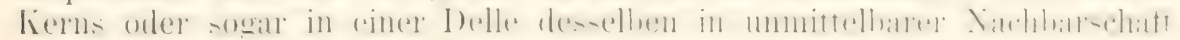
der Kermmembran. Eine Centrosphüre war in diesen Fällen meist nicht 
nachweisbar: zuweilen waren die beiden Zentralkörperchen, anstatt sich fest zu beriihren, ein wenig auseinandergerïckt, und war dam der erste Anfang einer Spindelbildung zwischen ihmen wahrunehmen.

Seit diesen ersten grundlegenden lieobachtungen sind 7entralkörperchen von Jahr zu dahr häufiger bald in dieser, bald in jener Zellenat machgewiesen worken. sowohl bei Wirbeltieren als bei Wirbellosen: so von

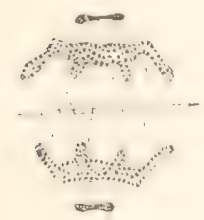

lij. 35. Zwei Tochterkene mit lappigen Fortsätzen aus dem Ei vou Ascaris megalocephala. Die leiden Kentralkïrperchen repuchren sich durch sellstteilung. Nach vax BExEDEN und Neyt.

Zimmermans in den verschiertenen Gerrebszellen des Menschen. inn Heidenhain und Cons in den Embryonalzellen von jungen Entenembryonen der ersten Bebriitungstage, von BALLowity in Epithelzellen von SALPEN (Fig. 36) und in den Endothelien der Descemetschen Membran. von LennosseK in Ganglienzellen des Frosches, von Ratu in Drïsenzellen hei Kinstazeen, von (iURwitsch und WinIwater in jungen Ovarialeiern bei Säugetieren usw.

Auf der anderen Seite sind die V'ersuche, Zentralkörperchen nachzuweisen, bei manchen Zellen und Tierarten vergeblich gewesen, z. B. bei den phanerogamen Pflanzen, bei denen man bis jetzt nach ihnen sowohl während der Ruhe des Kerns als auch selbst auf dem Spindelstadium der Karyokinese rergeblich gesucht hat.

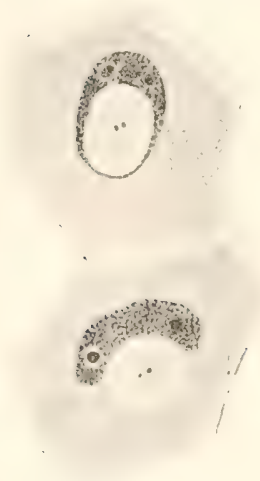

Das große Interesse, welches von den Histologen dem Zentralkörperchen entgegengebracht wird, ist zum groben Teil mit daduch geweckt worden, daß bei seiner Entrleckung in Ascarisei ED. VAN BENEDEN mol im Anschlus an ihn Boveri die Hypothese aufgestellt haben, es sei wahrscheinlich das Gebilde gleich dem Kern ein konstantes Organ jeder Zelle und müsse sich daher wohl stets im Protoplasma neben dem Kerne eingehettet finden.

1.ig. 36. Zwei Zellen aus dem Kloakenepithel von Salpa punctata von der Fläche gesehen mit sichelförmigem Kern. Die Sphäre ist radiärfädig und enthält 2 Centrosomen. Tach BALLOWITZ.

In der Tat ist es auch häufig gelungen, am leichtesten auf gewissen stadien der Karyolinese cine Vermehrung des Zentralliörperehens anf dem Wese der selhsteilung frotzustellen Fig. :3). Es strecht sich imnerhall, der Sphäre, wird darauf biquitförmig, die verdickten Enden rücken ,useinander, der Verbindungsfaden reißt ein, infolgedessen dann die Tochter-

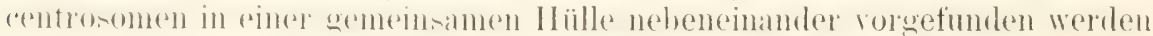
und bei einer nachfolgenden Karyokinese wieder die Centrosomen an dsn entgegengesetzten Polen der entstehenden Spindel liefern. Zu Gunsten der Hypothesen von VAN BENEDEN und BoverI spricht zweitens der Um-

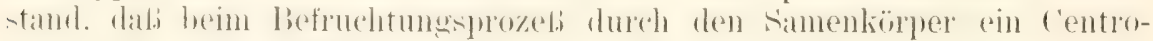
som in das Ei eingeführt wird und durch seine Teilung die Centrosomen der ersten Spindel liefert, ron welchen sich wieder die Centrosomen bei allen späteren Kernteilungen der Embryonalzellen herleiten. 
Vor Jahren habe ich die Vermutung ausgesprochen, dab in manchen

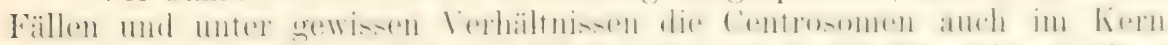

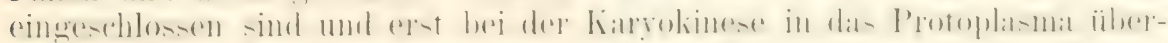
treten. Über Beobachtungen, die in rlieser Richtung remacht sind, vergleiche man das Kapitel über die 'Teilung der Zelle.

Gergen die Hypothese, dab die Centrosomen permanente Zellorgane wie der Kern sind und nur durch Teilung aus bereits vorhandenen Centrosomen entstehen können, haben Mokgdx und Wilsox gewichtige Einwïnde erhohen. Dadurch, dab sie unbefruchtete Eier von Seeigedn mit

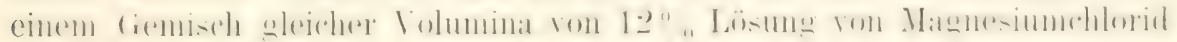
und ron Seewasser für einige Zeit behandelten und dann in reines See-

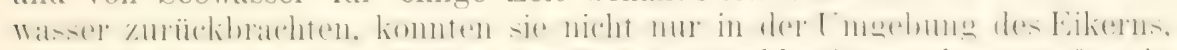

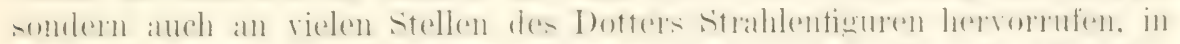

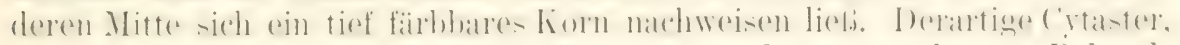
wie sie Wruson nennt, entwickeln sich bei der angegebenen Behand-

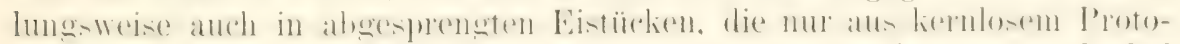
plasma bestehen. Daß das in der Strahlung eingeschlossene, sich bei

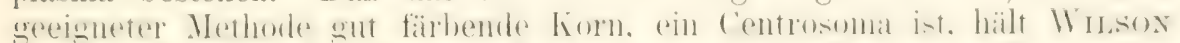

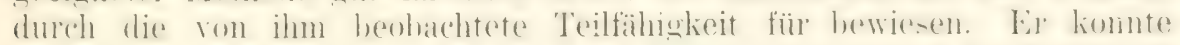

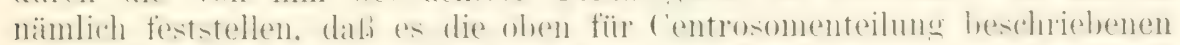

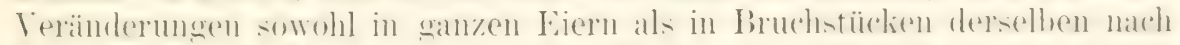

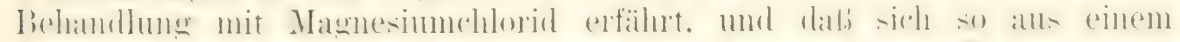

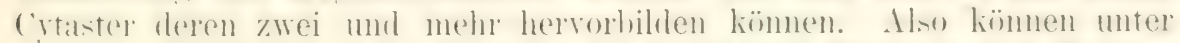
gewisten liedingungen im Fiplasma - so folgern Momadx mul Wilsox aus den von ilmen entrleckten Tatsachen - Centrosomen neu erzeugt werden.

Während auch BovERI diesen Beweis durch WILsons Entdeckung für erhratht hält. will MEVEs an de" Möglichkeit testhalten. dals durch

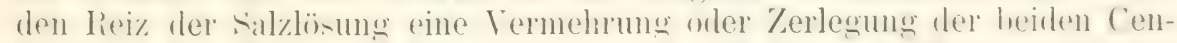

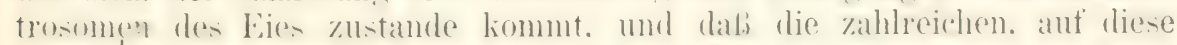
Weise entstamdenen Tochterebehilde sich im l'rotoplasma rerteilen mul mit

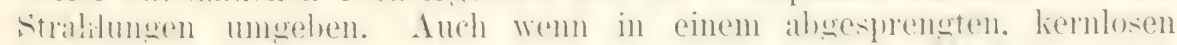

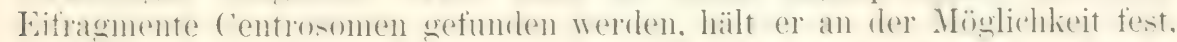

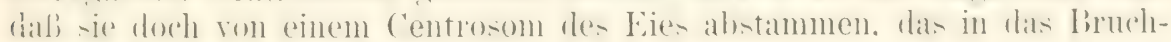
stiick mit hineingeraten war.

Daf. in der Centrosomeñlehre noch Vieles unsicher ist, kann nicht

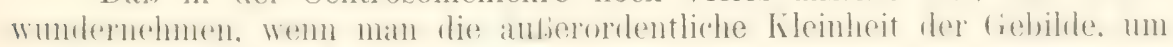
die es sich handelt. berïicksichtigt.

\section{Hypothesen uber die Elementarstruktur der Zelle.}

In den rorausgegangenen Abschnitten sind wir mit verschieden-

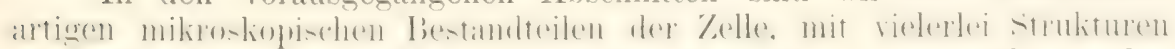
im Protoplasma und im Kern bekannt geworden. Gleichwohl werden wir uns sagen müssen, daB wir noch weit ron dem Ziele entfernt sind,

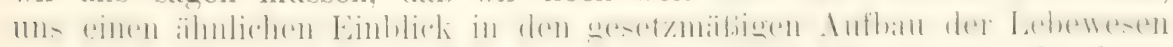
zu verschaffen. wie es den Chemiliern mit ihrer Lehre von den Struktur-

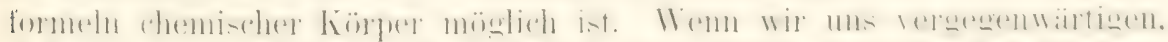

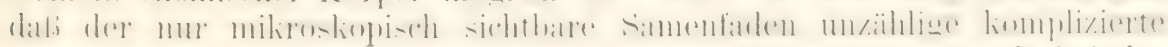
Eigenschaften dles Vaters auf das Ei überträgt, und daß er auch bei der

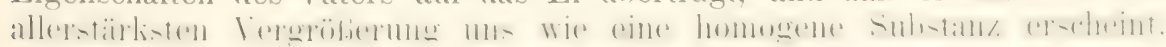
die bei einem Tier ebenso wie beim anderen aussieht, wenn wir uns

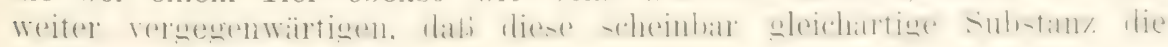




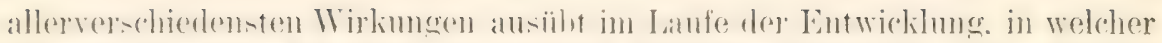
die im Ei und Samenfarlen latenten Anlagen allmälulich erst offenbar

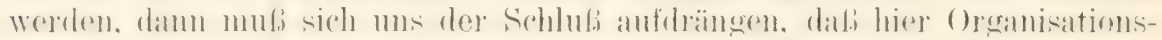
verhältnisse vorliegen, in welche wir mit dem Hilfsmittel auch unserer allerbesten Mikroskope überhaupt nicht einzudringen vermögen.

Wo die Kraft des leiblichen Auges versagt, sucht der Forscher durch Hypothesen das Verborgene verständlicher zu machen. Wie der chemiker anf cirmullage der Atomtherore eine Strukturehemie aufgehaut

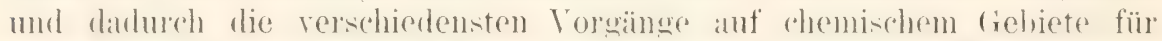
mis verständlicher semacht hat. so haben anch hiologicely. Forscher sich eine Vorstellumg von einer noch jenseits des mikposinpischen diebietes gelegenen elementaren (Mganisation der Zelle $7 u$ hilden versucht. Vom den vershiedenen Hypothesen verdienen zwei msere Beachtung, die Mizellarhypothese von NäGeLI und die Hypothese vom Aufbau der Zelle aus elementaren, ultramikroskopischen Lebenseinheiten.

1. Die Mizellarhypothese von NäGELI mag hier eine kurze Darstellung finden, welche sie schon allein wegen ihrer streng logischen Durchfiihrung verdient.

Eine der auffälligsten Eigenschaften der organisierten Körper ist

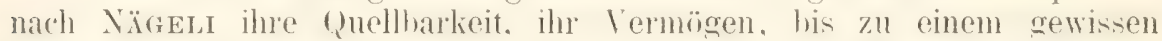

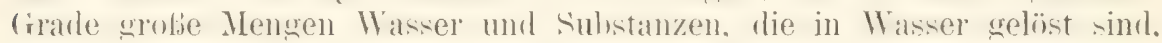
in ihr Inneres aufzunehmen. Es kann dies so weit gehen, daß in einem organisierten lörper überhaupt nur wenige Prozente fester Substanzen enthalten sind.

Fntsprechend der Wasseraufnahme nimmt das Volumen des Körpers zu. um sich bei Abgabe von Wasser wieder zu verkleinern. Dabei lagert sich das Wasser nicht in präexistierende. mit Luft gefüllte Hohlläume ein, wie bei einem porösen Körper, sondern es verteilt sich gleichmäbig zwischen die oranisierten 'Teilchen. die, je arober die quellung ist.

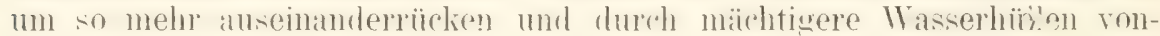
einander getrennt werden müssen. Trotz der beträchtlichen Wasseraufnahme findet dahei leine Auflïsung der organisierten Substanz statt. Sie verhält sich auch in dieser lie\%iehmo verschieden von einem liristall von Salz oder Zucker, dem auf der einen Seite die Fähigkeit der Quelluns abgeht, der aber auf der anderen Seite sich in Wasser auflöst, indem sich seine Ioleküle voneinanter tremnen und sleichmäliog im Wasser verteilen.

Quellungsfähigkeit und Unlöslichkeit im Wasser sind Haupteigenschaften der oranisierten hörper. ohne welche der Lebensurozeli nicht denkbar ist.

Manche organisierte Körper lassen sich durch geeignete Verfahren in eine Lösung überführen, so \%. B. Stärke und leimgebende Substanz, wemu sie in 11 arser gekorht werden. Sher auch Starke- mol Leiniösungen untersheishn sich in ihren Eigenschatten sehr wesentich vom Iösmugen von Salzen oder Zucker. Diese diosmieren leicht durch Membranen, jene nicht orler nur in geringen Mabe und bilden shleimige oder farlenziehende Lösungen. Schon GraHAM hat beirle Gruppen von Stoften, welche in Lismng wo mgleiche Eigensehaften zeigen. vomeinander als Kristalloide und Kolloide unterschieden.

NÄGELI sucht num alle hier namhaft gemachten Erscheinungen aus Interschieden $n$ der molekularen honstitution der Körper zu erklären. IVie Atome sich zu Molekülen verbinden und so eine grolie Verschiedenheit rhemischer Stoffe er\%eugen. so lälit er, damit die komplizierten Eigen- 


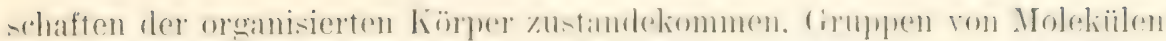
noch zu höheren Einheiten, den Mizellen, zusammentreten. Im Verhälnisse zum Molekül besitzt das Mizell eine betrachtlichere, wenn anch jenseits der Grenze mikroskopischer Wahrnehmung liegende Größe und kann nicht bloß aus Hunderten, sondern aus vielen Tausenden von Molekülen aufgebaut sein.

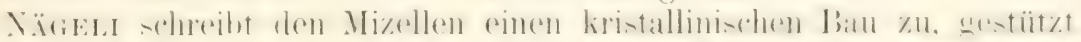

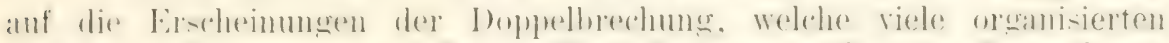

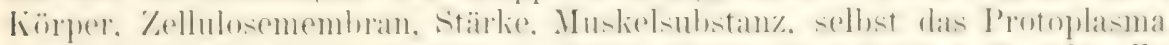

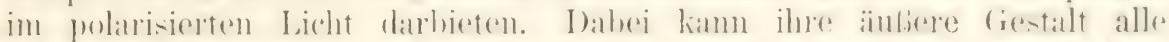

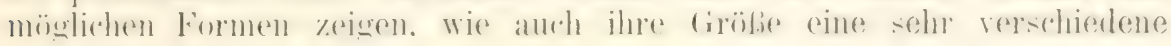
sein wirl.

Die Mizellen üben eine Anziehung sowohl auf das Wasser, als auch anfeinamble ans. Woraus die ()uellungserscheinungen zu pribiären sind. In einem trockenen. organisiorten hörper liogen die Mizellon dicht aneinander.

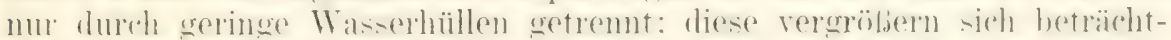

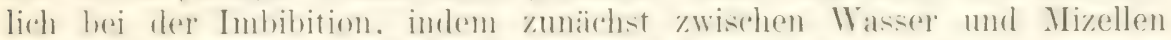

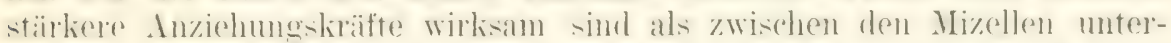
einamder. I)iese werdem durch das eindringende Waser wie durch einen

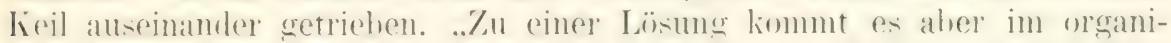
sierten lïrper nicht. weil die Anziehumeshaft zum IIaser mit der Entfermung in einem schmelleren lerhälnisise abnimmt. als die Anziehmurskraft der Mizellen untereinander. mul so, nachdem die Wasserhüllen eine

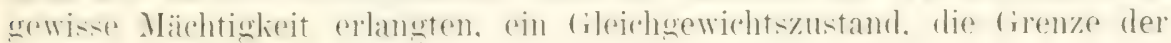
Quellung, srreicht wird."

Wenn trotzdem durch geeignete Verfahren der Zusammenhang zwischen den Mizellen ganz aufgehoben wird, so erhält man eine

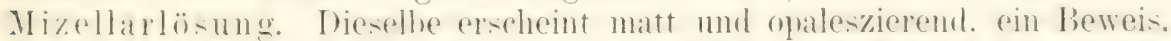

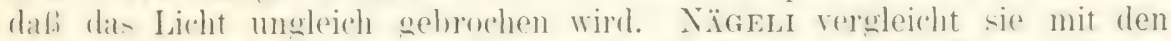
schleimigen. opalestierenten Massen. Welche spaltpilze dureh Aneinanderlagern erzeugen.

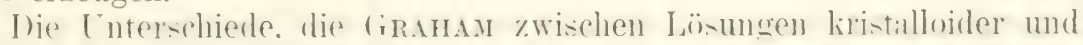

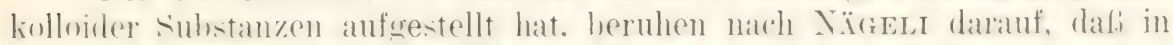

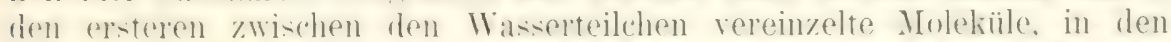

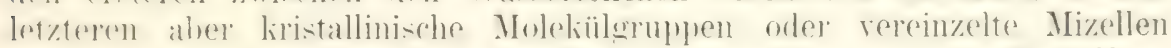
verteilt sind. Die einen sind also Molekular-, die anderen Mizellarlïsungen (Lï-muen von Eiweili. Leim. fimmi ete. Die Mizellen sellst setzen dom Zerfallen in Molekïle einen grölexen Wider-tamb enterenen. ferwhulich ist dieser Zerfill mit chemischen Lmwandlumeen verhmolen.

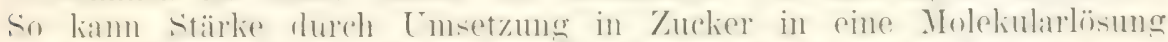

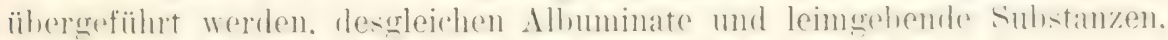
wenn sie sich in Peptone umwandeln.

In den organisierten Körpern sind die Mizellen zu regelmäfigen Verbämden vereinget. In diesen kïmnen die oimzelnen Mizellen ans der-

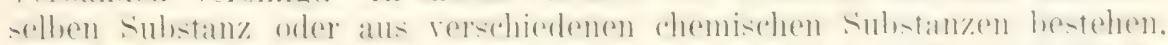

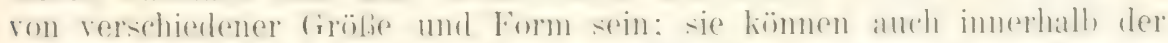

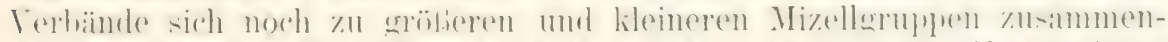
schlieden. In den Mizellarverhändens sheinensich im alleremeinen die Mizellen in Ketten aneinander zu hängen, die sich wieder zu einem Gerist oder Net\%werk mit engeren oder weiteren IIaschen verbinden. In den Lücken oder Mizellarinterstitien ist $\mathrm{W}$ asser eingeschlossen. „Nur auf diesem Wege ist es möglich. 
mit wenig substanz und viel Wascer ein festes diefüge herzustellen. wie es die Crallerte darbieten."

Das in organisierten Körpern enthaltene Wasser kann sich in drei verschiedenen Zuständen befinden, die von NäGELI als Konstitutionsoder Kristallwasser, als Adhäionswasser und als Kapillarwasser unterschieden werlen. Unter dem ersteren versteht man die Wassermolekïle, die wie bei einem Kristall mit den Substanzmolekülen sich zur lonstifuton des Mizells fest und in hestimmter Menge verbunden haben. Arlhïsionswasiel wird gebildet ron den Wassermolekiilen. Welche an der Oberfache der Nizelle durch Molekularattralition festechalten werden. „In der Wassersphäre, welche eine Mizelle umkleidet, ist in den konzentrischen Wasserschichten die Verblichtung und die Lnheweglichkeit des Wassei's sehr rerschieden. und diese erreicht natürlich ummittelhar an ler Oherfläche der Mizelle ihren güliten Wert” (Preffer). Das liapillarwasser endlich füllt auberhalh der attrabtiven Wirlumgstphäre der einzelnen Mizellen die Lücken zwischen den Mizellengerüsten aus. .Diese drei Arten von Wasser weichen in dem Grade der Beweglichkeit ihrer Moleküle voneinander ab. Das kapillare Wasser hat die vollen Molekularbewegungen des freien Wassers; in dem Adhäsionswasser sind die fortschreitenden bewegungen der Molekiile mehr oler weniger rermindert, und in dem Konstitutionswasser befinden sich die Molekïle in einem staren, unbeweglichen Zustande." ..Die Diosmose durch eine Membram kamn also nur durch das kapillare und das Adhäsionswasser vermittelt werden."

Wie an der Oberfläche der Mizelle Wasserteilchen durch Molekularattraktion festgehalten werden, so können sich ihnen auch andere Stoffe (Kalk- und Kieselsalze, Farbstoffe, stickstoffhaltige Verbindungen etc.) anlagerin, nachdem sie in gelöstem Zustand in den organisierten Körper aufgenommen worden sind. Das Wachstum organischer Substanz durch Intussuszeption stellt sich NäGELI in der Weise vor, daß Substanzteilchen in gelöstem Zustand in den organisierten lïrper eindringen, so \%. I. Zuckermoleküle in eine Zellulosemembran, und hier entweder sich den vorhandenen Vizellen anlagern und zur Vergrälierung derselben dienen oder zwischen den vorhandenen Mizellen zu nenen Vizellen gewisimmaben ausliristallisieren. Hierbei würten die als lieispiel benutzten Zuchermoleküle sich in Zellulosemoleküle chemisch umsetzen.

\section{Die Hypothese von elementaren Lebenseinheiten der Zelle, den} Bioblasten.

Vor NÄGELIs Lehre von den Mizellen, die sich ganz auf dem Molekulargehict bewewt. hietet die jetzt zu hesprechende Hypothese den grolien Vorzug dal, dab sie an eine Reihe wohlerforschter Tatsachen aus dem Zellenleten anknïpft, sie nur zu einer allgemeinen Iypothese erweitert and durch letztere auch der zuliunftigen Forschung einen gamgharen und ans-irhtswollen Weg tür weitere Entrlechmoen weist. Sie hilıte un einen Ausspruch von Wruson (III 1900 S. 328) zu gebrauchen, eine legitime Arbeitshypothese, da sie durch Tatsachen genügend gestützt ist.

In den folgenden Kapiteln werden wir als drei fundamentale Eigenshaften des lebenden Zelloreanismus das Vermö̈gen der Assimilation. des Wachstums mul der Teilung liennen lemen. Durch Assimilation, Wachstum mot Teilung untersheden sich lebende von leblosen Körpern. Behalten 
wir diesen Unterschied im Auge, so lïbt sich leicht an den uns schon

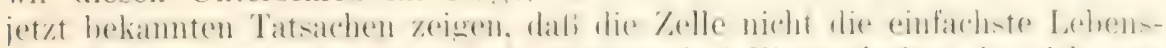

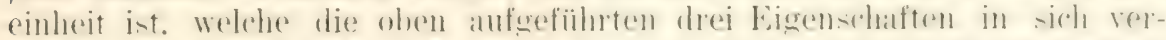

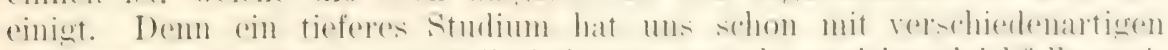

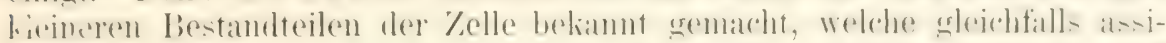
milieren. wachsen und sich selbsttiatig teilen. In erster Linie ist hier auf den Zellkern zu verweisen. von dem ja der Satz gilt: „Omnis nucleus e mucleo". Im Kern ist wieder die chromatische Substanz enthalten. von welcher wir beweisen können, dab sie von einer Teilung bis zur nächsten

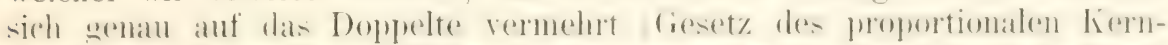

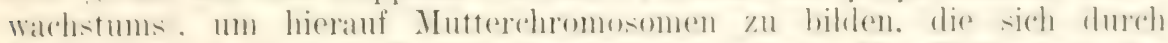

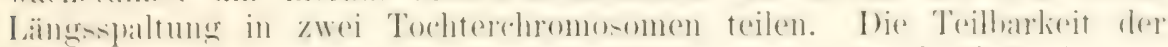
Chromosemen aber beruht wahrscheinlich wieder darauf, dab sie aus chromatinlï̈gelehen zusanmengesetzt sind, die. wenn sie dureh Warhstum

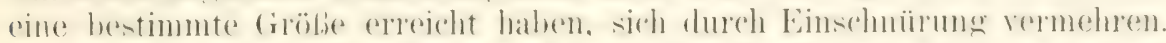

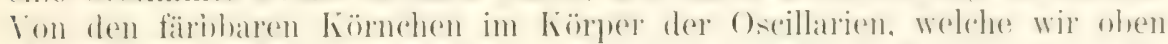
als eine Vorstufe der Kernhildung, als eine zerstrente liernsubstanz ge-

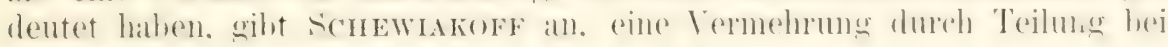
Achromatium beobachtet zu haben.

Als teilungsfähige Körperchen sind ferner im Inhalt der Zelle die

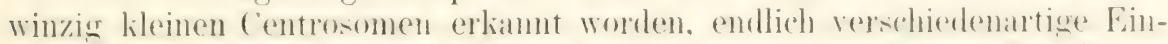
schliis-se im Protoplasma der P’hanzenzellen, die stärliebildner, die ('hlororphylliöner, die Farblïrner, die uns im t. Kapitel noch bechäftigen werden, und welche von den Botanikern unter dem Namen der 'Trophoplasten zusammengefalit werlen. Inter den Trophoplasten aher varsteht man individualisierte Differenziermespondulite des Protophasmas, welche wie der liern eine grobe funktionelle selhstandigheit hesit\%en mol nleich ihm assimilieren, wachsen und sich durch Teilung vermehren.

In derartigen sichergestellten latsachen ist eine gute dimulage für eine alluemeine Iypothese von dem elementaren Aufhan der Zelle gegrehen. Fine soldhe ist schon von versehiedenen Forshern. am lilarsten

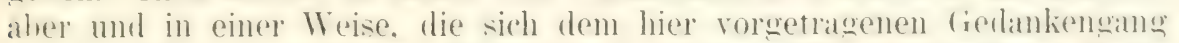

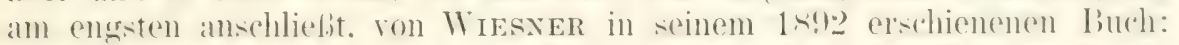
..Die Flementarstruktur und das Wachstum der lebenden substany" entwickelt worten. Mit Wresner können wir sagen: „Wenm im Leben der Oruanismen der Teilung eine so grobe Berlentume und eine so weit ans-

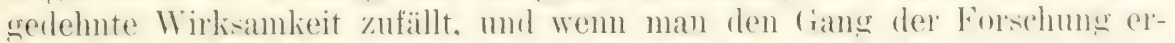
wägt. der uns fortwahrend mit nenen Formen der Teilung und mit nenen Teilkörpern helamnt macht. so mul, wohl zugestanden werden. dals wir in

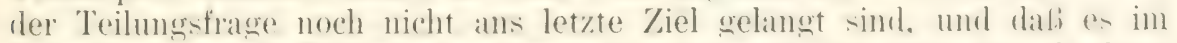
Organismus noch Teilungsvorgänge giht. die sich his jetzt dere direliten Wahrnehmung entzogen haben."

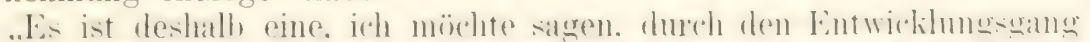

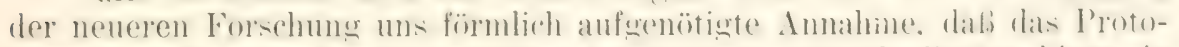

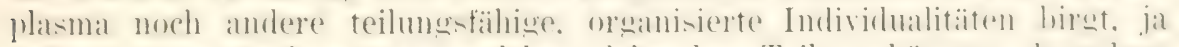

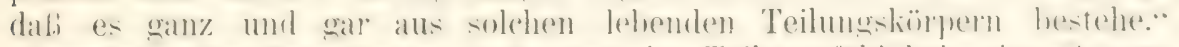

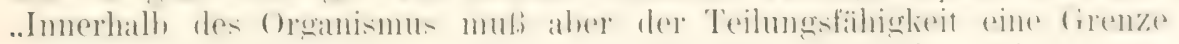
gesetzt sein." „Die letzten lebenden Teilkörper der Zelle sind es num,

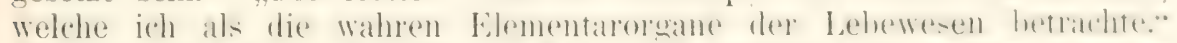

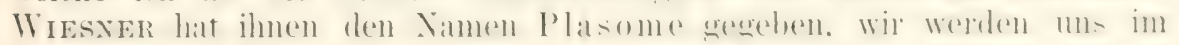
folgenden des Wortes Bioblasten berlienen.

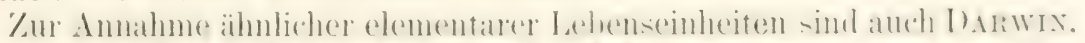

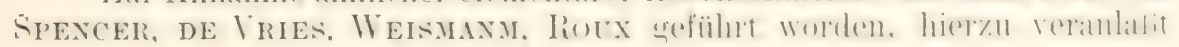


hauptsïchlich durch das IBestrehen. die komplizierten Er-cheinungen der Vererbmo zo reklïren. Fast joder hat semen hypothetisehen Einheiten rinen anderen Nimen beigelegt. ohwohl sie moter densellen in wesentlichen etwas ähnliches verstehen.

DArwa nennt sie in seiner provisorischen Hypothese ler Pangenesis Keimchen ader fiemmulate. SPEx(CER spricht in seinen Prinzipien der Lio-

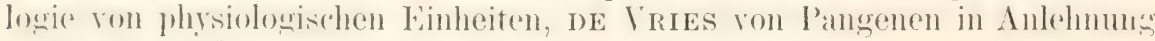
an Darwins Pangenesis, Weismanx von Biophoren.

Mit logischer Konsequenz nehmen alle diese Forscher Wachstum und Teilharkeit für ihre elementaren Lehenseinheiten, für ihre liemehen, Pangene, Biophoren etc. an.

Gehen wir jetzt noch etwas näher auf die Charakteristik unserer Bioblasten ein. Obwohl Kern, Chromosomen, Centrosomen, 'Trophoplasten ete. individualisierte Teilkïrper der Zelle sind, so wirl angenommen. daß wir bei ihmen noch nicht an der Grenze der Teilbarkeit in Lebenseinheiten angekommen sind. Sie sind daher schon Aggregate von mehr orler minder zahlreichen biohlasten. Fin Biohlant ist der letzte kleinste lebende Teillöruer der Zelle, über welchen hinams die Teilharkeit nicht weiter fortgesetzt werden kann, ohne die ihn charakterisierenden Eimenschaften zı zerstören. Diese aber sind, wie oben auseinandergesetzt wurde, das Vermögen der Assimilation, des Wachstums und der Vermehrung in Tochterbioblasten.

Der Bioblast ist eine Lebenseinheit, die unter der Grenze des miliroskopisch sichtharen liegt. dabei aher von den Atomen und Molekïlen der ('hemie und Physik durch seine Lebenseigenschatten Asimilation. Wachstum und Vermehrung durch Teilung) streng unterschieden ist.

I) Atume sind ja moteilhar, die Molekïle lassen sich zwa zerlegen, aber nur in 'Teile, welche nicht mehr die Eigenschaften des Ganzen besitzen. Ein bestimmtes Eiweißmolekïl kann nicht wachsen. ohne seine Natur zu verändern; denn wenn es sich neue Atomgruppen anlagert, tritt es in nene Verbindungen ein, wodurch sein früheres Wesen aufgehoben wirl, und ebensowenig kann es in zwei uleichartige Eiweilmolekiile zerfallen, da jerle Teihumg des Molekïls ungleichwertige Atomgrupuen liefert. Daher müsicen die Bioblasten zusammengesetztere Einheiten. Wenigstens Inolekïlgrmpen sem. In dieser firmulanschamung stimmen alle oben aufgeführten Forscher überein. So bemerkt SPENCER: „Es scheint nichts anderes ïhrig zu bleihen, als anzunehmen. dab die chemischen Einheiten sich zu Einheiten unentlich viel komplizierterer Art zusammentum, als sie selbst sind. so kompliziert sie auch sein mögen, und dal. in jedem Organismus die durch eine soldhe weitere Verbindung hoch zusammengesetzter Molekïle erzengten physiologischen Einheiten einen mehr oler weniger verschiedenen Charakter besitzen."

Über die Stellung der Bioblasten zu der Mizellarhypothese kann auf eine Bemerkung von Nð̈GELI selbst verwiesen werden, welche er in bezug auf I .urwax heimchen gemacht hat: .Ehensowenig wie Molekïle. hönnen sie cinzehe Mizellen liristallinische Molekülgrupnen sein, denn wenn diese anch als fiemenge ron verschiedenen Alluminatmodifikationen ungleiche Eigenschatten hesïljen, so wïrle ihmen doch die Fähigheit, sich zu vermehren und nene wleiche Mizellen zu bilden, mangeln. Wir finden alle

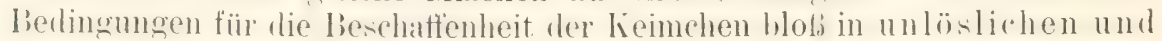
festrerbundenen (irupren von Alluminatmizellen: nur diese hömen vermöge ihrer ungleichen Anordnung alle erforderlichen Eigenschatten annehmen und vermittelst Einlagerungen ron Mizellen in lediebigen Mabe wachsen und durch Zerfallen sich vermehren." 
Was die Größe betrifft, so müssen jedenfalls die Bioblasten aulier-

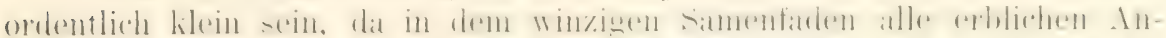

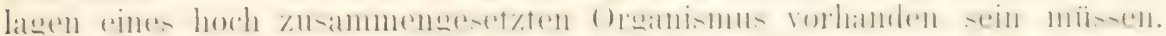

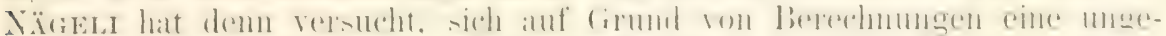

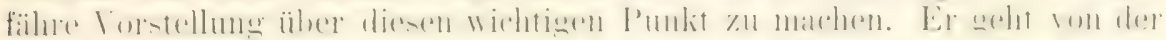
Annahme aus, dab die hypothetische Formel der Chemiker mit 72 Atomen

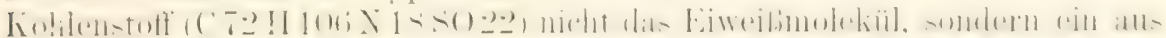

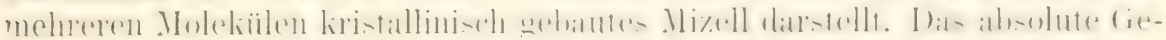
wicht desselben beträgt den trillionsten Teil von :3,53 mg. Das spezifische

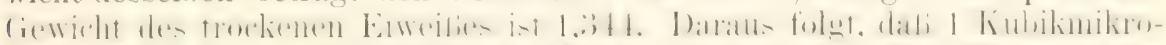

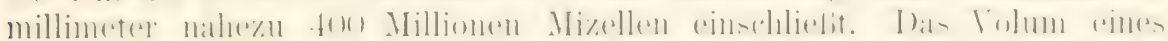
solchen Mizells berechnet Nïgeli auf Grund einiger weiterer Voraussetzungen auf 0.0000000021 Kubikmikromillimeter. Unter der Voraus-

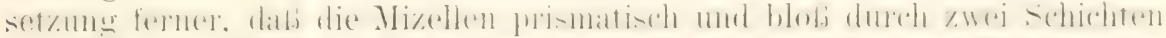

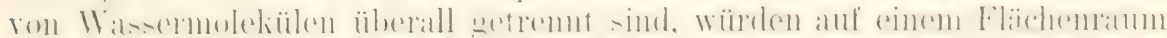
ron 0.1 Quadratmikromillimeter 25000 Mizellen Platz finden. In einem Körperchen von der Größe eines Samenfadens wärlen daher immerhin

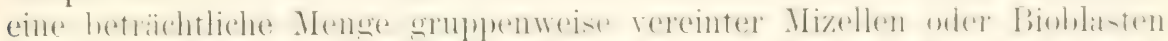

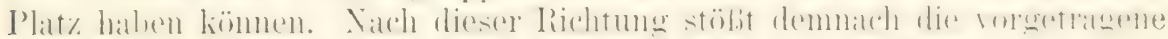

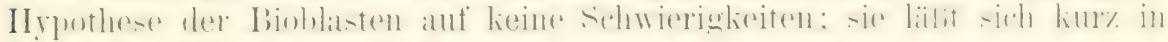
folgende Sätze zusammenfassen:

Wie Pflanze und Tier sich in Milliarden und aber Milliarden von Zellen zerlegen lassen, so ist die Zelle selbst wieder aus sehr zahlreichen

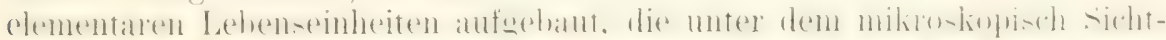

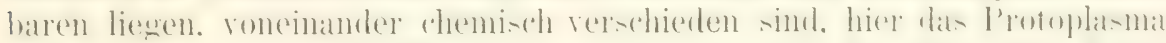

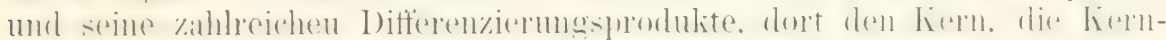
membran, die Lininfädlen, die Chromosomen, die Nukleolen usw. bilden,

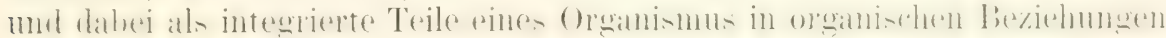
zueinander stehen.

..Wie die Physik und die Chemie auf die Moleküle und die Atome

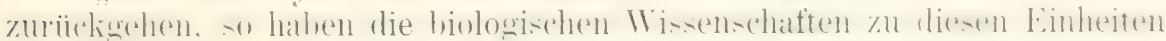

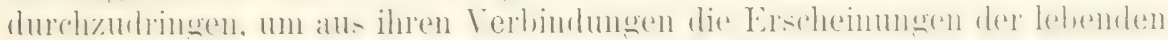
Welt zll erklären" (DE VRIES).

\section{Literatur III.}

1) Altmann, Die Elementarorsanismen \#. ihre Beraiehungen au den Zellen. Leipaig Ison.

2) Jul. Arnold, Über feinere Struktur der Zellen unter normalen zud pathologischen liculngungen. Firchozes Archiz. Bd. LAXITII. 1879. p. I8I.

3) Auerbach, Organologische Studien. lleft I. I874.

4) Balbiani, Sur la stmoture du noyen des cellule's salizaires chez les laraes de chirenomus. Zoologischer Anaeiger. I88I. p. 637.

5) Ballowitz, Über das Epithel der Membrane elastica post. des Anges, seine herme und

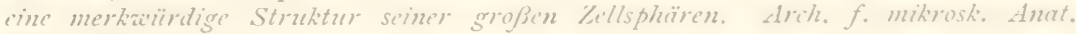
Bd. LIT. 1000 .

6) Derselbe, Zur Kenntnis der Zellsphäre. Arch. f. Anat. u. Phry. Anat. Abt. Jahlugans 1808. p. I 40 .

i) vam Beneden et Neyt, loucelles recherches sur la ficondation of la dizision mitosique chea l'ascaride mégalocéphale. Leipzis 1887.

S) Born, Die Struktur des Kémbläschens im Orarialei zon Triton taniatus. Archf. f. mikrosk. Anat. Bd. NLIII. IS94.

9) Boveri, Zellenatudien. Heft 1: Die Bildung der Kichtungshërper 1887; ILeft 2: Die

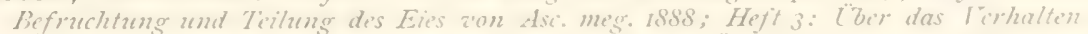
der chromatischen Fernsubstanz etc. 1800 ; Heft $t$ : L"ber die latur de' Centrosomen 1001. 
111 Bütschli, Einige bemerkmgen äber geaisse Organisationsverhältnisse der sogenannten Cilioflagellaten und der Voctiluen. Horphol. Jahrbuch. Jid. X. 1885.

111 Derselbe, Über den Ban der Bakterien und aeratandter Organismen. Leipzig 1800.

1:-1 Derselbe, Über die Struktur des Protoplasmas. Verhandungen des Vaturhist.-IVed.Fercins au Heidelberg. N. I. B.d. IV. Heft 3. 1880. Heft +. I800.

1:i) Derselbe, Untersuchungen äber mikroskopische Schäume u. idis Protoplasma. I89z.

11) Derselbe, Untersuchungen über Strukturen. Leipsig 1808.

1.i) Carnoy, Wehrere Abhandhungen in La cellule. Recaeil de Cytologie et d'histologie senerale.

1i) Derselbe, La cytodierèse chez les arthropodes. Iid. I. 1885.

1i) Derselbe, La iésicule germinatize et les glob. polaires chez diters nématodes.

14) Derselbe, Conférence domír à la societe belge de microscopie. Iid. III.

19t) Carnoy et Lebrun, La vésicule germinatiz'e et les globules polaires chez les batrociens. La cellule T. NII. 1807 .

211) Dieselben, Axoiotl et Triton. La cellule T. TIV. 1898.

21) Dieselben, Les globules polaires des Urodiles. La cellule T. TVT. I899.

2.) Engelmann, Über den fasrigen Bau der kontraktilen Substanzen. Pfiugers Archiz. Bi. XXVI. I88T.

2:i) Fischer, Alfred, Fixienung, Fürbung und Ban des Protoplasmas. Fritische Untersuchungen ïber Technik und Theorie in der neneren Zellforschung. Jena 1809.

21) Flemming, Zellsubstans, Lem und Zellteilung. Leipzig 1882.

2.) Derselbe, Über Jeilung und Kernformen bei Lnkocyten und über deren Attraktionssphären. Archiv f. mikroskop. Anat. Bit. XXYlII. p. 249. 1891.

¿(i) Derselbe, leuse Beiträge sur lienntnis der Zelle. II. Teil. Archiv f. mikroskop. Anat. Bi. XIXVII. p. 685. I80I*.

?-) Derselbe, Atraktionssphären und Zentralkörper in Gewebszellen und Handerzellen. Anatomischer Anzeiger. 13d. VI. I89IT.

2(-) Fol, Lehrbuch der iergleich. mikroskop. Anatomie. Leipzig I88.4.

2!) Frommann, Zur Lehre z'on der Struktur der Zellen. Jenaische Zeitschr. f. Ied. und Vature. Bid. IX. 1875.

(3) Derselbe, Zelle. Realencyklopädie der gesanten Heilkunde. 2. Anfl. 1890.

:1) Gerlach, J., Mikroskopische Studien. Erlangen 1858.

:i2) Gurwitsch, Idiozom und Centralkörper im Ovarialei der Säugetiere. Arch. f. mikroskopische Anatomie. Bd. LVI. 1900.

:3:) Haeckel, Generelle Morphologie. 1866.

.i) Hartmann, Studien am tierischen Ei: I. Ovarialei und Eireifung van Asterias glacialis. Zoolog. Jahrb. Bd. XV. I002.

iii) Häcker, Das Keimbläschen, seine Elenente und Lageverändemungen. Arch. f. mikrosk. Anat. Bd. XLI «. XLII. 1803.

:3(i) Heidenhain u. Cohn, Über die Mikrozentren in den Géeeben des Vogelembryos. 1Korph. Arbeiten. Bd. VII. 1897.

:i-) Heidenhain, Martin, Über Kern und Protoplasma. Festschrift für Kölliker. 1802.

:3i) C. Heitzmann, Untersuchungen über Protoplasma. Wiener Sitzungsber. mathem. naturie. Hilasse. Bd. LXVII 1873.

:3(1) Henneguy, Leşons sur la cellule, morphologie et reproduction. 1896.

(11) Richard Hertwig, Beiträge zu einer einheitlichen Auffassung der verschiedenen Kernformen. Morphol. Jahrbuch. Bd. II. 1876.

11) Oskar Hertwig, Beiträge zur Kenntnis der Bildung, Befruchtung und Teilung des tierischen Eies. Mlorphol. Jahubuch. Bd. I, II. IV. I875, I876, I878.

1.) Derselbe, Vergleich der Ei- u. Samenbildung bei Nematoden. Archiv f. mikroskop. Anatomic. Bd. NXXVI. 1890.

(i) Hofmeister, Die Lehre von der Pflanscnselle. Leipzig 1867.

1.1) E. Klein, Observations on the structure of cells and Vuclei. Quarterly journal of microscopical science. Vol. IVIII. 1878 . p. 315.

1.i) Kölliker, Handbuch der Gereebelehre. 1889.

(ii) Kossel, Zur Chemie des Zellkerns. Zeitschrift f. physiol. Chemie von Hoppe Seyler. Bd. HII. I882.

17) Derselbe, Untersuchungen über die Vukleine und iture Spaltungsprodukte. Straßburg 1881 .

1h) C. Kupffer, Über Differensierung des Protoplasma an den Zellen tierischer Getuebe. Schriften des naturaissenschafil. Tereins für Schlestoig-Holstein. Bd. I. p. 229. Heft 3. 1875 .

(1) Leydig, Untersuchungen aur Anatomie und Histologie ter Tiere. Bonn 1883.

.i1) Derselbe, Zelle und Gerebe. Bonn 1885.

i1) List, Beiträge sar Chemie der Kelle und Geatebe. Mitteil. ans d. zool. Station zu Neapel. Bit. XII. 1897. 


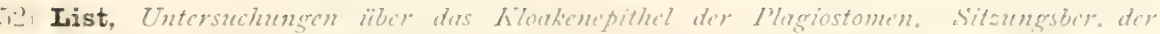

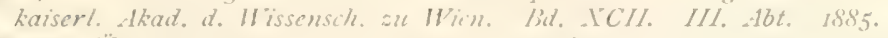

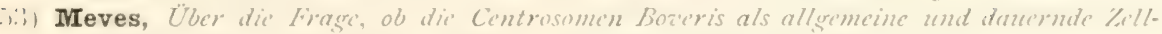

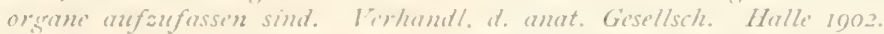

it) De'rselbe, Über oligoplrene und apyrene Spermien und über ihre Entstenng nach

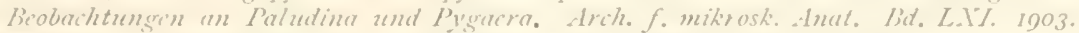

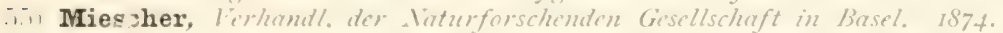

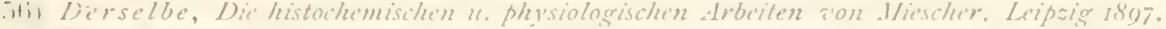

$\therefore$ i.) Montgomery, Comparative crtological studies, with especial refirence to the morpho-

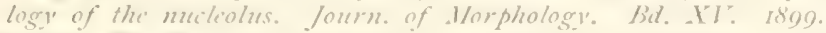

in Morgan, T. H., The production of artifical astrosphaeres. Arih. f. Entri-alech. Bit. III. 1806 .

i!l) Derselbe, The action of solt-solutions on the unfertilized and firtilized eges of Ar-

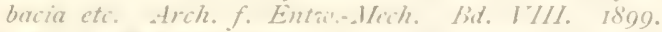

4itl Nägeli ". Schwendener, Das Mikroskop. Theoric u. Anzenduns desselben. 1877.

(i). C. Nägeli, llechanisch-physiologische Theorie der Abstommungsletre. München und Leipsig 1884 .

(i-) Obst, P., Untersuchungen ïber dess Ferhalten der Wucleolen bei der Eibildung aimiger

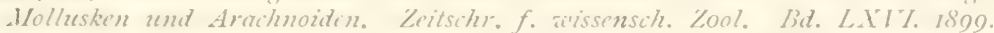

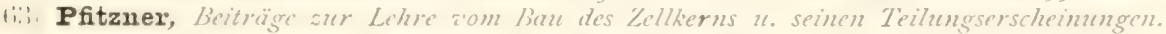

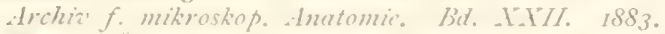

iil v. Rath, Uber cine cigenartige polyentrische Anordmeng des chromatins, \%oolog. Anseiger. 1800

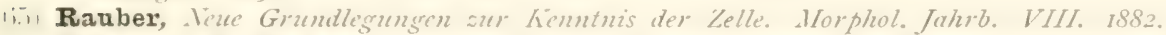

liti Reinke u. H. Rodewald, Studien n̈ber das Protoplasma. Untersuchungen aus dem botanischen Institut de' Universitüt Gütingen. Heft 2. I881.

(i, Sachs, Forlesungen über Pflunaenthusiologie. 1882.

(iv, Schäfex $\pi$. E. R. Lankester, Discussion on the present aspect of the cell question. Wature. Fol M.T.TY. 1887.

(i!) Schewiakoff, Ubir einen newn bakterienähnlichen Organismus. Hab.-Schrift. Iteidelberer 1893 und Faturh.-Ierein Hcridelbers 1893.

"1. Schieferdecker u. Kossel, Geriebelehre mit besonderer Berücksichtigung des menschlichen liörpers. 180 t.

71. Schmitz, Untersuchungen ïber die Struktur des Protoplasmas und der Zellkeme der Pflansenzellen. Sitoungsber. d. Viederrh. Gesellsch. fo Vatur n. Mleilk. Bonn r880.

-. Schwarz, Frank., Die morphologische und chemische Zusammensetzung des Protoplasmas. Beiträge aur Biologie der Pfanzen. Ba. I. Breslan 1887.

:.) Solger, Zur Kenntnis der Pigmentzellen. Anatomischer Anzeiger. Jahrg. VI. 1801.

-1) Strasburger, Zillbildung und Zellteilung. 2. Auf. Jenc 1876.

$\therefore$ Derselbi, Studien niber das Protoplasma. Jenaische Zeitschr. Bid. .Y. I876*.

ili. Derselbe. Das botamische Praktikum. 2. Auft. 1887.

-.) Verwom, Allsenzeine Phisiologie. Jena. 1. Anft. 1805.

Wiesner, Elementarstruktur und II achstum der lebenden Substanz. 1802.

(!) Wilson, E. B., Experimental studies on cytology I. a cytological study of artificial parthenogenesis in sea-urchin eggs, Arch. f. Entrit-allech. Bd. WII. IDOI.

(1) Derselbe, On protoplasmic structure in the eggs of echnoderms and some other animals. Journ. of Jorphology. Bd. XV. Suppl. I899.

1) Derselbe, The iell in development and inheritance. II. edition 1000.

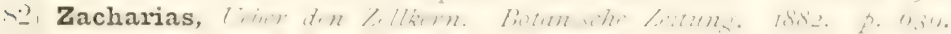

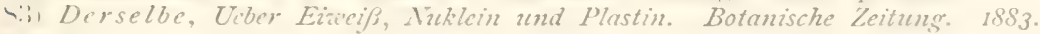

-1, Derselbe, Leber den Wukleolus. Botanische Zeitung. 1885.

$\checkmark$ - Derselbe, Beiträge zur Kénntuis des Zellkerns und der Sexualaellen. Botanisi-he Zeitung. Bat. ILV. 1887.

wil Derselbe, L̈ber die Zellen der Cyanophucen. Botanische Zeitung. I80o.

-i) Zimmermann, Beiträge zur Tenntnis einiser Drïsen und Epithelien. Arch. f. mikresk. Anat. Bd. LII. Iso8. 


\section{VIER'TES KAPITEL。}

\section{Die Lebenseigenschaften der Zelle.}

Die Grundrätsel des Lebens, welche Pflanzen und Tiere darbieten, treten uns auch schon in der emfachen Zelle entgegen. Wie der zusimmengesetzte ginze ()rganismus, hat auch jecle einzelne \%elle ihr eigenes Leben. Wollen wir daher noch tiefer in das Wesen von Protoplasma und Kern eindringen, so müssen wir ms ror allen Dingen noch mit dem Wichtigstem von allem, mit ihren Lebenseigenschaften bekannt machen. Das Lehen aber, anch das Leben des allereinfachsten Elementarorganismus, ist. ein auberordentlich zusammengesetztes und schwer definierbares Phänomen; es äubert sicls, im allgemeinen ausgerleückt. darin, dab die Zelle kraft ilırer eigenen Organisation und unter den Einflüs-en der Audenwelt heständig Veränderungen erfährt und Kräfte entfaltet. wohei ihre organische Substanz auf der einen seite unter hestimmten horaftäulierungen heständig zerstört, anf der amberen Seite wieder nen eryengt wird. Auf dem heständigen Ineinandergreifen organischer Zerstörmg und organischer Neubildung heruht, wie Claude Bernard (IV 1885̆) sich ausdrückt, der ganze Lebensprozeß.

Am zweckmäbigsten läbt sich dieses liomplizierteste aller Phänomene in rier verschienlene fruppen ron Frsheinungen zerlegen. Jerler lebente Elementarorganismus zeigt nns nämlich vier verschiedene (irumblunktionen oder Grundeigenschaften, in denen sich sein Leben zu erkennen gibt:

1. er kann sich ernähren, Stoffe aufnehmen, umwandeln und wieder abgeben, dabei formt er Substanzen, welche zum Wachstum, zur Gewebebildung und für spezitische Leistungen des Lebens dienen:

2. er kann seine Form verändern und Bewegungen ausführen;

3 . er reagiert auf bestimmte Reize der Außenwelt in verschiedener Weise, ist mithin reizbar;

4. endlich kann er sich durch Fortpflanzung vermehren.

Die Lehenseigenschaften besprechen wir daher in vier Kapiteln und zwar in folgender Reihenfolge:

1. den Stoffwechsel und die formative Tätigkeit,

2. die Bewegungserscheinungen,

3. die Reizerscheimungen,

4. (lie Fortpflanzung;

Daran schließen sich noch Kapitel über die Wechselwirkungen von Protoplasma und Kern und über den BefruchtungsprozeB. 


\section{Stofivechsel und formative 'ïigkeit.}

\section{Allgemeine Charakteristik.}

Die lebende Zelle besityt ihren eigenen Stoffwechsel, sie nimmt

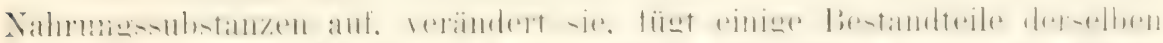

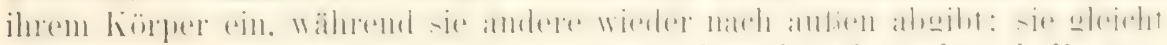
cinem kleinen. chemischen Laboratorim. indem fast fortwähend die ver-

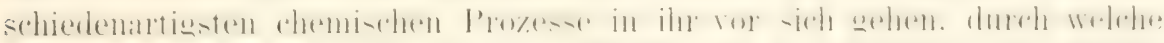

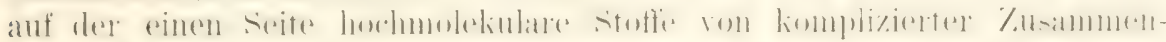
setzung gebihlet, anf der anderen Seite wieder zerstört werden. Die lehendige Substanz befindet sich, um so mehr, je intensiver der Prozeb des

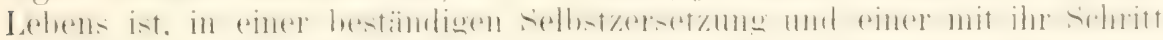
haltenden Neubildung. In dem Chemismus der Zelle sind daher zwei Hauptphänomene auseinander zu halten, die Phänomene der regressiven und der progressiven Stoffmetamorphose orler wie CLaude BERNard (IV 1885) sich ausdrïckt, les phénomènes de destruction et de création organique, de décomposition et de composition.

Bei ilner Zerstörung wird die lebendige Substanz durch eine Reihe

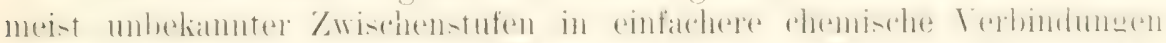

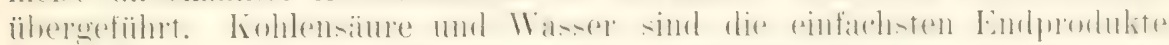

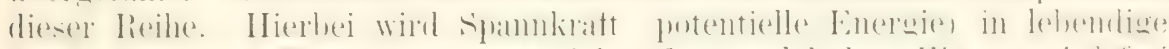

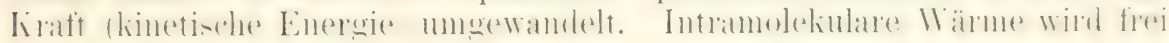
und bildet die lebendige Kraft, die zur Hervorbringung der Arbeitsleistungen des Zellkörpers die Vorbedingung ist.

IVie auberordentlich groß die Zersetzbarkeit (ler Lebenssubstanzen ist, geht schon daraus hervor, dab der geringste Anstoh oft genïgend ist,

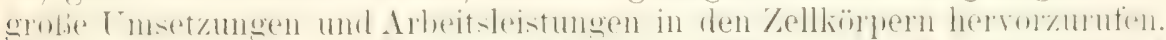

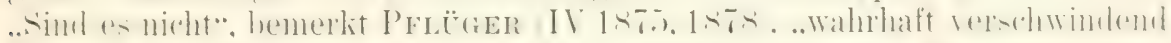

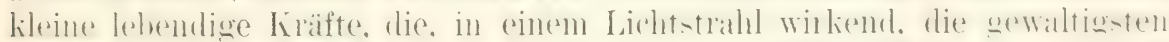

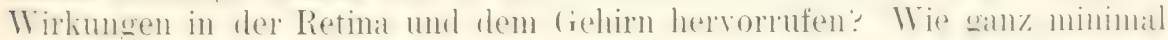
sind die lebendigen Kräfte der Nerven, wie ganz wunderbar lilein die

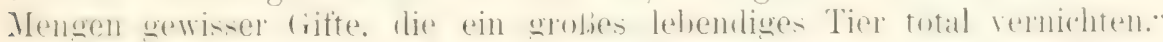

Lei der Neubildung lebender Substanz oder der progressiven Metamorphose werden zum Ersatz des Verbrauchten neue Stotfe von außen

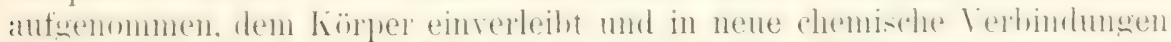

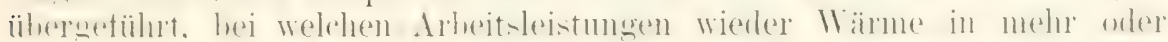

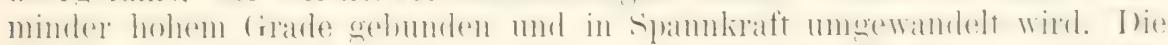

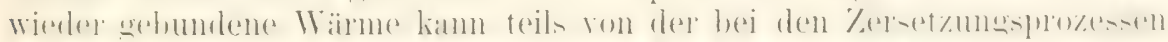

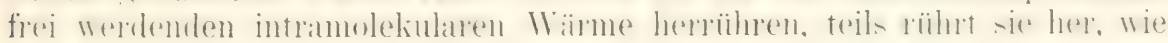
der Hauptsache nach in den Pflanzen, von der belebenden Wärme der

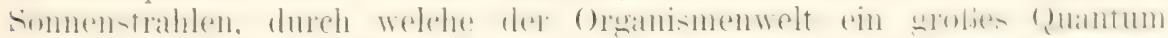

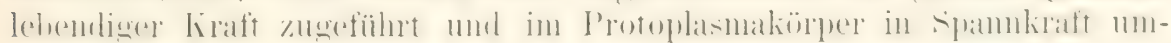
gesetzt wirl. Die von auben aufgenommenen Substanzen und die der

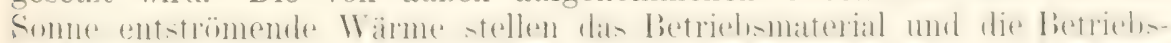

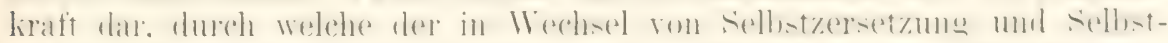

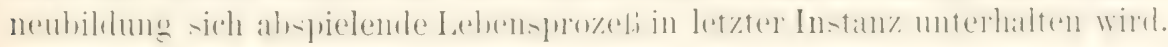

Nach der Definition von Pfutger ist, ,der Lebensprozeb die intramolekulare Wärme höchst zersetzbarer und durch Dissoziation - wesentlich unter Bildung von Kohlensäure und Wasser und amidartigen Körpern - sich zersetzender, in Zellsubstanz gebildeter Eiweißmolekiile, welche sich fortwährend regenerieren und auch durch Polymerisierung wachsen." 
Trot\% großer Verschielenartigkeit des Stoffwechsels in den einzelnen Oramismen giht su doch eine Reihe von fundamentalen l'rozessen. welche der gresamten orwanishen Natur geneinsan sind und sich im niedrigsten, einzelligen IV esen ehenso abspielen wie in Körper der Pflanzen und Tiere. so daß sich auch in ihnen die Eimheit der ganzen organischen Natur offenbart. Eine Ubereinstimmmor macht sich namentlich in folgenden drei Punkten geltend:

1. Jede Zelle, sei es von Pflanze oder 'Tier', atmet, das heißt, sie nimmt aus ihrer Émgehmes Sauerstoff nach Bedürfnis auf und verbremut mit Hilfe desselhen Kohlenhybate und Fiweibsulstanzen ihres eigenen Körpers. bei welchem Verbemumgsprozeli als letzte Endprodukte Kohlensïure und Wasser gebildet werden.

2. In beilen organischen Reichen treten in grober Zahl entsprechende Substanzen in Stoffichechsel auf, wie Pepsin. Diastase, Mỵosin, Xanthin, Sarzin, Zucker, Inosit, Dextrin. Glykogen, Milchsäme, Ameisensäure. Essigund Buttersäure.

3. In beiden Reichen sind manche Prozesse, durch welche komplizierte chemische V'erbindungen dargestellt werden, identisch orler wenigstens sehr :̈hnlich und unterscheiden sich wesentlich von den Verfahren, durch welche der Chemiker imstande ist, eine Anzahl organischer Verbindungen auf synthetischem Wege darustellen. Beim Chemismus der Zelle sowohl der Pflanzen wie der Tiere spielen Fermente eine große Rolle, Diastase. Pepsin. Trrpsin etc. Darunter versteht man organische Stoffe, welche in der lehenden Zelle erzengt, in auberordentlich geringer Menge eine grobe chemische Wrirkung entfalten. und ohne selhst in nemnenswertem Jabe dabei verbraucht zu werden. hier Kohlenhydrate, dort Eiweibliorver in charakteristiseher Weise chemisch verändern kïnnen. ..Le chimisme du lahoratoire est exécuté à laide dagents et d'appareils que le chimistre a créés, et le chimisme de l'être vivant est exécuté à l'aide d'agents et d'appareils que l'organisme a créés" (Claude Bernard IV 1885).

Im Folgenden werden wir die einzelnen Erscheinungen des Stoffwechsels hesonders ron hiologischer Seite näher betrachten. ohne dabei in die nneist sehr verwickelten und grolienteils noch unhekannten chemischen Prozesse näher eirzugehen. Wir kömmen im Verlauf des Stoffwechsels drei Stadien unterscheiden, die Stoffaufnahme, die im Innern des Protoplasma erfolgende Stoffumsetzung und die Stoffabgabe. Das erste und das letzte dieser Stadien wollen wir gemeinsam, alstann das zweite für sich allein besprechen.

\section{Die Stoffaufnahme und Stoffabgabe der Zellen.}

Alle Zellen nehmen sowohl Gase, als auch Stoffe in flüssigem orler gelöstem und daher diffusionsfähigem Zustand in sich auf; manche Zellen endlich benutzen als Nahrung auch Körper von festem Aggregatzustand. Die drei Reihen von Erscheinungen verlangen eine gesonderte Besprechung.

\section{Die Aufnahme und Abgabe gasförmiger Stoffe.}

In gasförmigem Zustand können die verschiedenartigsten Stoffe rom I'rotoplasma aufgenommen werlen: Sauerstoff, Stickstoff, Wasserstoff, Kohlensäure, Kohlen- und Stickoxyd, Ammoniali-, Chloroform-, Ätherdämpfe und dergleichen mehr.

Von allgemeiner Bedentung für den Stoffwechsel ist indessen nur die Aufnahme von Sauerstoff und Kohlensäure, besonders von dem ersteren. 
Ohne Aufnahme von Sauerstoff, welchen Vorgang man die Atmung nennt, kein Leben! Sauerstoffatmung ist mit wenigen Ausnahmen

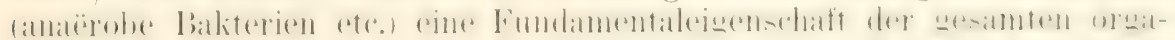
nischen Natur: sie ist für die Stoffiwechselprozesse, auf denen das Leben

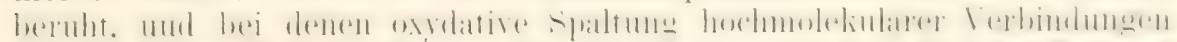

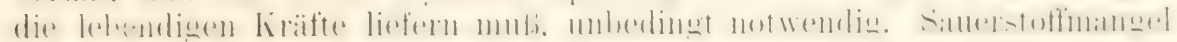
bringt in der Regel sehr rasch die Funktionen der Zelle, die Reizbarkeit.

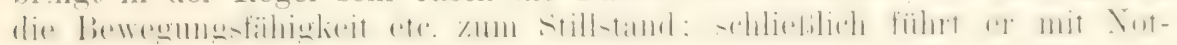
wendigkeit den Tod herbei.

Eine scheinbare Ausuahme von dem fundamentalen Prozeb der Atmung scheinen manche Gährungorganismen, die Spalt- und Sprobjpilze, zu liefern. Denn sie können bei vollstandigem Abschluß ron Sauerstoff in einer geeigneten Nährfliissigkeit wachsen und sich vermehren. In diesem Fall wird der für die Oxydationsvorgänge im Protoplasma erforderliche Sanerstoff und die Betriebskraft für den Lebensprozels durch Zerlegung ron Gahrmaterial gewomnen. Ebenso leben Darmparasiten in einer ziemlich samerstoffreien Ungebung durch Spaltung ron Verbindungen des ihnen im Überschub gebotenen Nahrungsbreies (BLxge IT 1889).

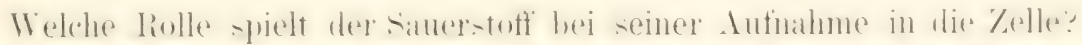

Frïher glaubte man, daf der Sanerstoff auf die Iebende Materie

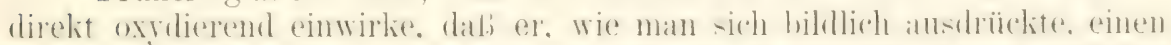

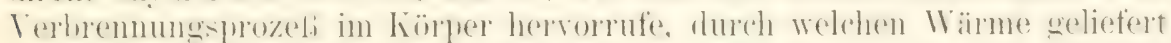
werte. I) Vorwang ist jedentalls ein lemplizierterer: vor allen J)ingen gehen die liräfte. welehe zur lindung des sanerstotfs tïhren. ron der

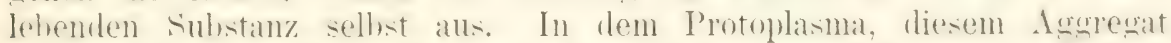
eigentümlicher Fiweilikïrper und ihrer I)erivate, in welehem anlierlem noch Fette und liohlenhribate als Einlagerungen enthalten sind, finden.

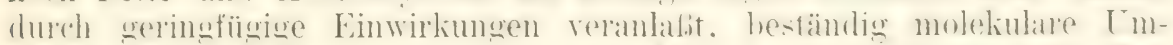

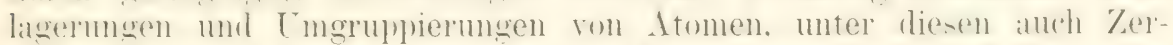
sctzungen uml I)i-soziationen. statt. .. Hierhei entwicheln sich in vielen

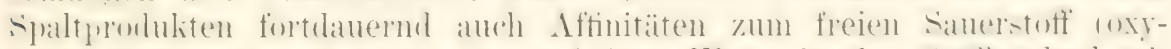

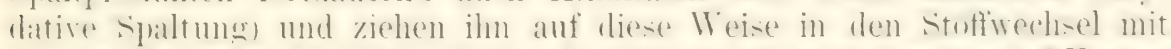

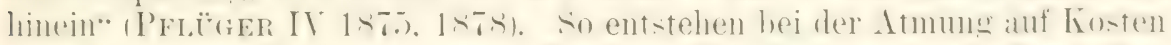

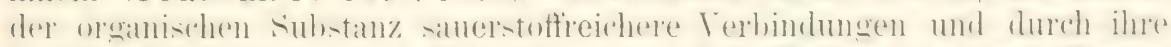

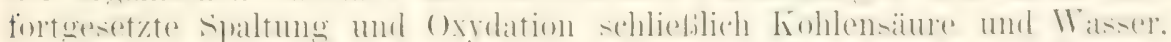

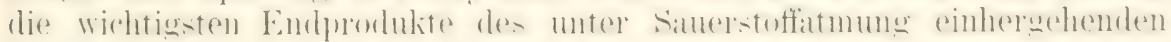
Zersetzungsprozesses der lebenden Substanz.

Es gilt dies für jerle tierische, für jede pflanzliche Zelle.

Wenn man Pflanzenzellen, in denen das Protoplasma lebhaft strömt

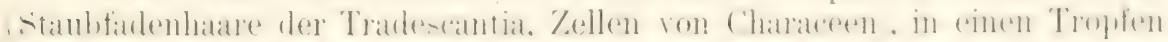

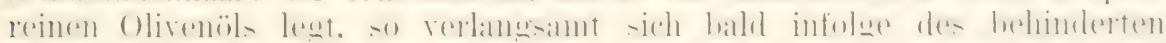

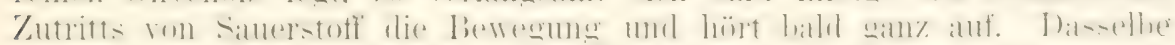

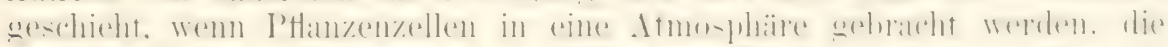

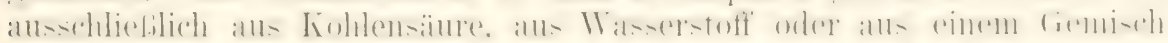
von beiden besteht. Zunächst sind nur die Funktionen des Protoplasmas

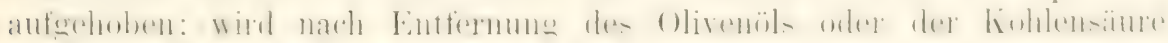
oder rles Trasserstoft's wieder reine Luft zugeleitet, so liehren nach einer

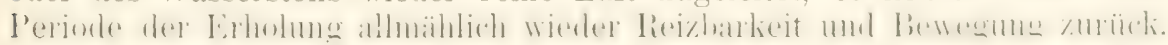
Bei längerer Entziehung des Sauerstoft's aber folgt der Lähmung der

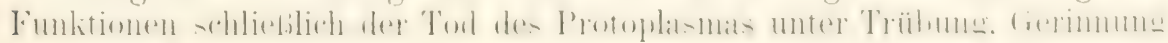
und Zerfall. 
Ebenso atmet jede tierische 'Zelle. Wenn ein bebrütetes Hühnerei

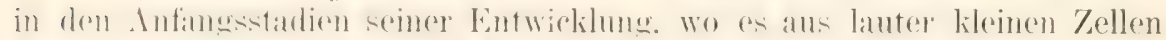

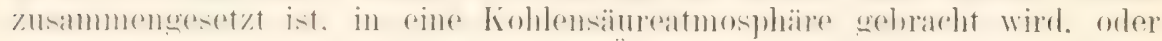
wenn man die poröse Kalkschale mit (O) durchtränkt, so daß ein Gasaustausch zwischen keim und Luft nicht mehr stattinden kann, so stirbt es in wenigen Stunden ab. Der bei dem Menschen dureh die Iungen auf-

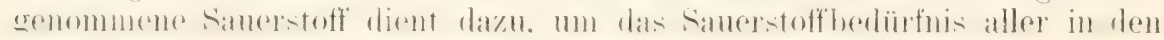

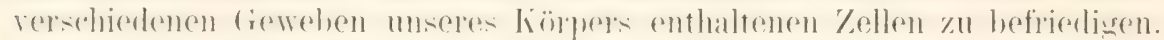
Letzteren Vorgang bezeichnet man in der Tierphysiologie im Cegensatz zur Aufnahme des Sauerstoff's durch die Lunge orler der Lungenatmung als innere Atmung.

Im ganzen Organismenreich ist der AtmungsprozeB mit Kohlensäureabgabe und mit Wärmebildung verbunden. Es ist dies ein einfach chemisches Gesetz: .Wie bei jeder anderen Verbrennung von Kohlenstoff und Wasserstoff zu Kohlensäure und Wasser muß auch bei der Atmung ein bestimmtes Quantum von Wärmebewegung erzengt werden" (SACHS IV 18s2). Ebensogut wie die tierischen, atmen daher auch die pttanzlichen Zellen Kohlensïne ans und bilken Wäme. Lei Ptlanzen ist Wiamehildung am leichtesten an lehhaft wachsenden T'eilen nachzuweisen. an lieinenden simen. besonders deutlich aher an den Blitenkolben der Aroideen. Letztere können sich zuweilen bis $15^{\circ} \mathrm{C}$ über die Temperatur der Umgebnng erwärmen.

Bei der Atmung reguliert die lebende Zelle selber die Gröbe ihres Sauerstoffrerbranches. Derselbe wird einfach bedingt durch das Maß ihrer funktionellen Tätigkeit, die mit einer

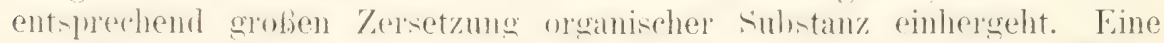
mbefruchtete Fizelle atmet sehr geringe (puantitäten vom Samerstoff ein, deschleichen ein ruhender Pflanzensamen: wenn aher die Eizelle hefruchtet

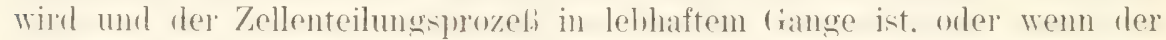
Pflanzensamen keint. dann wächst die Sauerstoffaufnahme. Sie ist eine

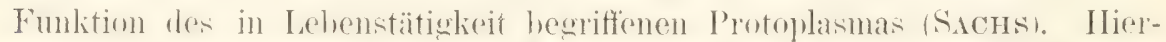

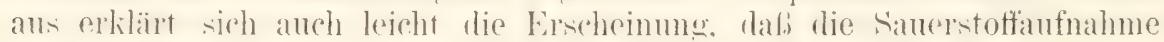
in die lebende Zelle .immerhalb) weiter (irenzen volliommen unabhängiog von dem Partialdruck des neutralen Sauerstoffs ist" (PFLÜGER).

Um das Kapitel der Atmung abzuschließen, ist noch auf eine wich-

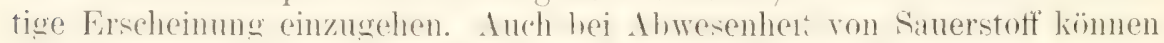
die Zellen bald kürzere, bald längere Zeit Kohlensäure ausatmen und Wäme erzengen. Leimptlanzen in ein Torricellisches Vakmum wehracht. fahren fort Kohlensäure answuhanchen. in den ersten Stunden wie normal. dann in allmählich geringer werdender Quantität. Frösche lassen sich nach den Versuchen von PFLÜGER in dem sauerstofffreien und mit Stickstoff gefiillten liamm einer filisglocke viche Stumben am Leben erhalten: in disere Zeit wird eine ziemlieh heträchtliche (suantität ron Lohlensänre ausgeatmet.

Beide Versuche lehren, daß in der Zelle eine Zeitlang auch ohne unmittellaren Zutritt rom Sillerstoff hlol.s durch Zersetzung oroanischer Substanz Kohlenstoff- und Sancrstoffatome zur Bildung ron Kohlensïure zusammentreten kïmen. Man hezeichnet diesen Vorgang als intramolekulare Atmung. So lange dieselbe anhält, lebt die Zelle und bleibt, wem anch mit stetig ahnehmender Energie, reishar und funktionsfähig, indem sic einen Teil des Saurestoffs. der in ihren eigenen Substanzer gehmolen ist. als Betriehskraft grehraucht. Bei länger fortgesetyter Entzichung des Sauerstoft's tritt aber immer der Tod ein. 


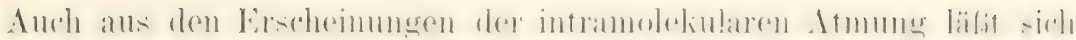

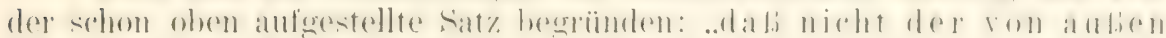
eindringende Sauerstoff den ersten Anstof. zu den chemischen Vorgängen der Atmung gibt, daB vielmehr innerhalb des Protoplasmas zunächst und primär eine hersetzung des Eiweibmolekiiles stattfindet. Welche mit Kohlensïurebildung endigt. dah aber durch den von auben her zutretenden Sanerstoff eine restitutio in integrum stattfindet."

Zu der Gärungy, durch welche Gärungserreger anch ohne Sauerstoffzutritt wachsen und sich vermehren und Kohlensäure produzieren, bietet die intramolekulare Atmung Vergleichspunkte dar, auf welche besonders PFEFFer (IV 1885) aufmerksam gemacht hat.

Während die Aufnahme von Samerstoff und die Abgabe von Kohlen-

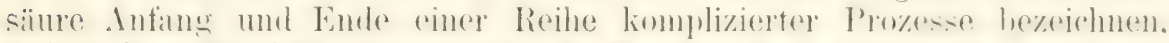

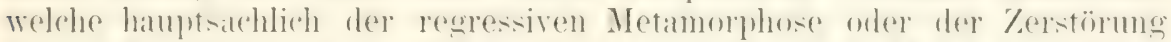

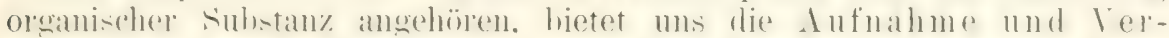
arbeitung der Kohlensäure in der Zelle einen Einblick in den ent-

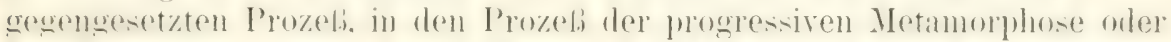

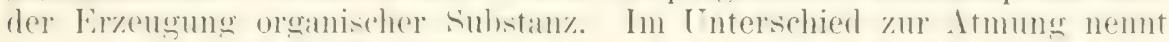
man diesen Vorgang Assimilation.

Sauerstoffatmung und Assimilation von Kohlensäure treten in jeder Beziehung in einen Gegensatz zu einander. Jene ist eine

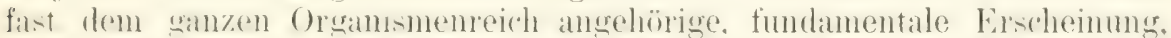
diese dagegen zeigt sich nur anf das P'tanzenreich heschü̈nlit. und anch hier ist sie lieine Eigenschaft aller. somblem nur solcher Zellen. die in ihrem

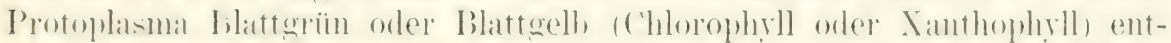
halten. Sallerstoffatmung führt zu oxydativen Zersetzungspozesson. Kollensämrasimilation dagegen zur Iexhlution der liohlensäure und zur sinthese horhmolelularer. orwinischer substanzen. Es sind dies liohlenhydrate. namentioh stärle. welche sich in Form kleiner Körnchen in dem grünen

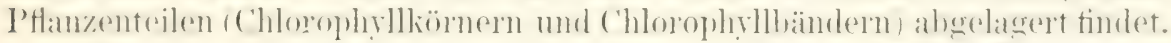

bei der Assimilation der Kohlensänre sind die einzelnen Phasen der in cler l'flanzenzelle stattindenden. snthetishen Prozese noch in Inmliol

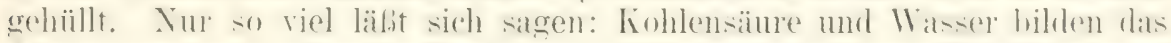

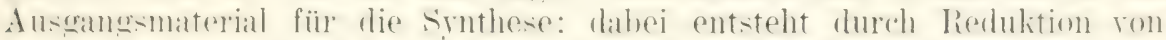

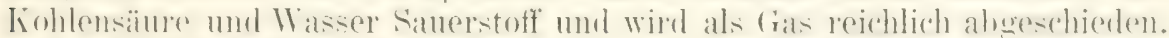

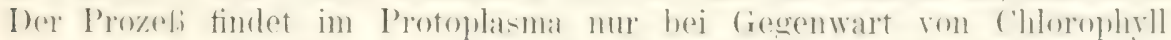

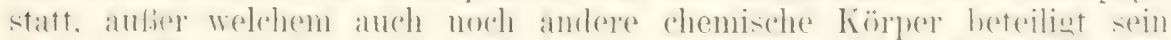

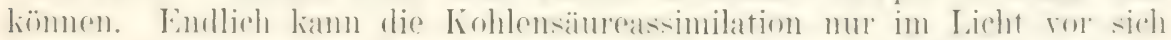

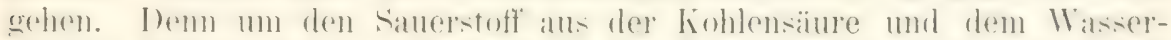

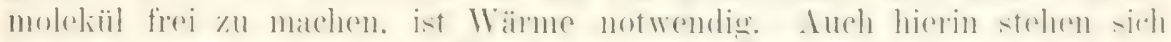

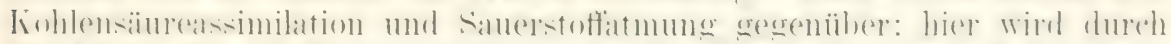

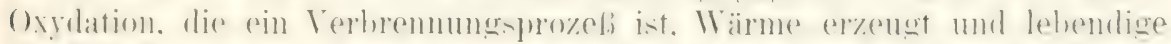

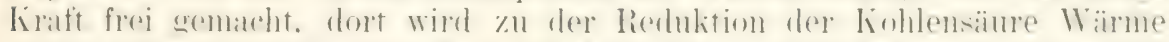

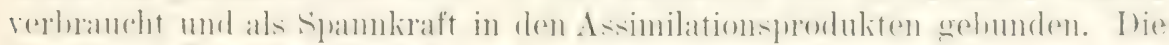
fiir diesen ProzeB erforderliche Wïme liefert das Somnenlicht.

Wemn man eine Wasserptlanze in kohlensänehaltiges Wasser lumet

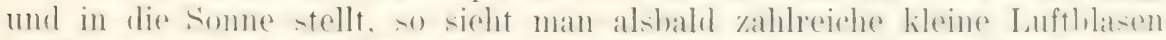

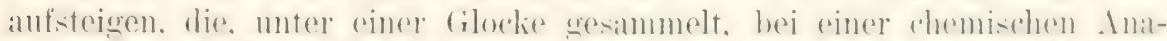

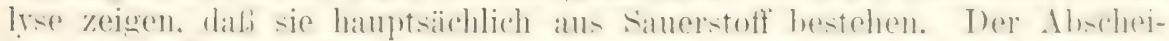

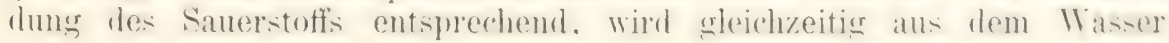


liohlensïure entuommon und zu Kohlenhyolraten verarbeitet. Der Vorgang der Assimilation ist im Lichte ein so lebhafter, daß daneben die

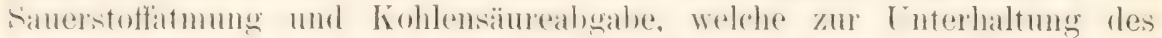

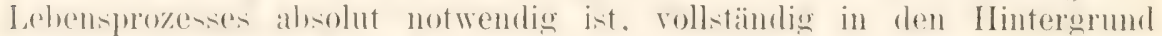
tritt und daher auch in früherer Zeit ganz übersehen wurde. Dagegen stellen Pflanzen, die ins Dunkle gebracht werden, sofort die Sauerstoffabscheidnng mol nicht minter auch die Kohlensiuntatuahme ein, fahren aber im Dunkeln, ebenso wie belichtete PHanzen, nach wie vor zu atmen fort. Das Gas, das jetzt freilich in viel geringerer Quantität als in obigem Versuch ausgeschieden wird, ist Kohlensäure.

Auf einen interessanten Unterschied, der zwischen Sauerstoffatmung und Kohlensäureasimilation bei den Pthanzen besteht, hat Chaten Ber-

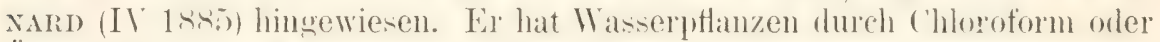
Äther in Narkose versetzt und gefunden, daß sie jetzt im Sommenlicht lieinen samerstoff mehr ansicheiden. Wie in der Narkose die Reizharkeit und Bevegungsfähigkeit des Protoplasmas (siehe Kap. VI), so wird in ihr auch die Chlorophyllfunktion, die Fähigkeit, auf synthetischem Wege aus Rohlensäture und Wasser Stärlie zu bilden, ahsolut aufgehohen: doch liehrt sie wieder zurïch. Wenn die Pthanze in reines Wasier gehracht wird. Noch bemerkenswerter aber ist bei diesem Versuch, daß während der Narkose die Atmung unter Abscheidung von Kohlensüure weiter vor sich geht. Dieser ['nterschied ist wohl darauf zurïckzuführen. dak die Sanerstoffatmung und die mit ihr verhundene Zersetzung mit dem ganzen Lebensprozel.j in einem viel innigeren Zusammenhang stehen und daher er'st mit dem Leben der Zelle ganz erlöschen. Ehe aher durch Narkose der 'Tod ıer Zelle herbeigefühnt wirl, werden schon längere Zeit zuror die Funktionen der Zelle gelähnt. unter ihnen auch die Chlorophyllfunktion.

\section{Die Aufnahme und Abgabe flussiger Stoffe.}

Die meisten Substanzen, welche dem Stoffiwechsel dienen, werden von den Organismen in gelöstem Zustand aufgenommen. Einzellige und Wasserptlanzen beziehen dieselben aus der ilmen zum Aufenthalt dienenden Flüssigkeit, die Landpthanzen mit Hilfe ihrer Wureln ans dem ron Wasser durchtränkten Boden. Die Zellen der höheren Tiere ernähren sich durch Aufnahme gelöster Suhstanzen aus flüssigkeitsmedien. die bei ihmen freilich erst in Iohlräumen jhres eigenen fïrpers durch komplizierte Eimrichtungen gehildet werden müssen. Diese Flüssigkeitsmedien sind der Chymushei des Darmkanals. das Iblut. der Chylus und die Lymplie. Sie spielen für die tierischen Zellen dieselhe Rolle, wie Wasser und Bodenfeuchtiglieit mit den in ihnen gelösten Sulstanzen für niedere Organismen und für Pflanzen.

Gegenüber veralteten Anschaumgen der Physiologie, nach denen die

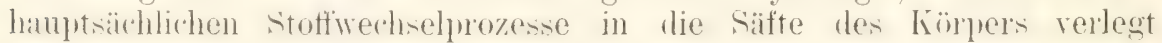
wurden, kann nicht scharf genug der Satz hervorgehoben werden: Die Zellen sind die Herde der Stoff-Aufnahme, Abgabe und Umsetzung. Die Säfte haben nur die Aufgabe, den Zellen das Nahrungsmaterial in gelöster Form darzubieten und die Zerfallsprodukte des Stoffwechsels wieder abzuführen.

Zwischen den Zellen und dem sie umspülenden Medium bestehen die hompliziertenten Wexhelleziehmuen physialischer und chemischer Art. Ihre Erforschung gehört zu den schwierigsten Aufgaben, auf die hier nur zum kleinsten Teil eingegangen werden kann. 
Jede Kelle ist in ihrer ganzen Organisation an das umgebende Me-

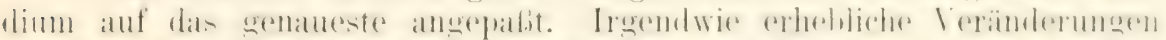

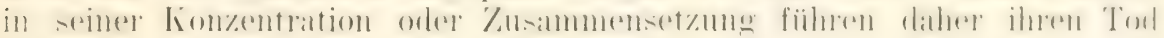
herbei; doch können in manchen Fällen größere Veränderungen auch

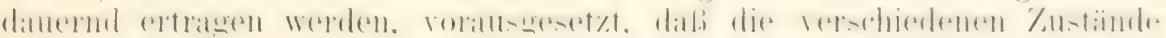
allmählich und in längerer Zeit ineinander übergehen, wodurch es den Zellen möglich gemacht wird, sich in ihrer Organisation für die anderen

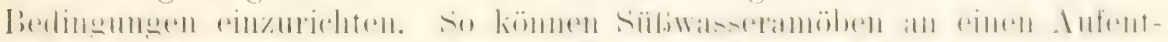

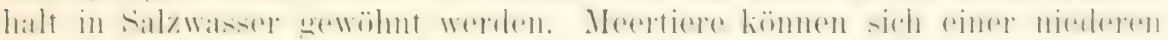

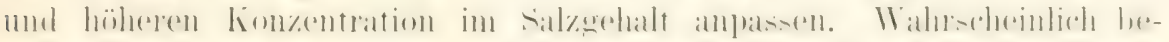
steht die Anpassung darin, daß ein Ausgleich zwischen der in Proto-

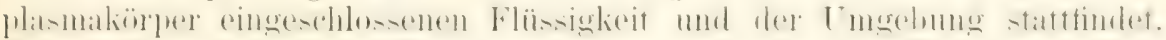

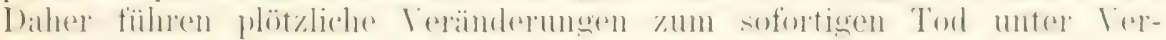
quellung oder Schrumpfung und Gerimnung des Protoplasmas.

Da bei den Wirbeltieren sich die vom Gewebssaft umspülten Zellen

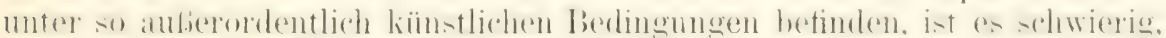

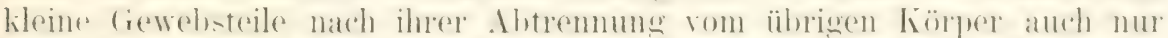

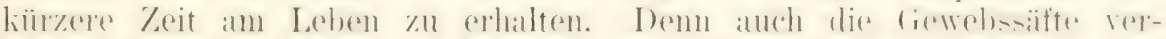

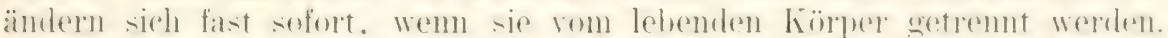

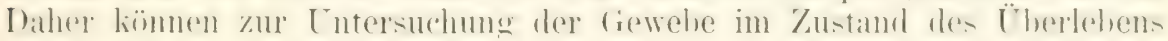

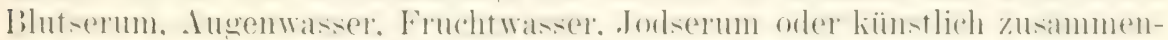

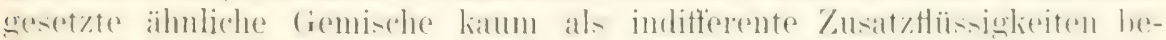

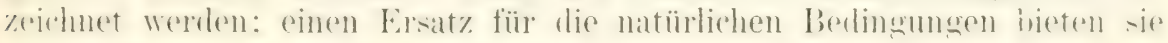
selbstverständlicherweise keineswegs.

Wenn man genauer das Verhältnis untersucht, in welchem die lebende

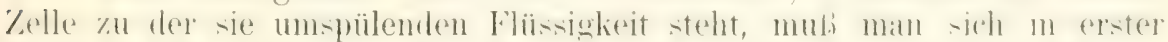
Linie vor der Vorstellung hüten, als ob die erstere von der letzteren einfach durchtrinkt werde. Fine solche Vorstellung wïrle eine durehaus

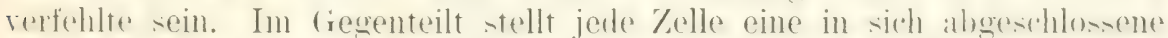

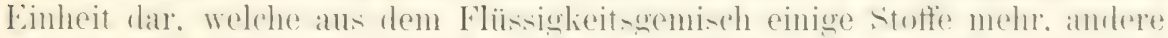

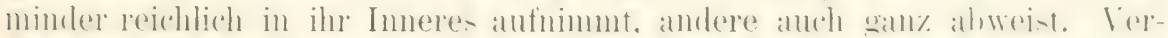

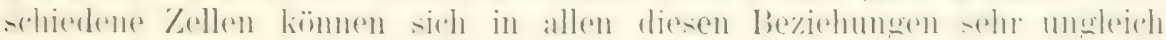
verhalten: mit einem Wort. die Zellen treffen unter den ihnen dargebotenen Stoffen gewissermaben eine Auswahl.

Ein solches oft sehr verschiedenartiges Wahlvermögen ist sehr leicht

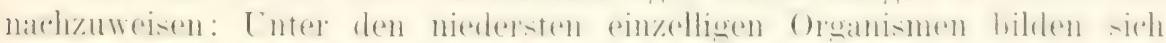

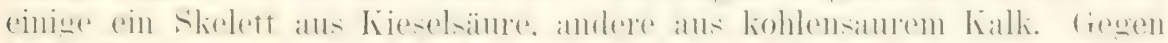

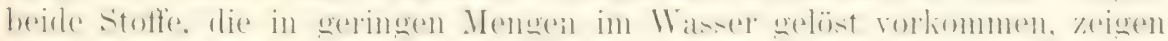

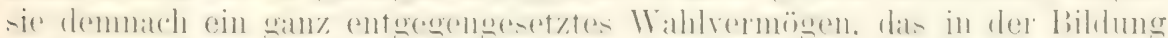

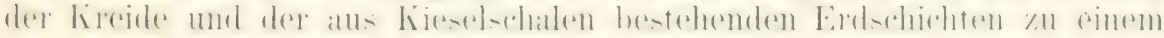
grobartigen Gesamtresultat geführt hat. Ebenso nelmen die Zellen ver-

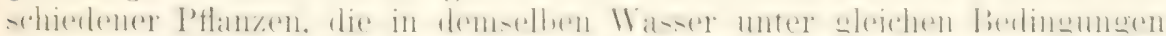

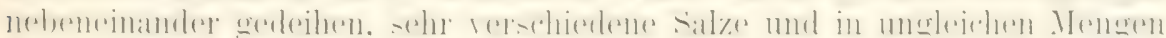
in sich auf. Jan kamn die hier rorkommenden relativen Verhältnisse leicht berechnen, wemn man die Pflanzen trocknet, verbrennt und die Gesamtasche in Prozenten der Trockensulustanz und die einzelnen Aschenbestandteile wieder in Prozenten der Reinasche ansdriickt. So führte dic Aschenuntersuchung yon Fucusarten, die an der Westküste von Schottland gesammelt wurden, zu folgenden Ergebnissen, welche PFEFFer (II 1s81) in semer Pflanzenphysiologic tabellarisch zusammengestellt hat: 


\begin{tabular}{|c|c|c|c|c|}
\hline & $\begin{array}{l}\text { Fincus } \\
\text { vesiculosus }\end{array}$ & $\begin{array}{l}\text { Fucus } \\
\text { nodosus }\end{array}$ & $\begin{array}{l}\text { Fucus } \\
\text { serratus }\end{array}$ & $\begin{array}{l}\text { Laminaria } \\
\text { digritata }\end{array}$ \\
\hline Reinasche $\%$ & $1: 3,89$ & 14,51 & $1: 3,89$ & 18.64 \\
\hline $\mathrm{K}, \mathrm{O}$ & 15,23 & 10,07 &,+ 51 & 22.40 \\
\hline $\mathrm{Na}_{2} \mathrm{O}$ & $2+, 54$ & 26,59 & 31,37 & 24,09 \\
\hline $\mathrm{CaO}$ & 9,78 & 12,80 & $16 . ; 6$ & 11,86 \\
\hline $\mathrm{MgO}$ & 7,16 & 10,93 & 11,66 & 7,44 \\
\hline $\mathrm{Fe}_{2}, \mathrm{O}_{3}$ & 0.33 & 0,29 & $0 .: 34$ & 0.62 \\
\hline $\mathrm{P}_{2} \mathrm{O}_{5}$ & $1, ; 66$ & 1,52 & 4,40 & 2,56 \\
\hline $\mathrm{SO}_{3}$ & 28,16 & 26,69 & 21,06 & 13,26 \\
\hline $\mathrm{SiO}_{a}$ & 1,35 & 1,20 & 0,43 & 1,56 \\
\hline $\mathrm{Cl}^{2}$ & 15,24 & 12,24 & 11,39 & $17,2: 3$ \\
\hline$J$ & 0.81 & 0.46 & 1.13 & $: 3,08$ \\
\hline
\end{tabular}

Überhanpt lehren Meerespflanzen am besten, in wie ungleichem Maße sie ans dem Gemenge von Salzen, das ihnen das Meerwasser bietet, das ihnen zum Jehen Xotwendige entnehmen. Denn vom liochralts, das etwa zu $3 \%$ gelöst ist, speichern die Zellen nur wenig in sich auf. dlagegen

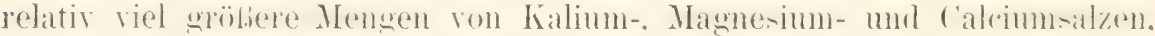

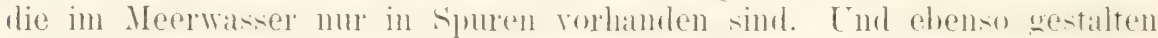
sich sehr verschieden die Aschenanalysen der auf demselben Boden neheneinander gedeihenden Landptlanzen.

Zu demselben Ergebnis führt die Stoffiwechseluntersuchung des tierischen Körpers. Nur bestimmte Zellen haben die Neigung, sich der Kalksalze zu bemächtigen, die in kaum nachweisbaren Mengen in der Säftemasse des Körper's enthalten sind, und sie im Knochengewebe aufzu-

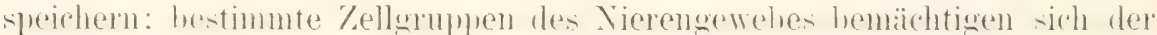
im Blutstrom zirkulierenden. zur Harnbildung dienenden Stoffe, andere Zellen des Körper's wieder stapeln Fette in sich auf usw.

Die Faktoren. die bei der Aufnahme und Nichtaufnahme von Stoffen mitsprechen, entziehen sich zur Zeit fast ganz unserer Beurteilung. Doch ist jedenfalls der Nutzen, den ein Stoff für den Hanshalt der Zelle bietet, durchaus nicht immer das Entscheidende. Zellen

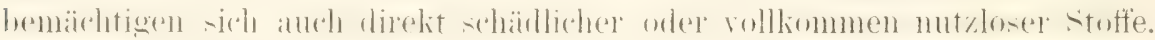
In dieser Beziehung ist die sehr verschietenartige Aufnahme der Anilinfarben in lebende Pflanzenzellen sehr lehreich. (PFeffer IV 1886.) Waihrend Lösungen ron Methylenblau, Methylviolett, Cyanin, Bismarcklıraun, Fuchsin, Safranin aufgenommen werden, ist dies nicht der Fall mit Lösungen von Nigrosin, Anilinblau, Eosin, Kongorot etc. Über Aufnahme oder Nichtaufnahme kam, nach der Angabe von PFEFfer, welcher eingehende Studien hierüber angestellt hat, nur die empirische Erfahrung entscheiden.

Wie mit der Aufnahme, verhält es sich auch mit der Abgabe von Stoften. Diese wird gleichfalls ron den besonderen Eigenschaften tles lebenden Zellkörpers bestimmt. Die rot- oder blaugefärbten Zellen der Blumenblätter einer phanerogamen Blüte lassen die in ihnen eingeschlossene, konzentrierte Farbstofflösung, solange sie lebensfrisch sind, nicht in das umgebende Wasser diffundieren. Sowie indessen die Zelle abgetötet wird, beginnt der Farbstoff durch die Zellwand durchzutreten.

Un alle diese komplizierten Verhältnisse wirklich zu verstehen, würde eine erschöpfende Kemntnis der Chemie und Physik der Zellen erforderlich sein. Denn was ich oben als ihr Wahlvermögen bezeichnet habe. wird sich in letzter Instanz zurvïckführen lassen auf die chemischen Affinitäten 


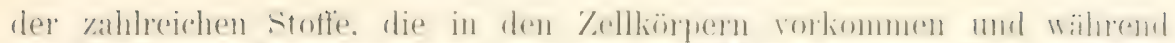

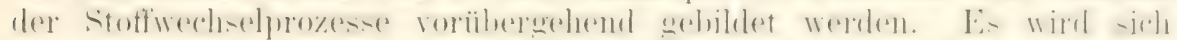
hier ebenso verhalten wie mit der Aufnahme von Samerstoff und Kohlen-

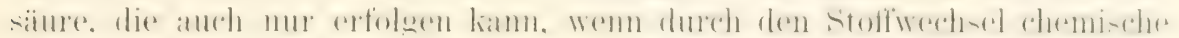
Affinitäten zu denselben frei werden. Daher wird im Dumkeln von der

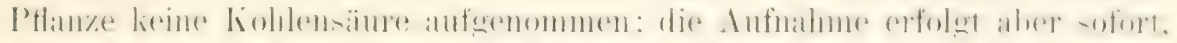

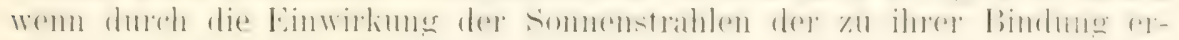
forderliche chemische Prozeh angeregt wird.

Anch die Aufnalme von Inilinfarben in die lebende Zelle lelurt ähnliches. Aus sehr dümmen Lösungen von Methylenblau saugen Azolla. Spirogyra, Wurzelhare von Lemma etc. allmählich so viel Farbstoft in sich auf, dab sie ein tiefblaues Kolorit gewinnen, wie es etwa einer ein-

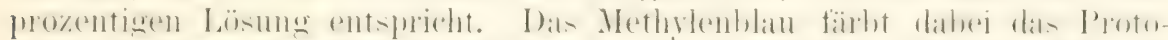

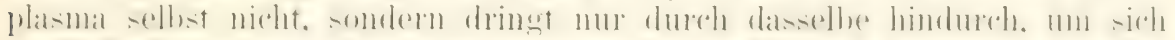

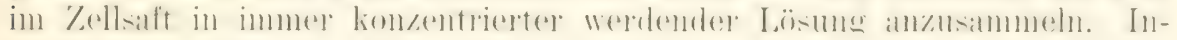
folgerlessen stirbt die Zelle selbst auch nicht ab, was der Fall sein wiurle.

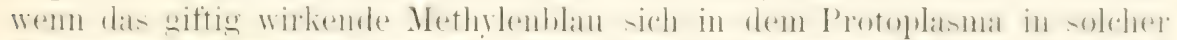

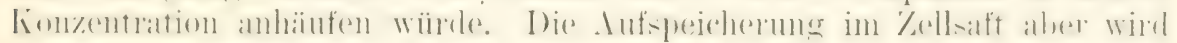

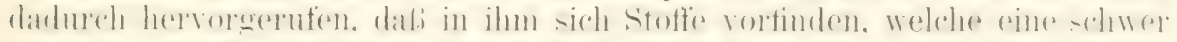

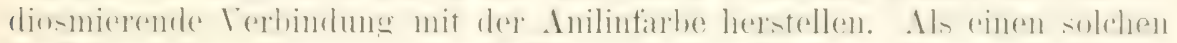

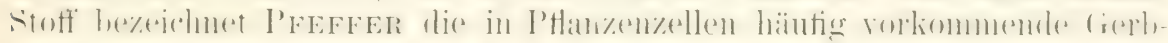
säure. Dieselbe geht mit den Anilinfarben V'erbindungen ein, die bald

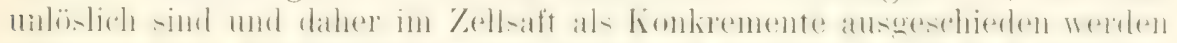

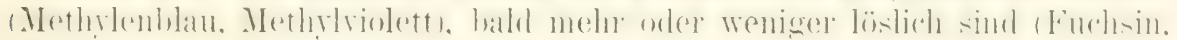
Methylorange, 'Tropäolin).

Auch Tiere bieten uns schöne Beispiele von Speicherung rler Farbstofte in lebenden Zellen dar. Befruchtete Seeigeleier erhalten in ganz mattgefürbten Lösungen von Methylenblau in kurzer Zeit ein mehr oder minder intensiv blaues Kolorit. (HerTwIG, IV 1890.) Bei geringeren Graden der Speicherung schreitet der Furchungsprozeh, wenn auch verlangsamt, doch in normaler Weise weiter und kam bis zur Bildung der Gastrula fülnren. Iler ist damn der Farbstoff besonders in den Entodermzellen angehäuft. was den Schlub erlaubt. dab durch Dottematerialien die

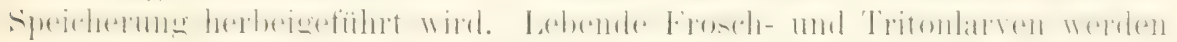
nach כ-s 'lagen in einer dïmnen Lösung von Methylenblau sehr stark gebläut. In diesem Falle ist der Farbstoff' an die Granula der Zellen gebunden (OsKar Sciultze IV 18s7). Nach tagelangem Aufenthalt in reinem Wasser tritt allmählich wieder Entfärbung ein. Wenn Indigharmin einem Säugetier direkt ins Blut eingespritzt wird, so wird es bald sowohl ron den Leberzellen, als yon den Epithelien der gewmdenen Harnkanälchen aufgenommen und damn weiter dort in die Gallenkapillaren. hiel in die Harnlianälchen ahogeschieden. (IIEIdexhaIx, IY 1881.) Methylenb)au ins Blut gespritzt geht mit der Substanz der Nerventibrillen eine Bindung

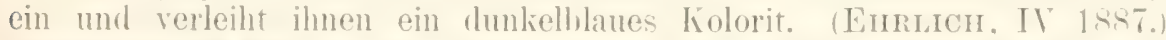
Krapufarbstoff wird in der (irundsubstanz des Kinochengewehes gespeichert.

Abesehen ron den chemischen Aftinitäten. Welche zwischen den im

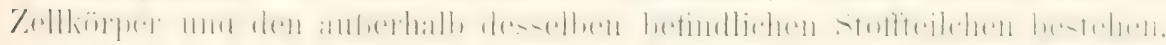
sind die physikalischen Vorgänge der Osmose für das Verstimdnis der Stofiaufnahme mol -ahgabe ron der gröften Bedeutumg. Hier ist dio grölere oder geringere Durchlissigkeit der Zellhant zu beachten in len Fälen, wo eine solche rorhanden ist. Die Zellhaut ist in der liegel füi. gelöste Substanzen viel durchlässiger als der Protoplasmaliörper selhst. Letzteres schliefit sich mach aufien (rol. S. 1t) durch eine Hautschicht 
ab. Welche I'FEFFE hei der ()mone die Hauptrolle spielen läbt. Soll

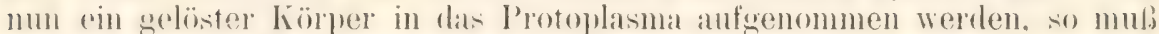
er zunäichst in die Hantschicht imbibiert werlen, ll. h. seine Molekïle miissen sich zwischen die I'lasmateilohen derselhen einlagern und von hier dann weiter in das Innere ahgegehen werlen. Ein gelöster kïrper kann aher auch damm, wenn er selhst nicht imbibiert wird. noch eine osmotische Wirknug in der Weise hervorrufen. diali er anf das in der Zolle enthaltene Wassel eine Anziehung ausibht und so einen nach anben gerichteten Wasserstrom veranlabt. .Das Wesen der Osmose beruht also darin, dab gleichzeitig zwei Körper nach entgegengesetzter Rishtung eine Membran durchwandern, und ron einem endomotischen Ïpuivalent tein Auslruck für die Relation dieses Austansches, auf welchen vielfach zu viel fiewicht gelegt wurde) kann in jenem Fall nicht die Relle sein, in welchem nur Wasser durch eine Membran diosmiert" (PFEFFER IV 1881.)

Bei der Zartheit und Kleinheit der tierischen Zellen stoßen osmotische Tntersuchungen auf grolie Schwierigkeiten. Der riegenstand ist daher mehr ron seiten der Botaniker bei den weit geeigneteren pttan\%lichen Zellen untersucht und besonders durch folgende Experimente gefördert worden:

W'enn man P'tlanzenzellen, die einen grölieren Saftranm enthalten, in eine 5-20)prozentige Lösung ron eimem geeigneten Salz oder ron Zucher oder Glykose bringt (Fig. 37), so verkleinern sich dieselhen etwas, indem

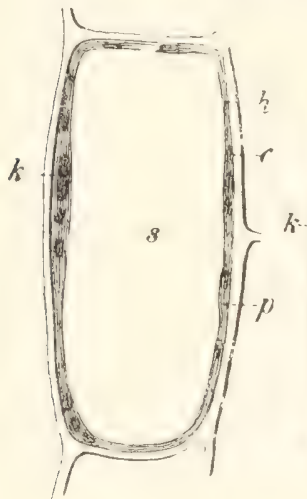

$\alpha$

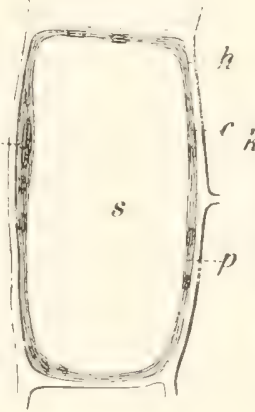

$\alpha$

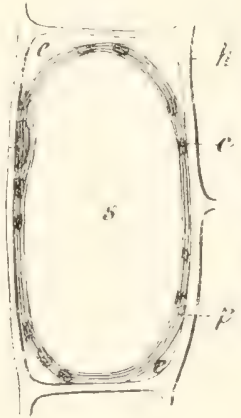

$\alpha$

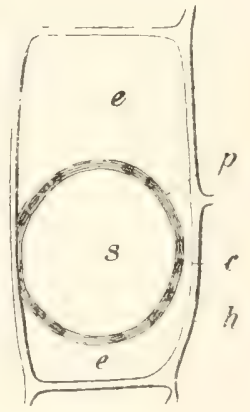

$\alpha$

Fig. 37. Nr. 1. Junge, erst halbwegs erwachsene Zelle ans dem Rindenparenchym des Bliitenstiels von Cephalaria leucantha. Nr. 2. Dieselhe Zelle in vierprozentiger Salpeterlösung. Nr. 3. Dieselbe Zelle in sechsprozentiger Lösnng. Nr. 4. Dieselbe Zelle in zehmprozentiger Lösmm. Nr. 1 u. 4 nach der Natur, Nr. 2 u. 3 schematisch. Alle im optischen Längsschnitt. $h$ Zellhaut. p Protoplasmatischer Wandbeleg. $k$ Zellkern. c Chlorophyllkömer. s Zellsaft. e Eingedrungene Salzlösung. Nach DE VrIEs (IV 18\%7).

Wasser von innen nach außen abgegeben wirl; darauf hebt sich, wenn die Wasserentziehung reiter fortgeht, der Protoplasmaschlauch von der

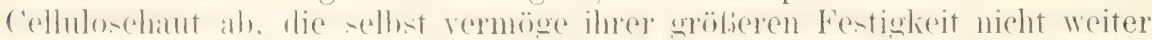
zusammenschrumpfen kann (DE VRIES IV 1877). Die Salz- oder Zuckerlösung ist also jetzt durch die Cellulosehaut hindurchgetreten und fährt fort, dem Protoplasmaschlauch weiter Wasser zu entziehen. Derselbe

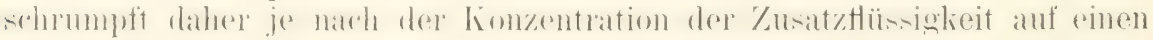
immer lileineren Raum zusammen. Der in ihm eingeschlossene Saft wird dementsprechend konzentrierter. Trotz dieser unter dem Namen der Plas- 


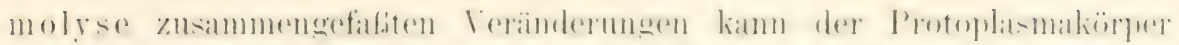

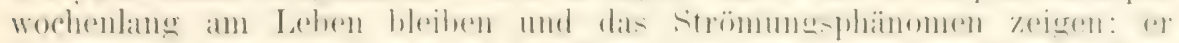

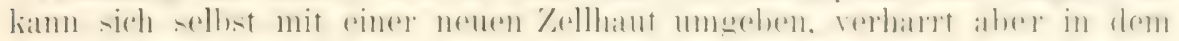
kollabierten /ustand.

Aus dem Verlauf der Plasmolyse kann man zwei Schlüsse ziehen:

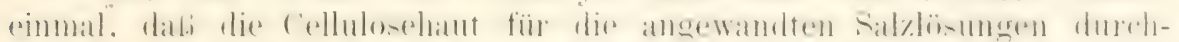

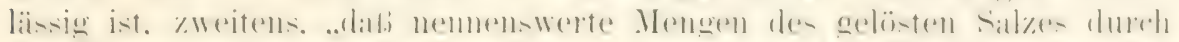

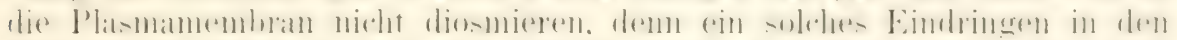

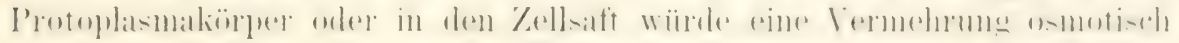
wirkender Stoffe im Innem der Plasmamembran und damit eine Volumzumahme des Protoplasmakörpers zur Folge haben' (PFeffer).

Wemn die durch Plasmolyse schlaff gewordenen Zellen wieder rorsichtig in reines Wasser ibbertragen werden, so tritt jetzt der umgekehrte

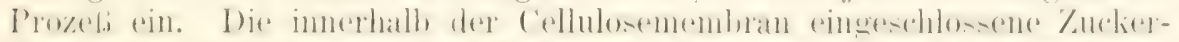

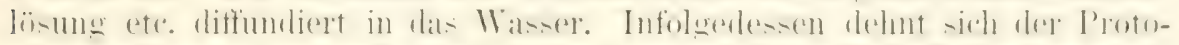

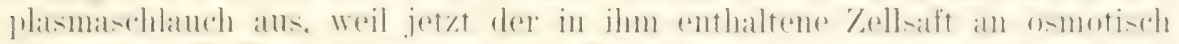

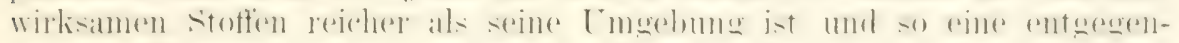

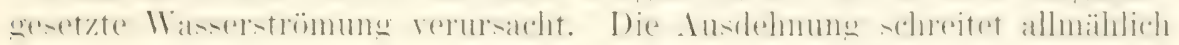
durch Wasseraufnahme so weit fort bis sich der Protoplasmaschlauch

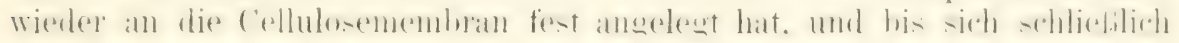
auch die ganze Zelle wieler zur ursprünglichen Größe gestreckt hat.

Andere Experimente haben gelehrt, dab der im Innern der Ptlanzen-

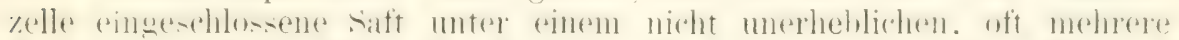

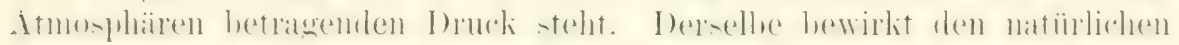
'T'urgor oder die Turgeszenz von Ptlanzenteilen. Er wird dadurch hervor-

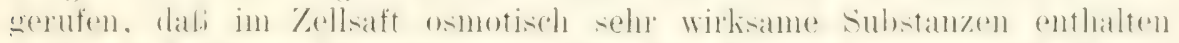

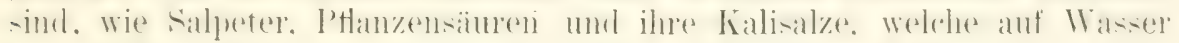
eine kräftige Anziehung ausïben (PFeffer IV 1881, DE V'RIEs II 1877).

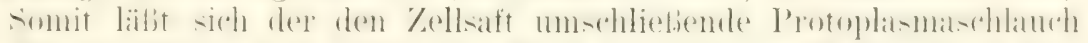

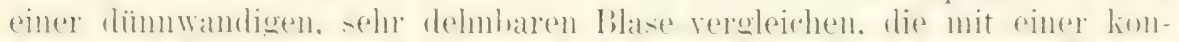

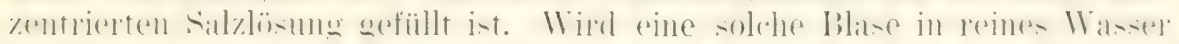
gelegt, so muf die Salzlösung Wasser anziehen und so einen Strom hervorlufen, der zur Folge hat, daß die Blase unter dem steigenden Druck

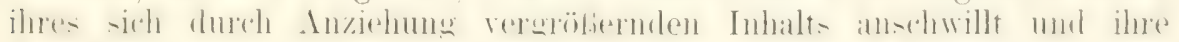
Wand immer mehr verdünnt wird. Die Dehmung der Blase findet erst

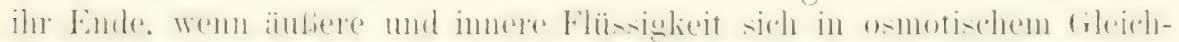

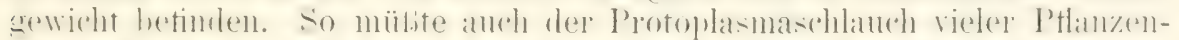

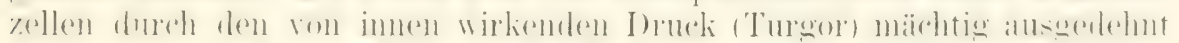

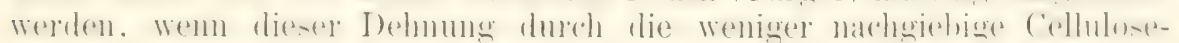
membran keine Schranke gesetzt würde.

Es kömnte nun freilich ein (ileichgewichtszustand zwischen Zellsaft

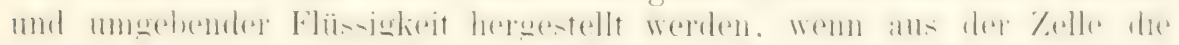
osmotisch wirksamen Stofte in das Wasser diffundieren wiürlen. wodureh die Ursache für den inneren Druck entfernt worken wäre. Dies wird aber

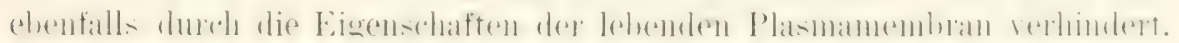
Wie dieselbe darüber entscheidet, ob ein Körper in das Innere der Zelle gelangt, so besitzt sie auf der andern Seite auch, wie schon oben erwähnt

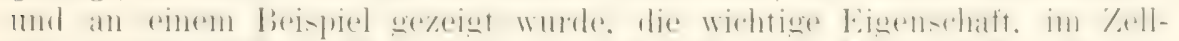

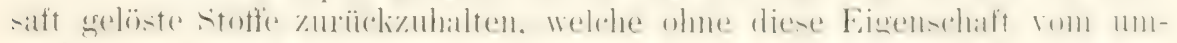
spülenden Wasser ausgewaschen werden müBten (PFEFFer IV 1s\$1).

Dab rer Zellsaft in der 'Tat unter einem höheren Druck steht. hei Wasserpflanzen z. B. unter einem höheren Druck als das umgebende Wasser, davon liann man sich durch einfache Experimente leicht über- 
zengen, wie N̈̈GELI (IV 1855) angegeben hat. Wenn in einer Spirogyra eine Zelle durch einen Schnitt geöftnet wird, so daf ihr Inhalt zum T'eil

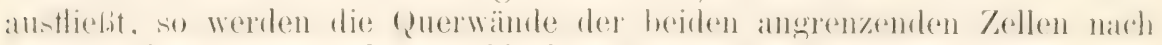
dem Hohlraum des verletzten Gliedes vorgewölbt. Der Druck in den unverletzten Zellen mul daher jetzt gröber sein als in der angeschnittenen Zelle, in welcher der Druck infolge der Verletzung auf die Spannuing des umgebenden Wasser's herabgesunken ist.

\section{Die Aufnahme fester Körper.}

Zellen, die von keiner besonderen Membran umschlossen sind oder in ihrer Membran Öffnungen besitzen, sind auch imstande, feste Körver in ihr Protoplasma aufzunehmen und zu verdauen. Rhizopoden fangen andere kleine, einzellige Organismen ein, die mit ihren im Wasser weit ausgestreckten Psendopodien in Berührung kommen (Fig. 2, 38). Die

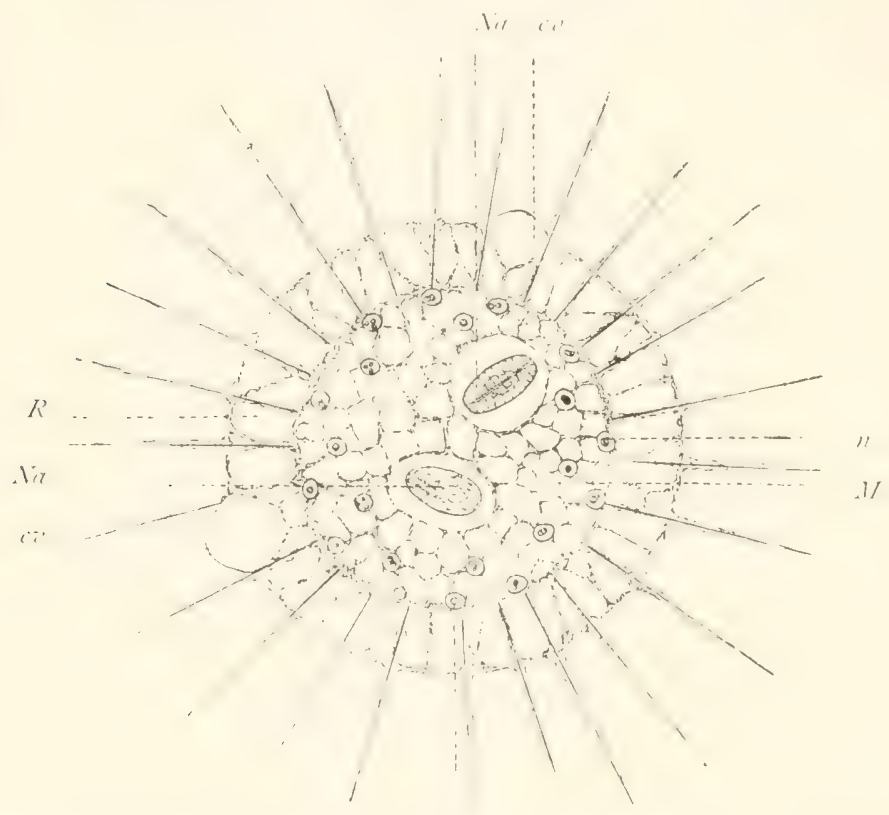

Fig. 38. Actinosphärium Eichhorni. Nach R. Hertwik, Zoologie Hig. 117. II Marksubstanz mit Kernen (n). R Rudensubstanz mit kontraktilen Vakuolen (cv), Va Tahrungskörper.

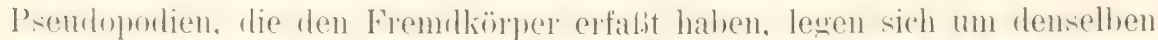
zusammen, verkïr\%en sich und ziehen ihn so allmählich in die Hanptmasse des Protoplasma hinein, wo die brauchbaren Substanzen verdaut werden,

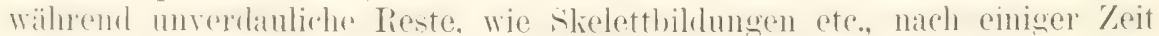
wieder nach außen hervorgestoßen werden. Auch feste Substanzen, die keinen Nährwert besitzen, werden aufgenommen. Wenn man Karmin- oder Zimnoberkörnchen in das Wasser bringt, so bemächtigen sich die Rhizopoden derselben so gierig, daß nach wenigen Stunden der ganze Körper ron ihnen dicht erfüllt ist.

Infusorien fressen kleine Flagellaten, einzellige Algen und Bakterien mul bringen sie durch eine als Zellmund bezeichmete, kleine Öffinung in 
ihrer Kutikula in das Körperplasma hinein. Hier bildet sich um jeden Fremakörper eine mit Flüssigkeit gefüllte Vakuole aus, in welcher die Verdaumg vor sich geht.

In ïhnlicher Weise wie einzellige Organismen fressen auch manche Gewebszellen der Metazoen feste, ihnen dargebotene Substanzen auf und rerdanen sie. Die intrazellulare Verdaumng. wie sie Merscrñkori (IV 1RSt) genamnt hat, ist bei wirbellosen Tieren weit verbreitet und läbt

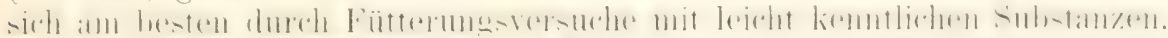

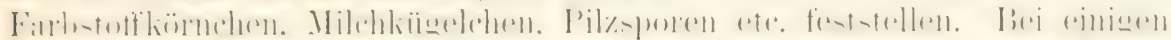

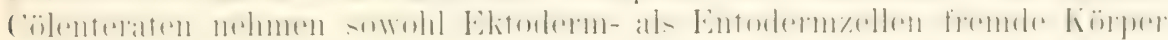
auf. Die Tentakelenden von Aktinien können sich mit Karminkörnchen helarlen. Solche findet man anch bei Alitinienlarven nach vorgenommener Füttermg im ganzen Entorlerm verteilt.

Die meiste Beachtung aber wegen ihrer Fähigkeit, feste Körper aufzunehmen und zu verdauen, verdienen die weigen Blutkörperchen, die

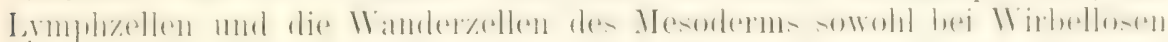
als hei Wirbeltieren. Die wichtige Tatsache ist zuerst durch HAEckeI (IV 1. 60 ) festgestellt worden. Als er eine Molluske (Tethys) mit Indigo injizierte, fand er nach kurer Zeit Indigokörnchen im Innern von Blutlörperchen auf. Metschnikoff (IV 1s8t) hat diese Erscheinungen sehr eingehend weiter untersucht. Bei einer andern Molluskenart, der durch-

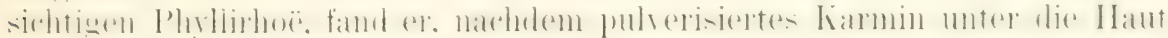
gespritzt worden war, die kieinen Körnchen von einzelnen Wanderzellen

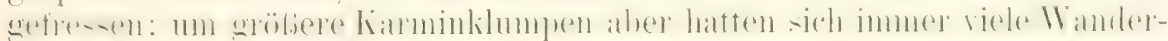

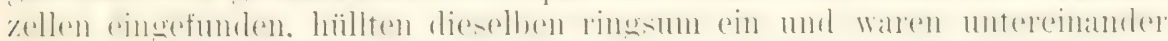

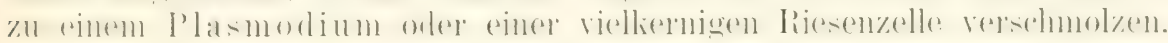

Ton derselben Erscheinung kann man sich auch bei Wirbeltieren leicht überzeugen, wemm man eimem Frosch in den dorsalen Lymphsack etwas Karmin einspritzt und nach einiger Zeit einen Lymphtropfen ent-

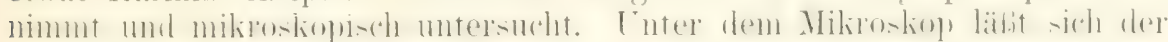
Vorgang des Fressens direkt verfolgen. Man muB dann etwas Karmin-

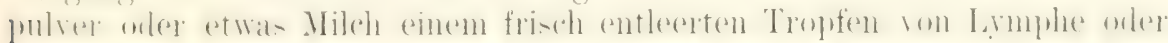

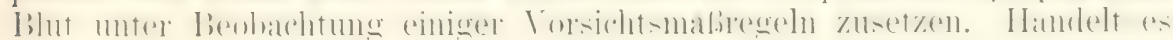
sich 1 m ein Präparat ron einem Säugetier orler rom Menschen, so mub

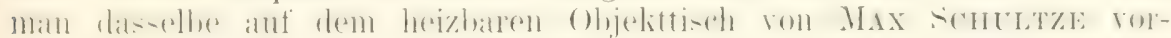
sichtig bis auf $30-35^{\circ} \mathrm{C}$ erwärmen (IV 1S60̃). Indem jetzt die weifen

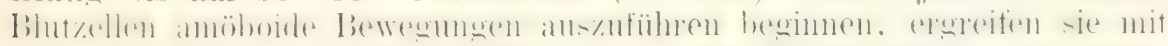

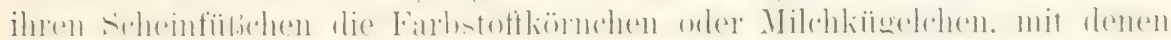
sie in Berührung kommen. und ziehen sie in ihren Körper hinein. Sie sind daher ron Metschxikof als Phagocyten, der ganze Torgang aber ist von ihm als Phagocytose bezeichnet worden.

Die Fähigkeit der amöboiden Elemente des tierischen Lioplers feste Substanzen aufzunehmen, ist von einer sehr hohen plysiologiscluen Bedeutung: denn hierin besitzt der Organismus ein Mittel. um aus seinen feweben ihm fremdartige und schädliche. geformte Teile zu entfernen. Es gibt besonders drei ver-

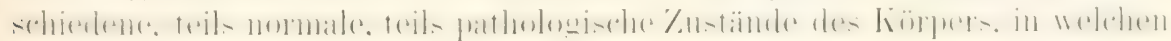
die Phagoerten ihre 'Täigkeit entfalten.

Erstens kommt es im Laufe der Entwicklung bei viclen Wirbellosen und auch bei Wirbeltieren vor, dab einzelne Larvenorgane ihre Bedeutung verlieren und unter Verfettung zugrunde gehen. So schwinden einzelne

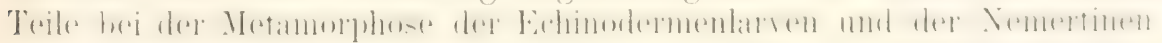
so wandelt sich die Kaul(guappe in den jungen Froseh um. indem sie ihren 
ansehnlich entwichelten Ruderschwanz verliert. In allen diesen Fällen er-

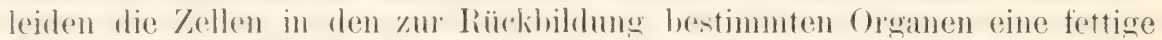
Metamorphose, sterben ah mol zerfallen. Wïrendem haben sieh in der Sachloarschatt schon reichlich Wamberellen oder I'hagocyten eingefumben,

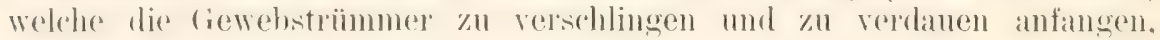
wie man bei durchsichigen Meertieren während des Lebens genau verfolgen kann.

Zweitens besorgen die Phagocyten, ähnlich wie in den normalen Vorwiingen der Fntwicklung. anch die Resorption ahgestorbener und in \%erfall befindlicher Teile. iiberall wo solche aus nor-

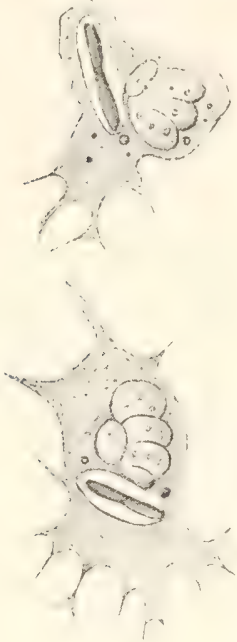

Fin. :3. Ein Leukocyt des Frosches, in dem ein Bakterium eingeschlossen ist und verdaut wixd. Das Bakterium durch Vesuvin gefärbt. Jie lidile Figuren repräsentieren zwei Stadien der Bewegung ein

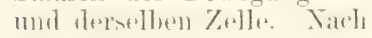
METSCHNIKOFF Fig. 54 . malen oder pathologischen Ursachen im Körper entstehen. Rote Bhutkörperchen zerfallen, wenn sie eine Zeitlang in Blutstrom gekreist haben. Im Milzblut hat man ihre Trümmer im Körper von weißen Blutkörperchen aufgefunden, die auch hier ihre Aufgabe, das Abgestorbene zu entfernen, erfüllen. Wenn infolge einer Verletzung sich ein Blutergub in das Gewebe bildet, und Tausende von Blutkörperchen und Elementarteilen zugrunde gehen, dann machen sich auch wieder die Wanderzellen an die Arbeit und rermitteln die Resol'ption und Heilung.

Drittens endlich biklen die Phagocyten bei Infektionskrankheiten eine Schutztruppe des Körpers, um der Verbreitung von Mikroorganismen im Blut und in den Geweben entgegenzuwirken. Es ist ein großes Verdienst von Metschnikoff, auf diesen Gegenstand die Aufmerksamkeit gelenkt zu haben (IV $188 \pm$ u. IV 1892). Es gelang ilm zu zeigen, dab hei Erysipel die liokken, bei Rückfalltyphus die Spririllen, bei Milzhrand die liazillen von Wanderzellen gefressen und darlureh unschädlich remacht werelen (Fig. 39). Die gefressenen Mikroorganismen. deren Zahl in einer Zelle oft $10-20$ betragen kann, zeigen nach einiger Zeit deutlich erkennbare Spuren der Auflösmm. Betinden sich die Mikroorganismen im Blut, so findet ihre Vernichtung vorzugsweise in der Milz, der Leber und in dem roten Knochenmark statt. Ist ihre Ansiedelung an einer Stelle im Gewebe erfolgt, so smit sich der Körper der Eindringlinge datureh zu entledigen. dab infolge der reaktiven Entzündumg zahlreiche Wanderzellen auf dem Platz erscheinen. Zwischen Mikroorganismen und Phagocyten wird, wie sich

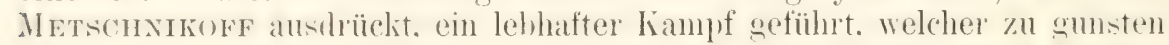
der einen oder anderen Partei entschierlen wird, und je nachdem die Ileilung orler den Tor des von der Infektion betroffenen 'lieres herbeiführt.

Die Fïhigkeit der Wanderzellen. bestimmte Arten von Mikroorwnismen zn vernichten. scheint bei einzelnen Tieren cine sehr verschierlene zu sein und anch sonst noch von den rorschiedensten liedingungen abzuhängen: s) spielen namentlich die chemischen lieizwirkmgen, welche später noch zul besprechen sind. (negativer und positiver Chemotropismus) eine Rolle. 


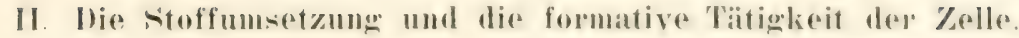

Die Gase, die flüssigen und die festen Substanzen, die in das Proto-

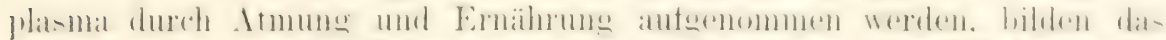

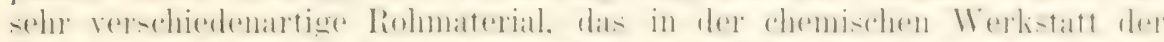

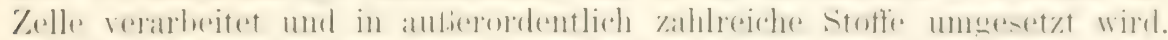

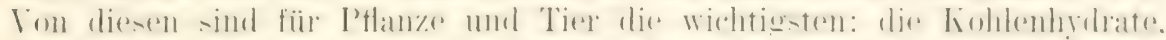

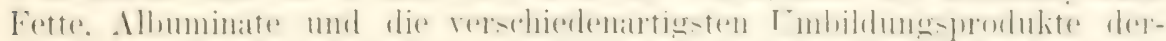

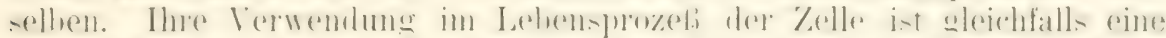

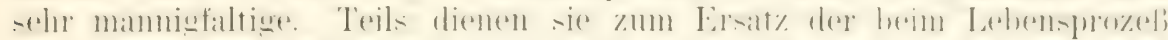

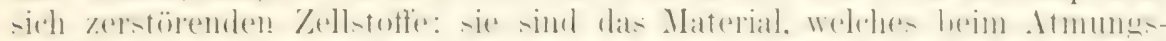

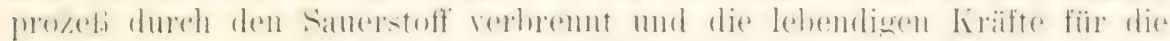
Arbeitsleistungen der Zelle liefert. 'Teils dienen sie zum Wachstum und

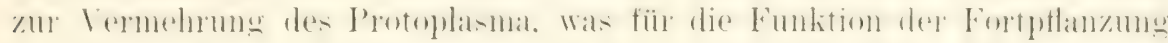
unentbehrlich ist. Teils werden die im chemischen Laboratorium neuge-

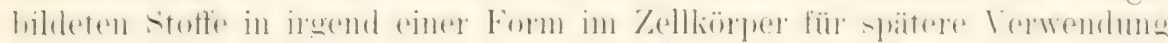
abgelagert; sie stellen also Reservestotte dar. Endlich kömnen sie inner-

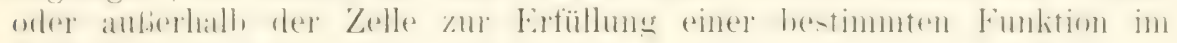
Zellenleben ausgeschieden werden.

So entstehen die namentlich im Tierreich sehr zahlreichen Stoffe. auf

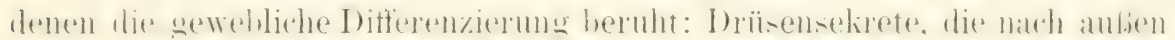
entleert werden. Membranen und Interzellularsubstanzen von chemisch

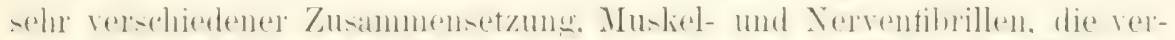
möge ilner eigenartigen Oramisation in hesomelerer Woise mit homtrali-

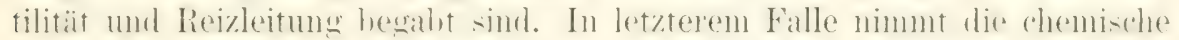
Arbeit der Zelle einen Charakter an. welchen MAx Schultze als ihre formative Tätigkeit bezeichnet hat. Das Protoplasma benutzt das ihm

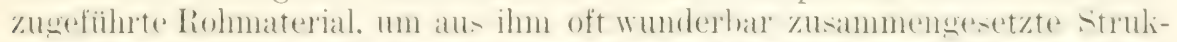
turen herzustellen. die ihm zu hesonderen Arbeitswerdien dienen sollen. In dieser Tätigleit erseheint uns die \%elle gewis-ermalien als rin tätgere

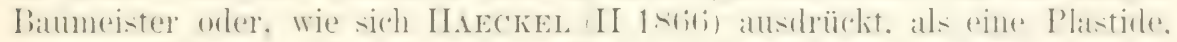

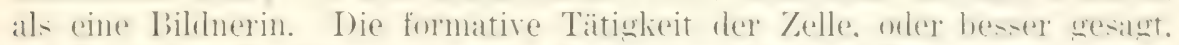

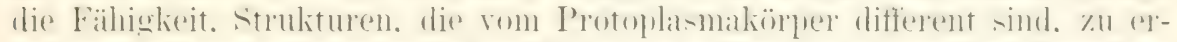

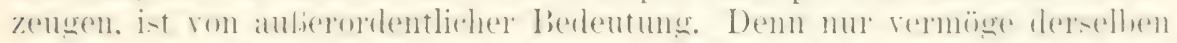

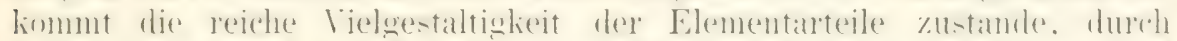

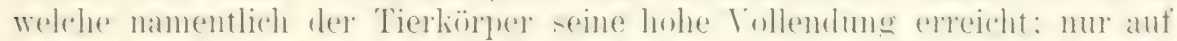

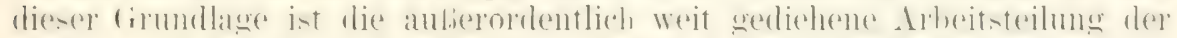

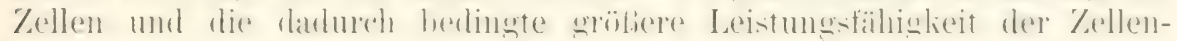
gemeinschaft herbeigefïhrt worden.

Das Kapitel von der Stoffumsetzung der Zelle bietet also der Unter-

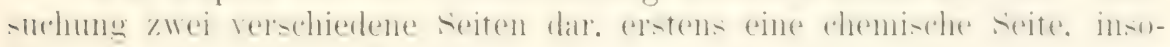
fern es sich um die Entstehumg der zahllosen, durch Vermittlung des

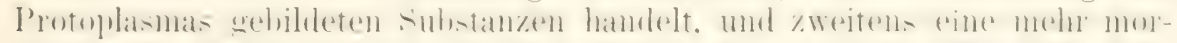

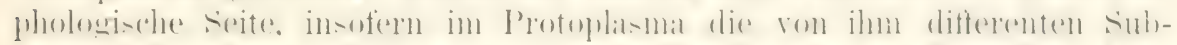

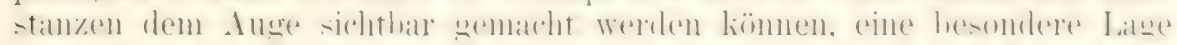

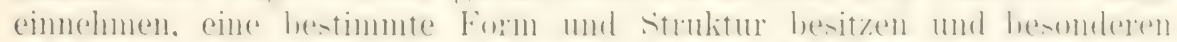

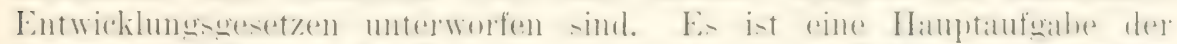

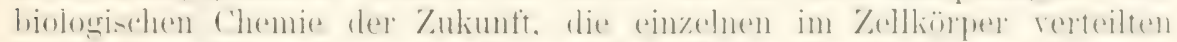

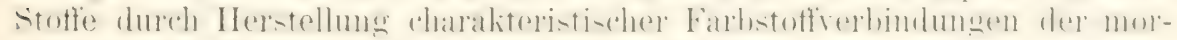
phologischen Untersuchung zugänglich zu machen. 


\section{Die Chemie des Stoffumsatzes.}

Die chemischen Vorgänge in den Zellen, die zum größten Teil noch in ein tiefes Dunkel gehüllt sind, können uns hier nur insoweit beschäftigen. als es sich um einige fundamentale Fragen handelt. Eine solche ist die Frage nach der Synthese der Kohlenhydrate, der Fette und Eiweilisubstanzen aus einfacheren Elementarstoften.

Es besteht ein anscheinend tiefgreifender Gegensatz zwischen der chemischen Arbeit im Pflanzenreich und im Tierreich. Nur das mit Chlorophyll versehene Protoplasma der Pflanzenzellen besitzt die Fähigkeit. aus Kohlensäme mol Wasser hochmolekulare. ternäze Verbindungen herzustellen : das nicht chlorophyllhaltige Protoplasma der Tiere und einzelner farbloser l'flanzenteile kamn nur mit diesen Ausangimaterial weitere synthesen vornehmen und unter ditsen auch fubternäre Verbindungen liefern. Welche chenischen Voroünge sich in grïnen Protoplasma unter Benutzung der lebendigen Krraft der Sonne unter Aufnahme von Kohlensäure und Wasser und unter Abspaltung von Samerstoff abspielen, ist noch nicht zu beantworten. Das erste sichtbare Produkt der Assimilation ist die Stärke. eine Vorstufe derselben vielleicht Zucker. DaB Zucker und Stårke durch cine direkte synthese ron Kohlenstoff uml Wasser entstehen, ist kaum anzunchmen: wahrschemlich billen sich beim komplizierten Prozeb manniwfache Zwischenprodukte. „Es ist sogar nicht unmöglich“, wie Sachs

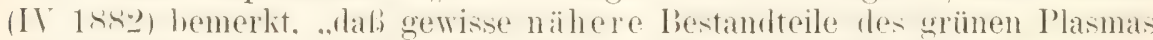
sellst sich an dem Vorgang beteiligen. daf, \%. B. dabei staltungen mol Substitutionen in den Molekülen des grimen Protoplasmas stattinden. Diese Mäglichkeit erhält einige Wahrscheinlichkeit durch die Wahrnehmung. dali in vielen nicht allen) Fällen die Chlorophyllsulstanz, währenı die Stärliekörner in derselben wachsen. nach und nach immer mehr an Masse abnimmt, endlich ganz verschwindet."

Die vermöge der Chlorophylfunktion in Pthanzenkïrper gewonnenen Kohlenhydrate (stärke) bilden das Material, dureh dessen Lmsetzung im I'rotoplasma die fetten (öle der P'flanzen entstehen. Die ternären stickstofffreien. organischen Verhindungen wehen ferner wieder die cirundlage für die sinthese von quaternären Eiweidsulstanzen ab und trasen so zur Ergänzumy und Vermehrums des Protophasma selhst hei. Doch müssen bei diesen Sinthesen noch sahpetersame und schwefelsaure Salze hinzuliommen. welche von den I'tlanzen mit ihren Wurzeln ans dem Borlen aufgenommen werden. Daf aus solchen Mitteln Proteinsubstanzen durch die lebende 7elle gelildet werlen kïmmen. hat I'Asteur experimentell sichergestellt. indem er niedere Spaltpilze, wie Mycoderma aceti. Hefe etc., in künstlich zu-immentesetzten Nährlösmgen kultivierte. So kamm Mycolerma aceti sich auch im Dunkeln lebhaft vermehren, wenn nur wenige Zellen in eine Nählösung wehracht werden, zusammengesetzt aus entsprehend verdiunntem

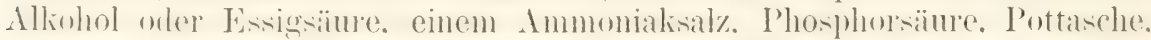
Mannesia. Wasier. Durch chemische Zersetzung dieser Stotte müssen die Pilzzellen. wenn sie sich auf ein Vielfaches vermehrt haben, außer Cellulose und Fetten, auch Proteinstoffe gebildet haben.

Indem vermöge ihrer Chlorophyllunktion die Pflanze Kohlenhydrate erzengt und diese wieder in Fette und EiweiBsubstanzen umsetzt, liefert sir die ternïren und guaternären Verbindungen. Welche der tierische Orgatnismus zu seiner Ernährung berlarf, und die er selbst sich nicht mit den einfachen Mitteln, wie die Pflanzen, zu bereiten vermag. $Z$ wischen Pflanzen- und Tierreich besteht infolgedessen ein Kreislauf des Lebens, in welchem beide eine gegensätzliche Stellung zueinander ein- 
nehmen und sich ergänzen. Der Gegensatz läfst sich in folgender Weise formulieren:

In der griunen Pflanzenzelle wird aus liohlensäure und II asser durch Symthese organische Substan\% elzeugt und die lebendige Kraft, die ill im Sonnenlicht zugefülrtwirl, in Spannliraft umgewandelt: die tierische Zelle dagegen benutzt als Nahrungsmaterial die bereits im Pflanzenreich erzengten ternären und quaternären Verbindungen und verbrennt sie zum grolien Teil dureh Oxydation; sie wandelt die in den hochmolekularen Verbindungen angesammelten Spannkräte wieder in lebendige Kraft um. indem sie Arbeit verrichtet und Wärme er-

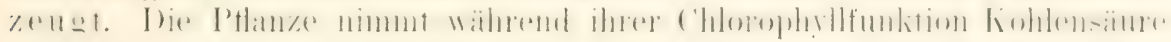
auf und spaltet aus ihr Sanerstoff ab; das Tier atmet Samerstoff ein und Kohlensänre wieder aus. Bei der Pthanze herrschen in den chemischen Prozessen die Reduktion und Synthese, beim 'Tier die Oxydation. Verbremung und Analyse ror.

Aus dem (iegensat\%, welcher im Haushalt der Natur zwischen I'flanzenreich und Tierreich besteht, darf man num aber nicht auf einen

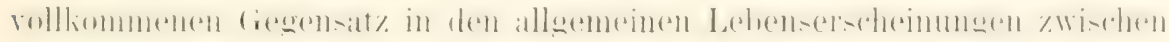
ptlanzlicher und tierischer Zelle schliefen. Ein solcher existiert nicht.

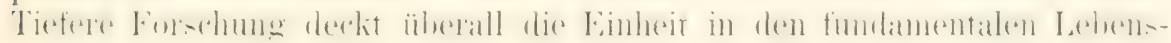
prozessen der ganzen Organismenwelt auf. Der oben betonte (iegensat\% rührt ja einfach nur daher, daf die Pflanzenzelle eine besontere. der

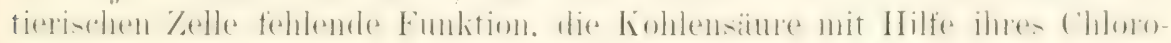
phylls zu zersetzen, ausgebildet hat. Von dieser Chlorophyllfunktion abgesehen, spielen sich viele für das Leben fundamentale Stoftwechselprozesse hier wie dort in übereinstimmender Weise im Protoplasma ab. liei

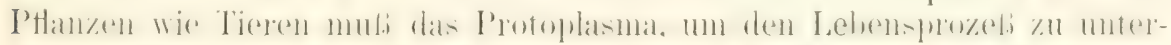
llalten, atmen, Sauerstoff aufnelmen, Wärme erzeugen. Kiohlensäure ab-

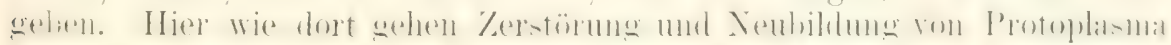

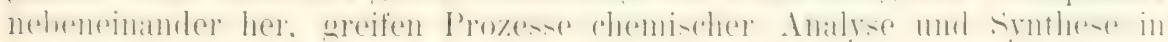
liomplizierter Weise ineinander.

Noch lilarer wird das Verhältnis, wenn man berïcksichtigt, daß in der

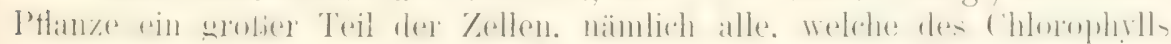

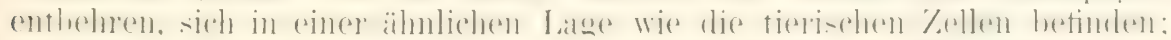
anch diese müssen, da sie nicht assimilieren könmen. das Material zur Erhaltung des Lebensprozesses und zum Wachstum und zur Vermehrung ihrer Substanz ron den grünen Zellen beziehen. Derselbe Gegensat\%, der im Haushalt der Natur zwischen 'Tier und Pflanze besteht, herrscht also in der Pflanze selbst zwischen den farblosen und den chlorophyllhaltigen rellen.

In treffender Weise hat Craude Bersard (IV 185.5) das Verlältnis in folgenden Worten lurz zusammengefabt: . Wenn in der Sprechweise

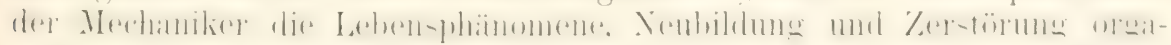
nischer Substan\%, dem Ieben und dem Fallen eines Gewichts verglichen werden kömen, damn werden wir sagen. dab Hebung und Fall sich in jeder lebenden Zelle vollziehen. sowohl in der tierischen als der ptlanzlichen. aber mit dem Unterschierl. daß das tierische Element sein Gewicht schon auf ein gewisses Niveau gehol)en vorfindet und es daher weniger zu heben braucht, als es darauf wierler herabfällt. Das Umgeliehrte findet bei der grünen Pflanzenzelle statt. Mit einem Wort, ..les deux versants, celui de la descente est prépondérant chez l'animal: celui de la montée chez le végétal" (Claude brrarad IV 1895., B(l. II). 
Nachdem so die Bedentung der Chlorophyllfunktion in das rechte Licht gesetyt ist. sei noch auf widhtige thereinstimmungen hingewiesen. welche in dom themismus des stoffwechsels zwischen tierischer und pHanzlicher Zelle bestehen. Hier sei zunächst noch hervorgehohen, daß eine sehr große Anzahl von Stoften der progressiven und regressiven Metamophose dem Tiel- mol Pthanzenteich gemeinsam sind. Ïhnlich seheinen ferner die Mittel $z u$ sein, mit denen sich einige sehr wichtige Prozesse in der tieriselen und pthanzlichen Zelle vollziehen. Kohlenhybate. Fette mul Eiweibstofte sind nicht in jedem \%ustand geeignet. 1 m im Iaboratorim der \%elle direkt verbrancht unel in andere chemische Verbindungen ïhergeführt zu werden. Eine Vorbedingung ist, daß sie in eine lösliche und leicht diffundierende Moditikation umgewandelt werden. Dies gerchieht z. B., wenn Stärke und Glykogen sich in Traubenzucker, Dextrose und Läivulose umsetzen, oder wem Fette in cilyzerin mol Fettiämen zerspalten. oder wenn Eiweibstoffe peptonisiert werden.

SAcHs' (IV 1882) bezeichnet die obengenannten Modifikationen der Kohlenhydrate, Fette und Eiweibstoffe als ihren aktiven Zustand im Gegensatz zum passiven Zustand, in welchem sie sich als feste Reservestoffe (Stärke. Öle. Fette. Eiweißkristalle) in den Zellen angesammelt finden oder vom Tier als Nahrung aufgenommen werden. Nur im aktiven Zustand können die plastischen Stofte die verschiedenartigen Wanderumgen. sowohl im pttanzlichen als andh im tierischen Körper vollziehen, durch welche sie nach den Orten ilner vorïhergehenden Auflewahmo orler ihres jeweiligen Verbrauches gehangen. Die Stärlie zum Beispiel, die sich in unterirdischen Teilen, wie den Knollen, oder in den Samen ansammelt, ist an diesen Stellen nicht assimiliert worden. Ihre Trsprumsorte sind die assimilierenden. wrünen Zellen. Von diesen sind sie durch Vermittelung aller dazwischenliegenden Zellseloilde oft anf weite Strecken mach den linollen und samen hintransportiert worlen. Dal nun Stärliekörnchen die \%ellhäute nicht pasieren kïnnen. liann die Stoffwanderung nur im gelösten Zustand (Zuclier) stattinden, worauf an Ort der Aufbewahrung wieder die Rückbildung in die unlösliche Modifikation (Stärke) erfolgt. Wenn dann in der Knolle oder im Samen sich der Keim entwickelt, werden die passiven Reservestotte ron neuem reaktiviert und mïssen in aktiven Zustand von nenem eine Wanderung nach den Verhrauchsortenj, den Zellen des sich entwickelnten Keins. durchmachen. Ehenso mïssen heim Tiere die Kohlenhydrate. Fette mol Eiweibstofte, die als Vahrung in den Körper gelangen. lïslich gemacht werden, damit sie an die Orte ihres Verbrauchs gelangen können, oder es müssen die zur Reserve im Fettgewebe abgelagerten Fette, wenn sie irgendwo im Körper zum Verbrauch dienen sollen, reaktiviert werden.

In der tierischen und pflanzlichen Zelle scheint num die so wichtige C̈herführung der Kohlenhrolrate. Fette und Eiweibsubstanzen aus dem gasiven in den aktiven Zustand in durehas entsprechender Weise ror sich zu gehen durch Vermittelung sehr eigentümlicher. (hemischer Kïrper, die man als Fermente bezeichmet. Dieselben sind den Eiweißkörpern velwandt und wohl durch Tomwallung ans denselben entstanden: sie finden sich in ler Zelle in seln seringen (guantititen. bringen aber trotzlem eine intensive ahemische Wirlimg hervor und leiten ahemische Prozesse ein, bei denen sie selbst nicht wesentlich verändert werden. Die Fermentwirliung ist ein für die chemie der Zelle auderordentlich charatiteristischer Vormang. Es wilnt Fermente für die Lmwandlumg der Kohlenhydrate. Fermente für die fmwandlung der Fiweifstotfe, Fermente für die Fettumsetzung. 
Überall. wo in den Pflanzen Stärke löslich gemacht wird. geschieht es durch ein Ferment. die Diastase. Welche sich aus keimenden Samen

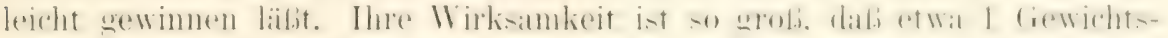
teil Diastase 2000 Gewichtsteile Stärke in kurzer Zeit in '/ucker umwandeln kann. Ein anderes, auf Kohlenhydrate wirkendes Ferment, das Invertin, kommt in Spalt- und Schimmelpilzen vor und spaltet Rohrzucker in Dextrose und Läivulose. Der ptlanzlichen Diastase entspricht beim Tier das Speichelferment (P'tyalin), welches Stiuke in Dextrin

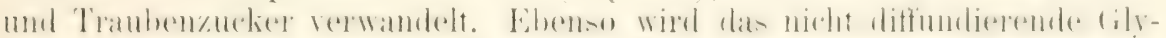
kogren. welches man seiner Eigenschaft nach als tierisches Amylum be-

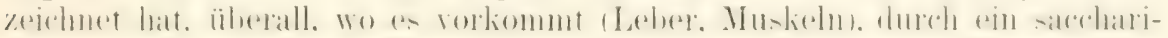
fizierendes Ferment in Zucker umgesetzt, wenn es weitere Verwendung finden soll.

Eiweikkörper werden, un weiter verwertbar zu sein, peptonisiert.

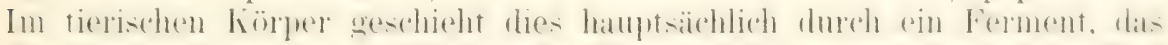

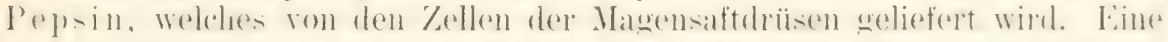
geringe Menge von Pepsin löst bei Gegenwart von freier Salzsäure im

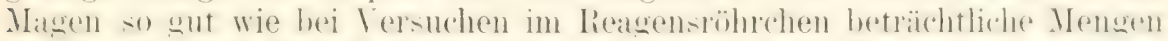

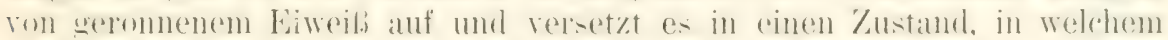
$\Leftrightarrow$ durch Dembramen himdureh diffundieren kimn. Ineh in Ptlanzenzellen

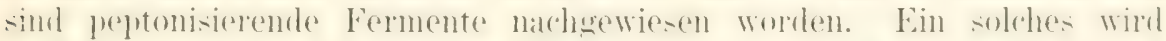
z. B. bei den Heischfressenden Pflanzen von den Organen, welche zum

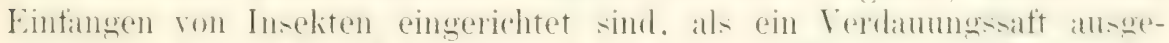

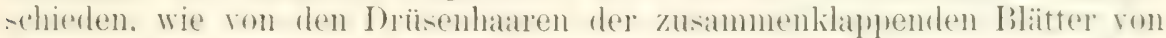

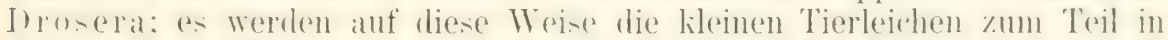

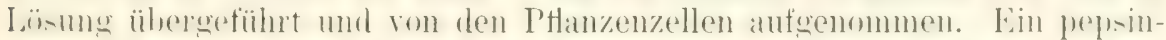
artiger Ferment hat sich auch in lieimptlanzen natehweisen lasisen. wo es

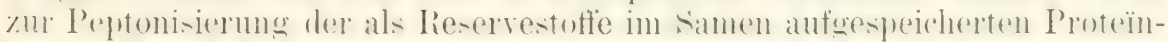

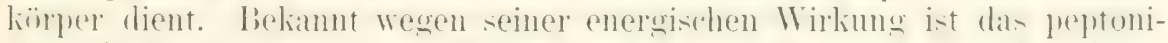
sierende Ferment aus dem Milchsaft von Carica papaya und anderen Caricaarten. Ein solches ist endlich auch im Körper der Mrxomyceten durch KRUKENBERG entrleckt worlen.

Bei der chemischen Umsetzung der Fette findet im tierischen

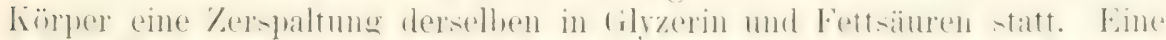

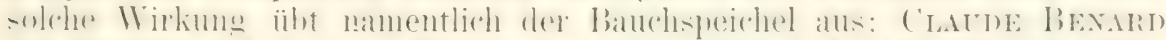

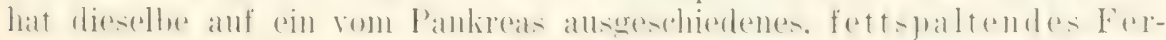

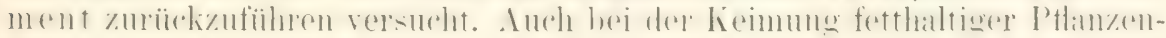
samen soll eine Zerspaltung des Ös in Glyzerin und Fettsäure durch Vermittelung von Fermenten erfolgen (SchüTzENBERGER).

Schon aus diesen wenigen Tatsachen läht sich erkennen. daß auch lier Stoffumsatz in der Zelle; so wenig bekannt uns (lerselbe zur Zeit noch

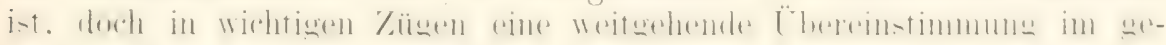
samten Organismenreich zeight.

Einer der dunkelsten P'mlite beim Stoftumsatz in der Zelle ist die

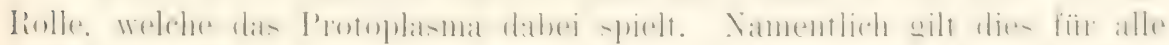
Vorgänge, welche oben als der formativen Tätigkeit der Zelle angrehörig bezeichnet wurden. In welchem Verhältnis stehen zum Protoplasma die

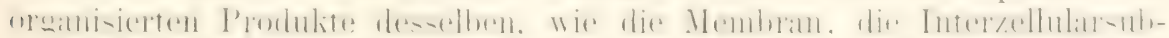
stanzen usw:? Zwei ganz entgegengesetzte Ansichten finden hier in der Tier- und Ptlanzenbiologie Vertretung. Nach der einen Ansicht entstehen

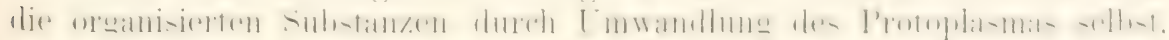
also dureh chemische Umsetzungen ouler Abspaltungen von Protoplasmamolekïlen; nach der andern Ansicht dagegen bilden sie sich aus plasti- 


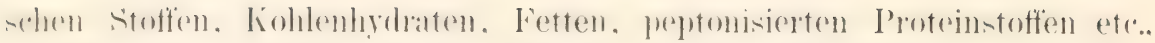
welche in das Protoplasma beim Stoffwechsel aufgenommen, an die Ver-

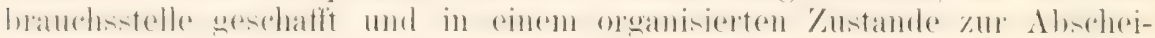
llumg gebracht werten.

Am besten läbt sich der Gegensatz an einem Beispiel klar machen, als welches ich die Bildung der Cellulosemembran der Pflanzenzellen wählen will. Nach einel Hypothese, welche u. a. besonder's von STRAsBURGER (IV 188\%, 1889) vertreten wird, verwandelt sich das mikrosomen-

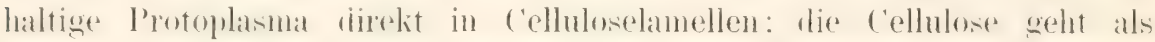
feste, organisierte Substanz ummittellar aus dem Protoplasma hervor.

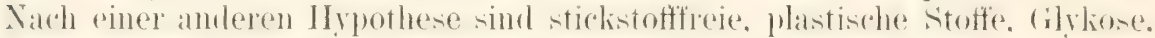
Dextrin oder irgend ein anderes lösliches liohlenhybat dat Material zur

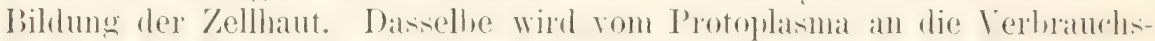
stelle geschafft und hier in die unlösliche Modifikation, die c'ellulose, umgewandelt. Da dieselbe bei ihrer Entstehung eine bestimmte Struktur erlält, wird auch bei dieser Bildungsweise das Protoplasma in einer uns unbekannten Weise mitwirken müssen, was man mit dem Schlagwort ,. formative 'Tätigkeit" ausclrückt. Nach der ersten Hypothese kann man die Cellulosehaut kurweg als ein Umwandlungsprodukt des Protoplasmas, nach der zweiten als sein Abscheidungsprodukt bezeichnen.

Derselbe entgegengesetzte Standpunkt tritt uns bei der Frage der Bildung der Chitinhäute, der Knorpel- und Knochengrundsubstanz, der leimgebenden und gallertigen Substanz entgegen; er spielt sogar mehr oder minder in alle Auffassungen vom Stoffwechsel der Zelle hinein. Cuaude Bernard (IV 1885) hat dies Verhältnis mit den Worten charakterisiert: .. Vom physiologischen Standpunkt ließe es sich vorstellen, dab im Organismus nur eine Synthese, die von Protoplasma, stattfindet, welches

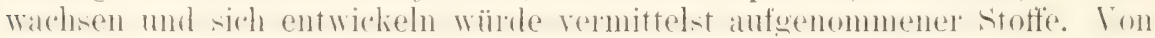

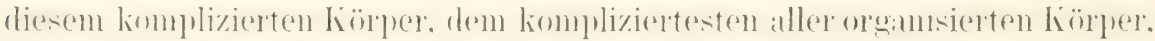
würten sich dann durch weitere Spaltung alle zusammengesetzten ternären und quaternären Verbindungen herleiten. deren Auftreten wir für gewöhnlich einer direkten Synthese zuschreiben." So mußte auch SAcHs bei der Assimilation der Stärke die Möglichkeit offen lassen, welche er aber für

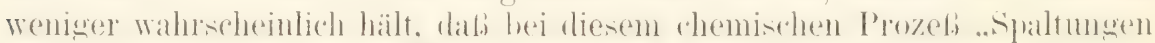

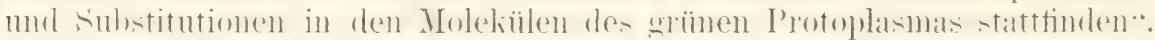

Aus diesen Äußerungen wird die Schwierigkeit der ganzen Frage erhellen. soweit sie die in Betracht kommenden chemischen Prozesse betrifft. Wenn es gestattet ist, aus analogen Verhältnissen Schlüsse zu ziehen, so muB ich der zweiten Hypothese, nach welcher das Protoplasma

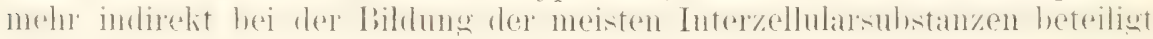
ist, entschieden den Vorzug geben. Denn wenn manche Organismen sich eine Menhran aus Kieselsäure oder aus kohlensaurem Kalk billen, so macht schon die Natur dieses Materiales den Schluß unabweishar. daß dasselbe nicht als feste organisierte Substanz ummittelbar aus dem Protoplasma hervorgegangen sein kann. Hier kam letzteres seiner ganzen chemischen Zusammensetzung nach nur eine vermittelnde Rolle gespielt haben, indem es die Stofte aus der Umgebung ausgewählt, aufgenommen, an den Verbrauchsorten angehäuft und in bestimmter Form als feste Verbindung und wohl stets an ein organisches Substrat gebunden abgelagert hat. Eine solche Vorstellung scheint mir auch für die Entstehmo der Cellulosemembranen näher zu liegen, wenn man die leichte Umwandlungs-

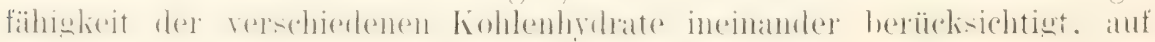




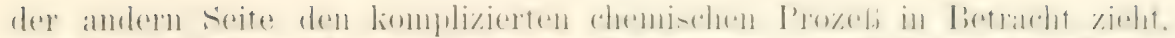

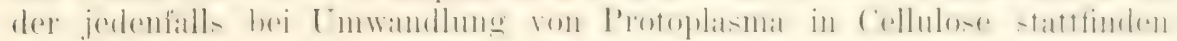
mübte. Und selbst die Inter\%ellularsubstanzen, die dem Protoplasma cheoisch mahe stehen, wie Chondrin, Glutin etc, kömuten unter dasselbe

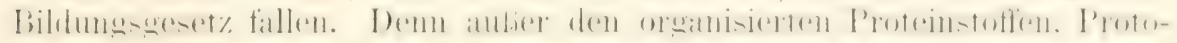
plasma und liernsubstanz, kommen in jeder Zelle anch Zahlreiche unor-

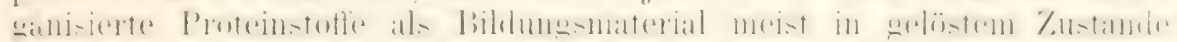
vor. wie im Zellsaft der Ptlanzenzellen, in Saft der Kerne. in IBlut und

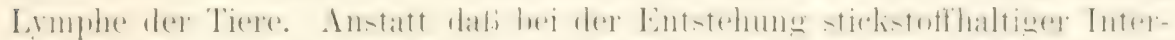

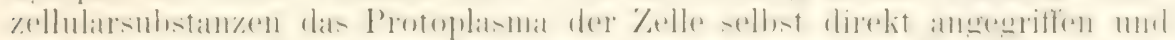

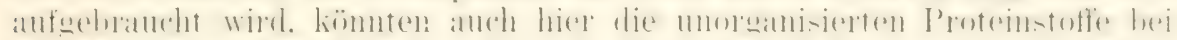

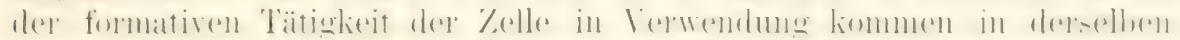
Weise, wie es oben für die Bildung der Cellulosemembran angenommen wurde.

In welcher Weise bei diesen Prozessen das Protoplasma die vel'mittelnde Rolle spielt, von der oben gesprochen wurle, entzieht sich 7ur

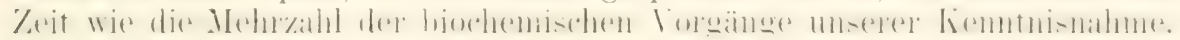
Die vermittelnde Rolle des Protoplasma könnte aber vielleicht darin bestehen. daf mit gewissen Einheiten desselben (Bioblasten) sich gewisse in der Nählösung befindliche Stoffteilchen durch Molekularaddition verbinden und dadurch zu einem organisierten Produlit umgewandelt werden. So würden sich lösliche

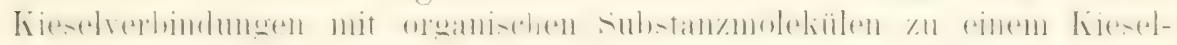
slielett vereinigen; so würden sich Celluloseteilchen aus löslichen Kiohlen-

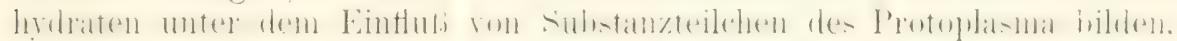
sich mit letzteren molekular verbinden (wahrscheinlich dauernd, vielleicht aber auch nu voribergehend) und so zu einer Zellhaut organisiert werden. Mit dieser Torstellung läbt sich sehr gut die Beobachtung verembaren. daß an manchen Objekten frisch gebildete Celluloseschichten und das angrenzende Protoplasma kontinuierlich ineinander ïbergehen.

\section{Zur Morphologie des Stoffumsatzes. Die formative Tätigkeit der Zelle.}

Die Substanzen, die beim Stoffirechsel rer Zellen gebildet werden. fallen in das Bereich der morphologischen Untersuchung, soweit sie rom Protoplasma optisch unterscheidbar werden. Sie können in geformtem oder ungeformtem Zustand entweder in Innern des Protoplasmas selbst oder auf seiner Obertläche zur Abscheidung kommen; ie nachdem werden sie als innere oder äubere Plasmaprodukte unterschieden. Doch ist, wie so oft bei biologischen Einteilungen. eine scharfe Grenze zwischen beiden Gruppen nicht immer zu zichen.

\section{a) Die inneren Plasmaprodukte.}

In Wasser relöste Substanzen könmen sich in rröheren und kleineren Tropfen im Protoplasna abscheiden und dadurch Höhlungen ouler Vakinolen hervorrufen. Sie spielen namentich in der Morphologie der I’tanzen eine grofie Rolle. Demn eine einzelne Pthanzenzelle (Fig. 40) liann sich (lurch Saftabscheidumg in sehr kurzer Zeit m mehr als das hundertfache vergröhern. Auf der summierten Wirkung zahlreicher derartiger Zellen heluht das betrïchtliche Wachstum, welches wir wihlend der Hauptregetationsperiode in Frühjahr bei lietrachtumg einzelner Ptlanzenorgane oft mit Erstamen wahrnehmen. Der (iehalt an fester Sulstanz kamn in einem 
sehr wassererohen Pthanzenteil schliefilich nur 50 " o ocler sogar nur $20 \%$ betragen.

Am besten kann man die Vakuolenbildung im Protoplasma Schritt für sehritt rerfolgen. wenn man die \%ellen an leagetationskegel e ves Zwoiges oder einer Wurzelspitze mit den weiter davon entfernten, sulizessive äler werlenten Zellen verwleicht. Am Vegetationsliegel selhst sird

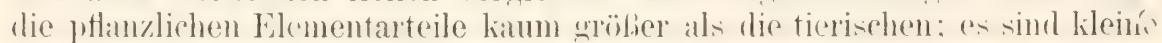
Protoplasmaklümprehen mit liern, eingehüllt in eine sehr dümne cellulosemembran (Fig. f(1). - I). In einiger Entfernung von ihm reroröbern sie sich allnählich. indem im Protoplasma kleine safttropten ansge-chierlen werden. die mit dem Alter der Zelle an Grälie rasch zunehmen. Inas Protoplasma gewimnt dadurch ein schaumiges Aussehen, wie Fig. $40 \mathrm{~B}$ s reigt.

Von einer Protoplasmaanhäufung, in welcher der Kern liegt, gehen dickere und feinere IÏutchen ans. Welche als Scheidewänte die einzelnen Saftrïume roneinander trennen und sich an der (bhertläche zu einer zusammenhängenden Wandschicht (Primordialschlauch) verbinden. welche sich der Innentläche der vergröberten und durch Wachstum rerdichten Cellulosemembran ( $/$ ) anschmiegt.
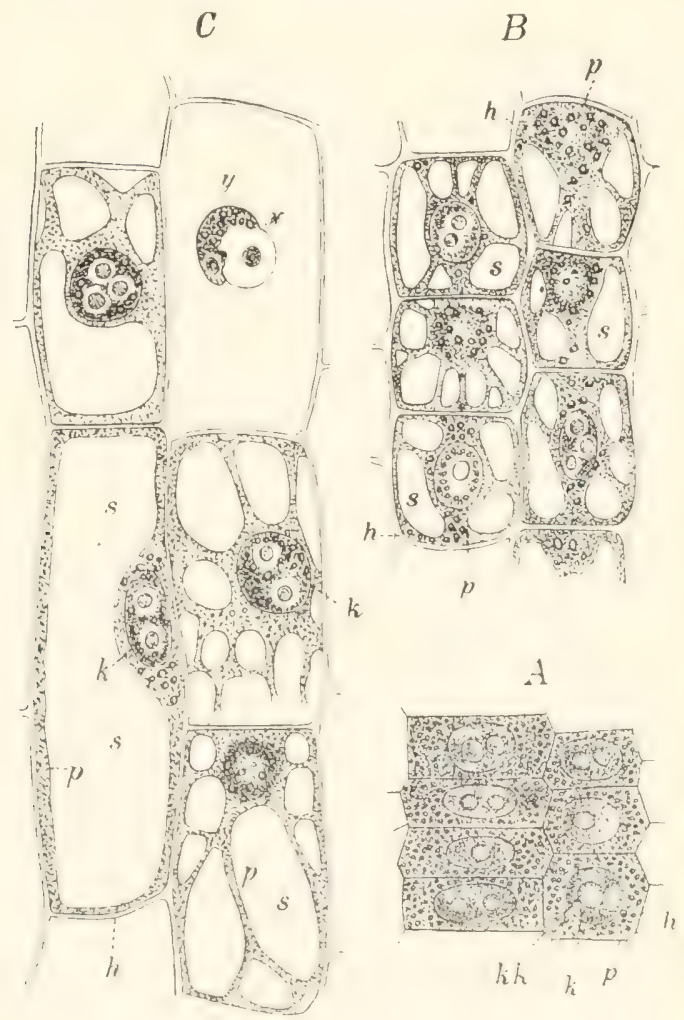

Fig. 40. Parenchymzellen aus der mittleren Schicht der Wurzelrinde von Fritillaria imperialis; Längsschnitte, nach 550 maliger Vergrößerung. Nach Sichs. $A$ dicht über der W $\mathrm{Wr}$ zelspitze liegende, sehr junge Zellen, noch ohne Zellsaft; $B$ die gleichnamigen Zellen etwa 2 IIllimeter ïher der Wurzelspitze, der Zellsaft $s$ bildet im l'rotoplasma $p$ einzelne Tropfen, zwischen denen Protoplasmawinde liegen: $C$ die gleichnamigen Zellen etwa 7-8 Millimeter über der Wurzelspitze; die beiden Zellen rechts unten sind von der Torderfläche gesehen, die große Zelle links unten im optischen Durchsehnitt gesehen; die Zelle rechts oben durch den Schmitt geöffnet; der Zellkern läßt unter dem Einfluß des eindringenden Wassers eine eigentümliche Quellungserscheinung wahrnehmen $\left(\begin{array}{ll}x & y\end{array}\right)$; $k$ Kern; kk Kernkörper; $h$ Membran.

Hiervon lassen sich zwei verschiedene Zustïndle ableiten. welche die ansogewachsene P'tanzenzelle darbietet. Durch weitere Vermehrung des

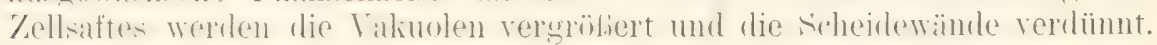
Letztere reilien endlich teilweise ein. so rali die einzelnen safträmme sich durch Öffnungen in Verbindung setzen und einen einzigen zusammen- 
hängenden Saftram bilden. Der Protoplasmakörver hat sich mithin jetzt umgewandelt in eine ziemlich diune. der Cellulosemembran anliegende Schicht und mehr oder minder zahlreiche P'rotoplasmabalken und Fäden, welche den einheitlichen groben Flüssigheitsraum durchsetzen (Fig. fo) C rechts 11 . Fig. +1\%. In anderen Fällen endlich sind auch diese Protoplariabalken in Innern der Zeile geschwunden. Der Protoplasmaköriver besteht damn einzig und allein noch aus einem diumen schlauch. welcher die Innentliiche des Kämmerchens. lein einen Ausdruck von Sicus (IV Iss:) Zu gebrauchen. wie eine Tapete die Zimmerwand bedeckt und einen einzigen grolien Saftraum einschlielst (Fig. $f() C^{\prime}$ links untere Zelle und Fig. 37). In sehr groben Zellen ist dieser Schlauch zuweilen so dümn. ilab man. ihn. vom Zellkern abgesehen. selbst bei starker l'ergröberung kaum wahrnimmt und daß man, um iln klar zur Anschaumg zu bringen, besondere Cntersuchungsmethoden anwenten muls.

Eine ebenso reiche Vakuolenbildumg und Sattahscheidung, wie sie sich in Ptlanzenzellen findet, zeigt uns zuweilen auch das hüilenlose Protoplasma niederer. einzelliger Organismen. namentlich einzelliger Rlizo-

Fig. 41. Eine Zelle aus einem Staubfadenhaar von Tradescantia virginica. Vergr. 241). Nich STRAsmeritir, Botanisches Praktikmm.

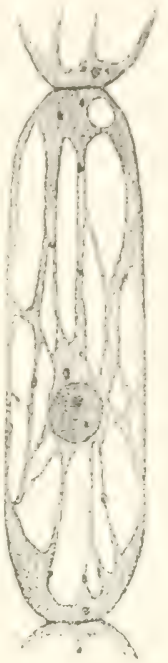

poden und Radiolarien. So bietet uns der in Fig. 38 dargestellte Körper

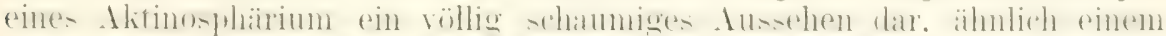

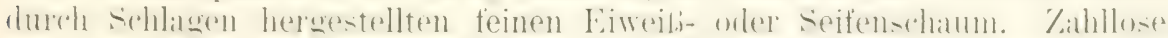

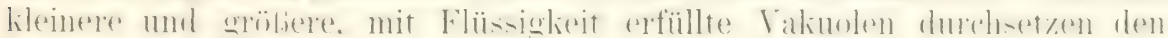
ganzen Körper und sind nur durch feine, zuweilen kaum mefibar dicke

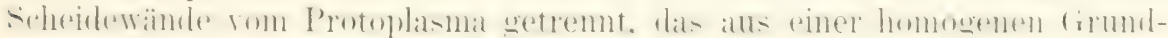
substanz mit eingebetteten Körnchen besteht.

Durch die Vakuolenbildung wird der Protoplasmakörper aufgelockert

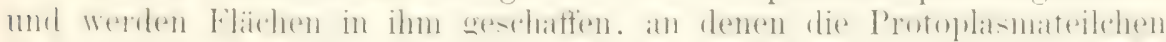

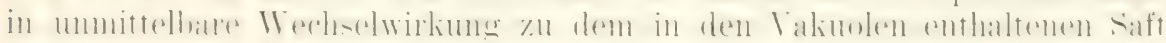
treten können. Durch die ganze Eimrichtung wird offenbar die Stoffanf-

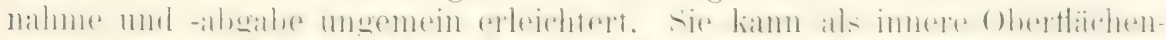

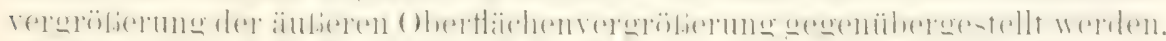

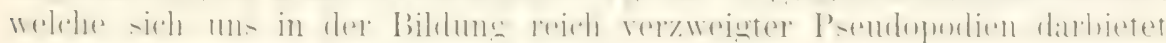
und wohl dem gleichen Zwecke dient.

In bezug auf seine chemischen Eigenschaften ist der Zellsaft eine

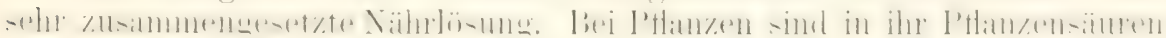
und ihre Salze, salpeter- und phosphorsaure Salze. Zucker, in geringer

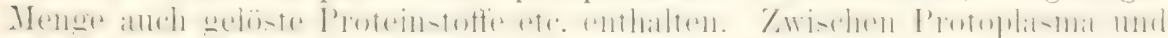

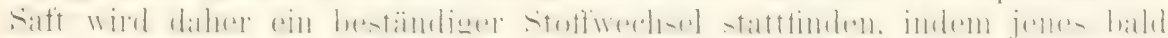
Substanzen zum Verbrauch aus dieser Quelle bezieht, bald andere Sul)stanzen wieder an dieselhe al)gibt. Indem der Saft eine konzentrierte Lösung osmotisch wirksamer Substanzen darstellt. ïbt er auf Wasser eine

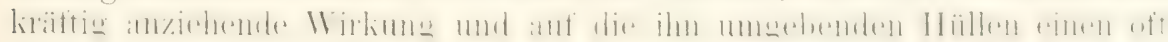
bedeutenden imneren Druck aus. so daß sie in einem prallen Zustand. der' schon früher (S. 69) als Turgor hesprochen wurde, erhalten werden. 
Manche Botaniler, wie mamentlich DE VRIES (IV 1885) und WENT,

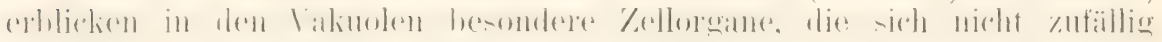

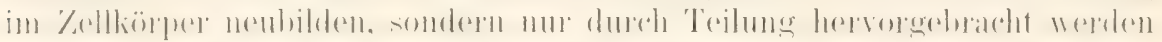

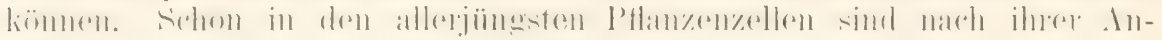
nahme auberordentlich kleine Vakuolen vorhanden, die sich durch Teilung fortwähend vermehren und bei der Teilung der Zelle auf die 'Torioterzellen verteilt werden. Infolgedessen sollen sich von den Vakuolen yes Meristems die sämtlichen Vakuolen der ganzen Ptlanze herleiten, was vòn anderen Forschern indessen in Abrede gestellt wird. Wie das Protoplasma sich nach auben durch eine Hautschicht abgrenzt, besitzen nach DE VRIES auch die Vakuolen eine eigene Wand (den Tonoplasten), welche

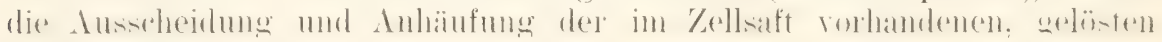
Stoffe regelt.

In geringer und konstanter Anzahl vorkommende Vakuolen kömnen, so namentlich häutio bei Infunorien. eine nit heronderer Kontraktilıtat ansgestattete Wandschicht erhalten und werden dann als kontraktile Vakuolen oder Behälter bezeichnet.

Im Gegensatz zu den pHanzlichen Zellen findet in den tierischen

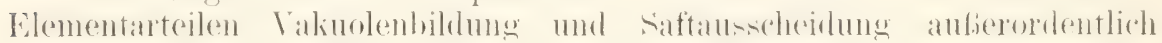
selten statt. Am häufigsten wirl sie noch in Organen angetrotten, die im

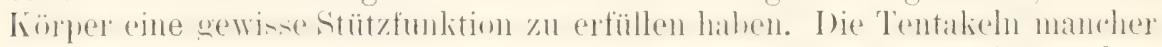
Cölenterarten, gewisse Körperanhänge von Anneliden besitzen in ihrer Achse, ebenso wie die Chorda dorsalis der Wirbeltiere, verhältnismäßig große, blasige Zellen, die nach außen durch eine dicke Membran abgegrenzt sind und im Imnern fast nur Zellsaft und eine sehr geringe Quantität Protoplasma enthalten. Dieses breitet sich in dünner Schicht unter der Zellmembran aus und schicht hie und da auch Fäden durch den Saftraum. Der Kern liegt meist in einer dichtern Ansammlung des Protoplasma entwerler in der Wandschicht orler im Netzwerk eingebettet. Auch hier werden wie bei den Pflanzen die festen Zellwände infolge osmotisch wirksamer Substanzen des Saftes prall gespannt sein. Obwohl über die Tur-

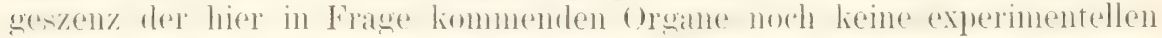
Intersuchungen vorgenommen worten sind, lälit es sich doch nur in dieser Weise vorstellen, daß die Chorda als ein stützender Stab im Körper der

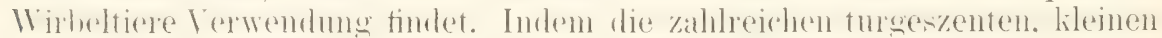
Chordazellen nach außen durch eine feste, elastische Scheide zu einem Organe verbunden und gegen die Umgebung abgegrenzt sind, werden ihre

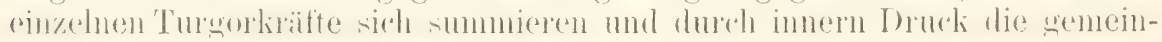
same Scheide in Spannung erhalten.

Saftaufnahme und Saftabscheidung kommen, wie beim Protoplasma, auch bei der Kermsubstanz vor. In beiden Fällen dienen sie wohl dem Zweck, den aktiven Substanzen eine größere Oberfläche zu verleihen und

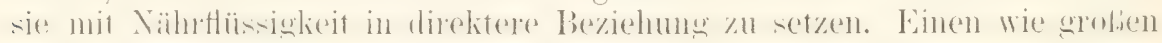
Umfang auch hier die Saftaufnahme erreichen kamn, erfährt man am besten, wenn man das Volumen der kompakt gewordenen Kerusubstanz im Kopt eines Samenfadens vergleicht mit dem Volumen, welches in kurzer Zeit

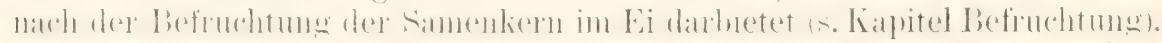

Während die Bildung von Saftvakuolen in tierischen Zellen selten ist, kommt es bei ilnen dagegen häutig zur Absonderung von weichen oder festen Substanzen: von Fett, Glykogen, Schleim, Albuminaten und Gemischen von mehreren festen Substanzen. Wenn die Einschlïsse sehr reichlich und zahlreich entwickelt sind, so kamn im Zellkörper das Proto-

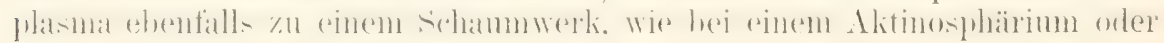


einem Netzwerk wie in der 'Tladeszentiazelle umgewandelt sein, nu dali die Zwischenriume anstatt mit Saft mit dichteren Substanzen erfiillt sind.

Fett kann sich. wie der Zellsaft in jungen Ptlanzenzellen, zuerst in kleinen Tröpfehen im Protoplasmakörper bilden. Wie dort die Vakuolen, vergrößern sich später die Tröpfchen, verschmelzen unteremander uns stellen schlieflich einen einzigen groben Tropfen dar, der den ganzen Bintenraum der Zelle ausfiillt und nach auken von einer diunneren L'rotoplasmaschicht, nit Kern und einer feinen Zellhaut umschlossen wirk.

Glyogen sammelt sich in den Leberzellen in einzelnen 'Tropten an. die bei Zusatz von Jodjodkalium eine mahagonibraune Farhe annehmen und sich darlurch kemntich machen lassen.

Schleimbildende Substan\% (Mucigen) füllt den Bimnenram dej' mit ihrer Bereitung betranten Zellen (Fig. 42) oft in solcher Menge an. dab die Zellen zu Blasen angeschwollen sind oder die Form eines liechers angenommen haben. Das Protoplasma ist meist an der Basis der Zelle. wo sich damn anch der Kern befindet, noch etwas reichlicher vorhanden, umgibt ron hier die mucigene Substanz mit einer diumen Ifülle und breitet sich auch mit einzelnen Fäden netzartig in ihr aus. Durch Färbung mit manchen Anilinfarben läbt sich die mucigene Substanz vom P'rotoplasma schärfer unterscheiden.

Gröbere Festiglieit gewinnen die inneren Plasmaprodukte sehr häutig in den Eizellen, die sich in der verschierlensten Weise mit Reservestoften belarlen. Nach ihrer Form werden dieselben als Dotterkügelchen (Fig. 4:), Dotterkörner, Dotterplättchen unterschierlen und stellen meist in chemischer Itinsicht ein Gemisch von Albuminaten und Fetten dar. Oft scheint die Eizelle fast ganz aus ihnen zu bestehen. Das Proto-

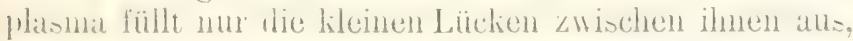
wie der Mörtel zwischen den Steinen eines Mauerwerks; auf dem Durchschnitt durch ein Ei erscheint es als ein

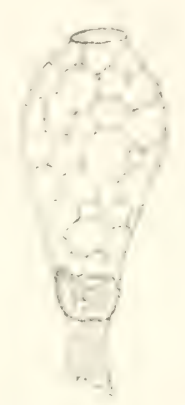

liig. 12, Becher. zelle aus dem Blasenepithel v. Squatina vulgaris in IMüllerscher Flüssigkeit erhärtet.

Nach LIsT 'Taf. I, Fijg. 9. zartes Net\%werk, in dessen kileineren und größeren Maschen die Reservestoffe liegen. Nur an der Oberfläche des Eies und in der Ungebung des Keimblïschens findet sich Protoplasma als eine dickere zusammenhängende Schicht.
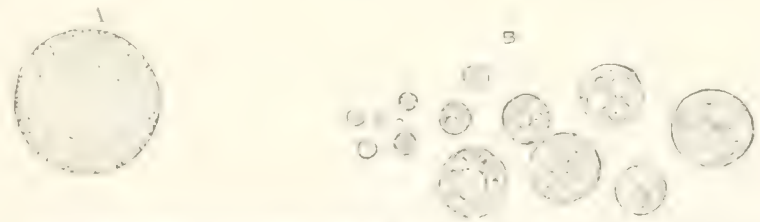

Fir. fi. Dotterelemente aus dem Ei des Huhns. Nach B.1LFour. A (ielber Dotter. B IV Ieilier I)otter,

Manche Plasmaprorhute zeigen eine kristallinische Beschattenheit, wie die Guaninlisistalle, von denen der Silberglanz in der Haut und dem Banchfell der Fische herrührt, oder wie die Pigmenthïrnchen in den l'igmentzellen.

Ännliche Plasmaprorhlite wie in tierischen kommen anch in pflanzlichen Zellen vor, hier aber gewöhnlich nur in einzelnen besonderen () r.ginen. die entweder speziell zur Aufspeicherung ron Reservestofien oder wie die 
Samen zur Reproduktion dienen. Dann finden sich die Zellen mit Öl-

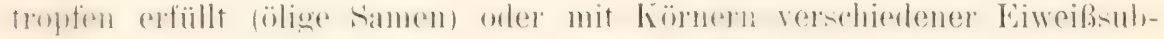
stanzen (Vitellin, Kleber, Aleuron) oder mit Eiweißkristalloiden oder mit Stärkekörnern, auf die später noch genauer einzugehen ist.

Während die bisher besprochenen in neren Plasmaprodukte beim Stoffwechsel voribhergehend angesammelt. dam wieder aufgehraucht werten und daher sehr veränderliche Bildungen sind, gilot es andere, die einen

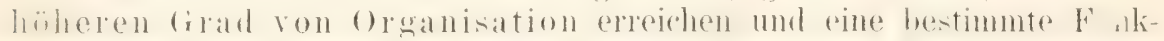
tion in der Zelle dauernd zu erfüllen haben. Hierher gehören die inneren skeletthildungen des Protoplasmakïrpers, dann ver-chedenatig-te

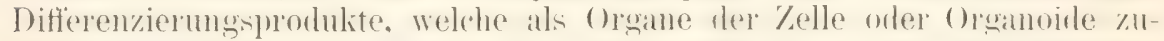
sammengefalit werlen lïmmen: die Trophoplasten in den P'tlanzenzellen. in tierischen Zellen die Vebenkerne. Dotterlierne, Mitohombren etr.. die Nesselkapseln der Cölenteraten, endlich die Muskelfibrillen, Nervenfibrillen usw.

Innere Skelette finden sich im Körper vieler Protozoen, namentlich aber in grober Mannigfaltigheit nul Zierlichlieit hei olen Rablobrien. vie

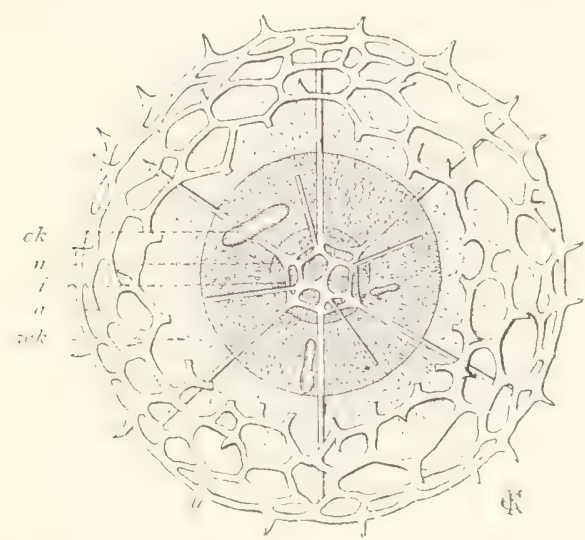

Fig. 44. Haliomma erinaceus. Ans R. Hertwig, Zoologie. a äußere, $i$ innere Gitterkugel, $c k$ Zentralkapsel, zok extrakapsulärer Weichkörper, n Binnenbläschen (Kern). setzen sich bald aus regehmäßig angeordneten Stäben, bald aus zierlichen, durchbrochenen Gitterkugeln, bald aus beiderlei Bildungen vereint (Fig. 44) zusammen. Bei einigen Familien der Radiolarien bestehen sie aus einer organischen, in Säuren und Alkalien löslichen substanz. hei den meisten dagegen ans hiestlsïure. die an ein oreanisches Suhstrat, wie im Knochen der Wirbeltiere die phosphorsauren Salze an das Ossein, gebunden ist. Alle diese Skelette haben eine für die Spezies lionstante und charakteristische form und lassen ganz gesetzmäßige Verhältnisse in ihrer Entwicklung (RICHARD Hertwig IV 1879) erkennen.

Unter 'Trophoplasten versteht man hochorganisierte Differenzierungsurodulite des ptlanzlichen Protoplasma, welchen dieselle Lonstanz wie dem Zellkern und eine orolie funlitomelle Selhstimbliglieit zuliommt. Für die ptlanzliche Frnïhrung sind sie sehr wichtig. da sich der

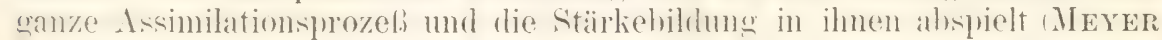
IV 1881, 1883). Die Trophoplasten sind kleine, meist kugelige orler ovale Kürier, aus einer dem Protoplasma verwandten, aber doch von ihm untershedilbaren substan\%. Sie sind leicht durch Waster und lieagentien hei der P'rijaration zerstöbar und werden am hesten durch Iodtinktur oder durd homyentrierte I'ikrinsïmre fiviert. In Nisrosin fürhen sie sich alshann stahlblau, so daß sie sich vom Protoplasmakörper scharf abheben. Sie finden sich oft in großer Anzahl in der Zelle und können in aktiver Weise ilne Form verändern. Nach den Untersuchungen von Schmiтz (IV 1882),

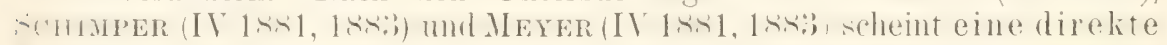
- auentstehung von Trophoplasten im Protoplasma nicht vorzukommen, dagegen vermehren sie sich wie die Kerne durch zeit- 
weise eintretende Teilung. Die Trophoplasten. die schon in der ptlanzlichen Eizelle enthalten sind. würden somit den entsprechenden (iebililen aller aus iln hervorgegangenen Zellgenerationen den Ursprung gegehen hahen. Sie kömmen fermer in versehiedenen Modifikationen auftreten und verschiedene Funktionen verrichten und werden danach als Stärliebiluner.

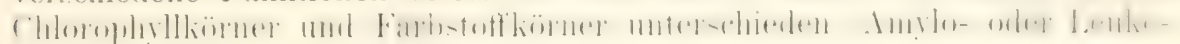
plasten, Chloroplasten, Cluromoplasten).

Die meisten Stäliebildner (Fig. fin) tinden sich in den nicht assimiherenden Zellen junger PHanzenorgane unt aller unterirdischen Teile. sowie in den Stengeln unt Blattstielen. In den Scheinknollen von Phajus mandifolius. die fiir die Lntersuchung besonder's geeignet sind. stellen sie von der filaiche gesehen, ellipsoide feinkörnige Scheiben dar, in der P'rotilansicht erscheinen sie stäbchenförmig und hehen sich hei Behandlung mit P'ikronigrosin durch stahlblane Farbe vom umgebenden Protoplasma ab. An einer Breitseite der Scheibe sitzt ein kleineres oder grobleres Stärkekorn. Ersteres ist ringsum ron einem dimmen Überzug der Substanz des Lenkoplasten umschlossen, letzteres

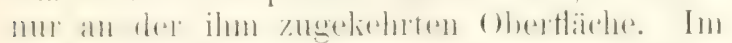
zweiten Fall zeigt es eine exzentrische Schichmone. mori zwar deralt. dali der lieru. mu den sich die Schichten hermmlegen, sich in

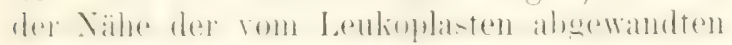

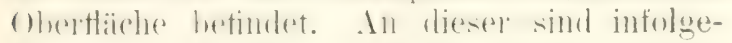
dessen die Schichten sehr dïnn und verdicken sich dann allmählich nach dem Stärkebildner zu, woraus hervorgeht, daf sie von ihm aus

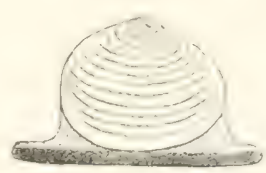
4

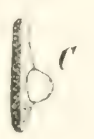

I3
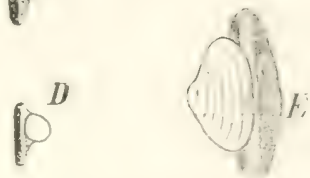

Fig. 4.). Plrajus grandifolius, Stärkebilduer ans der

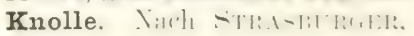
Botanisolies l'raktikum. A, C, $D$ und $E$ von der Seite. $B$ von oben, $E$ griin gefïrbt. Verer. 540 . wachsen und ermährt werden. Oft ist in der

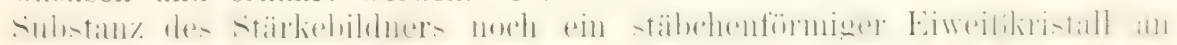

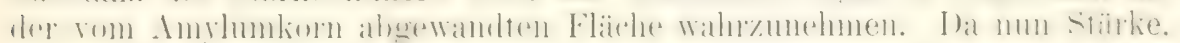
wie wir früher gesehen haben, nur in grïnen Ptlanzenteilen durch Synthese erzengt werden kann, sind lie weißen Stärkebildner nicht als ihre

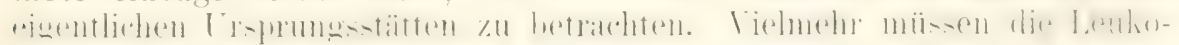
plasten die Stärke in gelöster Modifikation, vielleicht als Zucker, von den Orten. wo die Assimilation vor sich geht, bezogen haben, so dals dam ilme Aufigabe nur darin besteht, die gelöste Substanz wieder in ein festes und organisiertes Produkt unzuwandeln.

Mit den Stärkebildnern sind die Chlorophyllkörner (Fig. fii) nahe verwandt: demn sie könmen direkt aus ihnen durch Umbildumg hervorsehen, indem sich in ihrer Substanz unter dem Einfluß des Lichtes Chlorophyll entwickelt. Die Lenkoplasten elgrïnen dam, nehmen ail Grölie zu mul verlieren ihre Stärkekörner, die aufgelöst werden. Auf der andern Seite nehmen die Chlorophrllkörner auch aus den farblosen Trophoplatsten. clie an den Vegetationspunkten als indifferente Anlagen vorkommen, ihren Trsprung; endlich vermehren sie sich durch Teilung (Fic. $f(i)$ : mnter Zunahne ihrer Substan\% strecken sie sich in die Länge und werten biskuitförmig. worauf sie schlieblich in ihrer Mitte durchgeschüut werien.

Die Chlorophyllkömer bestehen aus einer Grundlage. welche (iie Reaktionen des Eiweilies darbietet, und aus einem das Stroma dureh- 


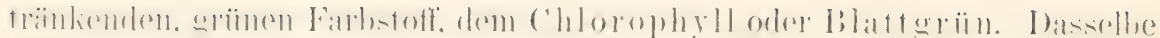
lïbt sich durch Alkohol extrahieren und zeigt in der Lösung deutliche Flıo-

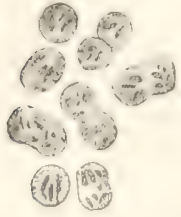

Fï. lii. ChlorophyllJörner aus dem Blatte von Funaria hygrometrica, ruhend und in Teilung. Virmp, ifl).

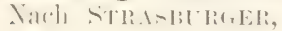
lintanishen l'raktikum reszenz, indem es in durchfallendem Lichte grün, in reflektiertem Licht blutrot aussieht. In den Chloro-

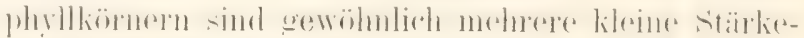

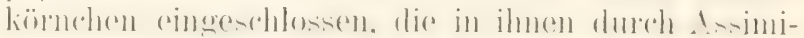

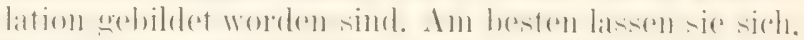

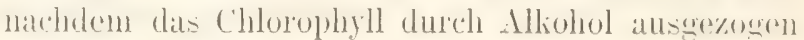
ist, durch Zusatz von Jodtinktur nachweisen.

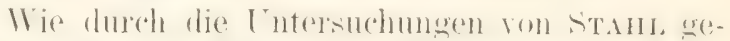

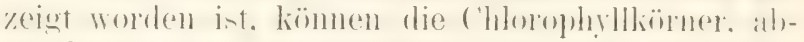

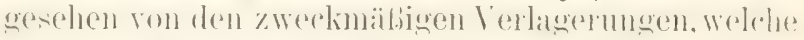

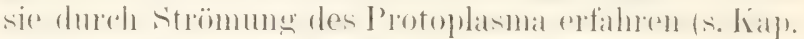
VI). anch alitiv ihre (iestalt in anffälliger Wreise nuter dem Rèiz der Lichtstrahlen veräntern. Währems sie in diffusem Tageslicht polygonale Scheiben darstellen. welche ihre Breitseite der Lichtquelle zugekehrt haben, ziehen sie sich in direktem Sonnenlicht zu kleinen liugeln oder ellipsoiden Körpern zusammen. Sie führen dadurch eine für die

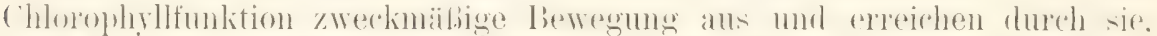
..labi sie dem Somnenlicht aine kileinere. dem diffusen Tageslicht aber eine

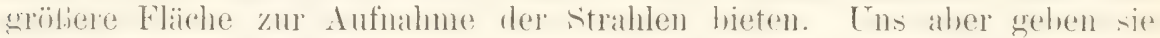
dadurch einen Einblick in den hohen Grad ihrer inneren Differenzierung, wie wir ihn durch das einfache Studimm ihrer chemischen Tätigkeit bei weitem nicht hätten gewimnen können" (DE VRIES IV 1899). Wie die Kerne, erscheinen sie in Hinblick auf ihre Vermehrung durch Teilung, im Hinblick auf ihr aktives Bewegungsvermögen und ilıe Funktion beim

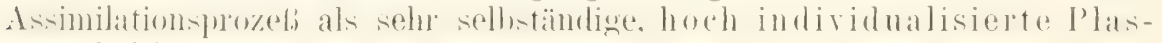
magebilde.

Endlich sind als eine besondere Abart del' Trophoplasten noch die Farbkörner zu erwähnen, auf welche namentlich die gelbe und orangerote Färbung vieler Blüten zurückzuführen ist. Sie bestehen aus einem frotoplasmativehen Substat. das meist sehr mregehuabig gestaltet ist mul

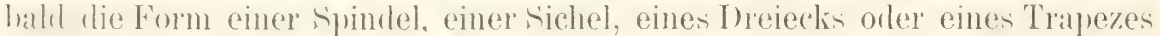
hat. In dem Substrat sind Farbstofflistalle abgelagert. Auch hier liabt sich an geeigneton Objekten die allmähliche Entstehumg der Farblärper aus farblosen Trophoplasten nachweisen. Auch hier hat Weiss spontane Bewegungen und Formveränderungen wahrgenommen.

Die liesurechung der verschiedenen Arten der Trophophasten schlieben wil ab, indem wir noch genauer auf die Struktur der Stärkekörner

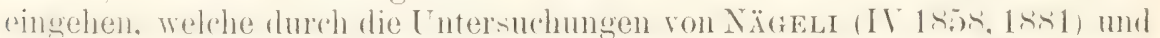

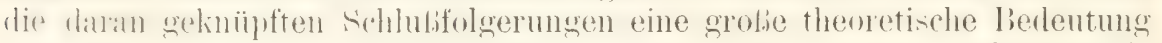
gewomnen haben. Die Stärkekörner (Fig. 47) zeigen in der Pflanzenzelle hinsichtlich ihrer Größre anBerordentliche Verschiedenheiten. Auf der einen Seite sind sie so klein, daß sie bei der stärksten Vergröberung nur als ein Punkt erscheinen, auf der andern Seite kömnen sie bis zu einem Unfang von 0,2 $\mathrm{mm}$ heranwachsen. Charakteristisch ist ihre Reaktion bej Zusatz von Jodlösungen. Je nach der Konzentration derselben nehmen sie eine hellblane bis schwarzblaue Färbung an. In warmem Wasser quellen sic beträchtlich auf und gehen beim weiteren Kochen in Kleister über. Die. Form der Stärkekörner ist bald oval, bald rundlich, bald mehr unregelmäßig. Bei stärkeren Vergröberungen ist an ihnen eine deutliche Schichtung zu erkennen, indem auf dem optischen Durchschnitt breitere, 
helle und schmilere. dunkle Streiten miteinander abwechseln. Nïrets

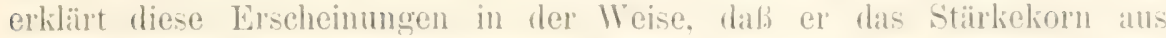
wasserïmeren und wasserreicheren Iamellen von Stïliesubstan\% \%usammen-

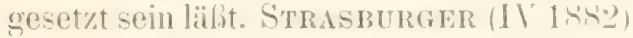
dageren dentet ..lie dunkleren linien als die hesonder's markierten MhaisionsHïchen der aufeinanderfolgenden Lamellen. die er sich mehr oder weniger rollständig gleichen lisit.."

Die Lamellen ( Fig. 47 ) sind um einen Liern angeorluet, der entwerler das Kentrum des ganzen liorns eimnimmt ( $\left.B C^{\circ}\right)$. oder. Was häutiger der Fall ist, selur exzentrisch ( 1 ) gelegen ist. Auch finden sich nicht selten Stärliekömer. bei denen um zwei ( $B C$ ) bis drei ( $D$ ) liene mehrere Lamellensysteme angeordnet sind: sie werden daher als zusammengesetzte

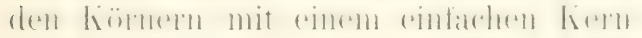

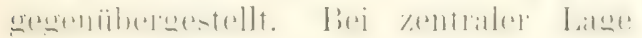
des lierns zeigen die ilm umgebenden Stärkeschichten iiberall nahezu die gleiche Dicke. Bei exzentrischer Lage dagegen
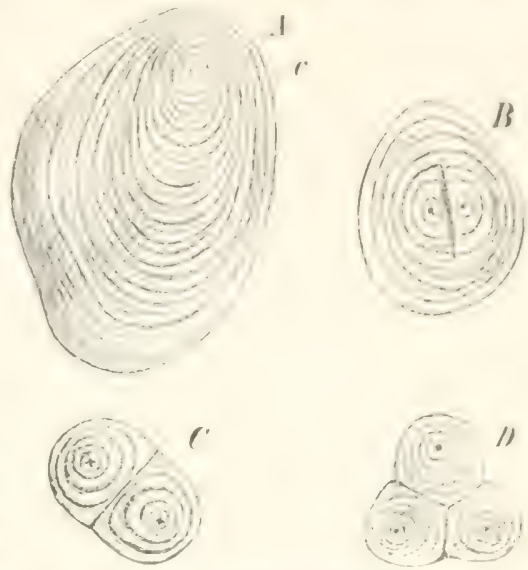

Fig. 4. Stärkekörner aus der

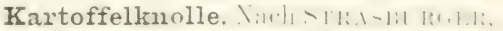

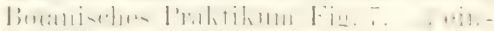

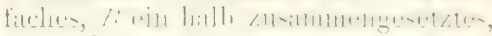
$C$ und $D$ anz zusammengeretzte Stärkekörner, c der organische liern. Vergr. 5to. gehen nur die immersten schichten kontimnierlich um ihn herum, die peripheren besitzen die gröbte Dicke an der vom Lern abgewandten Seite des Korns, verdünnen sich, je mehr sie sich dem Kern nähern. und werlen schlieblich an der Seite, nach welcher der exzentrische Kern zu liegt, so fein, daß sie von den Nachbarlamellen nicht mehr zu unterscheiden sind, oder laufen ïberhaupt ganz frei aus. In jeden Stärkekorn nimmt der Wassergehalt von der Obertläche nach dem Zentrum 7u. Der Kern ist am wasserreichsten. die oberflachlichste, an das Protoplasma angrenzende Schicht zeigt das dichteste Gefiige. Ilierauf ist die Erscheinung zurückzuführen, das bei dem Austrocknen der Stärliekörner Risse im liern und von diesem ausstrahlend nach der l'eripherie hin entstehen (Ẍ̈GELI IV 185s).

Wie schon oben erwähnt, nehmen bei den Pthanzen die Stärkekörner gewöhnlich nicht direkt im Protoplasma. sondern in besonderen Differen-

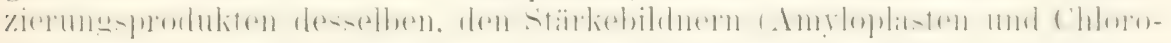
phythörpern) ilnen Ursprung. Je nachdem nun das Liorn im Innern eines solchen orler an seiner Obertläche angelegt wirl, erkiärt sich nach den Lutersuchungen von Scmmper (I I 1Sri) die oben beschriebene, verschiedenartige Schichtung. Im ersten Fall bilden sich die Stärkelamellen gleichmäbigs um den liern herum, da sie von allen Seiten her gleichmäbig von der Substanz des Stärkebildners ernihht werden. Im zweiten Fall

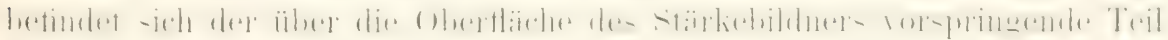
des Stärkekorns unter ungünstigeren Wachstumshedingungen. Jis wirl daher viel mehr Substanz an der dem Stärkebildner zugekehrten Fläche des Korns ausgebildet, die S̈chichten fallen hier dicker aus und verjüngen sich nach der entgegengesetzten Fläche. Infolgedessen wird der liern. un welchen die Schichten hertungelegt sind, immer mehr über die OherHäche des Stïrkebildners hinausgeschoben und nimmt dementsprechend immer mehr im Schichtensystem eine exmentrische Lage ein (Fig. 45-1). 
Daß die Stärkekörner durch Auflagerung nener Schichten an der Obertläche, also durch Apposition wachsen, geht namentlich aus einer Beobachtumg von Schimper (I I 1881) hervor. Derselbe fand Stärkekörner.

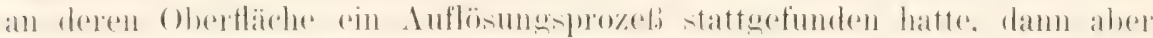
wieder unterbrochen worden war. Demn um das korrorlierte Korn hatten sich wieder frische Schichten herum gebildet.

Nach den Angaben von STRAsburger werlen Stäkekörner in einzelnen Fallen anch direkt im Protoplasma ohne Mitwirkung besonderer Stärliebildner erzeugt. In den Markstrahlzellen der Koniferen fand dieser Forscher ihre erste Anlage als winzige Körnchen in den Strängen des Plasmanetzes eingeschlossen. Wenn sie größer geworlen sind, liegen sie deutlich in Plasmataschen. deren Innenwand etwas lichthrechender ist und Mikrosomen führt.

Von den verschiedenen inneren Plasmaprodukten tierischer Zellen gehen wir erstens auf die Dotterkerne, zweitens die Mitochondrien. drittens die Nesselkapseln, viertens die faserförmigen Differenzierungen wie Bindegewebs-, Nerven- und Muskeltibrillen noch etwas näher ein.

1. Als Dotterkerne werden Bildungen bezeichnet, welche bei zahlreichen Tieraten wähend der Entwicklung im Li anftreten. unteremanter aber nicht nnerhebliche Verschiedenheiten darbieten. (O), sie daher äberall einander entsprechen und die gleiche Futstehmon und Bedentumg haben. läßt sich zurzeit nicht sicher behaupten, da unsere Kenntnis von ihnen noch in den meisten Fällen eine liickenhafte ist. Wir werden uns daher auf einige besser bekannte Beispiele beschränken.

Die interessanteste und auffälligste Form eines Dotterkerns besitzen mehrere spimenarten wie Tegeneria, hei welcher zuerst das (iebilde linti) von Wiтtich entrleclit und später zum Gegenstand sehr eingehenden Studiums von Balbiani, Henneguy, VAN DER STRICHT gemacht worden ist. Wie VAN DER STRICHT bemerkt, lassen sich in seiner Entwicklung drei Stadien auseinander halten. Auf dem ersten Stadium entwickelt sich in sehr jungen Eiesn in der ummitelbaren I'mgehung des Kemblär ohens eine hesondere, dünne Hülle einer feinkörnigen Suhstan\%, die Mantelschicht (ouche palleale) orler, wie sie WALDEYER zu nemen vorschlägt, das Dofterkernlager (couche vitteline perinucléaire) (Fig. $48 \mathrm{cv}$ ). Im zweiten Starlium (Fig. 49) ist an seiner dicksten Stelle ein kleines helleres Bläschen (nv)

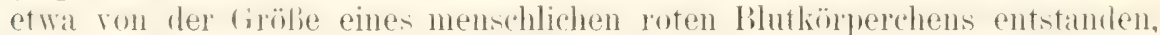
in welchem sich noch durch stärkere Färbung (z. B. durch Safranin) ein

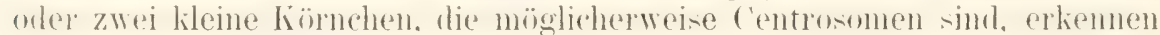
lassen. Das Bläschen ist der BALBIANIsche Dotterkern (noyan vitellin, yolk nucleus). In seiner Umgebung nimmt allmählich der Dotter eine eigentümliche Schichtung an (Fig. 50); zu innerst kommt erst eine Lage mehr homogener Substanz, darauf nach außen eine Zone mit deutlich ans-

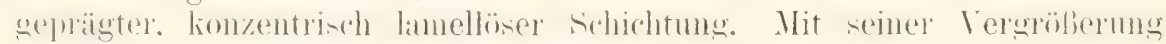
beginnt der Dotterkern die anliegende Wand das Keimbläschens $(\nu)$ zu einer Delle einzubuchten. Im dritten Stadium der Entwicklung (Fig. 51) beginnt die Mantelschicht oder das Dotterkernlager (cv) in Bruchteile zu zerfallen und im Ei sich zu verteilen (d) (starle de désagrégation). Del Dotterkern (nz) selbst bleibt noch erhalten.

VAN DER STRICHT hat auch in jumgen menschlichen Eiem ein ent-

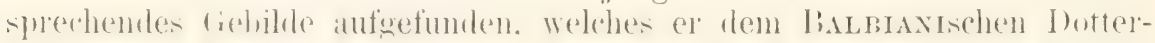
kern der Spinnen direkt vergleicht, wie er denn auch an ilum drei Entwicklungsstadien unterscheiden konnte. Im ersten Stadium (Fig. 52) finlet sich das lileine licimbliis hen nur von einem Dotterlager emgehült. 
im zweiten (Fig. 5:3) ist ein Dotterkern in-ihm entstanden, bestehend aus

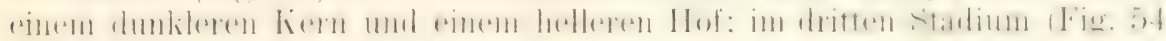
mol bo) geht wienter eine Verteilung des Dotterlagers vor sich.

Fir. 45 .

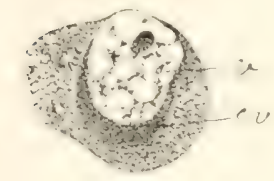

1.i... I!!

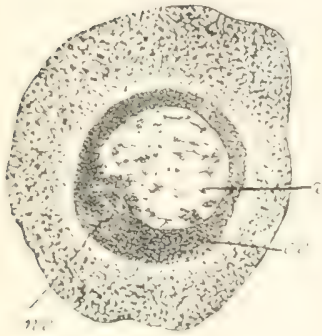

Fig. 5u.

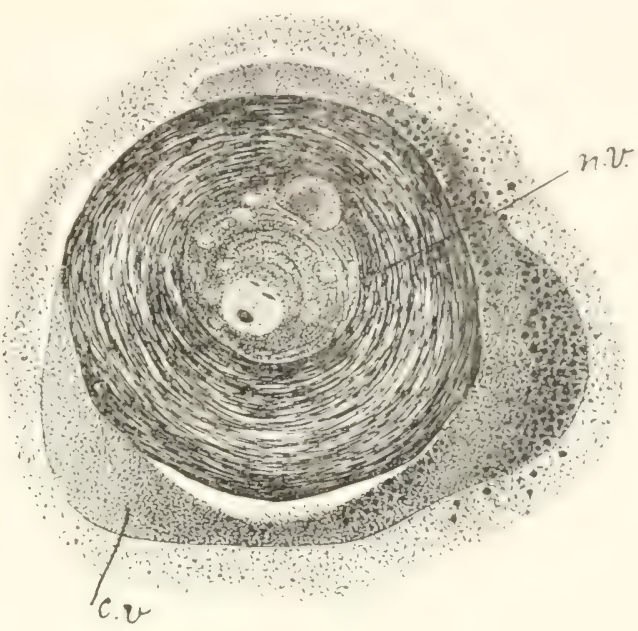

Fị. .i.

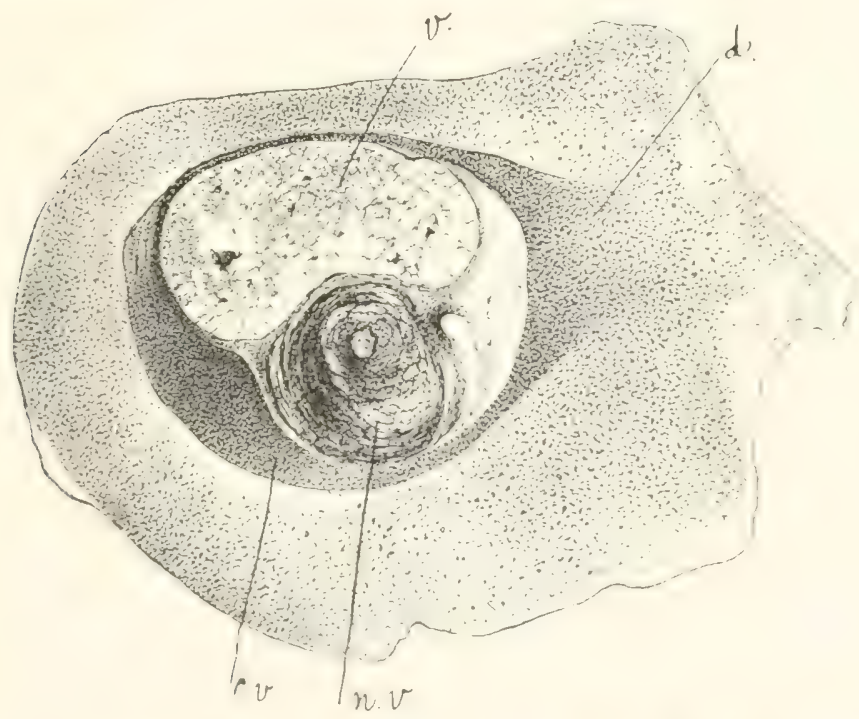

Fiq. 1S. Junges Ei von Tegeneria mit einem Keimbläschen, das von einem Dotterkemlager umgeben ist.

Fir. 4\%. Älteres Ei von Tegeneria, bei welchem in Dotterkermlager der Balbianische Dotterkern zu sehen ist.

Fị. 50. Ein älterer Dotterkern bei stärkerer Vergrößerung mit seinen Hüllen für sich allein abgebildet.

Fig. 51. Ein vorgerücktes Stadiun der Eientwichlung von Tegeneria, in welchem sich das Dotterkernlager hei d anfzulösen hegimnt. Fig. ts his 51 mach vas

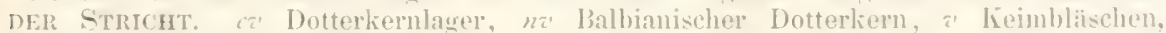
a Stelle, an der sich das Dotterkernlager aufzulüsen beginnt. 
Ton verschiedenen Forschern wie Balbiaxi, Mertexs, Julin, vaN DER STRICIT wird der Dotterkern für ein umgewandeltes Centrosom mit seiner Sphäre gedentet und ihm ein Einflub anf die Entstehung der Dotter-

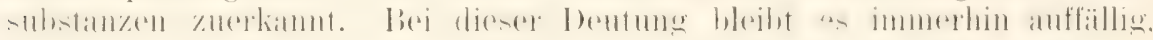
dlaß er bei nahe verwandten 'Tierarten (7. B. einigen Spinnen) ganz vermist wird. oder dab in anderen Fällen zwar eine umschriebene Dotteransammlung auftritt, aber in ihr kein besonderer Dotterkern sich hat nachweisen lassen. Letzteres ist \%. B. bei Pholcus nach der Darstellung

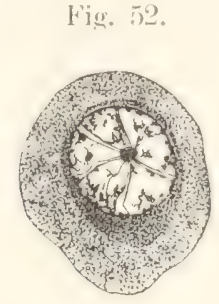

Fin. it

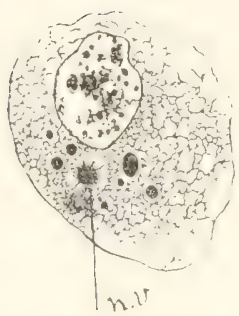

Iiv.

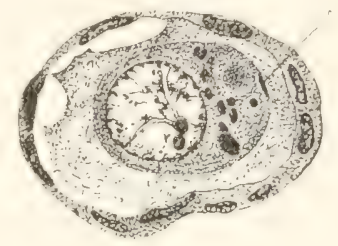

Fie. ....

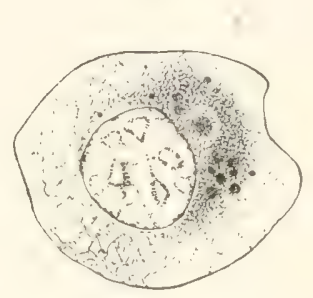

Fig. 52. Ei eines nougeborenen IMädchens, dessen Keimbläschen vom Dotterkernlag'er eingehüllt ist.

Fig. 53. Ei aus dem Eierstock einer erwachsenen Frau mit Follikelepithel. Im Dotterkernlager ist ein Dotterkern eingeschlossen.

Fig. 5t. Ei aus dem Eierstock einer erwachsenen Frau mit Dotterkem umgeben vom Dotterkernlager, das sich aufzulösen beginnt.

Fig. 55. Ei aus dem Eierstock einer erwachsenen Frau. Das Dotterlager ist aufgelöst, der Dotterkern liegt direkt im Eiplasma. nz' Dotterkern. Fig. 52_55 nach VAN DER STRICHT.

vaN BanbeKes der Fall. Hier bildet sich in der Nähe des Keimbläschens (Fig. 56 A-C) ein wurstförmiger Körper, welcher dem Dotterkernlager in den vorausgegangenen Beschreibungen vergleichbar ist. Aber es hat bis jetzt in ilm kein eigentlicher besonderer Dotterkern nachgewiesen werden können. Auch ist bei Pholcus die Bildung nur von kurzer Dauer: denn bald zerfällt sie in Bruchstücke, die überall im $\mathrm{Ei}$ verteilt werden (Fig. $5(; D)$.

Toch manche andere abweichende Befunde, auf die nicht näher eingegangen werden kann, finden sich in der Literatur zerstrent. Das ganze Liphitel der ('entrosomen in Ei, der verschiedenen Arten der Dotterlierne,

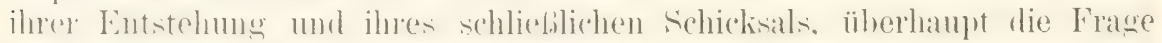
ber Entwicklung der Dotterkonkremente, bedarf noch eingehenderer mol

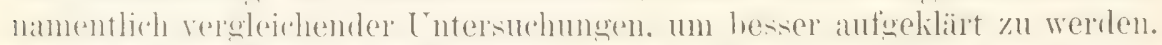
Auch anf den Eintlub des heimbläschens auf die I)otterbildung ist hierbei zil achten. 
2. Die Mitochondrien der Samenzellen (Nehenkëryer mul

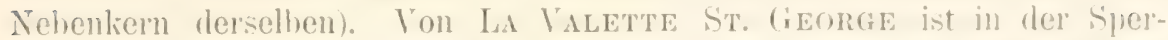
matogenese bei vielen Tierarten ein neben dem liern gelegenes riebilde entrleckt worden. welches el Nebenkörjer namte, mul fiir welches balit darauf Bütsculd den Namen Nebenkern einfülnte. Wie jetzt von

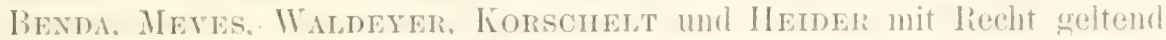
gemacht wirl. sind als Nebenkern verschiedenartige bilulungen. lie in einer Samenzelle gleichzeitig nehenemander vorkommen kïnnen. aber sich genetisch und funktionell scharf unterscheiden lassen, in der äleren lite-
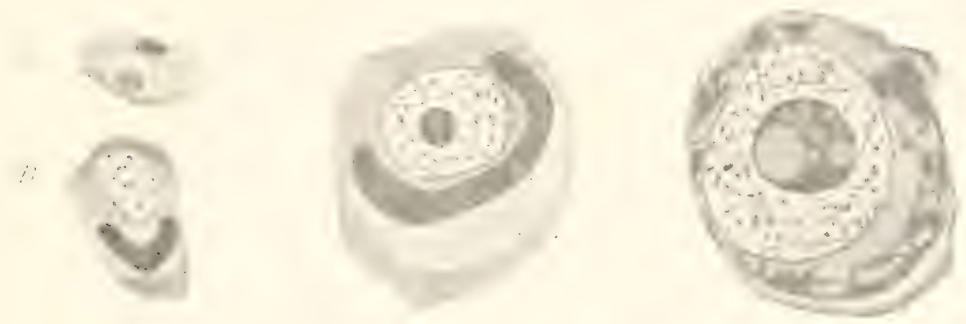

Fị. J) Verschiedene Stadien junger Eier von Pholcus phalangioides mit Dotterkern (nach VAX BAMBKK). Der Dotterkern ist dunkler gefirlit und in Fin. j(i/) in Auflösung begriffen.

ratur zusammengeworfen worklen, und man hat erst kïrzlich den Anfang gemacht, sie durch eine besondere Namengehung schärfer auseinander zu halten. Ich führe hier drei derselben auf:

Unter ihmen ist das funktionell wichtigste das Centrosom mit seiner

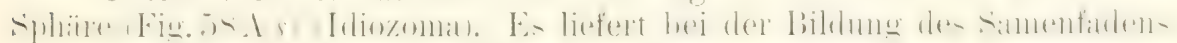
das Mittelstück, während die Substanz seiner Sphäre (das Idlozoma) in das Perforatorium orler in den Spitzenkörper (Acrosoma) ïbergeht.

Eine mehr untergeordnete Rolle spielt der Spindelrestiörper (Fig. 57 A). Er entsteht während der Teilungen der Samenmutterzelle in

Hig. ja. Gruppen voun Spermatocyten von Caloptenus italicus nach II Cistegtix. A mit den Verbindungsfasem, B mit Nebenliemen (Mitosoma).
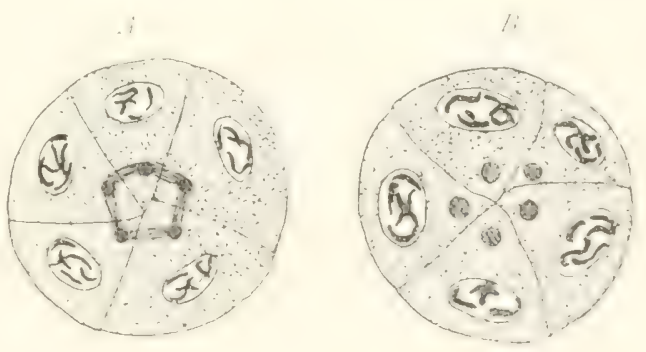

ihre Tochterzellen aus dem mittleren Teil der Spindelfasern, die sich

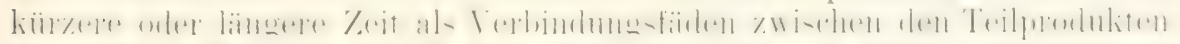

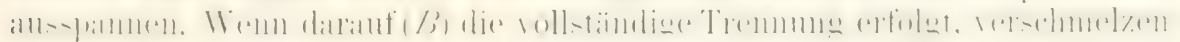
die einzelnen fasern unteremander zu einem homogenen liorn, das FuEImaxG bei der Karyolinese von gewöhnlichen Gewebsellen als Zwischenkörperchen heschrieben hat. Als Beispiel diene Fig. 57, eine (iruppe von Spermatocyten gemeinsamer Abstammung von Caloptenus. Im weiteren Verlauf scheint der Spindelrestkörper zu zerfallen und, ohne weitere Verwendung zu finden, aufgelöst zu werden. 
Von noch gröferem Interesse sind die Mitochondrien. die sich

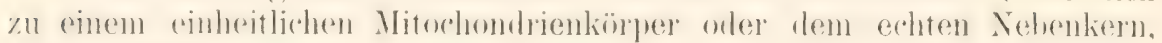
wie ihn JEves nennt, veremigen können. Sie sind von BENDA als cha-

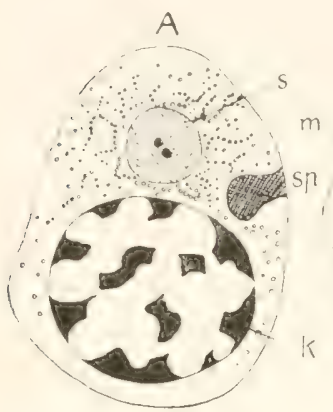

$B$

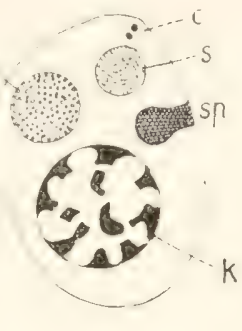

Fig. 58. Spermatogonie und Spermatide schematisiert nach Maris. A Spermatogonie. s Splä̈re mit Centrosom (Idiozom), sp Spindelrestkörper. B Spermatide. C Centrosom, s Sphäre (Idiozom), $k$ Kern, $m$ Mitochondrienkörper, sp Spindelrestkörper.

raliteristische Bentandteile simtlicher (ienerationen ron Samenzellen bei der Spermatogenese von Wirbellosen und Wirbeltieren erkannt und als
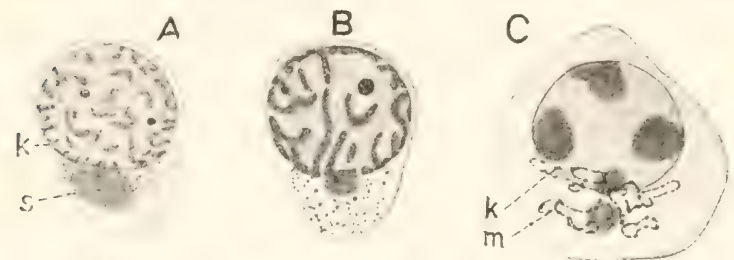

D
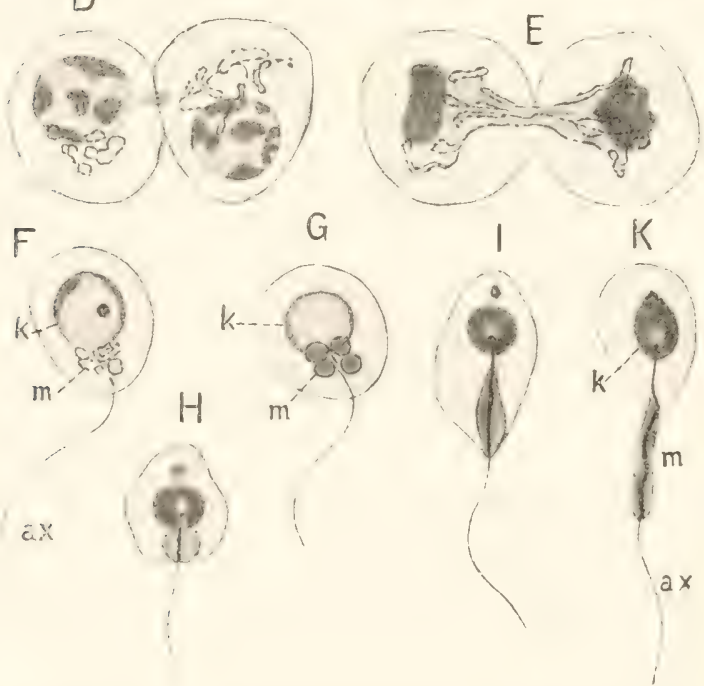

Fig. 59. A-K Spermatocyten und Spermatiden cler haarförmigen S|ermatozoen von Paludina vivipara. Nach Meves (aus líorscheit und Heider). ax Achsenfaden mit Centrosom, $k$ Kiern, $m$ Mitochondrien und Mitochondrienkörper (Nebenkern), S Sphäre (Idiozom). cyten liegen die Mitochondrien regellos zerstreut im Protoplasma neben dem Kern und seinem Centrosom mit Sphäre (Fig. õ9 A u. B). Während
Mitochondrien. in Fäden (uiros) aneinander gereilıte Körner (Xórdsıcv) beschrieben worden.

Ihre Bestandteile sind kleine Granula, die sich durch eine besondere, von BENDA ausgebildete Färbemethode gut darstellen lassen. Daß sie nicht in die Kategorie der durch Reagentien elzeugten körnigen Niederschläge gehören, findet Meves dadurch bewiesen, daß sie ..vielfach schon in der lebenden bezw. vital gefairbten Zelle sichtbar sincl". Auch die Regelmäbigkeit der Figuren. in welche sich anf einzelnen Stadien der Spermatogenese rie kleinen spricht dlafür. Als Beispiele sei auf die Samenbildung von Paludina nach MEves uml von Mus musculus mach BENDA verwiesen. In den ruhenden Spermatogonien und SpermatoGranula anordnen. 
der Vorbereitung der Spermatocyten zur 'Teilung und während derselben (C 1 . D) ordnen sie sich in Fäden (III) an, die sich zu Ringen zusammenlegen und während der 'Teilumg (E) in die Lïnge zu Schleifen (Dopy)elfïden) ausgezogen und halbiert und in die 'Tochterzellen ïbergefühnt werden. Jede Spematide besitzt schlieblich vier Ringe ( $\mathrm{r}$ und $\mathbf{G}$ m), die sich in Blasehen mmwandeln, und 11 m die Basis des zuliunftigen Achsenfadens und das Centrosom hermmlegen. Nach einiger Zeit sind sie zu einem einzigen Mitochondrienkörper (I 1 . K m) verschmolzen, welcher mit dem Samenfarlen in die Länge wächst und eine Umhällung um sein Mittelstïck liefert.

Bei Mus musculus legen sich die Mtochondrien bei der Umwandlumg der Spermatiden zum Samenfaden zusammen und sind so ebenfalls am Aufbat des Mittelstüchs beteiligt (Fig. (60). Da die Mitochondrien sich in mehreren Generationen von Samenzellen erhalten, schliekt BENDA. dab, sie Danerorgane der Zelle wie Kern und Chromosomen seien. Hiergegen erhebt HeIDENHAIN einige nicht unbegrindete Bedenken.

IInsichtlich der Rolle der Mitochondrien bei der Spermatogenese stimmen BENDA und MEves darin überein, daß von ihnen die Umhüllungen des Schwanzfadens geliefert werden, die bei den Wirbeltieren als sogenannter Spiralfaten, bei den Wirbellosen in dieser oder jener Form aufitreten.

Lin sehr kunstroll gebautes, inneres Plasmaprodukt stellen die Nesselkapseln (Fig. (61) dar, welche sich besonders bei Cölenteraten als Angriffswaffen in den über das Ektoderm verteilten Nesselzellen entwickeln. Sie bestehen aus einer ovalen Ḱapsel (a und b), die aus einer glänzenden Substanz gebildet ist und eine Öff̈nung an dem nach der' Obertïiche der Epidermis \%ugekehrten Enrle besitzt. Der Innentläche der Kapsel liegt eine feine I ammelle dicht an. die an dem Rande der Öffnung in den oft kompliziert gebauten Nesselschlauch übergeht (vergl. Fig. $(j 1 a$ u.b). In der vorliegenden Figur ist der letztere ans einem weiteren kegelfömigen Anfangsteil, der in das Imince der kiapoel eingestülpt und mit einigen kïrzeren

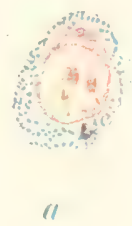

ll
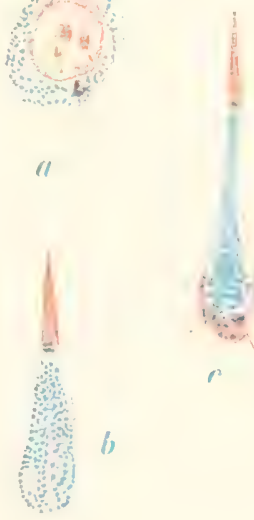

()
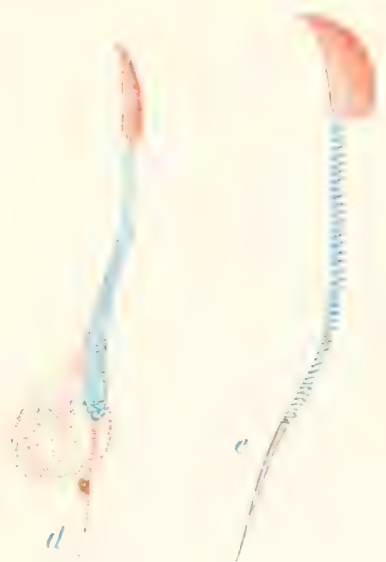

Fin. Entstelumg des Spiralfaclens am Mittelstück aus Mitochondrien. Umbildung einer Spermatide a durch die verselïedenen Entwicklungsstufen $b, c, d$ in den Samenfaden $e$ ron Mus muculus (nach BEXI)A).

\section{Wirlerhaken berleckt}

ist, und aus einem sehr langen und feinen Schlauch zusammengesetzt. Dieser geht von der Spitze des Kegels aus und ist 1 m denselben in vielen sniralen Windungen aufgerollt. Der freibleibende Bimnenraum ist 


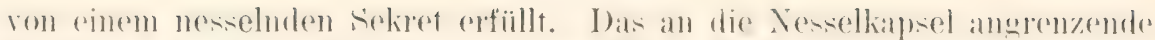

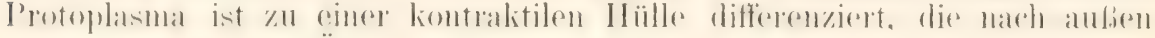
ebenfalls von einer Offinung durchbrochen ist (ScInNEIDER IV 1890).

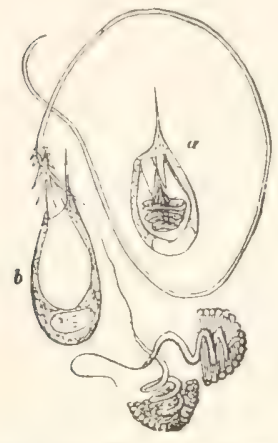

Fig. (i1. Nesselzellen der Cnidarien (alls LANG). Hertwig, Zoologie Fig. 161. a Zelle mit Cniducil und einem in der Kajsel aufgerolltell Vesicelfaden. b Vesselfaden aus der Nesselkapsel hervorgeschleudert, an der basis mit Widerhaken bewaffnet. c Klehzellen einer litenophore.

Auf der freien Oberfläche der \%elle erheht sich nahe der Kapselöfinumg ein starrer, glänzender, haarähnlicher Fortsatz, das Cnidocil. Wenn dasselle durch irgend einen Fremdkörper berührt wird, pflanzt es den Reiz auf das Protoplasma fort. Infolgedessen zieht sich die kontraktile Hülle in der Umgebung der Nesselkapsel plötzlich heftig zusammen, komprimiert sie und treibt den in ihrem Innern eingeschlossenen Schlauch nach außen hervor. wobei er wie der Finger eines Handschuhs umgestülpt wird (Fig. 6L b). Zuerst wird der erweiterte kegelförmige Anfangsteil mit den Widerhaken nach auben hervorge-sialpt, damn folgt der spiral aufgerollte, feine schlumch nach. Das nesselnde Sekret wird wahrscheinlich durch eine Öffnung im Schlauchende entleert.

Auf die Entstehung dieses auberordentlich lionplizierten Apparates wirft die Entwicklungsgeschichte Licht. Zuerst bildet sich in jungen Nesselzellen eine ovale Sekrethöhle, die sich gegen das Protoplasma durch eine feine Membran abgrenzt: damn wächst won dem freien Zellende aus ein feiner Protoplasmafortsatz in die Sekrethöhle hinein, nimmt Lage und Form des imneren Nesselapparats an und scheidet auf seiner Obertläche die zarte Schlanchmembran ab. Zuletzt differenziert sich noch die glänzende und derhere. äubere Wand der Kapsel mit der öffrnumg und um diese wierlerum dic kontralitile Hülle.

Eine besonders wichtige Gruppe innerer Plasmaprodukte bilden faserfömige Differenzierungen, welche bei der (iewehebildung eine hochwichtige Rolle spielen und je nach ihrer chemischen Beschatfenheit zu sehr verschielenen Funktionen dienen. Ich meine die Bindegewebstibrillen. die Nerventibrillen. die Muskelfibrillen.

Nach Beobachtungen von BoLL, welcher die theoretischen Ansichten von Max Schultze für die Genese des faserigen Bindegewebes zu bestätigen suchte, entstehen feinste bindegewebsfibrillen in embryonalen Zellen durch die .formative Tätigkeit des Protoplasma” aus kollagener Substanz. Je mehr allmählich die Anzahl der Fibrillen wächst und sich zu einem Fibrillenbündel zusammenschliebt. 1 m so melı nimmt das Protoplasma selbst an Masse ab und ist schlieblich nur noch in spårlichen

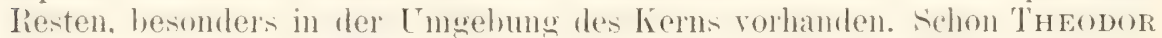
Schwaxy latte ebenfalls einen derartigen Bildumgomodus für die bindegewebsfasem in seinem berühmten Werk, den 1839 erschienenen mikro-

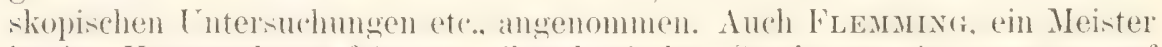
in der Lntersuchung femster mikioskopischer Strukturen. ist. gestützt auf eigene beobachtungen an dem parietalen Banchfell von Salamanderlaren, mit Entsrhedenheit für diese Lehre eingetreten. Seine limze Darstellung gebe ich mit seinen eigenen Worten wieder:

„Die jungen Bindegewebszellen sind sehr groß. Man sieht Dank ihrer Färbung (mit Safranin-Gentiana-Orange) sehr deutlich, daß die Fibrillenbündel in ihnen und ihren Amsiäuferm angelegt werden (Fig. (iz). 


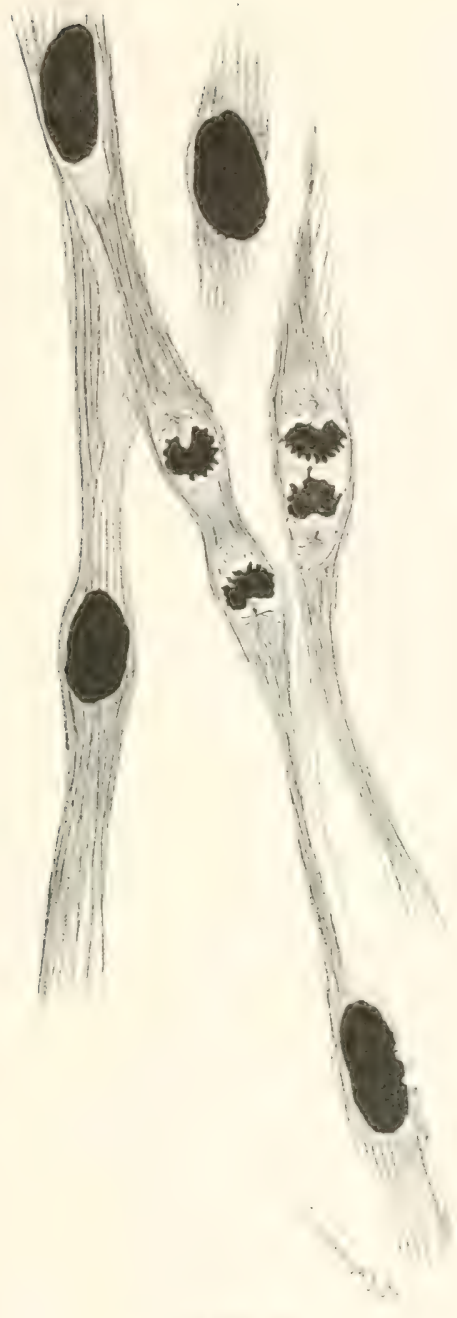

Fin. $1:-3$

Fig. 62 11. 63\% Entwicklung der Bindegewebsfibrillen im Bauchfell von Salamandexlarven (nach FIEMMTGi).

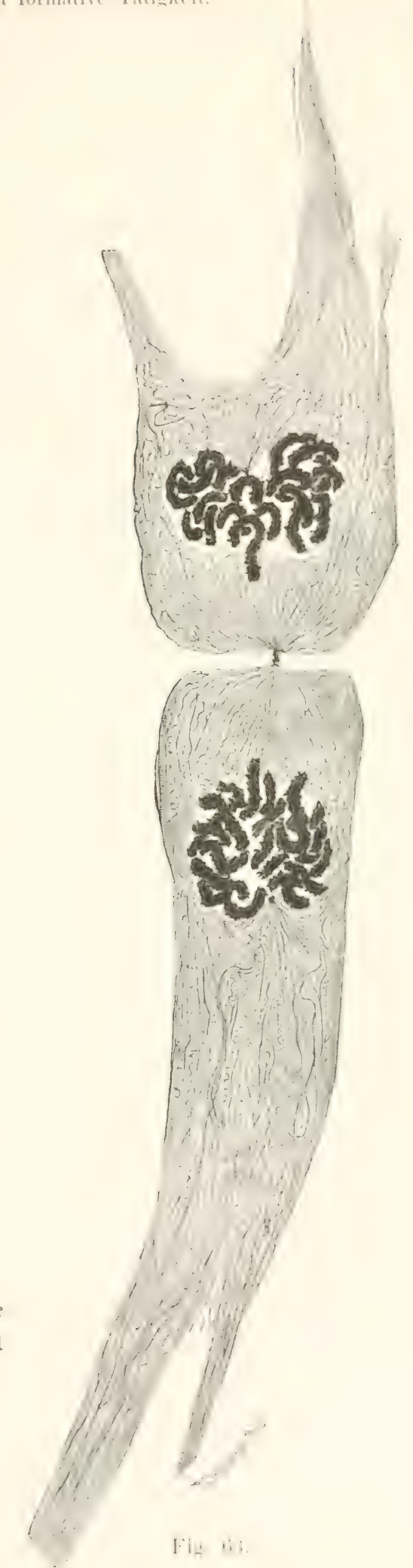


Ganz vorzüglich gut sieht man dies bei Zellen, die in Teilung stehen (Fig. 62 und 6:3). VAx BExEDEx und ich haben gefunden. dab bei Zellen, die in Mitose stehen, eine eigentümliche Verdickung des Zellkïrpers eintritt und alle fädigen Strukturen desselhen stärker färbbar werlen. Das zeigt sich hier auffillig an den jungen Fibrillen: schon bei schwächerer Vergrößerung (Fig. (j22) sehen die in Mitose stehenden Zellen dunkel und feingestreift aus, und bei stärkerer Vergröferung Ölimmersion, Fig. (93) kann man verfolgen, dah diese feinen Fibrillen bei derselben Einstellung da liegen wo die Ausläufer der Polstrahlung, also sich noch im Zellenleib selbst, wenn schon in seinem peripheren Teil, befinden. Vielfach sieht man diese Fibrillen geschlängelt (Fig. (;:3). oft ziemlich stark: dies rührt davon her, dab der Leib der Zelle während der 'Teilung sich wechselnd kontrahiert, und somit die darin enthaltenen Fibrillen bald geschlängelt, bald mehr gestreckt gefunden werden müssen. - Ich weiß, nicht, wie man solchen Bildern gegenüber noch in Zweifel bleiben

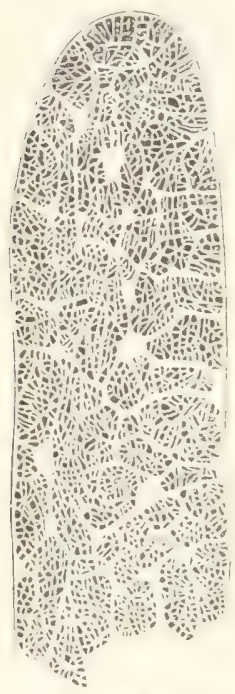

Fig. 61. Iruskelquerschnitt von Bombyx neustria mitCohnlıeimscher Felderung (nach HEII)EXHAIN). kann, daß die Fibrillen aus dem Zellprotoplasma selbst. durch eine ris formativa desselben entstehen kiomnen, unci zwar dann wohl durch eine Umprägung der Fadenstruktur dieses Protoplasmas."

Eine gleiche Genese besitzen höchstwahrscheinlich auch die leitenden Elemente der Nervenfaser und der Ganglienzelle, die Neurofibrillen, welche man in sehr passender Weise den Kupferdrähten einer T'elegraphen- oder 'Telephonleitung verglichen hat. Die ältere Lehre von Max Schultze hat in der Nenzeit ihre energischen Vertreter in Apathy und Beтнe gefunden. Wie sich durch spezifische Färbemethorlen, Behandlung mit Methylenblau, Goldchlorid etc., nachweisen läßt, ist die Neurofibrille etwas rom Protoplasma, in welches sie eingebettet ist, substanziell Verschiedenes, sie ist ein durch seine formative Tätigkeit enstandenes Produlit. ein Struliturteil, auf dessen Differenzierung die wesentliche Funktion des Nervensystems, die rasche Fortleitung eines Reizes auf größere Entfernung von einem Organ zum anderen, ron einer Zelle zur anderen beruht. Erst wenn Neurofibrillen

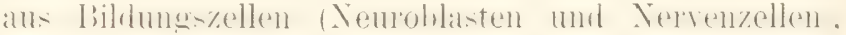

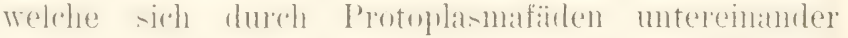
verbunden haben, gebildet worken sind, ist ein Nervensystem entstanden, aufgebaut aus Ganglienzellen und Nervenfasern. Auch hier erhalten sich Reste des Bildungsplasma zwischen den Neurofibrillen als intergranuläre Substanz, ihre Ernährung und Erhaltung vermittelnd. Wie aus Vereinigung parallel verlaufender Fibrillen Bindegewehsfasern oder Fibrillenbündel, so entstehen aus Tereingung mehr oder minder zahlreicher Nemrofibrillen stärkere oder di̊nnere Achsenzylinder, d. h. Neurofibrillenbündel.

Das wohl am allermeisten zusammengesetzte, faserfömige Bilungsprodukt des Protoplasma ist schlieflich die Muskel-oder Myofibrille.

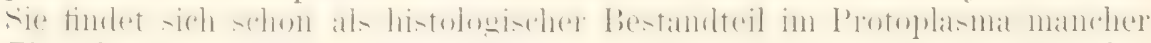
Einzelliger, zum Beispiel vieler Infusorien, namentlich aber im kontraktilen Gewebe der vielzelligen Organismen. Bei manchen Infusorien, wie Stentor, liegen unter der Pellicula in der Alveolarschicht des Körpers einzelne feine, kontraktile Fibrillen, die Myoneme oder Myoide, parallel und in 
kleinen Alständen voneinander angeordnet und rom vorderen zum hinteren Ende verlaufend. Die Myoide sind etwa 1 u dick und von ovalem Querschnitt. Üher ilnen erhehen sich, in seichten Furchen entspringend. Reihen von Flimmern. Bei den Vorticellidinen beginnen die Myoide am Peristonfeld, begeben sich von hier nach dem aboralen Pol, wo sie trichter-

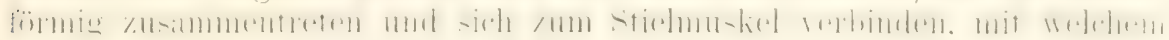
die 'Tiere an Gegenständen angeheftet sind. Der scheinbar homogene diche Faden ist demmach aus Fibrillen zusammengesetzt, die übrigens schwer sichthar zu machen sind. Fr wird nach aufen von einer zarten Stielscheide mmschlossen. von welcher er dureh einen schmalen Ramm. in dem sich die Alveolarschicht des Körpers fortsetzt, getrennt wirl. Bei den

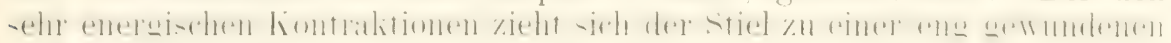
Spirale zusammen.

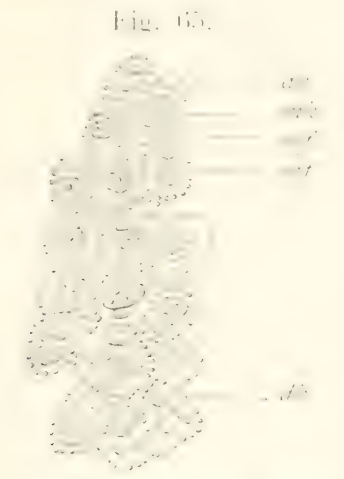

Fig. 66.

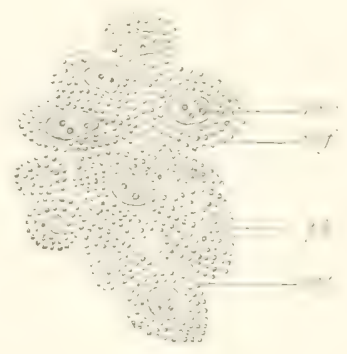

Fig. (6). Querschnitt durch die Rumpfmuskulatur einer 5 Tage alten Larve von Triton taeniatus. 500 mal vergrößert. mk IIukelkeme, mf quer durehschinittene Inskelfibrillen, de Dotterkörner.

lit. liti. Querschnitt durch die Rumpfmuskulatur einer 10 Tage alten Larve von Triton taeniatus. 50() mal rergrößert. to Mnskelprimitivüindel, mf quer durchschnittene IIuskelfibrillen, mk IIuskelkeme.

Bei den Metazoen baut sich die quergestreifte Muskelfibrille in außer-

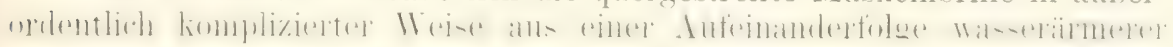
und wasserreicherer Proteinsulostanzen auf. welche man nach ilırer Lichtbrechung als anisotrope und isotrope Substanz bezeichnet hat. Iici Untersuchung junger Embryonen kam man leicht verfolgen, wie in den zylin-

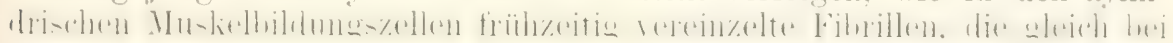
ihrem ersten Auftreten schon Querstreifung erkennen lassen. im Protoplasma an der Oberfläche ausgeschieden werlen (Fig. 65)). An Quer-

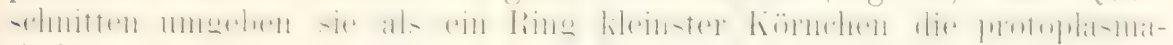
tische Achse mit ihrem Kern. Indem die Zahl der Fibrillen sich sulkzessive rermelurt (Fig. (it), tritt das Protoplasma immer melar in den Hintergrumel. bleiht in einzelnen Resten, welche die zahlreicher gewordenen Kíme einschliefon. zwischen der liontraktilen Substanz zurïck und bildet die sogenannten Muskelkörperchen.

Mit Recht hat Heidexmañ (IV 1899!, S. 116) bei Besprechung der kontraktilen Gewelse hervorgehoben, daß es sowohl heim Studium der Entwicklung der Muskelfaser, als auch beim Zerzupfen eines Muslielprimitivbïndels oder hei der Betrachtung eines Querschnittes bei stïrlister Vergröberung unmöglich sei anzugeben, ob man die feinsten. (duch Spaltung

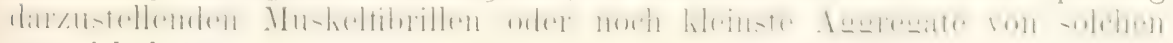
vol sich habe. 


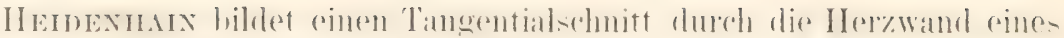
dreitägigen Entenembryos ab (Fig. 67) und bemerkt hierzu: „In der Figur findet man die ersten Fibrillen angelegt. mol shom zeigen sio eine

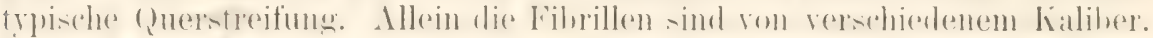

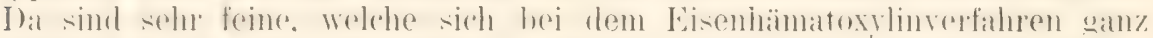

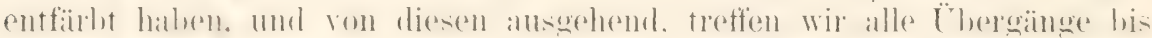

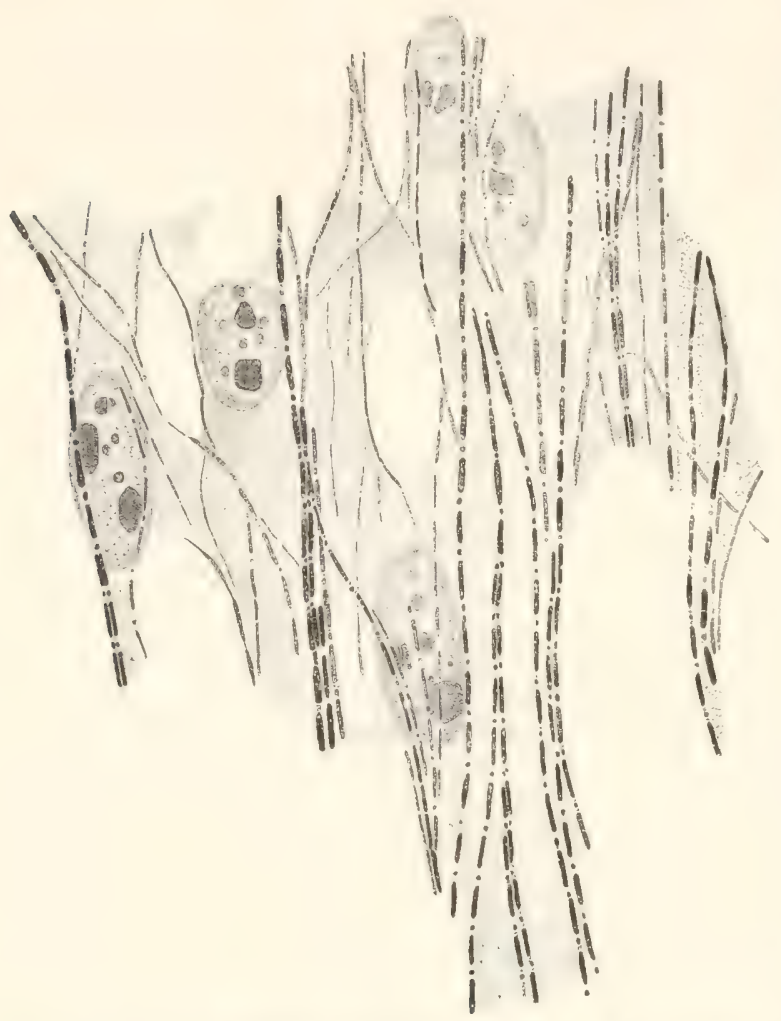

Fig. 67. Tangentialschnitt durch die Herzwand eines Entenembryos von 3 Tagen mit Muskelfibrillen nach Heidexhais. Sublimat, Eisenhämatoxylin. Vergr. 2500. zu recht groben, stark gefärbten Fibrillen, welche teils in ganzer Lünge einfach erscheinen. teils an einem Ende in mehrere Spaltfibrillen auseinanderfahren. Also ist es hier nicht möglich, genau zu bestimmen. was die zuerst erscheinenden Flementartibrillen wären." Zu demselben Ergebnis gelangt HEIDExHAIN durch das Studium ron Zupfupräparaten. Auch hier findet er eine schon 1868 gemachte Bemerkung von HeNSEN bestätigt:

Die Muskelsäulchen

lassen sich sehr leicht parallelihrer Längsachse in Fibrillen spalten, ihre Spaltbarkeit ist so grob, daß eine Grenze dafür nicht nachzuweisen ist. da die feinsten Fibrillen an Berhalb des Bereiches unseres Wahrnehmungs. vermögens liegen."

In dieselhe Verlegenheit gerät man nach HeIdeNHAIN, wenn man an feinsten, gut gefïluten ()uerschnitten durch Zuhilfenahme immer stärkerer Vergrablermen hestimmen will. weldhes der Ouershnitt der feinsten Fibrille ist. ...hehen wir uns die klemsten ()uershmittshiller näher an. so) erscheinen sie unter den mannigfachsten Formen; sie sind fast durchsehends eckigs, mitunter bandartig. häution auch am Ramdr eingelierbt. so dal. sie wie au- mehreren kleinen (Puershnittsiguren zu-immengeflosen erscheinen. Es könnte also sein, dab wir die Fibrillenquerschnitte hier noch nicht vor uns haben, wir müssen also hier zu höheren Vergrößerungen und schärfer differenzierten Präparaten fortschreiten. Wir gehen daher zu Okular Nr. 6 ibber. Es wird ersichtlich klar, dab einige der rermeintichen Fibrilenpursohnite trupuen ron solchen waren, sehen aher zurlem die foinsten Felderehen immer noch von mregelnäbigem L'mriB und mit Andentungen von Teilungen. Wir nelımen Okular Nr. \& zu Hilfe mit demselben Erfolge, wir gehen zu Nr. 12 und schließlich zu 
Nr. 18 ïber. aber wir erreichen das Ende nicht. Das mikrosko-

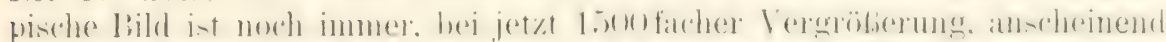

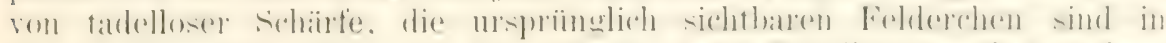

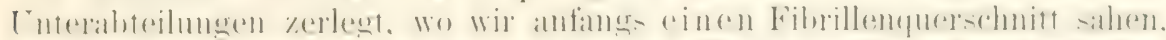

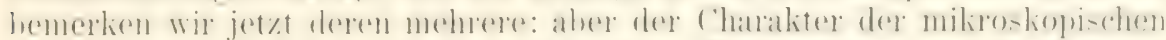

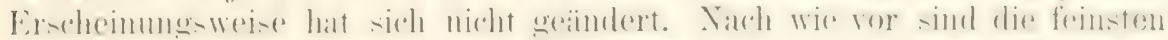

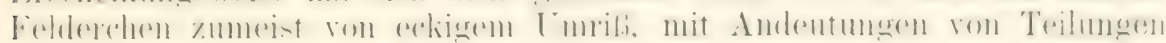
versehen und ror allen Dingen sehr verschieden im Durchmesser. Wann werden wir das Ende erreichen? Etwa damn, wenn die Optiker im

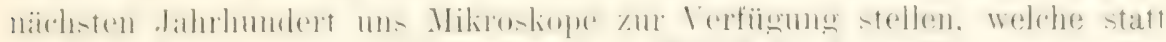

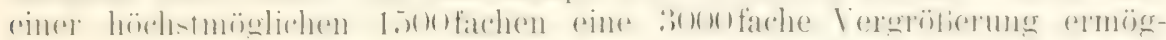
lichen: (iewis wïrden wir auch damn den .Fibrillenquerschnitt" nicht

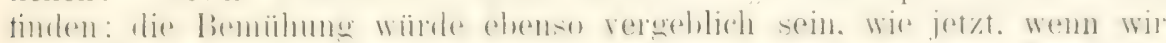
von Okular Nr. 6 zu 12 oder 18 übergehen!:6

Aus derartigen Erwägungen zieht Hembsnass den SchluB, dalo

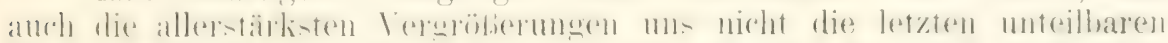

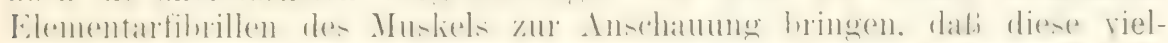

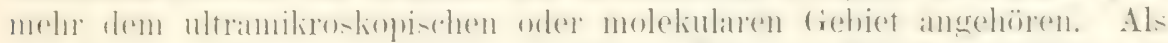

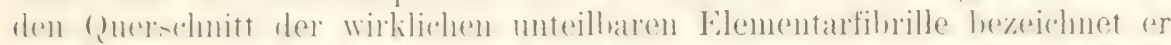

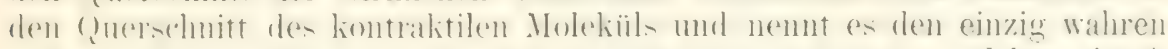

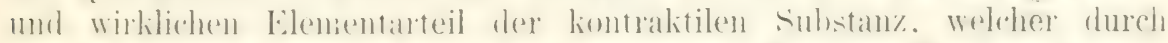

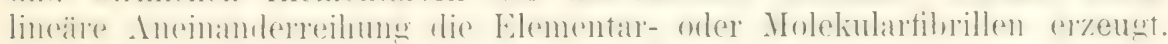
Er schließt sich hiermit der schon von FNGELMANN entwickelten Grundanschaumg vom Bau der Muskelsubstanz an, seiner Annahme von hypo-

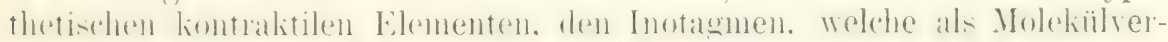
bindumgen (Thasex. FFEFFER) vorgestellt werden.

Es braucht kaum hervorgehoben zu werden, wie sich diese Annahmen

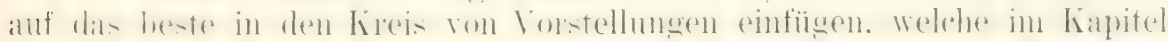
ron dem elementaren Bau der Zelle gewonnen worden sind. Wie beim

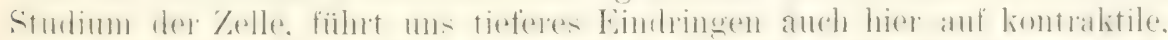

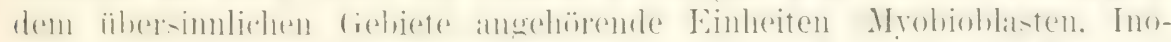
tagmen). Fïr die Elementareinheiten der Zelle hatten wir früher auf

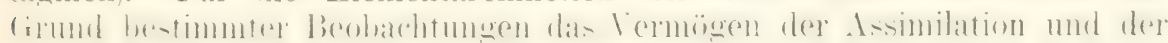
Vermelirumg durch Selbstteilung angenommen. Sollen wir auch den Ino-

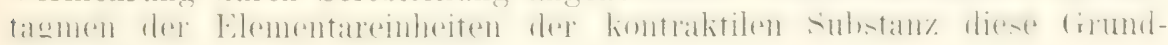
eigenschaften der lebenclen Substanz beilegen?

HrDDENHAx ist auch hierzu geneigt, worin wir uns ilm in Konsequenz der von uns vertretenen Auffassung der Organisation der lebenden

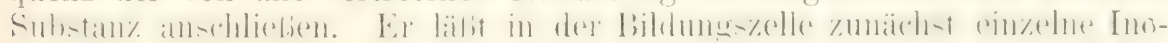
tagmenreihen gebildet werden, jecle einzelne assimilieren. in die Dicke wachsen und sich spalten usf.

Auch gewinnt er am (Yuerschnittspräiparat selbst den Eindruck, als ob die "Fibrillen" durch Spaltung sich vermehren, und er erblicht demgemäb die genetische Berleutung der Conxnensschen Felderung darin. diab die in je einem Felde. gleiehviel höherer oder niederer Ordnung: zu-

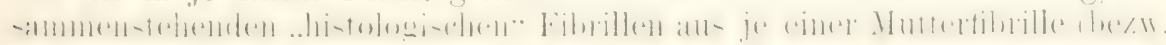
Inotagmenreile) hervorgegangen sind.

Tach der ersten Entstehung der Muskelfibrillen in der embryonalen Bildungszelle läbt HendexnAx in späterer Zeit das weitere Wachstum des Muskelprimitivbiundels nicht mehr auf Neubildung von Fibrillen in dem Rest des undifferenzierten Sarkoplasmas, sondern auf Wachstum und innerer Sonderung der schon vorhandenen beruhen. 
Ähnliche Erwägungen lassen sich auch über die Neurofibrillen und

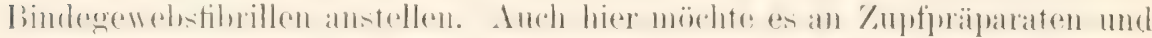
Puersehnitten momöglich sein anzugehen, oh, man im rinzolnen Fall wirklich die letzte fibrilläre 'Teileinheit vor sich hat. So nimmt denn auch

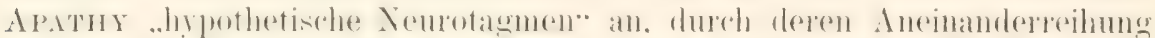

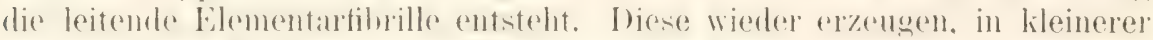

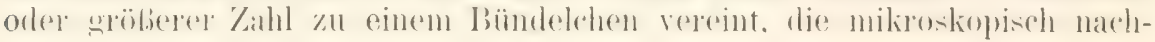
zuweisenden Primitivfibrillen (S. 508).

Zusammenfassend können wir daher in Anlehnung an HeIdeNHAIN

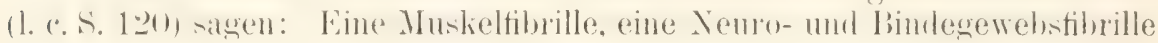
ist in jerlem einzelnen Spezialfall immer gerade das, was wir nach Maf-

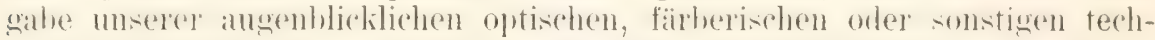
nischen Ilifsmittel als scheinhar einheithohes Fascrobilile aus der metamikroskopischen Fasertextur des Muskels, der Nerven- und der Bindegewebsfaser zu isolieren vermögen. Der Austruck „Fibrille" kann daher nur eine relative Geltung beanspruchen.

\section{b) Die äuberen Plasmaprodukte.}

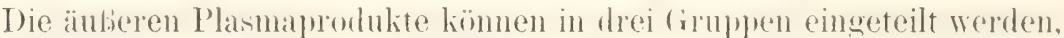
in die Zellhäute, in die cuticulargebilde und in die Interzellularubstanzen.

Zellhäute sind Absonderungen, mit denen sich der Zellkörper auf seiner ganzen obertlähe ungibt. Sie bilsen namentlich hei ptlanzlichen Zellen einen sehr wichtigen mol stark in die Angen fallenden liestandteil. während sie im Tierreich häufig fehlen oder so wenig ausgebildet sind, daß sie auch bei starken Vergrößerungen schwer zu erkennen sincl.

Im PHanzenreich besteht die Zellhaut aus einem der Stärke sehr nahe verwanlten Kohlenhybat, der Zellulose. I) Anwesenheit derselhen liabt sich meist leicht durch eine sehr charakteristische licalition fentstellen. Wenn man einen Schnitt dureh I'thanzengew ehe oder eine einzehe P'tlanzenzelle zuerst mit einer dünnen Lösung ron Jodjodkalium durchtränkt und

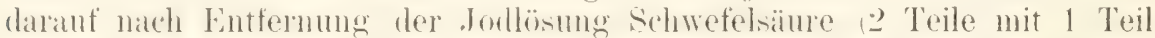
Wasser verdïnnt) zusetzt. so nehmen die Zellwände eine bald hell-, bald dunkelblaue Farbe an. Eine Zellulosereaktion erhält man auch durch Zusatz einer Chlorzinkjodlösung.

Die Membranen der Pflanzenzellen erreichen oft eine beträchtliche I)icke mul Festigkeit und lasen damm atuf dem Durchschnitt eine deutlich ausgesprochene schichtmug erkemmen. indem wie in stäliekorn streifen.

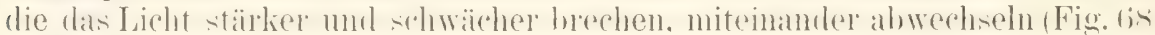
und $69 A, B)$. Aber auch bei Betrachtung ron der Fläche ist noch eine feinere strulitur häufig nachweishar. I)ie Zellhant zeigt eine feine streifung. als ob sie aus zahlreichen, parallel angeordneten Fasern zusammengesetzt sei. Dabei kreuzen sich die Fasern in entgegengesetzten Richtungen. Entwerler verlaufen die einen in der Längsrichtung, die anderen in der Querrichtung, also ringförunig um die Zelle herum, oder sie sind schräg zur Längsachse der Zelle angeorthet. Über die Beziehung dieser feinen Streifung zu den einzelnen Zelluloselamellen stehen sich die Ansichten ron Nïgeli und STrasburger gegenüber.

NÄGELI (IV 186t) läßt in jeder Lamelle beide Streifensysteme vorhanden sein: wie heim Stärkekorn sollen sowohl die Lamellen als auch die sich kreuzenden Streifen abwechselnd aus wasserärmerer und aus wasserreicherer Substanz bestehen und daher abwechselnd hell und dunkel erscheinen. Eine Lamelle ist daher parkettartig gefeldert mit quadratischrechteckigen oder mit rhombischen Feldern. „Diese zeigen ein dreifach 
verschiedenes Aussehen: sie bestehen nämlich aus dichter. weicher und mittlerer Substanz, je nachdem sie der Kireuzungsstelle zweier dichter. zweier weicher oder eines dichten und eines weichen Streifens entsprechen."

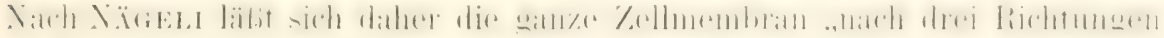
in Lamellen zerlegen, die alternierend aus wasserreicherer und wasserärmerer Substanz bestehen. und die sich in ähnlicher Weise wie die Blätterdurchgänge eines Kristalls kreuzen. Die Lamellen der einen lichtung sind die Schichten, die der beiden andern die zwei Streifensysteme. Die letzteren kömen sich fast unter jedem Winkel schneiden: beide stehen auf den Schichtenlamellen, wie es scheint, in den meisten Fällen rechtwinkligr".

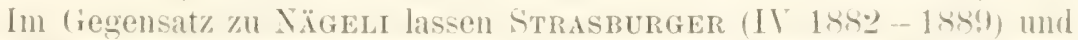
andere Botaniker, deren Angaben wohl nicht anzufechten sind, die sich

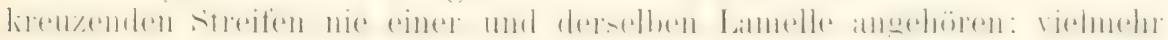
gestaltet sich nach ihnen das Verhältnis so. (laß wemn die eine Lamelle

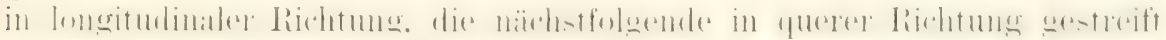
ist und so fort in wechselnder Folge. Nach STrasburger unterscheiden sich werler die einzelnen Lamellen noch die einzelnen Sitreifen durch

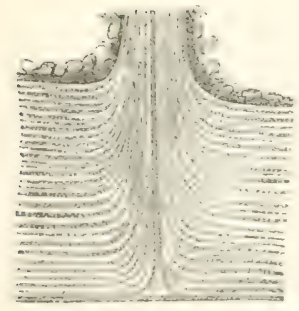

Fig. 6S.

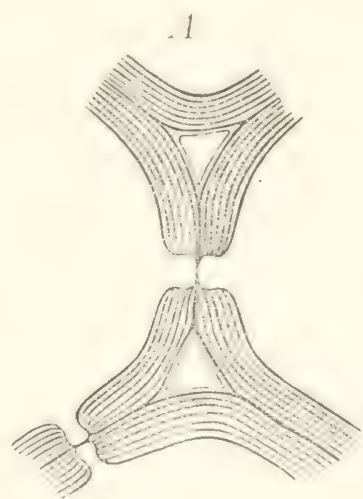

Fin. 69

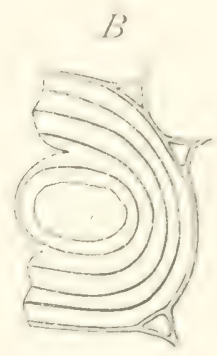

Fig. 6S. Querschnitt durch das Rhizom von Caulerpa prolifera an der Insertionsstelle eines Balkens. Nach STRASBLRGE Taf. I, Fig. I.

Fig. 69. A Teil einer iilteren Markzelle mit sechs Verdickmesschichten ron Clematis vitalba. Mach STRAsBLR(iER 'Taf. I, Fig. 13. Fig. 14 .

B Eine solche Zelle, in Schwefelsüure gequollen. Nach STraspurgar, Taf. I,

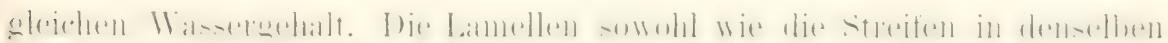

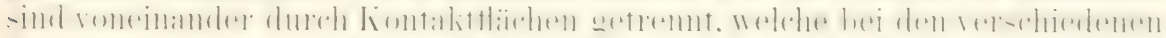

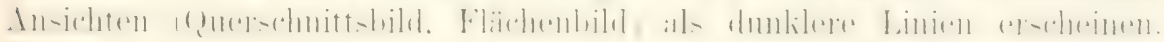
Die Anordnung ist daher im allgemeinen eine ähnliche. wie in emer IIornhaut, die sich aus Lamellen, mit gelireuzten Fasern aufbaut.

Vicht selten zeigen die Zellulosemembranen, und zwar meist an ihrer imneren Fläche feinere Skulpturen. So können Leisten nach innen vorspringen, welche entweder in einer Schraubenkinie rerlaufen oder in größerer Anzahl quer zur Längsachse der Zelle gestellt oder in melr unregelmailarger IVeise zu einem Netz untereinander verbunden sind. Auf der andern Seite kann die Zellwand an ein\%elnen Stellen, wo sie an eine Nachbaryolle stölit. verdümnt bleiben und so 'T'üpfel oder 'T'üpfellianäle erzengen (Figr. (i@) - 1). durch deren Vermittelung benachbarte Zellen Nahrungssubstanzen hesser anstauschen kïmuen. 
Auch in stofflicher Hinsicht kann die Zellwand bald nach ihrer ersten

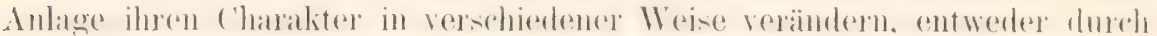
Inkrustation oder durch Verholzung oder durch Verkorkung.

Nicht selten werden in die Zellulose Kalksalze oder Kieselsäure

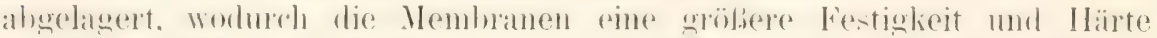

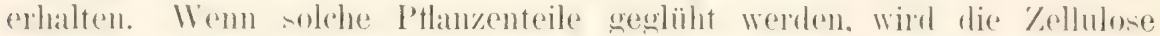

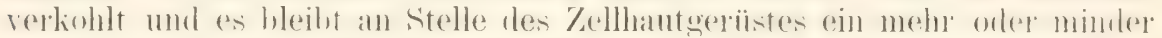
vollstänliges Kalk- orler Kieselskelett zuriock. Kalliahlagerung findet sich bei den Kalkalgen, bei Characeen, bei Cucurbitaceen, Verkieselung bei Diatomeen, bei Equisetaceen, bei Grïsern etc.

Durch die Verholzung erhalten die Zellmembranen gleichfalls eine bedeutend größere Festigkeit. Hier ist der Zellulose noch eine andere Substanz, der IIolzstoff (das Lignin und Vanillin). heigenengt. Ineredbe läbt sich durch Kalilauge orler durch ein remisch von Salpeter-änre nund chlorsaurem Kali auflösen und entfernen. worauf damn noch ein die Zellulosereaktion darbietendes Gerüst übrig bleibt.

Bei dem Prozeb der Verkorkung ist mit der Zellulose Kiorkstoft orler Suberin in geringerer oder reichlicherer Menge verbunden. Hierdurch werden weder die physikalishen Eigenshatten der Kellwand in der

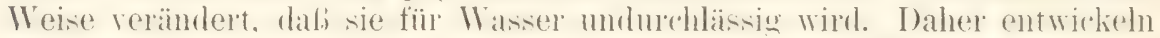
sich denn verkorlite \%ellen an der Obertlärler vieler P'flanzenorwane. Im die Wasserverdunstung zu verhüiten.

Während es bei der Verkalkung und Verkieselung auf der Hand lient. dald die lialkteilchen und die lieselteilehen durch Vermittelumg des I'rotoplasmas an Ort und stelle geschaftt und zwischen den Zelluloreteilehen ahgelagert worden sind. wohei wierler molekularen limslungen eine loolle zufallen wirl, bieten sich für das \%ustandekommen der Verholzung und der Verkorkung zwei Möglichkeiten dar. Entweder ist der Holz- und

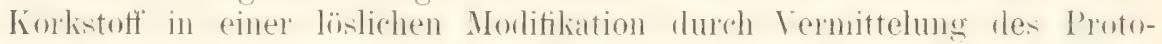
plasmas entstamblen und gleich den Kalk- mol Kienelteilchen in die Zellulosememhran in unlïslicher Morlitikation eingelagert worken. orler heile substanzen hahen sich an ()rt und stelle dureh chemische Emwambungen der Zellulose getrilatet. Es ist lies wieder eine Angelegenheit. welehe weniger der Morphologe mit seinen I'ntersuchmusmethorlen. als viehmehr der phy-

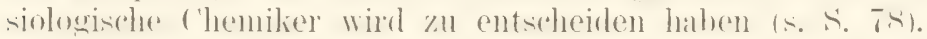

Eine viel diskutierte, sehr wichtige, aber nicht leicht zu entscheirlencle Frage ist das Wachstum der Zellhaut. Bei demselben haben wir ein Dicken- und ein Flächenwachstum zu unterscheiden. Das bei seiner Ent-

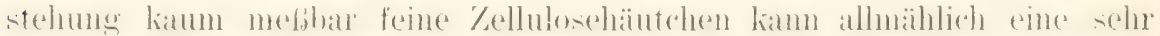
bedentende Dicke erreichen und sich hierbei aus immer zahlreicheren Lamellen zusammensetzen, deren Zahl der Dicke proportional zunimmt. Das Allerwahrscheinlichste ist, dab rom Protoplasma Schicht auf Schicht auf das zuerst abgeschiedene Häutchen neu abgelagert wird. Man nemnt dies ein Wachstum durch Apposition, im Gegensatz zu einer von

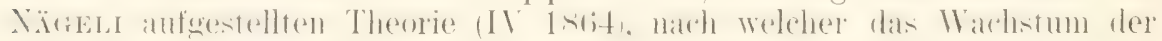
Häute durch Intussuszeption vor sich gehen soll, das heibt: durch Ein-

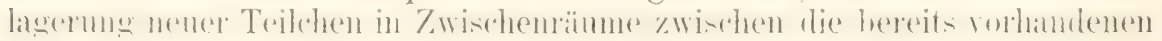
Teilchen.

Für die Appositionstheorie sprechen namentlich folgende drei Er-

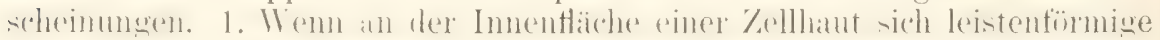
Verdickungen bilden, so werden dieselben schon ror ihrem Auftreten da-

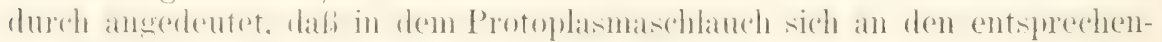

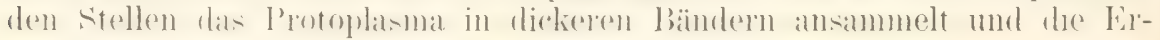




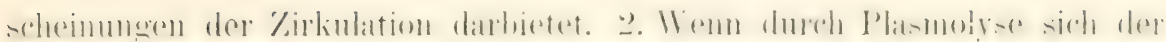

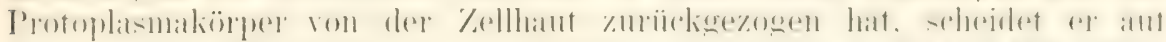

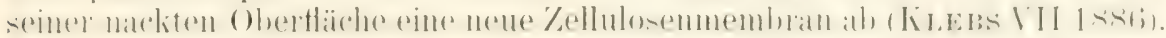
Man kamn die Plasmolyse rüickgingig machen. Der sich durch Wasser-

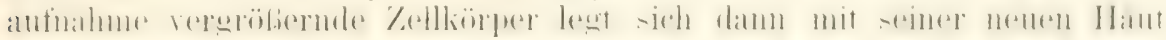
der alten wieder dicht an und verbindet sich mit ihr. :3. Bei der 'Teilung

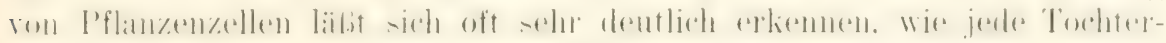
zelle sich mit emer eigenen. neuen Hïlle umgibt, so dab dann innerhalh, der alten Membran der Muter\%elle zwei neugebildete Membranen der Tochterzellen eingeschlossen sind.

Gröhere Schwierigkeiten bietet die Erklärung vom Flächenwachstum der Membran. Dasselbe könnte durch zwei verschiedene Prozesse hewirkt werlen. die entwerler allein oder miteinander kombiniert Platz greifen könnten. Eimmal kömnte die Membran sich durch Dehnung veroüliern. wie ein Gummiball. den man aufbläst. Zweitens aber könnte sie sich durch Intussuszeption, durch Aufnahme neuer Zelluloseteilchen zwischen die alten. ausilehnen.

Dafïr, dah eine Dehmung der Zellhaut stattfindet, sprechen manche Erscheinungen. Schon der früher erwähnte Turgor der Zelle ruft eine solehe hervor. Denn sowie eine Zelle der Plasmolyse ausgesetzt wird, schrumpft sie erst im ganzen unter Wasseraustritt etwas zusammen, ehe sich der Plasmaschlauch ablöst, ein Zeichen, dab sie durch imneren Druck gedehnt war. Bei manchen Algen läßst sich beobachten, daf die zuerst

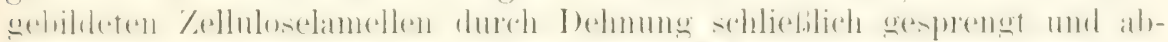

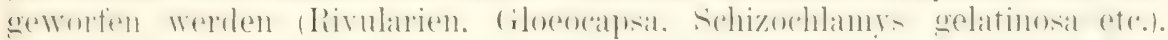
Jede Dehnumg und Verkïrzung mus mit Verlagerung der kleinsten Teilchen verbunden sein. die sich hier mehr in der Fläche, dort mehr in der

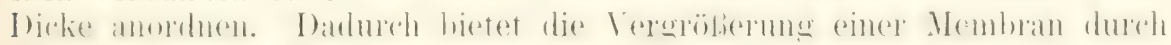

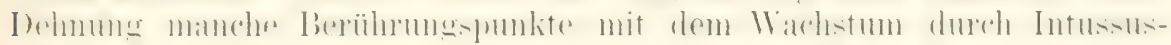

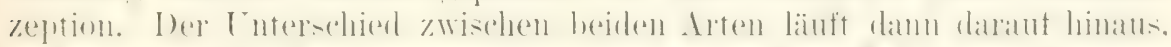

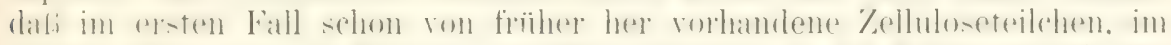

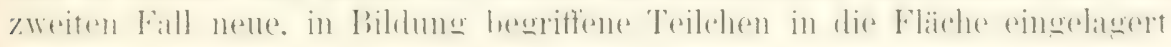
werrlen.

Das Wachstum durch Intussuszeption möchte ich num nicht, wie es

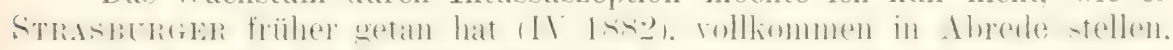

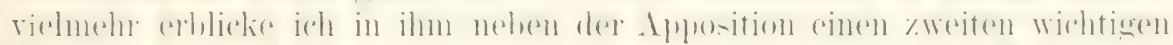

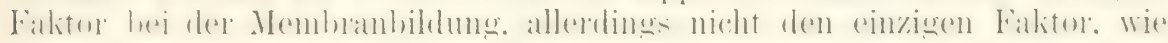
es in der 'Theorie von NïgeLI angenommen wird. Demn viele Erscheinungen des Zellenwachstums lassen sich. wie es von N̈̈GELI (IV 1855 und

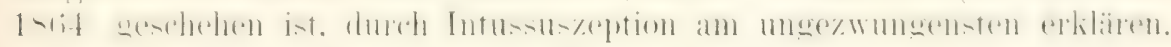
während die Appositionstheorie auf Schwierigkeiten stöbt.

Zerreifungen von Membranschichten durch Dehmung werden im ganzen doch in sehr seltenen Fällen beobachtet. 'Trotzlem vergröberm

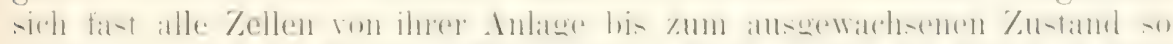

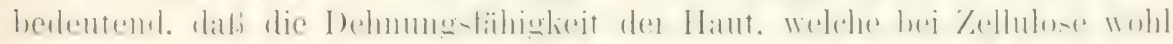

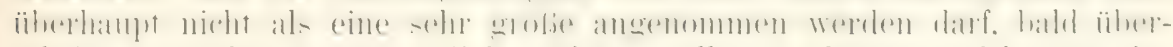
schritten werden mübte. Viele Pflanzenzellen verlängeen sich um das 100 fache und manche un mehr als das gooofache (Chara). Ferner zeigen

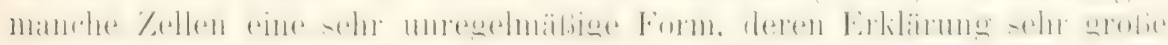
Schwierigkeiten bereiten wïrle. wenn die Zellhaut allein durch imnere I) sollte. Canlerpa. Acetabularia etc. sind, trotzdem sie einen einzigen Hohlraum enthalten, wie eine vielzellige Pflanze in Wurzeln. Stengel und 


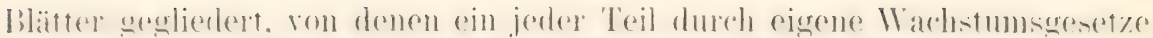

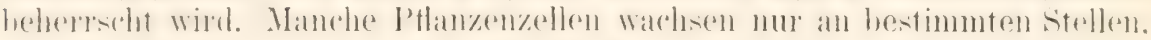
entwerler an der Spitze orler nahe der Basis orler entwickehn seitliche Ausstülpungen und Äste. Andere erfahren beim Wachstum komplizierte Drehungen, wie die Internodien der Characeen.

Endlich macht NäGELI noch für ein Wachstum durch Intussuszeption geltend, daß manche Membranen in der Fläche und Dicke berlentend zunehmen. nachlem sie durch T'eilung des Protoplasmakörpers von diesem infolge der bildung von sivezialmembranen um die Torditerzellen getremut worden sind. .Gloeocapsa und Gloeocystis treten zuerst als einfache Zellen mit dicker, gallertiger Membran auf. Die Zelle teilt sich In zwei. wovon jede wieder eine gleiche blasenförnige Membran bildet: und so geht die Einschachtelung weiter:" Die äuberste Gallertblase muf infolgedessen immer gröfer werden. Ihr Volumen betrug bei einer Art in diesen sukzessiven Entwicklungsstadien nach Berechmungen von NäGELI im Mittel $8: 30$ - 2442 - j(i15 - 10209 Kubikmikromillimeter. Bei einer anderen Art war eine Verdickung der zuerst gebildeten Gallertmembran von 10 auf be Mikromillineter, also un das rechsache eingetreten. ..Bei Apiorystis sind die birnförmigen Kolonien, die aus sehr weicher Gallerte mit eingelaserten Zellen hestehen, ron ainer dichteren Vembran unhüllt. Dienclbe nimmt mit dem Alter nicht bloß an Umfang. sondern anch an Miichtigkeit 2u: (tenn bei kleineren Kolonien ist sie blob:3 Mikromillimeter. bei den groben bis tis Mikromillimeter dick: an jenen beträgt die ohertläche etwat

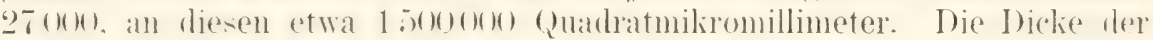
Hülle nimmt also von 1 auf 15 . der Flächeninhalt von 1 auf 56 , und der Kubikinhalt von 1 auf 83:3 zu. Von einer Apposition auf der immeren Seite dieser Inülle kann keine Rerle sein: lenn ihre innere glatte Fläche wird von den kleinen kugeligen Zellen entweder gar nicht oder nur an einzelnen wenigen Stellen berührt."

In allen diesen Fällen muf ich dem Ausspruch von NägeLI zustimmen, daß wir hier auf Unwahrscheinlichkeiten stoßen, wenn wir das

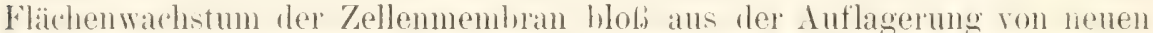
Schichen erklären wollen, während die oben namhaft genachten ..Erscheinungen fïnderung der fiestalt und Ridhtung, ungleiches Wachstum dep Teile. Drehung) -ich dureh Intussus\%eption auf die einfachste mol leichteste Art erklären lasssen. Alles hängt davon ab, daß die neuen 'Teilchen zwishen die schon vorhandenen an hestimmten stellen, in hestimmter Menere und in bestimmter Richtung eingelagert werden."

Der Prozeß der Intussuszeption selbst ist rollends nicht in Abrede zu stellen, wo Kalli- oder Kieselsalze in rie Membran abgelagert sind, da dies meist er'st nachträglich und oft nur in den oberflächlichen Schichten

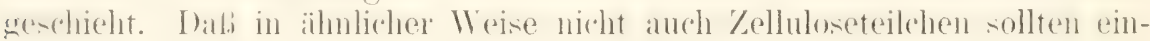
gelagert werden können, wïrde als ummöglich nur damn erwiesen sein, wenn gezeigt wäre, daf Zellulose in der 'Tat nur durch direkte Umwandlung von Protoplasmaschichten gebildet wirl. Dies ist aber doch nichts weniger als erwiesen. und wird der Pflanzenanatom es wahrscheinlich durch mikrosko-

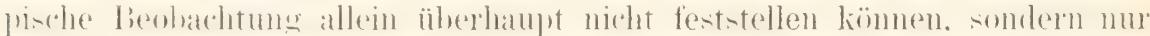

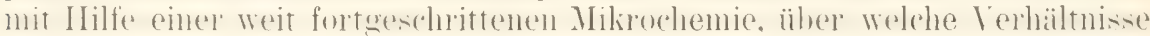
dlas auf Seite $77-78$. Gesagte zu vergleichen ist. Bei Berïcksichtigung der dort gegebenen Darlegungen wird man überhaupt finden, daf bei gewisen lindingungen der Zellulosebildung zwischen Iplosition und Intu-suszeption gar nicht der schroffe Gegensatz besteht. wie er von mancher Seite herausgekehrt wird. 
Cuticulargebilde sind hautartige Absonderungen, mit welchen sich eine Zelle anstatt allseitig nur einseitig an ihrer nach anden gekehrten Oherfliche bedeckt. In Tierreich sind häufig die Zellen. welche die Ober-

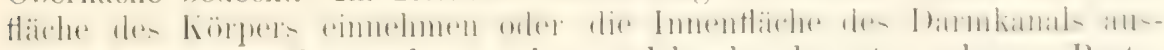
kleiden, mit einer Cuticula versehen, welche das darunter gelegene P'roto-

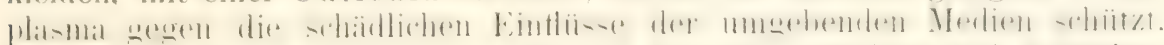

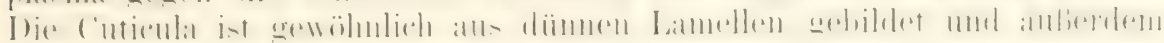
von feinen, parallel verlaufenden Poren durchsetzt. in welche rom darunter grelegenen Protoplasma zarte Fädchen endringen. Als Cuticulargebilde

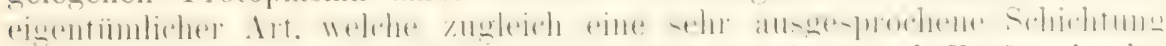
anfweisen. sind auch die Anfenglieder der Stäbchen und Zapten in der Netzhant anzufiihren.
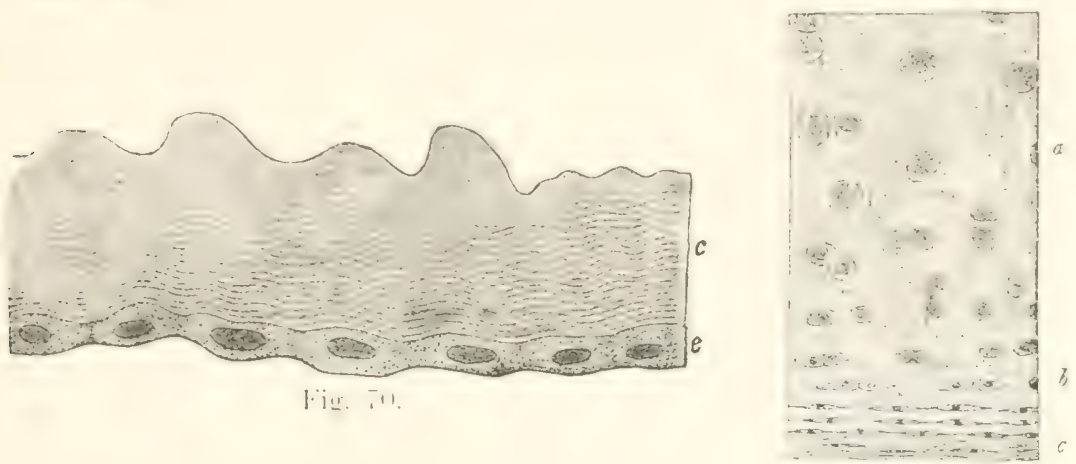

liig. Tl

fï. - Ep Eithel mit Cuticula einer Blattwespe. (Cimbex coromatus.) In R. Hentiris Zoologie i Cuticula. e Epithel.

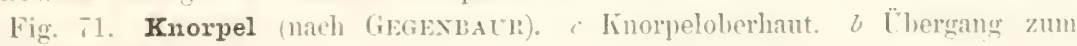
typischen Kinorpel a.

Cuticulare Abscheidungen menhluanartig angeordneter Zellen ver-

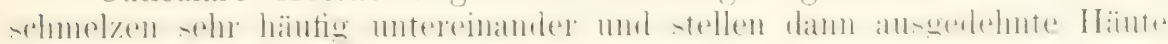

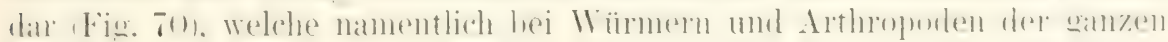

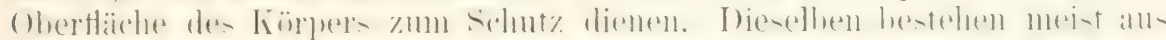

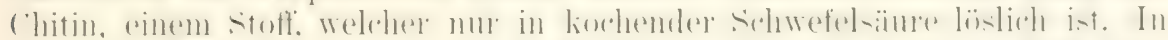

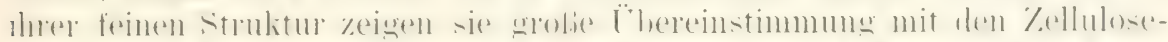

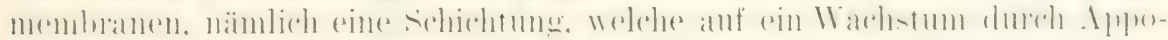
sition neuer Lamellen an der Innenseite der zuerst gebildeten hinweist. Zeitweise werden die alten Chitinhåute gesprengt und abgeworfen. nachdem sich unter ihnen eine jüngere, weichere Haut zum Ersat\% gehildet hat, ein Vorgang, der als Häutung bezeichnet wird. Zur Verstarkmug der Chitinhaut können Kallisalze auf dem Wege der Intussuszeption in sie abgelagert werden.

Interzellubarsubstanzen endlich entstehen, wem eine wröbere Anzahl von Zellen an ihrer ganzen Obertlïche feste Stotfe ansscheidet. ihre Abscheidungsprodulite sich aber nicht. wie die Zellmembranen. getrennt erhalten, sondern untereinander zu einer zusammenhängenden Masse verschmelzen. so dafs man nicht erkennen liann. was von der einen. was von der anderen Zelle abstammt (Fig. 71). Die fiewebe mit Interzellularsul)stanzen sind daher nicht in einzelne Zellen, wie ein Stïck Ptanzengewebe, zerlegbar. In der kontinuierlichen Grumbsubstanz. welche ans sehn' versehiedenen chenischen Stoffen Mucin. Chomdrin. (Hutin. Ossein. Elastin. Tunicin. Chitin etc.) bestehen kamn. welche ferner bald homogen. hald 
faserig answelıt, sind kleine Jöhlen vorhanden, in welehen die Protoplasmakïrper eingeschlossen sind. Da der die Höhle umgebende bezirk der Interzellularsubstan\% am meisten unter dem Fintlub des in ihr gelegenen

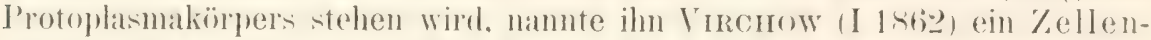
territorium. Dasselbe ist aber in der Natur, wie gesagt, von den Nachbarterritorien nicht abgegrenzt.

\section{Literatur IV.}

1) Balbiani, Sur lorisine des cellules du follicule et du norau ritellin de l'opuf ches les Geophile's. Zool. Anzeiger. 1883. Ni. 155, 156.

2) van Bambeke, Ch., Contributions it l'histoire de la constitution de l'oenf. Elimination d'éléments nuclémes dans l'oenf ovarien de Scorpaena. Arch. d. brol. T. XIIJ. 1893.

3) Baumann, Über den ron O. Löra zend Th. Liokornu erbrachten Nachareis won der chemischen Uisache des Lebens. Pflügers Archiz. 'Ba. IIIX. I882.

4) Benda, C., Die Mitochondriafärbung and andere Methoden aur Untersuchung der Zellsubstanzen. Ter/2, d. anat. Gesellsch. XV. Yers. in Bonn 100r.

i) Derselbe, Die Mitochondria. Merkel-Bonnets Ergegnisse. Ba. XII. I002. 1003.

(i) Bemard, Claude, Lecons sur les phénomenes de la vie commme anx animanx et anx. vigétunx. 1. Aufl. I878. 2. Aufl. 1885.

7) Bunge, Lehrbuch der physiologischen nud pathologischen Chenie. Leipaig I889.

i) Ehrlich, Über die Methulenblanreaktion der lebenden Nervensubstans. Biologisches Zentralblatt. Bd. ITI. 1887 .

(1) Engelmann, Wene Methode aur Untersuchung der Sanerstoffansscheidung pflanzlicher und tierischer Organismen. Botanische Zeitung. I88I.

10) Derselbe, Über den faserigen Baze der kontraktilen Substanzen ete. Pflügers Archiz. lit. T.1\%: ISist

11) Haeckel, Die Rirdiolarien. 1862

12) Heidenhain, MI., Beiträge sur Aufklämung des reahren llesens der fascrförmigen Differensikmingen. Anat. Anzeiger. Bd. XTT. I899.

1:i) Derselbe, Über die Zentralkapseln und Psezdochromosomen in den Samensellen ron I'rotens, soavie jüber ihr lerhältnis zu den litiozomen. Chondromiten und Archoplersmaschleifen. Anat. Anzeiger. Bd. XVIII. 1900.

14 Derselbe, Struktur der kontraktilen Materic. (Dic sogenannien Intersellularbräcken). Merkel-Bonnets Erecbnisse. Bd. X. I900. I90I.

1.) Heidenhain, R., Physiologic der Absonderungszorgängre. Hondbuch der Physiologie Bd. T. $788 \%$.

lii) Hennegny, Le corps vitellin de Babiani dans l'oenf des tertébrés. Journ. de l'anat. ct d. l. phys. Année XXIX. 1893.

1.) Hertwig, Oscar u. Richard, Experimentelle Studien am tierischen Ei ror, acührond und nach der Befruchtung. I890.

14) Hertwig, Richard, Der Organismus der Radiolarien. 1879.

1!) Derselbe, Eireife und Befruchtung. Handbuch der wroleich. u, experiment. Entieiklungslehre d. Hirbeltiere von O. Hertieig. IQ03.

(1) Hess, Untersuchungen sur Phagocvtenlehre. Virchon's Archiz. Bd. CTX. I887.

¿l L Langhans, Beobachtungen n̈ber Resorption der Extrarasate and Pigmentbildung in denselben. Iirchon's Archiv. Bd. XLIX. 1870.

.).) Löw $u$. Bokomy, Die chemische Ursache des Lebens. Mïnchen 1881 .

-:i) Marchand, Über die Bildungsteeise der Riesenzellen um Fremdkörper. Virchozis Archiv. Bd. XCIII. 1883.

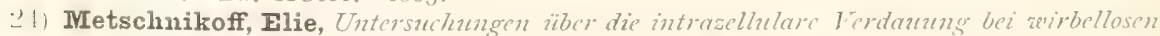
Tieren. Arbeiten ales zoologischen lnstituts in Wien. Ba. 1: Heft 2. I88.4.

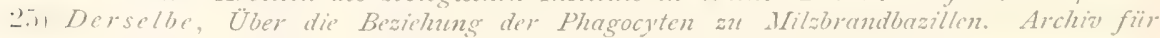
patholog: Anatomic u. Physiologic. BA. XCVI थ. XCVII. 1884.

¿fil Derselbe. Über den Kampf der Zellen gegen Erysipelkokken. Ein Beitrag aur Phagocrtenlehre. Archiz $f$. patholog. Anatomie 2 . Physiologie. Bd. CVII. 1887.

$\because$ - Derselbe, Über den Phagocytenkampf bei Rückfalltyphus. Tirchoa's Archiz'. Bat. CIX. 1887.

בhi Derselbe, Lesons sur la pathologie comparie de l'inflammation. 1802.

:!), Derselbe, Reactions phagacytaires. Verceniging secties z'oor IVectenschappelijken Arbeid. Antsterdam 1007. 


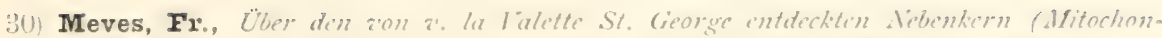

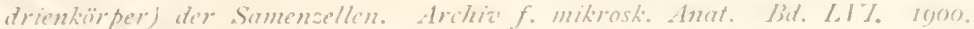

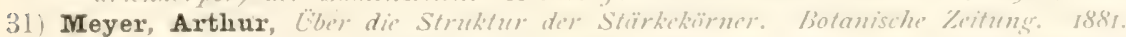

39) Derselbe, Ubere Krystalloide der Trophoplasten und ïber die Chromoplesten der Insinspermen. Biotumische Keilnene. ISE3.

3i) Derselbe, Das Chlorophullkorn in chemischer, morpholorischer und biologischer liesichume. Levipair 1883

34) Nägeli, 1) Primordialschlunch. 2) Diesmose der Pllansenselle. PHansenpleysiologische L'nlersuchumen. 1855.

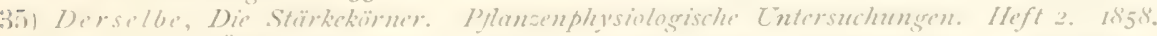

3(i) I) erselbe. Über den inneren lian der zeretabilisihen Zellenmembran. Sitzungsher. der bavristhen Akademie. Bit. I 21.11 .1864$.

\$3) Derselbe. 'Therie der Ciömus. 1879.

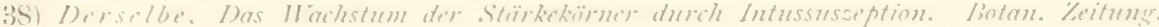
ISitis.

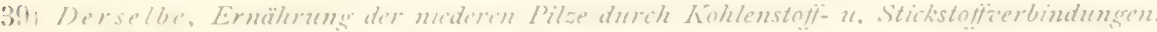

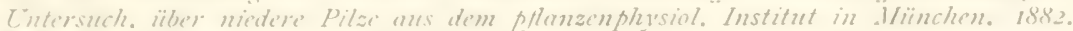

40) Pfeffer, W., Pflanzenplussiologic: Issis.

41) Derselbe, Über intramolekular Atmung. Ëntersuchnngen ans dem botan. Institut zll Tï̈bingen. Bd. I. 1885.

42) Dersilbe, Über Aufnalme a'on Inilinfarben in lebende Zellen. Untersuchunere ans dem boten. Institut an Tïbineen. Bd. II. 1886.

43) Derselbe, 1) Über Aufnohme und Ausgabe ungelüster Kürper. 2) Zur lienntuis der Plasmulant und der lakuolen nebst lemerkungen äber den Aggregataustand des I'retoplasmas u. äber osmotische lorgänge. Abhandl. d. Mathemat. phy'sik. Kilasse

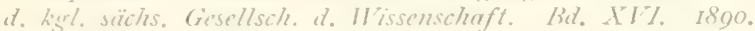

It Pflüger, ¿bur die physiolos. Terbrenmes in den lebendigen Organismen. Archiz f. Phy siologie. BA. I. 1875 .

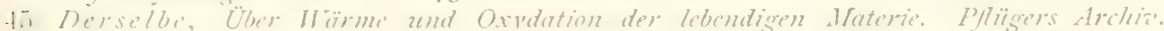
Bid. $17 / 1 / 1.7878$.

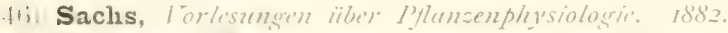

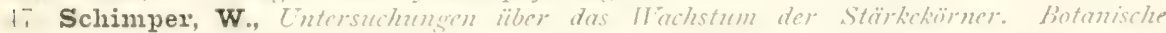
Keituns: $188 \%$.

it Derselbe, Über de Entricklung der Chlorophyllkörner und Farbkörper. Fotunische Zitung 1883.

14t Schmitz, Fr., Die Chromatophoren der Algens. Tergleichende Untersuch. niber Iiant und Entaicklung der Chlorophyllkörper nud der analogen Farbstoffiörper der allgen. Benm 1882 .

-il) Schneider, Camillo, Histologie von Ifydra fusca mit besonderer Berbickichtigung ates

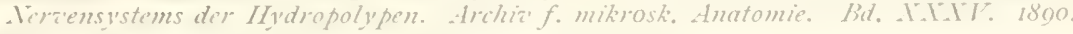

il) Schützenberger, Dic Gïmngserscheinangen. 1876.

-i-) Schultze, Max, Ein heisburer Objektisch und seine Teraendung bei Cuntersuchungen. des Bhates. Archia f. mikrosk. Anatomie. Bal. I. 1865.

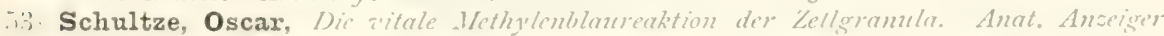
I88\%. p. $68 \%$.

15) Strasburger, ¿̈ber den Ban und das W Wachstum der Zellhänte. Jena lis82.

7.) Derselbe, Das botanische P'raktikum. 2. Aufl. 1887.

iti) Derselbe, Über alas If achstum iegrtabilischer Zellhänte. Histoiogische Beiträge? lleft 2. I880.

it) van der Stricht, Contribution is l'atude du noyan aitellin de bulbimi dans l'oencite we la femme. Terhandl. d. anat. Gesellsch. in hiel 1808, p. 128.

ii de Vries, Hugo, Cintersuchungen äber die mechanischen Crsachen der Zellstreckung $15 \%$ \%.

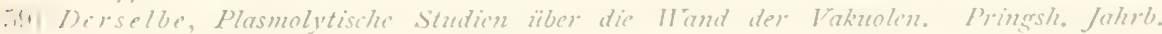
f. wissinsch. Jiotanik. Ba. I\% I885.

fin Dirselbe, Intrazellulare Pansenesis. Jene 1880.

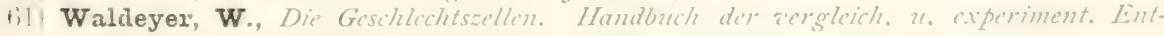

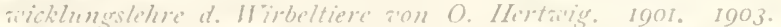

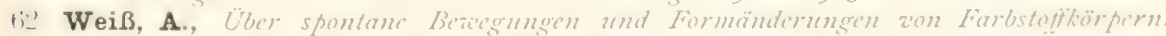

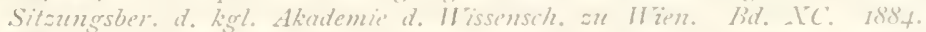

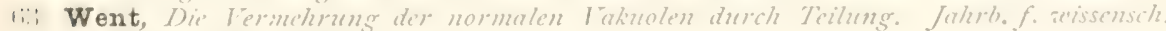

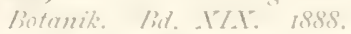

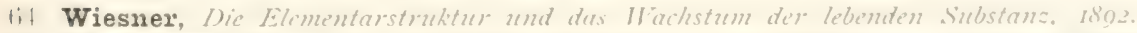

ii. Wortmann, Jul., C̈ber die lieziehungen der intramolekularen u. nomalen Atmuns

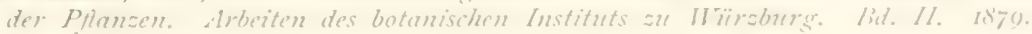


FÜNFTES RAPITEL.

\section{Die Bewegungserscheinungen.}

Eine der am meisten sichtbaren Lebensäußerungen der Organismen ist ilne Fähokeit, liewegungen auszuführen und dabei die änberen Formen des Kärpers oft in der auffälligsten Weise zu verändern. Diese Fähigkeit wohnt
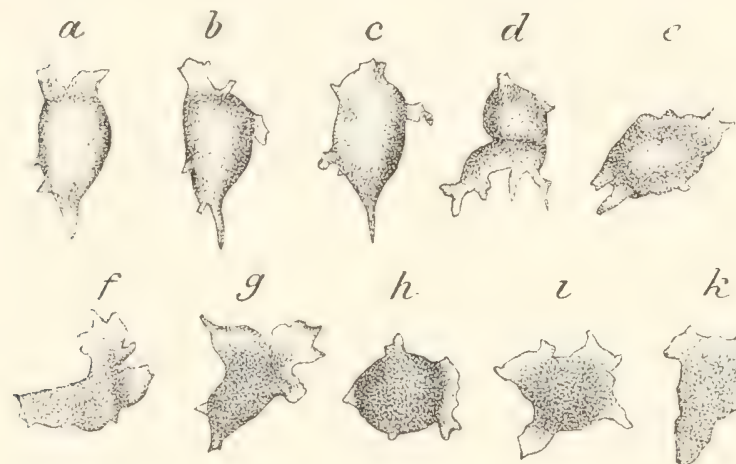

h
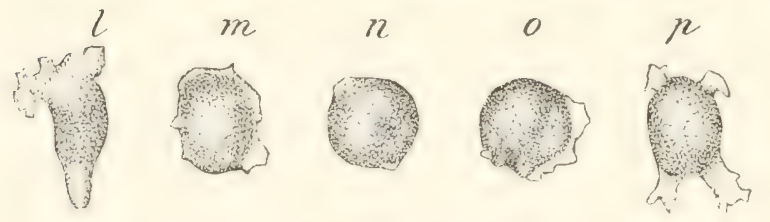

Fig. 72. Ein weißes Blutkörperchen des Frosches, welches unter dem Einfluf steigender (bis $m$ ) und wieder

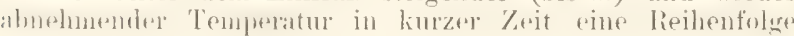
$(a-p)$ wechselnder Formen durchläuft. Nach ExGELMAxN. schon dem Protoplasma der Zelle inne und kann sich in sehr verschiedener Weise betätigen.

Wir unterscheiden hier: 1. Die eigentliche Protoplasmabewegung, 2. die Flimmer- und Geißelbewegung, 3. die Bewegung der pulsierenden $\mathrm{Va}$ kuolen, 4. die liewegungen und Formveränderungen, welche Zellkörper passiv erfahren.

AuBer diesen vier Arten gibt es noch einige besondere Bewegungsphänomene, rlie in späteren Abschnitten zweckmäßigerbesprochen werlen. Z. B. die Empfangnishïgel. die an der Eizelle infolge der Befrnchtumg entstehen. die sitrahlenfiguren, die in der Umgebung des in das Ei eingedrungenen Samenfadens

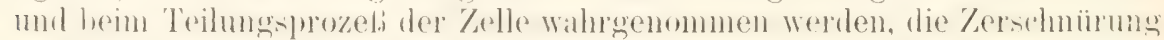
des Zellkörpers in zwei odler mehrere Stücke bei der T'eilung.

\section{Die Protoplasmabewegung.}

Obwohl ron jedem Protoplasma wahrscheinlich Bewegungen ausgefülırt werden können, so sind dieselben doch meist wegen ihrer außerordentlichen Lang-ambeit für unsere jetzigen Erkemntuismittel nicht wahrnehmbar; es sind immer nur vereinzelte Objekte im Ptlanzen- und Tierreich, welche sich zum Studium und zur Demonstration des Phänomens 


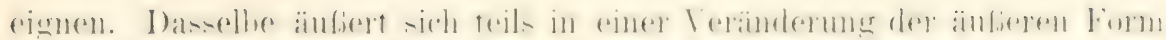

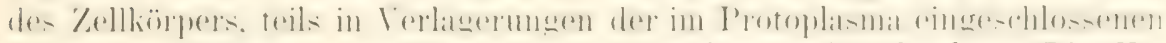
Teile. des Zellkerns. der Körner und Körnchen und Vakuolen. Die Erscheinungen fallen etwas verschieden aus, je nachdem es sich um Be-

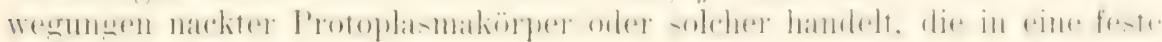
Membran eingeschlossen sind.

\section{a) Bewegungen nackter Protoplasmakörper.}

Kleine einzellige Organismen. Weibe Blut- und Lymphliörperchen. Bindegewebsellen usw. fühnen Bewegungen aus. welche man nach den Amöben, die das Schauspiel am schönsten darbieten, als amöboide bezeichnet. Wenn man ein weibes Blut-oder Lymphliörperchen des Frosches (Fig. 72) unter geeigneten Bedingungen. z. B. bei etwas höherer

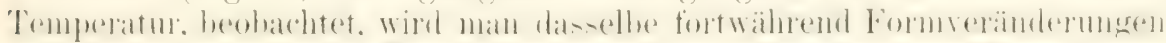

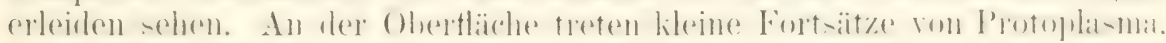
die Scheinfïljchen oder Pseudoporlien, nach aulien hervol: meist bestehen sie zuerst aus hyalinem Protoplasma, in welches nach einiger Zeit Kömerplasma nachströmt. Dadurch vergrößaern sich die Füßschen. breiten sich aus und können damn an ihrer OberHäche wieder neue kleinere Füßichen hervortreiben. Oder sie werden auch durch 7urïcktliefen des Protoplasmas schwächer und schließlich ganz eingezogen, während sich an einer anderen Stelle des Körpers neue Fortsätze bilden. Wie auf diese Art ein und dasselbe Blutkörperchen fortwährend seine äußeren línturen verändert, zeigt uns Figur 72, in welcher die Bewegungen in 15 aufeimanderfolgenden Stadien zur Darstellung gebracht sind. Durch Ausstrecken und Einziehen ihrer Pseudopodien fïhren die kleinen Protoplasmakörper Ortsrerändrungen aus und bewegen sich auf unterliegenden fiegenstïnden. an deren Obertläche sie anhaften, mit einer mikroskopisch mekbaren Geschwindigkeit kriechend

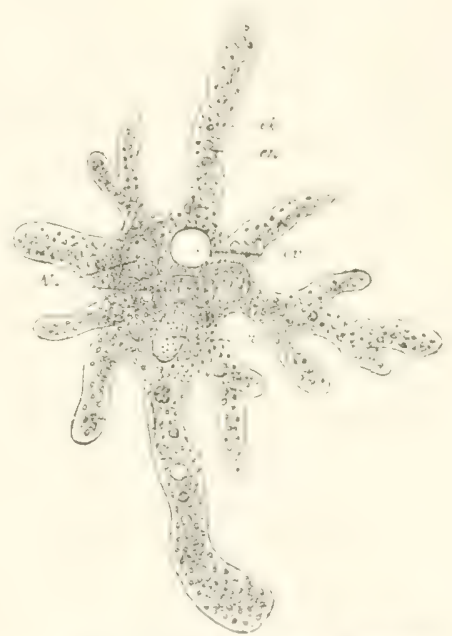

Fig. 73. Amöba proteus.

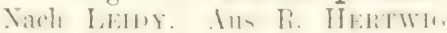
Fig. 16. "Kern, cr kontraktile Valimole, I Xahrumbslyallm, , . liömerplasma, ek Hautplasma.

fort. Amöben. kömnen in einer Minute eine Wegstrecke von 1/? mm zuriicklegen.

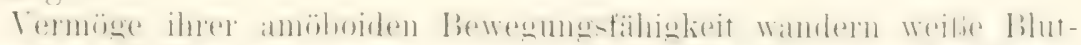

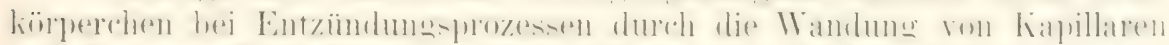

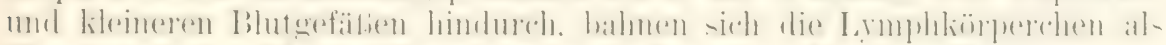

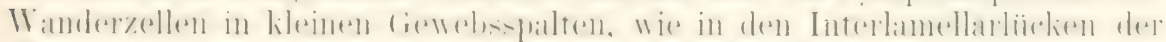
Hormhaut, ihren Weg. wobei sie nicht unerhebliche Widerstände äber-

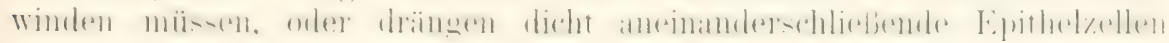
auseinander und gelangen so an die Oberthäche von Epithelmembranen.

Mit am lebhaftesten erfolgt das Ausstrecken und Einziehen der Pseudopodien bei einer kleinen Amöbe (Fig. 73), welche schon Roesed. yoN Rosenmof 1755 beschrieben und wegen ilues lehluaften formenwechsels den kleinen Proteus genamnt hat. 
Einen etwas abweichenden Anblick bietet uns die Protoplasma-

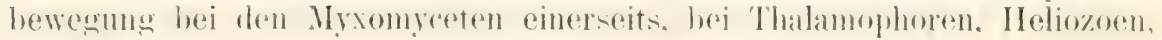
Radiolarien andererseits dar.

Um von Myxomyceten, deren Plasmodien sich bei einigen Arten.

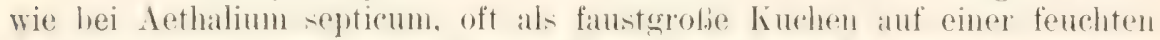
E'nterlage anshreiten, ein zur lieohachtung geeignetes Präparat zu erhalten. verfährt man am besten so, dlaß man an den Rand eines Plasmodiums

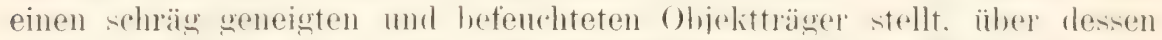
nasse ()hertlärhe man durch eine besondere Vorrichtung Wasser langsam herabrimmen lälot. I)ie Plasmodien des Aethaliums haben die Eigenschaft. sich dem Wasserstrome entgegen zu hewegen Rheotropismus): sie liriechen durch Austrecken zahlreicher Pseurloporlien auf der henetzten Cilastläche in die Höhe und breiten sich. indem sich henachbarte P'seukpodien durch (querïste verhinden, zu einem feinen, duchsichtigen Netzwerk aus (Fig. Tt.

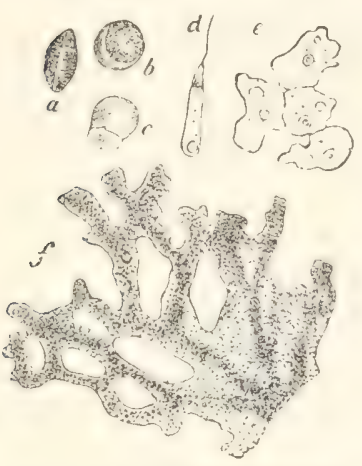

Fig. 74. Chondrioderma difforme. Nach STRASBURGER. f'T'eil eines älteren Plasmodiums, a trockene Spore, $b$ dieselbe im Wasser quellend, $c$ Spore mit austretendem Inhalt, $d$ Zoospore, $e$ aus Unwandlung der Zoo-

spore hervorgegangene

Amöben, die sich zum Plasmodium zu vereinen anfangen. (Bei d und $e$ Kern u. kontraktile Vakuolen zu sehen). einzelnen Stellen eine verschiedene sein und kann sich auch allmählich ändern; sie kann so groß sein. daß man bei starker Vèrgrößerung den vorbeieilenden fiomchen kaum mit dem Auge folgen kian, kamn aber auch so langsam werden, dald ein Körnchen kaum semen (Ort zu verändern scheint.

Die zweite Art der Bewegung besteht in einer Formveränderung der einzelnen Fïrlen und des sanzen Yetzwerkis. Wie hei einer Amöhe werlen hie und da neue Fortsätze bald ausgestreckt, bald wieder eingezogen; wie dort wölbt sich erst eine homogene Plasmamasse als Höcker hervor, damn folgt das hïrnerplasma nach. und sieht es hier zuweilen aus. als werte die Körpermasse, wenn die Strömung eine recht lebhafte ist, mit Gewalt in das sich neubildente Zweigende hineingepredit. Luf diese IVeise liann sich das I'lismodium. einer Amöhe gleich. auf einer L'nterlage nach einer lostimmten Richtmmg liriechend forthewegen. In einem Rambe. welchem 
die Könerströme vorwiegend zutließen. werden nene Fortsätze hervor-

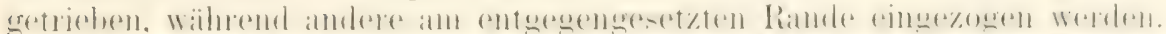

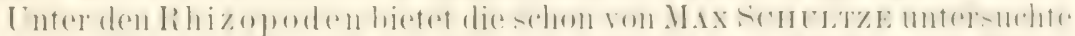

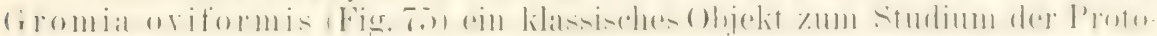
plasmabewegung. Von dem aus (ler Kapsel herausgetretenen Protoplasma entspringen, wenn der kleine Organismus nicht gestört worden ist, sehr zahlreiche, lange und feine Fäden. die sich in radiärer Richtumg wie Strahlen nach allen Seiten im Wasser ausbreiten. hie und da Seitenäste abgeben und zuweilen auch durch solche netzförmig untereinander verbunden werden. Anch die feinsten Protoplasmafäichen zeigen Bewegung. Bei starker Vergrößerung sieht man, wie M. Schultze (I 18693$)$ treffend beschreibt. .ein Gleiten, ein Fließen der in die Fadensubstanz eingebetteten Körnchen“. ...Mit größerer oder geringerer Schnelligkeit ziehen sie in dem Farlen entwerler dem peripherischen Ende desselben zu oder in umgekehrter Richtumg. oft sogar selbst an den dünnsten Fäden in beiden Richtungen zugleich. Körnchen, die sich begegnen, zielren entweder einfach aneinander vorbei orler bewegen sich umeinander. bis nach einer kleinen Pause beide ihre urspuriungliche Richtung fortsetzen orler eins das andere mit sich nimmt. Nicht alle Körnchen eines Fatlens bewegen sich mit gleicher Schnelligkeit, so daf oft eins das andere iiberholt oder an dem langsameren in seiner Bewegung stockt. .. Viele laufen oftenbar an der äuliersten Obertlïche der räirlen. über welehe man sie deutlich herrorragen sieht. Oft bemerkt man auch grölere Substanzklümpchen wie spindelförmige Anschivellungen oder seitliche Anftreibungen eines

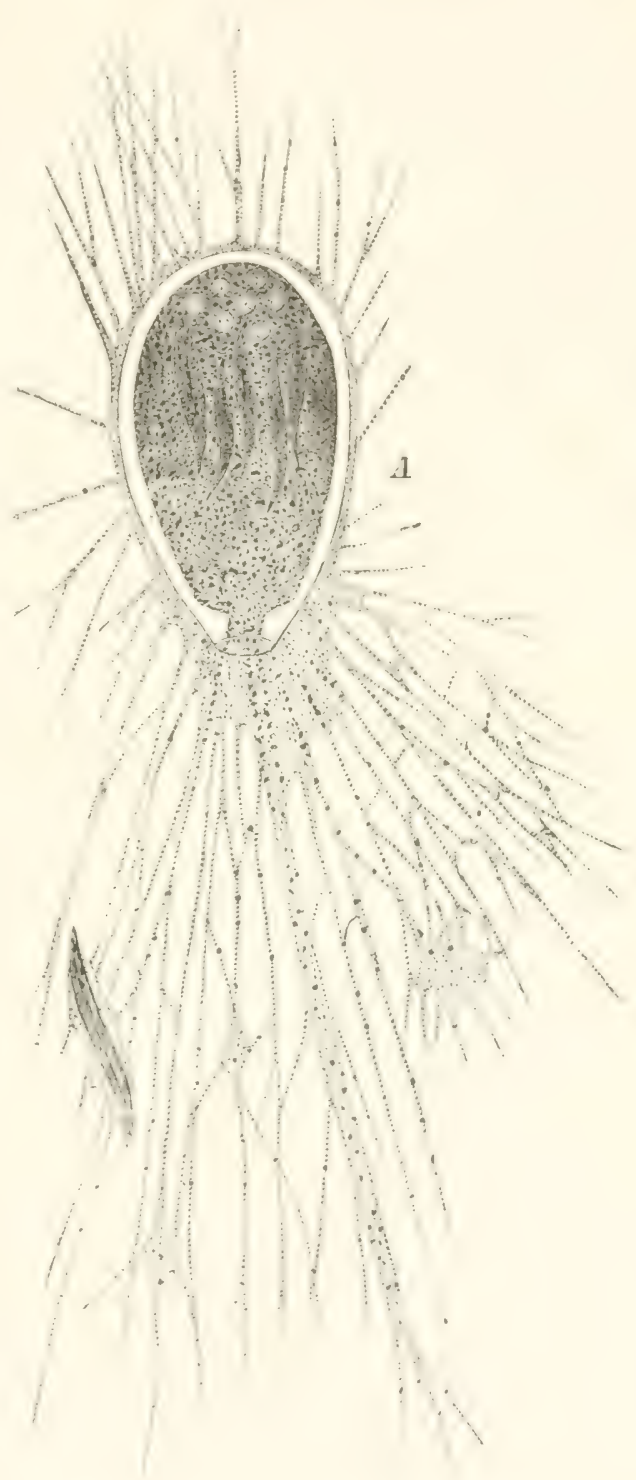

Fig. 75. Gromia oviformis. Nach $21 . \mathrm{x}$ SCIILI:TE Fardens in ähnlicher liewermng wie die Körnchen. Selbst fremde Körper, welehe der Fadensubstanz anhaften und in sie aufgenommen werden, schließen sich dieser Bewegung an. deren (ieschwindigkeit bis $0,02 \mathrm{~mm}$ in der Sekunde erreichen kann. Wo mehrere Fïlen zusammenstofen, sieht man die Körnchen von einem 
auf den andern übergehen. An solchen Stellen befinden sich oft breitere Platten, welche aus einer stärkeren Anhäufung der Farlensubstanz hervorgegangen sind.

Eine besondere Art der Protoplasmabewegung wird ron EngELmany ( 1879 u. 1879*) noch als Glitschbewegung beschrieben. Sie findet sich besonders bei Diatomeen und Oscillarien. Bei ersteren ist der Protoplasmakörper in eine Kieselschale, hei letzteren in eine Zelhulosemembran eingehüllt. Nach außen ron diesen Hüllen findet sich aber noch eine

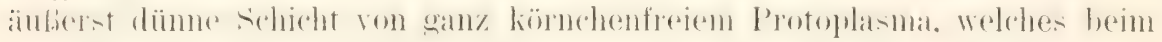
lebenden Organismus nicht wahrzunehmen ist, zuweilen aber nach Anwendung von Reagentien nachgewiesen werden kann. Darlurch, dab sich nun dieselbe auf der Kieselschale oder der Zellulosemembran nach einer hestimmten Richtung rerschieht. kimmen sich die lileinen ()roanismen ..aut

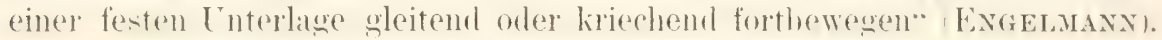

\section{b) Bewegung von Protoplasmakörpern im Innern von Zellmembranen.}

Diese Art der Bewegung findet sich hauptsächlich im Pflanzenreich und ist hier im allgemeinen in den Elementalteilen krautatiger fiewächse besser zu beobachten als bei Sträuchern und Bäumen. Nach DE Tries (I lisi) soll sie in lieiner Pflanzenzelle ganz fehlen, aher häutig so langsam sein, daß sie sich der direkten Wahrnehmung entzieht. Am besten heohachtet man sie in stoffaufipeichermben und leitenden fiewehen und zu jelien Zeiten. wo ein intersiver Thansprt plastischer stoffe. sei es zur Fortbildung orler zu lokaler Anhäufung oder zu eigenem Gehauch stattindet (DE VRIEs). Die Protoplasmabewegung soll daher auch direkt für den Stofftransport in der Ptlanze ron urolier berlentums sein. Seltener ist sie hei nieleren Organismen und im Tierreich zu bemerlien. so bei Nolitiluken. an den blasigen Zellen in der Achse der 'Tentakeln von Cölenteraten etc.

IIan unterscheidet in den Pflanzen zwei verschiedene Arten der Bewegung als Rotation und Zirkulation.

Die schönsten Objekte zum Studium der Rotation, die schon im Jahre 1774 durch Bonaventura Corti (I 1774) beobachtet, dann aber vergessen und von 'T'REviRANus wieder aufs nene entdeckt wurde, liefern uns die Characeen, ferner die Wurelhaare von Hydrocharis morsus ranae und Trianea bogotensis, die Blätter yon Vallisneria spiralis etc. In den großen Zellen der Characeen breitet sich das Protoplasma, wie schon auf Seite 81 beschrieben wurde, nur als eine zusammenhängende dicke Lage an der Innenfläche der Zellulosemembran aus und umgibt als ein ge-

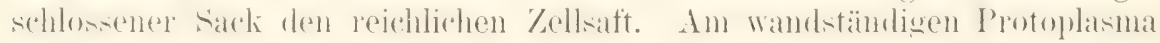
sind stets zwei gesonderte Schichten zu erkennen, eine äufere, an die Zellulose grenzende und eine innere, clem Zellsaft zugekehrte. Die erstere befindet sich stets in Ruhe; sehr dünn ist sie bei Hyrlrocharis, relativ dick bei Characeen, bei denen sie auch in großer Zahl die Chloroplyylliörner einschließt, an denen man keine Ortsveränderung wahrnimmt. Die ruhende geht allmählich in die innere bewegliche Schicht iiber, in welcher bei Chara zwar keine Chlorophyllkörner, aber Zellkerne und Körnchen liegen. Das

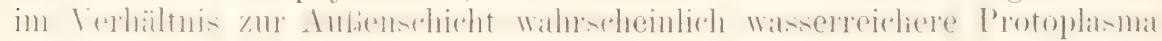
der Innenschicht zeigt eine rotierende Strömung in der Weise, daß in den langgestreckten Zellen der Strom an der einen Längswand in die Höhe steigt, damn an der oberen Querwand nach der anderen Längswand umbiegt, an dieser nach abwärts tlieft und endlich an der unteren Querwand wieder zum Ausgangspunkt zurückgelangt, von wo del Kreislauf von neuem 
begimnt. Zwischen auf- und absteigendem Strom betindet sich ein mehr oler minder breiter Indifterenzstreifen. in dessen liereich sich das Proto-

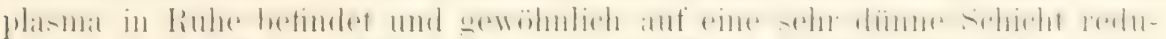

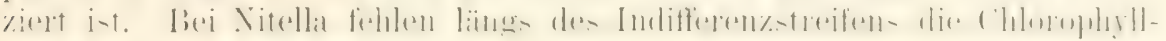
kïrner in der Aufenschicht.

Ein Übergang von der rotierenden Bewegung des Protoplasma zur Zirkulation wird durch die ., sogenannte springhrunnenartige Rotation vermittelt* (KLEBS Y 1Ss'). Diese in allgememen seltene form kommt in jungen Endospermzellen von Ceratophyllum, in jungen HolzgefäBen des Blattstiels ron Ricinus etc. vor. Hier bedeckt das Proto-

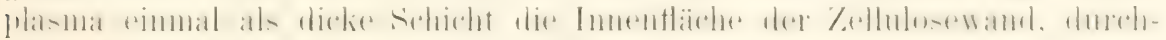
setzt aher auberdem noch als ein dicker. zentraler Strang den Saftram der Zelle ihrer Länge nach. Ein einziger Strom Hieft nun in zentralen Strang entlang. breitet sich dann an der Querwand. ant die el stöbt. nach allen Seiten wie bei einer Fontäne aus und bewegt sich ron hier im Wandbeleg zur entgegengesetzten (Querwand, an welcher die Strömung wieder in den Achsenstrom einbiegt.

Die als Zirkulation bezeichnete Bewegung beobachtet man bei solchen pHanzlichen und tierischen Zellen, bei denen das Protoplasma sich sowohl als dünne Schicht unter (ler Membran. als auch in feineren und stäkeren, net\%artig verbundenen Fäden im Saftraum ausbreitet. Die am meisten stulierten Untersuchungsoljekte sind die Staubfadenhare von den verschiedenen Tradescantiaarten, die jungen Haare ron Brennesseln und Kürbissprossen. Das Phänomen der Zirkulation ist ein ähnliches, wie wir es an dem Protoplasmanetz der Myxomyzeten und deil feinen Psendopodien der Rhizopoden liemen gelernt haben. Es setzt sich wie rlort aus zwei Arten von bewegungen zusaumen. Einmal unterscheidet man die Körnchenströmung. In den feinsten lädlen bewegen sich die liörnchen nach einer Richtung balk langsamer, bald rascher vorwärts: im IVandbeleg und in
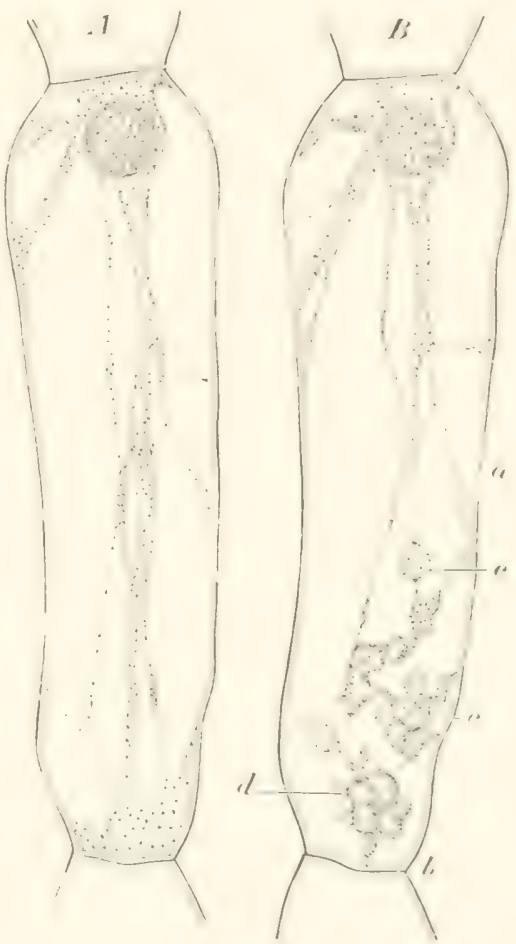

Fig. 76. A und $B$ Zelle eines Staubfadenhaares vou Tradescantia virginica. A Ungestörte Protoplasmaströmung. B P'otoplasma nach licizung kugelig zusammengeballt. 7.ellwand, ? Mmerwand 7wrier 7.nllem. c, d I'rotoplasma zu Kilmupen zusammengeballt. (Nach Kïrris.) dus VERWORA lig. lis. den breiteren Bündern zirkulieren oft meirere getrennte Ströme dicht nebeneinander, bald in der gleichen, bald auch in entgegengesetzter Richtung. Chlorophyll- und Stärkekörner. die in dem Protophasma liegen. werden durch die Strömung ebenso wie der Zelliern langsam mitgeführt. Auch hier befindet sich eine äulierste, der Zellulosemembran anliegende Schicht von hyalinem Protoplasma in relativer Ruhe. Zweitens bewegt sich auch langsam der Protoplasmakörper im ganzen und verändert infolgedessen seine Form. IBreite Ibinder werden 
verdümnt und können nach einiger Zeit ganz eingezogen werlen, feine

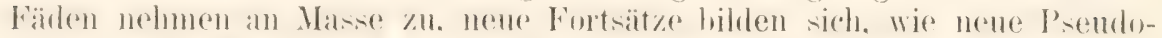

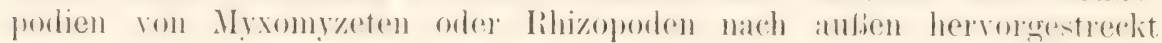
werden. Bald haben sich hier, bald dort im Wandbeleg größere Protoplasmamassen angehäuft, während an anderen Stellen Verdümnung eingetreten ist.

\section{c) Erklårungsversuche der Protoplasmabewegung.}

Von verschiedenen Forschern |Quncke ( $\mathrm{V}^{\top}$ 1888), Bütschu (III 18.92), Berthold (V 1886) u. a.] ist in letzter Zeit der Versuch ge-

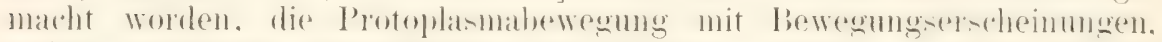

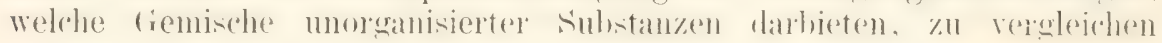
und aus ihnen zu erkiären.

Quncke hat die Bewegungserscheinungen. die an den Berïhrungs-

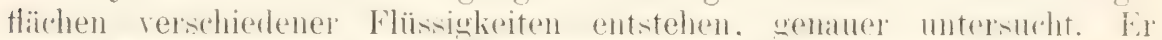

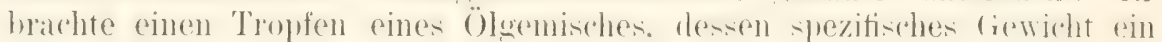
wenig größer als das des Wasser's war, und welches aus Mandelöl und Chloroform hergestellt wurde, in ein Glas mit Wasser und lieb darauf durch ein feines hapillarröhrhen einen Tropfen zweiprozentiger sodalösung an die Ölkugel herantreten. Dieselbe erfulı hierauf Gestaltsveränderungen ähnlich denen. welche gewisie Amöhen hei mikroshopischer

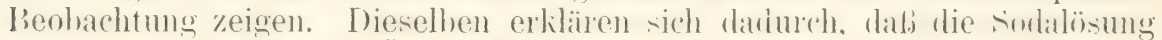

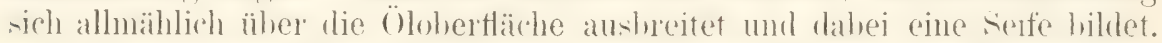

In analoger Weise beurteilt Quincke das Wesen der Protoplasmalewegmen. Bei der I'lasmolyse rom P'flanzenzellen zerfaillt ihr P'rotoplasmakörper zuweilen in zwei oder mehr Kugeln, die sich beim Ausdehnen entweder wieder vereinigen obler durch eine ehene Fläche getremt heihen, wie zwei gleich grobe Seifenblasen, die man miteinander in Berührung bringt. Aus diesen Erscheinungen wird mit Rücksicht auf die physikalischen Eigenschaften fester und Hössiger. diimnter Lamellen geschlosinn. daß der Protoplasmakörper von einer sehr dünnen, flüssigen Membran umgeben sein muisse, ähnlich wie bei einer Seifenblase die Luft ron einer dümnen Haut aus Seifenwasser eingeschlossen ist. .Die Substanz der den Plasmakörper umgebenden Membran“" so folgert (QuINCKE weiter. „muf eine Flüssigkeit sein. welche im Wasser Tropfen bildet. Da ron allen

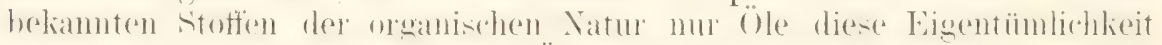

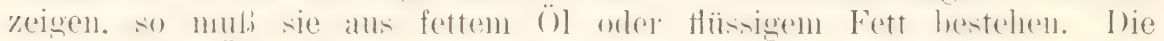
Dicke dieser ÖIschicht kann sehr gering sein, kleiner als 0,0001, so claf man sie mikroskopisch nicht mehr wahmehmen kam." Durch die Einwirkung des Eiweißes auf das Öl entsteht an ihren Berührungstlächen eine Substanz, die sich in Wasser löst und ausbreitet, ähnlich wie die aus Soda und Öl gebildete Seife. Sie wirl daher als Eiweißseife bezeichnet. Die Ursache für die Protoplasmabewegung erblickt nun (Quncre in der periodischen Ausbreitung ron Eiweißseife an der inneren Obertläche der Ölhaut, welche den Plasmakörper einhüllt. Die Seife wird an der Berührungsttäche in demselben Maße immer wieder neugebildet, als sie gelöst wird und in die umgebende Flüssigkeit diffundiert. Daraus, daß für den chemischen Vorgang die Gegenwart von Sauerstoft notwendig ist,

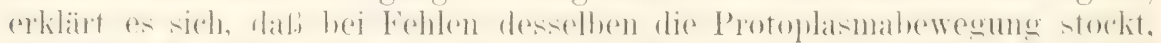

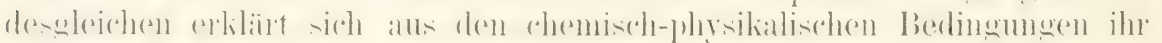
Stillstand bei zu hohen und zu niedrigen Temperaturen.

Angeregt durch Qunckes Untersuchungen und ausgehend von der

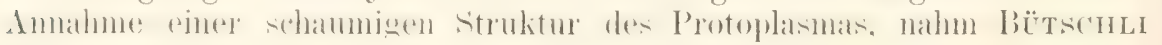


einige interessante Experimente vor. Welche ihm Licht auf die I'rsachen der Protoplasmabewegung zu werfen schienen, Er stellte sich in verschiedener Weise Öschäume her. Die feinsten und lehreichsten Schäume

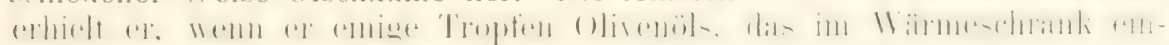
gedickt worden war, mit sehr fein pulverisiertem $\mathrm{K}^{2} \mathrm{CO}^{3}$ zn einem zïhen Brei remuischte und ein kleines Tröpfehen desselben in Wasser brachte. Der entstehende Schanm. dessen sehr likeine Vakuolen mit einer sich bildenden Seifenlösung gefüllt sind, sieht milchweib aus: durch Kusat\% ron diumem Gilyzerin lïbt er sich aufhellen. Dabei treten lehhafte Striomungen auf, die volle sechs lage an einem gelungenen Praiparate in

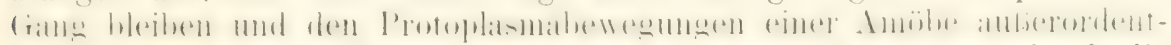
lich gleichen. .Nach einer Stelle des Randes zog der Strom durch die Achse des Tropfens hin, flob dam vom Rande nach beiden Seiten und hinten ab, um allmählich wieder in den zentralen Strom einzutreten." ..Bald hier. bald dort wird ein Hacher Fortsatz hervorgeschoben. wieder zuriekgezogen und so fort, ja manchmal geraten einzelne l'ropten auf

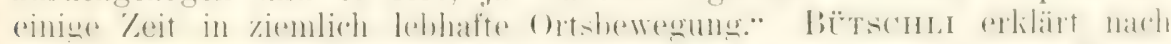
den Versuchen ron Quxcke die bewegungsphänomene in der Weise,

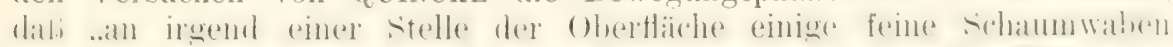

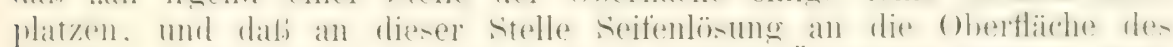

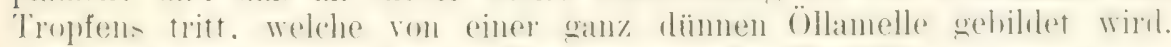

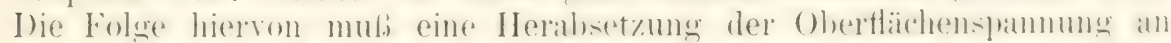
dieser Stelle und daher ein schwaches Vorwölben derselben und Abströmen von ihr sein. Beides veranlaßt, daß Schaummasse von imnen zu

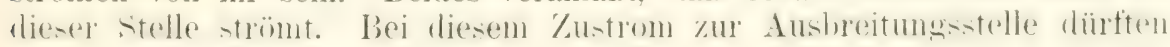
wieder einige Maschen platzen und so fort. so dab die cimmal angereste strömung an dieser stelle forthanert. Wenn nicht erhehliche störmugen

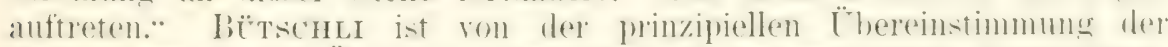

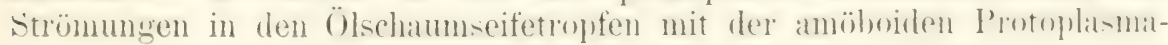
bewegung ïberzeugt.

Die von Quixcke und Bütschl angestellten Experimente sind ron

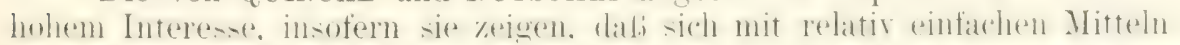

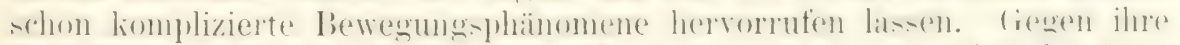

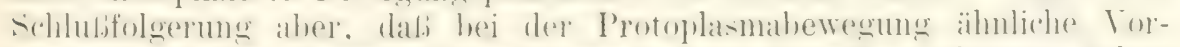

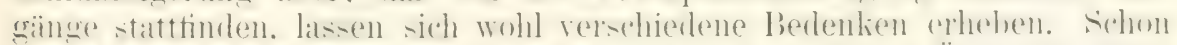

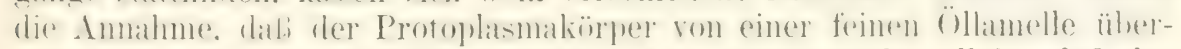
zogen sei, ist eine sehr fragwïrdige. Aus der Tatsache allein, daß das

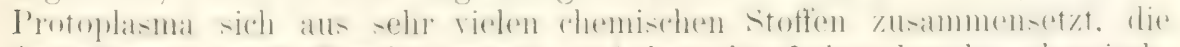

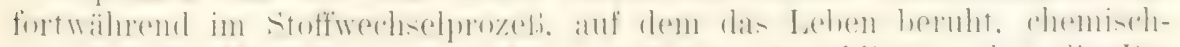

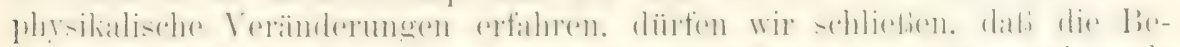

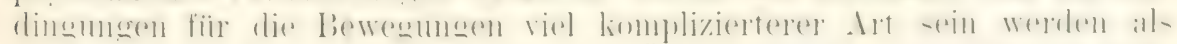
in einem sich bewegenden Tropfen von Ölschaumseife. und zwar in dem-

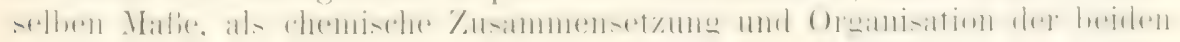
in Vergleich gezogenen Objekte eine himmelweit verschiedene ist. (Vergleiche auch hieriber (las auf Seite 2:) (iesagte und VERworx: Die hewegung der lebendigen Substanz ( I 1 S S.2.). Ferner bilden Protoplasmaströmung, radiäre Anordnung am Attraktionszentren, Flimmer- und reibelbewegung. Muskelliontralition eine (iruple zusanmengehöriger Vorgänge. die eine einheitliche Erlilärung verlangen. Eine solche können nun weder die ron Guracke noch die ron BürschLi angestellten Experimente geben. Die von ihnen an Stoffgemischen hervorgerufenen Bewegungen verhalten sich zu den Isewegungen der lebendigen Kö̈rper wie die Struktur der 


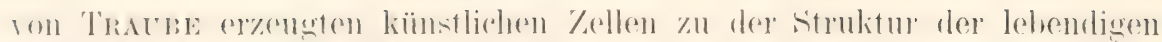
Yellen.

Um zu zeigen, wie schon durch einfache Ausbreitung eines Öltropfens

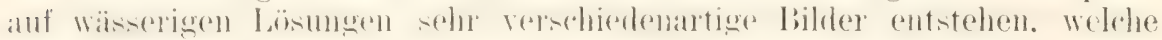
den einzelnen Arten von Psendopodienausbreitung selur ähnlich sehen, diene Fig. 77, welche einer Schrift von VERworN ( $V$ 1892) entnommen ist. $(z-d$, ist ein Tröptehen Provenceröl, das sich auf einer schwachen Sorlalosung yon verschiedener Konzentration ausbreitet und bei a die Form von Amöba guttula, bei $b$ und $c$ die Form von Amöba protens. bei $d$ die Form eines Myxomycetenplasmodiums zeigt. Fig. $77 e$ und $f$ ist Mandelobl. das heliozoen- nud ladiolarienähndiche Psendopodienbiduns be-

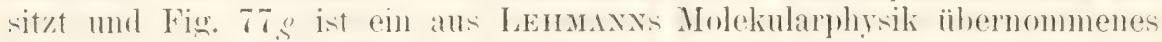

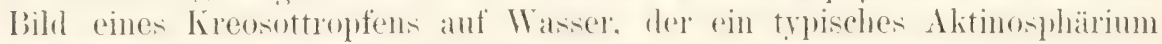
nachahmt" (VERWORN Y 1892. S. 47).

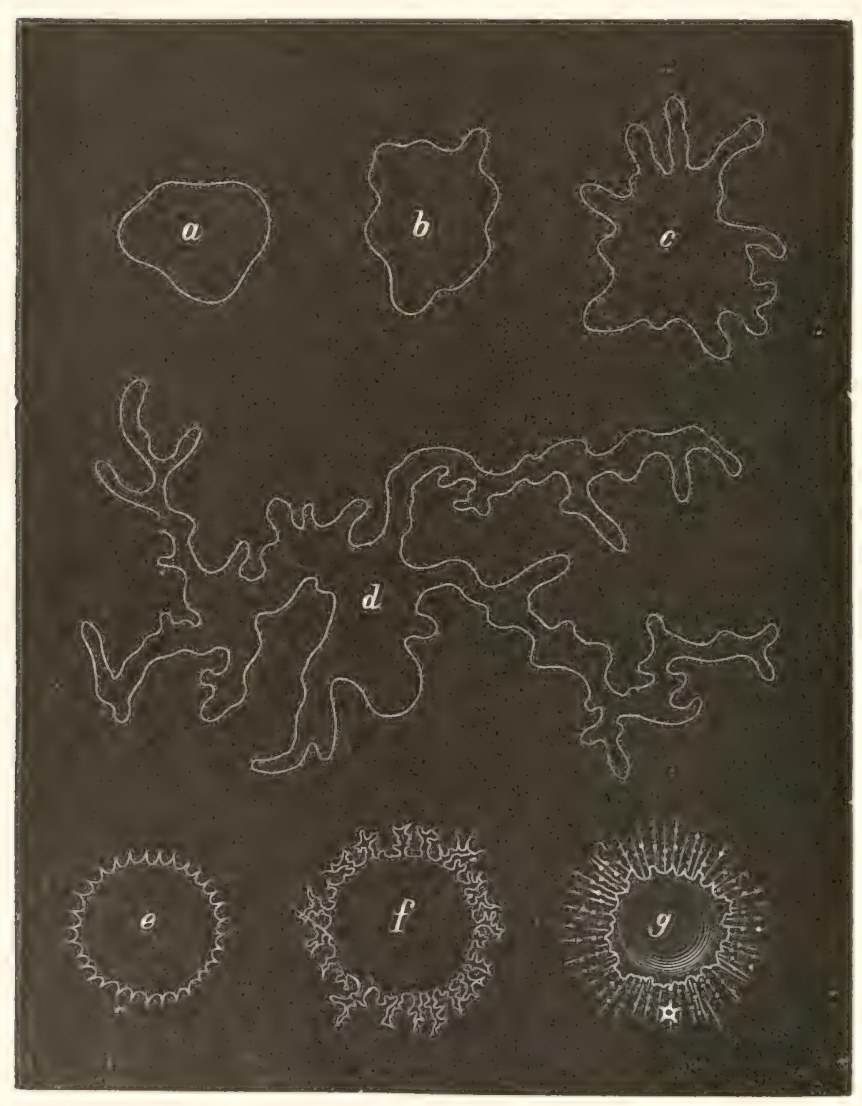

Fig. T. Ausbreitzngsformen von öltropfen. Nach Terwolix Fig. 11.

Andere Versuche. die Protoplasmabeivegungen zu erklären Engelmane (V 1875). HOFIEISTER (III 1867). SAchs|, führen uns anf das Gebiet der 'Theorien ïber die Molekularstruktur der organisierten Körper, indem als Ursache der Bewegungen die aktive Formveränderung kleinster 'leilchen angenommen wird. Wieder nach einer anderen Richtung bewegt sich der jüngste Erklärungsversuch von IERWORN ( $\mathrm{V}$ 1892). Eine Erörterung desselben wiirde uns zu weit fiïhren.

Alles in allem läßt sich wohl von allen bisher aufgestellten Hypothesen sagen, dab keine eine befriedigende Vorstellung von den Ursachen und mechanischen Verhältnissen der Plasmabewegungen uns zu geben vermag, und daß wir uns daher noch anf eine einfache Beschreibung der beobachteten Verhïltnisse beschränken mïssen. Anch ist dies kaum zu verwundern, wenn wir erwägen, wie schon üher die feinere Struktur des Protoplasmas 


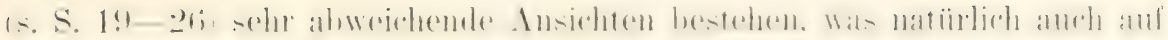
die Erklärung der Protoplasmabewegung von Einfluß sein mulj.

\section{Die Geißel- und Flimmerhewegung.}

Berlentendere Ortsveränderungen als durch Ausstrecken von I'seudo-

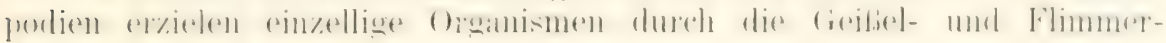
bewegung.

Geifeln und Flimmern sind feine. haarartige Fortsätze, die sich in

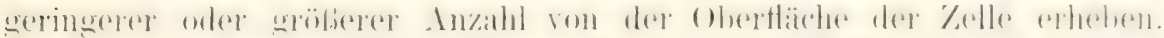

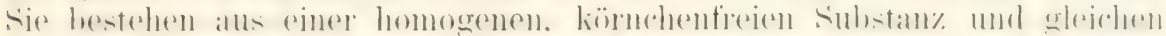

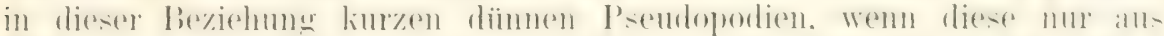

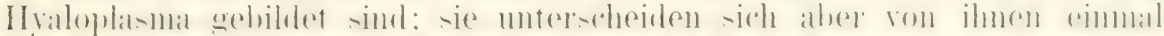

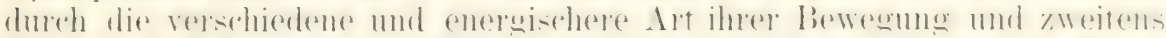

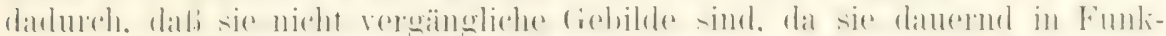
tion bleiben, ohne aus- und eingezogen zu werlen. Genetisch hängen in-

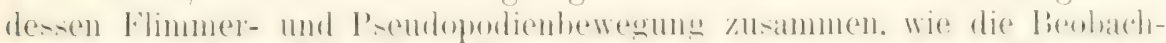

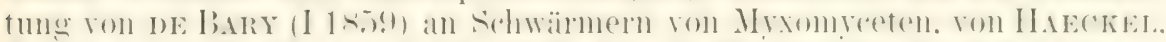

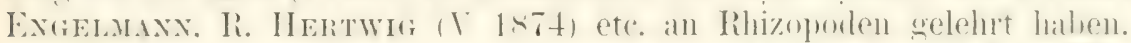

Viele nievere orwanismen pittanzen sich nämlich durch lileine keime fort. die wie Amöhen aussehen und sich auch nach Art derselhen forthe-

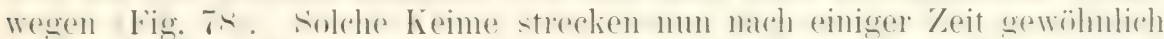

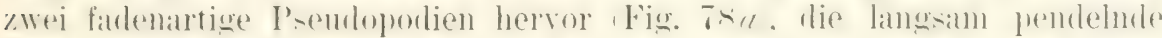

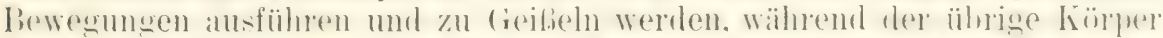

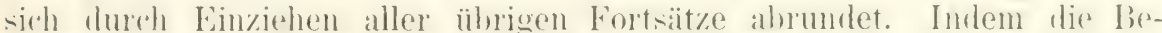
wegungen starker werden, eilt der Keim mit Ifilfe der beilen fieibeln im Wasser fort (Fig. 78b). Aus der kleinen Amöbe ist ein "Schwärmer" geworlen. Auf solche Befunde gestützt. können wir wohl sagen, daßs sich die Geißeln aus feinen Protoplasmafortsätzen entwickelt haben, die in besonderem Maße kontraktil geworlen sind und dementsprechemd eine rom ïbrigen Protoplasma etwas abweichemde lieschatfonheit gewommen habem. Sir lïmen daher anch als besondere, ans kontraktiler Substanz bestehende Plasmaprodukte oder Zellorgane betrachtet werden.

\section{Creißeln und Flimmern nehmen immer}

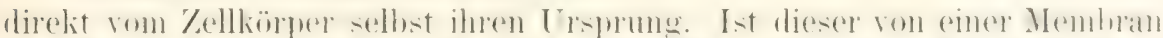

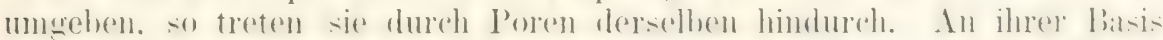
sind sie immer etwas dicker, begimnen oft an der Oberfliiche des Proto-

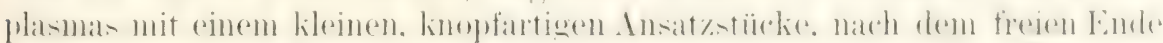
zu verjüngen sie sich allmählich zu einer feinen Spitze. Die Flimmeroreane finden sich entweder nur in geringer Inzahl of th an einem Entle

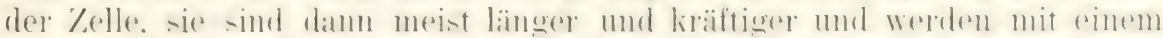

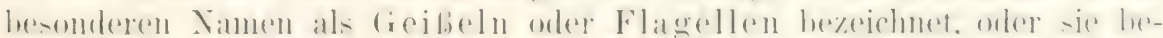

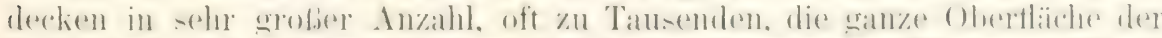

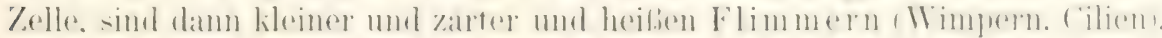




\section{a) Zellen mit Geißeln.}

Die Geigeln sind entweder am vorderen orler am hinteren Fnde des Körpers angebracht, was eine verschiedene Art der Forthewegung zur Folge hat. Im ersteren Fall gehen die Geißeln bei der Bewegung voran, während der Körper nachgeschleppt wird. Im zweiten Fall stöbt die Geibel durch ihre Bewegungen den Körper vor sich her. Das eine findet sich hauptsächlich hei den Flagellaten und verwandten organismen

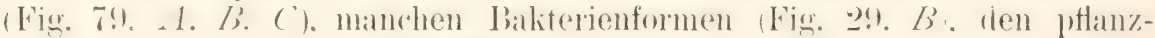
lichen samenfiulen (Fig. S1) (Moose, Farne. Equicetareen), sowie bei den Schwärmsporen. unter welehem Xamen die Fortpthanzmgskörper vieler Algen und mancher Pilze zusammengefalit werden; dats zweite zeigt sich bei den Samenfäden der meisten Tiere. (Fig. 80.)

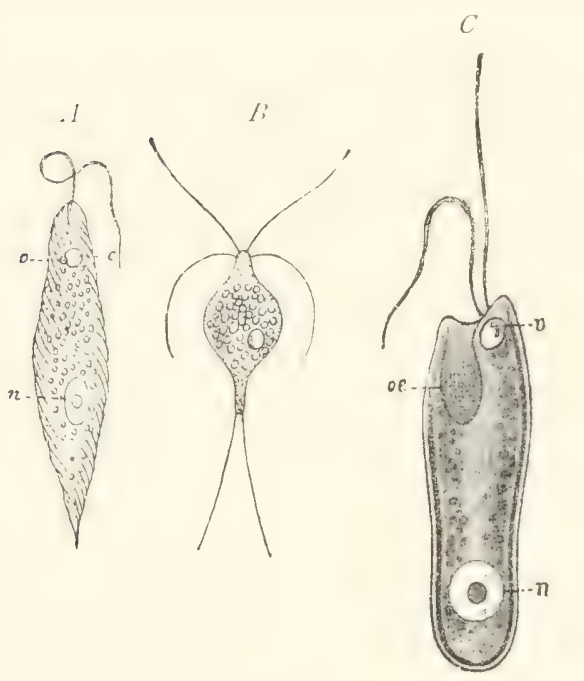

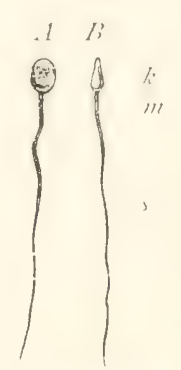

Fig. S1.

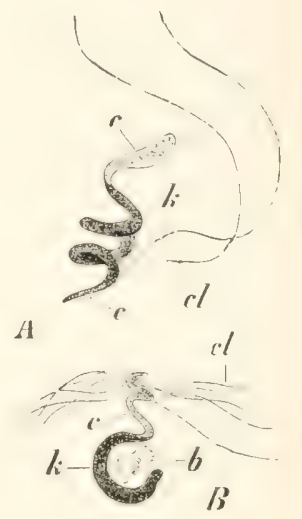

Fig. $\nmid 1$.

Fig. 79.

Fig. 79. A Englena viridis. Nach Sterx. n Kern. $c$ liontraktile Vakuole. o Pigmentfleck. $B$ Hexamitus inflatus. Nach Sters. $C$ Chilomonas Paramaecium. Nach Bütschur, oe Cytostom. $v$ Kontraktile Vakuole. $n$ Kern. Aus R. Hertwig, Fig. 130 bis 132 .

Fïg. (i). Reife Samenfäden des Menschen in zwei verschiedenen Ansichten. Dieselben bestehen aus Kopf (k), Mittelstïck ( $m$ ) und Schwanz (s).

Fig. 81. A Ein Spermatozoid von Chara fragilis. $B$ Spermatozoid des Farnes.

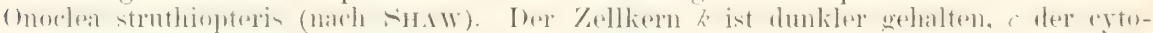
plasmatische Abschnitt, $c$ Cilien, in $B$ der dichten Kiante des Bandes entspringend, $b$ Blase. Vergr. $A 540, B$ 850.

I) ie Arbeitsleistung. welche die Flimmerorgane einzelliger ()romismen

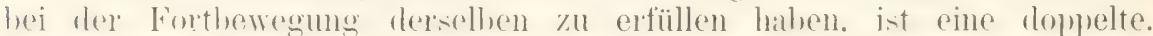

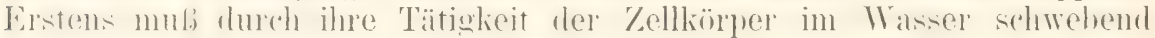
erhalten werden, da sein spezifisches Gesicht etwas größer als das des umgebenden Mediums ist. Es geht dies ja schon einfach aus. dem Umstande hervor, daf sich tote Schwärmsporen und Samenfäiden bald am Boden des Gefäßes niedersetzen. Zwweitens muf, durch die Flimmerarbeit rer Körver in bestimmter Richtung fortgetrieben werden.

Mit der Mechanik der Bewegung pHanzlicher Schwärmzellen hat

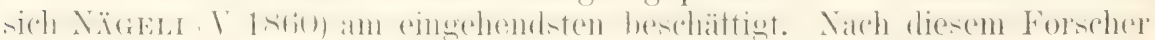
wird durch die Schwingungen der Geißeln dem Körper eine zweifache 
Bewegung mitgeteilt, ein Vorticken und eine gleichzeitige Drehumg mu seine eigene Achse. Die Bewegung ist daher eine ähnliche. wie von einer Kungel. die aus einem gezogenen Flintenlauf abgeschossen wirl. Dahei lialit dieselbe drei verschiedene Trpen unterscheiden:

.An vielen Schwämzellen, sie mögen in einer gerarlen oder etwas gebogenen Linie vorwärts gehen, bleiben das vordere und das hintere Ende ihrer Achse genau in dieser bahn: sie schwimmen steif und ohme Schwanken vorwärts. An anderen sieht man dentlich. dab sie eine gerarle oder etwas gebogene Schraubenlinie beschreiben. wobei eine Drehung um die Achse immer einem Umlauf der Schraube entspricht (so dab also die nämliche Zellseite stets nach aufen gekehrt ist), und wobei ihre Achse mit der Achse der Schraubenbahn parallel länt. Endlich gibt es noch andere Schwärmzellen, deren vorderes Ende in einer Schraubenlinie, deren hinteres aber in einer geraden Linie oder in einer Schraube von geringerem Durchmesser vorwärts geht. Die Natur der zweiten und dritten Bewegung erkennt man nur ganz deutlich, wemn sie langsam stattfinden. Sowie sie schmeller werden, erkennt man nur ein Schwanken, das besonders bei der letzteren einen eigentiimlichen Charakter hat."

Die Richtung. in welcher sich die Schwärmzellen um ihre Längsachse

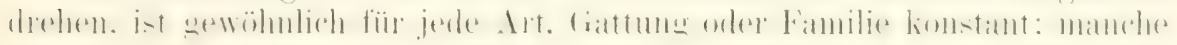
drehen sich ... südwestlich" (Ulotlrix), andere ..süı̈̈stlich" (Samenfüden der Farne), einige endlich sind drehmmgsvage, da sie sich bald südöstlich, bald südwestlich drehen ((ionium). Wenn Schwärmzellen an irgend einen Gegenstand anstolien, so hören sie eine Zeit lang auf. sich rorwärts zu

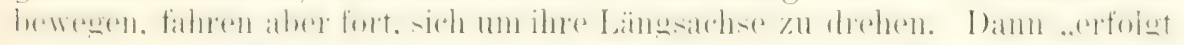
meist ein Zurückweichen, wobei sie mit dem hintern Ende vorangehen

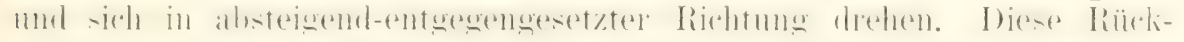
wärtsbewegung dauert meist nur kurze Zeit und ist immer langsamer: sie wird bald wieder durch die normale Bewegung vertauscht, die meist in einer etwas abgelenkten Richtung erfolgt."

Durch seine Beobachtungen ward Nägeli zu der Annahme geführt

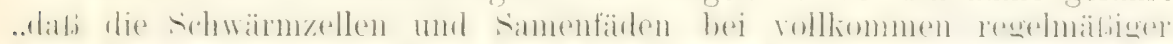

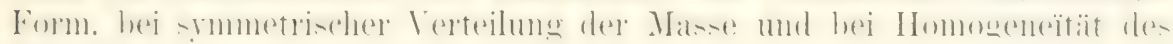
Mediums in einer geraden Linie dahinschwimmen würden, - und dafo

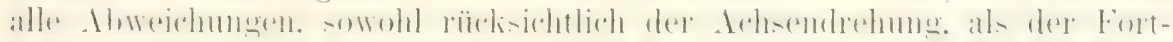

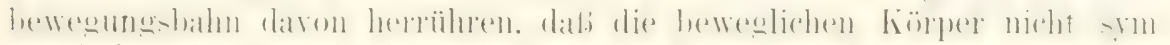
metrisch gebaut sind, ihren Schwerpunkt nicht im Zentrum haben ind nicht ringsum gleichmäbige Reibungswiderstände erfahren."

Mit Hilfe der Geibeh wird eine viel raschere Fortbewegung als durch das Ḱriechen mit Pseudopodien erzielt. Nach Nïgeli gebrauchen die Schwärmzellen, um den Weg von 1 Fuf zu durchlaufen, gewöhnlich eine Stunde, die schmellsten blok $1 / 4$ Stmule. Während der Menselr wïhend einer Selunde beim gewöhnlichen Gehen etwas mehr als die Hailfte seiner Länge zuriicklegt, heträgt der von einer Schwärmspore in derselben Zeit durchmessene Raum nicht ganz das Dreifache ihres Durchmessers. Wenn unter dem Mikroskop uns die Bewegung eine sehr lebhafte zu sein scheint, so mus man sich vergegenwärtigen. dab dieselhe. der angewandten Vergrölerung entsprechend, schneller erscheint, als sie in Wahrheit ist, da ja der durchlautene Weo auch vergrölert worden ist. Die Fortbewegung ist eine absolut geringe. „Olne Vergröberung wiirile man. anch wemn die Organismen vollkommen deutlich wïren. ilne liewegung wegen der Langsamkeit nicht sehen." 
Tierische Samenfäden (Fig. 81) unterscheiden sich dadurch von

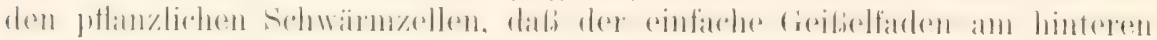
Ende des Körpers angebracht ist und so denselben vor sich hertreint. Der Faden führt dabei schlängelnde Bewegungen aus in ähnlicher Weise wie der Körper mancher Fische. In einigen Fällen besityt er noch eine liompliziertere Struktur, indem er mit einer feinen kontraktilen orler undulierenden Membran besetzt ist. Letztere ist dem Flossensaum eines Fisches vergleichbar; sie findet sich besonders schön am Schwan\%teile der groben Samenfäden von Salamandra und (-... Triton entwickelt (Fig. 82). Bei Untersuchung derselben vermittelst stärkerer Vergröberungen sieht man über die Obertläche der undulierenden Membran fortwïhrend von yorn nach hinten fortschreitende Wellen verlaufen. „Dieselben entstehen", wie HENsEN anseinandersetzt, „dadurch, daf sukzessive jerler Querschnitt des Schwanzes in die beiden extremen Stellungen (Fig. S3) übergeht. Hat dlas von oben gesehene Stück des Saumes I bis I ${ }^{1}$ (Fig. 83) zur Zeit O die angegebene Lage, so wird es am Ende des ersten Viertels der Perionle die Stellung II bis II $^{1}$ orler, was dasselbe ist, die Stellung II $^{1}$ bis $I^{2}{ }^{2}$ eimnehmen. Am Ende des zweiten Viertels ist $\mathrm{II}^{1}$ bis $\mathrm{II}^{2}$ in die Lage III bis III $^{1}$ oder. was dlasselbe ist. in III $^{1}$ bis III $^{2}$ ïbergegangen. Am Ende des dritten Viertels der Periode ist dann III $^{1}$ bis III ${ }^{2}$ in die Lage IV bis IV 1 übergegangen und wird am Ende der ganzen Periode wieder die Stellung I bis I $^{1}$ einnehmen. Alle diese Bewegungen erfolgen mit einer gewissen Kraft und Geschwindigkeit; es fragt sich, wie daraus eine Vorwärtsbewegung entstehen kann? Ein Flächenelement des Saumes (Fig. 83) bewegt sich, wie der Pfeil angibt, von $a$ nach $\gamma$ mit der Kraft $x=\alpha \gamma$. Die Krraft kamn zerlegt werden in die Komponenten

Fig. 82. Samenfaden von Salamandra maculata. $k$ Kopf, m Mittelstück, of Endfaden, sp Spitze, « undulierende Membran.

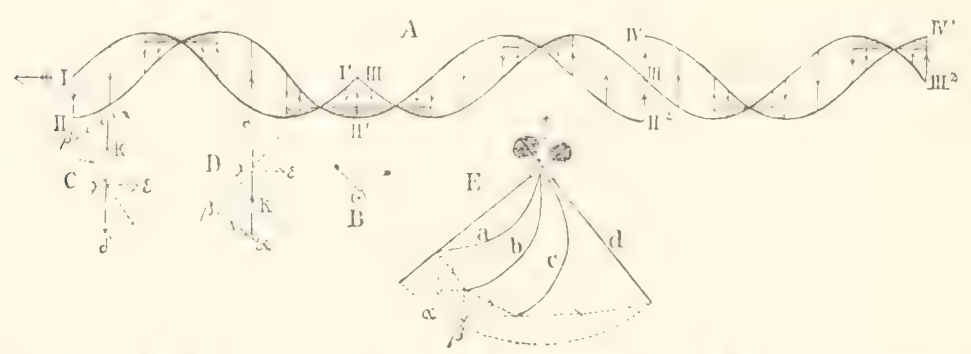

Fig. 83. Zur Erklärung des Mechanismus der Samenbewegung. Nach HExser lig. 2. A Die vier l'hasen der Stellung, welche der Wimpersaum einnimmt, wenn eine Welle äber inm hinläuft. I bis $I^{1}$ die erste, II bis II ${ }^{1}$ bis II $^{2}$ die zweite, III bis $I I^{1}$ bis $I^{2}{ }^{2}$ die dritte, IV bis $I^{11}$ die vierte Phase der Biegung des Samms in der Länge einer Welle. B Durchschnitt des Schwanzfatens und Saums in den zwei Stellungen stälister Elongation. C und /) Zerlegung der Kräfte des Saums. E Bewegung eines gewöhnlichen Samenkörperchens. a b c verschiedene Phasen der Bewegung 
a $\beta$ und $\beta \gamma$. Die Liraft a $\beta$ drïclit in der Richtumg des Samms, homprimiert ihn und gibt wahrscheinlich keinen änderen Eftelit. D)ie Kraft

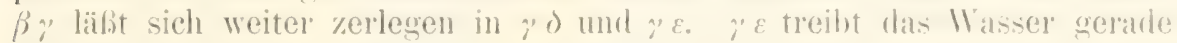
nach rïckwairts, und insoweit dieses dem Druck wirlersteht. treibt das hörperchen nach vorwärts. Die Kraft $\gamma$ ') wiurle das Kärperchen um die eigene Achse rotieren machen, doch ihr wirlit die gleiche, also entgergengesetzte Kraftiomponente entgegen. welche an allen Orten sich entwichelt. wo die P'feile in entgegengesetzter Richtung (also \%. li. ïher 1)) verlatufen. Im ïbrigen gibt Fig. D) dieselbe liraft $y \varepsilon$ wie Fig. C. Nur die schraticiten Flächen der Fig. A entwickehn der liomponente $\gamma \varepsilon$ entgersengesetzte Kräfte. Man sieht aber, dab die (irölie del betreffenden Flächen und damit ihre hraftiomponenten durchaus zurücktreten* (HExsEx l 1sis1).

\section{b) Zellen mit vielen Flimmern.}

Durch reichliche Bewimperung zeichnen sich unter den niederen. einzelligen Organismen besonders die Infusorien aus. die deswegen auch den Namen der Ciliaten fülıen (Fig. st). Im Vergleich zu den Geibeln sind die Cilien. Flimmern oder Wimpern von viel geringerer (rröbe meist ca. 0.1 bis $0.3, u$ dick und etwa 15 " lang. Ihre Zahl kann sich auf mehrere Tausende belaufen. So wride sie bei

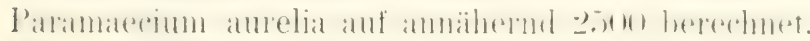

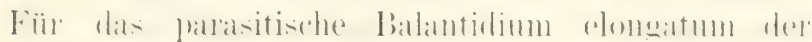
Frösche, welches eine Länge von ().:3 erreicht'mol

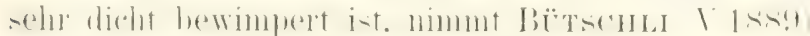
an. dafi seine Cilien wohl nach Zehntausenden geschätzt werden müssen. Gewöhnlich sind dieselben in vielen Längsreihen angeordnet, die entweder nur auf einen Teil der Lörperobertäche beschränlit sind orler dieselbe in spiralen Touren rings umziehen.

Neben den Cilien kommen hei vielen Infusorien noch besondere gröbere bewegungsorgane vor, die Cirren und die undulierenden Membranen. Erstere unterscheiden sich ron den Cilien durch gröbere Dicke und Länge und dadurch, dafs sie an der Basis breit entspringend in eine teine Spitze auslaufen (Fig. st). Ferner zeigen sie eine fibrilläre Differenzierung. wie Muslielfasern.

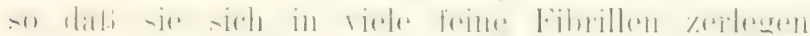

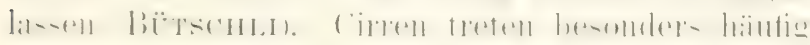
bei hypotrichen Infusorien und in der Tungebung der Mundöftnung auf. Auf letztere sind anch die undulierenden Iembranen in ihrer Mushreitung beschränkt. Sie sind flächenartig entwickelte Bewegungsorgane. welche häutig ron der basis wegen

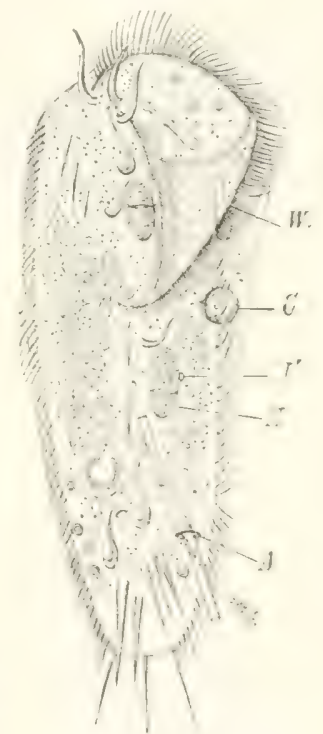

I.ig. St. Stylonychia mytilus, 11:at, $-11 \% 1$

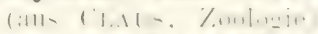
vou der Bauchfläche gesehen. IIz alomilo IIimperzone, $C^{\prime}$ liontraktile Vianuin, Y Yin leus, .1. Auejerulus, Ifterl: den freien Rand zu deutlich fein gestreift sind und daher wohl ehenfalls wie die Cirren eine filsrilläre Struktur hesitzen.

Die Bewegungsweise der Infusorien ist eine sehr mannigfaltige. Meist dreht sich ihr Körper, wenn er sich frei durch das Wasser hewegt. mu 
seme Längsachse. Die Richtung der lewegung kann wechseln. die Tätion-

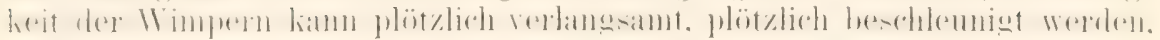
sie kann anch kurze \%eit stillstehen ohne hesondere

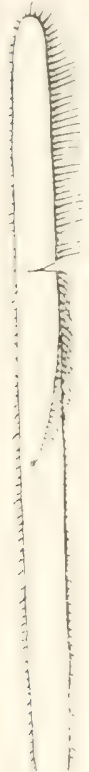

Fig. Se). Spirostomum ambiguum. Durch einen Einsclnitt ist die Kontimuität der die P'eristomwinpern tragenden Hautstrecke unterbrochen. Aus VERITOR (IV 40$)$ Fig. 25. andere Veranlassung. So kommen verschiedenatige Bewegungstormen, die scheinbar den Eindruck des Willkürlichen machen. zustande. Hierbei ist anch heachtenswert, dab die oft nach 'Tausenden zählenden Wimpern ein und desselben Individums streng lioordinierte Bewegungen ausfïhren. ., Sie schlagen nicht nur stets in derselben Frequenz, der Schwingungen (Rhythmus) bei gleicher Amplitude, sondern sie schlagen auch sämtlich nach derselben Richtung und immer in derselben Reihenfolge" (V'ERworN). Die Koordination der Bewegung geht sogar so weit, daß zwei Individuen. die aus Teilung eines Muttertieres entstehen, durchaus ïbereinstimmende und synchronische Bewegungen ausführen, so lange sie noch durch eine Plasmabrïicke vereinigt sind. 'Es folgt hieraus, dab zwar die Wimperorgane das Vermögen besitzen, sich selbsttätig zusammenzuziehen. dab ilı Zusammenwirken aber durch Reizübertragungen yom Protoplasmakörper geregelt wirl.

Bei der Reizübertragung scheint besonders das Ektoplasma von liedeutung zu sein, wie aus einem Versuch von VERwors (I 1s8!) hervorgeht. YERwORN machte bei Spirostomum ambiguum (Fig. 85 ) und Stentor coeruleus einen kleinen Einschnitt mit einer Lanzette in das die Wimperreihen tragende Ektophlama. „In diesem Falle konnte deutlich beobachtet werden, dab die Timperwellen nicht über die Schnittstelle hinwegliefen, sondern sich auf die eine Seite beschränkten und auf der andern Seite nicht wieder zum Vorschein kamen." Bisweilen beobachtete er auch, daß die Mittellage, um welche die Wimpern schlagen, in der einen Hälfte der Wimperreihen vorübergehend eine andere war. als auf der anderen Seite der Schnittstelle.

Flimmernde Zellen finden sich anch häufig im Körper vielzelliger Organismen, wo sie in großer Menge vereint das sogenannte Flimmerepithel bilden. Auf der freien Obertläche einer einzigen Zelle können 50), ja selbst 100 und mehr Flimmerhärchen entspringen. (Fig. 86-89.) Mit breiterer Basis beginnend laufen sie allmählich in eine außerordentlich feine Spitze aus. An geeigneten Objekten hat man bei Untersuchung mit starken Vergrößerungen noch zwei besondere Strukturteile in Verbindung mit jedem Flimmerhaar nachweisen können: 1, das Basalkörperchen und 2, die Wimperwurzel. Das Basalkörperchen ist ein kleines Korn, welches der Basis des Haares ansitzt. in die Rindenschicht des Proto-

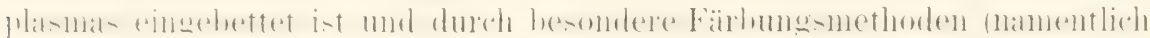
durch Heidenhains Haematoxylin) sich so intensiv imbibieren läßt, daß es sich scharf gegen die Umgebung absetzt. (Fig. s6.) Wie man bei betrachtung ron der freien Fläche wahrnimmt, sind häufig die Basalliörperchen in Reilien angeordnet, so 7. B. in der in Fig. 87 abgebildeten Zelle Yon Helix hortensis, die etwa 100 Cilien trägt. Mit jerlem Basalkörperchen hängt wiedel eine feine Fibrille zusammen, welche sich aus dem Proto- 
Fig. sit
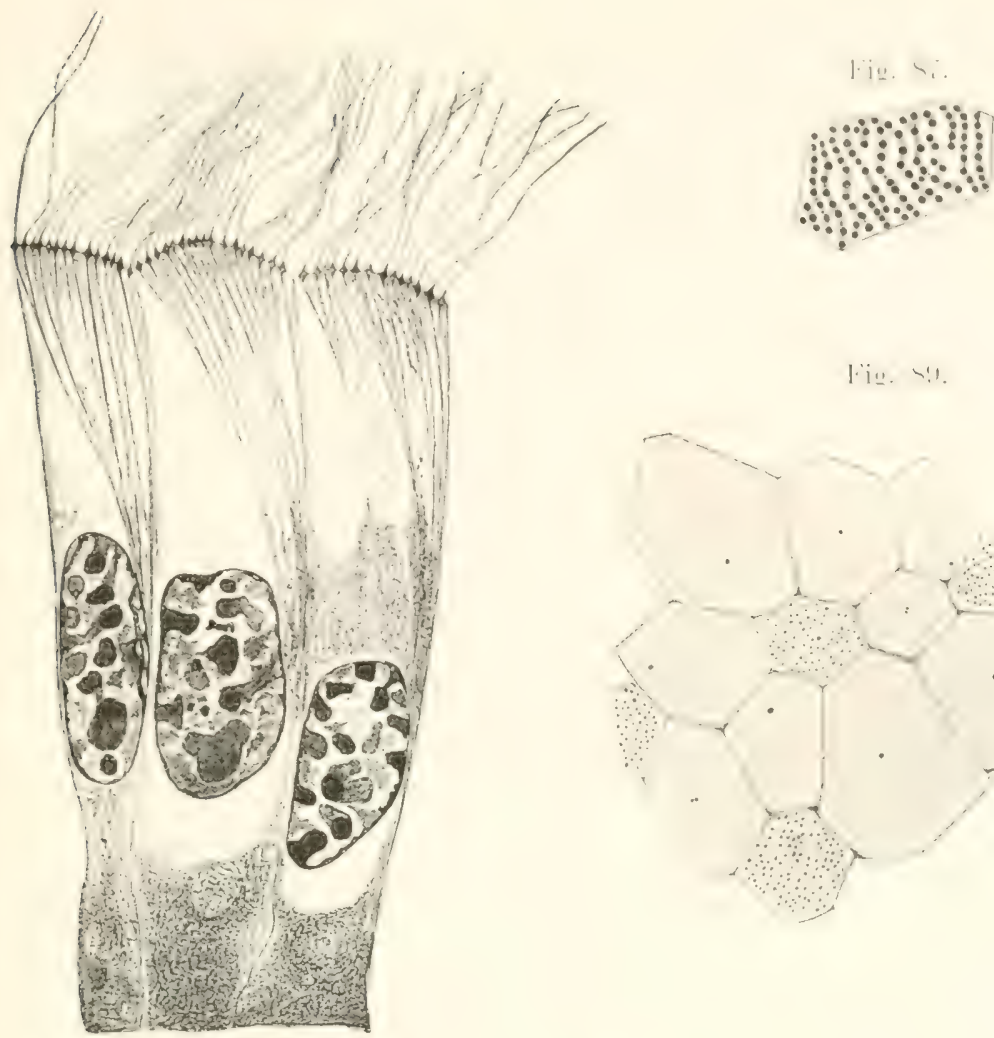

l:ï. ‘!

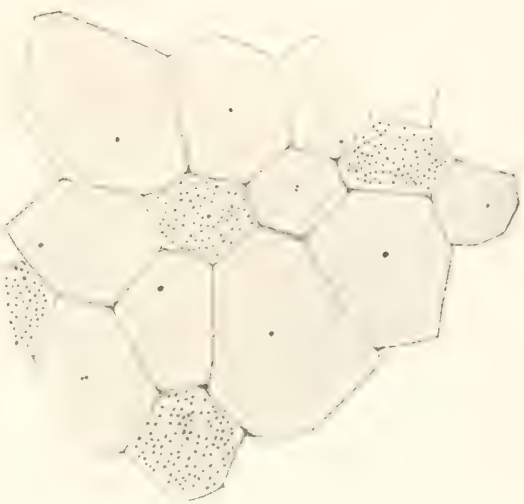

Fiig. «.

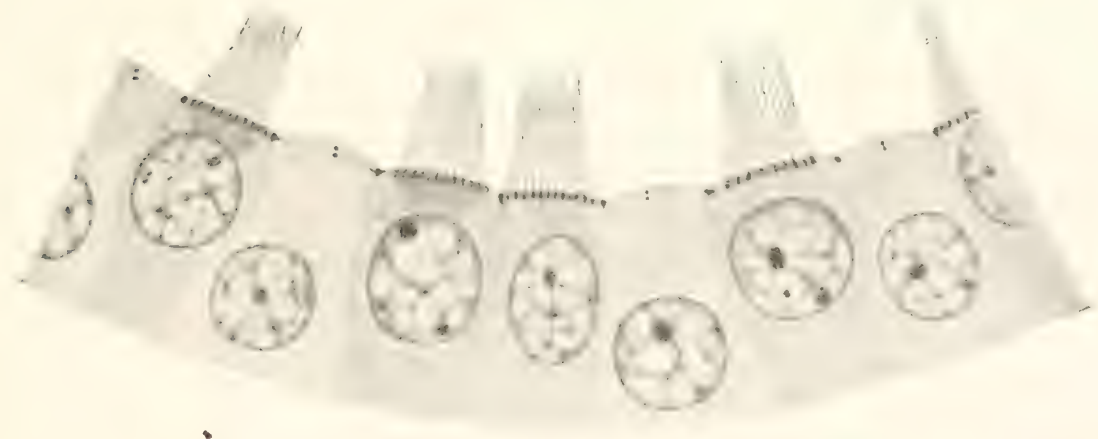

Fi.. vi. Flimmerepithelzellen aus einem Lebergang von Helix hortensis nach Himexhis, Verer. 2.500.

l'ix. 87. Flimmerzelle von Helix hortensis von der freien Oberfläche her gesehen. 110 Cilien sind rorhanden. Nach Hminsmar.

Fïig. SS. Flimmerzellen und flimmerlose Zylinderzellen aus dem Nebenhoden des Kaninchens nach l,wilostek.

[rig. S9. Flächenansicht des Nebenhodenepithels des Kaninchens nach LENHOSEEK. 


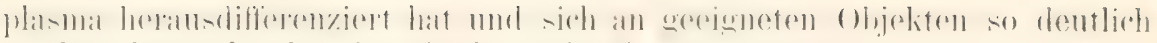
machen läbt, als ol , sie mit dem Lineal gezogen wäre."

Von Engedand wurlen sie die Wimperwurzeln genannt. Alle Fibrillen lassen sich im Körper der zelle nach abwärts bis in die Gegend des kierns rerfolgen, sie konvergieren dabei und erzengen auf diese Weise zusammen einen "Fibrillenkonus." Verfolgt man die Fibrillen von der Spitze des Kegels her gegen die Endtläche der Zelle, so gewahrt man. wie HEIDENHaIN glaubt feststellen zu kionnen, dal.) sie sich fortgesetzt dichotomisch teilen. Dabei bleiben die Fibrillen, die aus der 'Teilung einer Mntterfibrille hervorgegangen sind, gern zu einer kleinen Gruppe vereinigt, welche sich ron der nächsten ebensolchen (xruppe durch einen etwas größeren Zwischenraum scheilet. ENGELandN $Y^{T}$ 1879, HEIDENIIIL. M.. II Is!!!!
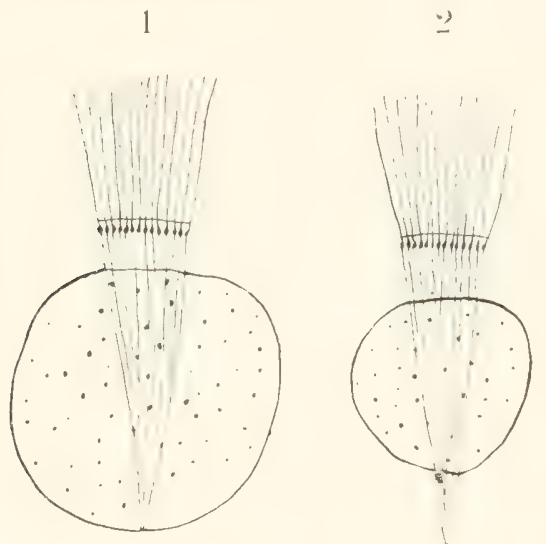

$: 3$
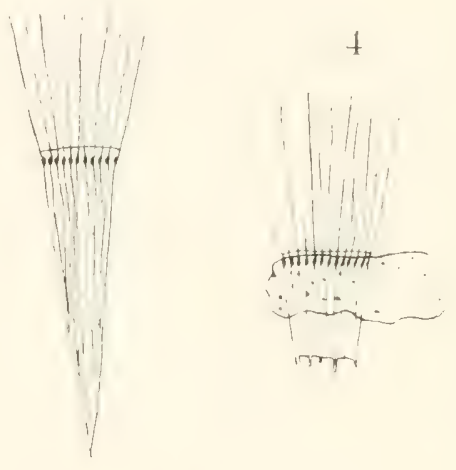

Fig: (M). Scliemata von kermloser Fragmenten von Flimmerzellen, welche noch lebhafte Flimmexbewegung zeigten. Dis l'rofonlasma ist punktiert, (ler Fibrillenkonus längsgestreift dargestellt nach l'Eter. Fig. 1 und 2 zeigen Plasma, das dem Fibrillenkonms anhaftet. Fig. 3 stellt ein isoliertes Flimmerorgan dax. Bei Fig. 4

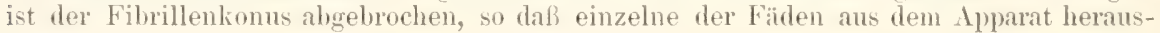
ragen.

Durch Zerrupfen lebender Flimmerzellen ist es möglich den Flimmerapparat vom Protoplasma teilweise, so daß ihm nur wenige Bröckchen anhaften, oder selbst vollständig zu tremnen. Durch solche von ENGELMANn und PETER ausgeführte Experimente (Fig. 90, 1-4) kanm man

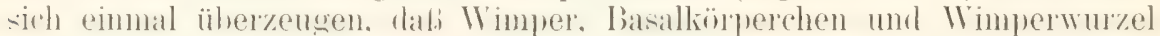
ein zusammengehöriges Ganzes bilden, das aber in drei substanziell verschiedene Abschnitte gesondert ist, und zweitens num die Frage unter-

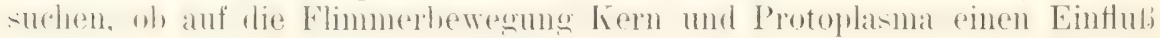
ausüben. Beides wird von PETER in Abrerle gestellt. Denn kernlos gemachte Fragmente von Flimmerzellen lieben in der fenchten Kammer 6\%. Stunden lang die Bewegung der Flimmern erkennen. Auch Trennung rom Protoplasma bringt nicht die Bewegung zum Stillstand. Daher liegt wie Peter ( $\mathrm{T}$ 1899) sich ausllïckt , (ler Motor für die Flimmerbewegung im Wimperorgan selbst."

Ferner glaubt Peter bei Zerlegung des Wimperorgans in seine

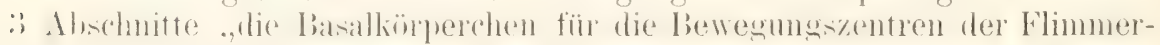
haare" erklären zu mïssen. Denn letztere hören zu schlagen auf, wenn sie, was häufig geschieht, durch das Zerrupfen rom Basalkörperchen ge- 
tremnt sind. „Dymamische Zentralorgane* hat sie daher Lexmosser grenamnt und zugleich den lieweis zu führen gesucht, dalib sie ans den \%entrosomen einer Zelle hervorgegangen sind und ihnen entsprechen. '/ugunsten seiner Ansicht beruft er sich 1. auf die starke Färbbarkeit der laasalliör-

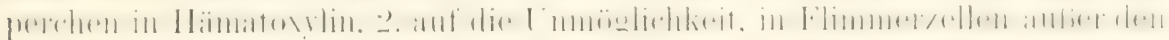
Zentralliörperchen besondere Zentrosonen nachzuweisen. während in jerler

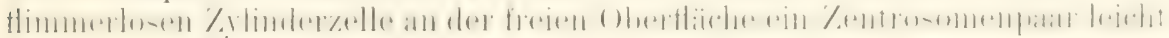
ausfindio zu machen ist. :3. anf den Bau der Samenfürlen. bei welehen das die fieibel tragende Mittelstiick vom Zentrosom der Spermatide abstammt.

Danach mïften die vielen Basalkörperehen einer Flimmerzelle durch Teilung ron einem Zentrosom abstammen.

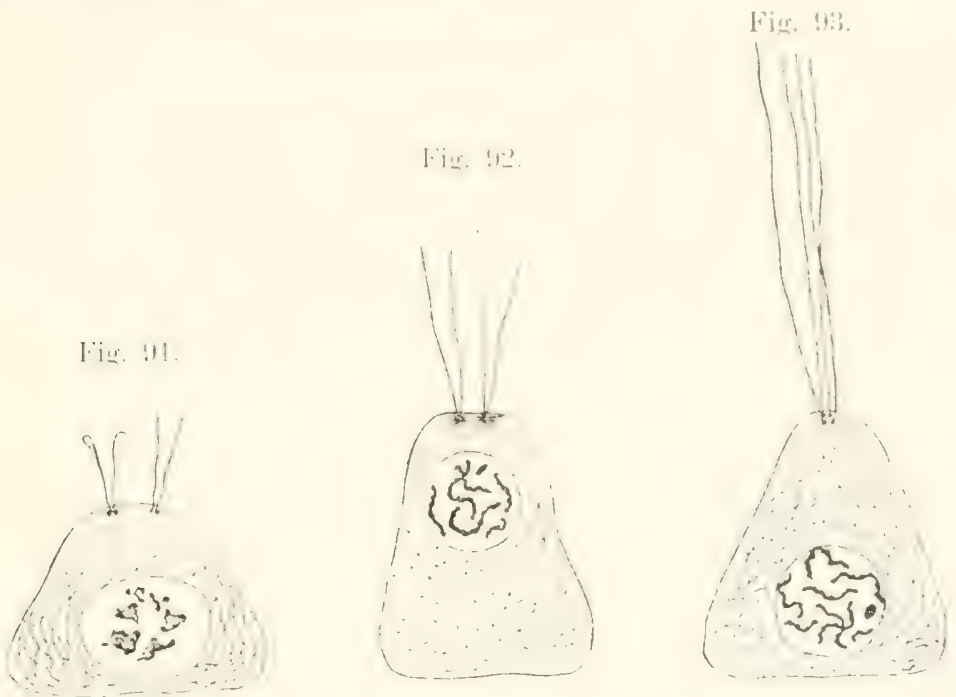

Fil. ! !1.

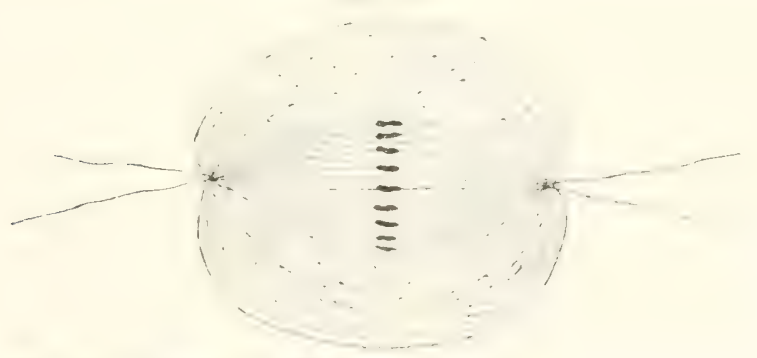

Fir. 91. Spermatocyte von Bombyx mori.

Fig. 32. Desgl. mit einer Centrodesmose zwischen den beiden Gruppen der geißeltragenden Centrosomen.

Fig. 93. Spermatocyte der zweiten Generation von Hyponomenta cognatella mit 4 geißeltragenden Centrosomen.

Fin. 9. Spermatocyte von Bombyx mori in Teilung begriffer.

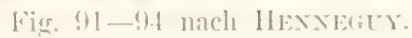

Fïr die Ansicht, nach welcher Basalliörperchen und \%entrosomen verwandte Bildungen sind, sprechen auch lieobachtungen von MEves und HexNegur an den Spermatocyten aus dem Hoden der Schmetterlinge (Fig. 91-94). Das Objekt zeigt die besondere Eigenschaft. dals schon die Spermatocyten. welche wie ein Epithel die Samenampullen anskleiden. 
auf ihrer freien Oberfläche zwei Paar Geißehn tragen. Diese sitzen auf

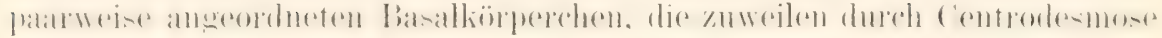
rerbunden sind. Wenn nun eine Spermatocyte sich zur 'Teilung vorbereitet, (Fig. 94) nimmt sie eine ovoile Form an. Die beirlen (rruppen der Centrosomen entfernen sich mehr und melır voneinander und hommen eine jede an das Ende des längsten Zelldurchmessers zu liegen. Wobei sie immer in Berïhrung mit den Geibeh bleiben und ihre periphere Lage beibehalten. Sie bilden dann die beiden Pole der Kernteilungs-

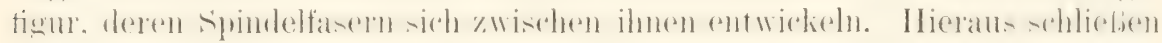
Meves (V 1897) und Hennegur (V 1898), dab die Körperchen an del Basis der Geibehn wahre Centrosomen sind.

\section{Die kontraktilen Vakuolen oder Behäler einzelliger Orwanismen.}

Kontraktile Vakuolen treten sehr häufig bei Amöben, Rhizopoden. Flagellaten (Fig. 73, 7s, 79) und Infusorien (Fig. 95 $\mathrm{c}^{\prime}$ ) auf. Bei letzteren. bei denen sie am genauesten untersucht worden sind. ist meist im ganzen Körper nur eine einzige Vakuole, zuweilen sind zwei (Fig. 95), selten einige mehr vorhanden; sie liegen stets dicht unter der Körperoberfläche mnter

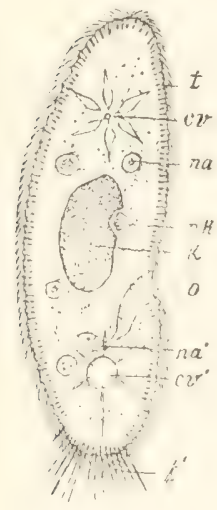
dem Ektoplasma. Von anderen Flüssigkeitsvakuolen, die im Körper in großer Anzahl verbreitet sein können. unterscheiden sie sich leicht dadurch, dab ihr Inhalt in regelmäbigen Intervallen vollständig nach außen entleert und wieder ergänzt wird. Sie verschwinden daher vorübergehend (Fig. $95 \mathrm{co}$ ), um bald wieder zum Vorschein zu kommen (c ' $)$. Die Entleerung geschieht durch eine oder mehrere besondere Poren, die an der Oberfläche des Infusorienkörpers ummittelbar über der Vakuole nachweisbar sind. ,Jeder Porus erscheint gewöhnlich als ein

Fig. 95. Paramaecium caudatum (halbschematisch). IR. HERTwri, Zoologie Fig. 139. k Kern, nk Tebenkern, o Mundöffnung (Cytostom), na' Nahrungsvakuole in Bildung begriffen, na Nahrungsvakuole, cr kontraktile Vakuole im kontrahierten, ca' im ausgedehnten Zustand. $t$ 'Trichocysten, hei $t$ ' her'vorgeschleuder.

sehr kleines, von einem dunklen Randsaum umzogenes und im Inneren

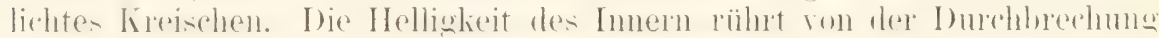
der Pellicula und Alveolarschicht her." Zuweilen setzt sich jeder Porus his zur kontraktilen Vaknole in ein feines AusthuBröhrchen fort. Nicht selten sind noch besondere Zufuhrkanäle (1, 2 und mehr) in ihrer Un-

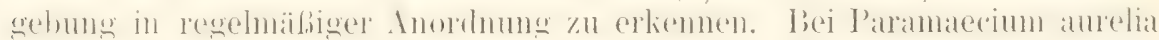
und P. caurlatum (Fig. 95), deren zuführendes Kanalsystem schon seit längerer Zeit bekannt ist und am häufigsten studiert wurde, strahlen von jeder der beiden dorsalen Vakuolen ca. - - 10 ziemlich gerade Ḱanäle aus, die fast über den gesamten Körper zu verfolgen sind. Jeloch greifen die Kanäle beider Takuolensysteme nicht zwischeneinander hinein." Sie sind in der Nähe der kontraktilen Vakuole am stärksten und verfeinern sich rlistal mehr und mehr.

Sehen wir uns nun die Wirkungsweise dieser eigentümlichen Apparate näher an, wozu sich Paramaecium als ein sehr geeignetes Objekt darbietet

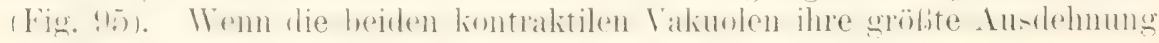




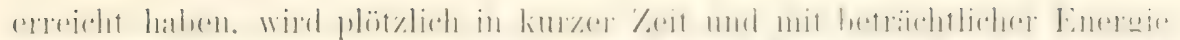

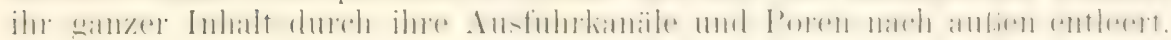
so dab die Vakuolenhöhle voribergehend ganz verschwindet. Wie bei der

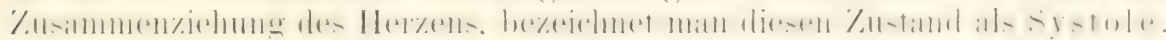
dagegen die Periode, in welcher sich die Vakuole wieder mit Flüssigkeit fiillt. ausdehnt und sichtbar wirl, als Diastole.

Die Füllung geht in der lWeise vor sieh: Sehon vor liegim der

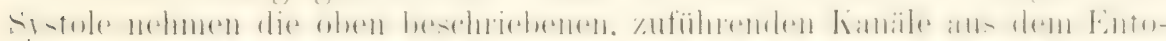

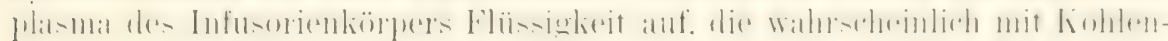
sïure und einigen Stoffwechselprodnkten belarlen ist. Die Fiillung geschieht wohl. wie ScmwLisE (V 1866 ) vermutet, infolge ..les Druclies. muter dem die durch immer nene Wasseraufnahme durch den Mund sich mehrende Flüssigkeit in Körper des Tieres steht.6. Zu dieser Zeit sind wegen der Füllung mit Wasser die zuführenden Kanäle gut sichthar. Sie

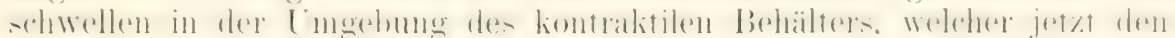

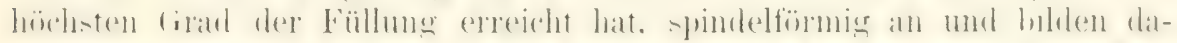

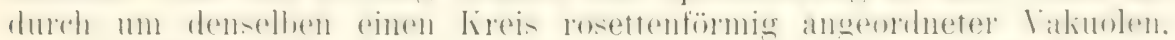

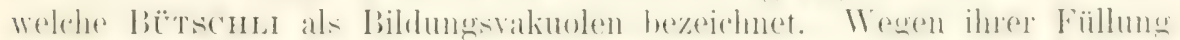

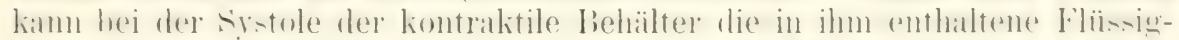

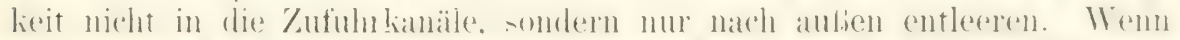

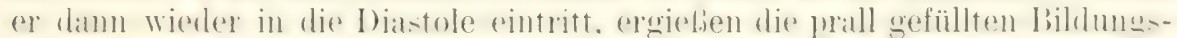

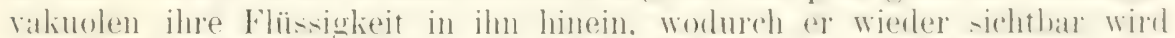

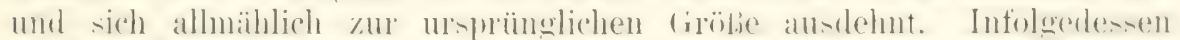

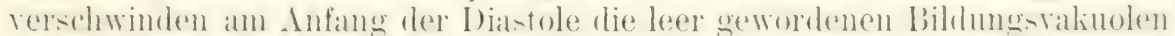
vorïhergehend. füllen sich aber von neuem ans dem Körperparenchym his zum Beginm der nächstfolgenden Systole."

..Bei gleichzeitiger Gegenwart mehrerer Vakuolen herrscht im All-

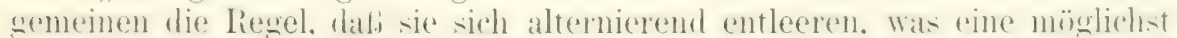

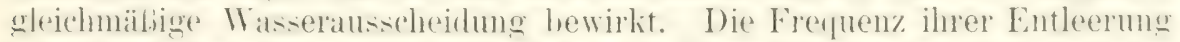
ist hei den einzelnen Infustrienarten im alleemeinen eine selur sohwan-

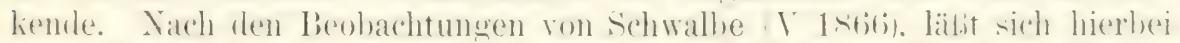

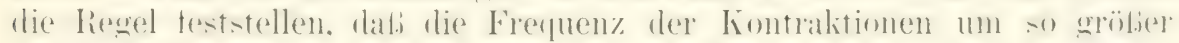

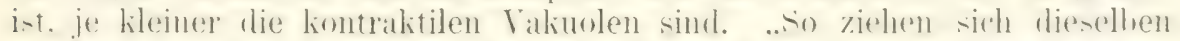

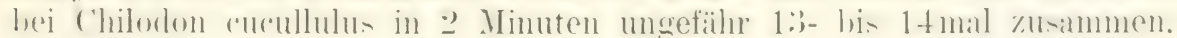
bei Paramaecium aurelia in derselben Zeit nur 10 - bis $11 \mathrm{mal}$. bei Vorticella milirostoma nur 1- bis 2 mal. Noch seltener erfolgen die Kontrak-

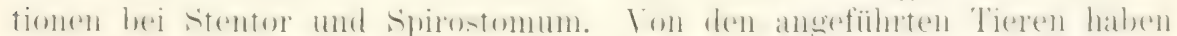

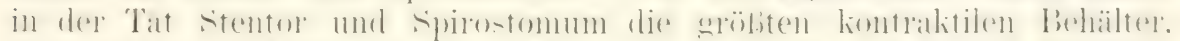

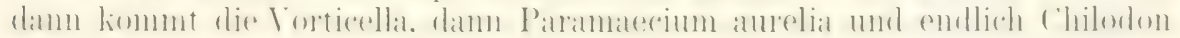
cucullulus. dessen Vakitulen wohl nur den halben Durchmesser von den bei Paramaecium vorkommenden haben: bei diesem beträgt der Durehmesser $0,0127 \mathrm{~mm}$, bei (ler Vorticella $0.0936 \mathrm{~mm}$.: (Schwalloe.)

Das Zeitintervall zwischen zwei Entleerungen ist bei derselhen 'Temperatur ein sehr gleichmäbiges, verändert sich aber sehr bei Erhöhung orler Erniedrigung derselben. (Rossbacn || 157t). MaUPAS). Während bei Euplotes Charon das Zeitintervall zwisehen zwei Kiontraktionen bei gewöhnlicher Temperatur (j1 Selunden beträgt. ist es bei 30 (rrad Cels. auf 2:3 Seliunden gesunken (Rossuıch.) Die Frequenz der liontraktionen hat sich demmach fast verdreifacht.

Der durch die kontraktilen Vakuolen erzengte Wasserwechsel ist ein erstaunlich grober. Nach Berechnungen von Maurss entleert \%. li. Paramaecium aurelia bei $27^{\circ}$ Celsius ein inrem Körpervolum gleiches Volum Wasser in 46 Minuten. 
Aus den mitgeteilten Beobachtungen scheint hervorzugehen, daß die

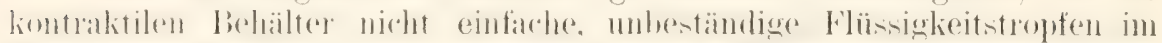

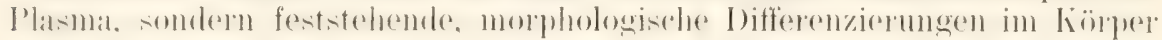
der Protozoen sind, wirkliche Zellorgane, die wahrscheinlich im Dienste der Atmung und Exkretion eine wichtige Funktion zu erfüllen haben. I) Ee bergie. mit weleher der behailter seinen Inhalt bis zum rollständigen Schwund entleert. spricht dafiir, dab die aus hyaliner Substanz gebildete

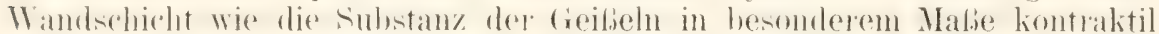
ist mol side dureh diese Eigensohaft vom Entoplasma des Infusorienliönels untersebeilet. Allerdings ist an dem kontraktilen liehälter mikioskopisch

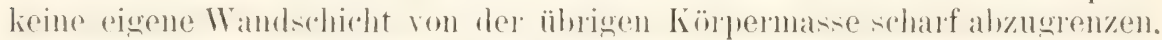
wie ja auch an der glatten Muskelfaser kontraktile Substanz und Protoplasma sich nicht immer sehr deutlich gegen einander absetzen, und wie die Geibeln auch an ihrer Basis in das Protoplasma der Zelle übergehen.

Mit Schwalbe (V 1866) und Engelmann bin ich also der Ansicht, daf. die Behälter eine kontraktile Wandschicht besitzen. welche von der

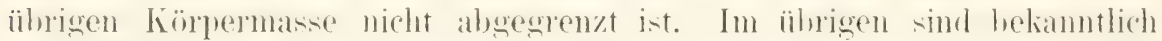
feine Häutchen oft mikrokopisch nicht nachweishar, obwohl sie unzweifelhaft vorhanden sind. An vielen Pflanzenzellen ist es unmöglich, den sogenamien Primordialschlauch zu sehen. solange er der Zellulosemembran fest anliegt, während man sich durch Plasmolyse von seinem Dasein iiberzeugen kann.

Mit dieser Auftassung befinde ich mich mit Bütschli (V 1889) im Widersuruch. Iütscutu hetrachtet lie kontraktilen Behäler als einfache Flüssigkeitstropfen im Plasma. .Jerle Vakuole hört mit ihrer Austreihung als solche zu existieren aut. Ihre Nachfolgerin ist ein ganz nenes (iebille. ein nen entstamlener 'Tropten, welcher wiederum nur bis zur Austreibung existirt." sie entsteht nach ihm turch Zusammentlub mehrerer Bildungsvakuolen, die als kleine Trönfchen in Plasma ansgeschieden werten, sich vergableren und dann durch Einreitien der Zwischenwände verschmelzen. Die auch von BüTschli beschriebene Existenz von zu- und abführenden Kanälen, die Konstanz in der Zahl der Behälter, der Umstand, daß sich der Behälter bei der Diastole an del gleichen Stelle wiederfindet, wo er bei der Sistole verschwumben ist. die Verhälnisse der Frefuenz hei gleichbleihender 'Temperatu' und bei Temperaturschwankungen scheinen mir gegen die Bütschusche Auffassung zu sprechen. Dals am Schlub der Systole der IBehälter nach Austreibung seines Inhaltes momentan nicht sichtbar ist, kann wohl nicht schwer gegen die Annahme seiner Konstanz in die Wagschale fallen, wenn man berïcksichtigt, daß selbst große Lxmphspalten und kapillare IBhtgefäbe bei den Wirbeltieren sich im uninjizierten Zustand der Wahrnehmung entziehen kömnen.

\section{Veräinderung der Zellkörpers durch passive Bewegung.}

Un das Bild der Protoplasmabewegungen nach allen Seiten zu vervollständigen. ist endlich noch der Formveränderungen zu gedenken. welche der Zellkörper gewissermaßen durch passive Bewegungen erfahren kann. Die Zelle befindet sich hier in derselben Lage wie ein Muskel, der durch eine von außen auf ihn einwirkende Kraft, die an den Gliedmaken ansetzt, gedehnt und wieder verkürzt wird.

So verändern die Zellen des tierischen Körpers zuweilen in auferordentlich hohem frarle ihre Form. indem sie sich allen Gestaltrerände- 
rungen anpassen müssen, welche einzelne Organe infolge von Muskelwirkung oder durch Dehmung bei Ansammlung von Flüssigkeit und Nahrung erfahren. Fadenförmige Epithelzellen müssen sich in Zylinder, diese in Platten umwandeln, wemn bei Dehmung eines Organs sich die Obertläiche vergröbert, und die umgekehrte Metamorphose mïssen sie wieder durchmachen. wenn sich das ganze Organ und mithin auch seine Ohertiache verkleinert.

Was für gewaltige und urplötzliche Fornueränderungen der Protoplasmakö̈lver einer Zelle ohme Vernichtung seiner feinen Struktur infolge passiver Bewegungen ertrïgt, zejgen uns am schönsten die Coelenteraten. bei welchen sich ausgestreckte Körperteile wie Fangfäden aut ein Zehntel oder mehr durch plötzliche, energische Muskelzusammenziehung verkürzen können. (HERTwig.

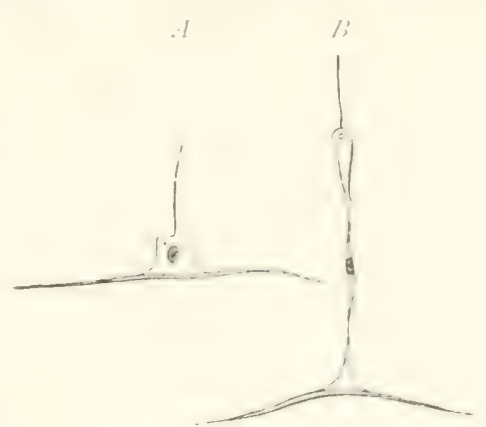

Fig. $)$ Epithelmuskelzellen aus der entodermalen Auskleidung der Tentakeln einer Actinie (Sagartia parasitica). Nach R. und (). HERTWIG, 'Taf. VI, Iig. 11 ; ans $H_{\mathrm{AT}}$ scHeK Fig. 10s. A im ausgedehnten Zustand, $B$ im stark verkiirzten $/ / 1$ stand der Tentakeln.

O. und R., Y 1879). Die Form. welche

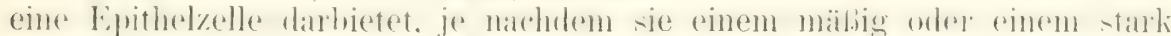

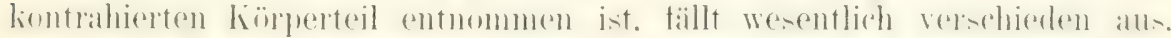
wie die Figuren $\$ 6$ A und $B$ lehren. Die erstere entstammt dem Tentakel einer nur mïbig kontrahierten Actinie. die durch rhemische stoffer

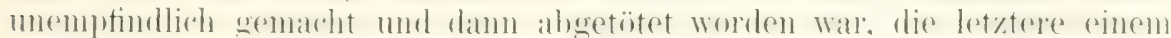
ber der Ahtönne stïlier kontrahierten Tontakel eines anderen Individumms.

\section{Literatur V.}

1) Apáthy, Das leitende Element des Nereensystems und seine topographischen Bealehumgen zul den Zellen. Mitteil. ans d. Koolog. Station an Leapel. Bd. XII. 1800.

2) De Bary, Die M/ycetosocn. Zeitschrift f. aissenschaft. Zoologie. Bd. I. I860.

3) Berthold, G., Sindien über Protoplasmamechanik. Leipzig 1886.

4) Bütschli, Protozoen. Erster Band von Bronns Klassen and Ordnungen des Tierreichs. 1880 .

5) Ecker, Alex., Zur Lehre z'om Boue und Leben der kontraktilen Substanz der niedersten There. Zeitschrift f. wissenschaftl. Zoologie. Bd. I. 1840.

(i) Engelmann, Physiolosic der Protoplasma- und fimmerbeaegung. Hermanns ITamtbuch der Physiologie. Bd. I. 1870.

7) Derselbe, Sontrakitität and Doppelbrechens. Archio für die gesamte Phusiolosit. bid. $\mathrm{X} \%$. 1875 .

8) Derselbe, Über die Bewemugen der Oscillarien und Diatomeen. Pflïgers Archiz', Bid. W/. $1870^{*}$

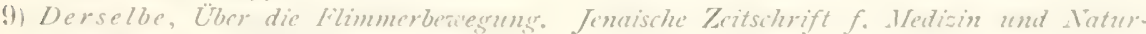
wissenschaft. Bal. II. I868.

10) Frommann, Beobachtungen ïber Struktur- und Benegungserscheinumeen de's Protoplasmas der P'plananzelle. Jena 1889.

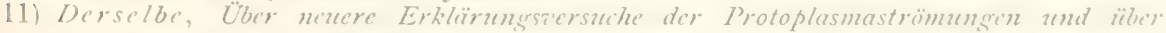
Schanmstrukturen Bietschlis. Anatom. Inzeiger. I80o.

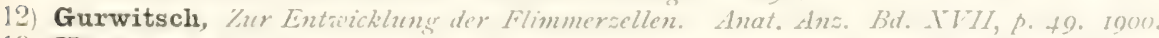

13) Henneguy, Sur les rapports des cils vibratiles azec le's controsomes. Archizes at Anutomie mikroscopique 1808 .

11 Hensen, Physiologic der Zenguns. Hanubuth der Physiologie. Bu. IY. ISSI.

i) Hertwig, 0. $u$, R., Die Actinim. Jena 7870 .

0. Hertwig, Allemeine Biologie. 2. Aufl. 
16) Hertwig, Richard, Über Mikrogromia socialis, cine Tolonie bildende Monothalamie des sïßen IIissers. Archiv f. mikroskop. Anat. Jid. A. I87t.

17) Jürgensen, ¿̈ber die in den Zellen der Fallisnerin spiralis stattfindenden Beategungserscheimungen. Studien des physiol. Instituts zu Breslan. 1861. lleft I.

1.4 Klebs, form und II esen der pflanzlichen Protoplasmaberieguns. Biologisches Central. blatt. Bat. I. $18 \$ 1$.

19) Kollmann, ¿̈be'tierisches Protoplasma. Biolog. Centralblatt. 1Bd. II. I882.

311) Lenhossek, Z̈ber Fimmersellen. Ferhandl. der anatom. Gesellschaft, p. Io6. I898.

21) Meves, Fr., Über Zentralkörper in männlichen Geschlechtsaellen von Schmetterlingen. Anat. Ans. Bid. TII. I897.

22) Nägeli, C., Die Bewegung im Pfansenreiche. Beiträge zur wissenschaftlichen Botanik. lleft 2. 1860 .

23) Derselbe. Rechts und links. Ortsbeziegungen der Pflanzenzellen z. ihrer Teile. Ebendas.

24) Petex, Karl, Das Zentrum für die Flimmer- und Geißelberegung. Anatom. Anz. Ba. X广: P. $271 . \quad 1899$.

25) Purkinje u. Valentin, De placnomeno generali et fundamentali motus vibratoril continuti. 1835 .

26) Quincke, G., Über periodische Ausbreitung an Flïssigkeitsoberflächen und adadurch hervorgerufene Berelegungserscheinungen. Sitzungsber. der Akademie der Wissenscluaften zu Berlin. 1888.

27) Rossbach, Die rhythmischen Bervegungserscheimungen der einfachen Organismen und ihr Verhalten gegen physikalische Agentien und Arzneimittel. Arbeiten ans dem zool.-zoot. Institut zu IVürzburg. 1874 .

28) Sachs, Experimentalphysiologie der Pflanzen. Leipzig 1865.

29) Schwalbe, Über die kontraktilen Behälter der Infusorien. Archiv f. mikroskopische Anatomie. Bd. II. 1866.

30) Velten, Einwirkung strömender Elektrizität anf die Bervegung des Protoplasmas etc. Sitsungsber. d. IViener Akademie. Bd. LXXIII. 1876.

31) Verworn, Studien zur Physiologie der Flinmerberegung. Pflïg. Arch. Bd. XLVIII. I890.

32) Derselbe. Die Bewegung der lebendigen Substana. Jena 1892.

33) de Vries, Uber die Bedeutung der Zirkulation und der Rotation des Protoplasmas für den Stofftransport in der Pfanze. Botanische Leitung. 1885. 


\section{SICHSTES KAPITEL.}

\section{Die Lebenseigenschaften der Zelle.}

\section{IIla. Das Wesen der Reizerscheinungen.}

Die wunderbarste Eigenschaft des Protoplasmas ist seine Reizbarkeit oder Irritabilität. Darmuter versteht man. wie SACHs (IV 185\%) sich ausdrückt. ..die nur den lebenden Organismen eigentümliche Art, auf die verschiedensten Einwirkungen der Aubenwelt in dieser oder jener Weise z.1 reagieren". Durch die Irritabilitit unterscheidet sich am meisten die belebte von der unbelebten Natur, und wurden infolgedessen ältere Naturforscher veranlabt, in ihr den Ausdruck einer besonderen. nur der organischen Natur zukommenden Lebenskraft zu erblicken.

Die morlerne Naturwissensehaft hat die vitalistische Lehre (Vitalismus) fallen gelassen; anstatt durch Annahme einer besonderen Lebenskraft. erklärt sie die Reizloarkeit als ein sehr zusammengesetztes. chemisch-

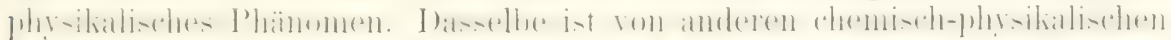
Phänomenen der unbelebten Natur nur graduell verschieden. nämlich nur

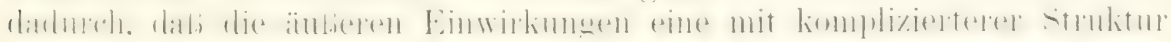
versehene Substanz, einen Organismus, ein hoch zusammengesetztes. materielles System, treffen und dementsprechend in ihm auch eine Reihe liomplizierterer Vorgänge verursachen. Durch eine Reihe von Betrachtungen

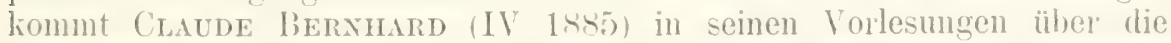
Phänomene des Lebens zu dem gleichen Endergebnis: ..Arrivés au terme de nos études. nous voyons quelles nous imposent une conclusion très générale. fruit de lexpérience. c’est. ¿ savoir, qu’entre les deux écoles qui font des phénomènes vitaux quelupue chose dabsolument distincte des phénomènes physico-chimiques ou quelque chose de tout à fait identique ì enx, il y a place pour une troisième doctrine. celle du vitalisme physigue. gui tient compte de ce quil y a de spécial danis les manifestations de la vie et de ce yuil y a de conforme à laction des forces générales: l'élément ultime du phénomène est physique: larrangement est vital."

Dahel darf man nicht in einen häufig gemachten Fehler verfallen. aus Analogien, die manche Erscheinungen der mbelehten Natur mit Lebensvorgingen haben, die letzteren direkt mechanisch erklïren zu wollen. Hier ist inmer in Auge zu behalten, dab eine Substanz ron so rerwickelter Struktur wie die lehende \%elle anch nicht im entferntesten

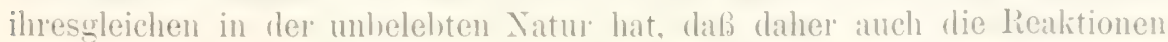


einer derartigen Substanz ein entsprechend liomplizierteres Gepräge an sich tragen.

So vollkommen unverständlich und mechanisch unerklärbar uns die meisten Lebensïufierungen der \%elle zur\%eit noch erscheinen, so vollziehen sie sich doch - hierin stimmen Philosophen und Naturforscher untereinander äberein - mach dem allgemein gïltigen Kausalgeset\%. liraft dessen jede Veränderung eines Zustandes die Wirkung von volausgegangenen Ursachen ist und selbst wieder die Ursache für nene Veränderungen wird. Es ist daher hier wohl am Plat\%. als Grundlage für weitere

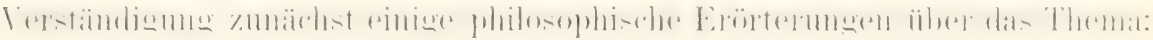

\section{Das Kausalitätsgesetz in seiner Anwendung auf den Organismus}

vorauszuschicken.

Die Ursachen, welche an einem liomplizierter beschaftenen mechanischen System von zusammengehörigen T'eilen Veränderungen bewirken, lassen sich in zwei Gruppen einteilen, in die cansae externae und die causae internae. Zu den ersteren gehören alle Veränderungen der Auljenwelt, welche das System treffen und es in seinen einzelnen Teilen beeinflussen, zur zweiten (iruppe rechmen wir die Veränderungen. die sich im System selbst vollziehen und dadurch Ursachen werden. indem sie weitere Folgen nach sich ziehen. Wenn im System ein Teil sich verändert, \%. B. infolge eines äuferen Anstoßes, so wird er wieder die Ursache für V'eränderungen in allen übrigen T'eilen. welche mit ihm in Beziehung stehen, und diese werlen nun ihrerseits wieder Ursachen für neue Wirkungen. durch welche das System in eine fortlaufende Reihe von Bewegungen versetzt wirl.

Dieselbe Unterscheidung läbt sich auch an der lebenden Zelle durchführen, welche ja, wie wir gesehen haben, ein zweckmäBig geordnetes System zahlreicher einfacherer Lebenseinheiten darstellt. Auf dasselbe wirkt, wie auf jerles andere Naturobjekt, rie gesamte AuBenwelt mit inren verschiedenartigen Kräften ein und liefert eine fortlaufende Reihe von äberen Ursachen (causae externae), welche in ihm Veränderungen hervorufen. Denn zwischen der Zelle und ihrer Umgebung tindet ein beständiger Stoft- und Kraftwechsel statt. Licht und Wärme. die verschiedenen mechanischen Kräfte und zahlreiche chemische Affinitäten. welche in den Stoffen der Luft, des Wassers und der Erde wirksam sind, treten hierbei ins Spiel und bilden eine unerschöpfliche (ouclle für biologische Untersuchungen.

Von den äuberen Ursachen sind dann die inneren Ursachen im Leben der Zelle zu unterscheiden. Denn ebenso wie die T'eile in einem mechanischen System stehen die einfacheren Lebenseinheiten, aus denen sich die Zelle, ihr Protoplasma, ihr Kern, die imneren und äuBeren Zellprodukte aufbauen, in derartigen Beziehungen zueinander, dab V'eränder'mgen, die in einem 'Teil des Aggregates eintreten, solche auch an anderen Teilen nach sich ziehen. Somit ist jerle Teränderung eines zusammengesetzten Srstems das mehr orler minder komplizierte Resultat sehr vieler Ursachen, die zum 'Teil von innen heraus sich im System seller geltend machen; auch liegt es auf der Hand, dab. je gröfer die Zahl aller in Betracht kommenden Faktoren wird. un so mehr das Ineinandergreifen der zahlreichen Ursachen und Wirkungen, die sich neben- und nacheinander im Prozef abspielen, sich einer erschöpfenden Analyse und einer klaren Erkenntnis entziehen muf. In höchstem Maße ist dies bei dem 
Lebensprozelo ptlanzlicher und tierischer Zellen der Fall, so dali uns der

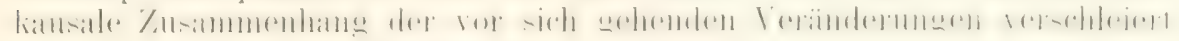
wirl. Daher hat SchopenmuUer

\section{Versehiedene Formen der Kausalitait}

unterschicden als Ursache in engstem Sinne, als Reizund als Motir.

.Die Lrsache in engstem Sinne ist die, nach welcher ausschlieblich die Verïnderungen im unorganischen keich erfolgen, also diejenigen Wirkmoen, welche das Thema der Mechanik, der Physik und der Chemie sind. Von ihr allein gilt das dritte NewToxsche Grundgesetz: "Wirkung mol fiegenwirkmer sind emander gleich"; es besagt, dab der vorhergehende Zustand (die Ursache) eine Veränderung erfährt, die an Grölie der gleichkommt, die er hervorgerufen hat (die Wirkung). Ferner ist nur bei dieser Form der Kausalitat der Grad der Wirkumg dem Grade der Ursache stets genau angemessen, so dab aus dieser jene sich berechmen lïbt und umgekehrt."

Daher erscheint nus die Kansalität am fablichsten bei mechanischen Wirkungen. Wenn eine ruhende Kugel durch den Stols einer rollenden lingel in bewegung versetzt wird, so gewinnt die erstere so viel an bewegmm, als die letztere verliert. „Hier sehen wir gleichsam die Ursache in die Wirkung hinüherwandern." "Das dabei doch noch rorhandene Geheimnisvolle beschränkt sich auf die Möglichkeit des Übergangs der Bewegung - eines Unkörperlichen - aus einem Körper in den andern."

„Die zweite Fol'm der Kausalität ist der lieiz, d. h., diejenige Ursache, welche erstlich selbst keine mit ihrer Einwirkung in Verhälnis stehende (regenwirkung erleidet, und zweitens zwischen deren Intensität mnd der Intensität der Wirkung durchaus keine Gleichmäßigkeit stattfindet. Folglich kamn hier nicht der Grad der Wirkung gemessen und vorher bestimmt werden nach dem Grad der Ursache: viehmehr liann eine kleme Termehrung des Reizes eine sehr große der Wirkumg verursachen oder auch umgekehrt die vorige Wirkung ganz autheben, ja, eine entgegengesetzte herbeiführen.: "Reize beherrschen das organische Leben als solches, also das der Ptlanzen, und den vegetativen, daher bewubtlosen Teil des tierischen Lebens."

As dritte Form der Kansalitit nemnt Scmopenhauer das Motiv: sie leitet das eigentlich animalische Leben, also das Tum, d. h. die äuberen, mit Bewubtsein geschehenden Aktionen aller tierischen Wesen. „Das Medium der Motive ist die Erkenntnis: die Empfünglichkeit tür sie erforlert folglich einen Intellekt." "Sie ist die durch das Erkennen hindurchgehende Kausalität."

Wahrend die mechanische Kausalität die am leichtesten fabliche ist. weil Ursache und Irirkung sich aneinander messen lassen, verliert bei den höheren Formen der Kausalitait. beim Reiz und beim Motiv. der kausale Vorgang an mmittelbarer Fablichkeit und Verständlichlieit: bei ihmen werden Ursache und Wirkmg heterogener. .Nur das Schema von Ursache und Wirkmg ist uns geblieben: wir erkennen dieses als Ursache. jenes als Wirkung, aber gar nichts ron der Art und Weise der Kausalität. Und nicht mur findet lieine qualitative Ähnlichlieit zwischen der Ursache mol der Wirkung statt, sondern auch kein quantitatives Verhältnis: mehr und mehr erscheint die Wirkung beträchtlicher als die Lrsache: auch 
wïhst die Wirkung des Reizes nicht nach Maßsgabe seiner Steigerung, sondern oft ist es umgekehrt."

liei seinen Erörterungen über die verschiedenen Formen der hansalität hat SchopenhaUER, um nicht Mibverständnisse aufliommen zu lassen, die Frage aufgeworfen, ob bei der mehr und mehr eintretenden

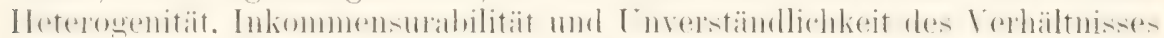
zwischen Ursache und Wirkung etwa auch die durch dasselbe gesetzte Notwendigkeit abgenommen habe. Und mit Recht antwortet er hierauf:

„Keineswegs, nicht im mindesten. So notwendig, wie die rollende Kugel die ruhende in Bewegung setzt, muß auch die Leidener Flasche, bei Berührung mit der andern Hand, sich entladen - mul, auch Arsenik jedes Lebende töten — muß auch das Samenkorn, welches, trocken aufbewahrt, Jahrtausende hindurch keine Veränderung zeigte, sobald es, in den gehörigen Boden gebracht, dem Einflub der Luft, des Lichtes, der Wärme, der Feuchtigkeit ausgesetzt ist, keimen, wachsen und sich zur PHanze entwickeln. Die Ursache ist komplizierter, die Wirkung heterogener, aber die Notwendigkeit, mit der sie eintritt, nicht um ein Haar breit geringer."

Da die durch das Wort Reiz bezeichnete Form der Kausalitit im

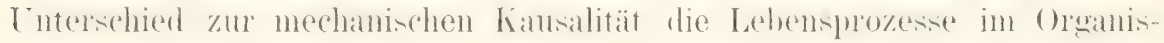
menreich beherrscht und für sie charakteristisch ist. sei hier noch etwas näher auf sie eingegangen. Wir werden hierbei das 'Thema etwas weiter fassen, indem wir uns nicht auf die Zelle beschränken, sondern rom Verhalten des lebenden Organismus gegenüber Reizen im allgemeinen hambeln.

Das Gebiet der Reizerscheinungen ist ein sehr umfangreiches, da es die gesanten Wechselhezichungen unfabt, welche zwishen den ()ranismen und der Außenwelt stattfinden. Denn unzählig sind die von auBen auf uns einwirkenden Reizursachen, welche wir später der Übersichtlichkeit halber in fünf Gruppen besprechen werden. Eine Gruppe umfaßt die thermischen Reize, eine zweite die Einwirkungen des Lichtes, eine dritte die Einwirkmuen der Elektrizitit. aine vierte die mechanischen licize und eine fünfte endlich dlas unerschöpfliche Gebiet der chemischen Reize.

Bei ihrem Studium wird man bald gewahr werden, daß sehr häufig zwishen Reizursache und Reizwirkung eine soldhe Inispoportionalitat besteht, daß man ohne vorausgegangene Erfahrung nicht in der Lage ist, die Reizwirkung im voraus für einen bestimmten Fall zu berechnen. Die I)isproportionalitit erkiart sich ans der komplizierten Natur der lebenden Substanz. Denn in ihr ruft der Reiz, wie schon oben angedeutet wurde, Reihen von V'eränderungen hervor, die sich imnerhalb des von ihm getroffenen Systems als, "imnere Ursachen und Wirkungen" in einer für uns nicht ummittelbar wahrnehmbaren mul daher unverständlichen Weise abspielen, um schließlich in einer Erscheinung, die wir als die Reizwirkung bezeichnen, für uns erkennbar zu werden. Die Ursache geht also hier nicht unmittelbar. wie es bei den einfachsten und daher am leichtesten faßlichen Verhältnissen der mechanischen Kausalität, \%. B. bei dem Aufeinanderstolien zweier Kugeln, der Fall ist, in die Reizwirkung über, sondern erst durch Vermittlung einer mehr oder minder langen Kette yon Ursachen und Wirkungen, die sich im zusammengesetzten System als Bindeglieder dazwischen schieben; sie sind es, welche der Reizwirkung den Charakter des Geheimnisvollen und Unverständlichen aufurägen. Denn die erste Ursache wird in der organischen Substanz, welcher man wegen ihres eigentümlichen Verhaltens auch das Prädikat "reizbar" beilegt. 
gewissermaben noch vieltach umgesetzt, ehe sie als Reizwirkmng in irgend einer frorm für uns wieder zum lorschein liommt.

Den ganzen Vorgang kömen wir uns anschaulich machen, wenn wil die reizbare Substanz mit emem irgend wie zusammengesetzten Maschinenwerk vergleichen.

Fin Mühland wird durch das ant seine Sehaufeln fallende Wasser hewegt, und aus dem Mahlgang einer Müllle fällt fein zerriebenes Melıl heraus. So oft das Wasser abgestellt wirl. hört das Mehl zu Hielien aut. liehrt aber wieler, wenn das Wasser auf das had faillt. Wir haben hier also ottenbar zwei Veränderungen, welehe in einem kausalen \%usammenhang miteinander stehen. Auch hier sind Ursache und Wirliumg. das auf ein Mühlad herabfallende Wasser und das aus dem Mahleang anstretende, fein zerriebene Mehl, einander seln heterogen, in almlicher Weise wie es im Organismus gewöhnlich Reiz und Reizeffekt sind. Es schieht sich eben auch lier eine ganze Kette von Ursachen und Wirkungen dazwischen, die sich für den Aufenstehenden unverständlich im Innern des ihm nicht zugänglichen Mühlwerks vollziehen: die Übertragung der Bewegung des Wasserrades vermittelst seiner Achse auf ein System anderer Räder, welche ihre Bewegung dam wieler in die Bewegung der Mahlsteine umsetzen, der Müllerbursche schlielilich, welcher immer nenes Korn in den Mahlgang einschüttet.

Die zwischen Reizursache und Wirkung zu Tage tretende Disproportionalität kamn sich in ciner doppelten Weise geltend machen: cimmal kann ein und derselbe Organismus auf verschiedene Reize immer in der gleichen Weise reagieren, zweitens kam ein und derselbe Reiz, auf verschiedene Organismen angewandt, ganz heterogene Wirkungen hervorr'ufen.

Auch hier wird ein Vergleich mit komplizierter gebanten mechanischen

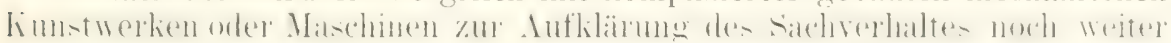
beitragen. Was die Frlklärung des ersten Falls betrifft, so kamn in einer Uhr eine Verlangsamung, eine Beschleunigung oder ein Stillstand des

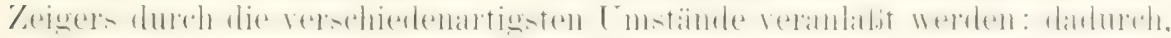
daf ich mit einer Nadel oder einem anderen passenden Instrument einen Druck gegen ein Rädchen ausübe. oder dadurch. daf ich an das Rädchen Säure bringe, worlurch sich Rost bildet, oder dadurch, dab ich durch lokale, in geeigneter Weise hervorgerufene Erhitzung ein Zühnchen an Rarle wegschmelze, orlel dadurch, dab sich das Öl, welches die Reibung im Räderwerk verringern soll, eingedickt oder ein festes Kömchen sich zwischen zwei Räilchen eingeklemmt hat etc.

Auf mechanische, thermische, chemische Einflüsse reagiert die ${ }^{\top} \mathrm{H}_{\mathrm{r}}$ in einer für uns sichtbaren Wreise unterschiedslos durch Verlangsamung. Beschleunigung oder Stillstand des Zeigers. Es längt dies eben mit der eigentïmlichen lionstruktion der Uhr zusammen. vermöge deren die verschiedenartigsten Störungen ihres Mechanismus sich jerlesmal im Gang des Zeigers äußern; die Qualitait der die Stönung bewirkenden Lrsachen aber bleibt für uns bei äuferlicher lietrachtung verborgen. Sic wircl erst oftenbar, wenn wir in das Innere des Lhrgetriebes hineinblicken und so gleichsam die inneren Ursachen der Störung zu ergründen suchen. Aus der Endwirkung allein labt sich nicht die Art der Ursache erschliehen.

Zur Erliärung des zweiten Falls kann die Art und Weise dienen wie gegen ein und dieselbe Ursache verschieden konstruierte Maschinen reagieren. Die fül die Uhr beschriebenen Eingrifte, angewandt anf ein

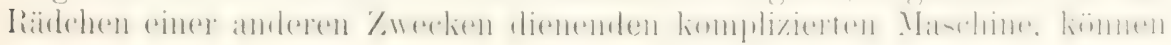


auch hier wieder eine Störumg des Mechanismus bewirlien, die sich aber ron der Störung im Gange der Uhr ganz verschieden äußert. in einer Spieldose zum Beispiel durch das Austallen einiger 'Töne.

Jele Maschine reagiert also auf den gleichen Eingriff in ilıer be-

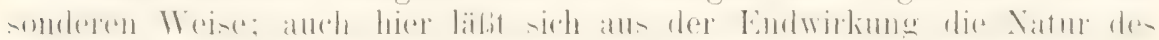
angewandten Lingriffes, die Qualität der Ursache, nicht erkemmen. Entscheidend ist die der Maschine eigentümliche Konstrulition.

In ähnlicher Weise wie verschieden konstruierte Maschinen verhalten sich demselben Reiz gegenüber rerschiedene reizbare Substanzen, sie reagieren gemäb ihrer besonderen Struktur. Man bezeichnet in der Physio-

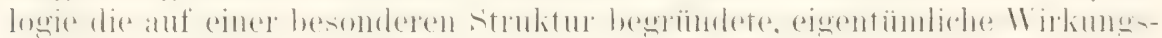
weise der Organismen, ihrer Organe und der Zellen mit einem Ausdruck, der yon JoH. MÜLter eingeführt ist. als ihre spezifische Energie. Wie eine Uhr auf verschiedene Eingriffe durch den Gang des Zeigers. so antwortet eine Nuskelzelle auf jede Art von Reiz durch Zusammenziehung, eine Drüsenzelle durch Sekretion; ein Sehnerv kann nur Licht

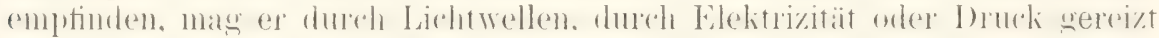
werden etc. In derselben Weise sind auch die Pthanzenzellen. wie SAcHs gezeigt hat, mit ihren spezifischen Energien ausgestattet. Ranken und Wurzehn krümmen sich in der ihnen eigenen Weise, gleichgültig, ob sie durch Licht, durch Schwerkraft, durch Druck oder elektrischen Strom gereizt werden. Und ebenso antworten auf die gleiche Reizursache ver-

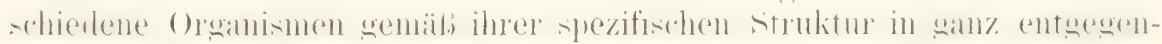

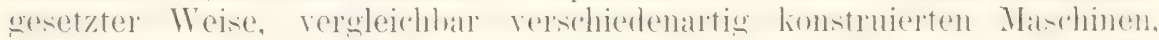

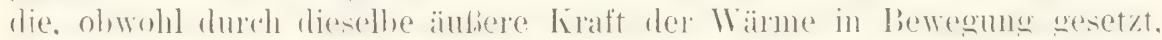
doch je nach ihrer inneren Konstruktion bald diesen, bald jenen Nutzeftekt liefern.

Wir werden im folgenden sehen. wie manche Protoplasmakörper durch Licht gewissermaben angezogen, andere abgestoben werden, und wie sich dasselbe Schauspiel bei dem Studiun der Wirkung chemischer Substanzen etc. wiederholt. Man spricht dann ron einem positiven und negativen Heliotropismus, einem positiven und negativen Chemotropismus, Galvanotropismus, Geotropismus ete.

Somit können wir zusammenfassend sagen: Die Reizwirkung erhält überall ihr spezifisches Gepräge durch die besondere Struktur der reizbaren Substanz. oder in anderen Worten, die Reizbarkeit ist eine Grundeigenschaft des lebenden Protoplasmas, aber sie äubert sich je nach seiner spezifischen Struktur unter dem EinfluB der AuBenwelt in spezifischen Energien und Reizwirkungen.

Denselben Gerlankengang hat CLaude Bernard (I T 1885) in folgender IVeise ausgedrïckt: La sensibilité, considérée comme propriété du système nerveux, n’a rien d'essentiel ou de spécifiquement distinct; cest l'irritabilité spéciale an nerf, comme la propriété de contraction est l'irritabilité spéciale au muscle. comme la propriété de sécrétion est lirritabilité spéciale a lélément glandulaire. Ainsi, ces propriétés sur lesquelles on fondait la distinction des plantes et animaux ne touchent pas á leur vie même. mais seulement aux mécanismes par lesquels cette vie sexerce. Au fond tous ces mécanismes sont soumis á une condition générale et commune. liirritabilité.

Um unser wichtiges Thema ron der Disproportionalität zwischen Reizursache und Wirkung noch erschöpfender zu behandeln, sei jetzt auch darauf hingewiesen, wie infolge der Kausalverkettung innerer Ursachen 
und Wirkmngen in der reizbaren Substanz der Zusammenhang zwischen erster Reiz-Ursache und ihrer Fnd-Wirkmong nach \%eit und Raum in der vershiedensten Wreise modifizient werlen liam.

So ruft in manchen Fïllen ein stärkerer Reiz von kïrzerer Daner an der reizharen Substanz Veränderumgen hervor, die sich über einen längeren Zeitraum erstrecken und in Wirkungen nach aulien hervortreten. Durch die Struktur der reizharen Substanz ist hier ein Verhältuis geschaffen. welches uns anch wieler durch Vergleich mit mechanischen honstruktionen. \%. B. einer Thr, verstündlich wird. Das in wenigen Sekunden beendete Autzichen emer Uhr ist die äubere Ursache für ihren Gang. der stunden. 'Tage oder selbst Wochen dauert: die nach auben hervortretende Whirkmg ist die gleichmabige Bewegmng des \%eigers. Mit der lionstruktion der L'hr hängt es zusammen. dab die durch das Aufziehen der L'H gegehene Lrsache sich erst in einem längeren Zeitraum als Wirkung ganz freimachen kamn. Denn infolge der Konstruktion kann die der Feder erteilte spannliraft sich erst dadurch. dab sie das den Zeiger treibende Räilerwerk in bewegung setzt, allmählich erschöpfen. In der sprache der Physik wïrden wir sagen, die in der Ursache enthaltene, d. h. die beim Antziehen der Uhr verbrauchte lebendige Kraft ist in der Zeit von Sekunden in Sinmmbaft umgewandelt worden, die gemäl. der lionstruktion der Uhr erst in längerer 'Zeit wieler in lebendige Kraft übergehen kann.

Bei den Reizerscheinungen lälit sich terner nicht selten beobachten. dab.) zwischen dem einwirkenden Reiz und dem Anftreten der Wirliung eine lïngere Pause liegt, die durch die inneren, der Wahrnehmung entzogenen Umsetzungen in Anspruch genommen wird. Hier sprieht man damn in der Physiologie von Reiznachwirkmngen und bezeichnet damit ein Gebiet. auf welchem gewöhnlich die hausalität für uns am meisten in ein geheimnisvolles Dunkel eingehüllt ist.

Wie zeitlich. so können auch räumlich Reizursache und Wirkung weit auseinander fallen, das heilit, der Reiz triftit nur eine kleine Stelle der reizharen Substanz. kommt aber an dieser selhst nicht zur sichtbaren Wirkung, sondern an einem nnter Umständen weit abgelewenen Ort. So tritt \%. B. (ler auf einen motorischen Nerven an seiner Austrittsstelle aus dem Rüickemmark ausgeübte Reiz als Wirkung in der Kontraktion eines mehr orler minder weit abgelegenen Muskels in die Erscheinumg. Hier tindet also eine Reizfortpflan\%ung oder Rei\%leitung statt: es schiebt sich zwischen die Eintrittsstelle des Reizes und und den Ort der sichtbar werdenden Wirkmug reizbare Substanz, in welcher durch eine liette innerer Ursachen der Reiz umgesetzt und von dem Ort des Eintritts zum Ort der zutage tretenden Reizwirlimg fortgepflanzt wirl. Die Reizleitung erfolgt im allgememen rascher im tierischen Körper. als im ptlanzlichen Protoplasma. Für die Verven des Menschen heträgt sie \%. I?. 3t $m$ in der Sekunde.

Man stellt sich vor, tab die reizhare Substanz ein in labilem (ileichgewicht befindliches System materieller, mit hohen Spammliäften ausgerïsteter Teilchen ist. In einem solchen System genügt ein geringer Instol.' eines 'Teilchens. mu anch alle anderen T'eilchen mit in liewegms zu rersetzen. indem das eine auf das andere seme Bewermug überträgt. Daraus erklärt sich noch eine letzte Form der Disproportionalitä, die zwischen Reizursache und Wirkung häufig stattfindet. Ein kleiner lieiz hat eine ihm gar nicht entsprechende, auberordentlich grobe Reizwirkung zur Folge, gleichwie ein durch einen Funken entzündetes Pulverliörnchen eine gewaltige Pulvermasse zur Explosion bringen kam. Namentlich ist 
dies bei fast allen Wirkungen der Fall, die durch Reizung von Nerven hervolgerufen werden.

Ein kontrahierter Muskel. der ein schweres fewicht hebt. führt eine

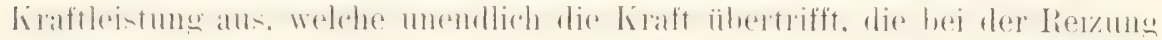
des Terven wirkte. welche die Muskelkontraktion hervorrief. Und dasselbe ist der Fall, wenn sich plötzlich aus dem Ausfïhrungsgang einer Drüse infolge Reizung ihres Nerven ein reichlicher Strom von Sekret mit seinen chemisch wirksamen Substanzen ergieft. In beiden Fällen erklärt sich die Disproportionalitait zwischen Reiz und Wirkung daraus, dafo der Reiz nur ein (ilied in der kette von vielen Ursachen ist. welche in der reizbaren Substanz das Zustandekommen des Reizeffektes bewirkt haben, und zwal ist es das letzte Glied in der Kette, das noch zum plötzlichen Eintritt der Wirkung erforderlich war. Wegen dieser besonderen Stellung in dem Ablauf der ganzen kausalen Verkettung wird die letzte Ursache auch als die auslösende bezeichnet. im Unterschied zu den ïbrigen Ursachen, welche das Ereignis oft von langer Hand her vorbereiten.

Bei der Muskelfaser sind die vorbereitenden Ursachen die durch den

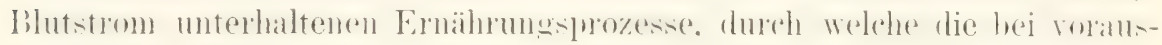
gegangenen Kontraktionen verbrauchten Stoffteile wieder ersetzt werlen: bei der Drüse wird die Sekretion vorbereitet durch Aufnahme von Stoffen. welche in den Drüsenzellen zu spezifischem Sekret verarbeitet und für spätere Verwendung aufgespeichert werden.

Für den Muskel und für die Drüse spielt der dem Nerven mitgeteilte Reiz eine gleiche Rolle wie die Öffinung rles. Ventils bei einer geheizten Lokomotive. Ihre besondere Art zu wirken ist durch ihre Kon-

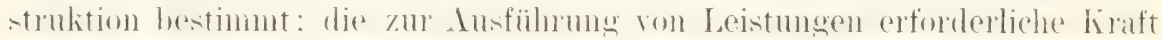
ist anch rothanden. Wem durch Einfuhr und Entzinndung rom Heizmaterial das in den Kessel gefüllte Wasser zum Kochen erhitzt und zum Teil in Dampf mit hoher Spannung verwandelt worden ist. Obwohl so alles für die Bewegung der Lokomotive vorbereitet ist, tritt sie dennoch nicht ein, solange das Ventil, das den Dampf aus dem Kessel zu dem Räderwerk leitet, geschlossen bleibt. Ein schwacher Druck auf das Ventil wird erst die letzte oder die auslösende Ursache, um eine große, in der Einrichtung der Lokomotive schon vorbereitete Wirkung zu entfalten.

\section{Die Bedentung der vielen Ursachen.}

In der vorausgegangenen Darstellung wurde hänfig von mehreren Ursachen gesprochen, die für das Zustandekommen einer Veränderung notwendig sind. Indem ich dies zum Schluß noch eimmal besonders her-

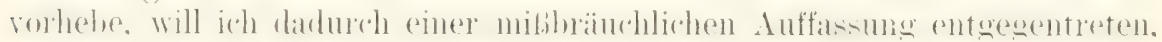
die man nicht selten mit dem Begriff der Ursache verbinclet. So ist man oft bestrebt, eine Veränderung als nur durch eine einzige Ursache veranlabt darzustellen. Besonders häufig wird dieser Irrtum in der Biologie und zumal in der Entwicklungslehre begangen.

Weil die Organismen wegen ilnes zusammengesetzten Baues die

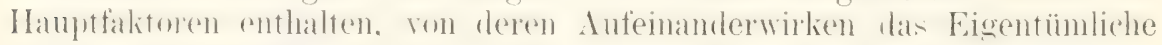
einer an ihmen eintretenden Veränderung abhängt, ptlegt man gern zu iibersehen, daß bei jeder Verïnderung auch noch andere, von außen kommende Ursachen mitwirken, oder man liebt es, wenn man sie nicht

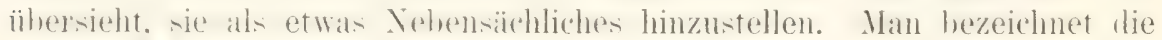
inmeren Faktoren als die „eigentlichen Ursachen“, als ob es eine uneigent- 
liche Lrsache überhaupt geben hömne, die äuberen Ursachen dagegen als bedingungen oder Reize und glaubt, sich dadurch mit ihnen abgefunden zu haben. Man übersieht hierbei. dat. doch die Bedingmugen, sowie sie eintreten. somit auf den Organismus einwirken. selbst ursïchlich werden. daher ..tubere Ursachen sind, und dab der Begritf Reiz mur ein besonderer Name für eine besondere Form der Kausalität ist.

Von den eine Verinderung bewirkenden Ursachen siml im cirunde genommen alle gleich notwentig: demn beim Versagen einer Ursache kam entweder die Veränderung. auch wem sonst alles für sie vorbereitet ist. nicht eintreten. wie die Explosion von Pulver, wenn der zindente Funken ansbleibt, oder sic erfolgt in anderer Weise, als es bei Mitwirkung der ansgebliebenen Ursache geschehen sein wïrle. Damit eine Lokomotive sich fortbewegt. ist ebenso notwendig, wie ihre zweckentsprechende lion-

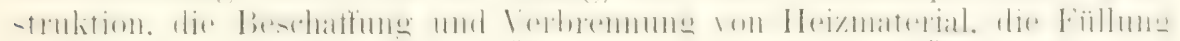
des Kessels mit Wasser. die Öfnumg des Ventils zur Überleitumg des Dampfes auf das Räilerwerk ete.

Ebenso wahl wie treftend bemerlit LotzE: ,Zu jeder Wirkung ist eine Nehrheit ron Ursachen nötig." ..Nach dem bestimmtesten Sprachgebrauch ist Ursache nie etwas anderes als ein wirliches Ding, dessen Eigenschaften, $\| \mathrm{enn}$ sie mit den Eigenschaften eines anderen ebenso wirklich vorhandenen Dinges in eine bestimmte beziehnng treten, mit diesen zusammen genommen den vollständigen Grund darstellen, aus den eine Folge hervorgeht. die hier. wegen der Wirklichkeit der Prämissen, ehenfalls ein wirkliches Ereignis, eine Crsache ist." - .Niemals kann es eine einzige Ursache einer Wirkung geben: demn wo beide Prämissen in einem Dinge vereinigt wären, könnte es kein Hindernis mehr geben. um dessentwillen die Folge zu entstehen zögerte, und so würde unverweilt alles zu einer ruhenden Eigenschaft zusammensinken."

Fs ist daher ebenso irreleitend als falsch. wenn man von der Entwicklung des Eies als von einer Selbstrifferenzierung redet, wie es nicht selten geschieht, als ob das Ei alle Ursachen zu seiner Entwicklung in sich vereinigte.

Allerdings ist nichts leichter. als durch ilialektische Kunstgriffe, deren man sich hei der Darstellung kansaler Verhältnisse bedienen kamn. jemanden zu veranlassen, aus einem Ursachenkomplex nur eine als Ursache für eine eingetretene Veränderung anzugeben, wie es im gewöhnlichen Leben so häutig geschieht. Ich habe dies Verhältnis schon eimmal bei anderer Gelegenheit durch ein Beispiel anschaulich gemacht, dessen ich mich auch hier wieler bediene:

IVir lassen vier befruchtete Eier von Rana fusca sich gleichzeitig bei vier verschiedenen Temperaturen entwickeln, das eine bei - 1 Grad C. das zweite bei ! jard. das dritte bei +15 Grad und das vierte bei $\frac{1}{25}$ cirad. Vergleichen wir am dritten 'Tage die vier Eier, so ist das erste noch ungeteilt, das zweite hat sich wahrscheinlich bis zur Keimblase

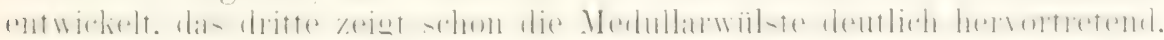
das vierte ist schon ein Embryo, an welchem die Achsenorgane, Medullarrohr, Chorda. Lrsegmente gebildet sind, und das lioptende sich vom Rumpfteil absetzt. Somit sind aus den vier hefruchteten und gleichzeitio während dreier verschiedener 'Tage in Entwichlung begriffenen Eiern vier

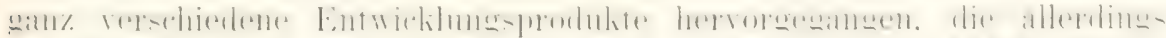

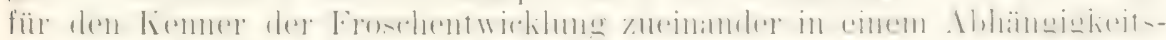

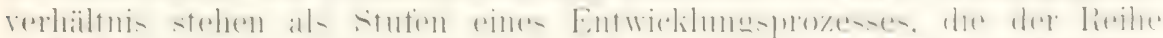

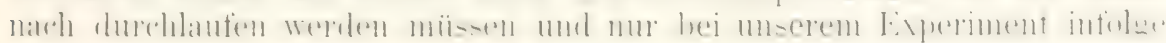




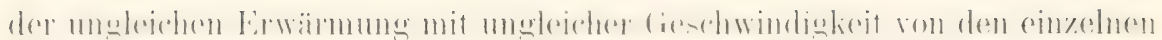
Eiern durchlaufen worden sind. Worin ist num ,.die eigentliche Ursache* (causal effieiens) dafür zu suchen, daß aus den vier Froscheiern in jedem emzelnen Fall etwas anderes geworden ist? Wie ich die Sache dargestellt habe. wird niemand um die Antwort verlegen sein. und die Antwort wird ohne Zaudern lauten. dab die ungleiche Wämezufuhr die causa efficiens ist, welche für die ungleiche Entwicklung der vier Froscheier verantwortlich $7 u$ machen ist und sie erklärt.

Als zweites Peispiel nehmen wir zwei befruchtete Froscheier und zwei frisch abgelegte Hühnereier und setzen von jerler Art eines einer 'Temperatur von $15^{\circ} \mathrm{C}$ und je eines einer 'Temperatur von $38^{\circ} \mathrm{C}$ aus. Wenu wir jetzt nach drei Tagen zusehen, so hat bei der ersten Versuchsbedingung das Froschei sich bis zu dem Hervortreten der Medullarwülste

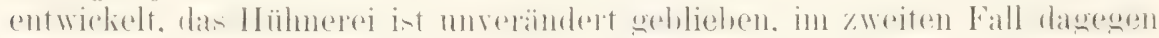
hat sich das Hühmerei schon zu einem kleinen Embryo mit pulsierendem Herz umgewandelt, während das Froschei zwar in Zellen zerlegt, aber abgestorben ist und Zerfallserscheinungen zeigt. Suchen wir auch bei diesem Experiment die Ursache dafür zu ergrürlen, dab die unter denselben Bedingungen befindlichen Eier sich so ungleich entwickelt haben, da6 das Froschei einen Embryo liefert, wo das Hühnerei unentwickelt bleibt und umgekehrt, so wird auch jetzt niemand mit der Erklärung zaulern: die ,eigentliche Ursache" ist in der verschiedenen Organisation orler Anlage der beiden Eier zu suchen.

Aus den für die zwei lieispiele gegebenen verschiedenartigen Erklärumgen läft sich leicht ein Widerspruch, wenigstens dem Anschein nach. herauskonstruieren. Man könnte uns vorhalten, dab wir dafïr, daß das befruchtete, in einer' Temperatur ron $15^{\circ} \mathrm{C}$ befindliche Froschei sich in drei Tagen zu einem Embryo mit Meclullarwülsten entwickelt hat, einmal die Erwärnumg auf $15^{\circ} \mathrm{C}$. das andere Mal dagegen die Organisation der Eizelle als die .causa efficiens" angegeben haben, das eine Mal also einen äußeren. das andere Mal einen imeren Grund: man könnte uns weiterhin fragen, welche yon den beilen Ursachen nun die ,wirkliche Ursache“ sei. Auf diese Weise können sich zwei Disputanten, je nach der Art und Weise, wie sie den Vergleich einrichten und die Frage formulieren, bald den äuberen, bald den inneren Grund als den eigentlichen Grund des Ge-

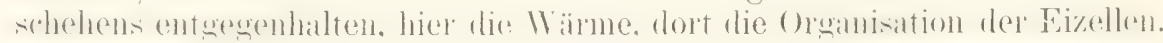

Der hierin liegende Widerspruch ist eben nur ein scheinbarer und leicht zu lösender. Da jerler Entwicklungsprozeß seinem Wesen nach, wie oben schon angeführt wurde, auf immeren und äuBeren Ursachen beruht, so hat jede Veränderung, die an einer Anlage eintritt, stets in beiden ihren Grund und ist aus beiden zu erklären. Bei einer allgemeinen und erschöpfenden Untersuchung eines Entwicklungprozesses ist es daher ebenso falsch. Wenn ich die Ursache in das Ei, als wenn ich sie auferhalb desselben verlegen wollte, da der ganze oder volle Grund stets in beiden ruht. Anders liegt die Sache, wenn ich im konkreten, der Beurteilung vorliegenden Fall den einen oder ander'n frund als eine für die Urteilsbildung nicht erforderliche Größe bei Seite setzen kann. Die inneren Ursachen kommen nicht in Betracht. wem ich den Grund für die Verschiedenheiten der bei ungleichen 'T'emperaturen ungleich entwickelten Froscheier wissen will: denn ich mache hier mit Recht die auf anderen Erfahrungen beruhende Voraussetzung, daß die zum Versuch benutzten Froscheier ein gleichartiges Material mit

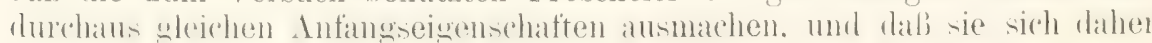


bei gleicher 'Temperatur auch gleich entwickelt haben würden. Folghich kömnen die später \%ur Erscheinmng kommenden Versehiedenheiten nur durch die ungleiche Erwämung in die Eier hineingetragen sein.

Und umgeliehrt kam jeh in dem Experiment, in welchem froschund Hühnereier bei sleicher 'T'emperatur gezüchtet wurden. bei den sich zeigenden Versehiedenheiten den äulieren (irund unberieckichtigt lassen.

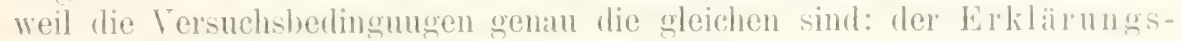
grund ist damn allein im Ei zu suchen.

\section{Vinterschiede zwischen Maschinenwesen und Organismus, gwischen Mechanischem und (organischem.}

bei unserer Erklärung der lieizwirkmgen haben wir zu Veranschanlichung häufjg anf die Vorgïnge verwiesen, wie sie in komplizierter gebanten Maschinen nud mechanischen Kunstwerken (in einer Dampefmaschine, einem Mïhlwerk, einer Uhr oder Spieldose) ablaufen. Da liegt es ziemlich nahe, sich die Frage voryulegen, ans welchem Grunde man nicht anch bei der Maschine von Reiz, Reizwirkung und Reizharkeit spricht.

In der 'Tat denlit man so wenig an eine derartige Gebranchsweise der genamten Worte. sowohl im gewöhnlichen Leben. als in der Wissenschât. dafi man. Wo es qeschähe, es sehr auftallig empfinden wïrde. SchorexhuUer nennt ja geradezu den Reiz als die das organische Leben beherrschende Form der Kansalität. und anch Sichs definiert in diesem Simne ganz mit Recht das Wort Reizbarkeit ,.als die nur den lebenden Organismen eigentïmliche Art. auf Einwirkmgen, welche dieselhen treften, zil reagieren."

Es muf dies doch wohl darin seinen firund haben, dab zwischen der Konstrulition einer Maschine und den durch sie ermöglichten Wirkungsweisen einerseits und der Oranisation der Iebenden Substanz und den durch sie ermöglichten Prozessen andererseits noch ein wesentlicher Unterschied besteht. Denselhen hier in das rechte Licht zu setzen. scheint nus un so notwendiger, als in unseren Tagen ja mehrfach das Bestrehen zu Tage tritt, den Organismus als ein Maschinenwesen zu verstehen und das Organische als ein Mechanisches aus den einfachen (irmulprinzipien der Mechanik zu erklären. Es soll aber jeder Anschein vermieden werlen, als ob durch unsere Veroleiche mit Maschinen einer derartigen Auffassmog gehuldigt wïrde. und soll im Gegenteil, wenn auch nur kury und im allgemeinen. gezeigt werten, daß selw wesentliche Unterschiede zwischen einem Organismus und einem Maschinenwesen bestehen.

Eine Maschine kann nur eine oder höchstens wenige bestimmte Verrichtungen in einer unabänderlich in ihrer bestimmten lionstruktion festgelegten Weise ausführen. Inre einzelnen Konstrulitionsteile liömnen sich nicht selbsttiitig auswechsehn, nene Kombinationen eingehen und sich für verschiedene Verrichtungen. Wechschnden Verhälnnissen entsprechenul. einstellen. Die Maschine kamn daher nicht auf beliebige aubere Eingriffe in einer zweckentsprechenden, vielseitigen Weise reagieren. Der Organismus dagegen ist kraft semes banes hierzu imstande; wie denn schon die einfache Zelle als das Lrbild eines Organismus gegen Mïrme und Licht. sowie gegen alle Arten mechanischer und chemischer Einfllïsse irritabel ist und durch sie \%u den mamnigfachsten Lehensäuljerungen veranlaft wirl. In der Maschine entwickelt sich ein in wanz he- 
stimmter Richtung gebundenes, im Organismus ein auberordentlich freies, vielseitiges Spiel der Kräte.

Der Unterschied läß sich durch einen V'ergleich anschaulicher machen. Maschinenwesen und Organismus verhalten sich wie eine für viele Melodien eingerichtete Spieldose und der lebendige, menschliche Kehliopf mit dem zugehörigen Lungengebläse nebst Nerven- und Muskelapparat. Beide kömnen viele Lieder hervorbringen, aber in wie grundverschiedener

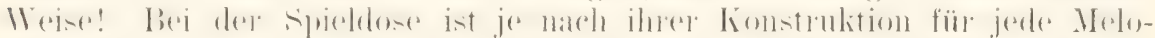
die entwerler eine besondere. mit Stiften versehene Walze oder eine Scheibe mit Einschnitten erforderlich. Bei jerler Melodie mur jedes Mal besonders eine Walze oder Scheibe eingestellt werden. Der Kehlkopf dagegen zeigt lieine, für bestimmte Melodien fest vorgebildete Einrichtungen, er erzengt die Töne willkürlich durch verschiedenartige, unter der Herrschaft

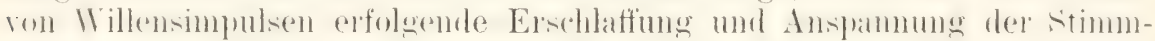
bänder, wobei durch die Stimmritze die Luft balı stärker, bald schwächer in ebenfalls vielfach varierter Weise hindurchgepreft wird. Beherrscht vom Nervenapparat, vermag er die 'Töne in jeder beliebigen Kombination zu Melorlien zu verbinden, was die Spieldose nicht kann, da in ihr die den 'Ton erzeugenden Stiftchen für jedes Lied immer in einer festen Anordnung gegeben sind. Er kam den Ton bald leise, bald stark

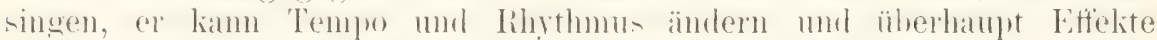

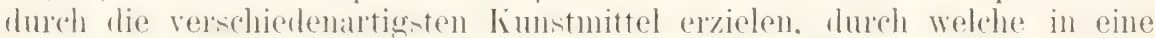
Melodie, wie man sich aushrüickt, erst Seele hineingelegt wird. Die Spieldose verfügt nicht frei über die Mittel zur Hervorbringung, Kombinierung,

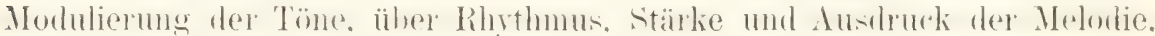
wie es einzig und allein nur der Organismus vermag.

Hierzul kommt ein zweiter Unterschied. Wenn durch einen Reiz der Organismus eine Veränderung erfahren, eine Drüse zum Beispiel das in ihr zur Abscheidung vorbereitete Sekret abgesondert hat, oder der Muskel durch lämere Tätigkeit in seiner struktur alteriert mul ermüdet ist, so trägt el in sich das Vermögen. llach einger \%eit der Ruhe wieder in seinen ursprünglichen Zustand zurïrlizukehren. so dab nun derselbe änlere Reiz wieder eine zu gleicher Veränderung fähige substanz vorfindet.

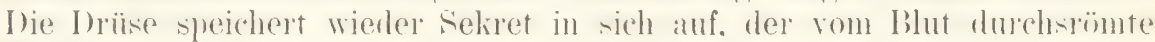
Muskel erholt sich wieder von seiner Emüilung und ist so imstande, wierler genau dieselben Leistungen wie früher hervorzubringen. Eine Maschine dageren hesitzt nicht in ihrer Lonstrulition die Mittel. schallatit weworlene lionstruktionsteile answschalten und gegen nene pinzuwechseh. sie, wenn es nötig ist, mit Oel zu schmieren, Staub und andere Schädlichlieiten zu entfernen, die als lietriedskalt verwendharen chemischen stoffe nach Erfordernis von auben selbsttätig zu beziehen und an die geeigneten

Verbrauchsstellen zu befördern. Die Maschine braucht daher einen Menschen als Betriebsleiter, der sie mit allem. was sie sich nicht beschaffen kann. versorgt.

Wemn schon in allen diesen Beziehungen ein ungeheurer (iegensatz im Wesen der Maschine und des Organismus besteht, so wird er doch noch erheblich vergrößert durch einen dritten Unterschied, der im Vermögen des zellemoranismus gegehen ist. soh in zwei oder mehr Torbterorganismen durch Fortpflanzung zu vermehren. Zumächst wenigstens ist es nach unseren gegenwärtigen Kenntnissen eine ungeheuerliche Vorstellung. eine Mascline zu konstruieren, die durch Vopvelfialtigung ihrer Maschinenteile imstande sein lïmnte, sich in zwei Maschinen zu teilen. 
Aus allen diesen Grïnden bezeichnet man mit richtigem 'Talit auch die volliommenste und in Tätigkeit gesetzte Maschine doch nie als ein lebendiges Wesen. sondern reserviert die Eigenschaft des Lebens nur dem. Organismus; und deswegen spricht man auch nur heim ()rganismus von Reizbarkeit, von Reizursachen und Reizwirkmgen. J)eswegen ist es aber auch ein ganz verfehltes bestreben. sich einzubilden. nach den Prinzipien der Mechanik einen Oranismus begreifen zu kïmnen.

In einer Maschine lassen sich in der 'Tat die ant ihrer lionstruktion beruhenden Wirkungen aus den in Zusammenhang erfolgenden bewe-

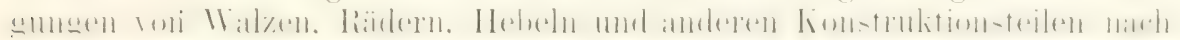
einfach mechanischen Prizipien erklären. In Organismus dagegen beruhen seine Wirkungen vorzugsweise anf den chemischen Prozessen seiner

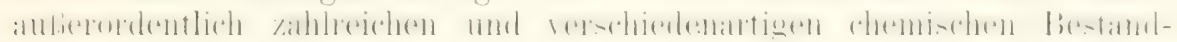
teile, gehören also einem Gebiet an, das zurzeit noch weit entfernt ist. einen Bestandteil der Mechanik anszumachen. Während in der Maschine die Wirkungen durch die Konstruktion der fest verbundenen Teile. die

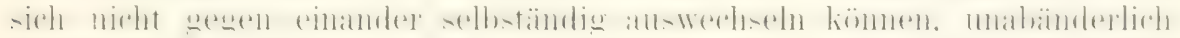

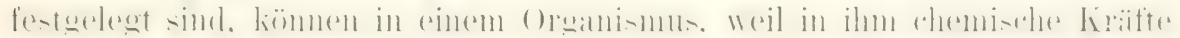
die Herrschaft führen. die Strukturteile seines Banes sich verändern in mannigfacher Weise, es kömnen sich unter den zahlreichen organischen

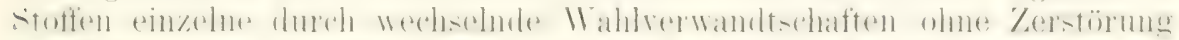

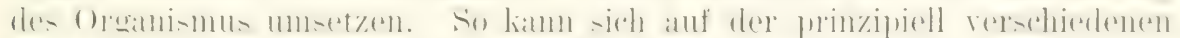

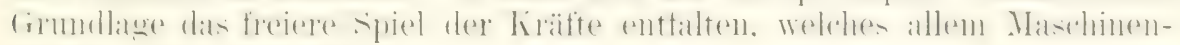
wesen durchaus fremd ist.

"Nur das Leben besitzt eine systematisierte Verwendung chemischer Prozesse und unterscheidet sich dadulch auch nach anderer Seite hin von allen bisherigen Hervorbringungen unserer menschlichen 'Technik." (Lotze.)

\section{Literatur VI.}

1) Driesch, H., Die Maschinentheorie des Lebens. Biol. Zentralbl. Bd. XTl. ISo6.

2) Merbst, Curt, L̈er die Bedentung der Reizphysiologie fïr die kansale Auffassung ron Forgängen in der tierischen Ontogenese. Biol. Zentralbl. Bd. Allu. AT. 1897-05.

3) Hertwig, Oscar, Mechanik und Biologie. Zierites llift der Keit- und Streitfragen der Biolosie. 1807. (Der Berrifl der Liansalitiat, D. 30.)

4) Lotze, Hermann, Leben, Lebenskraft. Ilagners Handüörterbuch d. I'rysiol. Bd. I. $18+2$.

5) Derselbe, Allocuncine Physiologie des kürperlichen Lebens. Leipaig 1851.

6) Sachs, Julius, I orlesmingen ïber Pllanzenphysiologie. 37. Iorlesung. Leipois 1892.

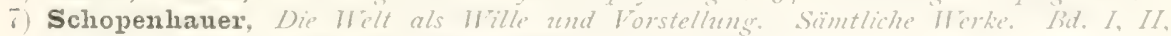

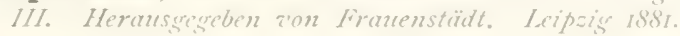




\section{SIETEN'TES KAPTTEI.}

\section{III). Untersuchung der einzelnen Reizarten.}

Ob ein Protoplasmakörper reizbar ist und auf Verïnderungen seiner Umgebung reagiert. sind wir gewöhnlich nicht imstande wahrzunehmen. Die meisten Reizwirkungen bleiben uns verborgen. Am deutlichsten sichtbar verden sie uns in den Fällen, in denen das Protoplasma durch auffällige Veränderungen seiner Form oder durch Bewegungen den Reiz beantwortet. Aber wie schon hervorgehoben wurde, ist dies nur ein heschränktes, kleines (iebiet der Reizwirkung, wenn auch für den Forscher das wichtigste, weil hier die Untersuchung angreifen kann. Infolgerlessen werden wir denn auch im Folgenden hauptsächlich zu untersuchen haben, wie das Protoplasma auf die oben (S. 1;t) angefühten 5 ( Reizursachen durch Bewegungen antwortet. Dieser Umstand hat mich auch veranlaft, bei der Besprechung der Lebenseigenschaften der Elementaroranismen die Kontraktilität vor der Reizbarkeit zu betrachten.

\section{I. 'Thermische Reize.}

Eine der wesentlichsten Bedingungen für die Lebenstätigkeit des Protoplasmas ist die Temperatur der Umgebung. Es gibt eine obere und eine untere Grenze derselben, deren Ueberschreitung in allen Fällen den sofortigen Torl des Protoplasmas zur Folge hat. Die Grenze ist allerdings nicht immer ein und dieselbe für alle Protoplasmakörper. Einige vermögen einen geringeren, andere einen größeren Widerstand extremeren Temperaturgraden entgegenzusetzen.

Das Maximum der Wärme bewegt sich gewöhnlich für tierische und pflanzliche Zellen um to ${ }^{\circ} \mathrm{C}$ herum. Schon eine Einwirkung von wenigen Minuten genügt, $u$ im Protoplasma Verquellungen und Gerinnumgen und dadurch eine Zerstörung der reizbaren Struktur und des Lebens ïberhaupt hervorzurufen. Amöben, in I'asser von $40^{\circ} \mathrm{C}$ gebracht, sterben sofort ab, indem sie ihre Pseudopodien einziehen und ..sich in eine kugelförmige. scharf und doppelt konturierte Blase umwandeln. welche einen groben, trüben, in durchfallendem Licht bräunlich aussehen(len Klumpen einschließt," (KüHNE VII 186t) Die gleiche Temperatur hat, wie man sich kurz auscliückt, den . Wärmetod bei Aethalium septicum unter eintretender Koagulation zur Folge. Für Actinophrys dagegen liegt die Grenze, wo augenblicklicher 'Tou eintritt, bei $45^{\circ}$ und für Zellen von Tradescantia und Vallisneria erst bei 47 - $48^{\circ} \mathrm{C}$ (MAX Schultze I 186:3)

Auf viel höhere Temperaturen ist das Protoplasma bei einzelnen Organismen angepaßt, die in heißen Quellen vegetieren. Im Karlsbader 
Sprudel fand Conx Leptothrix und Oscillarien bei b3 ${ }^{\circ}$ C und Enrexizarg: beobachtete ebenso Algentilze in warmen Quellen von Ischia. Hber anch damit ist die oberste T'emperaturgrenze, bei weleher sich lebende Substan\% eine Zeit lang zu erhalten vermag, noch nicht erreicht. Denn endogene Sporen von liazillen, welche auberordentlich derbe IIïllen besitzen. bleihen keimfähig, wem sie vorïbergehend in l'üssigkeit anf 10()$^{\circ}$ erhitzt werlen: manche ertragen 1050 bis $1300^{\circ}$ (de BArY VII 15.5.5. S. 41 ). 'Trockene Hitze von 1 fol0 vernichtet mit Sicherheit alles I,chen erst hei dreistündiger Einwirkung.

Viel schwieriger als die obere ist die untere Temperaturgrenze. durch welche mmittelbar der ,Kïltetod" herbeigefülnt wird, zu bestimmen. Im allgemeinen wirken Temperaturen unter (1) weniger schäilich auf das Protoplasma ein. als hohe Temperatmen. Liei Echinodermeneiern, die sich in den Vorstadien zur T'eilung befinden. wirl zwar der Teilungsprozel. momentan unterbrochen. Wemn sie in eine Kältemischung ron - 2 bis - 3 " C gebracht werden (IERTwig VII 1s90), spielt sich aber in normaler Weise weiter ab, wenn man die Fier nach viertelstündiger Daner der Jhkïhlung langsam wieder erwärmt. Ja selhst bei zweistündiger Abkïhlung erfährt ein grolier 'Teil der Eier lieine andauernde Schädigung. I’tanzenzellen können gefrieren. so dab Eiskrystalle in Zellsaft anschiefien. mnd reigen, wenn sie allmählich anfgetaut werden. wieder das Phänomen der Protoplasmaströmung (KüHxe VII 1Rlit).

Durch das plötzliche (iefrieren treten im Protoplasma von "flanzenzellen erhebliche Formveranderungen ein. werlen aber beim Auftauen wieder rückgängig gemacht. Als KüHNe (VII $18(i t)$ Trarlesc atiazellen in einer Kältemischumg von $-14^{\circ}$ ( etwas länger als 5 Minuten gefrieren lieb. fand er bei der Untersuchumg in Wasser an Stelle des normalen

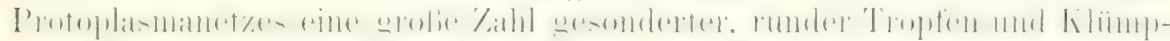
chen. Diese begammen aber schon nach wenigen Sekunden eine lebhafte bewegung zu zeigen, nach einigen Minuten sich zu verbinden und hald wieder in ein Netzwerk, das lebhafte Strömmog zeigte, ïberzugehen. Einen zweiten Versuch beschreibt KüHNE in folgender Weise: ..Legt man ein Präparat mit 'Tradescantiazellen mindestens während einer Stunde in einen mit Eis auf $0^{\circ}$ abgekühlten Raum, so reigt ihr Protoplasma bereits eine Neigung zum Zerfallen in einzelne Tröpfchen. Wo noch ein Netzwerk existiert, ist es aus auberordentlich feinen Fäden gebildet, die nur stellenweise mit gröberen kiugeln und Tropfen besetzt sind. Viele freie liugelu befinden sich umabhängig davon in der Zellflüssigkeit, wo sie unter leb-

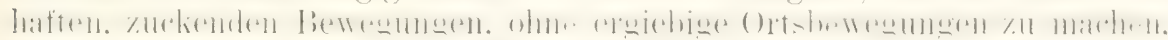
sich tum ihre Achse drehen. Wenige Jinuten später vereinigen sich jedoch diese freien Kugeln mit den feinen Fäden oder verschmelzen mit anderen daran hängenden Kungeh. bis das Bild des Hiebenden Protoplasmanetzes völlig wieler hergestellt ist."

bei den Pflanzen ist im allgemeinen die Widerstandshaft gegen îäle um so grölier, je wasserärmer die Zellen sind: Infttrockene Samen und Winterknospen, deren Zellen fast rein protoplasmatisch sind, können sehr hohe Kältegrade ertragen, wähnend junge blätter mit ihren saftigen Zellen schon bei Nachtfrösten alosterben. Doch auch die versehiedene spezifische Organisation der einzehnen Pthanzen, resp), ihner \%ellen, bedingt eine sehr ungleiche Wirlerstandsliraft gegen Kälte. wie die tägliche Erfahrung lehn't (SACIS VII lis(i)).

Auberordentlich hohe Kïltegrade kïnnen Mikroorganismen ausalten. IVie Friscu fand, wird die Entwicklunstähigkeit ron Lacillus antluacis 
sowohl von Sporen als anch von vegetativen Zellen nicht beeinträchtigt. wenn sie bei - $110^{\circ} \mathrm{C}$. in Flïssigkeit eingefroren und nachher wieder aufgetaut werlen.

Noch ehe die oben fiü einzelne Fälle näher angegebenen. extremen Temperaturgrenzen erreicht werden, welche den mmittelbaren Wämeoder Kältetod des Protoplasmas zur Folge haben, tritt schon zuvor eine Frscheinung ein, welche man als Wämestarre oder Wärmetetanus und als Kältestare bezeichnet. Man versteht darunter einen Zustand. in welchem die Eigenschaften des Protoplasmas, in denen sich sein Leben

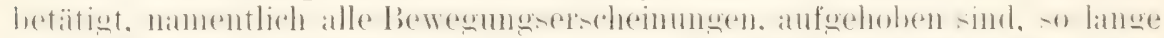

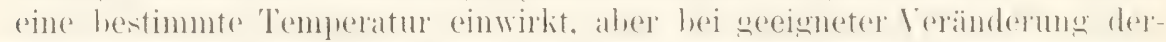
selben nach einer Periode der Erholung wiederkehren. Die Kältestarre stellt sich gewöhnlich bei T'emperaturen ein, die sich um $0^{0}$ herum be-

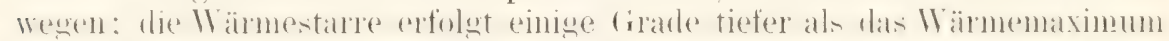
beträgt, bei welchem rlas Protoplasma sofort abstirbt. In beiden Fällen verlangsamt sich die Protoplasmaberegung mehr und mehr und hört bald ganz auf. Amöben, Rhizopoden. weiße Blutkőrperchen ziehen ihre Ausläufer ein und wandeln sich in kugelige Kilumpchen um. Ptlanzenzellen gewimnen häufig das schon oben mit den Worten von KüHNE beschriebene Aussehen. Langsame Erhöhung der Temperatur bei Kältestarre, Ernied-

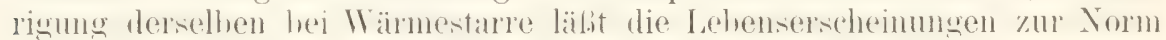
zurüickkehren. Hält freilich der Starrezustand lange Zeit an, so kann er' zum Tode führen, und zwar wird durchgängig Kältestare viel länger und besser als Wärmestarre vertragen. Beim Absterben gerinnt und trübt

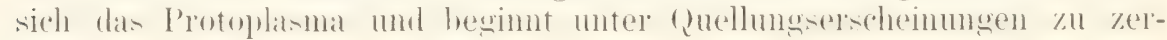
fallen.

Zwischen Kälte- und Wärmestarre liegt ein Gebiet, in welchem sich je nach der Höhe der Temperatur die Lebensprozesse mit ungleicher Intensität abspielen. Namentlich sind es die Bewegungen, welche sich mit verschiedener Schnelligkeit vollziehen. Sie nehmen bei Steigerung (ler Wärme bis zu einem bestimmten Maximum zu. Welches mit einem bestimmten 'lemperaturgrar zusammenfällt, den man als 'Temperaturoptimum bezeichnet. Dasselbe liegt immer mehrere Grad unter der Temperaturgrenze, bei welcher die Wärmestarre erfolgt. Wenn die Erwärmung noch über das Temperaturoptimum hinaus wächst, so hat sie einte inmer mehr zunehmende Verlang-ammug der Protoplasmahewerung zur Folge, bis endlich der Punkt erreicht ist, an welchem der Starrezustand einsetzt.

Ein wichtiges Objekt, an welchem man den Einflub der Erwärmung studiert hat, sind die weißen Blutkörperchen, wobei man sich am besten des heizbaren Objekttisches von Max Schultze oder des Sichsschen

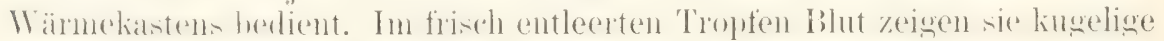
Gestalt und sind bewegungslos; unter den entsprechenden Vorsichtsmabregeln erwärmt, begimen sie langsam Pseudopodien auszustrecken und

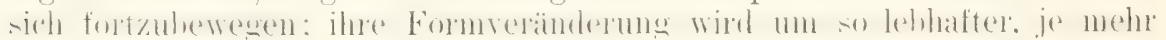
die Temperatur bis zu dem jeweiligen Optimum zunimmt. Bei Myxomyzeten, Rhizopoden und Pflanzenzellen äufert sich die Zunahme der Erwärmung in einer Beschleunigung der Körnchenströmung. So legten nach Messungen ron Max Schultze (I 1863) die Körnchen bei den Haarzellen von Urtica und T'radescantia bei gewöhnlicher Temperatur einen Weg von $0,004-0,005 \mathrm{~mm}$ in der Sekunde zurïck, bei Erwärmung bis auf $350 \mathrm{C}$. einen Weg ron $0,009 \mathrm{~mm}$ in der Sekunde. Bei Vallisneria ließ sich die Zirkulation bis $0,015 \mathrm{~mm}$ und bei einer Charaart sogar bis $0,04 \mathrm{~mm}$ in 
der Sekunde beschleunigen. 'Zwischen langsamer und beschlemigter bewegung kamn die Ditterenz so groß sein. daß im ersten Falle die Länge eines Fubes etwa in 50 Stunden, im zweiten Falle in einer $1 \%$ Stunde durchlauten wird.

Nïger ( 1 sio hat für die fieschwindigkeitszmahme der Körnchenströmung in den Zellen von Nitella bei Zumahme der 'T'emperatur folgende Werte erhalten: Lm einen Weg ron $0.1 \mathrm{~mm}$ zurückzulegen. hrauchte die I'lasmaströmung bo Sekmulen bei $1^{0} \mathrm{C}$. 24 Sekunden bei 50 (... S Se-

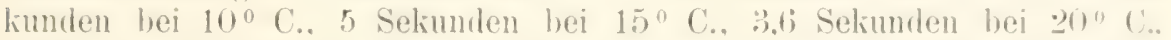

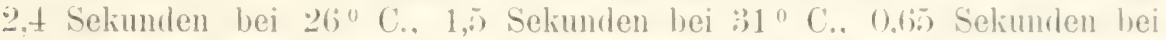
$37^{\circ}$ C. Aus diesen Zahlen geht hervor, dab ., die Zunahme der (ieschwindigheit für jeden folgenten Grad einen kleineren Wert darstellt" (NäGELI. (ELTEN.)

Bemerkenswert ist endlich noch das V'erhalten der I'rotoplasmakörper' gegen plötzliche, gröbere T'emperaturschwankungen und zweitens gegen einseitige orler ungleiche Erwärmung.

Die 'Temperaturschwankungen können entweder positive orler negative sein, (l.h., sie kömnen auf einer Erhöhung oder Erniedrigung der 'I'emperatur beruhen: die Folge eines solchen gröleren, thermischen Reizes ist vorubergehender Stillstand der Bewegung. Nach einiger Zeit der Ruhe kehnt die Bewegung wieder' und nimmt dann die der 'Temperatur

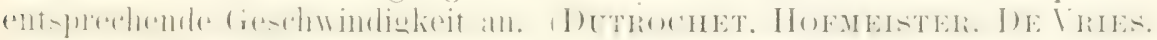
YELTEx (VII 1876) hestreitet due Richtigkeit dieser Beobachtungen. Nach

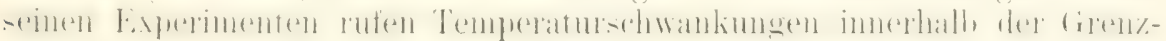
werte weder eine Sistierung, noch eine Verlangsamung der Protoplasmabewegung hervor: sondern es wird sofort die der betreftenden T'emperatur zukommende (ieschwindigkeit herbeigeführt.

Über die Folgen ungleicher Erwämung hat STAmL (VII 188t) sehr interessante Versuche an rlen Plasmorlien von Myxomyceten angestellt. Wenn an solchen, während sie sich netzartig auf einer Unterlage ausgebreitet haben, nur ein Teil abgekühlt wird, so wandert das Protoplasma aus dem abgekïhlten Teil allmählich in den wärmeren hiniiber: der eine T'eil des Netzes schrumpft ein, der andere schwillt an. Man liann den Versuch in rer Weise vornehmen, daf man ? Bechergläser dicht nebeneinander stellt und das eine mit Wasser ron $7^{\circ}$. das andere mit Wasser ron $30^{0}$ Wäme füllt. und ïher ihre sich berührenden Ränder einen nassen Papierstreifen. anf welchem sich ein Plasmodium anscehreitet hat. in der Weise legt, dah das eine Ende in das kïhlere. das andere in das wärmere. auf konstanter' 'Temperatur' erhaltene Wasser' taucht. Nach einiger 'Zeit

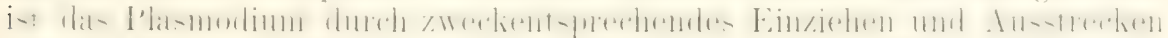
seiner Protoplasmafürlen mach dem ihm zusagenden Medium hinübergekrochen.

In dieser Weise fülıren frei lebende Protoplasmakörper wohl ïberhaupt Bewegungen aus, die den Stempel des Zweckmäßigen an sieh tragen. weil sie zugleich zu Erhaltung des Orgmismus dienen. Die Iobh)lïte wandert im Herbst infolge der Abkïhlung der Luft mehrere Iub tief in die wärmeren Schichten des Lohhaufens hinein. ın dort zu überwintern. Im Fribjahr erfolgt dam wieller bei eingetretener Erhöhmug der Lufttemperatur die Bewegung in entgegengesetzter Pichtung nach den num wierler mehr erwärmten oberflächlichen Sehichten.

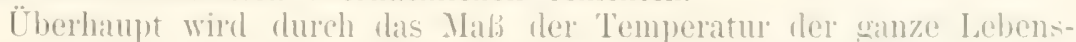
prozeb der \%elle, die chemisehe Arbeit, die in einer bestimmten \%eiteinheit von ilu geleistet wirl. der Stoflansat\% und -Limsat\%, infolgerlessen das 


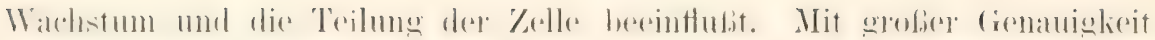
läßt. sich dies nachweisen. wenn man befinchtete Eizellen sich bei verschiedenen Graden entwickeln läbt, wie ich eine derartige Versuchsreihe an den Eien von Rana fusca und R. esculenta ausgefïlnt habe. Von

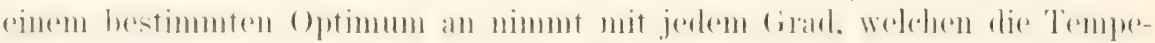

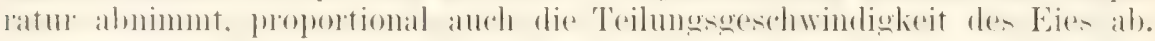
So trat bei Froscheiern, die sich bei $24^{0}$ entwickelten, die erste Teilung

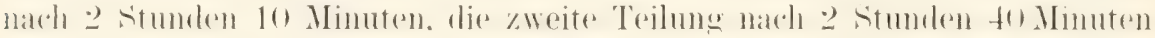
und die dritte Teilung nach :3 Stunden 25 Minuten auf, bei welchen Angaben die Zeit immer von der Vornahme der Befruchtung an gerechnet ist. Bei einer 'Temperatur von $1 \tilde{5}^{0}$ dagegen schickten sich die Eier zur ersten Teilung erst nach 3 Stunden, zur' zweiten 'Teilung nach 4 Stunden 10 Minuten und zur dritten 'Teilung nach 5 Stunden 35 Minuten an. Hier' ist also im Vergleich zu den bei $24^{\circ}$ erhaltenen Werten die erste Teilung um 50, die zweite um 90 und die dritte um 130 Minuten später als die inr' entsprechende 'T'eilung bei höherer 'Temperatur' eingetreten.

In noch beträchtlich rascherem Tempo nimmt die Geschwintigkeit des Entwicklungsprozesses innerhalb der niederen 'Temperatur von $7^{\circ}$ bis $2^{0} \mathrm{ab}$. Denn bei $5^{0}$ wird die erste Furche nach 9 Stunden 15 Minuten, die zweite nach 14 Stunden 50 Minuten und die dritte nach 18 Stunden 25 Minuten bemerkbar. - Bei :30 ist der Prozef noch in viel erhehlicherem Maße verlangsamt. Denn wir erhalten für die erste, zweite und dritte Teilung die Werte: 12 Sunden, 18 Stunden 15 Minuten. 26 Stunden. Bei :30 Wärme hat die Entwicklung bis zur dritten Teilung siebemmal mehr Zeit erfordert als bei $24^{\circ}$.

Indem durch die Wärme der 'Teilungsrhythmus der Zellen in so hohem Maße beeinflukt wird. werden mit der Vermehrung der Zellen in be-

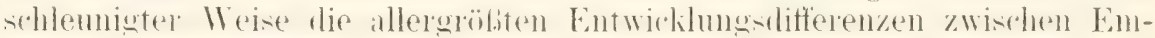
bryonen hervorgerufen, die ihre Entwicklung gleichzeitig, aber bei verschiedenen Temperaturen begonnen haben.

Durch eine systematisch durchgeführte Untersuchung habe ich für die Eier von Rana fusca und Rana esculenta nachweisen können. wie ein

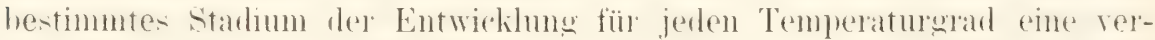

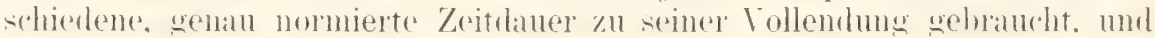
wie infolgerlesen durch Erhöhung mal Erniedrigung der Temperatur die allergröbten Entwicklungsdifferenzen hervorgerufen werlen können.

Zur Veranschaulichung des Verhältnisses diene Fig. 97. Sie zeigt uns vier Froscheier, die seit der Vornahme der künstlich ausøeführten Befruchtung genau drei Tage alt. dabei aber in ihrer Entwicklung sehr ungleich weit vorgerückt sind. Denn das erste Ei hat eben die Gastrulation heendet. das zweite hat die Medullarplatte entwiolelt. deren Ränder sich

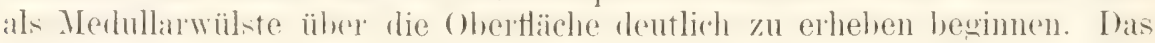
dritte hat sich schon zur Länge von $5 \mathrm{~mm}$ gestreckt. Hinten ist das Schwanzende, vorn der Kopf abgesetzt, an welchem sich die Haftnäpfe bereits angelent haben and die liemen als kleine Höcker hervorsurosene I)er vierte Embryo hat im Vergleich zum dritten eine Längenzunalme von $2,5 \mathrm{~mm}$ erfahren; ist also $7,5 \mathrm{~mm}$ lang geworten. Die Kiemenhöcker sind

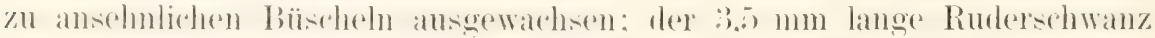
hat sich in einen aus chorda. Rü̈ckemmark und vielen Muskelsegmenten zusammengesetzten Achsenteil und in einen dünnen. durchsichtigen Flosiensaum gesondert.

Die erheblichen Differenzen in der Entwicklung der vier Eier sind einzig und allein dadurch hervorgerufen worden. dab das erste sich bei 
einer lionstanten $\mathbf{W a s s e r t e m p e r a t u r ~ v o n ~} 10^{\circ} \mathrm{C}$. das zweite bei $15^{\circ} \mathrm{C}$. das dritte bei $20^{\circ} \mathrm{C}$ und das vierte bei $24^{\circ} \mathrm{C}$ entwickelt hat. Um das Stadium. welches bei $24^{\circ} \mathrm{C}$ schon am Ende des dritten Tages eintritt, zu erreichen. braucht das Ei von Rana fusea bei $10^{\circ} \mathrm{C} 1 \%$ - $1 t^{\prime}$ 'age, bei $15^{\circ} \mathrm{C} 7$ Tage. bei $20^{0}+$ T'age.

Wenn ich oben hervorhob, dal. durch die 'Temperatur hesonder's die chemische Arbeit in der Zelle beeinflubt wird. so läbt sich dieser Ausspruch in unserem beispiel noch etwas genauer prizisieren. Beim Wachstum und der Teilung der Zellen erfährt die Kernsubstanz. besomders ihr Chromatin. wie später beim Studim der Karrokinese noch festgestellt werden wird. eine ganz gesetzmälige Zunahme und zwar vermehrt sie sich beim Furchungsprozela und in der weiteren Entwicklung in geometrischer Progression mit dem Quotienten 2. Da num VAN'T HOFF und ERNST Confy in ihren Studien

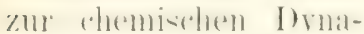
mik. hermeler: in dem

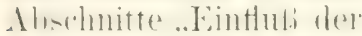
Temperatur auf die chemische Reaktion" nachgewiesen haben, dal.

Temperaturunterschierle auf die Reaktionsgeschwindigkeit chemischer Vorgänge

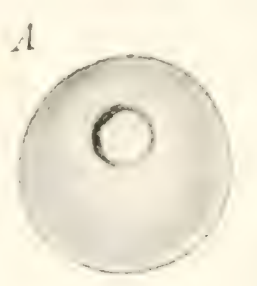

C.

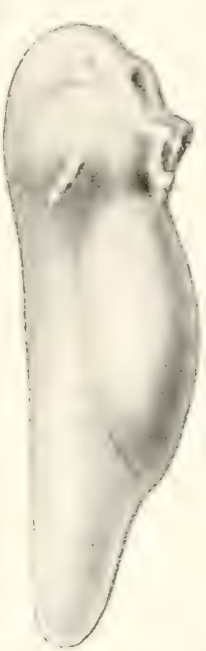

l;

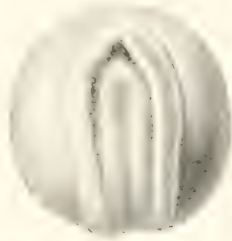

Fit. 11. Vier Froscheier, welche sich nach der Befruchtung drei Tage entwickelt haben.

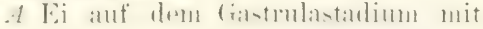
rundem Blastoporus, entwickelt bei $10^{\circ} \mathrm{C}$. $B$ Li mit Medullarplatte, deren Ränder zu Medullarwiilsten erhohen sind, entwickelt bei $15^{\circ}$ C. C Embryo mit kileinen Kiemenhörkern, entwickelt bei $20^{\circ} \mathrm{C}$. $D$ Embryo mit Kienenbüscheln und langem liuderschwanz, entwickelt hei $24^{\circ} \mathrm{C}$.

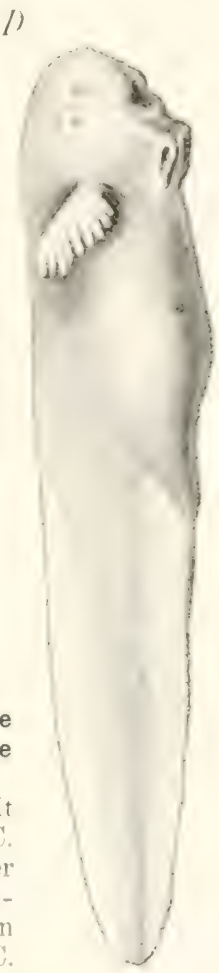

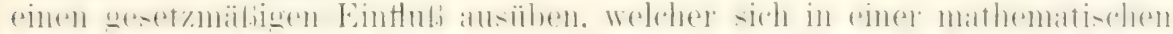

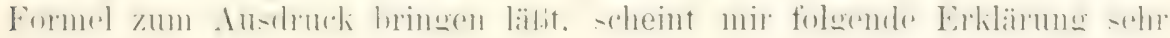
nahe zu liegen:

Die Beschleunigung des Entwicklungsprozesses bei höheren 'Tempe-

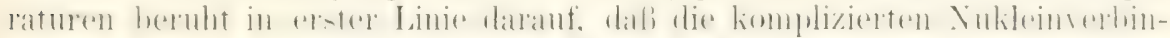
dungen etc. im chemischen Laboratorium der Zelle in einer gewissen Pro-

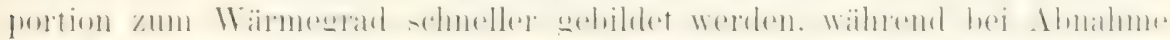
der 'Temperatur die chemische Arbeit verlangsamt und schlieblich ganz zum Stillstand gebracht wircl.

Natiurlich werden hierbei auch noeh andere chemische Prozesse und andere Vorgänge, die ich allerdings für minder wichtig halte. an dem Zustandelommen des Gesamtresultates nehenher mitwirken.

\section{Lichtreize.}

Wie die Wäme wirkt auch das Iicht in vielen Fällen als Reiz auf

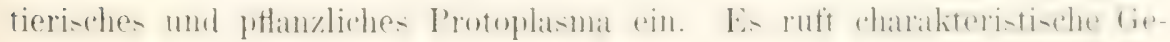




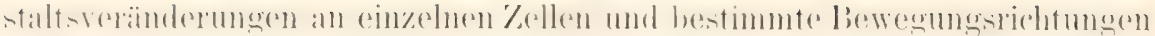
an frei lebenden, einzelligen Organismen hervor. Namentlich die Untersuchungen der Botaniker haben auf diesem Gebiete interessante Ergebnisse zutage gefördert.

Plasmodien von Aethalium septicum breiten sich nur im Dunkeln anf der Oberfläche der Lohe aus, wihrend sie sich im Lichte in die Tiefe derselben zurïckzielıen. Wenn man auf ein Plasmodium. das auf einer Glasscheibe zierliche Netze gebildet hat, einen Lichtstrahl in einem beschränkten Bezirk auffallen läßt, so strömt alsbald das Protoplasma von den belichteten Stellen hinweg und sammelt sich in den beschatteten an (Barenezio, Stahl VII 1884).

Pelomyxa palustris, ein amöbenartiger Organismus, führt im

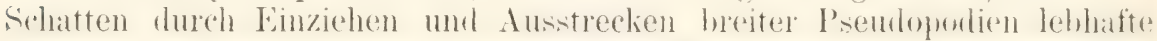
bewegungen ans. Wenn sie ron rinem mälig staken lichtstrahl getroften wird, zieht sic plötzlich alle P'sembopolien ein mol wandelt sich zu einem

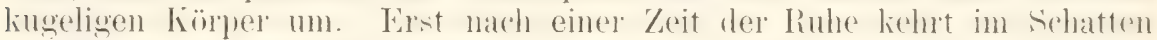

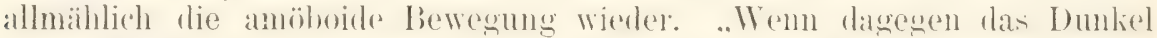

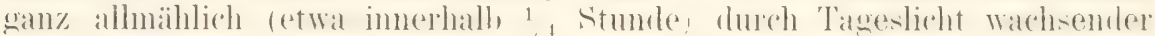
Helligkeit vertrieben wird, bleibt die Reizwirkmo aus, ebenso wenn nach

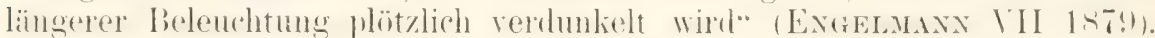

Sehr lebhaft reagieren auf Licht die sternförmigen Pigmentzellen vieler Wirbellosen und Wirbeltiere, welche in der Literatur unter dem Namen der Chromatophoren (Brücke VII 1854. Pouchet VII 1874) bekannt und die Ursache für den oft augenfälligen Farbenwechsel vieler Fische, Amphibien, Reptilien und Cephalopoden sind. Im Licht nimmt z. B. die Haut der Frösche eine hellere Färbung an. Es rührt dies daher, daß schwarze Pigmentzellen, die sich mit reichlich verzweigten Ästen in der Lederhaut ausgebreitet hatten, unter dem Reiz des Lichtes sich zu kleinen, schwarzen Kugeln zusammengezogen haben. Indem sie selbst weniger auffällig werden, kommen außerdem noch vorhandene, grün und

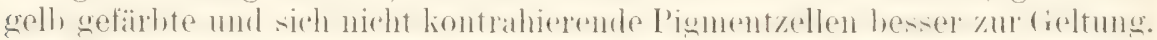

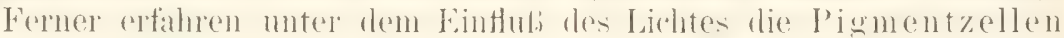
der Retina aufällige Formveränderungen, und zwar sowohl bei den Wirbeltieren (BOLL), als auch bei den Wirbellosen, z. B. in Cephalopodenauge (RAWITZ VII 1891).

Von vielen einzelligen, durch Flimmern oder Geißeln sich fortbe-

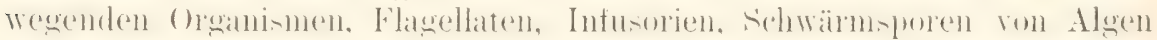

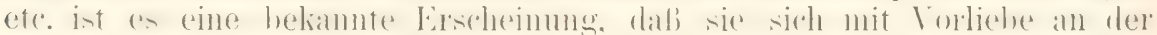

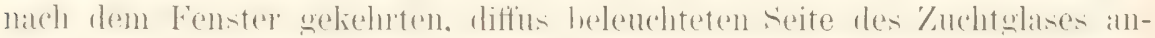
häufen oder umgekehrt. Sehr überzengend ist ein einfaches, von NäGELI ( $V^{r} 1860$ ) angestelltes Experiment. Eine drei Fub lange Glasröhre wird mit Wasser, in welchem sich grüne Algenschwärmer ('Tetraspora) befinden, gefüllt und senkrecht aufgestellt. Wenn man nun die Röhre mit schwarzem Papier umwickelt mit Ausnahme des unteren Encles, auf welches man Licht einfallen läßt, so haben sich in diesem nach einigen Stunden alle Algenschwärmer versammelt, so daß der übrige Teil der Röhre farblos geworden ist. Umwickelt man jetzt das untere Ende, läft dagegen das obere Ende frei, so steigen allmählich alle Schwärmsporen nach diesem empor und sammeln sich an der Oberfläche des Wassers an.

In hohem Grade ist Euglena riridis gegen Licht empfindlich (Fig. 79 A). Wird in einem auf den Objektträger gebrachten Wasser-

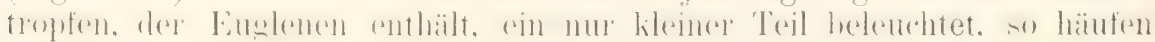
sich alle Individuen binnen kurzem im Lichtbezirk an, der, um einen 


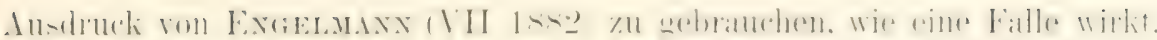

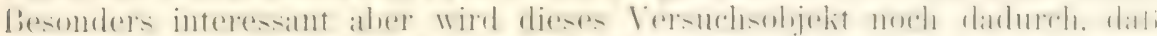

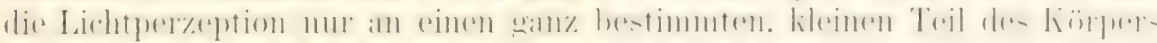

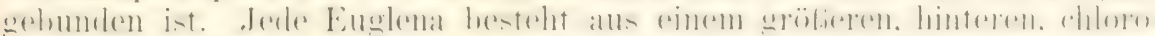

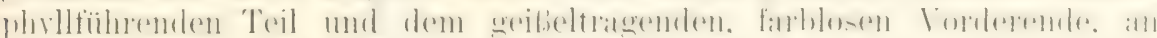
welchem sich ein roter Pigmentfleck findet. Nur wenn dieses Vorderende rom Lichtstrahl getroffen oder verdunkelt wird, reagiert der Organismus

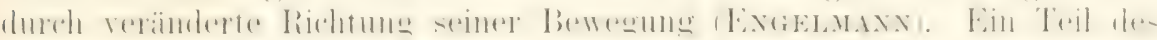
Körpers wirlit hier also gewissermaben als Auge.

Am eingehendsten haben sich mit der Einwirkung des Lichtes auf Schwärmsporen StanL (VII 1S80) und Strasburger (VII 1STS) beschäftigt. Ersterer faht seime Resultate in folgende Sätze zusammen: „Das Licht übt einen richtenden Einflub auf den Schwärmsporenkörper in der Weise. daf, dessen Längsachse annäherud mit der Richtung des Licht-

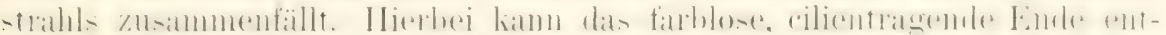
weder der Lichtquelle zu- oder von derselhen abgewendet sein. Beiderlei

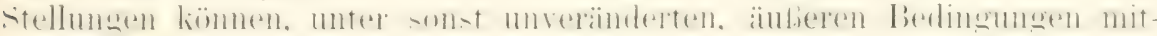
einander abwechseln und dies zwar bei sehr verschiedenen Graden der Lichtintensität. Den gröbten Einfluß auf die relative Stellung lat die Intensität des Lichtes. Bei intensiverem Lichte kehren die Schwärmer ihr Mundende von der Lichtquelle ab, sie entfernen sich von derselben: bei schwächeren Lichte bewegen sie sich lichtwärts."

Die Reizbarkit gegen Licht ist eine sehr verschiedene, sowohl nach den einzelnen Arten. als anch bei emzelnen Individuen derselben Art.

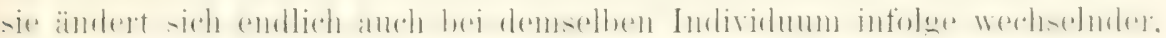
äuberer Bedingungen. STRAsBurger bezeichnet dieses umgleiche Reaktionsvermögen der Schwärmsporen als Lichtstimmung. 'Zwei zur. Unter-

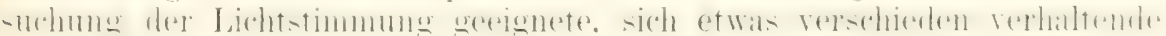
Objekte sind die Schwärmsporen von Botrydium und Ulothrix.

Wenn Schwärmsporen von Botrydium in einem 'Tropfen Wasser auf einen Objektträger gebracht werlen, so verteilen sie sich im Dunkeln gleichförmig im Wasser. Werden sie dagegen jetzt belenchtet, so richten sie sich gleich mit ihrem vordern Ende nach der Lichtquelle und eilen (lerselben in geraden, somit ziemlich parallelläufigen Bahnen zu. Nach wenigen. meist $1 \frac{1}{2}$ bis 2 Minuten sind fast sämtliche Schwämer an der Lichtseite des Tropfens, welche STrAsRurger der Kürze wegen auch als

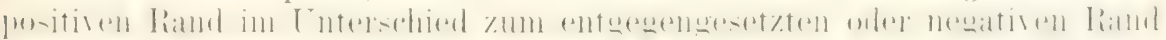

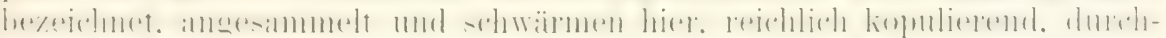
einander. Wird das Präparat um $180^{\circ}$ gedreht, so verlassen alle noch beweglichen Schwärmer momentan den jetat von der Lichteuelle al)gekehrten Rand des Tropfens und eilen wieder dem Lichtstrom zu. Wird die Beobachtung unter einem Mikrosliop) mit drehbarem Objelittisch angestellt. so kann man durch Drehumg des letyteren die Schwärmer zur

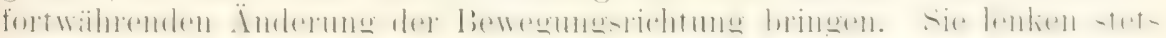
in die vom lienster gegen das Zimmer geradlinig gerichteten bahnen ein.

Ein etwas abweichendes Verhalten zeigen Ulothrixschwämer. .Auch diese eilen rasch und auch in fast geraden Bahneu nach dem positiven Tropfenrand; doch nur selten tum sie es alle, vielmehr wird man in den meisten Präparaten einen größeren oder geringeren 'Teil derselben. ebenso rasch in entgegengesetzter Richtung, also nach dem nequtiven Rand zu, sich bewegen sehen. Es gewährt nun ein eigenes Schauspiel. wemn die Schwärmer so in entgegengesetztel Richtung und daher mit

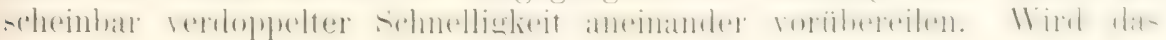


Präparat um $180^{\circ}$ gedreht, so sieht man sofort die an der zuvor positiven Seite angesammelten wieder der negativen Seite, die zuvor an der negativen seite angesmmelten wieder der positiven reite zueilen. Hier angelangt, bewegen sich die sihwämmer durcheinander, sich je nach den Praij)araten schärfer oder weniger scharf am Rande haltend. Ununterbrochen bemerlit man auch, sowohl an der positiven, als auch an der negativen Reite, eimzelne schwämer, die plötzlich den Ramb verlasien und geradeaus durch den Tropfen nach dem andern Rand eilen. Ein solcher Austausch findet ununterbrochen zwischen beiden Rändern statt. Ja nicht selten kann man einzelne Schwärmer, die eben vom entgegengesetzten Rande kamen. wieder dorthin zurückkehren sehen. Noch andere bleiben mitten in ihrem Laufe stehen und eilen nach dem Ausgangsort ihrer Wanderung zuriuck, um eventuell ron dort das Spiel lïngere Zeit pendelartig zu wiederholen."

Wie fein und rasch die Reaktion der Schwärmer auf Licht ist, zeigt folgendes von Strasburger mitgeteiltes Experiment. „Schaltet man, wihrem die schwämer auf dem Wege von dem einen Rande des Tropfens. zum andern sind, ein Blatt Papier zwischen das Mikroskop und die Lichtquelle ein, so schwenken die Schwämer sofort zur Seite ab, manche drehen sich selhst im Kreise, doch das danert nu einen Augenblick, und sie lenken in die verlassenen Bahnen wieder ein (Schreckbewegung)."

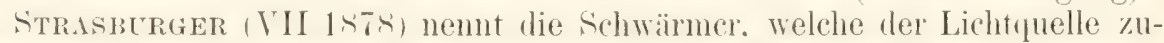
eilen, lichthold (photophil). solche dagegen. welche sie fliehen. lichtschen (photophoh). Wie schon ohen angedeutet wurle. ist die Ansammlung der Schwärmer am negativen oder positiven Rand des Tropfens, worin sich die besondere Art ihrer Lichtstimmung kund gibt, von äußeren Bedingungen abhängig. von der Intensität des Lichtes, von der Temperatur, ron der Durchlüftung des Wassers. von Entwicklungszustänlen. Wem man mit Schwärmern experimentiert. die hei intensiver lieleuchtung sich am negativen hand angesammelt haben, so kamn man dieselben zum entgegengesetzten Ramb hinïher locken. Man mil. dam das Licht auf einen ihrer stimmung entsprechenden ciral allmählich ahdämpfen, indem man einen. zwei, drei oder mehr Schirne ans matt geschliffenem Glas zwischen las Präprarat und die Iichtpuelle einschieht. In noch einfacherer Weise kann man das Resultat auch dadurch erreichen, daß man sich mit dem Mikroskop langsam weiter rom Fenster entfernt und dadurch das einfallende Licht abschwächt.

Durch die 'Temperatur der Umgebung wird der Grad der Lichtemptindlichlieit bei vielen Schwämern sehr beeinthut. Dieselhen werden gewöhnlich durch Erhöhumg der Temperatur. welche auberdem auch ihre lieweglichlieit steigert, auf höhere Lichtintensititen, durch Ernienrigung der Temperatur auf geringere Lichtintensitat abgestimmt. Im ersteren Fall werden sie also lichtholder, in zweiten Fall lichtschener gemacht. .Ferner rerindern die schwärner auch ihre Lichtstimmmog in Lanfe ihrer Entwicklung, so zwar, daß sie in der Jugend auf höhere Intensitïten als im Alter gestimmt erscheinen."

Wie durch, Experimente von Cohn, STrasburcer u. a. festgestellt ist, hahen nicht alle strahlen des spektrums auf die liewegungstichtung der Sporen einen Einfluß, sondern es sind vorzugsweise nur die stark brechbaren Strahlen, die blauen. indigofarbigen und vioJetten, welche als lieiz emptunden werden. Schieht man zwischen Lichtquelle und Präparat ein (iefäl’ mit dumkler Kupferoxydammonialiösung, welche nur blates. violettes Licht hindurchlabt. so reagieren die schwäm- 


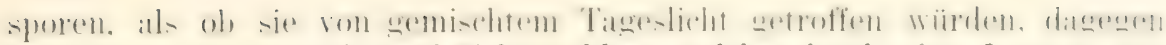
reagieren sie gar nicht auf Lichtstrahlen. Welche durch eine Lösung von

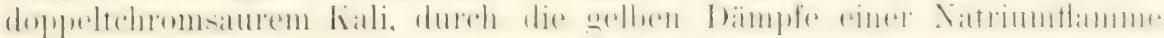
oder durch Rubinglas hindurehgegangen sind.

Fin anderes, mannigfaltiges und wichtiges (iebiet von Lichtwirliung bietet sich uns dar in der Chlorophyllwanderung pillanlicher Zellen.

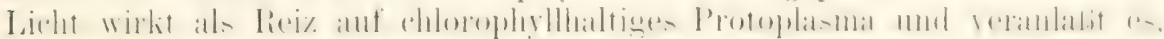

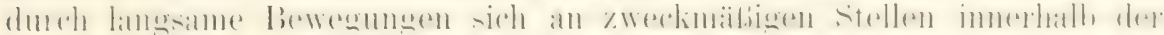

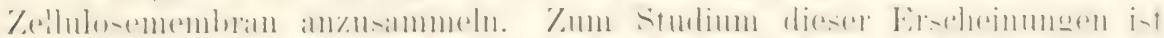
woh: das geeigneteste Objekt die Fadenalge Mesocarjus, an welcher STAHL (VII 1880) sehr überzeugende beobachtungen angestellt hat. In den zu langen Fäden vereinigten, zylindrischen Zellen spannt sich ihrer

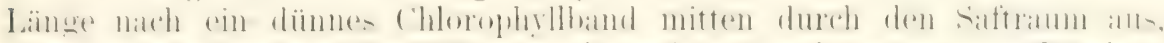

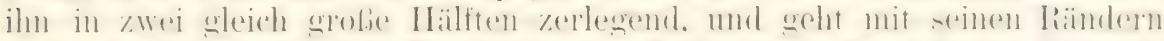

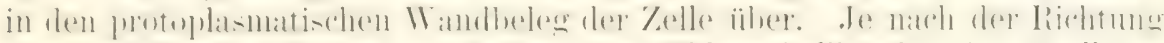

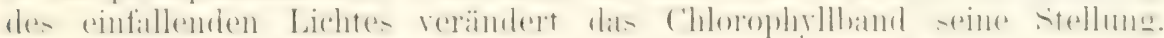
Wird es direkt von oben oder von minten durch schwaches Tageslicht getroffen, so kehrt es dem Beobachter seine Fläche zu. Wenn man da-

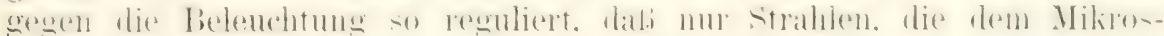
koptisch parallel verlaufen, von der Seite zum Präparat gelangen, so drehen sich die grumen Platten um etwa $90^{\circ}$, bis sie eine genan vertikale stellung einnehmen

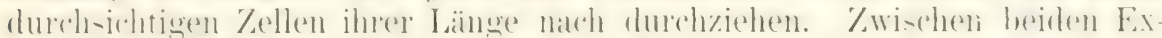

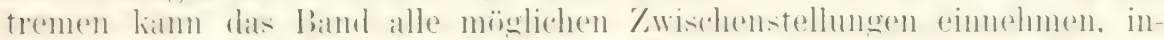

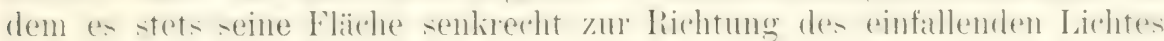
zu orientieren sucht. In warmen Sommertagen erfolgt der Stellungs-

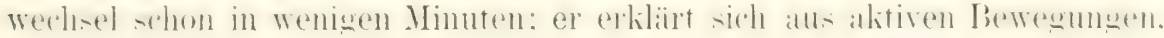
welche das Protoplasma innerhalb der Zellmembran ausführt.

Auch hier übt wie bei den Schwämsporen die Intensität des Lichtes einen verschiedenen Einflub aus. Während diffuse belenchtung das when beshriehene fesultat herbeiführt, hewirlit direktes

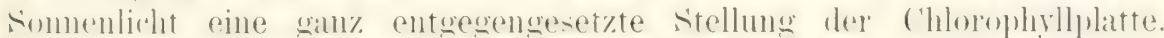
Diese kehrt jetzt ilıre eine Kante der Somne zu. Wir erhalten also fol-

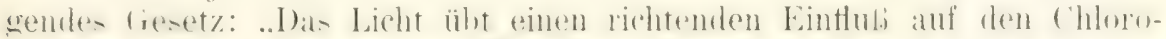

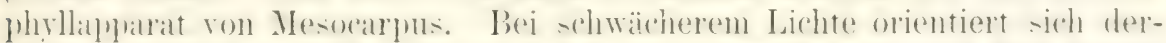

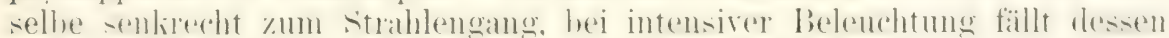
Ebene in die Richtung des Strahlenganges." Die erste Anordnung bezeichnet STAnL als Flächenstellung. die zweite als Profilstellung. -

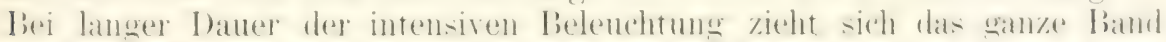

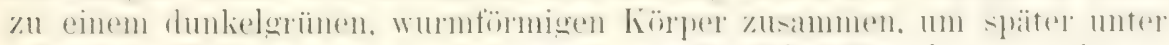

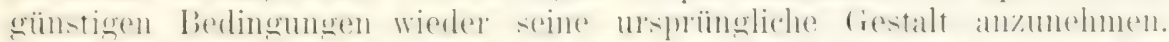

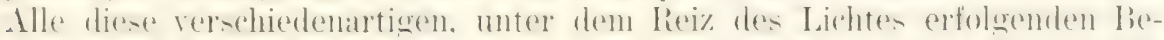

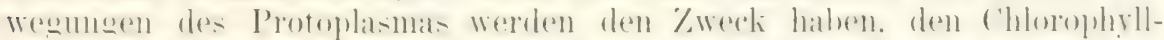

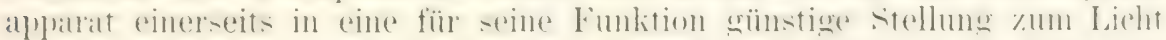

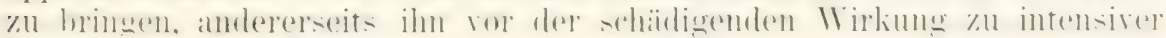
Belenchtung zu schützen.

Dem Einflub des Lichtes. (ler sich hei Mesocarpus in so klarer Weise änbert, sind übrigens auch die mit Chlorophyllkörnern versehenen,

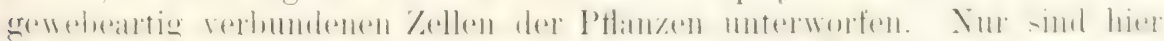
die Erscheinumgen von etwas komplizierterer Art (Fig. 94). Wie zuerst

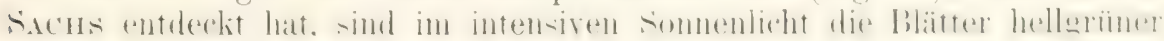
als bei matter Beleuchtung oder im Schatten. Auf Grund dieser Wahr-

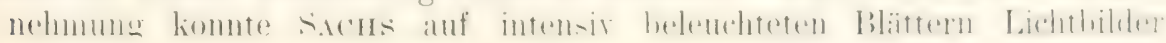




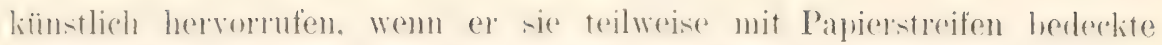
(IV 1882). Nach einiger Zeit erscheinen nach Entfernung der Papier-

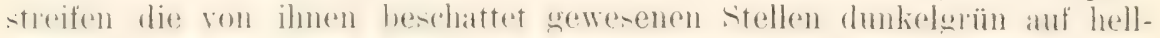
grimem Grund. Die ganze Erscheinung erklärt sich auch hier aus dem

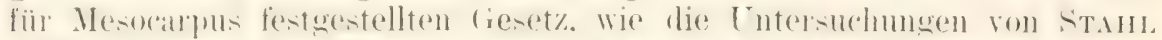

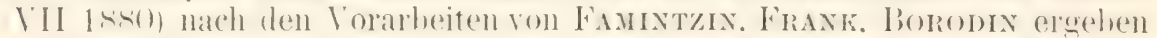

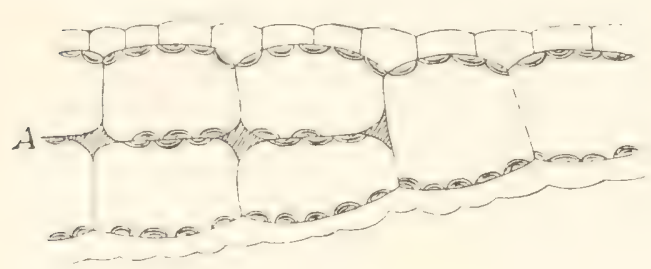
haben. Bei matter Beleuchtung und im Schatten führt das Protoplasma solche Bewegungen aus, daß die Chlorophyllkörner an die dem Licht zugekehrten Außenflächen der Zellen zu liegen kommen (Fig. 98 A), während sie an den Seitenwänden geschwumden sind. In di-

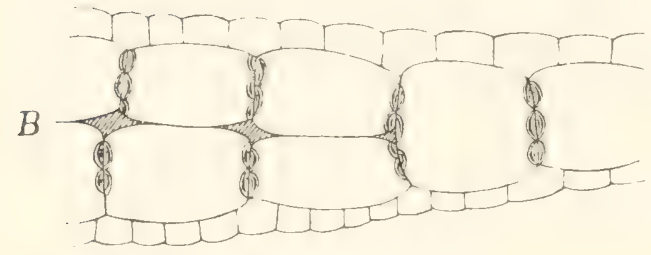
rektem Sonnenlicht dagegen strömt das Protoplasma mit den Chlorophyllkörnern den Seitenwänden (Fig. 98 B) zu, bis die Außenwand ganz chlorophyllfrei geworden ist. Im ersten Fall nimmt also der ganze Chlorophyllapparat wie bei Mesocarpus zum einfallenden Licht eine Flächenstellung, im zweiten Fall eine Profilstellung ein; dort erscheinen daher die Blätter dunkler, hier heller grün gefärbt.

Auferdem verändern die

Fig. 95. Querschnitt durch das Blatt von Lemna trisulca (nach STAHL). A Flächenstellung (Tagstellung). B Anordnung der Chlorophyllkömer im intensiven Licht. $C$ Dunkelstellung der Chlorophyllkörner. Chlorophyllkörner selbst noch ihre Gestalt in der Weise, dab sie bei intensivem Licht kleiner und kugeliger werden.

Alle diese Vorgünge führen zu ein und demselben Ziel: „Die Chlorophyllkörner schützen sich bald (lurch Drehung (Mesocarpus), bald durch Wanderung oder Gestaltsveränderung vor zu intensiver Beleuchtung. - Bei schwacher Beleuchtung wird der Lichtquelle die größte Fläche zugekehrt; das Licht wird so viel wie möglich aufgefangen. Ein entgegengesetztes Verlialten macht sich bei sehr starker Beleuchtung bemerkbar; es wird dem Lichte eine kleinere Fläche dargeboten."

\section{Elektrische Reize.}

Wie mamentlich die Experimente von Max Schultze (I 1863) und

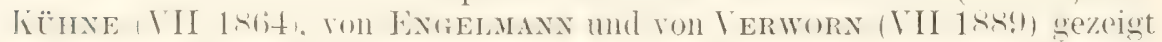
haben, wirken galvanische Ströme, und zwar sowohl die induzierten, als 


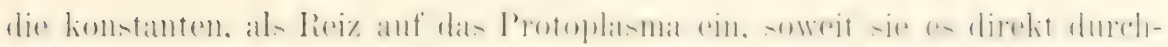
strömen.

Wemn man Staubadenhaare von 'Tradescantia (Fig. 99) quer

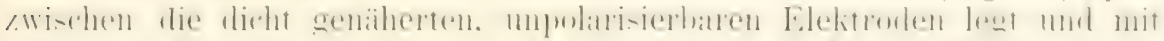

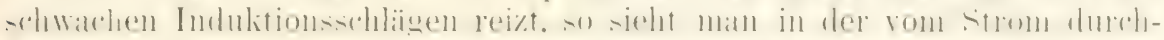

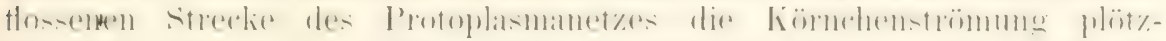
lich stillstehen. Es bilden sich umregehüßige Kilumpen und Kugeln an den Protoplasmafïden aus, die an den dïnnsten Stellen einreifen und in Nachbarfädlen aufgenommen werden. Nach einiger Zeit der Ruhe liehrt die Bewegung wierler, indem dis Kílumpen und Kugeln von den benachbarten Protoplasmaströmen allmählich ergriffen, mit fortgerissen und zur Verteilung gebracht werden. Bei starken und oft wielerholten Induktionsschlägen, welche die ganze '/elle getrotten haben. ist eine Rüickliehr zur Norm nicht mehr möglich, indem (ler Protoplasmakörper unter partieller fierinnung in trübe Schollen und Klumpen verwandelt wird.

Bei Amöben und weiben Blutkörperchen stockt die Körnchenbewegung und das Vorwärtskriechen, wenn sie durch schwache Induktionsschläge gereizt werden, eine kurze Zeit und wird dann wieder in normaler Weise fortgesetzt. Stärkere Induktionsschläge haben zur Folge, daf die Psendopodien rasch eingezogen werden und der Körper sich zur Kingel zusammenzieht: selır starke Ströme endlich rufen ein Platzen und eine Zerstörung les zur Kúgel liontrahierten Körpers hervor.

Durch längere Zeit fortgesetzte Indulitionsströme kann man niedere einzellige Organismen stïckweise zerstören und verkleinern. IBei Actinosphärium

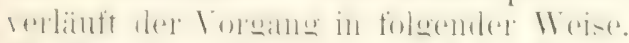

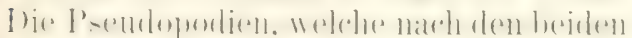

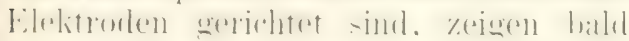
Varikositäten und werken allmählich. indem das Protoplasma zu Küügelchen und Spindeln zusammentließt, ganz eingezogen
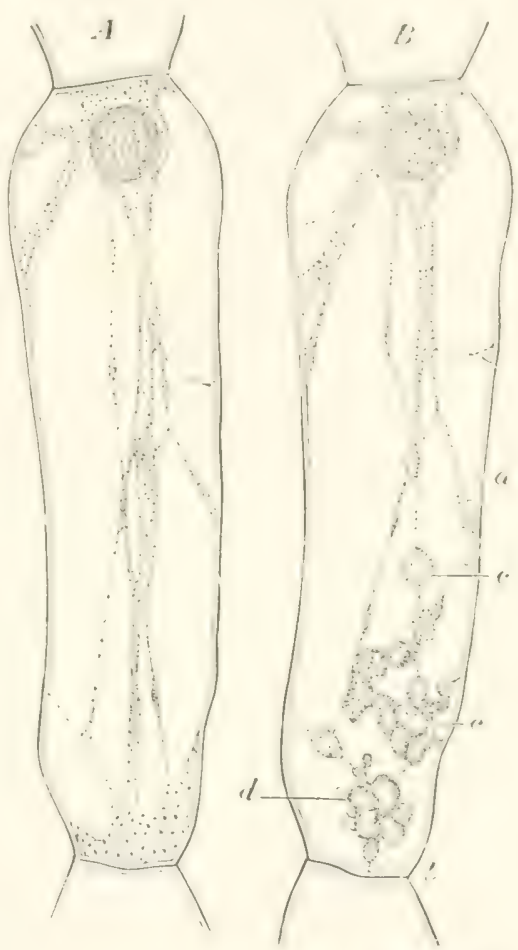

Fig. 99. $A$ und $B$ Zelle eines Staubademhaares von Tradescan-

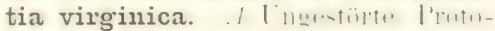

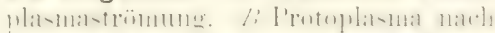

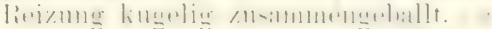
Zellwand, b (uerwand zweier Zellen. $c$, d Protoplasma zu Kilumpen zusammengeballt. (Nach KüHxE.) (Fig. 100 A). Dann fällt an diesen Stellen

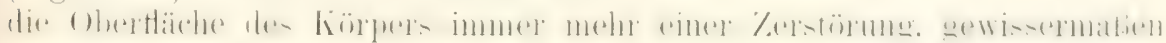
einer Art von Einschmelzung, anheim. wobei die im Protoplasma einge-

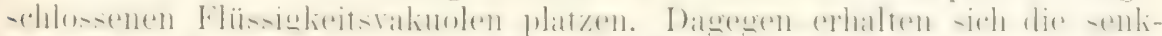

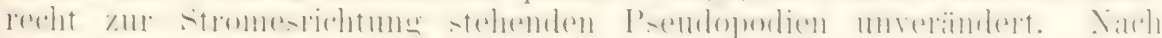
Beseitigung des Reizes erholt sich nach und nach das eventuell bis zur

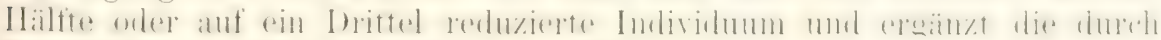
Einschmelzung verloren gegangenen Teile.

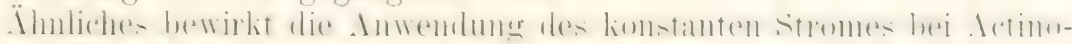

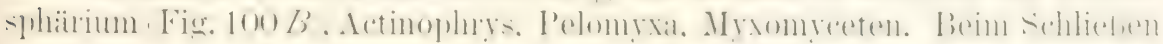




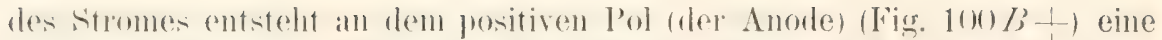

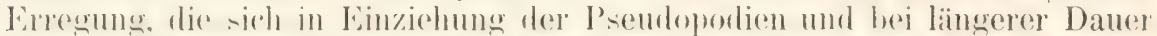
in einer zerstionume des Protoplasmats an der Eintritfsitelle des stromen

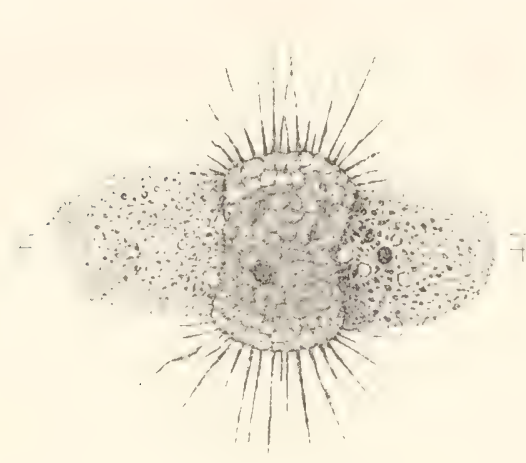

Fig. $1(1) .1$

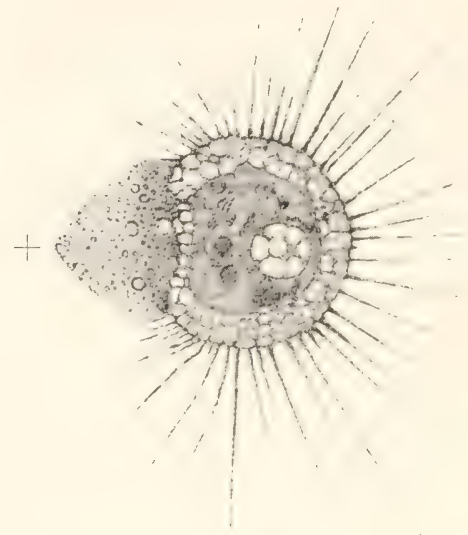

Fig. $100 \mathrm{~B}$.

Fï. 1111\%. Actinosphärium Eichhornii. Wirkung von Wechselströmen. In beiden Polen gleichmäßig fortschreitender Zerfall des Protoplasmas. Nach VERworx Taf. I, Fig. 5.

Fin. 11)/: Actinosphärium Eichhornii zwischen den Polen eines konstanten Stromes. Einige Zeit nach Schließung des Stromes beginnt an der Anode $(+)$ der körnige Zerfall des Protoplasmas. An der Kathode (-) sind die Pseudopodien wieder normal geworden. Nach Verwors Taf. I, Fig. 2.

kund gibt. Beim (jffnen desselhen hört die Finschmelzung an der Anorle sofort auf, und es tritt dagegen eine bald vorïhergehente Zusimmenziehung an der der Kathode zugewandten Körperobertläche ein.

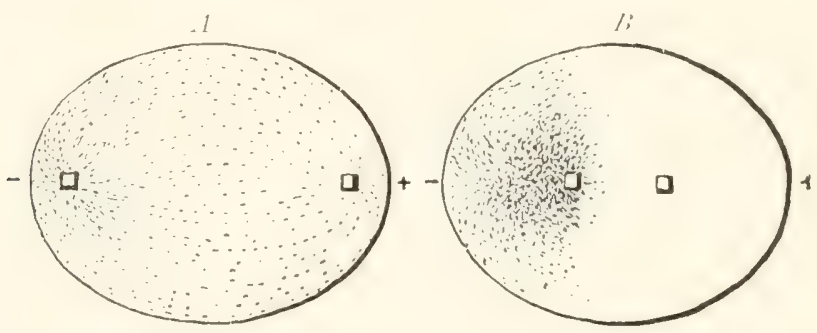

Fig. 101. Bei Schließung des konstanten Stromes schwimmen in einem Wassertropfen $(A)$ alle Paramaicien innerhalb der Stromkurven nach dem negativen Pol und haben nach einiger Zeit sich jenseits des negativen Pols angehäuft $(B)$. Nach Yerworx (VII 1889) Fig. 20.

Interessanter und wichtiger als diese Reizvorgänge sind vielleicht die Erscheinungen des Galvanotropismus,

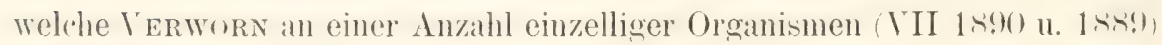
entrleckt hat.

Unter Galvanotropismus versteht VERwors die Erscheinung, daß durch den konstanten Strom manche Oroanismen zu Bewegungen in einer bestimmten Richtung veranlabt werlen, in ähnlicher Weise wie durch den 


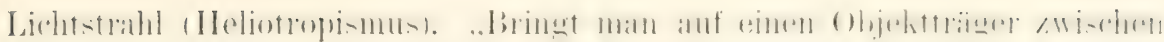

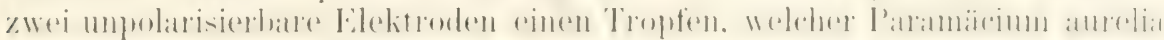
in möglichst großer Individuenzahl enthält. und schlielit dann den konstanten galvanischen Strom. so sieht man im Augenblick der Schliebuns saimtliche Paramäcien die Anote verlassen und als dichten Schwarm anf die Kathode zueilen. wo sie sich in groben Jengen ansammeln. Vach wenigen Sekunden ist der übrige Teil des 'Troptens vollkommen leer ron den Protisten und nur die kathodische Seite desselben zeigt ein dichtes Gewimmel ron ihmen. Hier bleiben sie wähend der ganzen Dauer des Stromes. Wird num der Strom geöftnet. so sieht man den ganzen Schwarm

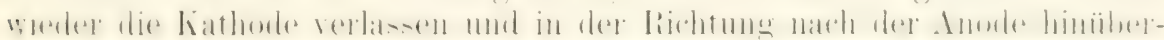
schwimmen. Diesmal tindet keine vollkommene Ansammlung an der Anode statt, sondern ein Teil der P'rotisten bleibt gleichmäbig im 'Tropten zerstreut, anfangs jedoch olne der Kathode näher zu kommen. was erst ganz

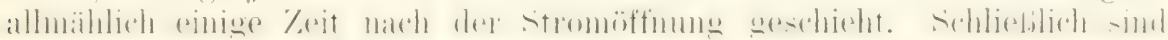
wieler alle Protisten sleichmäbig im Tropten verteilt."

Hat man spitze Elektroden angewandt, so schwämen die Paramäcien immerhalb der Stromkurve der Kathode zu (Fig. 101A). Es entsteht ein Bild, wie wenn Eisenfeilspäne von einem Magneten angezogen werlen. „Dabei macht man", wie VERWors bemerkt, ,die Beobachtung. daf. nach-

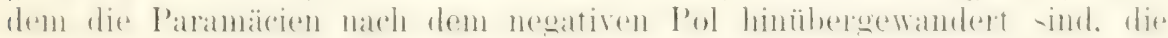
gröbte Anhäufung sich hinter, d. h. also jenseits des negativen Pols (vom positiven Pols aus gerechnet), gebildet hat. und dab sich nu wenige an der anderen Seite des Pols aufhalten (Fig. 101 B). Bei Öftnung des

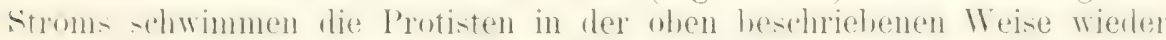

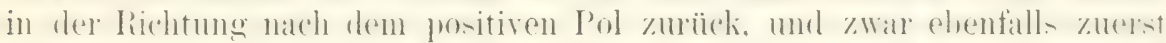
mit strenger Innehaltung der stromlinrven. his allmählich die liewermme und damit die Verteilung im Troppen wieder regellon wird." In derselhen

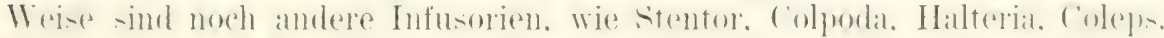

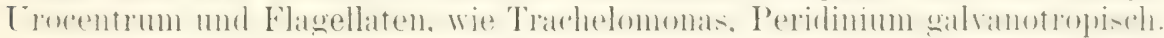

Galvanotropismus zeigen auch Amöben. Während sie im ersten Augenblick der Schließung des konstanten Stroms eine Sistierung der

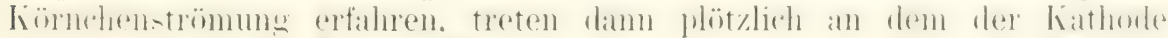

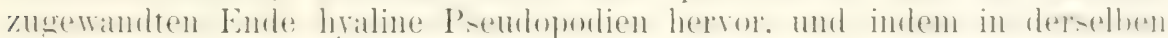

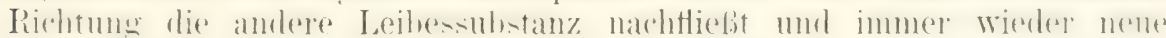
Psendopodien hervorgestreckt werden, kriechen die Amöben nach der Kathorle zu. Bei Umkehr des Stromes kam man auch eine plötzliche

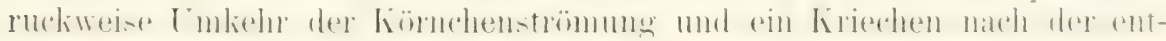
gegengesetzten Richtung beobachten.

Die Bewegung nach der Kathorle kam man als negativen Galvano-

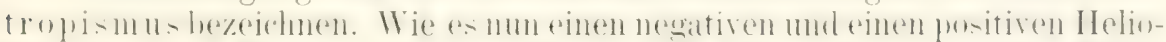

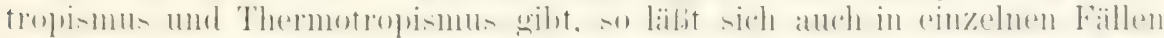
die Erscheinung eines positiven Galranotropismus nachweisen. VER-

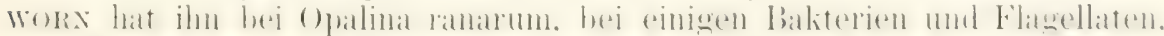

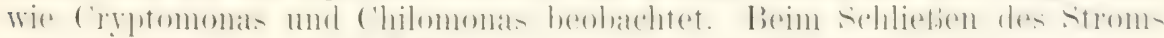
wandern die genannten Arten anstatt nach der Kathode nach der Anode hin und sammeln sich daselbst an. Sind in einem Tropfen gleichzeitig

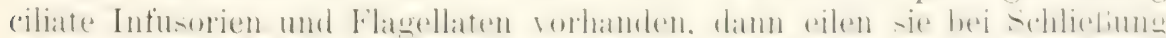

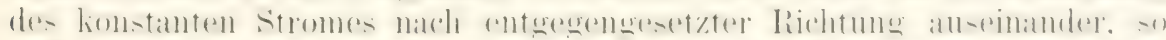

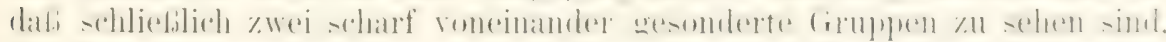
die Flagellaten an der Anode, die Ciliaten an der Kathode. Wurde der Strom num gewendet, so rückten sie wie zwei feindliche Heere gegeneimander los, bis sie sich wieder an den gegeniblerliegenden Polen an- 


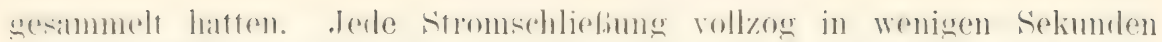

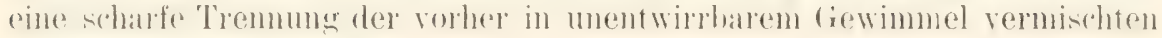
Infusorienformen.

\section{Mechanische Reize.}

Druck, Erschütterung, Quetschung wirken als Reiz auf das Protoplasma ein. Schwache mechanische Reize bleiben in ihrer Wirkung auf die nächst betroffene Stelle beschränkt, starke Reize breiten sich auf

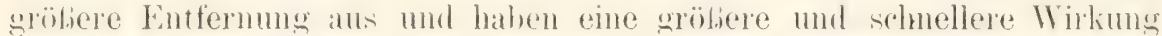
als schwächere. Wenn eine Zelle von 'Tradescantia oder Chara odler ein

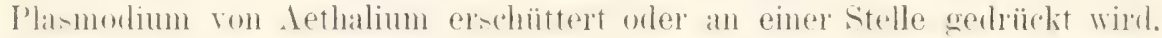
so steht die Körnchenbewegung eine Zeitlang still, an den Protoplasmafärden lïmnen sich sogal Anschwellumgen und kilumpen hilden, in ähnlicher Weise, wie nach Reizung mit dem elektrischen Strom. So kommt es häutien, dab heim Herrichten der Präparate shom durch das Auflegen des Deckgläshens die Protoplasmahewegmong zum stillstand gehracht wirl. Nach einiger Zeit der Puhe kehrt sie dann allmählich wierler zurück.
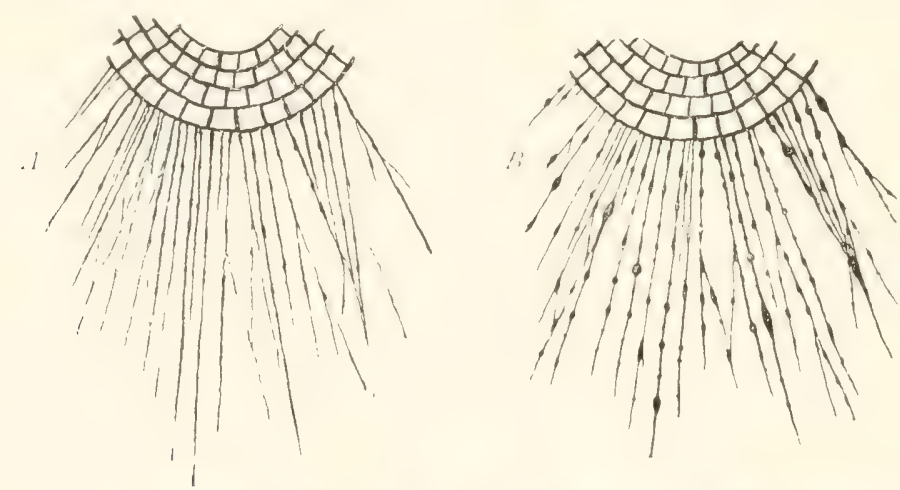

Fig. 102. Orbitolites. Ein Teil der Oberfläche mit Pseudopodien. Links ungestört, rechts total durch andauernde Erschiitterung gereizt. Nach VERworx ( $Y$ 1892) Fig. 7.

Amöben und weiße Blutkörperchen ziehen bei heftiger Erschütterung ihre Prendoporlien ein und nehmen Kugelgestalt an. Rhizopoden mit schön ausgebreiteten, langen Fäden tun dies oft mit einer solchen Energie, dab die Enden, welche an dem Objektträger kleben, abreißen (VERWORN).

Mit einer feinen Nadel kann man eine einzelne Stelle lokal reizen. Die Wirkung bleibt auf dieselbe beschränkt, wenn der Reiz schwach war, und äußert sich in einem Variköswerden und einer Verkürzung des Pseudopodiums. Starke und wierlerholte Reize rufen auch in den nicht direkt

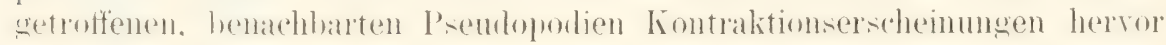
(Fig. 102 B).

Für die Nahrungsanfnahme der Phizopoden ist dies von Berleutung. Wenn ein Infusor oder irgend ein anderes kleines Tier mit einem ausgestreckten Psendopodium in Berührung kommt, wird es von ihm gleich festgehalten und rom Protoplasma rings umflossen. Dann wird es, indem sich das Pseudopodium allmählich verkürzt, wobei sich auch noch die henachbaten Fïden eventuell heteiligen. in die zentrale I'rotoplasmamasie geschaffit, wo es verlant wird. 


\section{Chemische lieize.}

Ein lebender Lellkönver kam sich bis zu einem rewissen Grarle chemischen Verinderungen seiner Ungebung anpassen. Wine Haupthedingung dabei ist freilich. dab die Veränderungen nicht plötzlich. sondern allmïllich eintreten.

Plasmodien von Aethalium gedeihen in einer zweiprozentigen Lösung von 'Traubenzucker, wenn man den letzteren in langsam steigender Dosis zum Wasser zusetzt (ST.нHL VII 18st). Würde man sie gleich aus reinem Wasser in die chemisch veränderte Lmgebung bringen. so würde der plötz-

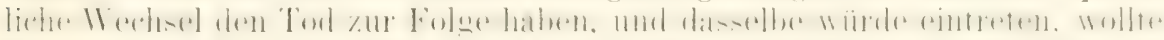
man sie aus der zweiprozentigen Zuckerlösung gleich in reines Wasser zuriickversetzen. Wie man hieraus sieht, mul, das Protoplasma Zeit haben, sich, wahrscheinlich durch Zu- und Abnahme seines Wassergehaltes, den veründerten Bedingungen anzupassen.

Meerwasseramöben und Rhizopoden bleiben an Leben, wenn durch

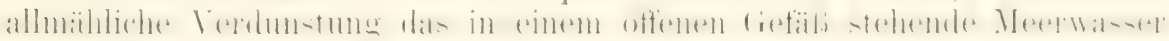
selhst einen Salzgehalt von 10 prozent erreicht hat. Süßwasseramöhen

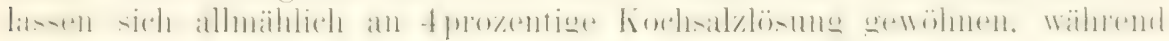
sie durch plötzlichen Zusat\% schon einer einprozentigen Lösung sich zu

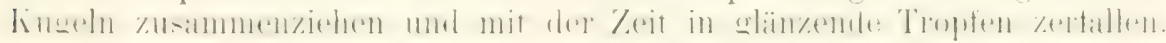

Bei der Anpassumg an eine neue chemische Umgebung werden die einzelnen Zellkörper mehr oder minder Veränderungen in ihrer Struktur und in ihrer Lebenstätigkeit erfahren. Wenn sich die Realition in einer fïr uns wahrnehmbaren Weise äufert, werden wir von chemischen Reizwirkungen sprechen. Die auf diesen aulierorlentlich unfangreichen Gebiete zu beobachtenden Erschemungen fallen verschieden aus, je nachdem das chemische Reizmittel allseitig und gleichmähig oder nur in einer bestimmten Richtung, also einseitig, auf den Zellkörper einwirkt.

\section{a) Erste Gruppe von Versuchen.}

Chemische Einwirkungen, die von allen Seiten den Zelliörper' treffen.

Unm die erste Gruppe der Erscheinungen zu erläutern, soll auf das Verhalten des Protoplasmas gegen einzelne Gase und gegen die unter dem gemeinsamen Namen der Anästhetica zusammengefabten Stofte näher eingegangen werden.

In den Ptlanzenzellen hört die Bewegung des l'rotoplasmas in kurzer Zeit auf, wenn man sie anstatt in Wasser in einen Tropfen Olivenöl einlegt und dadurch den Luftzutritt al)schliebt (Kümve VII 1s(jt). Nach

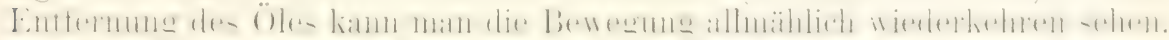

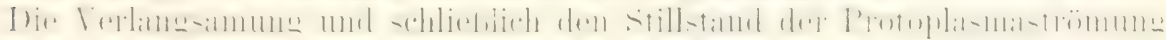
kamm man auch dadurch hervorrufen. daß man die atmospluärische Luft durch liohlensäure ofler durch Wassenstoft verdrïngt. '/ur Anstellung derartiger Experimente hat man besonlere Objeliträger mit (iaskammern konstruiert. durch welche man einen Strom von Kohlensiinre oder IVasserstotf' hindurchleiten liann. Sach einem Aufenthalt der P'Hanzenzellen ron ti) Minuten bis einel Stmmle im Kiohlensiunestrom ist die bewegung durchschnittlich iilserall erloschen: bei Anwendung des Wasserstotts ist eine etwas längere Zeit dazu erforderlich. Die Lïhmung des Protoplasmas kamm jerloch, wenn sie nicht zu lange Keit angerlauert hat. stets durch Sauerstottzufuhr wieder aufgehoben werten. ..Ottenbar bindet 


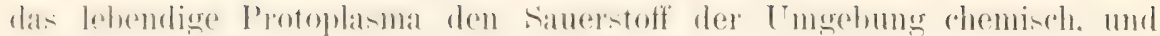
wird die so entstandene feste samerstoffierhindung. von der moter mormalen

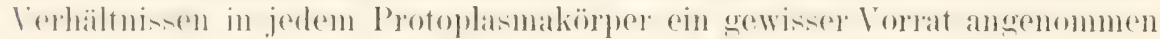
werden muli, während der liewergugen beständig zerstört. vermutlich unter Abspaltung von Kohlensäme." (Engelmans V 1879). Entziehung von

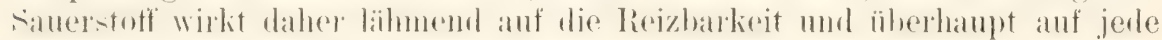
Lebenstätigkeit des Protoplasma ein.

Einen deutlich ausgesprochenen EinfluB auf die Lebenstätigkeit der Zelle haben die Anästhetica, Chloroform, Morphium, Chloralhydrat etc. Es wirken diese Stoffe nicht nur, wie man häufig glaubt, auf das Nervensystem ein, sondem ebensogut auch auf jedes Protoplasma. Die Wirkungsweise ist nur eine graduell verschiedene; es wird die Reizbarkeit der Nervenzellen früher und rascher herabgesetzt und endlich aufgehoben als die Reizbarkeit des Protoplasmas. Auch wird bei der medizinischen Verwendung der Narkotika beim Menschen nur eine Einwirkung auf das Nervensystem angestrebt, da eine tiefere Narkose der Elementarteile einen Stillstand des Lebensprozesses umb also den Torl zur

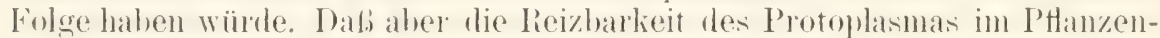
mol Tierreich ohne heihenden sharlen vorühergehend anfgehohen werden kann, wird aus folgenden Beispielen klar hervorgehen:

Die Sinnplanze oder Mimosa pudica ist gegen Berührung sehr empfindlich. Wenn ein Fiederblättchen etwas erschüttert wird, so klappt es sofort zusanmen und sinkt aus der aufgerichteten stellumg nade abwïts heral. Gleichzeitig ist sie ein leispiel für eine rasche lieizfortleitmo hei Ptlanzen, welche auch ohne Anwesenheit von Nerven, einfach in der Weise vor sich geht, daß der Reizanstoß von einem Protoplasmakörper auf den angrenzenden rasch übertragen wird. Infolgedessen schlagen bei einer Berührung, je nach ihrer Stärke, nicht nur die ummittelbar betroffenen Blätter. sondern auch die Blätter desselben Zweiges, eventuell sogar der ganzen Pflanze zusammen, wobei gewisse, hier nicht nåher zu bestuechende, mechanische Eimichtungen in Wirkismlieit treten. Lin num den Einflul, der Anästhetica zu studieren, stelle man eine mit voller Reizbarkeit auscestattete Simntlanze unter eine blasglocke und lege noch. wemn sie ihre Blätter vollständig ausgebreit hat, einen mit Chloroform oder

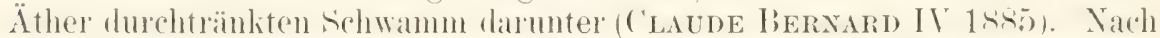
einer halhen stunde etwa hat das Protoplasma durch die chloroform- oder Ïtherdämpfe seine Reizharkeit eingebül. Nach Entfermmo der cilocke kann man die normal ausgebreiteten Blättchen berühren, sogar heftig quetschen oder ahschneiden, ohne das eine Reaktion eintritt: der Erfolg ist derselbe wie bei einem mit Nerven versehenen höheren Geschöpf. Und trotzdem ist das Protoplasma, vorausgesetzt, dafo der Versuch mit lor notwendigen Vorsicht angestellt worden ist. nicht abgestorben. Dem nachdem die simmptlanze einge Zeit in frischer Iuft zugehracht hat. sehwindet allmählich die Narkose: srst schlagen einzelne Blätchen bei kräftiger lieriblurmg noch langiam zusammen. enullich ist die volle Reizharkeit wienter zurückgekehrt.

In derselben Weise lassen sich Eier und Samenfäden in Narkose versetzen. Als Richard HerTwig und ich (VII 1887) lebhaft bewegliche samenfäden ron seepgeh in eine mit Meerwasser hergestellte 0,5proz. lïsung von ('hloralhychat brachten. wurle ihre Bewegung schon nach ¿) Minuten vollständig aufgeholsen, kehrte indessen. nachdem reines Meerwasser zugesetzt worlen war, sehr rasch wieder. Auch befruchteten die durch den vorübergehenden Aufenthalt in (1.5) Proz. Chloral selähmten 
Samenfärlen. als sie zu Eiern hinzugefïgt wurden fast ebenso bald als

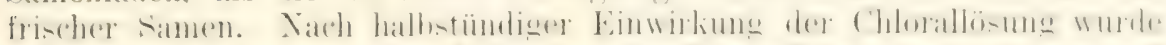

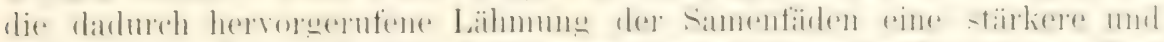

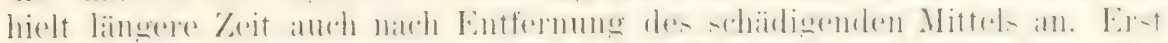

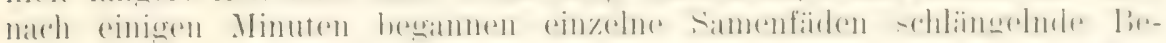
wegungen, die bald lebhafter wurlen. Ats sie zu Eiern hinzugefügt wurlen. waren diese nach 10 Minuten noch nicht befruchtet, obwoln auf

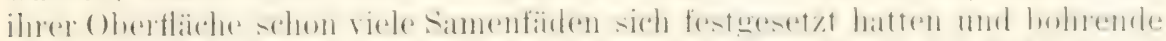

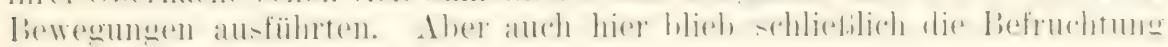
und normale Teilung der Eier nicht aus.

Wie bei den Samenfäden läBt sich auch bei den Eiern die Reizbarkeit durch eine $0,2-0,5$ proz. Lösung von Chloralhydrat und von ähn-

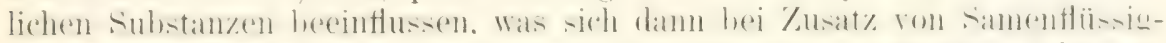

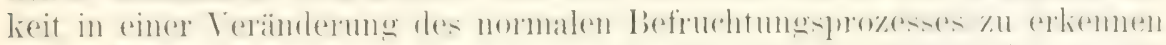

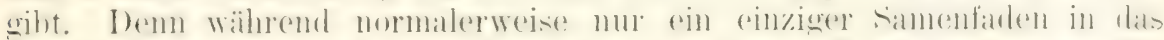

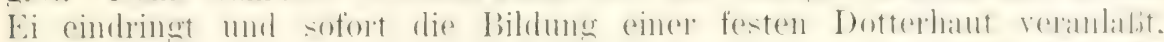

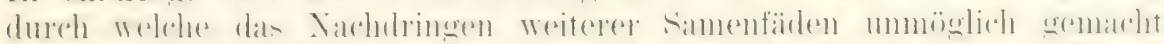

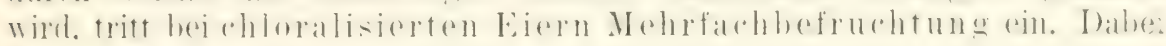
konnte festgestellt werden, daß je nach dem Grade der Chloralwirkung. je nach der Daner der Einwirkung und der Konzentration der Lösung.

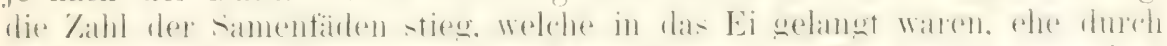

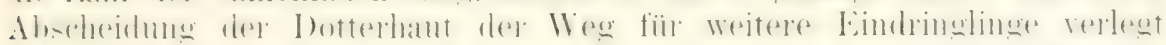
war. Offenbar ist durch die chemische Substanz die Realitionsfähiglieit fles Fiplasmas herabgesetzt, so dab der vormals durch einen Samenfarlen ausgeübte Reiz nicht mehr genügt. sondern durch das Eindringen von 2. 3 und mehr Samenfäden in entsprechender Weise gesteigert werden muB. $11 \mathrm{~m}$ das Ei zur Membranbildung anzuregen.

Ein letztes Beispiel wird uns endlich noch zeigen, dafs auch chemische Prozesse in der Zelle durch Anästhesieren eine Hemmung erfahren können. Wie bekannt. rufen die Spaltpilze. welche die Bicrhefe

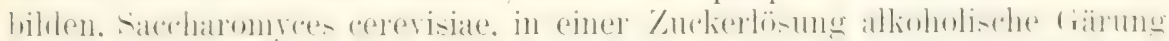

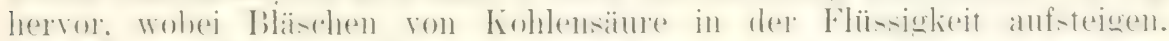

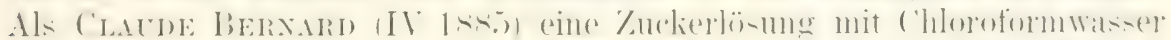

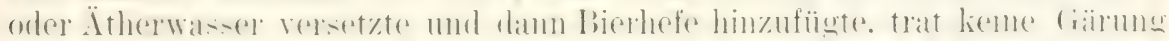
auch unter sonst günstigen Bedingungen ein. Als darauf die Hefepilze

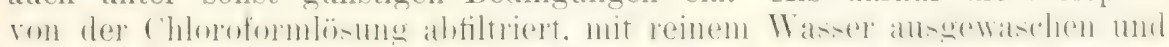
in reine Zuckerlösuing gebracht wurden, riefen sie in kurer Zeit wieder Gärung hervor; sie hatten also das Vermögen. Zucker in Alkohol und

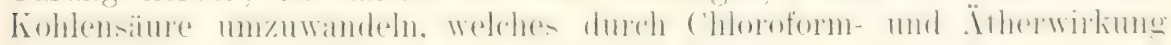
vorïbergehend aufgehoben war, wieder erhalten.

In ähnlicher Weise kann die Chlorophyllfunktion del Ptlanzen und

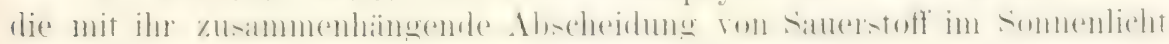
durch Chloroform sistiert werlen (CLAUDE BERNARD).

\section{b) Zweite Gruppe von Versuchen.}

Chemische Einwirkungen, die in einer bestimmten Richtung den Lellkörper treffen.

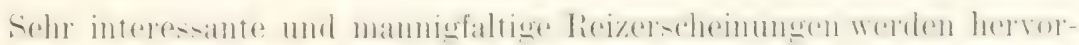

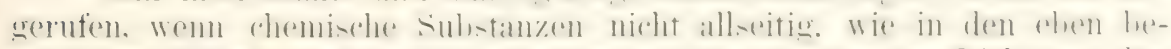

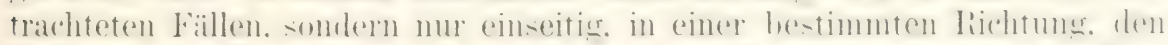

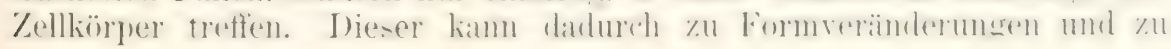




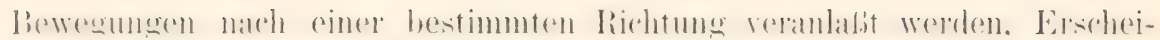
numgen, die man unter dem Namen des Chemotropismus (Chemotaxis) zusammengefaßt hat.

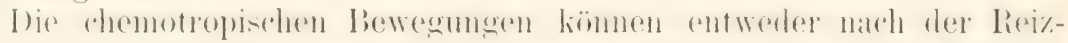

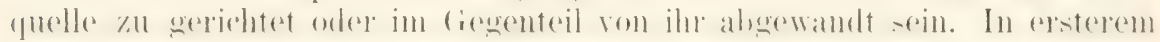
Falle wirken die chemischen Substanzen anziehend, in letzterem abstokend auf den Protoplasmaköryer ein. Es hängt dies teils von der chemischen Natur des Stoffes, teils auch von der Eigenart der dem Versuch dienenden Plasmaart, teils auch ron dem Konzentrationsgrad der chemischen Substanz ab. Ein Stoff, der in geringerer Konzentration anziehend wirkt, kann in stärkerer Konzentration abstoken. Es liegen hier

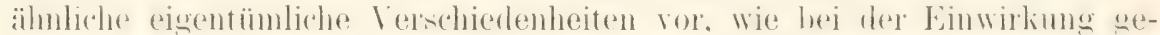
dämpften und starken Lichtes. Ebenso wie der Heliotropismus ein positiver und ein negativer sein kann, hat man auch einen positiven und einen negativen ('hemotropismus zu unterscheisen. Wir wollen andeh hier zuerst die Einwirkung von Gasen, alsdann von Lösungen in das Auge fassen und uns dabei mit einigen simmreichen Methoden bekannt machen. welche wir besonders dem Botaniker Pfeffer (VII 1886) verdanken.

\section{Gase.}

Ein gutes chemisches Lockmittel für frei bewegliche Zellen ist der Sauerstoff, wie namentlich die Experimente von Stahl, Engelmans und VERWORN lehren.

STAHL hat mit Plasmorlien von Aethalium septicum experimentiert (VII 1884). Er füllte einen Glaszylinder zur Hälfte mit ausgekochtem Wascer, das er zum Luftahschlub mit einer sehr dümen (O) schicht herleclite. mul lente an die Wand des \%ylmors emen streifen Filtrierpanier. auf dem sich ein Plasmodium ausgebreitet hatte, in der Weise, daß die Hälfte in das Wasser tauchte. Schon nach kurzer Zeit verlü̈nnten sich die in satuerstofffreien Was-er hefindlichen Protoplasmastränge. und hald war alles Protoplasma über die Ölschicht, die auf das Plasmodimm sonst nicht schädigend einwirkt, emporgewandert nach dem oberen 'Teile des Zylinders. wo der Sauerstoff der Luft zutreten konnte. Man kamn den Versuch auch in der Weise anstellen. dab man ein Plasmodium in einen

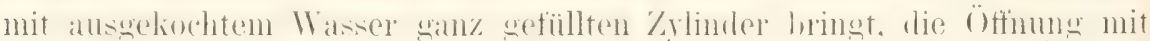
einem durchlïcherten Kork schlisht und den \%ylinder mit der ötthung nach unten in einen mit frischen $\mathrm{Wasser}$ gefüllten Teller stellt. Bald ist das Plasmodium durch die feinen Löcher des Korks hindurch dem sauerstoffreicheren Medium entgegengewandert.

Interessante Untersuchungen über den richtenden Einfluß des Sauerstoff's auf die Bewegungen der Bakterien hat Engelarans (VII 1881) angestellt und gezeigt, daf man manche Bakterienformen als ein sehr feines Reagens zum Nachweis sehr geringer Sauerstoffmengen benutzen kann. Wird in eine Flüssigkeit, die gewisse Bakterien enthält, eine kleine Alge oder Diatomee gebracht, so ist sie in kurzer Zeit von einer dichten Hülle von Bakterien umgeben, die durch den bei der Chlorophyllassimilation frei werdenden Sauerstoff angezogen werden.

IERWORN (VII 18S9) sah eine Diatomee von einem Wall berregungs-

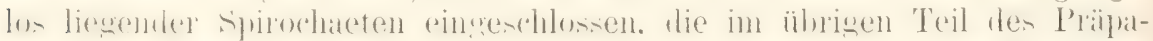

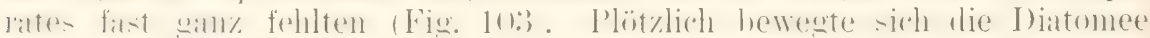
eine Strecke weit aus dem Baliterienhanfen heraus. Die Spirochaeten, welche so ron ihrer Sauerstoffquelle im Stich gelassen waren, lagen zunächst einige Augenblicke ruhig, fingen aber bald darauf an, sich lebhaft 
zu bewegen mol in dichten Scharen wieder zu der Diatomee himüberzuschwimmen. In 1-_- Minuten waren fast alle wieder um sie versammelt mal blieben bewegungslos an ihr liegen.

Aus der Reizwirkung des Sauerstoft's erkiärt es sich auch, daf, man

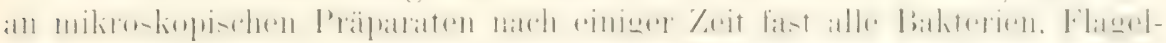
laten und Infusorien an den Rändern des Deckgläschens orler um Lufthasen. die sich im Wasser befinden, angesammelt sieht.

Eimen recht lehreichen Versuch teilt VERwors (III lss:9) mit. Man bringe eine große Menge Paramacien in ein mit sanerstotiamem Wasser

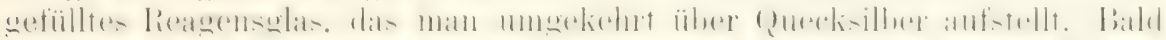

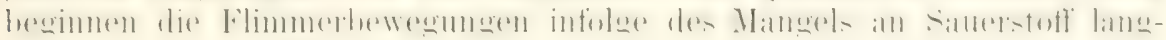
sam zu werlen. Wenn man jetzt eine Blase reinen Sanerstoffs von unten her in das Reagensglas hineinläbt, so sieht man dieselhe schon nach wenigen Sekunden von einer dicken. weißen Hülle von Paramaecien umgeben, ..die ron Sauerstoffdurst getrieben, wild auf die Sauerstoffblase losstiimen".

\section{Flïssigkeiten.}

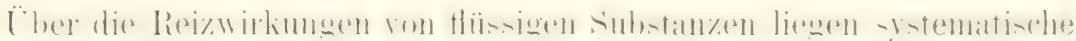
Untersuchungen voll STAHL und PFEFFER vol.

STamr. (VII 188t) hat als Untersuchungsobjekt auch hier wieder die Lohblüte benutzt. Auf diese kam schon einfaches Wasser als Reiz. wirken, eine Erscheinung, die STAHL als positiven und negativen Hydrotropismus beschrieben hat. Ein gleichmäligig auf einen Streifen fenchten Filtrierpapiers ausgebreitetes Plasmodium zieht sich stets. wem das Papier auszutrocknen beginnt. nach den Stellen zurïck. welche noch am feuchtesten geblieben sind. Wem man wïhrend des Austrocknens über das P'apier senkrecht einen mit (relatine bestrichenen Objektträger in $2 \mathrm{~mm}$ Abstand anbringt. so erheben sich an dieser Stelle. durch den ron der Gelatine ausgehenden Wasserdampf angezogen. einzelne Aste rom Plasmodiumnetz senkrecht in die Höhe. bis sie die Gelatine erreichen und sich anf ihr aushreiten: nach wenigen Stunden kamn so das ganze Plasmodium auf die feuchtere Unterlage übergewandert sein. Zur Zeit, wo sich die Myxomyceten zur Fruchtbildung anschicken, tritt an Stelle des positiven der negative Hydiotropisnus. bie Plasmudien stehen jetzt im regenteil die trockensten stellen ihrer Umgebung auf und weichen ror feuchten Gelatinestiichchen und angefenchtetem Fil-

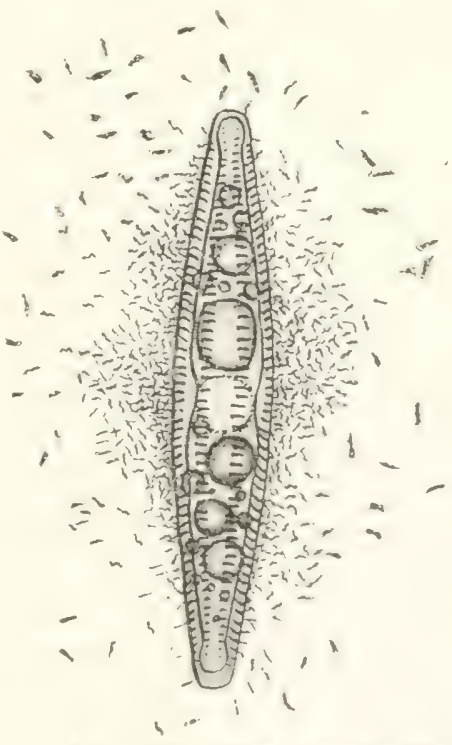

Fi... Ir:. Eine große Diatomee (Pinnularia) von einem Haufen von Spirochaete plicatilis umgeben. Nach Veriworx (III 1SS'), lig. 11. trierpapier, das man in ihre Nähe bringt. zuriek. Die Erscheinungen des Hydrotropismus finden leicht ilne Erklïrung darin, dab das Protoplasma ein gewisses (Quantum von Imbibitionswasser enthält, welches in gewisen firaden schwanken und anch während der Entwicklung des Zellkörper's zu- und abnehmen kamm. Je reichlicher rom Inbibitionswasser das Protoplasma durchtränkt ist. $11 m$ so lebhaftere 
bewegungen wird es im allgemeinen zeigen. Wähend der regetativen Periode hat das Plasmodium von Aethalium die Neigung, seinen Wassergehalt zu erhöhen und wird sich daher nach der Wasserquelle zu bewegen: beim Eintritt in die Fortpttanzungsperiode dagegen flieht es die Fenchtigkeit, weil bei der Sporenbildung der Wassergehalt des Proto. plasmas vermindert wird.

Manche chemische Substanzen wirken anziehend, andere abstofend auf Plasmodien ein. Wenn man ein auf feuchtem Substrat ausgebreitetes

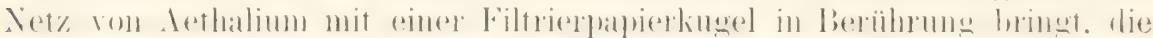

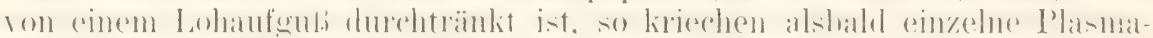
stränge nach der Nahrungsquelle hin; schon nach wenigen Stunden sind alle Zwichenrïume der Papierkugel rom Schleimpilz durchsetzt. - Em den negativen Chemotropismus zu studieren, bringe man an den Rand eines auf fenchtem Filtrierpapier ansgebreiteten Schleimpilzes einen Kochsalzkristall oder Salpeter oder einen Tropfen Glyzerin. Man wirl daun sehen, wie sich unter dem Reiz der im Filtrierpapier sich ausbreitenden, konzentrierten Salz- oder Glyzerinlösung das Protoplasma von der Reizyuelle in immer größerem Umkreise zurïckieht. So besitzen die leicht zerstörbaren, nackten Plasmorlien die wunderbare Fähigkeit, auf der einen Seite schädlichen Substanzen ans dem Wege zu gehen, auf der anderen Seite ihr Substrat nach allen Richtungen zu durchsuchen und die ihnen zusagenden Stoffe aufzunehmen. .'Trifft nämlich irgend einer der zahlreichen Zweige eines Plasmodiums zufällig anf einen an Xährstoften reichen Borlen, so erfolgt sofort ein Zuthub des Plasmas nach del begïnstigten Stelle."

In bahnbrechenden Untersuchumgen hat PFEFfer (VII 1ssio) den Chemotropismus kleiner, freibeweglicher Zellen, wie Samenfäden, Baliterien, Flagellaten, Infusorien, genaner erforscht und dabei ein sehr einfaches und sinnreiches Verfahren eingeschlagen. PFEFfer nimmt feine (ilaskapillaren, die $4-12 \mathrm{~mm}$ lang, an einem Ende zngeschmolzen sind und an dem andern Ende eine Mündung von $0,0: 3-0.15 \mathrm{~mm}$ im Lichten je nach der ( Dieselben werden etwa ein Drittel orler zur Hälfte mit dem Reizmittel gefïllt. während der nach dem zusimmengeschmolzenen Ende hetindliche Raum noch Luft enthält.

Um die Gebrauchsweise zu erläutern, diene $\ddot{A}$ pfelsäure, in welcher Pfeffer ein Reizmittel entdeckt hat. das die Samenfädlen der Farne in hohem Grade anlockt. mnd das wahrscheinlich $7 u$ diesem Zwecke auch in der Natur von den Archegonien ausgeschieden wird. Eine Kapillare. die mit $0,01 \%$ Äpfelsäure gefüllt ist, wird nach sorgfältiger Reinigung ihrer Obertäche in einen Tropfen Wasser, in dem sich viele Samenfärlen der Farne befinden, vorsichtig hineingeschoben. Bei 100- bis 200 facher Ver-

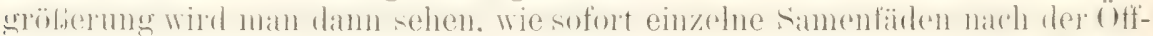
nung der Kapillare zusteuern, von welcher die Äpfelsäure in das Wasser zu diffundieren begimnt. Sie dringen alsbald in die Kapillare selbst ein: ihre Zahl nimmt rasch 74 und ist in 5-10 Minuten auf viele Hunderte gestiegen. Nach einiger Zeit sind fast sämtliche Samenfäden mit Ausnahme weniger Exemplare in das (ilasröhrehen hineingeschlüpft.

Wenn man in der angegebenen Weise eine Prüfung mit verschiedenen Konzentrationsgraden der Äpfelsäure vornimmt, so ergibt sich ein ähnliches Gesetz wie bei der Einwirkung verschiedener Wärmegrade auf die Protoplasmaströmung. Ton einem gewissen Minimalwert an, der bei $0,001 \%$ liegt, und den man als Schwellenwert bezeichnen kann, wächst die 
anziehende Wirkung mit zmehmender Konzentration der Lösung bis zu einem bestimnten Punlit, dem Optimum orler Maximum des Rei\%erfolges; hei weiterer Z/unahme der Konzentration nimmt erst die Anziehung ab, und hier endlich tritt ein Moment ein, wo der positive in den negativen Chemotropismus umschlägt.

Die stark konzentrierte Lösung wirkt geradezu entgegengesetzt und stölat die Samenfïden von sich ab. Wie gering die Menge Ipfelsäure ist. durch welche schon ein leizerfolg erzielt werden kann. wird man am besten daraus ersehen. dah in einem Röhrchen mit einer 0,001\% Lösung

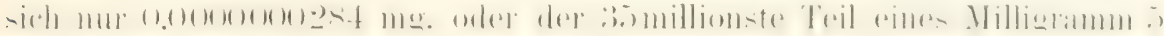
Apfelsiume befindet.

Wie schon oben hervorgehoben wurde, mub der chemische Reiz.

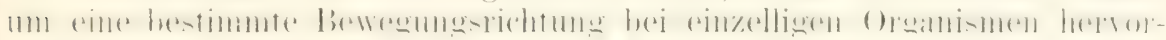
zuruten, nur einseitig oder wenigstens von einer Seite intensiver einwirken. Das ist nun anch in den mitgeteilten Experimenten der Fall: denn indem aus der Kapillarmündung die Appelsäure in die Ungebung diffundiert. geraten die Samenfärlen, wenn sie zur Kapillaröfhung und wenn sie dann weiter durch dieselhe in der Röhre vordringen, in Lösungen von all-

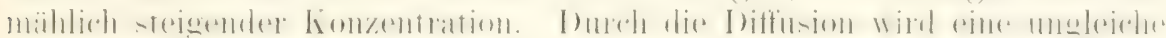
Verteilung des Reizmittels um den Körper der Samenfäden hergestellt: .erst durch Konzentrationsunterschierle wirkt die Ipfelsäure als ein die Bewegungsrichtung bestimmender Reiz."

In einer homogenen Lösung bleiben die Samenfärlen, wie nicht anders zu erwarten ist. gleichmäbig verteilt; doch wird anf sie auch unter diesen Verhälnissen eine spezifische Reizwirkung ausgeuibt, die aller(lings nur auf indirektem Wege und zwar daran zu erkennen ist. dal gewissermaben die Stimmung der Zellen gegen Äpelsäure eine Anderung erfahren hat. P'FEFFER konnte hier ähnliche lieziehmngen nachweisen. wie sie für die Sinneswahrnehmungen des Menschen durch das WEBErFechnersche Gesetz festgestellt sind. „Während der Reiz in geo-

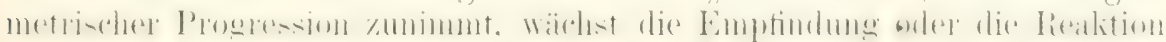
in arithmetischer Progression."

Das in vieler Beziehmng sehr wichtige Verhälnis soll wieder an dem

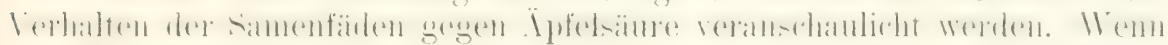
der Experimentator zu der Flüssigkeit, in welcher sich die Samenfüden

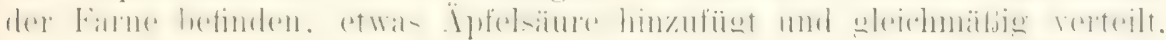
so dalo eine 0,0005$)_{0 /}$ ige Lösung entsteht, so wirkt eine $0,001{ }^{\circ}$ "ige Apfelsäure in einer Kapillarröhre, die zum Einfangen dienen soll, nicht mehr anlockent. wie es der Fall war zur Zeit, als die Samenfäilen in reinem

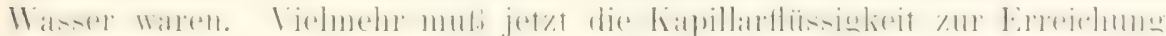
des Schwellenwertes $0.015,0$ und bei einem Gehalt des Wassers ron $0,05 \%$ Äpfelsäure $1.5 \%$ von diesem Reizmittel enthalten: oder allgemeiner ausgedrïblit: die Lösung in der Kapillare muls 30 mal so viel

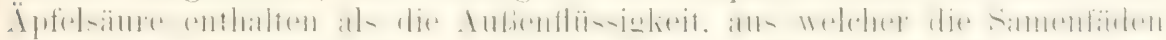
eingefangen werden sollen. 1)ie Reizempfänglichkeit ofler Reizstimmung der Samentärlen verändert sich also. Wenn sie in einem Medium relweilen, das schon eine hestimmte Menge der Substanz enthïlt, die als Reizmittel dienen soll. Man kamn sie so auf kiunstlichem Were anf der einen Seite unempfänglich machen gegen schwache Lösungen von Ajpfelsäure, die unter anderen Bedingungen als grutes Reizmittel wirken. auf der anderen Seite kömnen sie reizempfänglich gemacht werden gegen stärker konzentrierte Apfelsäurelösungen. Welche in reinem Wasser befindliche Samenfärlen abstofien. 
Wie gegen Licht, verhalten sich die einzehen Zellkörper auch gegen chemische Stofte sehr verschieden. Mpfelsäure, welche die Samenfäden von Farnen kräftig anlockt, erweist sich für Samenfäden der Laubmoose völlig wirkungslos. Fiur diese ist wieder Rohrzucker von $0,1 \%$ ein Reizmittel. Samenfäden endlich von Lebermoosen und Characeen reagieren auf keinen von diesen Stoften.

Eine 1\% ige Lösung von Fleischextrakt oder von Asparagin hat eine kräftig anziehende Wirkung auf Bakterium termo und Spirillum undula und manche andere einzellige Organismen. Schon nach 2 bis 5 Minuten hat sich ein förmlicher Pfropf von Bakterien an der Mündung

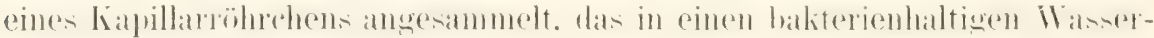
tropfen geschoben wird.

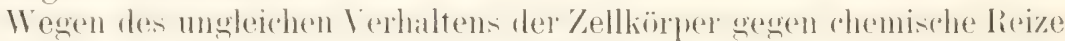

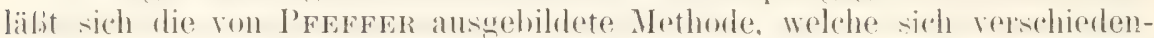
artig modifizieren läbt. nicht nur zum Einfangen entsureshend emptindlicher Organismen, sondern auch zur Trennung einzelner Arten in Gemischen verwenden, ähnlich wie der Galvanotrophismus und IJelotropismus.

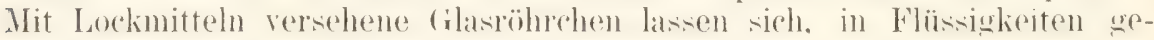
taucht, als Bakterienfalle und Infusorienfalle benutzen.

Ferner ergibt sich aus den mitgeteilten Experimenten, dab chemisch besonders emptindliche Organismen gewiscermatien als lieagentien henutzt

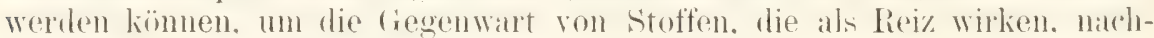
zuweisen. So sind nach ENGEIMaNN (VII 1881) gewisse Spaltpilze ein ausgezeichnetes Reagens für sauerstoff, indem sehon der trillionste Teil eines Milligramms genügt, um sie anzulocken.

Nicht alle Stoffe, die anlockend wirken. haben einen Nährwert für die ()rominimen ofler sind shnen unschällich: manche führen sogar alsbahl zur Vernichtung der angelockten Organismen, wie salizylsaures Natron, salpetersaures Strychmin orler Morphium. Indessen haben die meisten Stoffe, die schällich auf den Protoplasmakörper einwirken, auch eine abstofende Wirkung auf denselben, so die meisten sauren und alkalischen Lösungen. Zitronensäure und Natriumkarbonat wirken schon in $0,2 \%$

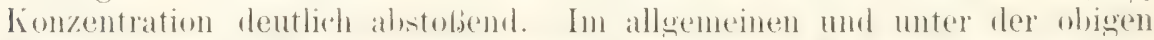
Finschränkmug lälit sich daher immerhin sagen. dali durch den positiven Chemotropismus die Organismen in den Stand gesetzt werden, ihnen zusagende Stoffe aufzusuchen, während sie infolge des negativen Chemotropismus schädlichen Stoffen ausweichen.

Die Erscheinungen des Chemotropismus sind von grober Bedeutung auch für das Verständnis vieler Vorgänge im Körper der Wirbeltiere und des Menschen. Auch hier gibt es Zellen, welche

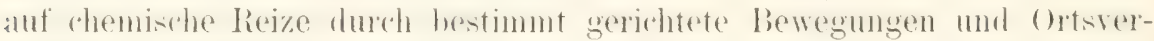
änderung reagieren. Es sind dies die weißen Blutkörperchen und die Lymphzellen (die Lenkocyten und Wanderzellen). Die chemische Reizbarkeit der Leukocyten ist durch Versuche von LEBER (VII 1888 und 1891). Massart uul Bordet (VII 1890 1891). Steinhaus (VII 1889). Gabritschevsky (VII 1890) und Buchner (VII 1890) und andere festgestellt worden. Wenn man nach dem Verfahren von PFeffer feine Kapillar-

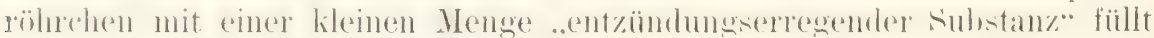
und in die vorder'e Augenkammer oder in den Lymphsack des Frosches einführt. so füllen sich dieselben in kurzer Zeit mit einer betråchtlichen Mense rom Lymphkïrperehen. Während Röhrehen mit destiliertem Wasiser nicht die gleiche Wirkung äußern. In das Unterhautbindegewebe gebracht, rufen die Röhrchen Auswanderung der Leukocyten (Diapedesis) 


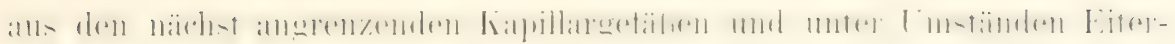
bildumg hervor.

Inter den entzïndungserregenden Substanzen stehen in erster Reihe obenan viele Miliroorganismen und ilne Stoffiwechselprodulite. So erwies sich hei den Versuchen von LEBER namentlich ein Extrakt von Staphylococens pyogenes sehr wirksm. Dadurch sreift die Lehre vom Chenotropismus in die Lehre der dureh pathogene Mikroorganismen erzeugten Krankheiten bedeutungsoll ein. Erst durch genaue kemntuis der ersteren werden viele wechselvolle Erscheinungen. welche uns das Studiun der Infektionskrankheiten darbietet, verstïndlich gemacht. Es kann num wohl von vornherein lieinem Zweifel unterliegen, daß. wenn die Lenliocyten überhaupt durch chemische, ron Mikroorganismen erzengte Substanzen in einen Reizustand versetzt werden können, dies nach ähnlichen Gesetzen wirl geschehen müssen, wie sie für die Kelle im allgemeinen haben festgestellt werden kömen. Positiver und negativer Chemotropismus. Reizschwelle. Veränderumg der Reizschwelle durch gleichmäbige Verteilung des Reizmittels. Reiznachwirkmo werden anch auf diesem (iehiete in Betracht kommen.

So gestaltet sich demn die Beziehung der Leukocrten zu den als Reiz wirkenden Substanzen zu einem komplizierten Prozef, der je nach den vorliegenden Berlingungen sehr verschieden ansfallen kann. Denn

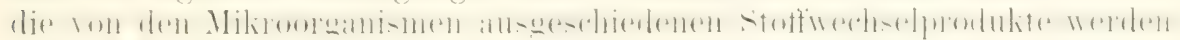
je nach ihrer Natur und je nach ihrer lionzentration bald eine anziehende. bald eine abstobende Reizwirkung ausüben müssen. Aulierdem aber wird die Einwirliung sich noch verändern, wenn die Stoftwechselprodulte der Mikroorganismen sich nicht nur an Ort ihrer Entstehmng in then ererlirankten (iewebsparticen vorfinden und ron da aus die Lenkocyten leizen. sondern auch noch im Blutstrom selbst in gleichnäliger Verteilung enthalten sind. Dann werden. wie es bei dem Reispiel mit den Samentaiden und der Ïpfelsäure der Fall war (Seite 16it. 16.), die im Blut

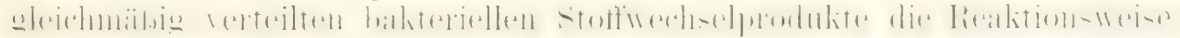
der Leukocrten gegen die am Orte der Erkiankung angehäuten Stofivechselprodukte modifizieren. Hierbei mur las relative Verhältnis der hier und dort vorhandenen, wirlsamen Substanz den Ausschlag geben.

Durch berücksichtigmo lieser Verhälnisse scheinen sich mir viele interessante Erscheinungen erliären zu lassen. welche durch französische Forscher. Roger. Charrix. Bouchard ( II 1s!) 1) ete. hei ihren verschiedenartigen Experimenten mit den Stottwechselprodukten des bacillus procratneus. des Milzbrandbarilhus ete. mol dureh KocH bei seiner Tuberliulintherapie beobachtet worden sind. Ich habe einen solchen Erkiarungsversuch unternommen in einer kleinen. gemeinverständlichen schrift: ..̈̈ber die physiologische frundlage der Tuberkulinwirliung. eine Theorie der Wirkungsweise bazillärer Stoffwechselprodukte" (VII 1,:1). und rerweise ich hiermit anf sie hetreffs der emzelnen zu erklärenden líankheitserscheinungen und physiologischen Experimente.

\section{Literatur VII.}

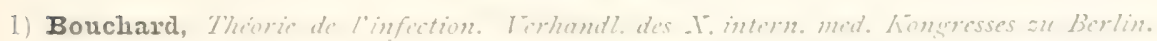
Bid. I. Is $(2$. .

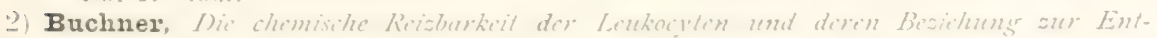

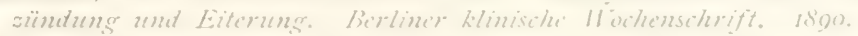

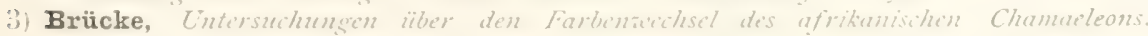

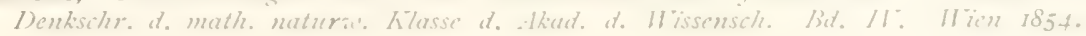


1. Bunge, fitalismus und Alechanismus. Lehrbuch der physiol. "t. pathol. Chemre, II. Anifl. I850.

De Bary, Vorlesungen vïber Jirkterien. 1885.

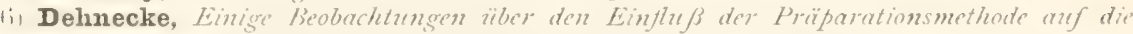
bertegungen des P'rotoplasmas der Pflansenzellen. Filora I88T.

Engelmann, lieiträge sur Phrsiologie des Protoplasmas. Pflïgers Archia'. Iid. II. I800. Derselbe, Uber Reizune kontraktilen Protoplasmas durch plütaliche Belenchtune. Pflïgers Archiz'. Bid. T/A. 1879.

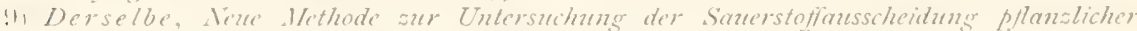

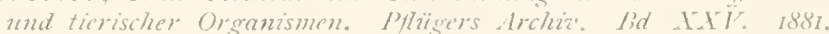

111) Derselbe, Übr Licht-nnt Firbenperseption niederster Organismen. Pflïgers Archaz. Bit. X.YT/. 1882 .

11, Derselbe, Bocterinm photonetrinum. Ein Beitrag zur a'ergleichenden Phzsiologie des Licht- nut Farbensinnes. Pflügers Archiz. Bd. XXX. 1883.

I.) Gabritschevsky, Sur les proprietés chimiotactiques des lezkocrtes. Annale's de l'ln. stitut de Pustcur. 1800 .

1:) Richard Hertwig, Erythropsis mgilis, eine nete Protozoe. Morph. Jahr-b. Bid. X. 1885.

11 Oscar 4. Richard Hertwig, Über den Befruchtungs- und Teilungsiorgang des tierischen Eies unter dem Einfuß äußerer Agentien. 1887.

1.i) Oscar Hertwig, Experimentelle Studien am tierischen Ei zon, wïhrend und nurh der Befruchtune. 1890 .

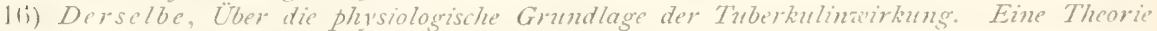
der Hirknnosacise bazillärer Stoffacchselprodukte. Jenu I80I.

1.) Klebs, Iriträge aur Physiologie der Pflansenzelle. Untersuch. ans dem botanischen linstitut an Tübingen. Bit. 11. p. 189. 1886.

14) W. Kühne, Untersuchungen über das Protoplasma und die fiontraktilität. 1864.

19) Künstler, Les yeux des infusoires flagelliferes. Journ. Micr. Paris. Io. Jahrgang.

2i) Leber, Uber die Entstelnung der Entzündung und die ITirkung der entä̈ndnngserregenden Schädlichkeiten. Fortschritte der Medizin. I888, p. 460.

21) Derselbe, Die Entstehung der Entä̈ndung und di IV irkung der entsündungserregenden Schädlichkeiten. Leipzis $189 I$.

2.) J. Ioeb, Der Heliotropismus der Tiere und seine Übereinstimnnug mit dem Heliotropismus der Pflanzen. ITïraburer 1800.

․: Derselbe, Heitere Untersuchungen ziber den Heliotropismus der Tiere. Pflïgers Archiz'. Bd. HLIII. I800.

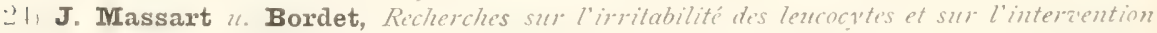
de cotte imritubilite dans la mutrition des cellules et dans l'inflammation. Jourmal de la Soc. $R$. de's sciences meiticales et muturelles de Bruxielles. I800.

I.) Dieselben, Annales de l'mstitut Pasteur. I89I.

ב(i) W. Pfeffer, Handbuch der Pflanzenphissiologie. Bd. I. 1881.

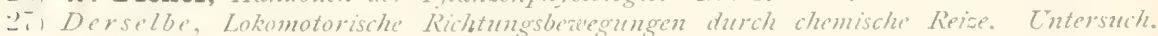
ans dem botan. Institut an Tübingen. Bd. I. 1885.

Zi) Derselbe. Zur Kenntnis dor Kontaktreize. Cntersuch. ans dem boten. Institut au Thibingen. Bd. I. I885\%

2!), Derselbe, Über chemotaktische Bearesungen won Bakterien, Flagellaten u. Voliocineen. Cntersuch. aus dem botan. Institut su Tïbingen. Bd. II. 1886.

(i) George Pouchet, D'un ocil véritable chez les Protozoaires. C. R. Soc. Biol. No. 36.

:il) Derselbe, Du role des nerfs dans les changements de coloration des poissons. Joum. de l'anat. et de phi's. I872.

:i-1 Derselbe, Wote sur l'infuence de l'ablertion des reux sur la coloration de certaines especes animales. Journ. de l'anat. ct de la phy's. Bd. X. $187+$.

i:i) $\mathbf{F}$. A. Pouchet, Sur la mutabilite de la coloration des reinettes et sur la structure de leur pean. Compt. rend. T: KIVT.

:i) Rawitz, Zur Physinlogie der Cephalopodenretina. Aritir f. Anat. ut. Physiologie. Isot.

(i.) Sachs, Handunch der Experimentalphysiologic der Pflanzen. 1865.

:3i) Seidlitz, Beitrüge sur Desaendenstherie. Leipaig 1876.

:ii) Stahl, (̈ber den Einfuß von Richtung und Stärke der Beleuchtums anf cinige Be'wegunsasescheinungen in Pfanamreich. Botan.-Zeitune. I8so.

ii) Derselbe, Zur Biologie der alyomuceten. Botan. Zeitung. $188+$.

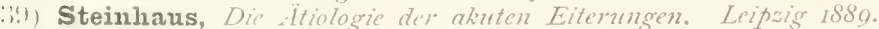

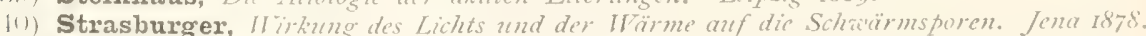

11) Velten, Einairkung der Temperatur anf die Protoplasmaberegungen. Flora 1876.

1.2) Verworn, Die polare Erremung der Protisten durch den galarinischen Strom. Pfïgers Archin, Bid. XLI at. ILIT, I880, 1800 .

1:i) Derselbe, Psicho-physiologische Protisten-Studien. Jenn I880. 
ACHTLS LAPITLI.

\section{Die Lebenseigenschaften der Zelle.}

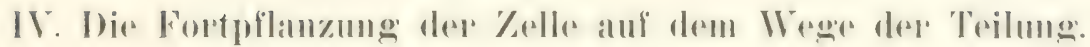

\section{Geschichte der Zellenentstehung.}

Eine der wichtigsten Eigenschaften der \%elle. insofern auf ihr die

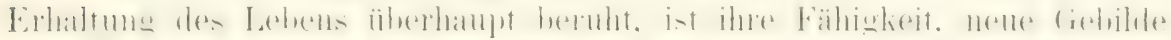
ihresgleichen zu erzeugen und so zur Vervielfältigung des Lebens den Grund zu legen. Wie durch zahllose beobachtungen immer sicherer gezeigt worden ist. entstehen neue Elementarorganismen nur in der Weise. dab. Mutterzellen auf dem Wege der Selbstteilung in zwei orler mehr Tochterzellen zerlegt werlen. (Omnis cellula e cellula.) Dieser für die Erkenntnis des Lebens grundlegende Satz ist nach mühsamer Arbeit auf mamnigfachen Umwegen und nach vielfachen Irrungen erreicht worden.

Schon SchleIDEx (I 1,38) und ScHwaxi (I 1s:39) legten sich bei Ansarbeitung ihrer Theorien die sich naturgemäb aufdrängende Frage vor: In welcher Weise entstehen die Zellen? Ihre Antwort. die sie auf' (irum sehr lïckenhafter und ungenaner Beobachtungen gaben, war eine verfehlte: sie liehen sich die Zellen. die sie mit Vorliebe Kristallen verglichen. wie diese in einer Muterlauge bilden. Die Flüssigkeit im Imnern einer PHanzenzelle bezeichnete SchleIDEx als Cytoblastem, als Keimstoft, als eine Art Mutterlauge. In dieser sollten sich junge \%ellen in der Weise entwickeln. daß. sich zuerst ein festes Körnchen, der Nucleolus des Kerns. bildet. daf. darauf um ihn sich eine Substanzschicht niederschliggt und, indem Flüssigkeit zwischen beide dringt, zur Kermmembran wirk. Der Kern ist wieder der Organisationsmittelpunlit für die Zelle: daher er auch Cytoblast genannt wird. Ls wiederholt sich derselbe Prozel, wie bei der Bildumg des Kerns um den Nucleolus. Der Cytoblast umgibt sich mit einer durch Niederschlag aus dem Zellsaft entstandenen Membran, welche ihm anfangs dicht autliegt, dam aber sich von ihm entfernt. indem wieder I'lüssigkeit zwischen beicle eindringt.

Schwasy (I 15:39) adoptierte die Schlembersche Theorie, verfiel aber dabei in einen zweiten, noch größeren Irrtum. Er lieb nämlich die jungen Zellen nicht allein im Innern von Mutterzellen, wie es Schineinex tat, ihren Ursprung nehmen, sondern auch auberhalb derselhen in einem or wanischen Stoff, welcher bei den 'Tieren als Interzellularsubstanz in manchen Geweben vorgetunden wird, und welchen er ebenfalls als Crto-

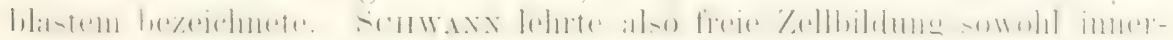
halb, als auferhalb von Mutter\%ellen. eine wahre Lryeusung ron \%ellen aus tormlosem lieimstoff. 
Das waren schwere, fundamentale Irrtïmer, von denen sich am raschesten die Botaniker losgesagt haben. Durch Moнt (VIII 18:35, 18:37). UNGER und besonders durch die vorziiglichen Untersuchungen NäGELIs (VIII ist5) komnte schon im Jahre 1846 ein allgemeines Geset\% formuliert werten. Nach diesem Gesetz bilden sich nene Pflanzenzellen stets nur aus bereits vorhandenen, und zwar in der Weise, dab Mutterzellen durch einen T'eilungsat. wie ihn MoHz zuerst beobachtet hat. in zwei oder mehrere Tochterzellen zerfallen.

Yiel hartnäckiger hat sich die Lehre von der Urzeugung von Zellen aus einem Crtoblastem in der tierischen Gewebelehre. namentlich auf dem Gebiete der pathologischen Anatomie, erhalten, wo die Geschwulst- und Eiterbildung auf sie zuriekgeführt wurde. Erst nach manchen Irrwegen

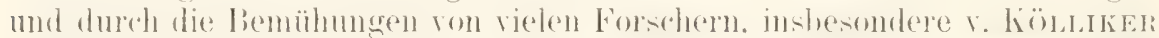
(VIII 1S44, 1S45), REICHERT (VIII 1846, 1847) und REMAK (VIII 1452, 1855) wurle auch hier mehr Klarheit in die Frage der Zellengenese gebracht und zuletzt noch das Schlagwort ,Omnis cellula e cellula" durch Virchow (I 1858) der Cytoblastemlehre entgegengestellt. Wie bei den Pflanzen existiert auch bei den Tieren keine Urzeugumg von Zellen. Die vielen Milliarden von Zellen. aus denen z. B. der erwachsene

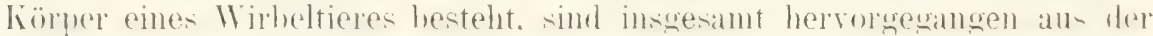
unendlich oft wiederholten Teilung einer \%elle. des Eies, mit welchem das Leben eines jeden 'Tieres begimnt.

So konnte Virchow mit Recht jetzt in seiner berühmten Cellularpathologie 1858 den allgemeinen Ausspruch tun: .Wo eine Zelle entsteht, da muß eine Zelle vorausgegangen sein, ebenso wie das Tier nur aus dem 'T'iere, die Pflanze nur aus der Pflanze entstehen kann. Auf diese Weise ist, wenngleich es einzelne Punkte im Körper gibt, wo del strenge Nachweis noch nicht geliefert ist, doch das Prinzip gesichert. dab in der ganzen Reihe alles Lebendigen, dies mögen nun ganze Pflanzen oder tierische Organismen oder integrierende Teile derselben sein, ein ewiges Gesetz der kontinuierlichen Entwicklung besteht."

Ueber die Rolle, welche der Kern bei der Zeliteilung spielt, gelang es den älteren Histologen nicht, zur Kilarkeit zu gelangen. Mehrere Jahrzehnte lang standen sich zwei Ansichten gegenüber, von denen bald die eine, bald die andere zeitweilig zu einer größeren Allgemeingeltung gelangt ist. Nach der einen Ansicht /die meisten Botaniker, REIchert (VIII 1st7) AuERBACH (VIII 1874 ete.)| soll der Kern vor jerler Teilumg verschwinden und sich auflösen, $n$ in jedler Tochterzelle wiedter ron neuem gebililet zu werden; nach der andern Ansicht dagegen [C. E. vow

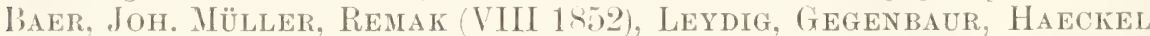
(III 1866) vaN BENEDEN ete.] soll der Kern in den Teilungsprozeh aktiv eingreifen, noch vor seinem beginn soll er sich strecken und der spätern Teilungsebene entsprechend einschnüren und in zwei Hälften zerfallen, welche nach entgegengesetzter Richtung etwas auseinander weichen. Dann soll sich auch der Zellkörper selhst einschnïren und in zwei Stïcke trennen. für welche die beilen 'Tochterkerne Attraktionszentren darstellen.

Jerle dieser diametral entgegengesetzten Ansichten enthielt ein kleines Stück Wahrheit, keine entsprach dem wirklichen Vorgang, der den älteren Histologen zum Teil wegen der von ihnen angewandten Untersuchungsmethoden verborgen blieb. Erst in den letzen Jahrzehnten ist die Erkenntnis des Zellenlebens durch die Erforschung der hochinteressanten

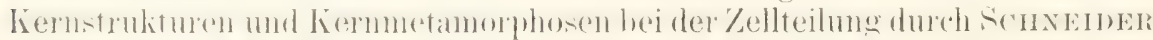
(VIII 1873), Fol. (VIII 1873, 1877), AUERBACH (VIII 1874), BÜTsCHLI 
(VIII 1876), Strasburger (VHI 1875, 1844, 1868), O. Hertwig (IIII $1875-1890)$, R. HerTwig (VIII 1875-1877), Flemang (VII 1879

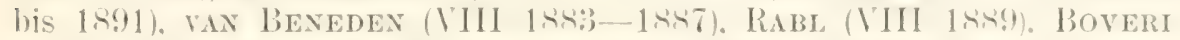
(VIII 1847-190:5) etc. in eingreifender Weise gefördert worden. Ihre Untersuchungen, auf die ich in diesem dbschnitt noch öfters zurïckkommen werde. haben zu dem allgemeinen Resultat geführt. dab der Kern ein permanentes Organ der Zelle ist, welchem eine sehr wichtige und namentlich bei der 'Teilung sich äufernde dufgabe im Kellenlehen zugefallen ist. Wie eine Zelle nicht durch Urzengung entsteht. sondern direkt anf dem IVege der Teilung von einer andern /elle hervorgeht, so bildet sich auch der liern niemals neu. sondern stammt immer von Substanzteilen eines andern liernes ab. Das Schlagwort .(0)mis cellula e cellula" findet eine Ergänzung durch den Kusatz ..Onnis nucleus e nucleo." (Hemming VIII 1862).

Nach dieser historischen Einleitung wollen wir zuerst die Veränderungen, von denen der Kern bei der 'Teilung betroften wird, alsdam die versehiedenen Arten der Zellvermehrung näher in das Auge fassen.

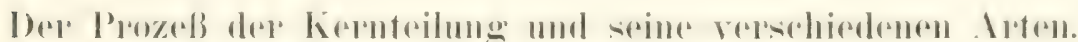

I Bei jerler Vermehrung der Zellen spielen ihre Kerne eine Hauptrolle und fesseln in erster Linie das Interesse des Beobachters. Je nach den Veränderungen, die sie hierbei erleiden, unterscheidet man zwei HauptArten der Kernvermehrung. die indirekte oder Kernsegmentiermg. und die direkte (FLEmaxg) oder liernzerschnürung.

\section{Die Kernsegmentierung.}

\section{Mitose (Flemmixa.) Laryokinese (SCHLEICHER.)}

Dieselhe verläuft unter sehr komplizierten und gesetzmäßigen Erscheinmoen, welche bei Tieren und Pflanzen und sogar bei vielen Protozoen in ganz auffallender Weise untereinander ïbereinstimmen. Das Wesentliche des Prozesses besteht darin. daf. die im ruhenden Kern rorhamdenen. verschierlenen chemischen Substanzen (siehe Seite $3(0)$ sich schärfer voneinander tremen, typische Umlagerungen eingehen. sich in faserige Gehilde (Spindelfasern. Protoplasmastrahlen. Chromosomen) mmandeln (Fig. 107) und unter Authösmg der liermmembran mit dem Protoplasmakörper in eine nähere Wechselbeziehmeg treten. lBesonders fällt hierbei die gesetzmäbige Anorinumg des Chromatins in die Augen: auch ist sie in ihren Einzelheiten hisher am genanesten und sichersten verfolgt worden, während betreffs des Schicksals der iibrigen Kernsub)stanzen noch manches in Dunkel gehïllt ist.

Die anze Chromatinmenge des Kerns wandelt sich bei der 'Teilung in eine für jerle lierart konstante Anzahl von teinen Farlenabschnitten um. welche untereinander nahezu gleich lang. meist gekriummt und nach den einzelnen Tier- und Pflanzenarten von abweichender Form mol cirölie sind: bald sehen sie wie Schleifen. wie Haken. wie Stähchen oder. wemn sie sehr klein sind. wie Körner aus. WALDEYER (VIII LS's) hat für die Farlenabschnitte die allgemein zutreffende Bezeichnung Chromosomen rorgeschlagen. Ich werde hierfür anch das bequencre und ebenso für alle einzelnen Fälle passende Wort .. Kernsegmente" gebratuch. 
Das Wort drückt zugleich flas Wesentliche der indirekten Teilung aus,

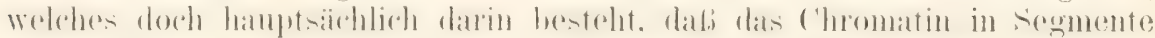
zerlegt wird. Deswegen scheint mir auch das Wort .Kernsegmentierung* dem längeren und weniger bezeichnenden Ausdruck ,indirekte

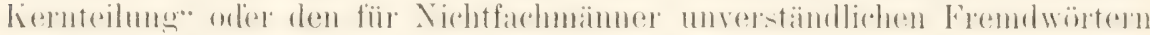
...Mitose und Karyokinese" vorzuziehen zu sein.

Im Verlaufe der 'Teilung zerfallen die Kernsegmente durch eine Liingsspaltung in je zwei, eine Zeitlang parallel verlaufende und noch eng verbundene Tochtersegmente. Dieselhen weichen dann in zwei (xruppen auseinander und werden in gleicher Zahl auf die Tochterzellen verteilt, wo sie die Grundlage für ihre bläschenförmigen Kerne bilden. (Vergleiche die Figuren 107-109.)

Für den Prozeh der Kernsegmentierung ist ferner charakteristisch 1. das Auftreten zweier Pole, welche allen Zellbestandteilen als Mittelpunkte für ihre Anordnung dienen; 2.) die Ansbildung der sogenamnten Kernspindel; :3. die strahlige Anordnung des Protoplasmas um die beiclen Pole.

Wras die beiden Teilungspole betrifft, so erscheinen sie schon früh am bläschenförmigen Kern zu einer Zeit, wo seine Membran noch nicht aufgelöst ist, und zwar in dem an die letztere unmittelbar angrenzenden Protoplasma. Sie liegen zи dieser Zeit dicht beieinander und bestehen aus zwei anderordentlich kleinen kügelchen. welche von dem schon früher beschriebenen Zentralkörperchen oder Zentrosom abstammen. Später

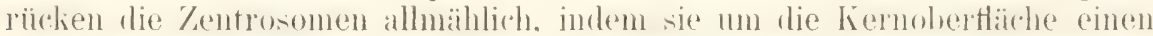
Halbkreis beschreiben, weiter auseinander, bis sie die entgegengesetzten Enden des Kerndurchmessers eimnehmen.

* Zwischen ilmen bildet sich die Kernspindel aus. Sie besteht aus zahlreichen, sehr feinen, parallel angeordneten Spindelfäserchen. die zum 'Teil rom Liningerüst des ruhenden Kerns herrühren. ' In ihrer Mitte liegen sie etwas weiter anseinander. während sie mit ihren Enden nach den Polen zu konvergieren, wodurch das Bündel der Fäserchen mehr oder minder die Form einer Spindel erhält. Die Spindel wird erst klein angelegt, wenn die Zentrallö̈perchen auseinander zu weichen beginnen, und ist dann schwer als ein sie verbindender Substanzstreifen sichthar zu machen. Mit zunehmender Entfernung der Pole wächst sie gleichfalls an Größe heran und hebt sich dabei schärfer von ihrer Umgebung ab.

Um die Pole der Kierntigur beginnt sich auch das Protoplasma der Zelle in einer Weise anzuordnen, als ob von ersteren gleichsam eine polare Wirkung ausgeübt wïrde (Fig. 120). Es entsteht eine Figur wie um die Enden eines Magneten, die in Eisenfeilspäne eingetancht sind. Das

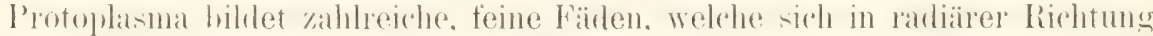
um die Zentrosomen als Mittelpunkte oder Attraktionszentren herum gruppieren. Erst sind sie kur\% und auf die allernächste Umgebung der Attraktionszentren beschränkt. Während des Verlaufs des T'eilungsprozesses aber werden sie immer länger, bis sie sich endlich durch den ganzen Zellkörper erstrecken. Die Protoplasmafigur um die Pole wird in der Literatur als Plasmastrahlung, Strahlenfigur, Stern, Sonne (wobei

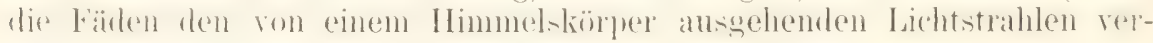
glichen werden), Attraktionssphäre etc. beschrieben.

Das sind kurz die verschiedenartigen Elemente, aus denen sich die Kernteilungstignen zusammensetzen. Zentrosmen. spindel und die heiden Plasmastrahlungen werden yon FLEmming als der achromatische 'leil der Kernteilungsfigur zusammengefaßt und den verschiedenen Bildern. 
die durch Umordnung des Chromatins entstehen und den chromatischen Teil der Figur bilden, gegenüber gestellt.

Alle einzehnen Bestandteile der gesamten 'Teilungstign ändern sich durch Tmgruppierung ihrer Elemente im Verlauf des ganzen Prozesses in gesetzmäbiger Weise. Um sich hesser zu orientieren, emptichlt es sich. viel verschiedene Phasen zu unterscheiden. die sich überall in regelmäbiger Folge ablösen. Wir bezeichnen sie mit Namen. die von StrasBURGer eingeführt sind, als Prophase. Metaphase. Anaphase und Telophase. grenzen aber die einzelnen Phasen. wie es anch von Wilsox geschehen ist, in etwas anderer Weise gegenemander ab. als es STRAsBurger versucht hat. Die erste Phase besteht in der Vorbereitung des ruhenden Kerns zur' T'eilung und führt zur IBildung der liernsegmente, der Kermpole mol der ersten Anlage der Spindel. In der \%weiten Phase gruppieren sich

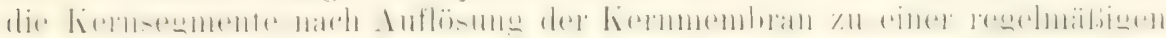
Figur in der Mitte zwischen beiden Polen im İquator der Spindel. In der dritten Phase verteilen sich die Tochtersegmente, welche aus Lüngsspaltung der Muttersegmente schon in einer der vorausgegangenen P'hasen enstanden sind, auf zwei Gruppen, die sich vom Ïquator in entgegengesetzten Richtungen entfermen und bis in die Nähe der Kermpole auseinanderweichen. Die vierte Phase führt zur Rekonstruktion bläschenfömiger. ruhender Tochterkerne aus den zwei Gruppen der Tochtersegmente und zur Teilung des Zellkörpers in zwei Toehterzellen.

Nach dieser aligemeinen Orientiermo soll der Verlauf der Kellteilung an einzelnen Beispielen in seinen Einzelheiten genauer beschrieben, dann soll zum Schluß in einem besonderen Abschnitt noch auf einzelne strittige Punlite eingegangen werilen.

In Tierreich sind die zam Studium geeignetesten und am häufigsten untersuchten Objekte die (iewebsyellen junger Larven von Salamandra maculata und von Triton, die Samenzellen geschlechtsreifer Tiere, ferner die Furehungskugehn kieiner. durchsichtiger Eier, namentlich von Nema-

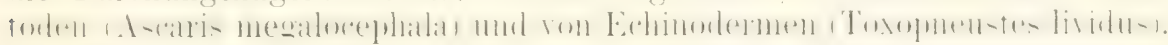
Im P'tanzenreich emptichlt sich zur Untersuchung der protoplasmatische Wandbeleg aus dem Embryosack. namentlich ron Fritillaria imperialis. die Entwicklung der Pollenzellen von Liliaceen ete.

a) Zellteilung bei Salamandra maculata unter Zugrumdelegung der von Fuemaxg entworfenen Schemata. (Flemmag VII lose.)

Erste oder Pro-Phase. Vorbereitung des Kerns zur Teilung.

liei Salamandra maculata gehen Veränderungen am ruhenden liern schon geraume Zeit vor Beginn (ler 'T'eilung vor sich. Die überall aut dem Liningeriist rerteilten Chromatinkörnchen (Fig. 10+A) rücken an einzelnen Stellen dichter aneinander und ordnen sich zu gewundenen, feinen Füdlen an, die mit kleinen Zäckchen und Höckern bedeckt sind. Yon diesen entspringen unter lechtem Winkel zahlreiche feinste Fiserchen, die nun sichtbar werdenden Strecken des Liningeriistes, von deren Ohertläche sich das Chromatin zurickgezogen hat. Später werten die Chromatinfäden noch deutlicher ausgeprägt und nehmen, indem die Zäickchen und Höcker schwinden, eine rolliommen glatte Oberfläche ( Fig. 10+ B $)$ an. I)a sie nach allen Richtungen den Kernraum in Windungen durchsetzen. erzengen sie eine Figur, welche Flemang als Kuäuelform (Spirem) lezeichnet lat. In den Spermatocyten von Salamandra ist der Knäuel viel weniger dicht als in den Epithelzellen. in denen der Farlen zugleich auch viel teiner und 
länger ist (lig. 10+C). Dariber, ob anfangs der Knäuel aus einem einzigen. langen Faden oder gleich aus einer gröberen Anzahl von solchen besteht. lauten die Angaben rerschierlen. Letzteres scheint mir mit RABL (VIII 1889) (las Wahrscheinlichere 74 sein.

In der Färbbarkeit tritt gegen frïher ein auffailender Unterschied ein. Je deutlicher und schärfer die Fäden ausceprägt werden, un so stärker färben sie sich und 1 m so energischer halten sie auch den Farbstoff fest. wie dies beim Gerïst des ruhenden Kerns nicht der Fall ist. Besonders bei Anwendung der Gramauschen Färbungsmethode läßt es sich erreichen, dab die ruhenden Kerne allen Farbstoff abgeben. während die in Vorbereitung zur Teilung begriftenen und die sich teilenden Kerne allein durch ihre starke Färbung die Aufmerksamkeit des Beobachters auf sich ziehen.

In den Anfangsstadien der Kunäuelbildung sind die Nukleolen noch vorhanden, verkleinern sich aber allmählich und sind bald spurlos verschwunden, ohne dab es bis jetzt gelungen ist, ganz sicher zn erforschen. was aus ihrer Substanz geworden ist.

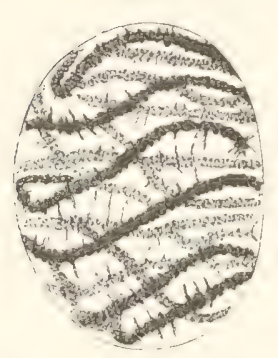

Iiig. 11)+A. B?.

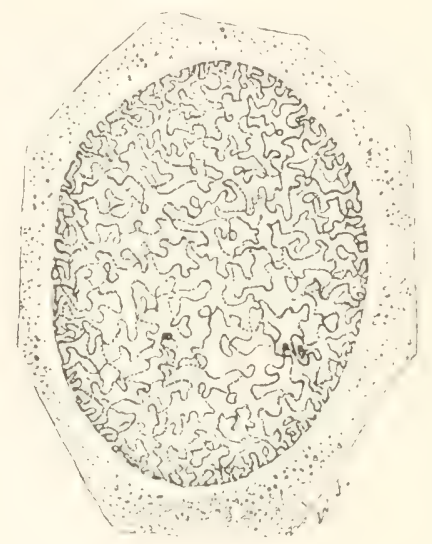

liig. $104(\mathrm{C}$

Fig. 164 A. B. A liuhender Kern einer Samenmutterzelle von Salamandra maculata.

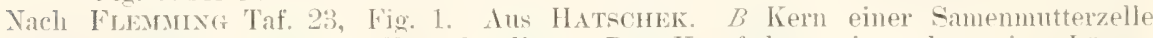
non Galamandra maculata. Kinänelstadimm. Der Kernfaden zeigt schon eine Lïngsspaltung. Schema nach Frmmong 'Taf. 26, Fig. 1. Aus Hatschek.

Fiu. $\mid 1 / 4$ Epithelkern im Anfang der Teilung von dex Mrundbodemplatte des Kiemengeruistes einer Salamanderlarve. Eng’e Knäuelform. \%wi Vuli|eolenreste noch erhalten. Wach Fiffurmat.

Während der Ausbildung rles Knäuels kann man bei sorgsamer Beobachtung an der Oberfläche des Kerns eine kleine Stelle erkennen. welche während des weiteren Prozesses sich immer deutlicher markiert und von RABL als Polfeld bezeichnet wirl (Fig. 105). Die ihr vis-ì-vis gelegene Oberfläche des Kerns ist die Gegenpolseite. Nach ihnen beginnen sich die Chromatinfälen immer deutlicher zu orientieren. Yon der Gegenpolseite kommend. ziehen sie bis in die Nähe des Polfeldes, ,biegen hier schleifenförmig um und kehren damn wieder in vielen kleinen, umregelmäßigen. zackigen Windungen in die Nähe ihres Ausgangspunktes zurück." Im weiteren Verlauf werden die Fäden kürzer und entsprechend dicker, sie sind weniger gewulen und rücken etwas weiter auseinander, so daf jetat der ganze Farlenknäuel viel lockerer geworden ist. Ihre Schleifenform tritt immer deutlicher hervor. Die Gesamtzahl der Schleifen oder Kernsegmente 
läbt sich in güustigen Fällen auf ø2t hestimmen. eine Kahl. welche für die Gewebszellen mul die Ursamenzellen von Salamandra und Triton gresetzmäbig ist.

Gleichzeitig haben sich im l'olfeld. wichtige (iebilde der Kernfigur. die beilen C'entrosomen und die Spindel angelegt. Sie sind auf diesem Stadium wegen ihrer geringen Firbbarkeit, ihrer Kleinheit und Zartheit schwer sichthar zu machen. da sie schon durch Körnchen. die sich im Protoplasma in ihrer Ungebung ansammeln mehr oder minder verdeckt

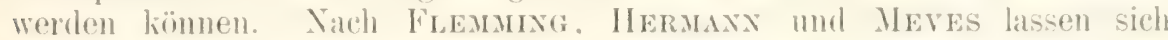
an gelungenen Präparaten zwei dicht beiemander gelegene Centrosomen beobachten. zwischen denen die erste Anlage der spaiteren spindel in Form verbindender Fäden auftritt (Fig. 105).

\section{Zweite oder Metaphase der Teilung.}

Der Begim der Metaphase läbt sich am besten wohl von der Zeit an rechnen. Wo die Kermmembran undeutlich wirl und sich auflöst. Indem der Kernsaft sich gleichmäßig in Zellkörper verteilt, kommen die Kernsegmente jetzt mitten in (las Protoplasma zu liegen (Fig. 106i). In ihrer Tähe befinden sich die beiden Centrosomen, die jetzt weiter auseinanderriicken. In demselben Mabe nimmt zwischen ihnen die Spindel-

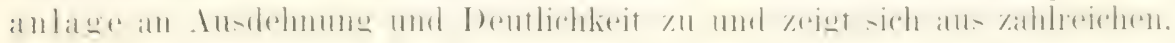
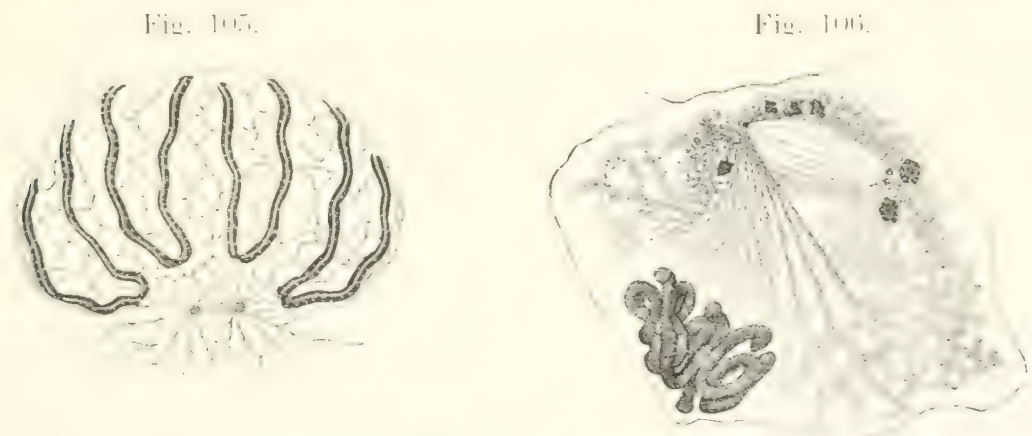

Fig. 105. Schematische Darstellung eines Kerns mit dem Polfeld, in

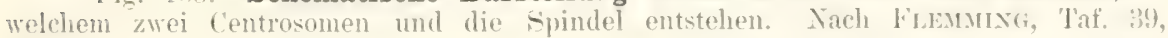
Fig. 37.

lig. 106. Kerm einer Spermatocyte von Salamandra maculata in Vorbereitung zur Teilumg. Anlage der Spindel zwischen den beiden Centrosomen. Nach Hremax (VIII 1S91) Taf. 31, Fig. T.

feinsten Fäserchen zusammengeset\%t, die sich kontinuierlich ron einem Centroson zum andern erstrecken. wie die ron Hermaxy und Meves dargestellten Präparate so schön zeigen. Jetzt beginnt anch von den Polen der Kernfigur sich ein Einflul. auf das umgebende Protoplasma geltend zu machen. Zahhreiche Protoplasmafïdchen gruppieren sich in radiärer Richtung um je ein Centrosom als Mittelpunkt herum und zwar so, dab sie vorzugweise nach der fiegend. wo die kernsegmente liegen. ausstrahlen und sich an ihrer Oberfläche anzusetzen scheinen. Rasch vergröbert sich von hier an die Spindel. bis sie die ansehnlichen Dimensionen der Fig. 107 erreicht hat.

Währendlem verändert sich auch die dhromatisehe Figur von firund aus (Fig. 107). Die Kernsegmente sind noch um ein Erhebliches kiirzer und dicker geworden, sie legen sich um die Mitte der Spindel als ein voll- 
ständig geschlossener Ring herum und gehen jetzt die ron Flemang als Mutterstern beschriebene. regelmäbige Anordnung ein. An den Segmenten ist die Schleifenform auf das deutlichste ausgeprägt. Ohne Ausmahme haben sie sich so orientiert, dab, die Winkel der Schleifen gegen die Spindelachse, ihre beiden Schenkel dagegen mach der Obertläche der Zelle gekehrt sind. Alle $2+$ Schleifen liegen ziemlich genau in einer Ebene, welche senkrecht durch die Mitte der Spindel hindurchgeht, als Äquatorialebene bezeichnet werden kann und mit der später auftretenden 'Teilungsebene identisch ist. Von einem der beiden Pole ans betrachtet, hat die chromatische Figur ..die Form eines Sterns, dessen Strahlen ron den Schenkeln

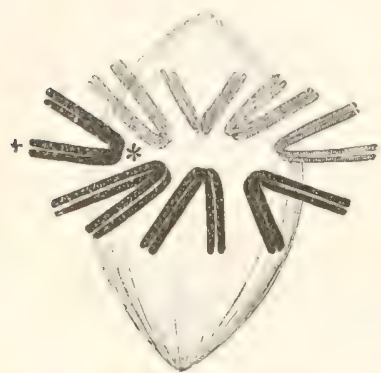

lig. 11) . Schematische Darstellung der Kermsegmentierung Hiall ILEMMING. Stadium, auf welchem die Kiernsegmente im $\ddot{A}$ yuator der Spindel angeordnet sind. I IS IATSCHEK. lockern Knäuels ein (Fig. 10:3 B), stets ist sie in der zweiten Phase des Muttersterns vollendet und am schärfsten ausgeprägt. Der ganze Vorgang; welcher zuerst von Flemuing (VIII 1879) bei Salamandra entrleckt. an diesem und andern Objekten von v. BENEDEN (VIII 1883), Heuser (IIII 1884). Guignard (VIII 18st). RabL (VIII 1889) und vielen anderen bestätigt worden ist, scheint bei der indirekten Kernteilung iiberall rorzu-

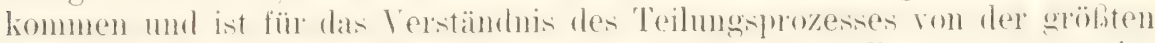

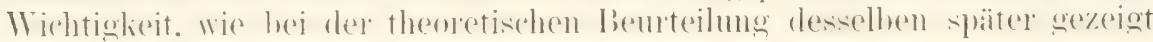
werden wird.

\section{Dritte oder Anaphase der Teilung.}

Die Anaphase der Teilung ist dadurch ausgezeichnet, dab sich die äquatorial gelegene, äuberlich noch einfache (ruppe (ler längs gespaltenen Nuttersegmente nummehr in die beiden Gruppen der Tochtersegmente immer schärfer datmeh sondert, dab sie nach entgegengesetzten Richtungen auseinanderweichen und in die Nähe der beirlen Pole der Kernfigur zu liegen kommen (Fig. 108 A $B C$ ). Aus dem Mutterstern entstehen, wie Finming sich aushücht. die heiden Tochtersterne. Der schwer zu beobachtende Vorgang vollzieht sich im einzelnen in folgender Weise:

Die durch Längsspaltung entstandenen Tochtersegmente je eines urs]rünglichen Muttersegments trennen sich an den Winkel der Schleife, welcher der Spindel zugekehrt ist, roneinander und weichen nach den Centrosomen zu auseinander, während sie an den Schenkelenden noch eine zeitlang in Zusammenhang bleiben. Schlieblich erfolgt auch hier eine Trennumg. Aus den 24 Mutterschleifen sind zwei Gruppen von je 
$2 t$ Tochtersohleifen entstamben, die bis anf einen geringen Abstand an die Centrosomen heranrïcken mol damm in ihrer Bewegmm Halt machen. Xie kommen sie an die Pole selhst zu liegen. Zwischen den heiden (iruppen spannen sich feine .. V erhindungstaden" aus. deren Uriprung wohl auf die Spintelfasern zuriuckzuführen ist.

Die einzelnen Schleifen haben .ihre Winkel nach den Polen. ihre

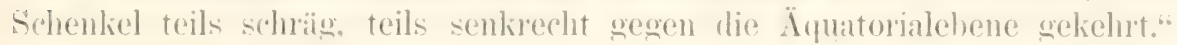
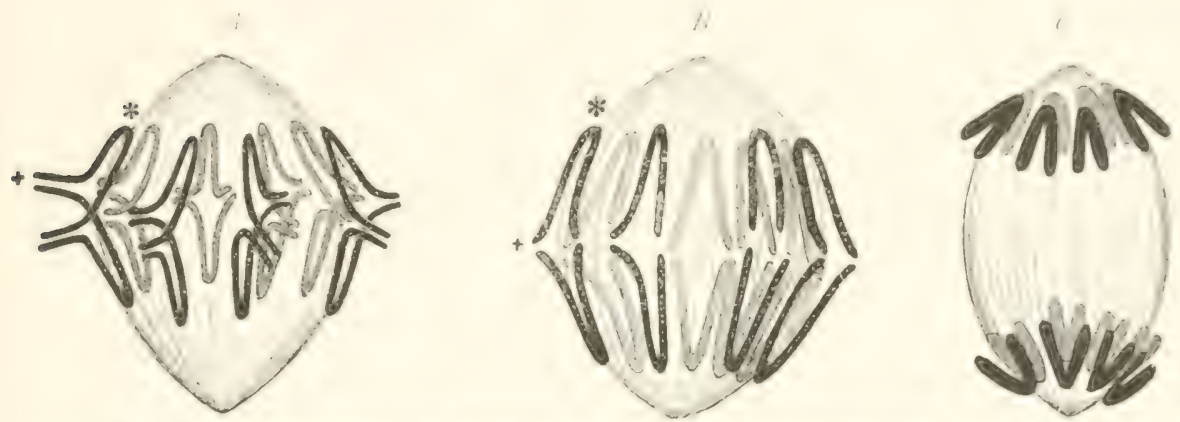

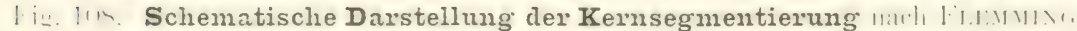
Die Tochtersegmonte weichen nach den Polen in zwei Gruppen auseinander.

Sie sind ihrer Entstehung gemäb anfangs viel dünner als die Mutterfäden. verkiurzen sich aber ron jetzt ab und werden dementsprechend dicker. Bei der Entstehung der Tochtersterne liegen sie ziemlich lose nobeneinander. damm rüblien sie dichter zusammen. so dah sich ihre Anzahl und ihr lerlauf wieler schwieriger und nur ansmahmsweise feststellen läbt.

\section{Vierte oder Telophase der Teilung.}

Wähend der Telosphase wandelt sich allmählich jede firupue von Tochtersegmenten wieder in einen bläschenförmigen, ruhenden Kern um (Fig. 109). Die Fïlen rücken noch enger zusammen, krümmen sich stärker und werlen durch Aufnahme ron Kernsaft dicker. sie erhalten eine rambe und zackige Obertfäche. indem sie kleine fortsätze nach auben hervorstrecken. Un die wanze Gruppe herum bildet sich eine zarte Kermmembran aus. Die Strahlung um das Centrosom wird allmählich schwächer und ist bald ganz gesehwumden. Auch das Centrosom und die Spindelfasern sind in vielen (iewebszellen schlieblich nicht mehr nachzuweisen. Was aus ihmen wird, ist noch nicht mit genügender Sicherheit aufgeklärt. In der regend des früheren Centrosoms zeigt der in Rekonstruktion begriftene Tochterkern eine Delle. RaBL erblickt in ihr das eingangs beschriebene Polfeld rles sich zur 'Teilung anschickenden Kerns und rermutet, lab sich in ihn' das Centrosom in das Protoplasma des Zellenleibes eingeschlossen erhält. In der letzten Generation der Spermatocyten ist das Centroson jederzeit aufzufinden und lisit sich von ilum der Nachweis führen. dal.s es bei der Verwandlung der Spermatiden in die Spermitozoen ihr Mittelstürck bildet. Almählich schwillt der Kern dureh Anfuahme von Kernsaft mehr an. wird kugelig und erhält wieder das fierïstwerk des ruhenden lierns mit unregehnabig verteilten, kleineren und größeren Chromatinkörnchen. Auch ein oder mehrere Nukleolen sind während der Rekonstruktion in (ieriistwerk wieder zum Vorschein gekommen. doch ist es noch nicht grelungen. ïber ilıre Herkmnt Sicheres zil ermitteln. 
Wenn am Anfang der vierten Phase die beiden Tochtersterne am weitesten auseinander geriickt sind und zur Umwandlung in die Tochterkerne die einleitenden Schritte tum. kommt es auch zur Teilung des Zellkörpers selbst. Die Strahlungen an den Centrosomen haben dam ihre grörte Austehning erreicht. Jetzt macht sich eine kleine Furche an der Obertäche des Zellkörpers bemerkbar, entsprechend einer Ebene.

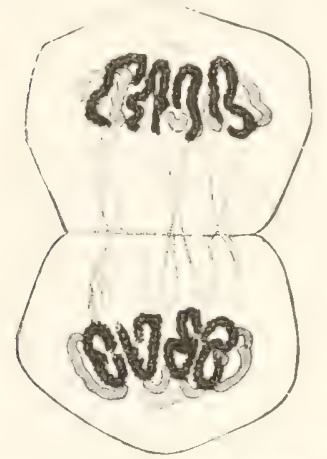

Fig. 109. Schematische Darstellung der Kermsegmentierung nath

Fleminga. Aus den Tochtrimengenten linginnt aich der ruhende liern zu bilden. welche senkrecht durch die Mitte der liernachse. welche die beiden Centrosomen verbindet. hindurchgeht und als Teilungsebene schon oben bezeichnet wurde. .Die Furche beginnt einseitig, greift nach und nach um den Äquator herum, bleibt aber auf (ler Seite, wo sie begann, tiefer als auf der entgegengesetzten" (FLEMMING). Die ringförmige Einschnürung schneidet bald immer tiefer in ilen Zellkörper ein und zerlegt ihn schließlich vollständig in zwei nahezu gleich große Hälften, von denen eine jerle einen in Rekonstruktion begriffenen 'Tochterkern einschließt. Mit Beendigung der Durchschnürung beginnt die Strahlung an den Polen zu erlöschen.

An vielen Objekten sind die oben erwähnten Verbindungsasern zwischen den Tochterliernen his zur Vollendung der Teilung nachzuweisen. Sie werden dann auch bei der Zerschnürung des Zellkörpers in ihrer Mitte durchgetrennt. Zu dieser Zeit kann zuweilen in ihrer Mitte eine geringe Anzahl sich

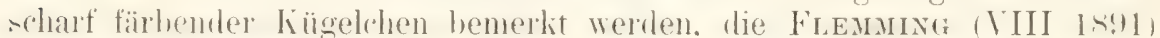

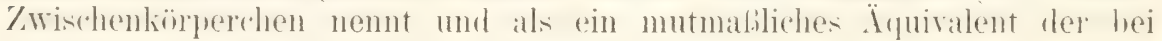
Pflanzen besser ausgebildeten Zellplatte deutet.

\section{b) Teilung der Eizellen von Ascaris megalocepluala.}

In den Eiern ron Ascaris zeichmen sich die Kerne durch die Größe und Deutlichkeit der Centrosomen und durch die geringe Anzahl der Kiernsegmente aus, die bei einer Art vier, bei einer andern Art sogar nur zwei beträgt. Besonders deutlich ist an diesem Objekt ein sehr wichtiges Phänomen, die Vermehrung der Centrosomen durch Selbstteilung, zu beobachten. Am besten nehmen wir die Untersuchung zu der Zeit auf, wo sich das Ei zum ersten Male gefurcht hat und sich zu beiden Seiten

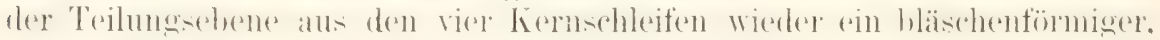
mmegelmäbig konturierter Kern hervorbildet (Fig. 110). Derselbe besitzt mehrere lappenförmige Fortsätze an der Gegenpolseite und zeigt das Chromatin in einem lockeren Gerüstwerk ausgebreitet. In der Gegend des fiihlieren Poles der 'Teilungsfigur ist noch das Centrosom zu erkennen, eingehiillt in körniges Protoplasma, welches gegen die Dottermasse des Eies absticht und von r. BENEDEN als Attraktionssphäre, von Boveri als Archoplasma beschrieben wird.

Ehe num überhaupt der Kern zur vollen Ruhe zurückgekehrt ist, ja zuweilen sogar vor Abschluß der ersten 'Teilung, setzen schon wieder die Vorbereitungen zur zweiten Teilung ein: sie hesimen mit Veränderungen des Centrosoms (Fig. 112). Es streckt sich parallel zur ersten Teilungsebene in die Länge, wird bisquitförmig und teilt sich, wie r. BENEDEN (VIII 1887) und BoverI (VIII 1887*, 1888) entdeckt haben, durch Ein-chnürmg in \%ei Tochtercentrosomen, die eine \%eitlang ron einer gemein- 


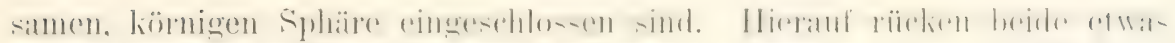

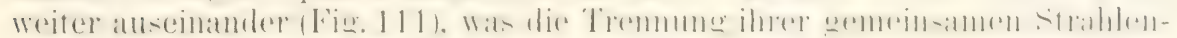
sphäre in zwei besondere Sphären zur folge lat.

Die Verdoppelung des Centrosoms gibt das Signal, dab auch der liern, noch ehe er ganz zur Ruhe zurückgekehrt ist. gleich wieder in die folgende 'Teihugsphase eintritt (Fig. 111). Aus dem Chromatin, das auf dem Liningeriist in feinen Könchen verteilt war, nehmen vier lange Schleifen ihren Ursprung, die erst mit Zacken bedecht sind, dam eine glatte Kontur erhalten. Sie sind ähnlich orientiert. wie die 'Tochtersegmente nach der ersten 'Teilung, infolgedessen boveri (VIII 1890) der sehon von RABL (VIII $1859)$ aufgestellten Ansicht zuneigt, dal.s sie sich direkt aus der Substanz. der letzteren ableiten und auch im Zustand der liuhe eine selbstandige
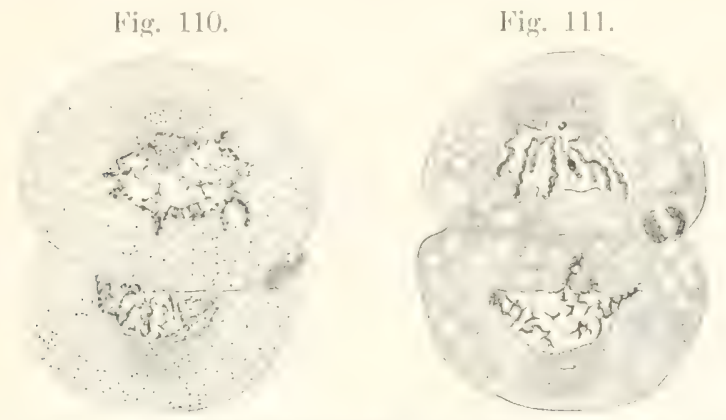

I"ig. 112.

Fig. 110. Zweigeteiltes Ei von Ascaris megalocephala; die Kerne im linhezustand; Centrosomen jederseits noch einfach. Nach Boreri 'Taf. IV, Jig. it.

fig. 111. Zweigeteiltes Ei von Ascaris megalocephala. Hie liene in Vor-

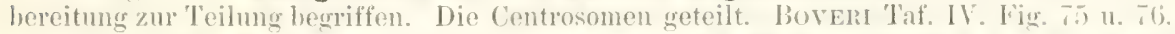

lin. $\mid l^{\prime}$. Zwei Tochterkerne am Anfang der Rekonstruktion mit lappigen Fortsätzen. Die Centrosomen vermehren sich durch Selhsteilung. Nach r. BrXErn:x und NEYT 'laf. VI, Hig, 13.

Individualitait bewahren. Die Schleifenwinkel sind nach dem ursprïnglichen Pol (dem Polfeld bei Salamandra), die liolbig angeschwollenen Schenkelenden nach der Gegenpolseite hin gewandt.

Mit Beginn der Metaphase rïcken die Centrosomen mit ihren Sphären weit auseinander und nehmen eine solche Stellung ein, (lal.) die sie verbindende Achse entweder etwas sehräg oder parallel zur ersten 'Teilungsebene zu liegen kommt. Die Kermmembran löst sich auf. Die vier Chromosomen orthen sich in der früher beschriebenen Weise im Iquator zwischen beiden Centrosomen an, in deren Umgebuug jetzt eine deutliche Strahlung im Protoplasma entstanclen ist; sie bieten, rom Dol aus gesehen. (las in Fig. 113 A dargestellte Bild dar. Es folgt die Längsspaltumg der vier Segmente und der Eintritt in die dritte Phase der'Teilumg (Fig. 11:3 B).

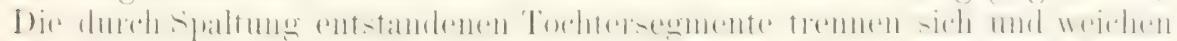
nach den beiden Polen zu anseinander. F. VAN BENEDEN (YIII 1S57) und Boveri ( III 1885, 1890) lassen hierbei die Spindelfasern eine alitive Rolle spielen (Fig. 11t). Nach ihrer Meinung ist die Spindel bei Ascaris

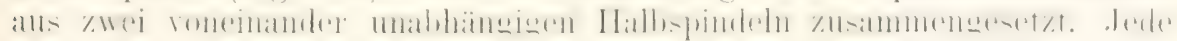
besteht aus zahlreichen P'rotoplasmafasern. die nuch dem Centrosom zu konvergieren und sich an ihm mit ihren Enden anheften, während die

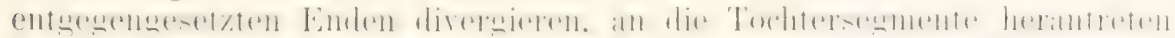
und sich an verschiedenen P'unkten der ilnen zugekehrten Ränder fest- 
setzen. Durch zunehmende Verkïrzung dieser Fasern infolge von Kontraktion sollen nach VAN BENEDEN und BOVERI die vier 'Tochtersegmente voneinander getrennt und nach den Centrosomen geradezu hingezogen werilen.

In der vierten Phase erfolgt die Durehschnürung des Zellkörpers und die Rekonstruktion des 'Tochterkerns. Nach vaN BEnEDEN geschieht dieselbe in der Weise (Fig. 115), dab die vier chromatischen Schleifen $(A)$

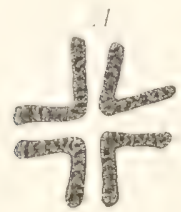

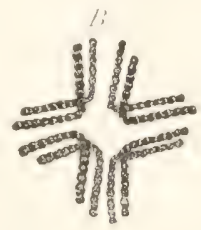

Fig. 11:;

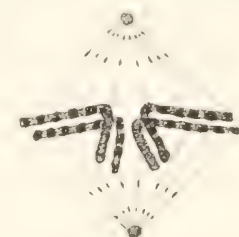

Fig. 114 .

Fig. 113. A Vier Mruttersegmente vom Pol der Kernfigur aus gesehen. Tach v. Bexenex und NEYT Taf. VI, Fig. I6,

li Längsspaltung der vier Muttersegmente in acht Tochtersegmente. Nach r. Bexenex und Next Taf. VI, Fig. 1\%.

Fin. 111. Zusammensetzung der Spindel aus zwei Halbspindeln, deren Fasern sich an die Tochtersegmente ansetzen. Nach r. BEYEDEN und NEYT 'T'af. I'I, Fin. ‘.

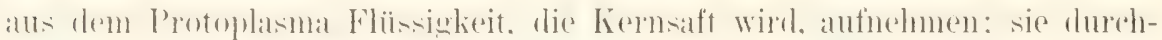
tränken sich nit ihr wie ein Schwamm und schwellen daher zu dicken Schläuchen (Fig. 115 B) auf. Das Chromatin verteilt sich in Körner, die durch feine Fïden verbunden und namentlich an der Obertäche der Schläuche gelegen sind. Diese rücken mit ihren mittleren Abschnitten dicht zusammen und verschmelzen hier untereinander. So entsteht ein biaschenförniger, gelappter, ron Kernsaft durchtränkter Kern (Fig. 115 C), der sich gegen das Protoplasma mit einer Membran abgrenzt und die chromatische Substanz wieder auf einem feinen (ierüst verteilt zeigt.

\section{c) 'T'eilung der Eier'von Echinodermen.}

Während die Eier yon Ascaris für das Studium der Centrosonen und Kernsegmente besonder's geeignet sind, bieten die kleinen Eier der Echinodermen (Hertwig VIII 1875-1878, Fol. VIII 1877. Boveri VIII 1901, Wilson)

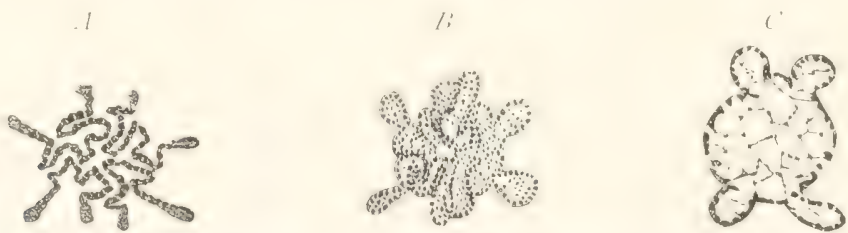

Fig. 115. $A$ Eine Gruppe von vier Tochtersegmenten vom Pol aus gesehen. Die Endansclnwellungen der Schleifen sind sehr ausgeprägt. Xirh Vi. Bexedex und Neyt 'Taf. VI, Fig. 19.

l: Rekonstrultion des Kerns auf Kosten der vier Toclitersegmente. Nirmatisch mach V. BENEDEX und NEYT Taf. VI, Fig. 20.

C Ruhestadium des Kerns vom Pol aus gesehen. Nach V. BExEDEx und Nextre Taf. VI, Fig. 21.

und einzelner' wirhelloser 'T'iere wieder andere Vorteile für das Studium dar; so zeigen sie uns namentlich schön auch bei Untersuchung der lebenden 
Zelle die Strahlungserscheinungen in Protoplasma auscrebildet. Es sei daher auch hierauf noch etwas näher eingegangen.

Wenige Minuten nach der Befruchtung (Fig. 116) sieht man anm lebenden Echinodermenei den kleinen kugligen Furchungsiom als ein helles Bläschen in der Mitte des Dotter's gelegen und ron Protoplasmafäilen, wie eime Somne von ihren Lichtstrahlen, ungeben. - Die Strahlung tritt waihrend des Lebens an unserem Objekt deswegen so klar hervor. weil die zahlreichen, im Dotter eingelagerten, kleinen liönchen der strahligen Anordnung des Protoplasmakörpers passiy folgend ebenfalls in radiären Reihen angeordnet sind. Nach kurzer \%eit begimnt dieses in den Briruchtungsvorgängen seine Erklärung findende Strahlensystem zu erblassen und sich allnählich in zwei an entgegengesetzten P'unkten des Lerns anfauchende Strahlensysteme umzubilden, die erst klein beginnen. damn von Minute zu Minute deutlicher ausgeprägt und gröber werden
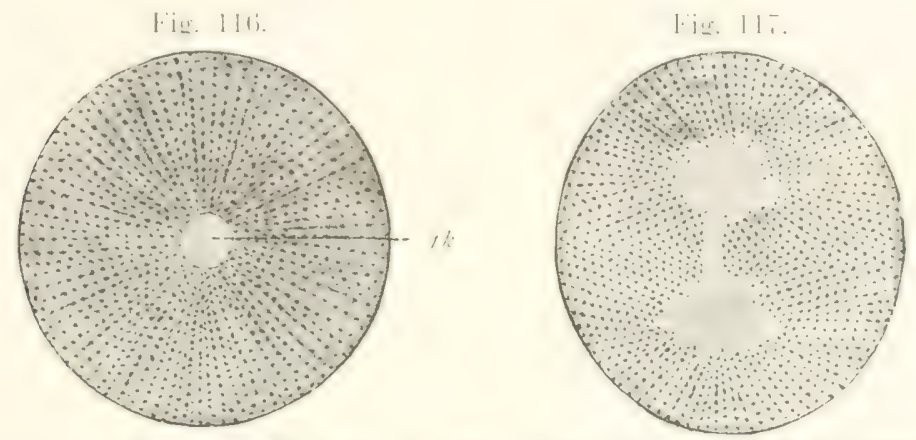

Iig. 116. Ei eines Seeigels gleich nach beendeter Befruchtung. Aus 0. Hertwig, Entwicklnngsgeschichte. Li mol Samenkern sind zum Furchmeksern $(f k)$ rerschmolzen, der im Zentrum einer l'rotoplasmastrahlumg liegt.

[ïg. 117. Ei eines Seeigels in Vorbereitung zur Teilung. Nach dem lehenden

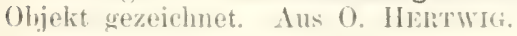

und sich sehließlich wieder ïber die ganze Dotterkugel austehnen und sie in zwei um je ein Attraktions\%entrum herum strahlig augeordnete Massen zerlegen (Fig. 117).

In der Nitte jeden Strahlensystems sammelt sich immer mehr homogenes, ganz körnerfreies Protoplasma an. Währenddem wird der bläschenförmige Kern im lebenden Objekt undentlicher und entschwindet bald vollstïndig unseren Blicken. Es erklärt sich dies daraus, dalo zu dieser Zeit der Kern die für andere Objekte schon beschriebene Spindelstrulitur annimmt, die sich wegen ihrer Feinheit der Beobachtung während des Lebens ganz entzieht. So kommt im körnigen I)otter das in Fig. 117 dargestellte, auberordentlich charakteristische bild zustande, welches man passenderweise einer Hantel, wie sie beim Turnen gebraucht wird, vergleichen kam. Die beiden Ansammlungen homogenen Protoplasmas entsprechen den Köpfen der Hantel; der sie rerbindende, kürnchenfreie Streifen zeigt die Stelle an. wo auf den voratusgehenden Statien der jetzt unsichtbar gewordene Kern gelegen war, der sich zur Spindel umgewandelt hat, welche mit ihren Enden bis in die Mitte der Hantelköple, wo sich anch Centrosomen nachweisen lassen. herameicht. I)en zwei Strahlensystemen hat for den Namen Amphiaster oder Doppelstern gegehen.

Jetzt beginnt sich das anfangs rein liuglige $\mathrm{ki}$ in der Richtung der Achse der Hantelfigur etwas in die Länge zu streclien und in die End- 
phase der T'eilung rasch einzutreten (Fig 118). Entsprechend einer Ehene, welche man mitten durch die Hantelfigur senkrecht zu ihrer Längsachse hindurchlegen kamn, bildet sich an der Obertläche des Eies eine Ringfurche aus. Dieselbe schneidet rasch tiefer in die Eisubstanz ein und zerlegt sie in kurzer Zeit in zwei gleiche Hälften, von denen eine jede die Ilälfte der Spindel nit einer Gruppe der Tochtersegmente, die Hälfte der Hantelfigur und ein protoplasmatisches Strahlensystem erhält.
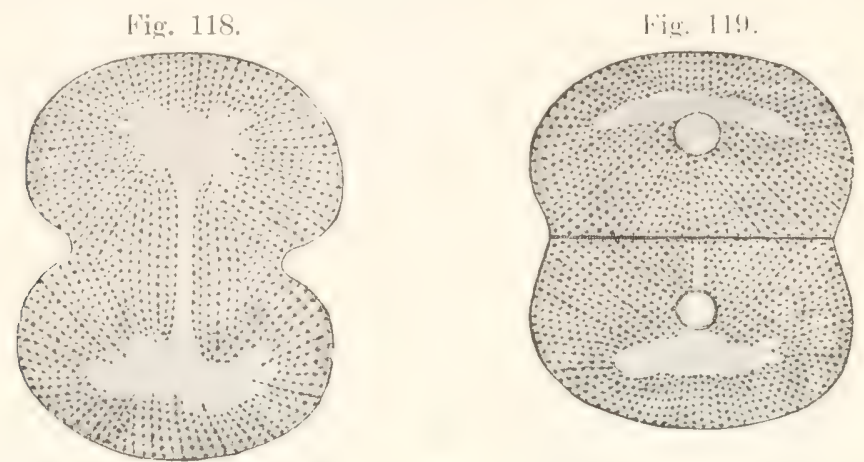

Fig. 118. Ei eines Seeigels im Moment der Teilung. Ans O. HERTwig, Entwicklumgsgeschichte. Eine Ringfurche schneidet in den Dotter ein und halliert ihn in einer Ebene, welche rechtwinklig die Hitte der Kernachse und die Hantelfigur schneidet.

Fig. 119. Ei eines Seeigels nach der Zweiteilung. In jedem Teilprodukt ist ein bläschenförmiger Tochterkern entstanden. Die strahlige Anordnung des Protoplasma heginnt undentlich zu werden. Beide Figuren sind nach dem lebenden Objekt gezeichnet.

Gegen Ende der Durchschnürung grenzen die sich trennenden Eihälften mur noch an einer likinen stelle ihrer ()herttäche, in der regend des Hantelstieles, aneinander. Nach Beendigung der Teilumg aber legen sie sich bald wieder mit ihren Teilungstlächen in ganzer Austehmung dicht aneinander und platten sich hier gegenseitig so ab, daß eine jede nahezu einer Halbkugel gleicht (Fig. 119).

Wïhrenddem wird am lebenden Objekt auch der Kern wieder sichtbar. Etwa in der Gegend, wo Hantelstiel und Hantelkopf ineinander ïherentern. also in einiger Entfermung von den centrosomen tanchen einige kileine Vakuolen auf. die sich datureh bilden. dab sich die Toohterkernsegmente mit Kernsaft durchtränken (Fig. 123). Sie verschmelzen damn in kurzer Zeit untereinander zu einem kugligen Bläschen, dem Tochterkern (Fig. 119). Die strahlige Anordnung des Protoplasmas wird immer undontidher mol macht. Wenn die Zelle sich rash wieder zur nächsten Teilung anschicht, einer neu sich ausbildenden Doppelstrahlung Platz.

Das Studium des lebenden Objektes findet eine Ergänzung an konservierten und gefärbten Eiern, von denen ich eine Reihe von Abbildungen nach Lovera zn-ammengestellt habe. Dic ('hromosomen. welche Häkchen bilden. lassen wegen ihrer gröberen Zaht und anderordentlichen Kleinheit thas feinere, oben beschriebene Detail viel schwieriger als andere. in dieser Ilin-icht sünstigere (Objekte (Ascaris) erkemen: anch die spomdelfasern sind ansmehmenol zart. die centrosomen sind viel sohwerer als bei Asaris darzustellen und zu deuten und zeigen, wie Boveri beschrieben hat, inter(rosinte Beronderheiten: die Strahlentiguren dagegen (Astrosphären) sind

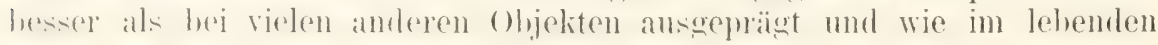


so anch im lionservierten Zustand zum Studium sehr geeignet. Die Rekonstruktion des Kerns in der T'elophase liefert — was hei den Eizellen im allgemeinen der ball ist - andere Bihler als in den Gewebszellen.

Fing. 120.

Fig. 121 .

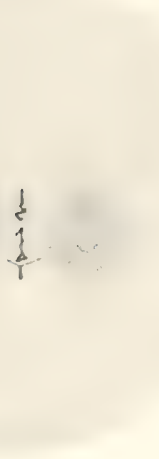

Fig. 122

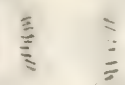

I'ig. 123.

Fig. 120-124. 5 Teilstadien vou Eiern vou

Fig. 121 .

Echinus mikro-tuberculatus, ca. 1000 fach vereriblsert,

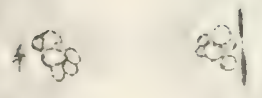
nach BOVERI (VIII 19)1).

Fig. 120. Stadium der Ïquatorialplatte. Kuglige Centrosomen mit schwammiger Struktur.

Fig. 121. Tochterplatten weiter auseinander geriicht. Die Centrosomen noch gröber.

Lig. 122. Ei ror der Teilung. Die Chromosomen herimnen sich in Kemblaschen muzuwandeln. Die Centrosomen sind scheilenförmig sewrorden.

Fig. 123. Streckmor des Eies. Die Kernblïschen sind vergröliert. Die Centrosomen beginnen sich zu teilen.

liig. 124. Das Ei ist in 2 \%ellen geteilt. Bläschenfürmiger 'T'ochterkern, üler' Welchem das Doppelecntrosom lang ausgezogen ist. Dentliche Doppelstrahlung der begimnenden neuen 'Teilumgsfigur.

Wenn wir nach diesen allgemeinen Vorbemerkungen zum genaueren Studium der einzelnen Präparate ïbergehen, so zeigt uns Fig. 120) (lie zweite Phase der 'Teilung, die zarte Spindel mit der Äquatorialplatte der Chromosomen. Das Centrosom bietet im Vergleich zul Ascaris und den 
Gewebszellen einen wesentlich anderen Anblick dar: es ist eine relativ grobe liugel, zusammengesetzt aus allerfeinsten, durch HeIDEninans Hämatoxylin schwarz gefärbten Körnchen, umgeben von einer schmalen hellen '/one und einer kräftig ansgeprägten Astrosphäre. Seine Vergrößerums wird von Bovers, worin ich mich ihm anschliebe, auf eine in der

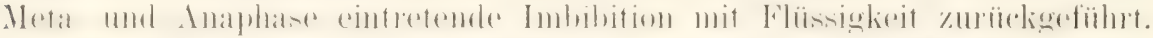

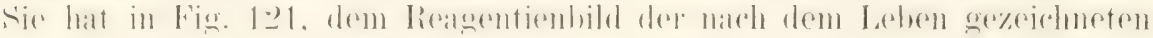
Fig. 117, noch zugenommen, ebenso wie der helle Hof um das in Körnchen aufgelöste Centrosom. Die T'ochterchromosomen sind in zwei Gruppen

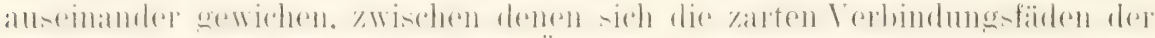
Zentralspindel ansspannen. Beim Übergang der dritten in die vierte Phase begimnt sich die Centrosomensubstanz wieder zu verdichten, indem die einzelnen Körnchen zu einer dünnen, den Spindelpolen breit aufsitzen-len Scheibe zusammentreten, welche uns Fig. 122 von der Kante in einem großen Hof hellen, körnchenfreien Plasmas zeigt. Die einzelnen in zwei Gruppen verteilten Tochterchromosomen sind durch Aufnahme von Kernsaft angeschwollen und weniger stark färbbar geworden. Die Anschwellung nimmt in der Endphase, deren Begimn in Fig. 123, einer Ergänzung

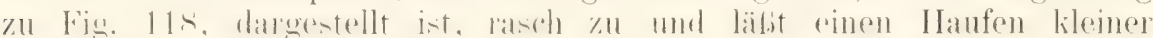
Kermblïschen (Karyosomen) entstehen, deren Zahl der Zahl der ursprüng-

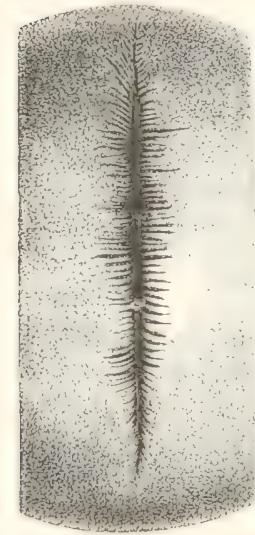
lichen Chromosomen entspricht und in denen die chromatische Substanz in feinen Körnchen, namentlich nach der Oberfläche zu verteilt ist. Die Astrosphären, die Köpfe der im lebenden Objekt zu sehenden Hantelfigur, sind stark in die Breite gezogen und schließen das wieder stark veränderte Centrosom ein, das zu einem schwarz gefärbten, in der Mitte verdünten Stab umgewandelt und wie der weitere Verlauf lehrt, in Zweiteilung begriffen ist.

In Fig. 124 ist der erste Furchungsprozeß beendet; durch Verschmelzung der Kernbläschen ist wieder ein einziger bläschenförmiger Kern

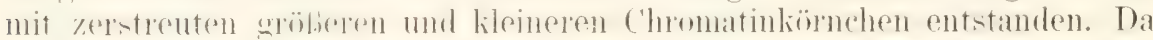

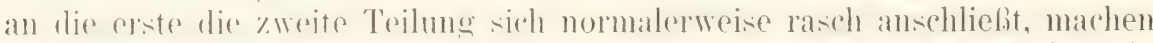
sich schon die Vorbereitungen zu letrterer bemerkbar. Das schon in Fig. 123 in Teilung begriffene, stäbchenförmige Centrosom hat sich wie ein Bügel um den Tochterkern herumgelegt. Seine Enden sind zu den hesilen 'Towherentrosmen. die nur noch durch einen feinen stiel zusammenhiingen. verdiclit mal zu den Mittelpunliten zweier nener Strahlenststeme reworden, welche die alte Sphäre verdrängt haben. Zwischen den gegen-

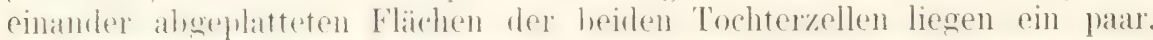

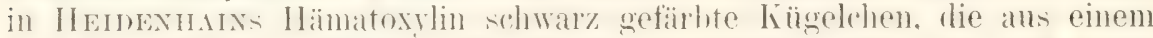

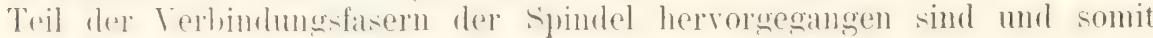

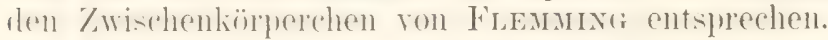


Der Durchschnïrungspro\%el nimmt an sehr grofien kierm, hei denen viel Dottermasse zu bewialtigen ist, wic \% li. bei den froscheiern, geramme Zeit für sich in Anspluch, so dah die zweite Teilung schon beginnen kann. noch ehe die erste ganz vollendet ist. Bei den Froscheiern läbt sich hierhei eine interessante Erscheinung heobachten. welche unter dem Namen des faltenkranzes von M. Scrutatze (VIII lis(i:3) beschriehen worlen ist (Fig. 125). D)ie erste furche beginnt zunächst anf der nach oben gekehrten, pigmentierten Hemisphäre des Eies in einem keinen liezirk anfzutreten: sie nimmt, indem sie in die Substanz tiefer emschneidet. an länge zu und dehnt sich im Laufe einer halben Stumde um die ganze Peripherie der liugel aus, so dab sie auf der nach abwïts gekehrten. hellen Fläche am spätesten sichtbar wird und von hier aus auch am wenigsten tief in den Dotter eindringt. Lei ihrem Anftreten erscheint nun die erste Furche nicht glatt, sondern sie ist - am deutlichsten zur Zeit, wo sie ein Dritteil der Lünge des Eiumfanges erreicht hat - mit zahlreichen. kleinen Furchen besetzt, welche meist miter rechtem Winkel zu beiden Seiten in sic eimmünden (60-100 anf jeder Seite, Fig. 125). So entsteht ein höchst anziehendes Bild, vergleichbar einem langen, tiefen (iebirgstal, von welchem nach beiden Seiten kileine, kurze Seitentäler in grober Zahl abgehen. Je weiter die T'eilung fortschreitet und die Hanpt. furche tiefer wird. um so mehr nehmen die Seitenfurchen an $/$ ahl ab und verschwinden endlich ganz.

Der so eigentümlich und scharf ausgebildete Faltenliran\% ist ein l'hänomen, welches mit der Zusammenziehung des Protoplasmas bei der Einschnïrung zusammenhängt.

\section{c) Teilung pflanzlicher Zellen.}

Um die grohe Übereinstimmung im Verlanf des Kernteilungsprozesses im 'Tier- und Pthanzenreich zu veranschaulichen, diene der protoplasmatische Wandbeleg des Embryosackes ron Fritillaria imperialis. Es ist dies ein zum Studium der Kernfiguren auberordentlich geeignetes Objekit - nicht minder emptiehlt sich auch (ler Embryosack anderer Liliaceen - weil das Protoplasmahäutchen ungemein diinn ist mol, zu geeigneten Zeiten untersucht, sehr viele Kerne auf verschiedenen Phasen der Teilung beherbergt (STAsBurger VIII $1875-188$. , (iugnard VIII 1884 ).

Der große, ruhende Kern besitzt ein feimmaschiges Liningeriist (Fig. 126 A). auf dessen Obertläche zahlreiche, kleine Chromatinkörnchen ziemlich gleichmäbig rerteilt sind. Die Nukleolen sind in Mehrzahl vorhanden. sie sind von verschiedener Größe und liegen zwischen den Masehen des Geriistwerks, denselben anhängend. Bei der Vorbereitung zur T'eilung läßt STRASBURGER sich das ganze Gerüstwerk in einige vielfach gewundene. ziemlich dicke Fälen umbilden (Fig. $\left.126 b^{3}\right)$; er beschreibt an ihnen eine ähnliche Querstreifung (Fig. 126 C). Wie sie BALBIAxI (III 1881) an Kernen von Chironomuslarven (Fig. 17) beobachtet hat, und erkiairt sie in

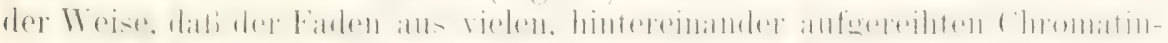

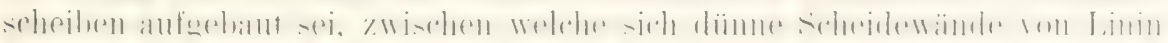
trennend himeinschieben.

Im weiteren Verlauf löst sich die Kermmembran aut. die Nukleolen zerfallen in kleinere Körnchen und verschwinden. die Chromatinfäden verkiurzen und verdicken sich und liefern 2t Kernsegmente: es bildet sich eine typische, aus zahlyeichen, feinsten Fasern zusammengesetzte spindel

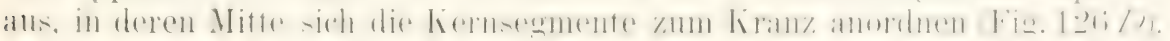

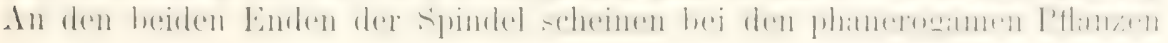




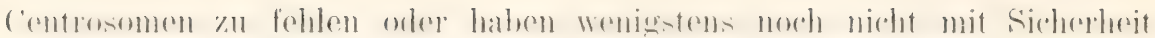
nachgewiesen werten können, wenn wir von einigen Angaben Guignards absehen. welche von verschiedenen anderen Beobachtern nicht haben bestïtigt werlen kömen. Ebenso fehlen Astrosphären entweder ganz orler sind nur sehr schwach ausgeprägt.

Auf dem Ilöhepunkt des 'T'eilungsprozesses spalten sich die Kiernsegmente ihrer Länge nach. Damm weichen die 'Tochtersegmente nach den beiden Polen zu, je $2+$ nach jeder Seite, anseinander (Fig. $126 \mathrm{E}$ ) und liefern so die Grundlage für die 'Tochterkerne, die sich wieder in ähnlicher Weise, wie es für salamandra maculata heschriehen wurle, anlewen. Sowie die Tochterleme hä̈chenfürmig werlen. treten mehrere Nukleolen in ihnen auf.

Wenn sich hisher eine fast vollstindige İhereinstimmung mit der tierischen lernteilung ergeben hat, so zeigt sich uns jetzt am Schlub des ganzen Prozesses noch eine bemerkenswerte und interessante Abweichung in der Entstehung der sogenannten Zellplatte. Zum Studium derselben
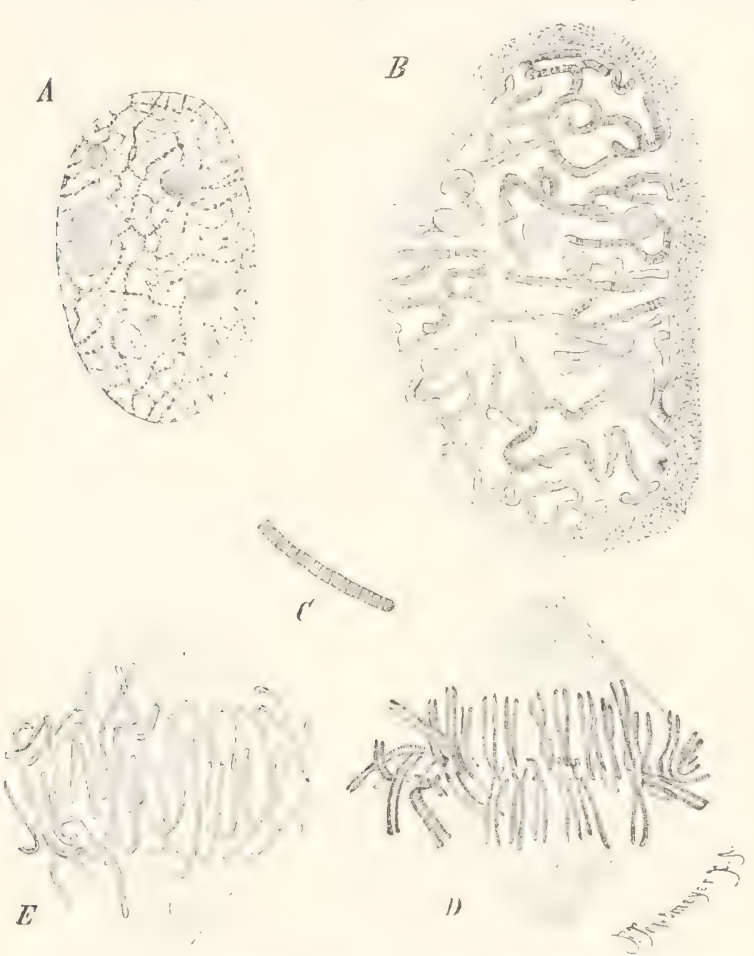

Fig. 126. Fritillaria imperialis, Ein ruhender Zellkern und Teilungsphasen der Zellkerne, dem freigelegten protoplasmatischen Wandbeleg entnommen. Nach STrasburger, Botan. Praktikum, A

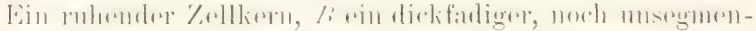
tierter Iínäuel, $C$ ein Stück dieses Kernfadens, stiirker vergröliert, $D$ eine Kiernspindel mit längsgespaltenen Segmenten, E die Trennung und Umlagerung der Tochter-

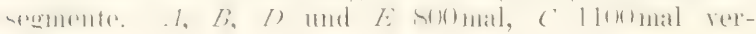
größert.

anf dem optischen I)urehsohnitt in ainer Reihe kommen. In ihrer Gesamtheit stellen sie also sind T'eilstadien von Pollenmutterzellen und andere Objekte geeigneter als der bisher der Beschreibung zugrunde gelegte Embryosack von Fritillaria, da es bei rliesem nach der Kernteilung nicht gleich $\mathrm{zn}$ einer Zellteilung kommt.

Die folgende Darstellung bezieht sich daher auf Pollenmutterzellen von Fritillaria persica (Fig. 127). Wenn bei diesen die Tochtersegmente in zwei Gruppen auseinandergewichen sind, so spannen sich zwischen ihnen feine Verbin(lungsfäden aus, die Strasburger (VIII 1888 ) von den mittleren Abschnitten der Spindelfasern ableitet (Fig. $127 f$ ). In der Mitte der Verhindungsaiulen entstehen mach liurzer Zeit kleine Anschwellungen, die als glänzende Körner erscheinen (Fig. 127 $g$ ). Sie sind höchst regelmäbig so angeordnet, daß sie nehemeinander zu liegen eine aus Körnclien zu- 
sammengesetzte, in der Mitte zwischen den beilen 'Tochterkernen in der 'Teilumgsebene gelegene Scheibe dar, welcher S'TrasiburaEr den Namen .Zellplatte* gegelsen hat. Ein Rudiment derselben bei tierischen \%ellen

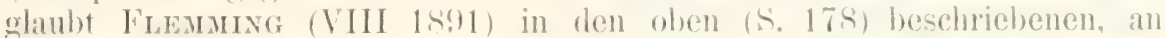
einzelnen Objekten aufgefundenen ' $/$ wischenkïgelehen wieder zu erkennen.

Die Zellplatte steht num bei den P'lanzen zur Bildung der Cellulosescheidewand, mit welcher der ganze 'Teilungsprozel, seinen letzten $\Lambda_{\text {b- }}$ schluß findet, in imniger Bezichung. (Fig. 127/2). „Sie dehnt sich schliel-
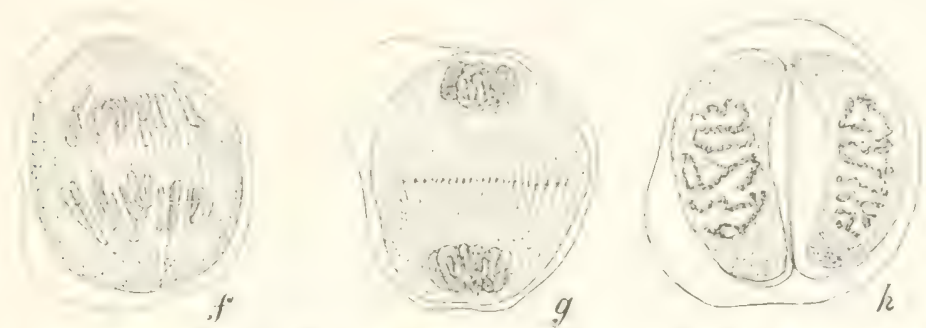

Fin. 12-. Drei Teilstadien der Pollenmutterzellen von Fritillaria persica.

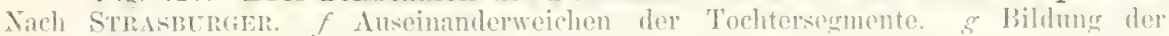
Tochterknäuel und der / $/$ ellplatte. I Verlauf des Kernfadens in den Tochterkernen und ansgel,ildete Cellulosescheidewand. so0mal vergrölert.

lich", wie STRAsBurger beschreibt, „über den ganzen Durchmesser der Zelle ans, ihre Elemente verschmelzen und bilden eine Scheidewand, welche die Mutterzelle in zwei Tochterzellen halbiert". Ein dïmes Cellusosehäutchen läßt sich bald in ihr nachweisen. Währenddem verschwinden die Verbindungsfäden, zunächst in der Nähe der 'Tochterkerne, damn auch im Bereich der Scheidewand ans Cellulose.

\section{Beispiele von karyokinetischen Teilungsfiguren bei cinzelligen Organismen.}

Anch bei einzelligen Organismen sind karyokinetische l'rozesse schon

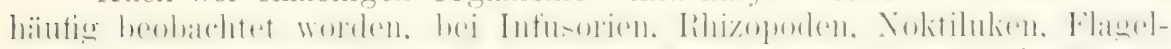

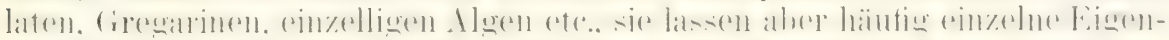

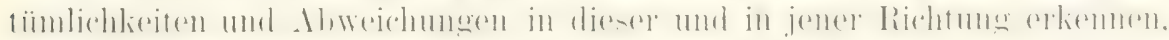
deren Studium von allgemeinem Interesse ist. Hier kann nur auf cinige Beispiele eingegangen werden.

Wie schon seit langer Zeit bekannt ist (BALBIANI XI 1861). wandeln sich bei den Infusorien die kleinen Nebenkerne zu typischen faserigen Spindeln um. wobei sie auf allen Stadien gegen das Protoplasma durch cine feine Kermmembran scharf abgegrenzt bleiben. Sie vergröbern sich durch Imbibition mit Flüssigkeit, strecken sich dabei in ciner Richtung und wandeln sich zunächst zu einem ovalen Körper. dann zu einer Sichel. endlich zu einer typischen Spindel um (BüTschli VIII 1s76, RicharD Hertwig XI 1889). Der Inhalt des Nebenkerns läbt achomatische und chromatische Substanz unterscheiden. Erstere ordnet sich, je mehr der Kern gestreckt wird (Fig. 128), um so deutlicher zu feinen Fasem an. die von einem Ende der Spindel zum anderen in welligen Linien verlaufen.

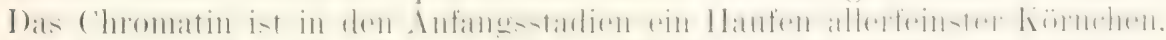
die sich in der Anaphase auf der Mitte der Spindeltasern verteilen und hier eine Art von Äquatorialplatte erzengen. Später (Fig. 12y) trennt 
sich dieselbe in zwei Seitemplatten, die nach den Spindelenden zu auseinanderweichen, wie es dem Dyasterstadium der Metazoenkerne entspricht. \%uletzt schnürt sich die Spindel in der Mitte ein (Fig. 1:30) und nimmt eine typische Hantelform an, an der man zwei ovale Endanschwellungen und ein Mittelstïck unterscheiden kann. „Die Hantelköpfe bewahren die faserige spindelstruktur und haben auch anfangs eine deutliche Chromatinplatte. welche sich später in einen Haufen feinster Körnchen auflöst. Das Mittelstuck dagegen verändert seme Struktur in gleichem Make, als es sich zum '/week der 'Teilung in die Iänge streckt und dïnner wird. So lange es noch liurz und gedrungen ist, setzt es die Faserung der Hantelköpte fort; bei mittlerer Streckung sieht man nur zwei seitliche Konturen und einen feinen axialen Faden, welcher die Faserung der Hantelköpte in sich vereint. Kur\% vor der Durchschnïrung kann man auch diesen Unterschied nicht mehr machen und das Verbindungsstiick ist ein einziger strukturloser feiner Farlen, der zuletzt auch schwindet."

An der Infusorienspindel fehlen Centrosomen, und damit hängt es wohl auch zusammen, dah eine sichthare Anteilnahme des Protoplasmas an den Kernveränderungen vollständig zu fehlen scheint. Denn auf keinem Stadium sind auch nur Andeutungen von Astrosphären zu bemerken. Das

Fig. 12S.
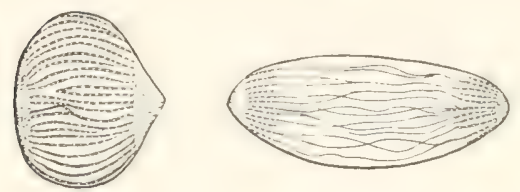

Teilung der Nebenkerne der Infusorien (Paramaecium).

Tach Richard Hertwit aus WIIsOx.

Fig. 128. Vergrößerming des Nehenkerns und Umwandhung zur Spindel. In der Nitte die Chromosomen; an den Enden die Polplatten.

Fig. 129. Streckung der Spindel. Zwischen den Tochterplatten breiten sich Verbindungsfiden aus.

Fig. 130. Teilung der Mutterspindel in zwei durch einen Stiel verbundene Tochterspindeln.

Protoplasma scheint sich bei der Karyolinose der Infusorien ab weichend im Unterschied zu tierischen Zellen ganz passiv zu verhalten.

Unter den Rhizopoden ist die Kernteilung am genanesten bei Actinosphärium durch Richard HerTwig (VIII 1898) und BraUER (VIII 1894) untersucht worden. Bei freilebenden Tieren ist häutig im bläschen-

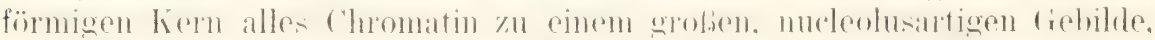

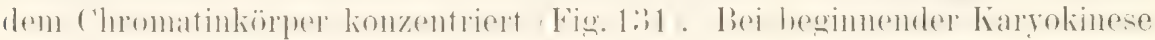
lockert sich seine Substanz und rerteilt sich in feine Chromatinkörnchen auf dem achromatischen Gerïst (Fig, 13\%). Das Protoplasma nimmt hier früh an der Kernteilungsfigur teil, indem es an zwei Polen des noch

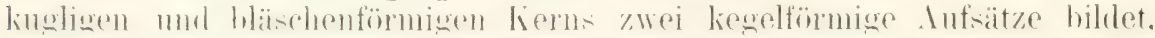
die wie zwei durch den Kern getrennte Spindelhälften aussehen. Sie zeigen eine feinfaserige Beschaffenheit und werden die ,polaren Protoplasmakegel" genannt. Zwischen ihnen plattet sich der Kiem, der seine Ahgrenzung gesen das Protoplasma in den ersten P'hasen verliert Fig. 13:3). zu einer Linse oder Scheibe ab und sondert sich in drei verschiedene Teile. Fimmal sammelt sich in den ahgeplatteten liermpolen, wo sie die Basis der Protoplasmakegel herïhren. eine homogene. im Lehen hellglämente. nach Hemenasseher Ifämatoxylinfüloung schwarz tingierte substanz an, die 
Polplatte: zweitens differenziert sich das achnomatische (ieriast in selne feine Fasern, die von einer zu' andern Polplatte linziehen und den Zentralspindelfasern vergleichbar sind. Durh Querfiddhen sollen sie unteremander zusammenhängen. Drittens gruppieren sich die Chomatinkömehen in rler Mitte des Kerus zu einer Äpuatorialplatte. Ans ihr entstehen dann, Wahrseheinlich idureh Spaltung der Körnehen und 'Tremung in zwei (iruppen die beiden Seitenplatten, die anseinander weichen und his dicht an die Polplatten heramrïcken (Fig. 1;4). Diese haben sich mittlerweile weiter voneinander entfernt und den Spitzen der P'rotoplasmaliegel mehr genähert. die entsprechend niedriger geworden sind.

Wenn Pol- und Seitemplatten einen ziemlich betrïhtlichen Abstand voneinander erreicht laben, hilden sich aus ihnen durch Saftaufnahme zwei bläschenförmige lieme (Figg. 135 ) 11.136 ), an denen die polaren Proto-

Fig. 131 .

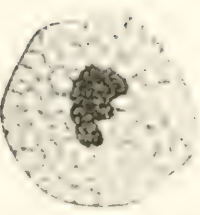

Fief. 1:3,

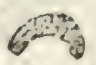

(3) 1050
Fijg. 1:39.

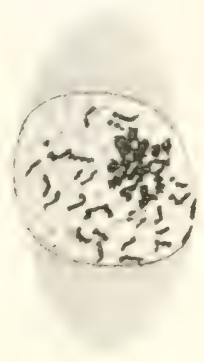

lii.. I:ici.

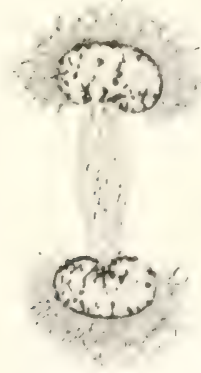

Fig. 1:3:3.

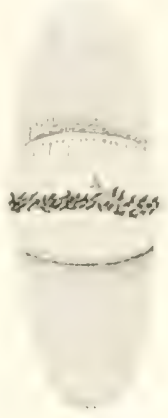

lïg. 131. Primärkeru aus einer Primarcyste von Actinosplaärium. Nach li. Hertwig.

Fig. 132-136. Die wichtigsten Stadien der Primärkaryokinese, d. h. der Teilung des Kerns bei der Teilung dex Primärcysten in die Sekundärcysten. Nach Richiri) Hertwin; (IIII i-!i).

plasmakegel und das chromatische Verbindungsstiick verschwinden, weil sie ihre Abgrenzung gegen die übrige Zellsubstanz verlieren. Diese lat sich während des ganzen Verlaufes ebensowenig wie bei den Infusorien

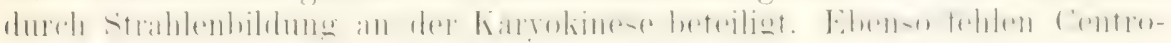
somen.

Dagegen werlen Centrosomen merkwirdigerweise bei den liern-

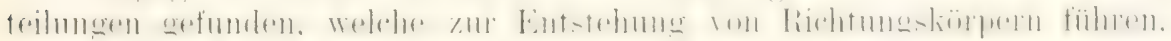

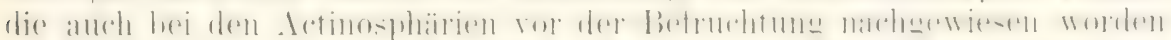
sind. Zum Veroleich sind auch solche etwas abweichende lierntormen in den Figuren 137-141 aus (ler Monographie von Richari) Hertwig abgebildet worden.

Welchen Bildungen der typischen Karyokinese man die Polplatten

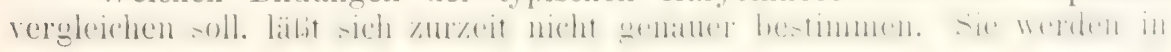


itmlicher Weise anch noch bei manchen anderen Formen der Einzelligen, besonders ausgeprägt \%. B. hei Spirochona (RICHARD HerTwig VIII 1876) beobachtet. Die Konzentration des Chromatins zu einem gröleren, kom-

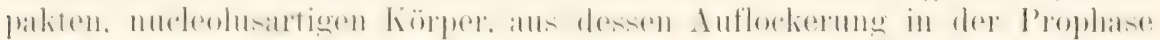

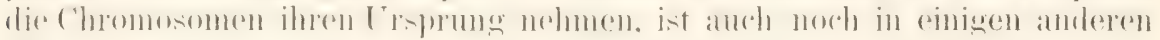
Fillen nachgewiesen und unter anderem bei Spirogyra durch Meunier, Molu und Hennegur genau verfolgt worden.

l.ig. $1: 3 i$

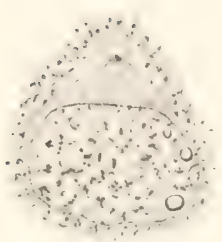

I.im. lis

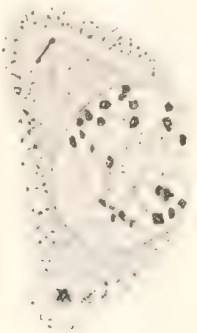

lic. 1:i:1

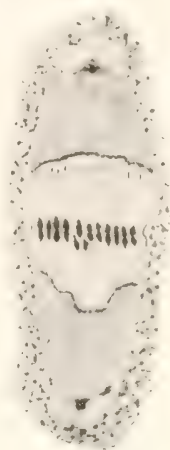

Fïg. 137-141. Fünf Stadien der Veränderungen, welche der Kern von Actinosphärium während der Richtungskaryokinese erfährt. Nachı L. IlenTwif (VIll 1s?s).

Fis. 137. Kern mit einfachem l'rotoplasmakegel und einem Centrosom.

Fig. 138. Kern mit zwei l'rotoplasmakegeln und zwei (imtrixoment.

Fig. 139. Spindelfigur mit Äquatorialplatte.

Fig. 140. Spindelfigur mit zwei Tochterplatten.

Fig. 141. Bildung zweier bläschenfömiger Kerne, von welchen der nach oben gelegene und der Oberfliche des Actinosphäriums zugekehrte dem liern einer P'olzelle gleichwertig ist. liig. 1|11.

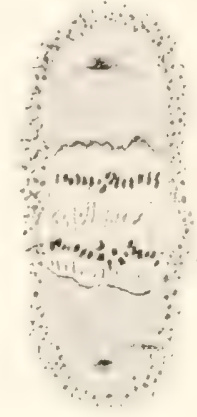

Fï. 111 .

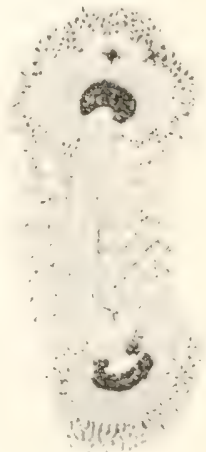

Eine interessante Besonderheit bietet nach den Untersuchungen von KEUTEN (VIII 1895) die Karyokinese bei Euglena viridis. Bei ihr trägt der ruhende Kern (Fig. 142) in seiner Mitte einen nucleolusartigen Körjer, der wegen der Rolle, die er bei der Teilung spielt, Nucleocentrosoma genannt wirl. In seinem Umkreis ist das Chromatin, das immerfort Faden-

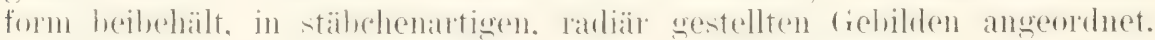
Bei Beginn der Teilung streckt sich das Nucleocentrosoma in die Länge (Fig. 14:). Seine Enden schwellen kenlenförmig an, wăhrend sich die Nitte mehr und mehr verdünnt (Fig. 14t), immer weniger färbt und schlieblich zu einem langen, feinen Faden auszieht (Fig. 145). Bei Beginn der Streckung haben sich die chromatischen Stäbchen um die Mitte des

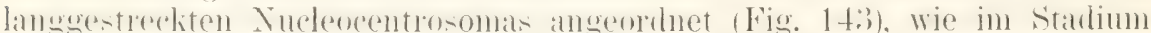
dere Äquatorialplatte: so spalten sich hierauf der Länge nach mol weichen zur Zeit, wo das Nucleocentrosoma eingeschnürt wird, in zwei Gruppen auseinander (Fig. 144 und 145). Indem zuletzt der Verbindungsfaden des Nurleocentrosomas einreibt. bilden sich aus seinen lieulenförmigen Enden und den im Umkreis ron ilnnen gelegenen Centrosomen zwei bläschen- 
fömnge Kerne von der anfangs angegebenen Beschaffenheit (Fig. 146). Das auffallendste Merkmal in der Karyokinese von Euglena bietet das Nucleocentrosoma dar, ron welchem líEuex hemerkt. dab. es von romherein auf die liüntige Richtung der Kernteilung und anf die liewegung der Chromosomen bestimment wirlit und somit den ganzen Lernteilungsvorgang beherrscht. Es ersetzt daher gewissermalien das Centrosoma und die Kentralspindel.

Fig. 1.42

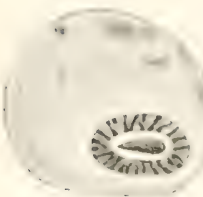

I.i.: Iiti:

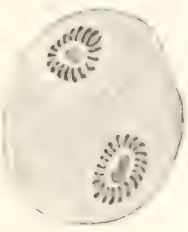

Fig. 143.

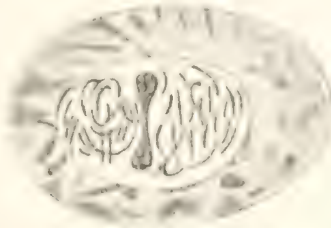

Fii.. 1 H.

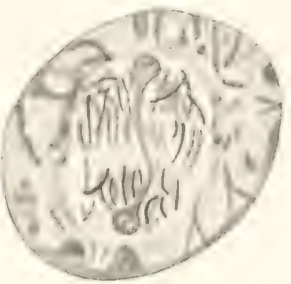

Fie. 14:

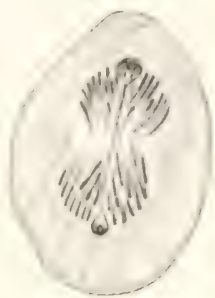

lïg. 1.12-1.46. Kernteilungsstadien nach Schnittpräparaten von linterex.

Fig. 1.12. Eine Englena viridis und ihr Kern in Ruheznstand.

Fig. 143. Liern in Vorbereitung zur Teilung. Das Nucleocentrosoma hat sich gestreckt und in der Mitte eingeschnürt. Das Chromatin ist in schleifenförmigen Chromosomen angeordnet.

F̈ig. 14.1. Die beiden keulenförmigen Enden des Nucleocentrosomas haben sich weiter voneinander entfernt, das mittlere Verbindungsstiick ist stark ansgezogen. Die Chromosomen sind in zwei (irupuen anseinander gewichen.

Fig. 145. Die Chromosomen sammeln sich um die Polstücke des Nucleocentrosomas, dessen Jlittelstïck als feinste Linie noch eben sichthar ist.

Fig. 146. Durch Teilung entstandenes, ruhendes Exemplar von Euglena mit zwei Tochterkemen, deren jeder ein Nucleocentrosoma enthialt.

\section{(l) Historische Bemerkungen, strittige Fragen und eigentümliche Sonderfälle der hernsegmentierung.}

Am Anfang der 70 er Jahre wurden durch die Arbeiten von BütscuLI

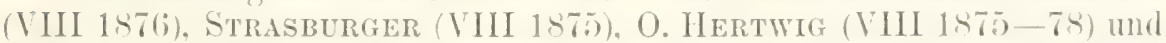
For (VIII 1877) die Veränderungen, welche der Kern bei der 'Teilung erfährt, in ihren gröberen Zügen im ganzen richtig dargestellt. Es wurde die faserige liernspindel, die Ansammlung glänzender, in Kíarmin sich

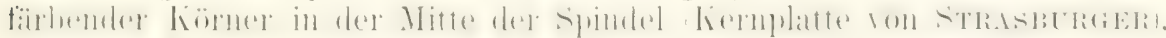
die hierauf folgende Verteilung der Körner in zwei Gruppen oder in zwei

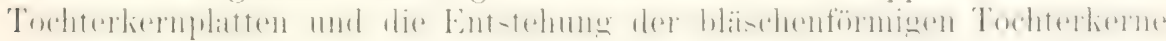
aus den letzteren entrleckt. Ebenso waren die Strahlenfiguren (Sterne. Amphiaster, FoL) an den Enden der Spindel bekannt, und ron mir und FOL waren in denselben auch stärlier glänzende Körnchen, die Zentrosomen, beschrieben, deutlich abgebildet und als Attraktionszentren gedeutet worken. Es war somit endgültig festgestellt, daf bei der Zellteilung keine Kernauflösung (Karyolyse, AUERBACH VIII 1874), sondern eine Kermmetamorphose stattindet. Indem ich ferner durch meine Untersuchumg der Eireife, namentlich bei Asteracanthion und Tephelis, und

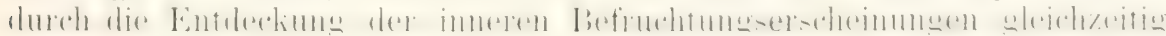
bewies, daß der Eikern keine Neubildung ist, sondern von geformten Substanzteilen des liembläschens abstammt uqd sich mit dem rom Kopf

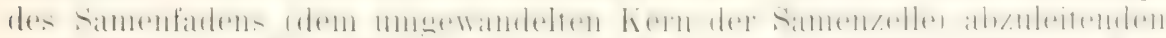

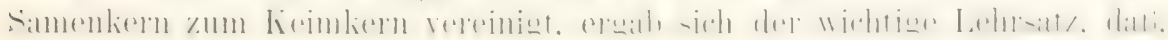




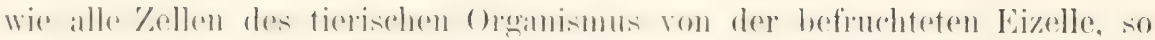
auch alle Kierne vom Kern der Eizelle in ununterbrochener Folge abzuleiten sind. (Omnis nucleus e nucleo. Fusming).

Das in den genamnten Arbeiten aufgestellte Kern- und Zellteilungs-

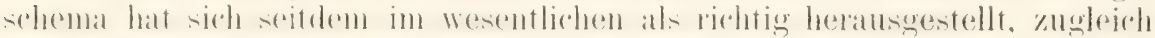
aber hat es die Grundlage für zahlreiche weitere Entdeckungen und für zahlreiche Aufgaben gebildet, die ihrer Lösung zum 'Teil noch immer harren. Die Aufgaben lassen sich kurz in den einen Satz zusammenfassen: Es galt und es gilt zum 'Teil auch noch jetzt, die bei der Kernteilung stattindenden und in charakteristisehen Figuren in die Erscheinmeg

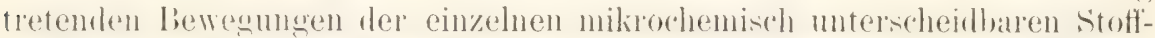
teilohen des korns mul der T'eilungstiguren noch genaner in allen Einzel-

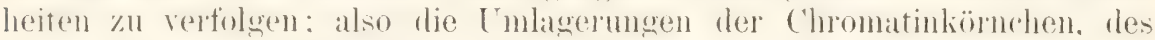
Liningerüstes, der Spindelfasern, der Centrosomen, der Nukleolen etc. Fortichritte in dieser Lichtung sind, abge-ehen von der Enteleckung günstiger

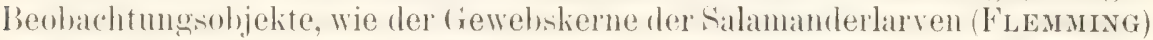
mond der Fier rom Asaris megalocephala (vax lienedex). durch den (iesbranch der neu konstruierten Ölimmersionen und Apochromate und dureh die bessere Ifandhahmug der Reagentien und Farbstofte ermöglicht worden.

Am weitesten ist die Forschumg zurzeit in dem studium der durch die I'mlagerungen des Chromatins arzeugten Figuren fortgenchritten, was in erster Linie den klassischen Untersuchungen von Flemming (VIII 1879-1891), VAN BenEDEN (VIII 1889-1887), RaBL (VIII 1889). Boveri (VIII 1887-1903), STrasburger (VIII 1875-1888), GUIGNard (VIII 1884) zu verlanken ist.

FLEmMng, der besonders die Kernteilung in Gewebszellen von Salamanderlarven verfolgt hat, unterschied mit gröberer Schärfe an der Kernfigur den achromatischen und den chromatischen Teil, die sich nicht färbenden spondelfasern mol Plasmastahlungen und die ihnen oberflachlich anfliegenden, gefärbten Kernschleifen. für Welche WALDEYEr den Namen Chromosomen einführte. An letzteren machte er auch zuerst (1879) die wichtige, hald durch Retzres (JII lsis) hestitigte Entrleckung. dabs sie sich der Länge nach spalten. Auf diese interessante Erscheinung fiel darauf das klärende Licht, als Heuser (1884), Guignard (1884), VAN BENEDeN

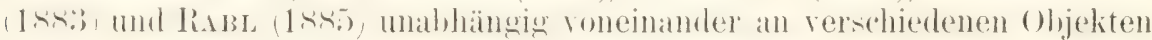
fanden, daß die Hälften der gespaltenen Fädlen nach den Kernpolen auseinanderrïcken und die Grundlage für die Tochterkerne abgeben.

Viel weniger genatu erforscht sind die substanzumbarerungen, die mit der Entstehung der Spindel und der Centrosomen und mit der Auflösung der Nukleolen zusammenhängen.

Was die Spindel betrifft, so sind nicht nur über ihre Herkunft, sondern sogar über ihren bau sehr verschiedene Ansichten geäuliert worlen. die zum 'Teil daranf beruhen, daß in der' Tat bei einzelnen Objekten Unterschiedle vorhanden sind. Während die ersten Beobachter der Ansicht waren, daß die Spinclel aus feinsten Fäserchen zusammengesetzt sei, die sich kontinuierlich vou Pol zu Pol erstrecken, ließen vaN BENEDEN (IIII 1887) und Boveri (VIII 1888, 1890) die letzteren im Äquator unterhrochen sin und stellten der alten die nene Lahre entgegen, dabi die spindel aus zwei gesonderten Halbspindeln aufgebaut sei (Fig. 147). Die Halbspindeln ließen sie mit den Enden ihrer Fasern sich direkt an die Kernsemente ansetzen: sie begränleten darate eine Mechanik der Kernteilung, indem sie annahmen, daß nach der Spaltung der Segmente in die 'Tochtersegmente diese durch eine Verkürzung oder Kontraktion der an ilmen an- 


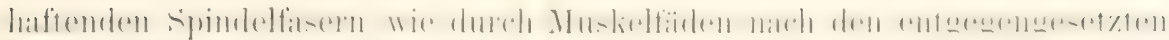
Polen hingezogen werden.

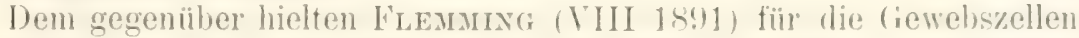
von Salamandra und S'TrismURGER (VIII 1s.t) fiil phlan\%liche Oljjekte anch nenerdings noch ihre ïleren Angaben aufrecht. dab es Sinindelfasem gibt. welche von Pol zu Pol ununterbrochen durchlanfen. wie dies jetzt wohl anch allgemein angenommen wirl. Besonders beweisend aber fiil die

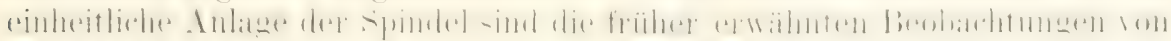

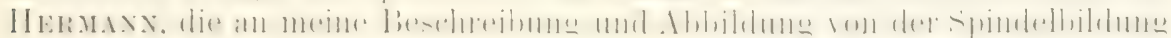
aus dem Keimbläschen von Asteracanthion erinnern. (HERTwG VIII 1577. Tat. VIII. Fig. :3 u. 4). In beiden Fillen biliet sich zwischen den noch nahe zusammengelegenen Polen (Fig. 148) ein sehr kleines, einheitliches Spindelchen aus, zu einer Zeit, wo die Kernsegnente noch weit entfernt von ihm liegen und es in keiner Weise verdecken: allmählich erst wächst es durch beträchtliche V'erlängerung der Fasern zu der definitiven Größe heran.

Fig. 147 .

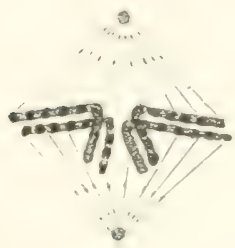

Fig. 148 .

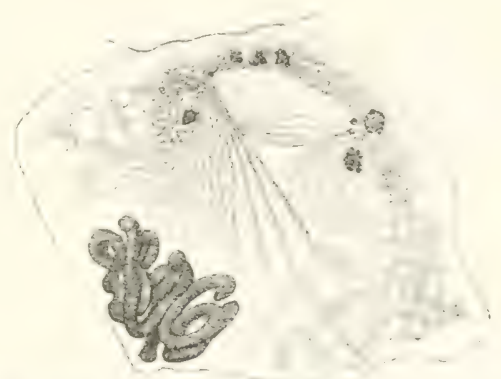

Fig. 14. Zusammensetzung der Spindel aus zwei Halbspindeln, deren Fasern sich an die Tochtersegmente ansetzen. Nach VAX BFNEDEN und NEYT 'Taf. VI, I'ig. S.

Fig. 1.48. Kern einer Samenmutterzelle von Salamandra maculata in Vorbereitung zur Teilung. Anlage der Spindel zwischen den beiden Centro-

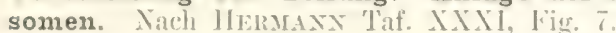

Die entgegengesetzten Auffassungen finden num aber, wie auch schon HERMaxy hervorgehoben hat, darin ihre Frklärung, dals das, was vax BExEDEx mol Boveri Halbspindeln nemnen, etwas ganz anderes ist als die spindeln der älteren Autoren. VAx BExEDEx und Boveri verstehen darunter einen Teil der ron den P'olen ausgehenden protoplasmatischen Strahlenfigur, nämlich alle diejenigen Färlen. die im Äquator in die Nähe fler Kernsegmente treten und sich an ihnen anheften. Die eigentliche Spindel liegt aber erst im Imnern dieser Protoplasmafäden und der Kiernsegmente. Hermax gab ihr daher zur Unterscheidung von der vax biexedexsehen Spindel den Namen Kentralspindel. Der Zusatz ..Zentral" erscheint mir aber entbehrlich, weil der Name spindel von jeher für diesen liestandteil der Kerntigur vergeben ist. und weil infolgedessen die sich zu den liernsegmenten hegehenden. jotoplasmatischen Polstrahlen. welche von VAN BENEDEN und BOVERI als Habspindeln beschieben worden sind. mit einem andern Namen benannt werden mülsten, sofern man einen solchen für erforderlich hält. Von manchen Seiten werlen sie dem anch als Mantelfasern bezeichnet.

Strittig ist ferner lange Zeit die stoffliche Herkunft der Spindelfasern gewesen. Manche Forscher Waren geneigt, sie rom Protoplasma 


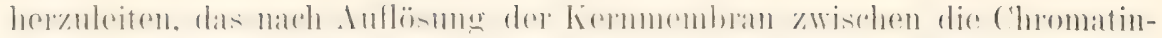
fälen eindringe (STrasburger VIII 1884, Hermann VllI 1891 etc.). Ich hatte früher den Standpunkt vertreten, daß, abgesehen von den P'olstrahlungen, die dem Protoplasmakörper der Zelle angehören, die verschiedenen Struliturteile der Kernfigur von den einzelnen Substanzen des l'uhenden Kerns abstammen. Die stoffliche Grundlage für die Spindel und die später aus ihr hervorgehendon Verbindungsfäden suchte ich in dem Liningerïst. Auch FLEmMng vertrat nach seinen Beobachtungen diese Ansicht, welcher auch die mikrochemischen Untersuchungen von ZaCharias nicht im Wege standen.

Bei eimer vergleichenden Prüfung der vorliegenden Tatsachen scheint sich jetzt die Streitfrage dahin zu lösen, daf die Spindelbildung in verschielener Weise erfolgen kann. Wie Meves (VIII 1897) in seinem zu-

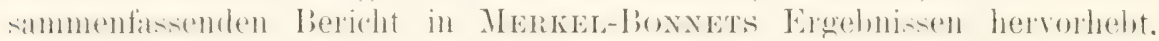
,ist es ohne prinzipielle Bedeutung, ob die Substanz, aus der die Spindelfasern gebildet werden, vorher dem Raum des Kerns oder des Zellkörpers angehört haben". Nach ihrem Ursprung lassen

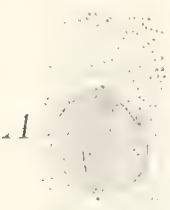

()

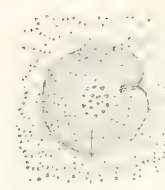

Iig. 149. A In Umbildung zur Spindel begriffenes Keimbläschen aus einem frisch abgelegten Ei von Phyllirhoë. E...igsianepräparat. HERTWIG Taf. XI, Fig, 2.

B. Keimbläschen aus clem frisch abgelegten Ei von Phyllirhoë, in welchem die Spindel auf dem optischen Querschnitt gesehen wird. Essigsiure-

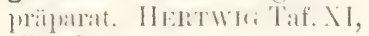
Fig. 2. (VIII 1894, S. 302) bei Copepodeneiern gemacht worden. So gibt für Ophryotrocha KonschelT an, dafs die Spindel sich auf frühen Stadien vollständig im Kern befindet, und bemerkt hierzu: .Die intranucleäre Entstehung der Spindelfasern liegt hier besonder's klar vor Augen. da die

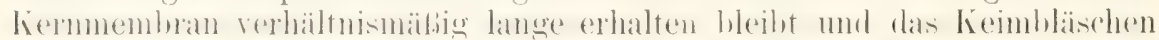

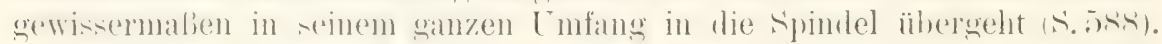

Für die Entstehung der Spindel aus dem Protoplasma sind die Fälle beweisend, in denen die Centrosomen etwas abseits von dem Kern gelegen

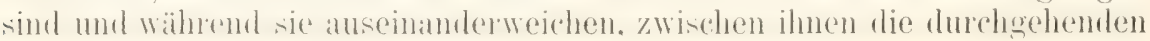




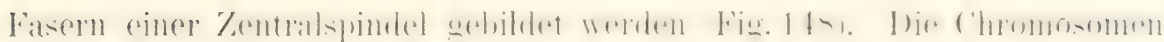
treten erst nachträglich an die Spindel heran und legen sich im Äquator um sie herum. Ein derartiger Hergang ist von Hermaxy, Fumming

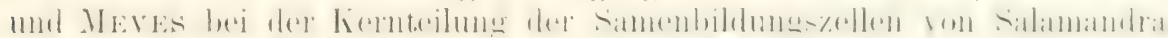

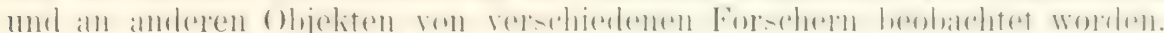

Häufig wird die doppelte Herkunft der Spindelfasern beschrieben,

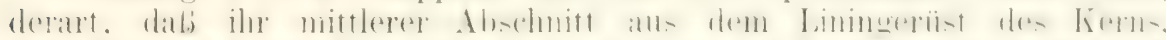

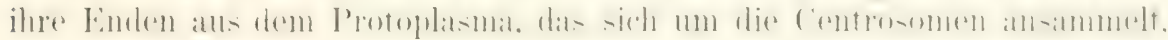
entstehen soll.

Die verschielenen Entstehumgsarten der Spindel verlieren ihr Über-

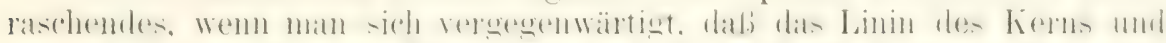

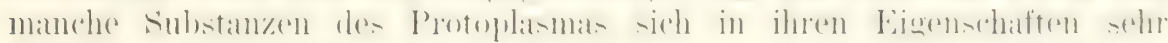
ähnlich. wenn nicht identisch sind.

Was die Centrosomen betrifft. so bedürfen noch manche Verhältnisse

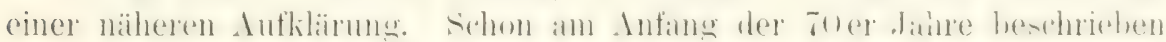

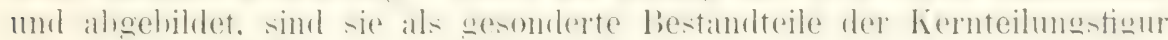
erst durch VAY BENEDEN (VIII 1883) zur Geltung gebracht worden, in-

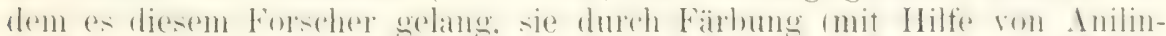

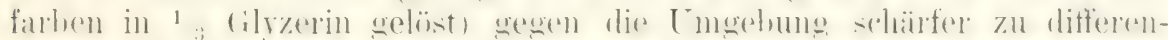

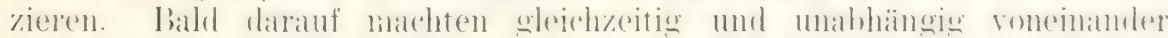

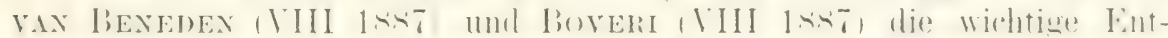

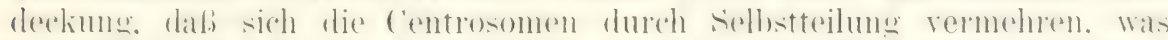

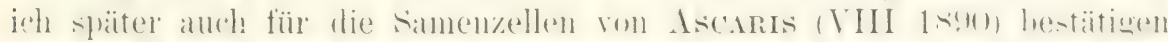
lionute. Vax bexenex hatte alls semen beobachtungen den sihlul.j gezogen, daß die Centrosomen ebenso wie die Keme permanente Organe

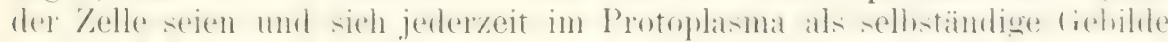
vorfinden mübten. Dieser Ausspruch fand eine gewisse Stütze in den Entrleckungen ron FLeming (VIII 1891**), Solger (VIII 1891) und

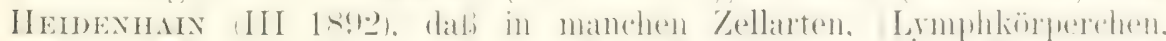

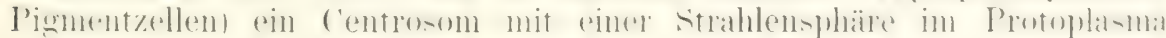
auch zu einer Zeit nachzureisen ist, wo der oft weiter abseits gelegene Kern sich in voller Ruhe befindet. (Siche S. 46, Fig. 30-36.)

In einer anderen Richtung wurde die Kenntnis der Centrosomen

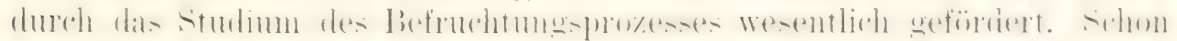
1884 sprach ich die Ansicht aus (VIII 1884), dab bei der Befruchtung

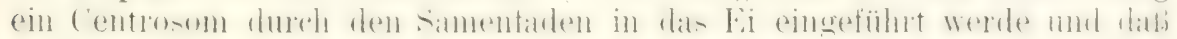
es allem Anschein nach das sogenannte Mittelstück oder der Ilals sei,

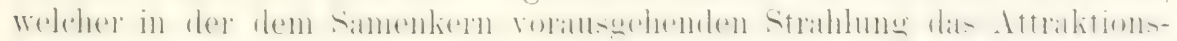
zentrum abgebe. Ich verglich dasselbe , der an den Enden der Kernspindel vorhandenen, geringen Quantität wenig tingierbarer, aber vom Protoplasma unterscheidbarer Substanz (der P'olsubstanz und dem Polkörperchen)" und ich kam so zu dem Schlub, daß. ..wenn der Vergleich

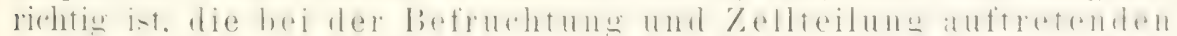
Strahlungen des Protoplasmas eine gemeinsame Ursache in der Anwesenheit ein und derselben Substan\% haben".

RICHARD HerTwig (VIII lsos:) sprach sich wiederholt wher die

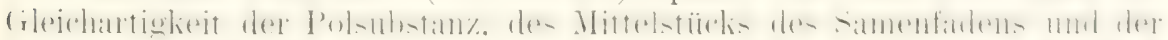
Substanz der echten Nukleolen aus. Boveri (VIII 1887) ließ gleichfalls den Samenfaden ein Centrosoma in das Ei hineintragen und gab die erste genaue Darstellung der hieraut bezüglichen V'erhältnisse.

'Trotz dieser Entdeckungen ist eine Frage noch nicht aufgeklät. Sind die Centrosomen als permanente Zellorgane zum Protoplasma hinzuzurechnen. sind sie während der Ruhe dauernd in dasselbe 
eingeschlossen und treten sie nur während der Teilung zum Kern in eine IVechselbeziehung oder können sie besondere bestandteile des kierns selbst sein, wie die Chromosomen, Spindelfasern, Nukleolen usw. kömnen sie anch während der Ruhe in dem Kern eingeschlossen sein und nur während der 'Teilung sich zum Protoplasma in Beziehung setzen?

Da die Centrosomen so auberortentlich klein sind unrl noch nicht durch bestimmte Farbstoffe mit Sicherheit unter allen Verhältnissen erkembar zu machen sind, stöbt ihr Nachweis zu manchen Zeiten des Zellenlebens und ebenso an diesem und jenem Objekt auf sehr große Schwierigkeiten. Während der Teilstadien selbst werden die Centrosomen
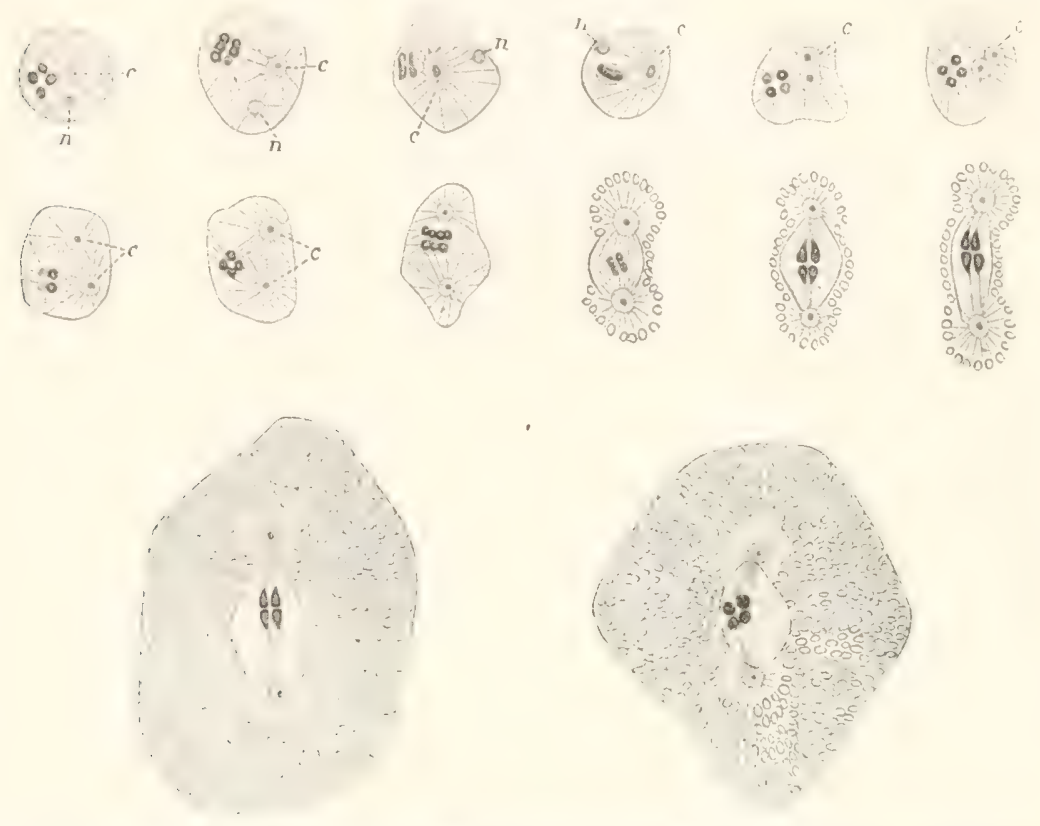

Fig. 150. Entwicklung der Samenzellen von Asc. megaloc. univalens nach BraUtr.

vornehmlich durch den Strahlenkranz, mit welchem sie sich umgeben, für uns unterscheidbar. während der Ruhe aber ist von einem Strahlenkranz nichts wahrzmehmen.

Während nach dem bis jetzt gesammelten Beobachtungsmaterial die Centrosomen in den meisten Fällen im Protoplasma der Zelle eingeschlossen sind, liegen auch einige wenige Beobachtungen vor, die betonen, daß sie dem Kern als Inhalt angehören können.

So beschreibt Brauer (VIII 1893) ein Centrosom in dem noch b]äschenförmigen Kern von Ascaris megalocephala univalens (Fig. 150); anch läßt er es sich noch im Kermram teilen und an die Pole einer gleichfalls nukleären Spindel treten. Hierzu kommen Beobachtungen von RÜCKERT an den Eiern von Cyclops, yon van DER STRICHT an den Eiern von Thysanozoon, von Schuudinn, der bei den Schwärmsporen ron Acanthocrstis das Centrosom innerhalb des sich zur Teilung anschickenden Kerns fand. Auch an das Nucleocentrosoma im Kern von Euglena (Ḱeuten VIII 1895 ) ist $\mathrm{zu}$ erinnern, das in mancher Hinsicht ja die Rolle eines Centrosoms zul vertreten scheint. 
RÜCKERT (VIII 1894, S. 302) fabt seine Ergebnisse in die Sätze zusammen: ..Das Keimblïschen ron Cyclops wandelt sich als solches unter

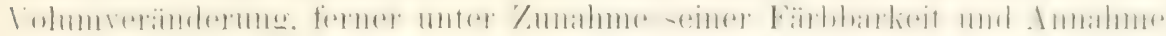
ciner ovoiden Gestalt zur ersten Richtungsspindel um. An den Polen dieser, aus dem lieimbläschen stammenden ovoiden ligur, aber noch innerhalb) derselben gelegen. befinden sich die Centrosomen. Da wo ich sie uachweisen komnte, erscheinen sie als kleine Kugeln innerhalb des liernes. sie liegen hier anz peripher und unterscheiden sich durch ilıre intensive Fairbung ron ihrer Umgebung.

Ein letzter noch wenig aufgeklärter Punkt ist das Schicksal der Xnkleolen. ihr Verschwinden bei Begimn der Kernteilung und ihr Wiederanftreten in den Tochterkernen. Was fïr Substanzumlagerungen haben

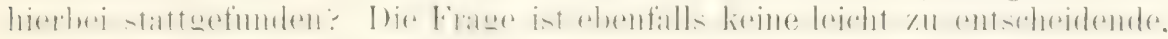
nun so mehr. als in manchen Fiallen die Nukleolen aus zwei verschierlenen Proteinsul)stanzen zusammengesetzt sind. (Siehe S. 41).

Nach der herrschenden Lehre werden während der Karyokinese die Ninkleolen aufgelöst. um später in den 'lochterkernen wieder neu gebildet zu werden. Was bei der Auflösung aus der Substanz wird und wie die Veubildung ror sich geht, konnte mit unsern üblichen Hilfsmitteln nicht genauer festgestellt werken. Die Kontinuität zwischen alten und neuen Nukleolen war jedenfalls unterbrochen. Der vollständige Schwund der Nukleolen geht auf rerschiedenen Phasen der T'eilung, bald rascher, bald langsamer yor sich. entwerler noch im Kerme sellst. ehe seine Membran aufgelöst ist. oder sie werlen dabei in das Protoplasma aufgenommen, wo sie schon zu manchen Mif,dentungen Anlab gegeben haben und in Pflanzenzellen zum Beispiel fïr Centrosomen sehalten worden sind. Der Auflösung geht häulg ein Lertall deo Nu-

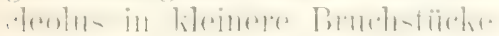
voraus: ich erwähne nur die [mbildung des Keimbläschens zur ersten Richtungsspindel. In diesem Falle bleiben Bruchstiicke des Tucleolus (Fig. 15) oft lïngere \%eit nehen der Richtungsspindel im Protoplasma sichthar. Es scheint mir eine dankenswerte Aufgabe, durch Ausbildung spezitischer Färbemethorlen für die Nukleolarsubstan\% genauer zu untersuchen, ol, sich die kleinsten Buruchstïcke der \%erfitlenden Nukleolen nicht noch weiter sichtbar machen und anf ihren Wegen verfolgen lassen. So scheint mir zur Zeit die Mönlichkeit nicht von der Hand zu weisen zu sein. dab kleinste Teile (ler Xukleolarsubstanz zum T'eil in das Protoplasma eintreten. zum andern Teil zum Aufhau der liernfigur mit verwandt werden und den (irmudstoff abgeben, aus dem sich dann wieder in den 'Tochterliernen junge Nukleolen aufbanen. Folgende Beobachtungen, die einer genaneren Durcharbeitung noch bediurfen. kiönnten hierbei als Richtschmur dienen. 
Bei den Samenmutterzellen von Ascaris, die mit schwachem FLrm-

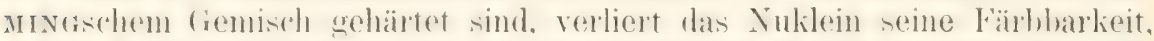
wïlrent die Nukleolen in Sïurefuchsin dunkelrot tingiert werden (Fig. 15:) $A$ und $B)$. Hier sah ich num, dab in den Vorbereitungsstadien der Nucloolus in mehrere stïclie zerfällt, dab von diesen sich klemste Kügelchen ahlö-sen, dab. - volche hochrot gefärhte lï̈gelehen sich auch auf den hernfïlden aufgelagert finden. Wenn in weiteren Verlauf die Chromosoment fertig angelegt sind und der Nucleolus ganz verschwumben ist (Fig. 15):3 ("). damn ist in jerles hermsegment ein dunkehot grefäbtes Korn eingeschlossen. das nach seinem Verhalten gegen Farbstoffe wie Substanz des Nucleolus aussieht.

Fïr die Anfuahme von Nukleolarsubstanz in die ('hromosomen, dann aher wahrscheinlich in einer viel feineren Verteilung. sprechen noch einige interessante Farbstoffreaktionen. Wie Wend hei P'flanzen gefunden hat, färbt sich das ('hromatingerïst der lierne ans dem Embryosack mehrever Liliaceen nach Behandlung mit Fuchsin-Jodgriün blaugrïn, die Nukleolen

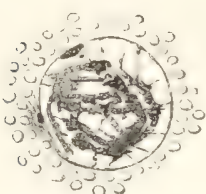

Fin. 1,i2.

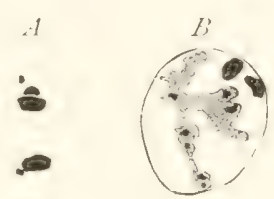

Fig. 153.

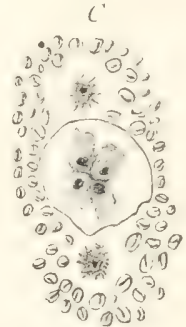

Fiv. 1., Kern einer Samenmutterzelle von Ascaris megalocephala bivalens. Die Nukleinsubstanz ist in Fäden angeordnet, die in zwei Gruppen auseinander weichen. Erstes Auftreten der Centrosomen. Rückbildung des Nucleolus. HerTwig 'Taf. III, Fig. 7.

Fig. 153. A Nukleolen mit sich ablösenden Köxnchen. Taf. III, Fig. $t$.

$B$ Kern einer Samenmutterzelle von Ascaris megalocephala bivalens aus dem Ende der Wachstumszone. Aus schwachem Fuenmxischem Chromosmiumgemisch. Färbung mit Säurefuchsin. Hertwig Taf. III, Fig. $\overline{5}$.

$C$ Kem einer Samenmutterzelle von Ascaris megalocephala bivalens aus der Mitte der Teilzone. Schwaches Fufmuxgsches Gemisch von Chromosmimmsïure. Färbung mit Säurefuchsin. Hertwig Taf. III, Fig. 9.

rot. Auf den Teilstatien dagegen, in denen sie Nukleolen aufgelöst sind. färben sich die Chromosomen violett. Wenn später damn in den Tochterkernen die Nukleolen wieler ershemen, nehmen die kernfïrlen ahermals

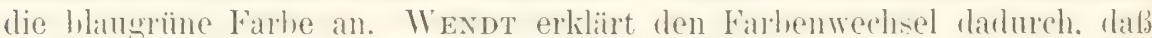
während der 'Teilung die Chromosomen Nukleolarsubstanz in sich aufnehmen und nach der Teilung zur Bildumg der Nukleolen in den Tochterkernen wierler abgeben.

Bei tierischen Zellen haben FLemung (VIII 1891) und auch HerM.Axy einen entsprechenden, mit der Auflösung mud dem Wiederershemen der Nukleolen parallel gehenden Harbenwechsel der Chromosomen bei Dopleltinktionen mit Sifranin-Ï̈matoxylin, Safranin-Nanvein, SafraninGentiana etc. wahrgenommen. „Es scheint mir bemerkenswert"“, erklärt Fleming bei dieser Gelegenheit, „dab in denjenigen Stadien. wo noch Nukleolen vorhanden oder eben erst verschwunden sind oder eben wieder aufteten, die Neigung der chromatisehen Figur zur Blaufirbung vorliegt. während die Formen, in welchen sie völlig dekonstituiert sind, sich rein safranophil verhalten, wie es ja die Nukleolen selbst sind." 
Ein für unsere Frage wichtiges Untersuchungsobjekt liefern Ei- und

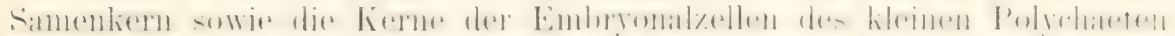

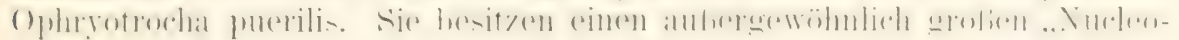
lus", der während der Prophasen der 'Teilung höehst eigentümliche Ver'inderungen durchmacht, deren genaueres Studium wohl noch weitere Aufschlïsse verheibt (KonschetT VIII 1895), p. 5)(i2-57\%).

Fir. $15 \mathrm{t}$

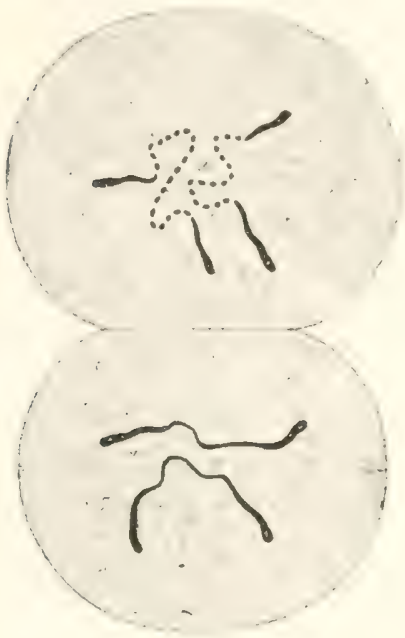

Fii.. 1.ili.

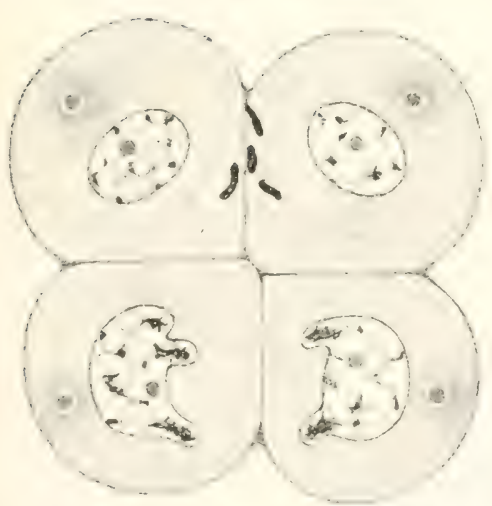

Fiiu. $15 \overline{5}$

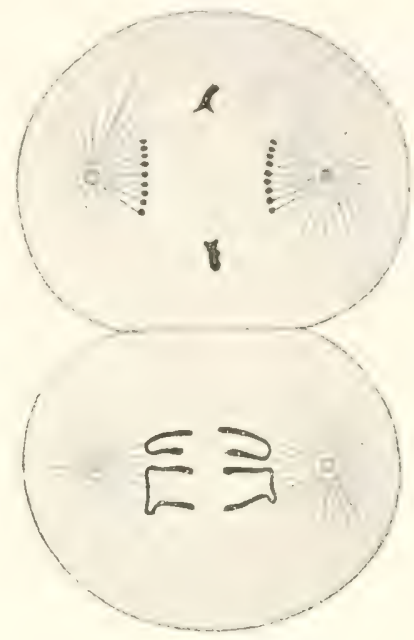

Fig. $1, \%$.

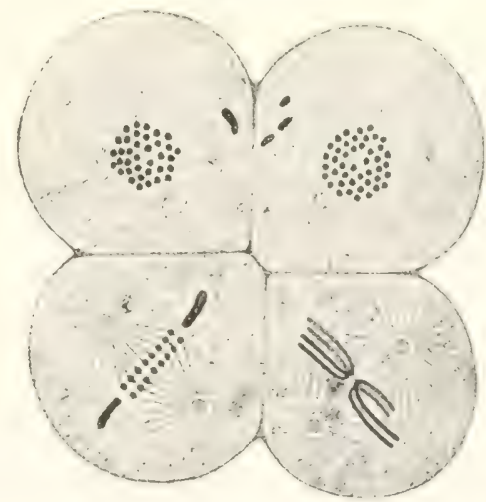

lie. 1.i) 1.\%. Vier Stadien aus ter Furchung von Ascaris megalocephala univalens, 1 m die Chromatindiminution zı erläutern. Nach Bover.

Eine interessunte Eigentimlinhleit der harroline-e. welehe sioh hisher

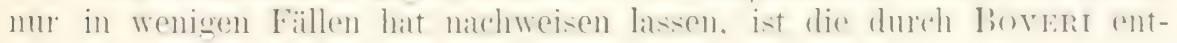
deckite

Clromatindiminution.

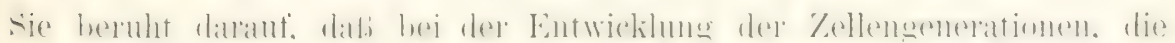

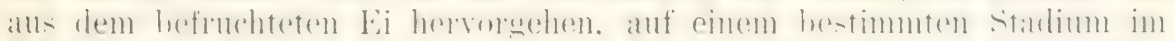

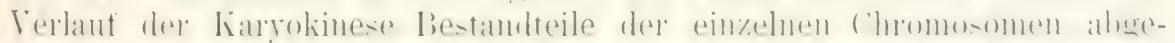

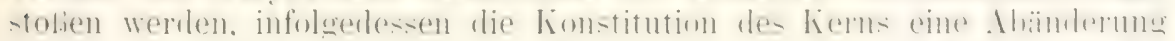
erfährt. Nachdem der Vorgang, den man als Chromatindiminution be-

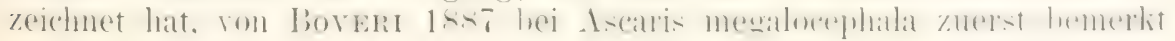


worden ist, hat er nicht nur an demselben Objekt vielfach Bestatigung gefunden (ZOJA, HerLa. ZUR STRASSEN), sondern ist auch in etwas modifizierter Wreise bei andern Nematorlen. wie Ascaris humbricoides. durch O. MeYer und K. Bonnevie, sowie in der Oogenese von Dytiscus durch Giardina nachgewiesen worden. Bei Ascaris megaloceph. mivalens ist der Hergang nach boveri folgender:

Wenn die aus der 'Teilung des befruchteten Eies entstandenen zwei Zellen sich zu einer neuen 'T'eilung anschicken, bilden sich in jerler wieder zwei Chromosomen, bieten num aber in jeder Zelle ein rerschiedenes Aussehen dar; in der einen, welche in Fig. 154 nach unten liegt, sind sie wie bei der ersten Teilung beschaffen, in der anderen, nach oben gelegenen. ist der dünnere mittlere Abschnitt jedes Chromosoms in eine einfache Reihe von Kö̈rnern zerfallen. während nur die verdickten Enden wie frïher homogen geblieben sind. Wir bezeichnen den ersten Zustand als Modus A,

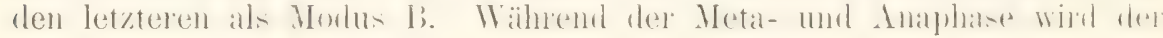

ling. 158.

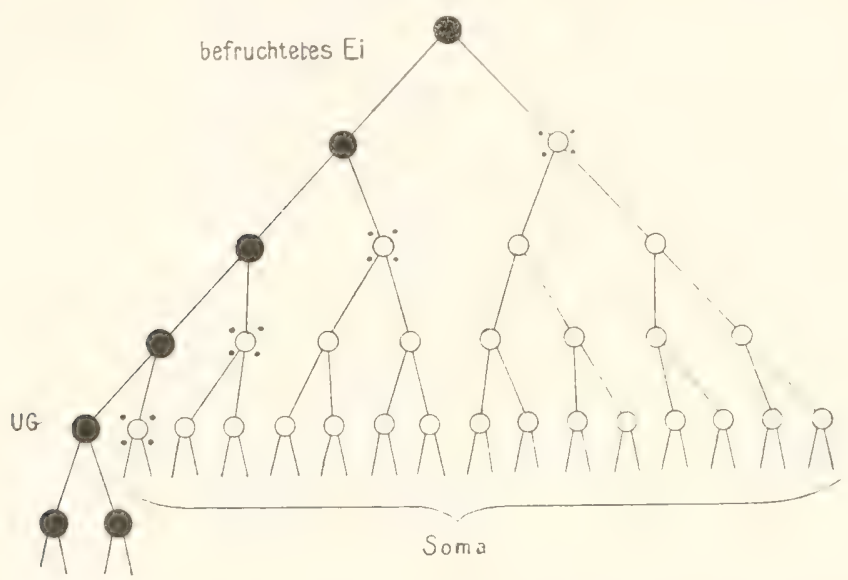

Nach Boveri.

Hig. 158. Furchungsschema von Ascaris megalocephala.

Fig. 159-161. Schemata der Chromatindiminution bei Ascaris lumbricoides. Nach BoverI.

Fig. 159. Urchromosomell.

Fig. 160. Differenziermo derselben in den persistierenden mittleren Teil und die dem Untergang bestimmten Enden.

Fig. 161. Die diminuierten Chromosomen in die Spindel eintretend, die abgestolenen Enden davon ausgeschlossen. [iig. 159.

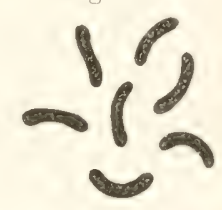

Iije. lin.

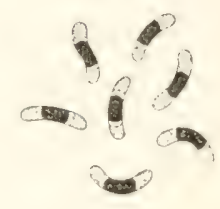

Fig. 161 .

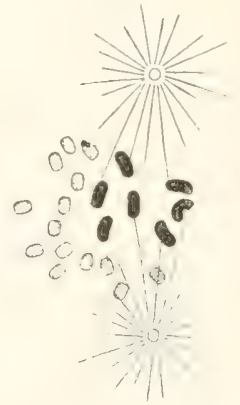

Gegensatz zwischen Modus A und B ein immer größerer. In der unteren Zelle sualten sich die beiden Kernschleifen (Fig. 155) der Länge nach in der anf Seite 175 beschriebenen Weise; in der oberen Zelle bildet sich aus den Teilstiicken, in welche das grobe Chromosom zerfallen ist, eine

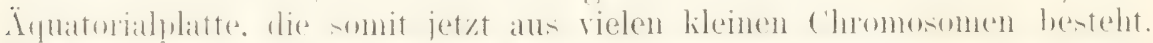

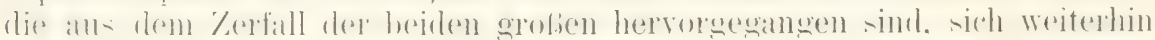

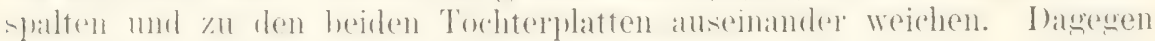
nehmen die nicht in kleinere Stïcke zerlegten kolbigen Enden der ursprünglichen Mutterchromosomen an der Karyokinese nicht mehr teil, sie liegen von aufen der Spindel in der Mitte unregelmäßig an und bleiben, während sich der blïschenförmige Ruhezustand der Tochterkerne ausbildet, nahe 
der 'Teilungsebene in Dotter liegen (Fig. 15)(i) und werden allmählich aufgelöst.

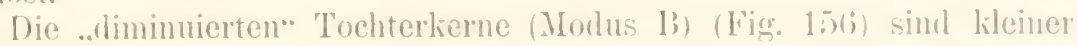
und chromatinärmer als die bläsehenförnigen Kerne, die aus dem 'Teilungsmodus A entstehen, anch fehlen ihmen die frïher (p. 17s) beschriehenen lappigen Fortsätze: ferner lassen sie hei jerler nenen Karyokinese nur wieder zahlreiche kleine Chromosomen aus sich hervorgehen (Fig. 1ñt). Die nach Modus A geteilten zwei Zellen dagegen sehlagen auf der nichsten Teilung wieler eine cntgegengesetzte Entwicklungsrichtung ein: währent die eine Zelle zwei grobe Schleifen bildet. macht die andere den l'rozel.; (ler Chromatindiminution durch und teilt sich nach Modus l) (Fig. 15\%). Derselbe Vorgang wiederholt sich noch zweimal. bei der Teilung der s in 16) und der 16 in 32 Zellen; spielt sich also im gamzen viermal ab. Bover lat dies in einem furchungschema (Fig. 15s) dargestellt, ,in welchem der schwarze Kreis eine Zelle mit ursprünglichem Kern, der weibe eine solche mit diminuiertem Kern, der von vier schwarzen Punkten umgebene weibe Lreis eine Zelle hedentet, in der die Diminution stattfincte. Zuletzt bleibt eine Zelle mit ursprünglichem Kern ïlorig, das ist die Croeschlechtszelle ( $\mathrm{U}(\mathrm{r})$ ". Ton ihr leiten sich durch Teilungen mach dem Modus A die Ei- und Samenzelien des Embryos ab): alle iibrigen 7ellen, welche die ..Chromatindiminution" (Modus B) erfahren haben, bauen (lie ülrigen (iewebe des Kïrpers auf (Somazellen nach WEIsuduxr).

Bei Ascaris lumbricoides ist der Verlauf ein etwas abweichender, da lier die Chromosomen von vornherein sehr zahlzeich (zirka ts) und entsprechend klein sind. Ein Zerfall eines größeren in kleinere Chromosomen findet daher in diesem Fall nicht statt. Die Diminution kommt in der Weise zustande, dab jedes Chromosom sich in einen mittleren 'Teil und zwei Endabschnitte sondert, wie das Schema (Fig. 160) erläutert, in welchem ron den th Elementen nur 7 auBerordentlich stark vergröfert dargestellt sind. Die Endstäcke werden während der Diminution abgestoben und

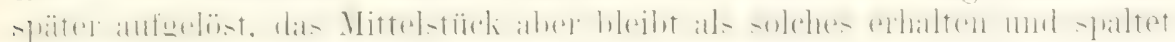
sich in der Metaphase in die zwei Tochterchromosomen. Im Unterschied zu Ascaris megalocephala ist somit bei Ascaris lumbricoides die Zahl der Chromosomen in den diminnierten liemen genan die gleiche wie in den nicht diminuierten. Der Unterschied findet wohl am einfachsten in der Annahme seine Erklärung, dab die so auffällig großen und an Zahl geringen Chromosomen ron Asearis megal. zusammengesetzte Elemente sind, die einer Vielheit klemerer Chromosomen der übrigen Nematoden und der Somazellen des Pferdespulwurms entsprechen. Häcker hat rorgeschlagen. solche zusammengesetzte Chromosomen als ..plurivalente. zu bezeichnen.

Noch eigentümlicher verläuft bei Dytiscus der Diminutionsroreang. Man vergleiche die Originalabhandlung von Gidroma oder das Referat. ron BOVERI ( VIII 1904 p. $3(1-34)$.

\section{Allgemeine Probleme der Kernsegmentierung.}

\section{Das proportionale Kernwachstum.}

Wenn man bei verschiedenen Tier- und P'Hanzenarten die Erscheinungen der liaryokinese durch verschiedene Zellgenerationen hindurch verfolgt, so läßt sich leicht feststellen, dal, aus emen jerlen Mutterker'n am liegimn einer neuen Teilung genau so viele Mutterchromosomen wieder gehililet werden, als die Zahl der Tochterchromosomen hetrïgt. ans welehen er hei einer vorausgegangenen 'Teilung entstanden war. Da num die Mutter- 


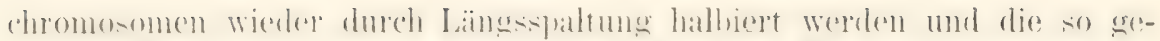

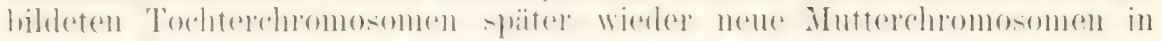

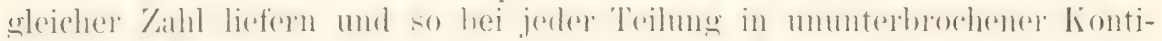
nuität, da terner' trotz aller dieser' wiederholten 'Teilmngen die chromatische Substanz an Masse ganz offenbar nicht abgenommen hat und auf spaiteren Teilstadien nicht geringer ist als auf früheren, so folgt daraus, daßs die

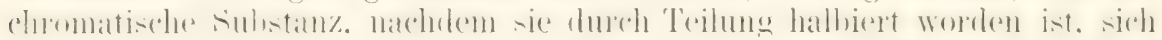
im bläschenförmigen Zustand der Kerne wieder durch Wachstum auf das Doppelte bis zur nächsten 'Teilung ergänzt und so fort.

Boveri hat dies Verhalten als das „Gesetz des proportionalen Lernwachstums" bezeichnet.

Aus vergleichenden Untersuchungen ergibt sich ferner als eine Ergänzung hierzu

\section{Das Zahlengesetz der Chromosomen.}

Man mag bei ein und derselben Tierart die Kernteilungsfiguren in diesem oder jenem fiewebe. in der Jugend oder im Mter untersuchen, stets wird man in der Metaphase genau dieselhe Anzahl ron Chromosomen finden. Eine Ausnahme machen blof hestimme Entwiolimgstarlien der Fi- und samenzellen. bei denen die Chomosomenzahl genan die Hälfte der normalen Zahl hetrïgt. wortiber in einem späteren kapitel noch gehandelt werden wird, und pathologische Mitosen mit sehr schwankenden mregehmäbigen Zahlen. Dagegen unterschejelen sich die einzehen 'Tier- und PHanzenirten voneinander' dadurch, daß die Anzahl der Chromosomen, die man am besten auf dem Stadium des Muttersterns bestimmen liann, eine selur ungleiche ist mol dalj sie in sehr weiten Grenzen von 2 bis 100 und mehr schwankt. So findet man als die niedrigste Zahl bei Ascaris megalocephala mivalens zwei Chromosomen, die höchste hisher ermittelte hei der Crustacee Artemia, bei welcher Brater 16is Kernsegmente gezählt hat: in anderen Fällen beträgt die Anzahl 4, 8, 12, 14, 16, 18, 20, 24. 36, z. B. bei zwei der bekanntesten Untersuchungsohjekte, bei Salamandra mac. und bei Lilium 24.

Die bis jetzt durch zahlreiche Forscher für verschierlene Objekte ermittelten Zahlen hat WILsox (III 19m) in einer Tahelle zusammengestellt, die ich hier folgen lasse:

In hesonders fraphanter Weise tritt das Zahlengesetz der Chromosomen unter ahmormen Verhältnis-en hervor. worther wir sehr interessante Beispicle den Untersuchungen von Boveri, Herla, ZoJa, zUR STrassen etc. verdanken. ()hwohl dieselben mit den Reifung- und Befruchtung-yrozessen der fieschlechtspurodulte. welche uns spätel erst heschäftigen werlen, zusammenhängen, so sei doch an dieser Stelle schon näher auf sie eingegangen.

Wie schon ohen bemerkt wurde. besitzen die Kerne der Geschlechtszellen nur die Inälfte der Zahl der Chromosomen. welche fiur die hetreffende (oramismenart typusch ist. Wemn num. Was hei manchen Echinolermenarten gelingt. ein kernloses Fifragment mit einem einzigen samenfarlen befruchtet wird, so lassen sich Laryen züchten, deren Zellkerne konstant nur die halbe Chromosomenzahl besitzen. (Boveri, Morgan.)

Namentlich viele abnorme Variationen, die durch die verschiedensten Ursachen hervorgerufen werden könmen, sind bei Ascaris megalocephala festgestellt worden. Dieser Eingeweidewurm tritt in zwei Varietäten, Ascaris mesalocephata hivalens und univalens, auf, deren eine zwei Chromosomen, die andere nur ein einziges in den Kernen der Geschlechtszellen besitzt. Mehrfach sind zwishen heiden hastardhefuchtmgen ron IIERLA mud Zorda heobachtet worlen. und dabei komnte festgestellt werlen. diab 


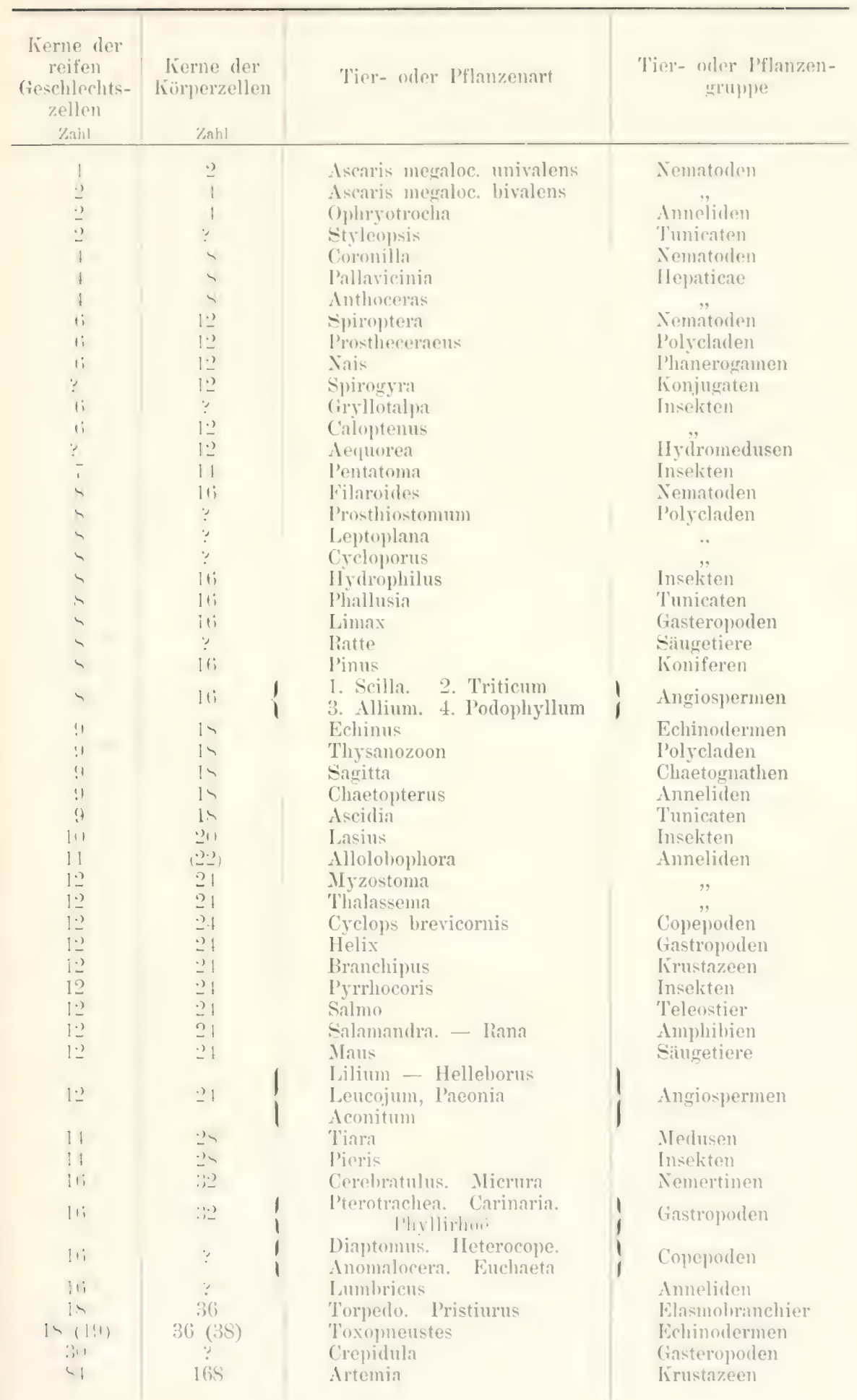


die Embryonalzellen der Bastardlarven bei der Karyokinese anstatt der für Ascaris megalocephala bivalens. resp. univalens typischen Zahl von vier, resp. zwei Chromosomen die anormale Dreizahl darboten (Fig. 162).

Die gleiche Zahlenveränderung kann aber anch die Folge einer anderen Störung im Entwicklungsverlauf sein. Es kamn. wie von Boven I und IIERLA ermittelt worden ist, die Ausbihdung einer Polzelle unterbleiben und

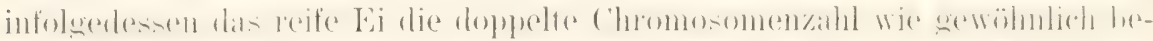

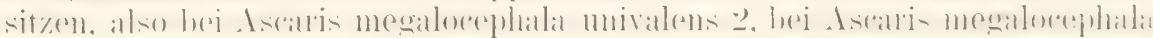
bivalens 4. Wen jetzt die normale Befruchtung geschieht, so erhält das befruchtete Ei im ersten Fall drei. im zweiten sechs Chromosomen, ein Verhältnis, das in der Folgezeit in allen Embryonalzellen wiederkehrt.

Fig. 162. Zweigeteiltes Ei voll Ascaris megaloceph. bivalens, das durch einen Samenkörper ron Asc. meg. univalens befruchtet worden ist und daher Kerme mit 3 Chromosomen enthiilt. Aus Herda. (Taf. XYI1, Fig. 14.)

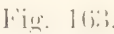

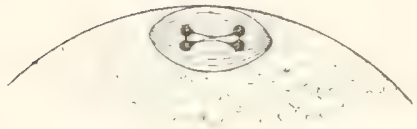

Fin. $\quad 11 ;$,

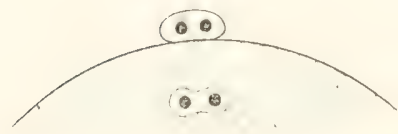

Fï. $16 i$.

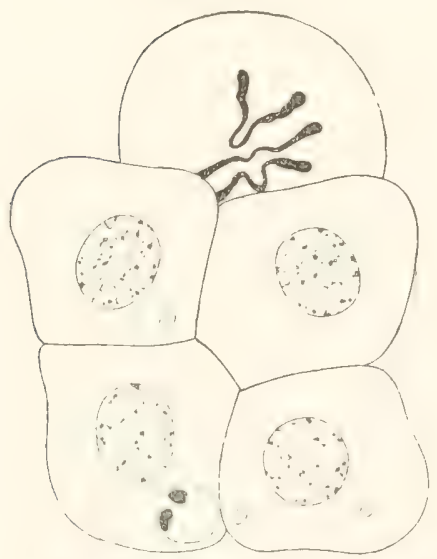

liin. liit.

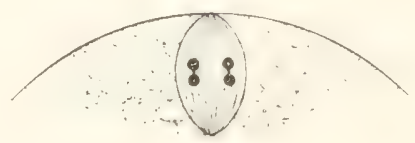

Hig. 16i;
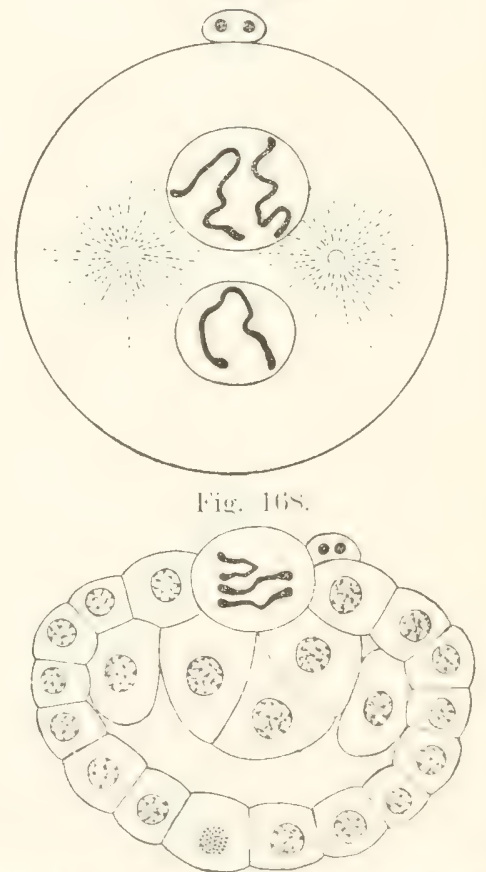

Fiv. lli,; liis. Abnormale Eireifung von Ascaris megalocephala univalens, in deren Folge nur eine Polzelle gebildet wird (Fig. 163-165) und der Fikern (Fig. 166) anstatt eines Chromosomen deren zwei enthält. Infolge der Befruchtung entstehen Kierne mit drei Chromosomen (Fig. 166). Das abnorme Zahlenverhältnis macht sich anch bei der weiteren Entwicklung an den Kernen der Embryonen bemerkbar (Fig. 167 mind 168). 
Fig. 16:3-16s giht uns ein Beispiel nach bover für Ascaris moualocephala univalens, Fig. 16!) ein beispiel nach Hersa für bivalens. In letzterem Falle kamn ührigens auch die Sechszahl anf einem anderen Wege. nämlich dureh befruchtung eines normalen Eies dureh \%wei Samenkïrper. verursacht werden.

Embryonalzellen mit einer noch höheren Chromosomenzahl kömen entlich bei Ascaris anch noch dardureh zustande lommen. dab durch alonorme Lingrifte zwei oder mehr Eier zur Verschmelzung zu einem Liesenei uebracht werden. das auber den mehrfachen Eiliernen infolge der Befruchtung zwei oder mehr Samenkerne einschliebt. So teilt zUR STRASSEN Befunde von Dopueleiern der Ascaris megalocephala hivalens mit. die von zwei Samenelementen befruchtet worden sind und in deren liernen bei (ler Mitose acht Chromosomen gezihlt werden lionnten (Fig. 17()).

lïic. 169. Ei von Ascaris megalocephala bivalens, das nur oinen Richtumeskiorper geliblet hat mud daher einen

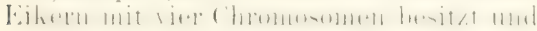

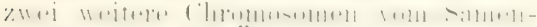

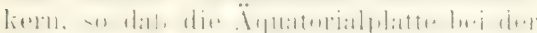
Kan Nach Herial. ('Taf. MYll, Fig. 54.)

Fin. 170. Äquatorialplatte eines doppelt befruchteten und aus Versclmelzum zweier Eier entstanclemen Doppeleies von Ascaris megaloceplnala bivalens mit acht (hromosomen, die aus Verschmelzung von zwoi Li- unl zwei Samen-

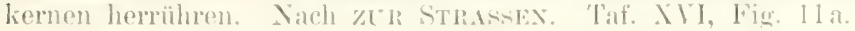

Alle hier angeführten Fälle von Abänderungen in der normalen Chromosomenzahl sind für die Yahlenkonstanz der Chromosomen insofern besonders wichtio. weil alle Tochterkerne, die in Laufe der Embryonalentwicklung aus einer Intterzelle mit veründerter Chromosomenzalil hervorgehen, den veränderten Charakter nicht wieder verlieren. Die \%elle besitzt oftenbar nicht das Vermögen, die eingetretene Störung in der Chromatinverteilung nachträglich wieder zu regulieren.

Zur Erklärung dieser gesetzmäbigen Erscheinungen hat Boveri

\section{3. die Theorie der Chromosomenindividualität}

aufgestellt. Er denkt sich. dab jedes Chromosom eine individuelle Stoffeinheit ist. die sich von anderen in Kern getrennt erhält, die selbsttätio wächst und sich durch Teilung vermehrt und in ihren Teilproduliten von Zelle auf Zelle übertragen wird. so dab) wir in den Chromosomen des Gewehszellen die individuellen Nachkommen der im Ei enthaltenen. ersten Ahnengeneration vol uns haben. An einer Stelle sciner Schrift nennt sie Boveri ..elementarste Organismen, die in den Kellen ihre selhständige Existenz führen". Auf diese Weise slaubt er es verständlich machen zu können. dab aus dem ruhenden kiern genau so viele Chromosomen herrorgehen, als bei der letzten Zellteilung in iln eingetreten sind, und dab für jede Organismenart die Zahl der Chromosomen eme linonstante ist. weil sie gewissermalien organische Individuen sind.

Der Auffassung ron Boveri. Welche das Zahlengesetz der Chromosomen gut erklären würde, stehen indessen einige Schwierigkeiten entgewen. Eine solche bieten die Verhïlnisse im ruhenden liern. insofern sich in ihm keine elnomatischen Individuen lange Zeit mehr nachweisen lassen: sie scheinen sich viehmehr in einzelne hörner aufoelöst umel auf dem achro- 
matischen (ieriist verteilt zu haben. Der Schwierigkeit sucht BoverI durch die Ammahme zu begegnen, dab bei der Rekonstruktion der Tochterkerne die chromatischen Individuen .aktiv werden"; sie senden feine Fortsaitze, gleichsam Pseudoporlien aus, die sich auf Kosten des Elementes vergröbern und verïsteln, bis das ganze Gebilde in dieses Gerüstwerk aufgelöst ist und sich zugleich so mit den in der nämlichen Weise umgewandelten ibrigen rerfilzt hat, dab wir in dem dadurch entstandenen Kernretikulum die einzehen konstituierenden Elemente nicht mehr auseinanderhalten können. Jeder Kern ist während der Ruhe gewissermaßen ans Teritorien zu-ammengesetzt, deren jeles ans einem einzehnen ('hromosom entstanden ist und sich später wieder in ein solches zusammenzieht."

Zugunsten seiner Annahme verwertet Boveri Beobachtungen an den Kernen von Salamandra maculata und Ascaris megalocephala.

Fig. 171.

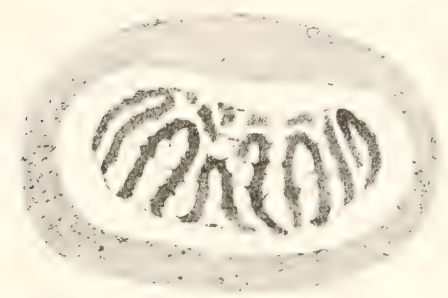

Fï. 1 -3:3.
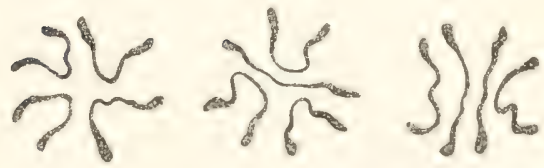

Fig. 171 und 172. Epidermiszellen der Lasve von Salamandra maculata nach C.RABL.

Fig. 171. Tochterchromosomen, im Begriff, den ruhenden Kern zu bilden.

Fig. 172. Iutterchromosomen, aus dem ruhenden Kerngerïst entstanden.

Fig. 173-179. Kernteilungsfiguren von Ascaris megalocephala bivalens nach BoverI.

Fig. 173-175. Äquatorialplatten aus befruchteten Eiern mit Variationen der Chromosomenstellung.

Fig. 176. Kiern einer $1 / 2$-Blastomere im (ieriiststadium, mit den durch die Chromosomenenden bedingten Aussackungen.

Fig. $17 \div-179$. Desgleichen in Vorbereitung zur Teilung.
Fig. 172.

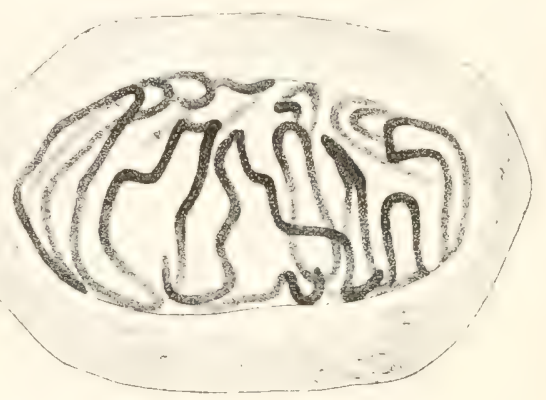

Fïg. liti.

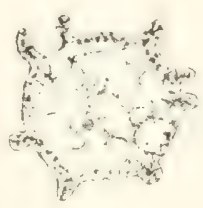

Fig. $17-$.

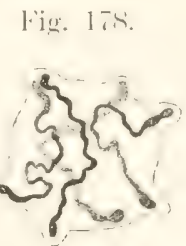

Fig. 17!?.

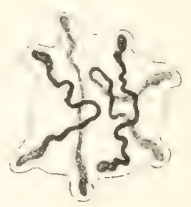

In Epidermiszellen von Salamanderlarven (Fig. 171, 172) hat RABL heohachter. dal.i im Drasterstalium (Fig. 171) die einzelnen Tochterchromosomen mit ihrem .,Schleifenwinkel" nach dem Pol der Spindel oder der „Polseite des Kerns", wie sich PABL ausdrückt, angeordnet sind. Wenn nun nach einiger Zeit der Ruhe der Tochterkern wieder zu einer neuen Mitose äbergeht, komnte er feststellen, daß in ihm in der Prophase die jutzt sich anlegenten Mutterohomosomen in derselben Weise zur Polseite des lerns orientiert sind. Fr hïlt es daher für undenkbar. daf im ruhenden Lirn keine simm dieser Anordmung mehr vorhamden sein sollte und ghaubt, 
daß sie nur durch eine Verzweigung der Chromosomen (Fig. 171) rerileckt

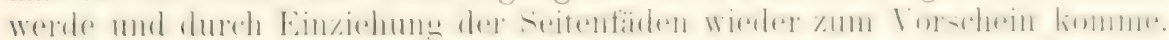

In ähnlicher Weise verwertet Bover Befunde bei Ascaris megralocephala. Wem aus den Tochterchomosomen, deren Zahl vier heträgt (Fig. 173-175), sich wieder ein bläschenförmiger liern bildet, so zeigt

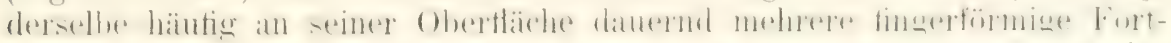
sätze, die von den kolbig verdickten, nach aulien gerichteten Enden der

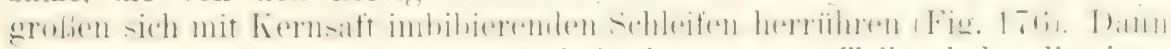
nehmen, wie Boveri vermutet, bei einer nenen 'eilperiorle die jetzt wieder auftretenden Chromosomen. bei ihrer Rekonstruktion aus dem chromatischen Gerüst (Fig. 177 und 179), trotzdem es vorher keine Spur

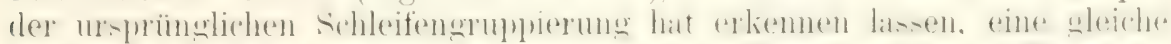

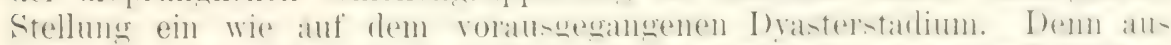

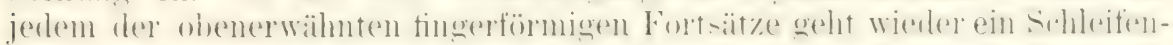
ende hervor.

Ein zwingender Beweis scheint mir aber durch alle diese interessanten

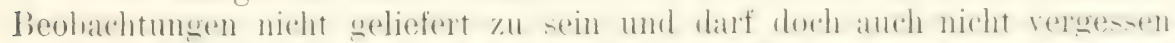

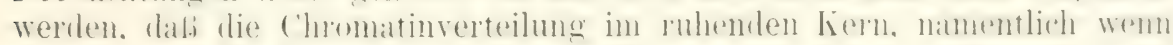
eine längere Zeit bis zur näichsten Teilung verstreicht. wie in den Eiund simmenmutterzellen sehr verschierlenartige. anfeinander folgemble Bilder

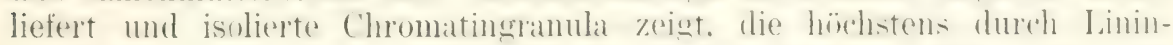
brïcken im Gerüst in einem Zusammenhang stehen. Daher sind anch

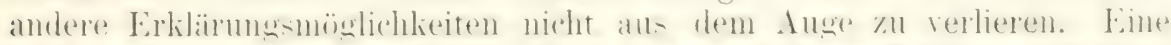

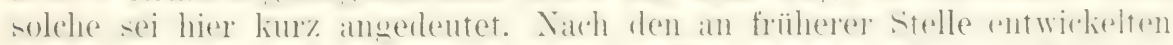

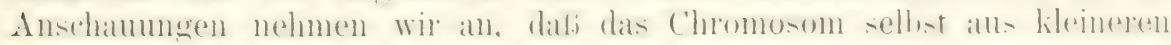
hiologischen Einheiten hesteht, die das Vermögen des Warhstums mul der Teilung besitzen. So wird ron manchen Forschern auf Grund von Be-

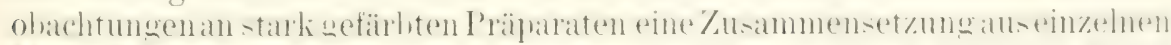

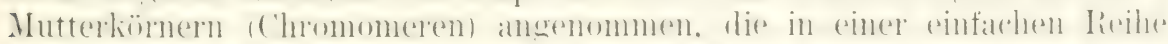

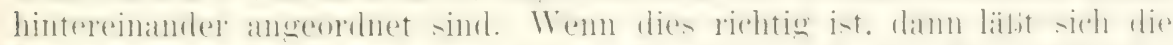

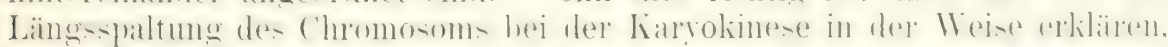

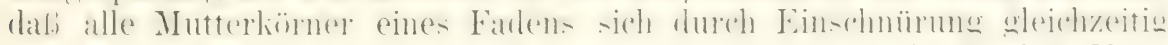
in derselben Richtung teilen und auseinander weichen. Ob in den Chro-

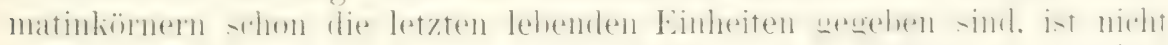
wahrscheinlich. viehmehr werlen sie sellst erst eine Vielheit von solehen

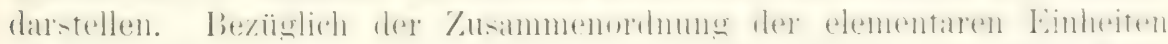
zu einem Chromosom scheinen mir nun zwei Vorstellungen möglich. Xach der emen. welche von Boveri. RABL u. a. vertreten wird. ist das Chromosom ein absolut fester taktischer Verband. in welchem eine summe von

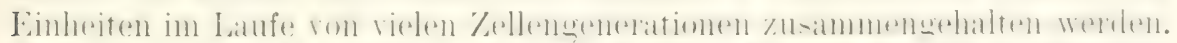

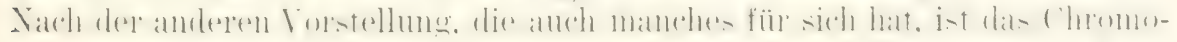
som ein taktischer Verband, der nur unter besonderen Umständen in Krraft

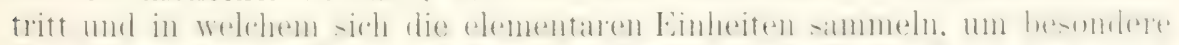

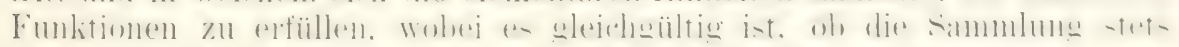
in derselben Ordnung wie bei anderen Gelegenheiten stattindet.

Der Unterschied zwischen beiden Auffassungen läbt sich noch anschaulicher machen, wenn wir die Chromosomen Kompagnien von Mann-

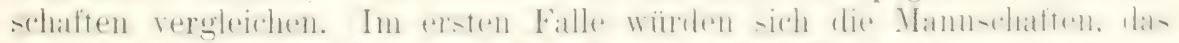

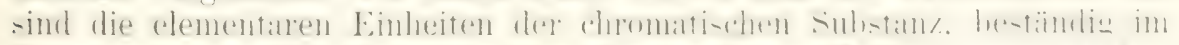

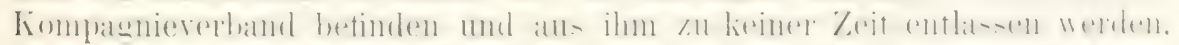

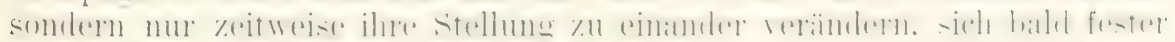
- zur Zeit der Laryohinese - aneinander schlieben, bald in verschiedener Weise eine lockere Aufstellung — im Ruhestadium des lierns - zu ein- 
ander nehmen. Im zweiten Falle dagegen wiurden die Mammschaften nur zur Erfüllung besonderer Zwecke zum Kompagnieverband zusammentreten mul sich in Reihe und (Ylied sammeln, nach erfüllter Aufgabe sich aber wieler zerstrenen. Daher ist auch die Möglichkeit gegeben, daß während der Auflösung die Elemente der verschiedenen Kompagnien sich mischen und

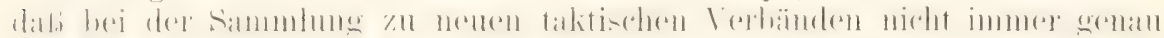

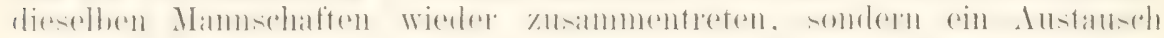
einzelner Elemente zwischen der einen und der anderen Kompagnie stattfindet. Man könnte der zweiten Vorstellung entgegenhalten, daf es schwer zn hegreifen sei, durch welche Kräfte die im Kern enthaltenen chromatischen Einheiten bei jeder Karyokinese immer und genau der gleichen Zahl etwa gleich starker Kompagnien zusammengeführt werden könnten. Doch läßt sich hierauf entgegnen, daß wir von den Kräften, durch welche die äuferst

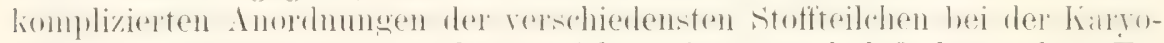
kinese geleitet werden, überhaupt nichts wissen, und daß der andere Erklärungsversuch ebensowenig beantworten kann, durch welche Kräfte die elementaren Einheiten aus der einen in die andere Anordnung übergefiihrt werden.

Mir scheinen daher zurzeit beide Auffassungen gleichberechtigt einander gegenüber zu stehen. die Auffassung, welche feste Strukturen in der Zelle zu Zeiten, wo sie nicht zu sehen sind, voraussetzt, und die andere Auffassung, welche mehr Berlenken trägt, Strukturen amzunehmen, wo sie nicht zu sehen sind.

Die eben behandelte Frage betrifft ïbrigens nicht nur die Chromo-

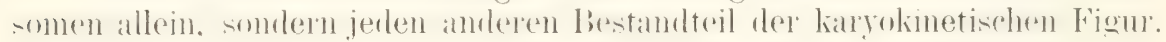
Auch die Spindelfasern werden, wie es scheint, stets in einer bestimmten Zahl angelegt, so daß man auch fragen kamn, ob sie schon im ruhenden Kiern vorgebildet sind odler nicht. Ton einigen Forschern ist sogar die Meinung ausgesprochen worden, dab die Strahlen der Astrophären permanente Zellorgane sind und in der ruhenden Zelle fortbestehen.

Die Erörterungen über die Individualitätstheorie der Chromosomen schliege ich ab mit einem Ausspruch you WILsON, der den von mir schon öfter's vertretenen Standpunkt wiedergibt: „In my opinion the chromosomes are not independent individuals, but only groups of numberless minute chromatin-granules, which alone have the value of individuals."

Die aulierordentlich komplizierten, in raschem Wechsel sich folgenden karyokinetischen Figuren sind in höchstem Grarle dazu angetan, die Aufmerksamkeit des Beobachters stets von neuem zu fesseln und zu der Frage anzuregen, durch welche Kräfte die Einzelheiten des wichtigen Zellphänomens wohl hervorgerufen sein könnten. Daher sind denn nicht wenige Ansichten schon, ïber die Mechanik der Kern- und Zellteilung"*

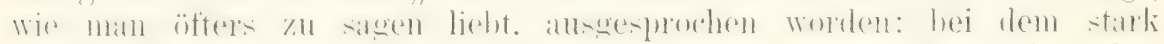
hypothetischen Charakter derselben werde ich auf Einzelheiten nicht näher eingehen, sondern $11 \mathrm{r}^{\circ}$

\section{4. die Bedeutung der ganzen Karyokinese}

im allgemeinen besprechen. Und da läft sich, olne Widerspruch zu erregen, wohl so viel sagen: Die Anordnung der rerschiedenen Substanzen

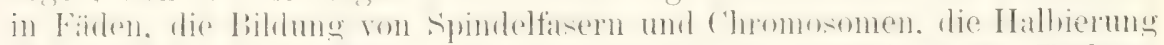

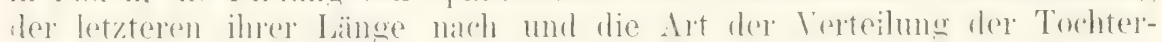
chromosomen auf die Tochterkerne hat offenbar keinen anderen Zweck, als die Kernsubstanz in zwei gleiche Hälften zu zerlegen und den Tochterzellen zuzuteilen. Der wichtigste Vorgang ist hierbei wohl die Spaltung 
der Xutterchromosomen. die auf dem Wachstum und der 'Teilung lileinster chromatischer Einheiten berulit.

Selur treftend hat Roux ( III 18sij) in einem lifeinen Aufsat\% .,ïber die bedeutmo der liemteilumestignen" dieselben als ..Mechanismen bezeichnet. welche es ermöglichen, den Kern nicht blol, seiner Masse. sondern auch der Masse und Beschaff'enheit seiner einzelnen (Yualitiiten marh zu teilen". Auch fïr Roux ist hierbei ..ter wesentliche liernteilungsvorang die Teilung der Mutterkörner: alle ïbrigen Vorginge loaben den Zweck. von den durch diese 'Teilung entstandenen Tochterkörnern desselben Mutterliernes immer je eines in das Zentrum der einen, das andere in das Zentrum der anderen 'lochterzelle sicher überzufïhren."

\section{Die Kernzerschnüung (direkte Kernvermehrung, Fragmentierung, Amitose, amitotische Teilung).}

Im (iegensatz zu der komplizierten, mit Segmentierung verbundenen Vorgïugen kann sich die Kernteilung bei einigen wenigen Zellarten in omer scheinbar sehr einfachen Weise vollziehen, die man als Fragmentiermog oder Kernzerschnürung hezeichnet. Hier kommt es nicht zur Entstehung von Spindelfasen. Chromosomen und Protoplasmastrahlungen. Vielmehr verläuft die 'Teilung melı' in del' von älteren Histologen schematisch dargestellten Weise. Die Kernzerschnimung ist am leichtesten an den I,ymphkörperchen zu beohachten, sowohl am lebenden, als an dem mit Reagenzien fixierten Objekt.

Taugliche Präparate lassen sich in verschierlener Weise herstellen: Entweder man sangt einen Tropfen Lymphe ans dem dorsalen Lymphsack des Frosches mit einer feinen Kapillaröhre ein, bringt denselben

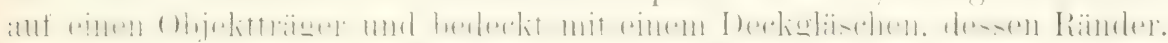
um die Verdunstung zu verhüten. mit Paraffin umsämmt werden. Oder man verfertist sich nach der Methorle ron ZIEGLER kleine Glaskammern. inclem man zwei lileingeschnittene Deckgläschen an ihren vier Ecken oder an zwei Seiten fest verbindet in der Weise, dab ein kapillarer Spaltraum zwischen ihnen frei bleibt. Man lent dann die Glaskammer für einen oder fiur mehrere Tage in den dorsalen Lrmphsack des Frosches, während welcher \%eit Lymphzellen in grofer Zahl zwischen die beiden Deckgläschen einwandern und V'eränderungen eingehen. Drittens hamn man nach der von Arxoud emptohlenen Methorle ein dümnes, durchsichtiges Scheibchen ron Holundermark in den Lymphsack bringen. Nach wenigen Stunden haben sich an seiner Oberflïche zahlreiche Leulocyten festgesetzt, die sich zur Untersuchung eignen. Xach längerer Zeit bilden sich um die Plättchen von Holundermark durch frerimmug düme Fibrinhäutchen, die sich abziehen lassen und mit den ansitzenden \%ellelementen chenfalls \%ur lieobachtung geeignet sind.

Bei emer Temperatur. Welche zwischen 160 und 1s:0 schwankte, hat RAvrier (VIII 1SSS) alle Erscheinungen (ler 'leilung einer Lymphzelle im

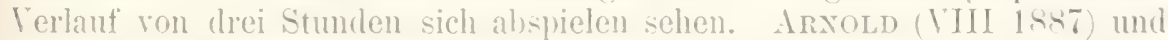
andere haben seine Angaben bestatjot und vielfach erweitert. I) er bläschenförnige Kern kann seine Form alitiv verändern und sich mit buckeln mul Höchern bedechen. An solchen liernen treten dann häutig Einschnürungen anf. die einen Zerfall in zwei. drei und mehr Stücke herbeiführen (Fig. 180. 4 und B). Die Kernstücke rücken auscinander und bleiben nicht selten noch längere Zeit durch feine Verbindungsfäiden im

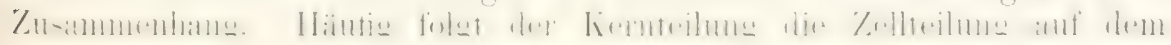


Fuß, wie die Figuren $180 A$ und $B$ veranschaulichen. Zwischen den

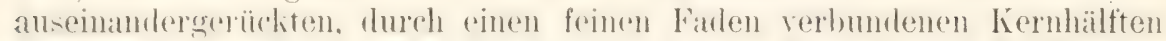
schnürt sich anch der Protoplasmakïrper ein. Seine beiden Hälften bewegen sich dureh Ausstrecken zahlreichor. amöboider Fortsätze nach ent-

A

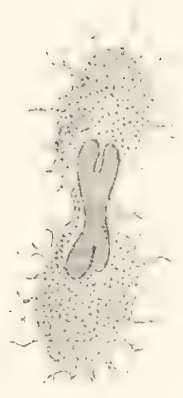

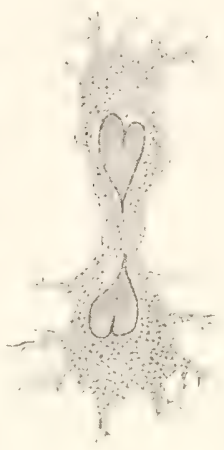

$B$

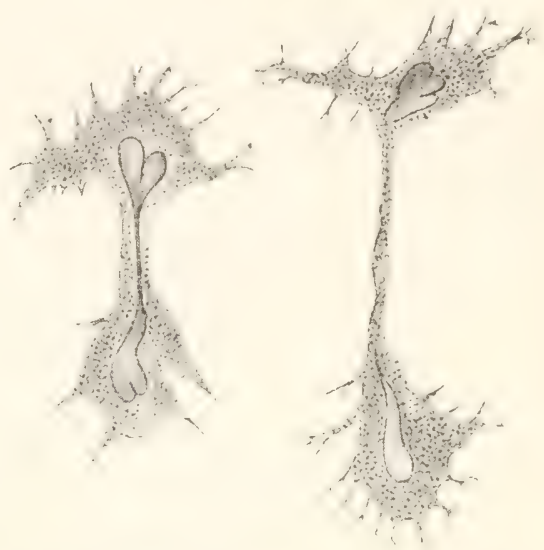

Fig. 14!. 1 Wanderzelle aus einem Holunderplättchen, welches 10 Tage im Lymphsack eines Frosches gelegen hatte. Zu Infang der lievhachtung war der Kern in seiner Mitte etwas eingeschnürt, an den Enden eingefurcht; schon nach 5 Minuten hatte sich die Teilung des Kerns vollzogen. Nach ARxold Taf. XII, Fig. 1.

$B$ Wanderzelle in Teilung. Nach 30 Minuten ist aus Figur $A$ die Figur $B$ entstanden. Nach Arxold Taf. XII, Fig. 3.

gegengesetzten Richtungen auseinander. Hierbei kann sich zuweilen die Verbindungshoücke zwischen ihnen, nacholem schon die heiden Tochterlierne sich getrennt haben, zu einem langen, feinen Faden ansiehen. .Die zeitliche Aufeinanderfolge der einzelnen Teilumgsabschnitte ist hei der Fragmentierung sehr häutig keine gesetzmälbige: viehmehr kïnnen kerne und Zellen in dem einen oder anderen Statium länger verharren" (ARxoLD).

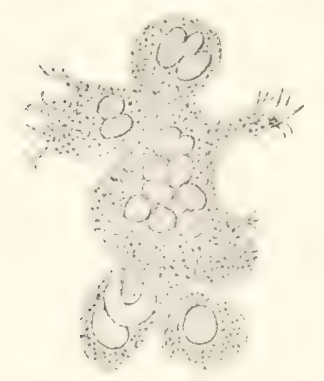

Fig. 181. Eine große vielkeruige Zelle zeigt randständige Abschnürung kernhaltiger Zellen. Narh ILXid, lat. XIV, Fig. 13 . sie zuror wiederholt eingezogten und wieller ausgesendet worden waren. später oder frïher abgeschnürt werken. bald erfolgt die Ihtrennumg bei schwacher oder vollständig nangelnder Bewegung des Körpers." 
Auber in Lymphliörperchen sind Zellteilungen, die unter den Er-

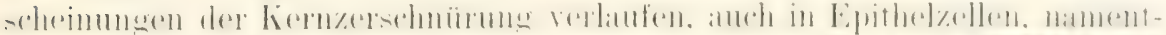

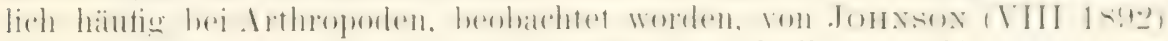
und Brocmung (VII 185, ) in den Embryonalzellen des Skorpions, von PLatrer (VII 1689) in den Zellen Malpighischer Gefäle, von CarNoy in verschiedenen Geweben der Arthropoten. von Meves in den Spermatogonien von Salamandra mac. und von anderen Forschern in anderen Olijekiten.

Eine eigentümliche Art der liernzerschnïrung haben (iöppert (VII 16!1). Flemmeg (VIII 166!), YoN hostanecki (VIII 1892) 11. a. be-

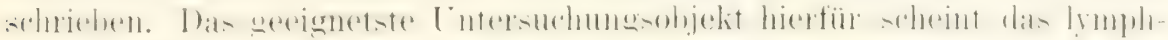
oide Gewebe zu sein, welches die Amphibienleber ïberzieht. Nach der

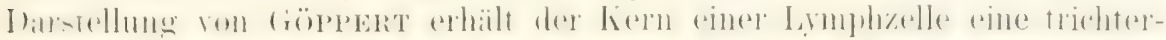

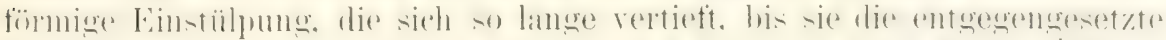

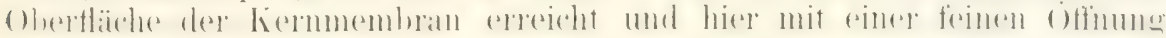
zur Ausmündung gelangt (Fig. $182 A$ und $B$ ). Auf diese IVeise ent-

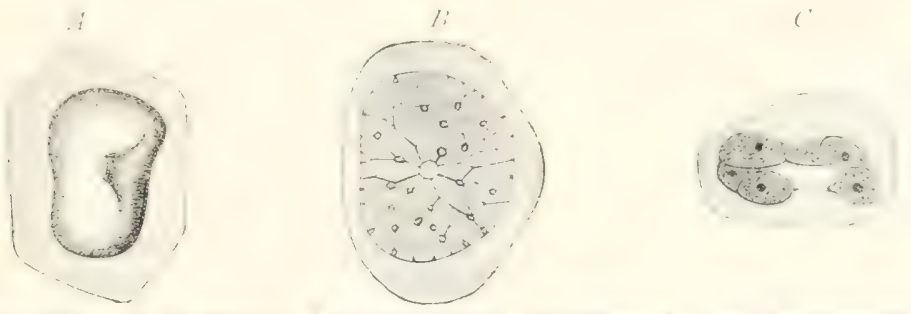

Fig. [.2. Seitliche Ansicht eines Lochkerns aus der lymphatischen Randschicht der Leber von Triton alpestris. Der liern ist in der lichtung der 1)urchbohrung ahgeplattet. Nach GöpPERT Taf. XX, Fig. 4.

f: Lochkern mit deutlich radiärer Anordnung des Nukleingerüstes. Yiah Göprert Taf. XX, Fig. 3.

( Ringfömiger, in melnere Abschnitte durch Einschnürung zerlegter Kern einer Lymphzelle. Nach GöpPFrT Taf. XX, Fig. 10.

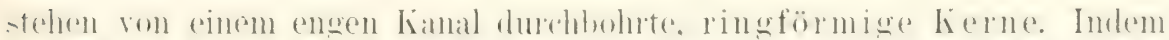

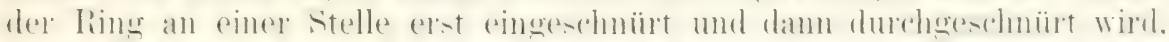

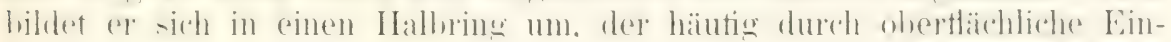
schnürungen in mehrere Abteilungen gesondert wird (Fig. 18: C). Durch weitere Zerlegung kann er in eine größere Anzahl klemerer liernchen

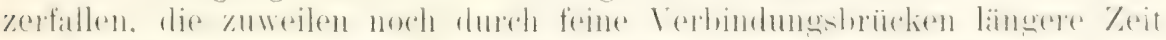
in Zusammenhang bleiben. Auch an anderen Orten sind derartige „Lochkerne", wie 7. B. im Epithel der Harnblase vom Frosch, durch FLenMrg (VIII 1ss:?) beobachtet worden. Zu einer 'Teilung des Zellenleibes scheint es aber in diesen Fiillen nicht zu kommen.

Wie in Tierreich tritt Kernzersehnüung hie und da auch im P'tlanzen-

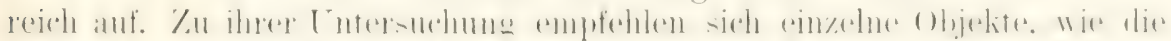

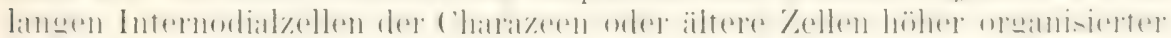
PHanzen. So beschreibt STRAsmurger (III 1S87) aus älteren Internodien von 'Tradescantia mehr oder weniger umregelmäbige lieme, die in verschieden grobe und verschieden gestaltete Abschnitte eingeschnüt sind. .. Ist der Linschnitt einseitig, so erscheinen die Zellkerne nierentörmig, bei

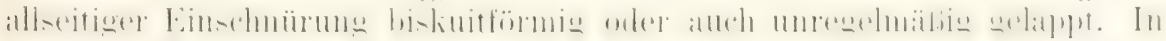
manchen Fällen haben sich die T'eilstïcke völlig getrennt und herïhren sich entweder noch oder liegen in gröberer oder geringerer Entfernung roneinander. Die Zahl der so getrennten Kerne in einer Zelle kann bis 
anf acht oder zehn anwachsen." Iei Charazeen gewimnen die Kerne durch

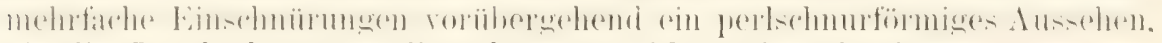
bis die Durchschnürung, die schr träge abläuft, beendet ist.

Vermehrung der Kerne durch Abschürung kommt endlich auch im Protistenreich vor. Sie findet sich häutig in der Gruple der Acineten, in

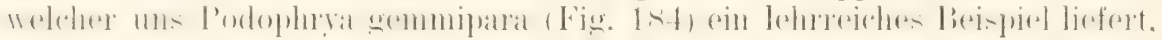
das auf Seite 240 genaner beschrieben ist.

Wenn wir zum Schluß noch nach der Bedeutung der Kernzerschnürung im Vergleich zur Mitose fragen, so spricht vieles zugumsten der Auffassung von Fleming, Ziegler und Rith. Nach ihrem Urteil geschieht die Vermehrung lebhaft wachsender, normaler Gewebe, vor allen I)ingen aller embryonalen Zellen nur auf dem Wege der Mitose. Dagegen stellt sich Fragmentation in alternden und dem Untergang entgegengehenden Geweben und bei pathologischen Prozessen ein. Gleichwohl geht ron

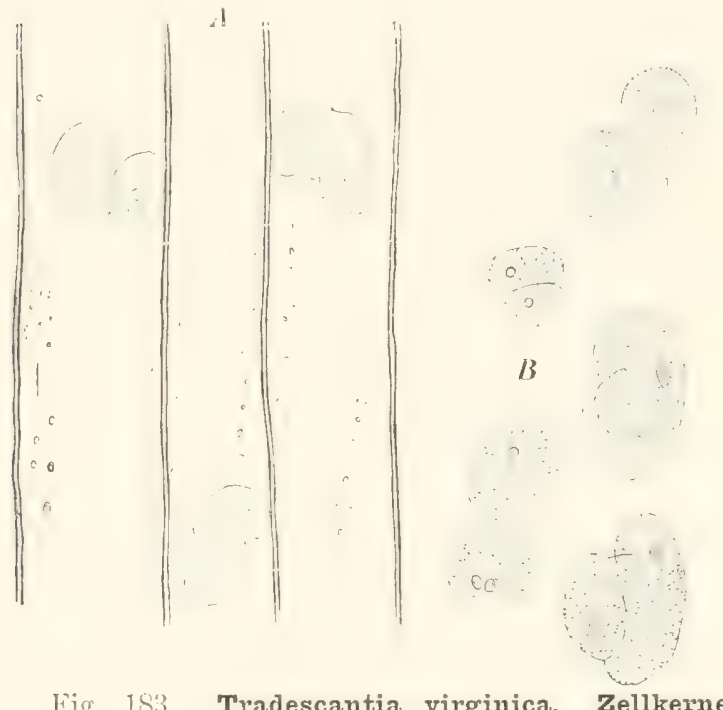
älterer Internodien in direkter Teilung. Nach STRASBURGER Fig. 193.

1 nach dem Leben, $B$ nach Essigsaiure-MethylgrünBehandlung.

RATH zul weit, wenm er behauptet (1.331): „Wenn einmal eine Zelle direkte Kernteilung erfahren lat, so ist damit ihr 'Todesurteil gesprochen; sie kann sich zwar noch einige Male direkt teilen, geht damn aber unfehlbar zugrunde. So ist nicht wohl denkbar, daß Zellkerne, die sich eimmal amitotisch geteilt haben, sich nachher wierler mitotisch teilen sollen." Zunächst. trifft dieser Ausspruch für einzellige Organismen, bei denen Amitose beobachtet worden ist. doch wohl nicht zu. Aber auch für mehrzellige lassen sich entgegenstehende Beobachtungen anfïhren.

Beachtenswert sind besonders Mitteilungen ron PFEFfer über Experimente, welche Nathaxson unter seiner Leitung an Spirogrra angestellt hat. Wenn diese Pflanze in Wasser, dem 0,5 Proz. Äther zugesetzt ist, kultiviert wird, so fahren ihre Zellen nach wie vor fort, sich durch Teilung zu vermehren, aber nicht wie normalerweise durch Karyokinese, sontern durch Amitose, wie man sowohl durch Beobachtung des lebenden Objektes als auch an konserviertem Naterial feststellen kann. Der in der Mitte der Zelle gelegene Kern zerfällt allmählich in zwei Hälften, die sich voneinamder tremnen und entfernen und zwischen denen dam in der Mitte in üblicher Weise eine trennende Zellulosehaut entsteht. Die amitotischen Teilungen fahren so lange fort, als sich die Spirogyra unter den anormalen Kulturbedingungen befindet. Trotzdem hat sie ihr Vermögen zur Mitose nicht verloren: denn wenn sie wieder in ätherfreies Wasser zurückgebracht wird, teilt sie sich wieder einzig und allein auf dem Wege 
der Karyokinese. Durch die mitgeteilten Experimente hält es PFEFFER fiir bewiesen, daß bei Spirogyra sich mitotische und amitotische T'eilungen physiologisch vertreten lïmmen und insofern gleichwertig sind, als in

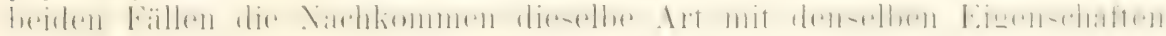
vorstellen.

\section{3) Endogene Kernvermehrung oder Vielkernbildung.}

Eine dritte, sehr abweichende Art der Kernvermehrung, welcher ich den für die Überschrift gewählten Namen geben möchte, ist von Ricinan Hertwig (VII. 1876) bei einer Abteilung der Radiolarien, den 'Thalassicollen, entdeckt, später von KArL Braxpt (VIII. 1890) bestïtigt und Ein ihren Einzelheiten noch genauer verfolgt worden.
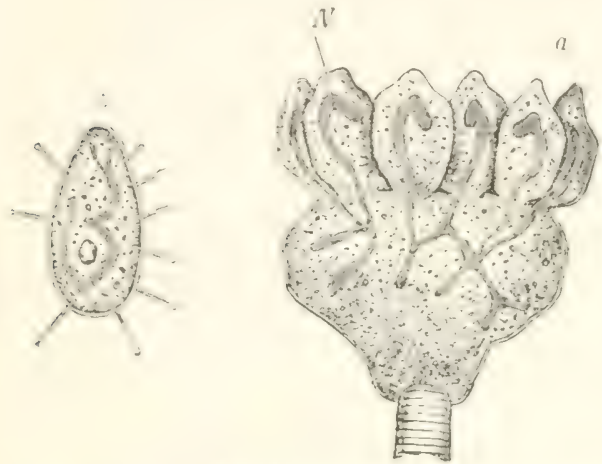

Fic. 1S4. Zellkmospung. Podophrya gemmipara mit Knospen. R. IЕнтwif, $-200-$ logie.

a linospen, die sich ablïsen und zinn schwirirmer $b$ werden, 1 Kerm.

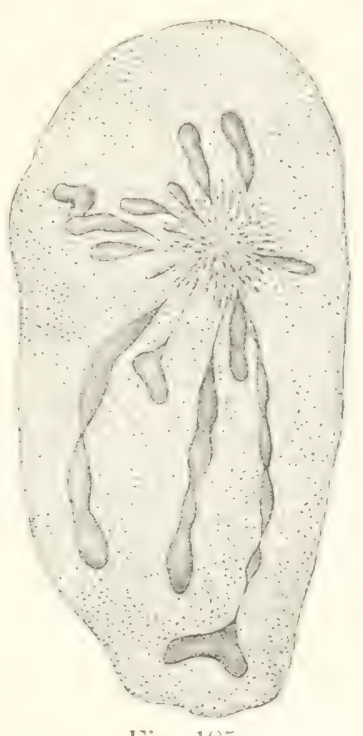

Fig. 185.

Fig. 15.5. Ein kleines Stück von einem Durchschnitt durch den großen, bläschenförmigen Kern, das sogenannte Binnenbläschen von Thalassicolla nucleata, mit strangförmigen, von einem gemeinsamen Punlt ausstralnlenden Binnenkörpern (Kernkörperm). li, Hertwa, Tafel V', Fig.

Die Thalassicollen, diese gröbten Radiolarienformen, deren Zentralkapsel fast den Durchmesser eines Froscheies erreicht, besitzen während des gröbten Teils ihres Lebens emen einzigen, riesigen, hochdifferenzierten Kern von etwa $1 / 2$ mm Durchmesser mit einer dicken, porösen Rermmembran, das sogenamte Binnenbläschen. Dieses bietet viel Ähnlichlieit mit den multinucleolären Keimbläschen eines Fisch- oder Amphibieneies dar. In seinem Inhalt finden sich zahlreiche. meist $\mathrm{mm}$

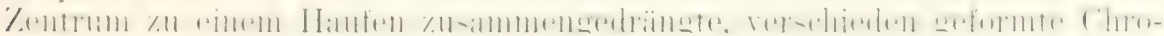
matinkörper vor (Fig. 1S.)). Inmitten derselben liegt sehr häutig ein helles Zentralkörperchen, eingehüllt von einer Strahlensphäre, welche Richard HERTwig schon gesehen mil abgebildet und welche nenerdings BRANDT genaner untersucht hat. Der letztere lonnte verfolgen. wie zur 'Leit der Fortpttanzung das Zentralkörperchen. welches mir dem von der pthanz-

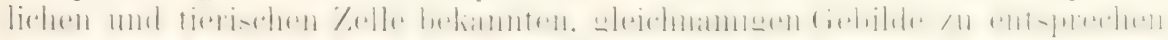
scheint, sich an die Obertä̈he des Bimenbläschens begiebt. die Strahlensphäre hinter sich herziehend. Hier tritt es durch die Kermmemban in 


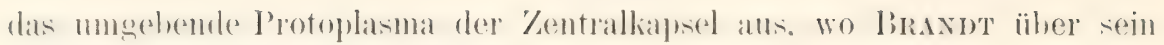
weiteres Schicksal nichts berichtet.

Um diese Zeit treten dann auch zahlreiche, kleine Kerne im Proto-

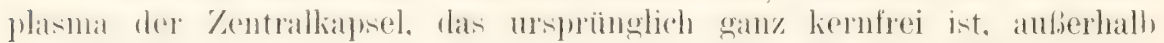
des Binnenblïschens auf; sie dienen als Zentren für die Bildung kernhaltiger schwärmsporen, deren Zahl sich schlielilich auf IImmlerttausende beläuft. W:ihrenddem besinnt dis Bimnenblischen zu selummpten und was es an Kernkörperchen besaß, in demselben Maße zu verlieren, als andierhalh im I'rotoplasma der hernreichtmm zumimmt: schlieblich wird en ganz aufgelöst. Hierbei stellt Branot in der hernvermehrmo Vershedenheiten auf, je nachdem sich Isosporen oder Anisosporen bilden.

Aus dem ganzen Vorgang ziehen R. Hertwig und Brandt den gewiß richtigen Schlub, dal.s die zur Schwärmerhildung dienenden und in der Zentralkapsel erst spärlich, damn immer roichlicher anftretenden lierne? von Substanzteilen des Bimenbläschens (den Kernkïrperchen, abstammen.

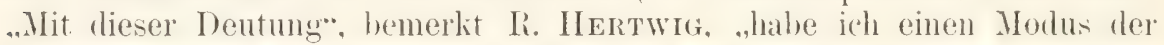
Kiernvermehrung angenommen, welcher sich wesentlich von dem bekannten unterscheidet und durch keme Beobachtungen der tierischen und pitlanzlichen Histologie bis jetzt bewiesen ist. Denn wenn wir den Vorgang histologisch zu deuten versuchen, so würden wir zu dem Resultate gelangen, dab Kierne sich nicht allein durch Teilung oder Knospung vermehren kïmnen, sondern daf sie auch entstehen, indem die Kernkinruer eines Kerns sich durch Teilung vervielfäligen, auswandern und im I'rotoplasma der zugehörigen Zelle zu selbständigen Kernen werden." ..Eine lerartige multinucleoläre Zelle kömnten wir dann ehenso für potentia vielliennig halten. wie eine vielkernige Zelle für potentia vielzellig, und würde so der allmähliche Ühergang, welcher zwischen dem einzelnen Zellindividum und dem aus Teilung desselben entstandenen Zellhaufen besteht. ein noch mehr durch Zwischenstadien vermittelter sein, als er ohnedies schon ist."

\section{Beeinflussung der Kernteilung durch äuBere Falitoren. Abnorme Kernteilungsfiguren. Kerndegenerationen.}

Das komplizierte Kräftespiel, das sich dem Beobachter bei jeder Zellteilung darbietet, kann ebenso wie das früher studierte Phänomen der Protoplasmabewegung durch äubere Falitoren in auffalliger Weise beeinflubt werden. Nur werden hier aus naheliegenden Gründen die Verhältnisse verwichelter als bei der Protoplasmabewegung. weil stofflich verschiedene Teile, Protoplasma, Kernsegmente, spinulelfasern. C'entrosomen von der Störung betroffen und in sehr verschiedenartiger Weise abgeändert werden können. - Das ganze Gebiet ist noch wenig experimentell in Angriff genommen. Wenn wir die Frage aufwerfen: wie verhalten sich die einzelnen stadien des hernteilungsprozesies thermischen, mechanischen, elektrischen und chemischen Reizen gegenüber? so kömnen wir nur eine sehr unbefriedigende Antwort darauf geben. Die zahlreichsten Untersuchumgen besitzen wir zur Zeit über Echinodermen-Eier, deren Verhalten gegen thermische und chemische Reize während der Teilung einer Prüfung unterworfen wurde.

Was zunächst die thermischen Einflüsse betrifft, so ist im allgemeinen bekannt, dab je nach dem Grade der 'Temperatur die Zellteilung langsamer oder rascher verläuft; wo aher das 'Temperaturoptimum, wo das Minimum liegt, und welche Veränderungen Temperaturen, die uber 
das Optimum himausgehen, an den Kerntiguren hervorufen, mul. dureh Experimente genaner festgestellt werlen. Über den Einflul.; von Kältearaden von 1 bis 4 Grad Celsius habe ich selbst (VIII 189(), 1891) eine lieihe von Experimenten ausgefïhrt:

"Wemn Echinolermen-Eier 15 bis 30 Minuten lang auf 1 bis 4 Crarl

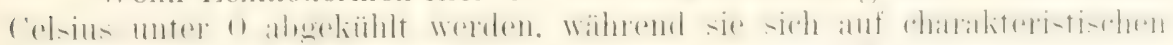
Teilungstadien befinden, so wird binnen wenigen Minuten der ganze

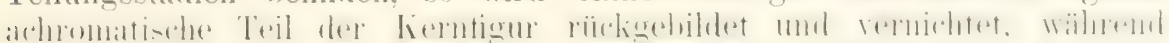

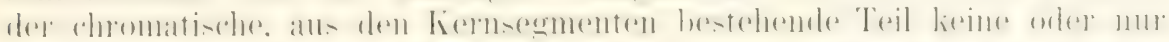

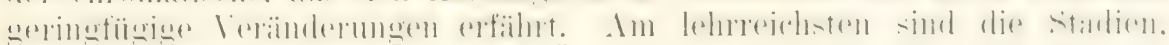
anf denen die Kernsegmente im İquator angeordnet (Fig. 186 A) oder schon nach beiden Polen verteilt sind. Wie Figur $186 \mathrm{~B}$ lehrt, sind die

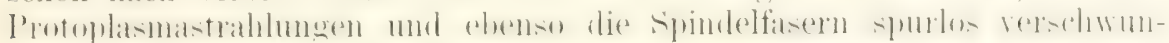
den; die Sphären in der Umgebung der: Centrosomen sind noch durch

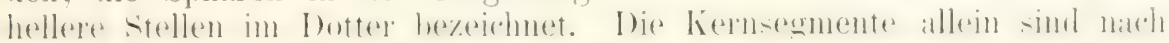
Aussehen und Lage ganz unverändert geblieben.
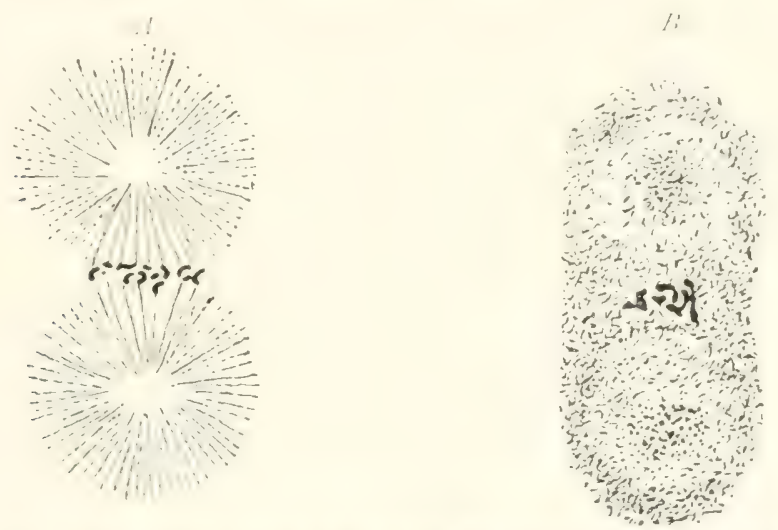

Fir. I ii. I Kermfigur eines Eies von Strongylocentrotus 1 Stunde 20 Min. nach der Befruchtung.

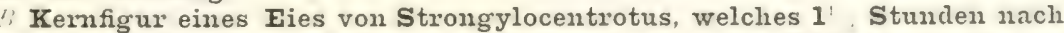
Vormalme der Befruchtung 2 Stunden 15 Minuten in eine Kältemischung von $2^{\circ} \mathbf{C}$ gebracht und dann getötet wurde.

Während der Dauer der Kältewirkung bleibt die Kernfigur in diesem Zustand fest gebannt; die Starre begimnt aber in kürzester Zeit zu schwinden, wenn die Eier in einem Tropfen Wasser auf einen Objekt-

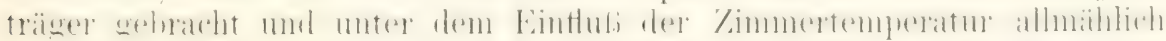
erwärmt werlen. Schon nach 5 bis 10 Minuten bilden sich die beiden

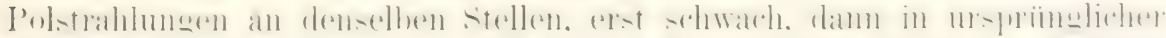

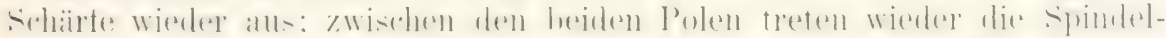
fasern hervor. worauf es bald zur regelrechten Teilung kommt. In diesen Fällen hat die Kälte nur als Hemmung gewirkt. Der TeilungsprozeB setzt einfach an dem Punkte wieder ein, an welchem er durch die Kälte zum Stillstand gebracht worden war.

Intensivere Störungen werden durch 2- bis : stiundige Abkühlung auf 2 bis :3 Grad Celsius unter o hervorgerufen. Die ganze liernfigur wird von frund aus umgeändert und mub sich. wenn die Kältestarre voribber ist. wieder von Anfang an neu aufbauen. wozu eine längere Zeit

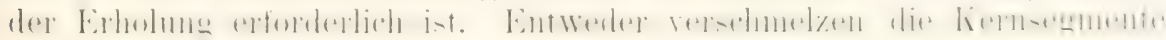




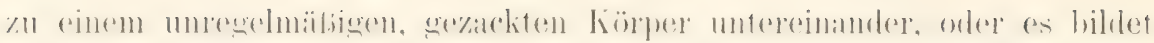
sich sogar aus ihnen wieder, wie bei dem Rekonstruktionsprozeb nach der 'T'eilung, ein kleiner bläschenförmiger Kern. Dann begimnen von nenem Veränderungen, welche zur Enstehung von Polstrahlungen und von häufig mehr oder minder abnorm gestalteten Kernteilungstiguren führen. Auch die 'T'eilung des Eikörper's erfolgt nicht nur sehr verspätet, sondern ist oft pathologisch abgeändert.

In analoger Weise wie die Kälte haben einige chemische Stoffe (Chinium sulfuricum in $0,05 \%$ iger Lösung und $0,5 \%$ Chloralhydrat) eine ïberraschende Wirkung auf den Teilungsprozeb. Werden Eier, welche

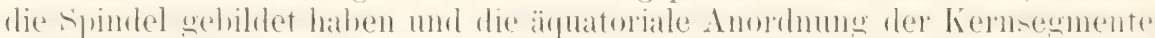
zeigen, 5 bis 10 Minuten der Einwirkung der obengenannten Stoffe ausgesetzt, so beginnen bald die Polstrahlungen vollkommen zu verschwinden, entstehen aber nach einiger Zeit der Ruhe wieder von neuem, worauf es zu normaler Teilung kommt. Bei einer Einwirkung der Stoffe während 10-20 Minuten jedoch wird die Störung eine tiefergreifende und führt in vielen Fällen einen sehr eigentïmlichen und in seiner Art typischen Verlauf des Teilungsprozesses herbei. Nicht nur die Polstrahlungen und die simindelfasern werilen vollkommen zurïckgebildet. somdern es geht anch aus den Kernsegrıenten in langsamer Umwandlung der bläschenförmige Ruhezustand des Kierns wieder hervor (Fig. 187 A). Derselbe gibt balı den Ausgangrumlit für einc nene, jetzt aher wesentlich morlitizierte Teilung ab (O. und R. HerTwig VIII 1857).
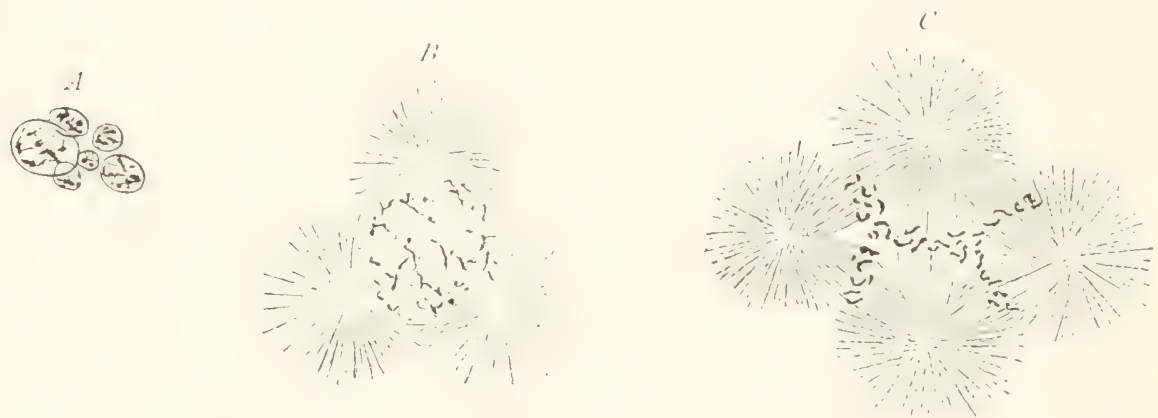

Fig. 18\%. Kerue von Eieru von Strongylocentrotus, welche 1\%, Stunden nach Vornahme der Befruchtung 20 Minuten in einer 0,025" "igen Chininlösung gelegen haben.

$A$ Kernfigur eines Eies, das eine Stunde nach Heransmahme aus der Chininlösung abgetötet wurde. B Kernfigur eines Eies, das etwas spater abgetötet wurle. C Kelnfigur eines Eies, das 2 Stunden nach Herausnahne ans der Chininlösung abgetötet wurle.

Anstatt zweier bilden sich gleich vier Strahlungen an der Obertläche der Kernblase aus (Fig. 187 B. in welcher eine Strahlung verleckt ist). Diese werden nach Behandlung mit Chinin bald scharf ausgeprägt, bleiben dagegen nach Chloratbehandluug auf die Dauer matt und auf die nächste Ungebung des liernes beschränkt. Hierauf löst sich die Kernmembran auf: zwischen den vier Polen entwickehn sich fünf Spindeln, auf welche sich die Kernsegmente in äquatorialer Anordnung verteilen und dabei eine charakteristische Figur erzeugen (Fig. 187 C). Dam weichen die Kernsegmente nach den vier Polen ausemander und geben die Grundlagge für vier b]äschenförmige Kierne ab, welche nach der Oberthiche des Dotters auseinander rïcken. Das Ei beginnt sich darauf durch zwei Kreuzfurchen 
den Kernen entsprechend in vier Lappen einzuschnüren; in der Regel

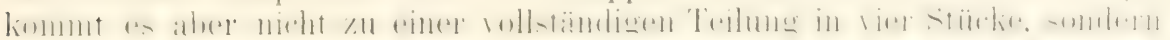
zuvor schicken sich die vier Kerne wierler zu einer nenen leilung an, indem sie sich in Spindeln mit zwei Polstrahlungen umwandeh. Dabei rel-

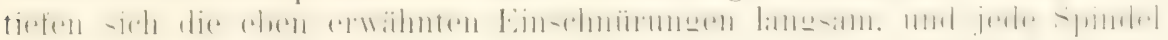
liommt in einen Höelier oder eine Knospe zu liegen. Entwerler wirl die Trenumg jetzt schon eine ziemlich vollstindigre, oder es treten, noch che die Furchen weit in den Dotter eingeschnitten haben, die vier Spindeln, indem die Kernsegmente nach den Polen auseinanderweichen, zuvor in Teilung ein. Dies hat damn wieller zur Folge, daß sich die vier ersten Höcker. noch ehe sie voneinander getrennt sind; abermals einzuschnüren begimen (Linospenfuchung).

Das Auffälligste bei den beschriebenen Erscheinungen ist clas plötzliche Anftreten von vier Polstrahlungen, denen nach allem, was wir wissen. ebenso viele Centrosomen zugrunde liegen müssen. Eine Erkiärung hierfür bjetet sich in den Vorgängen, welche sich an die Befruchtung des Echinodermen-Eies anschlieben und welche ihre Besprechung im Kapitel XI finden, auf welches hiermit verwiesen wird.

Modifikationen ron der in Figur $1 \times 7$ C dargestellten Form der Lernumwandlung kommen nicht selten vor; sie hestehen darin, daß eine Strahlung ron den drei übrigen etwas weiter entfernt liegt (Fig. 185). In
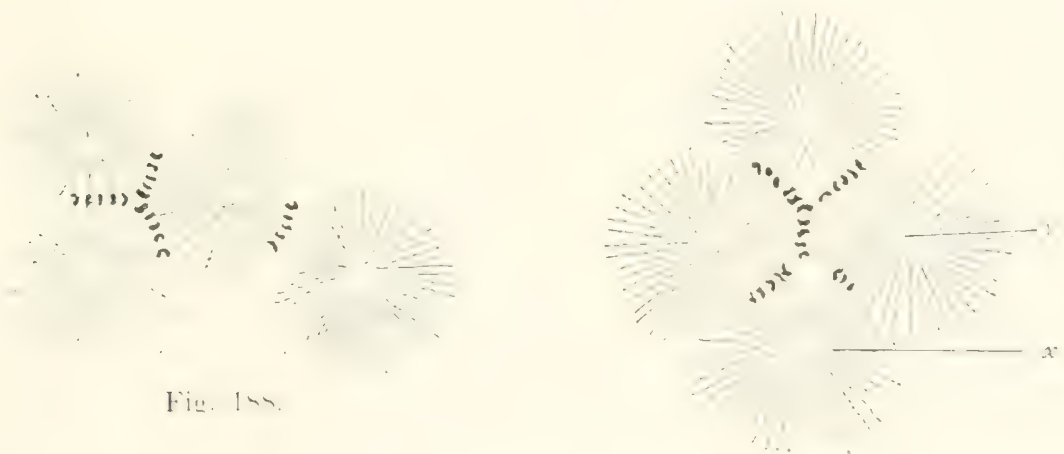

Lije. 1 lis?.

I:iu, In 11, I $4 !$, Vierpolige Kernfiguren vou Eiern vou Strongylocentrotus, die 1 Stunden nach Vornahme der Befruchtung 20 Minuten in einer 0,05 igen Chininlösung gelegen haben und mach Hexansmahme aus der Chiminlösung mach 2 Stunden getötet worden sind.

diesem Fall sind nur die drei näher zusammen gelegenen Strahlungen durch drei Spindeln zu einem Triaster vereinigt. Im Mittelpunkt des so

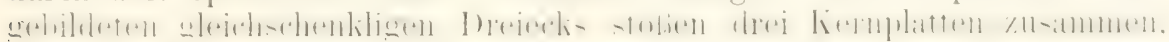
wieder eine regelmähige Figur erzengend. Die vierte abseits liegende Strablung verbindet sich durch eine einzige Spindel mit der nächsten Strahlung des Triasters.

ils ein Übergang zwischen den Figuren lst mul list läbt sich wohl Figur 18!) betrachten. Hier gehen von der mehr isoliert gelegenen Strahlung x zwei Spindeln nach dem ïbrigen Teil der lierntignr, welche einen Triaster darstellt. Von den beiden Spindeln ist die eine nur schwach und unvollständig ausgebildet und fällt sofort dureh die greringe Anzall ihrer liernsegmente auf. Sie würde wahrscheinlich gar nicht zur Anlage 
gelangt sein. wenn die Strahlung $\mathrm{x}$ noch etwas weiter von der Strahlung y entfernt wäre.

Drei-, vier- und mehrpolige Kernteilungsfiguren ('Triaster, 'Tetraster, Polyaster, pluripolare Mitosen) sind auch in krankhaft veränderten Geweben von pathologischen Anatomen, Arrold, Hansemans,

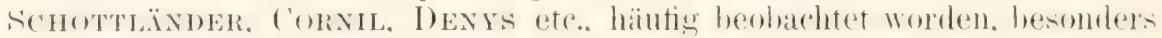
häufig in bösartigen Geschwülsten, wie in den Karzinomen. Sie gleichen in antiallender Weice den an Eizellen experimentell erzengten und in den

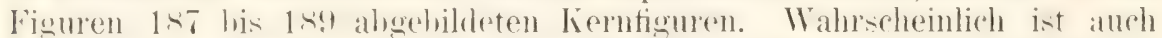
hier die I'sache für die ahmormen Erscheinmgen in chemischen Reizen

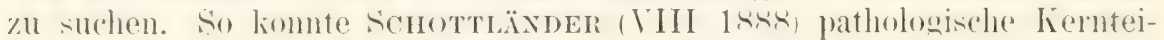
lumgen in Endothel der Descemetschen Vemban dadurch herrorrufen.

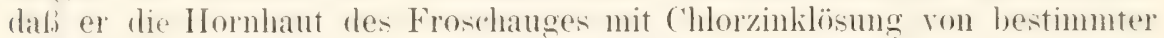
Konzentration anätzte und so in Entzündung versetzte. Bemerkenswert ist das veränderliche Zahlenverhältnis der Kernsegmente in den einzelnen Spindeln. Denn während in einigen spindeln zwölf Segmente. wurden in anderen nur sechs oder sogar nur drei von Schottländer aufgefunden. Dieselhe Frscheinung wurle hei den Echinodermen-Eiem beobachtet.

Mehrpolige Kernteilungstiguren kïnnen ührigens wahrscheinlich noch dureh anclere L'rsachen, von denen uns zur Zeit die wenigsten helamnt sincl, veranlabt werlen. Eine häutige Trache ist zum Beisjiel das Vorkommen vieler Kerne in einer Zelle. Man kann leicht einen solchen Zustand anf experimentellem Wege willkïlich hervortufen. Wenn man Eizellen durch irgendwelche geeignete Eingriffe schädigt und damn befruchtet (O. Hertwig VIII 1875, 1890, 1891, Fol VIII 1883, O. und R. Hertwig 1s8t). Anstatt eines einzigen Samenfadens, wie es bei der normalen Befruchtung die Regel ist. dringen dann zwei, drei und mehr in
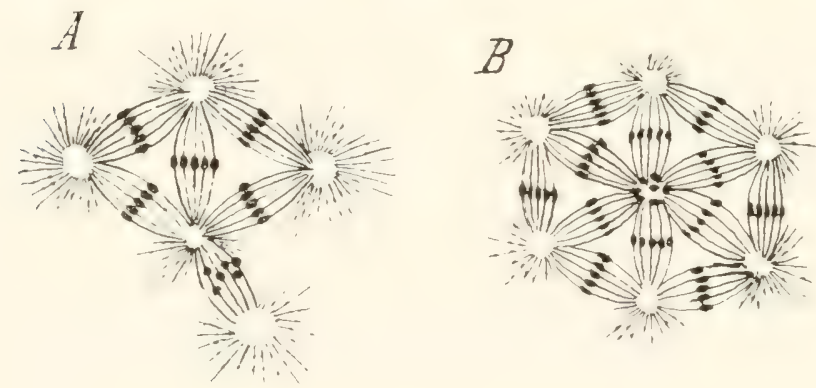

Fig. 190. Komplizierte Spindelaggregate aus Echinodermen-Eiem, welche infolge vorausgegangener Belkandlung mit Nikotin bei der nachfolgenden Befruchtung durch viele Spermatozoen befruchtet worden waren. (Nach O. und R. HERTWIG).

den Dotter hinein. Die Folge einer derartigen Überfruchtung (Polyspermie, ist die Aushildung vieler. der Zahl der eingedrungenen simenfailen entsprechender Samenkerne. Dieselben legen sich zum Teil dem Eikern an, und da jeder ron ihnen ein Centrosom mit in das Ei hineingehracht hat, entstehen um den Eikern entsprechend vicle Polstrahlungen. Und so wandelt sich, je nach der Zahl der Samenfäden, der Eikern in eine drei-, vier- und mehrstrahlige Kernteilungsfigur um.

Auch die nicht mit dem Eikern verbundenen, sondern bei der Überfrumtumg in Jotter isoliert wehliehenen samenlierne werden sehr häutig der dusang eigentümlicher. mehruoliger Kornfiguren. Zumächst weren

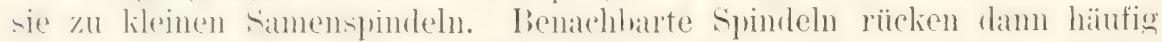
zusammen derart, daß zwei Polstrahlungen und mithin wohl auch die in ihnen gelegenen Centrosomen zu einem einzigen verschmelzen. Auf 


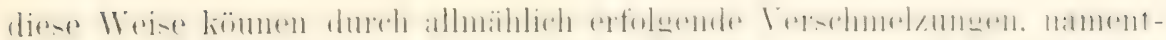
lich bei höheren (iraden der Überfruchtung, die verschiedenartigsten Spindelaggregate zustande kommen. Auch die rom mehrach befruch-

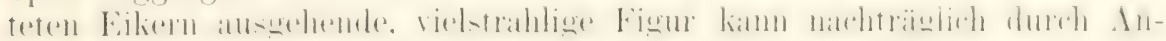
lagerung von Samenspindeln noch eine kompliziertere Struktur erhalten.

In ihnlicher Weise erkläre ich mir die interessanten Befunde, welche an den Riesenzellen des Knochenmarks von Dexys und an den

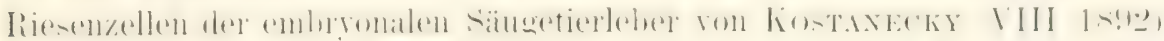
beobachtet worden sind. Im Verhältnis zu den zahlreichen Kernen werden auch viele Centrosomen in der \%elle enthalten sein. Wemn daher das ganze liernaggregat in l'eilung eintritt, werden sich viele I'olstrah-

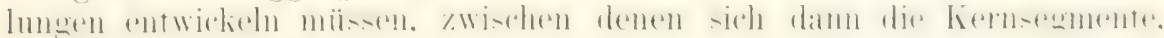
deren Zahl unter Cmständen mehrere hundert betragen kann, zu eigen-

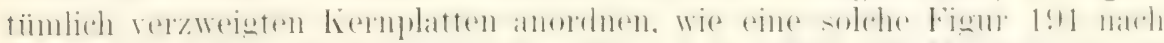

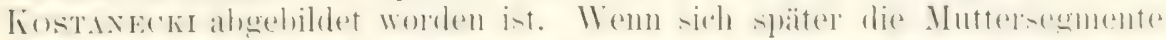

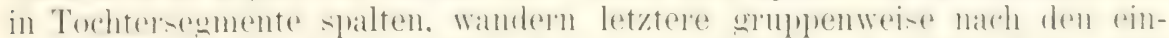

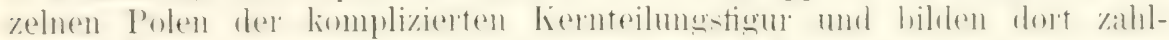
reiche, kleine Kreise (Fig. 192). Aus jedem Kreis wird weiterhin ein

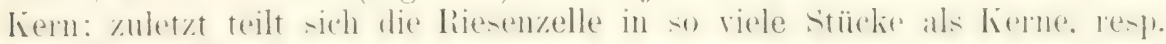
Kreise von Tochtersegmenten, vorhanden waren.

In dieselbe Reihe gehören die von Hexnegur (VIII 1891) am Fo-

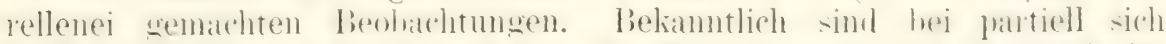
furchenden Eiern zahleiche Kerne, die Meroerten. in der Inotterichicht. welche unter den lieimzellen liegt. zerstreut. Zuweilen treten einigre von

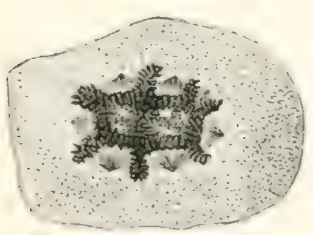

liv. 191

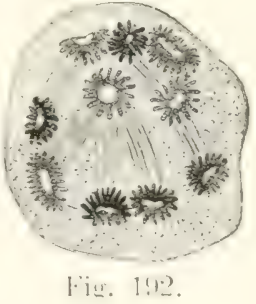

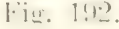

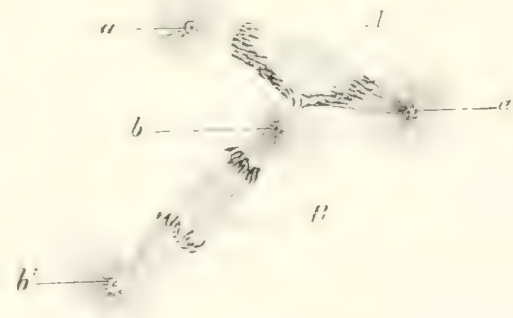

[־̈ig. 19:3.

FiL. 1!11. Vielpolige Kenteilungsfigur mit vielen Gruppen von Muttersegmenten aus einer Riesenzelle der embryonalen Säugetierleber. ioh lin-1XEKKI.

Fi.. [!.?. Vielpolige Kernteilungsfigur einer Riesenzelle aus der embryomalen Säugetierleber. Die Tochtersegmente bilden viele Gruplen, die nach den zahlreichen f'olen zu auseinander gerïcht sind. Nach liostaxicki.

Fi.. 1:\%, Zwei Kermspindeln aus dem Dotter einer Foxellenkeimscheibe. Das Centroson der einen Spindel ülst einen störenden EinfluB auf die Anordnung und Terteilung der 'Tochtersegmente in der zweiten Spindel aus Yach IIFxricr.

ihnen. indem sie sich zur Teilung gleichzeitig vorbereiten, zu kileinen Spindelaggregaten zusammen. Dafür, daß die Pole hierbei als Attraktionszentren wirken. ist sehr lehrreich der folgende, von HExvEGUY mitgeteilte Fall (Fig. 19:3): Zwei in Teilung begriftene Merocyten liegen in der gemeinsamen Dottermasse dicht bei einander, und zwar so, (lal) die Spindelaxe von $B$ in ihrer Verlängerung die Spindel $4 \mathrm{im}$ Äquator schmeiten wiurde und daf das eine Centrosom b sich in grofer Naihe von Spindel $A$ befindet. Dadureh ist bei der letzteren die Verteilung der 'Tochtersegmente in ganz auffälliger. Weise gestört worlen. Anstatt in zwei 
Gruppen nach den Polen $\alpha \cdot a$, wie bei normalem V'erlauf, auseinander zu weichen. hat sich eine Anzahl von ihnen. welche sich am meisten in der Wirkungssphäre des Centrosoms b der nahegelegenen, fremden Spindel befunden hat, nach b begeben. Mit einem Wort: das Centrosom der einen Spindel hat ganz offenbar einen störenden Eintlul, auf die Anor(lnumg und Verteilung der Tochtersegmente in der zweiten Spindel ausgeübt.

An demselben Objekt hat Hennegur in Keimzellen, die sich von der Merocytenschicht nachträglich abtrennen, auch Triaster, wie ein solcher in Figur 19t abgebildet ist, und 'Tetraster wahrgenommen.

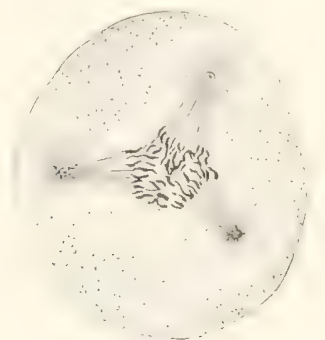

Fis. 194

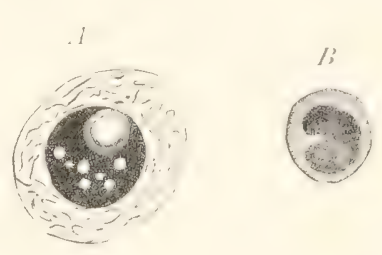

Fig. 19,5.

Fig. 194. Zelle mit einer dreipoligen Kernfigur aus dem Forellenkeim. Nach HexNegLY.

Fig. 195. $A$ Samenzelle mit entartetem Kern aus dem Hoden von Salamandra maculata. Alus Fifmixt, Taf, 25, Fig. 51 a. B Zwischenkörperchen (corps résicluel) aus dem Hoden von Ascaris megalocephala. Kernrückbildung.

Am Schlub dieses Abschnitts sei endlich auch noch auf Degenerationsvorgänge hingewiesen, denen zuweilen die Zellkerne nnterlicen. Wahrshemlich. weil sie sich unter schürllichen Fintlïssen befinden. Namentlich in den Geschlechtsorganen scheinen sich häufig einzelne liemzellen oder firupuen ron solchen. che sie die volle Reife erlangt haben, zuriekzubilden, wie von Flemming und Hermans für Salanandra maculata, von mir fïr Ascaris megalocephala festgestellt worden ist. In den Kernen geht das ferïst zuglume. Das Chromatin sammelt sich zu einem lompaliten kilumpen an. der sich durch eine auffallend starke Färbbarkeit in den verschiedensten Farbstoffen auszeichnet. Das Protoplasma nimmt im Verhiilmis zu entsprechenden normalen lieinzellen an Masse ab. Derartig verkïmmerte Zellen mit ganz desorganisierten Kernen sind in Figur 195 abgebildet. $A$ ist eine Samenzelle aus einem Hodenfollikel von Salamandra, $B$ eine Keimzelle von Ascaris, wie sie sowohl im Hoden als im Eierstock vorgefunden wird und in der Literatur unter dem Namen corps résiduel oder Zwischenkörperchen bekannt ist. Wasielewskr hat durch Injektion von Terpentin in den Hoden von Säugetieren die Kerne ron Keimzellen in einen entsprechenden Zustand dex Degeneration auf experimentellem Wege versetzen kömnen.

\section{Literatur VIII.}

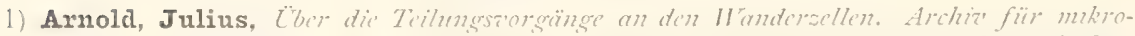

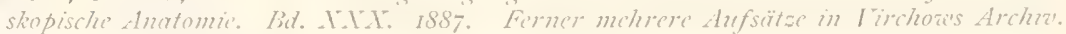
Bid. ICIII. HCITH, CIII.

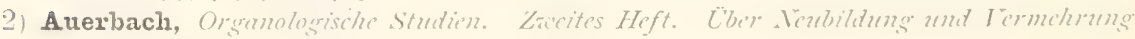
der Kellkermo. $187+$. 


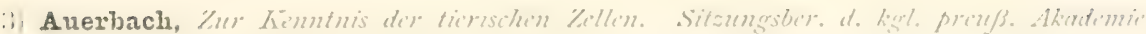
der Hössenschaften an lierlin. 1800 .

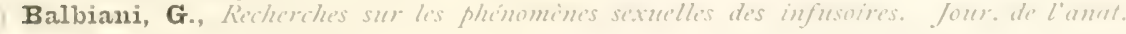
it de phys., 1: IV, 5801 .

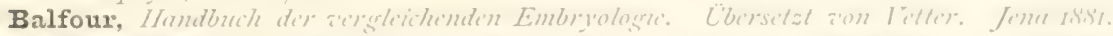

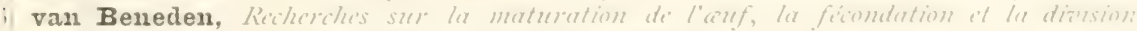

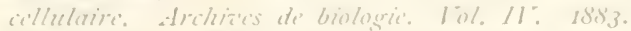

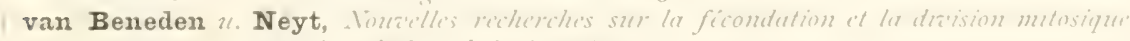

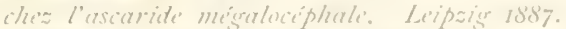

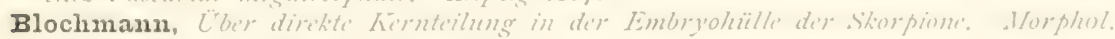
Juhrb. Bit. 1. I885.

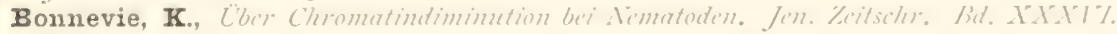
I) $) 1$.

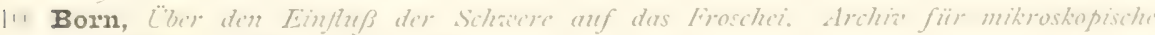

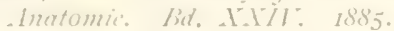

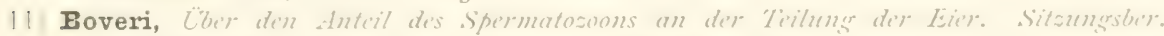
der Gisillsch. f. Morph. u. Whysiol. in Mïnchen. 1887.

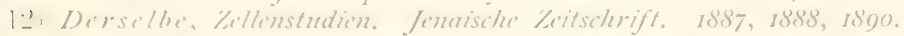

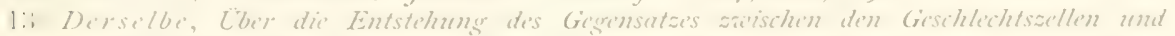
den somatischen Zillen bit Ascaris mesalocephala. Sitzungsber. der Gisellsch. f.

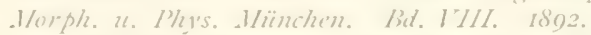

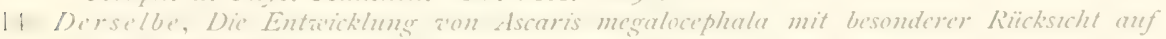

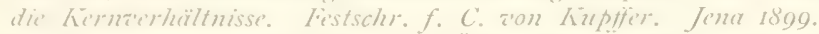

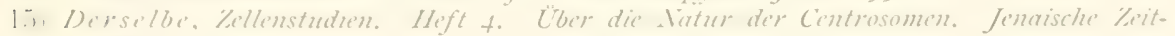
sithrift, 100I.

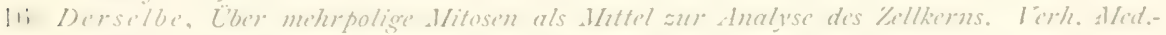
phl's. Gescllsch. Würzburg. I. IS. lid. XXXl. 1902.

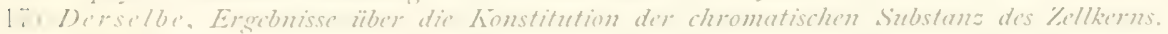
Jinkr 1904 .

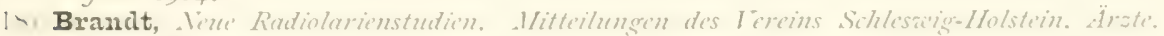
Jamuar 1800.

1:1, Brauer, Zur Kenntuis der Spermatogenese anon Ascaris meg. Arch. f. mikr. Anat. lid. 1LII. 1803.

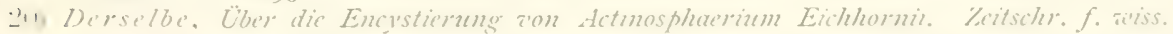
Zool. Bat. LITII. 1807.

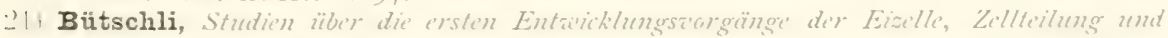
Konjusation der Infusorien. Abhandl. d. Senkenbers. Naturf. Ge'sellsch. 1876.

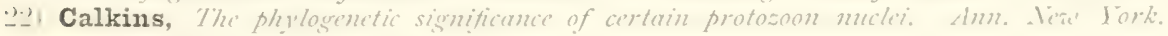
- ternt. Sit., Tol. XI. 1808.

… Carmoy, siehe Literatur I/I.

2-: Cormil, Sur la multiplication des cellules de la moelle des os par dizision indirecte dans l'inflammertion. Arch. de plups. norm. et patholog. 1887.

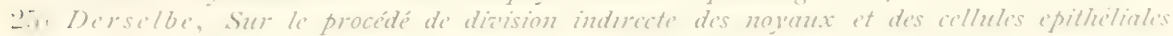

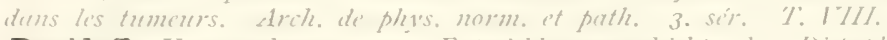

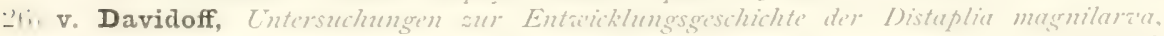

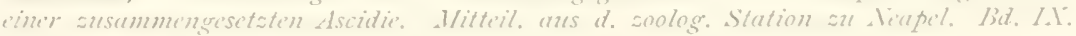
1880.

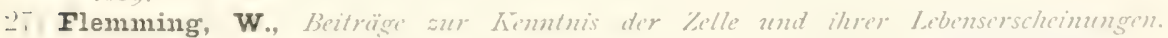

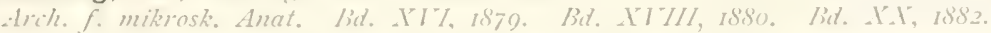

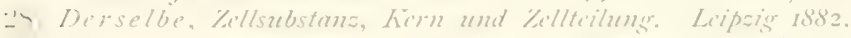

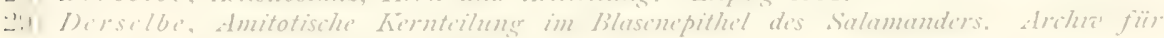

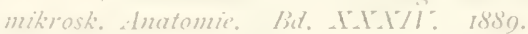

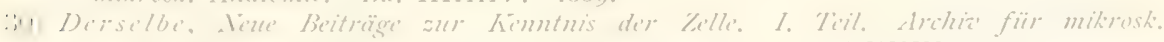

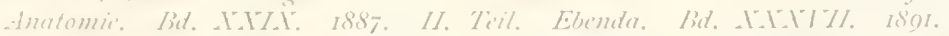

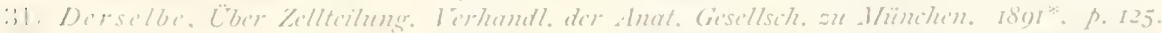

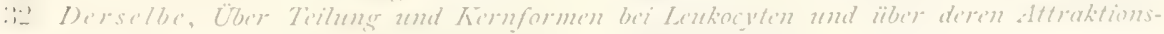

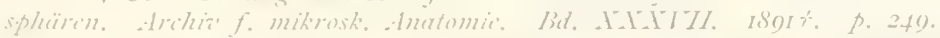

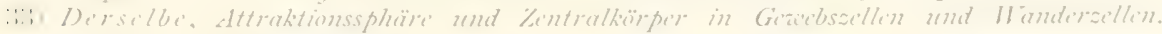

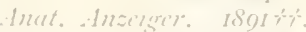

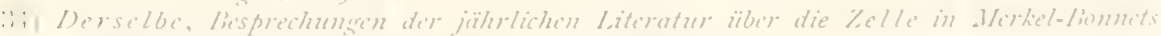

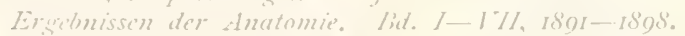

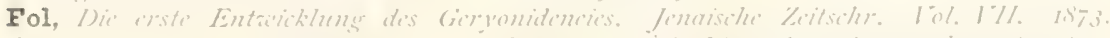

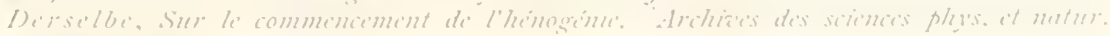
(iimizio $187 \%$.

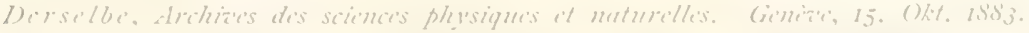

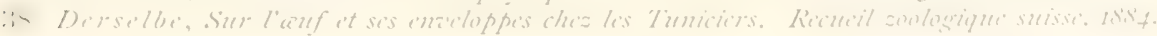




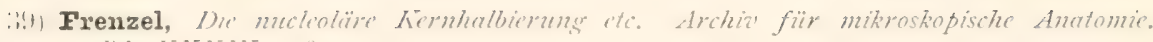
Bid. Y.Y.TIX. 1802 .

(11) van Gehuchten, A., Recherches histologiques sur l'appareil digestif de la larz'e de la Ptichoptera contaminate. La Cellule II. 1800.

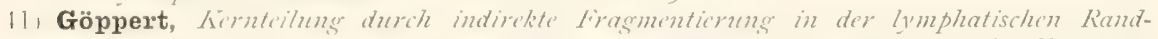
schicht der Salamanderleber. Archiz fïr mikrosk. Anatomie. Bd. XXXITI. 1801.

1.) Guignazd, Recherches sur ler structure et la division du noyone cellulaire. Annales des sciene. nat. 6. ser. T. TVII. 1884.

(ii) Derselbe. Donzelles études sur la ficondation, comparaison. Annales des sciene. nat. T. WIT. Botamique. 1801 .

1) Häcker, V., Die Eibildung bei Cuclops und Cinthocamptus. Zool. Jahrbücher. Abt. f. Anatomie und Ontogenie. Bid. V. 1892.

(i) Hansemann, David, Über pethologische Mitosen. Tirchozes Archiz'. Bd. CXXII. I8gI.

(ti) Derselbe, Über asymmetrische Zelleilung in Epithelkrebsen and deren biologische

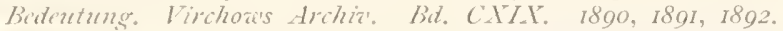

1.) Henking, Untersuchungen Insekten. Till I-3. Zitschr. f. wissenschuftl. Zoologie. Bd. XLIX, I89o. Bd. LI, 1801. Bid. LIV, I892.

thi Henneguy, Vourelles recherches sur ler division iellulaire indirecte. Journal de l'andtomic. Bal. XXVII. 1891 .

19) Herla, v., Etudes des variations de la mitose chez l'ascaride meg. Arch. de Brolog. T. XIII. 1893 .

i) Hermann, $\mathbf{F} .$, Bentrag sur Lehre zon ater Entstehung der karyokinetischen Spindel. Archiz f. mikrosk. Anatomie. Ba. XXXVII. p. 569. 1801.

.1) Hertwig, O., Beiträge zur Kenntnis der Bildung, Befruchtung und Teilung des tierischen Eies. Mlorphol. Jahrbücher. Bd. I, III u. IV. I875, I877, 1878.

i-) Derselbe, Das Problem der Befruchtung und der Isotropie des Eies, eine Theorie der Vererbung. Jenaische Zeitschr. 1884.

53) Derselbe, Experimentelle Studien am tierischen Ei vor, während und nach der Befruchtung. 1890 .

it) Derselbe, Vergleich der Ei- und Samenbildung bei Nematoden. Eine Gmundlage für zelheläre Streitfragen. Archiv f. mikrosk. Anatomie. Bd. XXXVI. 189o*).

.i) Derselbe, Über pathologische Veränderung des Kernteilungsprozesses infolge experimenteller Eingriffe. Internationale Beiträge zur aissenschaftl. Wedizin. I89r.

.) (b) Hertwig, R., Beiträge zur Kenntnis des Acineten. Morphol. Jahrbiicher. Bd. I. I875.

.7) Derselbe, Zur Histologie der Radiolarien. Leipzig 1876.

is) Derselbe, Über den Ban und die Entwicklung der Spirochona gemmipara. Jenaische Zeitschrift. Bd. XI. 1877.

-19) Derselbe, Über die Kernteilung bei Actinosphaerinm. Jenaische Zeitschr. f. Naturu. 1884.

(iil) Derselbe, Über die Gleichaertigkent der Geschlechtskerne bei den Seeigeln. Sitzungsberichte d. Gesellsch. f. Worph. 2t. Phis. in Wïnchen. Bd. II. 1888.

(il) Derselbe, Uber Kernstruktur und ihre Bedeutung fïr. Zellteilung und Befmachtung. Ebenda. Bd. II. I888*).

(i) Derselbe, Über die Tonjugation der Infusorien. Abhandl. d. bayer. Akad. d. Wiss. II. Kl. Bd. YVII. 1880.

(i:) Derselbe, Übor Kernteilung, Richtungskörperbildung und Befrachtung von Actinosphaerinm. Abhandl, der Kgl. bayr. Akad. d. Wiss. II. Kl. Rd. XIX. III. Abt. 1808 .

(i) Derselbe, Eireifung and Befruchtung. Der Furchungsprozeß. Handbuch der a'ergleichenden und experimentellen Entricklungslehre der Wirbeltiere z'on O. Ilertaig. Bid. I. I003.

(i.) Hextwig, O. u. R., Über den Befruchtungs- und Teilungszorganer des tierischen Eies unter dem Einfluß äußerer Agentien. Jena 1887.

(ifi) Heuser, E., Beobcihtungen über Zellteilung. Botanisches Zentralblatt. I884.

(ii) Hirschbruch, Die Fortpflanzung der Hefeselle. Zentralbl. f. Bakteriol., Parasitenkunde etc, II. Abt. Bd. IX. 1902.

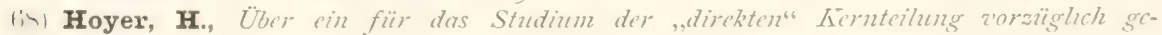
cimetes Objekt. Ancit. Anz. Bil. I. 1890.

i.!, Ishikawa, Stuties of reproductive elements. I. Spermatogenesis, orogenesis and fertilisation in Diaptomus. Journal of the college of science. Imperial uniarersity. Japon. Vol. V. I801.

¡i, Janssens, J. E., Beiträge an der Frage über den Kern der Hefeselle. Zentralbl. f. Bakteriol. u. Parasitenkunde. Ba. XIII. I893, p. 639.

i) Jennings, H. S., The carly development of Asplanchne. Bull. of llus. of comp. Zool. at Harward College. Vol. XXX. I806. 


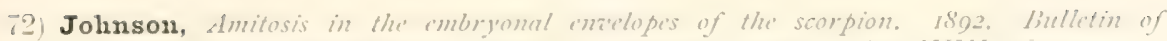

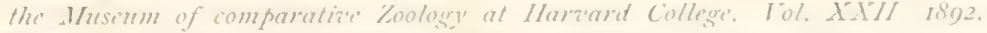

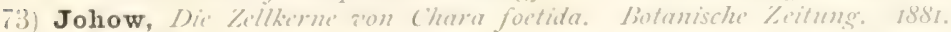

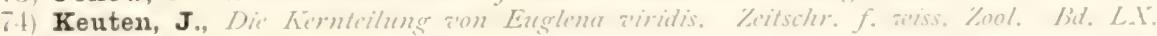
1895.

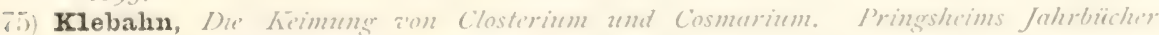
f. wissenschafll. Botunit. Jid. Nitl. 1890.

7(i) Korschelt, E., Die Kemtcilums, Eireifung and liefmechtung bei Ophryotrocha puerilis. Zitsche. f. aiss. Zool. Mal. L.I. 1805.

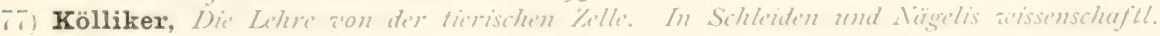
Botank: Heft 2. $18+5$.

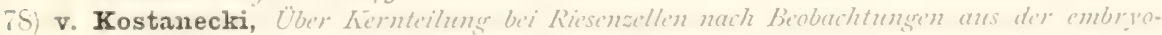
nalen Singetierleber. Anatomische llefte. Isige.

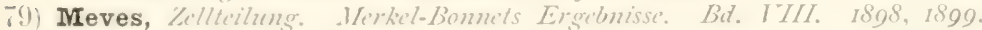

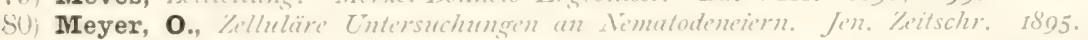

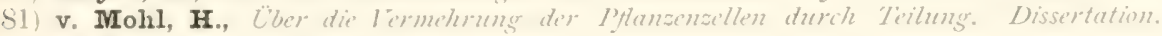
Tïbingen 1835 . Flora 1837.

S2) Morgan, T. H., The fertilization of non-nucleated fragments of echinoderm-egss. Arch. f. Entai-.-lYech. Bat. II. 1805.

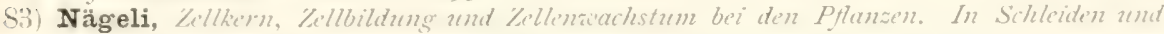

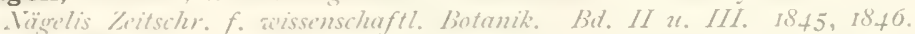

S1) Pfeffer, W., ¿̈ber die Enacugung und die physiologische Bedentung der Amitose. liericht der math.-phys. Kl. der Kgl. Sächs. Gesellsch. der Mliss. Leipsig. 1899.

S5) Platnex, Die Kiaryokinese bei den Lipidopteren als Granduge fiir eine Therie de'? Zelltcilung. Internationale llonatsschrift. Bd. III. 1885.

S6) Derselbe, Beitrëge zur Kenntnis der Lelle und iher Teilungserscheinungen. Archiz f. mikrosk. Anatomie. Bd. WTIIII. 1880 .

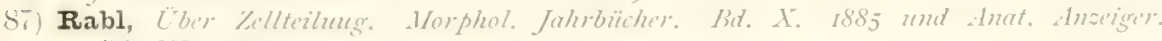
bid. II: 1880 .

SS) Ranvier, Technische's Lerbuch der Histologie. Leipzig 1888.

s9) vom Rath, O., Lber die Bedeutuns der amitotischen Kembilung in Iloden. Zool. Anverger. III: Jalue. 180I. D. 33 I.

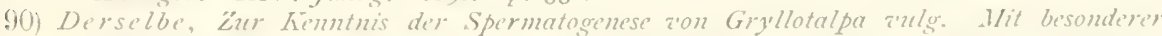
Berücksichtterung der. Frage nach der Reduktionsteitung. Archiz' f. mikrosk. Anatomit. Bid. NL. I802.

91) Reichert, Der Furchungsproseß und die sogenannte Zellenbildung um Inhaltsportionen. Wiillers Archiz $18+6$.

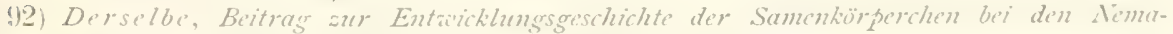
toden. Miillers Archiz' f. Anat. 26. Phrsiol. etc. 1877.

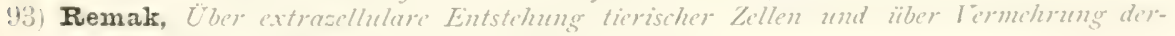
selben durch Teilung. Mïllers Archiz'. 1852.

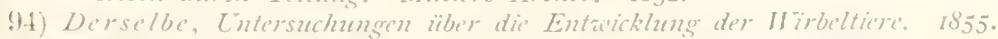

(5) Retzius, Studien ïber die Zelhenteitung. Biolog. Cntersuchungen. Jahrgang 1881.

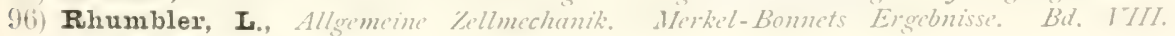
1898,1809 .

97) Roux, Ubue die bedentung der Kernteilungsfiguren. Lipaig 1883.

9S) Rückert, Zur Eireifung bei Copepoden. Anatomische Ilefte (Heft I2). 1897.

99) Schäfer, On the stmcture of the immature orarian orum in the common font and in the rabbit. Procectings of the royeal socrety. London 1880 .

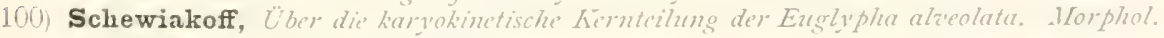
Jahrbïcher. Bd. XIII. I888.

101) Schneider, Entersuchungen wiber Plathelminthen. Jahrb. d. Oberhessischen Ge'sellsch. f. Latur- 11. Heikunde. 1873 .

102) Schottländer, ¿̈ber Sien-und Zellteilungszorgänge in dem Endothel der entzündeten Hornhaut. Archiz' f. mikrosk. Anatomie. Bd. KXXY. 7888.

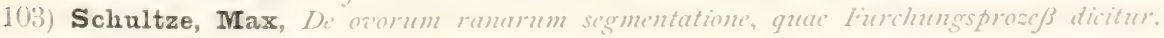
bonn 1863.

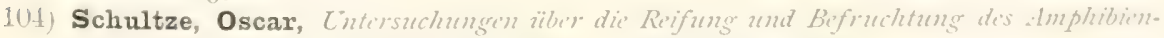
ches. Zeitschr. f. wissenschafth. Zoologite. Bd. ILI. I88\%.

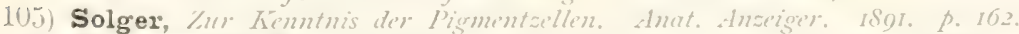

106) Strasburger, Ed., Zellbildung und kellteilung. 1875. 3. Aufl. 18890.

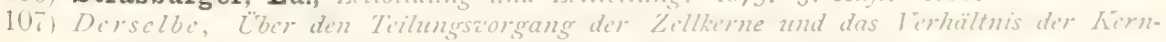
teiluns an Zellteilung. Arch. f. mikrosk. Anat. Bat. LTT. 1882.

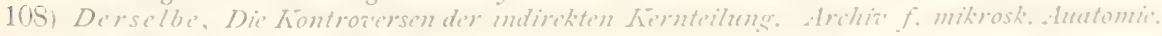
lid. N.TII. Bonn I884. 


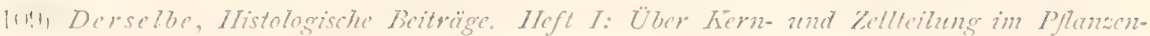
reiche etc. fena 1888 .

1111 Derselbe. Cytologische Studien etc. Jahrb. f. arissenschafth. Botunik. Bd. XXX. 1807.

111, zux Strassen, O., Über die K'iesenbildung bei Ascariseiern. Arch. f. Entä.-Alech. Bid. 171. 1898 .

11:- van der Stricht, La formation des globules polaires chez Thysanozoon. Arch. Biol. T. XV. 1808 .

11:; Vejdovsky, Entaicklunssgeschichtliche Untersuchungen. P'rag I888.

111 Vialleton, Recherches sur les premieres phases du dézeloppement de la seiche. P'yris I888.

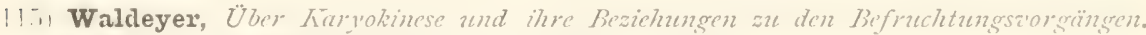
Archiv fo mikrosk. Anatomie. Bd. XXYll. 1888.

11 (i) Wilson, E. B., Archoplasm, Centrosome and Chromatim in the sea-urchin egg. Jonem. of Horph. Wol. XI. 1895 .

11.) Zandex, R., Über den gegenziditigen Stand der Lehre zon der Zellteiluns. Biolos. Zentralblatt. Bd. HII. 1802 .

114 Ziegler, H. E., Die biologische Bedentung der amitotischen Kernteilnug inn Therreich, Biolog. Zentralblatt. Bd. WI. 1891.

11 !) Ziegler u. vom Rath, Die amitotische Fernteilung bei den Arturopoden. Biolog. Zentralblatt. Ba. HI. I80I.

1.'1) Zoja, R., Sulla independenza della cromatima paterna e materna nel nucleo delle cellule cmbrionali. Anat. Anz. Bd. XI. 1895.

Ausführliche Literaturansammenstellungen ïber Kern- und Zellteilung findet man in den Berichten von Flemming und Weves in den verschiedenen Jahrgängen von llerkelBonnets ,Ergebnissen der Anatomie und Entreicklungsgeschichte". 


\section{NEUNTES KAPITEL.}

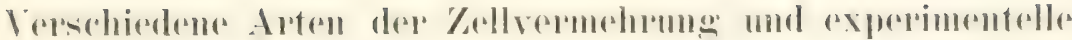 Abänderung des Verlaufs der Zellteilung.}

\section{I) Allgemeine Regeln.}

Abgesehen von den im letzten Abschnitt besprochenen l'rozessen der

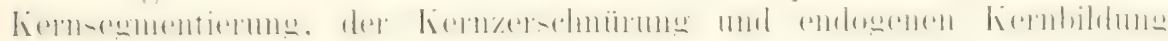
kann die Zellvermehrumg noch ein sehr verschiedenartiges Aussehen gewinnen, je nach der Art und Weise, wie sich der Protoplasmakörper bei rler Teilung verhält. Ehe wir uns mit den hierdurch bedingten Hauptarten umd Unterarten der Zellvermehrung bekannt machen. wird es zuror notwendic sein. auf einige allgemeine Beziehungen zwischen Kern und Protoplasma einzugehen. auf welche ich in meiner Schrift. . Welchen Einfluf. übt die Schwerkraft auf die Teilung der Zellen" (O. HerTwig IX 188t) die Aufmerksamkeit gelenkt habe.

In der ruhenden Zelle kamn der líern bald diese, bald jene Lage einnehmen, auch seinen Ort verändern, wie er denn zum Peispiel in Pflanzen-

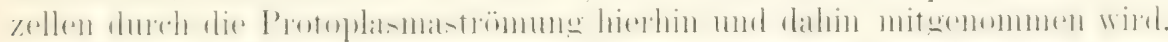
Unter besonderen Verhältnissen aber, von denen hier nur die zur Zellteilung in Beziehung stehenden erörtert werden sollen, während andere uns in Kapitel X beschäftigen werten, tritt der Kern zum Protoplasmaköryer in ganz bestimmte, gesetzmäbige Lagebeziehungen.

Zwischen Protoplasma und Kern finden während der T'eilung Weehselwirkungen statt. un mich eines Gleichnisses zu bedienen. wie zwischen Eisenteilchen und einem beweglich aufgehängten Magneten. Durch die magnetische Kraft werden die Eisenteilchen polarisiert und dadurch veranlabt. sich in Radien um die Pole herum zu gruppieren. Auf der anderen Seite aber üht die Massenverteilung des Eisens auf die Stellung des Magneten anch wieder einen richtenden Einfluf aus. In der Zelle erhalten

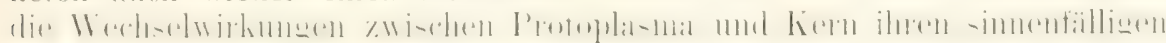
Anshruck in den frïher beschriebenen Strahlenfiguen. welche in der Ungebungrer Centrosomen entstehen. Die Folge dieser Wechselwirkungen aber ist. dab der Kern stets die Mitte seiner Wirkungssphäre einzunehmensucht.

Un diesen Satz zu beweisen. gibt es wohl keine geeigneteren Objekte als die tierischen Eizellen. die uns ja in ihrer (iröbe, Form und inneren Oroanisation sehr zahlreiche, interessunte Verschiedenheiten darbieten.

Bei den meist kleinen Eiern, in denen Protoplasma und Dotterbestandteile meln oder weniger gleichmälog verteilt sind. nimmt der Eikern vor der befruchtung (Fig. 196-1) keine fest bestimmte Lage ein. 
Wemn er dagegen nach der Befruchtung als Keimkern in 'Tätigkeit zu treten begimnt (Fig. $19(6, B)$, stellt er sich genau in (len geometrischen Mittelpunkt ein, also, wenn das Ei eine Kugel darstellt, in das Zentrum derselben, wenn es dagegen eine ovale Form hat (Fig. 200), in die Mitte
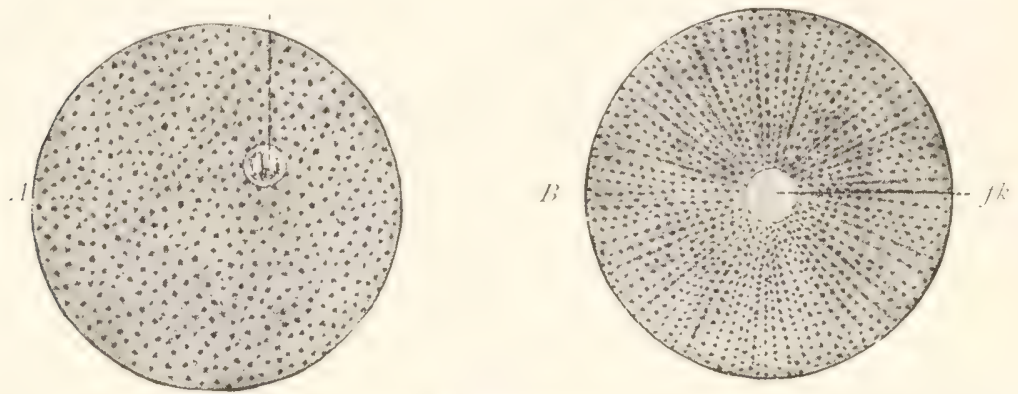

Fig. 196. A Reifes Ei eines Echinoderms. Dasselbe schließt im Dotter den sehr kleinen Eikern ( $e k)$ ein. Tach O. Hertwig, $B$ Ei eines Seeigels gleich nach beendeter Befruchtung. $f k$ Ei- und Samenkern sind zum Keinkern verschmolzen, der im Zentrum einer Yrotoplasmastrahlung liegt. Nach O. HertwiG.

der die heirlen Pole verhindenden Längiachse. Ton einer strahlensphäre umgeben, sieht man den Kiern durch das Protoplasma nach dem im voraus zu bestimmenden Ort hinwandern.

Ahweidhungen ron der Sormalstellung treten häufig infolge besonderer Verhälnisise ein. woldhe sich zum Teil feststellen lasien. zum Teil aber sich
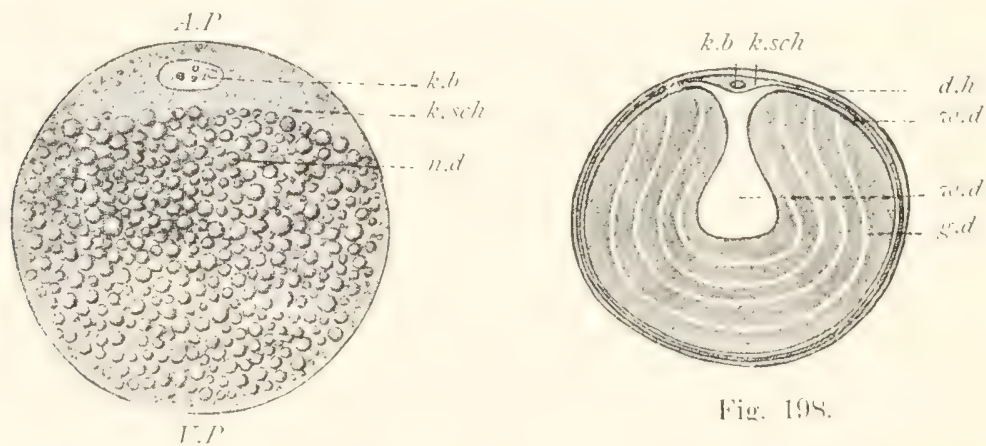

lig. $1: 4$.

Fig. 197. Schema eines Fies mit polständigem Nahrungsdotter. Nach 0. Hertwit. Der Bildungsdotter bildet an animalen Pole A.P eine Keimscheibe k.sch, in welcher das Keimblischen $k \cdot b$ eingeschlossen ist. Der Nahrumgsdotter nod füllt den ïbrigen Eiraum nach dem vegetativen Pol $(I . P)$ zu aus.

Fig. 1!M. Eizelle (Eidotter) des Huhns aus dem Eierstock. Narh (). Hwr'TwIt. k.sch Keimscheibe, k.b Keimbläschen, a'd weißer Dotter, g.d gelber Dotter, $d . h$ Dotterhaut.

noch unserer lienntnis entziehen, So bildet einen wichtigen Faktor, durch welchen die Stellung des Kerns reguliert wird, die Art und Weise, in welcher Protoplasma und Dotterbestandteile, von denen die letztern meist ein gröberes spezifisches Gewicht als clas erstere besitzen, ungleichmäBig im Eiraum verteilt sind. Sehr häufig nehmen dann die Eier eine polare 
Differenzierung an, die teils eine direlite Folge der Schwerliraft ist. muter deren Eintlub sich eine Sondermug der verschiedenen Substanzen nach ihrer schwere vollzieht. teils aber auch durch andere lorwinge wie dureh die Reife- und Befruchtumgerscheinumgen hervorgerufen wird.

Die polare Differenzierung besteht darin (Fig. 1976 u. 198). (lab sich nach dem einen Pol zu das leichtere Protoplasma, nach dem anderen Pol dagegen das schwerere Dottermaterial ansammelt. I) cie conderung hann bald weniger, bald schärfer durchgeführt sein. Bei den Eiern der Anphibien \%. B. ist sie in Durehsehnitten dureh ein Ei sehr wenig antfillig, indem nu in der einen Hälfte die Dotterplätchen etwas kleiner und dureh mehr Protoplasma voneinander getrennt sind, in der anderen Hälfte aber gröfer werden und dichter zusammenliegen. In anderen Fällen hat sich vom dotterhaltigen 'Teil des Eies eine kileine Menge ron mehr oder minder dotterfreiem Protoplasma abgesondert und wie bei den Reptilien und Vögehn (Fig. 198k.sch) die Form einer Scheibe angenommen.

Die beiden Pole des Eies unterscheidet man voneinander als ten animalen und den vegetativen: an jenem ist mehr Protoplasma, an diesem meln Dottermaterial angesammelt, jener hat daher ein geringeres. dieser ein grobleres spezitisches Gewicht. Infolgerlessen müssen polar differenzierte Eier stets ein und dieselbe Gleichgewichtslage einzunehmen suchen. ITährend bei kleinen Eiem mit gleichmäbig verteiltem Material der Schwerpunkt mit dem Mittelpunkt der Kugel zusammenfällt und ihre Lage daher eine wechsehnde sem kann, ist bei polar differenzierten Eiern her. Schwerpunkt exzentrisch geworden, und zwar hat er sich mehr orler minder weit nach dem vegetativen Pole zu verschohen. Es wird daher stets eine solche Orientierung in Raume eintreten, dab der vegetative Pol nach abwäts, der animale nach oben gekehrt. ist. Eine Linie, welche die beirlen Pole verbindet und als Eiachse bezeichnet wird,

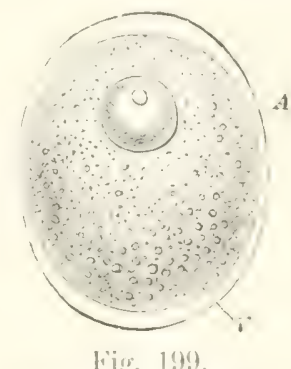

Eivon Fabricia. Nach HAECKL. A animaler Teil, $I$ 'vegetativer'Teil. muB sich. wenn keine Hindernisse der freien Bewegung der Eikngel entgegentreten, stets lotrecht einzustellen suchen.

Lehrreiche Beispiele hierfür bieten das Froschei und das Hühnerei.

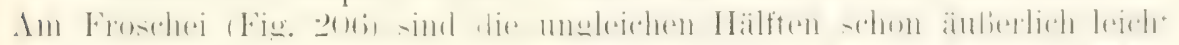

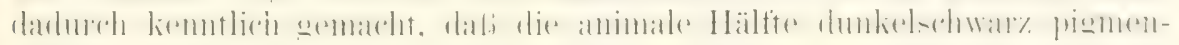
tiert ist. die regetative weibgell aussieht. Wird ein solches $\mathrm{Ei}$ nach der Befruchtung in das Wasser gehracht, so nimmt es in wenigen sekunden eine feste Ruhelage ein. indem sich stets die schwarze seite nach oben. die helle Seite, weil sie speritisch schwerer ist, nach abwärts kehrt. Fibenso mag man das Hïhnerei (Fig. 198) drehen, wie man will, stets wirl man die Keimscheihe (k.sch) den höchsten P'unkt der Dotterkugel eimnehmen sehen. weil letztere bei jerler Bewegung in ihrer Eiweibhülle mit rotiert und sich mit dem regetativen Pol nach abwärts einstellt. - Polare Differenzierung kommt ebenso wie hei kugeligen auch bei ovalen Eiern ror. As Beispiel diene uns dats bi emes Wumes, Fabricia (Wig. 19!9). Hier ist am einen Ende des ovalen Körpers mehr Protoplasma, am entgegengesetzten mehr I) ottermaterial angehïuft.

Bei polar differenzierten Eiern wird man num den hefruchteten liern rergebens an den Stellen. wo er bei dotteramen Eiern liegen würde. suchen. Nur einer ohertiählichen lietrachtuns wird dies als eine dusnahme von dem oben aufostellten fiesetz erscheinen: bei fieferem Virch- 
denken dagegen bilden solche Fälle eher eine Bestätigung des Satzes, daß der Kern stets die Mitte seiner Wirkungsphäre einzunchmen sucht. Wechsehwirmoen finden zwischen dem Kern und dem Protoplasma, nicht aher zwischen ihm und dem Dottermaterial statt, welches bei allen Teilungsmozessen sich wie eine passive Masse verhält. Ungleichmäßigkeiten in der Protoplasmaverteilung missen sich daher auch auf Grund des ohigen Satzes in der tage des Kerns geltend machen, und zwar muls derselhe nach den Orten der gröferen l'rotoplasmaansammlung himricken, sich also gerarle in entgegengesetzter Richtung wie der Schwerpunkt bewegen. Je mehr der letztere nach dem regetativen Pole, um so mehr wird der Teilkern nach dem animalen Pole zu liegen kommen. Und so lehrt es uns auch die Untersuchung in der Tat. In Froschei (Fig. 206) findet sich (ler. Keimkern etwas oberhall) der Ä (quatorialebene der Kugel in ihrer animalen Hälfte; in den Eiern, an denen sich das Protoplasma als Kieimscheibe noch schärfer vom Dotter gesondert hat (Fig. 198), ist der Keimkern in nächste Nähe des animalen Poles emporgestiegen und in die Keimscheibe selbst aufgenommen worden (Reptilien, Vögel, Fische etc.). Ebenso ist im Ei ron Fabricia (Fig. 199) der Kern nach der protoplasmareicheren Hälfte des ovalen Körpers verschoben.

Noch mehr tritt die Wechselwirkung zwischen Protoplasma und hiern, durch welche die Lage des letzteren berlingt wird, während der Teilung selbst hervor, von dem Moment an, wo sich die beirlen Pole bilden. Es läbt sich hier das zweite allgemeine Gesetz aufstellen. daf die beiden Pole der 'Teilungsfigur in die Richtung der gröhten Protoplasmamassen zu liegen kommen, etwa in derselben Weise. wie die Lage der Pole eimes Magneten durch Eisenteile in seiner Umgebung beeintlubt wird. Nach dem zweiten Gesetz kann z. B. in einem kugeligen Ei, in welchem Protoplasma und Dotter gleichmäbig verteilt sind, die

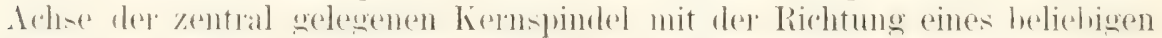
Rarlius, dlagegen in einem ovalen Protoplasmakörper nu mit seinem längsten Durchmesser zusammenfallen. In einer kreisrunden Protoplasmascheibe stellt sich die Spindelachse parallel zur Obertläche in einen beliebigen Durchmesser. in einer ovalen Scheibe dagegen wierler nur in den längsten Durchmesser ein.

Mit diesen Regeln stimmen die Erscheinumgen, wie sie bei der Zellteilumg und besonders bei der Eifurchung beobachtet werten, im allgemeinen ïberein. Namentlich aber sprechen für die Gültigkeit des an zweiter Stelle aufgestellten Gesetzes zwei Tatsachen: Beobachtungen ron AuERBACH (VIII 1874) an den Eiern von Ascaris nigrovenosa und Strongylus auricularis und Experimente von Pflüger, Roux, Hertwig, Driesch und anderen.

Die Eier (ler beiden von Auerbach untersuchten Nematoden (Fig. 200) haben eine ovale Gestalt. so dab zwei Pole an ihnen zu unterscheiden sind, welche bei der Befruchtung eine verschiedene Rolle spielen. An dem einem Pole nämlich. welcher dler Keimstätte des Eischlauches zıwewendet ist, bilden sich die Polzellen und entsteht der Eikern. an dem anderen, nach dem Uterusansgang zu gelegenen Pol dagegen findet die Befruchtung und das Eindringen eines Samenkörpers statt: hier erscheint

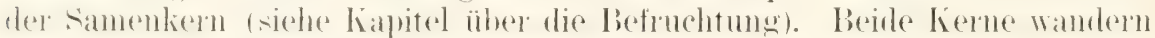

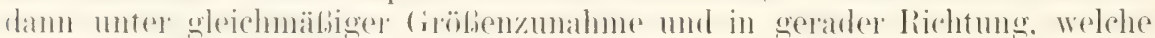
mit der Eiachse zusammenfällt. aufeinander zu. treffen sich in der Mitte der letzteren, nachdem sie zu zwei ansehnlichen Bläschen angewachsen sind. legen sich fent zusammen und platten sich an den Berïhrumgstlächen 
ab (Fig. 200 A). Es ptlegt mun die Achse der sich aushildenden Sinindel. an deren Enden die Centrosomen liegen, bei der liopulation der (ieschlechtskerne in ilue berïhungstläche orler in lie Kopulationsehene zu fallen. Wïrde dies auch hier erfolgen, so wïrle tie spindelachse entgegen des ohen anfwestellten Regel die Lïngsachse des Eies unter rechtem Winliel schmeiden. es wïrden die Centrosonen in der Richtung der kileinsten Protoplasmanengen eingestellt sein und es milfe schlieflich die erste 'T'eilungsebene das Ei seiner Länge nach lablhieren.
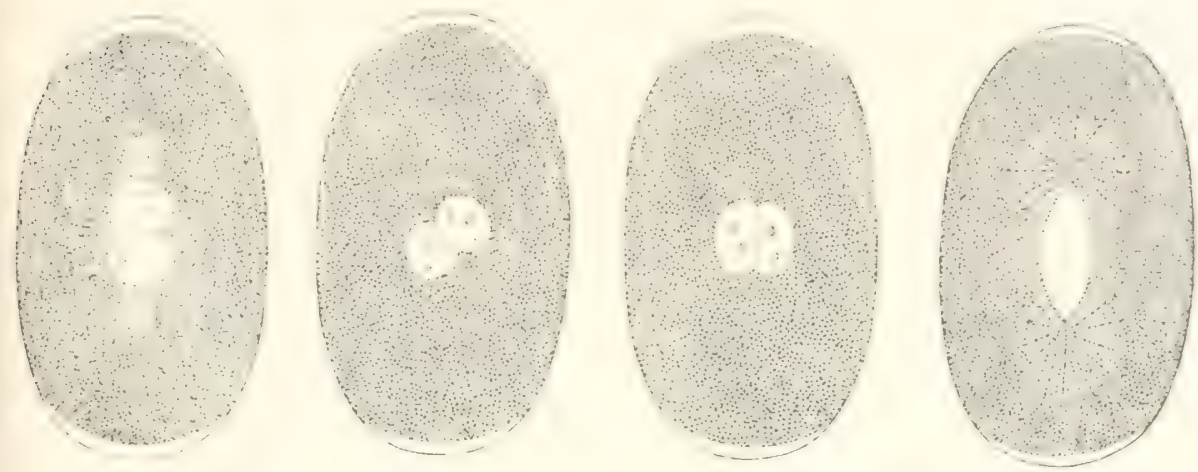

Fin 2n!. Eier von Ascaris nigrovenosa in stark komprimiertem Zustand

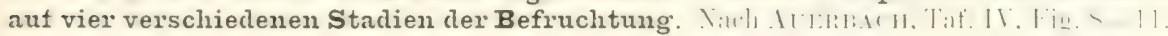

Ein derarticer, der Regel zuwiderlanfender Fall tritt num aber hier nicht ein. weil Protoplasma und Kern, indem sie anfeinander einwirken. ihr Lageverhätnis zu einander. den gegebenen bedingungen entsprechend. nachträglich regulieren. Die durch den Befruchtungsverlauf bedingte Ausgangstellung des kopulierten Kernpaares. welche eine für die Teilung durchaus unzweckmäbige ist. ändert sich. sowie sich die zwei Pole schärfer aushilden. Das Kermpar fämet an. sich um einen rechten Winkel zu drehen (Fig. 200 B), und zwar solange und in der Art. dab, die Kopulationsebene mit der Längsachse des bies zusammenfälit (Fig. 200C). ..Die Richtung, in weleher die Drehung unter dem Mikroskope erfolgt, geschieht bald im sime eines Urzeigers. bali im entgegengesetzten" (AUERBACH). Infolge des interessanten Rotationsphänomens kommen wierler. wie es die Regel verlangt, die beiden Pole der 'Teilungstigur in die Richtumg der gröbten Protoplasmaansammlungen zu liegen. während sich die geringste Menge in der (iegend der späteren Teilungsebene befindet (Fig. உ200 D).

Noch besser als durch die nach dem lebenden Ascarisei gezeichneten Figuren von AuerBacm wird die Notwendigkeit und Ursache der Drehmer des Kernpares verständlich werden durch die von mir entwortenen drei Schemata, in welchen die Lage der Centrosomen und ter sich bildenden Spindel und die um die Centrosomen entstehende und sich allmïhlich verstäkende Protoplasmastrahlung in die kopulierten kerne eingetragen ist. (Fi巛. $201 A B C$ ).

Ein zweiter Beweis für die (iültigheit unseres fieset\%es sind dic Experimente, welche PHïger (IX 18s:) 1884) am Froschei angestellt hat. Derselbe prebte ein frischbefruchtetes Foschei zwischen zwei rertikalen. 
palallelen (ilasplatten vorsichtig zu-immmen umb gah ihm dadurch ungefäh.

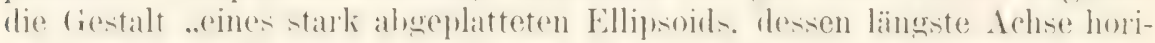
zontal, desien mittellange vertikal und dessen lïizeste wirder horizontal und senkrecht auf der längsten ist". In fast allen Fällen stand nun die

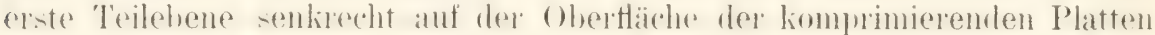
und war zugleich eine lotrechte. Die Kernspindel muß sich daher auch

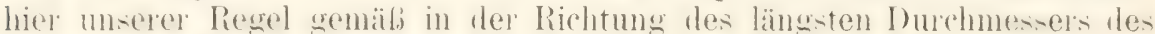
Ellipsoids eingestellt haben.

Aus der Regel, daß bei der 'Teilung die Lage der Kernachse von der Differenzierung und Form des umbiillenden Protoplasmaliörer's he-

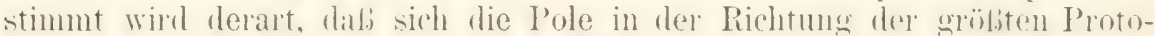
plasmaansammlungen einstellen, ergibt sich uns weiter noch die kausale Begründung für eine dritte Regel, welche Sachs (IX 1882)
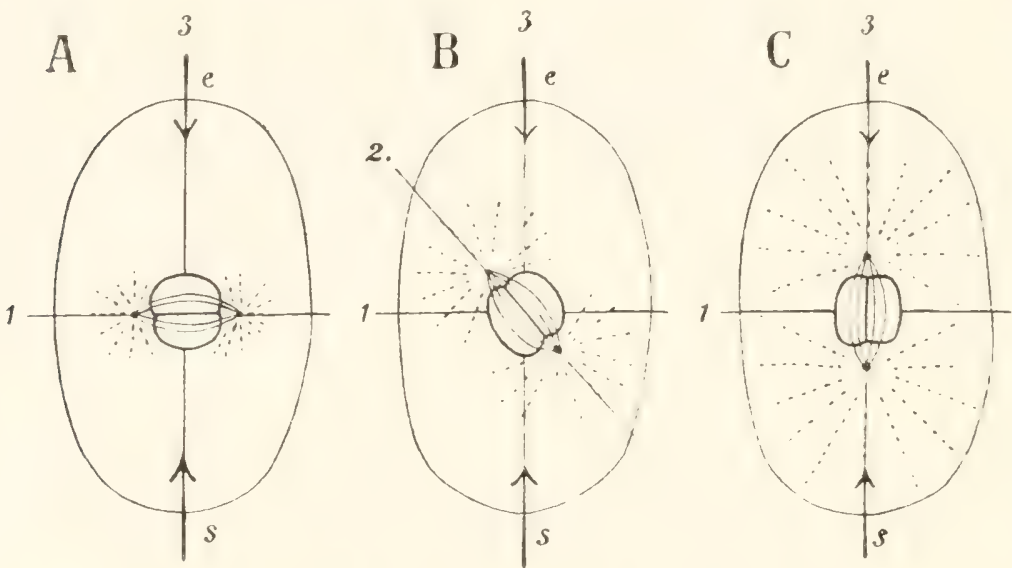

liig. 201. 3 Schemata des befruchteten Eies von Ascaris nigrovenosa, um die Drehung des kopulierten Kempares zu erläntern. Die P'feile $e$ und $s$ zeigen die Richtung an, in welcher sich Ei- und Samenkern aufeinander bewegt haben. Richtung 1 ist die Querachse des Eies, mit welcher die Teilebene später zusammenfält. Die Linie 2 zeigt die Richtung der Kopulationsfläche auf einem Zwischenstadium $B$ an. Nach O. HERTwIt.

beim Studium der Pflanzenanatomie erhalten und als das Prinzip der rechtwinkligen Schneidung der Teilungsflächen bei der Zweiteilung bezeichnet hat. Denn wenn wil die Ursachen wissen, durch welche die Lage der Spindelachsen bedingt wird, dann können wir unter allen Umständen auch im voraus bestimmen. wie die T'eilungsebenen zu

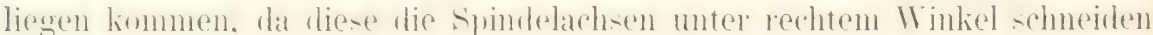
müssen. Eine weitere Konsequenz unserer Regel ist, daß die 'Trennung der Zelle in einer Fläche minimae areae erfolgt.

Im großen und ganzen wird num bei jeder Teilung einer Mutterzelle, wenn dieselhe nicht in einer Richtung außerordentlich in die Länge gestreckt ist, der Fall eintreten. dah in den Tochterzellen die Achse, welche

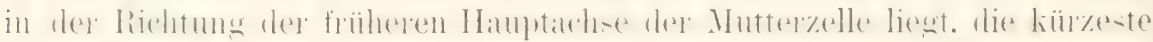
geworden ist. Die Achse der zweiten Teilspindel wird sich daher in diesem

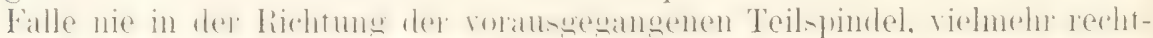

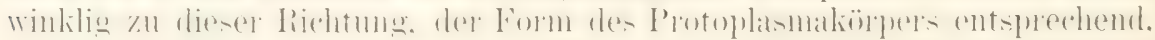
einstellen müssen. Daher wird die zweite Teilebene die erste rechtwinklig 


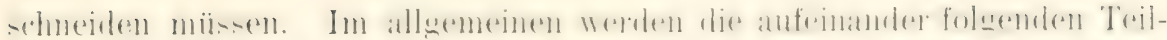
fïchen einer Mutterzelle, die in 2, 4, \& und mehr 'Tochterzellen durch

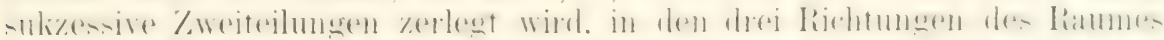

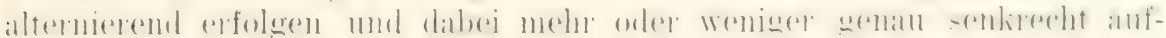
einander stehen.

Bei pHanzlichen Geweben ist dies oft sehr schön zu erkennen, weil

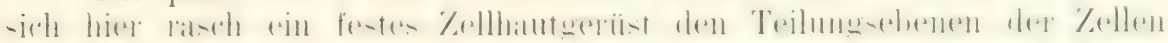

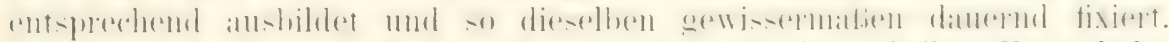
Bei tierischen Zellen ist es viel weniger der Fall, weil ihre Form beim Fehlen einer festen Membran sich zwischen den 'Teilungen häutig ver-

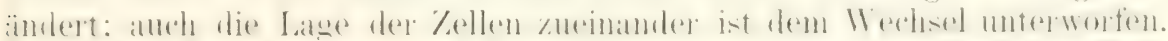

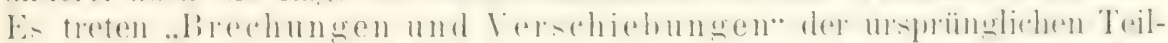

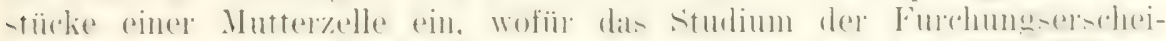

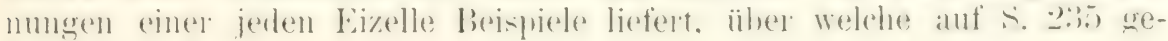
handelt wirt.

In der Botanik werden die in den drei Richtungen des Raumes sich

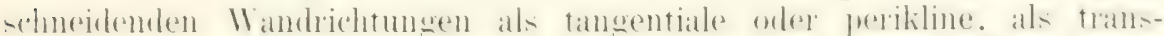

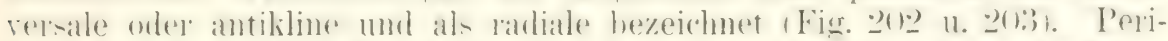

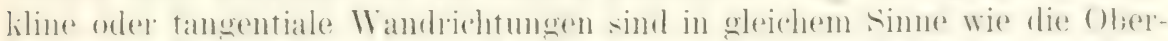

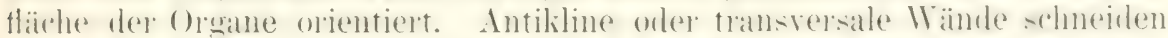

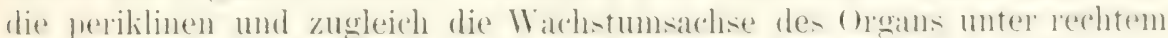

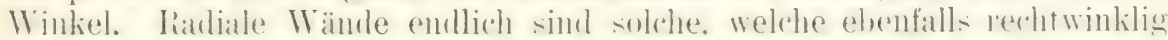

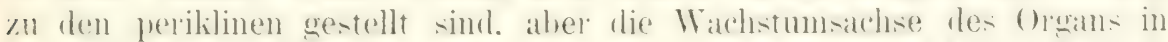
sich aufnehmen. Lm dieses Verhälnis an einem lieispiel litu zu machen, wählen wil gleich ein etwas schwierigeres Ohjekt, den Vegetationsmunt

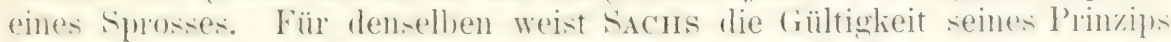

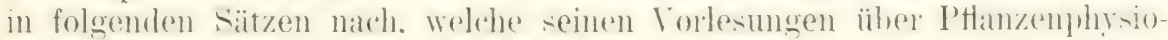
logie (III 1882) entnommen sind:

..Die Vegetationspunkte der Wurzeln und Sprosse zeigen auf richtig

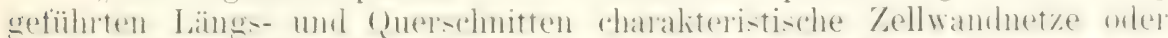

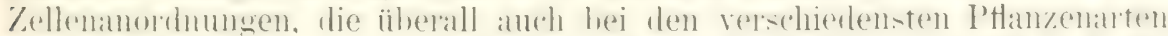

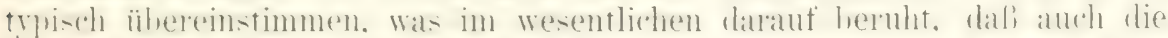

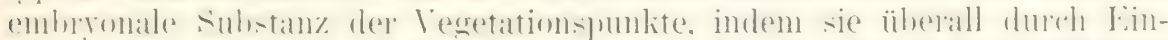

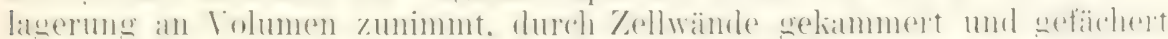

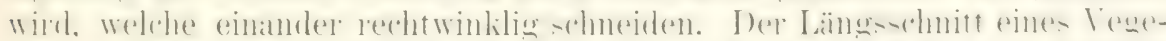

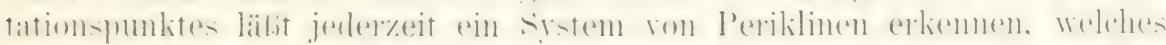

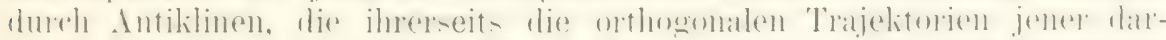
stellen, geschnitten wirl. Haben wir es dabei mit Vegetationspunkten fächenförmiger Gebilde zu tun, so sind auch nur diese beiden Systeme

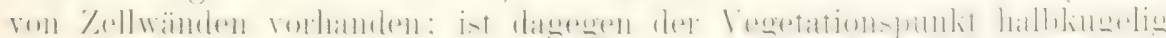

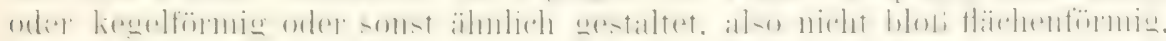
sondern körperlich gebildet, so ist noch ein drittes Srstem von Zellwänden vorhanden, nämlich Längswände, welche von der Längsachse des Vegetationspunktes aus rarlial mach außen verlauten."

..Es wird jedoch zur Erleichterung des V'erständnisses beitragen. wemn wir auch hier wieder unsere weiteren Betrachtungen an ein nach

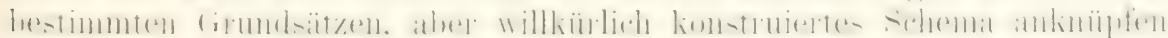
und zunächst für dassell)e nu die Flächenansicht eines Längsschnittes durch einen Vegetationspunkt (Fig. 202) zugrumde legen. Halten wir uns hierbei an unsere Figur, deren Umriß E E dem Längsschnitt eines liegelfömigen Vegetationspunktes entspricht, und setzen wir voraus, dalí) dieser Umrib, wie es auch häufig in der Natur nahezu eintrifft, die Form eines Parabel habe und daß die Fiticherung des Rammes, den die embronale 
Substanz des Vegetationspunlites erfüllt, wieder in der Art stattfinde, dab anti- und perikline Winde einander rechtwinklig schneiden. Unter dieser Toraussetzung kann man nun nach einem bekamnten Lehrsatz der Geometrie das Zellnetz in unserer Figur konstruieren: vorausgesetzt, daß $x$ die Achse mnd $y y^{\prime}$ die Richtung rles Parameters ist, sind alle die mit $P p$ bezeich-

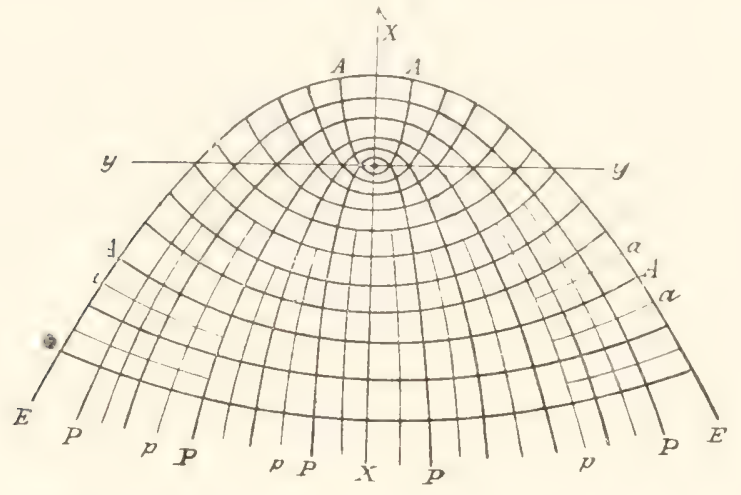

Fig. 202. Konstruktion des Zellnetzes an einem vegetationspunkt. Nach SiCHs, Fig. 284. neten Periklinen eine Schar von konfokalen Parabeln. Ebenso sind alle Antiklinen $A$ a eine Schar konfokaler Parabeln, welche Brennpunkt und Achse mit den vorigen gemeinschaftlich haben. aber in der entgegengesetzten Richtung verlaufen. Zwei solche Sriteme lionfokaler Parabeln schneiden einander ïherall rechtwinklig."

„Sehen wir num nach. ob ein medianer Längsschnitt durch einen volgewölbten. ungefähr parabolisch geformten Vegetationsumbt ein Zellnet\% darbietet, welches in den wesentlichen Eigenschaften mit unserem geometrisch konstruierten Schema übereinstimmt. da finden wir z. B. am Vegetationspunkt der Esleltame (Fis. o(1): sofort die entsprechende innere Struktur, wenn man nur beachtet, daß in unserer Figur die beirlen Vor-

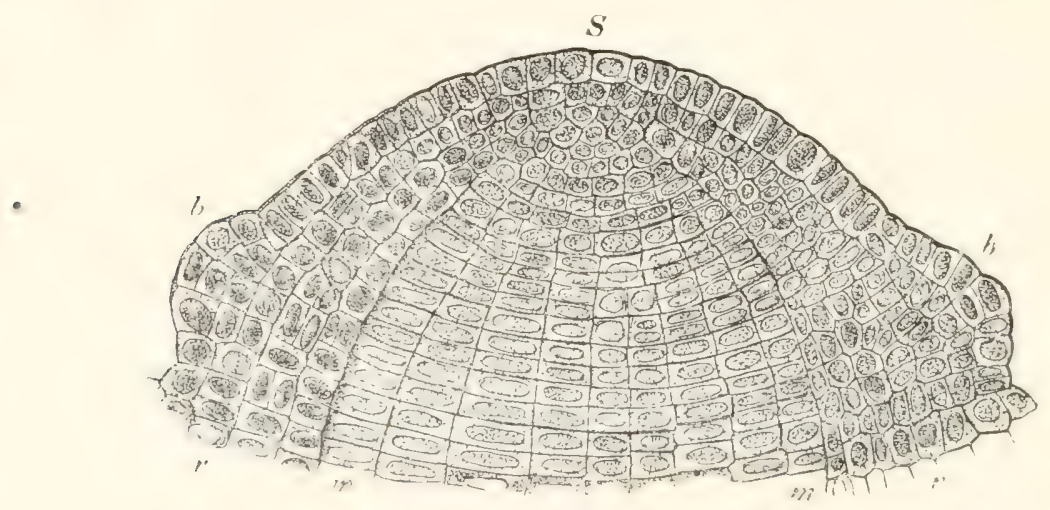

Fiv. - I:: Tängsschnitt durch den Vegetationspunkt einer Winterknospe der Edeltanne (Abies pectinata). Ungefähn $200 \mathrm{mal}$ vergrölert. Nach SAcHs, Wig. 25.). $S$ Scheitel des Vegretationspunlites, $b$ b jumgste Blatter, $r, \cdot$ Rinde, $m$ m Mark.

wölbungen $b 6$ das Bild einigermafen stören; es sind junge Blattanlagen, welche aus dem Vegetationspunkt hervorsprossen. Im übrigen erkennt man sofort die beiden Systeme von Anti- und Periklinen, deren Krümmungen kaum einen Zweifel darüber lassen, dah sie einander, wie in unserem obigen Schema, rechtwinklig schneiden oder die Antiklinen die orthogonalen Trajektorien der Periklinen sind. So wie in unserem Schema umlaufen auch nur einige wenige Periklinen unter dem Scheitel $S$ den ge- 
meinschaftlichen Brenmuntit aller Parabehn, die anderen reichen, von unten herkommend, nur bis in die Nähe des Brempunktes, d. h. mit anderen Worten: die entsprechenden Zellteilungen finden immer erst damn statt. wenn die Periklinen unterhall, des Krïmmungszentrums sich weit genug voneinander entfernt haben, so dal. neue Periklinen zwischen ihnen eingeschaltet werden müssen. und gan\% dasselbe gilt von den Antiklinen $A$ a. Man bemerlit leicht an unserem Schema (Fig. 202), dab um den gencin-

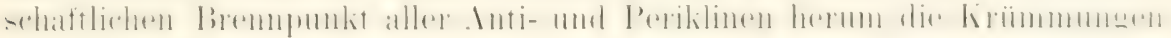
der honstruktionslinien besonders kräftig sind."

.. Viele Hunderte von medianen Lüngsschnitten durch legetationspunlite von Sprossen und Wurzeln, welche die verschiedensten Beobachter rezeichnet haben. ohne auch nur in entferntesten das zugrunde liegende Prinzip zu kennen, entsprechen der von mir gegehenen Konstruktion und beweisen die Richtigkeit ihres Prinzips."

Lm endlich einige Abweichungen von der normalen Zellteilung zu verstehen. ist noch eine vierte Regel zu beachten, welche von lialfour (VIII 1s-1) genaner formuliert ist und welche lautet: Die Schnelligkeit. mit welcher sich eine Zelle teilt, ist proportional der konzentration des in ihr befindlichen Protoplasmas. Protoplasmareiche Zellen teilen sich rascher als protoplasmaämere. aber dotterreichere. Der Satz erklart sich daraus, dab beim 'Teilprozel allein das

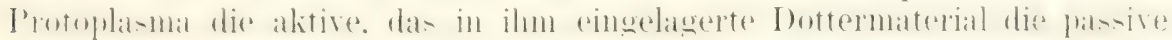
Substanz ist, welche durch die aktive mit bewältigt werden muß. Die Arbeit für das Protoplasma bei der Teilung ist um so gröber, je mehr Dotter vorhanden ist, und sie kamn in vielen Fällen sogar eine so grobe werden, daf sie nicht mehr zu Ende geführt werden kamn. Letzteres tritt häutis bei polar differenzierten Eiern ein. wenn hei ihnen sich der Hanpt-

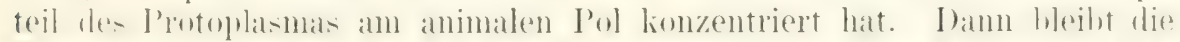

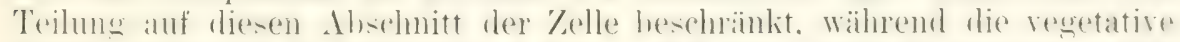

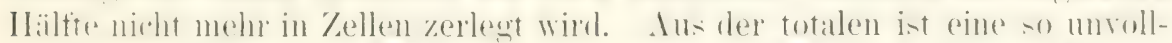

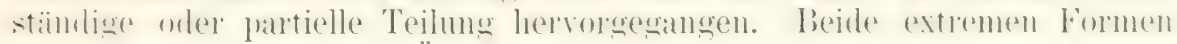
sind in der Natur durch Übergänge niteinander verbunden.

Wer sich etwas eingehender mit dem Studium des Furchungsprozesses und der über ihn handelnden Literatur beschäftigt hat, weib, dab

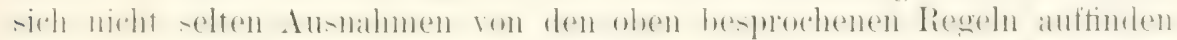
lassen. Es braucht hier nur an die Bildung der Polzellen, ïber welche im Kapitel XI noch gehandelt werden wird, hingewiesen zu werden. Nach

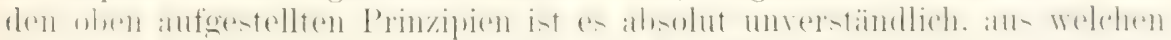

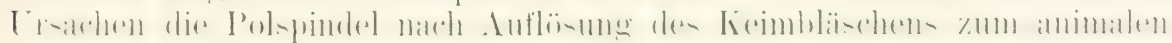
Pol hinaufwandert. bis sie mit ihrer Spitze die Obertäche berïhrt, warum sie in radiärel Richtung sich einstellt und zwei Teilprodukte liefert. ron denen das eine nur eine winzige Menge von Protoplasma besitzt. [nol so finden sich noch manche andere. wenn auch weniger auffälige Ausnahmen. die sich besonders in einer Abhandlumg von .J Exxisgs (VIII 1s(16) zusammengestellt finden; z. B. können sich zylindrische oder prismatische \%ellen des Cambinms. wie BERTHOLD (I iss(i) hervorheht. ilner Länge nach teilen. Solche Ausnahmen beweisen aber nichts gegen die Richtigheit del oben gegebenen Regeln, sonrlern zeigen uns nur wierler. was ich stets und überall zur (ieltung zu bringen bemüht bin. dals die Lebensprozesse von sehr vielen Faktoren beherrscht werden und daher in ihrem Verlaufe oft unberechenbar sind.

Mit Recht bemerkt Richard) HerTwig (VIII 1:4): S. 5it): ..Del Grumberlanke des von einigen Seiten angegriffenen Satzes: dalis sieh die Pole 


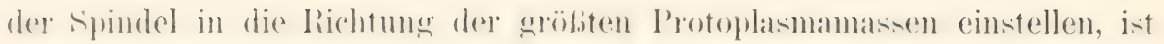
durchaus zutreffend. Nu mub man beriicksichtigen, dab er sich auf

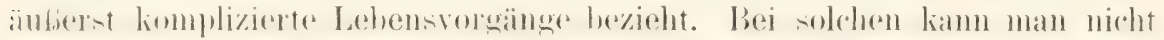

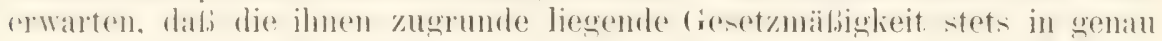
den gleichen Erscheinungsformen zum Ausilruck kommt. Welche Anorthmgen ein nath dem IIERTwischen Prinzip wirkender Teilungsapmarat herbeifühen wird, heruht anf dem Ineinandergreifen zahlreicher Einzel-

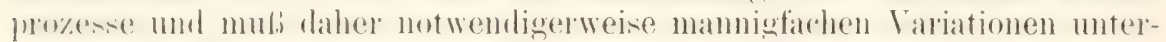
liegen, je nachdem die Wirkungsweise der einzelnen Faktoren in ihrer

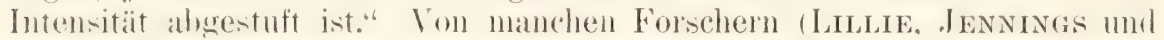

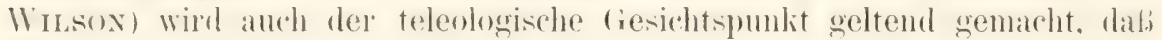
die Art der Zellteilumg durch dic suatere Verwendung der Zellen mit hestimmt werle. WILSON (III 1900, p. 377) erblickt hierin die Andeutung eines ..tiefer liegenden Wachstumsgesetzes. das die ganze Bildung des kingers heriihrt”. „We camnot comprehend the forms of cleavage without reference to the endresult: and thus these phenomena acquire a certain teleological character so happily expressed of LiLLiE."

Behufs richtiger Beurteilung der Verhältnisse ist endlich auch zu headnten, dab die Lage der Teiltächen, wie sie ummittelbar bei der Durchschmeidumg der Mutterzellen entsteht, sehr häufig noch verändert wird infolge nachträglich sich einstellender Vershiebungen. Da die Zellen weiche. wasserreiche (iebilde darstellen, so sind sie in ihrer Anordumng den ron Platead ermittelten Gesetzen über das Schammgewebe minterworfen. In einem solchen aber ordnen sich die einzelnen Sicheidewände. durch welche die Blasen oler "Zellen" des Schammes gegenseitig abgegrenzt werlen, nach dem Primzip der kleinsten Flächen, d. h. so an, dab bei dem gegehenen Volumen der einzelnen blasen die Summe aller (Obertächen ein Minimum wirl. ..Hierlei treffen läng einer gemeinsanen Kante nic mehr als drei Lamellen zusammen unter gleichen Winkeln von $170^{\circ}$ und in (inem Punkt nur vier Lamellen." Unter Zugrumdelegung dieses Prinzips lasien sich die Bredhungen und Verschiehmugen erhlären. welche die bie-

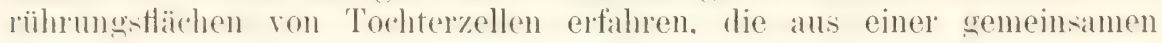
Mutterzelle hervorgegangen sind, wie man hesonders sehön an den Furchungszellen tierischer Eier beobachten kann. Aber auch im Pflanzengewebe treten diesellen ein. solange die jungen \%ellulosewände noch dümn. weich mol biegsam sind. Daher wird der Botaniker in allen Geweben, die nicht mehr in T'eilumg hegriffen sind, rergehlich nath rechtwinklig sich schneilenden Zellwänden suchen. „Endlich wölbt sich im Zellgewebe, wie im Seifenschamm. die Tremmungsmembran derjenigen Zolle zo, walche die groblere ist."

\section{2. Übersicht der Arten der Zellteilung.}

Überblicken wir mun die verschiedenen Arten der Zellteilung. so lassen sich dieselben in folgendes Schema bringen, welches ich der Einzelbesprechung zugrunde lege:

I. Typus. Die totale Teilung:

a) äquale.

b) inäquale,

c) Knospung.

II. Die partielle T'eilung.

III. Die Vielzellbildung. 


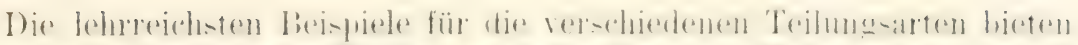

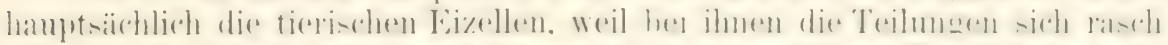

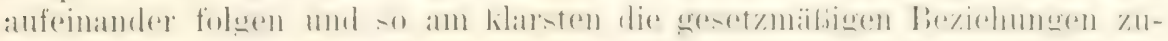
einander erkennen lassen.

\section{I". Die ïtuale 'T'eilung.}

Bei der äyualen 'Teilumg zerfällt das Ei, wenn es wie gewöhnlich die Form einer liugel besitzt, zuerst in zwei Halbkugeln; bei der darauf-

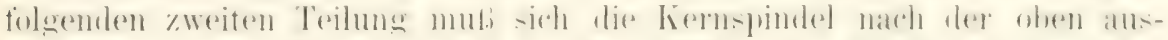

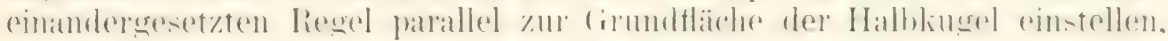
so dab diese sich jetzt in zwei Quadranten teilt. Hierauf muls die

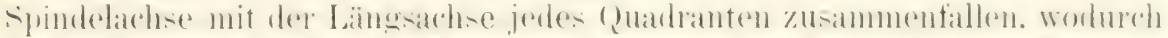
eino \%erlegung in je zwei Olitanten herbeigefïhrt wirl. Infolgedessen int

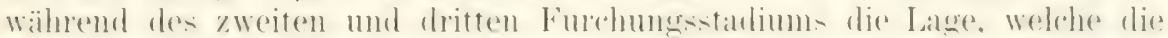

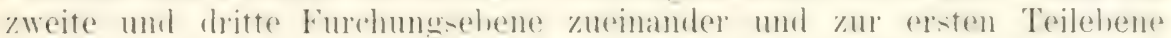
einhalten. eine streng genetzmäbige. Es halliert nämlich stets die zweite

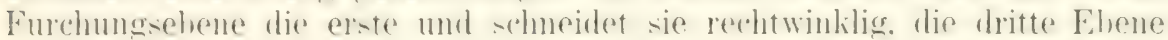
aber steht wieder senkrecht auf den beiden ersten und geht durch die

Fin. 211.)
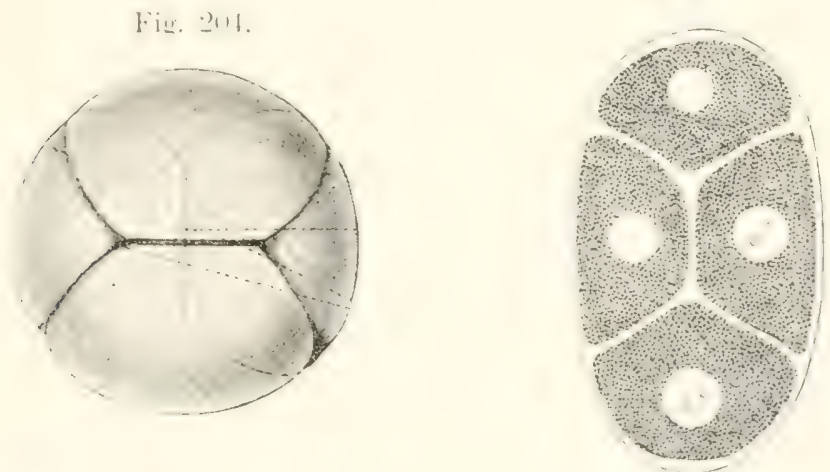

Fig. 204. Viergeteiltes Ei von Sagitta vom animalen Pol aus gesehen. 160 mal verorifiert. HertwIs, 'T'af'. $V$, Fig. 5.

Fig. 205. Viergeteiltes Ei von Ascaris nigrovenosa. Nach AUERBACH, Taf. IV, Fig. 19.

Nitte der Achse hindurch, in welcher sich diese schmeiden. Wenn man num die Enden dieser Achse als Pole des Eies betrachtet. so liann man die ersten beiden Teilungsebenen als meridionale, die dritte als eine iituatoriale bezeichmen.

Schon nach der zweiten Furchumg lassen sich in vielen Fillen die oben auf das Plateausche Gesetz zuriickgeführten Verschiebungen der vier 'Teilstücke anemander beohachten, welche zur Folge haben, daßs die von der zweiten 'T'eilung herrïhrenten Furchen sich nicht mehr an den

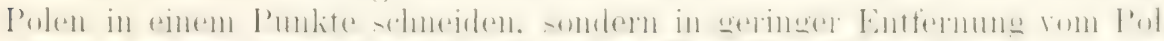

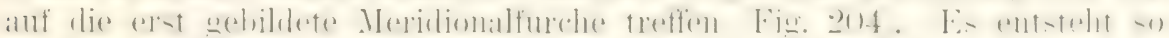
eine bald kïrmere, bald längere Querlinie, welche als Brechungslinie bezeichnet wird. Besonders schön ausgebildet habe ich (O. Hertwig. LX 1880) eine solche bei den Eiern von Sagitta (Fig. 204) beobachtet:

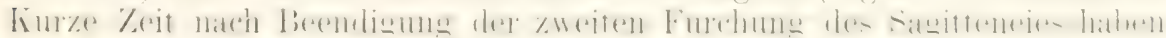
sich die vier Zellen so angeordnet (Fig. 204), dafo nur zwei von ihnen sich 
am amimalen Pol in einer kurzen queren Furche, der animalen Brechungslinie. treften: an die beiden Enden derselben stoken die beiden anderen Kellen, welche von der lierïhrung mit dem l'ole ausgeschlossen sind, mit zugespitzten Enden an. (ianz dieselben Verhälnisse wiederholen sich am regetativen Pol; nur treffen sich hier die beiden Zellen, welche den animalen Pol nicht erreichen, in einer vegetativen lirechungslinie, und diese ist damn stets so orientiert, daß sie die entgegengesetzte Brechungslinie,

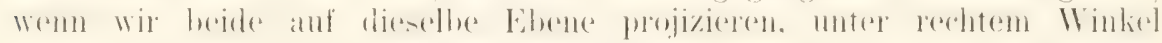
kreuzt. Die durch Vierteilung entstandenen vier Zellen sind also keine regehmäßigen Viertel einer Kungel; an jeder kömnen wir ein stumpfes und

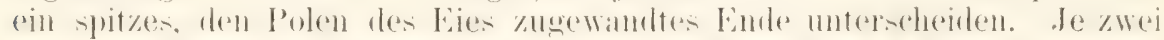
ans einer Italhlingel alstammende \%ellen sind damm in der Weise gruppiert. dab sie mit ihren stumpfen oder spitzen Enden nach entgegengesetzten Richtungen schauen.

Eine ähnliche Anordnung der vier ersten Furchungszellen ist an anderen

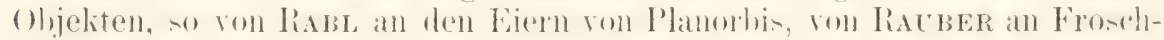
eiern beschrieben und von letzterem ausführlicher erörtert worden. Auch bei ovalgeformten Eiern, bei denen die erste T'eilungsebene nach unserem Gesetz quer zur Längsachse orientiert ist, finden während der zweiten Furchung, die senkrecht auf die erste erfolgt. bedeutende Verschiebungen statt,

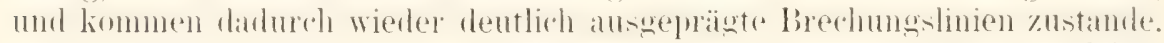
wie die Figur 205 von Ascaris nigrovenosa ohne weitere Erklärung lehrt.

\section{Ib. Die inäquale Teilung.}

Von der äqualen läßt sich leicht die inäquale 'T'eilung ableiten. Am häutigsten ist diesellue darlureh bedingt. dab in der \%elle Protoplasma num Dottermaterialien in ungleicher Weise verteilt sind. Als Beispiel diene
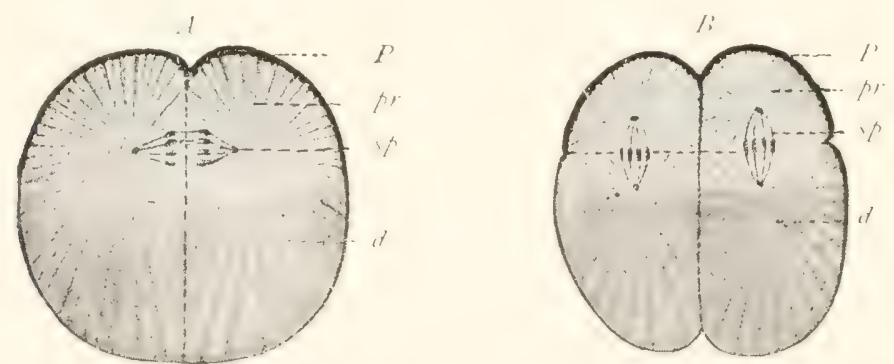

Fig. 206. Schema der Teilung des Froscheies. O. HERTwI;, Entwicklungsgeschichte, Fig. 31. A Erstes Teilungsstadium. B Drittes Teilungsstadium. Die vier

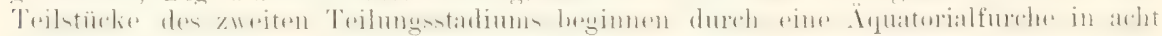
Stïcke zu zerfallen. P l'igmentierte Oherfläche des Fies am animalen Pol, pr protoplasmareicher, d deutoplasmareicher Teil des Eies, sp Iiemspindel.

das polar differenzierte Froschei. Bei diesem liegt, wie schon gezeigt

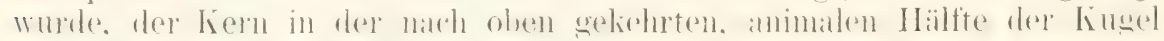
(S. 206). Wenn er sich hier zur Teilung anschickt, kann sich seine Achse nicht mehr in jeden beliebigen Radius des Eies einstellen; infolge der ungleichnäfigen Verteilung des Protoplasmas im Eiraum steht er unter dem Einflusse des protoplasmareicheren, pigmentierten Teils des Eies, welcher wie eine Calotte dem mehr deutoplasmahaltigen Teil aufliegt und wegen seiner geringeren, spezifischen Schwere obenauf schwimmt und horizontal ausgebreitet ist (Fig. 206 A). In einer horizontalen Protoplasmascheibe

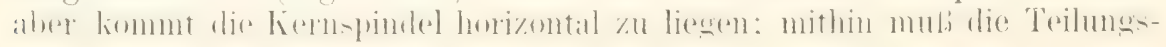


ebene sich in vertikaler Richtung bilden. Y/uerst beginnt sich eine lileine Furche an animalen Pole zu \%eigen. weil derselhe mehr unter dem EimHuf rler ihm genäherten Kermspindel steht und mehr P'rotopulasma enthält. ron welchem die liewegungserscheinungen bei der 'Teilung ansgehen. Die Furche vertieft sich langsam nach abwaits und schneidet nach dem vegetativen Pole zu durch.

Die durch den ersten Teilungsakt entstandenen zwei Ilalbkugeln sind aus einem protoplasmareicheren, mach oben gerichteten und ans einem nach abwäts geliehrten, protoplasmaämeren Qualranten zusammengesetzt. Dadurch wird erstens wieder die Lage und zweitens die Achse des hierns. wenn el in die zweite Teilung eintritt, fest bestimmt. Den liem laben wir nach dem frïher aufgestellten fresetz im protoplasmareicheren Quarranten aufzusuchen: die Achse ter Spindel muls sich hier parallel zur

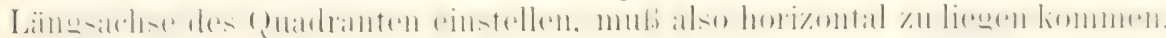
Die zweite Teilungsebene ist daher wie die erste lotrecht und schneidet sie rechtwinklig.

Sach Ablauf der zweiten Furchung besteht das Amphibienei aus vier

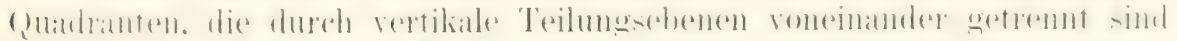

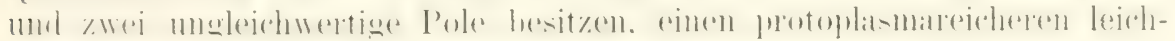
teren, nach oben gerichteten und einen dotterreicheren, schwereren, nach abwärts gekehten. Beim äqual sich furchenden Ei sahen wir, dab auf

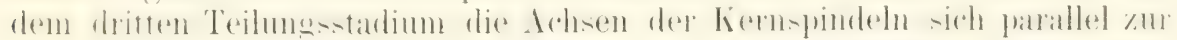
Längsachse der Quadranten einstellen. Das ist auch hier in einer etwas modifizierten Weise der Fall (Fig. 204 B $)$. Wegen des größeren Proto-
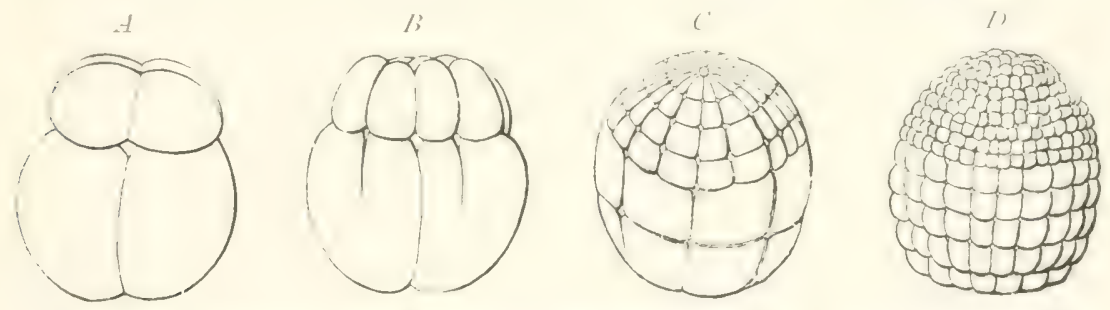

Fig. 20-. Furchungsstadien von Petromyzon. Aus HАтsснк, Fig. 72. A

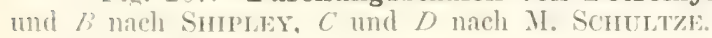

plasmareichtums der oberen Hälfte jedes (Quadranten kamn die Spoindel nicht wie bei dem äqual sich furchenden $\mathrm{Ei}$ in seiner Mitte liegen, sondern muf dem animalen Pol des Eies mehr genähert sein. Ferner steht sie genau vertikal, da die Quadranten des Amplibieneies wegen der ungleichen Schwere ihrer beiden IÏ̈lften im Raum fest orientiert sind. Infolgedessen mub jetzt die dritte Teilungsebene eine horizontale werden (Fig. 207.1), ferner mul. sie oberhalb des Äquators der Eilitugel mehr oder minder nach dem animalen Pole zu gelegen sein. Die Teilprodukte sind von sehr ungleicher Größie und Beschaffenheit und sind der Grumd. warum man diese Form der Furchumg als die inäquale bezeichnet hat. Die vier nach oben gelegenen Segmente sind lileiner und dotterärmer. die vier unteren viel gröfer und dotterreicher. Nach den Polen. denen sie zugeliehrt sind, werden sie auch als animale und als vegetative Zellen vonemander unterschieden. Den Eiern der Amphibien gleichen in diesem Verlauf der Furchung die Eier der Petromyzonten, denen als lieispiel Fig. $2(1)$ entnommen ist.

Der Gegensatz \%wischen den vier animalen und den vier vegetativen Zellen kann je nach den Tieren, deren Eier sich nach dem inäutualen Typus 


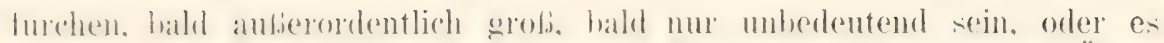
limmen in anderen Fällen zwirehen den Extremen alle mëglichen F̈bernaingf vorlommen. \%ur Illustration dieses lerhälnisces hat Wissox (III $1900)$ in Fig. $208 A-D$ vier interessante Beispiele zusammengestellt:
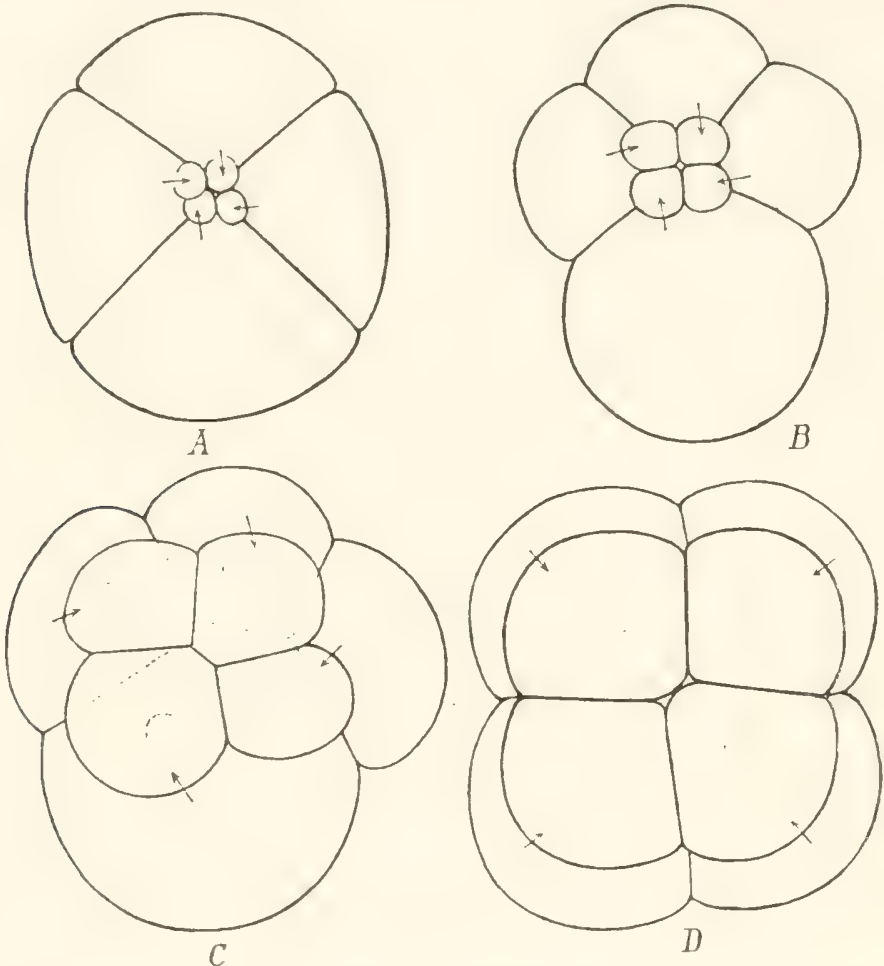

Fiig. 20S. A, $B, C, D$. Das Achtzellenstadium von vier verschiedenen Tieren, welche Abstufungen in der Größe der Teilprodukte des dritten inäqualen Furchungsstadiums zeigen. Nach Wrusox. A Ei von Clepsine nach WiItudx. B Ei des Chaetopoden Rhynchelmis nach VEJDovsky. C Ei des Lamellibranchiers Unio nach LILLIE. $D$ Ei von Amphioxus.

1. ein achtgeteiltes $\mathrm{Ei}(A)$ von Clepsine, dessen animale Zellen fast so klein wir Polzellen sind, 2. ein Ei $(B)$ von der Chaetopode Rhynchelmis,

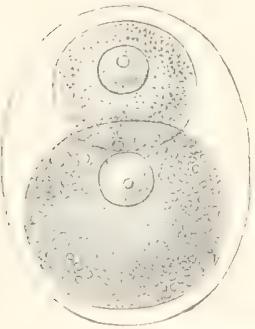

Fig. 209. Zweigeteiltes EivonFabricia. Nith HALKII. 8). von Unio $(C)$, 4. von Amphioxus $(D)$. Die drei letzteren zeigen, wie der Gegensatz zwischen animalen und vegetativen Zellen immer geringfügiger wird.

Auch bei ovalen Eiern kann eine inäquale Furchung vorkommen. So zerfällt bei Fabricia (Fig. 209) das Ei wegen der schon beschriebenen Ansammlung des Dotters an einem Pol (Fig. 199) in eine kleinere. protoplatmareichere und eine oröbere dotterreichere Zelle, die sich im weiteren Verlauf verschieden rasch weiter furchen.

Je größer bei inäqualer Furchung die Zahl der Zellen im weiteren Verlauf der Entwicklung wird (Fig. $207 B, C, D)$, um so mehr nimmt der Größenunterschied zwischen den animalen und den vegetativen Zellen zu; denn die "r-teren. welche protoplasmareicher sind, teilen sich rascher und häufiger. wie gleichfalls schon oben hervorgehoben wurle. 


\section{[c. Knospung n.}

Yon Knospung redet man. wenn das eine Teilprorlukt an ciroblise hinter dem andern so sehr zurïckbleibt, daß es nur als ein kileines An-

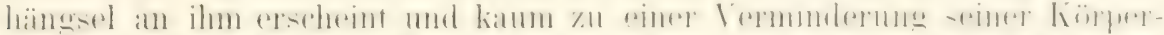

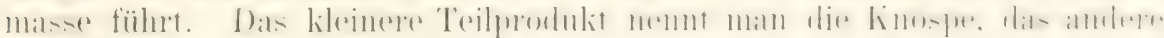
die Nutterzelle. Bei dieser Vermehrungsweise gibt es zwei Lnterarten. je nachdem eine oder mehrere Knospen an der Mutterzelle ihren Ursprung nehmen.

Im 'Tierreiche spielt der Knospungsprozeß bei der Reife des Lies eine Rolle und führt zur Entstehung der Richtungskörverchen oder

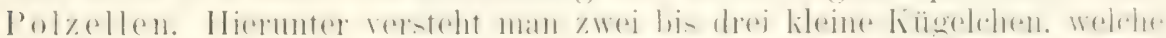

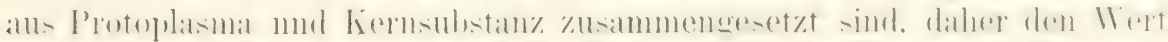

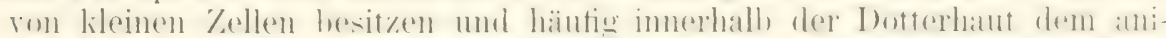

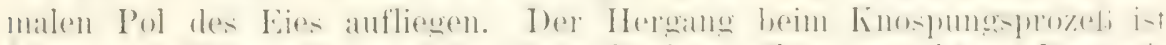

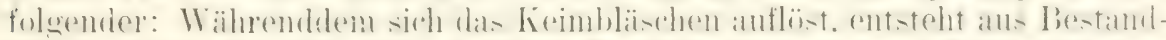

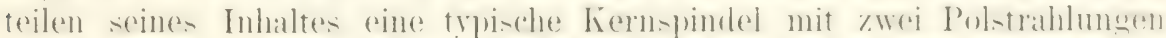

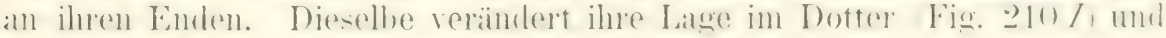

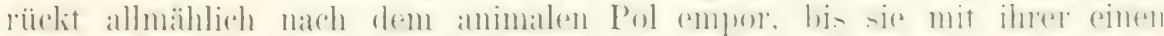

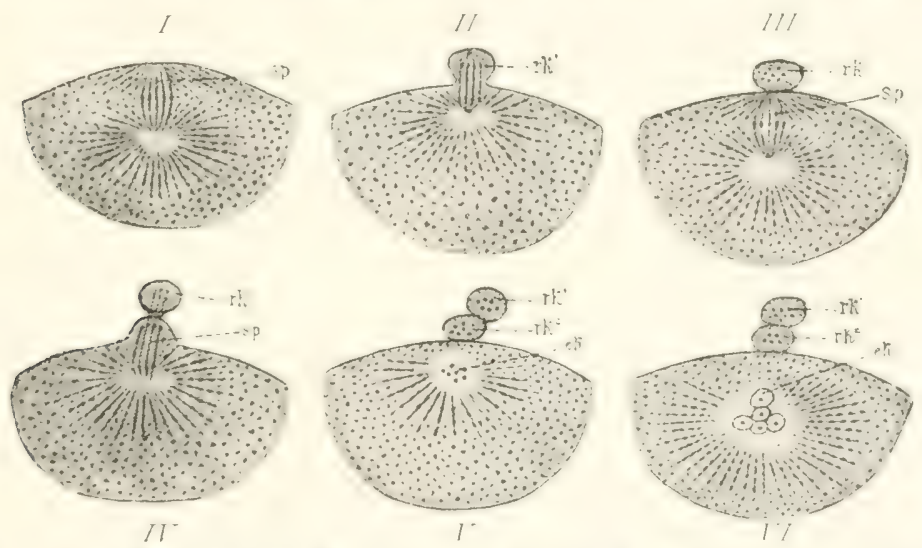

Fig. 210. Bildung der Polzellen bei Asterias glacialis. O. HArTwIG, Ent= wicklungsgesch., Fig. 13. In Fig. I ist die Kernspindel (sp) an die Oherfläche des Eies gerückt. In Fïg. II lat sich ein kleiner Hügel ( $\left.r k^{t}\right)$ gebildet, der die IIiilfte der Spindel aufnimmt. In Fig. III ist der llügel zul einer lolzelle ( $\left./ k^{1}\right)$ ahgeschuirt. Aus der Hälfte der früheren Spindel ist wieder eine zweite vollständige Spindel (sp) entstanden. In Fig. IV wölbt sich unter der ersten Polzelle ein zweiter Hügel hervor, der sich in Fig. $l^{r}$ zur zweiten l'olzelle $\left(r k^{2}\right)$ abgeschniut hat. Aus dem liest der spindel entwickelt sich der likiem (ek) in lige. $1 \%$.

Spitze an der Obertlïche anstöbt. Hier angelangt, stellt sie sich mit ihrer Längsachse in die Richtung eines Eiradius ein. Bald beginnt die Kinospung: an der Stelle, wo der eine Pol der Kerntigur die Obertläche lerïhrt. wölbt sich der Dotter zu einem kleinen Hügel empor, in welchen die Spindel selbst zur Iälfte hineinricht (Fig. 210//). Der Hügel schürt sich darauf an seiner Basis ein und löst sich mit der Hälfte der Spindel rom Dotter als eine sehr kleine Zelle al) (Fig. 210 /1/). Hierauf wienterholt

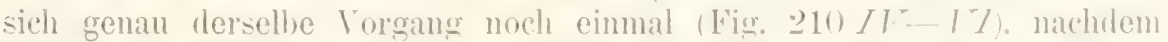
sich die im Ei zuriokgebliebene Hälte der spindel. ohme in das bläschenförmige Ruhestadium des lierns zuvor eingetreten zu sein, wieder zu einer ganzen spindel eroünzt hat. Auf die feineren Einzelheiten des Vor- 
gangs, welche die Kernspindel betreffen, wird noch im elften Kapitel gonauer eingegangen werden.

Knospungsprozesse kommen bei einigen Abteilungen einzelliger Organismen hänfiger vor, und entnehme ich aus ihrem liveise ein zweites lieispiel, die von R. HerTwig (VIII 1875) untersuchte Knospung der Podophrya gemmipara, einer marinen Acinete, relche mit ihem hinteren Körperente rermittelst eines Stiels an anderen fiegenstimden festsitzt. Am freien lï̈ryerende, welches Fangfäden und Säugröhren trägt, bilden sich nicht selten s-12 Kunospen aus, welche zu einem nu das Zentum der freien Fläche freilassenden Kranz angeordnet sind. Der Kern ist hierbei in eigentümlicher Weise beteiligt. Derselbe bildet. wie bei vielen Infusorien, solange die

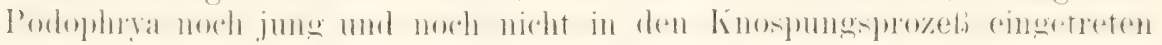
ist, die Folm eines langen, hufeisenförmig gewundenen Bandes (Fig. 211b).

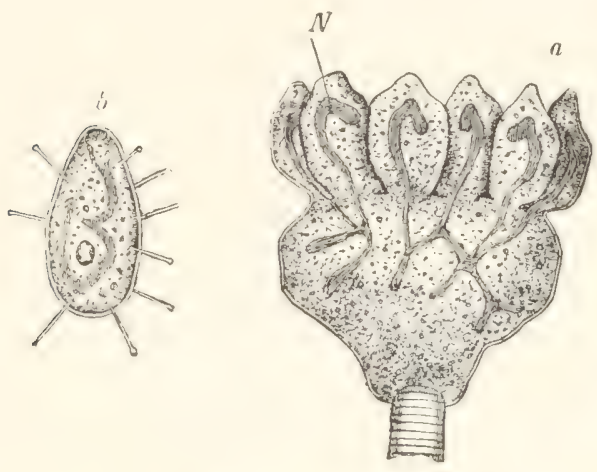

lïr. 211. Zellknospung. Podophrya gemmipara mit Knospen. (). HERTWIG, \%orulogir. Fig. :2l.

a Kinospen, die sich ablösen nud zum Schwirmer b werden, $\alpha$ Kern. Später wachsen aus ihm zahlreiche Fortsätze in vertikaler Richtung nach der freien Seite des Körper's hervor: sie schwellen mit ihren Enden bald kolbig an, während ihre Verbindung mit dem Hauptteil des Kerns sich meist zu einem feinen Faden rerdiumnt. Überall, wo die kolbigen Kernenden an die freie Fläche herantreten. bilden sich kleine Hügel, welche die Ken'nenden. wemn sie noch weiter vorwachsen, in sich aufnehmen. je ein Hügel ein kolhiges Kernende. Die ganze Kins-je vererrigert sich hierauf noch otwas. schnürt sich am Ursprung rom Mutterorganismusetwas ein; iler in sie hineingewachsene Kernteil nimmt die Form eines Hufeisens an und löst sich dann von dem feinen Verbindungstaden ab, durch den el mit dem mütterlichen Kern zusammenhing. Die Knospen sind jetst reif und bewegen sich nach ihrer Abtrennumg vom Mutterorganismus eine Zeitlang im Meerwasser als Schwärmer fort.

\section{Partielle Teilung.}

Die partielle Teilung kommt, von einigen Protozoen (Noctiluca) abgesehen, wohl nur bei Eizellen vor, sie läßt sich von der inäqualen ableiten und bilket sich in allen den Fällen aus. wo der Gehalt an Dentoplasma sehr grol, geworden ist und ein Teil des Protoplasma sich ron ihm schärfer abgesondert und als Scheibe am animalen Pol angesammelt hat (Fig. 197). Der in der Scheibenmitte gelegene Kern muf, wenn er sich zur Spindel umwandelt, eine horizontale Lage einnehmen. Die erste Teilebene entsteht daher in vertikaler Richtung und tritt zuerst, wie beim inäqual sich furchenden Ei (Fig. $206 \mathrm{~A}$ ), am animalen Pol in der Mitte der Scheibe auf. Während sie aber dort (Fig. 206 B) allmählich in die Tiefe dringt und bis zum vegetativen Pol durchschmeidet, zerlegt sie hier nur die Keimscheihe in zwei gleiche segmente, welehe wie zwei hospen der ungeteilten Dottermase mit hreiter basis aufsitzen und remittelst der- 
selben noch untereinander verbunden sind. Ibald darauf erscheint eine zweite, vertikale Furche, welche die erste unter rechten Winkel krenzt und gleichfalls auf die Keimscheihe beschränkt bleibt, die nun in vier Segmente zerlegt ist (Fig. 2012). Auch hier bildet sich eine Brechungslinie ans.

Jedes der vier Segmente wirl dam wielerum von einer radialen Furche halbiert. Dic so entstandenen 'Teilstücke entiprechen líreisausschnitten, die im Zentrum der Keimscheibe mit spitzen Enden zusammenstofen und mit ihren breiten Enden nach der Peripherie gewandt sind. Yon jedem dieser Segmente wird die Spitze durch eine quere oder dem

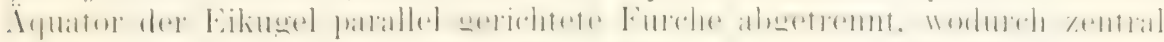
gelegene, kleinere, jetzt allseitig vom Dotter isolierte und größere, mit dem Dotter noch \%11-

sammenhäıgende, periphere 'Teilstiicke entstehen (Fid. 2 1:3). Indem von $111 \mathrm{~m}$ aII radiale und dem Äputor parallele Furchen alternierend auflueten. zerFig. 212 . Fix. 213.

fällt die lieimscheibe in immer zahlreichere Stiicke, welche so angeordnet sind. dal. die kleineren im Zentrum der Scheibe, die gröheren nach der Peripherie zu liegen (Fig. 214). Manche. der mit dem

Dotter verbundenen Segmente werden sch dabei in der Weise

Iị. 21:. Keimscheibe eines Hühnereies aus dem Uterus mit 4 Segmenten. Narh liöruKkr.

Fir. 21:, Keimscheibe eines Hühneleies aus dem Uterus mit 11 Segmenten. Nach KïLIKER.

Fic. 214. Keimscheibe eines Hühuereies aus dem Uterus mit vielen Randsegmenten. Nacli liöririkir.

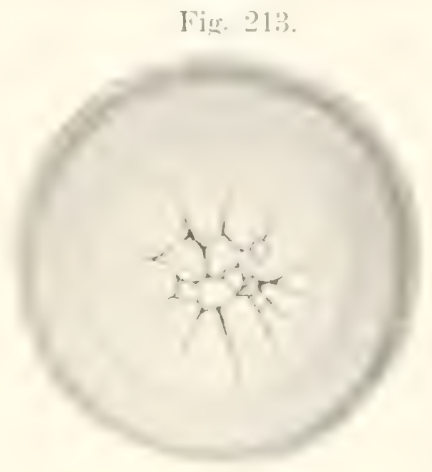

Fie. 311.

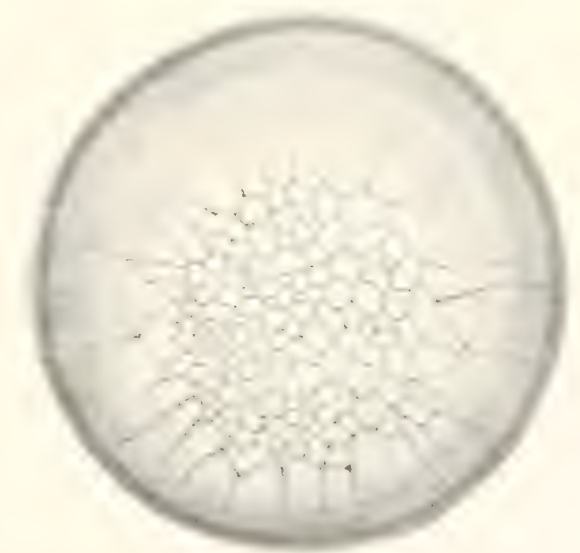

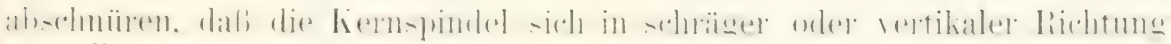
einstellt, was zur Folge hat, dab bei der 'Teilung der' eine Tochterliern in die Dottermasse zu liegen kommt. Auf diese Weise entstehen bei der

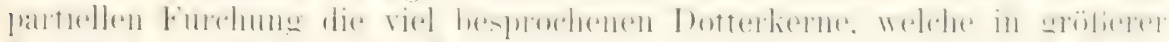

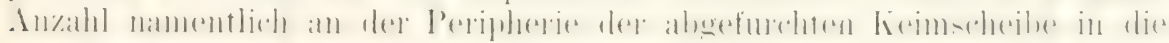
oberflächlichsten Dotterschichten eingebettet sind. Vergleiche auch die

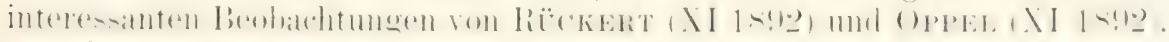
ans denen hervorgeht, dali bei Selachiern und Reptilien Dotterlierne infolge von Überfruchtung ihren Ursprung nehmen. 


\section{Die Vielzellbildung.}

Das Eigentïmliche der V'ielzellbildung besteht darin, dab sich der Kern in einer Zelle mehrfach hintereinander teilt. während der Proto-

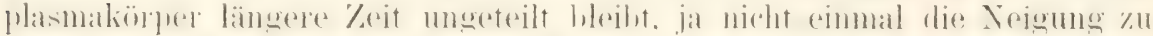
einer partiellen Zerlegung zeigt. Durch öfters sich wiederholende Zwei-

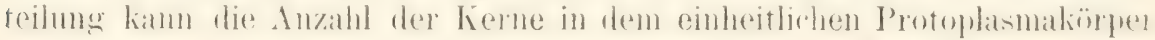
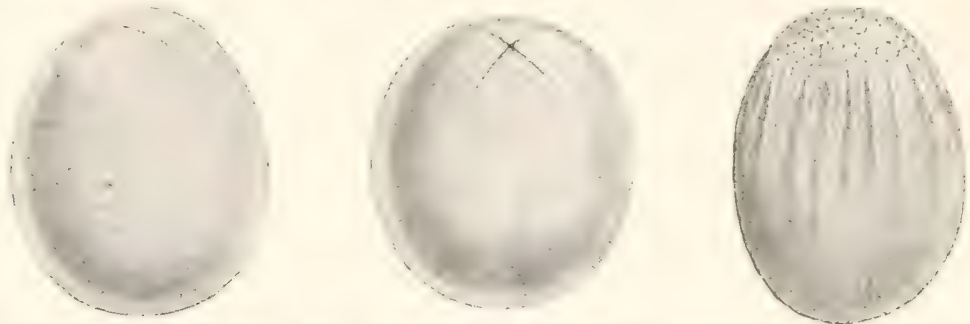

Fig. 115. Discoidale Furchung des Cephalopodeneies mach Watase. Aus R. HeRTWig Fig. 99.

sich alhmählich auf mehrere Inunderte belaufen. I)iese ordnen sich dann in regehmäbigen Abstanden ronemander an. Endlich tritt eine Zeit ein, in welcher die vielliernige Iutterzelle auf eimmal oder mehr allmählich in so viele Tochterzellen zerfällt, als sie Kierne einschlieft.

Vielzellbildung kommt bei Tieren und Pflanzen, namentlich bei der Entwicklung der dieschlechtsprodukte. häufiger vor. Zur Veranschaulichung wähle ich drei Beispiele: die supertizielle Furchung der zentrolecithalen Eier ron Arthropoden. die Bildung des Endosperms in dem Embryosack der Samenknospen von Phanerogamen. und die Sporenhihung in den Sporangien der Saprolegnien.
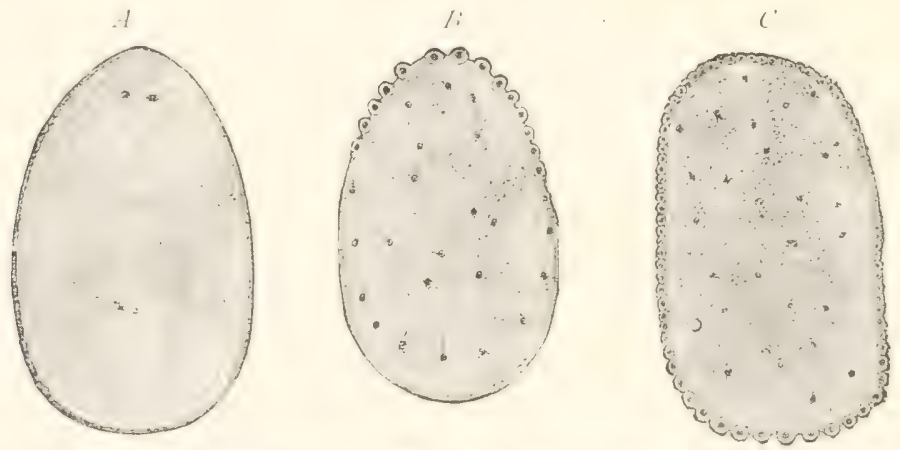

Fï. . 2li. Superfizielle Furchung des Insekteneies (Pieris crataegi). Niıl Bobretzky. Aus R. Hertwig, Fig. 100). A Teilung des Furchungskerns. B Heraufrïcken der Kerne zur Bildung der Keimhaut (Blastoderm). C' Bildumg der Kémhaut.

Bei den Eiern der Arthropoden ist gewöhnlich die Dottermasse im Zentrum des Eies angesammelt und von einer diumnen Rindenschicht von Protoplasma umgeben. Sie werlen daher als zentrolecithale Eier oder Eier mit mittelstündigem Dotter den telolecithalen Eiern oder Eiern mit polständigem Dotter gegenüber gestellt (BALFour III 1881). Der

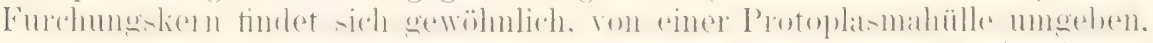
in der Mitte des Nahrungsdotters: hier teilt er sich in zwei Tochterkerne. ohne dar eine Teilung der Eizelle auf dem Fube folgt. Die Tochterkerne 


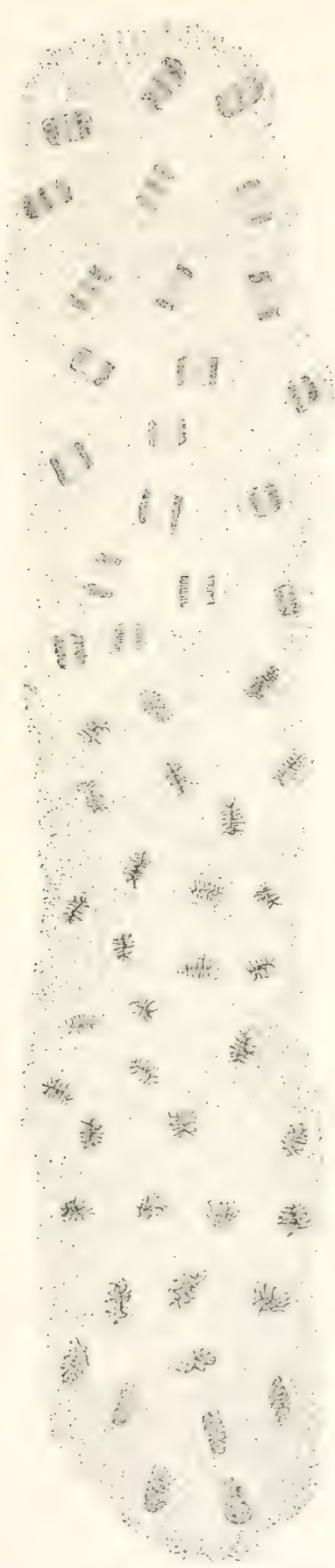

[ï. $1 \%$. Fritillaria imperialis. I'rotoplasmatischer Wandbelegr ats dem Embryosack. Ein Streifom, alle I'hasen der Kernteilung zeigend. Vergr.90. Nach STrusmorerre, lootan. Praktikimm, Fig. 190.
(Fig. 2164 ) teilen sich wierler in $t$.

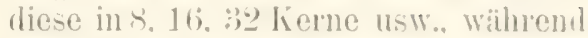
das Ei als Ganzes immer noch ungeteilt bleibt. Später rïcken die Kerne auseinander, wandern zum grïbten 'Teil allmählich an die Obertläche empor (Fig. $216 B$ ) und dringen in die protoplasmatische Rindenschicht ein. wo sie sich in gleichmäbigen Abständen voneinander anordinen. Jet»t erst erfolgt auch an $\mathrm{Ei}$ der Furchungsprozeb, indem die Rindenschicht in so viele Zellen zerfiillt, als lierne in ilı liegen, während der zentrale Dotter ungeteilt bleibt orler erst sehr viel später abgefurcht wirl. Letzteres tritt ein. wenn er wie bei den Insekten, ähnlich den Eiern mit polständigem Dotter, einige Dotterkerne oder Merocyten einschließt (Fig. $216 C$ ).

Der Embryosack der Phanerogamen wirl ron einem protoplasmatischen Wandbeleg ausgelileidet, der auf einem gewissen Entwicklungsstadium viele hundert regehmïbig verteilte Kerne einschließt, die man friher durch freie Kernbildung wie die Kristalle aus einer Mutterlauge entstehen

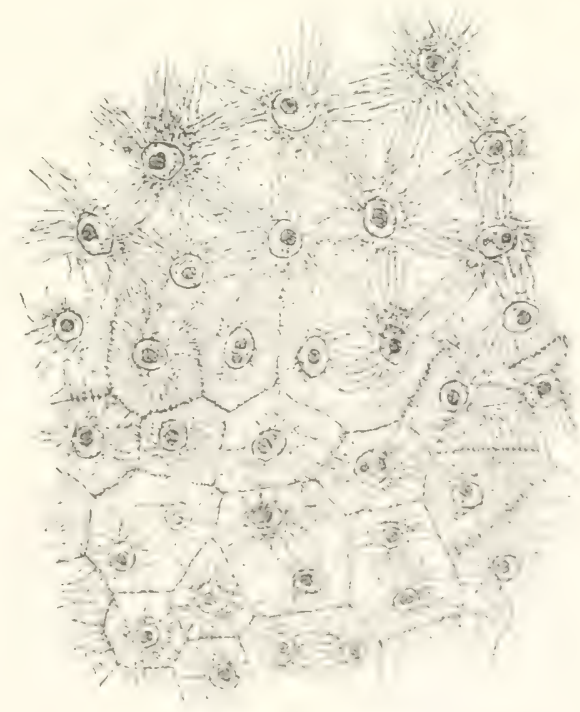

Fie. 21s. Roseda odorata. I'lotuplasmatischer Wamdhelace des lemblerosinclies zu liegrinn der freien \%ollbildung. Verer. 241). Nach str.siblacier, lootan. l'raktikum. livig. 1!). 
lieli. Wir wisen jetzt, dal. sie von einem Mutterkern durch oftmals wierlerholte \%weiteilung. wie in Ei der Arthropoden, abstammen (Fig. 216\%. Die Teilungen spielen sich in ainem Pezirk des Fmbryosarkes ziemlich gleichzeitig ah. IIat es daher bei Anfertigung eines Präjarates der /ufall gliuklich gefügt. so kann man auf kleinem Ram gleich IIunderte von Teilumpsstadien (Fig. 217) vor Augen haben.

Wenn Kerne in genïgend großer Anzahl entstanden sind, so tritt ein

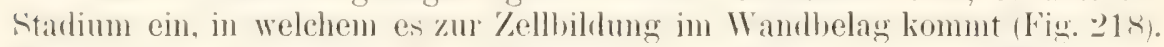
Zwischen den in regelmäbigen Abstanden verteilten Kernen differenziert sich das Protoplasma in radiaire Fälen. Es bilden sich nach allen Richtungon Verbindungsfäden aus. die sich in ihrer Mitte verdicken und eine Zellplatte erzeugen. In den Zellplatten entstehen in der frïher geschilierten Weise (pag. 187) zarte Zellulosewände, durch welche um je einen fiern ein Teil ses protoplasmatischen Wandhelegs zur Zelle abgekajselt wird. Zuweilen sind in einer Zelle zwei Kerne eingeschlossen, die dann entweder noch nachträglich durch eine Scheidewand getremnt werlen orler auch wie hei Corydalis cava zu einem einzigen Kerm untereinander verschmelzen.

Das Sporangium der Saprolegnien ist anfangs eine lange ron Protollasma erfüllte Zelle. In derselhen werden zunächst die Kerne durch Zweiteilung. die meist gleichzeitig eintritt. beträchtlich vermehrt. später verteilen sie sich regehmäßig im Zellraum. Trm jerlen Kern sondert sich die angrenzende Protoplasmapartie zn einem kleinen Klümpchen. welches sich auf seiner Ohertläche mit einer festen, glänzenten Hülle umgiht. und so zerfällt der Zellinhalt gleichzeitio in so viel einzelne șoren. als kleine Kerme vorher vorhanten waren. Dieselhen werten später durch Platzen (ler Membran der Mutterzelle (des Sporangiums) nach auben entleert.

Die frïher erwähnte Schwärmerbildung der Radiolarien (S.213) ist auch als ein besonderer Fall der Vielzellbildung zu betrachten.

\section{Experimentelle Abïnderung der Zellteilung.}

Wenn schon der Verlauf des Furchungsprozesses je nach der Form und Differenzierung des Eies ein sehr verschiedenes Aussehen bei den einzelnen Tierarten darbietet, so läßt sich eine noch größere Mannigfaltigkeit durch künstliche Beeintlussung anch an den Eiern ein und der-
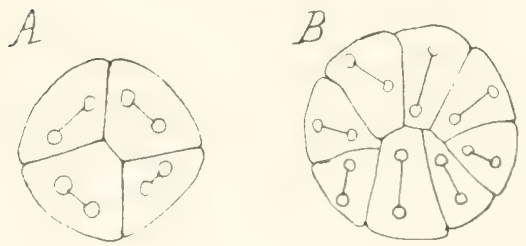

Fig. 219. Eier von Echinus unter Pressung. $A$ in dem vierzelligen, $B$ in dem achtzelligen Stadium. (Nach DRIEsCH.)

selben Tierart herbeifuhren. Durch Druck und Zug kann man die Form der Eier verändern und dadurch nach den oben auseinandergesetzten Pegeln die Kernspindel zwingen, eine andere Lage, als sie der Norm entsprechen würde, einzunehmen, woduch wieder Lage und Richtung der Teilebenen anormale werden.

Besonders geeignete Objekte für derartige Experimente sind die Eier von Echinodermen und Amphibien (Frosch). Wenm ein befruchtetes See-

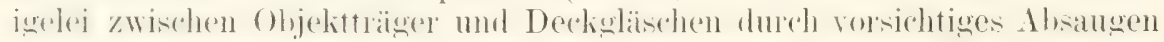
von Meerwasser zu einer Scheibe abgeplattet wird, so stellt sich die erste liernspindel parallel zu den komprimieremelen Platten ein: the erste Tril- 


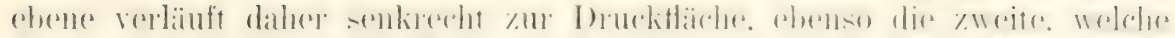

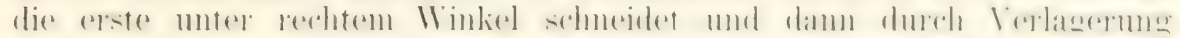

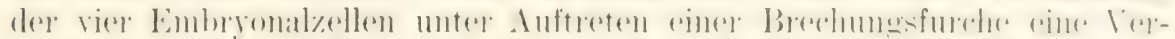

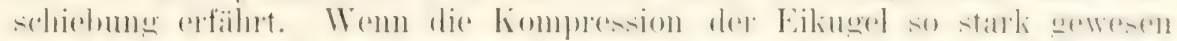

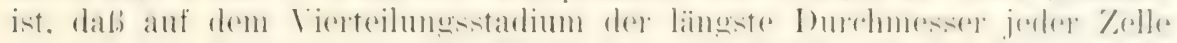

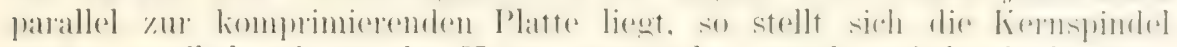
anstatt vertikal. wie es der Norm entsprechen wïrle, wieder in horizontaler Richtung ein (Fig. 219 $A$ ); also tritt auch beim dritten 'Teilungszyklus abermals eine vertikale leilebene auf (Fig. 219B B). Und das

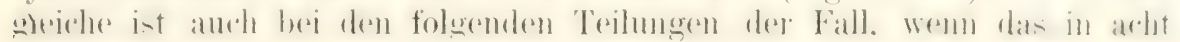

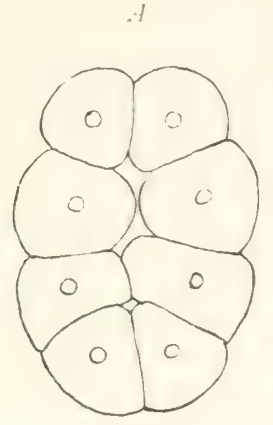

$C^{\prime}$

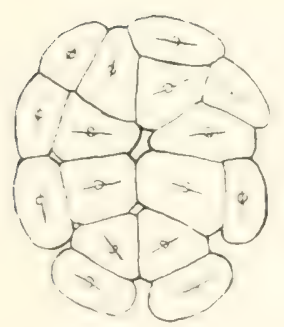

Fị. 2.) Befruchtetes Ei vou Echinus microtuberculatus im Durclströmungskompressorium gepreBt. Lus Verhandlunen der anatomischen (iesellschaft 1894, Seite 135, Fig. 1-5. A Stadium von acht Zellen, B von 16 Zellen. $C$ I)asselhe Ei in Vorbereitung zur nächsten 'T'eilung. D Durch 'Teilung der' 16 \%ellen (C) durch vertikale 'T'eilehenen sind 32 in einer Ebene nebeneinanderliegende Zellen entstanden. E Die Teilung in 64 Zellen erfolgt in' den meisten Faillen noch durch vertikale l'eilebenen, was durch horizontale Striche (Richtung der Spindelachse) angegeben ist. In den mit einem hrenz + hezeichneten Zellen steht die Spindelachse vertikal oder schräer, so dah die 'Teilehene in nelur oder minder horizontaler Richtunes erfolgt. Nach ZuEtiLER.

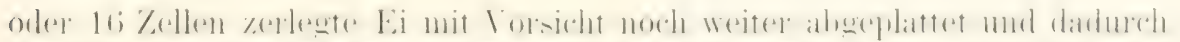

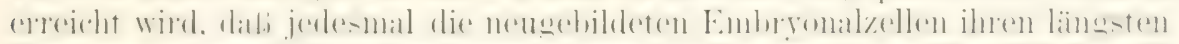

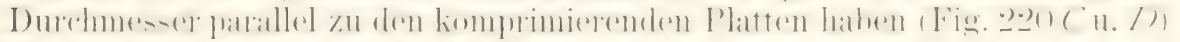
Teilungsebenen in horizontaler Richtung treten in den zahlreicher gewordenen Zellen erst yon dem Moment an auf. wo ihr längster Durchmesser

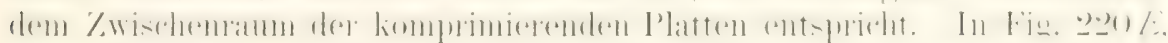
einem Stadium von 32 Zellen, die sich abermals zur Teilung anschicken.

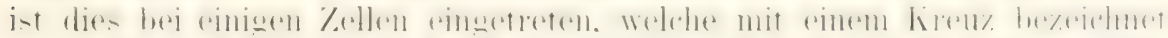

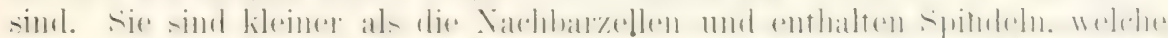

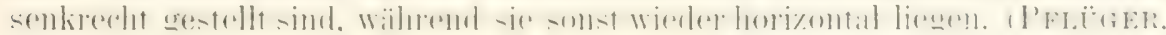


Roux, I) REsch. Hertwig, '/iegler ete.) Man kann in dieser Weise ein Ei zwingen, eine einfache Lage nebeneinander geordneter 'Zellen beim Furchungsprozel, zu liefern. Eine Grenze ist dem Verfahren nur darlureh gesetzt, daß das Zellenmaterial allmählich in verschiedener Weise geschädigt wird. durch die mechanischen Insulte, durch die betrïchtliche Vergrößerung der Oberfläche der wachsenden Kellmasse, durch die ungünstige Lage der zentralen 'Zellen für die Sauerstoftzufuhr etc.

Von besonderem Interesse sind die Kompressionsversuche an Froscheiern, weil bei ihmen außer der äußeren Form des Furchungsprozesses

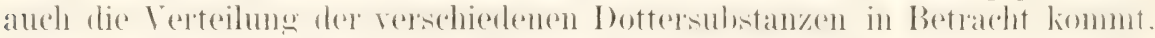
Diese fällt nämlich infolge der polaren Differenzierume verschieden ans. je nachdem die Eier nach der Befruchtung entweder zwischen parallelen,

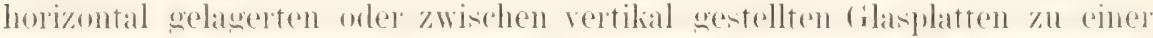
Scheihe zusammengejerebt werlen. In ersten Falle sind sie dorsorentral. d. h. in der Richtung rom animalen zu dem vegetativen Pol, im zweiten Fall senkerht zu dieser lichtung. also sedtich aberplattet und dementsprechend nimmt auch die animale und die regetative Substanz eine verschiedene Form an, worüber die beiden Schemata (Fig. 221 A u. B) Auskunft geben. Dadurch wird ein durchaus abweichender V'erlauf des Furchungsprozesses hervorgerufen.

Fig. 221.

Fig. 222.

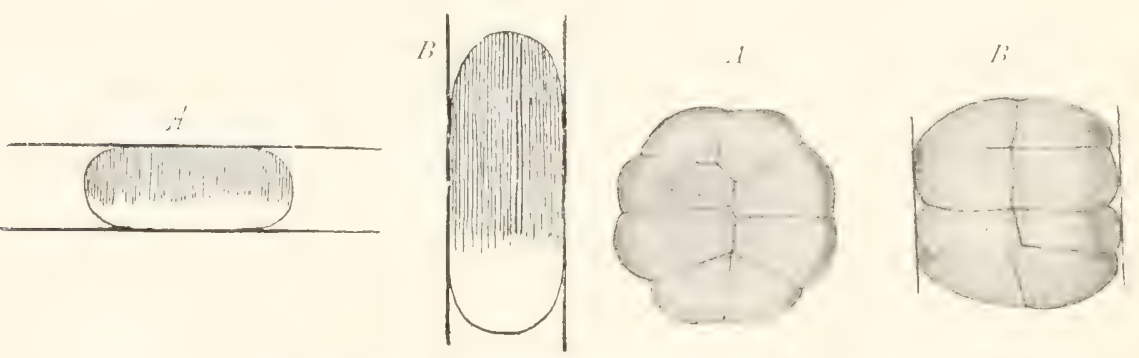

Fig. 221. Zwei Schemata gepreßter Froscheier nach Horgax aus KonscheLT und Henter. A Seitenansicht des zwischen horizontalen Platten gepreliten Eies. Die dunklere animale Eihälfte ist durch Schraffierung angedeutet. $B$ Seitenansicht des zwischen vertikalen Platten geprebten Eies.

Fig. 222. Eier von Rana temporaria auf dem dritten Furchungsitadiun voun animalen $\mathrm{Pol}$ aus gesehen. A zwischen horizontal gestellten Glasplatten geprelit. $B$ in ein horizontal gestelltes enges Rohr gesaugt. Nach O. Hertwig.

Bei dorsoventraler Pressung (Fig. 221 A) entsteht ein Furchungstypus, der mit der Furchung meroblastischer Eier grobe Ähnlichkeit aufweist. Die dritte Furche (Fig. $222 \mathrm{~A}$ ) wird nämlich lieine äquatoriale und horizontale, sondern es entstehen zwei der ersten Meridionalfurche parallele Vertikalfurchen. Erst auf dem vierten Teilstarlium bilden sich horizontale Furchen aus, wenn die Pressung eine geringe war; bei stärkerer Pressung dagegen verlaufen sie wieder in vertikaler orler in einer schriggen Richtung. Ein ähnliches Bild wie Fig. $222 A$ liefern Froscheier, die in enge und

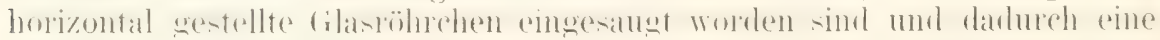
Zylinder- oder Tomnenform angenommen haben. Hier werden auf den drei ersten Furchungsstadien die Teilebenen senkrechte, und zwar schneidet die erste die Achse des Rohres unter rechtem Winkel, die zweite fällt mit seiner Längsachse zusammen; im dritten Starlim entstehen zwei vertikale Furchen parallel zur ersten. Erst vom vierten Stadium an treten äquatoriale Furchen aut. 


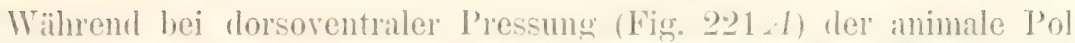
in die Mitte der Scheibe, lommt er hei lateraler Pressung (Fig. 221B) an ilne Kante zu liegen, was infolge der vollständig anderen Verteilung der Eisubstanzen auch einen ganz abweichenden Verlauf der 'T'eilung zur' Folge hat. Am prögnantesten findet die Teränderung in lem Auftreten der äpuatorialen Furche ihren Ausdruek. Erscheint diese hei dorsiventraler Pressung erst im vierten oder einem noch späteren 'Teilstalium, so tritt sie bei lateraler Pressung verfribht im zweiten Stadium anf und sehmeidet yon den zwei Hälften der Scheihe, welche lurch die erste vertikate lurche entstanden sind, zwei relativ lileine animale Zellen ab (Fig. 20:5 /a). In dritten Zyklus sind die Furchen wieder vertikal und zugleich parallel zur ersten (Fig. 20:3 Ib). Häutig wird bei lateraler Pressung beobachtet, dafs rlie erste Furche nicht genau vertikal ist, sondern mehr orler minder in schräger Richtung abweicht. Es ist dies offenbar eine Folge davon, dab
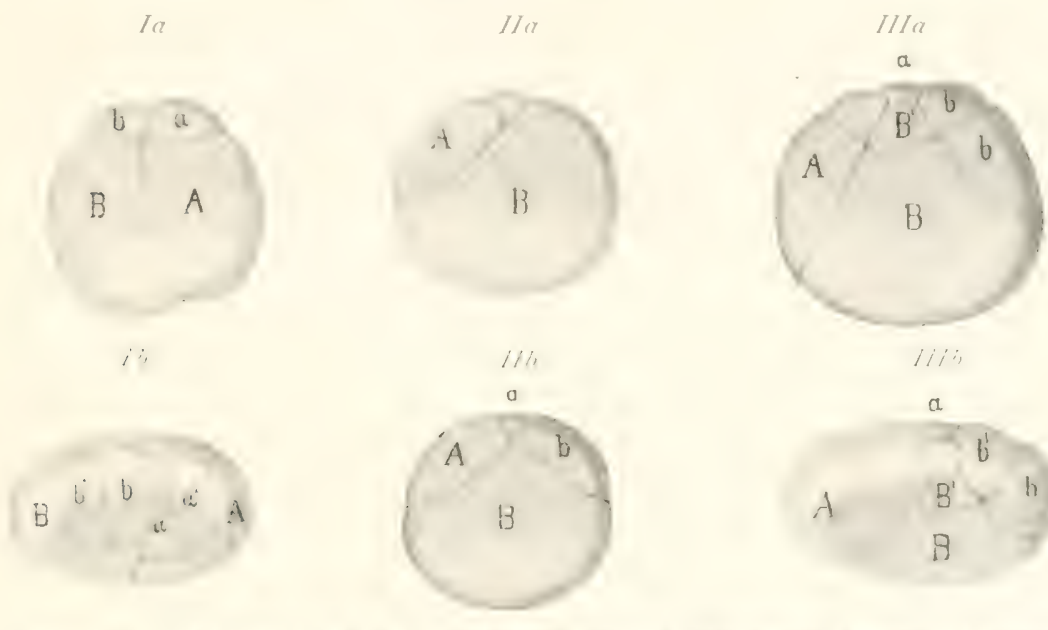

I:... …: Furchung von Froscheiern, welche zwischen senkrecht gestellten Platten gepreßt wurden. Io Stadimu der Vierteilumg in seitlicher Ansicht. Ib Stadium der Achteilume, rom animalen l'ol aus gesehen. II and I/b heginnende und beendete Vierteilung bei schüg gestellem Meridionalfurchen in seitlicher Insicht. II/ Acht-

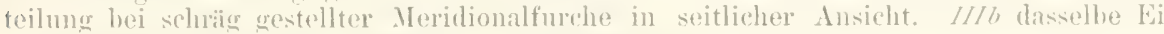
vom animalen l'ol schüïg gesehen. Xarh llertwig.

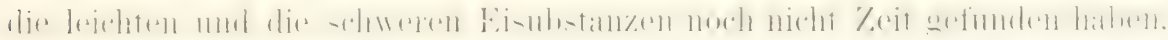
sich genau symmetrisch anzuordnen. Die Drehung des ganzen Fies seinem Schwerpunkt gemäb ist ja anch durch die grohen Reibungstlächen eine erschwerte. In solchen Fällen beobachtet man einen sehr unregehnäbigen Furchungsverlauf, wie ein solcher in der Fig. 22:3 $(I / a-I / / b)$ wiedergegeben ist.

Im großen und ganzen liefern diese und ähnliche Experimente eine rollkommene Bestätigung der oben ron mir aufgestellten 'T'eilungsregeln.

\section{Literatur IX.}

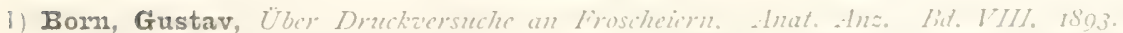

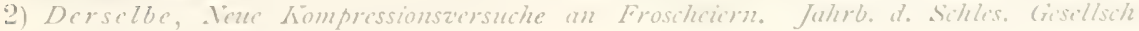
Zool.bot. Sikt. 180 . 
3) Driesch, H., Entaichongsmechanische Studien. 11. Zeitschr. f. arissenschaftl. Zool. Bd. LI. 1803 .

4) Derselbe, Zur lerlagernng der Blastomeren des Echinideneies. Anat. Anzeiger. Jahro. ITII. 1803.

i) Hertwig, Oscar, Die Chactognathen, eine Jlonographie. 1880.

(i) Dersclbe. IVelchen Einfuß übt die Schrerkraft anf die Teihung der Zellen? Jen. Jen. Leitscler. 1884.

¿) Derselbe, Experimentelle Untersuchangen ïber die ersten Teilangen der Froscheier und ihre Besichungen zu der Organbildung des Embryo. Sitzungsber. d. Agel. prenß. Lkat. d. Wiss. zu Berlin 1893.

(5) Derselbe, Über den Hert der ersten furchungssellen für dic Organbildung des Embryo. Experimentelle studien am Frosch- und Tritonei. Arch. $f$. mikrosk. Anat. Bid. XLII. I893.

9) Derselbe, Über sine Methode, Froscheier am Beginn ihrer Entwicklung im Ranme so su orientieren, daß sich die kichtung ihrer Teilebenen und ihr Kopf-und Scharans. ende bestimmen läßt. Festschr. zum 70. Geburtstag zon E. Haeckel 1907.

111) Jennings, The carly derelopment of Asplanchna. Bull. of llius. of comp. Zool. at Hariard College. Vol. NXY. 1806.

11) Kölliker, Entreickhungsgeschichte der Cephalopoden. $18+4$.

1.) Lillie, Adaption in cleavage. WVod's Holl Biol. Lect. 1898.

13) Derselbe, The organization of the egg of Unio. Journ. Morph. Bd. IVII. Igor.

14) Morgan, Th., Hunt., The development of the frogs egs. New York 1897.

15) Derselbe, A. study of zariation in cleavage. Arch. f. Entre-Alech. Bd. 11. 1895.

16) Pflüger, Über den Einfußß der Schwerkraft auf die Teilung der Zcllen. Archio f. die gesamte Physiologie. Bd. NXXI u. X'XII. 1883.

17) Derselbe. Uber die Einwirkung der Schwerkraft u. anderer bedingungen anf die Richtung der Zellteilung. 3. Abh. Archio f. d. gesamte Physiologie. Bd. XX.VIV. 1887 .

18) Rauber, A., Formbildung u. Celhulamechanit. Morpholog. Jahrbï̈h. Bd. VI. 1880.

19) Derselbe. Tier 11. Pflanze. Akademisches Programm. Zoolog. Anzeiger. I88I.

20) Derselbe. New Gimindlegungen zur Kenntnis der Zelle. Morph. Jahrb. Bd. IIII. 1883.

21) Roux, Wilh., Gesamnclte Abhandhugen ïber Entaicklungsmechanik der Organismen. 1895 .

22) Sachs, Die Anordnums der Zellen in jüngsten Pflanzenteilen. Arbeiten des botan. Instituts in Wiürbuirg. Bd. Il. 1882 .

23) Whitman, C. O., The inadequacy of the celltheory of development. Hood's Iloll Biol. Lectures. 1803.

24) Wilson, The cell-lineage of Nereis. Journ. of Morph. Bd. II. 1892.

25) Derselbe, Experiments on cleavage and localization in the Nemertine egs. Arch. f. Entre-Mech. d. Orr. Bd. XIT. 1903.

26) Zieglex, Über Furchung unter Pressung. Terhandl. d. Anat. Gesellsch. I89f. 


\section{ZEHNTES KAPITEL。}

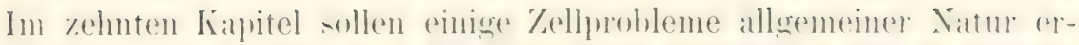

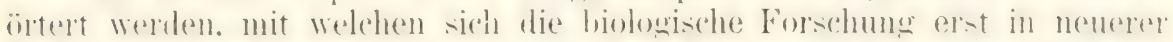

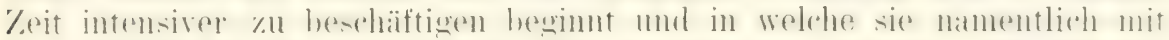

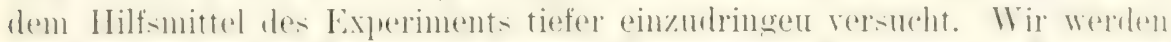

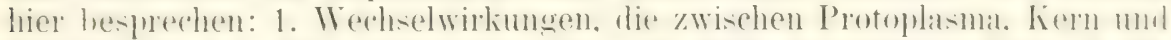

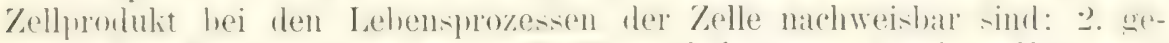

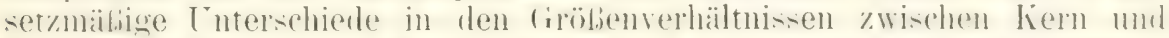

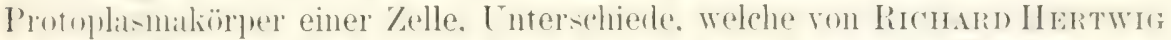
mit dem Samen ..Kermplasmanelation" hedent worden sind. Intitens wird noch das Problem der "Urzengung der Zelle“" kurz berïhrt werden.

\section{Wrohselwirkungen zwischen Protoplasma. Kern und /ellproblukt.}

In rinem lehenten ()romismus stehen notwendigerweise alle morpho-

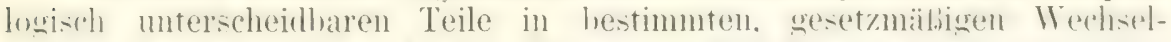
wirkmngen zu einander. In die-elhen einen Einblick zn gewinnen, is hei

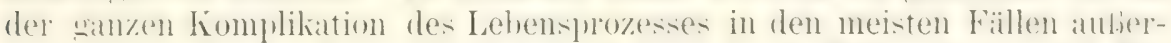

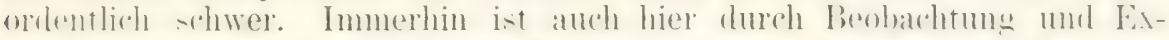
periment schon ein erfreulicher Anfang gemateht. mu das dunkle diehiet unserer Frkenntnis zu erschließen.

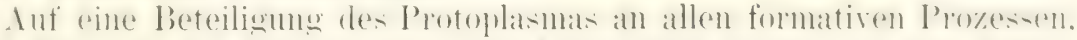

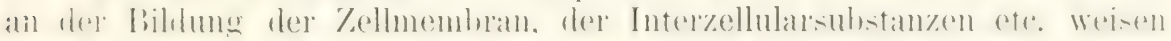
verschiedenartige Befunde hin, welche sich wohl kaum in einer anderen Weise erkiären lassen. Bei Pflanzen ist stets an den Stellen. von denen

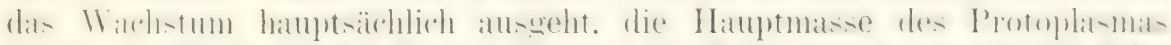

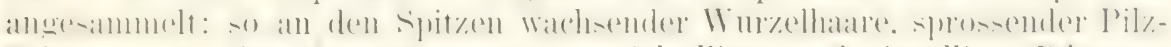

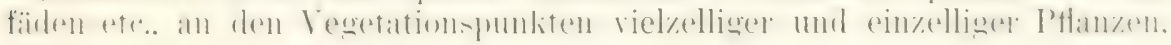
wie Caulerpar.

Auch in der einzelnen Zelle häuft sich das Protoplasma stets an den Orten gröfter formativer 'Tätigkeit an. Wenn in einer Ptlanzenzelle sich

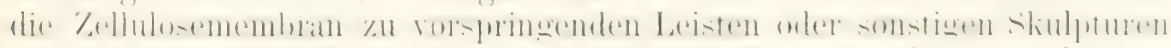
verdickt. geht das Protoplasma schon einige Zeit, ehe die Verdickungen angelegt werden, vorbereitende Veränderungen ein, indem es sich zu den

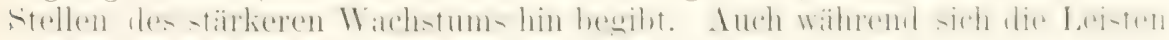
und Verdickungen bilden, gehen an ihnen fortwährend Strüme von kïrnigem Protoplasma entlang. 
Wenn hei Vaucheria ein kleines Stïck abgetrennt wirl, so sncht alsbald das Protoplasma den Defekt wieder zu ergïnzen. Man sieht ..zu der Wunde körniges Plasma in dichteren Massen herandrängen und sich zu einer nach auben scharf begrenzten Schicht zusammenschließen. An dieser begimnt sich alshald Zellhaut zu bilden" (KLEBS). Der P'otoplasmakörper einer Pflanzenzelle, welcher durch Plasmolyse von seiner Membran abgelöst ist, ohme dab er dadurch in seinen Lebensfunktionen gelitten hat, scheidet nach kurzer Zeit wieder auf seiner Oberfiache eine nene Zelluloseschicht aus, welche sich durch Zusatz von Kongorot zum Wasser rot fairben liafit.

Solange Zellen jung und in kräftigem Wachstum begriffen sind. enthalten sie die gröbte Menge von Protoplasma, während dasselbe in alten Zellen, namentlich wemn sie ihre formative Tätigkeit eingestellt haben, oft nur in geringen Spuren nachzuweisen ist. So kann in grofen. auswewarhsenen P'tanzenzellen der protoplasmatiche lielag an der Inmentlähe der Zellulosemembran so auferordentlich dünn werden, dab er als ein besonderes Häutchen nur vermittelst der Plasmolyse nachzureisen ist. Ebenso ist in den blasigen Chordazellen der 'Tiere etc. Protoplasma nur noch in geringen Spuren vorhanden.

Besonders ist gegenwärtig die Forschung auf die Beziehungen des Kerns zu den übrigen Bestandteilen der Zelle gerichtet. Daß der Kéern

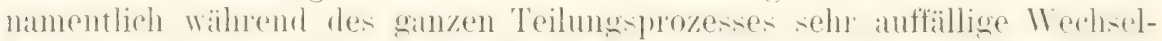

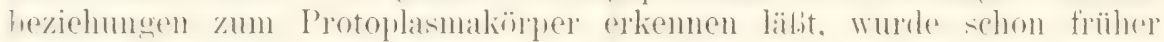
gezeigt (S. 225). Aber auch zu anderen Zeiten spielt er offenbar eine wirhtige physologishe Rolle im Lehen der \%elle: alle tomativen mol nutri-

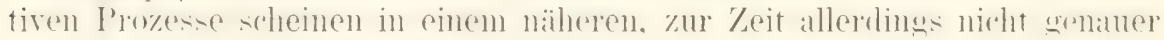
zu definierenden Abhängigkeitsverhältnis von ihm zu stehen, wie sich aus den jetzt nảher zu besprechenden Beobachtungen von HABERLANDT und Korschelt, sowie aus Experimenten vol Gruber, Nussbaum, Balbiani, KLEBs und HoFer schließen läBt.

\section{Beobachtungen iiber stellungen des lieprs. welche auf eine beteili- gung bei formativen und nutritiven Prozessen hinweisen.}

Nach den ausgedehnten, wichtigen Untersuchungen von HABERLAxDT (X 1857) betindet sich der Kern von jungen, sich entwickelnden Pflanzenzellen ..meist in gröberer oder geringerer Nähe derjenigen Stelle, an welcher das Wachstum am lebhaftesten vor sich geht orler am längsten andanert. Dies gilt sowohl für das Wachstum der ganzen Zelle als solcher. wie anch speziell für das Dicken- und Flächenwachstum der Zellhant. Ist mehr als eine Stelle im Wachstum bevolzugt, so nimmt ler liern eine solche zentrale Lage ein (Fig. $22+I I$ ), dab er von den Orten ausgiebigsten Wachstums ungeführ gleichweit entfernt ist. Zuweilen stellen Plasmastränge (Fig. 224 II) eine Verbindung der Kerne mit den Wachstumsstätten auf kiurzestem IVege her. In der augebildeten Zelle behält der Kern seine frïhere Lage nur in der kleineren Anzahl der Fälle bei. Gewöhnlich rerlïbt er den in der wachsenden Zelle innegehabten Platz und zeigt damn zumeist eine unbestimmte, in einzelnen Fällen jerloch aufs nene eine bestimmte Lagermug*.

Yon den zahlreichen Beobachtungen, an denen HaBERLANDT diese Sätze begriundet, teile ich einige besonders lehrreiche Beispiele mit. Die

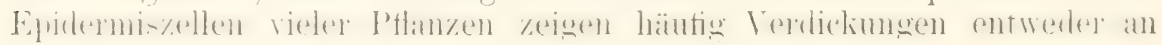
ihrer nach aufien orler nach imnen gerichteten Waudfläche. Je nachrlem 
liegt der hern entweder der Aubenwand oder der Innenwand, und zwar der Vitte der Verdickung dicht an. In sehr anschaulicher IVeise lehren dies die in Fig. 22+ zusammengestellten lieispiele: No. I eine \%elleihe von der Epidermis des Laubblattes ron Cypripedium insigne: No. II eine Epidermiszelle der Fruchtschale von Carex panicea; No. IV eine junge Ejpidermiszelle des Laubblattes von Aloë verrucosa.

Eine zweite Reihe von Beobachtungen betrifft das Wachstum ober-

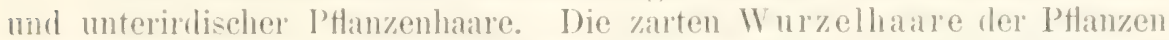
zeigen ein deutlich ausgesprochenes Spitzenwachstum. Hier findet sich demn auch der Kern, solange das Wachstum andauert, stets in der Spitze (Fig. 225. 1), während er in ausgewachsenen, alten Haaren sich weiter von ihr entfernt hat. Wenn ein Wurchlhar sich aus einer Epidermiszelle neu anlegt, so geschieht dies stets durch Ausstülpung der iiber dem Zelliern
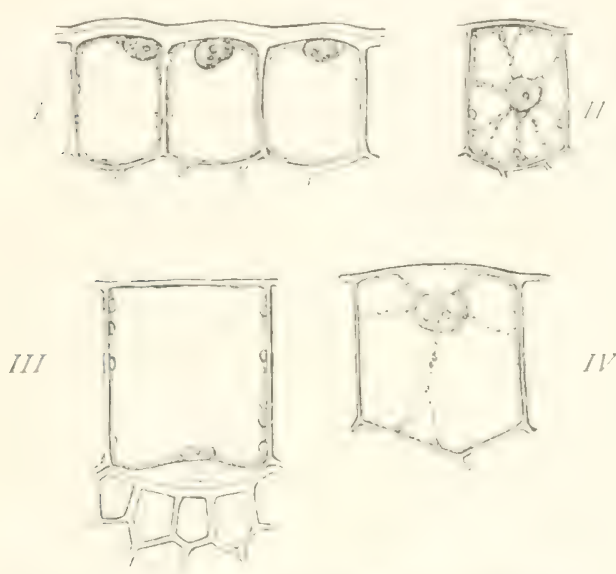

Fig. 2.). I Epidermiszellen des Laubblattes von Cypripedium insigne. Vach IIBERLAXIT, Taf. I; Fig. 1 .

II Epidermiszelle von Luzula maxima. Tach H.ublitaxd, Taf. I, Fig. 3.

II/ Epidermiszelle der Fruchtschale von Carex panicea. Nach llABERLANDT, 'Taf', I. Fig. 14 .

IV Junge Epidermiszelle des Laubblattes von Aloë verucosa. Nach IIARERL.AxDT, 'Taf'. I, Fig. 7 .

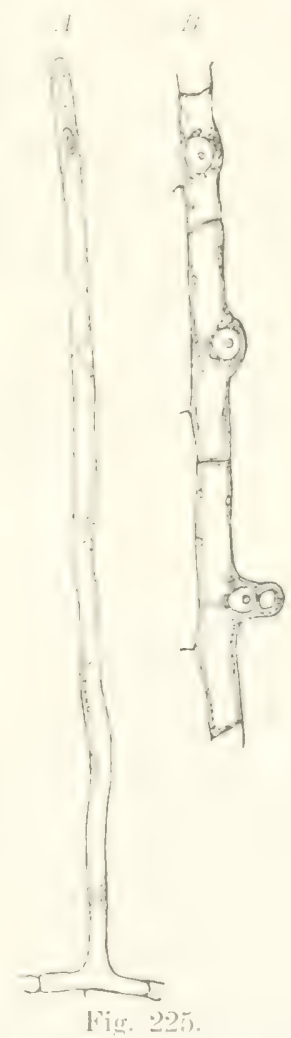

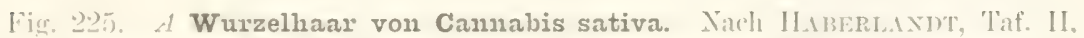
Fig. 2(\%. B Entstehung der Wurzelhare von Pisum sativum. Jach H.IIRIANIT, Taf. 11, Fic. 22.

gelegenen Partic der Aubenwand (Fig. 202 b'). Liei manchen Pthanzen (Brassica oleracea) kann sich die Zelle des Wurzelhanes verzweigen, wobei dann der einfache Kern in einen der 'sweige hineinriickt. Dieser wird damn sowohl der protoplasmareichste, als anch der längste, während die anderen Zweige zu wachsen aufhören.

Von den Wurgelharen mterscheiden sich die oberirtischen II a re dadurch. dals sie ein basipetales, interkalares Wachstum besitzen, wie

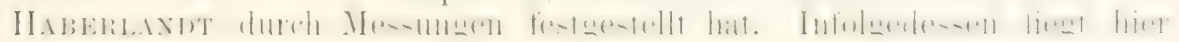


der Kern nicht in der Spritze. somblem ungefähr da. wo sich der sekmuläre. lasale Vesotationsmunkt befindet und das Iängenwadsstum am längsten andanert. Unter Sternhaaren (Fig. 226) versteht man eigentümliche, einzellige fiebilde, die sich nach ihrem peripheren Fnde in mehrere, in

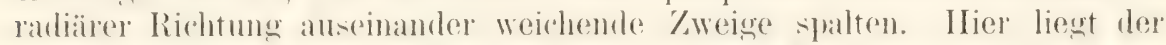
Kern in Mittelpunkt der Verzweigmu, solange die formativen Prozesos

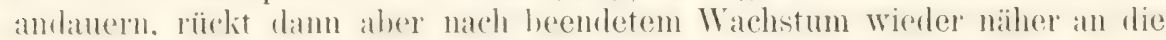
Basis heran.

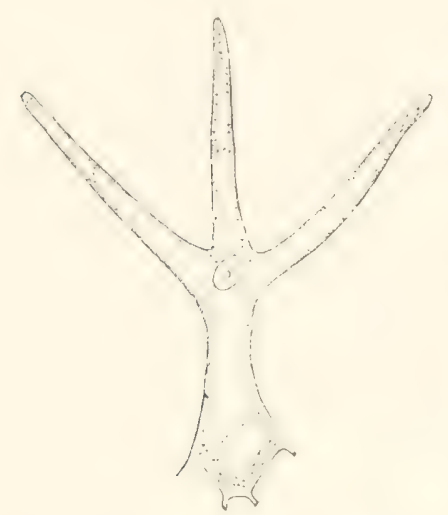

Fig. 226. Junges Sternlhar von Autrietia deltoidea. Nach IlABERLANot, Taf. II, Fig. 28.

jetzt treten in dem an der Wundstelle sich ansammelnden Protoplasma zahlreiche kleine Kerne auf: sie rïcken also an die Obertläche empor, die Chlorophyllkörner dagegen werden gerarle in entgegengesetzter Richltung zurïckezogen. Kerne und Chlorophyllkärner tauschen so ilne Platze weweneinander aus. Durch diese Wahnehmum widerlegt sich zugleich der sonst leicht zu erhebende Einwand, dab. der oder die Kerne einfach an den Stellen vorgefunden würden, zu denen das Protoplasma in gröberer Menge zuströme und sie mit sich schleppe. Denn damn wïre eine gleichzeitige entsprechente Verlagerung der viel klemeren ('horopliflkörner noch eher zu erwarten. zumal diese ja nuter dem Einflub verschiedener Beleuchtung sehr leicht ihren Ort verändern. Von dieser Wanderung bleiben num aber wieder die Kerne unberührt.

„Wir sehen also, bemerkt HABERLANDT, ,daß Zellkerne und Chlorophrllk̈̈rner unahhänsig voneinander bestimmte Ortsveränderungen zeigen.

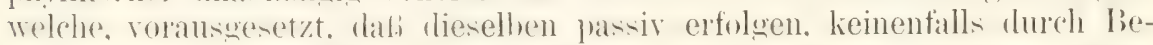

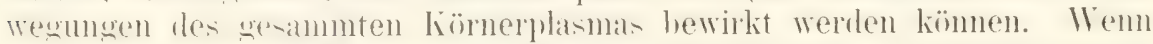

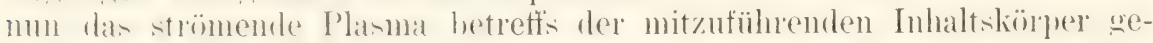
wissermaßen eine bestimmte Auswahl trifft, in dem einen Falle den

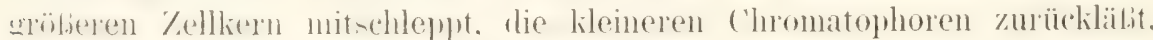
im anderen Falle wieder die Chromatophoren verschiebt und die ebenso kleinen oder oft noch keineren Zellkerne unverrỉckt läßt. so kann eine solche Verschiedenheit der Bewegungserscheinungen doch nur den Sinn haben. dab. durch dieselben bestimmte, mit der Funktion der Kerne, beziehmuswoise dex chromatophoren zusammenhängende Lagerungswrisen bezweckt werden." 
Ähnliche Beziehungen zwischen Lage und Funktion der Kerne. wie

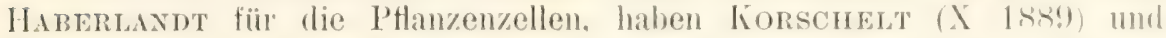
andere für tierische Zellen nachgewiesen. Zellen. Welche sich durch reichliche Aufnahme von Reservestoften beträchtich vergröbern. sind die Eier. Diese haben hänfig das Kieimblïschen an dem Orte gelagert, an dem vorzugsweise die Stotfiufnahme ror sich gehen muli. So nehmen z. 13. bei einem 'Teil der Cölenteraten die Eier ihre Entstehung aus dem Entoderm und werden aus dem Inhalt des Gastrovaskularsystems durch Vermittelıng von Entorlermzellen ernährt. In Übereinstimmmg mit dem oben aufgestellten Sat\% liegen in jungen Eiern die Keimbläschen gan\% obertlächlich. und zwar an der nach der (iastralhöhle zugewandten Seite (Fig. 207). liei manchen Aktinien (HerTwig I 1879) reichen die Eien. sogar noch lange Zeit mit einem sticlartigen Fortsatz in tas Darmepithel bis an seine Obertläche heran (Fig. 228). Der Stiel läbt eine regelmärige fibrilläre Struktur erkennen, wie sie ibberall da auftritt. wo ein reger Stottaustausch stattindet und dieser Stoftaustausch bestimmte Bahnen einhält: er läbt sich daher als ein besonderer Nährapparat des Eies in Anspruch nehmen. Auch hier liegt das Keimbläschen regehmäbig der lasis des Nïhraplarats unmittelbar an (Fid. 2208). Ein ähnliches Verhalten trifft

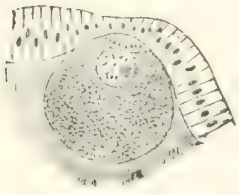

Fivi. 2i- Junges Ei von Adamsia rondeleti. Teror: 145. Nach liorschit, S. 47, Fig. 8.

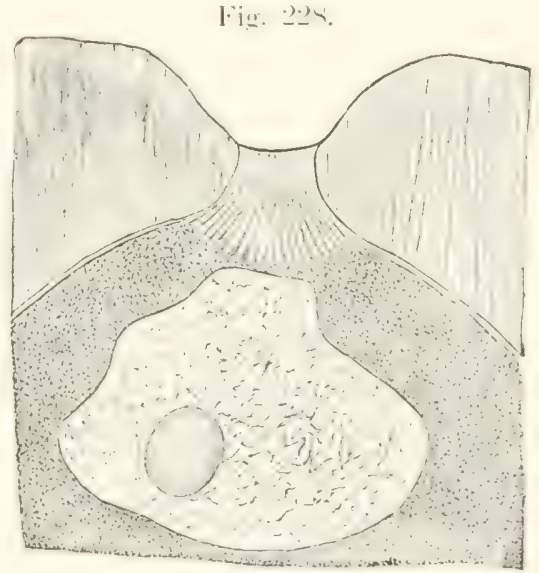

Fin. '-) Querschnitt durch clas periphere Ende und den Stiel von Eizellen der Sagartia parasitica (nach O. und R. HerTwig). Nach horschit, Fig. 10. Nach olen sieht man den gestreiften Stiel der Eizelle in das Epithel pindringen.

man in den schlauchförmigen Ovarien der Insekten, die in Eifächer und in Nähfächer gegliedert sind. Entweder ist hier wieder das Kemblischen

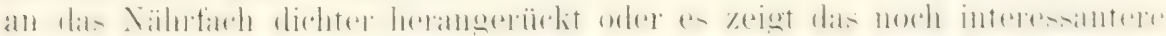
Verhalten. dal. es nach dem Nährfach zu zahlreiche, pseudopodienartige Fortsiitze (Fig. 29) ausstreckt und dadurch nach der Seite, wo die Stoff-

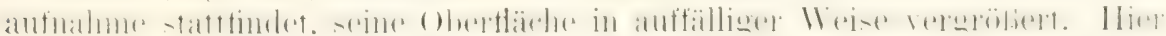
beginnt sich dem auch der Dotter in der Ungebung des lieinbläschens

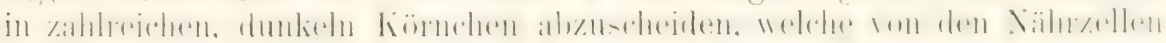
zungefïlnt worden sind. Bei den meisten Tieren werden die Eier dureh Vermittelung des Follikelepithels ernäht. Konscuest findet dementsprechend. dab bei Insekten die Kerne der Follikelzellen. solange die Bildung des Dotters und des Chorions vor sich geht. mnnittelbar an der nach dem Ei gerichteten Oberfläche liegen, dagegen nach Fertigstellung fles Chorions in die Mitte der \%elle zurückweichen. 
Noch frappanter ist das Verhalten der lierne in den sogenannten Doppelzellen, welche strahlenartige Chitinfortsätze an dem Chorion der Eier von Wasserwanzen (Ranatra und Nepa) erzengen (Fig. 2:30 A B). Die Protoplasmakörper der beiden Zellen, welche einen Strahl zwischen sich ausscheiden, verschmelzen. Während der Ausscheidung schicken die beiden ïheraus aroben lierne an der nach dem Strahl zugekehrten Seite zahlreiche, feine Fortsätze aus.

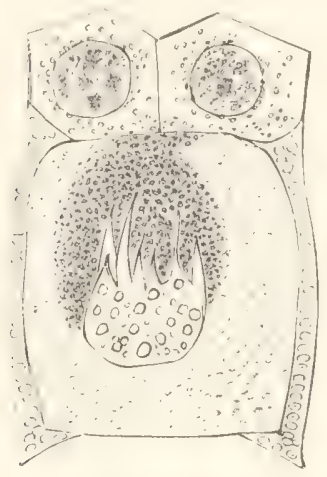

Fij. $\because-3)$
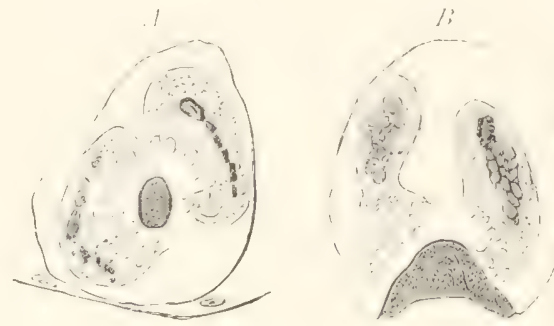

Fig. 230.

Fi(1. '). Ein Eifollikel von Dytiscus marginalis mit angrenzendem Nährfach, in wolchem eine reichliche Körnchenausscheidung stattfindet. Das Keimblïshen des Eies sendet Fortsitze aus nach der Richtung der Kürmchenanhäufungen. Nach Konschelt, Taf. I, Fig. 20.

Fic. von Nepa cimerea. Die Bildung des Strahles ist noch im Gange. Vergr. 270 fach. Nach Konschelt, Taf. V, Fig. 120.

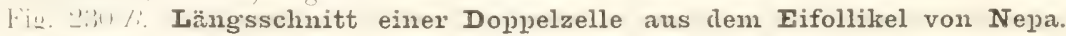
Bildung der Basis des Strahles. Vergr. 195 fach. Nach Konschet, Taf. V, Fig. 121.

Aus diesen und ähnlichen Beobachtungen ziehen HaBErLANDT und Korschelt folgende, die Funktion des Zellkerns betreftende Schlüisse:

1. .Die Tatsache, daß der Kern gewöhmlich bloh in der jungen, sich erst entwickelnden Zelle eine bestimmte Lagerung zeigt, weist darauf hin, daß seine Funktion hauptsächlich mit den Entwicklungsvorgängen der betreffenden Zelle zusammenhängt" (HABERLANDT).

2. .Aus der Art seiner Lagerung ist zu schließen. daß der liern beim Wachstum der Zelle, speziell beim Dicken- und Flächenwachstum der Zellhaut, eine bestimmte Rolle spielt. Damit ist nicht ausgeschlossen, dab er in der ansgebildeten Zelle eventuell noch andere Funktionen zu erfüllen hat" (HABERLANDT).

3. Der Kern ist wie bei der Abscheidung, so anch bei der Nahrungsaufnahme der Zelle beteiligt. Außer in der Lage kam sich dies auch darin kundgeben, daf der Kern nach dem Ort der Abscheidung und der Stoffaufnalme seine Oberflïche durch Ausstrecken zahlreicher Fortsätze vergrößert.

\section{Experimente aus denen sich auf eine Werlselwirkung zwischen} Kern und Protoplasma schließen lïßt.

Zu dem gleichen Ergebnis haben die experimentellen Untersuchungen von Gruber, Nussbaum, Hofer, Verwori, Balbiani und lilebs geführt. Die Methode besteht darin, daß man in irgend einer Weise einen 
einzelligen Organismus oller eine emzelne Lelle in ein liernhaltiges und in ein liernloses Stïck trennt und damn ihr weiteres Verhalten verfolgt und veroleicht.

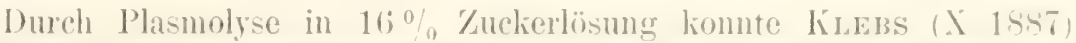
die Zellen ron Spirogyrafïlen in ein kernhaltiges mul mehrere liemlose Stücke zerlegen. Obwohl die letzteren zuweilen sechs Wochen am Lehen blieben. ehe sie zerfielen, bestand doch in ihrer Lebensfunktion ein crober Cnterschied im Vergleich zu den kernhaltigen 'Teilstïcken. Die liernhaltigen Stiicke fahren fort zu wachsen und umgeben sich mit einer nenen. durch Kongorot leicht nachweisbaren Zellhaut. Die kernlosen dagegen

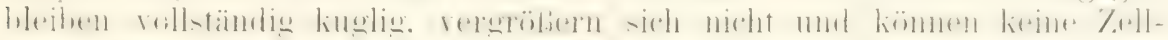
haut bilden. Wie weit der letztere Prozel, vom Vorhandensein des herns beeinflubt wird, geht in besonders auffälliger Weise daraus hervor, daßs.

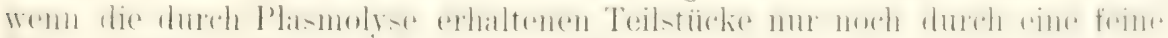

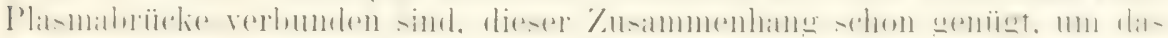
kernlose Stück zur Abscheidung von Zellulose zu befähigen.

Indessen gehen im Protoplasma gewisse Stoftwechselprozesse auch ohne Anwesenheit des Zellierns ror sich; zum Beispiel assimilieren die

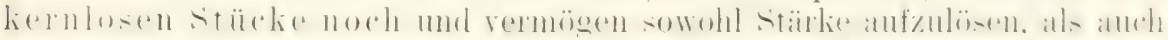

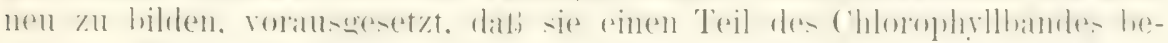
sitzen. Wenn sie längere Zeit im Dunkeln gehalten sind, werden sie

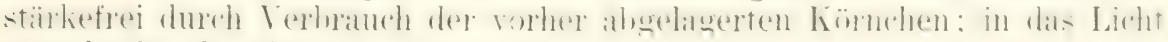
zurülekgebracht, füllen sich die Chlorophyllbänder wieller mit neuassimilierter Stälie: ja, es wird sogar reichlicher als beim kernhaltigen Teil Stärke angesammelt, wahrscheinlich aus dem naheliegenden Grunde. weil der Verbranch der Stärlie bei den Daniederliegen aller ïbrigen Lebensfunktionen auf ein Minimum herabgesetzt ist. Kernlose Teilstiicke von Funaria hygrometrica zeigen ein etwas abweichendes Verhalten, indem sie zwar Stärke auflösen. aber keine neue bilden kömmen, trotzdem sie sechs Wochen am Leben bleiben. Bein Zerschneiden von Vaucheria erhält man gröbere und kleinere Protoplasmaklumpen teils mit. teils ohme Kern. Die Lebensfähigkeit derselben, sowie das Abscheiden einer neuen Zellulosehülle ist an das Vorhandensein von mindestens einem Zellkern geknilpft (HABERLANDT X $18 \times \overline{\text {. }}$.

Nicht minder wichtige Ergebnisse wie bei den Ptlanzen sind durch Yer-

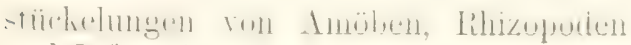
und Infusorien (Fig. 2:31) gewomen worden. Wie Nussbaum (X 1sta). Gruber
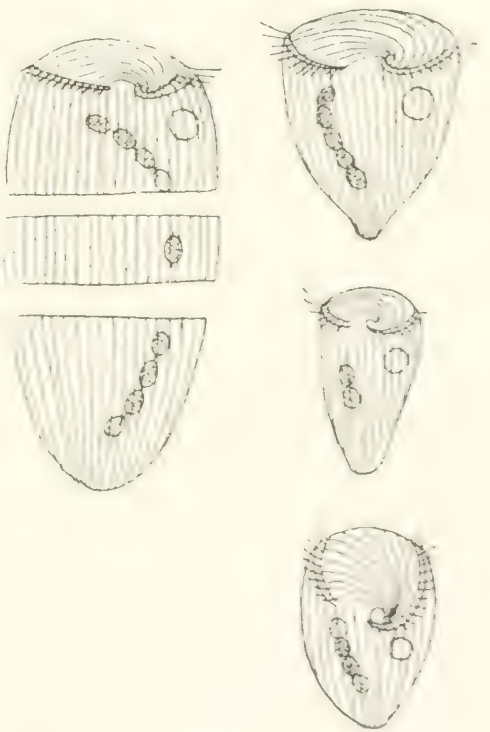

Fig. 231. Stentor, in drei kemhaltige Teilstïcke zerschnitten (links): die darass hervorgegangenen drei re-

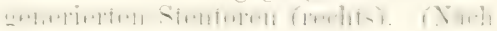

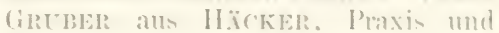
Themie etc.)

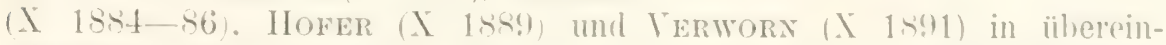
stimmender Weise mitteilen, kömnen nur kernhaltige Teilstäcke die verloren gegangenen Organe wieder durch Neubildungersetzon und sich zu emen normalen Individum, das wïchst mul sich rermehrt. mmgestaten. Kernlose Teile, selbst wenn sie grober als die kern- 
haltigen sind, können sich weder ergänzen noch wachsen, aber längere zeit. of mehr als 14 'Tage. eine Art von scheindasein führen: shlieblich alor zerfallen sie. Die formative Tätigkeit des Protoplasmas scheint daher in erster Linie unter dem Einfluß des Kerns zu stehen. Weniger sichergestellt ist dies für andere Funktionen der Zelle. wie für

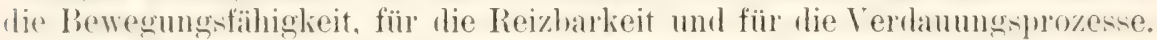
Die Urteile der einzelnen Beobachter gehen hier auseinander.

Bei Amöben sah HoFEr das kernlose 'T'eilstïck, nachdem das erste durch die ()peration hedingte Reizstadium ïherwunden war, 15-20 Minuten lang ziemlich normale Bewegungen ausführen; er erhlickt hierin norls eine Xachwirkung des liemes, welchem er einen regulatorischen Eintlub auf die Bewegungen des Protoplasmas zuschreibt. Denn während weiterhin das kernhaltige stück wie ein normales Individum die Pseudopodien ausstreckt und sich forthewegt, bleibt der kernlose Teil zu einem rumllichen hïrper zusammengezogen und macht nur ab und zu nach stundenlangen Ruhepausen anormale. ruckartige Bewegungen; er heftet sich an der Tnterlage nicht fest, wie herumkriechende Amöben tun, und beginnt daher hei der geringsten Wasserbewegung zu Hottieren.

Fine gröbere Unabhängigkeit der Protoplasmabewegung vom Einfluf. des Kerns fand Verwors hei Difflugia. Selbst kleine, kernlose Teilstiicke streckten in der für das unverletzte Rhizopod charakteristischen Weise lange. fingerförmige Pseudopodien aus und setzten noch nach fünf Stunden ihre Bewegungen fort. Auch waren sie noch rollkommen reizbar und reagierten auf mechanische, galvanische und chemische Reize durch liontraktion ihres Körpers.

Protisten. welche besondere lokomotorische Organe, wie Cilien. Wimpern. ('irrhen etc. entwickelt haben, lassen nach Verworn bei Teilungsversuchen eine vollständige Autonomie und Lnabhängigkeit derselben rom kern erkennen. Rei Lacrymaria führt jeller des Kerns beraubte hörperteil nach seiner Abtremnung rom Körper dieselhen Bewegungen aus. wie zur Zeit. als er noch mit ihm in Zusammenhang stand. Kleine Stücke von Stylonichia, die mit einer Anzahl Bauchwimpern versehen sint. machen mit diesen noch die eigentümlichen Laufbewegungen. Selbst bei einem kileinsten Plasmastïckchen. das nur eine einzige symugcirrhe lesitzt. fährt diese in ihren charahteristischen Bewegungen fort. Wenn sie nach hinten gerichtet war: wird sie ron Zeit zu Zeit plötzlich nach vorn geschmellt. wodurch dem Teilstïck ein kurzer Ruck nach rïckwärts erteilt wird: darauf kehrt sie selhst wierler in die Ruhelage zurïck usw. Cileich den Cilien und Cirrhen zeichnen sich auch die kontraktilen Vakuolen der Protisten durch vollständige Autonomie aus. Denn anch an kernlosen stücken kann man sehen, wie sie sich tagelang rhythmisch kontrahieren (VERwORN).

In bezug anf die Verdaumg endlich macht sich ein erhehlicher ['nterschied zwischen kernlosen und keruhaltigen Teilstücken bemerkbar. IV̈̈hrend von letzteren gefressene. kleine Infusorien. Rïblertierchen etr. in der normalen Weise verdaut werden, hat bei ersteren die Verdauung sowohl der Keit nach. als anch an Intensität eine erhehliche Ahahme erfahren. Man könnte hieraus schließen. daß es dem Protoplasma nur unter der Mitwirkung de- lierns möglich ist. verdauende selirete zu probluzieren (IIofEr. VERTORN).

Daf zwischen einzelnen Beobachtungen und Experimenten, die im zehnten hapitel mitgeteilt wurden. noch Widersprüche bestehen, wird nicht wmoler nehmen. wenn man die Sichwierigkeit der zu lösenden Aufgahen im Auge behält. 


\section{Die Kermplasmarelation.}

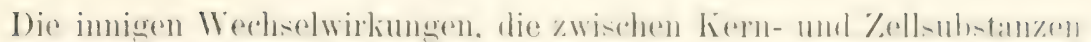

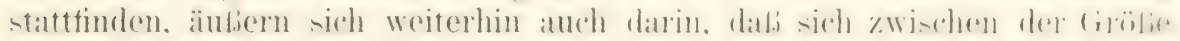

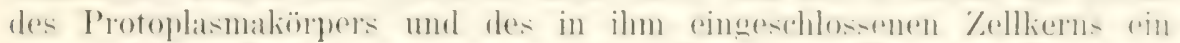

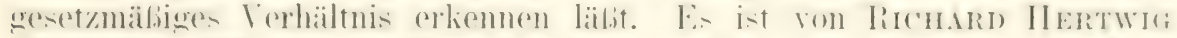

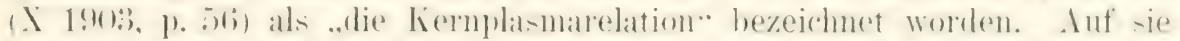

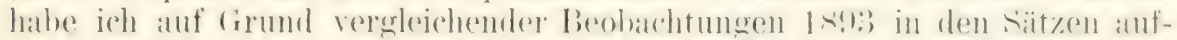
merksam gemacht: „Die Größe, welche ein Kern erreicht, steht in der

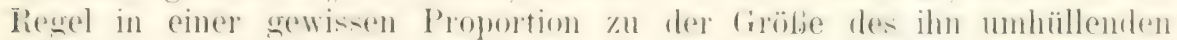

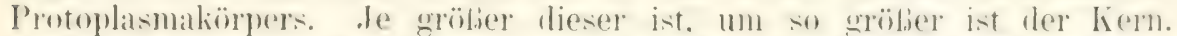
So timben sich in den grolien tranglienzellen der Spimallinoten anffallend grolie. bäschenfömige Korne. Ganz riesige I)imensionen aber errejohen

II
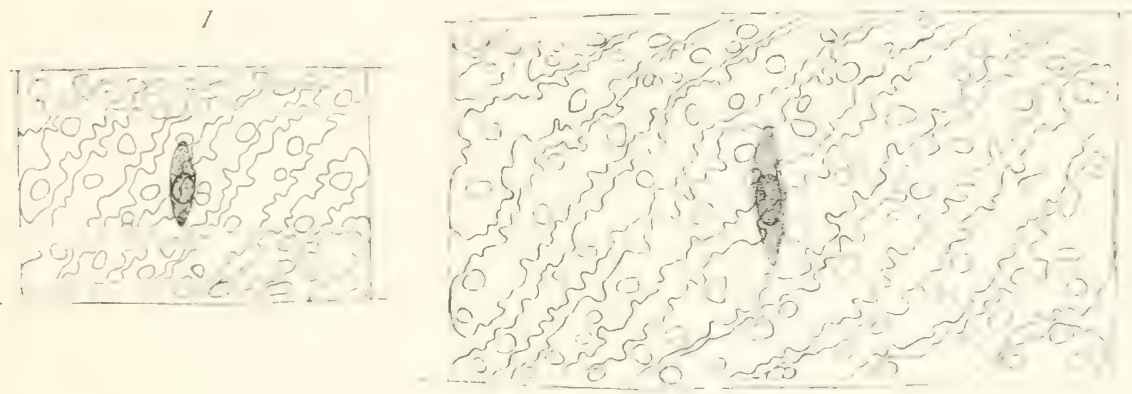

lïg. 232. I Gewölnliche Zelle ron spirogyra bellis. II Infolge der Kältewirkung entstandene große Zelle mit einem einfachen grolien liern, der doprelt so viel Kernmasse als ein Normalkern besitzt. II/Unter gleichen Bedingungen entstandene grobe \%elle mit zwei hemen. 4. Juni 1900. Vergr.315. Nach Gerissimow. Ton dem Inhalt der Zellen sind nur die lionturen der Chlorophyllbänder einer wïhrend der Beobachtung oberen Hälfte der Zelle mit den ïulieren Fonturen der Stärkehüllen un die Pyrenoide herum und die Konturen der lieme mit den Nucleolen abgebildet. Alle Abbildungen sind mit IIilfe der Camera von lebenden \%ellen ahgezeichnet worden.

sie in unreifen Eizellen, und zwar in einem ihrer (irölie entsprechenden Makstabe:"

Durch interessante Experimente haben (ierdssmow (X 1901 u. 1902). boveri (X 1904 u. 1905) und Richard HERTwig (X 1909 ) eine Reihe

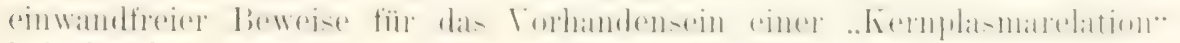
beigebracht.

Gerassmow hat auf Zellen von Spirogyra bellis im Momente der

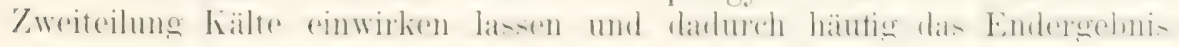


so abgeändert, dah von den sich bildenden 'Tochterzellen die eine keinen Kern erhält, die andere dagegen entweder beide durch Teilung entstandene 'Tochterkerne oder einen einzigen groben Kern einschließst, der das gesamte, beiden 'ochterkernen entsprechende Material in sich rereinigt. Wenn solche abnorme Zellen, welche doppelt so viel Kermmasse als nor:

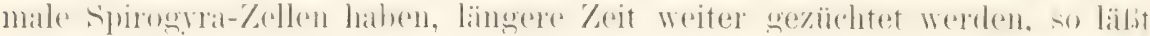
sich jedesmal feststellen, daß sie bald stärker zu wachsen beginnen als die

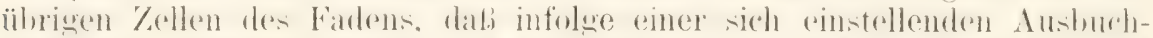

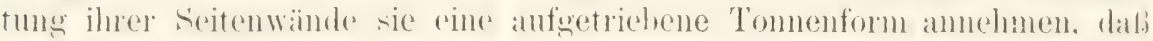
ihre Chlorophyllbänder $11 \mathrm{~m}$ den Kern herum stärker entwickelt werden,

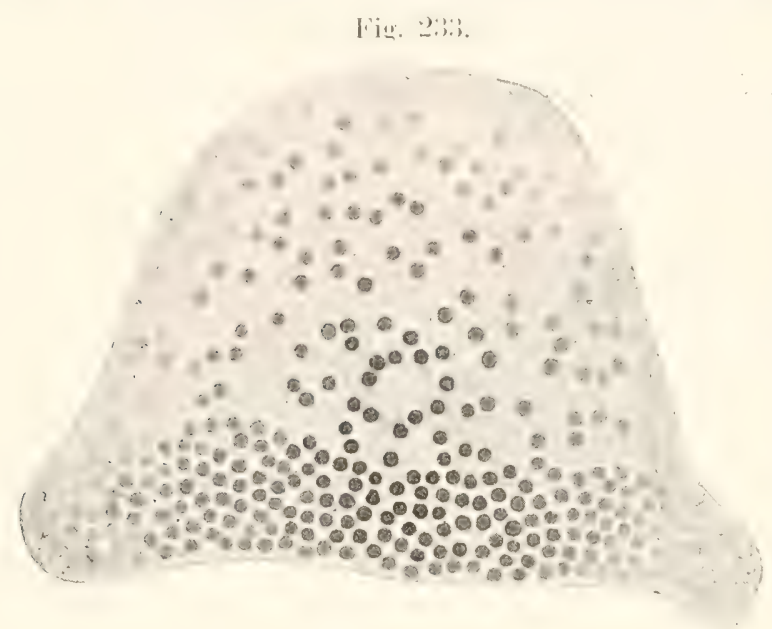

F'ig. 2.:3.

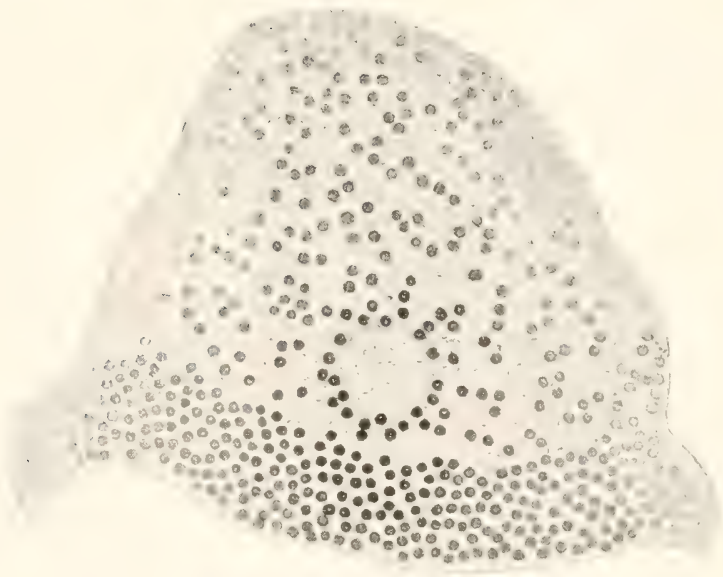

Nig. 233. Stück von der Oberfläche eines jungen Pluteus von Echinus microtuberculatus, all pillell liemhaltigen Eifragment gezüchtet. Nach Boveri.

Fig. 234. Desgleichen von den gleichen Eltern aus einem kernlosen Eiframent gezüchtet. Nach Boreri.
Łlaß ilıre nächste T'eilung sich verspätet und nun wieder Tochterzellen liefert, welche ebenfalls an Größe ihres Kernes und des Protoplasmakörpers normale Spirogyrazellen übertreffen (Fig. 232). Es ist dies der Fall sowohl bei Zellen mit doppelter Kermmasse, als auch mit zwei kleineren Kemen. Gerassimow, welcher an seinem Beobachtungsmaterial genaue Berechnungen über die relative Größe der Kerne und Zellen, ilure Länge, Dicke und $\mathrm{V}_{0}$ lumina angestellt hat, gelangt zu dem Ergebnis, daß „eine unzweifelluafte Abhängigkeit des normalen Wachstums der Zelle von der 'Tätigkeit des Kerns besteht und dak unter sonst gleichen Bedingungen die Größe der Zelle eine Funktion der Menge ihrer Kernsubstanz ist". Zu dem gleichen Ergebnis auf tierischem Gebiet ist BOver I durch eine Reihe auberordentlich interessanter $\mathrm{Ex}_{\mathbf{X}}$ perinente an seeigeleiern gefiihrt worden. Indem er reife Secigeleier durch Schiitteln in

kernhaltige und kernlose Stücke teilte, sie damn befruchtete und aus dem

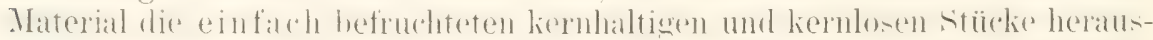
sortierte, konnte er ihre weitere Entwicklung verfolgen und zwischen beiden 


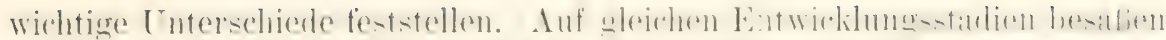

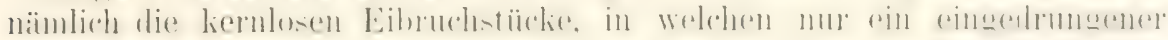
Samenkern vorhanden war und sich teilte (Fig. 2:)4), kleinere und ent-

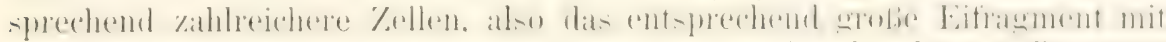
dem Eikern, der sich mit einem Samenkern verbunden latte (Fig. 2:30). Im ersteren Falle sind auch die Kerne der Furchungszellen in auffälliger Weise kleiner als im zweiten Fall. Jene enthalten etwa nur halb so viel Kermmasse als die aus der Verschmelzung

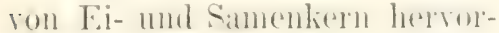

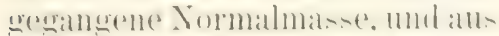
diesem limmle bleiben sie kibiner

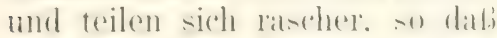
nun anch das Eibluchariucli in zahlerehere und lileinere \%ellen zerfällt.

Zuweilen war es bei seinen Experimenten BOvERI gelumgen, auch Eier mit Kernen zu erhalten (Fig. 236), deren Chromosomenzahl auf das Doppelte der Norm, so bei Strongylocentrotus von 36 auf ca. 72, vermelnt war. „Dann enthielten die Larven dementsprechend viel gröbere Kerne als the ans momalen Kontrolleiern (Fig. 235) und im Zusammenhang damit viel gröfere murl weniger Zellen. Sie zeigen nur "twa die Ihalfte der normalen Mesenchrmzellenzahl..

Irim enullich in ein $\mathrm{E} i$ zwei Samenliorne eingerlungen sind, von denen nur einer sich mit dem Eikern rerbindet, während der andere abseits liegen bleibt und sich für sich weiter entwickelt ( siehe Kap. XI), so ent-

Fir. 23). Normale Gastrula vou Strongyiocentrotus lividus, rom animalen l'ol gresehen. Nach lioveri,

Fii. gleichen Eltern, nats experincutell erzeugter lerdoppelung der im befruchteten Ei vorhandenen Chromosomenzahl. Nach IBoveri.

Fig. 23\%. Ein Stück der Wimperschnur eines Pluteus von Strongylocentrotus lividus aus einem doppeltbefruchteten Ei. Nach Boviri.

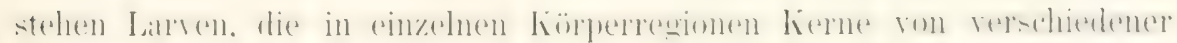
Größe einschließen, je nachdem sie rom befruchteten Eikern oder vom

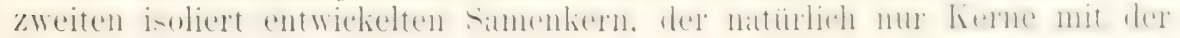


halben Chromosomenzahl liefert. abstammen. Welche Kontraste hierbei

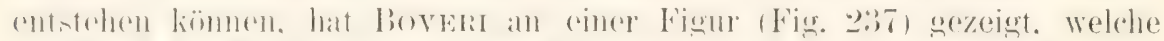

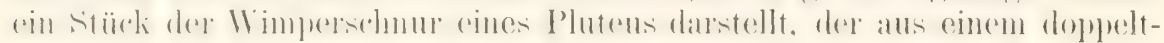
befuchteten Ei hervorgegangen ist.

Boveri zieht hieraus den auch aus den Experimenten von Gerassniow sich ergebenden SchluB, ,dab von zwei identischen Eiern, die nur in (ier Venge ihres Chromatins verschieden sind, nicht dasjenige sich öfter und rascher teilt, das den gröberen Kern besitzt, sondern das mit dem kimeren. so daß also die entstehenden Larven nicht nur durch die ver-

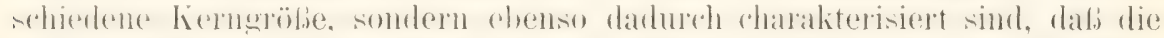

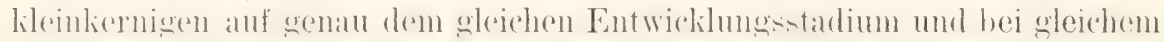
Alter mehr \%ellen besitzen als die grobliernigen. Der Grumb für rliese

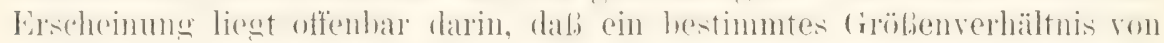
Kern und Protoplasma, R. Hertwigs Kernplasmarelation, angestrebt wird

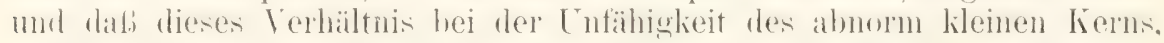
sich über seine ursprüngliche Anlage hinaus zu vergrößern, nur dadurch

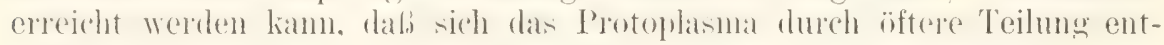
sprechend verkleinert". Das Ungekehrte ist der Fall bei abnorm großen Kernen mit vermehrter Chromosomenzahl.

Zugunsten der Kernplasmarelation hat endlich RICHard HerTwig anch Beobachtungen an Protozoen verwertet, die lange Zeit hungerten. IBei solchen Arten, die viele Hunderte von Kernen haben, wie Actinosphaerium und Dileptus, nimmt eimmal das Protoplasma ab, so dab die 'Tiere immer kleiner werden, außerdem aber werden auch einzelne Teile der gesanten Kernmasse, wie man mikroskopisch nachweisen kann, aufgelöst, während andere intakt bleiben. „Ein Dileptusriese hat so enorm viele Kernstücke, đlaß man sie nicht zählen kann, wohl über 1000; Dileptuszwerge nur etwa 50-100. Bei der Reduktion der Körpergröße sind die meisten Kernstücke resorbiert worden." Ähnlich verhält sich Actinosphaerium, bei dem sich feststellen lief, dafs von den Hunderten von Kernen schlieblich nur noch einige wenige, $1-2$ in extremen Fällen, vorhanden waren. "Schwund des Plasmas ist hier also", wie R. Hertwig bemerkt, , ,lie Veranlassung zu einer Reduktion des Kermmaterials geworden." Er glaubt dies Verhältnis nur durch die Annahme erklären zu kömmen, „daß jeder Zelle normalerweise eine bestimmte Korrelation ron Plasma- und Kermmasse zukommt".

\section{Das Problem von der Urzeugung der Zelle.}

Da die Zelle die einfachste, uns bis jetzt bekannte Form des Lebens ist, läbt sich an die vorausgegangenen Kapitel, welche von der Vermehrung der Zelle handelten, wohl am besten die allgemeine Frage anknüpten: Wie stellt sich die Naturforschung zu dem vielerörterten Problem von der ersten Entstehung des Lebens auf unserer Erde und überhaupt zu der Lehre von der Urzengung? Mit dem Problem hat sich die Menschheit von dem friblesten Altretum an heschäftigt und dutworten auf dasselle zu verschiedenen Zeiten gegeben, welche eine etwas besser unterrichtete und auf-

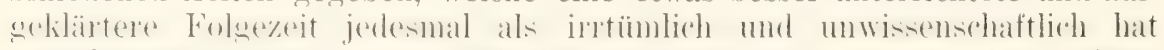

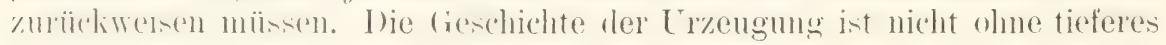
Interesse.

Im klassischen Altertum trug selbst ein so großer Forscher und

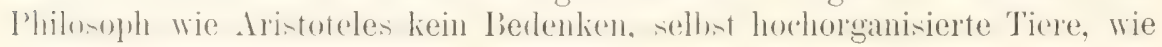


Fische und Amphibien, aus dem Schlamm von Gewiissern, oder Inseliten aus faulenden Substanzen sich biklen zu lassen.

Noch im 17. Jahrhundert waren derartige, auf ungeschulter Natur-

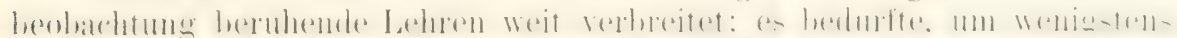

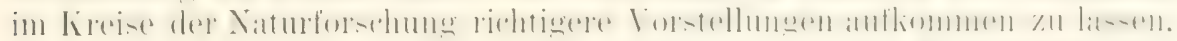
der genauen Untersuchungen von SwAMMERDAM und der Experimente von REDI und anderen, welche zeigten, daß Fische, Amphibien und Inseliten in allen angeblichen Fällen von Urzeugung aus Eiern ihren Ursprung nehmen. „Omme virum ex ovo" lautete daher der beliannte, für seine Zeit epochernachende Ausspruch ron HARver, welcher das wissenschaftliche Schlubergebnis aus diesen Erfahrungen zog.

Trotzdem haben auf dem Gebiete der Helminthologie viele Forscher,

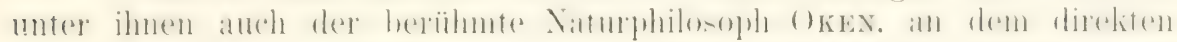
Ursprung von Organismen aus in Zersetzung begriftenen Stoffen bis in

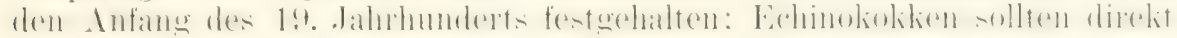
in ter Leber, Coenurus im Gehi'n, Finnen in den Muskeln, Bandwiimmer

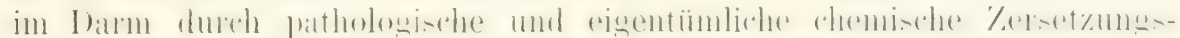
prozesse in der Leber, Hirn- und Muskelsubstanz entstehen. Auch dieser Irrtum wurle beseitigt und das ,Omme virum ex ovo" zur Geltung ge-

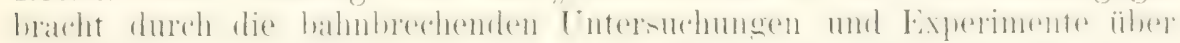
die Entwicklung und Lebensweise der Eingeweidewïrmer, welche von SIFBOLD. KüCHENEISTER, LEUCKART 11. a. angestellt worden sind.

Je kileiner und einfacher die Organismen sind, um so leichter können sic als Beweismittel für die Urzeugung benutzt werden. Infusorien und Bakterien bilden daher seit der Zeit, wo durch das Mikroskop diese Welt

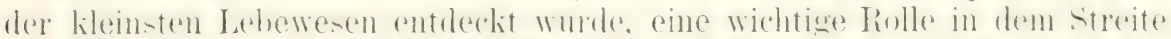

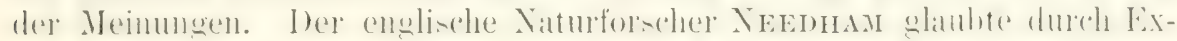
perimente beweisen zu könmen, dab die in Aufgüssen oder bei der Fäulnis

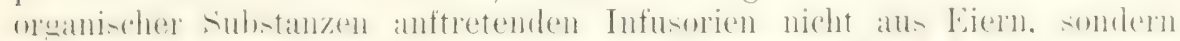

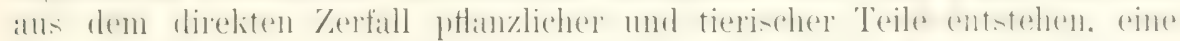
Meinung, die auch von BüFFON und OKEN geteilt und zum dusgangspunkt von umfassenden Theorien gemacht wurde. Der Abt SPAnLANzaxi

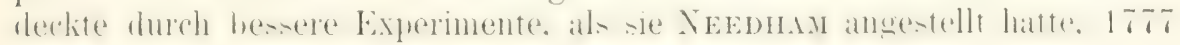
auch diesen Irrtum auf.

Aber noch einmal wiederholte sich der Streit über die Urzengung bei der Frage nach der Entstehung der Bakterien in der zweiten Hälfte des 19. Jahrhunderts. Pouchet versuchte zu beweisen, dab die Bakterien

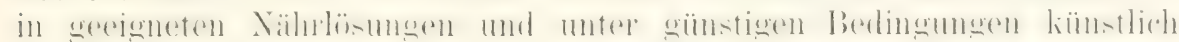
aus lebloser Substanz erzengt werden könnten. PAsTEuR tat dureh Gegenexperimente dar, daß auch für die Entstehung von Bakterien in Nährlösungen die Keime von solchen vorhanden sein müssen, und dab man durch geeignetes Verfahren jerle Nählösung steril machen kamm. Dank

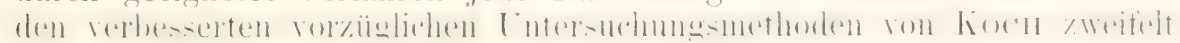
jetzt liein Biologe mehr daran, dab die Bakterien ebensowenig als die Infusorien als Beweismittel für die Urzengung dienen können.

Endlich sei noch ein letzter Versuch erwähnt, die Kluft zwischen Organismen und Anorganen zu überbrïcken. HAECKEL glaubt, dals dies durch I ebewesen geschehe, welchen er den Tamen Moneren gegeben und

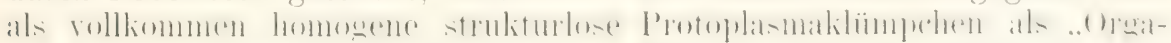
nismen ohne Organe: beschrieben hat. Er hält es für leicht möglich, dab ein solches einfaches Lebewesen aus einer Eiweißlösung direkt entstehe. wie ein Kristall aus einer Mutterlauge. Die Möglichkeit der Lr\%eugung auf diesem Wege schien noch näher gerïclit, als man bei (ielegenheit der 
challengerexpedition in den Sohbmmproben, die aus den gröbten Meeres-

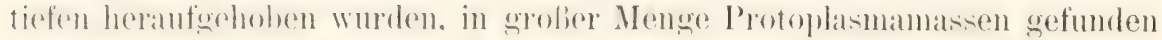
zu haben glaubte, welchen Huxuey den Namen Bathybius Haeckelii

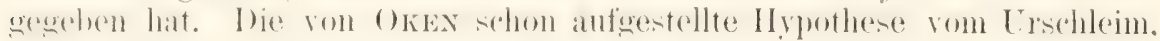
der im Meere gebldet werde, schien hier eine Bestätigung gefunden zu haben.

Allein auch die Möglichlieit, auf diesem Wege die Frage nach der fryengung ihrer Lösmng näher zu führen. hat sich als illusorisch erwiesen. Jin ()rounismus Bathybius, der als Protoplasmanetz den Meereshorlen bedeckt, existiert nicht, wie spätere Untersuchungen ergeben haben. Und was die Moneren betrifft, so sind sie nicht so einfach beschaffen, als HAECKEL glaubte annehmen zu müssen. da in den meisten der niedersten ()romismen, die man frïher für einfach und kernlos hielt, meist kleine lerne in grölerer Anzahl oder wenigstens Kernsubstanz nachgewiesen werden lionnte. Dal.) sie aher in anderer Weise als durch Eltemzengung entstehen könnten, muß nach den Erfahrungen, die man über die Fortptlanzung der Protisten bisher gemacht hat, als sehr unwahrscheinlich bezeichnet werden.

Die Vergeblichkeit der Bemühungen, die Entstehung des Lebens durch Trzeugung auf unserer Erde zu heobachten ofler nachzuweisen, hat wohl den Anstol.) gegehen, auch die Mäglichkeit zu erörtern, oh nicht die Keime des Lebens von anderen Weltenkïrpern auf unseren Planeten übertragen worden sind. Die berïhmten Physiker. William Thomson und IIEsumotzz halten es für denkbar, dali Meteorsteine, die äberall den Weltentam durchschwämen, 'Träger von lehenden liemen sein kïmnen. Denn wenn auch ihre Oberfläche beim Durchtritt durch unsere Atmo- whäre erhitzt werde. so bleibe doch ihr Inneres für die Erhaltung lebender Keime gen̈̈gend kïhl. Mit Recht hat man dieser Hypothese vorgeworfen. (lal.) sie nicht nur an sich in höchsten frade unwahrscheinlich ist, sondern auch, dalj durch sie nichts gewonnen ist; demn das Problem der Lrzengung wird durch sie nur von unserem auf einen anderen Planeten verlegt.

'Trot\% dieser erfolghosen Bemiühungen ist die Ammahme einer Lrzeugung für den Naturforscher, der auf dem Boden der Entwicklungslehre steht, ein philosophisches Berlürfnis. Denn nicht ron Ewigkeit her kïnnen Lebewesen anf unseren P'laneten existiert haben, da nach der liosmogonie von KANT und LAPLACE er sich einst vor undenklichen Zeiten in cinem feurigtlüssigen Zustand hefunden hat, wie ihn jetzt noch andere Weltenkïrper im Iimmelsam zeigen. Lebewesen kömen daher erst bei (ler Abkühlung der Erde, wie HAECKEL mit Recht geltend macht, entstanden sein. als die feste Erdrinde mit Wasser sich bedeckte. Wie das weschehen ist, mag dahin gestellt bleiben, aher der Entwicklungstheoretiker wird HAEckEL Recht geben, wenn el sagt (III 1866, Bd. I, S. 179): „Wir müssen diese Hypothese als die unmittelbare lionsequenz und als die notwendigste Eroünzung der allgemein angenommenen Erblildungstheorie von KANT und LAPLACE hinstellen und finden hierzu in der Gesintheit der Naturerscheinungen eine so zwingende logische Notwendiglieit, dab wil deshall, diese Deduktion, die Vielen seln gewagt erscheinen wirl. als unabweisbar bezeichnen müssen."

Einen ähnlichen Standpunkt nimmt NäGELr (III 1884) ein. In dem Kapitel: Irzeugung in seiner mechanisch-physiologischen Theorie der Altrammung lehre, bemerlit er: ..Die Entstehme des organischen aus dem Enorwanischen ist in erster Linie nicht eine Frage der Frfahrung und des Experiments. sonder'n eine aus dem fesetze der Erlallung ron Kraft und 
Stoff' folgende 'Tatsache. Wenn in der materiellen Welt alles in ursiel-

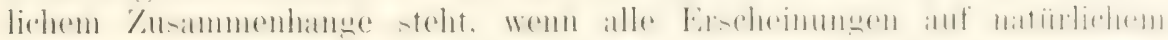
Wege vor sich gehen, so müssen auch die Organismen, die aus den nämlichen Stoffen sich anfhanen und schlieblich wieder in dieselben Stoffe

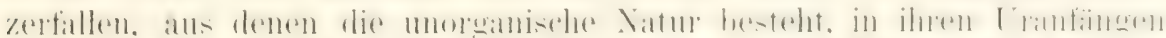

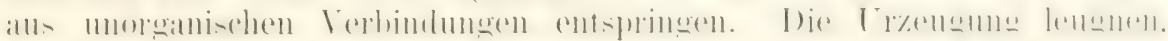
heift das 1 under verkïnden."

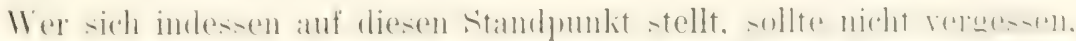
dib anch die tiefere Erkenntnis. welche wir von den einfacheren Organismen gewomnen haben, und überhaupt unsere bessere Einsicht in das Wesen des Lebensprozesses nicht imstande gewesen sind, die tiefe und

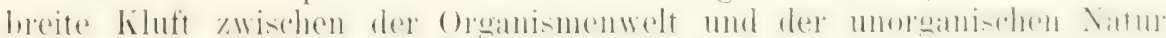
zu

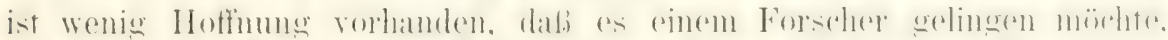

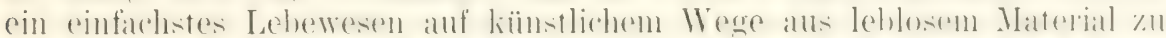
erschaffen. Er hat gewib nicht mehr Aussicht auf Erfolg, als Wagner

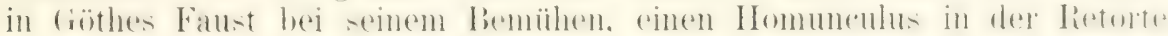
zı brauen.

Diese Kluft erkennt auch NägELI ohme Vorbehalt an: er selbst hat

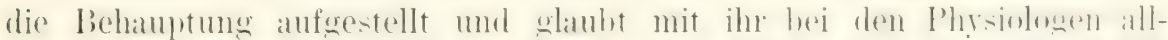

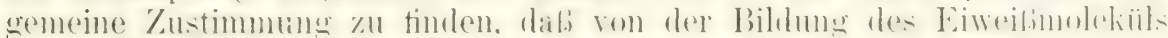

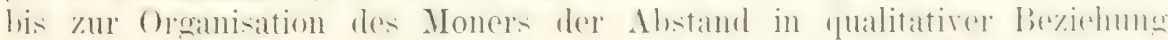

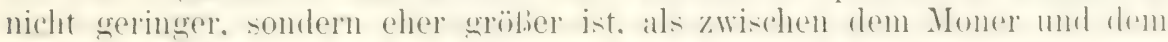

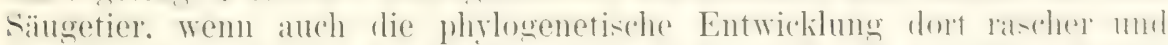

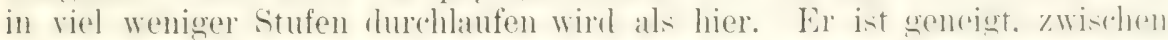

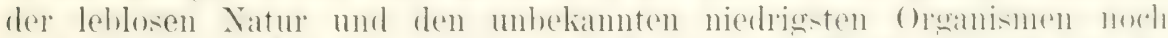
zwei \%wischenstufen einzuschalten. Anf der ersten stufe vollzioht side die sinthese ron Eiweilirerbindungen, auf der zweiten stufe ant-tehen ans

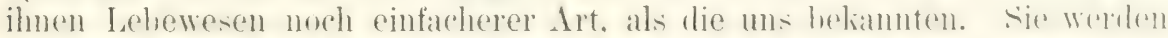

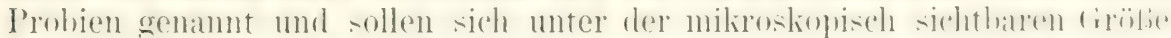
befinden (N̈̈GELI, III 1886, S. 86).

Doch kehren wir aus dem luftigen Reich der Spekulation auf den festeren Boden der Wirklichkeit wieder zuriick. Dann müssen wir bei

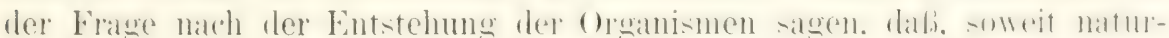
wissenschaftliche Erfahrung reicht, ein Organismus stets von einem

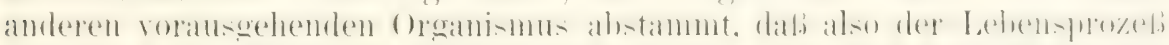

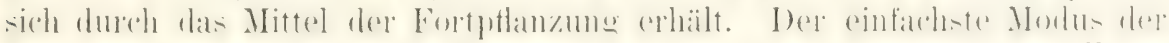
Fortpflanzung ist wieder die Teilung der Zelle; Zelle stammt von Zelle in

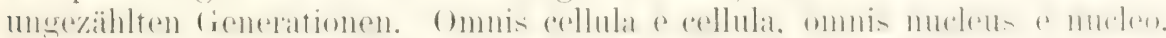

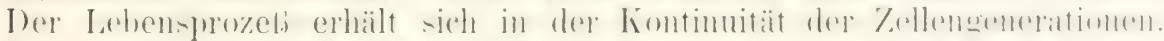
Die lebende Substanz, die uns in einem Protozoon oder einel' l'flanze

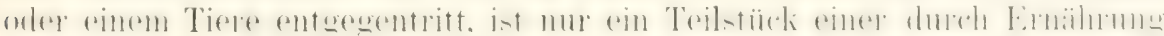
wachsenden und durch periodisch wiederkehrende 'Teilungen sich ver-

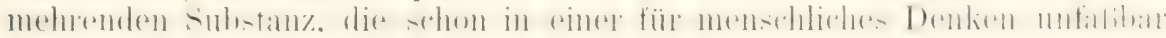
langen Zeit vor uns gelebt hat.

\section{Literatur X.}

1) Balbiani, Recherches expérimentales sur la merotomil dis Infusoires cilles. Prim. part. Recucil. Zool. Suisse. IS89.

2) Boveri, Ein geschlechtlich ersengler Oroanismus ohne mïtterliche Eivenschaflen. Gesellschaft f. Morphol. "1. Physiol. zu Miunchen. 1880. 
(i) Dersclbe, Ergebnisse Zïbr die Konstitution der ihromatischen Substanz des Zellkerns. Jenc 1004 .

1) Derselbe. Zcllenstudien. Heft $V$. Über die Abhängigkeit der Kerngröße u. Zellenzahl der Seeigellarven von der Chromosomenzahl der Ausgangszellen. Jena 1905.

i) Gerassimow, Uber den Einfluß des Kerns auf ders Wachstum der Zelle. Buulletin de la Socititimpirimle des naturalistes de Moscau. 19or.

(i) Derselbe, Die Abhängigkeit der Größe der Zelle z'on der Alense ihrer Kermmasse. Zeitschr. f. allgemcine Physiol. Bid. I. 1902.

i) Gruber, Über die Einflußlosigkeit des Kerns anf die Bereegung, die Ernährung und das Il iuchstum cinselliger Tiere. Biol. Zentralbl. Bat. III. 1884.

(i) Derselbe, Über künstliche Teilung bei Infusorien. Biol. Zcntralbl. Bid. IV u. V. I885 u. 1886 .

(1) Haberlandt, Über die Beziehungen arischen Frunktion und Lage des Zellkerns bet den P'flanien. Jena is87.

111 Hertwig, Oscar $\%$. Richard, Die Aktinien, matomisch und histologisch mit besonderer Berücksichtigung des Vervenmuskelsy'stems untersucht. Jend 1879 .

11) Dieselben. Über den Befruchtungs- und Teihngstorgang des tierischen Eies unter dem Einfluß äußerer Agentien. Jona 1887.

12) Hertwig, Richard, Uber Lorrelation von Zell- and Kerngröße und ilhe Bedeutung fïr die geschlechtliche Differenzierung und die Teilung der Zelle. Biol. Zentralbl. Bit. TXllI. Heft I u. 2. 1903.

1i) Hofer, Experimentelle Untersuchungen über den Einfluß des Lims anf das Protoplasma. Jenaische Zitschr. f. Vatura'issenschaft. Bit. IXIV. I889.

14) Klebs, Über den Einfluß des Kems in der Zelle. Biol. Lentralbl. Bd. VII. I887.

1i) Korschelt, Bciträge zur ITorphologie und Physiologie des Zellkcrus. Zool. Jahrb. Abt. f. Anatomie. Bd. IV. IS89.

16) Nußbaum, Über die Teibarkeit der lebendigen Materie. Archiv f. mikrosk. Anatomic. Bd. XXYT, 1886.

17) Strasburger, E., Über dic IIrkhngssphäre der Terne und die Zellgröße. Histologische Beiträge. Bd. IT. 1893.

18) Verworn, Die physiologische Bedeutung des Zellkerns. Archiz. f. d. ges. Physiologic. Ba. LI. I89R. 


\section{ELFTES KAPITEI.}

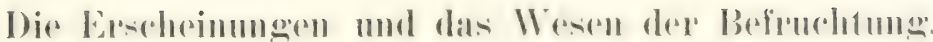

Die im achten Krapitel besprochene Fortpflanzung der Zellen auf dem Wege der Teilung scheint, wenigstens für die Mehrzahl der Organismen, keine in sich unhegrenzte zu sein; der Vermehrungsprozeß kommt nach kïrzeren oder längeren Zeiträumen zu emem Stillstand. wem er nicht durch Vorkehrungen, die man unter dem Namen der Befruchtung zusammenfassen kann, wieder von neuem angefacht wird. Nur die aller-

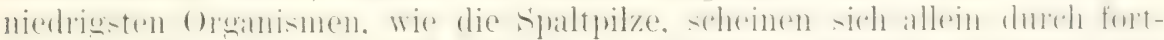

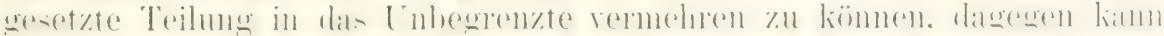
für den gröbten T'eil des Pflanzen- und Tierreichs das allgemeine Gesetz. aufgestellt werten, daß, nach einer Periode der Massenzunahme durch

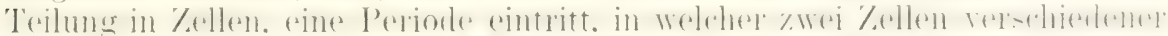

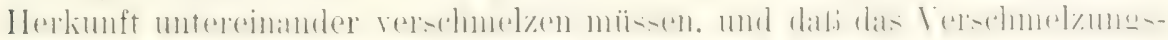
produlit erst wieder einen Elementarorganismus liefert, der den Ausgang für eine nene Periode der Vermehrung durch Teilung bildet.

Infolgedessen gestaltet sich die Vermehrung der Elementarorwanismen und damit das Leben selbst zu einem zyklischen Prozesse. Nachdem Generationen von Zellen durch Teilung entstanden sind, führt der Kreislauf des Lebens immer wieder zu demselben Ausgangspunlit zurïcli. dafì sich zwei Zellen im Befruchtungsakt vereinigen und zum Anfang einer neuen Generationsreihe werken. Derartige Zyklen nemut man Zeugungskreise. Sie treten uns im ganzen Organismenreich in den mannigfachsten Formen entgegen.

IBei den Einzelligen z. B. besteht der \%eugungshreis aus zahlieichen. unter Umstïnden nach Tausenden zählenden, einzellehenden Individuen. Der befruchtete Elementarorganismus vermehrt sich durch wiederholt eintretende Teilungen in Tachkommen, die der Befruchtung nicht bedürfen, bis ein Zeitpunkt eintritt, wo ein nener Zeugungsalit zwischen den ungeschlechtlich entstandenen Generationen stattfindet. Im venauesten hat man diese Verhälnnisse bisher bei den Infusorien untersucht. So hat Maupas (XI 1789. S. 407) hei emer Art derselben. bei Lencophrys patula, durch zahlreiche Experimente festgestellt, dah elst nach 300 renerationen. die aus einem befruchteten Individum durch Teilung hervorgegangen sind, der Zeugungslireis abgeschlossen wird, indem dic Nach-

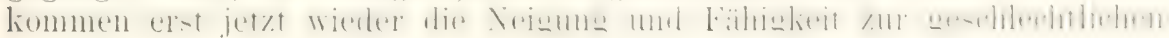




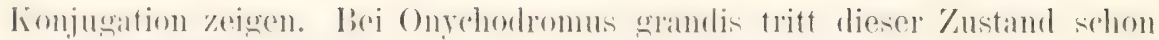

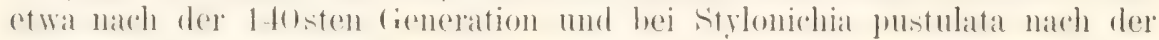
130sten Generation ein.

Bei vielzelligen Organismen bleiben die Zellen, die aus dem befruchteten Ei durch 'Teilung ihren Ursprung nehmen, vereint, um einen \%ellenstant oder ein organisches Individum höherer ordnung zu bilden. vie lassen sich von dem allgemeines (iesichtsumnlit aus. von dem wir hier dir Sexualfrage behandehn, der tiesamtheit der sich durch Teilung ungeschlechtlich rermehrenden Zellindividuen vergloichen. die nach der liopulation aus einem IIuterinfusor entstanden sind. Der Zeugungskreis wird wieder geschlossen. wemn sich im vielzelligen Oroanismus feschlechtszellen anlegen und wenn sie dureh ihre Vereinigung infolge des befruchtungsprozesses zum Ausgangspunlit für nene cienerationen sich teilender Zelleri werden. Die Zeugurgskreise können in diesem Falle ein sehr verschiedenes Bild darbieten und zuweilen eine sehr liomplizierte Beschaffenheit annehmen.

Den einfachsten Fall bieten manche niedere, vielzellige Algen, wie Eudorina, Pandorina. Durch wiederholte Teilung der befruchteten Zelle entsteht eine Zellenkolonie (Fig. 2:38. Nach einer bestimmten Lebensdauer werden alle Zellen zu Geschlechtsellen. Zum Zwecke der Zeugung löst sich der ganze durch Zellteilung entstandene liomplex wieder in seine einzelnen Bestanlteile auf. welche zum Ausgang für nene Zeugungskreise dienen.

Die hier zur Geltung kommende Fähigkeit jerler Zelle, den ganzen vielzelligen ()rganismus wioder zu reproduzieren. hört auf wirksam zu werden, sowie der violzellige Organismus einen irgendwie höheren Grad von Ausbildung erreicht. Dann sondert sich das aus einem befruchteten Ei alstammende, sich durch Teihung ins L'ngemessene vermehrende Zellenmaterial in zwei Gruppen, in Zellen, die zum Aufbau der Gewebe und Organe der P'tanze oder des Tieres dienen, und in Zellen. die zur Zeugung bestimnt sind. Infolgedessen hleiht gewöhlich der Organismus. auch wenn er in die Zeit der Geschlechtsreife eingetreten ist, als solcher erhalten: er sondert nur die (ieschlechtszellen von sich ab, um sich in neuen Zeugungskreisen zu vervielfältigen, bis er sellst durch Abnutzung seiner Körperzellen oler durch irgendwelche andere Ursachen dem Untergang unterliegt (Nussbaum XI 1880, Weismann XII 1883, 1885).

In seiner reinsten Form ist ein streng geschlossener Zyklus nur hei den höheren Tieren anzutreffen, bei welchen eine Vervielfältigung der Individuen allein auf dem Tege der geschlechtlichen Keugung möglich ist. In viclen Abteilungen des 'Tier- mul Ptlanzenreichs aber läuft neben der geschlechtlichen noch eine ungeschlechtliche Vermehrung einher. Auber den hefruchtungherlürtigen Zellen lösen sich vom ()rganismus auch einzehe, der Befruchtung nicht hedürftige \%ellen (Sporen, Jungferneier) oder gröbere (rrupuen von solchen ab (Knospen, Sprossen) und gehen auf ungeshlechthohem Wege durch fortgesetzte Teilumg neuen Organismen den Ursprung (vegetative Vermehrung). Oder allgemein ausgedriickt, zwischen zwei Befruchtungsakte schieben sich zahlreiche Folgen von Zellteilungen ein, die aber nicht einem einzigen physiologischen Individum höherer Ordnungangehören, sondern sich auf zahlreiche Individuen verteilen. Zwei Unterfälle sind hier wieder möglich:

In einem Fall ist der aus dem befruchteten Ei entstandene Organismus selbst nicht imstande. Geschlechtszellen zu hilden: er rermeht sich 


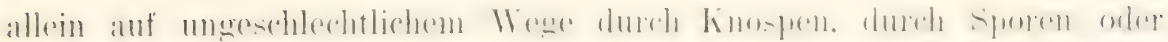
parthenogenetische Eier. Erst diese oder noch entferntere. anch unge-

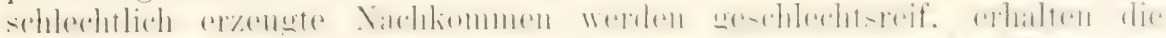

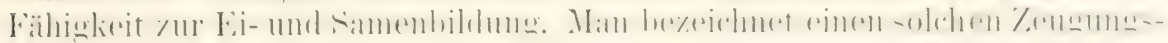
kreis als einen regelmähigen Generationswechsel (Hydroidpolypen,

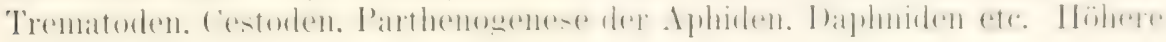
Kryptogamen).

Fig. 235. Entwicklung von Pandorina IMorum nach P'RINGSHFIM. IUS SACHS.

I Eine schwirlmende lamilie; II eine solche in 16 Iochterfamilien geteilt; III eine geschlechtliche familie, feren einzelne Zellen ans der rerschleimten IIiille austreten ; $I V, \quad$ I laarung der Schwämer: $V I$ eine eben entstandene, VII eine ansgewachsene Zygote; VIII Umlildung des Inhaltes einer $/$ yote in eine grofie Schwärmzelle; IX dieselbe frei; 1 junge familie ans der letzteren entstanden.

\section{Im zweiten}

Fall vermehrt sich der aus dem befruchteten Ei entstandene Organis-
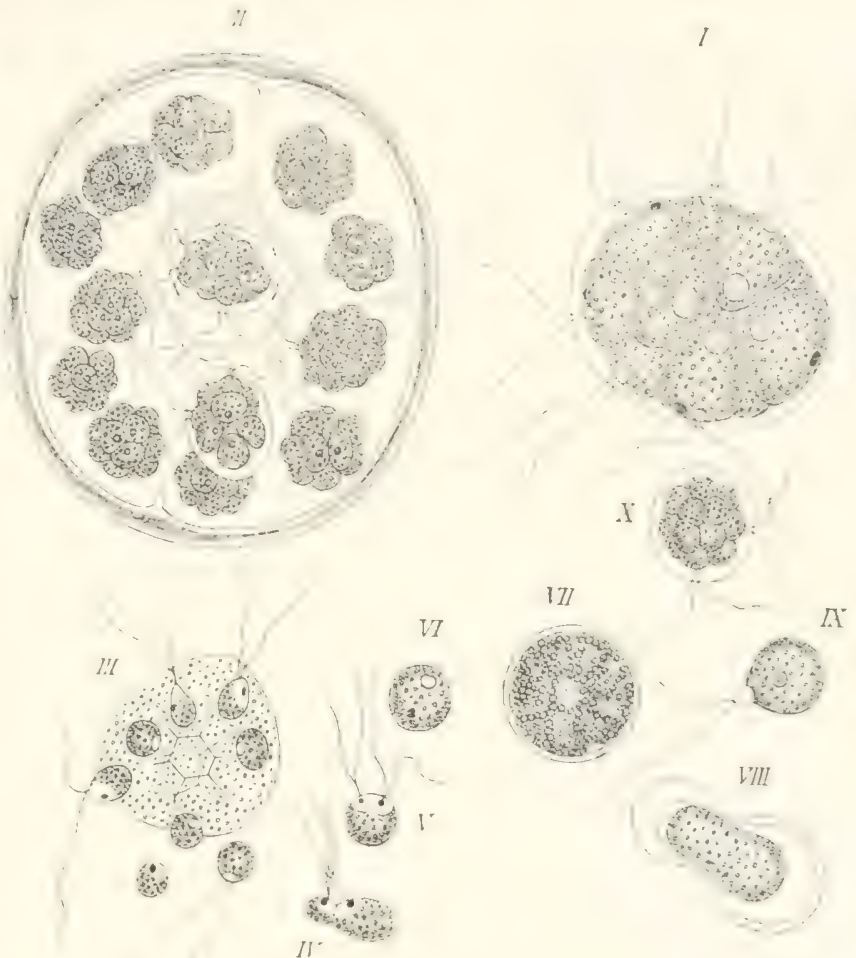

mus sowohl

durch Geschlechtszellen als auch auf ungeschlechtlichem Wege

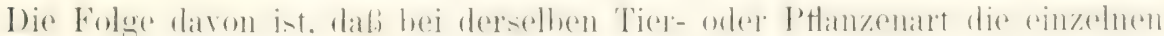

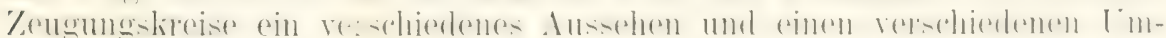
fang gewimnen müssen. 'Lwisc 'len der ersten und dem Eintritt der zweiten

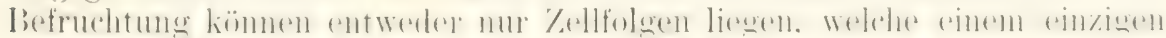

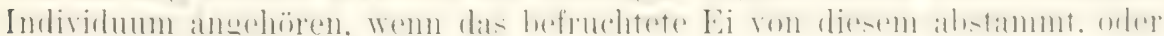
es schieben sich Zellfolgen dazwischen. welche sich auf mehrere. unter Umständen sehr zahlreiche Individuen verteilen. indem erst die Eier eines durch Knospung erzeugten Individums wieder befruchtet werden. In-

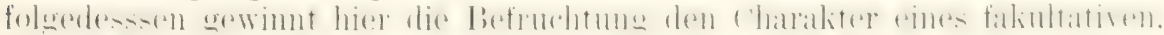

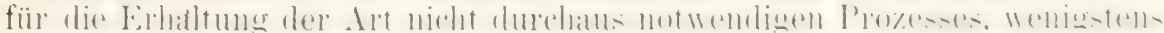
solange nicht der Beweis gefiilurt ist, dab der vegetativen Vermehrung bestimmte Grenzen gesteckt sind. Ein solcher Beweis aber ist zur 'Leit für viele Ptlanzen nicht zu fülıren. welche sich durch Reiser. Knollen efc. anscheinend ins Unbegrenzte vermehren lassen.

Wenn wir im Hinblick auf derartige Fälle anch zugeben müssen.

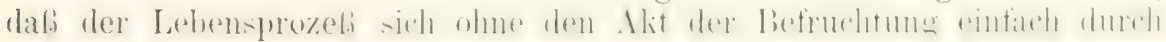




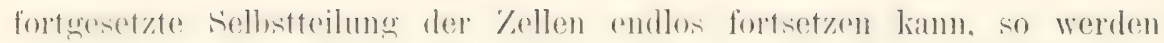
wir auf der anderen Seite doch bei der weiten Verbreitung der Befruch-

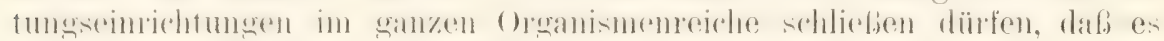
sich hier um fundamentale Fragen des Zellenlebens handelt. In letzter Hinsicht ist die Befruchtung ein zellulares Problem. Wenn wir jetzt zu seinem Studium ïbergehen, wollen wir es in zwei Abschnitte zer-

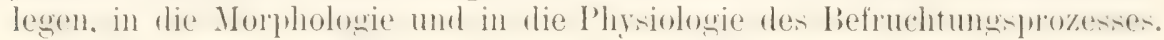

I. Die Morphologie des Befruchtungsprozesses und der mit ihm zusammenhängonden Ei- und Samenreife.

Weit ausgerlehnte Untersuchungen, die sich anf fast alle Klassen des

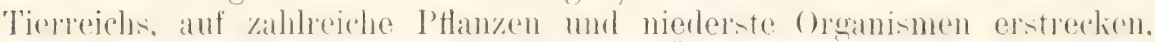

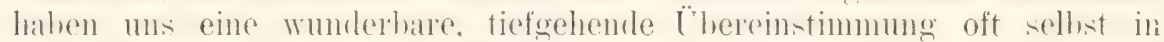
scheinhar mbedentemben Einzelleiten der liefinchtumgr- und lieifeerscheinumgen enthïlt. Dali die hiologische Forschung hier im begriff ist. ein großes allgemeines Naturgesetz zu enthüllen, wird ein kurzer Überblick über die wichtigsten 'Tatsachen, die man bei 'Tieren, PHanzen und Protisten entleckt hat, und die Verwertung dieser Tatsachen zu einigen allgemeinen Schlußfolgerungen lehren.

Iiig. 239. Schema über den Befruchtung sprozeß des Eies von Toxopneustes. Nach Hertwir.

$I$ Das reife $\mathrm{Fi}$ in Noment der Befruchtung mit Eikern (cik) und Empfängnishügel. Am eingedrungenenSamenfaden ist der Kopf (k), das Mittelstiick (m) und der Endfaden zil unterscheiden. 2 -43 Stadien in der Annäherung von Samen- mol Eiken bis zur gegenseitigen Anlagerung, Sk Samenkern, eik Eibern, c Centrosom, d/z Dotterhaut. c Empfängnis. hiïgel.

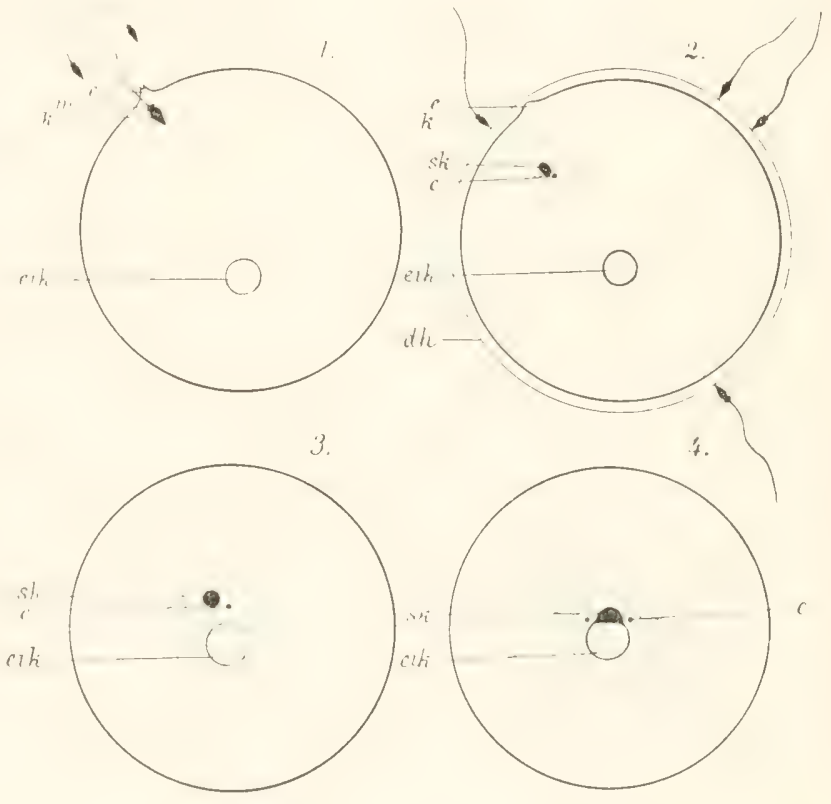

I) Die Befruchtung und Reifung der Geschlechtszellen im Tierreich.

A. Die Befruchtung des Eies.

Die klassischen Objekte für das Studium der Befruchtungsvorgänge sind die Eier der Echinodermen (Hertwig VIII 1875-187s, Fol. VIII 1877) und die Eier von Ascaris megalocephala (van Beneden VIII 1883, 1887, Boverr VIII 1887, 1888 etc.). Beicle ergänzen sich gegenseitig, indem einzelne Phasen des Prozesses an dem einen Objekt leichter als an dem andern haben festgestellt werden können. 


\section{a) Echinodermeneier.}

Bei den meisten Fichinodermen werden die sehr kleinen, durchsichtigen Eier in völlig reifem Zustand in das Meerwasser abgelegt, nachdem sie bereits die Polzellen, anf welche wir später noch einmal zurichkommen werden, gebildet und einen kleinen Likern erhalten haben. Sie sind nur von einer weichen, für die Samenfäden leicht durchgingigen Gallerthiille umgeben (Fig. $240 A$ ).

Die Samenfäden (Fig. 239) sind sehr klein und bestehen, wie es bei den meisten Tieren (ler Fall ist, 1) aus cinem einer Spitzkugel ahnlich aussehenden Kopf $k, 2)$ aus einem darauf folgenden Kügelchen, dem Mittelstïck orler Hals $m$ und :3) aus einem feinen, kontraktilen Faden.

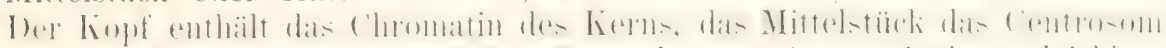

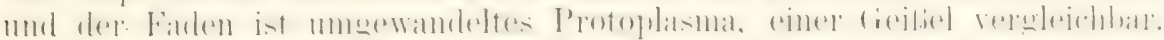

Werden im Meerwasser die beiderlei (ieschlechtsprodukte mit einander vermischt. so setzen sich sofort viele Samenfäden an die Gallerthülle eines Eies an; ron diesen befruchtet aber normalerweise nur ein einziger, und zwar derjenige, welcher sich zuerst durch die pendelnden Bewegungen seines Fadens der Eiobertläche genährt hat (Fig. 240A-C und Fig. 239). Wo er mit der Spitze seines lioptes an

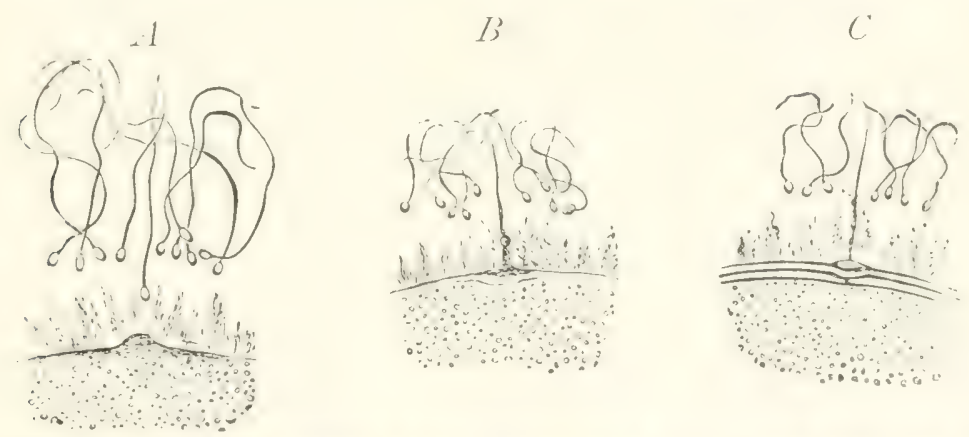
nach liol.

Fig. 240. A, B, C Kleinere Abschnitte von Eiern von Asterias glacialis

Die Samenfiaden sind hereits in die Schleimhülle, welche die Eier überzieht, eingedrungen. In $A$ beginnt sich eine Vorrasming gegen den an weitesten vorgedrungenen Samenfaden zu erheben. In B sind Vorragung nud samenfaden zusammengetroffen. In $C^{*}$ ist der Samenfaden in das Ei eingedrungen. Es hat sich jetzt eine Dottermembran mit einer kraterfömigen öfnung ausgebildet.

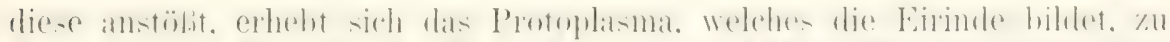

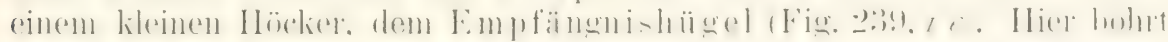
sich der Kopf, getrieben von den pendelnden Bewegungen des Fadens. in das Ei hinein. welches in diesem Moment, angeregt von dem lieiz, eine

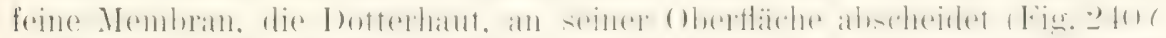

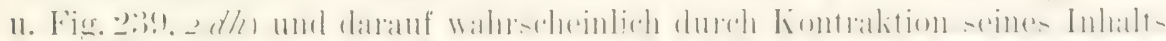

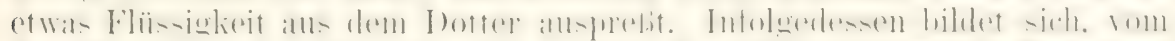

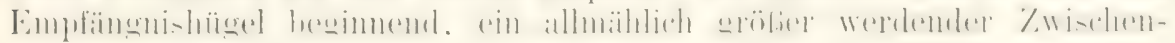
raum zwischen Dotter und Dotterhaut aus. Das Eindringen eines weiteren Samenfadens ist hierdurch unmöglich gemacht.

Der äuBeren Kopulation ler beiden Kellen schlieben sich Vorgänge im Innern des Dotters an. welche als innerer Befruchtungsalit zusammengefabt werlen liönnen. 
Der Faden hört zu schlagen auf und entzieht sich bald der Wahrnehmung, der Kopf aber dringt langsam weiter in den Dotter hinein

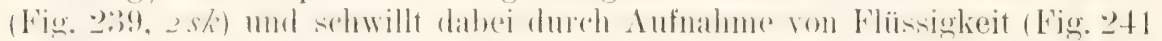
mo 239) zu eimem kleinen Bläschen an, das man, da sein wesentlicher bestandteil das chomatin des Samenfarlenkopfes ist, kmyweg als samenkern bezeichnen kann, wie er sich denn auch in Karmin etc. sehr intensiv

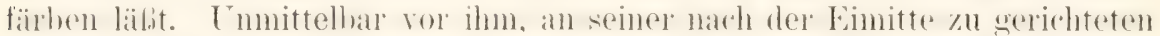

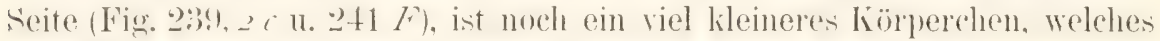
sich schwer sichtbar machen läßt, nachgewiesen worden. Auf die Stelle. wo es im Ei liegt. wird die Aufmerkisamkeit des Beobachters am meisten dadurch gelenkt, daß sich der Dotter in radiüren Bahnen anzuordnen hegimnt und eine allnählich immer schïrfer au-geprägte und auf gröhere Entfernung hin ausgedehnte Strahlenfigur (einen Stern) bildet. Das Körperchen leitet sich von dem Mittelstück des Samenfadens und dem Centrosom der Spermatide ab. Es hat, wie von Boveri zuerst klargestellt worden ist, heim Befruchtungsprozeli die Aufgabe zu erfüllen, die beiden Centrosomen für die erste Teilspindel des Eies zu liefern.
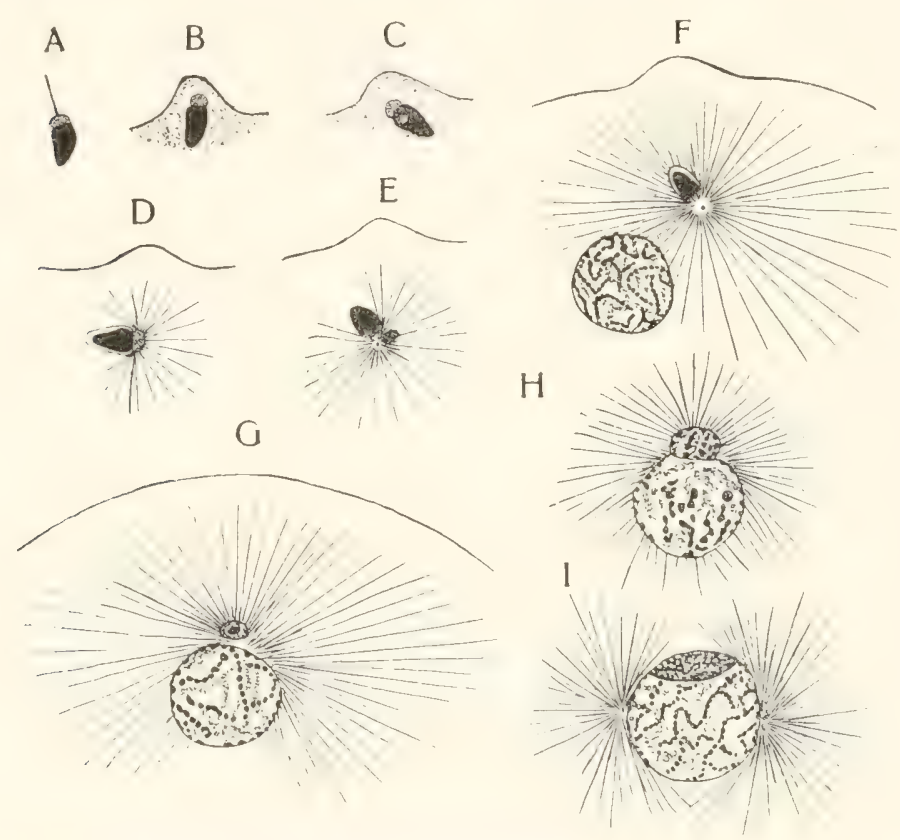

Firi 211. Eintritt des Spermatozoenkopfes in das Ei eines Seeigels (Toxopneustes), sowie die Rotation und allmähliche Umwandlung dessellsen und die Vereinigung mit dem Eikern (nach WrLson und MATHEWs).

In $B-F$ ist die Eintrittsstelle als Empfängnishügel noch nuarkiert, $B-E$ Rotieren des Spermatozoentiopfes, $F$ Tremung rom Alittelstiick, $G-I$ Vereinigung des kleineren Spermakerns mit dem weit unfangreicheren Eikern.

Daß das Centrosom bald nach der Befruchtung von der Obertläche des Eies weiter entfernt ist als der Samenkern, erklärt sich daraus, daß ummittelbar, nachdem sich der Samenfaden mit seiner Spitze in die Eirinde eingebohrt hat, sich sein hopf und Mittelstück zu drehen heginnen

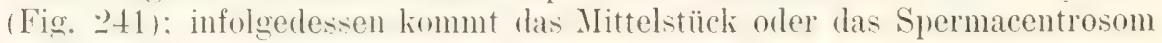
mehr nach dem Mittelpunkt des Eies zu liegen. 
Jetzt beginnt ein interessantes Phänomen das Auge des Beobachters zu fesseln (Fig. 239 y--t u. Fig. 242). Ei- und Samenkern riehen sich

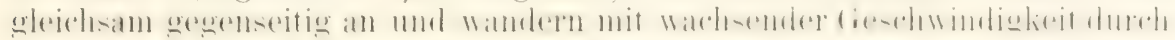
den Dotter einander entgegen; der Samenkern (sk), dem seine Strahlung

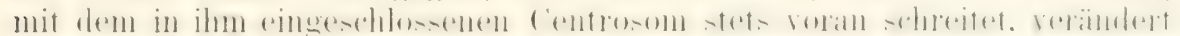
rascher seinen Ort, langsamer der gröbere Eikern $(c k)$. Balı tretten sich beide in der Mitte des Eies und werden hier zunächst von einem kömchen-

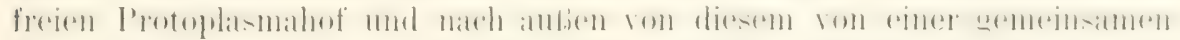
Strahlung eingeschlossen (Sonnenstarlium und Aureola von FoL).

Im Laufe von 20 Minuten verschmelzen darauf Ei- und Samenkern untereinander zum einfachen Keim- oder Furchungskern (Fig. 2:39 \& u. $241 / /$ u. I); erst legen sie sich dicht aneinander, platten sich an der be-
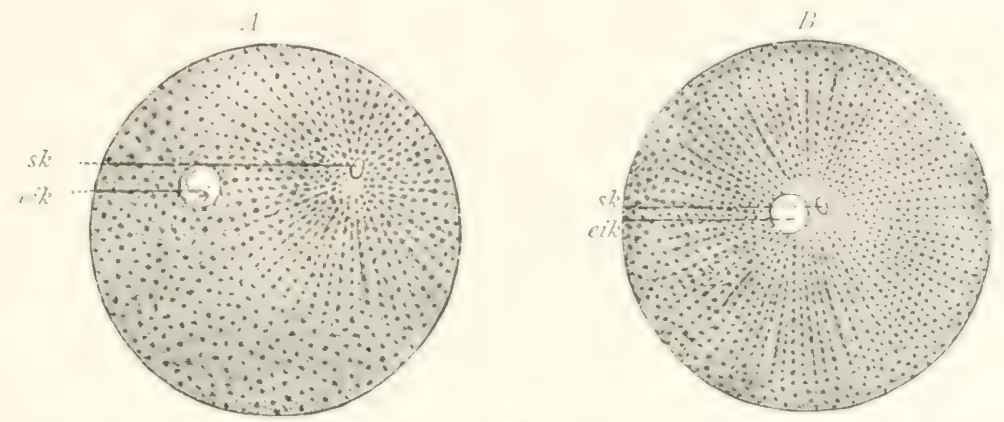

Fig. 212. A Befruchtetes Ei eines Seeigels. O. HErTwIr, Entwicklmngsgeseh., Fig. 18. Der hopf des eingedrungenen Samenfadens hat sich in den von einer P'rotoplasmastrahlung eingeschlossenen Samenkern ( $s k$ ) ungewandelt und ist dem Eikern (cik) entgegengerïckt.

B) Befruchtetes Ei eines Seeigels. O. Hertwit, Entwicklungsgesch., Fig. 19. Der Samenkem sk mind der Eikem eik sind nahe zusammengerïckt und sind beide ron einer P'rotoplasmastrahlung umgeben.

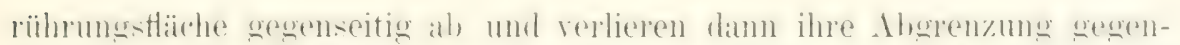

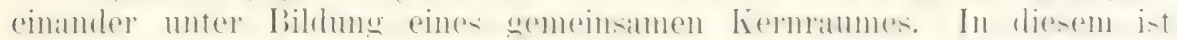

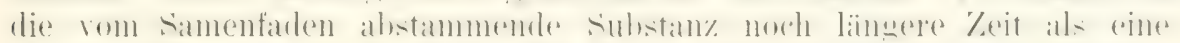

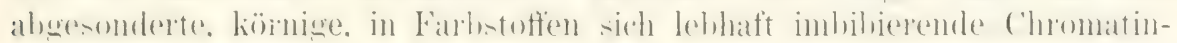
masse zu erkemen.

b) Ascaris megalocephala.

Einen weiteren Einblick in den Befruchtungsvorgang liefert uns das Ei von Ascaris megalocephala. Hier dringt schon vor der Bildung

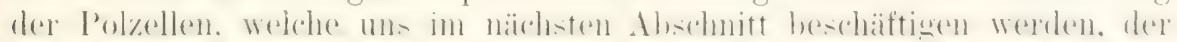

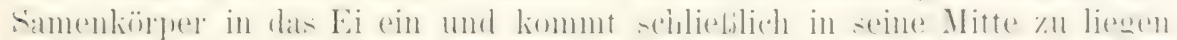

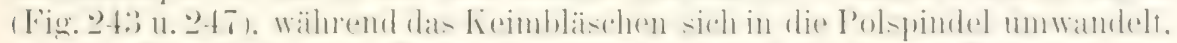

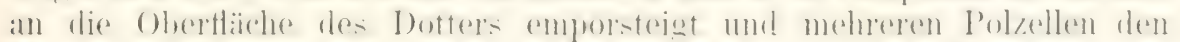

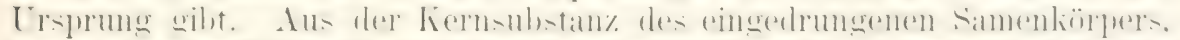

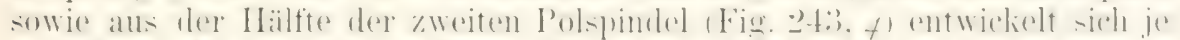

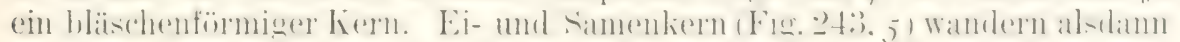

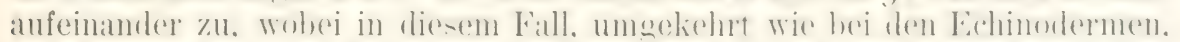

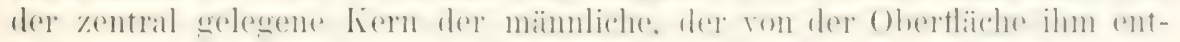

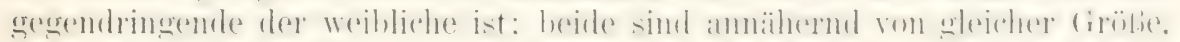

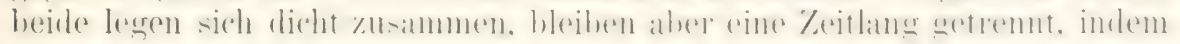
sie in ein kurzes Ruhestadium eintreten. Auch wenn sie sich später zur

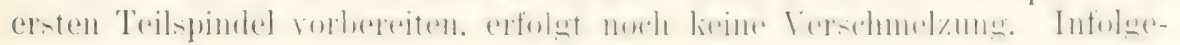


dessen und wegen des weiteren Umstandes, daß bei Ascaris megalocephala sich wähend der liernteilung nur wenige, beträchtlich grolie und daher
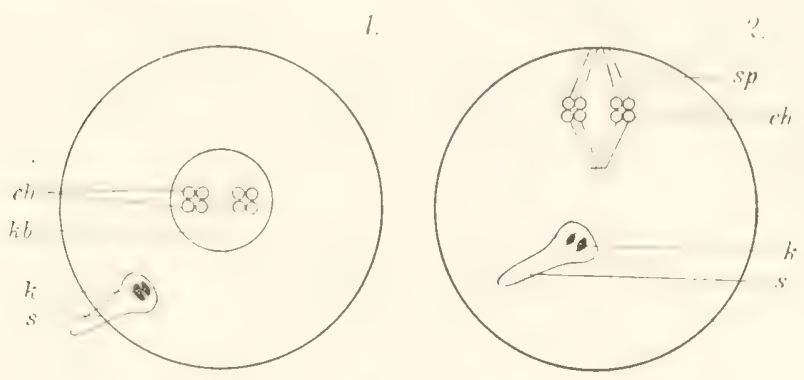

Fig. 243. 8 stadien vom Befruclitungsprozeß, der Bildung der Polzellen und der ersten T'eilung des Eies von Ascaris megaloc. bival. Nach O. Hertwig.

I. Keimblischen (kb) mit 2 Vierergruppen (Tetraden) von Chromosomen (c/r), die zur Unterschei-
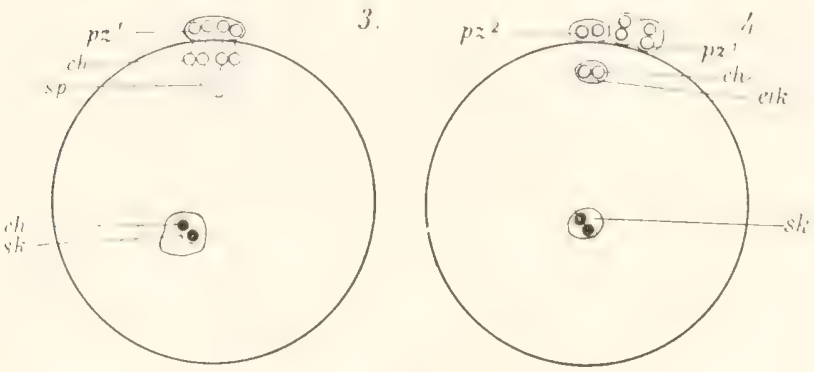
dung von den Chromosomen mämnlicher Herkunft als helle

lireise gezeichnet sind. Samenkörpers mit zwei schwarz gezeichneten Chromosomen.

2. Erste Richtungsspindel $(s p)$ mit 2 Vierergruppen $(c h)$, $s$ Samenkörper mit

2 Chromosomen.

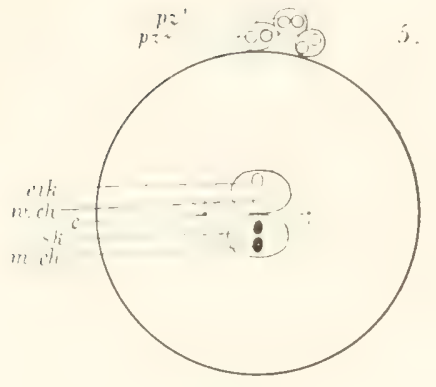

6.

3. Bildung der ersten Polzelle $\left(p z^{1}\right)$ und Entfernung von 2 Chromosomen jeder Vierergruppe. Aus dem Samenkörper entstelyt der Samenkelll $(s k)$.

t. Bildung der zweiten Polzelle $p z^{2}$ und des Eikerns (cik), der von jeder Dyade der zweiten l'olspindel je ein Chromosom $(c / 2)$ erhält.

5. Ammäherung ron Ei- mol Samenkern (eik, sk), deren Chromosomen zur Unterscheidung als helle und schwarze lireise $(w . c h$ u. m.ch) dargestellt sind, c Centrosom.

6. Befruchtetes Ei mit erster Teilspindel, deren vier Chromosomen zur Iülfte $(x, c h)$ vom Eikern, zur anderen Hälfte (m.ch) rom Samenkern abstammen.

7. Die weiblichen (w.c/2) und die männlichen Chromosomen yon 6. haben sich der Länge nach gespalten und sind in zwei Gruppen von Tochterchromosomen anscinander gewichen. sp Spindel, c Centrosom.

8. Die beiden Teilhälften des Eies enthalten Tochterkerne, deren vier Chromo-

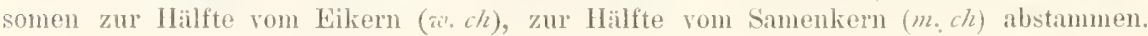


leicht zu zihhende Chromosomen anlegen, war vax BExEDEx in der Iuge,

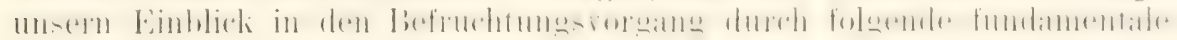
Entdeckung zu vervollständigen:

Bei der Vorbereitung zur ersten 'Teilspindel wandelt sich das Chromatin im Ei- und Samenkern, während sie noch voneinander getremt sind. in einen feinen Faden $1 m$. der sich in mehreren Windungen im Kernraum ausbreitet. Jeder Faden wird darauf in zwei gleich grobe Chromosomen abgeteilt. Zu beilen Seiten des Kernpares treten zwei Centrosomen | Fin.

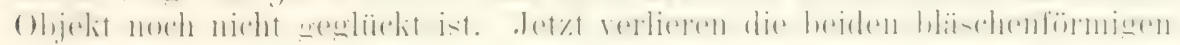
Kerne ilıre Abgrenzung gegen den umgebenden Dotter.

Zwischen beiden Centrosomen (Fig. 2436 u. 247 VI), die von einem

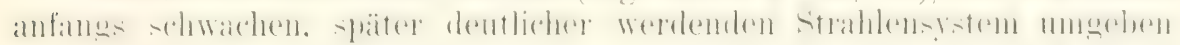
werten, bilden sich Spindelfasern aus und ordnen sich die durch die Auflösung der zwei Kernblasen frei gewordenen vier Chromosomen so an, daß sie der Mitte der Spindel von außen aufliegen.

Beim Ei vom Pferdespulwurm erfolgt also die Vereinigung der beiden

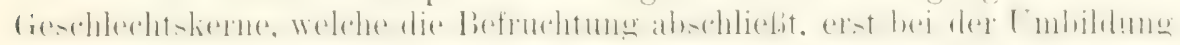
zur ersten Teilspindel, zu weleher sie gleichviel beitragen. Der von VAx Bexenex festgestellte, wichtige Fundamentalsatz heibt daher: Die Chromosomen der ersten Teilspindel stammen zur einen Hälfte rom Eikern (die hellen Kü̈gelchen), zur anderen Hälfte rom Samenkern (die sehwarzen Kügelchen in Fig. 24:3 5 . 6) ab, sie können als männliche und. weibliche unterschieden werden. Da nun auch hier wie sonst bei der Kernteilung die vier Chromosomen sich der Länge nach spalten und dann nach den zwei Centrosomenzu auseinander weichen (Fig. 243 7 ), bilden sich zwei Gruppen von vier Tochterschleifen, von denen zwei männlichel und wei weiblicher Herkunft sind. Jede Gruppe wandelt sich dann in den ruhenden Kern der Tochterzelle um (Fig. 2438). Damit ist der un umstöliche Beweis geführt, daß jedem Tochterkern in jeder Eihälte, die durch den ersten Furchungsprozeb entsteht, genau die gleiche Menge Chromatin rom Eikern wie rom Samenkern zugeführt wird.

Was für Ascaris sichergestellt ist, darf auch als gültig für alle übrigen

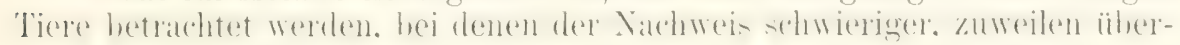
haupt nicht zu führen ist.

Und noch ein anderes, anBerordentlich wichtiges Verhältnis ist bei

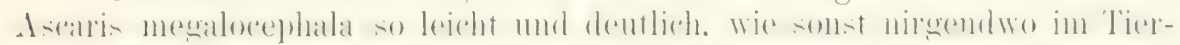

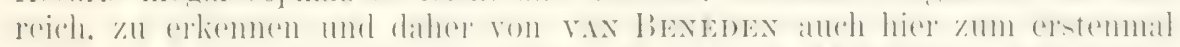

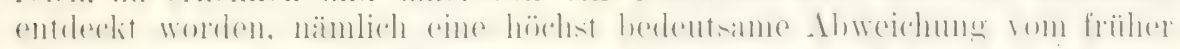

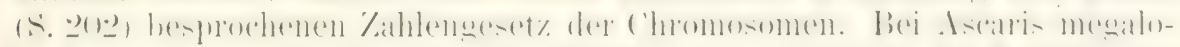

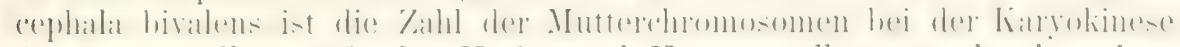
der Körperzellen sowie der Ureier und Ursamenzellen ausnahmslos vier";

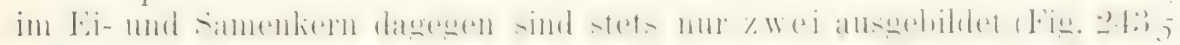
и. $247(V)$, mit anderen Worten: ilne Zahl ist auf die Hälfte der für die

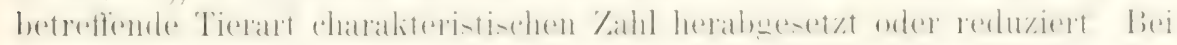
Ascaris megalocephala univalens findet sich mithin in den Geschlechtskernen nur ein einziges Chromosom, was ja die denlibar niedrigste Zahl ist. Aus der früher aufgestellten 'Tabelle, welche das Lahlengesetz der' Chromosomen für eine Reihe von Tieren nachweist, läfot sich dem oben

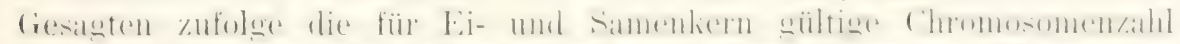

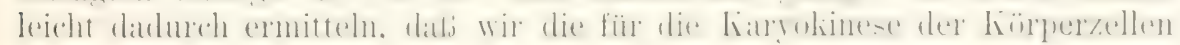

0. II ortwig, Allgomeino Biolorie. 2. Aufl. 
ermittelte Zahl durch den Faktor Zwei dividieren. Wir erhalten so das Zahlengesetz für die Geschlechtskerne.

Zwei Fragen werden sich hier einem jeden unwillkürlich aufdrängen, erstens die Frage, in welcher Weise die Zahl der Chromosomen in den

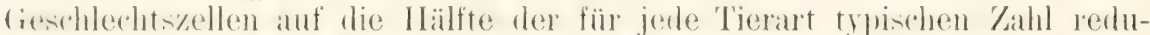
ziert worden ist, und zweitens die Frage, zu welchem Zweck und aus wolehem firmole die Redulition stattgefunden hat. Anf heide Fragen sind wir imstande, gestützt auf zahlreiche vortreftliche Untersuchungen verschiedener Forscher, eine im ganzen befriedigende Antwort zu geben durch ein genaueres Studium von Erscheinungen, die man als den Fuifeprozeß der Geschlechtszellen zusammengefaßt hat.

\section{B. Der Reifeprozeß von Ei- und Samenzelle}

Zum Studium auch dieser Verhältnisse ist Ascaris megalocephala wie liamm ein zweites Ohjekt aus den rershiedensten cirimden, besonders aher deswegen geeignet, weil sich bei ihm ein Vergleich der Ei- und Samenbildung leicht bis ins feinste Detail ausführen läßt.

IBei den Nematoden stellen nämlich die Geschlechtsorgane lange Iïhrchen dar, in deren hlindem Ende sich die jünssten Keimzellen finden und sich von dieser Stelle an bis zum Ausführungsgang allmählich zu reifen dieschlechtsproduliten muwandeln, deratt. dafs alle einzehnen Entwicklungsitalien der Reihe nach anfomanterfolgen. Zweckmäbigerweice unterscheidet man sowohl in der Hoden- wie in der Eierstocksröhre drei Hauptabschnitte, eine Keimzone, eine Wachstums- und eine Reifezone.

In der Keimzone sind beim Hoden die auBerordentlich kleinen Ursamenzellen (Spermatogonien, LA TALETTE), beim Eierstock die Ureier (c) vogonien. BoverI) eingeschlosien: heide sind einander zum Verwechsehn ähnlich. Bei ihrer sehr lebhaften Vermehrung entstehen während der Karyokinese aus den Kernen stets vier Mutterchromosomen. wenn es sich ImI Ascaris megalocephala bivalens handelt. und diese zerfallen damn in zwei Gruppen von vier Tochtersegmenten, die sich auf die 'Tochterzellen verteilen. Die Kahl der Chromosomen ist also hier noch genau die gleiche. wie bei der befruchteten, in T'eilung begriffenen Eizelle.

Beim Übertritt in die Wachstumszone oder den zweiten Abschnitt der (ieschlechtsröhre hören heiderlei fieschlechtszellen auf. sich weiter zu vermehren. Wachsen dagegen. namentlich die Fier. dhrch Substanzanfuahme zu beträrhtlicher (irölie heran, erlatten einen sehr ansehmlichen, bäschenförmigen Ken'n und lïmnen jetzt als Fibildungs- nnd Samenbildungszellen erster und später zweiter Ordnung - Ovocyten (BoverI) und Spermatocyten (LA VALETTE) erster resp). zweiter Ordnung - bezeichnet werden.

Nach diesem Ruhestadium, das längere Zeit währt, gelangen die Eibillungsellen, welche duch reichliche Dotteramsammlung ihre definitive froblie erreicht haben, und ehenso die samenhildungzellen. welche an firibe hiviter den Eiern erhehlich zurb̈ckgehlieben sind, in den dritten Abschnitt, die Reife-orler Teilzone, in welcher ihre Kerne die so charakteristischen und wichtigen beiden Reifeteilungen durchmachen. Die Vorbereitung dazu hat schon in der Wachstumszone begonnen.

\section{a) Spermatogenese.}

In der Spermatogenese tritt ein Stadium ein, in welchem sich aus der ehromatischen sulstan\%, die zuvor im Kermnetz verteilt war, acht lange gekrïmnte Kernfïden ahsondern, wälırend der Atucleolus in einzehne St ïckchen 
zerfällt und ein Centrosom an der Außenfliche der Kernmembran wahrnehmbar wịd (Fig. 2 $\$ 4 /$ u. II). Die liernfäden liegren häutig zu einem Paar verbunden parallel dicht bei einander, nur durch einen feinen spalt getrennt, und legen die Deutung nahe, dals sie durch Liingsspaltung aus

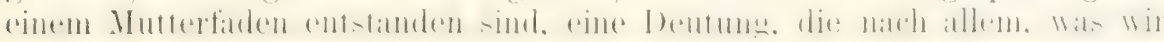
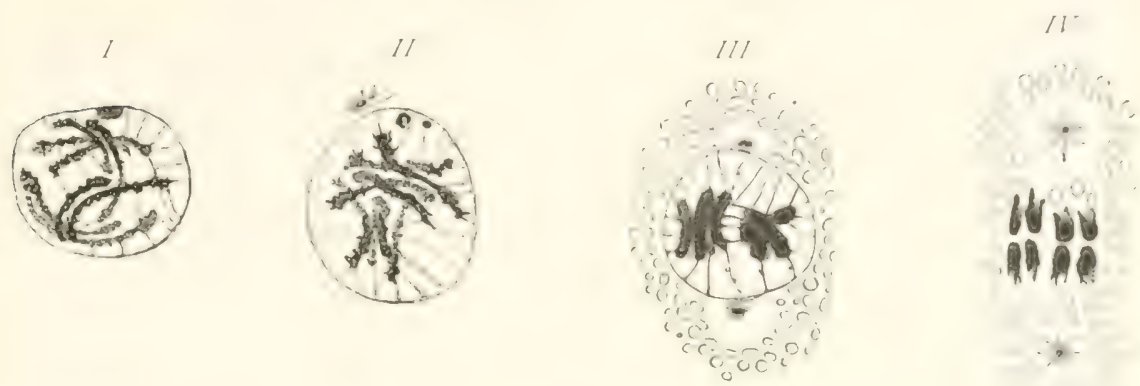

[ig. 214. Vier Kerne der Samenmutterzellen vou Ascaris megaloceph. bival. auf vier Vorbereitungsstadien zur Teilung.

yon anderen Objekten erfahren haben, als richtig angenommen werden

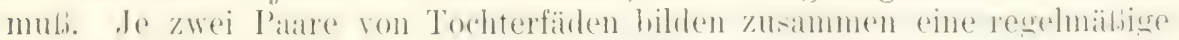
Gruppe, in welcher das eine Paar das andere in seiner Nitte kreuzt, durch Linin mit ihm fest verbunden ist und eine Figur gibt, welche ich einer achtarmigen Ophine onter einem seestern rerolichen hahe. Feine Lininfäten stamen sich nach allen lichtungen zwischen den heiden dimplen und von diesen zur Kernmembran aus. Während hierauf die 'Teilstüclie des Nucleolus ganz schwinden, das Centrosom sich teilt und die Tochter-

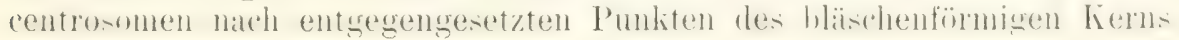
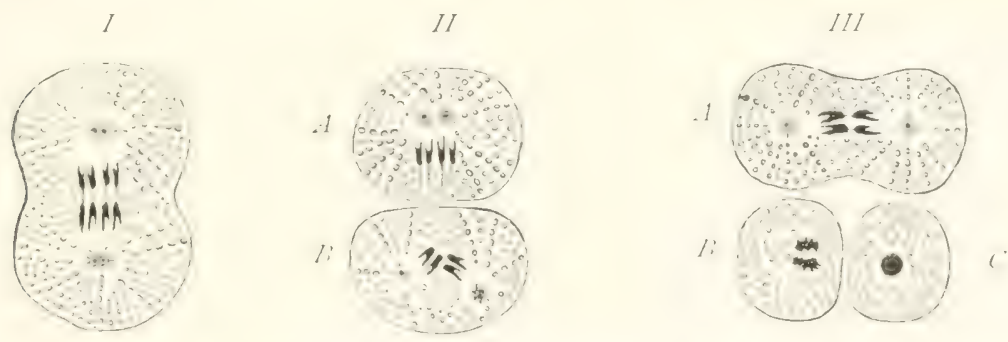

1.iu. : ‥ Die Entstehung von vier Samenzellen aus einer Samenbildungszelle von Ascaris megalocephala bivalens. I Teilumg der Samenbildungselle oder

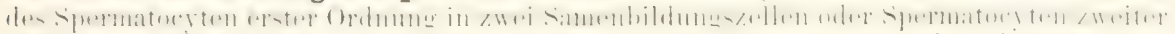
Ordnung. II Die beilen Samenhildungszellen zweiter Orolnung ( $A$ und $I^{\prime}$ ) bereiten sich aleich mach der ersten 'Jeilung zu einer zweiten Toilung vor. III Die Samenlildungszelle zweiter Ordnung it teilt sich in zwei Samenzellen (Spermatiden) b und C. Diese werden zu Samenkërpern oder Spermatozoen.

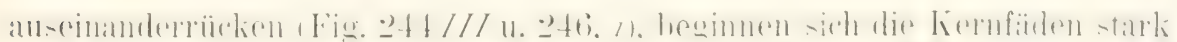

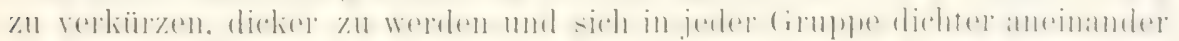
zu legen. So entstehen die für die Geschlechtszellen so ïberaus charaliteristischen Vierergruppen oder Tetraden von Chromosomen.

Wenn jetzt die Metaphase begimnt, löst sich die Kermmembran auf, (Fig. $2+4 / T$ und Fig. 246,2 ), eine Spindel entsteht $z$ wischen den beiden 
('mutrosmen, in ihre Mitte kommen die zwei Vierereruphen zu liegen und nehmen hier eine solche Stellung ein, dab zwei Chromosomen nach dem einen Centrosom, zwei nach dem andern gekehrt sind; damn weichen die

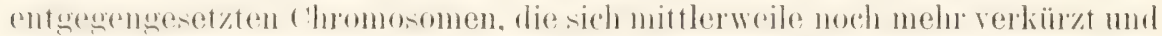

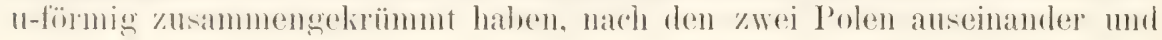

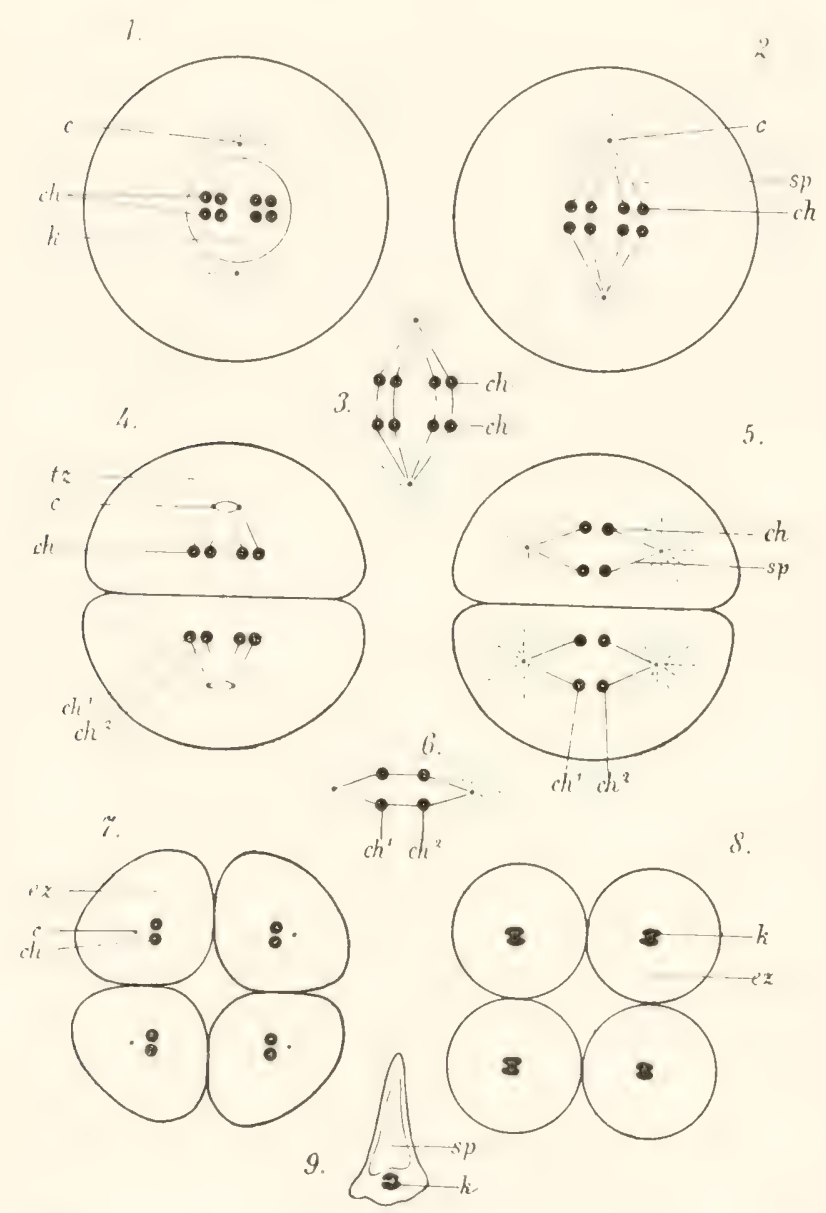

Fig. 246. Schema der Spermatogenese vou Ascaris megaloc. bivalens. Nach O. HERTWI 1 r.

Entwicklung der Samenkürper aus der Samenmutterzelle(Spermatocyt).

I Samenmutterzelle mit zwei Vierergruppen (ch) (Tetraden) im Kiern (k), $c$ Centrosom mit Strahlung.

2 Dieselbe im 'Teilstadium mit Spindel $(s p)$ und zwei Vierergruppen $(c h)$.

3 Spindel eines näichstfolgenden Stadiums, auf dem sich jede Tetrade in zwei Chromosomenpare (Dyaden) gesondert hat.

4 Zwei aus Teilung der Samenmutterzelle entstandene 'T'ochterzellen $(t z)$, von denen jede die halbe Spindel mit zwei Chromosomenparren (Dyaden) (ch) einschließt. Das Centrosom hat sich wieder in zwei 'Tochtercentrosomen geteilt, zwischen denen sich eine nene kleine Spindel anlegt.

5 Die neue Spindel $(s p)$ in jeder Tochterzelle hat sich veroriouert und in ihrer Mitte die

beiden Chromosomenpare ( $c h^{1}$ und $\left.c h^{2}\right)$ anfgenommen.

6 An der Spindel haben sich die Chromosomen $\left(c h^{1}\right.$ und $\left.c h^{2}\right)$ jeden Pares voneinander getremnt und den beiden Spindelpolen genähert.

7 Die beiden Samentochterzellen haben sich in vier Enkelzellen (cz) geteilt. Ton diesen birgt jede mur zwei Chromosomen (ein Element ron jeder Vierergruppe der Fig. I und ein Centrosom (c).

8 Die zwei Chromosomen der Samenenkelzellen (ez) platten sich aneinander ab und bilden schließlich einen keinen kompakten, kugeligen liern $(k)$.

9 Jede Samenenkelzelle wandelt sich in einen Samenkörper ( $s p$ ) von der Form viner Spitzkugel $u$ ( $k=$ Kern).

können als Dyaden bezeichnet werden (Fig. 245 I und Fig. 2463). Die simmenmutterzelle zerfällt hierauf durch Eimschnürung in zwei gleich grobe

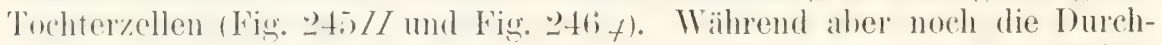
shnürtung im Gange ist, heginnen schon die Verändermgen, die zur zweiten 'Jeilung führen. Jedes Centrosom spaltet sich in zwei Hälften, welche, 


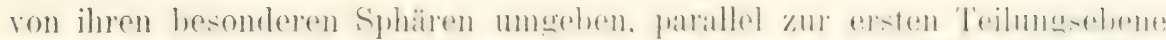

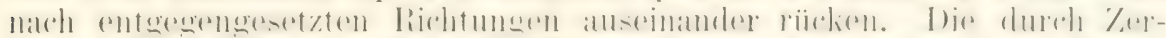

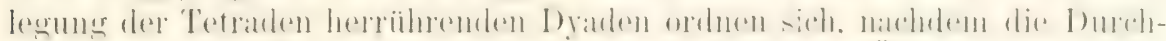
schnürung der Mutterzelle beendet ist, sofort mit Überspringung des

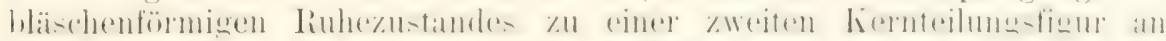
(Fig. 245 III und Fig. 2465). In der Mitte einer nengebildeten Spindel

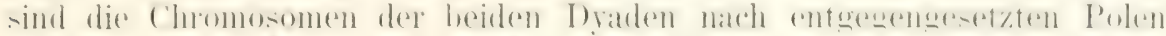

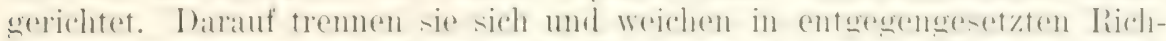

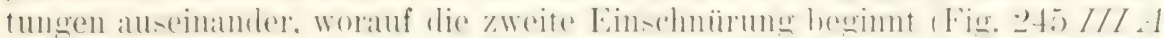

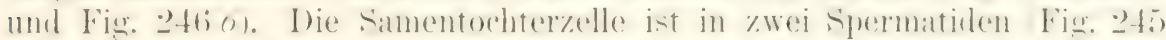
III $B$ u. $C$ zerlegt worlen, welche sich weiterhin in die reifen Samenkörper umwandeln.

Durch den zweimaligen Alit der Reifeteilung sind somit vier Enkel-

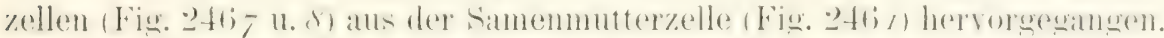
Dahei sind die im Kern der letzteren vorbereiteten acht Chromosomen.

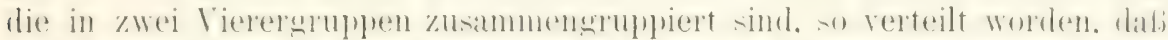

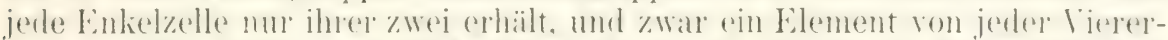

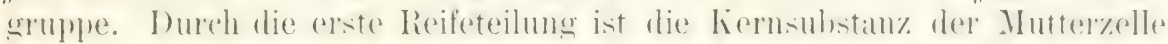

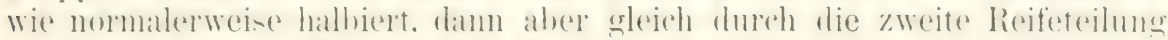
geviertelt worden. Denn während der zwei Reifeteilungen hat ja - und

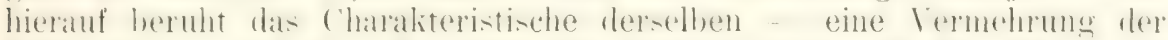

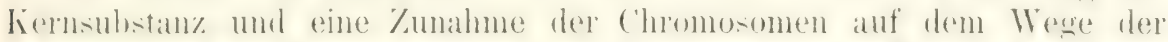

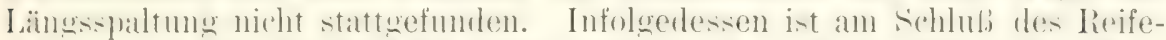
prozeses sowohl die Kahl der ('hromosomen als anch die Nasise des ('hromatins anf die Hälfte der für jede Tochterzelle typischen Zahl und Masse herabgesetzt oder reduziert worden.

Wenn wir diese Prozesse mit dem Verlauf einer gewöhnlichen Mitose vergleichen, so sind drei unterscheidende Merkmale hervorzuheben.

Anstatt vier Fäden, wie im Kern einer Körper- oder einer Embryonal-

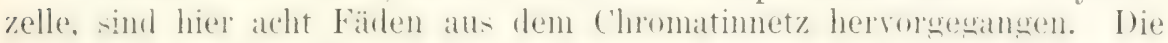
Verdoppelung der Zahl erklärt sich aus einer sehr frïl eingetretenen

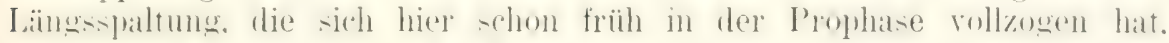
während sie sonst erst in der Metaphase erfolgt, wir haben es schon mit

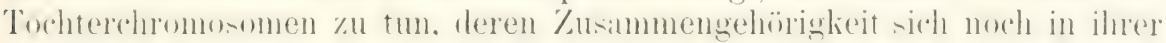
parweisen Anordnung zu erkennen gibt.

Das zweite Merkmal ist die Zusammenordnung der Chromosomen

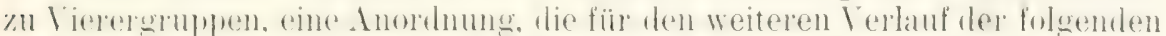
zwei Reifeteilungen offenbar von Wichtigkeit ist.

Mit Recht betrachtet sie Boveri als die mechanische Voraussetzung

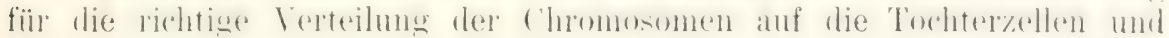
findet hierin ihre gentigende Erkiärung. Er meint, dab, wenn von einer

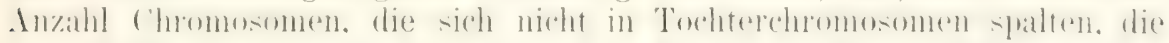
eine Hälfte an den einen, die andere an den andern Pol befördert werden

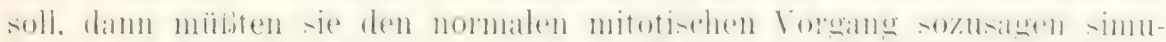

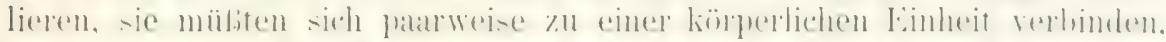

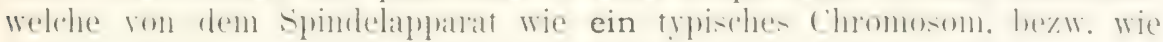
zwei in Bildung begriffene Schwesterelemente behandelt werden.

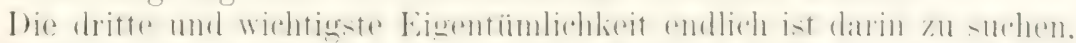

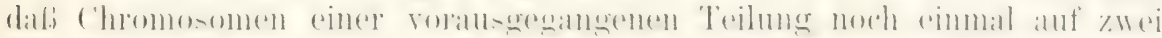
Zellen verteilt werden, ohne sich zuvor durch Wachstum zu Mutterchromo-

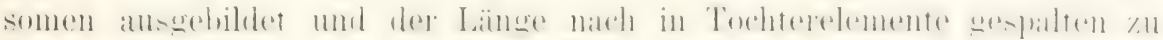
haben. Nach der verschiedenen Rolle, welche in dieser Hinsicht die

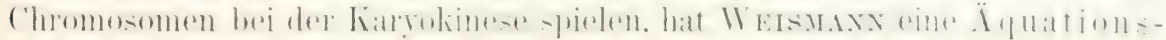
teilung und eine Reduktionsteilung unterschierlen. 
Lei der Äpuationsteilung wird, wie bei der gewönliehen Karyolinese.

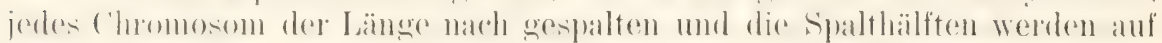
die 'Tochter\%ellen verteilt. Mit Roux kann man in der Längsspaltung des fablens cinen Mochanismus erblicken, das ('homatio, wie schon anf seite

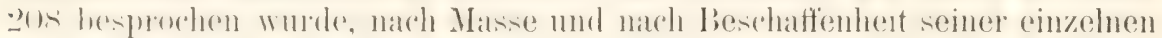
Qualitäten gleich zuteilen. Machen wir die Anmahme, daß das Mutter-

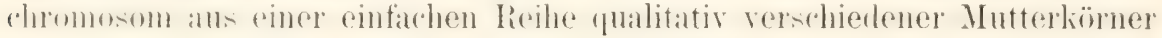
besteht, so wïrden diese bei der Längsspaltung halbiert, und in der-

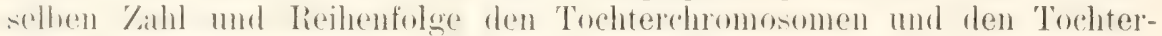
zellen zugeteilt werden.

Bei der Reduktionsteilung dlagegen werden die Chromosomen, olme sich durch Warhstum vergröbert mol der Länge nach grespalten zu haben. in zwei Hälften verteilt. Die 'Tochterzellen erhalten daher nur die Hälfte der Chromatinmasse und die halbe Zahl der für den Kern nach dem Zahlengeset\% typischen ('hromosomenzahl. Hier macht mum Wessuxws noch die Anmahme, dal, die einzelnen ('hromosomen eines Kems qualitative I'nterscherle voneinander darthoten und dab infolgedesen die hei der Teilung entstandenen 'Tochterkerne auch fualitativ verschieden voneinander werden. Man headite. dab letzteres nur eine noch unbewiesene Hyothese, dagegen die an erster Stelle genannte Wirkung der Reduktionsteilung eine Tatsache ist.

\section{b) Oogenese.}

In wesentlich derselben Weise vollzieht sich bei Ascaris megalocephala eine Reduktionsteilung während der Reifung des Eies. Der Simemmutterzelle (Nivermatocyte) entspricht das umeife Fi oder die Eimutterelle (Ovocyte). Auch hier entstehen im liemblaschen acht in zwei Vierereruppen angeordnete (hromosomen (Fig. 243/ 11. 247I). Nach Auflïsmg der liernmemhran bildet sich eine spindel, deren Mitte sich die heilen Vierergrupen anlagem. Ton hier tritt zwischen Spermatogenese

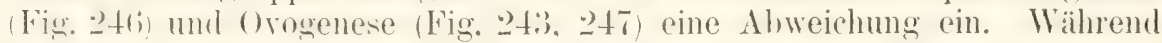
hei jenex die liemfigur eine zentrale Iage in der Zelle beibehät, steigt sie hei diesel alluählich an die Oberfiähe des Dotters empor und beteiligt sich an der bildumg der sogenamnten Polzellen, die für das reife Ei charak-

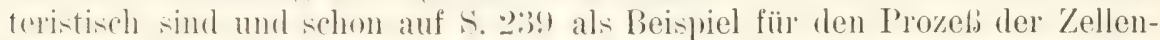
linosimng ilne Beschreihung gefunden hahen. Die Iildung der ersten Polzolle entspricht der Teilung der Samemnuterzelle in zwei Tochterzellen (Fig. 2433 11. 247 III). Wie dort, werden auch hier die in den zwei Vierersmplen vereingten ('hromosomen auf die Teilprodukte der Zellkmosung so verteilt, daf die Eitochterzelle und die erste Polzelle je zwei Paar von Chromosomen oder zwei Dyaden erhalten. Auch hier folgt mit Überspringung des Ruhestatiums gleich eine zweite Teilung (Fig. 247/V). Aus dem Material der in der Eitochterzelle zurïckgehliebenen halhen Spindel bildet sich direkt eine zweite volle Spindel aus mit vier nun paarweise verbumbenen ('homosomen obler zwei J)yalen. Aus der zweiten Knosjung entsteht die zweite Polzelle und das reife Ei (Fig. 2434); ein jedes Teilprodukt birgt jetzt nur zwei isolierte Chromosomen, also nur den vierten Teil der im Keimbläschen vorbereiteten Elemente oder nur ein einziges Element von jerler Vierergruppe.

Inoi manchen Tieren (Hirulineen, Mollusken ete.) teilt sich gleichzeitig alteh die erste Iolzelle noch eimmal. Täre dies bei Ascaris negalocephala der Fall, so würden auch aus der Eibildungszelle, wie aus der Samen-

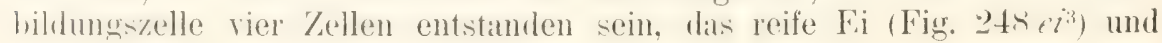


die drei Polzellen $\left(p \sim^{2,3,4}\right)$, ron denen eine jerle wie das Ei mit zwei cin-

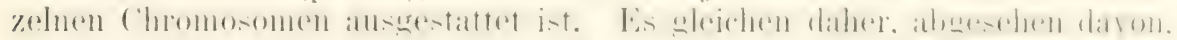
daß die Teilprodukte infolge der Knospung bei der Eireife von so un-

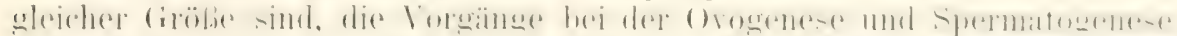

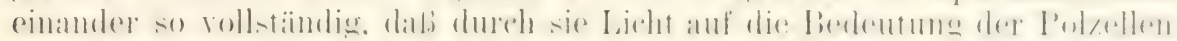

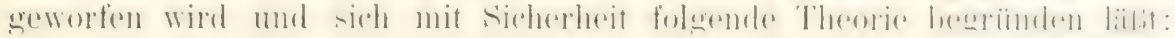

Die Polzellen sind Abortiveier, die durch einen letzten Teilungs-

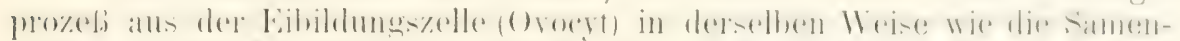

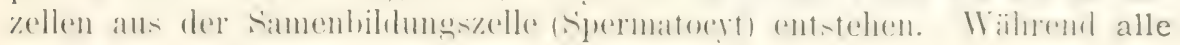

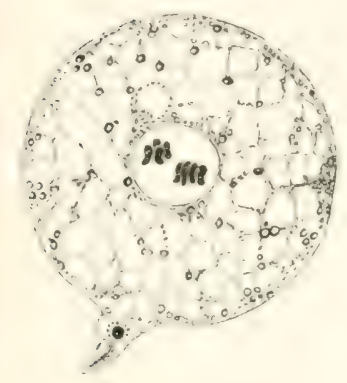

$1 I^{-}$

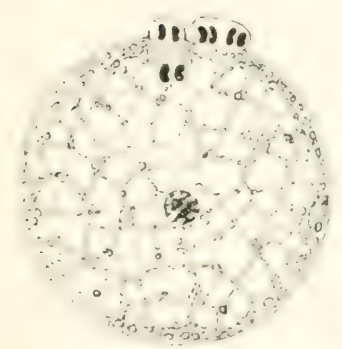

II

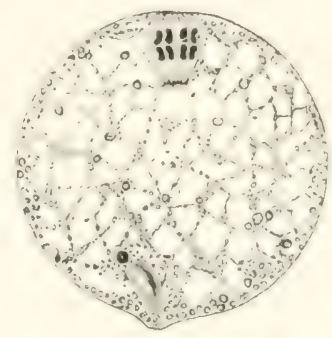

$l^{\prime}$

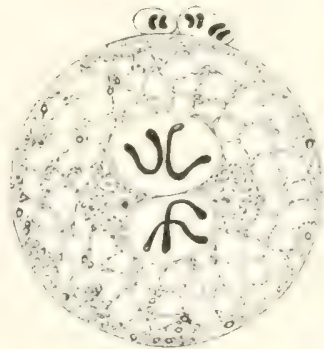

III

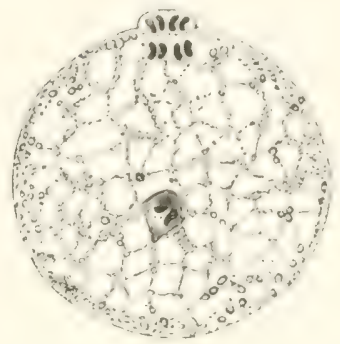

$1 /$

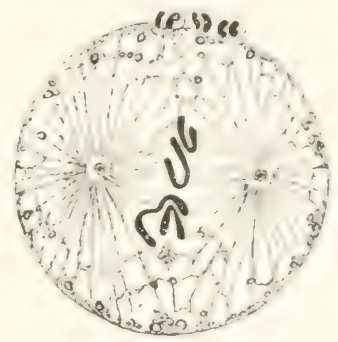

1.ï. "I: Die Bildung dex Polzellen und die Befruchtung des Eies von Ascaris melagocephala bivalens. I Fi mit lieimbläschen nud einem seiner ()herfläche aufsizzenden Samenkörner. II Ei, bei welchen sich aus dem líeimbläschen die erste Polspindel gebildet hat und der Samenkörper in die Oberfliche des I)otters eingedrungen ist. III Ei, bei welchem sich die erste Polzelle gelsildet hat. IJ Fi, hei welchen sich die zweite Polzelle abgeschnürt hat und der Samenkörper bis in die Mitte des Dotters gewandert ist. $V$ Ei mit zwei Polzellen, mit Eikern und Samenkern, in welchem sich das Chromatin in je zwei Kernsegmenten angeordnet lat. $V I$ Fi, in welchem sich die Kernspindel mit vier Kernsegmenten ausgebildet hat, ron welchen zwei vom Eikern, zwei vom Samenkern alstammen.

Teilprodulte der letzteren als hefruchtung a

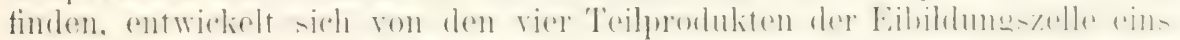

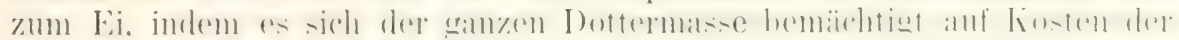
übrigen, die sich in rurlimentürer Gestalt als Polzellen erhalten.

Un die wichtigen und interessanten Beziehungen zwischen li- und

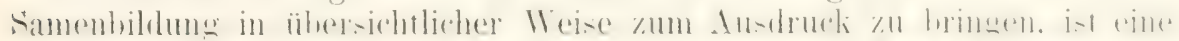

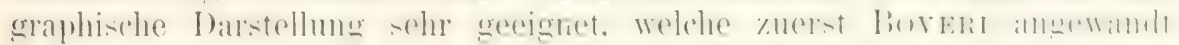

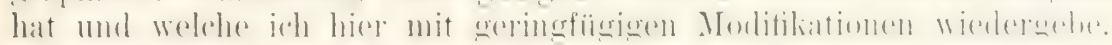

Man sieht in Fig. 348 in Form von zwei Stammbämen die Zellen-

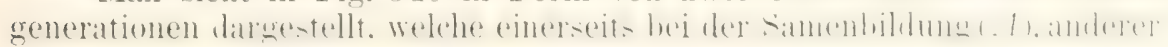


seits bei der Eibildung $(B)$ ausemander hervorgehen. In der Keimzone sind aus der mit der 'Lahl / bezeichneten Ursamenzelle $A$ und dem Urei B durch rasch sich folgende Teilung eine zweite (II) und eine dritte

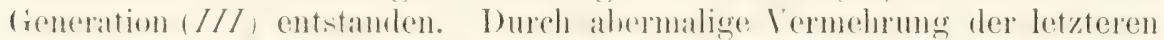
bahen je acht \%ollen ihren Lrspumg genommen, welche in hezug anf ihr Vermehrungsvermögen in ein Ruhestalium von lingerer I)aner eingetreten sind und daher von jetzt ab mit einem besonderen Namen als Samen- und als Eibildungszellen (Spermatocyt und Ovocyt) bezeichnet werden. Im Ruhestadium (Wachstumszone) heginnen hesonders die Fibildungsoellen durch beträchtliche Aufnahme von I)ottermaterial sich sehr ansehnlich zu vergrößern, was in dem Schema $A$ und $B$ nur für eine der acht Zellen je durch eine vertikale, von oben nach unten allmählich dicker werdende Linie graphisch dargestellt ist. Die so reränderten Samen- und Eibildungs-

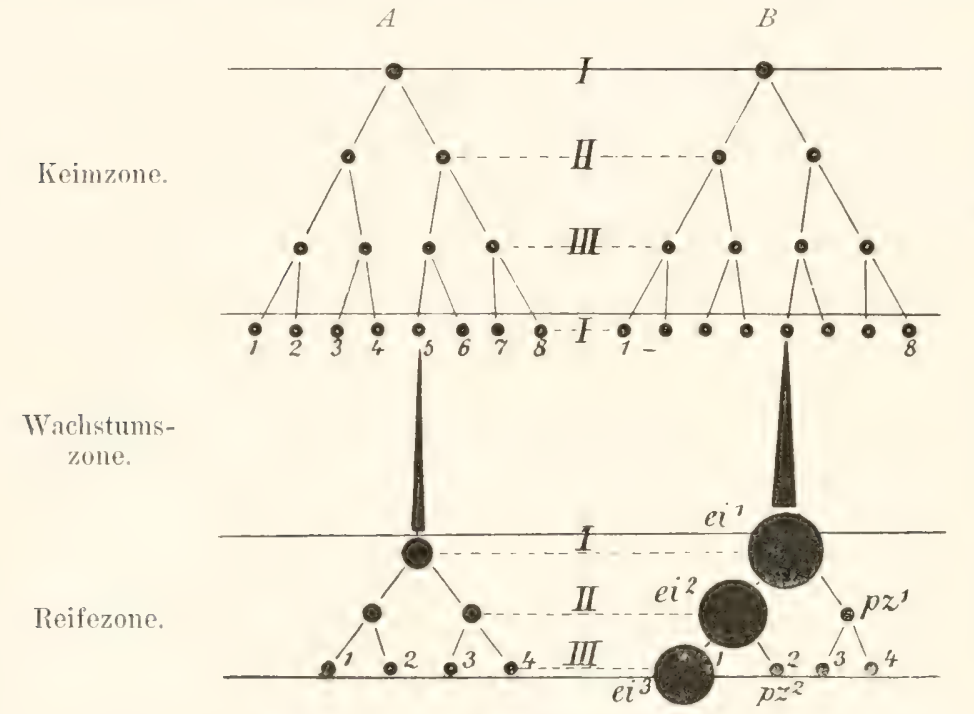

I, II, III Gieneration von Spermatogonien und Orogonien.

Spermatocyten (Samenbildungszellen) u. Ovocyten (Eibildungszellen).

I, II, III Generation von Zellen der Reifezone.

Fig. 248. Stammbaum der Zellgenerationen, welche bei der Samenbildung $(A)$ und bei der Eibildumg $(B)$ aufeinander folgen, abgeindert nach Bover. $e i^{-1}$ unreifes Ei (Eibildungsstelle, Ovocyt erster Ordnung), teilt sich in $e i^{2}$, Eibildungszelle zweiter Ordnung, und $p z^{1}$ erste Polzelle. Erstere teilt sich wieder in reifes Ei und $p z^{2}$ zweite Polzelle, die erste I'olzelle kamn ebenfalls noch eine weitere Generation $(3$ und 4$)$ hervorbringen.

zellen $(I)$ treten hierauf in das Reifestadium ein, in welchem sie wieder ihr' 'T'eilungstermögen hetätgen und zwei neue frenerationen von Zellen (II und $I I I$ ) hervorbringen. Die letzte Generation sind hier vier Samenzellen oder Spermatiden. welche sich weiterhin direkt in die spermatozoen umwandeln; dort sind es die drei Polzellen $(2,3,4)$ und ein reifes Ei $\left(c i^{3}\right)$.

\section{c) Theoretische Betrachtungen.}

Um die zweite der oben aufgeworfenen Fragen zu beantworten, zu welchem Zweck und aus welchem Grunde eine Reduktion des Chromatins überhaupt stattfinden muB, ist es nötig, sich von dem eigentlichen Wesen iles liefruchtungsurozesses eine klare Vorstellung zu hilden. Wir müssen von den Ericheinungen ausgehen. mit welchen wir auf den vorhergehenden seiten beliannt geworden sind. und müssen bei den Lehren, die sie uns geben, zugleich berïckischtigen, was aus dem Produkt der Befruchtung wird und 


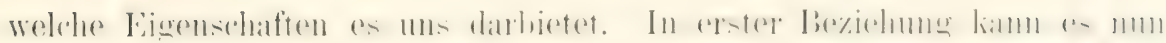
keine Frage sein, daß bei der Befruchtung eine Vereinigung von zwei Zellorganismen stattfindet. Hierbei ist die wichtigste Erscheinung, die am meisten in den Vordergrund tritt, worauf ich zuerst bei der Entdeckung

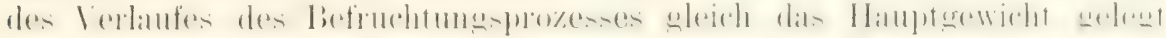
habe, die Vereingung zweier Kerne, die von der Ei- und Samenzelle

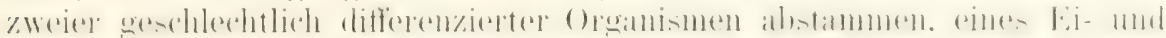
eines Samenkerns. Und hierbei ist wieder die auffalligste und offenbar

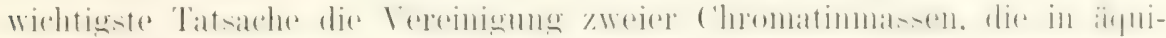
valenten Mengen in Ei- und Samenkern enthalten sind.

Diese Tatsachen sind die sichere morphologische Grundlage des liefruchtungsprozesses. Ziehen wir num ferner in Betracht, was aus dem Ver-

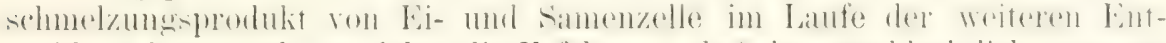

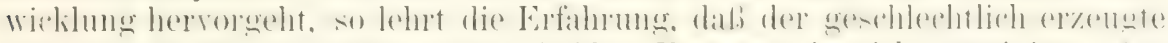

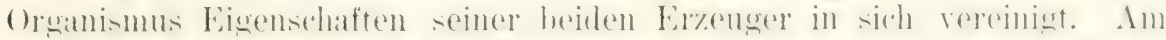

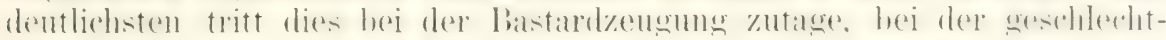
lichen Vereinigung zweier Individuen, die verschiedenen, wenn auch nahe verwandten 'Tier- oder Pflanzenspezies angehören. Denn dann rereinigt

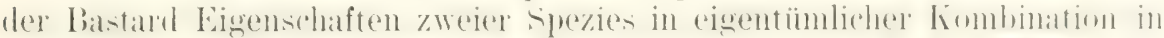

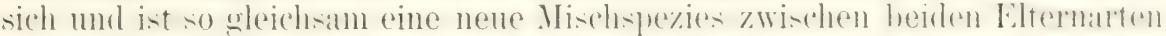
geworden. Somit können wir das Wesen der Befruchtung mit Richard

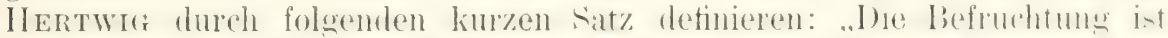
die Versehmelzung zweier getrennter Zellorganisationen, des Fion und les

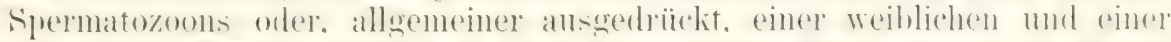
mïnnlichen veschlechtszelle zu einer kombinierten Zelle. welehe die Gigrolschaften beider Zellen in sich vereinigt."

Eine Amphimixis hat daher Weisuans den Befruchtungsprozel

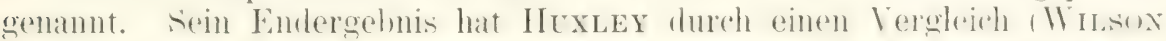
III 1940), pas. 178, zu veranschanlichen gesucht: .. It is anmerivahle and indeed probable, that every part of the ardult contains moleciiles derived both from the male and from the female parent, and that, regarded as a mass of molecïles, the entire organism may be compared to a web, of which the warp is derived from the female and the woof from the male."

Durch unsere Definition wird der Befruchtungsprozef auch mit der Lehre von der Vererbung auf das innigste verknïpt. Auch die Vererbungslehre hat, wie in einem späteren Kapitel noch ausfïlurlicher klar-

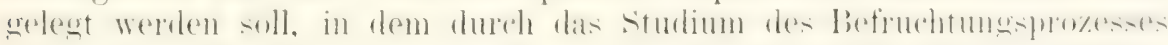

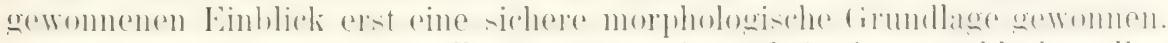

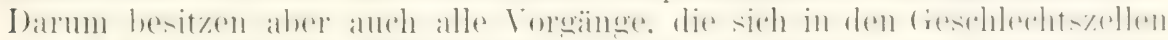

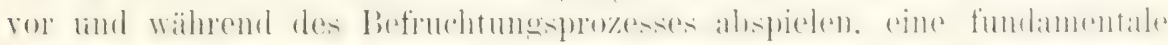
Bedeutung. Denn es ist die Hoftnung berechtigt, (lab von ihnen aus auch auf das Vererbungsproblen Licht fällt.

Als der wichtigste Alit bei der Befruchtung wurde oben die Ver-

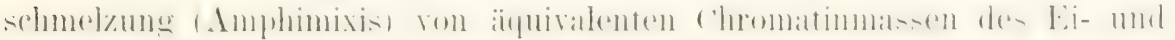
Samenkerns bezeichnet. Würden num ihre Kierne wie die Kerne gewöhnlicher Körperzellen beschaffen sein, so würden aus der Verschmelzung

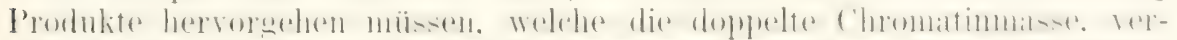

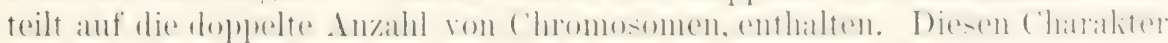
mïBten aber auch alle Zellkerne zeigen, welche die Nachliommen des Keimkernes sind. Denn wie uns das aus unzahligen Erfahrungen festgestellte Zahlengesetz der Chromosomen gelehrt hat, erhält sich in

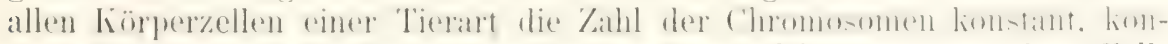
stant bleibt auch die Masse des Chromatins, welche zwar ror einer Zell- 


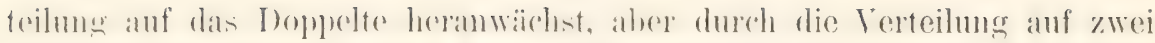

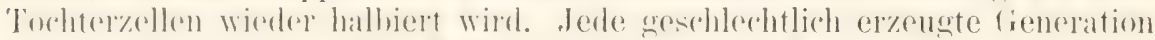

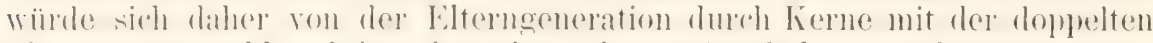
('hromosomenzahl mon dem doppelten ('hromatingehalt moterscheiden müssem.

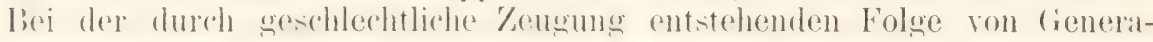
tionen würde durch die Befruchtung eine beständige Summation der Kernsubstanzen von Ei- und Samenzelle herbeigefüht werden. Unhalthare Zustämle, ein Mibverhältnis ron liern und Protoplasma, wïrde bald die notwendige Folge eines solchen Prozesses sein.

Der Summation des Chromatins mus daher im Leben der Zelle in irand ciner Weise durch einen entgegengesetzten Vorgang, durch eine lieduktion, entgegengewillt werden. Dies genchieht hei der lieifung der deschlechtsprodulite. fïr welche uns ein Verständnis erst dadurch. dab wir sie zum Befruchtungsurozel, in ursïchliche bezichung setzen, eröffnet wirl. Wie sich leicht erkennen läBt, wird durch die Bildung zweier Polzellen beim unreifen Ei und durch die zweimalige, ohne dazwischen tretende Ruhepause erfolute T'eilung der Samenbilumeszelle in einfarhster Weise verhimlert, dab, heim Befruchtumgsalit durch die Verschmelzung zweier herne eine Summierung der Chromatinmasse und der Kernsegmente auf das Doppelte des für die betreffende Tierart geltenden Normalmalies hrorbeigeführt wird. Durch den Reifeprozeß wird ja sowohl in den männlichen wie den weiblichen fiechlechtsmorlukten die fühblare Kernsubstanz ihrer Masse und der Zahl der Kernsegmente nach, aus denen eine jede entstanden ist, auf die Hälfte eines Normalkerns reduziert. Erst durch die Befruchtung, welche auf der Verschmelzung zweier Kerne beruht, wird dann die volle Substanzmasse und die volle Anzahl der Segmente eines Normalkerns wienler hergestellt. Fi- und Samenkern sind laher Ialblierne. die durch Verschmelzung zum Keimkern wieder einen Vollkern bilden.

Yon den hier dargelegten Gesichtspunkten aus hat die Reifung der (ieschlecht-produlite in jeder Beziehnug den charaliter eines Vorbereitungsprozesses für den Befruchtungsakt.

\section{C. Übersicht über Modifikationen der Reife- und Befiuchtungserscheinungen im Tierreich und strittige Fragen.}

Üher Finzelheiten des Reife- und Befruchtungwrozesses hestehen in den Angaben der zahlreichen Untersucher, die sich bei vielen Arten von Wirbellosen und Wirheltieren mit ilnen heschaftigt haben. noch Verschiedenheiten. Sie rühren offenbar zum 'T'eil daher, daß in der 'Tat der Vorgang hoi einzelnen 'Tieren mehr oder minder hedentungsolle Modifikationen darbietet, zum Teil aber hängen sie auch mit einer verschiedenen Dentung der Befunde zusammen. Es würde uns zu weit führen, die überaus umfangreiche Literatm hritisch durchzuarbeiten: die Wichtigkeit des ciegenstandes lablit es aber wünschenswert erscheinen. wenigstens auf diesen und jenen Punkt näher einzugehen. Wer noch tiefer eindringen will, sei auf die ziemlich cingehonde vortreffliche liearheitumg von liorscnest und

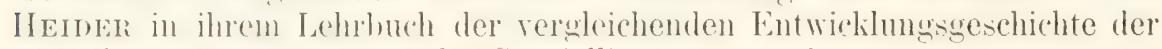
wirbellosen 'Tiere und auf die Spezialliteratur verwiesen.

\section{Das Reduktionsproblem}

ist werler soweit welialit, dal, es eine linaple, einheitliche Darstellumg erlaubt, noch kamm seine Erforichung als algeschlosen betrachtet werden. Nur in seinen Grundzügen ist es festgestellt; in Einzelheiten wirl noch 
manche wichtige Entrleckung zu machen, aber auch noch manche irrtimliche Darstellung zu beseitigen sein. Besonders gilt dies von der Entstehung der Yierergruplen. Die verschiedenen hierïber gemachten

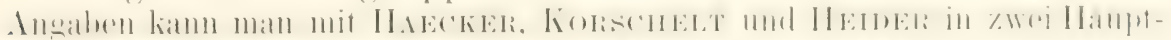

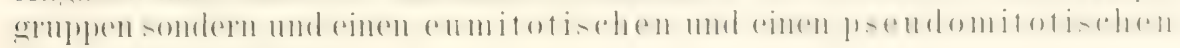
'Typus unterscheiden.

a) Die eumitotische Reifungsteilung.

Als Beispiel fiir dieselbe wird gewöhnlich Ascaris megalocephala auf-

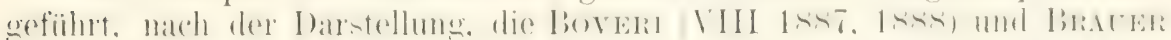
(XI 1893) gegeben haben. Ursprimglich hat Boveri jede Vierergruppe

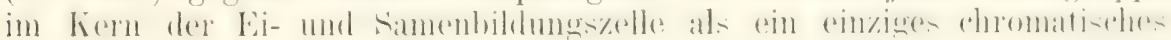
Element betrachtet. mol da ihre Anzahl nur hall, so grob ist als die zahl

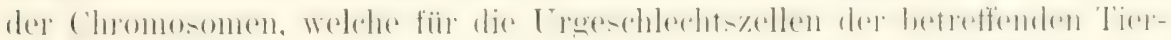
art charakteristisch ist. wurle er zu der Ammahme genötigt, dafo schon in einem fribheren Stadium eine Reduktion der Chromosomen auf die IIälte eingetreten sei. Ob ein Teil der Chromosomen verkïmmert oder. wie sonst die Reduktion eingetreten ist, mufte als offene Frage behandelt werden. Nach einer' zweiten Anmahme von Boveri, die von BruUer als den l'at-

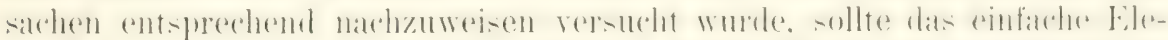

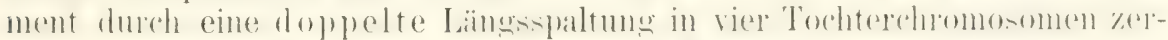

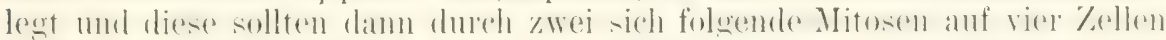
verteilt werden. Hiernach findet eine Reduktion der Chromosomenzahl

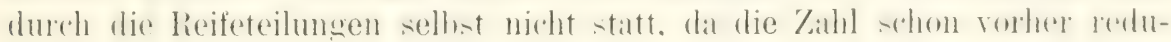
ziert war.

Einen hiervon abweichenden Standpunkt habe ich schon in meiner

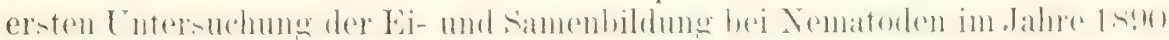
eingenommen und im Gegensatz zu Bover immer betont, dafi die Vierergruppe, wie es auch von CARNOY dargestellt wurde, aus vier durch Lininhrürlou zu-ammengehaltenen ('homosomen besteht, dali mithin shre duzahl nicht auf die Hälfte reduziert, sondern im Gegenteil, wie bei einem Kern in (ler Metaphase, verdoppelt ist. Die Reduktion der Chromosomenzahl

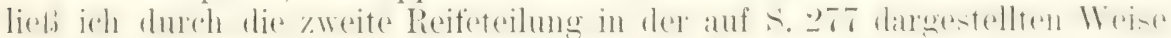
bewirkt werden. Über die Entstehung der Vierergruppen war ich im un-

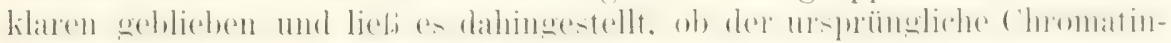
faden sich nur einmal, was ich für sehr wahscheinlich hielt, orler zweimal der Lïnge nach gespalten habe. In ersten Falle müßten mehr Stücke durch Querteilung des Fadens als im zweiten Falle gebildet sein.

In letzter Zeit hat loveri (VIII 1904) an del' Entstehung der 'T'e-

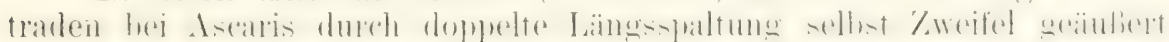
und neigt mehr der Deutumg zu, daf, zwei einfach gespaltene Fäden sich

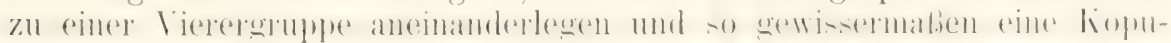
lation ausführen, einen Vorgang. auf welchen ich in cinem späteren $A$ bschnitt noch eimmal zuriekkommen werde.

Auch ich halte die Angaben von Brauer nicht fül entscheidend und

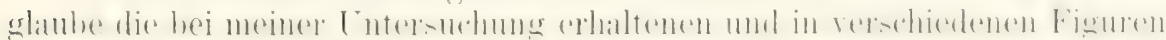
dargestellten Befunde so deuten zu müssen, (lab) zwei schon frühzeitig in

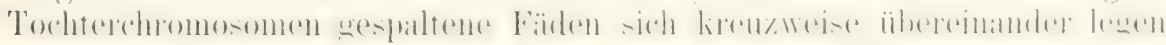
und durch Linin verbinden, wie ich es anch auf $\mathrm{S} .275$ beschrieben habe.

Wäre in dieser Dentung das Richtige getrofien, was ernente Unter-

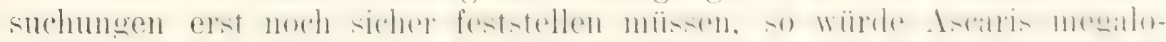

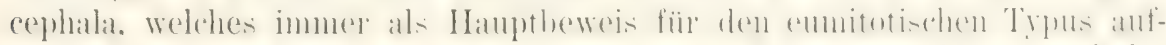

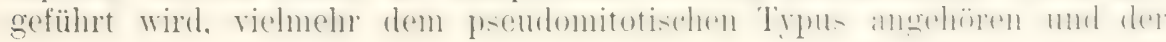


Zweifol hereditigt sein, oh der erstere, 1. h. die doppelte Iängsipaltumg eines Chromatinfalens, überhaupt vorkommt. Vorläufig wird letzteres noch

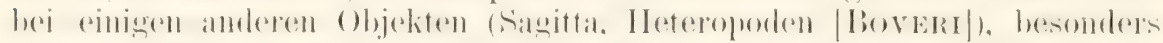

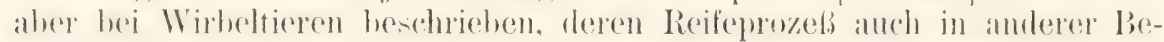
ziehung Besonderheiten darbietet.

\section{Die pseudomitotische Reifeteilung}

ist bei verschiedenen Arthropoden durch RüCKERT (XI 1894), HAECKER (XI 1895 1. 1898), HeNKING (XI 1890-92) und vou RatH (XI 1895), sowie bei den Ameliden Ophryotrocha von Korschelt XI 1895) beobachtet und bis ins Detail so genau festgestellt worlen, daß an der Richtigkeit der ähereinstimmenden Angahen der genannten Forscher wohl kaum zu zweifeln ist.

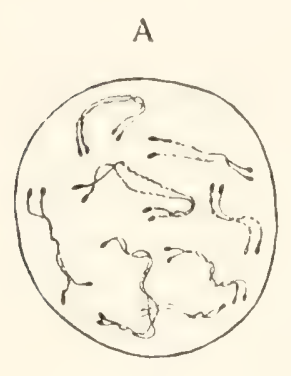

D)

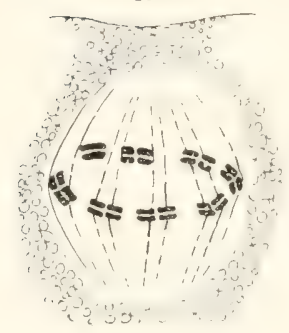

B
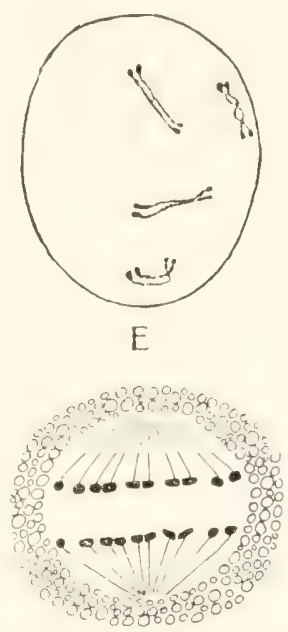

C
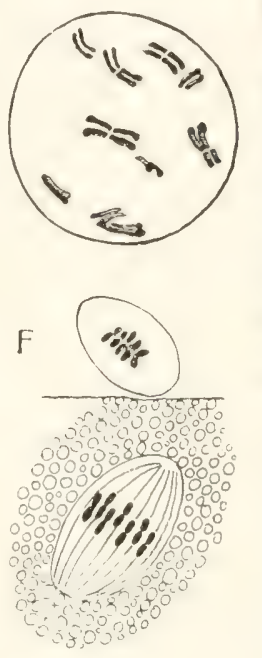

Fig. 249. Die Bildung der Vierergruppen im Ei von Cyclops in etwas schematisierter Darstellung. Nach RÜCKFRT.

$A$ u. $B$ die Längsspaltung der Fiiden, deren Zahl in geringerer '/ahl eingezeichnet ist, im Keimbläschen. C Querteilung derselben und Bildung der Vierergmupen. $D$ Anordnung der Vievergruppen auf der Spindel. E Auseinanderweichen der Schwesterchromosomen und Äquationsteilung. FZweite Polspindel mit begimnender Reduktionsteilung.

Der Darstellung lege ich die von RüCKERT ermittelten Verhältnisse bei der Krustazeenart Cyclops zugrumde (Fig. 249). Hier ordnet sich im Keimblïschen des Eies wähend der Wachstumsperiode die chromatische Substanz in langen und dünnen, gewundenen Fäden an, deren Zahl der Anzahl der späteren 11 Vierergruppen entspricht und halb so groß ist wie die Zahl der Mutterschromosomen eines sich zur T'Teilung vorhereitenten Kerns einer lï̈rperzelle. Wie ron verschedenen Forschern festgestellt ist, werden die 11 Fäden nur einmal ihrer Länge nach gespalten.

I) De Doplelfärlen verkürzen sich hierauf allmählich zu dicken. kleinen

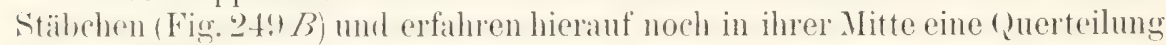
(Fig. 249 C). "Die letztere", bemerkt RückERT mit Recht, „würde den Ausfall an Segmenten wieder decken, der durch das Ausbleiben einer Querteilung beim Zerfall des kontinuierlichen Kinäuels hervorgerufen war und kömnte daher als eine verspätete Segmentierung aufgefaßt werden. Sie würde die bis dahin vorhandenen "Doppelsegmente" wieder in je zwei einfache segmente, in gewöhnliche ('hromosomen zerlegen, wenn anch zunächst in unvollständiger Weise, denn die letzteren werden zunächst 


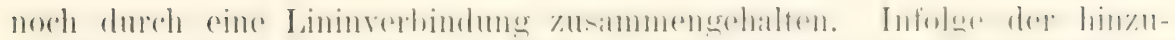

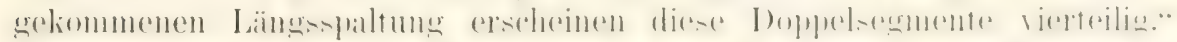
Rückent sieht daher in der Verringerung der Anzahl der Fiaden, die

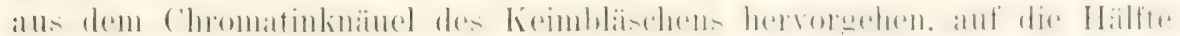
der normalen Zahl nur eine scheinbare Redulition, eine l'seudoredulition.

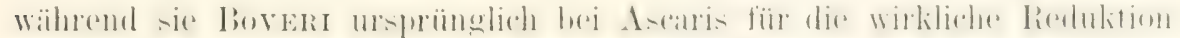
gehalten hatte; sie ist scheinbar. weil jeder Faden, wie der weitere Ver-

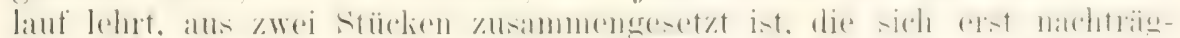

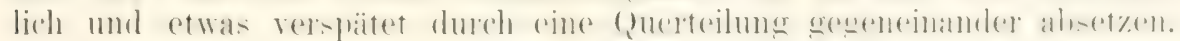

HAECKER hat vorgeschlagen, derartige Elemente, die in Wahrheit

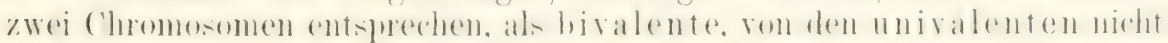
weiter zerlegbaren zu unterscheiden. Ferner nennt er plurivalent ein Chromosom, das in viele Stücke zerlegbar ist. Als Beispiel hierfür

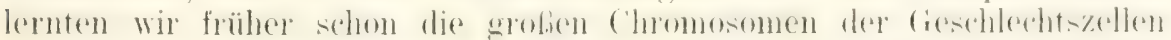
von Ascaris megalocephala kennen, die bei der Embryogenese in den

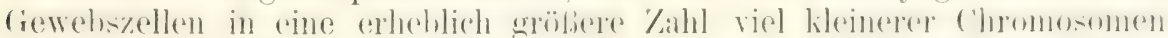

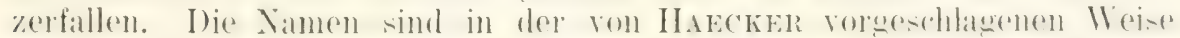
wohl mit Vorteil verwendbar. Dagegen empfiehlt es sich, den Namen

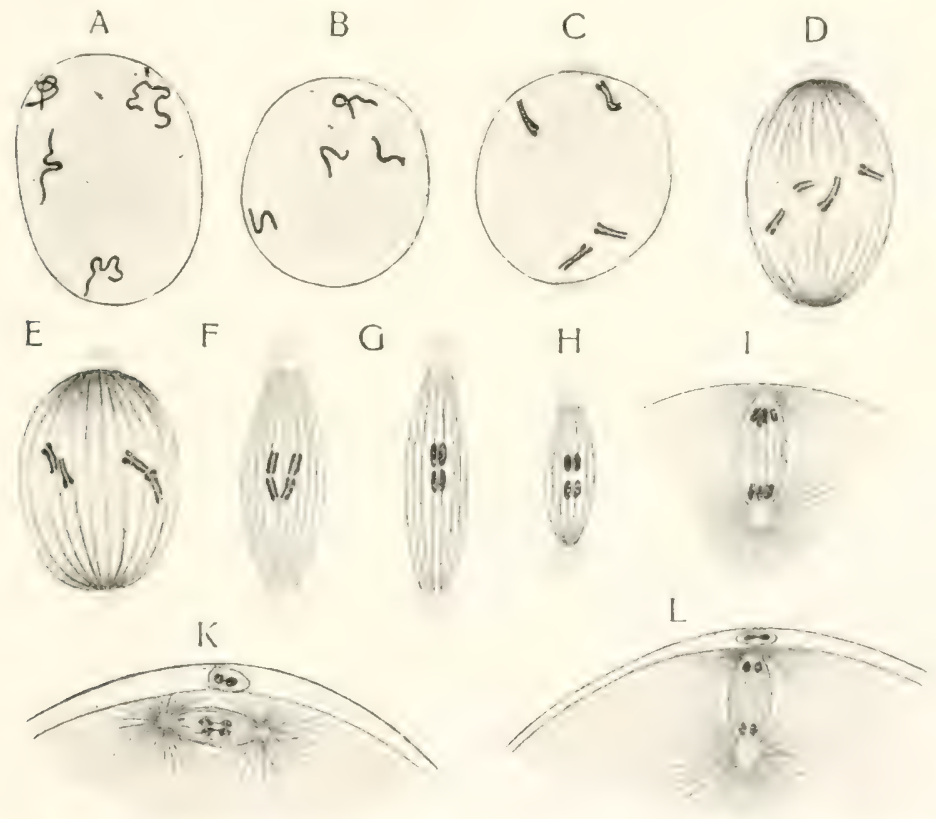

Fii. … Einige Stadien aus den Reifungsteilungen des Eies von Ophryotrocha puerilis.

A-C Auftreten und Lïngsspaltung der Chromosomen. D Anordnung zur Äquatorialplatte der ersten Polspindel. E Vereinigung zweier Chromosomenpaare zur Vierergruppe. F Trenmung der Tetraden in die Dyaden. $G, Z I, I$ Weitere Stadien der ersten Polspindel. $K$ und $L$ Zweite Polspindel. Nach lionschelt.

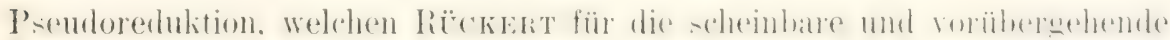
Verringerung der Chromosomenzahl in lieimbläschen gelorancht hat. ganz fallen zu lassen. Denn es ist wohl einfacher unel richtiger, die

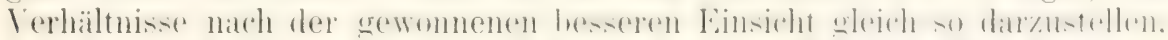

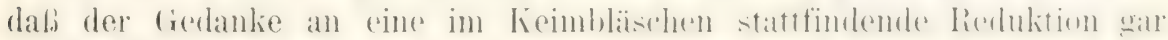
nicht aufkommen kann. 
Durch die Iängsspaltung und später nachfolgende Querteilung der 19 aus dem Chromatinknäuel abstammenden Fäden sind bei Cyclops 11 Vierergruppen (Fig. 249D) entstanden, deren Genese sich viel genauer als bei Ascaris hat verfolgen lassen. Das Endergebnis aber ist genan dasselbe wie dort. Die Chromosomen sind durch Linin immer zu vier in einer Gruppe vereinigt. Ihre Gesantzahl betriggt daher jetzt bei Cyclops 4t, also das I)opnelte der narh dem Zahlengenetz emittelten Vormalzahl oder so viel, wie die Anzahl der Tochterchromosomen im Kern einer Gewebszelle im Dyasterstadium beträgt.

Über die Art ihrer weiteren Verwendung bei der Bildung der Polzellen hat uns RückERT durch das Studium von Cyclops ebenfalls genane Auflärung gehen kömnen. Er heschreiht, wie die Vierergruplen im Äquator der ersten Polspindel so angeordnet werden, daß ihr Längsspalt sich in die Äquatorialebene einstellt, (ler Querspalt senkrecht zu ihr (Fig. 249D). Infolgedessen werden bei der 'Teilung, welche die erste Polzelle liefert, die durch Lïngsinaltumg entstandenen Tochterchromosomen, paarweise durch Linin zu Dyaden vereint, nach den Polen (ler Spindel verteilt (Fig. 249E). Bei der zweiten 'Teilung (Fig. 249 F') dagegen werlen die dureh querspaltumg gehildeten stïclie der ursprünglichen Vierersupe, welche eine Zeitlang zu den einzelnen Dyallen rereint sind, roneinamler getrennt mul die Reduktion im letzten 'Teilungsakt der Eireife vollzogen.

In noch größerer Klarheit läßt sich ein ähnlicher Ablauf der Reifung, der zugleich zwei lileine Modifikationen darbietet, hei Ophryotrocha, einer von Korscnest untersuchten Anmelide. heobachten, hei welcher die Normalzahl der Chromosomen eine sehr geringe ist, da sie wie bei Ascaris bival. nur vier beträgt (Fig. 250). Im Keimbläschen des Eies zerfällt hier der Kernfarlen gleich in vier Schleifen, die im Unterschied zu Cyclops univalent sind, da sie der Normalzahl der Chromosomen entsprechen (Fig. $250 A$ und $B$ ). Die Schleifen spalten sich der Länge nach und verkiüzen sich zu vier Paar 'Tochterchromosomen, wie bei einem gewähnlichen Kern in der Metaphase der Karyokinese (Fin. gind) C). Während

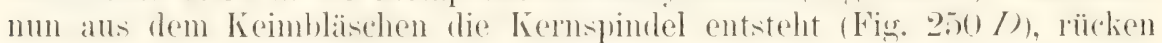
die Chromosomenpaare in den Äquator derselben und verbinden sich je zwei, indem sich ihre Stäbchenenden aneinanderlegen, zu zwei Vierergruppen (Fig. $250 \mathrm{E}$ und $F$ ). Während also bei Cyclops die Vierergluppen durch unvollständige Querteilung des Chromatinfadens, kommen sie hier durch sekundare, parweise Vereinigung schongetrennter Fadensegmente zustande. Vielleicht ist letzteres auch bei Ascaris der Fall, nur dab.j hier die Verlötung in der Mitte, der lirewzweise äheremandergelegten Fäden (Fig. 24tII), erfolgt.

Eime zweite Abweichung von Cyclops ist nach Korschelt in der Verteilungsweise der vier Elemente der 'Tetrade gegeben. Während dort der Längsspalt, soll sich hier der Querspalt zuerst in die Äquatorialebene einstellen, und es sollen bei der Bildung der ersten Polzelle die zuror in Verbindung getretenen Chromosomenpare wieder an der Verlötungsstelle getremut und anf die erste Polzelle und Eitochterzelle verteilt werden (Fig. 250 G, H, I). Die durch den Längsspalt entstandenen Schwesterdemente wiolden demmach hei ophryotrocha erst durch die zweite Reifungs-

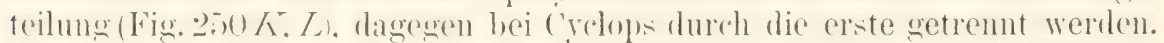

I)a die meisten Forsher im Anschlulis an Wersusx das Wesentliche bei der Redulition darin sehen, dab Chromosomen, die nicht von demselhen Intterchromosom durch Teilung abstammen, auf zwei Zellen 
verteilt werlen. so haben KonscmedT und Hemper auf (irumb dieser Differenzen zwei Unterarten des Reduktionsprozesses als P’rä- mond P'ost-

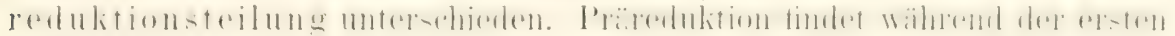
Reifungsteilung, wie bei Ophryotrocha, Postreduktion erst wähend der zweiten Reifungsteilung, wie bei Cyclops, statt. An Ophryotrocha sollen

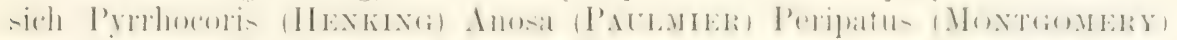

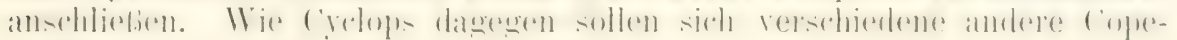
poden und die Orthopteren verhalten.

In verschiedenen Abteilungen des 'Tierreichs, von denen schon eine

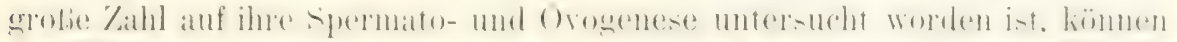

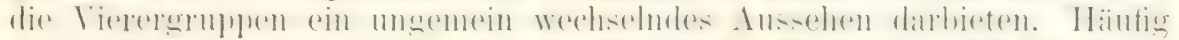

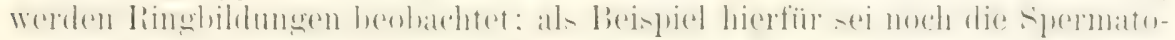
genese von (iryllotalpa (Fig. 25)1), welche vesi RATi untersucht hat, kur\% angeführt. Aus dem Knänelstadium (Fig. 251 A) gehen sechs Fäden hervor, die mach der' früher besprochenen 'Terminologie bivalent sind (lig. 251 B); dem die Normalzahl der Chromosomen beträgt bei Gryllotalpa 12. Jeder Faden spaltet sich der Lïnge nach in zwei Fäden. die

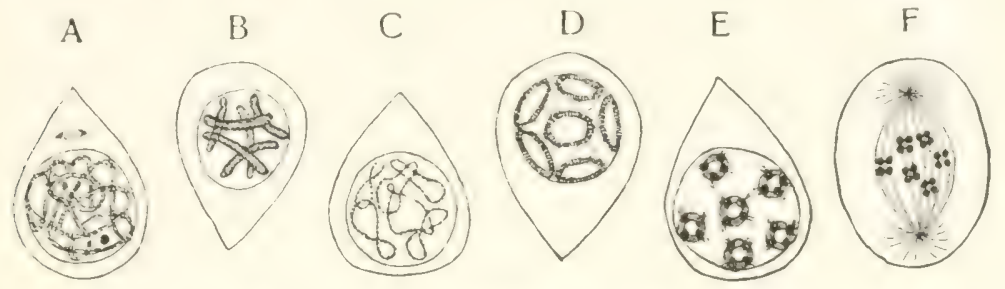

1.ik. 2.1. Bildung der Vierergruppen in den Spermatocyten von Gryllotalpa vulg. Nach vou liATH.

in der Mitte auseinander zu weichen begimmen, an den Enden aber verkloht bleiben. Auf diese Weise lommen sechs Chromatinringe (Fig. 2a) $C$ und D) zustande, die durch Verkïrzung und Verdickung des Fadens

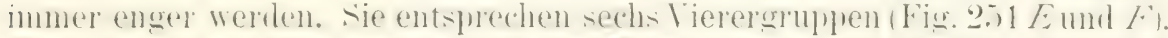
Honn in rinem jeden sondert sich das Chmmatin an vier stellen wom Linin und bildet so vier durch Lininbrïcken zum Ring verbundene Chromosomen. welehe dured rine Läng-ybaltumg und rine querteilung des hisatlenten Fadens wie bei Cyclops etc. zustande gekommen sind. Bei dem

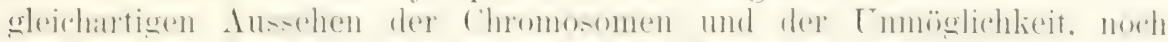

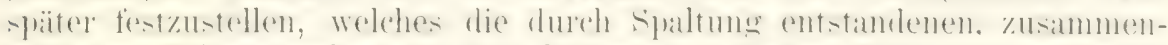

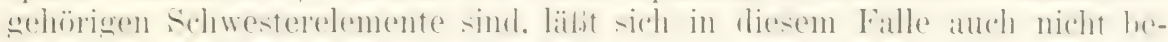
stimmen. ob die Redulition im II Essusxischen sime durch die erste oder zweite Reifeteilung erfolgt.

Alnhliche ringfömige Vierergruppen sind auch bei Pyrhocoris von

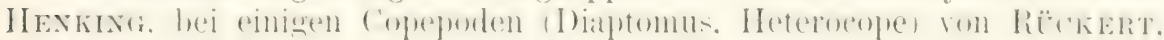
HAECKER und RATH, bei Caloptenus ron Widcox und noch bei anderen Arten beobachtet worken.

Es würde uns hier zu weit führen, auf die zahlreichen, sonst noch beobachteten Variationen in der form der Tetraden und Chromosomen

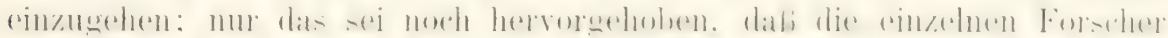

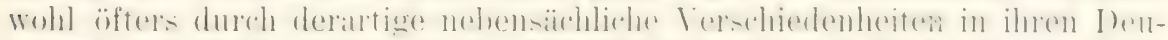

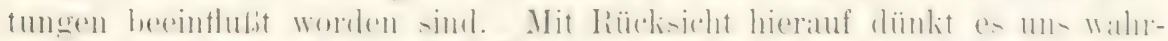

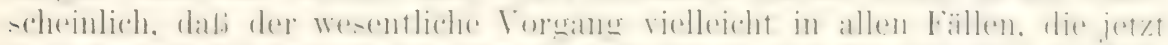

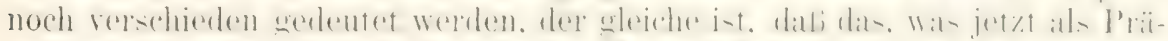

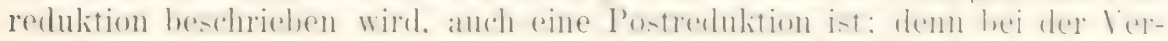


liir\%m, der Chromosomen, ihrer Formverinderung, den Drehungen, die sie

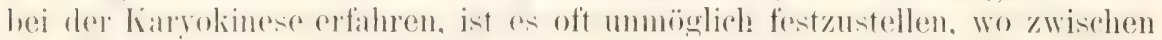

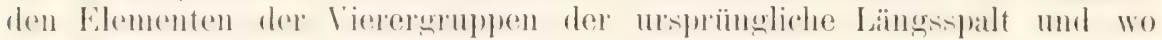
die Quertrennung später zu suchen ist. Daß in den Dentungen hier leicht Irrungen möglich sind, liegt wohl auf der Hand.
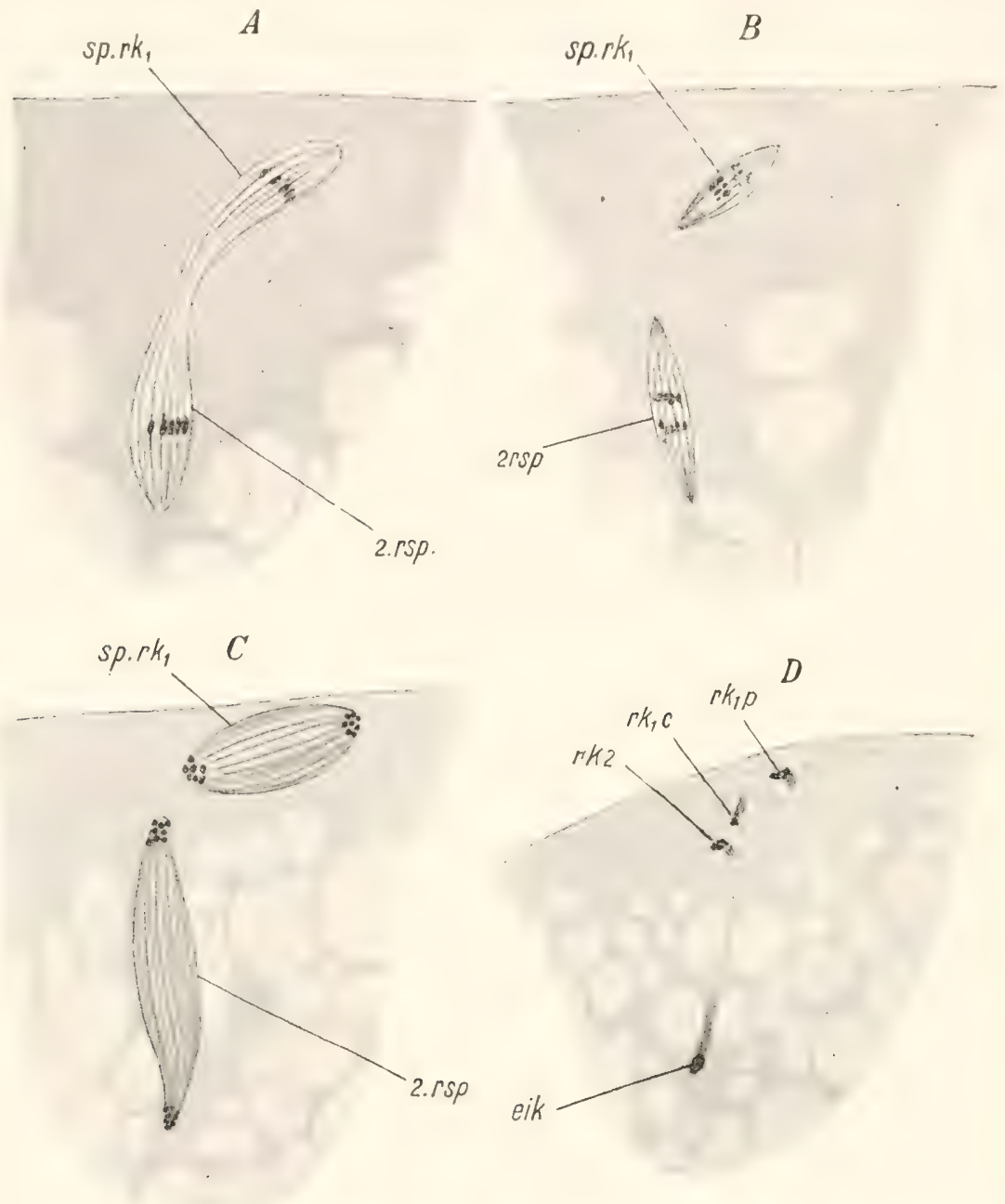

Fig. 2. Die Reifungsteilungen im Drohnenei von Apis mellifica. Nach P'Etrunkewrisch. A Die erste Spindel, welche sich in zwei Tochterspindeln teilt. $B$ und $C$ Nach außen liegt die Tochterspindel, welche der Spindel der ersten Polzelle entspricht, mehr nach innen die Tochterspindel, welche im gewöhnlichen Verlauf den Kern der zweiten Polzelle und den Eikern liefert. D Ei mit vier Gruppen ron Clromosomen, von denen die drei peripher gelegenen den Kernen der drei Polzellen entsprechen, die vierte Gruppe zun Eikern wird.

Als eine Eigentïmlichlieit, die noch näherer Aufklärung bedarf, kommen bei manchen 'Tierarten akzessorische Chromosomen vor'. Sie zeichnen sich vor den ibbrigen durch ihre besondere Größe und Färbbarkeit aus und werlen gewhinlich in muglechmäljiger Weise nur einzelnen Tochterzellen bei den Reifeteilungen zugeteilt. 
Eine andere Abweichung vom gewöhnlichen Hergang ist bei der

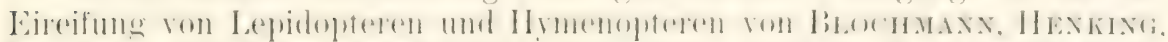

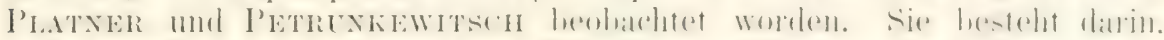

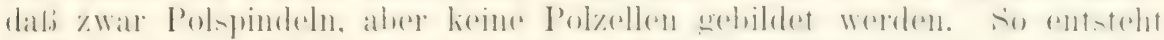
z. B. bei einem Bienenei in typischer Weise eine Spindel, die zur Eirinde emporsteigt (Fig. 252), Ihre Chromosomen sondern sich auch in zwei

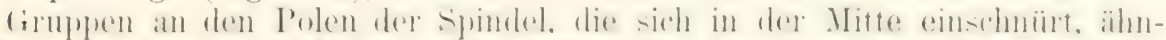

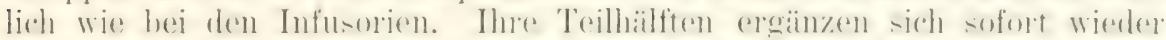

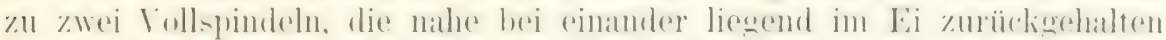

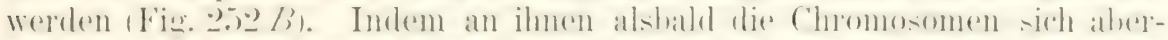

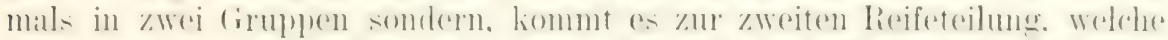

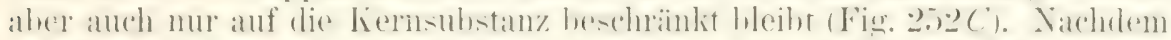

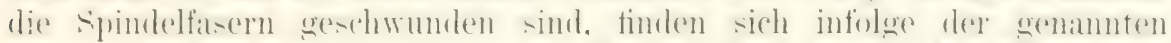

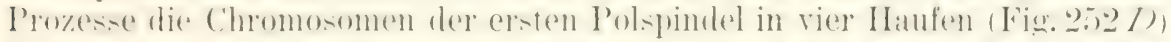
verteilt nahe hei einamber in der Firinde. Vom ihmen gehen drei Inafen.

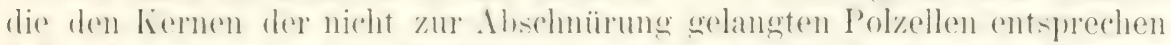

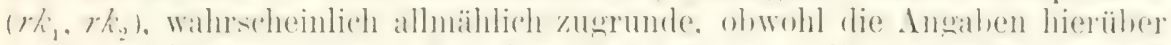
moch vershieden lanten. Ans der vioten diruppe, die an writesten nach dem Eizentrum zu liegt, wird der Eikern (cik), der somit wie bei der

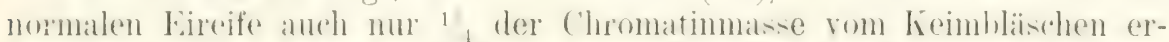
halten hat. Wem anch die Bildumg dex l'olzellen sellst muterdrüelit ist, -o) hat doch die liedulition der Kernsulstan\%, auf welche es hei der lieifung einzig und allein ankommt, wie sonst im Tierreich, stattgefunden.

\section{Beobachtungen, betreffend das weitere Schicksal des beim Befruchtungsakt vereinten} väterlichen und mütterlichen Chromatins des Keimkerns.

a) Die Autonomie des vaterlichen und müterlichen Chromatins.

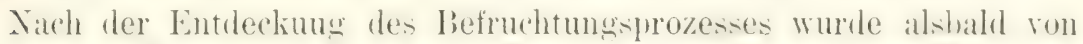
versehielenen seiten mit liecht die Frage anfgeworfen. ob in linmliern sich das vïterliche und das mütterliche chromatin heim weiteren Verlauf der Entwicklumg getremnt erhalten oder ob zwischen beiden allmählich eine

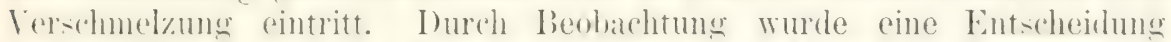
lerheizufïhren versucht. Zugumsten der ersten Alternative liels sich die

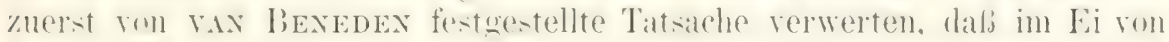
Ascaris Ei- und Samenkern lange Zeit getrennt bleiben, jeder für sich

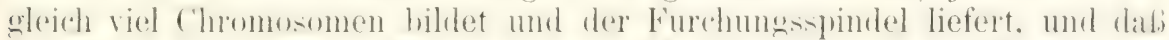
die Toilprodukte die-er Chromosomen anf die beiden ersten Embryonalzellen so verteilt werden, dab jede gleich viel Tochterchromosmmen vom Eikern wie vom Samenkern erhält.

Es konnte auf diesem Fundament die Hypothese (van Beneden,

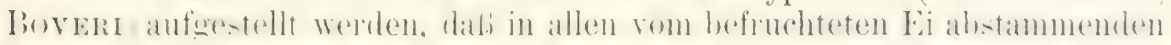

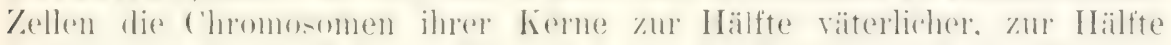

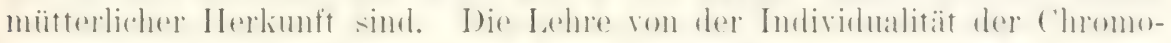
somen gab ja dieser Annahme auch eine weitere, theoretische Stuitze.

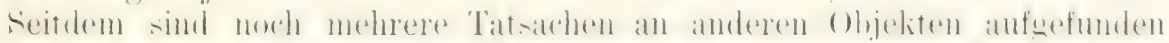

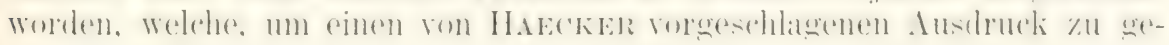
branchen. für die Autonomie der väterlichen und mütterlichen Kernsubstanzen sprechen. Während bei Ascaris sich die Autonomie

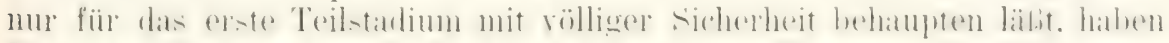

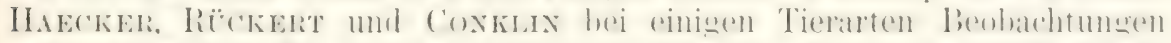

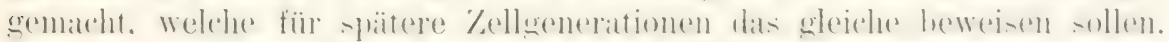

HAECkEI hat für Cyclops brevicornis, Rücker' für Cyclops strenuus

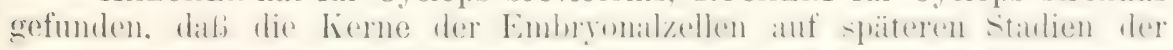

O. Hertwig, Allgemeine Biologie. 2. Aufl. 
Entwicklung eine Zusammensetzung aus zwei Hälften erkennen lassen (Fig. 25:3). In vielen Zellen sahen sie statt eines einfachen zwei dicht

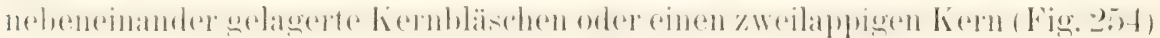
mit einer nach innen einspringenden Scheidewand. Wenn die Kerne sich
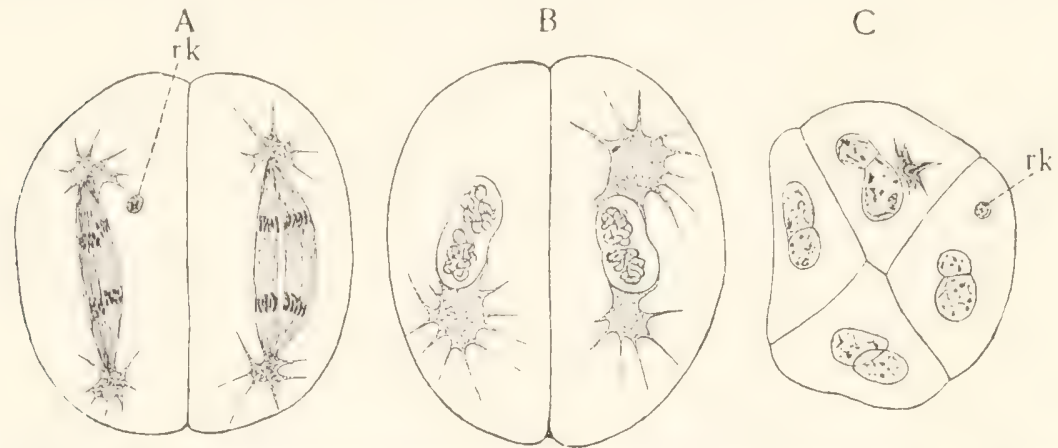

Fig. 253. Furchungsstadien des Eies von Cyclops (strenuus $A$ u, $B$, brevicornis $C$ ), um die Gonomerie der Kerne $(C)$ und die Antonomie des väterlichen und des mütterlichen Chromatins zu beweisen. Nach Rǘckert und HAECkER.

z.nr Teihng anschickten, bildeten sich zwei mehr orler minder getrennte Farlenkin̈uel (Fig. 2.5:3 B). Auch die Spindel erscheint häutig wie aus zwei parallel selagerten spindeln mit zwei getremten diruppen von chromosomen (Fig. $253 \mathrm{~A}$ ) zusammengesetzt.

Zweiteilige Kerne fand Conkuin auch bei Crepidula (Fig. 255). HaEcker hat den zweiteiligen Zustand der Kerne als Gonomerie orler ihren gonomeren Zustand und die beiden Hälften (Fig. 255) als die Gonomeren hezeichnet. Wie Rüchen'T ist el der Ansicht, dabs derartige Bilder

Fig. 254

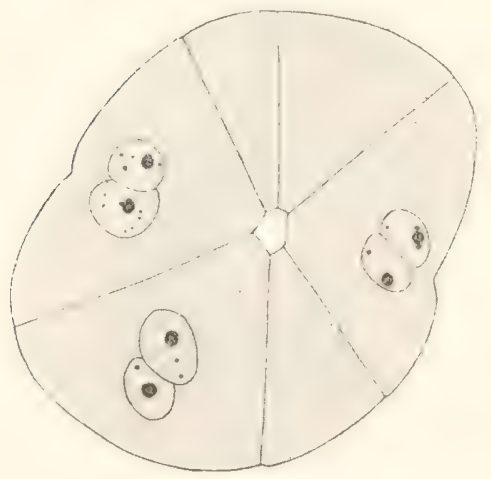

Fig. 255 .

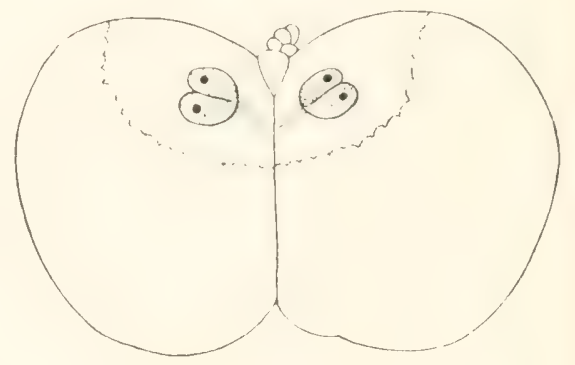

Fig. 254. 16 Zellenstadium von Cyclops brevicomis. Nach HAECKER.

liig. 255, 2 Zellenstadium von Crepidula. Nach Conktiv.

sich als Beweis für das Selbständigbleiben oder für die Autonomie der mütterlichen und der väterlichen Kernsubstanzen und gegen die Amahme einer gegenseitigen Vermischung beider verwerten lassen. IIAECKER will ferner einer Hinweis auf die Zusammensetzung des Kerns aus einer väterlixhen und einer mütterlichen Inilfte anch in dem häufig zu beohachtenden. symmetrishen Auftreten zweier Nucleolen erkennen. Doch will uns scheinen. als ob dieser Beweis etwas weit hergeholt sei und als ob ein innerer Zu- 
sammenhang zwischen dem paurgen Aufreten der vincleolen und dem gesonderten Forthestehen indivilueller Chromosomen fehle. Denn wie

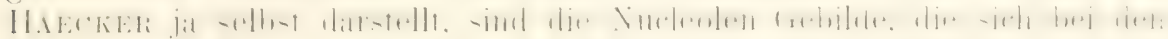
Teilungen auflösen und dann wieder neu bilden: anch beschreilst er selbst. (lab) bei längerer liermuhe beide Nucleolen zu einem einzigen verschmelzen und dabauch häufig noch Nebenumeleolen nehen zwei grölieren Hauptnucleolen heoharchtet werilen.

sionit ist das Beohachtungsmaterial, auf welches sich die lohre von der Autonomie der väterlichen und mïterlichen Kernsubstanzen begründen liebe. zur Zeit noch als ein sehr spürliches zu bezcichnen. Anf die theoretische Seite ler Frage soll erst später in anderem Zusammenhang noch nither eingegangen werden.

\section{b) I) Sic Syansis.}

Die beiden in naher Bezichung zu emander stehenden Hypothesen ron der Individualität der Chromosomen und von der Autonomie der väterlichen und der mïterlichen Kerusubstanz haben in den letzten Jahren eine Eroünung durch eine dritte Hypothese erfahren. die. wenn sie eine richtige Interpretation der Tatsachen giht. von grolier Bedentung ist. Ihr zufolge soll es am lieginn der Reifung der Ei- und Samenzelle zu einer Konjugation oder Kopulation der bis dahin getrennt gebliebenen räterlichen und mütterlichen Chromosomen kommen. Die Iypothese ist ron den amerikanischen Forschem MoxtgouERY (XI 1901). SuTTOx (XI 19()). 19)(3). M. Chuxg (XI 1901) anfgestellt und ron HaEcker. Boveri. StrasBLRGER U. a. angenommen worten.

Die Konjugation soll vor sich gehen auf einem Stadium der Wi- und Samenreife, das Moore in seiner Arbeit ïber die Spermatogenese der

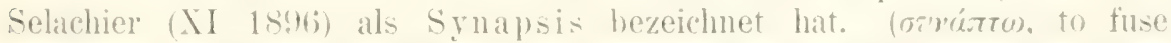
together). Auf dem Stadium, das längere Zeit währt. findet man das Chromatin in einer Hältte des Kerns dichter zusammengedrängt. in einer (iegend, wo nach auben ron der Kermmembran im Protoplasma auch die Sphäre mit dem Centrosom gelegen ist. Im Anschlub hieran tritt dam später wieder eine Lockerung ein und es zerfällt jetzt der sich dentlicher differenzierende Kiernfaden. wie schon friher besprochen wurle, in Segmente. welche der halben Chromosomenzahl entsprechen und daher bivalent sind. Die weitere Folge ist die Bildung der Yierergruppen, die wir ja schon früher auf die parrige Vereinigung von Nutterchromosomen, die früh in Tochterchromosomen gespalten sind. zurückgeführt haben.

Hier läbt sich die Frage anfwerfen. Was hat diese Vereinigung für eine liedeutung und für einen / week:

Moxtgomery. überzengt von der Richtigkeit der Indivirlualitätshyothese der Chromosomen. sprach zuerst die Insicht aus. dab während der Srnapsis eine lionjucation oder liopulation zweier univalenter Chromosomen zu einem hivalenten Element stattfinde und dab' ron den kopulierenden Chromosomen das eine mitterlicher. das andere väterlicher Herkunft sei. Bei der Reduktionsteilung werde die Copula wieder in ihre bestandteile getrennt. Zugunsten seiner Hypothese füht Moxtönery folgende drei Argumente an:

Bei Ascaris megalocephala univalens sei 2 lie normale C'homosomenzahl: Ei- und Samenkern besïhen nur ein einziges Element. erst dureh ihre Vereinigung erhalte der Keimkern wieder zwei. Wem daher heim Reifeprozeb der Spermatocyten und Ovocyten der nächsten (ieneration sich 
zwei univalente Chromosomen zu einem bivalenten in der Symapsis verbinden, so müsse eimes väterlicher. das andere mütterlicher Herkunft sein.

Zweitens beobachtete Moxtgomery bei manchen Hemipteren, das in ihren Ovo- und Spermatogonien zwei Chromosomen durch ihre Gröbe von den ïbrigen in auttallender Weise abweichen, daher sie von ihm als lleterochromosomen bezeichnet werden. Wähend der Synapsis rereinigen sich letztere und werden durch die Reifeteilungen so verteilt, daß jeder Samenkörper und jedes reife Ei nur eines erhält. Wenn daher in der Synapsis der nächsten Generation wieder zwei Heterochromosomen in Paarung getrofien werden, so mub das eine vom Samenkerm, das andere vom Eikern abstammen.

Drittens war ron Montgomery bei mehreren Spezies, sowie von SutTon bei Brachystola bemerkt worken, dab die Chromosomen in der Spermato- und Ovogonie parrweise von sehr verschiedener Größe sind. In der Synapsis konjugieren aber stets nur Chromosomen von gleicher Gröbe und werden bei der Reifeteilung so verteilt, dab sowohl jede Eizelle als jede Samenzelle nur ein Element der Serie erhält. Bezeichnet man die Serie für den Samenkern mit A, B, C . N und für den Eikern mit a, b. c...n, so kommen durch rie Befruchtung beide Serien in einem Kern zusammen. Später muls damn nach dem oben Gesagten in der Synapsis A mit a, B mit b, C . mit c. . N mit $n$ kopulieren, also ein Chromosom väterlicher mit einem solchen mütterlicher Herkunft.

Indem Boverr (VIII 190t) sich diesen Ausführungen von MoxTGOMERY und SUTton anschließt. hält er es für wahrscheinlich, daf es sich hei der Zusammendrängung des chomatins in der symapsis um das gegenseitige Aufsuchen homologer, zuvor weit auseinander gelegener Chromosomen handele, daß sie jetzt eine Anziehung aufeinander ausüben und

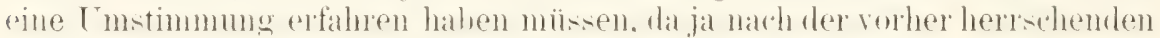
Autonomie der väterlichen und mütterlichen Kernsubstanzen die räterlichen (hromosomen untereinander und die müterlichen moteremander eine engere Affinität gezeigt hätten. Ferner ist Boveri geneigt, der Kopulation

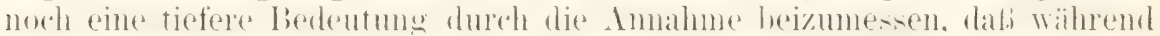
ihrer Daner die konjugierten Chromosomen gewisse Substanzen, wie zwei konjugierte Paramäcien austauschen und daher, wemn sie sich tremnen, nicht mehr die gleichen wie zuvor sind.

Indem ich mich auf eine sachliche Darstellung der Befunde und der an sie geknüpften weitausschauenden Hypothesen beschränke, werte ich an anderer Stelle, nachdem wir unsern Gesichtskreis zuvor noch mehr erweitert haben, auf ihre Beurteilung zurïckkommen.

\section{2) Die Befruchtung der Phanerogamen.}

Mit den Ergebnissen auf tierischem Gebiet harmonieren in vollliommenster Weise die Entrleckungen des Befruchtungsprozesses bei den Phanerogamen, welche wir in erster Reihe den Arbeiten von STRAsburger (XI 1884). (iuIGxard (XI 18!)1) und NAwASCHIN (XI 1899, 1901) verdanken. Die für das Studium geeigneten Objekte bieten uns hier die Lilia-

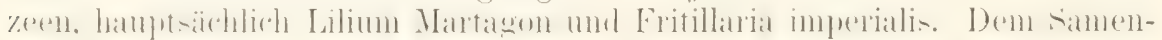
farlen entspricht bei den Phanerogamen das Pollenkorn, dem tierischen Ei die im Fruchtknoten des Stempels eingeschlossene, den wichtigsten Teil des Embryosaclies bildende, ptlanzliche Eizelle.

Wenn das Pollenkorn auf die Narbe des Griffels gelangt ist, beginnt sein Inhalt aus einer erweichten Stelle der Membran hervorzutreten und 
zu einem langen Schlauch (Fig. 256) auszuwachsen, der sich im firiffel nach abwärts einen $\mathbf{W e g}$ bahnt, bis er einen Embryosack erreicht hat. Hier dringt er noch zwischen den beiden Synergiden hindurch zur Eizelle selbst heran. Pollenkorn und Pollenschlauch enthalten zwei Kierne. einen vegetativen und einen generativen Kern. Letzterer. der den tierischen Samenkern entspricht und daher ebenso benamnt werten kann, liommt in die Spitze des Pollenschlauchs zu liegen. wenn dieser zur Eizelle vorgedrungen ist: you hier tritt er durch die wanz erweichte Zellulosehaut hindurch in das Protoplasma des Eies ein (Fig. 257 B' sn) und trifft bei seiner Wanderung bald den etwas umfangreicheren Eikern. Beide verschmel\%en hierauf zum, lieimliern.

Wie bei den tierischen (ieschlechtszellen wirl anch hei der Bildung des Pollens und der Eizelle der Phanerogamen das Chromatin und die Anzahl der aus ihm hervorgehenden Kernsegmente ant die Hïlfte eines Normallierns herabgesetzt. Während zum Beispiel bei Lilium Martagon die gewöhnlichen lierne bei ihrer T'eilung 24 liernsegmente entwickeln. die sich in zweimal 2t 'Tochtersegmente rler Länge nach spalten. ist beim Ei- und Samenkern eine Reduktion auf 12 Segmente herbeigeführt worden. Erst aus ihrer Vereinigung entsteht wieder ein Vollkern. die erste Teilungsspindel mit 24 Muttersegmenten. ron denen 12 vïterlicher. 12 miitterlicher Abstammumg sind

[Yig. 25), Medianer Längsschnitt duxch die empfängnisreife Samenamlage von Picea excelsa. c Embryosack mit dom Prothallium gefiillt, a Bauchteil, c Halsstiel eines Archegonium, o Fizelle, n der Eikern, no der Nucellus, l'ollenkörnerauf und in der hinospenwarze, $t$ Pollenschlïuche, i Integnment, s der Samenflügel.

Fig. 25. Befruchtung des Eies von Picea excelsa. Jacil CotrTER mal CH.MUERLAIX A reifes Ei mit Eikern on. liamehkanalzelle $\mathrm{cl}$. B Fintritt dos befruchtenden, männlichen Lirms $s n$ ins $\mathrm{Fi}$ aus dem l'ollensehlauch to (: Versinigung von Eikern und suermakern zum Eikern. (f) fache Verer.

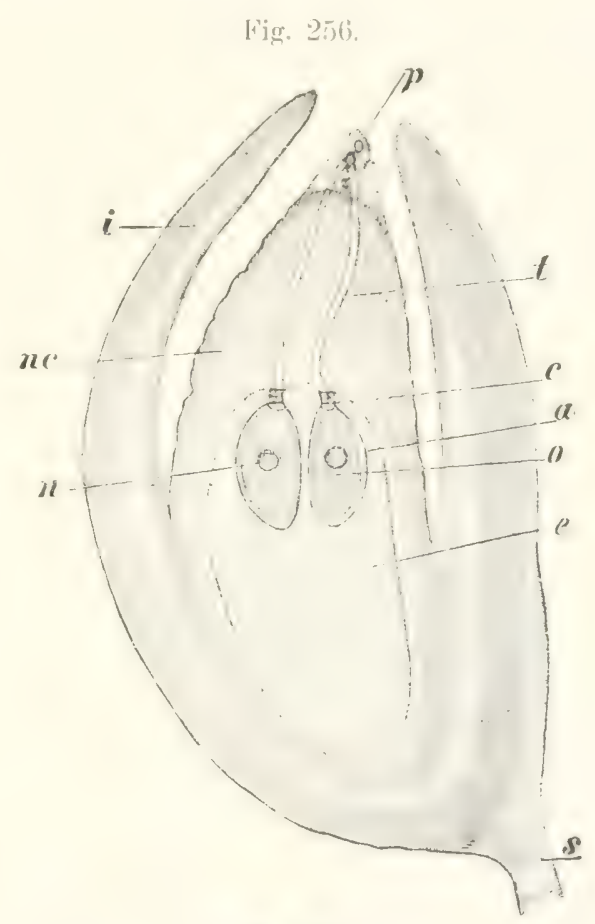

Fï. )...

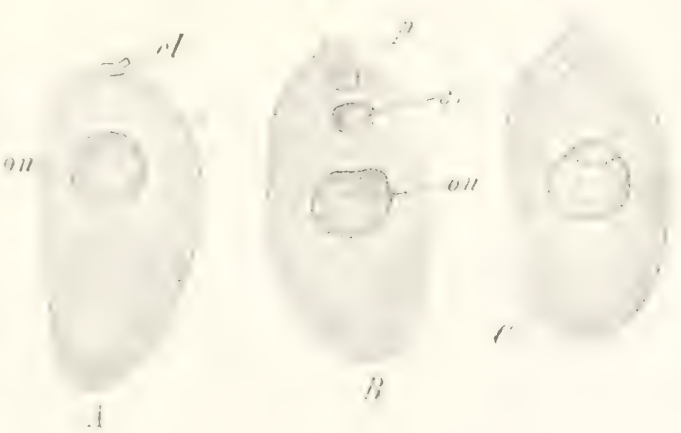

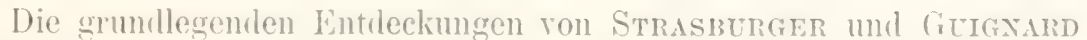
haben später durch XaWascurx (XI 1899), 1901) eine seln interessante Er- 
gïnzung erfahren. Durch ihn wurde bei verschiedenen Vertretern der Angiospermen noch eine ..\% weite Befruchtung enteckit, welche für die Botanilier. wie Strasburger (XI 1900) sich ausdrickte, ..eine Über-

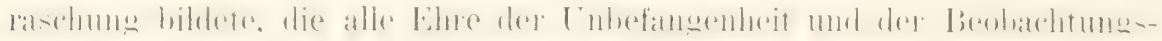
gabe desjenigen machte, dem sie gelangi“.

Die zweite Befruchtumg besteht darin, dab mit dem sekundialen Enbryosackkern. der selbst durch Verschmelzung der beiden Polkerne hervorgegangen ist (Fig. $258 A \mathrm{ck}$ ), sich der vegetative Kern des l'ollenschlauches $\left(s p_{2}\right)$ verbindet und so gleichfalls einen gemischten Kern entstehen läßt, der die Substanzen zweier Elterindividuen, einer weiblichen

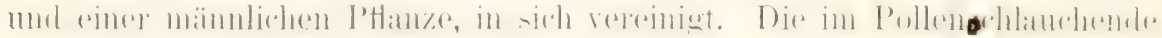
eingeschlossenen zwei lierne sind bei manchen Angiospermen wurnförmig gestaltet (Fig. 258 B sp und $s p_{2}$ ).

Die beilen bei Angiospermen beobachteten Kernkopulationen hat Strasburger (XI 1900, 1901) als die generative und die regetative

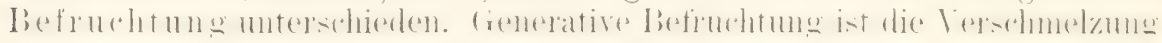
yon Ei- und Samenkern, welche zur Entstehmg einer nenen PHanze führt. Vegetative Befruchtung ist dagegen die Verschmelzung von sekundärem Embryosackkern und regetativem Pollenschlauchkern. Nach NAwaschix ist sie erforderlich, damit es zur Bildung des Endosperms kommt. Dieses

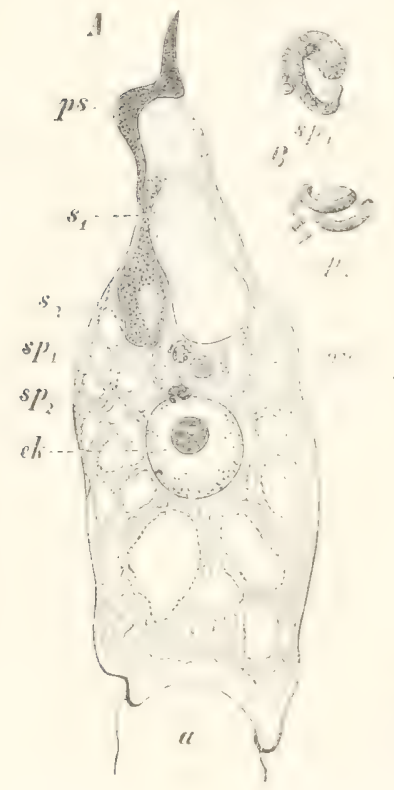
zeigt daher auch gemischte elterliche Eigenschatten. wie sehr deutlich bei Bastardierungen verwandter Pflanzenarten in der Entstehung eines "Bastarlendosperms" festzustellen ist. Mit Recht sieht STrasburger hierin einen nenen, schönen Beweis für die Ansicht. .ola l.' die Zellkerne wirklich die Träser der erblichen Eigenschaftensind". Auf diesen Punkt wirl später noch eimmal zurückzukommen sein.

\section{3) Die Befruchtung der Infusorien.}

Ein außerordentlich wichtiges Objekt für die allgemeine Befruchtungslehre sind die Infusorien, bei denen die geschlechtlichen Vorgänge zuerst durch die bahnbrechenden Untersuchungen von BALBIANI ( XI 1861 ) und BüTSCHLI (XI 1876) entdeckt und neuerdings durch die

Fig. 25s. A Embryosack von Helianthus annuus. Nach X.AWAschix, B'Die männlichen Kerne daraus stärker vergrößert. ps I'ollenschliuch, $s_{1} s_{v}$ Synergiden, sp, sp., mämnliche lieme, oz' Eizelle, ek Embryosackiern, a Antipoden.

klassischen Arbeiten von Maupas (XI 1ss9) und Richard Hertwig (XI 1889) nach allen Richtungen hin noch weiter klargelegt worden sind. ...... Bekanntlich zeichnen sich die Infusorien ror anderen niederen Organismen durch die sehr interessante Eigentïmlichkeit aus, daß ihr Kernapparat sich in zwei physiologisch ungleichartige Kerne gesondert hat. in emen Hauptiern (Makronucleus) (Fig. 259k) und in einen oder melnere Neben- orler Geschlechtskerne (nk) (Mikronuclei). Bei guter Ernährunщ vermehren sich die Infusorien, die man zur Beobachtung in einem kleinen

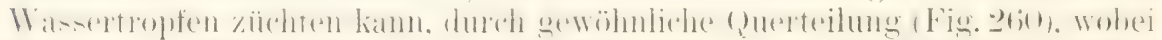

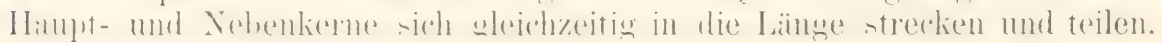


Die ungeschlechtliche Vermehrmg ist unter gïnstigen Bedingungen eine so lehhatte. dab ein einziges Individum sich in der \%eit von sechs

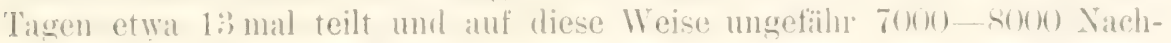
liommen ilen Lrsprung giht.

Fes scheint num namentlich ans hulturversuchen von MaUpas und

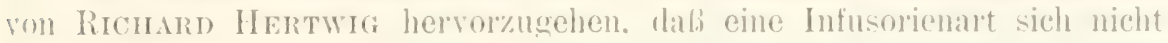
iiher längere Zeit hinaus allein durch Ernïhrung und Vermehrung dureh Teilung erhalten kann. Die Individuen erleiden Veränderumgen an Kiernapprarat, können den letzteren vollständig verlieren. teilen sich nicht mehr und gehen dureh Altersveränderung ofer, wie sich MaUpas auslriekt, durch senile Degeneration \%ugrumbe. '/ur Erhaltumg der Art scheint es durchaus notwentig zu sein. dalis nach hestimmten Zeitabschniten sich zwei Individuen zu einem (ieschlechtsalkt verhinden. Ein solcher ptlegt sewöhnlich bei Individuen, die einer Kütur angehören, zienlich grleichzeitig stattzufinden. so dab man von zeitweise auftretenden honjugationsepidemien redet.

lïg. 259.

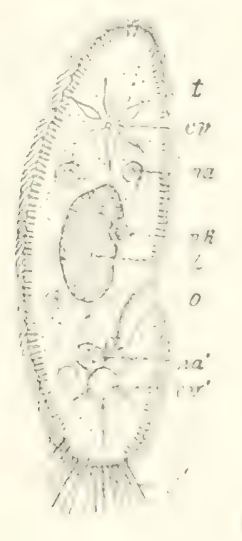

Fig. 2(i).

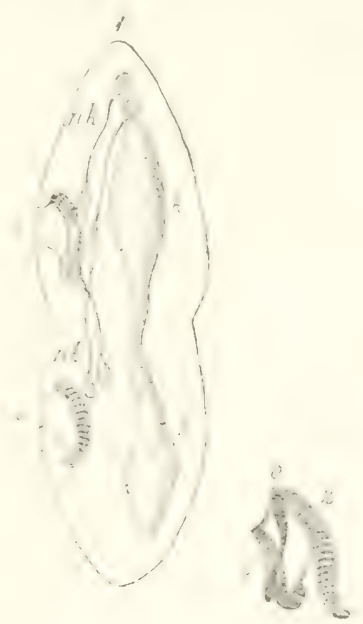

Fin. 259. Paramaecium caudatum (halhschematiseh). R. IrrTwis, Knologie.

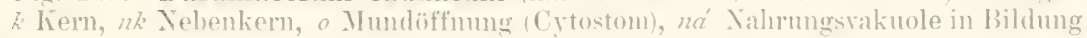

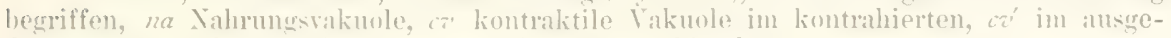

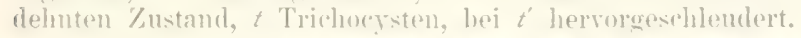

Fir. 260). Paramaecium aurelia in Teilung, daneben in Fig. 2 die Art, wie auf einem froulreren Stadium das Cytostom des hinteren Tieres durch Absclnürung vom vorderen entsteht. L. HERTwi, Ko(s)l.

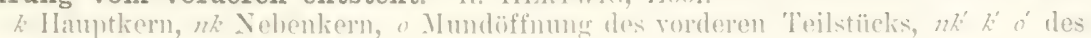
linteren T'eilstioks.

Während einer Epidemie, die mehrere large währt, findet der lieobachter in einem liulturefaili statt vereinzelter Infusorien fist nur Palrlinge vor. Von Lencophrys patula giht Macpas an, dab die lionjugation

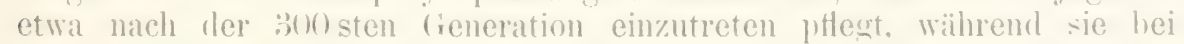
Onychodromus schon nach der 140 sten und hei stylonichia nach der 120 sten (ieneration stattfindet. Das Eintreten emer Konjugationsepiolemie wird in einer liultur befördert durch Abmahme der Silnumg. durch reichliche Ernährung dagegen hinausgeschoben, eventuell ganz verhindert. wobei damm die Individuen infolge seniler Degeneration zustumble gehen. 
Wenn wir nach diesen Vorbemerkungen den Befruchtungsprozeb selhst näher in das Auge fassen, so nehmen wir bei den Infusorienpaarlingen folgende eigenartige und interessante Veränderungen wahr, die sich über einen Zeitraum von mehreren 'ágen ausdehnen. Zur Grundlage der Darstellung diene Paramaecium candatum, welches insofern, als es nur
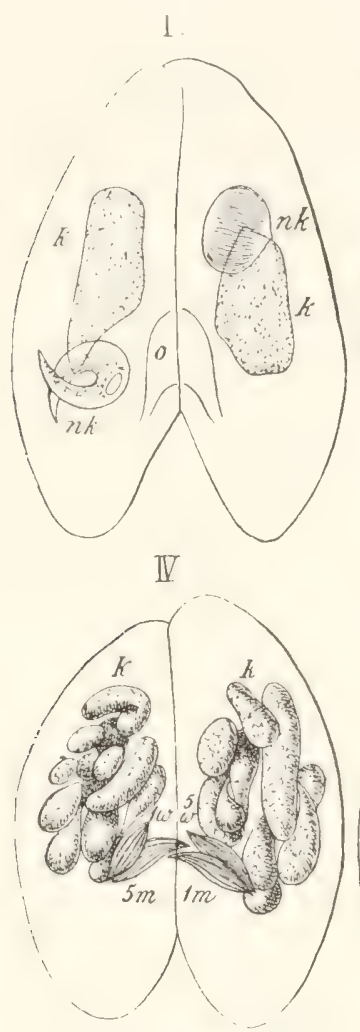
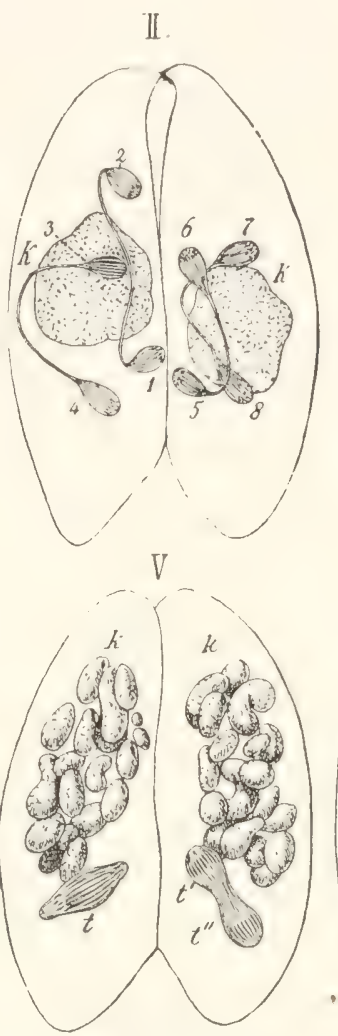

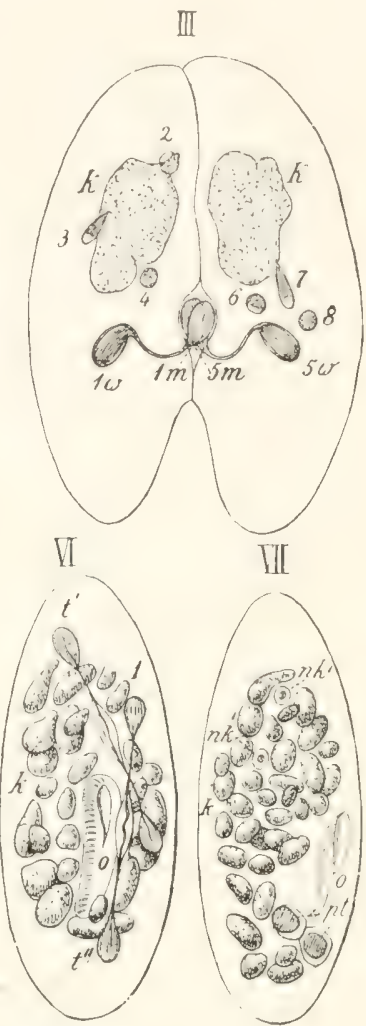

Fig. 261. Konjugation von Päramaecium. R. Hertwig, Zoologie. $n k$ Nebenkern, $k$ Hauptkern der konjugierenden Tiere.

I Der Nebenkern wandelt sich zur Spindel um, im linken Tier Sichelstadium, rechts Spindelstadium.

II Zweite T'eilung des Nebenkerns in die Hauptspindel (links mit $I$, rechts mit 5 bezeichnet) und die Nebenspindeln (links 2, 3, 4, rechts $6,7,8$ ).

III Die Nebenspindeln in Rückbildung (links $2,3,4$, rechts $6,7,8$ ), die Hauptspindeln teilen sich in männliche und weibliche Spindeln, links $I$ in $I m$ und $I z$, rechts 5 in $5 m$ und $5 w^{\prime}$.

IV Austausch der männlichen Spindeln nahezu vollendet (Befruchtıng); dieselben stecken noch mit einem Ende in ihrem Nuttertier, mit dem andern Ende haben sie sich mit der weiblichen Spindel des zweiten Paarlings vereint. $I m$ mit 5 ond $5 \mathrm{~m}$ mit $I z$. Hauptkern in Teilstiicke ausgewachsen.

$V$ Die aus Vereinigung von männlichen und weiblichen liernen entstandene primiire 'Teilspindel teilt sich in die sekundïren 'Teilspindeln $t$ ' und $t^{\prime \prime}$.

VI und VII Nach Aufhebung der Konjugation. Die sekundären Teilspindeln teilen sich in die Anlagen der neuen Nebenkerne $\left(n k^{\prime}\right)$ und die Anlagen des neuen Iauptkerns pt (I'lazenten). Der zerstückelte, alte Hauptkern füngt an zu zerfallen. (Da Paramaecium caudatum für die Anfangsstadien, P'. aurelia für die Endstadien leichter verständliche Verhältnisse bietet, wurde für $I$-III P. caudatum, für IV-VII P'. aurelia gewälltt. Der Unterschied beider Arten beruht darauf, đaß P'. caudatum 1 Nebenkern, P. aurelia deren 2 hat, daß bei letzterem der Kernzerfall schon auf Stadium $I$ beginnt). 
einen Hauptkern und einen einzigen Tehenkern besitzt, einfachere Verhältnisse als die meisten anderen Arten darbietet (Fig. 2261).

Wem die Neigung zu Kopulation eintritt, legen sich ,zwei Paramicien. zuerst mit ihren Vorderenden, spaiter mit ihrer ganzen ventralen

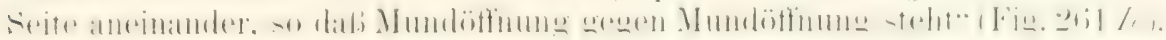
In der Nachbarschaft der letzteren bildet sich, wenn die Kopulation schon eine Zeitlang gedanert hat, eine feste Verwachsung in emem kleinen Bezirk aus. Mittlerweile hat schon der Kermapparat, der Hauptkern sowohl als anch der Nebenkern, tiefgreifende V'eränderungen erfahren.

Der Hauptkern vergöbert sich etwas, erhält zuerst eine unregel-

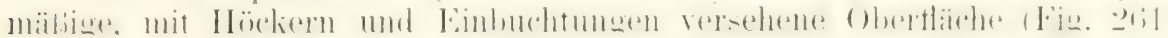
$I J-I V k)$, die Höcker wachsen zu längeren Fortsätzen aus, die sich spüter abschnüren und allmählich noch weiter in kleine Stïcke zerlegt werden ( $Y, T / k)$. Der ganze Hauptkern zerfällt auf diese Weise in viele kleine

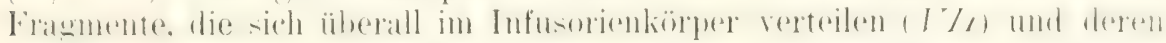
Schicksal, wenn wir den Vorgïngen gleich weit vorauseilen, schlieflich

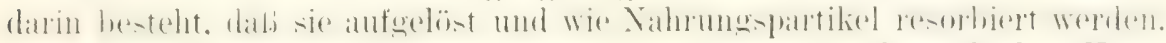
Nit einem Worte: der Hauptkern geht wähend und nach der Konjugation als ein Organteil, der seine Aufgabe ausgespielt hat. vollständig zugrunde.

Wïhrend der regressiven Metamorphose des Hauptkerns macht der kleine Nebenkern hochbedeutsame und stets in gleicher Weise wieder-

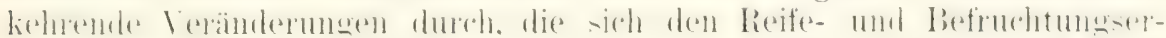

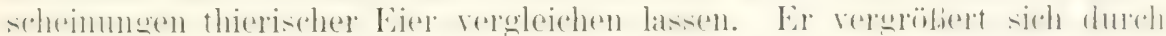
Aufnahme von Fliissigkeit aus dem Protoplasma, sein Inhalt nimmt eine faserige Beschaffenheit an und wandelt sich in eine lileine Spindel 1 m (Fig. 261 Ink). Die Spindel teilt sich, ihre Hälften gehen bald wieder

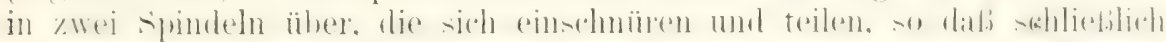
neben dem in Umwandlung begriffenen Hauptkern vier aus (lem Neben-

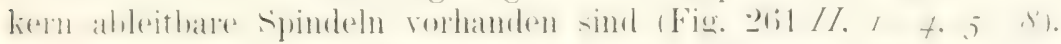

Von den vier Spindeln gehen im Laufe der weiteren Ereignisse drei, die Tebenspindeln, regehmäBig zugrunde (III, 2. 3. 4, 6. 7, 8). Sie wandeln sich in kleine Kü̈gelchen um. die schlieblich zwischen den

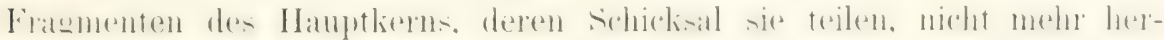
auszuerkemen sind. Sie erinnern an die Bildung der Polzellen bei der Reife der tierischen Eier und sind mit ihnen daher anch ron manchen Forschern verglichen worden.

Die vierte oder Hauptspindel allein (II, I u. 5) bleibt erhalten. sie vermittelt den befruchtungsprozeb und dient dann zur Neuerzeugung des ganzen Kernapparates im Infusorienkörper. Welche von den vier aus dem ursprünglichen Nebenkern ab-

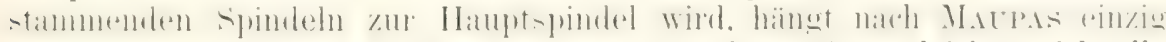
und allein von ihrer zufälligen Lage ab. In ihrem Ban gleichen sich alle

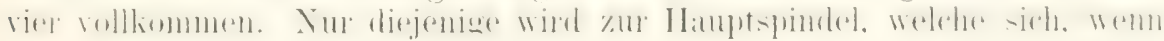
die obenerwähnte Verwachsungsbrïcke entstanden ist, in der gröbten Nïhe ron ihr befindet $(I I, I \quad$, 5). Sie stellt sich hier senkrecht zur Körperfläche ein, streckt sich in die Länge und teilt sich noch einmal in zwei Hälften (I/I, Iw U. Im, $5 \pi$ u. $5 \mathrm{~m}$ ).

Von den beiden 'Teilhälften enthält eine jede wahrscheinlich nur efwa halb so viel Spindelfasern und halb so viel chromatische Elemente. wie eine der früheren Spindeln. Nach diesen Beobachtungen von Richard

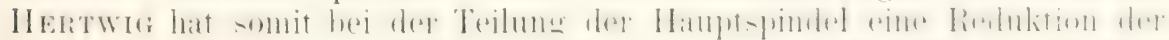
Spindelfasern auf die Hälfte stattgefunden; es, ist dadurch ein gleiches 
Verhälnis wie hei den Kemen der tierischen und der ptlanzhchen Geschlechtszellen geschaften worden. Die so gekennzeichneten Kerne spielen dem auch dieselbe Rolle wie Li- und Samenkern und werden daher als näinnlicher und weiblicher Kern oder als Wanderkern und stationärer Kern roneinander unterschieden.

Welcher ron den beiden Kernen Wanderkern oder stationärer liern ist. Jabt sich an der Struktur und stofflichen Zusammensetzung wierler nicht erkennen, sondern hängt eimzig und allein von der Lage und ver dadurch hedingten Verwendung beim Befruchtungsprozeb ab. So werden demn die der Verwachsmgsstelle zunächst gelegenen Teilhälften (III. Im u. 5 m) zu den Wanderkernen; sie werden zwischen beiden kopulierten Tieren ausgetauscht, indem sie sich auf der zu diesem Zweck gebildeten Protoplasmabrïcke aneinander vorbeischieben. Während des Austausches besitzen die männlichen Wanderlierne Spindelstruktur (IV, $5 \mathrm{~m}, \mathrm{Im})$. Nach dem Austausch verschmilzt ein jeder mit dem ebenfalis spindeligen, stationären oder weiblichen Kern $(I \bar{V}, I \pi, 5 \pi)$, so dab nun jedes Tier, abgesehen von den Fragmenten des Hauptlierns und den Nebenspindeln, welche dem almählichen Untergang verfallen sind, nu eine Spindel. die T'eilsuindel, besitzt ( $V t)$.

Die Übereinstimmung mit den Befruchtungsvorgängen der Tiere und der Phanerogamen ist eine frappante. Wie bei diesen

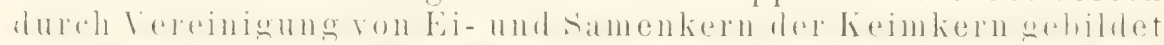

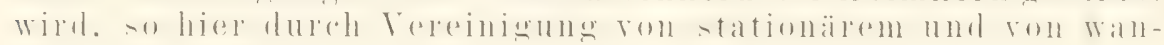
derndem Kern die Teilspindel. Dieselbe dient zum Ersatz des alten, in Auflösung hegriffenen Kernapparats. Sie nimmt an Cröße beträchtlich zu (Fig. 261 Vt). Die chromatischen Elemente ordnen sich in

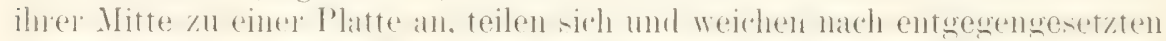

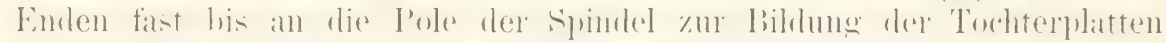
auseinander ( $V$ rechts $\left.t^{\prime} t^{\prime \prime}\right)$. Die beiden 'Teilhälften bleiben noch längere Zeit durch einen Verbindungsfaden in Zusammenhang. Sie wandehn sich damn meist auf Umwegen in Haupt- und Nebenkern um; bei Paramaecium aurelia (Fig. 261 VI) z. B. wiederholen die aus der primären Teilspindel hervorgegangenen 'Tochterspindeln ( $t^{\prime}$ und $t^{\prime \prime}$ ) noch eimmal den Teilungsakt mol liefern so vier Kerne ( $Y I I)$, von denen zwei zu Nebenkernen (nk', $\left.n k^{\prime \prime}\right)$ wer(len, während die zwei andern zum Hauptliern verschmelzen $(p t)$. So führt bei den Infusorien, ,die Befruchtung zu einer vollkommenen Neugestaltung des Kernapparats und damit auch zu einer Nenorganisation des Infusol's" (Richard Hertwig).

Küuzere oder längere Zeit nach dem Austausch der Wanderkerne tremnen sich die Paarlinge voneinander (Fig. 261 VI und VII). Bei den getrennten Individuen nimmt die Resorption der unbrauchbaren Kiernteile mul ihr definitiver Ersatz durch Nengestaltung noch einen längeren Zeitraum für sich in Anspruch. Die so ., verjüngten Individuen" haben darauf

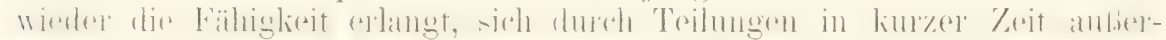
ordentlich zu vermehren. his wieder die Notwendigkeit für eine neue "Konjugationsepidemie" eintritt. Die Befruchtungsperiode bedeutet im Leben der Infusorien zugleich einen länger dauernden Stillstand in ihrer Vermehrung, wie MAUPAs an einem Beispiel treffend gezeigt hat. Bei Onychodromus grandis dauert dieselbe rom Beginn der Konjugation bis zur ersten 'Teilung 6\%, Tag bei einer Temperatur ron 17 bis 18 Grad.

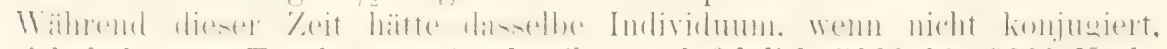
sich bei guter Ernährung 13mal teilen und folglich 7000 bis 8000 Nachkommen hervorhringen liönnen. 
Bei den meisten Infusorien, wie in den hier heschriehenen Fiillen, verhalten sich die kopulierenden Individuen emander wleichwertig: jedes ist in bezug anf das andere sowohl mämmlich als weiblich, sowohl hefruchtend als empfangend. Festsitzente Formen der Infusorien, wie die lortizellen etc.. zeigen indessen eine interessante Abweichumg vom urspringlichen lerhalten.

Is Beispiel diene Epistylis umbellaria (Fig. oㅡ). Leim Heramahen einer Konjugationsperiode teilen sich manche Individuen der Vortizellenloolonie mehrmals lasch hinteremanter mul liefern so eine Vachlommenschaft $(r)$, die an Gröbe hinter dem Muterorganismus weit zurückhleiht. Andere Individuen des stöckehens bleiben ungeteilt und von normaler (iröre. Man muterscheidet beirle vonemander. die elsteren als Mikrogameten. die letzteren als Malirogameten. beide sind jetzt in einen geschlechtlichen (iegensat\% zu eimander getreten.

Die Mikrogameten lösen sich ron ihren stielen ah. schwimmen in Wasser umher und setzen sich nach einger \%eit an eine Malirogamete an. um mit iln zu kopulieren (Fig. 262\%). An ilem Kermapparat der Parlinge gehen hierauf ähnliche Veränderungen vor sich, wie sie für Paramaecimm ausfülılicher geschildert wurden. Auch hier werden die Wanderkerne ausgetauscht. Damm aber entwickelt sich nur die Makrogamete weiter. indem Wanderkern und stationärer Ker'n zur primären T'eilspindel verschmeizen. während sie in der Mikrogamete gleichsam wie gelähmt sind und, anstatt zu verschmelzen und sich weiter zu entwickeln, gleich den Fragmenten des Hauptkerns und den Nebenspindeln. rüickgebildet und aufgelöst werden. Infolgerlessen verliert die Milirogamete ilıre selbståndige Individualität und wird

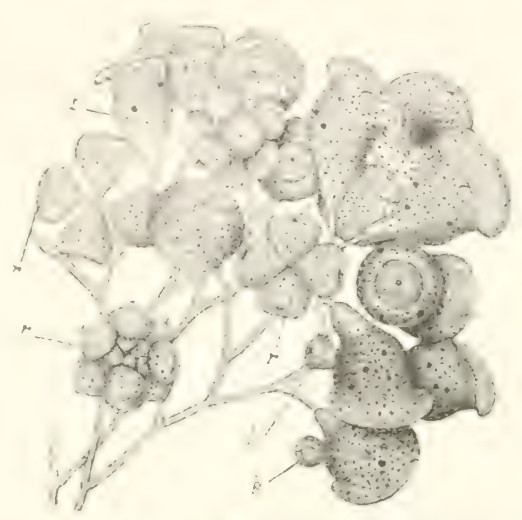

Fiu. 20 6 . Epistylis umbellaria narli fir.dEFE. Ans IR. Hertrici.

Teil einer in ,knospenförminger Konjugation" begriffenen Lobonie.

Dis: dureh Teilume entstandeners Mikirospotes. $k$ Mikrogameten in lionjugation mit den Makrogameten. allnählich in die Makrogamente mit aufgenommen, zu deren Vergröberung sie beiträgt.

So hat sich infolge der festsitzenden Lebensweise bei den Vortizellen ein eigentümlicher (ieschlechtsclimorphism us ausgebildet: derselbe hat den Untergang des kleineren der liopulierenden Individuen zur Folge. nachdem es gewissermaben als männliches Element die Malirogamete hefruchtet hat. Doch trifit del Vergleich mit Ei- und Samenfarlen nur teilweise zu, da ja auch hei den Vortizellen wie hei den Paranübien lie liefruchtung mit einem wechselseitigen Austausch von liermuaterial beginnt und nur im weiteren Verlanf zu einseitiger Entwicklung fülnt.

41 Die verschiedene Form der Geschlechtszellen, die Äquivalenz der beim Zeugungsakt beteiligten Stoffe und die Begriffe .mannliche und weibliche Geschlechtszellen".

Nachlem an verschienlenen Beispielen nacherewiesen ist. dab im Verlant des Befruchtumgsprozesses und namentich im lerhalten der licrne eine prinzipielle Übereinstimmung zwischen l'ieren. I'Hamzen ma Protozoen besteht. soll jetzt auch ein Unterschied, welcher zwischen den beiden zum 
liefinchtungsakt sich vereinigenden Zellen bei den meisten Organismen wahrgenommen wirl, schärfer in das Auge gefast und seine Bedeutung genauer festgestellt werden. - Der Unterschied betrifft die ungieiche Gröbe und Form der weiblichen und der männlichen Keimzellen. Weiblich nennt man diejenige Zelle, welche größer, unberveglich und daher die empfangende ist: im Gegensatz zu ihr ist die männliche Zelle viel kleiner. oft verschwindend klein; entwerler ist sie beweglich, so dab sie sich aítiv der Eizelle durch amöboide oder Geißelbewegung nähert und die Be-

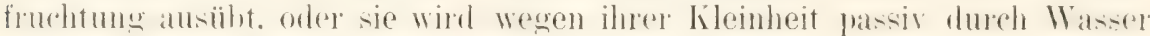
orler Luft zur Eizelle hingeführt.

Was für eine Berleutung hat dieser Unterschied! Hängt ei' mił dem IVesen der liefruchtung selhst zusammen oder ist er durch Momente nehensächlicher und sekundärer Art hervorgerufen worden? Es ist von prinzipheller Wichtigkeit fïr die Entscheidumg dieser Frage dab wir genau feststellen, anf walche Stoffe und Formteile sich die Verschiedenheit der heilerlei (reschlechtszellen erstreckt.

Je(le Zelle besteht aus Protoplasma und Kernsubstanzen. Von diesen ist das Protoplasma, wie der Augenschein sofort lehrt, zuweilen in außerordentlich ungleicher Menge in den beiderlei fieschlechtsellen vorhanden:

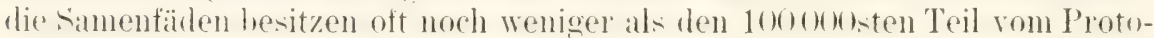
plasma des Eies. So beträgt nach einer Schätzung von THüret das Ei von Fucus an Masse so viel. wie 30-60000 Samenfüden derselben Art. Zwischen tierischen dieschlechtsproduliten aber sind die I'nterschiede gewöhnlich noch unendlich viel größere, besonders in den Fällen, wo die Fizellen mit Revervestotfen. wie Fettlïgelchen. Dotterplittchen ete. reichlich helarlen sind. liei trpisch ausgel,ildeten samenfärlen kamn die Anwesenheit von Protoplasma überhaupt in Zweifel gezogen werden; denn der an das Mittelstäck sich ansetzende Sichwanzanhang ist kontralitile sulstanz, ist wie die Muskelfibille ein I)ifferenziermespodukt des Protoplasmas der Samenzelle. Unreifen Samenfäden sitzt das Protoplasma noch in Form größerer und kileinerer Tropten an. die hei der vollstänligen Reife aufgehraucht. eventuell auch abgestreift werden.

Das Gegenstiick zum Protoplasma biklen in ihrem Verhalten die Kernsubstanzen. Mögen Ei und Samenfaden an Größe auch noch so sehr voneinander abweichen, so enthalten sie doch stets äquivalente Mengen von wirksamer Kernsubstanz. Wenn die Richtigkeit oliger Behauptung auch nicht direkt aus einer einfachen Vergleichung der beiden feschlechtszellen hervorgeht, so lälit sie sich doch aus dem Verlaut des liefruchtumgsprozesses und aus der libdungsgeschichte der reifen Ei- und Samenzelle erweisen. Denn Ei- und Samenkern enthalten die gleiche Masse von Chromatin und sind beim Reifeprozeb aus einer sleich grolien Kahl von liernsegmenten gehildet worden. Der Samenkern ron Ascaris megalocephala bivalens z. B. entsteht wie der Eikern aus zwei Kernsegmenten der Mutterzelle; jeder von ihnen trägt somit bei der Befruchtumg zu gleichen Teilen zur Bildung des Keimlerns hei (Fig. 24:3, 5).

Unserer Beweisführung könnte man entgegenhalten, daß die Kernteile von Ei- und Samenzelle vor jhrer Vereinigung gewöhnlich ein unsleiches duschen mul ane hald mehr, hald minder anffälige Verschiedenhesit in ihrer (iroblie darbieten. I)as erklart sich aber in einfacher Weise darans, dab der wirlismen Kernsulstanz Hüssige Substanz bald in gröberer, bald in geringerer Menge beigemischt sein kann. Der sehr kleine Kopf des samenfadens besteht ans ziomlich linmuaktem und daher stark färhharem Chromatin. In dem viel gröberen Eiliern ist die äquivalente Menge 
von Chromatin mit viel Kernsaft durchtränlit und in dem Saftraum in feinen Kärnchen und Fäden verteilt, so (lab) sich der Fikern als fanzes nur sehr wenig färbt und wenig lionsistenz besitzt.

Der Unterschied in Gröbe und honsistenz, zwischen lid- nnd Samenkern gleicht sich beim Ablauf der inneren Befruchtumgserscheinumgen gewöhnlich bakl aus: denn der anfangs kleine Samenkern schwilt durch Autnahme von Flïssigkeit aus dem Dotter rasch zu derselben Gröbe wie der Eikern an, während er zu diesem hinwandert (Fig. 24:5), wie die meisten Wïrmer. Mollusken. Wirbeltiere lehren. In selteneren Fïllen freilich sind die beiden Kerne. wenn sie sich unteremander verbinden, verschieden groli. wie bei den Eiern der Seeigel (Fig. 2.39, 3 u. f); dann hat der Samenkern eben eine geringere Menge von Saft als gewöhnlich in sich aufgenommen und besteht aus einer dichtern Substanz, so dab wir trotz der Gröbenverschiedenheit eine Äquivalenz der festen, wirksamen Bestandteile annelimen diurten.

An geeigneten Objekten läbt sich beweisen, dal die ungleiche Grölie von Ei- und Samenkern wesentlich mit bedingt wird duch den Zeitpunkt. in welchem die Fizelle befruchtet wird. ob vor. während orler nach der Bildung der Polzellen. Wenn z. B. zum Ei von Asteracanthion Samen während der Entwicklung der Polzellen zugesetzt wird, so mub der Samenkern bis zum Eintritt der Verschmelzung längere Zeit im Dotter verweilen und schwilt mittlerweile durch Aufnahme von Kernsaft zu derselben Grölie wie der Eikern an, welcher sich nach der Abschnürung der zweiten Polzelle bildet. Wenn dagegen die Befruchtung erst später erfolgt zu einer Zeit. wo die Eizelle schon mit Polzellen und Eikern versehen ist. so verweilt der Samenkern als selbständiger Körper nur wenige Minuten im

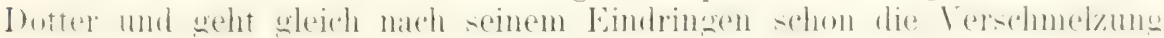
mit dem Eikern ein. Er bleibt dann klein. da er sich in diesem Falle nicht in demselben Mabe wie sonst mit Kernsaft hat durchtränken kömnen.

Wir können somit den wichtigen Satz als bewiesen ansehen. dab die beiden Gieschlechtszellen trotz ihres oft auberordentlich verschiedenen Aussehens und trotz ihres so moleichen Gehaltes an Protoplasma doch genan äquivalente Mengen von Kernsubstanz (Chromatin in einer bestimmten

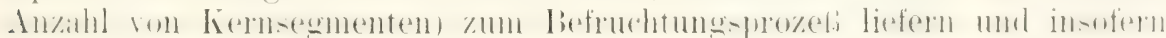
einander genau gleichwertig sind.

An diesen Sat\% schliebe ich gleich die These an: die Kernsubstanzen, die in äquivalenten Mengen ron zwei rerschiedenen Individuen abstammen. sind die besonders wirksamen stoffe. aut deren Vereinigung es beim Befruchtungsakt hauptsächlich ankommt; es sind die eigentlichen Befruchtungsstoffe. Alle anderen Substanzen (Protoplasma, Dotter, Kernsaft etc.) laben eine mehr untergeorinete Bedentung.

Die These läßt sich durch zwei wichtige Verhältnisse unterstützen.

Eimmal lassen sich zu ihren Gunsten die komplizierten Vorbereitungs-

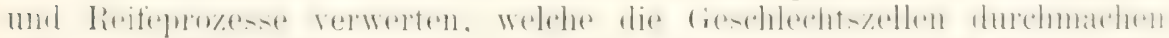
müssen. Wie aus der auf S. 280 - 282 gegehenen Darstellung hervorgeht. soll durch sie wohl hauptsächlich nur das eine erreicht werden, dab durch

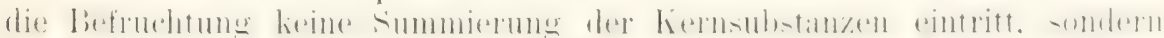
das für die betreffende 'Tier- und Pflanzenart hestimmte Maf ron Kernsubstanz eingehalten wird.

Zweitens sprechen für die These die Befruchtungsvorgänge bei den Infusorien. Hier sind es, wie MaUpas und Richard HERTwig in übereinstimmender Weise hervorheben, gleichwertige Individuen, welche sich num 
vorühergehend aneinander legren, um Teilhälften gleichwertiger Keme mitcinander auszutauschen. Wit dem Austausch der Wanderkerne ist die liefruchtumg heendet. Damn trennen sich die Paarlinge wieler. Das Endergebnis der verwickelten Voroünge hesteht hier offenbar darin. daf., wenn Wanderliern mud stationärer liern verschmolzen sind, der Ki ermaprarat cines jeden befruchteten Individums aus Kernsubstanz von doppelter Herkunf zusammengesetzt ist.

Wenn hei der Befruchtung die lierne die hauptsächlich wirlisame Substanz bergen, damn liegt die Frage nahe, ob die Kernsubstanz des Samenfadens etwas anderes ist als die Kernsubstanz der Eizelle. Die Frage ist in sehr verschiedenem Simme beantwortet worden: namentlich in früheren Jahrzehnten hat die Ansicht vorgeherrscht, dab durch den Samenfaden. wie SACHS sich aushliuckt, in die Eizelle doch eine Substanz hineingetragen werde. rie in ihr noch nicht enthalten sei. Namentlich hat eine Ansicht Beifall gefunden. welche man als die Lehre vom Hermaphroditismus der Kerne und als die Ersatztheorie bezeichnen kam.

Viele Forscher lassen die Körperzellen hermaphrodite lierne. i. h. Kerne besitzen, welche sowohl männliche als weibliche Eigenschaften haben. Unreife Ei- und Samenzellen - so lautet z. B. die am klarsten ausgeführte Hypothese von vAN BENEDEN — sind hermaphrodit: sie gewimnen ihren Geschlechtscharakter erst darhurch, dab sich die Eier der mämnlichen mol die Samenzellen der weiblichen bestandteile ihres hermaphrodit angelegten Kernapparates entledigen. Vom Ei werden die mämnlichen Bestandteile seines Kerns in den Kernsegmenten der Polzellen entfernt. Bei den Samenzellen geschieht das Ungekehrte durch einen entsprechenden Prozeh. Fi- und Samenkern sind dadurch Halbkerne (Pronuclei) mit einem entgegengesetzten Sexualcharakter geworden.

Ton diesem (iesichtspunkt ans betrachtet, besteht das ITesen der Befruchtung in einem Ersatz der aus dem Ei ausgestobenen, männlichen Elemente durch gleich viel neue mämnliche Elemente. welche durch den Samenfaden wierler eingefiulirt werden.

Die Lehre rom Hermaphroditismus des Kerns und die mit ihr zusammenhängende Ersatztheorie läbt sich bei genauerel Prüfung nicht aufrecht erhalten. Denn sie hat ihre empirische Grundlage, auf welcher sie aufgebaut war. durch den auf S. 279 geführten Nachweis verloren. dab die Polzellen morphologisch nichts anderes sind als rudimentär gewordene Eizellen. Es ergibt sich dies aus einem Vergleich der Ei- und Samenbildung bei den Nematolen. Daher kömmen die in den Polzellen aus dem Ei entfernten Kernsegmente auch nicht die ausgestobenen männlichen Bestandteile des Keimbläschens sein, wie es durch die Ersatztheorie behauptet wirile.

Hiervon abgesehen, läbt sich mit den uns zu Gebote stehenden Untersuchungsmitteln auch nicht die geringste Verschierlenheit zwischen den Kernsubstanzen der mämnlichen mol der weiblichen Zelle aufilecken. Beide sind nicht nur ihrer Masse nach, sondern anch stoftlich einander gleich; sie sind nur insofern rerschieden. als sie ron zwei verschiedenen Individuen abstammen.

Wenn demnach ein geschlechtlicher (iegensatz im Sinne der Ersatztheorie zwischen Eikern und Samenkern in Abrede gestellt werden muls, was für cine Bedentung haben dann noch die Begriffe: männliche und weibliche (reschlechtszelle, männlicher und weiblicher liern? Wie kommt es, lab sich zwischen den im Befruchtumgsakt zusammentretenden zwei Zellen so anffällige Unterschiede in jhrer Gröhe und Form ausgebildet haben? 
Hier dürfte folgendes zur Orientierung dienen: Bei der Bildung eines entwicklungstähigen lieimes. der dureh Veremigung zweier Zellen entsteht. kommen zwei Homente in Betracht, die miteinander konkmrieren und in emen Gegensat\% zneinander stehen. Erstens mïssen die zwei Zellen. dio sich zu einem Mischprodukt, einer gemischten Anlage, vereinigen, selher in der Lage sein. sich aufzusuchen und zu verbinden. Wweitens abep int es auch von Wichtigkeit, wenn sich der Entwicklungsprozel. eincs ()rganismus in einem kurz bemessenen \%eitram abspielen soll. dal. gleich von Anfang an viel entwickhngstaihge Sulstanz vorhander: ist und nicht erst auf dem zeitraubenden Umweg der Ernähnung von den sich bildenden und difterenzierenden Embryonalzellen selbst herbeigeschatft zu werden braucht.

Lm der ersten Aufgabe zu genügen. müssen die Zellen beweglich und daher alitiv sein: für die zweite Aufgabe dagegen müssen sie entwicklungstïhige Sulostanz ansammeln, sie müssen daher an (irölje zunehmen. was naturgemäl, eine Becinträchtigung ihrer Beweglichleit zur Folge hat.

So konkurrieren zwei Nomente mitemander, von denen das eine die Zelle beweglich und alitiv, das andere dagegen unbeweglich mol passiv zu machen sucht. I) Natur hat beide Aufgaben gelöst. indem sie Eigenschaften, die ihrem Wesen nach in einem Körper mvereinbar, weil gegensätzlich zueinander sind. nach dem Prinzip der Arbeitsteilung auf die beiden zum Befruchtungsalit verbundenen Zellen verteilt lat. Sie hat die eine Zelle alitir und befruchtend. d. h. mämnlich. die andere Zelle dagegen fassir und empfangend. d. h. weiblich' gemacht. Die weibliche Zelle oder das Ei hat die Aufgabe übernommen. für die Substamzen zu sorgen. welche zur Ernährung und Vermehrung des Zellprotoplasmas hei einem laschen Ablauf der Entwicklungsprozesse erforderlich sind. Sie hat daher während ihrer Entwicklung im Eierstock Dottermaterial aufgespeichert und ist dementsprechend groß und umbeweglich geworden. Der mämnlichen Zelle dagegen ist die zweite Aufgabe zugefallen. die Vereinigung mit der ruhenden Eizelle herbeizuführen. Sie hat sich daher zum Zwecke der forthewegung in einen kontraktilen Samenfaden mugebildet und hat sich, je rollkommenes sie ilmer Aufgabe angepabt ist. um so mehr aller Substanzen entlerligt. welche. wie \%. I). (las Dottermaterial orler selbst das P'rotoplasma. diesem Hauptzweck hinderlich sind. Dabei hat sie zugleich auch eine form anwenommen, welche für den Durchtritt durch die Hüllen, mit welchen sich dis Ei zum Sehut\% umgiht, und für das Eimbohren in den Dotter die zwechmäbigste ist.

Von den so seschlechtlich difterenzierten Zellelementen liönmen wir die Ansdrüche ..männlich und weiblich" ant die in ihnen enthaltenen lierne übertragen, auch wemn diese an Masse und () ualität ihrer Substanz einander äquivalent sind. Nor dürfen wir unter der Bezeichnung: männlicher und weiblicher liern nichts anderes verstehen als eimen Kiern. der von einer männlichen oder weiblichen Zelle abstammt. Auch bei den Infusorien kann der Wanderkern als männlich. der stationäre Kern als weiblich im Simne der frïher gegebenen Definition hezeichnet werden. insofern der erstere den letzteren aufsucht.

Der (iegensat\% der sich zwischen den (ieschlechtszellen durch Arbeitsteilung und Anpassung an entgegengesetzte Aufgaben entwickelt hat. wiederholt sich in ganzen Organismenreich in allen den Fiallen, wo die Individuen. in welchen sich die männlichen und weiblichen (reschlechts\%ellen entwickeln. durch Sexualcharaktere untershieden sind. In allen das reschlecht hetreftenden Eimrichtungen wird ein und dasselbe Thema variert: eimmal

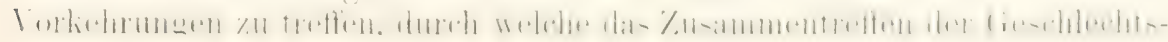


zellen ermöglicht wird, und zweitens für Einrichtungen zu sorgen, durch welche das Ei ernährt und geborgen wird. Das eine nennen wir männ-

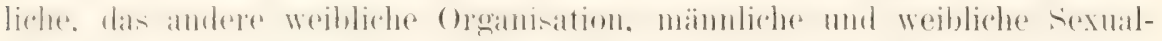
charaktere. Alle diese Verhälnisse sind sekundärer Art und haben mit dem eigentlichen Wesen des Befruchtungsvorganges. Welcher eine Veremi-

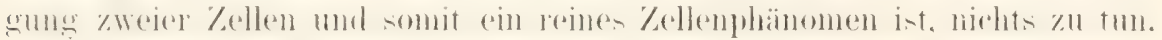
Hierin stimmen wir mit Weismann, Richard Hertwig, Strasburger

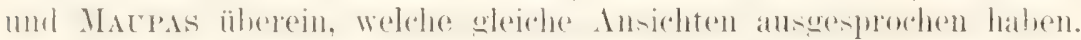

Die Befruchtung ist also eine Vereinigung zweier Zellen und insbesondere eine Verschmelzung zweier äquivalenter Kernsubstanzen, die von zwei Zellen abstammen, aber sie ist nicht ein Ausgleich sexueller Gegensätze, da diese nur auf Einrichtungen untergeorlneter Art beruhen.

Die Richtigkeit obigen Satzes läht sich noch besser, als es bisher geschehen ist, beweisen, wenn wir die Zeugungsprozesse im ganzen Orga-

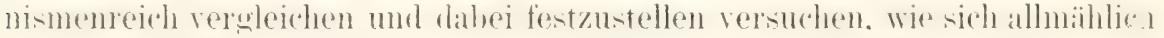
Verschiedenheiten zwischen den zur Befruchtung verbundenen Zellen en iwickelt haben. Die Reiche der Einzelligen und der Pflanzen liefern uss

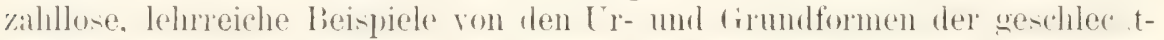
lichen Zeugung und von der Entstehung del'Geschlechtsdifferenzen: $m$ 'Tier- und Pflanzenreich.

\section{5) Die Ur- und Grundformen der geschlechtlichen Zeugung und das erste Hervortreten von Geschlechtsdifferenzen.}

Das Studium der niedersten Organismen, der Noctilucen, Diatomeen, Gregarinen, Konjugaten und anderer niederer Algen lehrt, daß bei vielen von ihmen in regehmäßigen Zyklen Verschmelzungen von zwei Individuen eintreten, die wir als rimen befruchtungsmozel. deuten kömen.

Bei den Noctilucen beginnt die Konjugation damit, daß zwei gleich groblie. in nichts romemander untershierlene Individuen sich mit ihren Mundöftnungen zusammenlegen und von hier aus unter Auflösung der Zellmembran verschmelzen. Es bilket sich zwischen ihnen eine immer breiter werdende Verbindungsbrïcke aus, nach welcher die Protoplasmamassen von allen Seiten zusammenströmen, bis aus beiden Individuen eine grole Zellblase entstanden ist. Die beiden Kerne, ein jeder von einem Zentralkörperchen begleitet, wander'n aufeinander zu und legen sich aneinander, verschmelzen aber nicht, wie uns die Untersuchungen von IsHikawa berichten (XI 1891). Nach einiger Zeit teilt sich das konjugierte Noctilucenpaar wieder durch Auftreten einer Scheidewand in zwei Zellen. Bei Begim dieser Teilung strecken sich auch die beiden zu einem Paar verbundenen Kerne, werden in ihrer Mitte eingeschnürt und halbiert und weichen bei ihrer Tremnung so auseinander, dab die Hälften von jedem liern in je eines der beiden Teilstücke der Noctiluca zu liegen kommen. So gehen aus dem Lopulationsprozeb wieder zwei Individuen hervor, von denen jerles Kernsubstanz doppelten Ursprungs besitzt. Auf die Befruchtung folgt damn nach kürzerer oder längerer Zeit lebhafte V'ermelıung durch Knospung und Schwärmerbildung.

Besonders wichtig für das Studium der Grundformen der Befruchtung ist die Ordnung der Konjugaten (FALKEnberg XI 1882), die wieder in

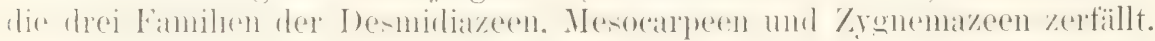

Bei zwei Arten ron Desmidiazeen, bei Closterium und Cosmarium, hat KLEBAHN (XI 1S90) auch feinere Details des Befruchtungsrorgangs 


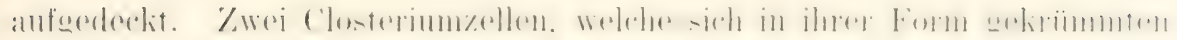
Spindeln vergleichen lassen, legen sich tler Lïnge nach aneinander. wohei

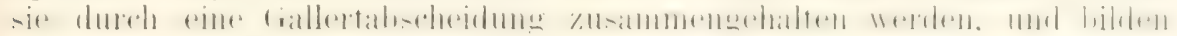
damn in ihrer Mitte eine Ausstülpung. Beide Ausstülpungen berïhren sich in größjerer Ausdehmung und verschmelzen unter Auflösung der sie trennenden Scheidewand zu einem gemeinsamen Kopulationskanal. In diesem sammelt sich allmählich das gesamte Protoplasma der beiden honjugierten Closterimmellen an, inlem es sich von (ler alten Zellmembran ablöst, und verschmilzt, dabei zu einem einheitlichen, kugligen liörner, der sich zuletzt noch mit einer eigenen Membran ungibt. Die so (lureh Verschmelzung zweier gleichartiger Individuen entstandene Kiopulationsspore oder Zygote macht ein mehrere Monate dauerndes Ruhestadium durch (Fig. 26:3). Sie besitzt zwei Kerne, die von den gepraaten Zellen

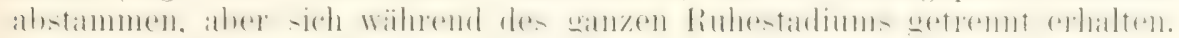
Erst mit dem Wiederbegimn einer neuen Vegetationsperiode in Fribliahr

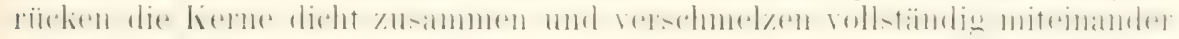
zum Keimkern.

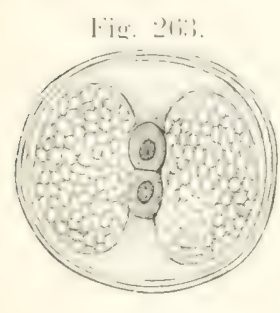

Fie. - Sti.i.

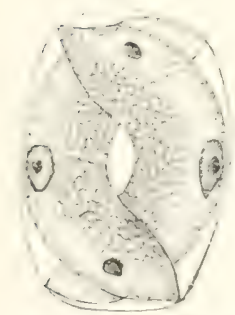

Tig. 263. Zygote von Closterium kurz vor der Keimung. Nach KL.sb.4Fx, Taf. Nill, Fig. '3.

Ïig. 26t. Verschiedene Keimstadien von Closterium. Nach LiLlBAH: Taf. XIII, Fig. (ib, S, (9, 11, 13 .

lig. 265. Zwei aus einer Kopulationsspore entstandene Closterien vor dem Verlassen ihrer Hülle.

Zn dieser Zeit schlïpft die 'Zygote, von einer feinen Hant umgeben. aus der alten Zellulosehiille aus: ihr Kemkern wandelt sich in eine grofie

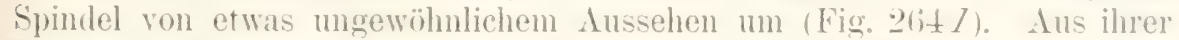
T'eilumg bilden sich darauf (Fig. $26+/ /$ ) zwei Spindelhiilften. (lie aber nicht in das Stadium des ruhenden Kerns eintreten. sondern sich sofort noch zu einer zweiten Teilung anschicken (Fig. $2(5+$ III). So entstehen aus dem Keimkern dureh zwei, ohne Pause aufeinanderfolgende Teilungen vier Kierne (Fig. $2(i+/ V)$. Währenddem hat sich auch der Protoplasmakörper der Zygote in zwei Halbliugeln (Fig. $26+/ V$ ) geteilt. von denen eine jerle zwei aus 'Teilung einer Spindel hervorgegangene Kerne einschlieft. Die heiden líerne gewinnen rasch ein verschiedenartiges Aussehen, indem der eine 
(der Grobkern nach líEBAIN) groß und bläschenförmigr wird, der andere (der Kleinkern), Klein bleibt, sich besonders intensiv färbt und später spurlos verschwindet. Wie mir scheint, geht der Kleinkern zugrunde und löst sich auf. ähnlich wie die Bruchstücke des Hauptkerns und die Nebenspindeln hei Infusorien. Noch ehe die Auflösung beendet ist, nehmen die beiden 'Teilhälften der Krgote allmählich die Form einer gewöhnlichen Closteriumzelle an (Fig. 265).

Was haben die dopyelten. ohne Pause aufeinander folgenden 'T'eilungen des Keimkerms für eine Berleutung? Mir scheint durch sie derselbe Zweck. wie durch die Reduktionsteilung bei der Reife der Ei- und Samenzelle, nur in einer etwas anderen Weise, erreicht zu werden. Wie hier vor der Befruchtung durch die doppelte T'eilung des Kierns eine Reduktion der Kernsubstanz auf die Hälfte eines Normallierns herbeigeführt und so eine Summierung der liernsubstanz durch Verschmelzung zweier Kerne infolge der Befruchtung verhindert wird. so scheint mir bei den Desmidiaceen erst nach der Befruchtung eine Reduktion der Kernsubstanz noch nachträglich vorgenommen und die durch die Kopulation zweier Vollkerne herrorgerufene Verdoppelung der Kermmaße wiedev zum Normalmaß zuzückgefiihrt zu werilen. Der Keimkern wird anstatt in zwei Tochterkerne durch sich ummittelbar folgente T'eilungen in vier Enkelkerne zerlegt, also

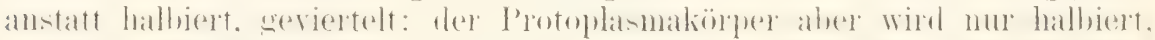
mul jerle T'rilhälfte erhält nur einen in Funktion tretenden liern, während zwei der vier Kerne als entbehrlich geworden zugrunde gehen.

Durch eine genaue Zählung der Kernsegmente in den verschiedenen Stadien mübte sich meine Anmahme zur Gewißheit erheben lassen. Zu ihren Gunsten läßrt sich vorläutig eine von KLEBAHN häutig gemachte Beobachtung anführen, daß bei Cosmarium die vier rom Keimkern ab-

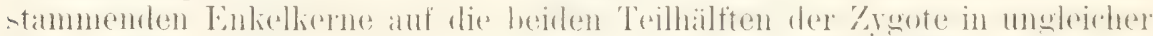

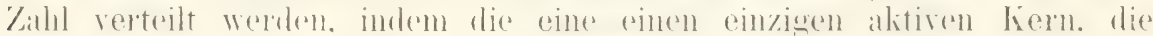
andere drei lierne enthält, von denen zwei rüickgebildet werden. Bei den zwei dem Untergang verfallenen Kernen ist es eben gleichgültig, ob sie beiden orler nur einer Zelle bei der Teilung zufallen: sie verhalten sich dabei wie Dottereinschlüsse.

Während bei den Desmidiaceen Kopulation isoliert lebender Zellen beobachtet wirk, lehren uns die Zygnemaceen. wie sich die Kopulationsprozesse auch bei Zellkolonien abspielen können, bei denen viele Einzelzellen zu langen Färlen in einer Reihe untereinander verbunden sind. Wenn in dem dichten Fadenfilz, mit welchem die Alge die Gewässer iiberzieht, zwei Fïlen eine längere Strecke nahe bei einander liegen, kommt es zwischen benachbarten Zellen zu Konjugationen. Gewöhnlich treten alle Zellen gleichzeitig in die Vorbereitung zur Fortptlanzung ein: sie treiben seitliche Ausstülpungen einander entgegen. Diese verschmelzen an den Berïhrungsstellen, indem sich die Scheidewand auflöst, und stellen so quere Kanäle dar, welche in regelmäbigen Entfernungen die beiden in lionjugation begriffenen Fäden wie die Sprossen einer Leiter rerbinden (Fig. 266). Die Protoplasmakörper ziehen sich darauf von der Zellulosewand zuriick und rerschmelzen nach einiger Zeit untereinander.

Bei verschiedenen Arten der Zygnemaceen zeigt sich hierbei ein an und für sich geringfügiger, aber gerade dadurch interessanter und be-

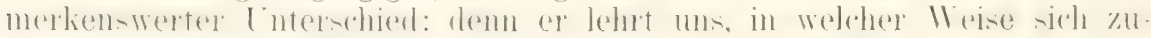
erst Geschlechtsdifferenzen ausbilden können. Bei Monjeotia z. 13. treten

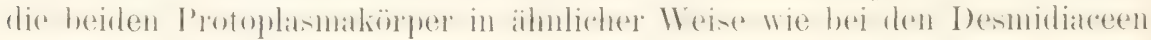
in den Kiopulationskanal ein und verschmelzen hier untereinander zu einer 
Zygote. die sich kugelig abrundet, Flüssigkeit ausprebt und mit einer Membran ungibt. In diesem Fall verhalten sich beide Lellen genau gleichartig: man kann weder die eine noch die andere als mänlich oder weiblich bezeichnen.

Bei anderen Arten. wie bei Spirogyra (Fig. 26(i). bleibt die eine Zelle passiv in ihrer Zellhaut liegen und wird ron der anderen Zelle. welche daher als die mämnliche bezeichnet werden kam, aufgesucht. Diese nämlich wandert in den Kopulationskanal ein und durch ihn hindurch zu der weiblichen Zelle hin, als ob sie ron ihr angezogen wïrte. und verschmilzt mit ihr zur Zygote (Fig. 26(5-La). Durch Behandlung mit Rea-
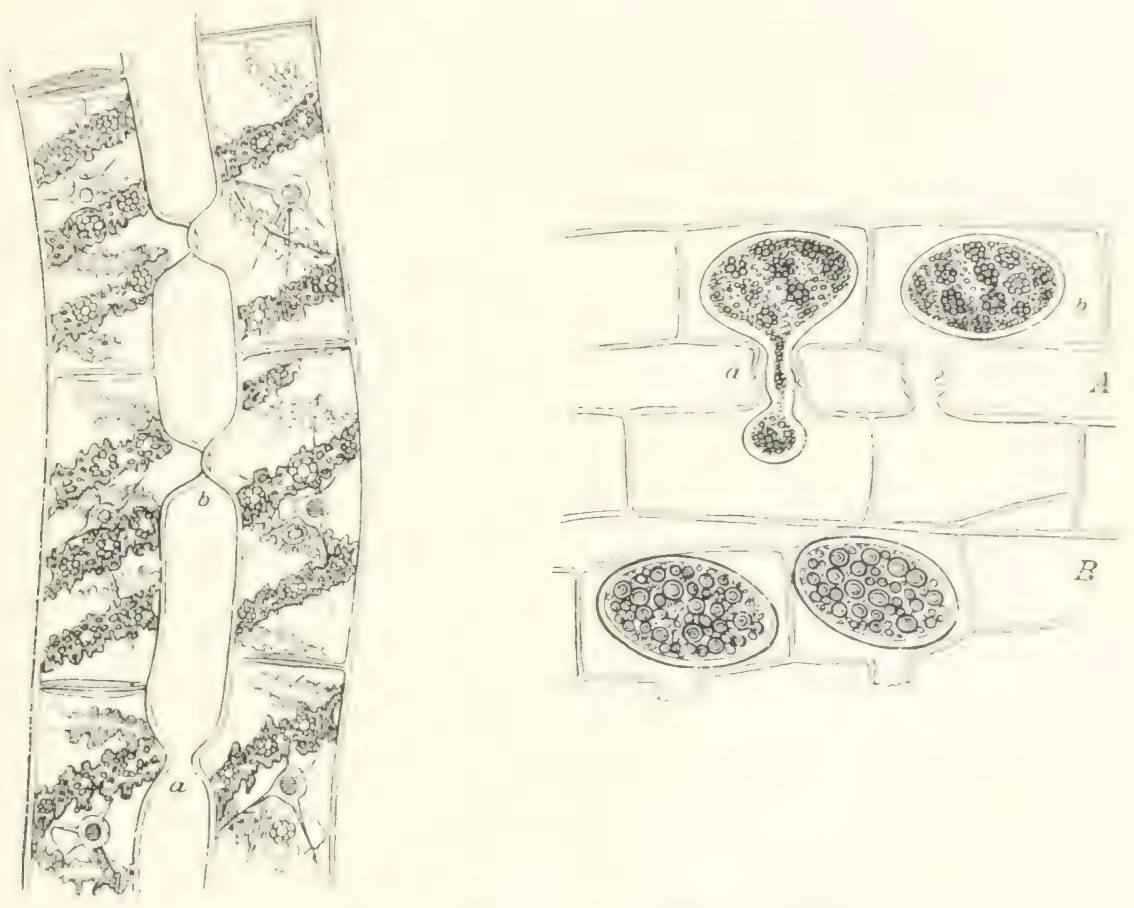

lïg. 266. Spirogyra longata. Nach Siciss, Fïg. 410.

Links einige Zellen zweier sich zur Kopulation worhereitender Fidden; sie zeigen die schrauhenfömig gewndenen Chlorophyllhänder, in denen an verschiedenen stellen kranzartige Anordnungen ron Stiirkekörnern liewen: ankerdent sind kleine Ötröpfechen in ihnen verteilt. Der Zellkern jeder Zelle ist ron l'lasma ungeben, ron welehem aus Fialen zur Yellwand gehen. Bei b Vorbereitungen zur Kopulation. Rechts $A$ in Kopulation bexriffen: in a schlïpft der. J'asmakörper der einen Zelle soeben hinüber in die andere: bei $b$ haben sich die beiden Plasmakörper schon rereinigt: in $B$ sind die jungen $/$ ytroten schon mit einer Haut unkleidet.

gentien und Farbstoften läbt sich an ihr noch weiter feststellen, dab bald nach der Vereinigung der Zellen auch ihre kerne sich nähern und zum Keimkern verbinden. Da in einem Farlen sich alle Zellen entweder nur mämnlich oder weiblich verhalten. so hat von zwei kopulierten Fäilen gewöhnlich der eine den Inhalt aller seiner Zellkammern entleert. während der andere in jedem Fach eine Zygote einschliebt (Fig. 2266B). I)iese

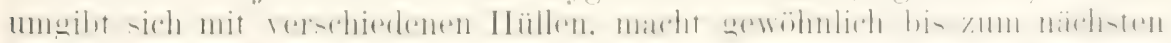
Frühjahr ein längeres Ruhestadium durch, beginnt dann zu keimen und

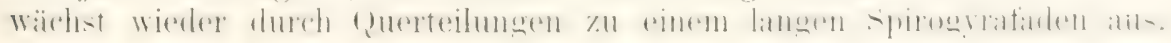


Der ohen hervorgehobene Unterschied zwischen männlichen und weiblichen Spirogyrafiiden ist übrigens keineswegs ein streng durchgeführter, sondern mehr ein relativer. Es kann nämlich der Fall eintreten, daf ein und derselbe Spirogyrafaden umbiegt und dab sein eines Ende in die Nähe rom anderen Ende zu liegen liommt. Unter solchen Bedingmgen erfolgen Paarungen zwischen den an entgegengesetzten Lnden desselben Fadens gelegenen Zellen, so daß Zellen, die unter anderen V'cr-

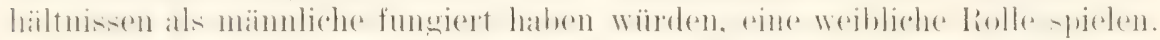

Bei den bisher betrachteten Familien der Noctilucen und Konjugaten, denen sich andere wie die Diatomeen, Gregarinen etc. anschlielien, sind es große, in Vembranen eingehüllte Protoplasmakörper, die sich paaren, machdem sie Perioden vegetativer Vermehrung durch einfache 'T'eilung durchgemacht haben. Eine zweite Reihe von Urformen der geschlechtlichen Zengung liefern uns niedere, pHanzliche Organismen aus der Klasse

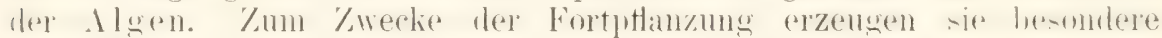
Zellen, die Schwärmsporen, die sich durch ihre geringe Größe. durch das Fehlen einer Zellhaut und durch den Besitz von zwei Geifeln oder zahlreichen Flimmern, mit denen sie sich selbsttätig im Wasser fortbewegen, von den vegetativen Zellen unterscheiden. Sie sind von besonderem Interense dadurh. dali sie uns zeigen. wie sich durch allmähliche bifferen-

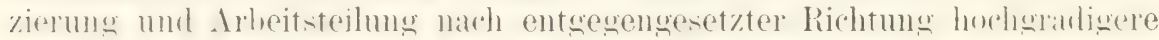
(iegensäte trpische Fier und typische sannenfailen - entwickelt haben.

Die Schwärmsporen sind kleine, bewegliche. membranlose Zellen von meist birnenförmiger Gestalt (Fig. 2067, 268, 269, 270). Thr zugespitztes Ende, der Schmabel, ist das vordere und schreitet bei der Forthewegung im Wasser voran; es besteht aus hyalinem Protoplasma. das

Iiill. $2 i_{i-1}^{-}$

Schwäxmspore voll IMilkrogromia socialis. Nach R. HERTIIIT. häutig einen loten oder bramen Pigmentfleck (Augenfleck) einschliebt: der übrige Körper ist je nach der Irt hyalin oder durch Farbstoff' grün, rot odler braun gefärbt und enthält eine oder zwei kontraktile Vakuolen (Fig. 267). Zur Fortbewegung dienen Geißeln, die rom hyalinen Torderende entspringen, gewöhnlich ein Par (Fig. 2667), seltener eine einzige oder vier oder mehr (Fig. 79 $A$ u. B). Die Schrärmsporen entstehen zu gewissen Zeiten entwerler durch wierlerholte Zweiteilung orler auf dem Wege der Vielzellbildung (S. 242 bis 244) aus dem Inhalt einer Mutterzelle. Bei Zweiteilung ist ihre Anzahl eine geringe und beläuft sich auf 2, 4, 8 oder 16, bei der Vielzellbildung dagegen kann die Zahl eine auferordentlich große werden, weil dann auch die Mutterzellen einen betrïchtlichen Umfang besitzen, und kann bis auf 7000 und 20000 steigen. Durch Platzen der Membran der Mutterzelle an irgend einer Stelle wird die Brut nach auken entleert.

Es gibt zwei Arten von Schwärmsporen, die zu verschiedenen Zeiten gebildet werden, Schwärmsporen, die sich auf ungeschlechtlichem Wege vermehren und neuen, kleinen Algenptlänzchen den Ursprung geben, und Schwärmsporen, die der Befruchtung bedürfen. Die Mutterzellen, aus denen die ersteren entstehen, nemnen die Botaniker Sporangien, die Mutterzellen der letzteren dagegen Gametangien.

Uns interessieren hier nur die Geschlechtssporen oder Gameten. Bei vielen niederen Algen kömmen die sich paarenden Schwärmsporen (Fig. $268 C a, b, c, d$ ) in keiner Weise, weder nach ihrer Größe, noch nach ihrer Bewegung oder nach ihrem sonstigen Verhalten voneinander unter- 
schieden werden (Ulothrix, Bryopsis, Botrydium. Acetabularia etc.). Bei

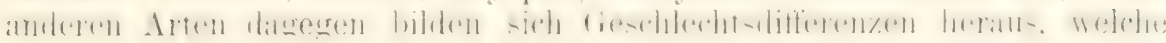
Ims männliche und weibliche Gameten zu unterscheiden gestatten. Im ersteren Falle redet man yon einer isogamen. im zweiten Fall von einer oogamen Befruchtung.

Als Beispiel isogamer liefruch-

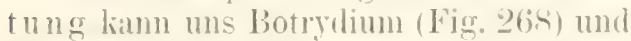
Clothrix (Fig. 2099) dienen. Wenn man in einem Wassertropfen die lieinen Schwärmer ans verschiedenen /uchten zusammenbringt und mit starker Vergrölerung beobachtet, so kamn man leicht wahrnehmen, wie alsbald einzelne mit ilren hyalinen Vorderenten sich einander nähern $(b)$, sich beriihren und nach kurzes. Zeit zu verschmelzen begimen. Zuerst legen sie sich mit ihren Seiten anemander (c), damn schreitet die Verwachsung allmählich von vorn nach hinten fort. Die Paarlinge $(d)$ tummeln sich noch weiter im Wasser hermm. Ihre bewegung ist eine unregelmäbig intermittierende uml nimmt einen tammelnden Charakter an. Nach einiger Zeit ist die Verschmelzung so weit rediehen, dal, beide (rameten einen einzigen ovalen, entsprechend dickeren Körper bilden, an welchem nur noch die Anwesenheit von zwei Pigmenttlecken und vier Geifehn den Ursprung durch Paarung zweier Individuen verrät $\left(c_{0}, j\right)$. Jetzt verlangsamt allmählich das Pärchen (die Lygote) ihre Bewegungen, kommt schlieblich zur liuhe, verliert die vier Geifeln, indem sie eingezogen oder abgeworfen werlen, rundet sich ab und

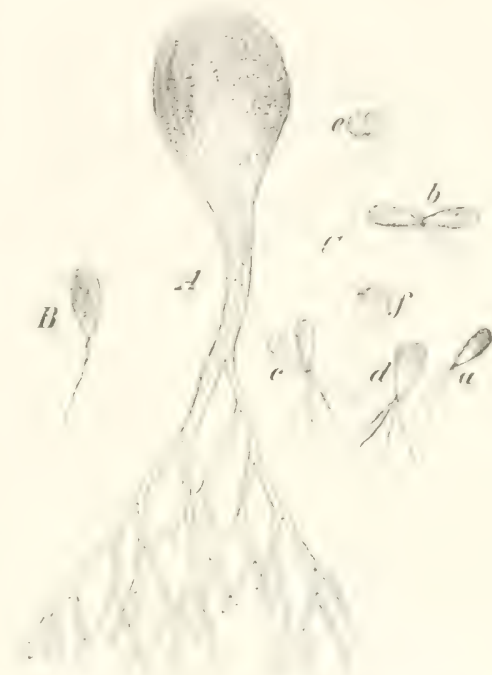

Fig. 265. Botrydium granulatum. Nach STR.:BlitiER, ling. 139. 1 Ein frei relegtes I'flämzchen mittlerer (irölie. Tergr. 28. B Eine Schwitmsuore mit Jodlösung fixiert. Verer. 5) (1). C lsoganeten, und zwar hei a ein einzelner Isogamet, hei $b$ 7.wei Isoganten in der ersten Beriilurumg, lei $c$, und $c$ in seitlicher Verschumelzung, bei $f$ die $/$ yogospore nach rollzogener Verschmelzung der Gimeten. Vergr. j. 10.

umgibt sich mit einer besonderen Membran. Häufig tritt das Ruhestadium schon wenige Minuten nach Beginn der Paarumg ein. in anderen Fällen aber kann die Zrgote noch membranlos und mit vier Cilien versehen drei

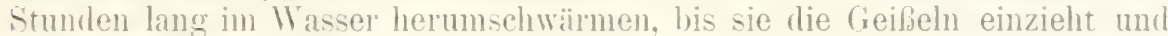
zul Borlen sinkt.

Noch besser als bei den Konjugaten läbt sich das allmähliche duf-

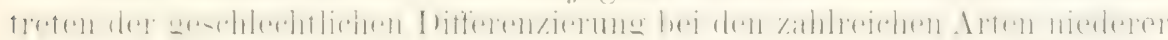
Algen mit (iametenbefruchtung verfolgen. Wie hei Spirogra (Fig. 266 ron den beiden sonst völig gleichartigen Paarlingen der eine als weiblich bezeichnet werden kann. weil er in liuhe verharrt und zum Zweck der Kionjugation von dem anderen aufgesucht werden muß. so bildet sich ein amaloges Verhältuis bei den Phaeosporeen und Cutleriaceen heraus.

Bei einzelnen P'haeosporeenarten sind männliche und weibliche Schwärmzellen bei ihrer Entleerung aus den Mutterzellen voneinander nicht unterscheirlbar, sie sind von cleicher (irölie und mit einem Piomentflecki und zwei Geibeh versehen. In der '/eit des Herumschwärmens tritt eine Paarung nicht ein. Bald aber macht sich ein Unterschied zwischen den Gameten geltend. Einige von ihnen liommen frühzeitig zur liuhe, sie 


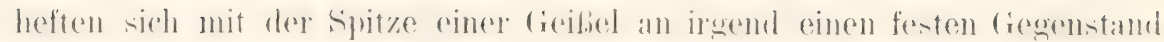
an und hringen demselben ihren Plasmakïrper dureh Verkïrzme und Finziehung der Geißel näher, wobei auch die zweite Cilie eingezogen wird.

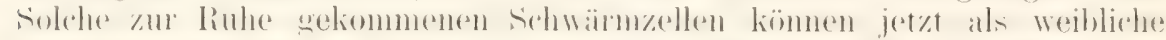

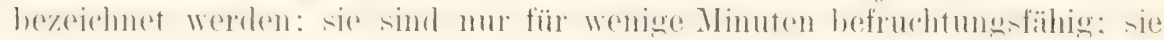
üben, wie BERTHOLD sich ausdrïckt. auf die längere Zeit im Wasser herumschwimmenden

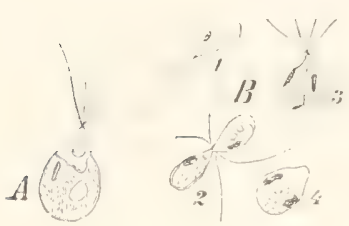

Fig. 269. A cine unge-

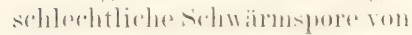
Ulothrix Zonata. Br ein Gamet, 2 u. 3 kopulierende Gameten, 7 vine dureh lipulation exzengte \%ygote. Vergr. 500. männlichen Gameten „eine starke Anziehungs-

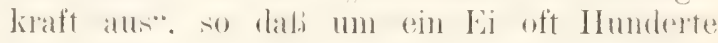
von sichwïmern in wenigen dugenhlielien vereint sind, von denen einer mit ihm verschmilzt (BERTHOLD XI, 1881).

Schon deutlicher ausgeprägt ist die Geschlechtsdifferenz bei den Cutleriaceen. Hier nämlich gewinnen die geschlechtlichen Schwïrnzellen während ihrer Entstehung in der Mutterpflanze eine ungleiche Größe, indem die weiblichen einzeln. die mïmlichen wewöhntich in Achtzahl in einer Mutterzelle gebildet werden. Der Größenunterschied fällt daher schon zienlich auf. Beide Gametenarten schwärmen eine Zeitlang in Wasser herum; eine Befluchtung kann aber erst erfolgen, wemn der weibliche Schwärmel

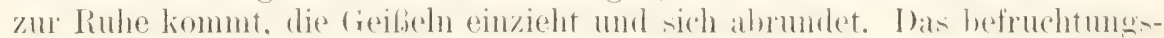
fähig gewordene Ei zeigt einen hyalinen Fleck, welcher durch das Einziehen des vorderen, schmabelartigen Endes entstanden ist. den sogenamnten Empfängnisfleck. Das ist die eimzige Stelle, an welcher einer von den kleinen, männlichen Schwärmern, welche bald die zur Ruhe gekommene. weibliche Zelle umlagern, die Paarung ausführen kann. Nach vollendeter Befruchtung umgibt sich die Zygote mit einer Zellulosehülle.

Die bei den Cutleriaceen schon schärfer ausgeprägte Geschlechtsdifferenz findet sich noch mehr gesteigert bei den Fucaceen, Characeen und anderen Algen. Hier treten die weiblichen Zellen, die eine sehr beträchtliche Gröbe erreichen, auch nicht vorübergehend mehr in das Stadium einer Schwärmzelle ein. Entweder werden sie als kuglige, unbewegliche Eizellen bei der Reife nach auBen ausgestoßen (Fucaceen) (Fig. 270G) oder sie werlen an ihrem Ursprungsort, im Oogonium, befruchtet. Im fiesensatz zu den Fizellen sind die männlidhen sidnwimzellen (Fig. $270 \mathrm{~F}$ ) noch kleiner und beweglicher als die bisher betrachteten Schwärmsporen geworden und haben den charakteristischen Habitus ron Samenfäden angenommen; sie bestehen fast nur aus Kernsubstanz und den beiden Geibeln, die als Fortbewegungsorgane dienen.

Die Ansicht, daß Eier und Samenfärlen der höheren Algen sich genetirh von schwämmellen ahleiten hasen. die sich nach entgegengenetzten Lichtungen geschlechtlich differenzient und allunihlieh einen spezitisch weihlichen und mämnlichen Habitus angenommen hahen. lïbt sich noch schlatgender als durch die eben angestellte Vergleichme der ainzelnen Algenfamilien an der kleinen Familie der Volvocineen beweisen.

Für die uns beschäftigende Frage sind die Volvocineen dadurch besonders interessant und wichtig, daß hier einzelne Arten, die sich sonst in ihrem ganzen Auschen auberordentlich ähnlich sint. Pandorina morum. Eudorina elegans, Volvox globator, teils keine, teils eine deutlich auswoprägte fieschlechtslifferenz der beiden dieschlechtszellen, teils ein vermitteludes Zwischenstadium erkennen lasien. I as ganze Verhältnis ist so 
beweisend. dab es sich wohl verlohnt, hierauf noch etwas näher einzugehen.

Pandorina molum, in der Literatur dadurch besonders bekannt geworden, dab Proxgsmen (XI 1869) an dieser Art die Parung zweier Schwämsporen zuerst im Jahre 1869 entelect hat, l,ildet kleine Kolonien von etwa 16 Zellen, die in eine gemeinsame Gallerte eingeschlossen sind (Fig. 271II). Jede Zelle tright an ihrem vorderen Ende zwei Geibehn. die über die Obertlache der (iallerte hervorsehen und zur Fortbewegung dienen. 'Lur Zeit der geschlechtlichen Fortphlanzung zerfïllt jede der 16 Zellen gewöhnlich in acht Zellen, die nach einiger Zeit frei werden

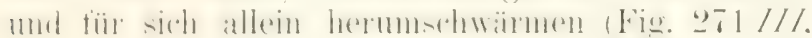
$1 V^{*}$ ). Die ovalen Schwärmzellen, deren Körper grün ist mit Ausnahme des vorderen, etwas zugespitzten Endes. welches lyalin ist, einen roten Pigmentfleck und zwei Geibeh besitzt, sind nicht genau von gleicher Gröbe. Hierin ist indessen ein Geschlechtsunterschied bei Pandorina nicht ausgeprägt. Denn wenn von zwei verschiedenen Kolonien Schwärmzellen zusammenkommen, so bemerkt man in dem (iewimmel bald solche, die sich paarweise (Fig. $271 / \mathrm{V}$, $V)$ nähern, bald zwei kleine, bald zwei gleich große, bald eine lileine und eine große. Bein Zusammentreffen berülren sich die Paarlinge zuerst mit ilıren Spitzen $(I V)$, verschmelzen damn zu einem biskuitförmigen Körper, der sich nach und nach zu einer Kugel zusammenzieht (VT, VII). Diese umgibt sich einige Jinuten nach der Befruchtung mit einer

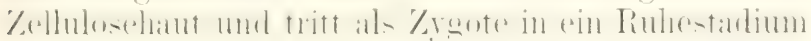
ein, in welchen ihre urspruinglich grüne Farbe in ein Ziegellot übergeht.

Eine geschlechtliche Verschiedenheit macht sich bei Eudorina elegans bemerkbar, bei einer Art, welche der Pandorina sonst auberordentlich ähnlich und wie diese eine Gallertblase ist. die 16-:32 Zellen enthält (Fig. 272). Zur Zeit der Fortpflanzung differenzieren sich die Kolonien in mänliche und weibliche. In den weiblichen Kolonien wandeln sich die einzelnen \%ellen. olne sich weiter" zu teilen. in

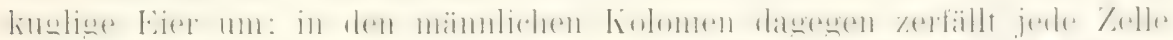

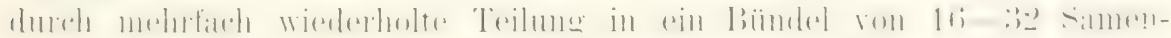
färlen (Fig. 272 $M^{1}$ ). Diese sind . langgestreckte liörperchen, vorn mit zwei Cilien. deren anfangs grüne Farbe sich in gelb verwandelt". Die einzelnen Bündel lösen sich von der Mutterkolonie los und schwïrmen im Wrasser herum. ..Treffen sie auf eine weibliche liolonie, so rerwickeln

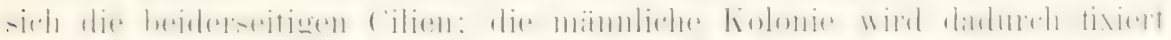
und fällt dabei auseinander, woranf sich die vereinzelten Samenfäden. die sich jetzt noch bedeutend strecken, in die Gallertblase (ler weiblichen Kolonie eimbohren. Sie dringen hier bis zu den Eizellen vor und legen sich (oft in Mehrzahl), nachdem sie an denselben tastend herumgekirochen sind, an sie an. Man darf annelmmen. was in vielen anderen Fiillen ja beobachtet ist. daf eine dieser Samenzellen in je eine Eizelle eindringt" (SACIIS). 
Fig. 271

Bei Volvox

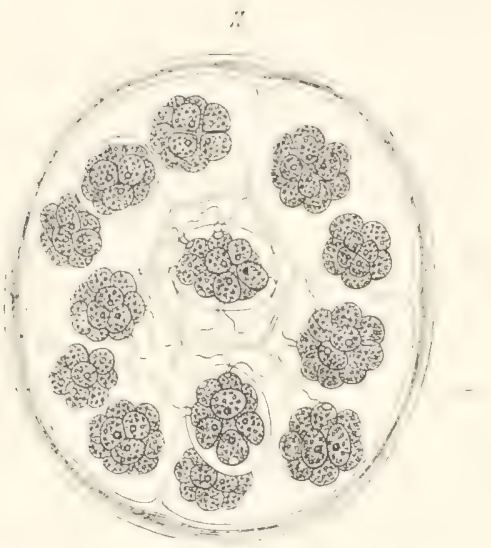

I

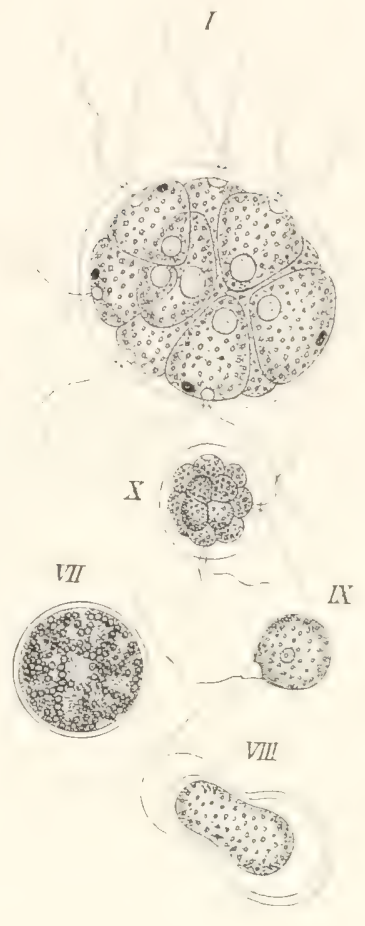

clobator (Fis. $273)$ endlich ist die Differenzierung

am weitesten durchreführt, indem ron den selir zahlreichen Zellen, welche eine kuglige liolonie zusammensetzen.ein 'Teil veretativ bleibt. der andere 'Teil sich in (ieschlechtszellen umwandelt. Bei Volvox erreichen die Eier (O) noch eine viel bedentendere Gröbe als bei

Fig. 271. Entwicklung von Pandorina ITorum mach J'RINGSHEIM, AUS SACHs, Fig. 411. I Eine schwirmende Familie: II eine solche in 16 'Tochterfamilien geteilt; III eine geschlechtliche Familie, deren einzelne Zellen aus der verschleimten Hülle austreten: $I V, \quad V$ Paarung der Schwirmer; $Y /$ eine eben entstandene, $F I I$ eine ausgewachsene Zygote; VIII L'mlildung des Inhaltes einer Zyrote in eine grobe Schwärmzelle: $I X$ dieselhe frei; $X$ junge Familie ans der letzteren entstanden.

Hig. 2:2, Eudorina elegans, eine weibliche Kolonie (Coenobium) von Zoospermien (Sp) nmschwärmt. Nach GOEBEL. $/ H_{1}-M$ Bündel von Samenzellen. Aus SACHs. Iig. $11 \%$. 
Eudorina und werden von den sehr kleinen, mit zwei (ieifeh herumschwainmenden Samenelementen $(S)$ befruchtet.

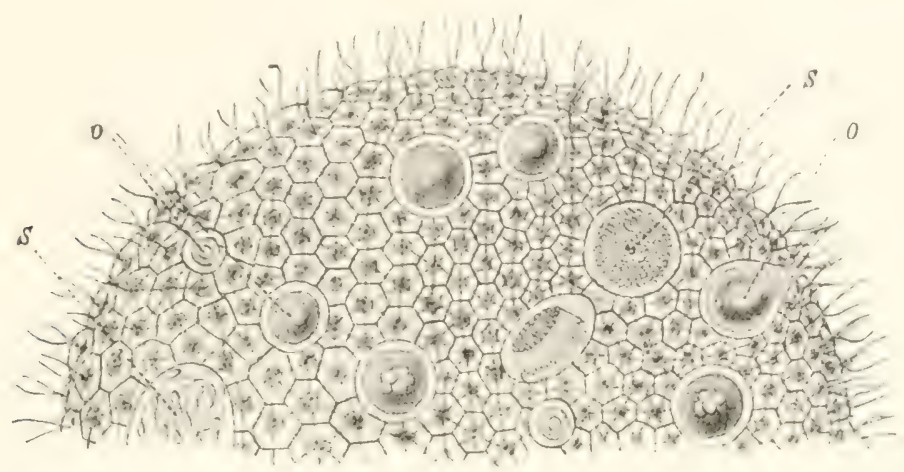

lig. ㄱ.: Volvox globator, geschlechtliche, hermaphroditische Kolonie. Nach CrexkoYsky und Bërschut kombiniert und etwas sehematisiert. Nach LANi, Fin. 21. S mämnliche (iameten (Spermatozoen), O weibliche (iameten (Eier).

Angesichts der im fünften Mbschnitt zusammengestellten, zahlreichen Tatsachen kam wohl der Satz als feststehend betrachtet werden, daB Eiund Samenzellen aus ursprüuglich gleichartig beschaffenen, nicht unterscheidbaren Foltpflanzungszellen durch Differenzierung nach entgegengesetzten Richtungen entstanden sind.

\section{Literatur XI.}

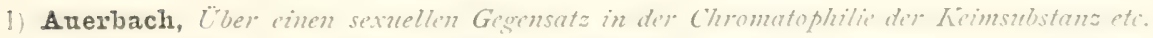

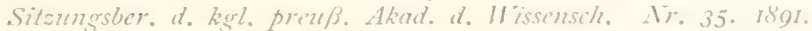

2) Balbiani, Recherches sur les phénomines sevuels des infusoires. Jonm. de le physiol. T. $I V .180 \%$.

3) van Beneden, siche Kapitel VIII.

4) van Beneden et Julin, La spermatogénise chez l'ascaris megalocephala. Bizull. de l'Acad. Belo: ze sér. T: 1\%11. 1884.

5) Berghs, La formation des chromosomes hítérotypiques dans la sporogénèse régétulé.

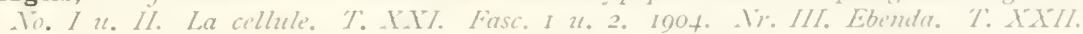
I (1) 0 . .

(i) Berthold, Die seschlechtliche Fortpflanzung der eigentlichen Phareosporeen. Witterl. unes der zool. Station zu Neapel. Bit. II. I881.

7) Böhm, Über Reifung und Befruchtung des Eies ion Petromyzon. Archiz' f. mikrosk. Ancrtomir. LA. A'IXII. 1888.

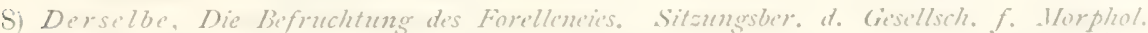
u. Physiol. an Mïnchen. I807.

9) Boveri, Th., Über die Beateutung der Richtungskürper. Gésellsch. f. Morphol. u. Phrsiol. an Miunchen. I886.

10) Derselbe, Brefruchtuns. Merkel-Bonnets Ergebnisse der Anat. us. Enfaicklungsgesch. $\therefore /$. $\therefore$,

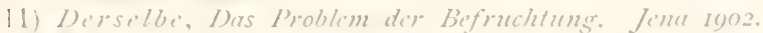

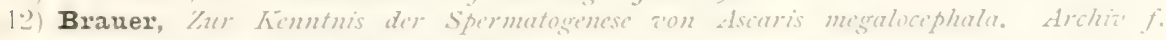
mikrosk. Alut. bit. ILIJ. 1803.

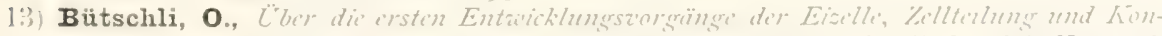

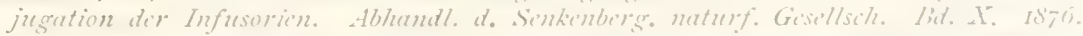

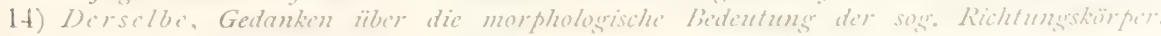
bink. Zentralbl. Bit. I1. 1885.

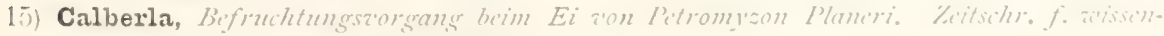

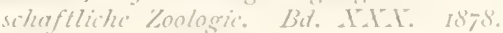


iti) Canmon, W. A., Studies in plant hybrids. The spermatogenesis of hyorid pers. Contributions from Were bork Bot. Garden. 1903.

17) Carmoy, J. B., La a'sicule serminatize et les globules polaires chez l'ascaris mégalocepherler. La cellule. T. H. 1880. T. III. 1887.

I,i Carnoy et Lebrun, La z'ésicule serminatize et les globules polaires ihes les batraciens.

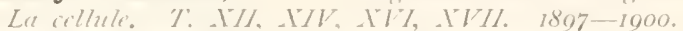

15, Clung, IMc., lotes on the acessory chromosome. Anat. Anz. bid. XX. rgor.

2)(1) Conklin, E. G., The mbryology' of Crepidula. Joum. Mlorphol. Fol. Wlll. 1807.

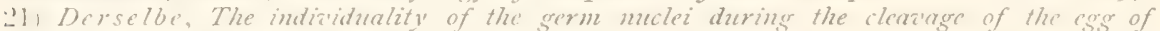
Crepidulu. Biol. Bull. Iol. II. Igor.

?.1 Derselbe, Karrokinesis and iytokinesis in the maturation, fortilization and cleavage of Crepidula and other Gasteropoda. Journ. Akad. Nat. soc. Phila. II. ser. Fol. XII. I. 1902.

‥) Dublin, Louis, The history of the germecells in Pedicellina americand. Annals of the liae York Acat. of sciences. Fol. ITT. 1005.

:4) Engelmann, Uber Entricklung und Fortplanzung zon Infusorien. Morphol. Jahrbuch. BA. 1. 1875 .

25) P. Falkenberg, Die Befruchtnug und der Giencrationswechsel von Cutlerir. Mlitteilungen ans der zoologischen Station su Neapel. 1879.

26) Derselbe, Die Algen inz weitesten Simn. Schenks Handb. d. Botanik. Bd. II. 1882.

I- Farmer and Moore, On the essential similarilies existing between the heterotype melear dizision in animals and plants. Anat. Anz. Bit. HY. 1806.

'Si Fick, Über die Reifung und Befruchtung des Axolotleies. Zeitschr. f. wissenschaftl. Zool. Bd. LIT. 1803.

2ub Fol, H., Archives des sciences phrysiques et naturelles. Gènèu', 15. Okt. I883.

311) Derselbe. Le quadrille des centres, un épisode nouveau dans l'histoire de la fecondation. Archizes des scienc. phys. et nat. le Génere. Troisième pér. T. XXYT. I8pr.

:il) Gardiner, E. G., The growth of the cinum, formation of the polar bodies and the fertiliation in Polychoems candatus. Journ. Alorphol. Vol. MV. 1898.

":-1 Giard, A., Sur la signification morphologique des globules polaires. Rante scrent.

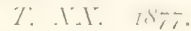

:3:) Dersilbe, Sur les modifications qui subut l'oeuf des Méduses phanérocarpes aćant la fécondation. Comptes rendus dul l'Acal. d. scienc. Paris. I877.

it) Giardina, A., Origine dell'oocita e delle cellule nutrici nel Dutiscus. Intemat. Ironatsschrift f. Anat. "2. Physiol. Bit. ITlll. I901.

:iin Derselbe. Sui primi stati delloosenesi o principalmente sulle fasi di sinapsi. Anat. Anz. Ba. 1.1\% 1002.

(iti) Grégoire, V., La reduction mumérique des chromosomes et les cinèses de maturation. La cellule. T. K.IT. I00 t.

:i.) Griffin, Studies on the maturation, fertilization and ilandage of Thalassema and

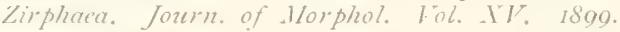

(in) Guignard, I., lonvelles études sur lu ficondation. Comparaison des phinomines morpholog. obserne's ches les plantes et ihes les amimanx. Annales des sciences matur. T. IIT. Botanique'. 1801 .

:3in Derselbe. Sur les unthérozoules et la double copulution ihez les régetantr angiospermes. Compt. rend. Paris. 1899.

11) Derselbe'. L'apparil scinal et la double ferondation dans les tulipes. Ann. d. si. nat. Biot. ge sér. T. XI. Igoo.

11) Derselbe, La double ficondation dans le Mais. Joum. de Bot. 1. IT. Igor.

1.) Häcker, v., Dic Eibildung bei Cuclops and Canthocamptus. Zool. Jahrb. Abt. f. Anat. 11. Ontos. Bit. I. 1892.

1.3) Derselbe, Die Torstadien der Eireifung. Archic f. mikrosk. Anat. Bat. XLI. 1895.

It Derselbe, Über die Selbständigkeit der äütrlichen und der mütterlichen Ternbestandteile. Archiv f. mikrosk. Anat. Bd. ILVI. I805.

(i)) Derselbe, Die Reifungserschimmgen. Ergebn. Anat. u. Entaickhungsgesch. Fid. FIII. 1808.

Hii Derselbe, Praxis und Theorie der Zellen- und Befrachtungslehre. Jend I809.

1.) Derselbe. Über aie Autonomie der ä̈̈terlichen und mütterlichen Kernsubstanz z'om Ei bis an den Fortpflanzungsallen. Anut. Anz. Bd. X.Y. Igoz.

1h, Derselbe, Uber dus Schicksel der elterlichen und großelterlichen hernanteile. IVorphol. Beiträge sum Ausban der Vererbungslehre. Jenaische Zeitschr. f. Naturà. 1902.

1!1 Hartog, IM., Some problems of roproduction, a comparative study of gametogeny and protoplasmic senescence and rejusenescence. Quarterly Joumal of microsc. scimec. 1891 .

in Henking, Untersuchungen n̈ber die ersten Entzicklungszorgänge in den Eicrn der Insckten. Zeitschr. f. arissenschaftl. Zoologie. BA. XLII, LI, LIV. 1890, I891, I892.

i) Herla, Etude des zariations de la mitose chez l'ascaride mig. Arch. Biol. T. IVII. I895. 
Hertwig, Oscar, siehe Lit, VIII, $1875,1877,1878,1800$.

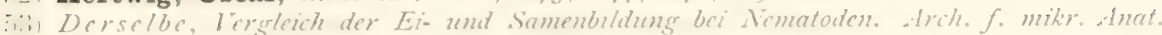

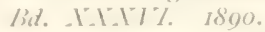

i. Derselbe. Ergebnisse und Problene der Zcugungs-und lererbunssletre. Iortrage anf dem internat. Longreß Sept. $100+216$. St. Lonis. Separat. Jena 1005.

‥ Hertwig, Richard, Eber die Gilcichaethekeit der cieschlechtsherne bei den Seeigeln.

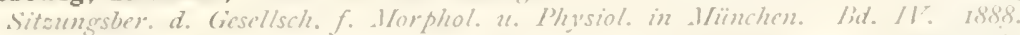

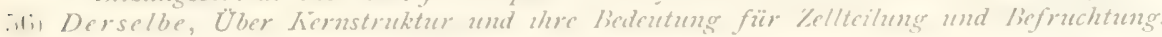
Ebenda $1888^{*}$.

$\therefore$ Derselbe, Über die Konjugation der Infusorim. Ahandl. der bay. Akad. der

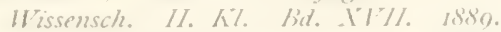

in Derselbe, ¿̈bcr liefruchtung und honjugation. Verhandl. der deutschen Zool. Gicsellschaft. 1892 .

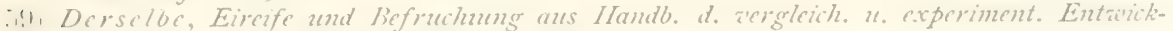
lungslehre z'on O. Hertaig. lid. I. 1903.

ti" Ishikawa, Vorlänfige Mitteilungen ïber die honjugationserscheimmsen bei den loctiluken. Zool. Anzeiger Xr. 353. Is9l.

(ii) Derselbe, Studies of reproductize elements. 1. Spermatogenesis, ozogenesis and fertilization in Diaptomus. Journ. of the college of science. Imper. Unizersity. Yokio. $15 \%$ I: $180 \%$.

(i-) Julin, Ch., Oziogénèse, spermatogénèse et ficondation ches Styelopsis. Bull. Sc. Firance. belo. T: 1:1\%. 1803.

(ii.) Kingsbury, The spermatogenesis of Desmognathus. The Americ journ. of Anat. 1. \%l. 1. 1002

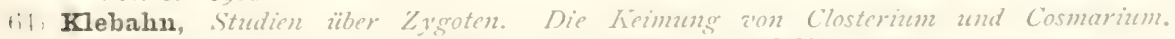

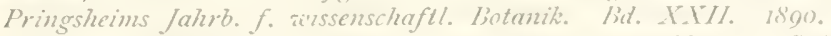

i.i) Dersclbe, Beiträge zur Kenntnis der Luxosporenbildung. Pringslueins Jahrb. $f$.

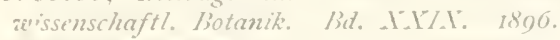

bili จ. Klinckowström, Benträge zur Kenntuis der Eireifung und liefrachtung bei Prostheceracus. 1rch. f. mikrosk. Anat. Iid. HLITI1. 1897.

i. Korschelt, E., ¿̈ber Ternteilung, Eireifung und Befinchtung bei Ophryotrocher puerilis. Zeitschr, f. wissenschaftl. Zool. Bd. LX. I895.

tin Korschelt u. Heider, Lehrbuch der rergleichenden Entreichlungsgeschichte der wirbellosen Tiere. Alloeneiner Tezl. 1002.

lit, v. Kostanecki, Die befruchtung des Eies a'on Mrzostoma gl. Arik. f. mikrosk. Anat. Bid. I.I. 1808 .

-W Kostanecki u. Wierzejski, Uber das truhalten der sogen. achromatischen Substanz

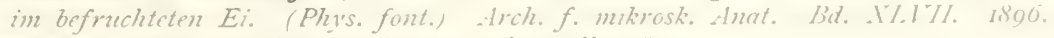

i1, Lameere, Etudes sur la réproduction. limulles 1800.

-.) Lebrun, La z'esicule germinatize et les globulez polaires chez le's anonres. La Cellule. T: . TIL: 1902,

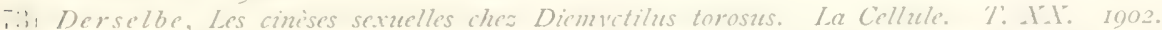

i) Mrark, E. I. Maturation, ficondation and segmentation of Limax campestris. Bublet. of the musezme of comp. Yool. at Htariard college. 162. 1\%. 1881 .

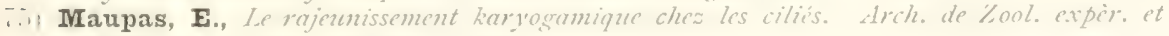
ginter. 2" sime. $10 \%$. 17l. 1889 .

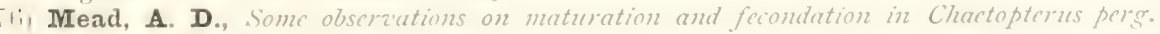
Journ. Wlorphol. Iol. A. 1895 .

i) Meves, Fr., Uber die Entaicklung der männlichen (ieschlechtszellent żon Salamandra maculosa. Irch. f. mikrosk. Anat. u. Entrickhungsgesch. Bat. ILIT/1. I897.

(s) IMontgomery, The spermatomenesis up to the formation of the spermatid. \%ool. Jahrb. Bd. TII. 1898 .

79) Derselbe, Chromatin reductino in the Ilemiptera. Zool. Anz. Bid. I.III. 1890.

Si) Derselbe, 1 study of the chromosomes of the germ-cells of lletazoa. Trans. Amer. phil. Soc. Iol. l. IOOI.

81) Derselbe, Some obserations and considerations upon the maturation phenomena of the germecells. Biological bulletin. Fol. Vl. Igot.

S.) Moore, J. E. S., On the structural changes in the reproduction cells during the spermatogenesis of Elasmobranchs. Quart. joum. of micrase. Si. Bid. IIIITIII. ISO).

8.3) Nawaschin, Resultate ciner Revision des Befruchtungsiorganges bei Lilinm ilartagon

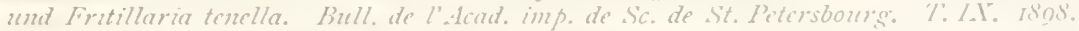

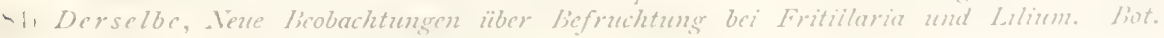

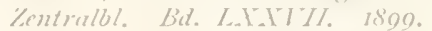

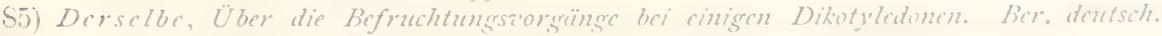
biot. Gesellsch. Hid. IVIII. Igoo. 
S6) NuBbaum, Zur Defferensiemeng des Geschlechls im Timmeich. Arch. f. mikroskop. Ancyt. Bit. NVIII. 1880.

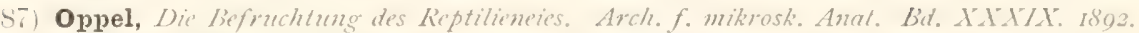

S8) Paulmier, F. C., Chromatinreduktion in der llemiptera. Anat. Ant. Bad. XII. IS08.

S9) Derselbe, The spermatogenesis of Anasa tristis. Journ. Morph. Suppl. Iol. XI. 1809.

(1)) Platner, Über die Befmachtung bei Arion empiricomm. Arch. f. mkrosk. Anat. lid. XYTTI. 1886.

91) Derselbe, ¿̈ber die Bedentung der Kuchungskörperchen. Biol. Zentralbl. Lid. IIII. $1888 / 80$.

9) Pringsheim, Uber die Befruchtung der Algen. Monatsber, der Berl. Akad. 1855.

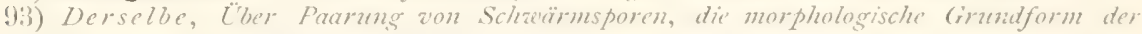
Zengung in P'flanzenreich. Ebender 1860 .

9.1) Prowazek, Zur Vierergmppenbilutug bei der spermatogenese. Zool. Anz. lid. AX': 1001 .

(95) vom Rath, O., Zur hemntuis der Spermatogenese von Grollotalpa etc. Arch f. mikrosk, smat. Bd. XL: 1802.

96) Derselbe, Benträge zur Kemminis der Spermatogenese von Salamandra maculata. Zentschr. f. arissenschaft. Zool. I3d. LIII. 1893.

97) Derselbe, Nene Beitrige aur Frage der Chromatinreduktion un der Samen- und Eireife. Arch. f. mikrosk. Anat. Isa. ILVI. 1805.

9S) Rosenberg, O., Über die Tetradenbilang eines Drosera-Bastards. Ber. d. dentschen Bot. Gesellsch. lid. WXII. 1004.

(95) Rückert, J., Zur Eireifung der Copepoden. Anat. Hefte. B'd. II. I89t.

100) Derselbe, Lber physiologische Polyspermie bei meroblastischen II irbeltiereiem. Anat. Anzeig., VII. Jehrog. 1802.

101) Derselbe, Die Chromatineduktion bet der Reifung der Sexualzellen. Merkel-lionnets Ergebnisse. Bd. III. I804.

102) Derselbe, Über das Selbständigbleiben väterlicher und mütterlicher Kernsubstanz etc. Arch. f. mikrosk. Anat. Bid. XLI. 1895.

103)"Derselbe, Die Befrachtung z'on Cyclops stremme. Anat. Anz. Bd. X. 1895 .

104) Derselbe, Nochmals aur Reduktionsfrage. Arch. f. mikrosk. Anat. Bd. XLIII. 1896.

105) Sabaschnikoff, Beiträge zur Kenntnis der Chromatinreduktion in der Ovogenesis ion Ascaris. Bull. Soc. Nat. Moscoze. 1897.

106) Sala, I., Experimentelle Untersuchungen Ẅber die Reifung und Befruchtung der Eier bei Ascaris megalocephala. Arch. f. mikrosk. Anat. Bd. XLIV. 1895.

107) Selenka, Befruchtuno der Eier von Toxopneustes z'ariegatus. Leipzig I8y8.

10S) Schreiner, Die Reifungsteilungen bei den II irbeltieren. Ein Beitrag zur Frage nach der Chromatinreduktion. Anat. Anz. Bd. NYII. Ar. 22. 1907.

109) Strasburger, Neue Untersuchungen zuber den Befruchtungsvorgenng bei den Phanerogamen als Grundlage fïr eine Theorie der Zenigung. Jena 1884.

110) Derselbe, Über periodische Reduktion der Chromosomenzahl im Entroicklungsgang der Organismen. Biol. Zentralbl. Bd. XIV. Nr. 23 4. 24.1894.

111) Derselbe, Über Reduktionsteilung, Spindelbildung, Centrosoma und Cilienbildner im Pflanzenreich. Jena 1900.

112) Derselbe, Einige Bemerkungen zur Frage nach der ,doppelten liefruchtung" bei den Angiospermen. Bot. Ztg. Jahrg. LIIII. 1900.

113) Derselbe, Über Befruchtung. Bot. Ztg. Juhrg. LIX. Igor.

114) Derselbe, Über Reduktionsteilung. Sitzungsber. d. königl. preuß. Akad. d. Iriss, Berlin. Igot.

115) Sutton, W., On the morphology of the chromosome gront in brachistola magna. Biol. Bull. Fol. II: I002.

116) Derselbe, The chromosomes in heredity. Biol. Bull. Fol. II. 1903.

117) Tretjakoff, Die Spermatogenese bei Ascaris megalocephala. Arch. f. mikrosk. Anat. Bd. LAT: 1007 .

118) Wagner, Jul., Einige Beobachtungen iüber die Spermatogenese der Spimen. \%ool. Anz. Bit. XIX. 1896

119) Derselbe, Beiträge zur Kenntns der Spermatogenese bei den spinnen. Arb. $d$. Kaiser\%. naturf. Gesellsch. in St. Petersb. Bd. XXIT. 1800.

120) Waldeyer, w., Befruchtung und Tererbung. Tortrag auf der 60. Ters. der Nat. u. Arute. 1807.

1'21) Weismann, Benträge zur Natureschichte der Daphnoiden. Zeitschr. f. missensch. \%ool. Bd. IXITIII. I880.

122) Derselbe, Über die Zahl der Richtungskörper und ïber itre bedeutung für die lererbung. Jena 1887

123 Weismann und Ishikawa, Uber die Bildung der Richtungskörper bei ticrischen Eiern. Berichte der naturf. Gesellsch. zu Freiburg. Ba. III. 1887. 
I24) Weismann und Ishikawa, Hitere Untersuchungen anm Zehlengesets der Richtunci-

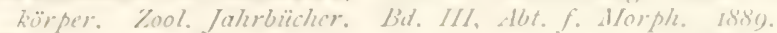

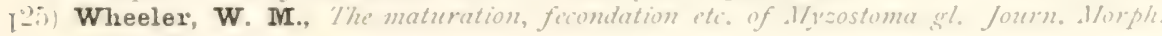
lol. I. IS०5.

126) Wilcox, Spermatogenesis of Caloptemis and Cicadr. Anat. Ana. Bd. 1. 1805.

127) Derselbe, Longitudnal and transverse dizision of chromosomes. Anat. Anzeiger. lid. HT. 1001.

12S) Wilson, E. B., An atlas of the fertilization and harpokinesis of the ozmo teri lork is'o5.

129) Wilson and Mathews, Maturation, fertilization and polarity in the cchinaterm ess. Joum. 110rph. 102. 1. I895.

130) Zacharias, Otto, Nene Untersuchungen über die Liopulation der (ieschlechlsprodulele

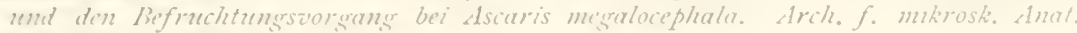
:3. 1:1: 1887

$131)$ Zoja, R., Sulla independensa della cromatimet patema e materna mel mucleo delle cellule embrionali. Anat. Anz. Bd. I\%. Isq6.

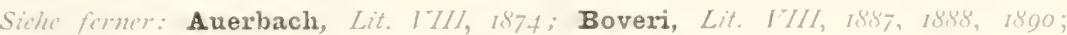

Fol, Lit. THII, 1874 


\section{ZWÖLFTES KAPTTEL.}

\section{Die Physiologie des Befuchtungspinzesses.}

Narh der besprechume der morphologischen Frscheinumgen, die sich

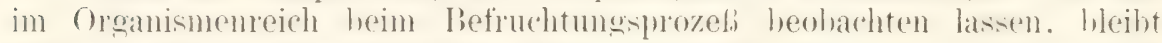

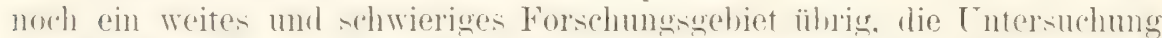

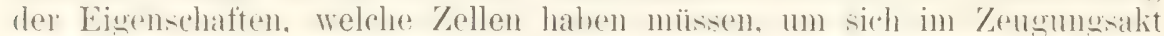
rereinigen mol den Ausgang für einen nenen Entwirklungsylilus billen zu können. Zunächst ist klar, dlaß nicht jede Zelle eines vielzelligen Organismus in die Lage kommt, zu befruchten oder befuchtet zu werden, und daB auch die Geschlechtszellen nur in einem oft kurz bemessenen Zeitraum für die Zeugung tauglich sincl. Es müssen also in den Zellen zum 'Zweck der Zeugung bestimmte Dispositionen bestehen, welche wir einstweilen unter dem algemeinen Austruck ,Befruchtungsbedürtig-

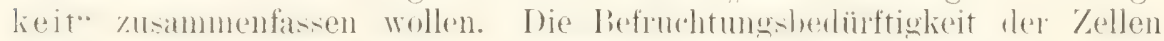
allein garantiert aber noch lange nicht den Erfolg der Befruchtung. Dies lehrt schon die einfache Tatsache, daß reife Eier und reifer Samen, von ver-vhichenen Organismen zusimmengehracht, sich nicht entwielieln. Zur

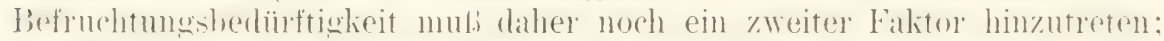

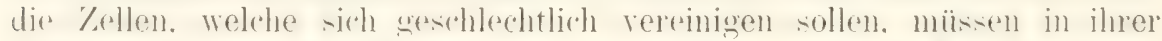

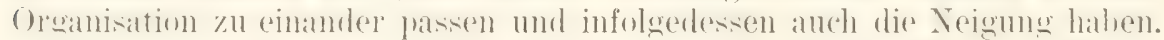
sirh mitrinander zu verbinden. Wir wollen den Inbegriff diesar Eimenschaften als sexuelle Affinität bezeichnen.

Die Physiologie des Befruchtungsprozesses läft sich mithin in zwei

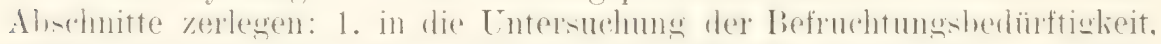

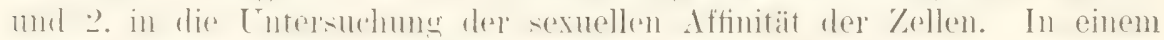

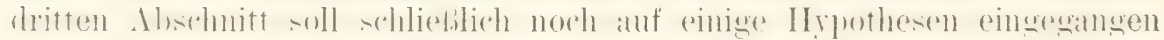
werden. welche von verschiedenen Seiten über das VVesen und den Zweck der Befruchtung aufgestellt worden sind.

\section{Die Befruchtungsbedurftigkeit der Zellen.}

Unter Befruchtungsbedürftigkeit verstehen wir einen Zustand der zelle. in welchen sie für sich allem die Fühigkeit redoren hat, den Lethens-

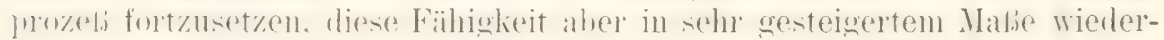
erlangt, wenn sie sich mit einer zweiten Zelle im Befruchtungsalit verbunden hat. Ein tieferer Einblick in das Wesen dieses Zustandes fehlt uns zurzeit noch durchaus; demn es handelt sich um Eigenschaften der 


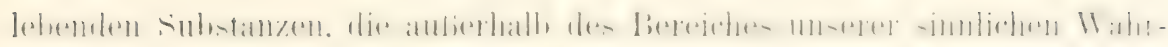
nehmung liegen und sich uns nur in ihren Folgeerscheinungen zu erkennen geben. Anch ist das dunkle Gebiet ron seiten der I'hysiologie noch wenig einer plammäbigen Bearbeitung unterworfen worden. Wis

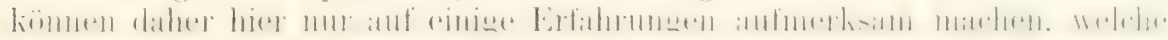
die physiologische Untersuchung in Zukunft zu vermehren und zu vertiefen haben wirl. Am meisten wirl hierbei eine lertiefung unseres IVissens von dem Studium der niedersten Organismen zu erwarten sein. weil bei ihnen die einzelnen Zellen eine absolute oder wenigstens noch eine sehr grobe Selbständigkeit besitzen und nicht. wie bei den höheren Orga-

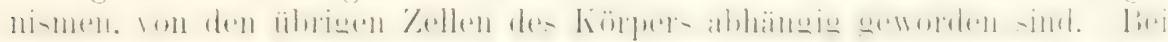
ihnen sind daher die Grundphänomene des Lebens in gröberer Klarheit zil erkennen.

Die zurzeit rorliegenden Erfahrungen lassen sich in folgende Sätze

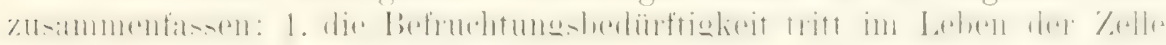
periodisch ein: 2. sie ist überall nur von kurer Zeitdauer: :3. sie ist bis zu einem gewissen (irade von äußeren Einflüssen abhängig. und dannit hängt es dann wohl t. zusammen, daß sie in manchen Fällen autgehoben und in Parthenogenese und Apogamie umgewandelt werden kann.

Dab die Befruchtungsbedürfigkeit eine im Lebensprozel der Zelle periodisch eintretende Erscheinung ist. läbt sich am besten auf experimentellen Wege durch das Studium der Infusorien beweisen. MaUpas (XI 18sig) hat hierüber sehr zahlreiche. verdienstrolle Untersuchungen angestellt. Er unterscheidet im Leben eines jeden Infusors eine Periode der (ieschlechtslosigheit und eine P'eriode der Geschlechtsreife oder Befruchtungshediütigkeit. Die erstere beginnt. wem sich zwei Tiere gegenseitig befruchtet haben und sich trennen: sie führt zu einer Vermehrung der Individuen durch rasch sich wiederholende Teilungen. In dieser Periode kamn man Individuen aus verschiedenen Kulturen zusammenbringen und sie Bedingungen aussetzen. welche für die Konjugation an günstigsten sind, olne dab. es jemals zu Paarungen liommt. Erst lïngere Zeit nach Ablauf einer Parung werden die Infusorien wieder befruchtungshediurftig. Werden dann aus

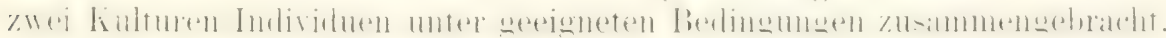
so erfolgen reichliche Paarungen in wenigen 'agen. So hat Mauras festgestellt. (laß bei Leukophrys patula Individuen. welche der 300sten bis tousten Generation nach einem Befruchtungsakt angehören, allein fruchtbare hopulationen ausführen können. Für Onychodromus fällt diese

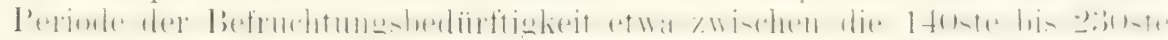

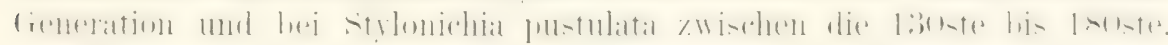

Del zweite Satz lautet: Der Zustand der Befruchtungsbedürftigkeit ist üherall nur ron kurzer Zeitdaner. Wenn Zellen. die für die Befruchtung reif sind, nicht rechtzeitig befruchtet werklen. so gehen sie bald zugrunde. Infusorien, Algenschwärmer, tierische Eizellen liefern uns Beispiele zur Bestätigung des Satzes.

Wenn die einzelnen Individuen der oben als Beispiel benutzten In-

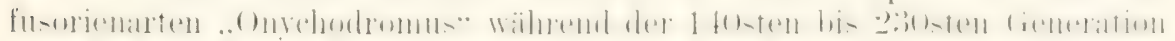

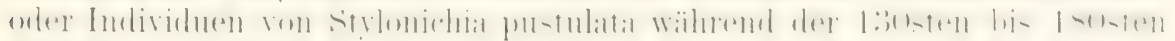
Generation nicht Gelegenheit erhalten, sich zu paaren, so werden sie geschlechtsalt oder überreif. Sie fahren zwar noch fort. sich durch Teilung

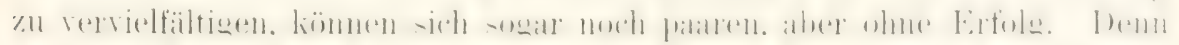

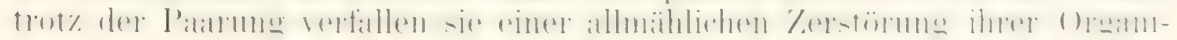
sation durch .,senile Degeneration". wie sich MAUPAs aushrielit. Ihr 


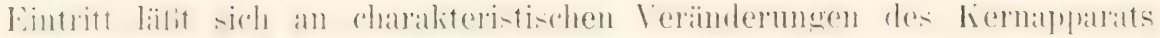
erkemen.

Schwärmsporen oder Gameten von Algen sterben oft schon nach einigen Stunden ab, wenn sie im Wasser herumgeschwärmt sind, ohne zur Paarumg mit geeigneten Individuen gelangt zu sein. Die Empfängnisfïhigkeit der großen weiblichen (xameten von der Algenart Cutleria,

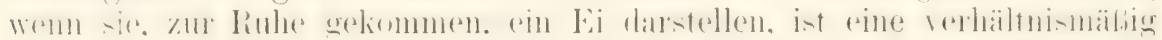
kurze. Mehrfache, von FALkenBERG (XI 1579 ) angestellte Versuche zeigten, ..dal. am dritten Tage nach eingetretener Ruhe noch nahezu alle Eier, am vierten Tage noch etwa die Hälfte derselben befruchtungsfähig waren.

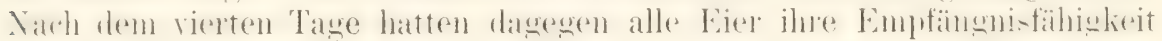
eingebülst, und wenn man ihmen auch jetzt noch Spermatozoiden zusetzte, so begannen sie doch nunmehr unter denselben Erscheinungen wie die

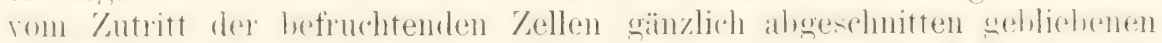
Eier abzusterben".

Reife, tierische Eizellen endlich haben, auch wenn sie sich in ihrer normalen Umgebung im Eierstock oder in den Eileitern befinden, nicht minder eine kurze Lebensdauer; sie geraten bald in einen Zustand der Überreife (HERTwig VIII 1890). Ihre normalen Funktionen sind geschwächt; sie lassen sich zwar noch eine Zeitlang befruchten, aber in anor-

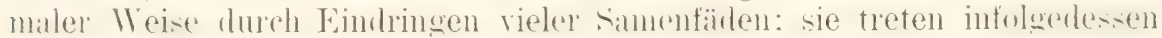
auch nur in einen gestörten Entwicklungsprozeß ein. Hierin liegt unverkennbar eine Analogie mit der senilen Degeneration ron Infusorien vor, die zur geeigneten Zeit an der Paarung verhindert waren.

Der dritte Satz, daß das frühere oder spätere Eintreten der Be-

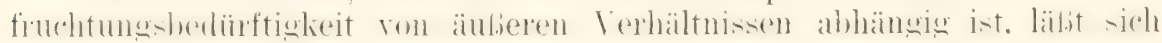
in einigen Fällen sehr deutlich nachweisen. So kamn man durch stets erneute, reichliche Zufuhr von Nahrung Kulturen von Infusorien an der Parung verhindern (Maupas XI 1889). Sie fahren fort, sich zu teilen,

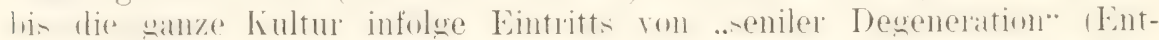

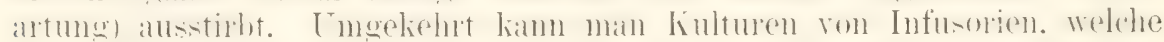

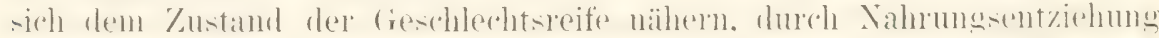
sofort zur Paarumg bestimmen. .Une riche alimentation“" bemerkt Maupas, ..endort l'appétit conjugant; le jêne, an contraire, l'éveille et l'excite."

Ebenso hat KLEBS (XII 1889) für das Wassernetz (Hydrodiktyon) einen Einfluh der äuberen Lebensbedingungen auf die lildung der (ieschlechtszellen wahrnehmen und sie bald früher hervorrufen. bald verhindern können. - KĹLEBS hat gesunde, aus der freien Natur stammende Netze zur Gametenbildung darturch gebracht, dab el sie in einer Rohrzuckerlösung von $7-10 \%$ kultivierte. Nach 5-10 Tagen zerfällt das

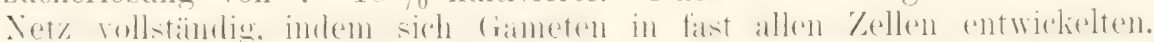
Ferner wirl in den Zellen die Neigumg zur Gametenbildung gesteigert, wenn man frische Netze in niedrigen Glasschalen mit relativ wenig Wasser an einem sonnigen Fenster kultiviert. Nach KLEBS besteht der Einflub der Zimmerkultur darin. ..laf. durch sie das Wachstum zum Stillstand gebracht, dagegen die Erzeugung organischer Substanz mit Hilfe der Assimilation nicht behindert wird. wähend gleichzeitig ein gewisser Mangel an Nährsalzen eintritt. Auf der anderen Seite läbt sich, in ähnlicher $W^{\top}$ eise wie bei den Infusorien. die geschlechtliche Fortpflanzung unterdrïcken. Zul dem Zwecke braucht man nur ein Netz, welches in seinen Zellen Gameten zu bilden begimnt, in eine $0,5-1,0 \%$ ige Nährlösung zu über-

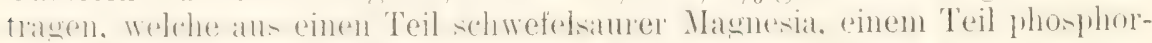

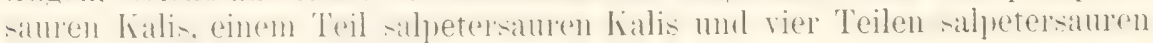


Kalks besteht. Nach einiger Zeit liefert es mueschlechtliche Schwïmsporen, namentlich wenn es dam in frisches Wasser zurïckgehracht wird.

Nach beobachtungen yon Eman bildet ein kleiner Pil\%, Iiasidioholus randrum. auf reichlichem Nährsubstrat aus Konidien gezüchtet.

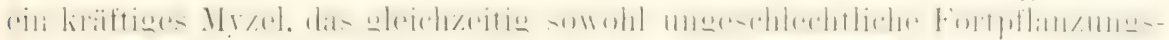

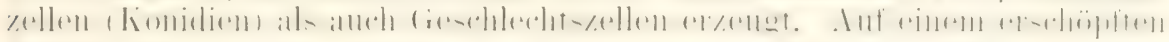
Nährboden dagegen liefern die Konilien ein spärliclies Myzel, welehes sich sofort und ausschlieflich durch fieschlechtszellen, die sich zu 'tyogosporen verluinden, fortpflanzt.

Reichliche Ernährung hegiunstigt bei Pflanzen, wie die Erfahrung der Gärtner lehrt, die vegetative Vermehrung und behindert die Samenbildung, während ungekehrt Blïten- und Samenbildung befördert wird

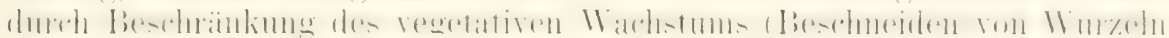

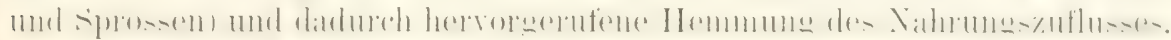

Auch fïr 'Tiere, die sich auf parthenogenetischem ITege vermehren, liegen entsprechende Beobachtumgen vor. Wenn der Plyylloxera vastatrix die Nahrung entzogen wird, so kommen alsbald, wie KELLER (XII 1887) durch Experimente gezeigt hat, die geflügelten Geschlechtsformen zum Vorschein, und es werden befruchtete Eier abgelegt.

In manchen Fallen, namentich bei niederen Organismen. ist die Befruchtungsbediuftigkeit nur eine relative.

Wemn bei der Alge Ectocarpus (Berthold XI 1ş1) die weibliche

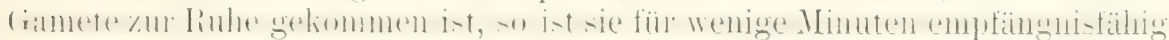
geworden. ..Erfolgt in dieser Zeit keine Befruchtung, so wird der (ieibelfarlen vollständig eingezogen, das Ei rundet sich ah). und scheidet eine Zellnlosehaut aus. Nach 24-48 Stunden zeigen sich damn die ersten Spuren

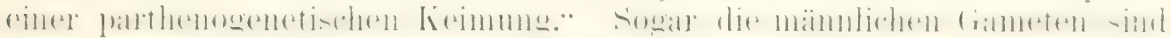
hier, wenn anch in geringerem Grade als die weiblichen, spontan entwick-

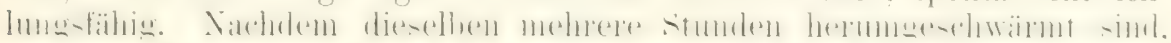

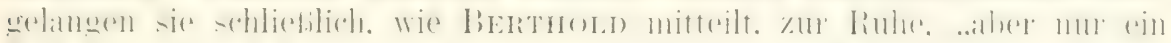

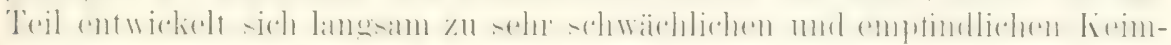
ptlanzen, ein anderer Teil desorganisiert sich sogleich orler nach Verlauf yon ein his zwei 'Tagen".

Ein sehr eigentümliches, faliultatives Verhälnis zeigen die Bienen, deren Eier sich, gleichgültig. ob sie befruchtet werden oder nicht. wieder zu Bienen entwickeln. Nu liefern sie im unbefruchteten Zustand Drohnen.

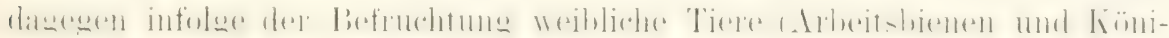
gimen). Zuweilen entstehen Zwitter, wie LECCKART meint, aus Eiern, bei alenen die Befruchtung zn spät erfolgte, un die in männlicher Richtung

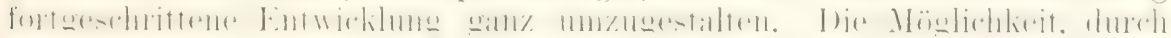
änbere Eingrifie den Eintritt der liefruchtungsbedürftigkeit in den (ieschlechtszellen zu beschlemigen orler sie im entgegengesetzten Fall aufzuhalten und eventuell aufmheben. wirft Licht auf die Erscheinungen der Parthenogenese und Aposamie, auf welche wir jetzt noch näher einzugehen haben.

\section{a) Die normale Parthenogenese.}

In den meisten Fällen sind die Geschlechts\%ellen im Tier- und Ptlanzenreich. wenn sie nicht rechtzeitio zur liopulation gelangen. unfehllar dem raschen Untergang verfallen. Ohwohl aus eminent entwicklungsfihiger Substanz bestehent. kömnen sie sich trotzilem nicht heim Fehlen der einen Ledingung entwickeln. Yon der Unmöglichkeit spontaner Entwicklung der Eizellen waren die meisten Naturtorscher in frïheren dahrhunderten so 


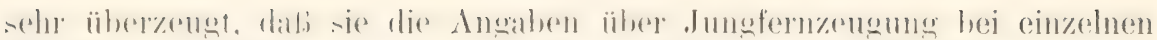

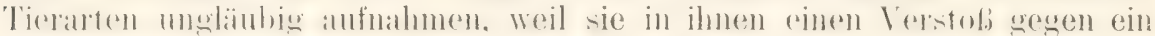
Naturgesetz erblickten. Und in der 'Tat kann es ja für die Sängetiere

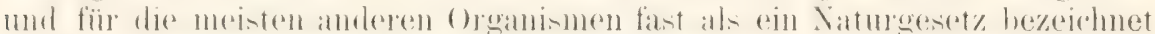
werden, dlak ihre mämnlichen und weiblichen Geschlechtszellen fïr sich

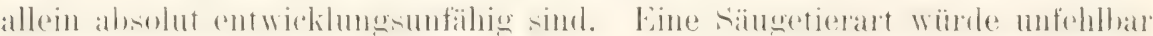
aussterben. wenn ihre männlichen und weiblichen Individuen sich nicht zum Zeugungsalit velbänden. Trotzdem kamn es nicht als ein allgemeines

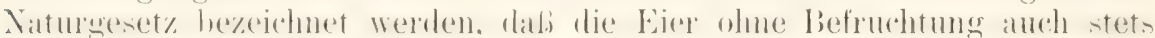

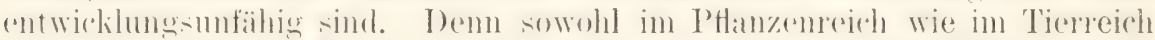

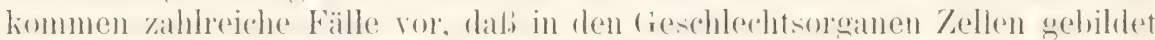
werken, welehe ihrer ganzen Anlage narh ursmeünglich hestimmt waren. sich als Eier durch liefruchtung zu entwioliehn, welde aher die Beffuchtungshediüftimkeit nachträglich verloren laben und sich infolgerlessen wanz wie vegetative Fortptlanzungszellen, wie Sporen, verhalten.

Eine höhere Alge, die Chara crinita, findet sich im ganzen nördlichen Europa nur in weiblichen Exemplaren. Trotalen werden in ihren ougonien Eier gehildet, die sich anch olme Lofruchtung zu normalen, keimfähigen Früchten entwickeln.

Noch lehrreicher sind die Fälle ron Parthenogenese im Tierreich. Sie sind namentlich bei kleinen Tieren aus dem Stamm der Arthropoden, bei Rotatorien, Aphiden, Daphnoiden, Lepidopteren etc. beobachtet worden. Dieselhen Weibchen bringen zu gewissen Zeiten in ihrem Eierstock nur Eier hervor, welche sich ohme Befruchtung entwickeln, und zu anderer Zeit wieder Eier, welche der Befruchtung beäurfen. Beide physiologisch so verschierdenen Eier untersheiden sich gewöhnlich and in ihrem Auschen. I) prerthenogenotischen Eier sind anderondentlich kiein und dotteram und werden demgemäß in größerer Zahl und in kurzer Zeit entwickelt. Die hefruchtungsherburtigen Fier dagegen ïhertreffen sie un ein Vielfaches an

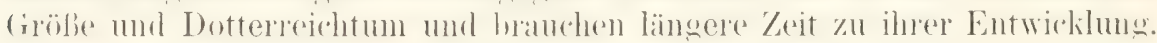
Da die ersteren allein im Sommer, die letzteren hauptsächlich bei Beginn der kalten Jahreszeit gebildet werden, hat man sie auch als Sommerund Wintereier mterschieden. Letztere heißen auch Danereier. da sie nach der Befruchtung eine längere Ruheperiode durchmachen müssen, während die Sommereier immer sofort wieder in den Entwicklungsprozeß eintreten (Subitaneier).

Eine Beziehung zu åuberen Bedingungen ist bei der Entwicklung der parthenowenetischen sommereier und der hefruchtumgsediurfigen Winter-

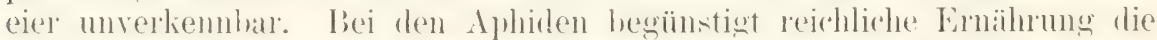

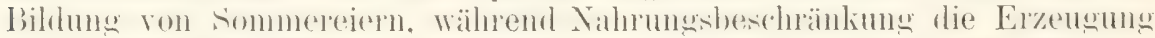
befruchtungshediuftiger Eior verandalit. Auch bei den Daphnoiden bestehen angenscheinlich beziehungen zu den äuberen I, shenshedingungen. wenn anch rlie einzelnen Falitoren sich experimentell weniged leirht feststellen lassen. Es geht dies schon daraus hervor, dab bei den einzelnen Arten der Daphnoiden, je nach den Lebensbedingungen, unter denen sie sich befinden, der Generationszyklus ein verschiedenes Aussehen gewinnt. Bewohner kleiner Pfützen, die leicht austrocknen, bringen nur eine oder

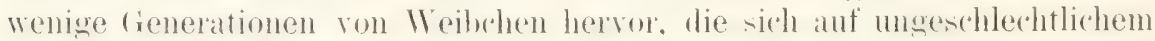
Wege vermehren: damn werden sehom hefruchtungsherlïftige fier erzengt. so daß im Laufe eines Jahres mehrere Zeugungskreise (bestehend aus Jumgfermweihwhen und fieshlechtstieren) aufeinander folgen. See- und Meerbewohner dagegen erzengen eine lange Reihe von .Jungfernweibchen. ehe es gegen Ende der warmen Jahreseit zur Ablage von hefruehtungs- 
bedürtigen Daucreiern kommt. Ein Zengungskreis füllt daher lier cin ganzes Jah aus. (Polyzyklische und monozylische Arten von Wrismaxy.)

WEIsmaxy (XII 16-60), der den fiegenstand einer sehr eingehenden Pröfung unterworfen hat, bemerkt, .. lab ein- und zweigeschlechtliche fene-

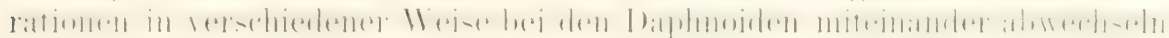
und dal.) der Modus ihres Wechselus in auffallender Bezielıung zu den äuleren Lebensverhälnissen steht. Je nachdem Vernichtumgsurachen (Kialte. Austrocknen usw.) mehrmals im Jahre oder nur eimmal oder gar nicht die liolonien einer Art heimsuchen, finden wir Daphnoiden mit mehrfachem

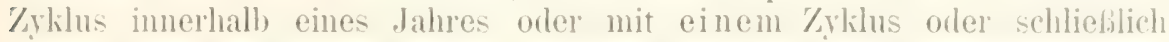
sogar Arten, welche gar keinen Generationszyklus mehr erkennen lassen. und wir kömnen danach polyzyklische, monozyklische mul arylische Arten unterscheiden." Bei manchen Arten, die häufig wechsehnden Pedingungen ausgesetzt sind, beobachtet man, daf., von den im Eierstock sich entwickelnden Eiern einige sich zu Sommereiern ausbilden. wïhrend andere den Ansatz machen. zu Wintereiern zu werden. Ws findet nach einem Ausspruch von Wersudax im Körper der Weibchen .gewisimalien ein Kample statt zwischen der 'Tendenz zur Bildung ron Dauereiern und derjenigen zur bildung von Sommereiern". So kann man namentlich bei Daphnia pulex zwischen mehreren Sommereiern ötters die Anlage eines Dauereies im Ovarium erkennen, welches einige lage wächst. sogal beginnt. den feinkörnigen. charakteristischen Dotter in sich abzulagern. damn aber in ter Entwicklung stille steht, um sich sodann allmählich aufzulösen und vollständig zu verschwinden. Wenn Wintereier entwickelt worden sind, aber infolge der Abwesenheit von Mänmchen nicht befruchtet werden kïmmen. so zerfallen sie nach einiger Zeit, und es kommt jetzt wieder zur Entstehung von Sommereiern.

ITie erlilït es sich num. dab von Eiern. die in demselhen lieimstock nacheinander entstehen, die einen der Befruchtung bediurfen. die

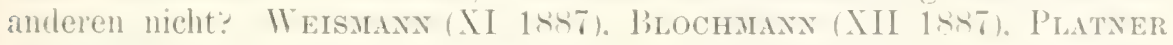
(XII 185!) u. a. haben die sehr interessante Entrleckung gemacht, dal.) in der Bildung der Polzellen (siehe darüher S. 239. 27-

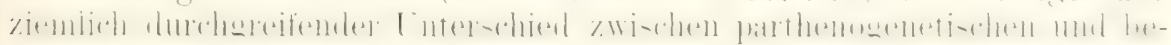
fruchtungsbediurftigen Eiern besteht. Während nämlich bei letzteren zwei Polzellen wie gewöhnlich abgeschnürt werlen. unterbleibt hei ersteren die Entwicklung der zweiten Polzelle und infolgedessen auch die mit diesem Vorgang sonst rerbundene Redultion der Kernsubstanz. Der Eiliern des Sommereies der Daphnoiden z. l). besitzt daher a uch ohne befruchtung die ganze Tucleinmasse eines Tormalkerus.

Es ist aber leicht einzusehen. dal. durch dies interessunte Verhalten das Wesen der Parthenogenese selbst in kemer Weise erklärt wirl. Denn das Sommerei hat ja die Neigung. sich ohne Befruchtung zu entwickeh. schon ehe es zur Bildung der Polzellen schreitet. wie aus der geringen Ansammlung des Dotters. der abweichenden Beschatfenheit der Iü̈llen ete. hervorgeht. Das Ei wird nicht dadureh parthenogenetisch. Weil es die zweite Polzelle nicht billet. somdern weil es schon für parthenogenetische Entwicklung hestimmt ist. hildet es lie zweite Polzelle nicht: es hildet sie nicht. Weil unter diesen Verhältnissen eine Redulition der Kermmase. die ja eine nachfolgende befruchtung zur Voraussetzung hat. keinen \%weck mehr hat.

Auf dem (iebiete der Parthenogenese sind noch manche eigentümliche Erscheinungen beobachtet worlen, deren genameres Studium wahrscheinlich zur liburung dieser und jener frage noch manches heitragen 
wird. Eine solche Erscheinung, deren 'Tragweite zurzeit noch nicht iihersehen werden kamn, ist die 'Tatsache, daß der Vorbereitungsprozeß für die Befruchtung sogar dann, wenn er schon weiter als bis zur Bildung der ersten Polzelle geschritten ist, wieder rückgängig gemacht werden kam.

Bei manchen Tieren machen die Eier, wenn sie nicht zu normaler Zeit befruchtet werden, gewissermaßen noch einen Ansat\% zu einer parthenogenetischen Entwicklung. Von den Eiern mancher Würmer, einzelner Arthropoden, Echinodermen werden Angaben gemacht, dab sie auch bei Abwesenheit von mämnlichem Samen sich zu furchen, eventuell selbst Keimblätter zu bilden begimmen, damn aber in ihrer Entwicklung still stehen bleiben und absterben. Abnorme. äußere Verhältnisse scheinen das Zustandeliommen solcher Parthenogenese in einzehnen Fällen zu begünstigen, wie z. B. bei Asteracanthion. In derartigen Fällen ist num von Boveri (VIII 1890) bei Nematoden und bei Pterotrachea, von mir (VIII 1890) bei Asteracanthion (Fig. 27.t) folgender bemerkenswerter Vorgang bei der Entstehung der Polzellen beobachtet worlen.

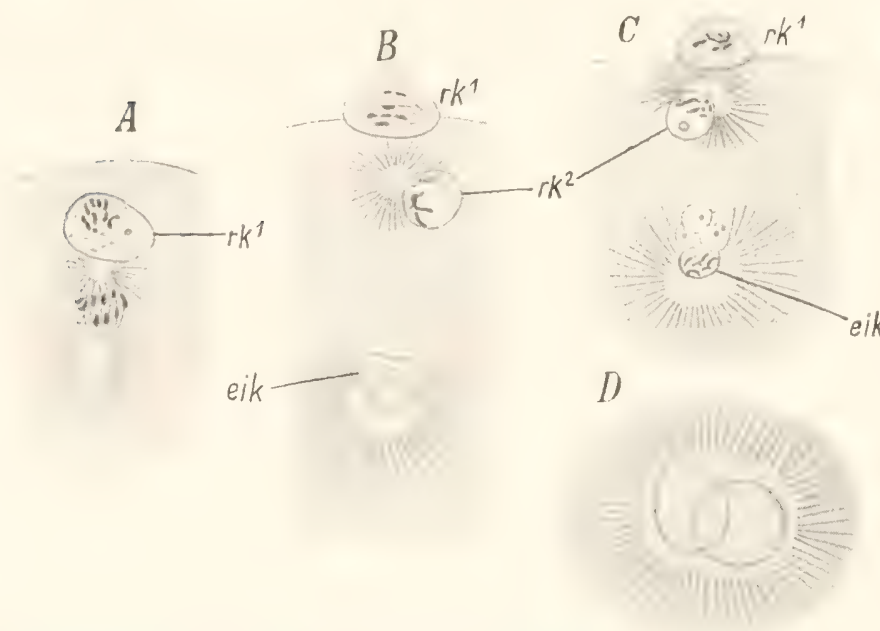

Fig. 274. Die AnlagezurBildung des zweiten Richtungskörpers und Einbeziehung desselben an einem zur parthenogenetischen Entwicklung neigenden Ei von Astropecten. Nach O. Hertwitis aus KORSCHEIT 11. HEIIER. 1 Die zweite Liv'htumu-y pindel umd darüber liegend der ersteRichtungskürper $\left(r k^{1}\right), B$ und $C$ unter dem exsten Richtungskörper der Kiern des zweiten lichtungskiorpers $\left(\% \%^{*}\right)$ nach Teilumg der ersten Richtuugsspindel, weiter nach inmen der Eikern (erk), $D$ der Eikern und der Iern des zwriten Richtungskörpers, dicht aneinander gelagert.

Nach der Abschnürung der exsten Polzelle (Fig. 27t $A, r k^{1}$ ) ergänzt sich die im Ei zurüchgebliebene Spindelhälfte wieder zu einer Volspindel, als ob jetzt noch die zweite Polzelle abgeschnürt werden soll. Trotzdem

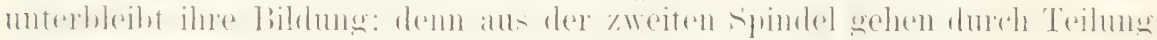
nur zwei Kerne hervor, die im Ei selbst bleiben (Fig. $27+B$ u. C. $\% k^{2}$ u. cik). Hier verschmelzen sie nach einiger Zeit, inlem sie sich nach der Nitte rles Dotter's hin bewegen, nachträglich wieder miteinander und liefern so (Fig. 27+D) wieder einen Kern, durch welchen die bald nachfolgenden, parthenogenetischen Prozesse eingeleitet werden. Es wird hier also die zweite Teilung, welche die Reduktion der Kermmasse und eine nachfolgende Befruchtung zum Zweek hat, wieder rückgängig gemacht. Daß hierdurch kein ausreichender Ersatz für den Ausfall der Befruchtung geschaffen ist, lehrt der weitere Verlanf des in Szene gesetzten, parthenogenetischen Entwicklungsprozesses, nämlich das mehr oder minder frülı erfolgende $A b$ sterben des Keimes. 
Aus dem Limstand, dab bei parthenogenetischer Entwicklung die Bildung der zweiten l'olzelle unterbleibt oder wierler rüikgïngig gemacht wird. liömnte man den Schlub ziehen. dafi eine Entwicklumg in allen Fällen unmöglich sei. in welchen sich sehon die lienlution ler Kermmasse auf die Hälfte des Normalmakes vollzogen habe. und dab sie damn nur durch Befruchtung wieder hervorgerufen werden könne.

\%urzeit kamm auch diesel' Schlulj, der vielleicht etwas Wahres in sich schlielit. nicht als ein allgemein gïltiger bezeichnet werden. Demn von

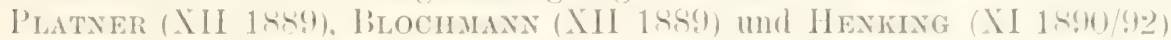
werien Beobachtungen mitgeteilt, dab Eier ron gewissen Arthropoden (Liparis dispar. Bienen), trotzlem sie wie befruchtungshediurftige Eier zwei Polzellen geliefert haben, sich doch auf parthenogenetischem Wege zu normalen Tieren entwickeln. Allerdings ist in diesen Fällen eine genanere Feststellum des Sachverhalts mit Rücksicht auf die Kahl der Kernsegmente noch wïnschenswert.

Prinzipiełl mub, jedenfalls die Möglichkeit zugegeben werlen. daß Eier. die nach Bildumg zweier Polzellen reduzierte Kerne enthalten. sich doch noch parthenogenetisch weiter entwickeln können. Denn an Tucleinmasse reduzierte Kerne haben lieineswegs ihr Teilvermögen verloren. wie man leicht glauben könnte. Besonders schlagend wird dies durch die Merogonie und durch die kiunstliche oder experimentelle Parthenogenese bewiesen.

1) Die Merogonie.

Unter Merogonie (DELAGE) versteht man die Entwickinng kernlos gemachter Eifragmente, die durch das Eindringen eines Samenfarlens einen neuen Kern, allerdings jetzt einen Samenkern, erhalten haben. Bei Seeigeleiern haben zuerst O. 1. R. HERTWIG (XII 1887) die Merogonie in folgender Weise festgestellt. Durch kräftiges Schütteln in einem Reagenzröhrchen mit Seewasser zerlegten sie reife Seeigeleier. die nur von einer diimen Gallerthiille umgeben sind, in mehrere kleinere und gröbere stücke. von denen die meisten kernlos geworden sind. Wenn man feinste Glasplitterchen vol dem Schütteln dem Meerwasser zusetzt. Kann man die Zerlegung der' Eier noch heschlemigen und durch minder kräftiges Schïtteln erreichen. Die Fragmente beginnen sich. auch wenn sie keinen Kern melı enthalten. abzurunden und wälnend längerer Zeit ihre Lebenstähigkeit zu bewahren. Sie lassen sich daher bei Kusatz von sumen befruchten. Hierbei komnte regehmäligig festgestellt werlen. dab der Samenkern orler, was noch häutiger der Fall war, die in Mehrahl eingedrungenen Samenkerne (Polrspermie) sich zu kleinen. typisch gehanten Kernspindeln mit zwei Strahlungen an ihren P'olen umwandelten. Die Anzahl ihrer Chromosomen. Welche Morgax durch Zühlen festgestellt hat, heträgt nur die Hälfte der '/ahl eines Normalkerns, ist also, wie ja anch kamm anders zu erwarten war: reduziert. Indem hierauf der Samenliern sich in 'Tochterkerne teilt. die sich ihrerseits wieder dureh indirelite Teilumg vermetren, zerfiallt das Eiframent. das man in einem Uhrschälchen isolieren und getremnt weiter züchten kam. in einen Haufen von vielen. Lileinen Embronalzellen.

Boveri (XII 1889) hat diese Entrleckung noch weiter verfolgt und ist. indem er Teilstüclie isoliert kultivierte, zu den wichtigen Ergehnis gelangt. lar., sich aus einem gröberen, kernlosen, einfach hefruchteten Eifragment sogar eine normale, nur entsprechend kleinere Lallve zübhten lälst.

Dalo Samenkerne auch ohne Verschmelzung mit dem Eikem l'eilfähigkeit besitzen, greht übrigrens auch schon aus dem Studium der P'oly- 
spermie hervor. Denn wenn viele Samentiiden in ein pathologisch verïndertes Ei eindringen, so sind es gewöhnlich nur ein orler zwei. welche sich mit dem Eikern verbinden, die anderen bleiben isolient im I)otter und beginnen nach einiger Zeit, wie 0 . und R. HerTwig gezeigt haben, sich in Spermaspindeln umzuwandeln; diese wieder können sich in Tochterkerne teilen, was schlieblich zur Folge hat. dah das von vielen Kernen

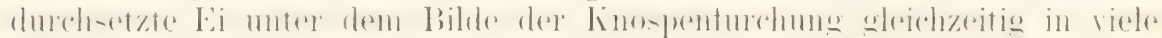
ungleich große Stüclie in unregelmäBiger Weise zerschnünt wirt.

Die Erscheinumgen der Merogonie sind auch von anderen Forschern bestätigt und weiter untersucht worden, von Morgas. ZIEgler und Delage, ron welchem der Name Merogonie herrührt. Die am meisten für solche Experimente geeigneten und benutzten Objekte sind Echinodermeneier, doch wurde das Studium der Merogonie auch auf andere 'Tierarten ausgedehnt. so von I)ELAGE auf je einen Repräsentanten der Ameliden und Mollusken.

WinkLer hat auch die Frage geprüt, ob Bruchstïcke, die ron schon hefruchteten Eiem ahweyrengt werden. sich moh eimmal hefruchen lason und ist zu dem Resultat gekommen. daß dies nur bis zum lieginn der ersten 'Teilung möglich ist. .,Sowie dagegen die erste Furchung vollzogen ist, wird das anders. Von den ersten (oder späteren) Blastomeren ab)getrennte Plasmastücke olne Kern ergaben bei erneutem Spermazusatz. so oft der Versuch wiederholt wurle, niemals irgend eine Entwicklung.

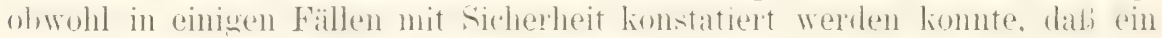
Spermatozoon eingedrungen war. Hieraus folgert WrinkLer, daß zwischen dem Protoplasma des Eies vor der ersten 'Teilung und dem der ersten Furchungszelle tiefgreifende Verschiedenheiten existieren. Schon früher hatte DELAGE gefunden, was auch ron WIXKLER bestätigt wird. (laß kernlose Fragmente von umreifen Seeigeleiern, die noch das Keimbläschen besitzen, sich nicht befruchten lassen.

Auch an geeigneten ptlanzlichen Objekten läl, sich Merogonie hervorrufen. Als ein solches hat WINkLER (XII 1901) eine Fucacee, Cystosira

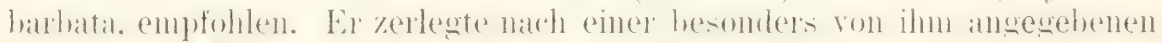

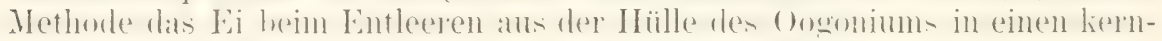

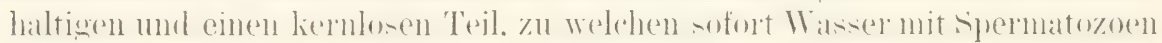
zugesetzt wurde. In mehreren Versuchen ließen sich aus beiden Stïcken Keimlinge züchten; konstant entwickelte sich ron diesen das Stïck mit \{lem befruchteten Eikern rascher, als das andere, das nur den eingedrungenen Samenkern enthielt.

c) Künstliche oder experimentelle Parthenogenese.

Es ist eine durch Erfahrungen der Pathologen wohl bekannte Erscheinung, dab durch Reize rerschiedener, aber namentlich chemischer Art Zellen nit ruhenden liernen zu Teilungen veranlaßt werden können. Als Beispiel sei auf die geätzte Hornhant hingewiesen, in welcher sich einige Zeit nach Ätzung mit dem Silher- orler Kupferstift reichliche Kernteilungsfiguren einstellen. oder auf die Gallen bei den PHanzen, welche infolge der durch Insektenstich herrorgerufenen, entziudlichen Gewebswucherung in

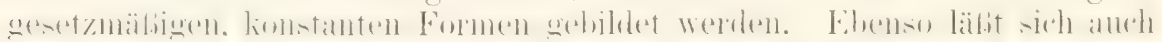
die reife Eizelle durch äuliere Eingriffe zu T'eilungen und eventuell zu einer mehr oder weniger weit fortschreitenden Entwicklung anregen, welche

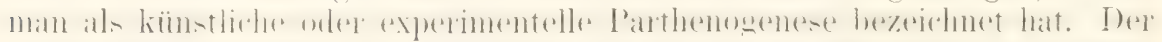

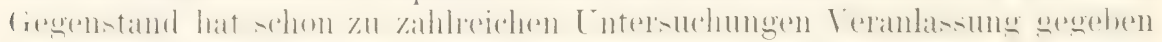
und eine um so gröbere beachtung gefunden, je mehr einige Forscher 
durch ihn das Wesen der liefruchtung glaubten aufliaren zu kömmen in einer Weise. Welche sich, wie in einem späteren Abschnitt besprochen werden wirl. in keiner Weise rechtfertigen lisht.

Um die Ertorschung der experimentellen Parthenogenese haben sich

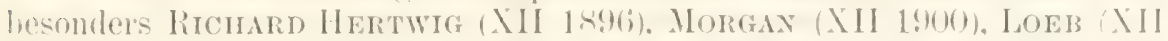

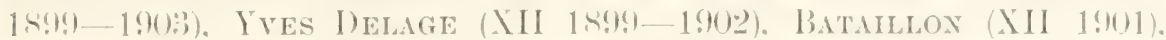
Wixker (XII 1!)(), 1901). WILSON (XII 1901) remient gemacht. Wie R. HerTwig feststellte und WassulefF (XII 10(0)2) später bestätigte, begimmen bei reifen Seeigeleiern, wem sie $1 \frac{1}{2}$ bis ; Stmulen in Meerwasser mit einem. Zusatz von 0.1 "' strychnin übertragen werden, die lierne sich nach kurzer Zeit in mehr oder minder abgeänderte Teilungstiguren, in einund zweipolige Spindehn, umzuwandeln. Doch kommt es trotz dieser Kernverïnlerungen in der Regel nieht zu einer 'Teilung des Eies.

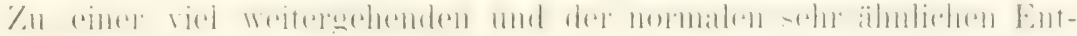
wicklung haben LoEs und Yves DEIAGE die Eier vou Echinodermen und Würmern zu bringen vermocht. Wenn sie dieselben in geeigneter Weise mit Salzlösungen behandelten. LOEB hat zahlreiche (iemische ausprobiert. indem er Meerwasser entweder mit $\mathrm{MgCl}$, oder $\mathrm{KCl}$ oder $\mathrm{NaCl}$ oder $\mathrm{CaCl}_{2}$ in verschiedenen Prozenten versetzte. Xachdem die reifen Eier ron See-

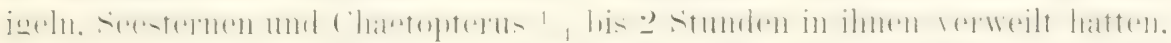
wurlen sie in reines Meerwasser zurïckgehracht. Je mehr $\mathrm{MgCl}$, orler $\mathrm{KCl}$ dem (iemisch zugesetzt war, um so kürzer mubten die Eier, wenn normale Entwicklung eintreten sollte, in ihm belassen werlen. Je nachdem das richtige Verhältnis getroften war, komnte ein mehr oder minder grofer Prozentsatz der Seeigeleier bis zum Stadium der Blastula und sogar des

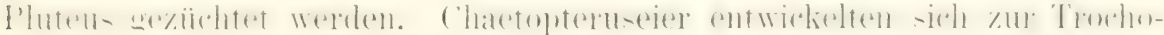
phora; besonders stark reagierten sie auf Zusatz von $\mathrm{KCl}$ zum Seewasser: (lenn wemn sie nur ;) Minuten lang in ein (remisch ron 2 cem $21 / 2 \mathrm{n} \mathrm{KCl}$ $198 \mathrm{cem}$ Meerwasser gebracht wurden, trat kiunstliche Parthenogenese ein. Auch Zusatz von sehr geringen Mengen von Salzsäure ergab giunstige

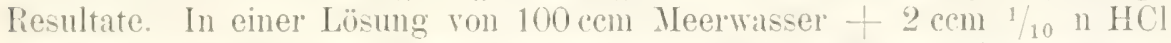

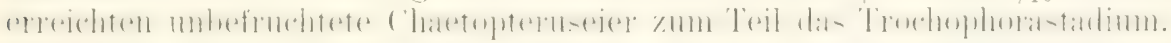
fiemische, die für Chactopterus gecignet waren, erwiesen sich für lichinodermeneier unwirkam.

Je nach der Zusammensetzung der angewandten Flüssigkeit kömnen pathologische Entwicklungsmozesse hervorgerufen werden: so können anstatt einer Larve aus einem Ei drei. vier oder selbst sechs Blastulae den Ursprung nehmen. Letzteres ist der Fall. wemn das Meerwasser mit MoCl., oder \aCl versetzt wirl, während bei Zusat\%, ron gleicher Menge licl aus einem bi anch nur eine Larve hervoreht.

Fiir die Wirkmo (ler yon ihm hergestellten Flüssigkeiten giht LOEB zwei Erlabungen. In einem Teil der Fälle läbt er die Parthenogenese durch 'Zunahme des osmotischen Druckes infolge der stärlieren Konzentration der Versuchsthïssioneit hervorgerufen werklen. Es soll hierdureh den Eiern Wasser entzogen werden. Andere Fälle wieder sucht LoEn durch spezifische chemische Einwirkmgen zn erklïren. durch Substanzen. welche chemische mut physikalische Prozesse heschlemigen und daher hatalytische genamnt werlen. So nimmt er hesonders fiur rlie Versuche mit liCl an. dal. hier K-Ionen katalytisch wirken, indem sie einen Prozeli. welcher sonst zu langsam verlaufen würle, heschlemigen.

Zu ähnlichen Ergebnissen wie LoEp ist Yves Detalge geland. Welehel die meisten Versuche des amerikanischen Physiologen einer Viachuriftung muterzogen und sie zugleich noch in anderer lichtumg erweitert lat. so 
findet er, daß bei den Eiern ron Asterias glacialis auch Wärme allein Parthenogenese herrorruft, und zwar erhielt er hier die besten Ergebnisse. wemn die Wärme während kuzer Zeit und in so hohen firaden einwirkt. dab sie die Eier hei längerer Daner abtöten wïrle (XII 1901. S. 309). Wie LoEB, erzielte el günstige Ergebnisse nicht nu mit konzentrierten Salzlösungen, welche dem Ei Wasser entziehen, sondern auch mit chemischen Substanzen. welche den osmotischen Druck unverändert lasson. und sogar mit liypotonischen Salzlösumgen. Der Erklärung von LoEB hält er entgegen, daf jeder passende Reiz das Ei, welches sich in einem Zustand labilen (rleichgewichts befinde, zur Entwicklung anregen köme, (dab) der Reiz daher nicht spezitisch sei. Verschiedenartige physikalische und chemische Reize kömnen das gleiche Resultat bewirken. Wasserentziehung (Osmose) und Wirkung der Ionen sind nur ein 'Teil dieser Faktoren. Die Idee, dah die chemischen Substanzen katalytisch wirken. verwirtt el (S. 323$)$.

Die Auffassung von DeLAGE ist wohl begründet. In der 'Tat kam man auf sehr verschiedenen Wegen experimentelle Parthenogenese erzielen. Mathews komnte durch die einfach mechanische Wirkung des Schïttelıs es erreichen, daß sich aus unbefruchteten Seesterneiern Bipimarialarven entwickelten. WINkLER bereitete sich aus dem Samen von Seeigeln einen Extrakt. den er dem Seewasser zusetzte. und stellte fest, daß im Extrakt ein Stoff vorhanden ist, der unbefruchtete Eier zu einigen 'T'eilungen, im güustigsten Falle bis zum 16 Zellenstadium veranlaßte. Allerings fiel ein grober T'eil der Versuche negativ aus.

Ein ausgezeichnetes Mittel für eine experimentelle Parthenogenese bei den Seesternen fand DeLAGE in der Kiohlensäure.

Bei den Versuchen über kïnstliche Parthenogenese sind noch drei Punkte zu beachten. Einmal ist das Ei in gewissen Phasen seinel Ent-

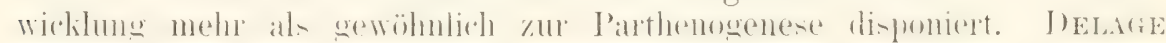
bezeichnet es als das kritische Stadium und findet ein solches für die Seesterneier in der Zeit. wo das Keimbläschen sich auflöst und wo die erste Polzelle gebildet wird. Nach der Bildung der zweiten Polzelle und dem Auftanchen des Filierns int lï̈nstliche Panthenowenese sehr viel schwieriger hervorzurufen.

Zweitens ist im Auge zu behalten, dal, zwar in einigen Fällen Seeigel- und Seesterneier sich parthenogenetisch bis zum Pluteus und zur

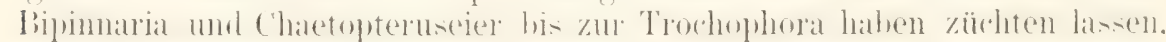
bei den meisten Versuchen aber kommt die Entwicklung schon nach den ersten 'Teilungen oder auf dem Keimblasenstadium zum Stillstand. Das Ei stirbt dam ab oder zerfällt. Daraus geht hervor. dak die Eingriffe zwar einen Entwicklungsreiz abgegeben, dabei aber die ganze Konstitution des Eies geschädigt und zerstört haben. Auch sonst erweist sich die experinentelle Parthenogenese in ihrem sinzen Verlanfe häution als eine gathologische. Nicht nur entstehen, wie schon erwähnt. in manchen Fällen aus

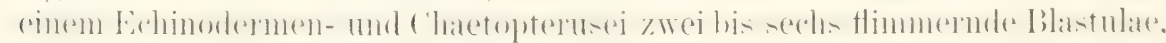
die später zerfallen, sondern der Teilungsprozeb ist schon von Anfang an nicht der normale. So tanchen im Protoplasma, wie R. Hertwig. Morgan und WiLsox eingehend untersucht haben, viele Strahlensysteme unter Nenbildung von Centrosomen (WILSON) auf. Die karyokinetischen Figuren fallen vielfach abnorm aus (R. Hertwig. Wassilieff). Fächerkerne, unipolare Mitosen, muegelmähige Verteilungen der Chromosomen werden beobachtet. Bei Asterias treten in vielen Fällen viele Kerne im Ei auf. ohne dab es eine Zeitlang in Zellen zerlegt wirl. Erst später stellt sich 
linospenfurehung oder eine Framentation ein, durch welehe das Li in kleinere Stïcke zerfällt unel sehlieblich noch in eine Blastula umgewandelt wirl. Wie DeLage hervorhebt, lassen sich in diesen Vorgingen unzaihlige Variationen beobachten. Dab man es hier zum Teil mit pathologischen Erscheinumgen, die durch die angewandten Reize hervorgerufen sind (XII Is)1. S. 31s). zu tum hat, kamn wohl kamm einem /weifel muterliegen. Auch in dieser lieziehung ergehen sich V'ergleichspunkte zu den Zellwucherungen. die sich durch Reizzustände in fieweben hervorrufen lassen und auf welche schon olen hingewiesen wurde.

Drittens rerdient ausdrïcklich hervorgehoben zu werden, dal.j. wemn rei ganz reifen Eiern. welche die zwei Polzellen schon abgeschnürt haben, ziinstliche Parthenogenese eintritt, lie sich teilenden Kerne nur die halloe Chromatimnenge und die halhe Chromosomenzahl eines Normalkerns besitzen. Eine Zunahme der Chromatinsulstanz ist also spontan nicht einzetreten. Fs ist genau dieselbe Sachlace wie bei der Merogronie, bei welcher die von Samenker'n abstammenden Kerngenerationen anch nu die halbe Chromosomenzahl haben. Fiur das parthenogenetisch sich entwickelnde Seeigelei ist dieser l'unlit von W ILsox besonder's durch Zïhlungen festgestellt worden. Er fand in den liermspindeln sich furchender Embryonalzellen nur is anstatt der normalen :36 Chromosomen (siehe Tabelle aut $\leqslant .2(1:)$.

Auf die Folgerungen, die LoEB aus den Erscheinungen der experi-

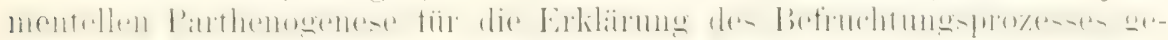
zogen hat. wird später noch eingegangen werden.

\section{(l) Die Apogamie.}

An die Parthenogenese lassen sich noch die ihr sehr nahe stehemen Erscheinungen anschließen. welche DE BARY (XII 187R) unter dem Namen Apogamie zusammengefabt hat.

Apogamie wurde bei einigen Farnkriutern beobachtet. liei denselben findet bekanntlich eine Entwicklung mit Generationswechsel statt.

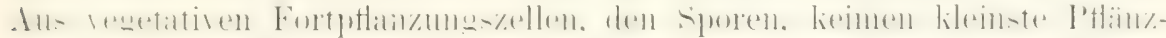
chen. die Prothallien. hervor. die bestimmt sind. mämnliche und weibliche Geschlechtsorgane und aus letzteren Eier zu bilden. Wenn die Lier befruchtet werden. liefern sie wieder auf vegetativem Wege ein sich fortpflanzendes Farnkraut.

Bei Pteris cretica und Asplenium filix femina cristatum und falcatum ist num der sonst. so konstante (renerationswechsel durchbrochen. Entweder erzengen die Prothallien dieser drei Arten äberhaupt keine Geschlechtsolgane oder nur solche, die nicht mehr in lunktion treten, also

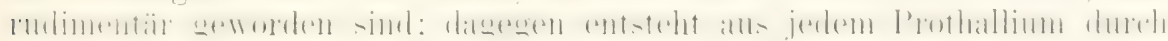
vegetative Sprossung ein nenes Farnliraut.

Da es sich bei den drei Farnarten um Lúulurptlanzen handelt. so liegt die Vermutung nahe. dab die Entwicklung befruchtumgshedüttiger Zellen durch die überreiche Frnährung unterdriickt und die vegetative lermehrung heginnstigt worilen ist.

\section{2) Die sexuelle Affinität.}

Lnter sexueller Affinität verstehe ich Wechselwirkmoen. welche befruchtungsberürftige Zellen verwandter Lrt aufeinander ausiben in des Weise, dabs sie, in bestimmte Nähe zu cinander gebracht. sich anziehen. sich verbinden und in eins verschmelzen. gleichsam wie zwei chemische 
Körper, zwischen denen nicht gesättigte, chemische Affinitäten bestehen. Wenn beide Geschlechtszellen beweglich sind, so stüzen beide aufeinander z11: wemn die eine Zelle als Ei unbeweglich geworden ist. so wird die wechselseitige Anzichung sich in der bewegungsrichtung des Samenfarlens besonders bemerkbar machen. Aber anch nach der Verschmelzung der heiden Zellen wirlit die sexuelle Affinitiit noch weiter und äubert sich in der Anziehung, welche Ei- und Samenkern mit ihren Zentrosomen aufeimander ausüben und zu den frïher beschriebenen Aneinanderlagerumgen und Verschmelzungen führen.

Es bleibt num zweierlei in diesem Abschnitt an Beispielen zu beweisen, erstens, (lab) zwischen befruchtungsbediuftigen Zellen überhaup. Wechselwirkungen stattfinden, welche mit dem Namen „sexuelle Affinitä" bezeichnet werlen können, und zweitens, daß diese Affinität nur zwischen Zellen bestimmter Art in Wirksamkeit tritt, woran sich die Frage schliebt, welcher Art die befruchtungsbedürftigen Zellen sein miissen.

\section{a) Die sexuelle Affinität im allgemeinen.}

Daß Geschlechtszellen auf eine gewisse Entfernung hin eine deutlich

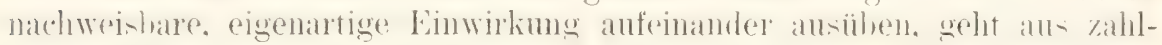
reichen Mitteilungen zuverlässiger Beobachter hervor. Ich beschränke mich auf einige besonders lehreiche Fälle, welche von FALKExBERG, DE Bary, Engelmann, Juranyi, Fol beschrieben worden sind.

FALKENBERG (XI 1879) hat den Befruchtungsvorgang an einer nimbren . Mgengattung. Cutleria. verfolgt. Zu emptängnisfähigen. zur Ruhe gekommenen Eiern von Cutleria adspersa setzte er lebhaft schwärmende Samenfäden von der nahe verwandten und äuferlich nur durch geringe I) ifferenzen unterscheillaren ('utleria multifida hinzu. ..In solehen Fiallen sah man die Spermatozoiden unter dem Mikroskop ziellos umherirren und endlich absterben, ohne an den Eiern der verwandten Algenspezies den

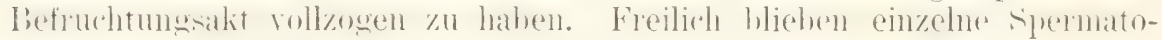
zoiden, welche zufällig auf die ruhenden Eier stießen, momentan an diesen

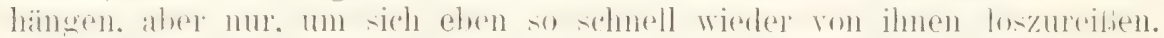
Ganz anders aber wurde das Bild unter (dem Mikroskop, sobald man auf herartigen Präparaten den Spermatozoiden anch nu ein einziges hefruchtung-

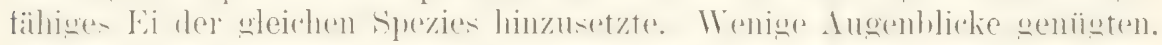

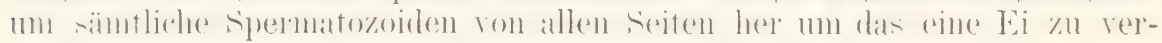
sammeln, selbst wenn dasselbe mehrere Zentimeter von der Hauptmasse

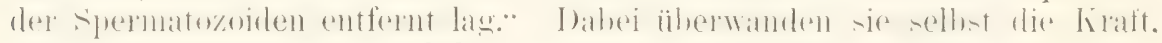
welche sie sonst dem einfallenden Licht entgegenführt, und wurden befähigt, die dem Lichteinfall entgegengesetzte Richtung einzuschlagen.

FALTEnBerg zieht aus seinen Beolachtungen den Schlub, dab) die Anziehungskiaft zwischen den Eiern und den Spermatozoiden ron Cutleria sich auf verhältnismäbig bedeutende Distanzen geltend macht und in ihnen selbst ilnen Sitz haben muf. daf auf der anderen Seite aber diese An-

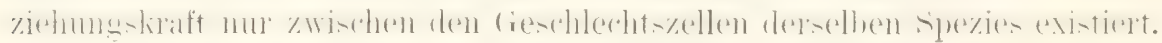

Bei Untersuchung der geschlechtlichen Fortpflanzung ron Peronosporeen lat DE BARY (XII 1Rs1) beobachtet, daf in durcheinander gewachsenen Thallusfäden sich zunächst die Oogonien anlegen. Etwas später entstehen die Antheridien, aber stets nur in unmittelharer Nachbarschaft der Eizellen und zwar sehr häufig aus Thallusfärlen, die mit dem Faden, aus dem das Oogonium abstanmt, selbst keinen Zusammenhang haben. DE BART schliebt hieraus, daf, rom Oogonium auf eine geringe Distanz 
eine Wirkmg ausgehen mïsse. durch welche der Thallustarlen zur IBildung

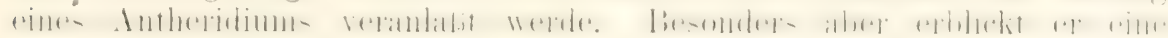
Fernwirkung darin, dal., der das Antheridium liefernde schlanch bei seines Annähermng an das Oogonimm von seiner Wachstumsrichtmog abuelenkt wird. sich mit semem Ende ilm zuneigt und sich ilm damn dicht anlest. DE BARY schätyt die Distanz, in welcher das Oogonium ablenkend wirkt. anf ungefïh die cröbe des Oogonimmdurchmessers und bemerkt dazı: .Die beschriebene Ablenkmmg der Yehenäste lïbt sich auf keine andere

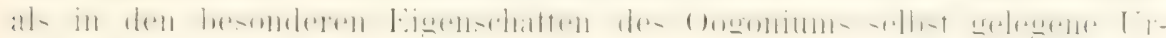
sache zurvickfïhıren."

Nieht minder interessant und bemerkenswert sind die Angaben. die ExgELMaxy (XI 1875) über die Konjugation von lonticella microstoma gemacht hat. Bei dieser Art bilken sich durch Kinospung (siehe S. 2f()) kleine, mänmliche Schwärmzellen, die dam wie Samenfäden die grofen weiblichen Individuen befruchten (S. 299). In vier Versuchen räichte es Exgedmax, die Kinospe nach ihrer Abtrennung von der Mutterzelle zu rerfolgen, bis sie sich mit einem anderen Individum verbunden hatte.

.Anfangs schwänte die Knospe., so lantet die Darstellumg von ENGELMANx, .mit ziemlich lionstanter Geschwindigkeit (etwa $0.6-1 \mathrm{~mm}$ in der Sekunde) und immer um ihre Längsachse rotierend. meist in zienlich gerader Richtung durch den Tropfen. Dies dauerte ŏ-10 Minuten oder noch länger, ohme daß etwas Besonderes geschehen wäre. Damn

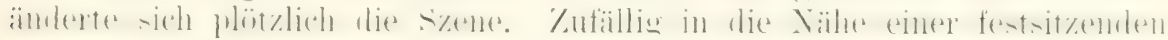
Vorticelle geraten, änderte die Linospe, zuweilen wie mit einem Ruch, ilure Richtung und nahte nun, tanzend wie ein Schmetterling. der um eine Blume spielt, der Vorticelle, glitt wie tastend und dabei inmer um die eigene Längsachse rotierend auf iln hin und her. Nachdem dies Spiel

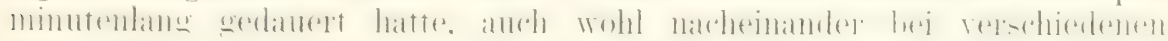
festsitzenden Individuen wiederholt worden war, setzte sich die linospe endlich fest. und zwar meist an aboralen Ende. nahe dem Stiel. Nach wenigen Minuten war die Verschmelzung schon merkbar im Gange."

Ein in physiologischer und speziell psychophysiologiseher Beziehung noch merkwurdigeres Schauspiel," bemerkt ExGELudxy im Anschlub an die oben gegehene Schilderung, .beobachtete ich ein anderes Mal. Eine frei schwämende hnospe kreuzte die Bahn einer mit arofer Geschwindigkeit durch den Tropfen jagenden. groben Vorticelle, die auf die wewöhnliche Weise ihren Stiel verlassen hatte. In Augenblicke der Begegnung - Berïhrung fand inzwischen durchaus nicht statt - inderte die Kinospe plötzlich ihre Richtume und folgte ler Vorticelle mit sehr arober fieschwindigheit. Es entwickelte sich eine förmliche Jagd, die etwa ఏ) Sekmulen danerte. Die Knospe blieh während dieser Keit nur etwa 1/15 mm hinter der Vorticelle, holte sie jedoch nicht ein. sondern verlor sie, als dieselhe eine plötzliche Seitenschwenkung machte. Hierauf setzte die hnospe mit der anfänglichen, geringeren ( reschwindigkeit ihren eigenen Weg fort."

Eine Einwirkme auf Distanz ist auch bei den Tieren durch For. (VIII 1575). und zwar an Seesterneiern heohachtet worlen. I)ieselhem sind von einer dïmen fiallerthülle mugehen. Sowie nene Samenfäden derselhen Art sich der Oberfläche der (rallerte nähern. ïbt der am weitesten vorgedrungene eine deutlich wahrnehmbare Einwirkung auf den Dotter ans (Fig. 275-4). Die hyaline Rindenschicht desselben erheht sich als ein kleiner Fortsatz und streckt sich als Emplïngnishïgel (cône dattraction) dem Samenfaden entgegen. Bald ist er zart und in Form einer Taulel oder einer Zunge ausgezogen. bald ist er breit und kiur. Tremn die Be- 
rührung mit dem Samenfaden hergestellt ist, wird der Empfängnishïgel eingezogen.

FoL hält die Beobachtung für ganz sicher und bemerlit zu ihr: .Wenn die Tatsache selhst, dab der Samenfarten auf den Dotter, von welchem er noch durch einen relativ beträichtlichen Zwischenraum getrennt ist, eine Wirkumg ausübt, unbestritten ist, so ist doch der Mechanismus (lieser Fernwirkung (Action à distance) nichts weniger als klar."

Ich beschränke mich auf die angeführten Beobachtungen, deren Zahl sich leicht vermehren lieke, und fïge noch folgende Worte des Botanikers SACHS (III 1890) hinzu:

„Zu den überraschendsten Tatsachen im Bereiche der Befruchtungs-

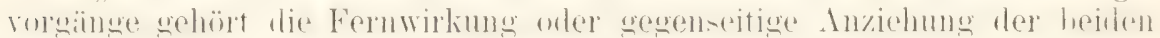
Sexualzellen aufeinander. Ich wähle diesen Austruck für die nähır zu beschreibenden Tatsachen, weil er kurz ist und den Sachverhalt wenigstens bildlich klar bezeichnet; mit den Worten Fernwirkung und Anziehung soll aber zunächst nicht gerade der in der Physik damit verbundene Sinn verstanden sein." ".In den zahlreichen Beschreibungen,
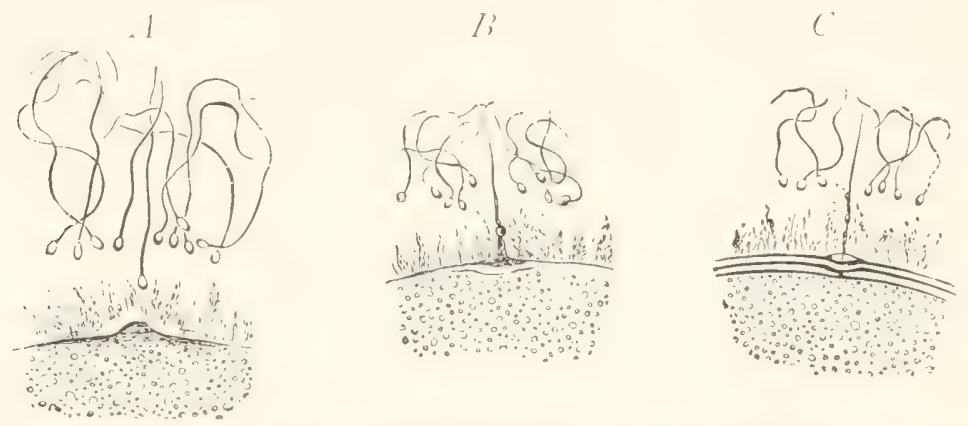
Nach FoI.

Fig. 2\%). A, B , C Kleinere Aloschnitte von Eiern von Asterias glacialis.

Die Samenfaden sind hereits in die Schleimhülle, welche die Eier überzieht,

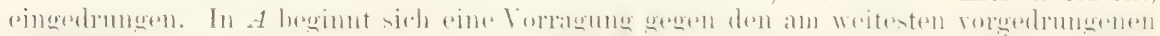
Simmentalen zu erheben. In $l$ ' sind Vorragung und Samenfaden zusanmengetruffen. In $C^{\prime}$ ist der Samenfaden in das Ei eingedrungen. Es hat sich jetzt eine Dottermembran mit einer kraterförmigen öffnumg ausgebildet.

welche die Beobachter von dem Verhalten der Samenfäden in der Nähe der Eizelle, der schwïmenten tameten mud der Antherilien in der Sartrharrobaft der ()ogonion gehen. begegnet man ansmahmslos den hestimmtesten Ausdrücken dlafür, dab irgend eine gewisse Einwirkung der Sexualzellen auf sine gewisie bintfermung hin sich geltend matht. mol zwar

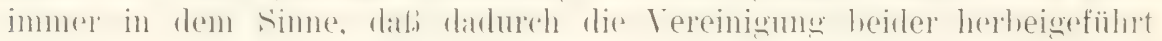
odler begünstigt wird. Dieser Vorgang ist um so merkwürdiger, als un-

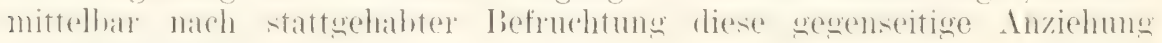
verschwunden ist."

Man wird sich naturgenäb die Frage vorlegen, welche Art von Kräften denn bei den geschilderten Erscheinungen zur Erklärung dienen kann. Pfeffer hat auf Grund der früher besprochenen Experimente (S. 16t) die Ansicht ausgesprochen, daß bei den von ilm geprüften Objekten die Samenfärlen durch chemische Substanzen, welche die Eizelle ausscheidet, zu dieser hingelockt werden. Man muß sich hïten, diesen Beobachtungen eine zu weittragende Berleutung beizulegen, was der Fall sein würde, wenn man mit ihnen die Vereinigung zweier Geschlechtszellen glaubte erklären 
zu können. Nach meiner Ansicht liönnen die chemischen Substanzen. welche von den Eizellen ausgeschieden werden, nur untergeordnete Hiilfsmittel bei der Befruchtung sein, welche etwa eine aihnliche liolle spielen. wie die schleim- und (iallerthïllen mancher Eier, durch welche die Samenfäden festgehalten werden, Dagegen kömnen sie zur Erklärung der unmittelbaren Vereinigung der Geschlechtszellen selhst, also zur Erlitirung des eigentlichen Befruchtungsvorgangs, nichts beitragen. Is geht dies schon atts einer einfachen Erwignng hervor. Nach den Lntersuchungen von PFEFEr wird Äpfelsäure von den Arehegonien der verschiedensten Farne ausgeschieden. 'Trotzdem verschmelzen nu' die Samenfärlen derselben Art mit der Eizelle. während Samenfäden einer anderen Art gewöhnlich die Befruchtung nieht ansführen kömnen. Hier liegen demmach Ieviehungen der (ieschlechtsprodulite zu einander you. Welche sich nicht dunch lieizwirkung ansgeschiedener, chemischer Stofte erklïren lassen. Dasselhe gilt von der lereingung sehwirmender fimeten, ron der bikhung des Empfännishügels tierischer Eier, von den Entgegenwandern des Ii- und Samenkerns.

Nigel (II 1sit) spricht die Vermutumg aus. dab der geschlechtliehen Anziehung elektrische Kräte zugrumble liegen möchten. was mir schon eine weiter reichende Erlibirung zu sein scheint. Solange aber ein Beweis dafiur nicht erbracht ist. wirl es richtiger sein, die geschlechtlichen Erscheinungen allgemein auf die Wechselwirumgen zweier etwas verschiedenatig organisierter Protoplasmakörper zurïckzuführen und diese Wechselwirkmgen als sexuelle Affinität zu bezeichnen. Wir müssen uns noch mit einem solchen allgemeinen Ausdruck bescheiden. da wir die in Wirkung tretenden Kräfte nicht genauer analysieren können. Vermutlich handelt es sich hier nicht um eine einfache. sondern un eine sehr z.lsammencesetzte Erscheinumg.

Es wird uns dies noch lilarer werden, wenn wir jetzt den zweiten P'unlit untersuchen: Welcher Art die befruchtungsbedürftigen Zellen sind. wenn zwischen ihmen eine sexuelle Affinität besteht.

b) Diesexuelle Affinität imeinzelnen und ihre rerschiedenen Abstufungen.

Die Möglichleit und der Erfolg einer Befruchtung wird wesentlich mitbestimmt von dem Verwandtschaftsgrad, in welchem die fieschlechtszellen zu einander stehen. Da aber der Verwandtschaftswarl auch der Auscluck für eine gröbere oder geringere Ïhnlichkeit in ihrer Organisation ist, so wiurden damit Unterschiede in der' Organisation das Ausschlaggebende sein.

Die Verwandtschaftsgrade zwischen zwei Zellen kömnen anfierordentlich abgestufte sein. Die Verwandtschaft ist am engsten, wenn die beilen für liefruchtung hestimmten Zellen unmittelbar von ein und derselben Mutterzelle abstammen: sie wird eine entferntere. Wenn ans der Minterzelle vicle Zellgenerationen hervorgegangen sind, von deren Endprodukten erst Geschlechtszellen erzengt werden. Auch hier sind wieder Linterfälle näherer und entfernterer Verwandschaft möglich. Wenn wir als beispiel eme höhere Blütenptlanze wählen, so liömnen die männlichen und weiblichen (ieschlechtszellen von ein mud demselhen Geschlechtsalyparat. also von einer Iilite, oder aber von verschiedenen Blïten desselhen Sprosses orler endlich verschiedener Sprosse ahstammen. Wont drei verschiedene lerwandtschaftsgrade gegeben sind. liei zwitterigen Tieren kömnen sie cin 
und demselben Individuum angehören, bei Tierstöcken entweder demselben Individum oder verschiedenen Individuen desselhen Stockes.

Noch mehr erweitert sich der Grad der Verwandtschaft. wenn die Geschlechtsprodulite von zwei verschiedenen Individuen ein und derselben Art abstammen. Auch in diesem Falle ergeben sich wieder viele Verwandtschaftsgrade, je nachdem die beiden erzeugenden Individuen $A b$ kömmlinge eines gemeinsamen Elternpares sind oder in entfernterer. noch nachweisbarer oder überhaupt in keiner mehr erkembaren Blutsrerwandtschatt zueinander stehen. Daran schlieben sich die Vermischungen der (ieschlechtsprodukte zweier Eltern, die sich in ihrer Organisation so weit voneinander unterscheiden. daß sie entweder als Varietäten und liassen einer Art oder als Angehörige verschiedener Arten oder gar verschiedener (iattungen vom Systematiker bezeichnet werden.

Die zahllosen Möglichkeiten, welche uns die sexuelle Affinitüt in den eben anfgestellten Reihen darbietet, ordnet man gewöhnlich in drei Gruppen zusammen, indem man 1. von Selbstbefruchtung und Inzucht, 2. von Normalbefruchtung und 3. von Bastardbefruchtung rellet. Meist ist aber viel Willkür mit der Art und Weise verbunden. wie man die einzelnen Fälle unter die drei Gruppen unterordnet. Dem es fehlt an einem Maß. nach welchem man in einer für das ganze Organismenreich gültigen Weise das Verwandtschaftsverhältuis der Geschlechtszellen bestimmen könnte.

Ein Üherblick ïber das Tatsachenmaterial wird uns lehren. dlaf sowohl zu nahe als auch zu enge Verwandtschaft der Fortpflanzungszellen - wobei ich den Ausdruck Verwandtschaft im weitesten Sinne fasse die geschlechtliche Affinität entweder beeinträchtigt oder ganz aufheht. Daher bewegt sich im allgemeinen die IIöglichkeit der Befruchtung auf einem mittleren Gebiet, welches für einzelne Arten bald weiter bald enger ist.

Auch hier wird sich zeigen, daß äußere Einwirkungen die geschlechtliche Affinität umzustimmen imstande sind. Wir besprechen zuerst die

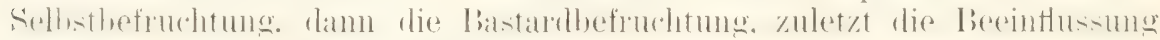
derselben durch äuBere Eingriffe.

(a) Die Selbstbefruchtung.

Die Selbstbefruchtung liefert uns sehr verschiedenartige Ergebnisse.

In manchen Fällen bestcht keine geschlechtliche Atfinität zwischen befruchtungsherlürftigen Zellen, die in einem nahen Verwandtschaftsverhältnis zu einander stehen, sei es, daß sie in direkter oder entfernterer Weise von einer gemeinsamen Mutterzelle oder von einem und demselben höher differenzierten, vielzelligen Mutterorganismus erzeugt worden sind. Niedere Algen, Infusorien, phanerogame PHanzen, zwitterige Tiere liefern uns hierfür eine Anzahl Belege.

Bei Acetabularia findet die geschlechtliche Fortpflanzung in der Weise statt. dab Schwärmsporen in größerer Anzahl aus dem Inhalt ron Danersporen erzeugt werlen. Eine Kopulation zwischen zwei Schwärmern tritt aber nur dann ein, wenn sie, wie STrAsburger und DE BARY berichtet haben, von zwei verschiedenen Dauersporen abstammen, während die aus einer und derselben Dauerspore erzeugten einander atusweichen.

..Ich sah um die Mittagsstumde," berichtet STrasbUrger (X̃ 1854), .zwei benachbarte, durchaus nicht voneinander unterscheirlbare Sporen sich unter meinen Augen ötthen und die Schwärmer beider in gerarter Richtung dem Fensterrande des Troptens zueilen. Hier bot sich alsbald ein von dem gewöhnlichen durchaus verschiedener Anblick dar. Während ich. 
nämlich sonst die Schwärmer einer und derselhen Spore in gleichmäliger Verteilung sich sichtlich ausweichen sah, bildeten sich jetzt alsbald hopulationsknoten, wenn ich so sagen darf, nämlich hanfenweise Ansammlungen. in welche sich die einzehnen Schwärmer rleichsam hineinstüzten. Solchen lopulationszentren sieht man num immer neue Pabre vereinter Sohwämer enteilen."

IBei seinen Infusorienstudien hat MaUpas (XI 1ss9) durch mehrere hundert Experimente für vier versehiedene Arten (Lencophrys. Onychodromus. Stylonichia. Loxophyllum) festgestellt. dab auch in der Zeit der

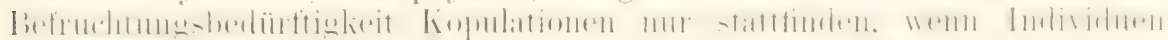

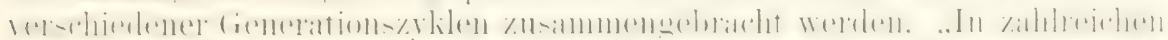

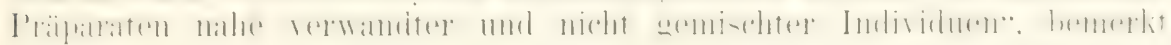
MuUPss, .endete das Fasten. welehem ich sie muterwarf. entwerler mit Fncystierung oder mit dem 'Tod durch Hunger. Nur zu einer 'Zeit. wo schon senile Degeneration in den Kulturen um sich zu greifen begommen hatte. sah ich in den Versuchsprijparaten lionjugationen nahe verwandter Individuen eintreten. Aber alle Konjugationen der Alt endeten mit dem Untergang der gepaarten Infusorien, welche nach ihrer Vereinigung nicht imstande waren. ihre Entwicklung fortzusetzen und sich zu reorganisieren.

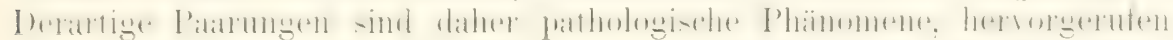
durch senile Degeneration." MAUPAs glaubt daher auch für die Infusorien eine gekreuzte Befruchtung zwischen Individuen verschiedenen Ursprungs annehmen zu müssen.

Anch bei phanerogamen Pflanzen ist für einzelne Fälle die Wirkmgslosigkeit der Selbstbefruchtung nachgewiesen worden. So berichtet Hildebraxd (XII 1867. S. 66 ) ron Colydalis cava: . 11 en die Blïten dieser Pflanze, bei welchen die geöftheten Antheren der Narhe eng anliegen, ror Insektenbefruchtung ganz geschïtzt werten. bildet sich aus ihnen niemals eine Frucht: dab hier nicht etwa der Lmstand an der Fruchtlosigkeit Schuld ist, daf. vielleicht doch der Pollen nicht an die emptaingliche Stelle der Narbe komme, geht daraus hervor. daß auch solche Blïten. deren Yarben rings mit dem Pollen der umgebenden Antheren bewischt wurlen, demnoch keine Frucht ansetzten. Zu einer vollständigen Fruchtbildung kommen die Blüten nur dann, wenn man den Pollen ron den Blïten der einen PHanze auf die Narbe der Blïten einer anderen bringt: zwar entstehen anch Früchte, wenn die blüten einer und dersell)en 'Traube miteinander gekreuzt werden. aber. diese enthalten bedeutend weniger Samen und kommen nicht immer zur vollständigen Ausbildung**

Roggen ist selbst steril, d. h. der Pollen wirkt in der eigenen Bliite nicht befruchtend. Die grobblïtige Viola tricolor bringt nur durch Krenzbefruchtung, bei der Insekten behülflich sind. keimfïligen Samen hervor.

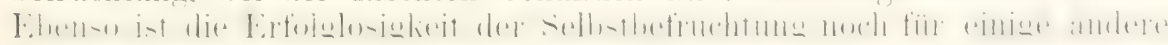
Pflanzen. einzelne Arten von Orchideen. Malraceen. Reseda, Lobelia, Verbascum beobachtet worden.

C̈ber das Verhalten bei zwitterigen 'Tieren liegen leider noch seln' wenige Versuche vor. Dieselben sind in der Regel atuch mit bedeutenden Schwierigkeiten verbunden. Bei einer Reihe ron Experimenten. die anf meine Veranlassung vorgenommen wurlen, konnte Gutrenz (XII l!)(1)t) feststellen, dab) bei der hermaphorditen Ascidie, Ciona intestinalis, die mit eigenen Samen künstlich befruchteten Eier sich nicht entwickeln oder zuweilen nur in einem geringen l'rozentsat\%. während dieselben Eier bei Kreuzbefruchtung ausnahmslos oder nur mit wenigen Ausmahmen zur Entwicklung gebracht werden. Zu demselben Ergebnis war schon vor ihm 
CASTLE (XII 1895/96) an dem gleichen Versuchsoljekt gekommen.

Zwitterschmeken wird dies ebenso der Fall sein.

Den angefïhrten Beispielen stehen andere gegenüber, die zeigen, dab zwischen sehr nahe verwandten (ieschlechtszellen sowohl volle sexuelle Affinitiit besteht, als auch normale Entwicklung bei Selbsthefruchtung eintritt. So kömen bei einzehen Konjugaten (Rhynchonema) Schwesterzellen mitemander kopulieren oder Zellen, welche, wie bei Spirogrra ein und demselben Faden angehören. (Siehe S. 308). Bei manchen Phanerogamen lassen sich die Eizellen mit dem Pollen derselben Blïte nicht nur befruchten, sondern liefern auch kräftige Pflanzen, und zwar lälot sich diese Inzucht viele Generationen hindurch mit gleich gïnstigem Erfolg fortsetzen. So ist bei der Gerste im Gegensatz zum Roggen Selbstbefruchtung möglich; auch

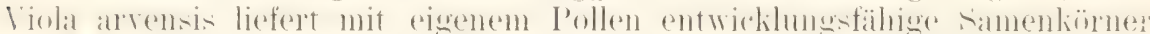
11.s.w. Von Cione verhält sich eine andlere Ascidie, Phallusia mamillata, verschieden, da bei ihr sich alle oder fast alle mit eigenem Samen befruchteten Eier entwickeln ((

Zwischen beiden Extremen. dem Mangel jeder sexuellen Affinität und dem vollen Bestand einer solchen bei nahe verwandten Geschlechtszellen kommen Abstufungen vor. Ton den zahlreichen, in einem Fruchtknoten cingeschlossenen Eizellen entwickeln sich hei hünstlich vorgenommener sellsthefruchtum mit dem Pollen derselhen libite nur einzelne und writen Zu reifen Samenkömern. Es läbt sich hieraus schliefen. dab sich die einzelnen Eizellen in ihren Affinitäten etwas verschierlen verhalten. dab einige sich befruchten lassen mit dem eigenen Pollen, andere nicht, Differenzen, die uns in ähnlicher Weise auch bei der Bastardbefruchtung wieder begegnen werden.

Endlich scheint auch der Fall eintreten zu kömmen, daß zunächst zwar die Eizellen befruchtet werlen, auch sich zu entwickeln beginnen, damn aber frühzeitig absterben. Hierauf möchte ich die Erscheinumg zul'ïckführen, dab manche Blüten, bei denen man die Selbstbefruchtung küustlich auszuführen sucht, rascher verwelken, als wenn der Versuch nicht gemacht wird, und dab dabei die Blïten gewisser Orchideen schwarz und nekrotisch werden. Wahrscheinlich ist dies eine Folge rom frühzeitigen Absterben und Zerfall der in Entwicklung begriffenen Embryonen (DARWIN XII, No. 14).

Die aus Selbstbefruchtung erzielten Samen liefern häufig nur schwächliche Pflanzen, die in ihrer Konstitution irgend einen Nachteil zeigen; auch sind die Samenkörner selbst. häufig unvollkommen entwickelt.

Aus den 'Tatsachen, daf bei vielen Organismen sich nahe rerwandte Geschlechtszellen überhaupt nicht verbinden, dab bei anderen, wenn Befruchtung zustande kommt, der Embryo bald in seiner Entwicklung gehemmt wird und abstirbt, daß endich häufig, anch wem die Entwicklung ungestört verläuft, doch die so erzeugten Organismen schwächlich ausfallen, läßt sich der allgemeine Schlub riehen, dah Selbstbefruchtung in grofen und ganzen ungünstig wirkt. Wenn in einzelnen Fällen eine ungünstige Wirkung nicht zu verspüren ist, so wird durch solche Ausnahmen die Richtigkeit dieses Satzes ebensowenig aufgehoben, als aus dem Vorkommen von Parthenogenese sich ein Einwand gegen die Ansicht, dab ein grober Vorteil mit dler Befruchtung verbunden sein muß, erheben läßt.

Daß der Selbstbefruchtung irgend etwas Schädliches anhaften mub, läßt sich indirekt auch aus einem Überblick über das Organismenreich erschlielien, welches uns, um mit DARWIN (XII. No. 1t) zu reden, in eindringlicher Weise lehrt, daß die Natur beständige Selbstbefruchtung ver- 
ahscheut. Denn ïberall sehen wir oft anferordentlich liomplizierte Einrichtungen getrofien, um Selbsthefruchtung in dieser oder jener Weise zu verhüten.

Solche Einrichtungen sind: 1. die Verteilung der (ieschlechter auf zwei verschiedene Individuen, so dab das eine nur weibliche, das andere nux mämnliche (ieschlechtszellen zu exzengen imstande ist; ¿2. die werhselseitise Befruchtung zwitteriger Tiere: :3. die ungleiche lieifezeit von liern und Samenfälen bei Pyosomen. manchen Mollusken ete. f. die ron Koez-

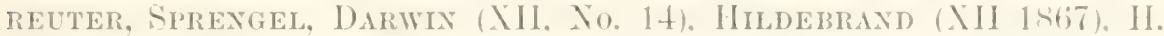
MÜLLER (XII 1s7: 1 . a. entrleckten Eigentünlichkeiten in der Oroanisation der '/witterbliiten der P'hanerogamen, die Dichogamie, Heterostylie. die vermittelnde Rolle der Insekten. welche den Pollen von einer Blüte auf die andere ïbertragen und dadurch Kreuzung hervorrufen. Namentlich bei den Blïtenptlanzen sind zur Verhütung von Selbstbefruchtung die Vorkehrungen so vielseitige und springen oft so deutlich in die Augen. dab schon SPRExGEL (XII 179:3) in seinem grundlegenden Buch: ..Das entrleckte (ieheimnis der Natur, die Befruchtung der Blumen durch Insekten" sagen komnte: .Die Natur scheint es nicht haben zu wollen, daß irgend eine Zwitterblume durch iluen eigenen Staub befruchtet werde."

\section{(i) Die bastardbefruchtumg.}

Das (iegenstück zur Selbstbefruchtung und zur Inzucht bildet die Bastardzeugung. I)arunter versteht man die Verbindung der Geschlechtsprodukte von Individuen, die in ihrer Organisation solche Unterschiede zeigen, daß sie vom Systematiker zu verschierlenen Varietaiten und Rassen einer Art oder 711 verschiedenen Arten und (iattungen gerechnet werden.

In allgemeinen ist der Grumdsatz festzuhalten. daf. die (ieschlechtsprodulite ron Individuen, die im Srstem sehr weit anseinander stehen. sich nicht miteinander verhinden lassen. Jeder wird es ron rornherein für unmöglich halten. dal.) sich das Ei eines Sängetieres mit dem Samen eines Fisches befruchten lasse oder das Ei eines Kirschbamms durch den Pollen einer Lionifere. Je näher sich aher die verschiedenen Individuen im System stehen, sei es, dal.' sie nur verschiedenen Familien orler Arten angehören oder selbst nur Varietäten einer Alt sind, um so ummöglicher wirl es, a priori das Ergebnis der liefruchtung vorauszusagen: nur das Experiment kamn uns daribler (iewilheit verschaffen, und dieses lehrt nus. daf. die einzelnen Arten im 'T'ier- und Pflanzenreich sich gesen liastardbefruchtung nicht immer gleich verhalten. (lab manchmal Individuen, die sich in ihrer Form bis auf geringü̈giue Merlimale gleichen. sich nicht kren\%en lassen. Wälend wieder ab und zu zwischen anderen, mehr ungleichartigen Individuen lireuzung möglich ist.

Mit einem Wort: die seschlechtliche Affinität stimnt nicht immer iiberein mit dem (irad der änbern Ännlichkeit. welche zwischen einzelnen PHanzen und einzelnen Tieren wahrgenommen wirl.

bei so geringfügigen Unterschieden, wie sie zwischen Anagallis arvensis und A. coerulea bestehen, die wesentlich nur durch die Farbe ihrer Ibliten unterschieden sind, ist eine hrenzung zwischen heiden trotzdem ohne Erfolg. Von Apfel- und Birmbaum. von Primula ofticinalis und Pr. elatior hat man noch keine Bastarde erhalten. wähend man auf der anderen Seite zwischen Arten. die verschiedenen (iattungen angehören. 
wie zwischen Lychnis und Silene, Rhododendron und Azaleen etc. Krenzungen mit Erfolg ausgeführt hat.

"In noch auffallenderer Weise," bemerlit SACHS. ..wird die Verschieden-

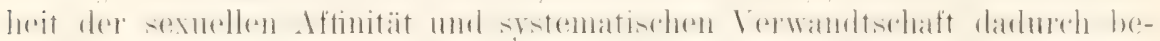
wiesen, dab zuweilen die Varietäten derselben Spezies unter sich ganz oder teilweise unfruchtbar sind. \% B. Senile inflata var. alpina mit var. angustifolia, var. latifolia mit var. litoralis $u$. a."

Im Tier- und Pflanzenreich gilst es einzelne Gattungen, deren Arten

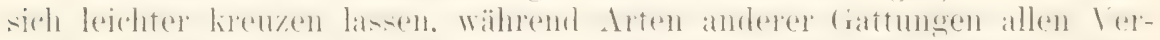

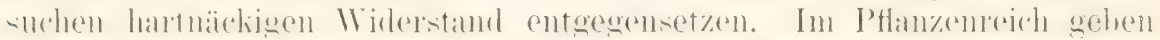

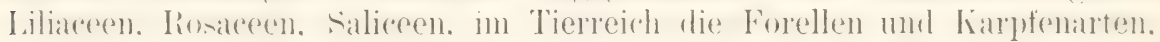
die Finkenarten etc. leicht Bastarte. Die Rassen ron Hunden. die sich

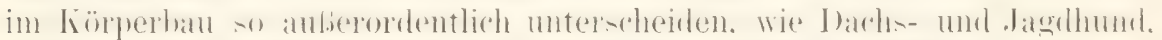
sidenpinseher und liernhardshumb, erzeumen miteinander Mischtormen.

Wie umberechenbar für uns die Faktoren sind. um welche es sich bei der Bastardbefruchtung handelt. geht nicht minder klar aus der sehr häufig zu beobachtenden Erscheinung hervor, dab die Eier einer Art A sich zwar mit dem Samen einer Art B befruchten lassen, nicht aber umgekehrt die Eier ron B mit dem Samen von A. In der einen Richtung

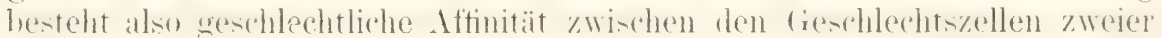
Arten, in (ler anderen Richtung aber fehlt sie. Der ausschlaggebende Falitor sheint mir ährgens herbei in der ()rwanisation des Eies zu surhen zu sein, was sich aus später mitzuteilenden Experimenten schließen läßt.

Einige Beispiele für solche einseitige Kreuzung seien hier angeführt:

Eier yon Fucus resiculosus lassen sich mit Samen ron Fucus serratus befruchten, aber nicht umgekehrt. Mirabilis Jalappe gibt mit dem Pollen von Mirabilis longiflora befruchtet Samen, während die letztere Art bei entgegengesetzter lireuzung unfruchtbar bleibt.

Ähnliches findet sich häufig im Tierreich, wo namentlich solche Arten ron Interesse sind, bei denen man liünstliche Befruchtung durch Vermischung der Geschlechtsprodukte ausführen kamn. So nahmen mein Bruder und ich (XII 1885) Kreuzungen zwischen verschiedenen Echinodermenarten ror und fanden, dab. wenn Eier von Echinus microtuberculatus mit Samen von Strongylocentrotus lividus vermischt werlen, nach wenigen Minuten überall Befruchtung eingetreten ist, indem sich die Eihaut vom Dotter abhebt. Nach 1\%, Stunden waren alle Eier in regelmäBiger Weise zweigeteilt. Am folgenden Tage hatten sich flimmernde Keimblasen, am dritten Crastrulae entwickelt, am vierten Tage hatte sich

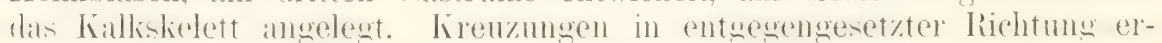
gaben abweichende Resultate. Als in einem Uhrschälchen zu Eiern von strongresentrotus lividu- samen von Echinus mikrotuhereulatus zugetünt wurde. hol, sich die Eihant nur in sehr seltenen Fällen ron dem Dotter ab. Fast alle Eier blieben @anz unverändert. Nach zwei Stunden war nur hie und da ein Ei zweigeteilt. Bei den auberordentlich wenigen, sich

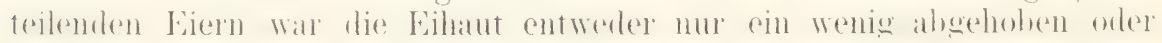
sie lag dem Dotter noch ziemlich dicht auf. Am anderen Tag waren im Lhoschälchen einige wenige flimmernde heimblasen zu hemerlien. Währemel die Hauptmasse der Eier noch ganz unverändert war.

Ein ähnliches Verhältnis beobachtete PFLÜGER (XII 1882) zwischen Rana fusca und Rana esculenta. Eier der ersten Art in Wasserextrakt des Hodens ron Rana esculenta versenkt, blieben stets unbefruchtet. Als jedoch Eier von Rana esculenta mit Samen aus dem Hoden von Rana fusca vermischt wurden, entwickelten sie sich in regelrechter Weise mit 
Ansnahme einzelner, die sich ahmorm teilten: nachdem aber das liastulastadium erreicht war, starben sie auch wieder ohne Ausnahme alb.

Die weiteren Folgen der bastardbefruchtung, wie sie sich spiiter in (ler Entwicklung des Krenzungsproduktes zu erkennen geben. bieten vielfach Vergleichspunkte zu den Folgen der Selbsthefruchtung. Wemn auch Befruchtung eintritt, sterben in vielen Fillen die Embryonen fribzeitig ah orler erhaiten cine schwächliche lionstitution.

Bei Lreuzung einzelner Echinorlermen kommen die Larven nicht äher das ciastrulastadium hinaus. Ehenso sah P’Fü̈GEr die hastardierten Fier (Rama fusca mit Samen von R. esculenta) schon als Keimblasen absterben. Tierische Bastarde. wenn sie in das Mlter der (ieschlechtsreife

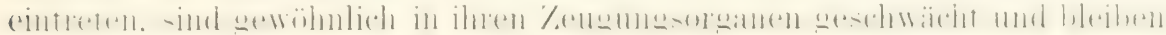
selbst unfruchtbar.

Ahuliches lehrt das Pflanzenreich durch noch zahlreichere Beispiele. Zuweilen bildet sich infolge der Bastardbefruchtung zwar Samen aus, derselbe ist aber mangelhaft entwickelt und hie und da nicht keimungstähig. IVenn lieimung eintritt, entwickehn sich die Pflänzchen bald schwächlich, bald kräftig. . Bastarde zwischen beträchtlich verschiedenen Arten sind häufig sehr zart. insbesondere in der Jugend, so daß die Aufzucht der

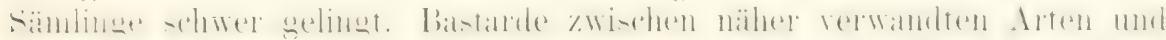

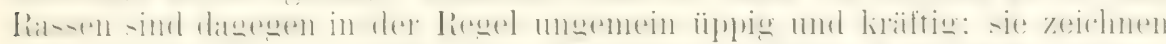

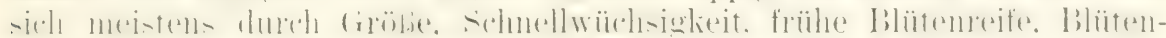

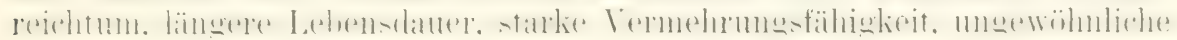
Gröbe einzelner Organe und ähnliche Eigenschaften aus."

.. Bastarde ans verschiedenen Arten bilden in ihren Antheren eine geringere Zahl normaler Samen aus, als die Pflanzen reiner Abkunft;

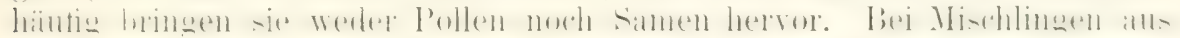

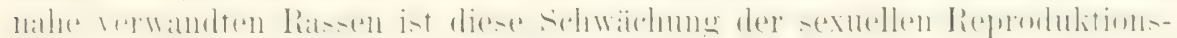
fïhiglieit in der Regel nicht vorhanden."

Im allgmeinen gedeiht das Bastarlprodukt $n$ so besser,

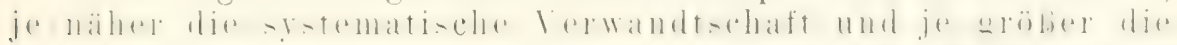
geschlechtliche Affinitat der Eltern ist. In einzelnen Fällen kam es dam sogar besser gedeihen, als ein normal befruchtetes Ei. So liefert Nicotiana rustica mit Pollen ron N. Californica gekreuzt eine Pflanze, die sich zur Höhe der Eltern wie 228:100 verhält (HExsex XII 1881).

y) Beeinflussung der geschlechtlichen $\Delta$ ffinitit durch äubere Eingriffe.

IVir laben bisher in den Experimenten über Selbstbefruchtung und

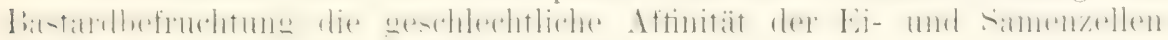
schon als einen auBerordentlich unberechenbaren Faktor liennen gelernt. mit welchem eine lieihe der verschiedenartigsten Folgeerscheinumen Lintritt oder Nichteintritt der liefruchtumg. frïhzeitig gehenmte orler geschwächte oder kräftige Entwicklung ete - zusammenhängt. Die geschlechtliche Affinität erweist sich aber als ein noch liomplizierteres l'bänomen. da sich zeigen läft, dab sie durch äubere Eingritte in vielen Fällen beeinthusst werden kann.

Höchst eigentümliche Verhälnisse liefien sich durch experimentelle Entersuchungen über die Bedingungen der bastardbefruchtung bei einzelnen Echinodermen fetsstellen (XII 1ssio). Die unbefruchteten Fier sind hüllenlos. 'Trotzdem tritt in cler Regel keine liefruehtung cin. wenn samenfälen nahe verwandter Arten, die in ihrer Forn nicht zu unterseheilen sind. hinzugefïgt werden. obschon sie sich an die Oberfliiche der Eier 


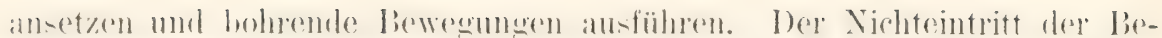
fruchtung kann hier nur dadurch erklärt werden. daß das Ei, wenn ich so sagen darf, die ihm nicht adäquaten Samenfüden zurückweist.

Das ist nun aber nicht ansnahmslos der Fall. liei Krenzungen, die zwischen Strongylocentrotus lividus und Sphaerechinus granularis vorgenommen wurden, kam unter Hunderten immer eine bald kleinere, bah arößcre Anzahl von Eiern vor, die duch den fremden Samen befruchtet wurden, während die große Mehrheit der Eier nicht reagierte, Die Eier ein und desselben Tieres waren also verschieden voneinander, in ähnlicher Weise wie zuweilen die Schwärmsporen ein und derselben Art auf Licht verschieden reagieren kömmen, indem einige den positiven Rand, andere den negativen Rand aufsuchen und wieder andere zwischen beiden hin und her schwanken (siehe S. 152). Wie die Schwärmsporen eine verschiedene Lichtstimmung. so zeigen hier die Eier eines und desselben Tieres eine rerschiedene fieschlechtsstimmung und, was noch wumblerbatrer ist, diese Geschlechtsstimmung kann durch äuBere Einflüsse in hohem (rrarle beeinflubt und abgeändert werden.

Das Verfahren ist ein sehr einfaches. Es lassen sich nämlich die reifen Echinodermeneier nach ihrer Entleerung aus den Eierstöcken 24 bis 48 Stunden unbefruchtet in Meerwasser aufheben, ohne ihre Entwicklungsfähigkeit zu verlieren. In dieser Zeit aber gehen Veränderungen in ihnen ror. die sich in ihrem Verhalten gegen fremrlen samen kimn tum.

Bei den Experimenten wurlen zwei verschiedene Methoden eingeschlagen, von denen die eine als die Methode der sukzessiven Nachbefruchtung bezeichnet werden kam. Sie besteht darin, dab der Experimentator ein und dasselbe Eiquantum zu wiederholten Malen und zu rerschiedenen Zeiten mit fremdem Samen kreuzt. Dabei wurde das wichtige Ergebnis gewonnen: Eier, welche gleich nach ihrer Entleerung aus lem strotzend gefullten Eierstock bastardiert wurden, wiesen mit Ausnahme eines verschwindend kleinen Bruchteils den fremden Samen zurück, aber nach 10, 20 oder 30 Stunden, bei der zweiten, dritten oder vierten Nachbefruchtung hatte eine immer gröBere Anzahl von Eiern ein dem früheren entgegengesetztes Verhalten angenommen, indem sie sich bastardieren lieben und eine Zeitlang auch völlig normal weiter entwickelten. Das Resultat fiel immer in derselben Weise aus, mochten die Eier von strongylocentrotus lividus mit samen von sphaerechimus gramularis onler Echinus microtuberculatus, oder mochten die Eier von Sphaerechinus granularis mit Samen von Strongylocentrotus lividus gekreuzt werden.

Das (rolingen oler Nichtgelingen der liastardierung lälit sich in diesen Fälen nicht auf eine Verschiedenheit des samens zurürlifïhren. da derselhe jedesmal neu aus dem strotzend gefüllten Hoden entnommen wurde und daher bei den Versuchen als ein relativ konstant bleibendel Falitor angesehen werden komnte. Hier ist es über jeden Zweifel erhaben, daß sich allein die Eizelle in ihrem Verhalten regen die Einwirkung des fremden Samens verïnlert hatte.

Wenn aber iberhaupt in der Eizelle Veränderungen eintreten oder künstlich hervorgerufen werden könmen, durch welche die Bastardierung gelingt, dann muB es vom theoretischen Standpunkt aus auch möglich sein, die Geschlechtsprodukte zweier Arten, zwischen denen ein gewisser

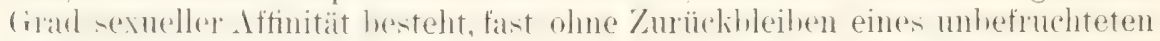
Restes zu bastardieren. Man wird dann je nach den Bedingungen, unter 


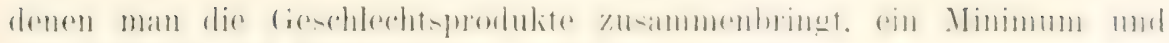
ein Optimum der Bastardierung gewinnen können.

Um diese Verhälnisse festzustellen, nimmt man die Experimente am besten in der Weise vor, dab man das Eimaterial eines Weibchens in mehrere Portionen teilt und zu verschierlenen \%eiten befruchtet. Stets

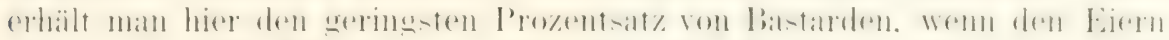
gleich nach der Entleerung aus den Ovarien der fremde Same zugesetzt wird. Je später die Befruchtung geschieht, sei es nach 5 oder 10 oder 20 oder 30 Stunden, um so mehr wächst der Prozentsaty der bestardierten

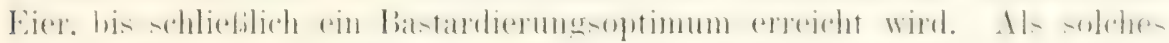
bezeichnet man das Stadium. in welchem sich bei Zusatz fremden Samens das möglichst gröbte Eiquantum in normaler Weise entwickelt. Das Stadium ist von kumer Daner. da sich in den Eiern für uns unsichthare

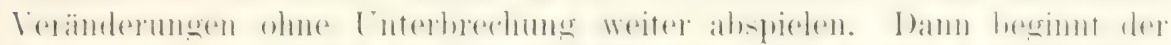

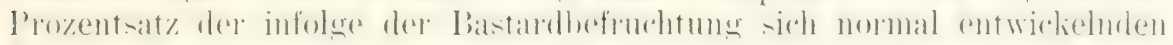

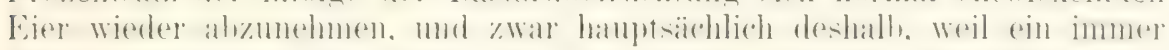

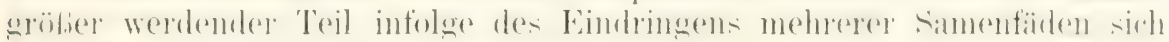
ganz umregelmäbig teilt und mißgebildet wird.

Die Erfolge, die man erhält, wenn das Eimaterial zu verschiedenen Zeiten gekreuzt wird, kann man sich unter dem Bilde einer auf- und ah)-

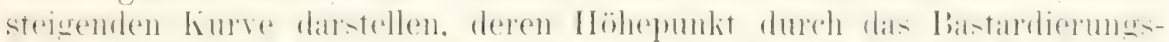

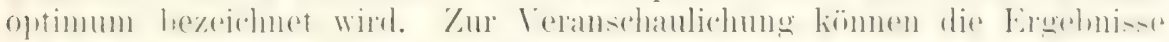
von Krewzungen der Eier von Sphaerechinus granularis mit Samen von Strongylocentrotus lividus dienen. 1/4 Stunde nach Entleerung aus tem Ovarium befruchtet entwickeln sich nu äuferst vereinzelte Fier (Bastardierungsminimum). Nach $21 / 4$ Stunden lassen sich $10^{1} \%$, nach $6{ }^{1} / 4$ Stunden schon etwa $60 \%$ und nach $10 \%$ Stunden fast alle Eier mit Ausnahme von etwa $5 \%$ befruchten, wobei sie sich meist in normaler Weise weiter entwickeln (das Bastardierungsoptimum ist erreicht), Bei Befruchtung nach 25 Stunden entwickelt sich ein 'Teil normal. ein nicht unherleutender'

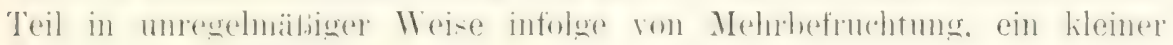
Rest bleibt umbefruchtet.

Aus den an Echinodermeneiern erhaltenen Resultaten scheint sich mir eine Erklärung fül die bekannte 'Tatsache zu bieten, dab domesti-

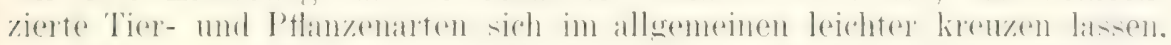
als nahe verwandte Arten im Naturzustande. Durch die Domestikation wird eben im ganzen die Konstitution verindert und biegsamer gemacht.

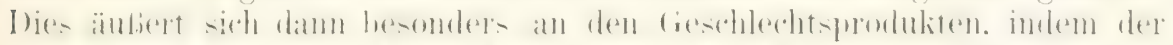

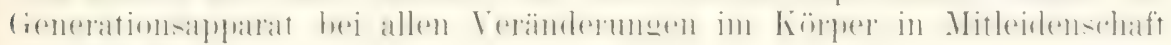
gezogen wird.

Wie bei der Bastardierung. läbt sich anch bei der Selbstbefruchtung

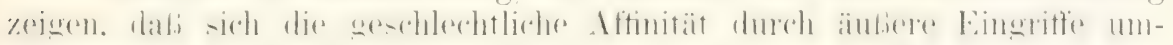
stimmen laibt. Wie DARWIN (XII. NI.1t) mitteilt. ist Eschscholtzia californica in Brasilien nicht selbstfruchtbar, nach England gebracht, wird sie es; Samen von England nach Brasilien zurïckgebracht. Werden dort sehr bald wieder fïr Sellostbefruchtung untauglich. Auch individuelle Verschiedenheit zeigt sich hier in ähnlicher Weise. (Heichwic bei den Echinodermen von Eiern eines Eierstocks einige sich mit fremdem Samen lirenzen lassen, andere nicht, so hat sich durch das Experiment ergeben. dab von Reseda odorata einige Individuen mit sich selbst fruchtbar sind, andere nicht. Ehenso wird es auf älnliche individuelle Unterschiede der Eizellen einer Blïte zurtiekzufïhren sein. daf. bei manchen Pflanzen sowohl Selhstbefruchtung als auch Bastardbefruchtung immer nur viel weniger Samen 
liefert als Normalbefruchtung. Eine gewisse Anzahl von Eiern werden eben entweder den fremden Pollen gar nicht annehmen, oder, wemn sie befruchtet werden, friihzeitig absterben.

d) Rückblick und Erklïrungsversuche.

Wenn wir jetzt noch auf die im letzten Kapitel besprochenen Erscheinungen einen Rückblick werfen, so kann es keinem Zweifel unter-

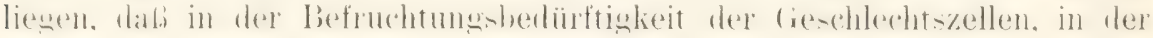
damit eng zusammenhängenden, geschlechtlichen Affinität und im Be-

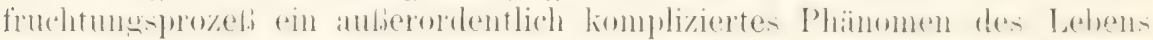
vorliegt. Die Faktoren, die hierbei mabgebend sind, entziehen sich unserer grenauen Kenntnisnahme.

Mancherlei Hypothesen sind aufgestellt worden, von denen einige eine kurze Besprechung verdienen: Zur Klärung vieler Fragen wird es

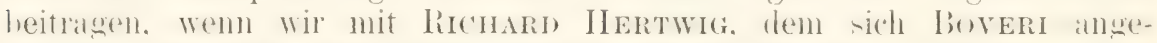

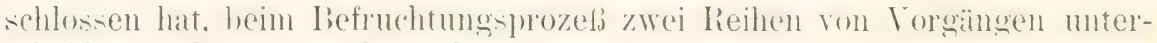
scheiclen und getrennt betrachten.

Der eine Vorgang ist die Verschmelzung zweier Zellen, die von einem weiblichen und einem männlichen Individuum abstammen. Und hierbei ist wieder, wie auf Seite 280 auseinandergesetzt wurle, das Wesentliche die Vereinigung orler, um einen Ausdruck von Weismass zu gebrauchen, die Amphimixis von Ei- und Samenkern. Hierdurch entsteht eine in ihrer feineren ()ranisation abgeänderte Zelle mit einer gemishten

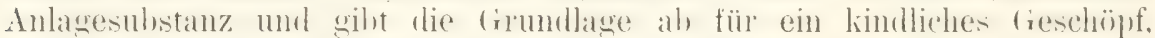
welches die Figenschaften seiner heiden birenger in sich rereinigt. So steht der befruehtungsiorgang in untremblaren Zusammenhang nit der fundamentalen Frage der Vererbung. mit der C̈bertragung der väterlichen und der mütterlichen Eigenschaften auf das Kind.

Der zweite Vorgang, der meist in auffäliger Weise als unmittelbare Folge der Befruchtung sich bemerkbar macht, ist, wie R. HerTwiG sich austrïckt, die Entwicklungserregung. Die reifen Eier, die bis dahin teilumg-unfähig waren und ohme befruchtung hald ahgestorben sein wïrden, werden durch den Zutritt des simenfarlens zu Teilungen angeregt und direkt zum Eintritt in den Entwicklungsprozeß veranlaßt, aus dem das kindliche Geschöpf hervorgeht.

Auf den zweiten Vorgang hat man nicht nu in früheren Zeiten, sonrlern häutig auch jetzt noch ein viel zu grobes (iewicht gelegt. so dab man in ihm oft das Wesentliche der Befruchtung erblickt hat. Das ist zum Beispiel in den theoretischen Betrachtungen von BoverI (XI 1902), besonders aber von dem amerikanischen Physiologen LoEB der Fall.

BoverI hat in seinem interessanten Vortrag über das Problem der

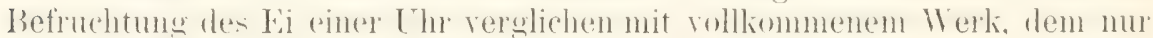
die Feder fehlt und damit der Antrieb. Indem er num der Ansicht ist, dah die-en Mangel ahzuhelfen Aufgabe dex liefruchtumg sei, wirft er die Frage auf, was das Spermatozoon neues in das Ei hineinbringe (S. 11), um seine T'eilung und als Folge alle weiteren Teilungen zu bewirken. Das Neue sucht Boveri in der Eimptlanzung eines vom Samenfaden eingefuihrten Centrosoms, durch welches dem Ei die verloren gegangene Teilungsfähig-

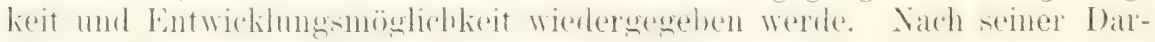

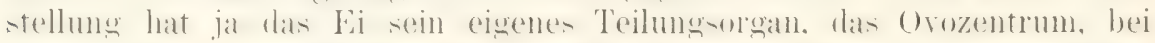

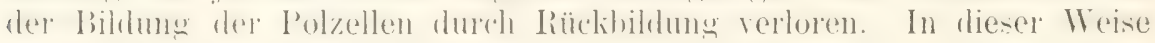
versucht Boveri die Befruchtuug auf die Physiologie der Zellteilung zu- 
rü̈kzuführen und damit im Prinzip zu erklären. Er betrachtet die liefruchtung in erster Linie als einen entwicklungseregenden Faktor.

Von der gleichen Vorstellung wird auch LoEB bei seinem Bemühen geleitet, eine Erklärung für die befruchtende Wirkung auf dem Gebiete der physikalischen Chemie zu suchen. Durch seine Experimente ïher

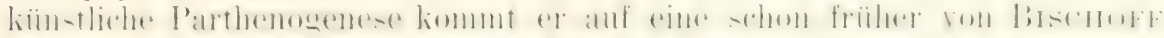

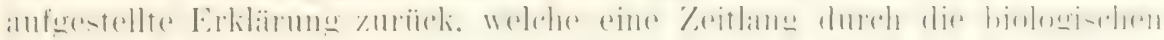
Entrleckungen beseitigt $2 u$ sein schien. Im Anschlub an die epochemachenden Arbeiten LuEBrgs hatte Biscroff die Theorie aufgestellt, dab. .der Same beim liontakt, bei Berührmg durch katalytische Kraft wirkt.

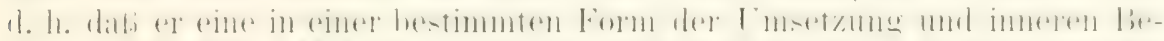

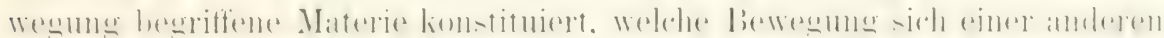
Materie, dem $\mathrm{Fi}$, die ihr nur einen höchst geringen Widerstand entgegensetz.t. mitteilt und in ihr eine gleiche und ähnliche Lagerungsweise der Atome hervorruft."

Aus seinen Experimenten, daß bei vielen Eiern sich kiunstliche Parthenogenese durch chemische Agentien bewirken läbt. zieht LoEB den Schluf: .Der Samenfaden kamn nicht länger als die Ursache oder der Anreiz für den Entwicklungsprozeli. sondern nur fiur eins der Agentien gehalten werlen, welches einen Prozeß beschleunigt, welcher auch ohnedem. allerdings nu langsamer ablaufen liamn. Substanzen. welche chemische oder physikalische Prozesse, welche auch ohme sie eintreten wiirlen. beschleunigen. werden katalytische genannt (OsTwaLD). Gemäh dieser Defi-

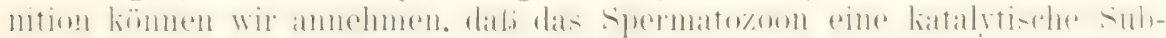
stanz in das Ei bringt, welches den Prozeh beschlemigt, welcher auch sonst beginnen wïrle, aber sehr viel langsamer." Die K-Ionen z. B.. welche die Chaetopteruseier zur Parthenogenese veranlassen, läßt LoEB

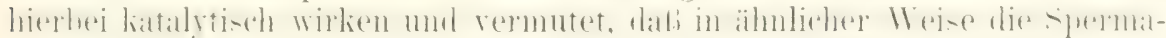
tozoen Träger von Enzymen sind, welche man auf dem von WIxkLER cingeschlagenen Wege zu isolieren versuchen mïsse.

LOEB sucht seiner 'Theorie, nach welcher die Spermatozoen und Substanzen, welche Parthenogenese hervor'ufen, einzig und allein kataly-

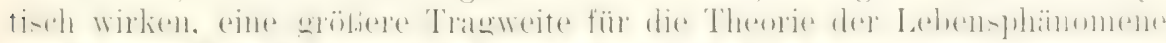

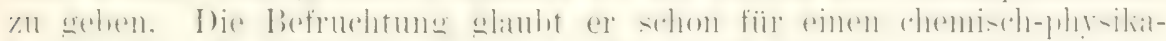

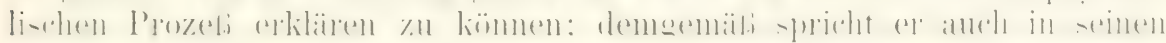
Schriften öfters von einer osmotischen oder einer chemischen Befruchtung.

Die Experimente und Folgerungen ron LoEB sind in unserer Zeit. in welcher wieder die Neigung, komplizierte biologische Probleme gleich radikal als chemisch-physikalische Prozesse zu erklären, stark vorherrscht, nicht ohne Eindruck geblieben. So messen Korschert und HeIDER in ilnrem Lehrbuch den neneren Lrgebnissen von LOEB cine arofe Betleutung bei, , ola er unter Anwendung der Ionentheorie auf die Liweibkörper zu einer föritichen chemischen Theorie der Befruchtung geführt worken sei. Durch seine Experimente sehen sie bewiesen, dab der Stimulus des eindringenden Spermatozoons auch durch andere Reize ersetzt werlen könne."

Nach meiner Ansicht haben Bover und LOEB die Erkiärung für das Wesen der Befruchtung auf einem (rehiet gesucht, dem die ilm zugeschriebene Berleutung gar nicht zukommt. Denn die Entwicklungserregung. welche oft mit dem Eintritt des Samenfadens in das Ei verliniipft ist, gehört nicht zum eigentlichen Wesen der Befruchtung; sie ist num eine mit ihr häufig verknïpfte liegleiterscheinung. welche unter Lmstanden auch sanz fehlen kann, so dab dann das W'esentliche der Befruchtung rein zutage tritt. Denn wie an vielen verschiedenatigen Beispielen sich zeigen 
likst. kamn das Ei befruchtet werlen, ohne dadurch den ummittelbaren Anstol, zur Entwicklung empfangen zu haben; im Gegenteil tritt es in

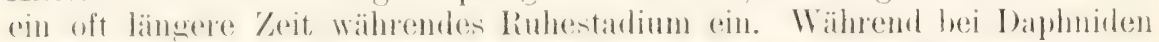

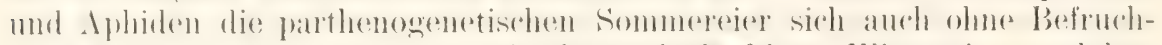

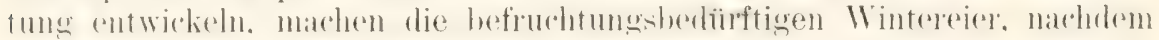
sie befruchtet worden sind, ein Monate dauerndes Ruhestadium durch. in welchem sich der Furchungskern nicht einmal zur ersten Teilung anschickt. Bei Algen und vielen niederen einzelligen Organismen ist das Resultat der Befruchtung, wie bekannt, eine Dauerspore, also ein Produkt, welches unter Umständen jahrelang ruht, ehe es zu keimen beginnt. Auch bei den Infusorien hat die Konjugation, bei welcher es zu einem Austallsh ron Kernsubtanzen, daher zu einer gegenseitigen befruchtumg kommt, nach der Trennung der Paarlinge keine Vermehrung zur unmittelbaren Folge: anstatt als Entwicklungserreger, tritt sie mugekehrt zunächst eher als ein die Vermehrung hemmender Faktor auf. Während der Befruchtung und längere Zeit nach ihr hören die Infusorien, die sich bei genïgender Nahrung vorher geteilt haben, üherhaupt auf, sich durch Teilung zu vermehren, bis erst im Inneren eine durch die Kopulation eingeleitete Reorganisation des Organismus, die Verjüngung in der Sprache von BüTSCHLI, beendet ist.

Daß die Entwicklungserregung nicht zum Wesen der Befruchtung gehört. läbt sich in entgegengesetzter Richtung elsensogut beweisen. Denn auch ohne Befruchtung kann sich das Ei entwickeln, wie die früher besprochenen Fïlle won natürlicher mul experimenteller Parthenogenese gelehrt laben. ('hemische, thermische, mechanische, osmotische Einwirkungen kömen ruhende, mhefruchtete Fier zu Teilungen und eventuell überhaupt zu weiterer Entwickinns anregen. Richard Hertwa bemerkt daher mit Lecht: . Wie es Befruchtung ohne Entwicklungserregung. so gibt es Ent-

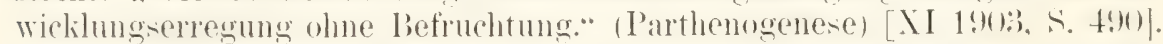

Aus derartigen Erwägungen ergibt sich der unabweisbare Schluß, laß das Wesen der Befruchtung einzig und allein in der Amphimixis zweier Zellen beruht, die von einem mütterlichen und einem väterlichen Erzeuger abstammen, daß alle außerdem noch beobachteten Vorgänge sekundärer Art odler mehr untergeordnete Begleiterscheinungen sind.

I) ie befruchtung ist ein hiologischer P'rozel. so komplizierter Art. daf Versuche, seine Erklärung auf dem Gebiete der Chemie und Physik zu suchen, verfrïhte sind und nur zu unhaltbaren Torstellungen führen hïmmen. Was schon Rudolph Whiser gegen Bischoff geltend gemacht hat. dal.s durch die katalytione Theorie die T̈hertragung der Figenschaften des Vaters auf die Nachkommenschaft nicht erklärt werde, ist auch gegen LoEB wieder hervorzuheben, nur jetzt mit dem Hinweis, daß uns in den Vorgang der Übertragung mittlerweile die Biologie schon einen tiefen Einblick sewäht mul feste (immolagen genchaffen hat. Die mannigfachen chemischen und physikalischen Reize (thermische, mechanische.

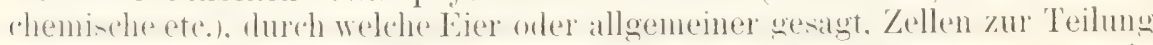

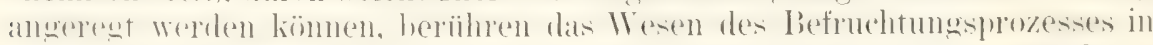
gar keiner Weise und könmen daher auch keinen Ersatz für die Wirkung des rifumatozoms anf das Ei abgehen. Ehemsowenig. wie man dem silherstift, durch welchen die Hornhautkörperchen bei der Ätzung zu Teilungen veranlakt werden, eine befruchtende Wirkung zuschreiben wird, ebensowenig geht eine solche ron den Salzgemischen mit KCl, MgCl etc. aus, wemn durch sie die Eizellen 7.11 Teilungen und selbst zu weiterer Entwicklung gebracht werden können. 
Tremn der befruchtungsprozeb in der Verschmelzung zweier cellulärer Organismen besteht, dam sind auch in den feineren, uns zum gröbten

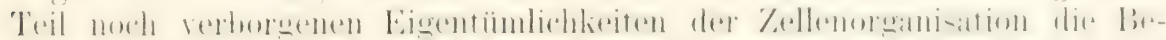

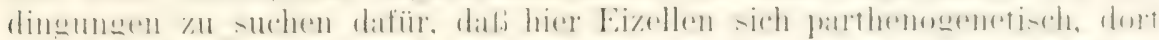

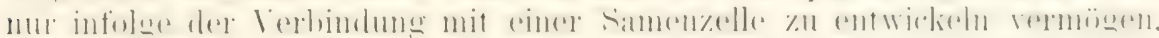

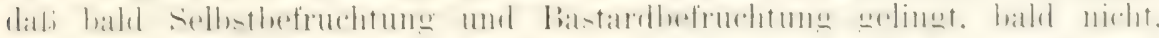
daß die Eizellen ein und desselben Individum sich oft bei Sellost- und

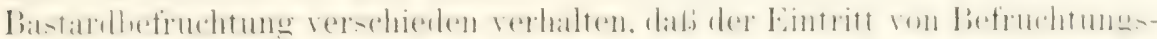
bediurftigkeit und von Parthenogenese, das (xelingen von Selhst- und

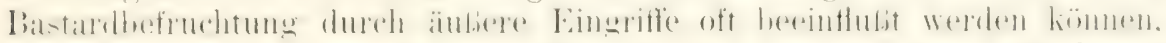
dab das Gedeilren der Zeugungsprodulite von der Art der Befruchtung abhängig ist.

Lälit sich nun darüber eine Vermutung aussprechen, wie die zum

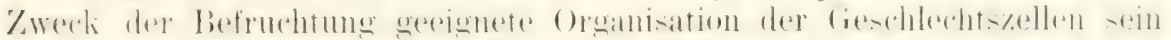

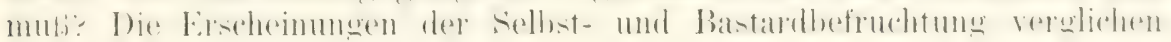
mit der Normalbefruchtumg sind wohl imstande, uns wenigstens einen wichtigen Fingerzeig zu geben.

Wie aus den zahlreichen Beobachtungen wohl klar hervorgeht. wird

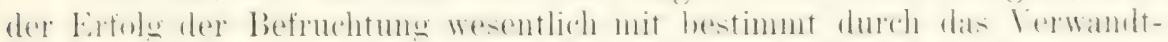

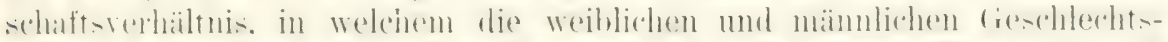

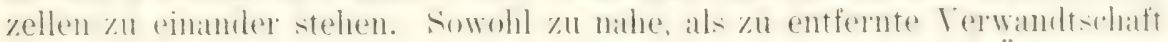
oder. wie wir anstatt dessen wohl richtiger sagen, zu große Ähnlichkeit

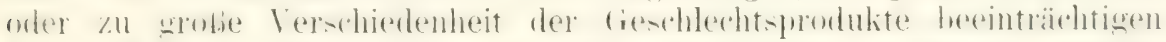

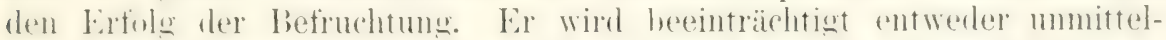
bar in der Weise, daß sich die ( reschlechtszellen gar nicht verbinden, da

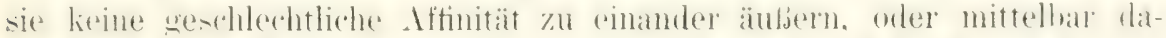

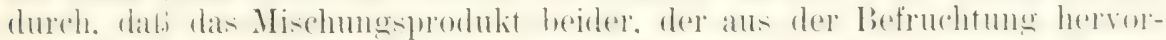

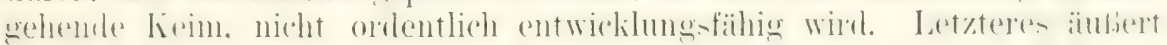
sich bald darin. daß schon nach den ersten Anfangsstadien der Entwick-

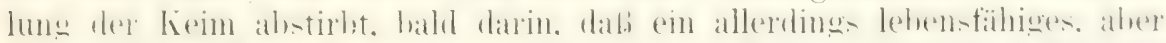

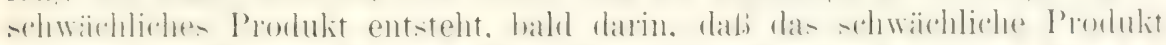

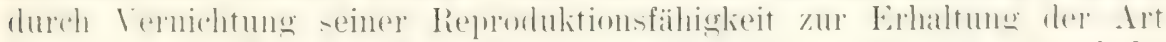
nichts taugt. Unter allen Fällen gedeiht das Zeugungsprodukt an besten, wenn die zeugenden Individuen und infolgedessen auch ihre Geschlechtszellen unbedeutend in ihrer Konstitution oder Organisation roneinander verschieden sind.

Es ist ein grobes Verdienst ron DARwir (XII No. 14), durch ausge-

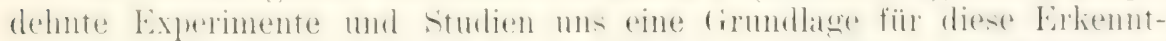
nis verschafft und sie zuerst klar formuliert zu haben. Ich fülre drei Sätze von ihm an: "Kreuzung von Formen, welche unbedeutend ver-

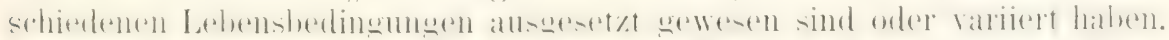

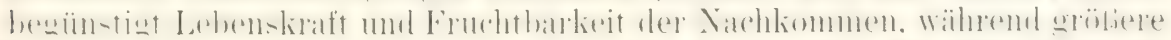
Verïnderungen oft nachteilig sind." .Der bloße Alit der Kreuzung tut an und für sich nicht gut. sondern das Gute hängt davon ab, dal.s die Individuen. welehe gekreuzt werden, umbedeutend in ihrer Konstitution yonemander verschieden sind, und zwar infolge daron, dab ihre Vortahren

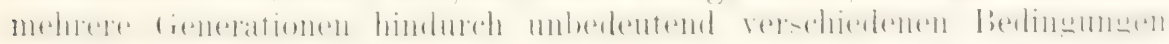
oder dem, was wir spontane Abänderung nemnen, ausgesetzt gewesen sind." Der Nutzen der Befruchtung besteht in der .. I ermischumg der unbedeutend rerschiedenen physiologischen Elemente unbedeutend verschiedener Individuen".

Die Darwixschen Erfahrungen hat HerberT SPExcer (XII 1876) benutzt. um auf molekularem Gebiete eine Hypothese von dem Wesen 
der Befruchtung aufzubauen, (iie als ein vorläufiger Versuch erwähnt zu werden rerdient.

Spexcer stellt gewissermaBen als ein Axiom den Satz auf. dab die

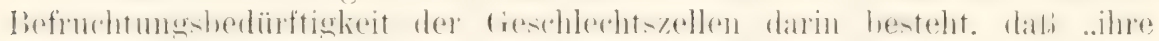
organischen Einheiten (Micellen) sich einem Gleichgewichtszustand genähert haben“ und daß ,ihre gegenseitigen Anziehumgen sie verhindern, ihre Anordnung anf die Einwirkung äuberer Kräfte him leicht zu rerindern."

Wäre diese Annahme fester zu begründen, wähend sie augenblicklich mir nur eine Möglichkeit zu sein scheint, so könnte man wohl ohne Berlenken der Erklärung von SPExcer zustimmen: „Der Hauptzweck der geschlechtlichen Zeugung ist, eine nene Entwicklung durch Zerstörung des annähernden Gleichgewichts herbeizuführen, auf welchem die Moleküle der elterlichen Organismen angekommen sind." Denn ,wenn eine Gruppe von Einheiten des einen Organismus und eine Gruppe von etwas verschiedenen Einheiten des anderen miteinander vereinigt werden, wird das Streben nach dem Gleichgew ichtszustand vermindert, und dievermischten Einheiten werden in den Stand gesetzt sein, ihre Anordnung durch die auf sie einwirkenden Kräte leichter abändern zu lassen; sie werlen so weit in Freiheit gesetzt sein, dab sie nun jeder Andersverteilung fähig sind, welche das Wesen der Entwicklung ausmacht."

In diesem Sinne kann die Befruchtung auch als ein Verjüngungsprozeli hetrachtet werlen, wenn man sich dieses yon BütschLI (XI 1876). MaUpas (XI 1889) u. a. gebrauchten Ausdruckes bedienen will.

\section{Literatur XII.}

1) Abderhalden, Nenere Versuche ïber kïnstliche Parthenogenesis u. Bastardiemus. Arch.f. Rassen- u. Gesellschaftsbiolosie. I904.

2) de Bary, A., Über apogame Farne und die Erscheinungen der Apogamic im allgemeinen. Botonische Zeituns. Ba. IXXYTl. I878.

3) Derselbe, Briträge sur Morphologie und Physiologic der Pilat. Ablandl. d. Scnkenberg. naturf. Gesellschaft. I88I.

4) Bataillon, E., La pression osmotique et les grands problemes de la biologit. Arch. f. Entrit-dYech. Bit. MI. Igor.

5) Bischoff, L. W., Theorie der Befruchtung und über die Rolle, aiclche die Spermatozoiden alabei spielen. Arch. f. Anat. u. Physiol. $18+7$.

6) Blochmann, F., Über die Reifung der Eier bei Ameisen und Wespen. Uniz'-Festschrift. Heidelberg. 1886.

7) Derselbe, Über die Richtungskörper bei Inscktenciern. Norph. Jahrb. Bd. - TII. I887.

8) Derselbe, Über die Zahl der Richtungskörper bei befruchteten und unbefruchtetent Bienenciem. Horph. Jahrb. Bd. XV. 1889 .

9) Born, G., Heitere beiträge zur Bastardiems anischen den cinhcinischen Anuren. Arit. f. mikrosk. Anat. Bit. I.17TI. I880.

10) Boveri, Th., Ein geschlechtlich erzeuster Organismus ohne mütterliche Eigenschaften.

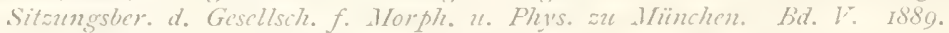

11) Derselbe, Über dic Befruchtung und Entricklungsfühigkcit Fernloser Secigeleier. Arch. f. Ent.-1Yech. Bid. 11. IS95.

12) Brauer, Zur Tenntnis der Reifung des parthenogenetisch sich entrickelnden Eies von Artemia salina. Arch. f. mikrosk. Anat. Bd. YLIII. 1897.

13) Castle, W. E., The carly cmbryology of ciona intestinalis. Bull. Mus. compar. Zoology. Harvard College. Vol. H.YVII. I895igo.

14) Darwin, Die IIrkungen der Kreus- und Selbstbefuchtung in Pfansenreich. 
1.i, Delage (Yves), Etudes sur ia mirogonit, Arch. zool. exp. sir. 3. Vol. VIl. ISou.

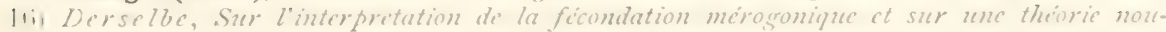
i'elle de la ficondation normale. Librnda. $18999^{*}$.

1., Derselbe, Sur la maturation citoplasminue chez les Eichinotermes. Arit. de soolog. cxpir. ctc. 3 sér. T. LI. 100I.

14. Derselbe, Les thiories de la firomiation. Verhandl. des V. internat. Zool-Kongr. zu berlin. $1001^{*}$

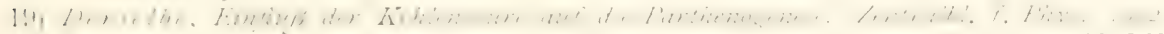

-11, Dubois, Sur la spermase et l'omelase. Compt. rend. Hebd. de let soc. de biol. T. LII. 1(1) 00 .

21) Fischer, Martin und Ostwald, Wolfgang, Zur physikalisch-chemischen Theoric der biefruchtung. Pflügers itrchiz. Bid. ClV\% 1005.

Focke, Die P'flenaenmischlinge. Botanische Zeitumg. $188 \%$.

$\therefore$ Garbowshi, T., Uber parthenogenctische Entrickhung der Askeriten. Bull. de l'Aead. d. science de Cracotic. 1003.

¿', Gutherz, S., Selbst- und Krencbefmehtuns bei solitüren Ascitien. Arch. f. mikrosk. Anat. Bd. L.YII. 1004.

Guyer, M., Spermatogenesis of normal and hybrid pigeons. A. dissertation. The unizersity of Chicago. 1000 .

Hensen, Die Physiologic der Zeugnns. ITandb. der Physiolgie. Bd. VT. IS8I.

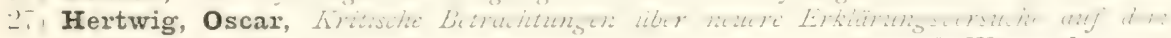
Gebiele der Befruchtungslehre. Situngsber. d. kgl. prenß. Akat. d. Wissensch. 1905.

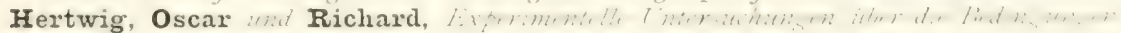
der Bastardbefruchtume. Jena 1885.

2!" Dieselben, Uber don Befrichtungs- und Teilungstorgang des tierischen Eies unter dem Einfluß änperer Agentien. Jena 1887.

Hertwig, R., Uber die Entricklum des unbefruchtelcn Sceigeleies. Festschrift fïr Gegenbaner. Leipaig 1806.

:1) Hildebrand, Die Geschlechtererteilung bei den Pflanzen etc. Leipzig 1807.

:-) Keller, Die Whrkung des Aahrungsentauges auf Phulloxera vastatrix. Zeol. Anzeiser. Bid. 1, p. 583.1887.

Klebs, Zur P'zysiologie der Fortptanaung. Biol. Zentralbl. Bd. IX. 7889.

: A von Kostanecki, K. Über kiunstliche befruchtung und kïnstliche parthenogenetische Furchung bei ITactra. Bull. Akal. Soc. Krakau. 1902.

$\therefore$ Loeb. Jaques, On the nature of the process of fertilization and the artifical produc-

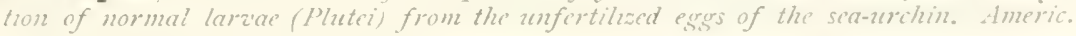
lourn. of phi's. Vol. III. I899.

ati Derselbe, Further experiments on artificial parthenosenesis and the nature of the process of fertilization. Imeric. Journ. of phys. Vol. IV. 1900.

$\therefore$.: Derselbe, Experiments on artificial perthenogenesis in anneluts (Chactopterus) and the nature of the process of fertilization. Americ. Journ. of pluys. Tol. II. $100 \mathrm{or}$.

Derselbe, Uber Eireifung, natürlichen Tod und Terlängemung des Libens beinn un-

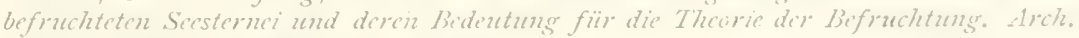
f. d. aces, Phrsiol. Bd. LC'lll. 1002.

14. Loeb, Jaques and Warren, H. Lewis, On the prolongation of the life of the

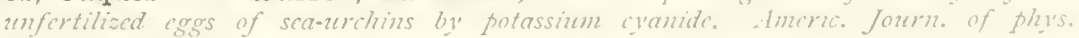
lol. HI. 1002.

H. Loeb, Jaques, Fischer, Martin und Neilson, Hugh, Weitere Versuche ïber künst-

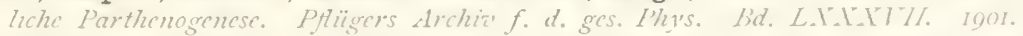

4I Derselbe, On a method by which the egers of a sen-umchin (Stronsylec.) can be firtilized with the sperm of a starfish (.Isterias ochr.). Unizersity of Calif. publuc. Plen's. 15. I. 1003.

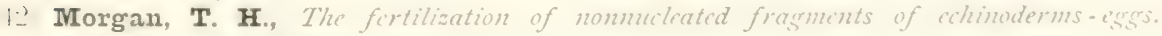
Arih. f. Entrit.-Alech. Bat. I/. Itig5.

1.: Derselbe, Further studies in the action of salt-solutuns and ofluer asens on the eges of Hrbacia. Areh. f. Ent.-1lech. lit. l: 1000.

1) Mathews, Artificial parthenogenesis producd by mechanical agitation. Americ. Journ.

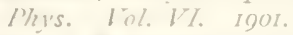

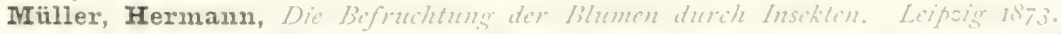

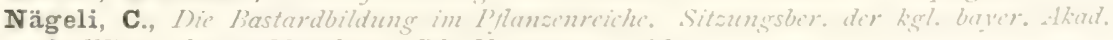
d. Missensch. zu .Mïnchen. Mat. II, P. 395. 1805,

it Derselbe, Die Theorie des Bastardbilduns. Sitzungsber. der kgl. bayer. Akert. der Wissensch. au Mrinchen. Bid. I. IS60.

1- Petrunkewitsch, Alex, Die Richtuneskërper und the Sichickst im befouchteten und

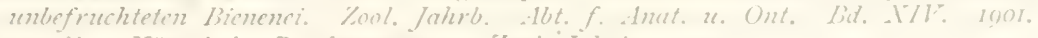

i:4, Derselbe, Künstliche Purthenegenese. Zool. Jahrb. 1004. 
5) Pf Pfüger, Die Bastardaengung bei den Batrachiern. Arch. $f$. d. ges. Jhysiologite. Bil. ITTX T882.

i) Pieri, J. B., Un nouzeau ferment soluble: l'ozulure. Arch. de zool. experr. et ginér. 3 sir. T. IT/, p. 20. 1809.

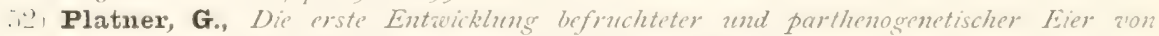
Liparis dispar. Biol. Zentrall]. Bd. IVlll. 188880.

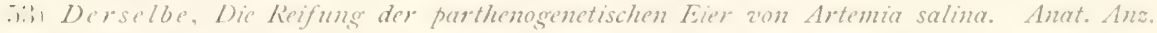
BA. IXY. 1002 .

i) Schücking, Zur Phrsiologie der Befunchtung; Parthenogenese und Entricklung. Arch. f. d. ges. Phasiol. Bid. ICVII. 1903.

$\therefore$.i. Spencer, Herbert, Die Prinzipien der Biologie. Ubersetst ron Vetter I876.

ilit Sprengel, Das entdeckte Geheimnis der Natur, die befruchtung der Blumen durch Insekten. I793.

$\therefore$ Stevens, N. IM., Experimental studies on egos of Echinus mikrotuberculatus. Arch. f. Ent.-allech. Bd. IV I002.

in) Tichomirow, Die kinnstliche Parthenogenese bei Insekten. Arit. f. Anat. ur. Physiol. Suppl.-Bd. I886.

59) Derselbe, Eigentümlichkeiten der Entwickhung bei künstlicher Parthenogenese. Zool. Anz. Bd. TIT. I002.

(i) de Vries, H., Befruchtung and Bastardierzng. Vortrag. Leipag roo3.

(i1) Wassilieff, Über kïnstliche Parthenogenesis des Seeigeleies. Biol. Zentralbl. Bd. XIII. 1002 .

(62) Weismann, Beitrïge zur Aaturgeschichte der Daphnoiden. Zeitschr. f. wissenschafth. Zool., Bd. XXYIII, 1880.

63) Derselbe, Über die Virerbung. Jena 1883.

(it) Derselbe, Die Kontinuität des Keimplasmas als Gmudlage ciner Theorie der Iercrobung. Jenct 1885.

(5.)) Wiesner, Elemente der wisscnschaftlichen Botanik. Bd. III. Igoz.

(ibi) Wilson, E. B., The chemiarl fertilization of the sea-urchin. Scionc. N. S. Fol. XIII, 1900 .

(i) Winklex, H., Über Furchung unbefruchteter Eier unter der Einwirkung von Extraktivstoffen ans denz sperma. Nachrichten d. K. Gesellsch. d. Wissensih, zu Göttingen. Nath. phys. Kl. 1900.

(i) Derselbe, Über Merogonie and Befruchtung. Tahrbücher fïr arissensch. Botanik. lid. XXXYT. IgOT.

(i, Ziegler, H. E., Experimentelle Studien über die Zellteilung, Furchmg ohne Chromo-

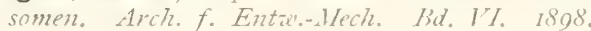




\section{DRFI\%EHNTLS KAPITEL.}

\section{Die Zelle als Anlage eines Organismus.}

Schon aus der Fähigkeit der Zelle, anf die verschiedenen äubern Einwirkmoen, auf thermische oder optische oder chemische oder mechanische Eingriffe in gesetzmäbiger Weise zu reagieren, ferner aus der

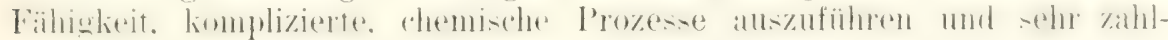
reiche. mit besonderer Struktur rersehene Substanzen zu bilden. müssen

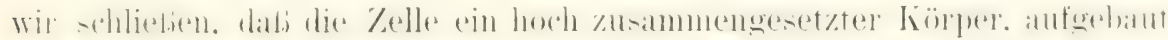

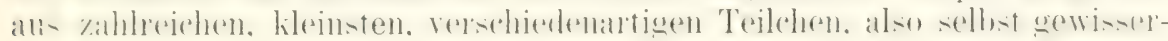
maken ein kleiner Elementarorganismus ist.

Noch mehr wirl uns dieser Gedanlie aufgedrängt. wemn wir sehen, wie die Ei- und Samenzelle durch ihre Vereinigung die Grundlage bilden für die Entwicklung eines Organismus, welcher ju großen und ganzen

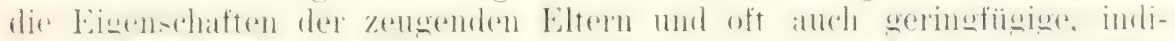

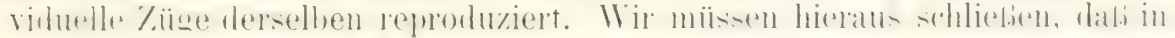

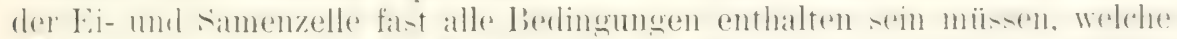

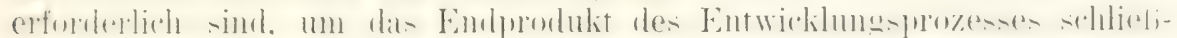
lich zustande kommen zu lassen. Unserer Wahnehmung entzichen sich

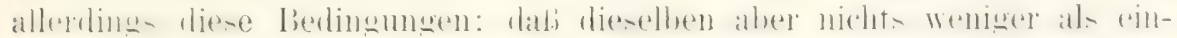
facher Art sein werden. geht schon aus der auberordentlichen Zusammensetzung hervor, welche das Endprodukt der Entwicklung bei den höchsten Organismen erreicht.

Die Geschlechtszellen müssen daher zahlreiche, uns rerborgene Eigenschaften und Merkmale besitzen. durch deren Vorhandensein die Ent-

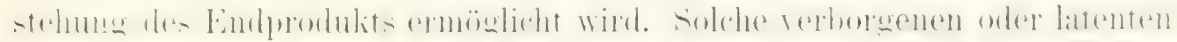

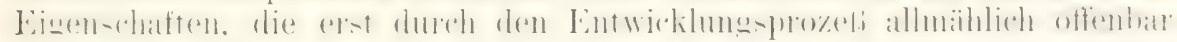
werden, nemnt man Anlagen. In der Gesamtheit der Anlagen ist der entwickelte Organismus gewissermalien vorgebildet oder potentiell enthalten.

Yun gleichen sich auf einem gewissen Stadium ilner Entwicklung alle Organismen auberortentlich, insofern sie einfache Zellen sind. Die Eier des Menschen, eines Nagetieres, eines Wiederkïlers, jal selbst mancher wirbellosen Tiere sind scheinbar sehr wenigr voneinander verschieden. Ihre sichtbaren Unterschiede sind auberordentlich viel geringer als die Unterschiede zwischen dem Fi und der Samenzelle ein und desselhen Oruanismus.

Solche formalen Ähnlichkeiten und formalen Unterschiede haben aber wenig zu bedeuten, wenn wir tiefer auf den Grund der Sache gehen. 
Vielmehr ist folgendes zu berlenken. Wenn Mensch. Nagetier. Wiederkianer und wirbelloses Tier in ihrer Organisation melı oder minder tiefgreifende, uns äuberlich wahrnehmbare Unterschiede darbieten, so müssen anch die von ihnen abstammenden feschlechtszellen, sofern sie die An-

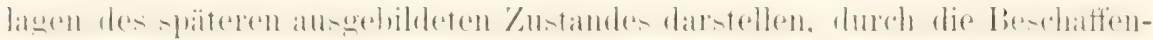
heit der Anlagen in entsprechender Weise voneinander unterschieden sein, nur dafis die unterscheidenden Nomente jetzt auf einem unserer Wahrnehmung noch verschlossenen (iebiete liegen. Auf der anderen Seite müssen Ei- und Samenzelle ein und desselben Organismus, die äuberlich so sehr ungleich aussehen, in ihren wesentlichen Eigenschaften, durch welche die Anlage des ausgebildeten Geschöpfs repräsentiert wird, nur in geringem Grarle voneinander abweichen.

Treffend bemerkt N̈̈GELI (XIII 1884): „Die Eizellen enthalten alle wesentlichen Merkmale ebenso gut, wie der ausgebildete Organismus. und als Eizellen unterscheiden sich die Organismen nicht minder voneinander, als im entwickelten Zustande. In dem Hühnerei ist die Spezies ebenso vollständig enthalten, als im Huhn, und das Hühnerei ist von dem Froschei ebenso weit verschieden, als das Huhn vom Frosch."

Was von den Eiern, gilt nicht minder auch vom Samenfarlen, ïberhaupt von jeder Zelle und jedem Zellenkomplex, welcher, als Spore und Kinospe vom Mutterorganismus abgelöst, imstande ist, den letzteren wieder zu erzeugen. Auch sie müssen alle wesentlichen Eigenschaften des Ganzen

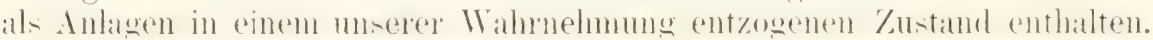

Welche Vorstellungen können wir uns zurzeit von diesen unsichtbaren Eigenschaften der Zellen bilden, durch welche sie die Anlage für einen zusammengesetzten Organismus abgeben? In welchem Verhälnis stehen Anlage und ausgebildeter Zustand zı einander?

Bei der Beantwortung dieser Fragen stehen wir vor den allerschwierigsten Problemen, welche die Lehre rom Leben darbietet. Mit ihnen haben sich Naturforscher und Denker zu den verschiedensten Zeiten be-

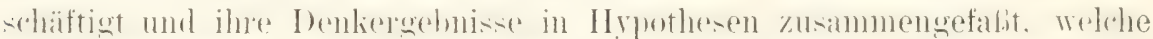
die Forschung in manchen Zeiträumen in nachhaltiger Weise beeinflußt haben. Auf die historisch wichtigsten derselben in Küurze einzugehen, dürfte sowohl von allgemeinem Interesse als anch eine passende Einleitung für den Versuch sein, die Anschauungen zusammenzustellen, zu denen die morlerne Naturforschung hinleitet.

\section{Geschichte der ilteren Entwicklungstheorien.}

Zwei berlentende Theorien haben sich in der Wissenschaft bis in den Anfang unseres Jahrhunderts hinein schroff und unvermittelt gegenüber gestanden, die Theorie der Präformation oder Evolution und die Theorie der Epigenese.

Der Präformationstheorie huldigten viele der Geistesheroen des

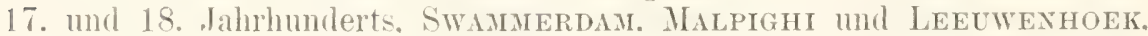
Haller, Bonnet (XIII 1762) und Spallanzani (vgl. His XIII 1871). Sie waren der Ansicht. dab die Keme in ihrem Bau mit den erwachsenen Organismen auf das rollständigste übereinstimmen und daher von Anfang an dieselhen Organe in derselben Lage und Verbindung wie diese, nur in einem auBerorlentlich viel kleineren Zustand besitzen sollten. Da es nun aber mit den damaligen Vergröferumgsgläsern nicht möglich war, in den Eiern an Anfang ilirer Entwicklung die vorausgesetzten Organe wirklich zu sehen und nachzuweisen, nahm man zu der Hypothese seine Zuflucht, 
dal.) die einzelnen 'Teile, wie Nervensystem, I)rïsen, Knochen etc. nicht nur in einem sehr keinen, sondern auch in einem durchsichtigen Zustande rorhanden sein mïssen.

Lm sich den Vorgang verstandlicher zu machen, wies man als erläuternde Beispiele auf die Entstehung des Sichmetterlings aus der P'uple und namentlich auf die lintstehung einer l'flanzenblüte aus ihrer huospe hin. Wie in einer kleinen linospe von den grinen, noch fest zusummengeschlossenen Hüllblättern doch bereits schon alle libïtenteile. wie die Stanbfäden und die gefärbten lielchblätter, eingehüllt werden, wie diese 'Teile im Verborgenen wachsen und sich damn plötzlich zur blüte entfalten, wolsei alle bis dahin verborgenen Teile enthiillt werden, so sollten auch in der Tierentwicklung die bereits vorhandenen, aber kleinen und durchsichtigen Teile wachsen. sich almählich enthüllen und unserem duge erlennhar werden.

Daher der alte Name ..Theorie der Evolution orler Enttaltung a.*. an dessen Stelle man nenerdings die noch zutreftendere und klarere

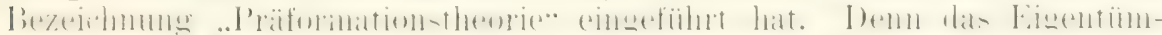
liche dieser Lehre ist, dab sich in keinem Augenblick der Entwicklung etwas Nenes bildet, vielmehr jeder 'T'eil von Anfang an vorhanden oder präformiert ist, dab also das eigentliche Wesen der Entwicklung, das Werden, in Abrede westellt wird. .Es gibt kein Werden," heibt es in den Elementen der Physiologie yon HaLber: .Kein Teil im Tierkörper ist vor dem anderen gemacht worden, und alle sind zugleich erschaften."

In schroftem Gegensatz zur Präformationslehre steht die Theorie der Enigenese. welche ihren Hauptrertreter in der Mitte des 1\%. Jahrhumlerts in Caspar Friedrich WOLFF (XII 176t) gefunden hat. Der-

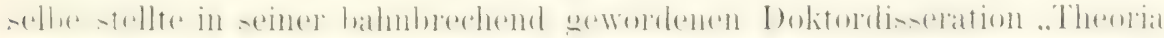
Generationis: im Jahre 175!) (deutsche Ausgabe 176t) dem damals all-

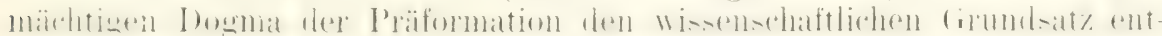
gegen: was man nicht mit seinen Simmen wahrnehmen könne, sei anch nicht in lieime präformiert vorhanden. An Anfang sei der lieim nichts anderes als ein unorganisierter, von den Geschlechtsorganen der Eltern ausgeschiedener Stoft, welcher sich erst infolge der Befruchtung während

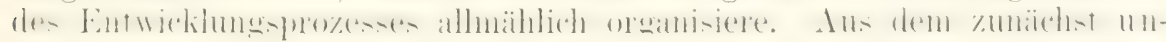
gesonderten Keimstoffe läßt WoLFF sich nacheinander die einzelnen Organe des Körpers sondern, welchen Prozef er in einzelnen Fällen

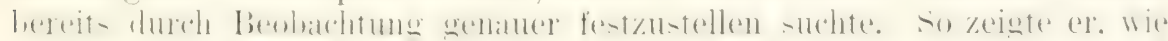

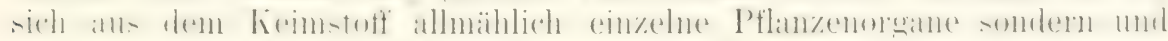
dabei in ihrer Form Metamorphosen eingehen; er lehrte, dab sich der Darmkanal des Hühnchens aus einer blattförmigen Anlage entwickelt.

Indem WOLFF an der IIand von genauen Untersuchumgen an Stelle

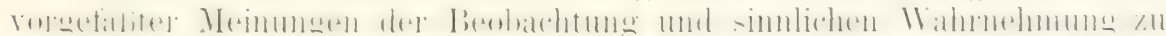
ihrem Rechte verhalf. hat er den Grundstein gelegt zu dem stolzen bau. zu dem sich in unserem Jahrhundert die Entwicklungslehre auf Grund von Beohachtungen alluählich gestaltet bat.

Tergleichen wir jetzt beide Theorien priffend miteinander, so lassen uns beide in ihrer älteren Fassung unbefriedigt. lieide laben ihre Achillesferse. an der sie rerwunthar sincl.

Was zunächst die Präformationstheorie anbetriftt, so trug sie einen

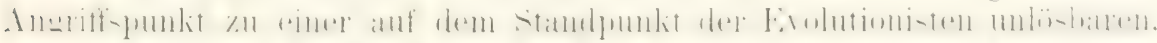

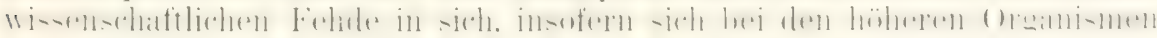
ein jedes Individum durch das Zusammenwirken zweier gretrennter Geschlechter entwichelt. Als man daher auber dem tierischen Ei später auch 
mit den Samenfïden durch LEEuWExHoEks Entleckung (16iT) hekannt geworden war, erhob sich alsbald die lebhaft diskutierte Streitfrage. ob das Ei oder ob der Samenfaden der vorgebildete heim sei.

Ein Jahrhumblert lang stanclen sich die feindlichen Schulen der Oristen und der Animalculisten entgegen. Wie die Oristen. SPALdazari z. B.. dis unbefruchtete Ei des Frosch geradezu als ein kleines Fröschchen bezeichneten und len samen nur ein Reizmittel sein ließen. das die betätigung des Lehens und das Wachstum anrege. so glaubten Vertreter der Animalculisten bei Zuhilfenahme der damaligen Ver-

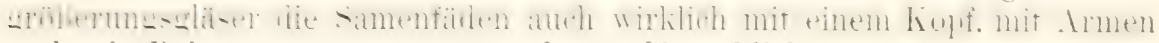
und mit beinen ausgestattet zu sehen. Sie erblickten im Ei nur den ge-

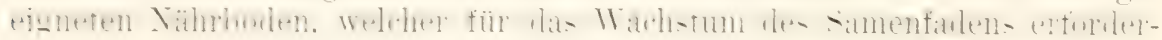
lich sei.

Aber auch auberdem mubte die Präformationstheorie bei einer ins einzelne genauer durchgeführten Durchbildung zu sehr bedenklichen Lonsequenzen führen. Eine solche Konsequenz, die auch die Physiologen HALLER und SPALLAxzAxi nicht glaubten umgehen zu liönnen. ist der Satz. dab in einem Keim auch die Keime für alle späteren Geschöpfeschon angelegt odler eingeschlossen sein müissen. Dieser Satz ist die notwendige Folgerung aus der Tatsache. dah sich die Tier-

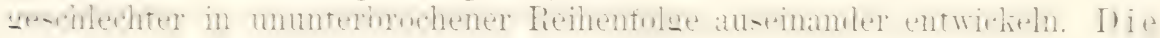
Präformationstheorie hat so aus ihrem Schoolie als naturliche Frucht die ..Einschachtelungstheorie" erzengen müssen oler. wie sich Blumexbach (XIII 17-1) scherzend ausdrïcht: the Lehre ron den ..eingewickelten Keimen". Im Eifer ist man sogar so weit gegangen. zu berechnen. wieviel Menschenkeime im Eierstock der Stammutter Era zum mindesten eingeschachtelt gewesen sind. wohei man damals auf die Zahl ron 20000 Millionen ham (Elemente der Phrsiologie ron HatLer).

Auf der anderen Seite führt aber auch die Theorie der Epigenese in der älteren Fassung bei einer tieferen Durchführung auf Schmieriglieiten. Denn in welcher Wreise. so ham man fragen. vermag die Tatur mit den uns behannten hräften aus einem unorganisierten Stoff in wenigen Tagen oder Wochen einen tierischen Organismus. ähnlich seinen Erzeugern. neu zu bilden": Hierüber vermag keine Lehre. welche den Organismus als eine vollständige Veuzeugung betrachtet. uns eine irgendwie annelımbare. zufrierlenstellende Auskunft zu erteilen.

ButyexBach (XIII 17.21) nahm daher seine 7uflucht zu einem besonderen .. Tisus formativus" oder .. Bildungstrieb". welcher die

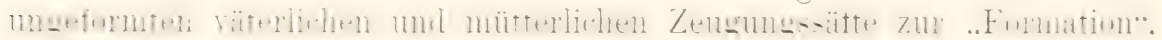
I. h. eine bestimmte Gestalt anzunehmen. veranlaft und auch später dafür sorgt. dab Verstümmelungen wieder ersetzt werden. Aber mit der Annahme eines besonderen Bildungstriebes ist doch nicht viel mehr als ein leeres Wort für eine unbehannte Sache gewonnen.

Teue Grundlagen für die Aufstellung verrolliommneter Zengungs- und Vererbungstheorien wurlen erst ilurch die Zellentheorie und ihre weitere Ausbildung ron der Mitte unseres Jahrhunderts an allmählich geschaffen. Diese Grundlagen sind: erstens die Erhenntnis, daf. Ei und Samenfaden einfache. rom Organismus zum Zwech der Fortptlanzung sich ablösende Zellen sind und dab die entwickelten Organismen selbst nichts anderes sind als geordnete Ver-

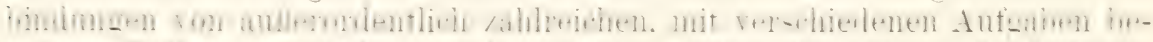

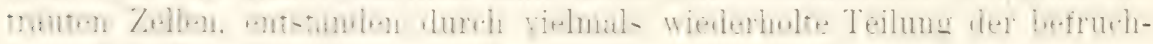
teten Eizelle. Eine zweite Grundlage ist die sich immer mehr Bahn 


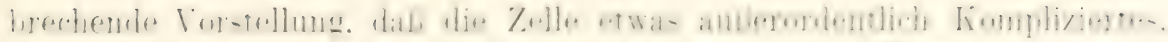
d. h. daß sie selbst ein Elementarorganismus ist. Hierzu gesellt sich

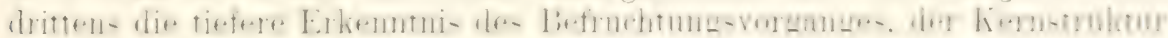
und des Kernteilungsprozesses. namentlich der Längsspaltung und Ver-

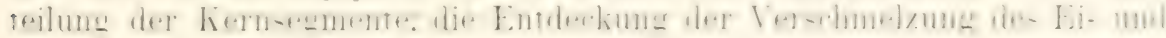
Samenkerns, der Äquivalenz der männlichen und weiblichen liernmasse und ihrer Verteilung auf die Tochterzellen. der Einhlick in die kompli-

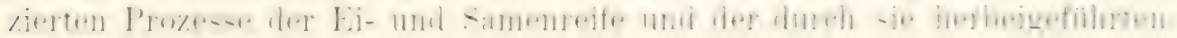
Rerluktion der liernsubstanz.

\section{Nenere Zeugungs- und Entwicklungstheorien.}

Die neuen Zeugungstheorien sind ror allen Dingen von DARWIA (XIII), von Spexcer (XIII 187(i). und NäGELI (XIII 1884), von mir (XII $1864-18.92)$ und STRAsBurer (XIII 18-4. 186-6). von WEISMANY (IIII 1853-1891) und DE VRIES (XIII 18591) ausgearbeitet worlen. In ihnen erscheint der schrofte Gegensatz, in welchem sich frïher die Theorien der"

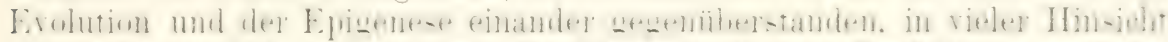

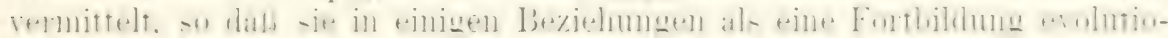

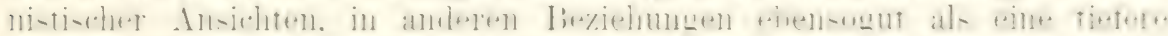

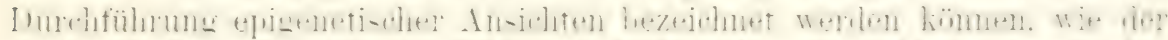
Inoliessle I. sich die neuen Lehren. trotzdem sie nicht mehr als den Jamen ron Hrpothesen verdienen. dadurch. (laf) sie sich auf einem reichen und wohl gesicherten Schatz zum Teil fundamentaler Tatsachen aufhanen.

Es würde mich zu weit führen. wollte ich hier eine gesonderte Darstellung der Ansichten der obengenannten Forscher gehen, die trotz

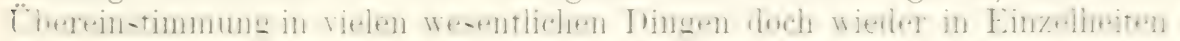
weit auseinandergehen. Ich werde mich daher auf eine kurze IViedergabe dessen, was mir die Guintessenz der modernen Zeugungsund Entwicklungtheorien zu sein scheint. beschränken.

Alle die zahlreichen Eigenschaften. welche in dem entwichelten Oroa-

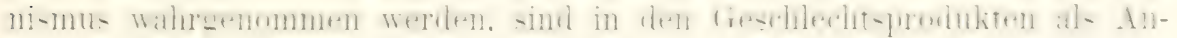
lagen enthalten. Sie werden von dem Erzeuger wiedlel auf dlas Zeugungs-

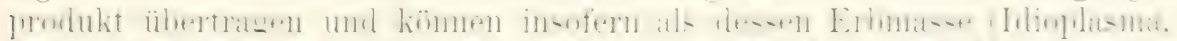

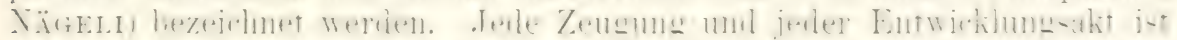

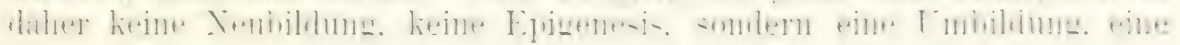
Verwandlung von Anlagen oder einer mit potentiellen Kräften ausge-

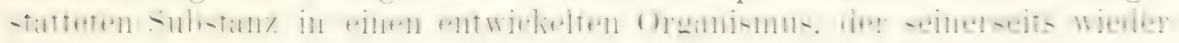
Erhmasse erzeugt, ähnlich der Erhmasse, aus der er selbst herrorgegangen ist.

Wenn wir uns nun die Frage vorlegen. Welche Vorstellung wir uns von dem Aufbau der Erbmasse aus Anlagen machen können. so ist ron rornherein zu betonen. (iaf.) der Biologe zurzeit noch nicht in der Lage ist, eine Hypothese auszuarbeiten. welche sich der Hrpothese des Chemikers und Plirsikers ron den Atomen und Molekiülen an die Seite stellen liefie.

Wir bewegen uns bei Erörterung derartiger Fragen auf einem noch sehr dunklen Gebiet. etwa wie die Naturforscher des vorigen .Jahrhunderts. als sie für den tierischen Körver einen Aufbau aus Elementareinheiten machzuweisen versuchten. Naturgemäb wird die (iefahr. auf thwege zu geraten. un so gröfer werlen. je mehr man beim Aushau einer solchen Hypothese auf das Spezielle einzugehen versucht. 
Die meisten Forscher, welche über das Problem der Vererbung tiefer nachgedacht haben, stellen sich vor, dab die Erbmasse sich in kleinste

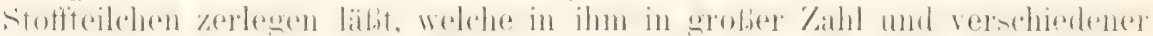
Qualität enthalten sind. Sie sind je nach ihrer verschiedenen stoftlichen Natur die 'Träger besonderer' Eigenschaften und rufen durch direkte Wirkung oder durch verschiedenartig kombiniertes Zusammenwirken die

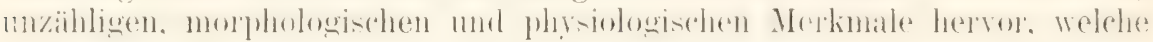
wir an der Organismenwelt wahrnehmen. Sie lassen sich, um mich zweier Bilder zu bedienen, einmal den Buchstaben des Alphabets vergleichen, die gering an Zahl, doch durch ihre verschiedene Kombination Wörter und durch Kombination von Wörtern wieder Sätze von verschiedenartigstem Simn bilden. Oder sie sind den 'Tönen vergleichbar, durch deren zeitliche Aufemanderfolge und gleichzeitige lombination sch mendliche Harmonien erzeugen lassen.

Nach NäGELI. dem sich DE Vries anschliebt, sind ..die Merkmale. Organe, Eimrichtungen, Funktionen, die alle uns nur in sehr zusammengesetzter Form wahrnehmbar sind, in der Erbmasse in ihre wirklichen Elemente zerlegt:. Als solche bezeichnet DE VRIEs Stoffteilchen, welche

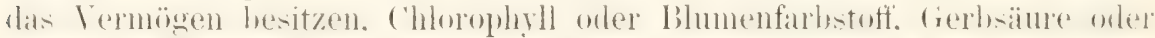
atherische Ole und fügen, wir weiter hinzu. Muskelsuhstanz. Nervensubstanz. etc. zu bililen.

Schon in einem früheren Kapitel waren wir auf einem anderen Wege bei der Besprechung der Elementarstruktur der Zelle zur Anmahme von

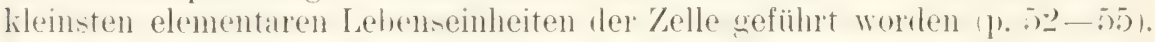
Wir hatten ihnen dort den .Namen Bioblasten gegeben und ihnen zwei fundanentale allgemeine Lehenseigenschaften zugeschriehen: 1. das lermögen, durch Asimilation von Stotten und Imwandlung in cigene substanz zu wachsen und 2. das Vermögen, sich durch Selbstteilung zu vermehren. Dieselben zwei Fundamentaleigenschaften lebender Substanz werden wir auch ,den wirklichen Elementen der Erbmasse", denen wir im folgenden auch den Namen Biobasten geben wollen, beilegen müssen.

In den obigen, hauptsächlich im Anschluß an NäGELI entwickelten Gedlankengängen erblicken wir eine logische Grundlage für eine mole-

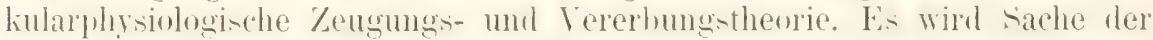
zukiunftigen Forshung sein. durch Beobachtung und Experiment Beweismateriel für die Richtigkeit der einzelnen Ammahmen hrobeizuschatten und darlurch das fiedankengebände mit simnlich wahnehmbaren und daher der beoharhtung und dem Experiment zuginglichen Verhältni-sen in Beziehung zu setzen. Ebenso wie der physiologische Gedanke von dem Aufbau der ()wanismentelt ans Elementareinheiten und ron der darauf hegriundeten Chereinstimmung in der Struktur der I'Hanzen und Tiere rinen realen Inhalt in dem Erfahrumg-chat\% der \%ellen- mol Protoplasmatheorie gewomnen hat, so mul ein entsprechender Zustand auch für die Vererbungstheorie erstrebt werden. Mehrere Versuche sind auch bereits schon in dieser Richtung gemacht worden. Sie knüjfen an die bei (ler Befruchtung der Tiere, Ptlanzen und Infusorien beobachteten Erscheinungen an.

\section{Der Kern als Träger der erblichen Anlagen.}

Strasburger und ich haben, veranlabt durch das Studium des Be-

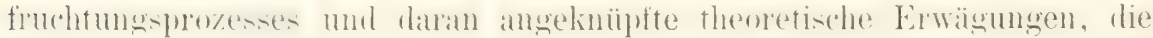
Hypothese aufgestellt, daß die Kerne die Träger der erblichen Eigenschaften sind; wir haben der Kermsubstanz dadurch eine rom Protoplasma 
verschiedene Aufgabe zuerteilt. Kurze Zeit vorher war schon NïGELI

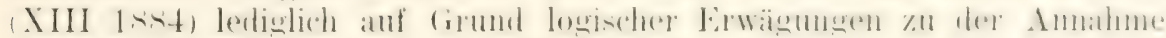

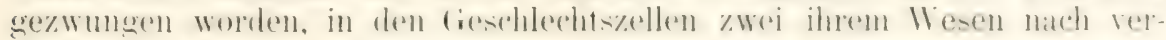
schiedene Arten von Protoplasma zu unterscheiden: eine Art, welche in genan gleichen Mengen in der Ei- und in der Samenzelle vorhanden ist

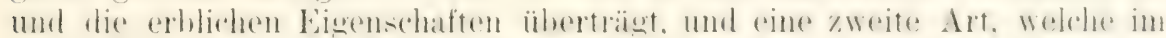

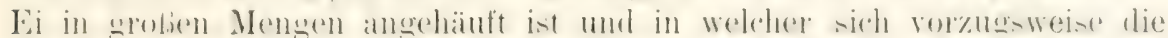

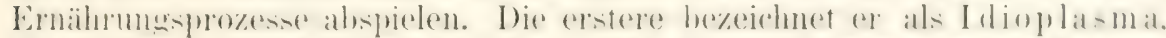

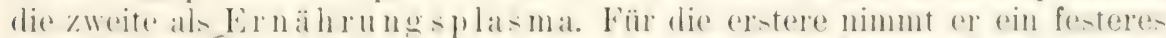

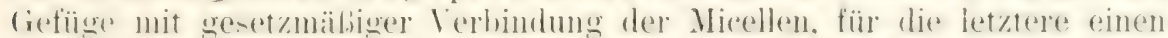

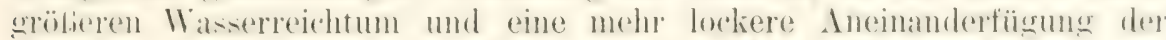
Micellen an. Das Llioplasma läbt er als ein feines Netzwerk im ganzen Zellkörper verbreitet sein.

IV ä üherhaupt die logische lierechtigung für die Ammahme aines besonderen Idiophlamas zugibt, wird sich dem jetzt genauer zu begrimdenden Gedanlengang. dab die liemsubstanz das Iolioplasma sei. nicht entziehen lïmnen. Auch hat diese Theorie den nicht zu unterschätenden Vormg.

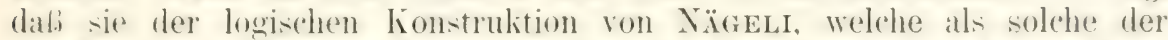
Beohachtung mongänglich und daher nicht forthildungsähig. also anf die I) auer unfruchthal ist, einen realen Inhalt gegeben hat: sie hat sie dadurch in das Bereich der Boobathtung und weiterer wiscenschaftlicher Dislinsion hineingezogen. sie also fruchthar gemacht.

Für die Hrpothese, dal. der Kern der Träger der erblichen Anlagen ist, lassen sich vier Gesichtspunkte geltend machen.

1. Die Äquiralenz der männlichen und weiblichen Erbmasse.

2. I) gleichwertige Verteilung der sich vermehrenden Erbmasie anf die aus dem befruchteten Ei hervorgehenden Zellen.

\%. Die Verhuitung der Summierung der Erbmasse.

4. Die Isotropie des Protoplasmas.

\section{Die Äquivalenz der männlichen und der weiblichen Erbmasse.}

Es ist ein als Wahrheit sich ron selbst aufdriangender und daher gleichsam als Axiom verwertbarer Gedanke, daB Ei- und Samenzelle zwei einander entsprechende Einheiten sind, von denen eine jede mit allen erblichen Eigenschaften der Art ausgestattet ist und jede daher gleichviel Erhmasse dem hind ïlorliefert. Das Kind ist im allgemeinen ein Mischprodukt seiner beiden Eltern; es empfängt von Vater und Mutter gleiche Mengen von T'eilchen, welche Träger der vererbbaren Eigenschaften sind (Bioblasten).

Nun gleichen sich aber nur bei den allerniedrigsten Organismen die

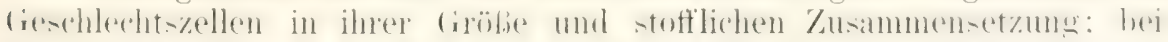

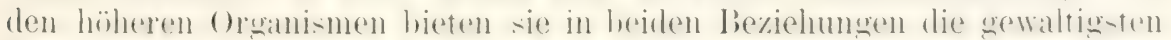
Unterschiede dar. so daf in extremen Fälen cin tierischer Samenfaden

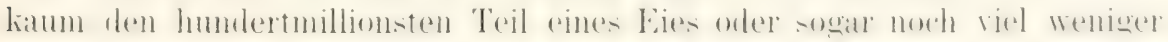
ausmacht. Es ist wohl nicht denkbar. dab die 'Träger der Anlagen. die

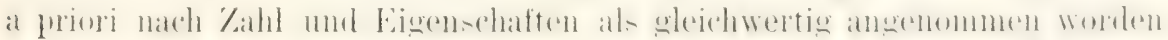
sind, derartige Differenzen in ihrem Volum darbieten liömen. Dagegen erklärt sich die Tatsache, dal.) zwei an Masse ganz verschiedene Zellen die

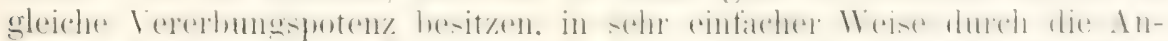

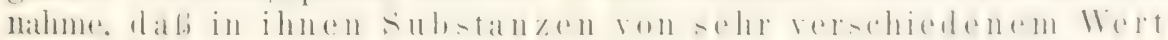
für die Vererbung, idioplasmatische und nicht-idioplasmatische. nebeneinander enthalten sind. 
Hieraus erwächst für uns die Aufgabe, im Ei und Samenfaden das Idioplasma aufzusuchen und von den übrigen Substanzen zu sondern.

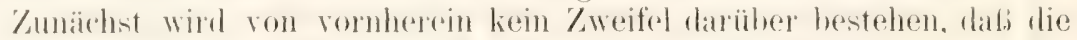

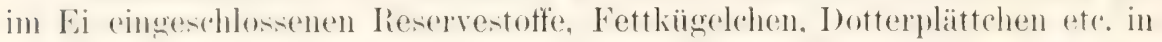
die Katerorie der für die Vererbung unwirkimen liem-totfe zu rechnen sind. Wenn wir von denselben aber auch ganz absehen, so sind Ei- und simmenzelle noch immer nicht gleichwertig hinsiohtlich der Mense ihner ïhrigen Bestanteile. Denn auch das Protoplasma einer groben Eizelle heträgt nach dhzug aller Dotteremschlüse andierordentlich viel meln als die fresantsubstanz eines Samenfarlens: es entipricht daher gleichfalls nicht der oben gestellten Bedingung. Ihr genügt nur ein 'Teil der Ei- und Samenzelle: das ist ihre Kernsubstanz.

Das Studium der Befruchtungserscheinungen im Tier- und Pflanzenreich liefert hierfïr die untriiglichsten Beweise. Wie im elften Kapitel heschriehen wurle. besteht das Wesen des Befruchtungsprozesses darin, daß ein vom Samenfaden und ein von der Eizelle abstammender Kern. ein Samenkern und ein Eikern. sich zusammenlegen und zu einem lieinkern verschmelzen, von dem in weiterer Folge durch vielmals wiederholte T'eilprozesse alle Kerne des entwickelten Organismus abstammen. Bei den Infusorien legen sich sogar zwei Individuen nur voribergehend anemander, um die Wanderkerne auszutauschen, welche darauf mit den stationären Kernen der Paarlinge verschmelzen.

Soweit die genaueste Beobachtung zeigt, liefern Ei- und Samenkern vaillig gleichwertige stotfmengen zur Bildung des liemlierns. Hierfür sprechen in unwiderleglicher Weise die Beobachtungen var Benedens (VIII 1883) über den Befruchtungsprozeß von Ascaris megalocephala.

Wir ziehen somit aus den Tatsachen der Befruchtungslehre den wichtigen Schlub:

Da bei (ler Befruchtung die Kernsubstanzen (Chromatin) die einzigen an Masse äquvalenten Stoffe sind, die sich zu einer neuen Anlage, dem Keimkern. vereinigen, so können sie auch allein die von den Eltern auf das Kind ïbertragenen Erbmassen sein.

\section{Die gleichwertige Verteilung der sich vermehrenden Erbmassen auf die aus dem befruchteten Ei hervorgehenden Zellen.}

Eine gleichmäßige Verteilung der sich vermehrenden Erbmasse zwishen den Destendenten der Eizelle wird durch zahloeiche Tatsachen der \%engung und liegeneration unmmänglich verlangt: zuerst durch die einfache Tatsache, daß jeder Organismus wieder zahlreiche Ei- oder Samenzellen hervorbringt, die wieder dieselbe Erbmasse in der gleichen Menge enthalten, wie die Geschlechtszellen, aus denen er entstanden ist.

Zweitens wird diese Annahme notwendig gemacht durch die Beobachtung, das bei vielen Pflanzen und ebenso auch bei vielen niederen Tieren fast jedler kleinste Zellenkomplex des Körpers imstande ist, das Ganze aus sich zu reproduzieren.

Wird das Moosphlänzchen Funaria hygrometrica zu einem feinen Brei zerhackt, so läbt sich auf feuchter Erde aus jedem kleinsten Fragment

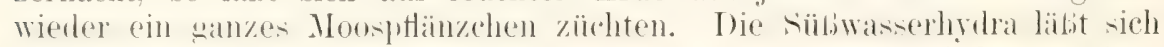
in kleine Stückchen zerschneiden, von denen sich jedes wieder zu einer ganzen Hydra mit allen ihren Eigenschaften umbildet. Bei einem Baum kïmnen sich an den rershiedensten stellen durch Wucherung vegetativer 


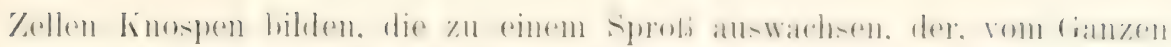
abgetrennt und in Erde verptlanzt, sich bewurzelt und zu einem vollständigen Baum wird. Bei Cölenteraten, manchen Würmern und T'unicaten

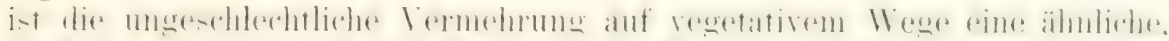

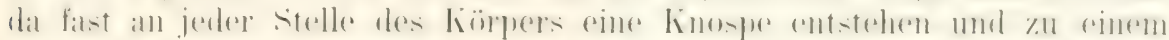

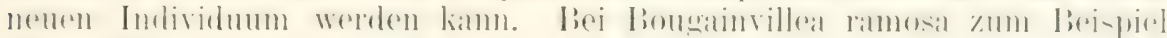
(Fig. 276) entwickeln sich neue Individuen nicht nur als Seitenzweige

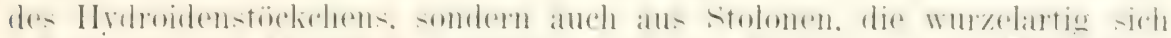

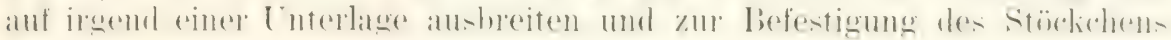
dienen.

Drittens zeigen viele Vorgiinge der Regeneration oder Wiedererzengung verloren gegangener 'Teile, daß in der Zelle auber den oftenbar gewordenen Eigenschaften anch noch andere, latente Eigenschaften schlummern. welche durch (lie ab)normen Bedingungen zur Entfaltung gebracht werden können.

Ein abgeschnittener und ins Wasser gestellter Weidenzweig entwickelt wurzelbildende Zellen an seinem unteren Ende. und so wird hier von Zellen. die im Plane des ursprünglichen Ganzen eine sehr abweichende Funktion zu erfuillen hatten. eine den neuen Berlingungen entsprechende Aufgabe ïbernommen, ein lieweis, daß die Anlage dazu in ihnen gegeben war. Und so können sich umgekehrt auch aus abgeschnittenen Wurzeln Laubsprosse bilden, die dann zu ihrer Leit selbst männliche und weibliche Geschlechtsprodukte

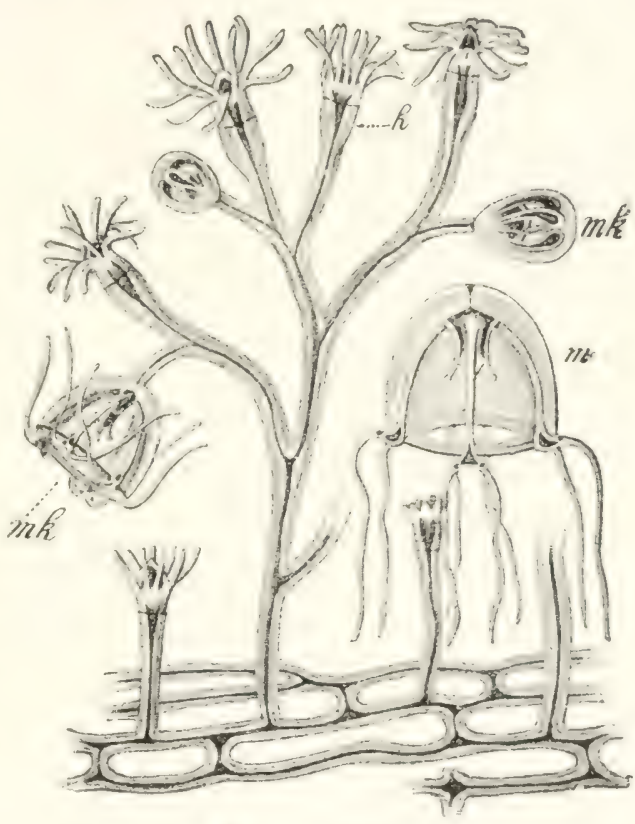

Fig. 276. Bougainvillea ramosa. Aus LANG.

h Hydranthen, welche Medusenknospen ( $m$ k) erzengen (Amme). m Losgelöste Meduse Marmleis ramosa.

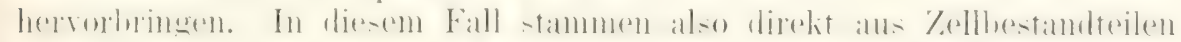

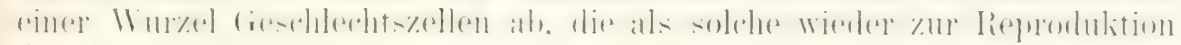
des Gianzen dienen.

Aus diesen und ähnlichen Erscheinmgen, die in einem späteren Abschnitt noch genaner erörtert werden sollen, können wir schließen, daf heiden P'lanzen und beiniederen Tierenallevom Fiabstammenden Zellen in gleichen Verhältnissen Erbmasse enthalten. Dieselbe mulo daher vor jeder Teilung in den Zellen sich durch Wachstum auf das Doppelte rermehren. Alle bioblasten der Erbmasse müssen sich teilen mnd müssen dann in qualitatir und quantitatir gleichen beträgen auf die Tochterzellen übertragen werden.

Denselben Gesichtspunkt hat NïGELI entwickelt (IX. 20 S, 521), indem el erklärt: ..Das Idioplasma zerfällt, indem es sich fortwährend im entsprechenden Nabe vermehrt, bei den Zellteilungen. durch welche der Organismus wächst, in ebensoviel Partien, die den einzelnen Zellen zu 
kommen." Dobler ist .jolle Zelle des (O)ganiomus ielioplasmatiseh befähigt. zum Keim für ein nenes Individum zu werden. Ob diese Befähigung sich verwirklichen kann, hängt von der Ieschaffenheit des Ernährungsplasmas $a b^{66}$.

Wenn wir von diesem zweiten Gesichtspunkte aus die Lebensprozesse der Zellen überhlicken, so kam es wohl wielerum kemem Zweifel unterliegen. dab ron allen uns bekamnten Zollteilen die Kernsubstanz allein allen geltend gemachten beningungen, mol zwar in vollem Malie genügt.

In allen Elementarteilen bei Pflanzen und Tieren zeichnet sich der Kern durch eine ïherraschende (ileichförmigkeit aus: Wenn wir ron einzelnen Ausnahmen absehen, die cine besondere Erklärung erheischen, erscheint uns der Kiem in allen Elementarteilen desselhen Orwanismus immer nahezu in derselben Form und cröbe, während das Protoplasma an Masise auberordentlichem Wechsel unterworfen ist. In einer Endothelzelle, einem Muskel- oder Sehnenkörperchen, ist der Kern nahezu ehenso beschaften und ebenso substanzreich, wie in einer Epidermis-, einer Leber- oder Knorpelzelle, während in dem ersten Falle das Protoplasma nur noch in Spuren nachweisbar, im letzteren reichlicher vorhanden ist.

Aber wichtiger als dies sind die so auffälligen, komplizierten Erscheinungen des Kernteilungsprozesses, die im Lichte unserer Theorie erst eine tiefere liedeutung gewinnen und dem Verständnis erschlossen werden. Wie schon auf Seite ¿os bei der Frage nach der bedeutung der Karyolinese auseinandergesetzt wurde, hat die Anordnung der Sulstanz in Fäden, die aus kleinen, aneinander gereihten Mikrosomen bestehen, die Schleifen- und Spindelbildung, die Italbierung der Fäden ihrer Lünge nach und die Art ihrer Terteilung auf die Tochterkerne oftenhar keinen anderen Zweck, als die Kernsubstanz in zwei gleiche Hälften zu zerlegen und den Tochterzellen zuzuteilen.

Bei der Bedeutung der Kernsubstanz als Erbmasse begreift es sich auch, warum sie den gröberen Voroüngen des Stoffwechsels, wie sie sich im Protoplasma abspielen, mehr entzogen und zum hesseren sichutz in so auffälliger Weise in ein mit besonderer Membran versehenes Bläschen eingeschlossen worden ist.

\section{Die Verhutung der Summierung der Erbmassen.}

Als ein sehr wichtiges Moment in der Beweisführung betrachte ich den dritten Punlit, nïmlich die Verhütung der summierung der Erhmassen bei der geschlechtlichen Zeugung.

Infolge des Wesens des Kernteilungsprozesses erhält jede Zelle dieselbe Quantität Kernsubstanz wie die befruchtete Eizelle $A$. Wenn daher zwei ihrer Deszendenten als (ieschlechtszellen sich wienler vereinigten, so mïlite das Zeugungsprodukt $B$ die doppelte Kermmasse erhalten, als die Zelle $A$ besaB, die uns zum Ausgang diente. Erfolgte eine neue Kopulation in der dritten Generation, so mübte $C$ wieder die doppelte Kernmasse von $B$ oder die vierfache von $A$ erhalten, und so würde bei jeder nenen Zengun duch den Befruchtungsprozel, die Kermmasse in geometrischer Progression anwachsen. Ein solches Anwachen mub daher in der Natur durch irgend einen Torgang in besonderer Weise verhindert werden.

Dieselbe Betrachtung ist auf das Idioplasma anwendbar, wenn dasselbe in voller Masse auf jede Zelle vererbt und jedesmal durch den Befruchtungsakt verdoppelt werden würde. An und für sich würde zwar 
darhreh seine Natur nicht verändert werden. Denn anstatt zweimal wïrden alle einzelnen Anlagen viermal, achtmal und noch mehr vertreten sein. So würde bei Zumahme der Ouantität die (Oualitit immer dieselbe bleiben. Aber es lierrt aut der Hand, dals die Massenzunahme nicht eine unbegrenzte sein kann. Auch Nïgeri und besonders Wers-

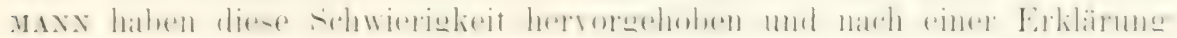
gesucht.

. Wemm bei jeler Fortptlanzung durch Befruchtung", bemerkt N̈̈GELI.

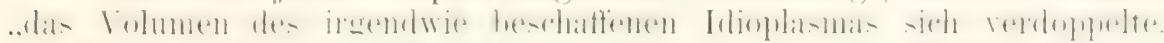

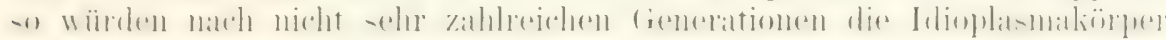
so sehr anwachsen, dab sie selbst einzeh nicht mehr in einem Spermatozoid Platz fänden. Es ist also durchaus notwendig. daf. bei der digenen

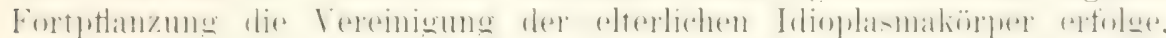
ohne eine den vereinigten Massen entsprechende, dauernde Vergrößerung dieser materiellen Systeme zu verursachen." NïgELr sucht diese

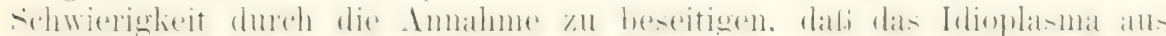

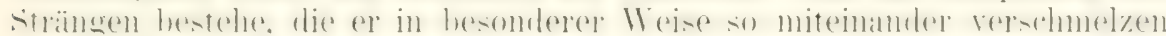
liißt, daß der Querschnitt des Verschmelzungsprodulites derselbe wie im einfachen Faden bleiht, dagegen eine Zunahme in der Länge erfolgt (Nïgel XIII 1sist S. 224).

Namentlich aber hat sich WEISIdNx (XIII 1885-91) mit (lem hier

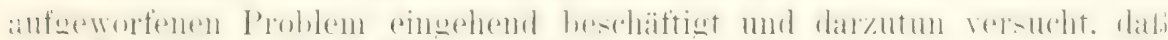

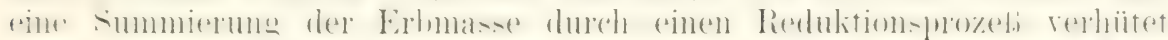

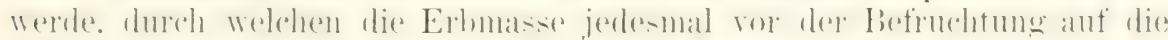
Hälfte verkleinert werde. $\mathrm{Er}$ hält die theoretische Forterung einer bei

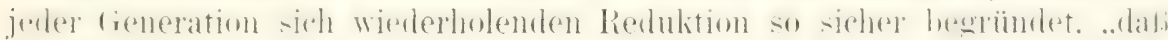

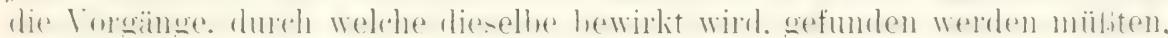
wenn sie in den von ihm so gedeuteten 'Tatsachen noch nicht enthalten sein sollten".

WeIsmaxx ist allerdings zu dieser Forderung durch Anschaumgen

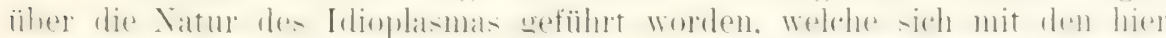
entwickelten nicht decken. Sie sind von ihm als Ahnenplasmatheorie

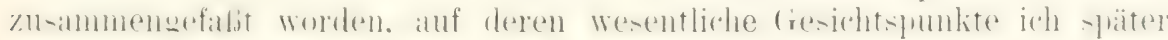
zuriekliommen werde.

Es führen also die Untersuchungen des Befruchtungsprozesses und

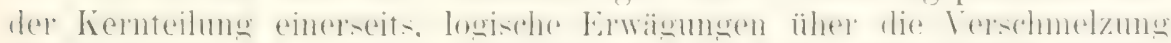

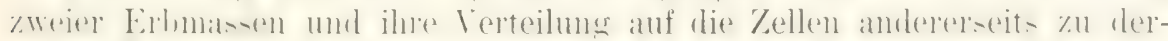

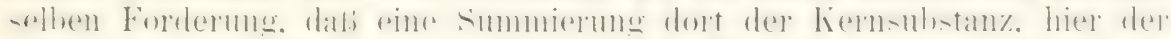

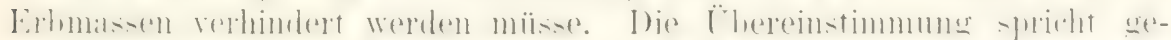
wif in hohem Maße für die Annahme, dab. die Kernsubstanz selbst die gesuchte Erbmasse ist, zumal wenu sich bei der Kernverschmelzung Vorgänge nachweisen lassen, durch welche in recht angenfälliger Weise der als notwendig erkannten Forderung entsprochen wird.

Um zu verhüten. das durch die Adrition zweier an Masse gleichwertiger 'Teile das Produlit an Masse nicht mehr beträgt, als einer der Teile für sich. kann man a priori wohl nur zwei Wege einschlagen. Entweder man halbiert vorher die zu vermischenden Teile oder man halbiert das durch die Vermischung erhaltene Produkt. Die Natur scheint sich beider Verfahren beim Befruchtungsprozeb bedient zu haben.

Das eine Verfahren findet sich bei phatrerogamen Pthanzen und bei

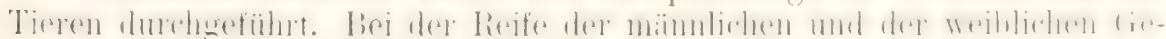

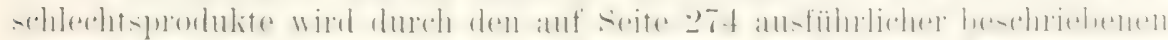

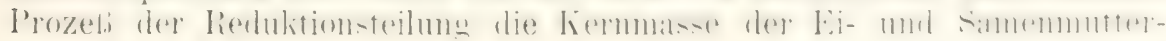


zelle auf vier Enkelzellen so verteilt, daß jede von ilmen nur noch die halle Kormmase einer gewöhnlichen \%elle und in antsprechender Weises auch nur die halbe Zahl von Kernsegmenten erhält.

Das zweite Verfahren sehe ich bei dem Befruchtungsprozels von Closterium verwirklicht. Hier teilt sich nach den Beobachtungen von

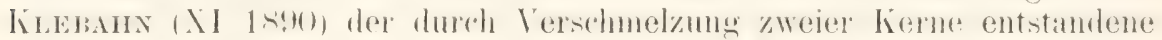
Keimkern sofort zweimal hintereinander, wie bei der Bildung der Polzellen, ohne in ein Ruhestadium einzutreten. Von den vier bläschenfömigen Kernen gehen zwei zugrunde. so dals jede Teilhälfte der Mutterzelle nur einen Kern erhält, der anstatt die Hälfte, wie bei einer Normalteilung, nur ein Viertel der Substanz des Keimkerns besitzt. (Siehe die Darstellung und Abbildungen auf Seite 305.)

Wenn nach unserer Annahme Kernmasse und Erbmasse ein und dasselbe sind, so wïrde sich aus dem Prozeß der Reduktionsteilung die Folgerung notwendig ergeben, daB die Erbmassebis zu einem gewissen crade teilbar ist, ohne ihre Eigenschaft, aus sich das Ganze zu reproduzieren, zu verlieren. Es fragt sich, inwieweit sich diese Auffassung rechtfertigen läbt.

Weismann und ich, welche beide die Notwendigkeit einer Massenreduktion betonen, sind im einzelnen zu sehr verschiedenen Auffassungen gekommen.

In seiner Ahnemplasmatheorie geht Wersmaxs von der Voraussetzung aus, daß in der Erbmasse sich die väterlichen und die mütterlichen Anteile arenent erhalten und Einheiten bilden. die el Ainemplasmen nennt. Für dieselben nimmt er einen sehr verwickelten Ban und eine Zusammensetzung aus ungemein zahlreichen, biologischen Einheiten an. Bei jecler neuen Befruchtung kommen nun immer zahlreichere Ahnenplasmen zusammen. Wenn wir uns an den Anfang des ganzen Befruchtungsprozesses zurïckversetzen. so müssen schon bei der zehnten Generation 1024 verschiedene Almenplasmen in die Zusammensetzung der Erbmasse eingegangen sein. Damit aber die Gesamtmasse der letzteren bei jerler Befruchtung nicht auf das Doppelte anwachse, läßt Weisuswn auf den Anfangsstufen des Befruchtung-porozeses die Ahmenplasmen teilhar sein und jerlesmal anf die II:ilfte verlibinert der folgenden fiencration ïberliefert werden. .Zuletzt aber muß einmal", so wird weiter gefolgert, ,eine Grenze dieser steten Verkleinerung der Ahnemplasmen erreicht werden, und zwar damn, wenn die Substanzmenge, welche nötig ist, damit alle "Anlagen" des Individuums darin enthalten sein kömnen, ihr Minimum erreicht hat."

Von diesem Zeitpunkt an, der übrigens bei niedrigen, sich rasch vermehrenden Organismen in wenigen Jahren erreicht sein würde, mübte infolge der nicht mehr möglichen Verkleinerung der Ahnenplasmen wirler vine summierunw der Erhmasien durch jede neur Befruchtung horbeigeführt werden, wenn nicht eine neue Eimrichtung getroften würde.

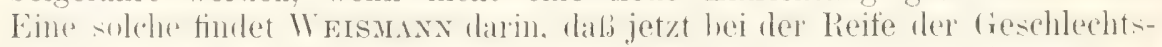

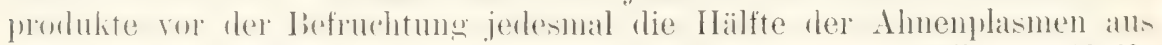
der Frbmasse ausgestoben werde (Polzellenbildung). An Stelle der Teilbarkeit der einzelnen Ahnenplasmen also tritt von dem Zeitpunkt an, wo sie zu nicht mehr teilbaren Einheiten geworden sind, die Teilbarkeit der Zahl der Ahnemplasmen.

So gestaltet sich nach den Annahmen von Wersuraxy die Erbmasse zu einem anderoricntich lomplizierten Mosiliwerli. zusammengesetzt aus zahllosen. ihrer Natur nach unteilbaren und mit anderen nicht mischbaren Einheiten, den Ahmenplasmen, von denen jedes wieder zusammen- 
gesetzt ist aus zahlreichen Anlagen, die zur Hervorbringung eines rollständigen Individum notwendig sind.

Demmach wïrle jede Erbmasse ihrer Zusammensetzung nach zahllose Individuen aus sich hervorbringen müssen, wenn jedes Ahnenplasma aktiv werlen kömnte. Das Wesen des Befruchtumgsvorganges gestaltet sich zu einer Eliminierung und Jenersetzung von Almenplasmen. Eine

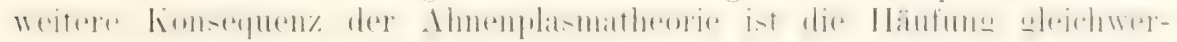
tiger Anlagen in der Erbmasse. Dem als Glieder einer Art sind die

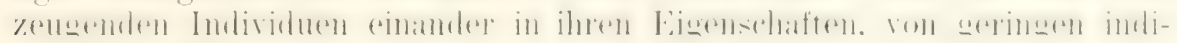
viduellen Färbumgen abgesehen. wesentlich gleich. Alle Ahnenplasmen

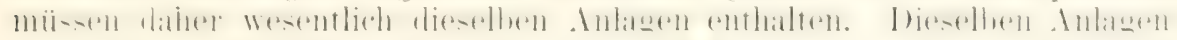
werden in der Erbmasse so vielmals vertreten sein. als die Kahl der

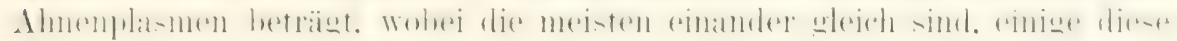
orler jene Nüance darbieten. Alle diese gleichartigen oder nuancierten Anlagen aber wirden in keiner direkten Beziehung zu einander stehen,

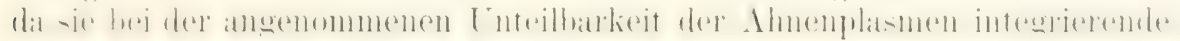
liestandteile derselben bleiben mïssen.

Durch die Ahnemplasmatheorie ron Wersusax wirl die Frage der

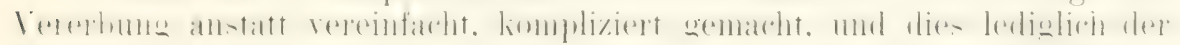
Annahme zuliebe, dab die väterlichen und die mïtterlichen Erbmassen nicht miteinander mischbar seien.

Ich sehe ein Verdienst der Weisuaxsschen Konstrulition darin gezeigt zu haben, zu welchen Schwierigkeiten gerade diese Ammahme führt. Dieselbe erscheint aber röllig übertlïssigr: verler NäGEL noch DE VRres machen sie. setzen viehmehr eine Mischbarkeit der in den zwei Frbmassen enthaltenen Einheiten voraus. Auch ich ziche vor, mir den P'rozeh erblicher Übertragung so rorzustellen, dab die Bioblasten väterlicher mud müterlicher Herkunft sich nicht mehr als Teile zweier getrennter Anlagen forterhalten, sondern sich in irgend einer Weise zu einer Mischanlage vereinigen.

Wie liabt sich dann bei dieser Toraussetzung die durch die geschlechtlichen Zeugungsalite bedingte Summierumg der Erbmasse ver-

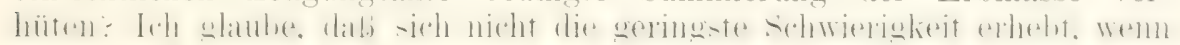
wir eine Teilbarkeit der ganzen Erbmasse annehmen. Diese Annahme hat ja auch Wersmaxx für die Anfümge der geschlechtlichen Zeugung gemacht, da sonst eine Summierung der Ahnenplasmen, ohne eine Zumahme der Erlmasse zu veranlassen, ïberhaupt nicht hätte eintreten kïmmen.

'Teilbar kann aber die Erbmasse, ohne ihr Wresen zu rerändern. nur sein. Wenn in ihr die lioblasten verschiedener Art in mehrfacher Anzahl vorhanden sind. Da num die Kinder aus zwei nahezu gleichwertigen Anlagekomplexen der Eltern hervorgehen, so werden in der lindlichen Anlage gleichwertige Bioblasten wenigstens in doppelter Zahl vertreten sein müssen. Es steht aber auch nichts im Wege. anstatt einer doppelten Zahl eine vier-, acht- odler, allgemein gesagt, überhaupt eine mehrfache Zahl gleichwertiger Bioblasten in der Erbmasse vorauszusetzen. Dann ist aber eine Massenredulition. olme die Natur des

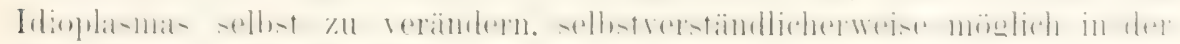
Art. wie sie bei der Reife der Geschlechtsprodulite beobachtet wird, und sind weitere komplizierte Hülfshypothesen überthüssig.

Lm die sogenannten Rückschläge bei der Vererbung zu erklären. kommt man auch ohme die Ammahme ron dhmenplasmen aus: denn wie wir später sehen werilen, können sich Anlagen latent erhalten. 


\section{Die Isotropie des Protoplasmas.}

Von manchen Seiten ist versucht worden. dem ganzen Ei eine Organisation zuzusehreiben, derart. dali es ans kleinsten Teildhen zusammen-

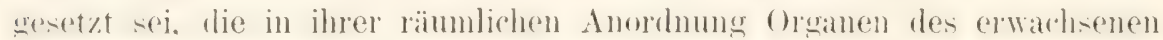
Tieres entsprechen und ihre Anlagen darstellen. Am klarsten ist die Auffassung yon His für das Hühnerei formuliert worden in seinem Prinzip der organbildenden Keimbezirke. Danach mub, „einesteils jeder Pmbit in Embryomaliezirk der lieimsheihe emem späteren orwan oder Organteil entspreclien und anderenteils mub jedes aus der lieimscheibe hervorgehende Organ in irgend einem räumlich bestimmbaren Iiezirk der thachen scheibe seme vorgehildete Anlage hahen. I)as Material zur Anlage ist schon in der ebenen Kieimscheibe vorhanden, aber morphologisch nicht abgeglierlert und somit als solches nicht ohne weiteres erkemnhar. Auf dem Wege rïckläufiger Verfolgung werden wir dahin kommen, auch in der Periode unvollkommener oder mangelnder morphologischer (iliederung den Ort jeder Anlage räumlich zu bestimmen: ja wenn wir konsequent sein wollen, haben wir diese Bestimmung auch auf das eben befruchtete und selbst auf das unbefruchtete Ei auszudehnen*.

Es braucht wohl kaum hervorgehoben zu werden, in welchem schroffen (iegensatz das I'rinzip, der organbillenden heimbezirke zu der ohen vorwetragenen Vererhungstheorie steht. Dasselhe bietet - was ihm von vornherein vorgeworfen werden muB - für die Wirksamkeit der väterlichen Anlage auf die Formbildung des Embryos lieinen Raum: es mülite schon lediglich aus diesem dirunde fallen gelassen werden. Aber hiervon ahgesehen, lälit es sich auch auf cirund verschiedener experimenteller Tatsachen, welche, wie PFLÜGER sich ausgedrückt hat, eine Isotropie des Eies beweisen, direkt widerlegen.

Unter Isotropie des Eies versteht PfLüger (IX 1884) die Erscheinumg. dab der Inhalt des Eies nicht in der Weise gesetzmäbig angendnet ist. dati rich auf diesen oller jenen Teil die einzelnen Organe zurïcliführen lasien. Auf zahlreiche Fxperimente und andere Verhälnisse. Welche zugunsten von PFLÜGERs Ansicht sprechen, werden wir in einem späteren Kapitel noch genauer einzugehen haben; vorläufig heben wir nur das eine hervor, dal., wie rielerlei Experimente lehren, der Zellkern. in einen heliehigen Bruchteil des Eiłlotters einge-schlossen noch einen vollständigen ()rganismus hervorzuhringen imstande ist. Dies ist für die Isotropie des Eies heweisend mul widerlegt das Prinzip der organbildenden Keimbezirke. Es ist zugleich ein weiterer Beweis für die Ansicht. dab das Idioplasma nicht im Protoplasma. sondern im Ke'm 7.1 suchen ist. Zngleich lassen sich hieraus einige Schlüsse über den Aufbau des Protoplasmas und del' Kernsubstanz, ziehen.

Das Protoplasma muß aus mehr gleichartigen, locker untereinander verbundenen Teilchen oder Micellen bestehen. Auf eine stabilere Anordnung der liemsubstanz dagegen weist die hompliziertheit der wanzen Kernsegmentierung hin. Einen solchen Unterschied zwischen dem Er-

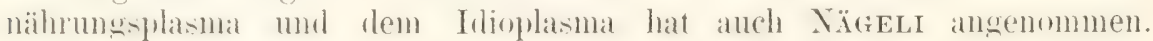
.Wenn die Anordnung der Micellen," heißt es bei ihm (p. 27. 41), ,die srezifischen Figensolaften des Iolioplasmas hegründet. so muda das letztere cine ziemlich feste sulstanz darstellen. in welcher die Vicellen durch die in dem lebenden Organismus wirksamen Kräfte keine Verschiebung erfahren und in welcher der feste Zusammenhang bei der Vermehrung 


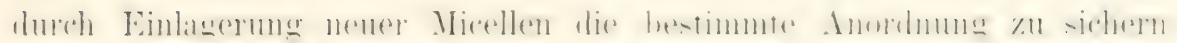

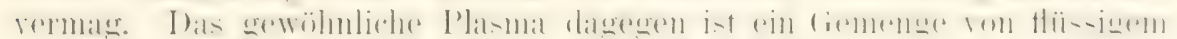
und festem Plasma, wobei die beiden Modifikationen leicht ineinander.

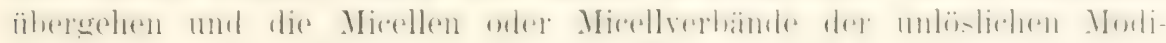
fikation. wie dies für das strömende Plasma nicht anders angenommen

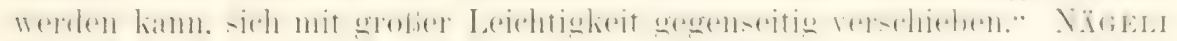
bezeichnet es daher als ..eine kaum von der Hand zu weisende Annahme.

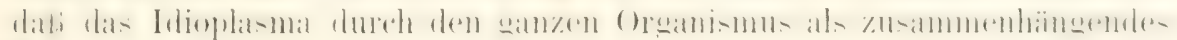
Netz ausgespannt sei."

\section{Die Entfaltung der Anlagen.}

Wenn wir cine besondere Anlagesubstanz orler Idioplasma in der Zelle unterscheiden. so bleibt zu untersuchen, in welcher Weise sie wirksam wird mol die spezifischen Eigenschaften oder den Charakter einer Zelle bestimmt.

Da wir später auf die Frage noch ausführlicher eingehen werden, so sei vorläufig nur hervorgehoben, dab, um die Sache verständlicher zu machen, sich uns zwei Hypothesen darbieten, eine dynamische und eine materielle: die eine ist yon Nïger. (XIII 1884), die andere von DE V'ries (XIII 1s,!) entwickelt worden.

NäGeli läbt. um die spezitische Wirksankeit des Idioplasmas in der

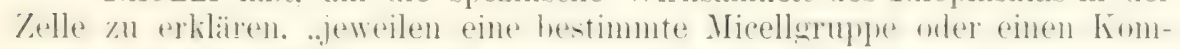

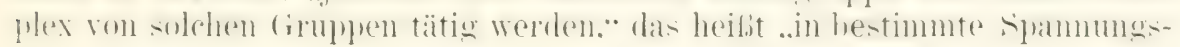
und Bewegungszustände geraten,“ und el läßt „diese lokale Erregung

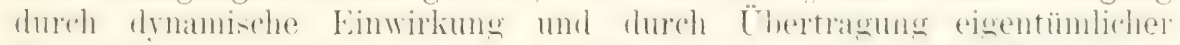

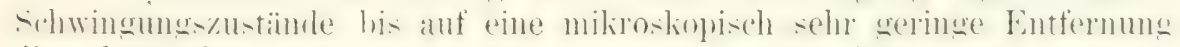
die chemischen und plastischen Prozesse beherrschen." „Es erzengt

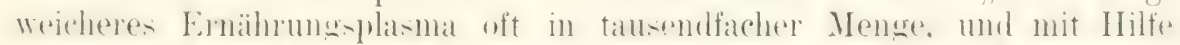

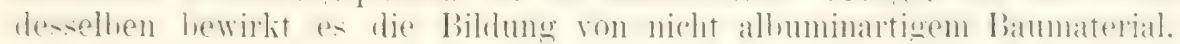

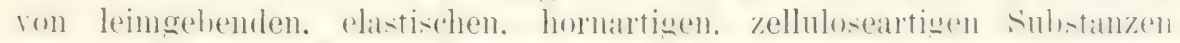

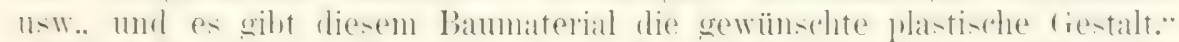

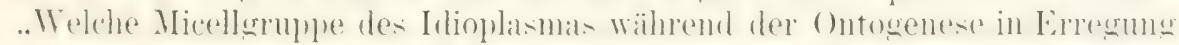

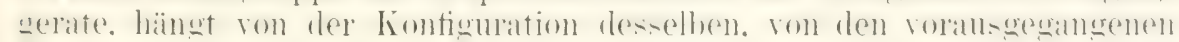

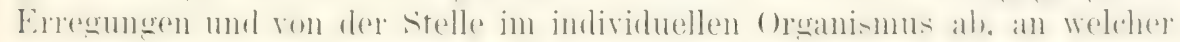
sich das Idlioplasma befindet."

Anstatt der dynamischen Hypothese nimmt DE VRres (XIII 1889)

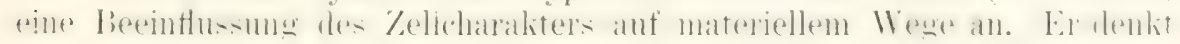
sich, daß in der Anlagesubstanz, während die meisten Bioblasten oder ,Pangene (DE Vries) inaktiy bleiben, einige in Wirksamkeit treten. Wachsen und sich vermehren. Dabei wandert ein Teil von ihnen aus dem Kern in das Protoplasma aus, $u$ hier ihr IVachstum und ihre Vermehrung in einer der Funktion entsprechenden Weise fortzusetzen. Das Verlassen des Kerns kann aber stets nur derart geschehen, dab alle Arten von Bioblasten in ihm vertreten bleiben.

Die Hypothese von DE I'RIEs scheint mir zurzeit die einfachere Erklärung zu sein und sich manchen Erscheinumgen besser anzupassen. So sind \%. B., wie fribler heschrieben wurle. in der Ptlanzenzelle als 'T'üger einer spezifischen Funktion besondere Stïrkebiluner. Chromato-

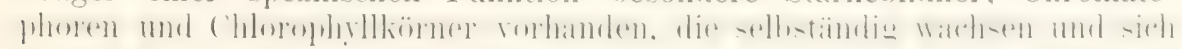
vermehren und hei jeder Zellteilung von einer anf die andere Zelle mit 
übergehen. DE VRIEs nennt dies, Erblichkeit auberhalb der Zellkerne". Nach seiner Hypothese wïrlen es aktiv gewordene Bioblasten sein, die sich im Protoplasma vermehrt und zu gröheren Einheiten verbunten haben, während sie auberdem noch im Kern, in der Anlagesubstanz, inaktiv vertreten sind.

Durch die Hypothese der ,intrazellulären Pangenesis“ wird der schate fiegensat\%. der anschemend durch die folioplamatheorie zwischon

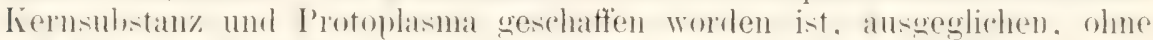

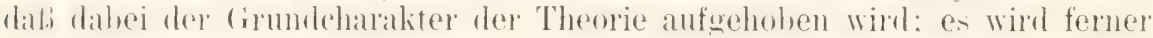
der Weg gezeigt, wie eine Zelle die Gesamtheit der Eigenschaften des ganzen zusammengesotzten Orwanismu, latent enthilten lumb dabei dow spezifisch funktionieren kann.

Die Überlieferung eines Charakters und seine Entwicklung sind, wie DE VRIEs mit Recht hervorhebt, verschierlene Vermögen. Die Überlieferung ist die Funktion des Kernes, die Entwicklung ist Aufgahe des Protoplasmas. Im Kerne sind alle Arten von Bioblasten des betreffenden Individuums vertreten; - daher ist er das Vererbungsorgan katexochen; ras ïhrige Protoplasma enthält in jerler Zelle im wesentlichen nur die Bioblasten, welche in ihr zur Tätigkeit gelangen sollen und in einer entsprechenden Weise auberordentlich rermehrt sein kömmen.

Wir haben daher zwei Arten der Termehrung der Bioblasten zu unterscheiden, eine auf die Gesamtheit sich erstreckende, die zur hernteilung und zur gleichmäßigen Verteilung auf die beiden Tochterzellen führt. und eine gewissermalien funktionelle Vermehrung. weldhe nur die in Alition trotenden libolasten betrifft, anch mit stofflichen Veränlerungen derselben verbunden sein wird und sich besonders aukerhalb des lierns in Protoplasma abspielt.

Schon früher (Seite 52) wurde ron uns die Hypothese ausgesprochen, daß, wie der Kern, auch das Protoplasma aus zahlreichen, kleinen, durch

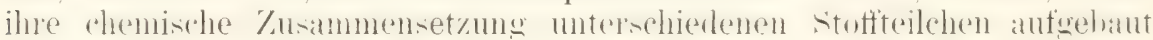
ist, welche das Vermögen besitzen, Stoff zu assimilieren, zu wachsen und sich durch Selbstteilung zu vermehren. (Omne granulum e granulo, wie sich ALtuidnn ausdrückt.)

Die vom Irloplasma des Kerns abstammenden, gleichsam aktir geworlenten biohlasten wïrden wieder den Ausangsonnkt für die zahlreichen Plasmaprodukte der Zelle bilden, indem sie je nach ihrer spezifischen Natur diese oder jene anderen Stoffe an sich binden; es könnten z. B. gewisse Arten von Plasomen durch Verbindung mit Kohlenhydraten die Zellulosehaut oder durch Verbindung mit Stärke die Amylumliörner erzeugen: sie könnten demnach als Zellhautbildner und Stärkebildner bezeichnet werden.

So lassen sich die verschiedensten Vorgänge im Zellenleben von einem einheitlichen Gesichtspunkt aus als Lebensprozesse kleimster, organisierter, sich selbständig vermehrender. verschiedenartiger Stoffteilchen erfassen, die im Kern, im Protoplasma und im organisierten Plasmaprodukt in verschiedenen Phasen ihrer Lebenstätigkeit vertreten sind.

WIESNER hat seine hiermit übereinstimmende Auffassung in den

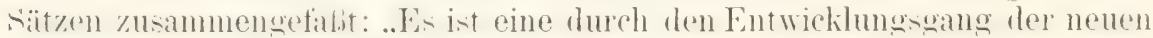
Forschung uns förmlich aufgenötigte Aufuale, dab das Protoplasma noeh andere teilungabligere ormanisierte Individualitäten biret. ja dab es ganz und gar aus solchen lebenden Teilungskörpern bestehe." Durch ihre 
T'eilung ..wird das Wachstum vermittelt" und, ..an sie sind alle Voruainge des Lebens innerhalh des Organismus gekniipft." ..Sie sind also als die wahren Elementarorgane des Lebens zu betrachten."

\section{Litex atu XII.}

1) R. S. Bergh. Lirith einer modernen IIypothese zon der Übertragung erblicher Eisenschaften. Zoolog. Anseiger. 1802.

$\because$ Blumenbach. Über den libimnestritb und ders Zeugungsueschät. I78r.

Bonnet. Considérations sur le's corps organisés. Amstertam 1702.

Boveri. Ein seschlechthich ersengter Organismus ohne müterliche Eigenschaften. ciscllschaft f. Morphol. "16. I'hysiol. an Miinchen. 1880.

i) Chabry. Contribution it l'mbrvologie normale et térntologrique des Ascrities simples. Jourmal de l'anat. et de la phy's. IS\$7.

(i) Darwin. Das Jarieren der Tiere und Pflanzen im Znstande der Domestikation. Bit. II.

- Driesch. Entatikhungsmechunische Studien. Der Hert der beiden ersten Furchungsallin in der Echinodermenentricklung. Experimentelle Eraengung an Teit-

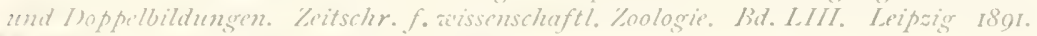

Haeckel. (jonerelle lorphologie. I\$66.

Dorselbe. Die Ferigenesis der Plastidule. 1875 .

!+ V. Hensen. Die Grandlage der Vererbung nach dem gerenaiörtisen Wissenskreis. Landatirtschafth. Jahrbïcher. Bat. WIV. 1885.

lil Oscar Hertwig. Das Problem der Befruchtung und der Isotropie des Eies, eine Theoric der Fererbuns. Tenu 1887.

11. Derselbe. Tergleich der Er- and Samenbildung bei Vematoden. Eine Grundlage fiir cellulüre streitfrasen. Archiz für mikrosk. Anatome bit. XXXVT. 1890.

1.' Derselbe. Urmund und Spinabifida. Archiz f. mikrosk. Anatomie. Bd. IXXIX. 1802.

1:) Derselbe. Altere nud newere Entaicklungstheoricen. 1802.

111 W. His. Die Theorien der seschlechthichen Yeusung. Archiz f. Anthropologie. lid. $11^{\circ}$ u. T. 1871.1872 .

1.it Derselbe: Cinsere Förperform u. das phrsiologische Problem ihrer Entstehung. limife an cinen befrenutiten latuforscher. 1874 .

lit von Köllikex. Bedentung der Zellkerne für die Vorgänge der leverbung. Zeitsihrift f. üissenschaftl. Zoologie. Lit. ALII. 1885.

Dersilbe. Das Larvoplasma und die Fererbung. Eine Kritik der IVeismannschen Thorie aon der Kontimität des Keimplasmas. Zeitschr. f. wisscnschaftl. Znologie. Bid. WLIT. I886.

1. Loeb. Untersuchungen ant physiologischen Iforphologie der Tiere. Organbilumg and IIrichstum. ISn?.

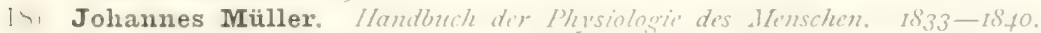

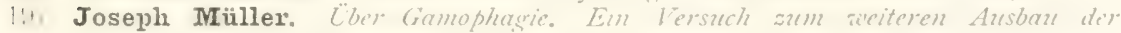
Theorit der Befmechtung u. Vererbuns. Stuttgart r89?

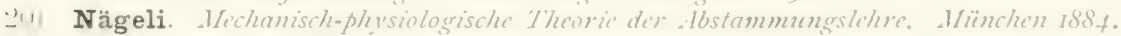

'I Nußbaum. Zar Differenaicums des Geschlechts un Tierreich. Archiz fo mkrosk. Anatomie Bd. NTIIT. I8SO.

Dersclbe. Über die Teränderungen der Geschlechtsprodukte bis zur Eifurchung,

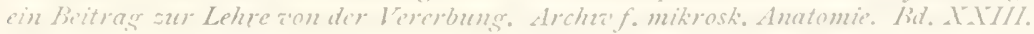
1884.

Pfinger. Loc, eitat. Liap. I'Tl.

Roux. leiträge zur Entricklungsmechanik des Embryos im froscher. Keitschr. f. livolocis. Bat. 1XI. 1885.

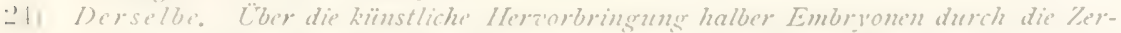

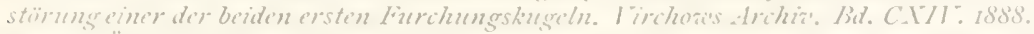

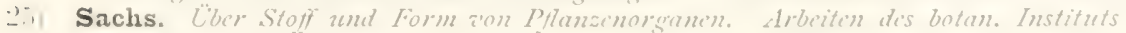
llïrzuns. Bi\%. I/ 21. III. Is 83.

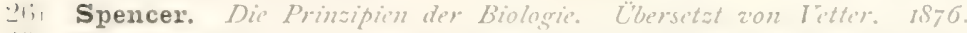

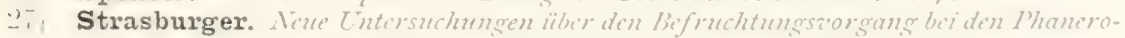
samen als Grundlage für cine Theorie dor Zerewne. Jema ISS't 
28) Strasburger. Über Kern- und Zellteilung im Pflanammich, nebst cinem - Anhang ïber befruching. Jena 1888 .

29) Vöchting. Über Organbilanng im Pflanzenreich. J'onn 1878.

30) Hugo de Vries. Intrazellulare I'angenesis. Jena I880.

31) Weismann. Über Vererbung. 1883.

Derselbe. Die Kontinuitat des Keimplasmas als Grundlage einer Theorie der lererbung. 1885 .

3.), Derselbe. Die Bedentung der sexuellen Fortpflanzung für die Selektionstheorie. 1886.

:ii) Derselbe. Über die Zahl der Richtungskörper und ïber ihre Bedontung für die Vererbung. 1887 .

it) Derselbe. Amphimixis oder die Vermischang der Individuen. Jena 1801 .

(3.) Wiesner. Die Elementarstuktur und das IVachstum der lebenden Substanz. 1802.

(it) Kaspar Friedr. Wolff. Theorie von der Generation. 1764.

;ii Born. Über den Einfluß der Schacre auf das Froschei. Archit f. mikrosk. Anatomice BA. T.T/T. 
ZWEITER HAUPTTEIL.

Die Zelle im Verband mit anderen Zellen. 

Der erste Hauptteil handelte von den allgemeinen fundamentalen

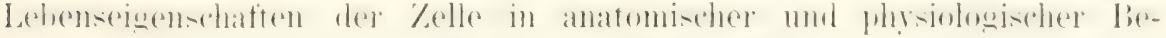
ziehung. Die Zelle wurde als ein in sich abgeschlossener Elementarorganismus betrachtet. Von diesem Gesichtspunkt aus wurden ihre chemisch-

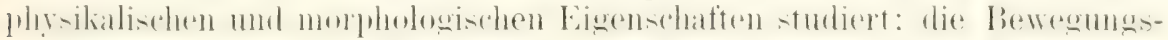

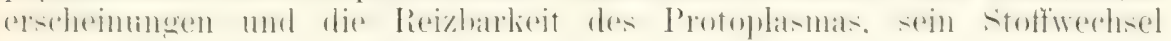
und seme formative 'Tïtigkeit, endlich die Vermehrung der Zelle auf dem Wege der Teilung und ihre sexuelle Affinität, die zur Besprechung der

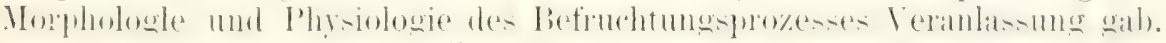

Nun führt aber die Zelle in der Natur nur in den wenigsten Fïllen ein Leben als Organismus für sich, nämlich nur in den Fällen, wo es sich um die niedrigsten, einzelligen Lebewesen, oder in den Fällen, wo es sich um die allererste Entwicklungsstufe der vielzelligen Organismen, um Eier und um Samenfäden. handelt. In allen anderen Fällen tritt uns die Zelle nur als ein untergeordneter und daher unselbständiger Teil einer höheren, zusammengesetzteren Organisation entgegen. Die Zelle hat ihre Selbständigkeit als elementares Lebewesen verloren; sie wirl, je höher Tier und Ptlanze organisiert sind, in ihren Lebensäuberungen anch noch

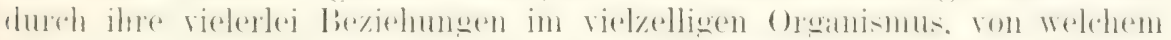
sie ein 'Teil geworden ist, bestimmt orler determiniert. In diesem Prozef offenbart sich uns erst das organische Leben in seinem ganzen Reichtum

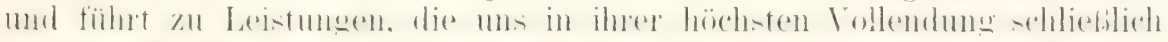

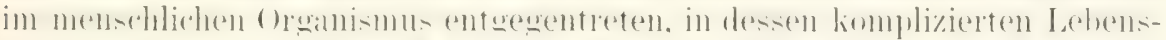

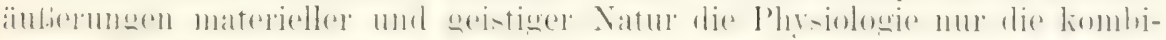
nierte Wirkung zahlloser kleiner, einander neben- und untergeordneter, zu einer höheren Lebenseinheit verbundener Elementarzellen erblickt. Die Zelle selbst aber erscheint uns bei diesem Prozed in zahllosen neuen. mendlich verwickelten Beziehungen, welche bisher unberïcksichtigt gelassen wurden.

Somit haben wir uns jetzt noch mit den allgememen Beziehungen

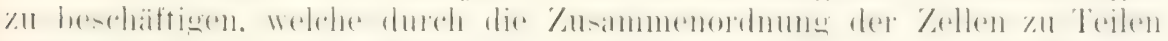
eines höheren Ganzen weschaffen werten: mit der Lehre ron den ver-

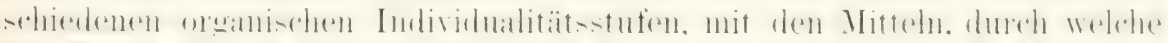

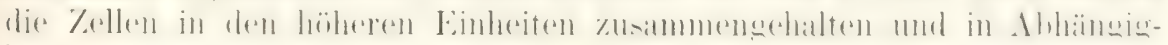
keit voneinander gebracht werden, mit den äuBeren und inneren Faktoren der organischen Entwicklung. mit dem Gesetz der Arbeitsteilung und Differenzierung, mit den Gesetzen und Erscheinungen des Wachstums und

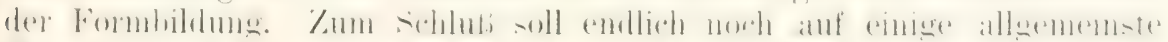

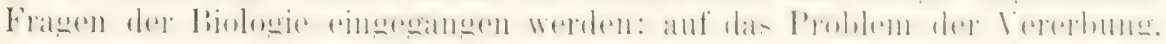




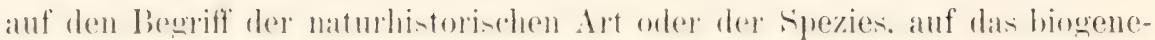
tische Grundgesetz usw.

So wird der zweite T'eil meiner allgemeinen Biologie eine Theorie der organischen Entwicklung enthalten. Ich nemne sie die Theorie der Biogenesis, da sie sich in vielen Punkten, besonders aber in der Art der liewrisführung und Ibarstellung. von ähnlichen Theonien meiner Vorwänger. ron der Theorie der Epigenesis, der Pangenesis, der Keimplasmatheorie etc. bald mehr. bald minder wesentlich unterscheidet. Wie ich schon bei vershiedenen Gelegenheiten hemerkt habe. hängt mit der weiteren wisonschaftlichen Ausbildung der allgemeinen Biologie der Zelle auch die weitere Aushildung der allgemeinen Entwicklungotheorie auf das engste zusammen. 


\section{VIERZEHNTES KAPTTEL.}

\section{Die Individualititsstufen im Organismenreich.}

Unter phanzichem und tierischem Individum versteht man in physiologischer Hinsicht eine Lebenseinheit, die nach außen abgegrenzt, sich selbst zu erhalten imstande ist, weil sie mit den Grundfunktionen des Lebens, die im ersten Hauptteil besprochen wurden, ausgeristet ist, mit der Funktion, sich zu emähren und zu wachsen, sich fortzuptlanzen, gegen Reize der $\Lambda$ ubenwelt irritabel zu sein und auf sie in verschiedener Art zu reagieren. So unendlich verschieden auch sonst die organischen Individuen voneinander sein mögen, hierin stimmen sie alle üherein, von der einfachsten Amöbe bis zum höchsten Wirbeltier.

In morphologischer Hinsicht dagegen bieten uns die oræanischen

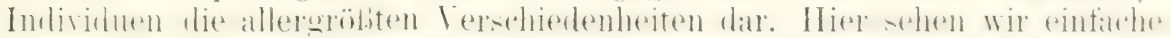
Zellen als selbständige Organismen leben, dort sind viele unteremander zu einem zusammengesetzten Lebewesen. zu vielzelligen PHanzen und 'Tieren verbunden, und wieder in anderen Fällen sehen wir 'Tiere, die uns in vielen Arten im System als selbständige Lebenseinheiten begegnen, in einigen Fällen abermals zu höheren Lebenseinheiten. zu Tierstöcken. in mamnigfacher Weise vereint. So bietet uns das Organismenreich gewissermalien eine Stufenfolge niederer und höherer organischer Individualititen dar, oder in anderen Worten: die zahllosen organischen Individuen lassen sich wieder in Individuen niederer und höherer Ordnung einteilen.

Die einzelnen Individualitätsstufen stehen in einer gan\% bestimmten gesetzmäbigen Beziehung zu einander. Organische Formen. welche uns

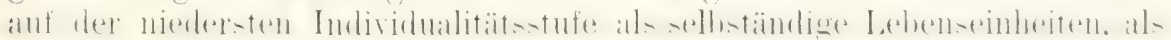
einzellige Ptlanzen und T'iere, bekannt geworden sind, ausgerüstet mit

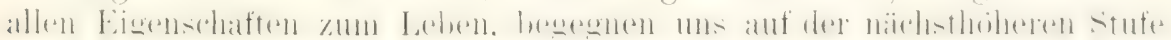
wieder, aber jetzt nu als untergeordnete und daher unselbstindig gewordene T'eile einer höheren und zusammengesetzteren Lebenseinheit; diese besitzt zwar alle Bedingungen zum Leben, ihre T'eile aber sind, losgetrennt vom Ganzen, sehr häutig nicht mehr für sich lebensfähig. Es sind Form-

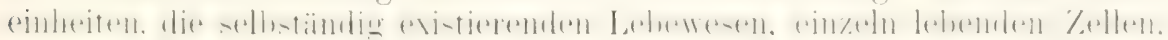
sehr ähnlich sein kömmen. trotzdem aber, da sie sich nicht mehr als

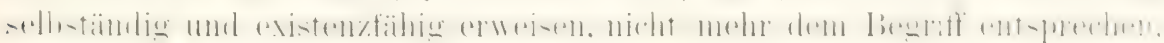
welehen wir oben mit dem Wort ..Individum"* verbunden haben.

Aus diesem Grunde sind mehrere Forscher veranlabt worklen. zwei verschiedene Arten des Individualitätsbegriffes aufzustellen: das physiologische und das morphologische Individum. Ersteres ist ein selbstäniges Lebewesen nach der oben 
gegebenen Definition; letzteres dagegen ist eine Formcinheit, welche zwar morphologiseh, das heibt nach Aussehen, Struktur und Zusammensetzung, einem physiologischen Individum gleicht, aber nicht in physiologischer Beriehung; denn es stellt keine selbständige Lebenseinheit mehr lar; es ist als ein abhängiger 'T'eil in eine höhere physiologische Individualität eingegangen oder mit anderen Worten zu einem anatomischen Element von ihr geworden.

An dor hier gegehenen schärferen Fassung des Individualitatshenriftes. über welchen sich in der Literatur so viele abweichende Darstellungen vertreten finden, soll im folgenden festgehalten werden. Wir werden damn den Individualititshexriff anf manche Teile nicht anwenden dürfen. für welche el in anderen Lehrbüchern gebraucht worden ist. So führt zum Beispiel HaEcker, in seiner generellen Morphologie als morphologisohe Individuen zweiter Ordnung die Organe auf, die Zellfusionen, Gewebe, Organsysteme und Apparate, als Individuen dritter Ordnung die Antimeren oder Gegenstücke eines Körpers, als Individuen vierter Ordnung die Metameren oder Folgestïcke.

Nach unserer Definition können derartige 'Teile nicht mehr untel' den Individualitätsbegriff fallen. Denn was man für gewöhnlich ein Organ, ein Antimer, ein Metamer nennt, ist irgend einer Art der im System vorkommenden physiologischen Individuen in lieiner Weise veroleichbar. Eas sind Bildungen sui generis. Organische Individuen, seien es physiologische orler anatomische, können nur auf dem Wege der Zeugung entweder durch 'Teilung oder Krospung ihren Ursprung nehmen. Organe, Metameren und Antimeren aber entstehen durch einen Sonderungs- oder

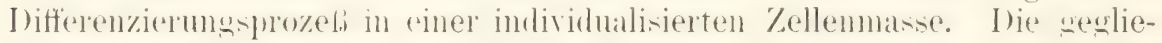
derten Wïmer, die Arthroporlen, und Wirbeltiere stehen daher auf heiner löheren Individualitätotufe als die sogenamnten einmefamerigen Tierformen (Wïmer, Mollusken etc.), denn sie sind keine Aggregate von solchen. Was sie iiber jene erhebt, ist nur durch eine größere Differenzierung ihrer verschiedenen Organsysteme hervorgerufen.

Allerdings kamn es vorkommen, daß sich ein Organ von einem Organismus abtrennen und ihn längere Zeit überleben kann. Als Beispiel hierfiur wird so häufig dler bekannte Hektocotylus aufgeführt, welcher in friblerer Zeit für das rudimentäre Männchen eines Tintentisches gehalten wurde, aber nichts anderes ist als der abgelöste und kriechend sich fortbewegende Arm eines solchen. Nach unserer Definition ist der Hektocotylus nur ein währemb kürzerer Zeit üherlehender Teil eines ()roanismus; er ist kein eigenes physiologisches Individumm, da ihm die wichtigste Eigenschaft eines solchen, sich danernd selbst zu erhalten, fehlt: denn er liam weder sich durch Nahnumg-aufnahme ernähren, moch sich durch Fontptlanzung vermehren.

Desgleichen können wir nicht der eigenartigen Fassung, welche Huxley dem Individualitätsbegriff zu geben versucht hat, das Wort reden. Tm Schwierigkeiten, die hei der Festmmmm der Individualitït in manchen Fällen entstehen, zu vermeiden, hat HuxLEy vorgeschlagen, als d as organische Individum schlechtwegdie Summe aller. Formen zu bezeichnen, welche aus einem befruchteten Ei hervorgrehen können.

Nach Huxleys Definition kann das Individum zwar in vielen Fälen ein konkretes Einzelwesen sein und so den entsprechen, was man für gewöhnlich darunter versteht, wie bei den Wirbeltieren, bei welchen 
aus dem Ei ein einziger Organismus entsteht. der wierler Zeugungs-

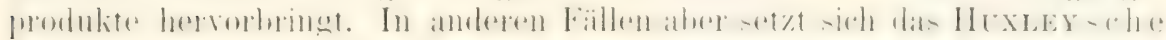
Individum ans vielen Einzelgröben zusammen, die teils neben-. teils nacheinander existieren; es ist also gar kein einheitlicher Körper, sondern eine Summeunter den gemeinsamen liegriff der Abstammung gebrachter. Einzelwesen. Das ist zum lieispiel stets der Fall. wenn aus dem befruchteten Leim, wie so häufig, ein Oranismus entsteht, der

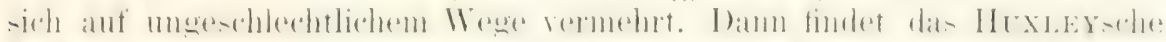

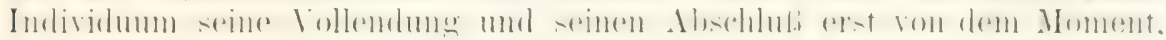
wo in Leben der Art wieler Geschlechtsprodukte von dem Organismus gebililet werden.

So bezeichnet, un ein Beispiel zu geben. Huxley 1) (lie aus einem befruchteten Medusenei hervorgehende Polypenform, 2) die von ihr auf

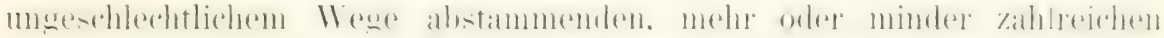
Polypen und :3) die zum Schlub auftretende Medusenform, die endlich wieder Eier und Samen produziert, als das organische Individum katexochen. Man hat es anch, weil es sich, wie in obigem Beispiel, aus einer Folge von Formen zusammensetzt, die durch Zeugung auseinander hervorgehen, als das genealogische Individum m, und die Fassung, welche Huxley dem Individualitätsbegriff gegeben hat, als die genealogische bezeichnet.

Wir halten es nicht für wünschenswert, den Begriff' des Individumms in dem Huxbexschen Sinne zu fassen. was so vollständig der gewöhnlichen Sprech- und Denkweise widerspricht. Uns scheint es viel empfeh-

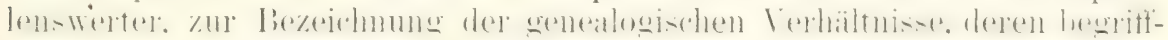
liche Zusammenfassung wir mit Huxcey allerdings für notwendig halten, das Wort Zeugungskeis zu gebrauchen. wie es bereits ron vielen Forschern und so auch schon im ersten Teil dieses Werkes (S. 206.).326) geschehen ist. Wir sind mit Spexcer der Ansicht. dab es unstatthaft ist. das Wort..Individum" auf eine Anzahl gesondert lebender Körper anzuwenden. ..Es steht, wie SPExcer bemerkt.

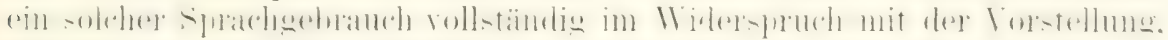
welche dieses Wort gewöhnlich in uns hervorruft. Es wïrie jedem zum mindesten sonderbar erscheinen, wenn man die zahllosen Massen von Anacharis Alsinastrum, die innerhalb weniger Jahre in unseren Flüssen. Kianälen und Sümpfen gewachsen sind, alle als Teile eines einzelnen Individum bezeichnen wollte: und trotzlem mühten sie so bezeichnet werlen. wenn wir die HuxLexsche Definition annehmen wollten. da die Ptlanze in England keinen Samen erzengt und die zahllosen Massen derselben etnfach durch diskontinuierliche Ausbildung entstanden sind."

Nach dieser allgemeinen Ausemandersetzung über die Fassmng des Indivirlualitätsbegriffes soll auf die emzelnen drei Stufen. zu denen sich im Organismenreich die Individualität entwickelt hat, noch etwas genaner eingegangen werden.

\section{Die organischen Individuen erster Opdnung.}

Die Zellen sind die elementaren Einheiten des ganzen Organismenreichs. Die unzähligen Arten von Pflanzen und Tieren, die uns beliannt sind. verharren entweder dauernd auf der Stufe einzelner Zellen oder sie treten uns wenigstens stets am Anfang ihrer Entwicklung in der Form einer Zelle entgegen. So viele spezies die Systematik in der. Organismenwelt unterscheidet. so viele spezifisch unter- 
schiedene Zellen oder so riele Spezies von Zellen, so viele Artzellen mulos geben, verschieden voneinander in ihrem stofflichen $A u f b a u$.

Wie in dem Abschnitt „Die Zelle als Anlage eines Organismus* näher ausgeführt werden wird, müssen die spezifischen Charaktere, durch welche sich zwei Säugetiere orler zwei Vögel vonemander unterscheiden. in der Eizelle bereits der Anlage nach vorhanden sein. Wird ein Hühnerund ein Entenei in derselben Brutmaschine gleichzeitig bebrütet, so entsteht unfehlbar nach bestimmter Zeit aus jenem ein Hühner- und aus diesem ein Entenküchlein. Da beide Eier sich gleichzeitig unter genau

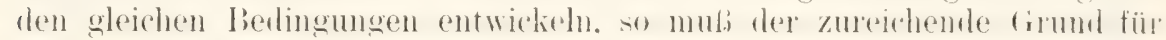
die zutage tretenden Speziesunterschiede schon in der unbebrïteten Eizelle notwendigerweise gegeben sein. Doch diurfen wir bei unserem logischen Schlus nicht in den oft gemachten Fehler verfallen, das wir alle in der ausgebildeten Huhn- und Entenspezies wahrnehmbaren unzïhligen Enterschiele einfach in die Eizellen zurückverlegen und zu einem kleinen Miniaturhild zusammenschachteln. Viehmehr ist hierhei nicht zu ïbersehen, daf. die ganze Entwicklung eines Vogels sich in eine unendliche stufentolue ausemander hervorgehender und sich sehritt für singritt homplizierender Prozesie zerlegen läbt. und dab schon wenige umb lisine Unterschiede zweier Anlagen an Anfang des Prozesses dadurch, daß sie sich millionen- und milliardenfach in notwendig gesetzmäniger Weise lawinenartig anwachend summieren, zum frumb für zahlreiche umb grolie Unterschiede in den Endresultaten werden können.

Nügeli. Herixg und Wigaxd haben sich eines Gleichnisses bédient. ım den Unterschied zwischen den Verschiedenheiten der Eizellen und und den Verschiedenheiten der aus ihnen entstehenden Spezies zu versimbildichen; sie haben dazu die Natur der krummen Linien gewählt. „Thre analytischen Formeln enthalten die nambichen Bestandteile; geringe Veränderungen in der Formel hingen bald eine andere Linie der nämlichen Art, bald eine spezifisch verschiedene Linie hervor. Ihre Anfänge; d. h.

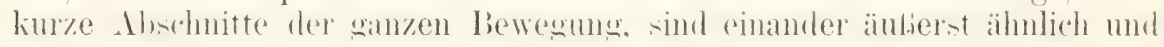
dem Auge kaum unterscheidbar; aber sie sind rerschieden im Prinzip, und wenn sie verlängert werden, so treten ihre Verschiedenheiten immer deutlicher hervor, und die Linien geben sich als Kireis, Ellipse, Hyperbel, Parabel usw. zu erkennen. Auch darin stimmen diese geometrischen Figuren mit den Pflanzenarten überein, dab, wenn wir in einer komplizierten Formel gewisse Grölien vershwinden lassen, darats eine einfachere Linie entsteht: auf älnnliche Weise unterscheidet sich die PHanzenart einer höheren Stufe von derjenigen einer tieferen Stufe dadurch, daß bei jener ein Element rorhanden ist. Welhes hei dieser mangelt, dali im cinzelligen Zustande bei jener gewisse Differenzen wirksam werden. welche bei dieser Null sind." (NäGELI, XIV 188t, S. 67.)

In der Form des Elementarorganismus oder der ,Artzelle* sehen wir daher die spezifischen Eigenschaften der organischen Spezies in ihre einfachste Formel gebracht, freilich in eine Formel, welche für den Forscher zurzeit noch nicht zu entziffern ist. Doch diurfte wohl der Schuß nahe liegen, dab die feinere, in ihrem micellaren Aufbau begründete Organisation der Zelle bald einfacher, bald mehr oder

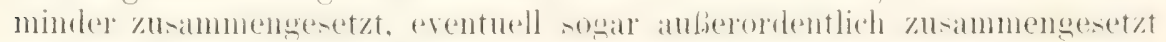
sein wird. je nachlem die orwanismenspezies, die dureh sie repräsentiert wird. einen einfaheren wher höheren Entwicklungswang einschlägt. Eine Algenoder Pilzzelle, die nur wieder isoliert lebende oder zu Fidden oder anderen 
einfachen Gestalten verbundene MJgen- und Pil\%ollen in ihrem Entwicklungszyklus hervorbringt, wird in ilner Organisation tief unter Zellen

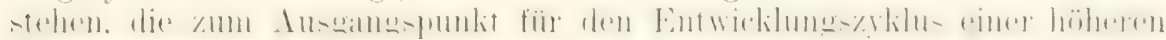
Pffanze, geschweige eines höheren l'ieles dienen.

Indem im Organismenreich alles Leben von der..Altzelle" ausgelt, ein jeder Entwicklungsprozel. mit ihr beginnt und wieder zu ihr zurïckführt, bildet sie die allgemeinste und wichtigste Form, in der sich das organische Leben äubert. das organische Individum einfachster Art.

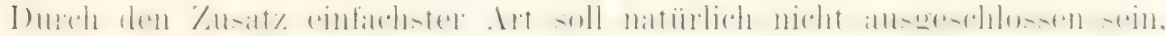
(lab) nicht die Zelle selbst noch in einfachere Lebenseinheiten zerleghar sei: haben wir doch selbst schon im ersten Teil (S. 5)2, :36t) die Per-

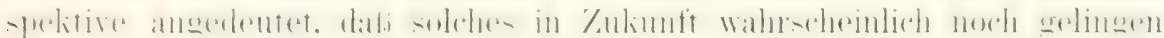
wird und daf jetzt schon in dem Kelleninhalt kleinere, sich durch leilung vermehrende Stoffeinheiten nachweisbar sind. Doch können wir solche so lange nicht als selbständige Elementarorganismen bezeichnen, als nicht der Nachweis geführt ist. dab sie auch auBerhalb der

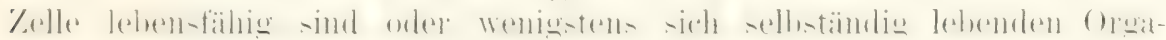

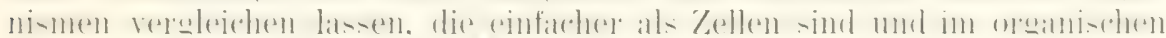

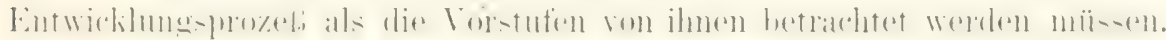
Solange es aber auf diesem (iebiete zurzeit an jedem auf Erfahrung

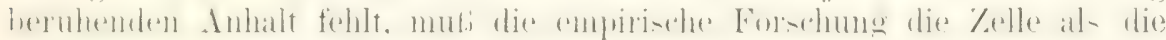
einfachste elementare Form des Iebens hinmehmen.

\section{Die organischen Individuen zweiter Ordnumg.}

Das System des Organismenreichs lehrt uns Vereinigungen von Zellen in der mannigfachsten drt kennen. Die sich hier darbietenden zahllosen Formen kann man in zwei Gruppen einteilen: in lose Verbände oder Zellkolonien und in feste, innige Vereinigungen mit mehr oder minder weit durchgefühter Arbeitsteilung zwischen den einzelnen Elementarindividuen erster Ordnung. Beide Gruppen sind

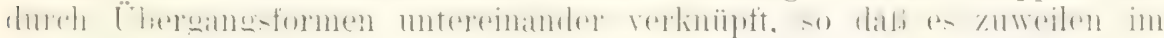
einzehen Fall schwer ist. zu entscheiden, zu welcher der beirlen Gruppen man eine Form hinzurechnen soll.

\section{Zellkolonien.}

Zallkolonien finden sich imerhalb der Ordnungen der niederen Algen, der Flagellaten, der Infusorien etc.

Bei den Algen liegen die einzelnen Zellen in einem Mantel von

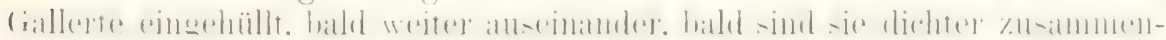
geriickt; je nach der Art sind sie in Reihen hintereinander angeordnet

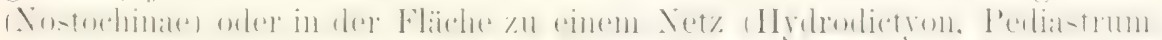

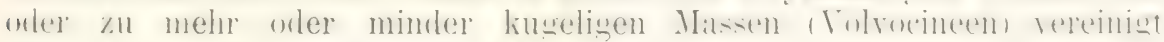
(Fig. 277). In manchen Fällen sind die einzelnen Zellkörper ganz voneinander gesondert, von der verbindenden Gallerte abgesehen, in anderen

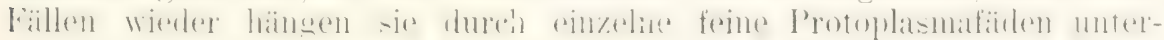
einander zusammen oder berïlren sich mit ilıen Obertlächen unmittelbar. Zu gewissen Perioden trennen sich bei vielen Spezies die einzelnen Eilementarteile als Fortptianzungskörper vollständig voneinander, indem die Kolonie aufgelöst wird. 
Bei Vergleichung verwanlter Arten kam man den Ühergang von loseren zu festeren Veleinigungen auf das deutlichste beobachten. Als ein derartiges Beispiel gibt NäGEL, welcher sich mit dem Studim der niederen Algen so eingehend heschäftigt hat, die in Higur 278 wierlergegebene bildliche Darstellung a einer Chroococcacee, b einer Nostochacee und $c$ einer Oscillariacee in 4 aufeinander folgenden Generationen $I$, II. III, II .

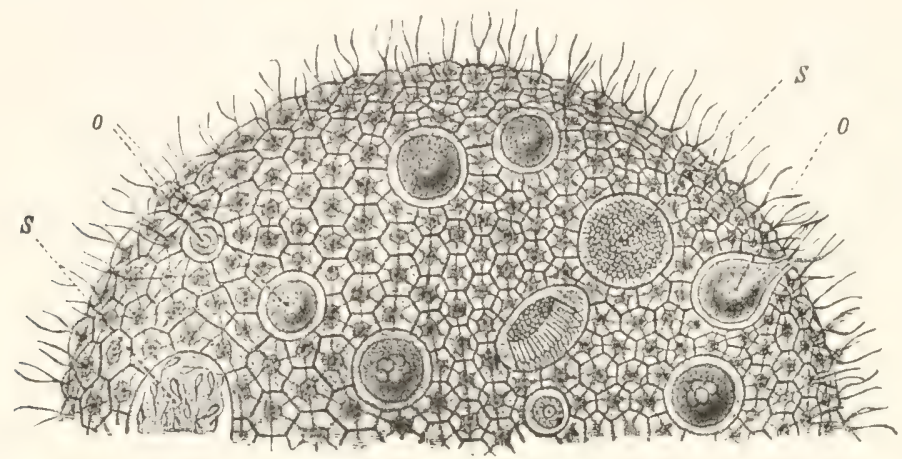

Fig. 27. Volvox globator, geschlechtliche hermaphroditische Kolonie. Nach Cifskovsky und Bütachid kombiniert und etwas schematisiert. Nach LAx(r. $S$ Mimnliche Gameten (Spermatozoen). O Weibliche Gameten (Eier).

.Bei den Chroococcaceen $(a)$ können die Zellen, nachdem sie sich voneinander losgelöst haben, sich im Wasser zerstrenen oder durch Gallerte in geringer Entfernung vonemander festgehalten werden. Bei den Nostochaceen (b) sind die meln oder weniger kugeligen Zellen nur mit einer kleineren Stelle der Obertläche. bei den Oscillariaceen (c) sind die zylindrischen Zellen mit den ganzen Endtlächen verbunden." Zu diesem

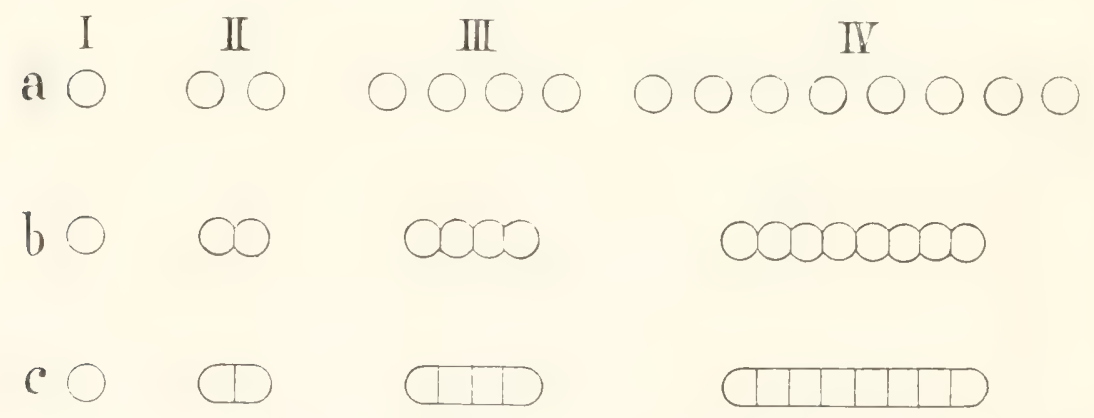

Fig. 278. Schematische Darstellung a einer Chroococcacee (Gloeothecee oder Syneshococeus), b einer Nostochacee und i einer Oscillariacee, in vier aufeinanderfolgenden Generationen $I$, II, III, II: Nach Nitied.

Beispiel benerkt NäGELI, dal, man bei den niederen Algen ,oft in Zweifel gerät, ob man ein mehrzelliges Gebilde als eine Kolonie einzelliger Indiriduen oder als cin mehrzelliges Indivialum ansluechen soll".

Losen Vereinigungen begegnet man zuweilen auch bei den Rhizopoden, bei Flagellaten und bei Infusorien. Ich erinnere an die von Richard Hertwig beschriebene Mikrogromia socialis (Fig. 279), eine 


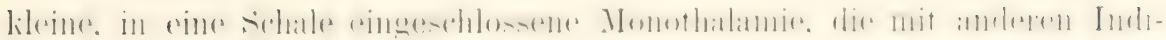
viduen gleicher Art durch ihre sich verzweigenden P'sendoporlien bald zu kugeligen Haten. bald mehr zu Netzen verbunden ist. Ich erimere an manche Infusorienarten. welche eine weiche reichliche fallorte abscheirlen.

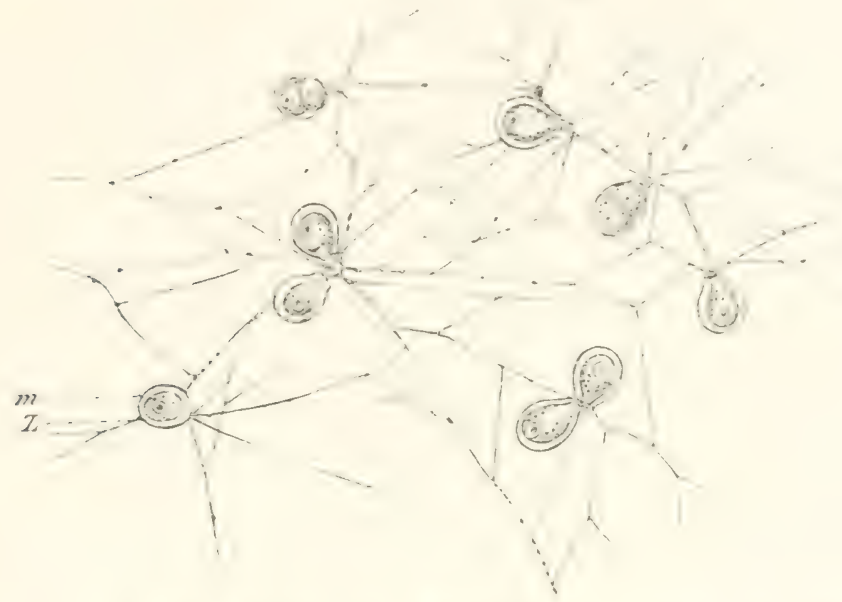

Fig. 279. Eine Kolonie von Mikrogromia socialis im ausgebreiteten Zustand. Tach Ronari) Hertwig. Ein Teil der Individuen (au) ist durch (puerteilung in zwei Teilstioke zerfallen: $b$ und b zwei mit ihren I'seudopodienstielen zusammenhängende Individuen.

in welcher' die durch 'Teilung entstehenden Generationen zu größeren. meist liugeligen Kiolonien verbunden bleiben.

Eine andere Art kolonialer Vereinigung liommt wieder dadurch zu-

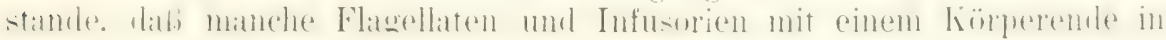

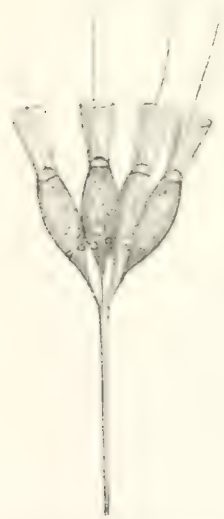

IVig. 2SO. Codonocladium umbellatum. Eine koloniale Flagellate nach STEx aus li. HERTIG:

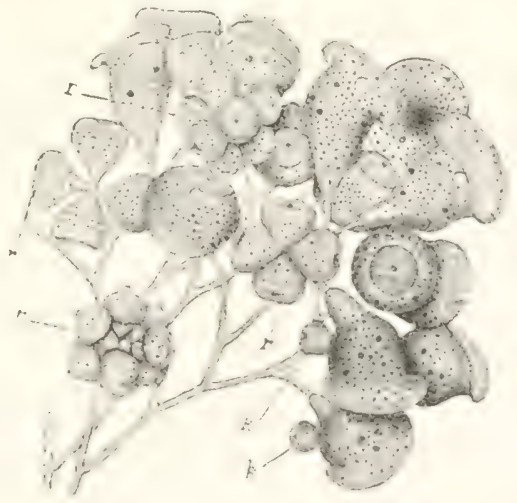

I"irr. 2\$1. Epistylis umbellaria. Nach

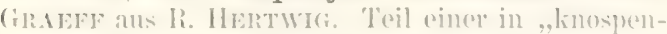
fömniger lonjugation" heuriffenen liolonie. r- D)ie dureh Teilung entstandenen . Mikirosuoren, k. Milirogameten in limpijugation mit den Malirogameten.

eimen langen kontraktilen Stiel iibergehen, durch welchen sie an cine Unterlage hefestigt sind. Wenn sie sich dureh Teilung vermehren. hleihen bei vielen Arten die T'ochter- und Enkelzellen an dem Stielende ver- 
bunden (Fig. 280). Oder es entstehen baumförmig verzweigte liolonien (Fig. 281), zusammengesetzt aus einem kontraktilen Hauptstamm. von welchem dichotom sich teilende Nebenäste ausgehen, an deren Enden die einzelnen Individuen wie beeren an den Stielen einer Tranbe ansitzen.

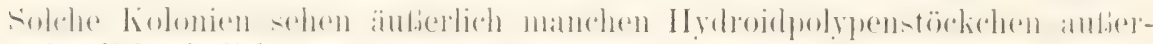
ordentlich ähnlich.

\section{Durch innigen Zellverband entstandene, mehrzellige Organismen (Personen).}

Wie schon oben bei den Algen bemerkt wurde, führen von ren losen

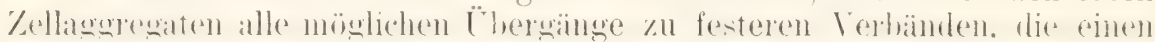
mehr einheitlichen Charakter tragen. Während wir in den oben beschriebenen Fällen (Fig. 277-281) mehr geneigt sind, den Verband als Kolonie vieler einzelliger Individuen zu bezeichnen, sind wir bei den jetzt zu betrachtenden Formen nicht im Zweifel, den Verband als ein einziges mehrzelliges Indivirhum aufzufassen. Bei jenen sehen wir in physiologischer Hinsicht mehr die Vielheit, bei diesen mehr die Einheit der zu-

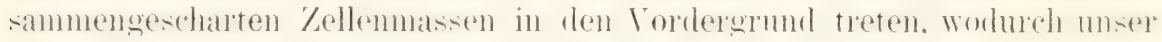
Urteil ïber die Individualität des Aggregats bestimmt wird.

Auch hier kommen indessen wieder zwei Verschierlenheiten zum Torschein; auf der einen Seite finden wir vollständige Verschmelzung der Zellen, so daf jede Abgrenzung zwischen ihmen verloren gegangen ist. auf der anderen Seite bleiben die Zellen voneinander durch deutliche Grenzen gesondert und sind nur meist bis zu unmittelbarer Berührung dicht aneinander gelagert. Im ersten Fall bestehen die Organismen aus

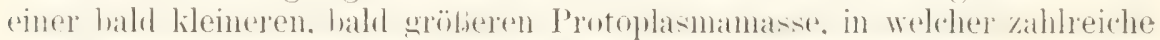
Kerne, zuweilen viele hunderte und tausende, in regelmäßigen Abständen verteilt sind. Man hat ein solches Gebilde ein Syncytium oder eine Zellenfusion genannt.

\section{a) Symeytien oder Zellenfusionen.}

Syncytien können in zweierlei Weise entstehen. In selteneren Fällen sind es kleine, einkernige. amöboide Zellen, welche in größerer Anzahl zusammentreten und mit ihren Protoplasmaleibern verschmelzen, während sich die Kerne getrennt erhalten. Als Beispiel sei die Entwicklung der Myxomyceten angeführt (Fig. 282), Aus den Sporen derselben (a und $b$ ) kriechen kleinste, einkernige Amöben $(c)$ hel'vor und wandeln sich bald in Schwärmzellen (d) um, die sich eine Zeitlang mit Geißeln im Wasser fortbewegen. Die Schwärmerzellen gehen darauf wieder, indem sie die Geißeln einziehen, in einen amöboiden Zustand ïber und beginnen hierbei bald in größerer Anzahl untereinander zu kleinen vielkernigen Plasmodien (c) zu verschmelzen. Diese nehmen auf dem Wege der Ernährung an Größe allmählich zu und können ansehnliche Dimensionen ( $f$ ) erreichen. Dabei findet unausgesetzt eine Vermehrung der lierne durch Teilung statt.

Am häufigsten indessen entstehen vielkernige Protoplasmakörper nicht

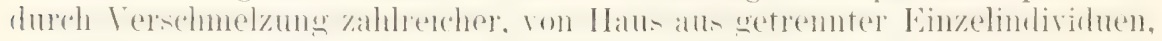
sondern leiten sich von einem einzigen einkernigen Keim einfach in der Weise her, daß sich sein Kern durch häufig wiederholte Zweiteilung in 2, 4, 8, 16 lieme und so weiter vermehrt. Hierbei erfährt das Protoplasma lieine Zerlegung in eine entsprechende Anzahl von Stücken: es nimmt nur mit der Vermehrumg der Kerne an Masse allmählich zu. 
Ls lälit sich dariber streiten, of man eine vielkernige Protoplasmamasse als eine einzige Zelle mit vielen Kernen oder als aquivalent eines vielzelligen Orwanismus beurteilen soll. IBei der Rolle. welche nach unserer Auftassung der Kern in Zellenleben spielt, ist wohl die zweite $\Lambda$ uffassung die richtigere. Wemn in einer Zelle die liernsubstan\% durch den komp) lizierten Prozeb der Kernsegmentierung in zwei gleiche Ifilften zerlert worden und wieder in den Ruhezustand zweier Bläschen übergegangen ist. damn ist die Zellteilung der Hanptsache nach beendet, mul es ist von einer mehr nebensächlichen bedeutung. ol) an die Kernteiluner sich noch die Zerlegung des Protoplasmakörpers sofort oder einige Zeit später oder gar nicht anschliefot. Lehreech in dieser lBeziehung ist die erste Entwicklung des Inseliteneies. Wïhrend sich die tierischen Eier gewöhnlich durch den Fuchumgsprozel, in 2, t. s usw. Zellen sondern. bleibt das Insektenei eine zusammenhängende einzige Dottermasse, in welcher sich nu ihr Kern in 2. t. s und schlieflich in Hunderte von Kernen vermehrt. Erst nach einiger Zeit zerfaillt dann plötzlich die vielkernige Dottermasse in so viele Stücke, als vorher Kerne in ihr gebildet worden waren. Es liegt hier auf der Hand, dafo das anscheinend einfache Ei nicht mit einem Schlage in eine vielzellige Bildung umgewandelt worden ist. Viehmehr war es schon vorher potentia vielzellig und hat mit Ausmahme der Proto-

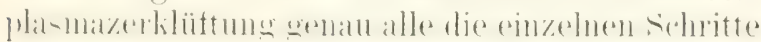
zurüclilegen müssen wie ein $\mathrm{Ei}$, bei dem liern-

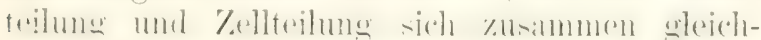
zeitig vollziehen, Genau in lerselben Weise wie das vielkernige Insektenei ist ein viel-

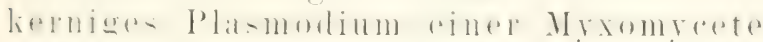
potentia vielzellig. Denn wemn es in einen Fruchtlörper sich umwandelt. zerfällt es in so riele einzehe Sporen odler lieine für nene Organismen. als vorher Kerne in der gemeinsamen Protoplasmamasse rorhanden waren.

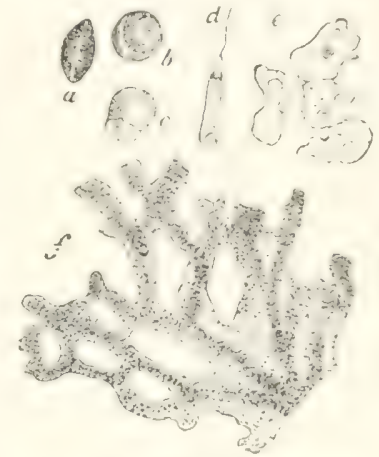

Fig. 282. Chondrioderma difforme. Xilctl silili-

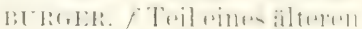
Plasmodiums, or Trockene

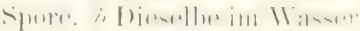
quellend. $c$ Spore mit austretendem Inhalt. d $\%(00-$

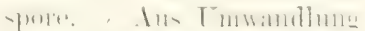
der \%usapore herroruegangene Amöben, die sich zum Plasmodium zu rereinen anfangen. (Bei d und $c$ Kern und liontralitiele- Vakwolen zu sehen).

Organismen rom Formwert eines Syncytiums gibt es an der Wrurzel des 'Tier- mond Pflanzenreichs. Sehr zahlreiche Arten der Protozoen sind Syncytien: das vielkernige Actinosphaerium Eichhornii (Fig. 24:3), zahl-

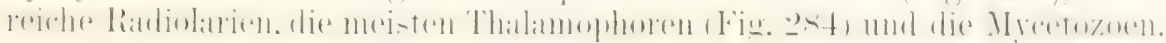

Von seiten des PHanzenreichs sind zu nennen die interessanten Coeloblasten. Ein Coeloblast ist mehr oder minder ein vielfach verzweigter Schlauch, oft ron recht ansehmlicher Größe. Nach außen ist der Schlauch abgegrenzt von einer dicken Zellulosemembran, welcher nach imnen eine bald diunnere, bald dickere Protoplasmaschicht anliegt. Sonst ist das Innere des Schlauches von Zellsaft ausgefiillt, durch welchen sich zuweilen auch einzelne Protoplasmafäden von einer zur anderen WandHäche hindurchziehen.

Nach dieser Beschreibung könnte man den ganzen Schlauch als eine einzige riesige Zelle autfassen und demmach einen Coeloblasten zu den einzelligen Pflanzen hinzurechnen, wie es von manchen Forschern auch geschieht. Unser Urteil wird indessen anders ausfallen. wenn wir noch folgende Momente in Rechumg zichen. Erstens lassen sich im Proto- 
plasma zahlreich lileine Kerne - oft sind es viele hunderte, ja tausende nachweisen: zweitens nimmt der Schlauch bei manchen Arten. zum Beispiel bei Caulerpa crassifolia (Fig. 24ō) eine komplizierte Glierlerung

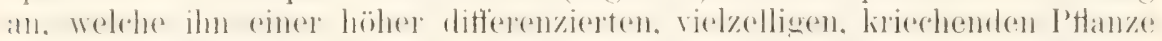
sehr ähmlich aussehen läbt. Demn der Schlauch hat sich gesondert in einen auf dem Boden kriechenden Stamm (s), in Wurzeln (w), welche sich vielfach verzweigt in die Erde einsenken und in viele nach oben gerichtete. hattantige Ausiälpungen fbh). welche Fiederhlätehen nicht unähnlich aussehen. Drittens endlich wächst der hochgegliederte Schlanch von ein zelnen bestimmten Vegetationspunkten $(v)$ aus in ganz gesetzmäroger Weise gleich einer höheren, vielzelligen Pflanze. Die Übereinstimmung wirl noch dadurch weiter' erhöht, (lak an den Vegetationspunkten sich

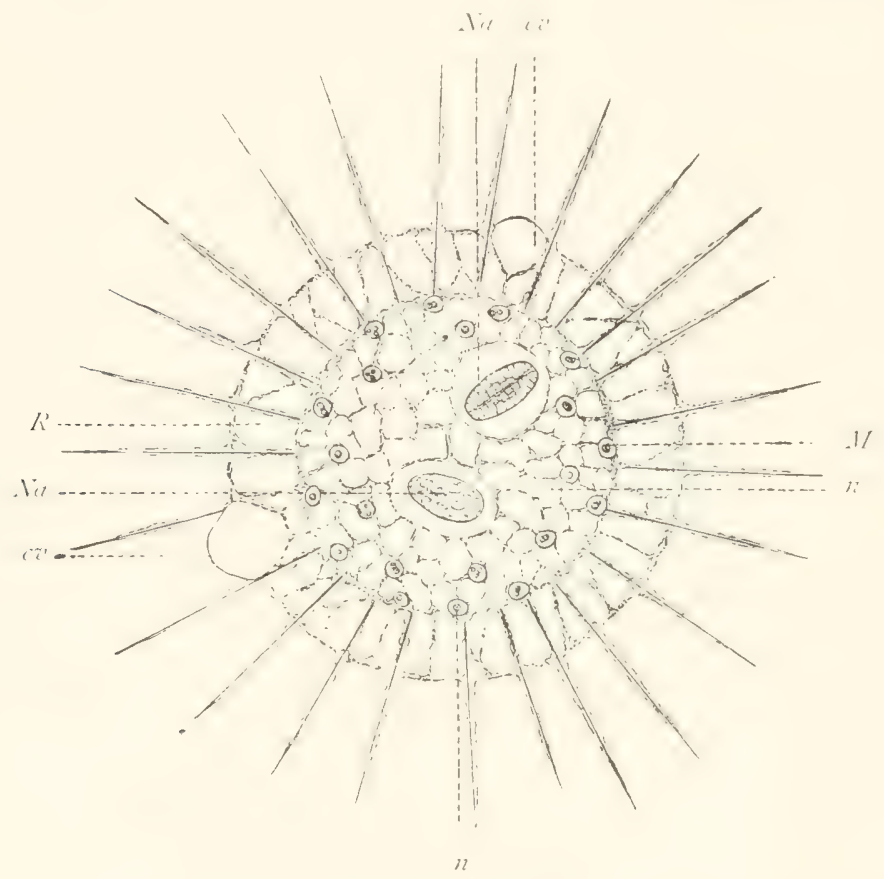

Fig. 283. Actinosphaerium Eichhornii. Nach R. HERTwig, Zoologie. M Marksubstanz mit Kernen $(n)$. $R$ Rindensubstanz mit kontraktilen Vakuolen ( $\left.c r^{\prime}\right)$ Na Nalnumgskörper.

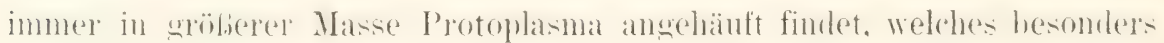
zahlreiche Kerne enthäit, wie auch bei den vielzelligen Pflanzen an den Vegetationskegeln in dem kleinzelligen Gewebe viel Protoplasma und viel Kermsubstanz auf engem Raum zusammengerlrängt ist.

Bei Erwägung aller Verhälınisse werden wir daher den Coeloblasten als einen potentia vielzelligen Organismus, als ein Syncytium, bezeichnen müssen; auch wird es uns bei solcher Sachlage jetzt weniger merkwürdig erscheinen, dab der nur scheinbar einzellige, aber potentia vielzellige Schlauch sich in der Entwicklung von Sprossen, Wurzeln und Blättern ähnlich wie eine ausgeprägt vielzellige Pflanze verhält. Nit Recht hat Sichs, der dieses Verhältnis schon treffend erörtert hat, in semem Lehrbuch der Physiologie bemerkt: 
.. Wir brauchen uns nur bei einer nicht allzu kompliziert orominsierten, zellulären P'tlanze, einer höheren Alge, einem Moos. selhst einer Gefäbptlanze zu denken. dab immerhalh der von der äuferen Zellwand der Epidermis ungehenen PHanzensubstan\% die Zellwinde einfach fehlen, wogegen das Protoplasma mit den in ihm verteilten Zellkernen sich im wesentlichen gerade so verhält, als ob jene Zellwände vorhanden wären, so laben wil im groben und ganzen die Struktur eines Coelolshsten: und

1.i. -1

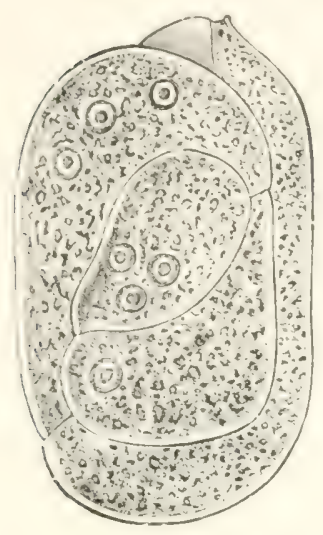

$1 \cdot 1-2$

\section{Eig. 25\%. Junge Miliola mit vielen Kernen. Aus Lang.}

Fig. 255. Caulerpa crassifolia. Die ganze Pflanze besteht aus einem nicht zellulïr gekanmerten Schlanch. ar Der Vecetationspunkt der kriechenden, dorsiventralen Sproliaches s. bb IDie Blitter. "Die Wureh. (Etwas renkleinert.) Nach Sicht.

umgekehrt brauchen wir uns nur zu denken. dab der innere Raum eines

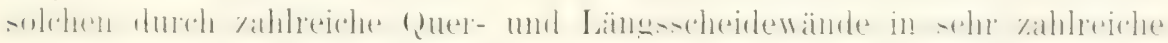
kleine Kammern eingeteilt sei, deren jede einen orler einige der rorhandenen Zellkerne umschliebt, so hätten wir eine gewöhnliche zelluläre Phanze."

\section{b) Der zellige Verband.}

Die letzte und höchste Form des Verbandes zeigt uns die einzelnen Zellen dentlich abgegrenzt roneinander, aber sonst dicht zusammengelagert. so dab sie sich unmittelhar berihlen und dadurch gewissermafen in enger und beständiger Fühlung zu einander stehen. Das Resultat ist ein einheitlicher Organismus mit einer relativen und teilweisen Sellyständigkeit seiner ihn auflanenden Elementarteile.

Als höehste habe ich diese Art des Verbandes hezeichnet. indem ich mich von der einfachen 'Tatsache leiten lieb, dab alle höher or misierten PHanzen und Tiere ihm zuzurechnen sind. Erst innerhalh soleher Zellverbänle kommt es zur Entstehung der mannigfaltigsten Strukturen. zur Sonderme zahlyeicher und rersehiedenartiger Organe, zu einer Fülle ungrleicher Differenzierungen ron einzelnen Zellen und Zellengruppen. So entsteht jene wunderbare. reiche Stufenfolge organischer Formen in l'Hanzenwie im Tierreich, vom einfachsten Moospthanzchen his zur höchstent-

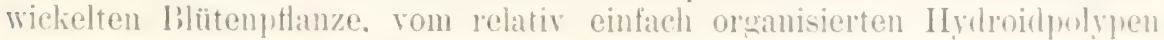
his zum Wirbeltier mit seinen für die rerschiedenartigsten Detailfunli- 
tionen eingerichteten Organen und Geweben. Im Vergleich zu solcher

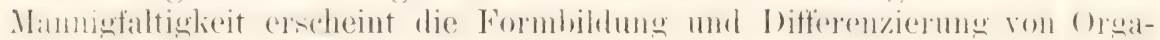

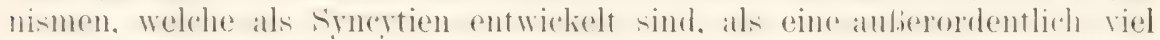
einfachere und niedere. Denn wemn auch die höchst organisierten Coelo-

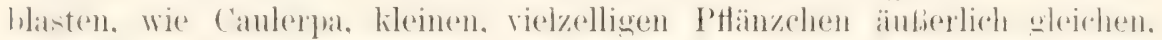
so stehen sie doch auch wieder tief unter ihnen durch den Mangel jeder gewehlichen Differenzierum. dureh den Mangel der \%ur stoffleitung dienenden Gefäße, der mechanischen und der Oberhantgewebe etc. Radiolarien kömnen hörhst zirldiche und zusammengeretzte Slielette hilden. ja is lïmmen sogar Muslieltihrillen, welche sich an die Kieselstäle ansetzen,

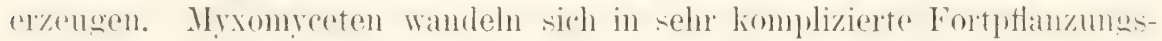
körper um. Gleichwohl treten alle Syncytien über ein sehr geringes Mafo der Differenzierung nicht hinaus. Schon ihre Gröbe ist eine beschränkte. Denn auch die gröbten Arten sind klein im Vergleich zu den Tieren und Pflanzen, die aus Verbänden gesondert bleibender Zellen herrorgegangen sind.

Der so greifbare Unterschied mus im eigensten Wesen der zwei Verbindung-arten bergündet sem. Durch die sombermeg des Protoplatmas in kleine Klümpchen um je einen Kern wird eine größere Obertlächen(21) wicklung herheigeführt. Was für die stoffwechselprozesse. für die dufnahme und Abgabe von Stoffen, von Vorteil ist. Die kleinen Bausteine können sich ferner zu regelmäßigen und verschiedenartigen Verbänden anfinanderlegen, sie kömmen sich nach aulien durch Membranen abgrenzen und sich in dieser oder jener Weise verschieden differenzieren. lierne in einer \%usammenhängenden. gemeinsamen Protoplasmamaste dagegen kömnen nicht einen festen Ort eimnehmen, sie ändern schon infolge der Protoplasmaströmung fortwährend ihre stellumgen zu einander. so dalid alle ehen hervorachobenen, eine höhere Entwicklung herbeiführenden Monnente in Wegfall kommen. Auch für die Größe der aus Zellen aufgebauten Organismen besteht ein viel weiterer Spielraum, da die Zellen durch ihre mamnigfache Verhindungsweise innere Hohlräme erzeugen und auch die zur Stütze einer größeren Masse weicher, organischer Substanz erforderlichen mechanischen Einriehtungen liefern kömnen. Inagegen ist wienter eine richlernige. einheitliche I'rotoplasmamasse hala an dem P'unkt angelangt. wo nach dem fiesetz von Lacckart die ohertliche nicht mehr in einem entsprechenden Verhältnis zu der nach innen von ihr gelegenen Protoplasmamasse steht und wo die zur Erhaltung des Lebens erforder-

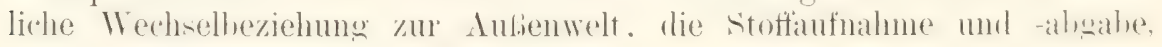
mehr ungestört vor sich gehen kann.

Es ließe sich noch vieles der Art anführen, wodurch der Verband ron mehr selfständig gehliohenen \%ellen sich ïher das syncrtimn als eine höhere Entwioklungsorm der organischen sinhstanz erheht. Doch liamn ein weiteres Eingehen hierauf jetzt unterbleiben, da die in den späteren Kapiteh darwestelten Verhälnisse zum weiteren Erläuterumg und liestä-

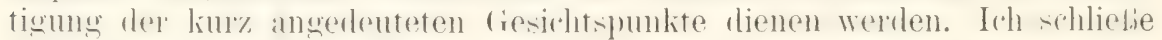
daher diese Betrachtung mit einem Ausspruch, zu welchem SACHs durch

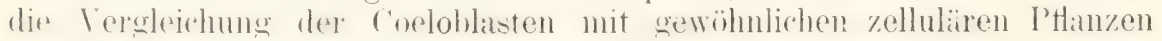
veranlaßt worten ist. „Es ist sehr leicht begreiflich, daf nicht nur die

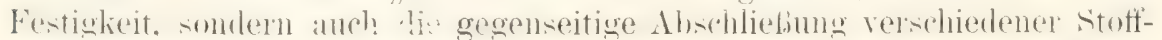
wechselprodukto, die Leitung der Sïfte von Ort zu Ort etc. eine gröbere. Vollkonmesheit erreichen mub, wenn die gesante Substanz der PHanze durch zahlreiche Quer- und Längswände in scharf voneinander abgegrenzte Zellkammern eingeteilt ist." 


\section{Die ormanischen Individuen dritter Ordnung.}

Derselbe Prozeb, den wir im vorausgegangenen Abshnitt kennen gelernt haben, wiederholt sich noch eimmal. Individuen zweiter Orduung. welchen HaEckel den Namen .. P'ersoneno gegeben hat. treten abermals zusammen und rufen durch ihre Vereingung eine neue, zusammengesetztere Form organischer Individualität, ein Individum dritter

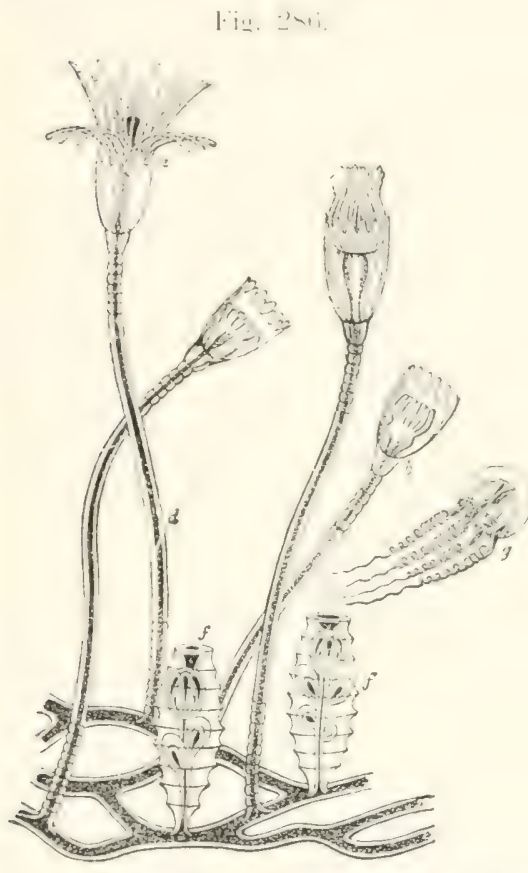

Fig. 286. Campanularia Johnstoni. a Irilnathen mit Hydrotheka, b im zuriickgezogenen Lustande, $d$ Hydrocaulus, $f$ Gonotheka mit Blastostyl und Medusenknospen. g Mhgelöste Meduse (nach MLImAx). Ans Richarp Hertwis Zoologie.

Fig. 287. Schema einer Siphonophore. Ans Luxgr. sb Lufthammer. sp Schwimmelocken. ds Deckstuicke. t 'lentakeln. go (xonophoren. hy Frelipolypen. I' 'aster. st Stamm. 1- II Cerschiedene Arten der Ausbildung mand der (irmpierung der Individuen.

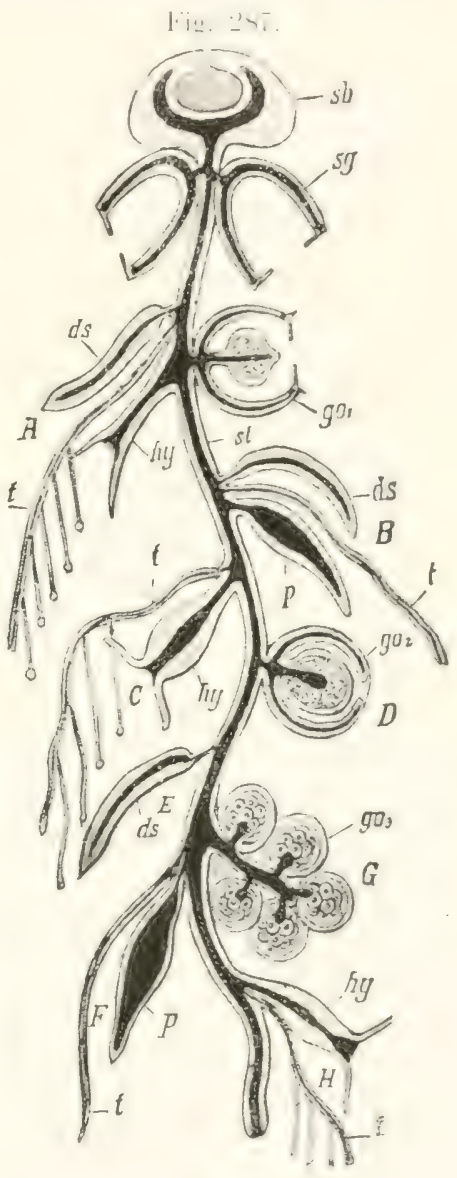

Ordnung oder einen Tierstock hervor. Auch hier lassen sich wieder zwei (iegensätze unterscheiden, erstens weniger innige und zweitens festere Verbände von Personen, und zwar heide verknüpft durch eine Reihe von Ubergangstormen.

\section{Stöcke von mehr locker verbundenen Personen}

In dem Stock, dem organischen Individum dritter Ordnuner. sind die einzelnen 'Teilindividuen sofort als solehe zu erkemnen und zeisen in ilnen Lebensäuberungen einen hohen (rrad von Selbstandigkeit und [nabhängigkeit rom dianzen. Das Teilindividum läbt sich abtrennen, ohne 


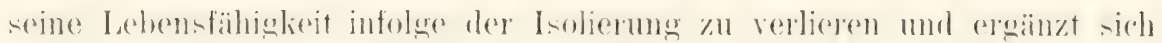
nach kurzer 'Leit wieder durch Vermehrung, entweder durch 'Teilung oder häufiger dureh Knospung, zur zusammengesetzten Form. Die T'eilindividuen sind hierbei, wie die Einzelzellen eines Vorticellenbäumchens. entweder einander vollstindig gleichartig oder nur in geringem Maße voneinander verschieden. Beispiele solcher Aggregate finden sich in beicien Organismenreichen in großer Fïlle. Im Tierreich liefert solche besonders der Stamm der Coelenteraten, Bryozoen, der Würmer und T'unikaten. Es soi an die \%usammensetzung eines Iydroidpolypenstockes (Fig. Zsib) abler eines Korallenstockes, einer Kolonie von Bryozoen und von Clavellinen erinnert, die uns sofort als Aggregate gleichartiger 'Teilindividuen erscheinen.

\section{Stöcke von fester verbundenen und zugleich verschieden differenzierten Personen.}

Auf der andern Seite könmen im Aggregat die Teilindividuen so verschiedenartig von einander werden wie die in die einzelnen Gewebsarten sich sondernden Zellen eines Individuums zweiter Ordnung. Es bedarf dam oft schon eines wisterschaftlich geschulten fuges und Denlivermögens, um in richtiger Weise aus dem Ganzen die einzelnen verschiedenen 'Teilindividuen heraus zu erkennen. Hand in Hand damit geht eine gewisse Abhängigkeit der' Teilindividuen voneinder; sie wird oft so grob. dlab ein einzelnes, abgelöst vom Ganzen, nicht mehr fort zu bestehen vermag. Viele Siphonophorenstöcke (Fig. 287) erscheinen in ihrer mannigfachen Differenzierung wie ein einheitlicher Organismus, einer Person vergleichbar, obwohl sie aus Teilindividuen zusammengesetzt sind. Aber letztere sind im Stock vielfach durch Netamorphose stark abgeändert und mit besonderen Funktionen betrant: sie werden hiernach als Frefipolypen $(h y)$, als Decksticke $(d s)$, als Schwimmglocken $(s g)$, als weibliche

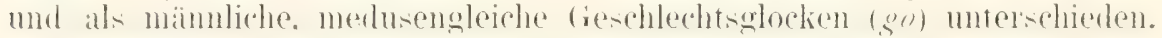
In bestimmten Verhältnissen und Zahlen an einem Stamm verteilt. funk-

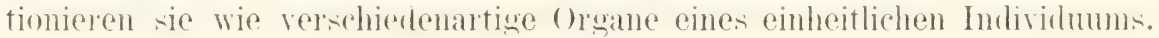

\section{Literatur zu Kapitel XIV.}

1) Alexauder Braum. Das Indizidunm acr Pfanze in scincm Vertältuiss zur Spezies. Abhandl. der Berliner Akad. 1853.

2) Victor Carus. System der tierischin Morphologze. I853. II. Buch, 6. Fapitel.

3) Haeckel. Generelle IYorphologic. Bd. 1. 23I-363. 1866.

4) B. Hatschek. Letwbuch der "Koologie S. 224. 1888.

5) Richard Hertwig. Lehrbuch der Zoologie, to Aufl., S. I35. 1897.

6) Th. Huxley. Upon animal individuality. Proced. of de royal institution. A. ser. Vol. I. p. 187.1855.

i) Leukart. Uber dez Polymorphismus der Indiziduen oder die Erscheinungen der Arbeitstrilung in der Vatur.

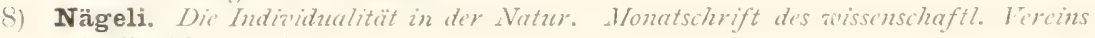
in Zï̈rich. I856.

9) Dirselbe. Mechanisch-physiologische Therie der Abstammungstehe. 7887.

10) Herbext Spencer. Prinsipicn der Biologie. Bit. I. D. 219. VI. Cap. Indiziduculitiot, 1870 . 


\section{FÜNFZEIINTES KAPTTEL.}

\section{Arteleiche. symbiontische, palrasitäe tatlyereinigung.}

\section{Artoleiche Vereinigun@.}

\section{Die Lehre von der vegetativen Affinität.}

Eine der wesentlichsten Grundbetingungen dafür, daß einzelne Zellen sich zu Aggregaten zusammenfügen. ist ihre Artgleichheit, ihre Verwandtschaft (siehe S. 37t). Diese ist das Band. welches die Einzelindividuen

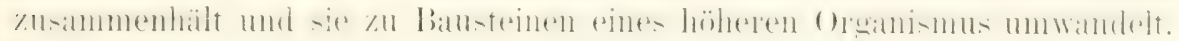
Da num artgleich am meisten die Zellen sind. welche von einer gemeinsamen Mutterzelle abstammen, so sehen wir. dab.s die Eigenschaft der Zelle. sich auf dem Wrege der Fortptlanzung zu rermehren, nicht nur die Grundlage und den Ausgangspunkt für die Erhaltung der Art. sondern auch fiir die Erschaftung höherer Organismenformen abgibt. Teilstïcke einer IIntterzelle, anstatt wieder zu selbständigen Individnen wie die erzengende Mutterzelle zu werden, bleiben verbunden und stellen num blof T'eile einer höheren Individualität dar. Aus selbständigen Artzellen sind sie zu Gewebszellen geworden. So wird das Fortpthanzungsvermögen der or canischen Substanz auf der einen Seite Mittel zur Erhaltung der Art. auf der andern Seite Mittel zu löherer Formbildung.

Die Verwandtschaft der Gewebszellen zu einander bezeichnet man als vegetative Affinität. Sie bildet ein Gegenstück zur sexuel-

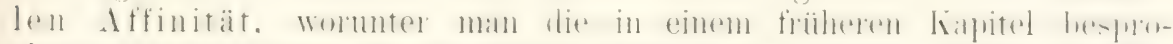

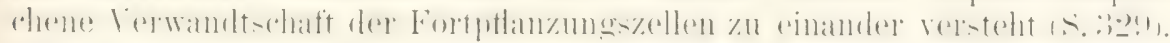
Wie man sich in das Wesen der letzteren durch Kreuzung der Geschlechts-

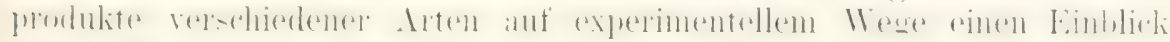
verschaften kann, so kamn man auch in das Wresen der vegetativen Affinitiit tiefer eindringen durch das Experiment des Pfropfens oder der Verbindung zweier vegetativer Körper derselben ofler verschiedener Art.

Am leichtesten lassen sich derartige Experimente bei den Pflanzen anstellen, so daß die meisten Erfahrungen in der vorliegenden Frage von seiten der Botaniker gewomnen worlen sind. Bei den Pflanzen kann man leicht einen abgetrennten 'Teil, das Reis, von einem Individuum auf cin anderes derselben Art, auf den Grundstock oder die Unterlage. trans-

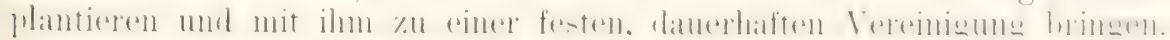
Es verwachsen nach kurzer Zeit die entsprechenden Gewebe von Reis und Unterlage miteinander olne jede Störung. Aus zwei verschedenen. 
Individuen, ist so ein einheitlich funktionierender Organismus auf künstlichem Wege hervorgerufen worden. Bei Individuen derselben Art gelingt die Vereinigung zweier Stücke sogar, wenn sie in abnorme Stellungen zu einander gebracht werlen oder wenn sie nicht direkt zusammengehören, wie Wurzel und lilatt.

Der Erfolg des Pfropfens wird dagegen ein unsicherer oder ein von vornherein aussichtsloser, sowie es sich darum handelt. Stücke zweier verschiedener Arten miteinander zu verbinden. Im allgemeinen ist auf ein Gelingen der Verbindung um so eher zu rechnen, je näher sich die zu verbindenden Arten im System stehen, oder in anderen Worten: die vegetative Affinität wird in ähnlicher Weise wie die sexuelle Affinität durch den Grad der systematischen Verwanltschaft bestimmt.

Doch gibt es ron dieser Regel sowohl bei der Pfropfung wie bei der Bastardbefruchtung unerwartete Ausnahmen, aus welchen NäGELI schliebt. dab die äulieren Merkmale kein vollkommen zuverläsiger Malistab für den Grad der inneren. konstitutionellen Verwandtschaft, sowohl der vegetativen, als auch der sexuellen Aftinität zwischen zwei verschiedenen Arten sind.

Als Beispiel hierfür führt Vöchtsng in seinem Werk über .,Transplantation am Pflanzenkörper" die Rassen des Birnbaums an, die sich mit dem derselben Gattung angehörenden und nahe verwandten Apfelbaum nur schwer durch Pfropfung veremigen lassen, während die meisten auf der (suitte vortrefflich redeihen. ohschon diese zu einer versohiedenen Gattung gehört. In diesem Fall wird übrigens anch zwischen ihren Geschlechtsporlukten die sexuelle Affinitat remibt. Demn Apfel- und IBimbaum lassen sich gleichfalls nicht miteinander bastardieren.

Je nachdem es nun zur Entstehung einer einheitlich funktionierenden Individualitat kommt oler nicht, unterscheidet Vöchtsca die Verbindungen von Reis und Grundstock als harmonische und als disharmonische. Die letzteren lassen verschiedene Abstufungen erkennen, die für uns ebenfalls ron Interesse sind. Während gewöhnlich die nicht zu einander passenden Pflanzenteile sich von vornherein gegenseitig abstoßen, so daß es zu keiner Verwachsung kommt und das Reis rasch zugrunde geht, gelegentlich anch ein stück des frumbtockis. gleichsam rom heis rergiftet. abstirbt, tritt in anderen Fällen die Disharmonie in weniger schroffer Weise auf. Reis und Grundstock beginnen untereinander zu verwachsen, nach kïrzerer oder längerer Zeit abel treten störungen ein, die allmählich zum Zerfall führen. Die störungen bestehen gew ̈̈hnlich hei hrautigen Ptlanzen darin, dab das Reis an seiner Basis Wurzeln zu bilden beginnt. die gelegentlich auch in die Unterlage selbst hineinwachsen.

Ein lehrreiches Beispiel liefert die von Vöchtrsg versuchte Pfropfung zwischen zwei Kalituaten. Rhipsalis paraloxa und Opuntia Lahouretiana (Fig. 285). Zwischen Reis und Grundstock ist zwar äuBerlich eine Vereinigung eingetreten, die schon etwa 20 Monate besteht; aber sie ist keine physiologisch normale wie bei gelungener Pfropfung. Denn der Grundstock ist durchzogen von den Wurzeln des Reises, deren längste in etwa $110 \mathrm{~mm}$ Entfermung von der Einfügungsiselle die Ejplermis durchlorochen hat. Andere sind unter der Oberhaut hin gewachsen, ohme sie aber durchbohrt zu haben. An diesen Orten ist die Haut selbst abgehoben und zugrunde gegangen. Infolge der Wurzelbildung des Reises sind die Gewebe des Grundstockes, der miBfarbig und etwas durchsichtig aussieht, selbst verändert und teilweise in eine (rallerte verflissigt worden, welche an einer Stelle $(g)$ als Tropfen an die Oberfläche getreten ist. 
In solchen und anderen Fiallen benutzt das Reis zu seiner Ernährung die durch die Unterlage herbeigeschaften Säfte und Salze, will sich aber selbst mit der Unterlage nicht zu einer Lebenseinheit verbinden:

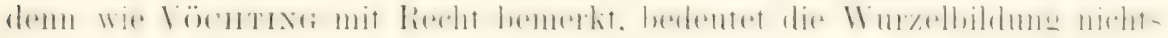
anderes als das Streben, sich zu einem selbständigen Individum abzurunden. Anstatt zu einem dem Grundstoek eingeordneten Teil zu werden. macht das Reis den Versuch. sich zu einem Parasiten desselben umzugestalten. Die weitere Folge ist, dah auch der Grundstock öfters auf den sich ihm nicht anpassenden Fremulling zu reagieren beginnt. So sah Vöchtixg, als er Rhipsalis paradoxa auf Opuntia Labouretiana aufpfropte, dab un die Wureln der ersteren das Gewebe des Grundstockis teils Korkscheiden herum gebildet und teils sich zu einer gallertigen Masse umgewandelt hatte.

In manchen wälen hat der Experimentator die Disharmonie zweier Arten $A$ und $B$ in der Weise überwinden können. dab er sich einer dritten Ant $C$ bediente. welche zu den untereinander disharmonischen Formen eine vegetative Affinitä besab. Er schob sie als Mittelglied zwischen die beiden disharmonischen Formen ein und stellte so einen aus Stücken dreier verschierlener Arten zusammengesetzten, einheitlichen Organismus dar, in welchem auf. $A$ als Grundstock ein Reis ron $C$ und auf dieses wieder ein Reis von $B$ aufgepfropft war.

Schwieriger und daher auch seltener ausgeführt sind Pfropfungen und Transplantationen bei Tieren. Doch scheinen bei ihnen nach dem wenigen, was sich bereits hat feststellen lassen, ähnliche Gesetze wie bei den P'flanzen zu gelten.

T'REMBLEY hat zwei Individuen von Hydra fusca der Quere nach in zwei Stiicke zerschnitten und ilne vorderen und ihre hinteren Hälften rertauscht und dam zusammengeheilt. Während a ihm en leirht glüekte. T'eile zweiey Indiviluen zu einer neuen Individualität zu vereinigen. haben weder er noch neuerdings WETzEL, welcher zahlreiche Experimente ausgefuiht hat, es fertig ge-

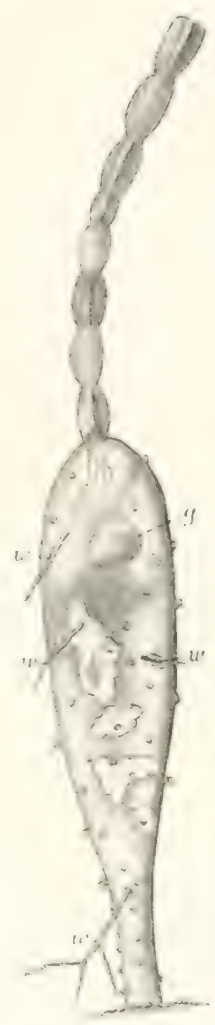

Fig. 2ss. Opuntia Labour. mit Rhipsalis paradoxa als Reis. Bei ura sieht man die rom Reis in die Unterlage hinabgesandten II urzeln, welche hie und da die Oherhaut durehhrochen haben. of I ie aus

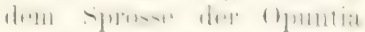
hervorgetretene und prhärtete Gallertmasse. bracht, Polypenstücke von verschiedener Art, von Hydra viridis und von Hydra fusca, nach demselben Verfahren für die Dauer zusammen zu pfropfen.

Borx hat ohne grobe Schwierigkeit geeignete Teilstïcke ron zwei Embryonen von Rana esculenta, wemn sie genügend jung waren, zu einel

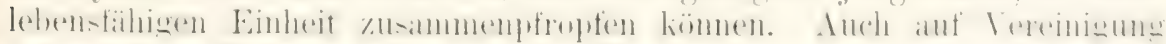

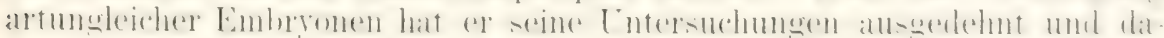
bei dlas folgende Resultat erhalten.

.Die vegetative Affinität zwischen embryonalen Teilstücken, die An-

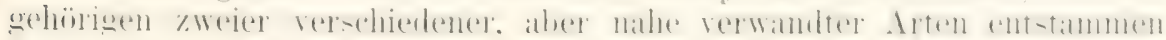


(R. fusca, arvalis und esculenta), erwies sich als ziemlich ebensogrob

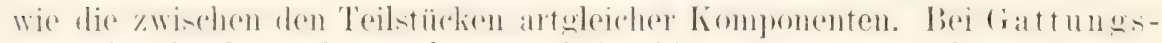
verschiedenheit (R. esculenta und Bombinator igneus) erschien die vege-

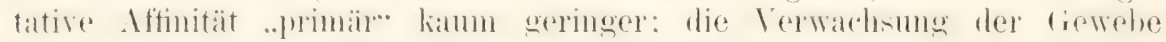
trat in den meisten Fällen leicht. sicher und vollkommen ein. - Ob) das Ausbleiben der Verwachsung der Darmrohre und der Vereinigung der bauchlöhlen in dem enen untersuchten Falle von bauchveremigung zwi-chen li. esculenta und B. ignens auf mangender vegetativer Affinität der Zellen beruht, muls solange unentschieden bleiben. als nicht weiteres einwandfreies Material vorliegt. In späterer Zeit sind mir bisher alle Zusammensetzungen zwischen R. esculenta und B. igneus, nachdem sie gefressen hatten und sich sicher schon ein Bhumstausch etabliert hatte. zugrumde gegangen,"

BORN selbst läßt es vorläufig noch dahingestellt, „ob hier ein Zufall vorliegt, oder ob das bei solchen Versuchen immer der Fall sein wird," ..ob die Todesursache bei diesen Formen in der mangelnden ,vegetativen Affinität der '/ellen oder mehr in unvereinbaren Unterschieden der Gesamtorganisation zu suchen ist."

Nenerdings hat JoEst auf Korschelts Anregung Transplantation zwischen verschiedenen Arten ron Regenwürmern (heteroplastische Vereingungen, wie er sie nennt) ausgefïht, Während an dem Versuchsmaterial artgleiche (homoplastische) Vereinigungen leicht gelangen mul auch von Daner waren, blieben bei 59 Versuchen mit artungleicher Verbindung ..vielfach die Stücke eine wanz kurze Zeit vereinigt. um sich dann einfach zu trennen oder zugrunde zu gehen. Am besten hielten sich in erster Linie die Verbindungen von Albobophora terrestris und Lambricus rubellus, wie atuch die von Allolohophora caliginosa und Allolohophora 'Yanea einerseits und Lumbricus rubellus und Allolobophora terrestris andererseits, wohingegen solche von Lumbricus rubellus mit Allolohophora fortila und Allolohophora chlorotica üherhaupt umöghich erschienen. Letztgenamnte Vereinigungen liönte man in analoger Weise wie hei den PHanzen als ,disharmonische bezeichnen".

Seine Ergebnisse faßt Joest in den Satz zusammen: Dauernde Vereinigungen von Teilstïcken verschiedener Art sind zwar nicht so leicht zu erreichen wie homoplastische Verhindungen. gelingen aber doch in vielen Fällen, und zwar verschmelzen die Teilstücke zu einem neuen Individum. desien Organisation, ahgesehen ron dem Speziescharakter der vereinigten Teilstïcke, eine einheitliche ist."

Anstatt ganzer Körperteile hat man bei Tieren häufiger einzelne kleinere Gewebstïcke von einem Individum auf ein anderes zu übertragen gesucht. Denn solche Experimente sind auch für den Chirurgen yon besonderem Interesse. OLLIER und A. ScHmitt haben mit lobemler Knochenhat und Knochenstächchen experimentiert und ihre Einheilung und ihr Weiterwachstum erreicht, wenn es sich um Übertragungen zwischen Individuen derselben Art oder von einer zu einer anderen lizrperstelle descelhen Individums handelte. Dagegen blieb der

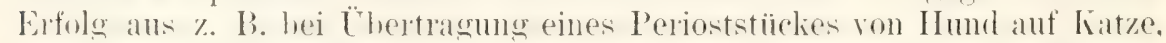
Kaninchen, Ziege, Kamel etc. oder umgeliehrt; entweder wurde das transplantierte Stück ganz resorbiert, orler es bildete sich um dasselbe ein Eiterherd, oder es wurde in eine Cyste eingeschlossen.

Eigenartige Experimente hat P. BERT angestellt: el tremte ron weißen, einige Tage alten Ratten ein 2-3 $\mathrm{cm}$ langes Stück vom Schwanz ab und brachte es nach Abtrennung der Haut dem operierten Tiere an 
einer anderen Stelle ins Unterhautbindegewebe. Schon nach wenigen 'Tagen war' die 'Zirkulation in der Schwanzspitze durch Verbindung mit den Gefäben der Ungebung wieder hergestellt. Muskeln und Nerven

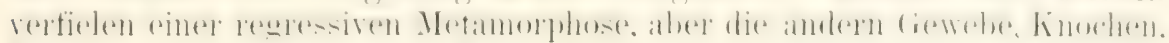
Knorjel, Bindegewebe ete. fuhren lebhaft zu wachsen fort, so dafo die Schwanzspitze, die bei der 'Transplantation 2-:3 cm grof war, bei einigen 'Tieren, welche einen, zwei oder drei Monate nach der Operation getötet wurden, zu einer Liinge von 5-9) cm ausgewachsen war.

Dagegen fiel das Resultat bei Verpflanzung von einer auf die andere Art abweichend aus. Bei Übertragungen der Schwanzspitze von Mus decumanus odel' Mus rattus auf Eichhörnchen, Meer-

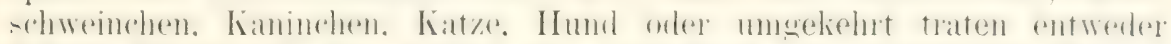

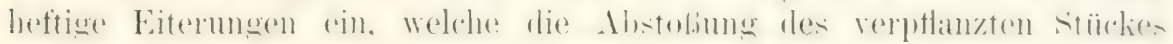
und häutig auch den 'Tod des Versuchstieres zur Folge latten, oder es

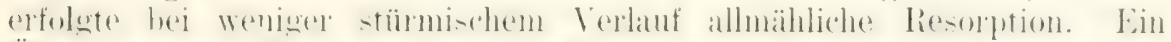

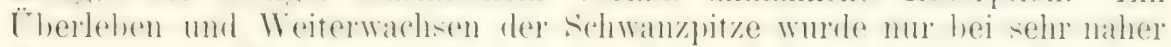
srstematischer Verwandtschaft deg zum Versuch hemutzten zwei Tierarten erzielt. So glïckten Transplantationen von Mus rattus auf Mus decumanus und umerelielirt. diageren nicht ron Mus slvaticus auf Mus rattus.

Zu demselben Ergebnis führt die Vermischung der Blutarten von zwei rerschiedenen 'T'ieren, wie alle Experimentatoren, die sich eingehender mit der Lehre von der 'Transfusion beschäftigt haben, in ähereinstimmender Weise herichten. Anch her kann man harmonische und disharmonische Verbindungen unterscheiden, die wieder vom Grade der systematischen Verwandtschaft der Tierarten bestimmt werden.

Bei Vermischung disharmonischer Blutarten treten sofort schwere störumgen im Oreanismus auf. Shlon nach wenigen Yinuten hegmnt ein \%erfall roter Iblutkörperchen, eine Auflösung des IJämoglobins im Plasma I Iarlifurbigwerden des Blutes) einzutreten. Was in kurzer Zejit IBlutharn zur Folge hat. Schon in schwachen Dosen wirkt moleichartiges Blut

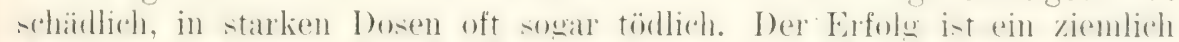

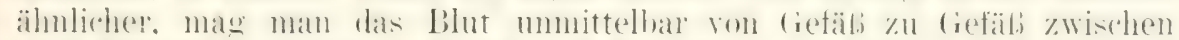
zwei Tieralten. zwischen Humb und Kaninchen orler Hund und Itammed

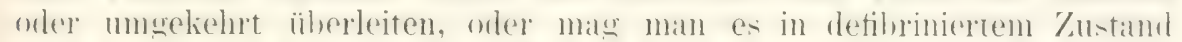

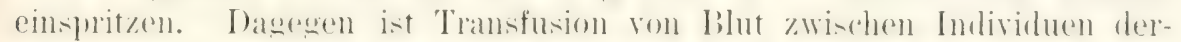
selben oder sehr nahe stehender Arten ohne Schaden ansführbar. Die

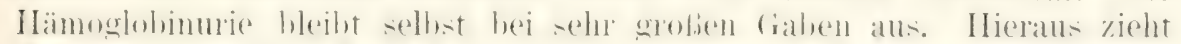

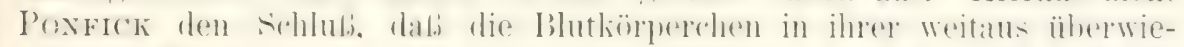
genden Melizahl in dem fremden Organismus unverändert bestehen bleiben.

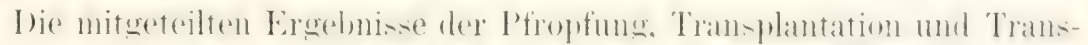

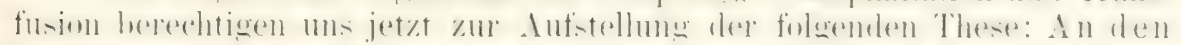
fieweben von Pflanzen und Tieren sind zwei verschiedene Arten von Eigenschaften zu unterscheiden: erstens die Eigenschaften, welche mit der besonderen Leistung des Gewebes zusammenhängen, und zweitens die Eigenschaften, die ihnen als T'eilen einer besonderen Organismenart zukommen.

Die funktionellen Eigenschaften prägen sich meist in einer besonderen Struktur der (rewebe aus. sie sind daher für unser Auge häufig leicht erkennbar und der mikroskopischen Untersuchung zugänglich. Ferner bedingt gleiche Funlition der Zellen auch eine gleiche Struktur. Daher sehen wir. dab gleich 
funktionierende Gewebe bei den verschiedensten Organismen sich auberordentlich ähnlich sind. Eine Sehne, ein Nerv, ein Knochenund kinorpelstiick oder Blut eines Hundes und eines Pferdes sind mög-

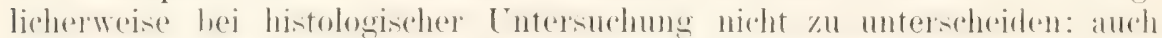
nach ihren spezitischen Leistungen für den Organismus würden sich die entsprechemben 'Teile der heiden Sïngetierarten gegeneinander austansehen und wedholsoitig arsetzen lassen müsien. Gine entsprechend grolie rehne des Hundes, mit ainem Nuskel des Pferdes vereinigt. würde den Zug vom Muskel auf den Knochen ebensogut übertragen und somit einen Ersatz für die medhanische leistung der I'ferdesehne bilden kïnnen und ehenso ein Knochen-, ein Knorpel- und ein Nervenstück. Bei allen Säugetieren erfillen die roten Bhutkïruerchen dieselhe Funktion. den Sauerstoft an sich zu binden. Gleichwohl ist das Hämoglobin, von welchem diese Bindung ausgeht, wohl bei keinem Säugetier genau die gleiche Substanz. Dies spricht sich schon in der verschiedenen Art, zu kristallisieren und in der verschiedenen Form der Kristalle aus. Während das Hämoglobin beim Eichhörnchen im hexagonalen System, kristallisiert es hei den meisten anderen säugutieren in rhombischen. Auch im gelosten Zustand erhalten sich die Hämoglobine wegen ihrer Eigenart wohl voneinander getrennt. Wenigstens für das Fichhörnchenhämoglohin hat es RoLberT bewiesen. Er hat Blut rom Eichhörnchen und von der Maus gemischt und es lackfarhen gemacht. Ils beim stehen sich släter die Hänoglobinkristalle ausschieden. Waren sie je nach dem Mischungsverhältnis im hexagonalen und im rhombischen System auskristallisiert.

Durch die äuBerlichen Ähnlichkeiten in der Struktur und Übereinstimmung in der Funlition darf man sich also nicht verleiten lassen, atuch eine innere Ännlichlieit zwischen gleich aussehenden Zellen und Geweben anzunehmen. In dieser Annahme liegt ein großer Irrtum vor, in den schon manche Forscher verfallen sind. Denn es werden hierbei die an zweiter Stelle oben hervorgehobenen Eigenschaften, welche einem Gewebe als 'Teil einer besonderen Organismenart anhaften, die konstitutionellen oder Arteigenschaften, ganz übersehen; sie werden so leicht übersehen, weil sie sich unserer Wahmehmung nicht aufdrängen. da sie auf einem für unsere Erkenntnismittel noch unzusünglichen Gebiete liegen und nur auf Grund der obenerwähnten Experimente und allgemeinen Erwägungen erschlossen werlen können.

Der Sachverhalt ist bei den Gewebszellen ein ähnlicher wie bei den Geschlechtsprobluten. Nach ihren histohgischen Eigenshatten sind einerseits die Eier, andercrseits die Samenfäden der verschiedencn Säugetiere einander außerordentlich ähnlich und in vielen Fällen für uns gar nicht unterscheidbar: als 'Träger der Artcharaktere aber, die in diesem Zustand für uns nicht wahnehmbar sind. müssen sie, worüber ein Zweifel nicht bestehen wird. so weit voneinander verschieden sein. wie Art von Art.

Worauf beruht nun die Verwandtschaft der Zellen. ihre sexuelle und ihre vergetative Affinitit? Anf der (irleichleit ilner unseren Entersuchungsmitteh unzuginglichen, feineren Organisation, auf dem micellaren Aufbau derjenigen \%ellhestamlteile. welche wir in dem XIII. Kapitel als die Figenschaftsträger des Organismus orler als seine Erbmasse nachzuweisen versucht hahen. Inementsprechend werden artungleiche Zellen sich auch in ihren chenisch-physikalischen Eigenschaften voneinander unterscheiden: der ganze zelluliire stoffirechel wird einen für die Art spezitischen charakter haben und hewirken, dal.j nur Zellen mit gleichartigem Stoffwechsel und mit sleichen chemisch-physikalischen Eigenschaften zu einander pasien. 
Die hier yon mir zum ersten Male entwickelten Anschaumgen iiber die Arteigenschaften der Zellen und (iewebe eines Organismus haben eine

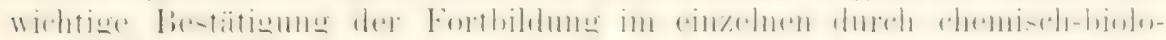
gische Forschungen der letzten Jahre erhalten. Der weitere Ausbau der

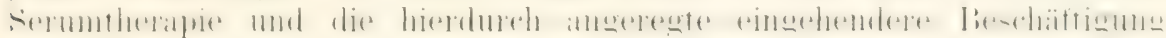
mit den Eigenschatten der körpersifte haben gelehrt, daß die Sera der

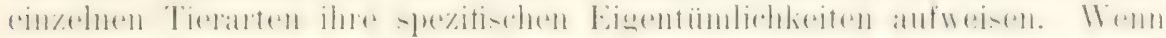
man dieselben auch noch nicht durch exakte chemische Analyse genau bestimmen kann, so kamn man sich doch von der Verschiedenheit der Sera

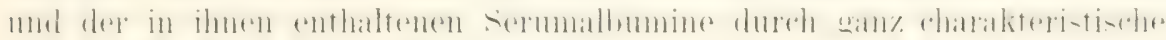
.biologrische Reaktionen" über'zengen.

Wenn man einem Säugetier artfemdes Blut einspritzt, zum Beispiel einem Kaninchen Rinderblut, so erhät man von ihm nach einigen Tagen ein Serum. das. nun mit dem Rinderblut vermischt, mehrere auffallige Reaktionen darbietet. Es löst. wie BORDET zuerst beobachtet hat. die roten bluthörperchen in ilm auf. Es ergibt ferner, mit Rinderserum versetzt. einen Nierlerschlag von Eiweibkörpern, ein Präzipitat. Die Reaktion

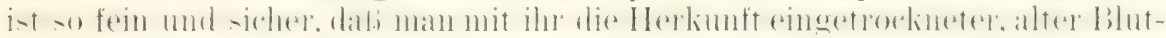
Hecke bestimmen kam. Nach den Untersuchungen von UHLExiutu und WAssermaxx entsteht in einer Lösung des eingetrockneten, näher zu be-

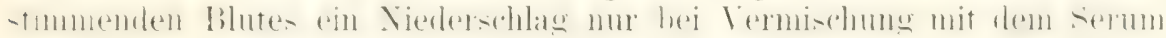
emes Tieres. welches mit dem Blut der 'Tierart. von welchem der BlutHeck herrïhrt, in der oben angegebenen Weise vorbehandelt worden ist. Beide Reaktionen, die Autlösung der roten Blutkörperchen und die Bil-

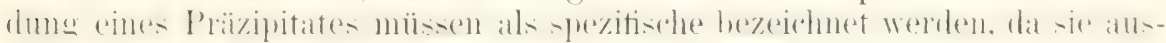
heiben. wenn man das als Reagens dienende Kaninehensermm ansatt mit Blut vom Rind, mit Blut von Pferd. Hund. Schaf, Meerschweinchen etc. mischt. Nur das Bhut nahe verwandter Tierarten verhält sich bei der Fïllungsreaktion gleich, wie durch ausgedehnte Versuche von Nuttalu. UHLENHUth. WASSERMANY und FrIEDENTHAL festgestellt worden ist.

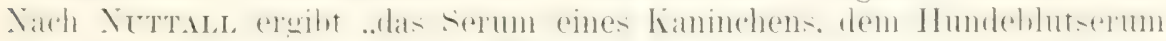
injiziert worken ist, mit dem Blutserum ron acht verschiedenen Caniden Fällung. nicht aber mit dem Blut irgend eines anderen 'Tieres". Ebenso

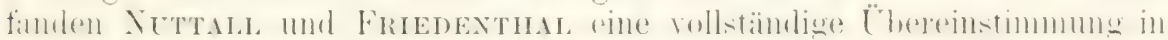

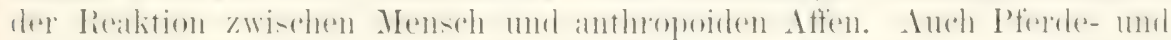
Eselhlutserum verhalten sich bei der Reaktion gleich, ferner das Serum von Hund und Wolf usw.

Friedextial hält daher das Bordetsche V'erfahren für sehr ge-

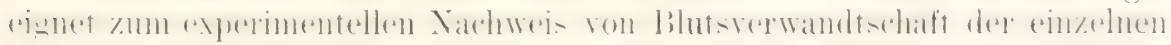
Tierarten, und ABDERHALDEx geht sogar so weit, zu prophezeien. dab ein plammähiger Ausbau der erst begomnenen Forschung noch weitere, die .Art" und das "Einzelindividum" charakterisierende Merlimale zutage fördern werde und daß die vergleichend biologisch-chemische forschung auch berufen sein werde, in Fragen der stammesgeschichtlichen Verwandtschaft die führende Rolle zu spielen“".

Gleich wie das Blut, sind aber atuch alle Körpersäfte und Selirete der einzelnen Tierarten roneinander verschieden. Wenn man einem Versuchstier Kuhmileh injiziert, so kamn man von ihm ein Serum gewimen, welches nicht nur Kuhmilch fällt. sondern auch die roten Blutliörperehen eines Rindes autlöst und in seinem Serum eine Fällung erzeugt, nicht aber bei einem andern Süugetier. Auch Injektion von Organ- und Gewelsteilen.

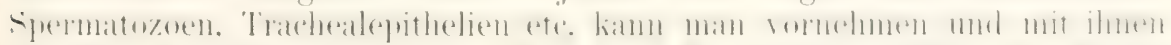

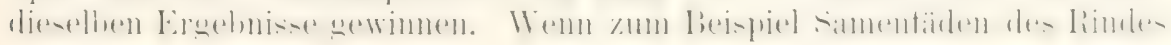




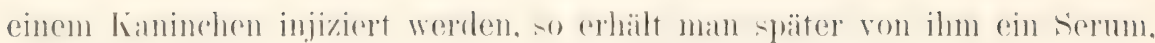
in welchem Rindersamenfädlen rasch ihre Bewegung verlieren. Aber auch rote Blutkörperchen werden in (lerselben Weise aufgelöst, als ol) anstatt Samenfïrlen Rinderblut injiziert worden wäre.

Man nimmt an, daß durch die Einführung körperfremder Stoffe im

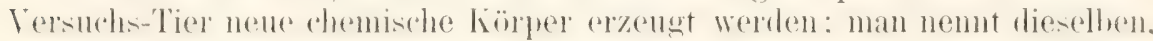

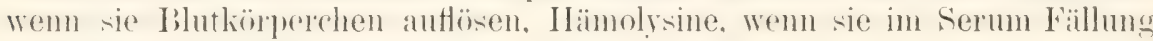
erzengen, Präzipitine.

Aus den chemisch-biologischen Untersuchungen kommt HAMBURGER in einer schrift .. Arteigenheit und Assimilation" zu ähnlichen Sidhlïs-sen. wie ich sie schon frỉher auf Grund anderer Erscheinungen und Erwägungen gezogen hatte, und bezeichnet das Ergebnis als ,das Gesetz von der biochemischen Artemheit und Artverschiedenheit". Nach ihm hesitzen die rerschiedenen Zellen und Körperflissigkeiten derselhen Spezies Atomkomplexe, die Träger der Arteigenheiten sind und die ihnen allen als Angehörigen eben dieser Spezies zukommen und durch welche sie sich vor allen anderen Sipezies unterscheislen. Meinem lieispiel folwent, unterscheidet er ehenfalls an jeder Zelle zwei Eigenschaften: 1. die durch ihre Funlition bedingte Eigenschaft, mol 2. die ihr als einem Oromismus von hestimmter Art (Rasse und Indivilualitä) zukommende. artcharaliteristi-rhe Eigenschaft.

\section{Die symbiontische Vereinigung (Symbiose).}

So richtig im allgemeinen auch der Satz ist. daß nur Zellen gleicher Abstammung sich zu höheren Stufen der organischen Individualität zusammenfüsen, so bietet die Natur mit ihrem unerschïpttichen Reichtmm an Mitteln doch auch manche Ausnahmen von der Regel dar, nämlich Verbindungen von Zellen, die nicht auf innerer Verwandtschaft beruhen und die wir daher den artgleichen als artungleiche gegenüberstellen können. Diese selbst aber lassen sich wieder in zwei Gruppen sondern.

In der einen Gruppe, mit welcher wir uns zunächst in diesem Al)schnitt beschäftigen wollen, lernen wir Verbindungen kennen, in denen zwei artungleiche Zellen sich zwar in ihrer Organisation und ihrem Stoffwechsel wesentlich unterscheiden, aber dabei doch auch wieder so beschatfen sind. dath die eine Art neten der anderen ohne gegenseitige beeinträchtigung bestehen kann. Ja es kamn sogar der Fall eintreten, daß beide Arten von Zellen aus ihrem Zusammensein in mancher Hinsicht einen wechselseitigen Nutzen ziehen. Ein solches Verhältnis hat der Botaniker DE BARY eine Symbiose genannt.

Das lehrreichste und interessanteste Beispiel einer Symbiose bieten uns die Flechten; sie wurden noch vor einigen Jahrzehnten wegen ihres rharakteristischen Auschens für eine wanz eigenatige hlase von nieleren Pflanzen gehalten, bis durch die morphologischen Untersuchungen von DE liARY und Scuwexdexer, denen sich die experimentell-entwicklungs-

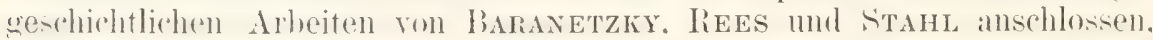
der Nachweis geführt wurle, dab sie keinen einheitlichen Organismus, sondern ein Aggregat zweier imnig zusammenlebender, im System weit auseinander stehender Organismenarten, eine Symbiose einer Pilz- und einer Algenart, darstellen.

Pilzfäden aus der Abteilung der Ascomyceten bilden ein Getlecht (Fig. 289) $P$ ) und liefern so die gewebliche Grundlage, in deren Maschen zahllose kleine Algenzellen (.4), die bahl srünen. roten oder gelben Farh- 
stoff fühluen, eingeschlossen sind. Die zahlreichen verschiedenen Arten

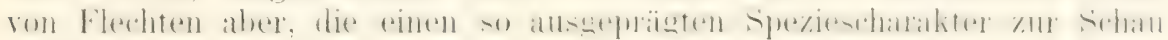
tragen, kommen dadureh zustande, dab immer eine bestimmte Pilzart sich nur mit einer bestimmten Algenart rergesellschaftet.

In solcher Genossenschaft leben zwei Zellenarten mit ganz entgegen-

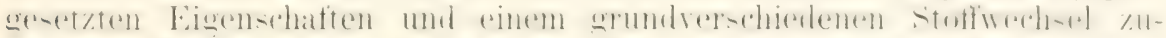

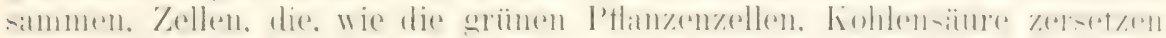

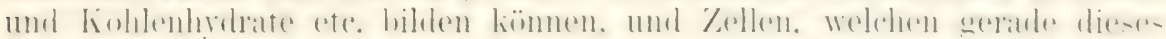
Vermögen fehlt und die nur von schon gebildeter organischer Substanz leben kömen. Aber gerade aus diesem Gegensatz ziehen die beiden

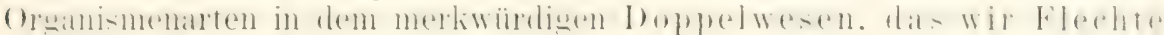
nennen. besondere Vorteile, durch welche sie sich in ihrem fiedeihen gegenseitig förolern.

Infolge des hohen Anpassungsgrades der Pilz und Algenzellen aneinander und der damit Hand in Hand gehenden spezitischen Formbildung des durch sie gemeinsam erzengten Agrregates erscheint jede Flechte in hohem Mabe als ein einheitlicher Organismus, der sich von

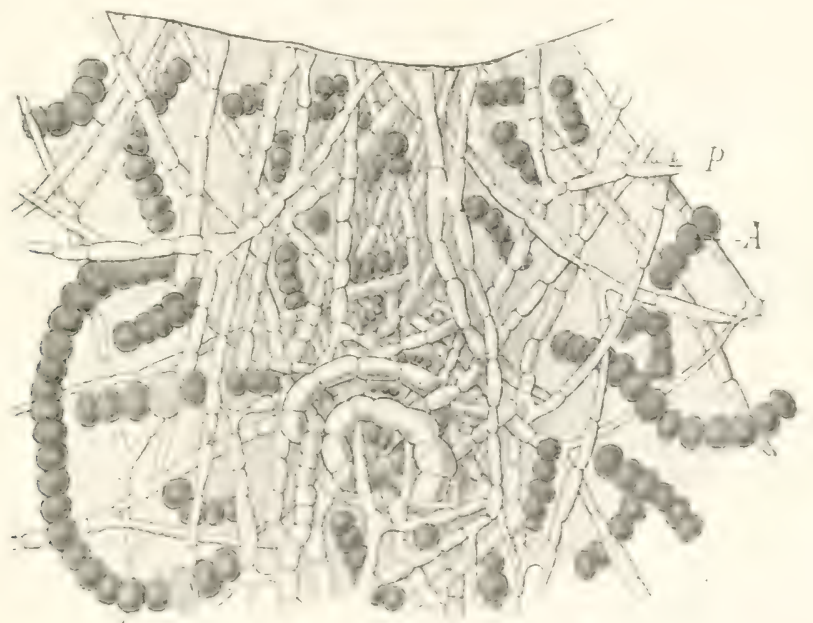

Fin. 259. Stark vergrößerter Durchschnitt durch ein Stück Flechte. Nach ST.HL. Die F'lechte setzt sich zusammen 1) ans den l'ilzfälen ( $P$ ), die, sich in allen lichtungen durchkreuzend, ein dichtes (ieflecht bilden, und 2) ans den Algenzellen (A), die, griun gefairbt und wie Stïcke einer Perlschmur aneinander gereiht, im l'ilzeflecht liegren.

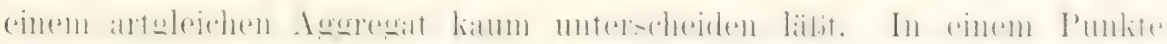
aber tritt in voller Ḱlarheit die Natur des Doppelwesens zutage, nämlich in der Art ihrer Fortpttanzung. Eine Pilzzelle besitzt niemals die Fähigkeit, eine Algenzelle, und diese ebensowenig die Fähigkeit, eine Pilzzelle hervorzubringen. Die eine Zellenart kann auf die andere ihre

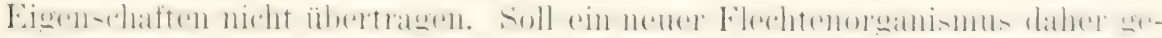

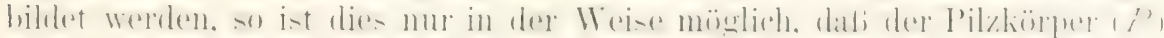
und der Algenkörper $(A)$ ihre eigenen Fortptlanzungszellen liefern und

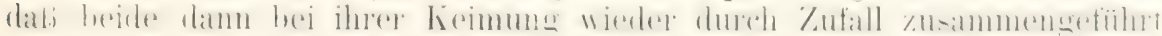
werden und sich zu einem Aggregat von nenem vereinigen. Aus der Pilzspore wächst ein lieimfaden hervor, der sich zwar eine Zeitlang durch 
Sprossung weiter vermehren kann, aber schlieblich zugrunde geht. wemn er nicht mit der zugehörigen Algenart zusammentrifft. Ist dies aber ge-

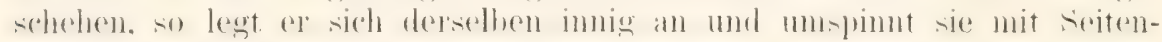

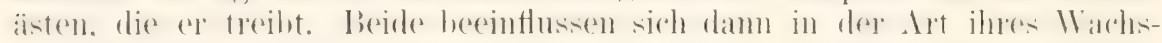

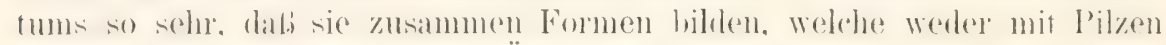
noch mit Algen eine entfernte Ähnlichkeit haben.

„Es leuchtet ein," bemerkt SACHs, „daß die chlorophyllhaltigen Algen im Flechtenkïrper geradeso als Asinilationsoreane wirksum sind wie die rhlorophyllhaltigen Zellen etwa in der Rinde rines grünen stengels oder

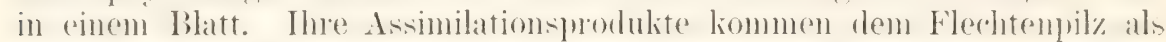
Nahrumgsmaterial zugute. Während momgeliehrt die zur Asimilation nötigen Aschenbestandteile den Algenzellen durch den Pilz zugeführt werden. Durch dieses Konvivium aber werden die Flechten nummehr unabhängig von einem organischen Substrat. Während alle übrigen Pilze Parasiten oder Itumusbewohner sind, kömnen sich die Flechten auf rein mineralischem Borlen, selbst auf der Obertlïche liristallinischen fiesteins ansiedeln, lat ja. die in ihnen enthaltene Alge sie unabhängig macht." Wir finden sie ,befähigt, die unorganische Substanz von Gesteinen, z. B. des Granites, zu zersetzen. un. ähnlich wie die Wurzeln der höheren Pflanzen. diejenigen Dineralstoffe zu gewinnen, welche ihre chlorophyllhaltigen Zellen. die Algen in ihrem Gewebe, zur Assimilation bediüfen. 'Indem also diese Pilze mit bestimmten Algen sich vereinigen, um sich von ihnen ernähren zu lassen, gewinnen sie eine Freiheit in der Wahl ihrer Wohnorte, die keinem anderen Pilz zu Gebote steht." Entwerler bilden sie, wie die Laubflechten, Hächenartig ausgebreitete Blätter und Ḱrusten, oder sie stellen, wie die Bartflechten, vielfach verzweigte Sträucher dar; mit einem Wort. sie erzeugen fiestalten, .. wie sie sonst nur den typisch dhlorophyllhaltigen I'tanzen eigen sind.: Es handelt sich. wie bei diesen, so auch hier darum, die grümen Zellen in geeigneter Weise mit dem Licht und der Luft in Beziehung zu retzen. Was entwerler durch blattartige Ausbreitung oder dureh rielfache Verzweigung des fiewehes zu erreichen ist (J. SAcHs).

Der Simbiose der Flechten lassen sich ehenso in Tierreich Erscheinungen zur Seite stellen, welche auf innigem Zusammenleben \%weicr artverschiedener Zellen beruhen. allerdings ohne ein so interessintes fiesamtbild darzubieten, wie es für die Flechten einzig in seiner Art ist. Es handelt sich auch hier um ein konstantes Zusammenleben tierischer Zellen mit niedersten, einzelligen Algenarten.

Wie 1si1 durch den russischen Botaniker ('IExkowsix auf firmul entwickhussgeschichtlicher Studien liachgewiesen wurle, kommen mit Konstanz in Protoplasmakörper gewiscer Rarliolarienarten niederste einzellige Algen vor, die sich in ihm durch Teilung vermehren und von anderen Forschern shon als gelhe Zellen heschriehen, aber für Bildungsprodukte des Radiolarienkörpers selbst gehalten worden waren.

Einige Jahre später machten mein Bruder und ich die Entdeckung, daß bei zahlreichen Aktinienarten in der den Urdarm auskleidenden

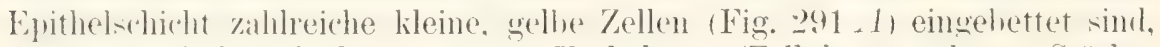
die wir auf Grund ihres ganzen Terhaltens (Zellulosemembran, Stärke-

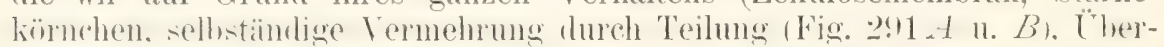
lehen heim Toule ihres Wirtess fïr niederste, einzellige Algen erklärten. sie haben sich direlit in die geilieltragenden Zylinderzellen des Darmdrüsenblattes (Fig. 290) eingenistet, so daß fast jede einzelne von ihnen 2 bis 5 einschlieft. Sie gehören so sehr zum charakteristischen Bestandteil gewiser Alitinienarten, dadi sie in keinem Individum rermilit werden, 
(lal) sie hei ihrem massenhaften Vorkommen der hetreftenden Alinienart inre spezitische. grünliche. gelbliche orler bräunliche Färbung verleihen.

Almliche Genossenschaftsverhälnisse wie hei den Alinien wurlen mmittelhar darauf noch in vielen anderen Fällen durch IBRANDT. GEDDEs. (iRAFF. GEZA ExTz ete. nachgewiesen. nämlich hei mehreren Infusorien. hei Hydra viridis. hei Spongilla viridis, bei Medusen und Velellen, bei Stachelhäutern. Würmern und Schmekken. Meist sind hier die eingenisteten Algenzellen intensiv chlorophyllgrün gefarbt und dabei noch von einer viel geringeren (iröße als die gelben Algenzellen der Radiolarien und Alitinien. Auch tragen sie. wie bei Hydra viridis. zum charakteristischen Habitusder hetreffenden Art so wesentlich bei. daf sie geradezu ein wichtiges Artmerkmal abgeben.

Wie bei den Flechten scheint aus der Srmbiose ron Tier- und Algenzellen ebenfalls ein gegenseitiger Sutzen zu erwachsen, so dab man ron einem parasitischen Verhälnis nicht gut reden kann. Wahrscheinlich kommt die Lohlensäure. welche in dem tierischen forwebe als dhfallsprodukt bereitet wird, den Algen zulgute, während der Sauerstoff. welcher im Stoffwechsel der Algen entsteht. ron den Tierzellen wieder aufgemommen mol 7.u Oxydation der als Nahrung dienenden, organischen Substanzen verwendet wird. Dazu gesellen sich vielleicht noch andere Vor-

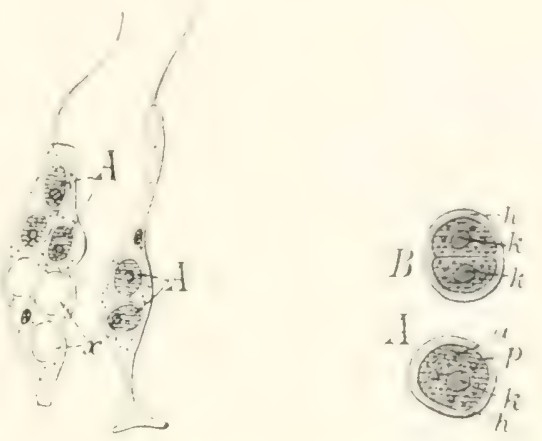

Fig. 290. Zwei isolierte Entodermzellen einer Seerose (Inthea celeus). Stark vergröbert. Man sieht in der links stehenden Darmzelle drei grelhe Algenzellen (A), in der anderen zwei gelhe dlgenzellen

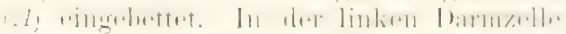
gewahrt man noeh drei IIolilrïmme, in welchen ursprïnglich auch Algen gelegen haben, die aber bei der Priparation herausgefallen sind,

Fig. 291. Gelbe Algenzellen, aus der Darmwand einer Seerose herausgedrückt. A Ungeteilt, B In Zweiteiluns. h Zellulosehïlle. k Lern. a Stärkekürnchen.

teile anf beiden Seiten. Eingenistet in den Geweben der Tiere. sind die

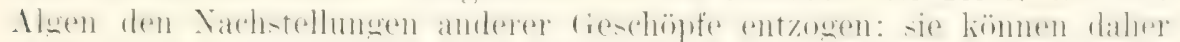

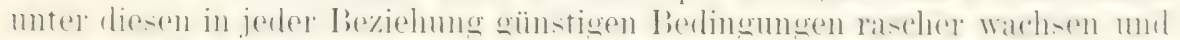

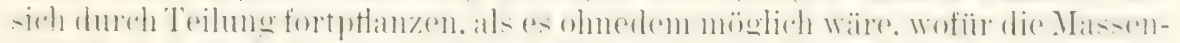

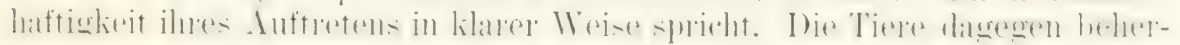

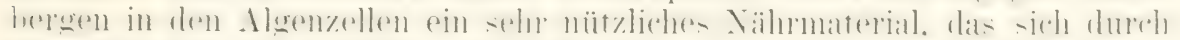

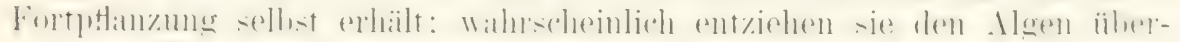
schïssige Produlite ihrer Assimilation, wie Stärke und Zucker.

Ion solchen Gesichtspunkten aus betrachtet. bietet uns der Haushalt eines mit Algen zusammenlebenden Tieres ein interessantes Schanspiel lar. In ihrer Symbiose vollzieht sich gewissermaßen derselbe Kreislauf der Stofte, der in der gesanten Natur zwischen Tier- utd Pflanzenreich

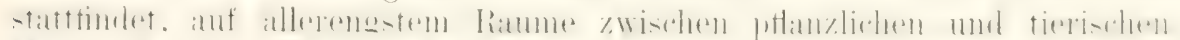

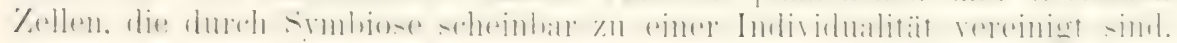

\section{Die parasitisehe Vereinigung.}

Von der Srmbiose sind als eine zweite Grupue solche Verhindungen zweier artungleicher Zellen zu unterscheiden. innerhall, welcher die eine

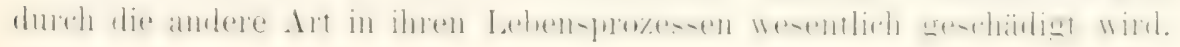




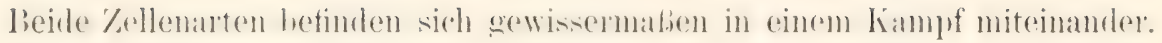
Im Gegensatz zur Symbiose bezeichnen wir die Verbindung daher als eine parasitare, und wir begeben uns bei ihrer Betrachtung vom normalen auf das pathologische Gebiet.

In die Gewebe höherer Organismen können fremdartige Zellen, durch hesmelere Verhälnisse beginstigt, eimbingen, in ihnen einen geeigneten Boden für ihre Vermehrung finden und durch ihren EinfluB auf die Wirts.

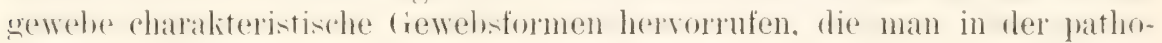
logischen Anatomie Infektionsgeschwïlste nennt. Diese zeigen je nach der Iolialitit, in der sie entstanden simb. und je narh der fremolartigen ()ranismenart, welche sie veranlabt hat. ein durchans eigenatiges fepräge. aus welchem man sofort einen sichluli anf den spezitischen Kíankheitserreger machen kann.

Auf die Anwesenheit von 'Tuberkelbazillen sind die eigentümlichen Miliartuberkel und die knötchenförmigen freschwülste in der Haut bei Lupus zuriekzuführen. I)as sphlilitische Lontagium bedingt je nach den oroanen. in denen es zur Entwicklung gekommen ist, eine ganze Reihe typischer Geschwulstformen. Kondylome. (immuata ete. Die verschiedenen Arten der Karzinome und Sarkome endlich sind vielleicht auch parasitaren Trsprungs. wenn es auch noch nicht geglückt ist. den Mikroorganismus nachzuweisen, geschweige denn in Reinkultur zu züchten und zu überimpfen.

Durch das Zusammenleben zweier artverschiedener Zellen wird in den pathologischen (ieschwïhsten die gegenteilige Erschemung wie hei der Srmbiose hervorgerufen. Irahrend hier die Stoffwechselprozesse der heirlen verbundenen Organismen trotz ihrer Verschiedenartigkeit doch zu einander passen, so daß der eine den andern nicht schädigt, im Gegenteil ihm in vielen Fällen sogar ganz offenbaren Nutzen bringt, uibt dort der Eindringling orlex Parasit durch seinen Stoffwechel eine bahl mehr, bald weniger intensive Schädigung auf die ungebenden Gewebe des Wirtes. ja schließlich auf seinen ganzen Organismus aus. Er wird für ihn zu einem Verderben bringenden. unter Umständen tödlichen Gift.

Die Schädigung beruht weniger darauf, daf der Parasit dem Wirtsgewebe Nahrung entzieht, sondern ist in dem Umstand begründet, dab er bei seinem Stoffiwechsel organische Verbindungen erzeugt, die schon in geringsten Dosen eine ganz erstaunliche diftwirkung anf die Zellen

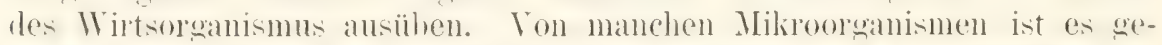
lungen, die giftigen Stoffe ofler 'Toxine zu isolieren und in konzentriertem Zustande diuzustellen, das Tuberkulin, das dift des Staphylokoklius. des Diphtheriebazillus etc. Es ist überraschend, in welchen geringen Dosen die T'oxine, welche in die Reihe der Proteinverbindungen gehören, wenn sie in den lireinlanf eines Tieres gebracht werden, die gefährlichsten Vergiftungsinnptome hewirken, hohes Fieher. Lähmmuen in Bereiche des Nervensystems, fettige Entartungen der Zellen, namentlich der Nierenepitholien. dureh welche die Ans-cheilume und Entfermumg der Toxine andem blute besorgt wird.

Im Gegensatz zur Symbiose, bei welcher man z. B. die eingedrumgenen dlenzellen als integrierende bestanteile der diewebsellen selhst gehalten hat. erscheinen die pathologischen fieschwïlste als etwas dem Organismus Fremdartiges, als Störungen seines Normalzustandes. Auch zeigen sie uns teils eine direkte Schädigung der Wirtszellen, teils reaktive Erscheinungen rom Wirtsorganismus zur Abwehr der ihm fremdartigen Mikroben. 
Um ein Beispiel anzuführen. so hat die Ansiedelung von Tuberkelbazillen zur Folge, daß durch den von ihmen ausgeübten lieiz die umgebenden fixen Gewebszellen in Wucherung geraten und ein hirseliorn-

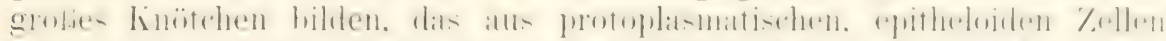

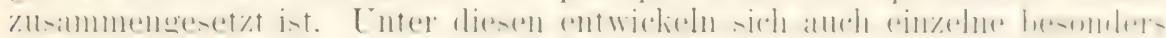
protoplasmareiche und ron vielen liernen erfüllte Riesenzellen. 'Teils in

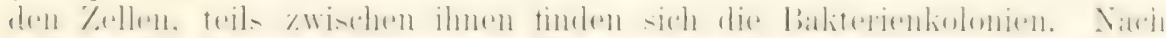
einiger Zeit lassen die von den T'uberkelbazillen befallenen Zellen Ver-

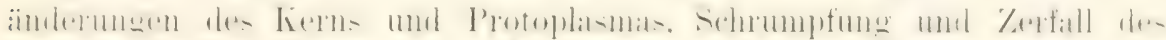

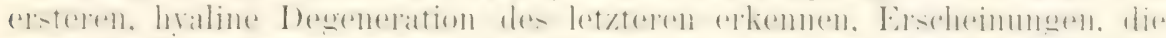

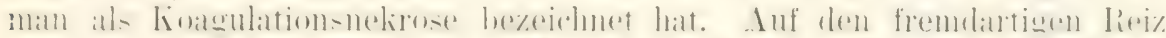

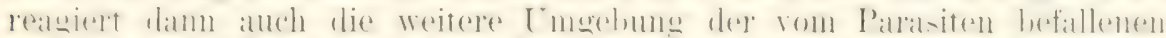

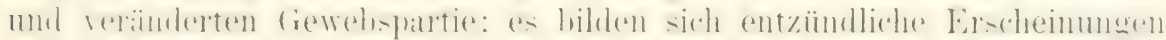

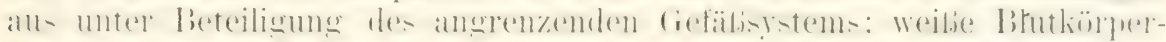

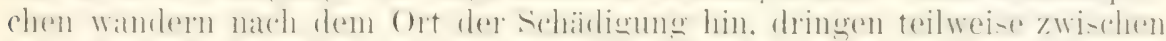

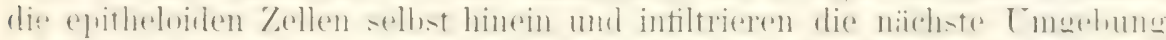

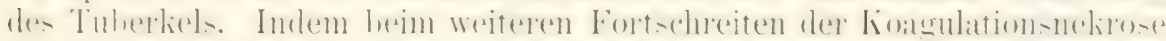
die zentralen Partien absterben, hommt es schließlich zur sogenannten Verkïsung des Tuberkels.

\section{Literatur zu Kapitel XV.}

1) Abderlualden, Emil, Der Artenbegriff und dif Artenkonstana auf biologisch-chemi-

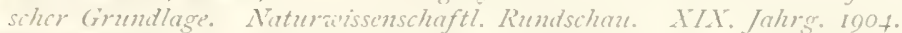

2) Beresowsky, Lber die histolugischen lorgänge bei der Transplantation zon IIantstücken anf Tiere ciner andercu Spezics. Zieglers biciträge zur patholog. Anat. und sul allecmeinenz Pathologie. Jena 1803.

3) Bert, $\mathbf{P}$., Recherches expérinemtales pour servir à l'histoire de la vitalite propre des tissus animanx. Annales des sciences naturelles, sir. 1 . Zoologie to I. I886.

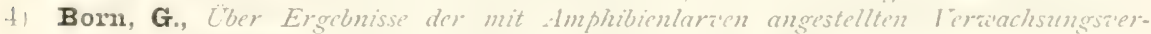
sache. Terhandl. at. anatomischen Giesellsch. in liusel 1805.

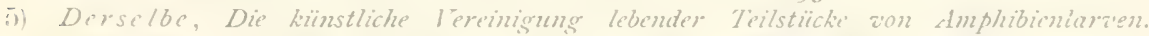

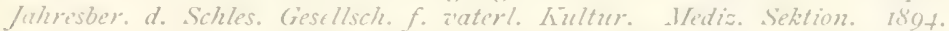

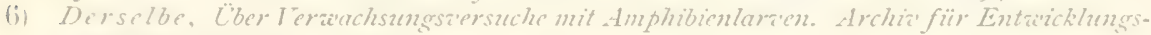
michanik, I3d. II. I897.

i) Brandt, Übr das Zusammenleben ion Tieren und Aloen. I crinandl. der phisiol. (iesellsch. an Berlin IS8I.

(i) De'selbe, Über die morphologische und physiologische bedentuner des Chlorophylls bei den Türen. Mitteil. aus der zoolog. Station an Neapel, Bd. II: IS83. (Dasellost auch ausfuhrlicher Literaturbericht.)

()) de Baxy, (ber die Erscheinung der Simbiose. Straßburg Is70.

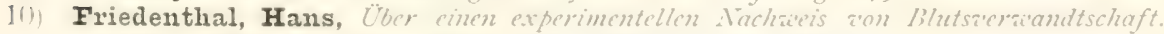
Arih. f. Anert. u. Phys. Phys. Hot. Jahre. 1000 u. I005.

11) v. Gärtner, lersuche und lienbachtungen ïber die liastarderzeugung inn Pflanzenreich. 1840 .

12) Geddes, $\mathbf{P}$., On the nature and functions of the yellow cells of the Rerdiolarians and Coclentirates. Proceedings of Royal Socicty of Edmbursh 1892.

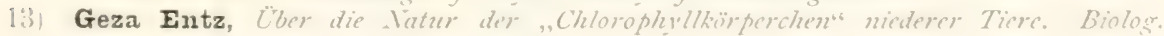
Zentralbl., lid. I w. I1. 1882. 1883.

14) Graff, Monographic der Turbellarien. Lerpzic Is\&2.

15) Hamburgex, Franz, Artcigenheit unt Assimilation. Leipsig 1003.

14i Hertwig Oskar, ". Richard Hertwig, / . cti. zentersucht. 1879. Die gelben Zellen im Käper der Aktimien. Site 39.

16) Hertwig, Oskar, Die Simbiose oder ders Genossenschafisleben im Tierreiche. IS\&3.

1S) Dersclbe, Zeit-und Sitreitfragen der Biolosie. Meft S. Präformation oder Epigenese. cont. Seite 62. Die Erscheinungen der aegetatreen iffinitiöt.

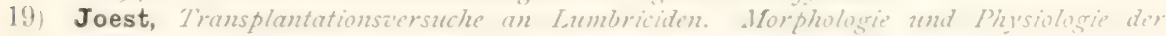
Tiansplantationen. Archio f. Entuicklungsmechunik, Bit. I: 1897.

2(1) Landois, Die Transfusion des Blutes. Leipzig 7875. 
21) Olliex, Léopold, Recherches expérimentales sur la production artificielle des os an moyen de la transplantation du perioste etc. Journal de la physiologie de l'homme et des animaux. 1. 11. 1859.

2.) Derselbe, Recherches expirimentales sur les greffes osseneses. Ebendu t. 111.1860.

$\therefore$ L. Michaelis $u$. C. Oppenheimer, Ube Immunität segen Eitucißlörper. Arih, f. Anatomie u. Physiologic (Phys. Abt.), Supplbat. Igoz.

2) Nuttall, blood immunity and blood relationshrp. London Igot.

.).i) Ponfik, Experimentello Beiträge zur Lehre z'on der Transfusion eti. Iirchon's Arch. Bi, L.YII.

S.) v. Recklingshausen, Die Wiedereraeugung (Kegenerution) and die Überpflanzuns ('Transplantution). Handbuch ator allgemeinen Pathologie des Lreislanfs aus: Dentsche Chimugie 1883.

2-) Sachs, Julius, Forlesungen z̈ber Pfanzenphysiologie. Seite $+72--476 . \quad 1882$.

(2) Schmitt, Adolf, Uber Osteoplerstik in klinischer und cxperimenteller Beatehumg. Arbeiten ans der chimer. Klinik der Iönigl. Unizersitiot lievlin.

(31) Schwendener, Untersuchungen ïber den Flechtenthallus etc. Vägelis Beiträge aur wissenschaftl. Botanik. 1860. 1862. 1868.

:il) Stahl, Beiträge aur Entaicklungsgeschichte der Flechton. Heft 2. Leipsig 1877.

3:-) Trembley, Mcmoires pour seruir ì l'histoire d'un genre de Polypes d'enu douce. I7tf.

:i.) Vöchting, $\mathbf{H}$., Über Transplantation am Pflanzenkörper. Untersuchungen aner Physiologie und Pathologie (ausführliches Literaturaeracichnis). Tïbingen 1892.

31) Wetzel, Georg, Transplintationszersuche mit Hydra. Archiv f- mikroskep. Anat., Bi. XLV. I895. 


\section{SECHZEHNTES KAPITEI.}

\section{Tittel und Wege des Verkehrs der Yallen im Opermismus.}

Als Teile eines Organismus stehen alle Zellen in Beziehung zu-

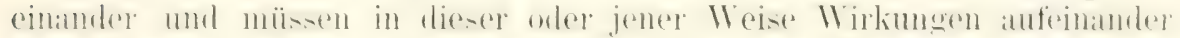

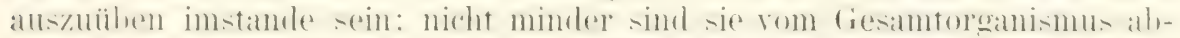

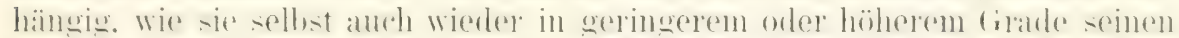
Gesamtzustand mit bedingen. In die Mittel und Wege, auf denen im Ge-

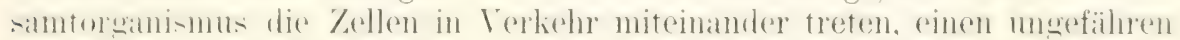
Einblick zu gewinnen, ist die Aufgabe des sechzehnten Kapitels.

Daf. zurzeit auf dem Gebiet unsere Kemntnisse noch recht oberHärhliche sind, sei gleich hervorgehohen. Tielleicht sibt die folgende Darstellung zu eingehenderen Untersuchungen eine Anregung. Es werden hier vier Wege unterschieden, auf denen die Zellen des Organismus in Verkehr miteinander treten:

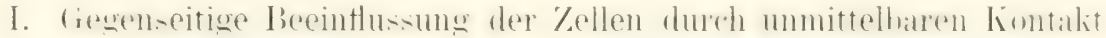
ihrer Oberflächen.

II. Verbindungen der einzelnen Zellen untereinander durch Protoplasmafäiden.

III. Verbindungen der Zellen dureh Nervenfibrillen.

IV. Verkehr der Zellen durch die im Organismus zirkulierenden Säfte.

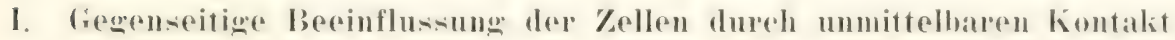 ihrer Oherflichen.}

Solange die Zellen nicht yon Membranen umgeben sind, wird eine

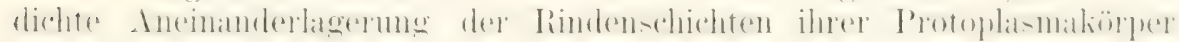
schon himreichen. daß sich Reize von dem einen auf den anderen ummittelbar fortpthanzen. Es ist daher denkbar, daf bei den Tieren am Anfang.

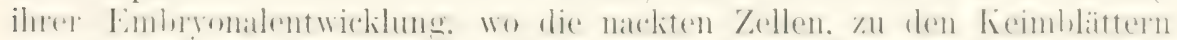

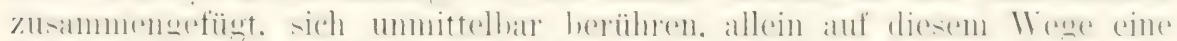

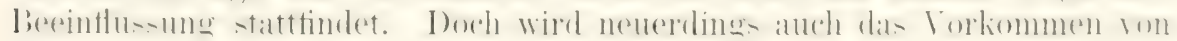
Protoplasmabriicken beschrieben (siehe S. 405).

Durch bloßen Kontakt der Zellen können vielleicht auch im ent-

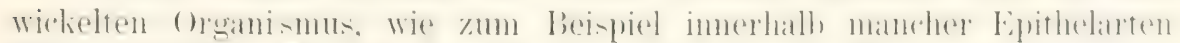

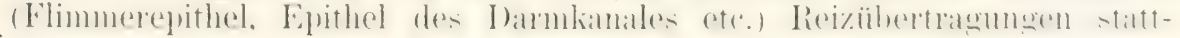
finden.

Es genïgt, auf diese Möglichkeiten aufmerksam gemacht zu haben. da genauere Kenntnisse hierüber zurzeit noch fehlen. 


\section{Verbindungen dep einzelnen Zellen dureh Protoplasmafïilen.} (Interzellularbriicken.)

\section{Histologische Befunde.}

Auf Grund verschiedener Beobachtungen haben einige Botaniker ind Tierphrsiologen die Hypothese aufestellt, dali wahroheinlich alle einzehnen Zellen eines vielzelligen Oreanismus durch feine Fälen untereinander in direktem Zusammenhang stehen. Sie sprechen sich schon vom physiologischen Standpunkt aus gegen das Wort Zellenstaat aus, mit welchem man so häutig den ptlanzlichen und tierischen hörjer bezeichnet findet. und erkiären ihn für einen einheitlichen, mächtigen Protoplamaliörer. in welchen von Strecke zu Strecke Kerne als Mittelpunkte des Stoff- und Kraftwechsels (Synergiden von Sachs) eingebettet mol Membranen und Zwischensubstanzen zu teilweiser Sonderung, zur Stütze und zu anderen Zwecken eingelagert sind. Nach J. SAcHs und Russow ist "flie

$\cdot 1$

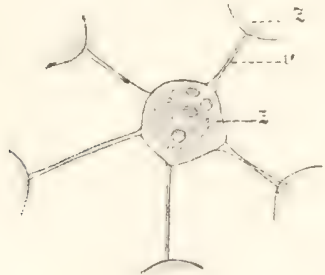

1)

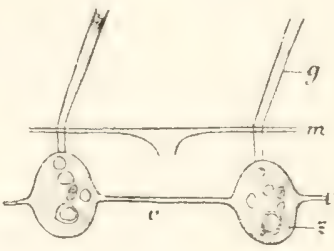

Fig. 292. A Lebende Zelle von Volvox aureus von oben gesehen, mit fünf Plasmaverbindungen. I; Zwei Zellen von Volvox aureus, welche ihre Geißeln durch die Hüllamelle hindurchsenden, im Längsschnitt; heidi \%(t) sind durch eine rom Schnitte getroffene Plasmaverbindung verknüpft. Nach ARTHUR MExER. z Volvoxzelle, v Verbindungsfaden. m Membran. g Geißel.

multizelluläre Ptlanze von der unizellulären nur dadurch verschierlen. dal.i in ersterer das Protoplasma von zahlreichen, sieb- oder gitterartig durchbrochenen Platten durchsetzt wird. während hei letzterer das Protoplasma ungekammert bleibt".

In der von SACHS gegebenen Fassung ist die Lehre von dem kontinuierlichen Znsammenhang aller Protoplasmateile eines vielzelligen Oroanismus ohne Frage nicht halthar: sie ist den Tatsachen nicht ent-prechent. Denn in sich abweschlosicne. isolierte Zellen giht es unfehlhar bei P'tanzen sowohl. wie bei Tieren. Bei ersteren sind die Schliebzellen der Atemspalten. hei letzteren die Lrmphlïrperchen, IBlutzellen, manche Knorpelzellen. querostreifte Musielurimitivhindel ete. zu nemen. Ton solchen Fiblen aldgecehen, sind allerdings Protoplasmaverhindungen zwischen henachbarten Zellen sehr håufig nachweisbar, und es ist wohl auch zu erwarten, dafo die Nachweise derartiger Verbindungen sich noch erheblich mehren werden, je mehr man anf den wichtigen Gegenstand achtet und eigene Methoden zu dem Zwecke ausbildet. Von den Beobachtungen, welche über die Verbreitung von Protoplasmaverbindungen zwischen ptlanzlichen und tierischen Zellen vorliegen, seien einige Beispiele hier zusammengestellt: 
1. In einer sehr typischen und regelmäBigen Verbindung nntereinander stehen die Zellen im Körper der versehiedenen Volvoxarten,

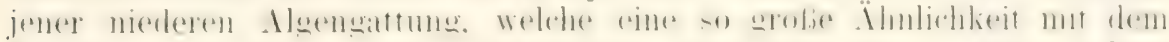
Leimblasenstadium in der Entwicklung der Tiere zeigt. Bei Volvox

Fiv. $2+4: 3$

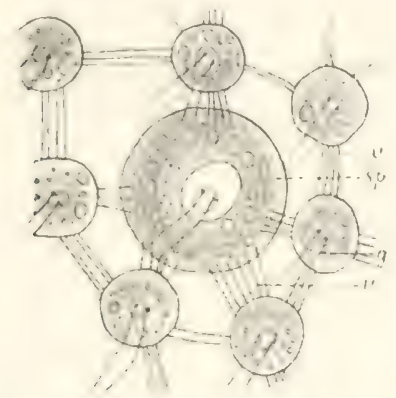

Fig, (2)1.

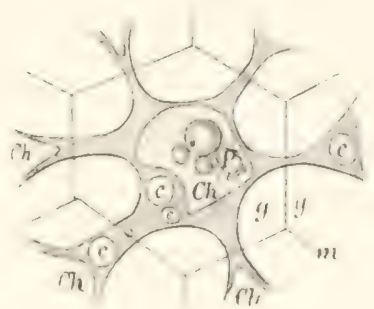

Fiu. . S1:. Spore aus einer jungen, noch nicht ausgeschlïpften Kugel von Volvox aureus, mit den Nachlrarzellen durch Plasmafäden verbunden. Nach ARTuUn MFYER.

Fie. ㄴ.14. Einzelnes Zellenindividuum der trophischen Hemisphäre von Volvox globator, von oben gesehen. Nach ArTuvr MEYer. c liontraktile Vakuolen, Ch Chromatophor. P l'yrenoid. m Die Hüllamelle. g Gallerte der Membran. sp Spore. $s$ Geiliel. v Verbindungsfaden.

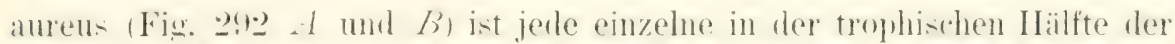
blasemolertläche gelegene Zelle in eine dicke. weiche fallerte cingehïllt.

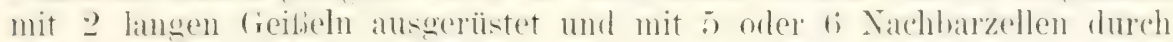
je einen langen. feinen Protoplasmafaten verbmalen. In der gencrativen

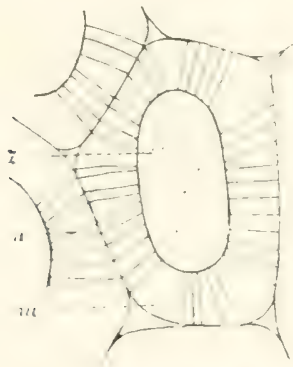

Fig. 295. Zelle aus dem Endosperm. von Chamaerops excelsa aus der Pexipherie des Endosperms. Nach 1 . MAYER. Die Kellen wurden erst mit Kialilauge, dann mit Schwefelsiure $(1+3$ Wasser) hieranf mit Jodjodkalium II und wieder mit Schwefelsiure $(1+3)$ und schießlich mit Methylviolett hehandelt. So wurden die hanäle dentlich gefirlot, in denen die Plasmaverbindungen verliefen. bitofach veroribliert.

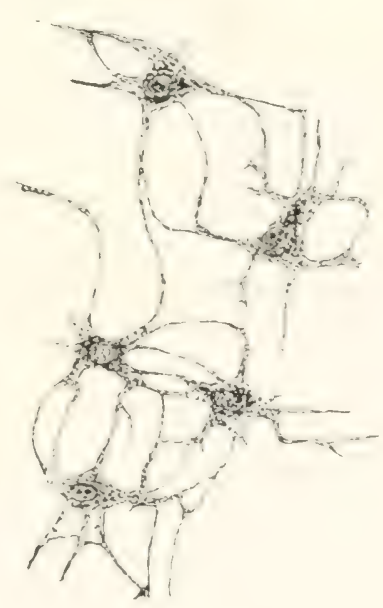

Fig. $29(i)$

Fii. 2!ni. Hormhautkörperchen, durch Protoplasmafäden zu einem Netz verbunden, aus einem Flächenschnitt einer vergoldeten Hornhaut vom Kalbsauge.

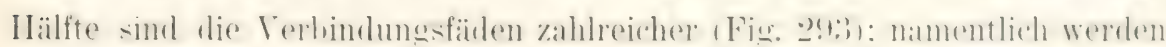
die hier entstehenden großen Sporen durch Bündel von 3 bis 6 Fäiden

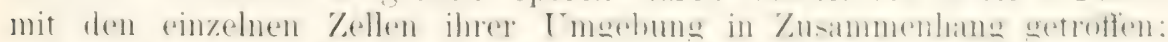


die Verbindungen bleiben sogar noch einige Zeit erhalten, wenn die Spore schon in 2, 4 und mehr 'Teilstïcke zerfallen ist. Bei Volvox globator ist das Verhältnis ein etwas anderes (Fig. 294). Die einzelnen Zellen senden einander 5 bis 7 dicke Arme entgegen, welche aber an den Stellen, wo sie sich treffen, vonemander durch eine feine Membran (m) getrennt werden, von welcher der Gallertmantel $(g)$ der einzelnen Zellen noch besonders umhüllt ist. Die Membran verhält sich ähnlich wie die Schliebhant zwischen den aneinander grenzenden T'üpteln zweier Pthanzenzellen. Sie wird von 2 bis :3 feinen Poren durchsetzt, durch welche sehr zarte Verhindungsädehen ron einem Protoplasmaarm zum andern hiniberziehen.

2. Seit der Entdeckung von 'TANGL (1879), dab im Endosperm der

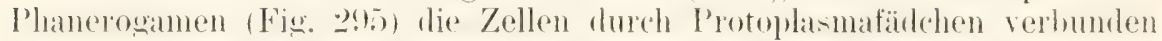
sind, ist die Aufmerksamkeit der Botaniker anf die Frage nach dem Zusammenhang der Zellen untereinander hingelenkt worden. Russow, GaRdener. Hicks. Hillhouse, Kienitz. Gerloff und andere haben an den vershiedensten pthanzlichen Objekten den Nachweis geführt. dab in der Zellulosemembran feinste Poren vorkommen, durch welche sehr schwer sichtbar zu machende Protoplasmafälchen hindurehtreten und den protoplasmatischen Inhalt einer Zelle mit dem ihres Nachbarn verbinden. Am leichtesten sind solche Verbindungen an den Siebröhren zu erkennen. langens, aufeinander folgenden Schläuchen. die durch quere sicheidewände. die Siebplatten, getrennt sind. Jede Platte ist wie ein Sieb von zahlreichen Poren durchsetzt, durch welche die Protoplasmakörper der aneinander grenzenden Schläuche kontimuierlich ineinander ïbergehen.

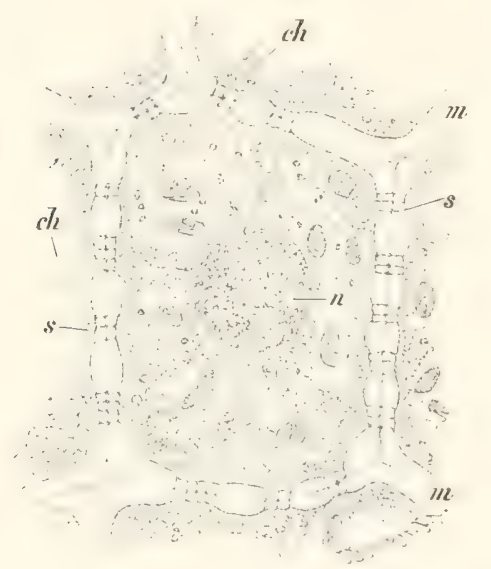

Fig. 297. Eine Zelle aus der Rinde der Mistel (Viscum alb.) mach entsprechender Härtung und Färbung der Protoplasten und (ouellung der Wände $(m)$. Die Schlielhäute (s) der T'ïpfel ron P'lasmodesmen

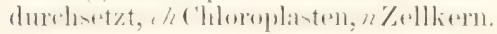
Verer. 1000. Aus STRAsBLRgER. vig. velmehr nur diejenigen. die bei Ausführung des schnittes in keiner Weise gelitten hatten, und die rasch durch die Schwefelsäure fixiert wurden. Die lädierten, respektive die nicht rasch genug fixierten Zellen haben ihre Fortsätze eingezogen“. 
Ein besonders geeignetes Objelit zum Studium der Plasmaverbindungen bei Pflanzen scheint die Mistel zu sein (Fig. 297). liei ihr hat sich fest-

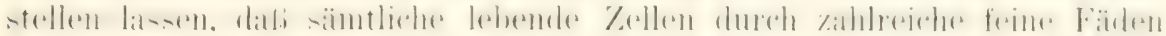
miteinander vereinigt sind und dab dabei lieine fiewebsart ein System fïr sich bildet. bei langgestreckten Zellen finden sich die meisten

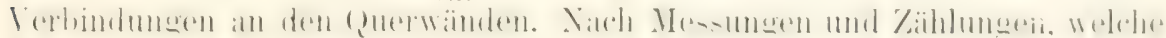
KuHLA vorgenommen hat, besitzt eine Markstrahlzelle, die 4000「】u

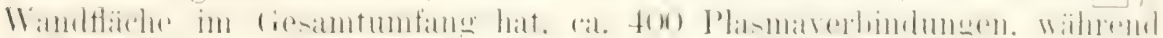

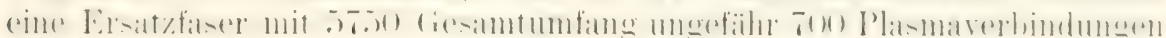
nach allen Seiten aussendet.

:3. Im tierischen Körper sind lerbindungen der Zellen untereinander schon seit langer Zeit bekannt. Am leichtesten sind sie in manchen Formen der Bindesubstanz nachzuweisen. Die sternförmigen Zellen im Gallertgew ebe sind durch zahlreiche, fein verzweigte Ausläufer in einer noch reichlicheren Weise untereinander in Zusammenhang gesetzt als die Zellen einer Y'olvoxkugel. Ton faserigen Bindesubstanzen liefert uns die Hornliat (Fig. 296) ein sehr beweisendes Präparat, wie die in den Saftlïcken eingeschlossenen Hornhautkörperchen sich durch sehr zahlreiche Protoplasmafälchen zu einer Art Netzwerk verbinden. Im Zahnbein hängen die Eltenbeinzellen durch ihre auf's feinste verzweigten Zahnbeinfasern, im Knochen die Knochenkörperchen durch ihre Allsianfer zusummen. wïheml im Kinorper die Eilemente allerrlings für gewöhnlich für sich isoliert zu sein scheinen. wemn

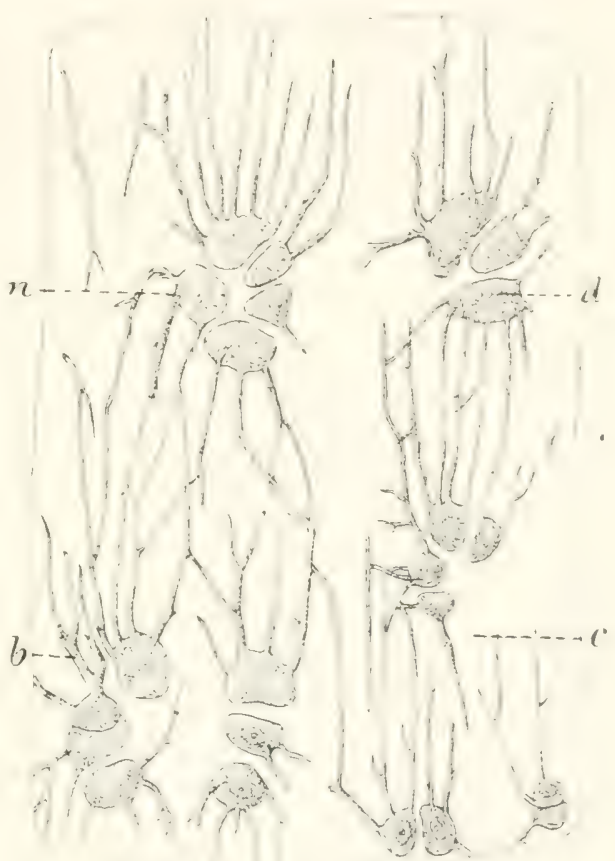

|i... 2!! K. Kopfknorpol vom Calmar, in Pikrinsäure und Glyzerin untersuclit. Niı/ Risirier. c firundsulstanz. d Zellkörper. b Anastomosierende Ramifikationen der Zellen. man vom Knorpel der Schädelkapsel der Cephalopoden (Fig. 298) und einigen anderen Ausnahmen absieht.

Gröbere Schwierigkeiten bereitet der Nachweis der Zellverbindungen bei rlen Epithelien. Doch hat anch hier die Lehre von den Zellbrücken allmählich einen festeren borlen refaßt, seitrem Bizzozero und andere machgewiesen haben. dab die von MAX ScuuLTzE zuerst beschriebenen Stacheln und Riffe der Zellen des Rete Malpighi nicht wie die Zühne

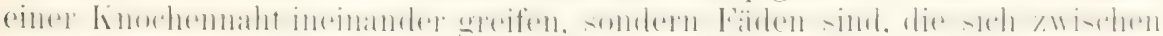

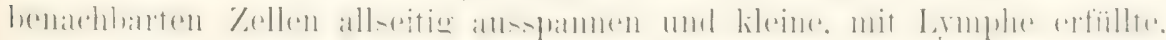
interzelluläre Spalten ïberbrïclien. Man liann daher jetzt die unter dem Stratum corneum der Oberhaut gelegene weiche Schicht als ein einziges. der Lederhaut aufgelagertes Netzwerk ron Zellen betrachten. welches den Köner überzicht. Das Netzwerk (Fig. 299) setzt sich aus kleinen, teils

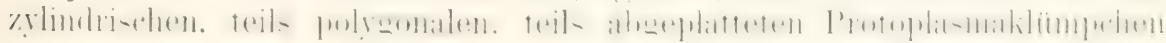


mit ihren Kernen zusammen, welche auf der einen Seite durch feine. dem

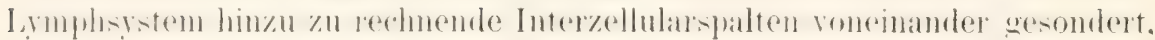
auf der andern Seite aber auch wieder durch zahlyeiche feine, durch die

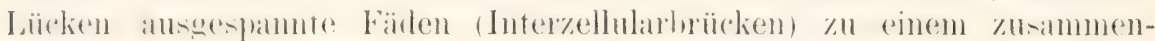
gesetzten System verbunden werlen.

Von verschiedenen Forschern (Neyt, Kolossow. Cohn, Garten, Carlere ist (ler Versuch gemacht worden, einen Zusammenhang der Zellen auch für andere Formen des Epithels mittelst besonderer Präpa-

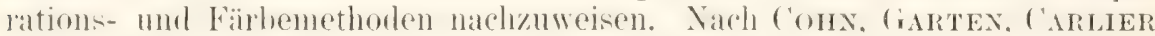
sollen sich die Zylinderzellen des Magens und Darmkanals an ihren seitenwänten durch zahlreiche quere Fädchen rerbinden. Koussow beschreiht Interzelluhmö̈cken von den emfachen I'lattenepithelien der serösen Hänte, NExT von der einfachen Zellschicht der DESCE IETschen Membran.

Zellenverbindungen werden drittens auch in der Gruppe der Muskelgewebe angetroffen. Schon zur Zeit ScHwann's hat man das einzelne Muskelprimitivbündel eine Zellfusion genant. Es ist, wie wir jetzt besser sagen, ein Syncytium, zusammengesetzt aus vielen Hunderten

Fig. 299 .

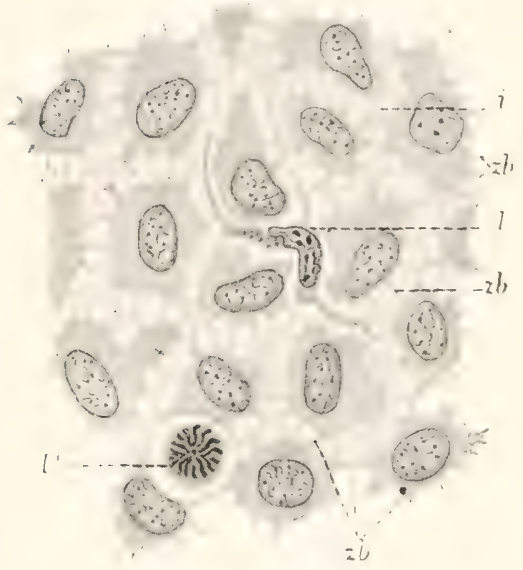

Fig. 300 .

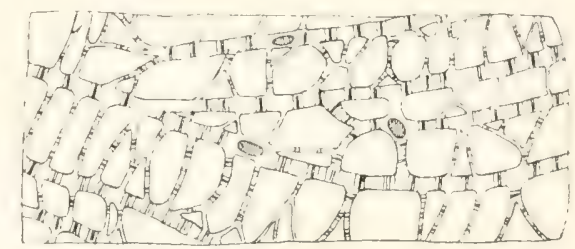

Fig. 299. Untere Zellenschicht vom Kiemenblattepithel einer Salamanderlarve bei Flächenbetrachtung: Nach Fuemanxis. Die Interzellularliicken (i, hell) sehr weit, die Zellenkörper anf zackige Formen kontrahiert. In der Mitte eine Wanderzelle in den Lücken mit lang ausgestreckten Fortsiatzen; ferner eine solche, zur Kungelform kontrahiert, in Mitose. $z \sigma$ Zellenlurücken.

Fị. (;). Muskulatur eines Darmarüsenschlauchs von Porcellio scaber. Nach WEBER.

yon Zellen. Welche als -rogenamute Muskelkïrverchen ïherall in der kontraktilen Substanz verteilt und wahrscheinlich untereinander durch feine l'rotoplasmafidlelen rereint siml. Eigenartige netzö̈mige Verbindumgen quergestreifter, sich verästelnder Muskelzellen (Fig. 300) finden sich in der Darmwand der Insekten und im Herz der Wirbeltiere.

In unserer Aufzählung sind viertens auch die Eizellen nicht zu vergessen (Fig. 301). Nach den Untersuchungen von PaLAdixo und RETzıus hängen sie während ihrer Entwicklung im Eierstock, ähnlich wie die Sporen emer Volvoxkugel mit den benachbarten Zellen, so hier mit den Follikelzellen zusammen, Letztere verlängern sich in zarte Protoplasmafortsätze, welche in die Porenkanälchen der Zona pellucida eindringen und in den Dotter des Eies übergehen.

Die bisher heschriebenen Zusammenhänge finden zwischen den zusammengehörigen Elementen einer Gewebsgruppe entwerler des Binde- 


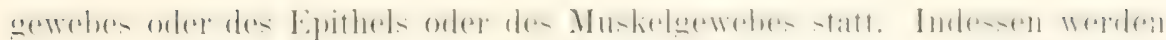
von einigen Forschern, wie von LEYDIG und namentlich in jüngster Zeit von SchuberG, Befunde mitgeteilt, nach welchen an diesen und jenen Körperstellen verschiedener Tiere auch direkte protoplasmatische Ver-

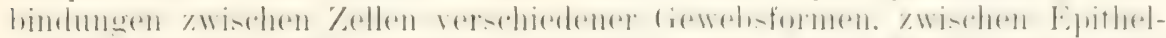

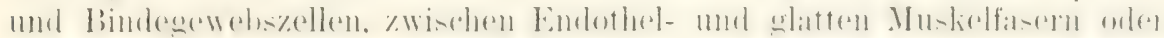
diesen und Bindegewelszellen vorkommen sollen. In seinen nenesten ..Untersuchungen über Zellenverbindungen'betrachtetSCHUBERG $(1,9(): 3)$ es als erwiesen, daf in der Haut vom Axolotl Zellen der Epidermis und bindegewebszellen der Lederhant durch einzelne feine Protoplasmafädchen untereinander znsammenhängen.

Zum Schluß der Zusammenstellung sei noch erwähnt, daf neuerdings HAMmaR auch den Silchweris zu fiuluren surht. Mal. zwischen den Furchungszellen der Eier yon Echinus miliaris an den

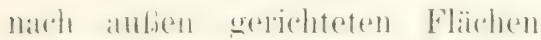
primäre Zusammenhänge bestehen.

Inwieweit in einem T'eil der

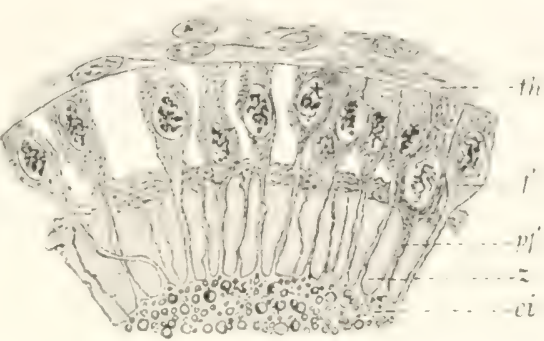

Fir. 301. Stück eines Durchschnitts durch einen Eifollikel vom Kanincheneierstock. Nach Perzits. ci Stïck del Eirinde mit Protoplasmafiden ( $p f$ ), welche,

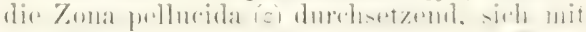

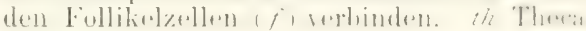
folliculi. hier referierten Angaben der Sach-

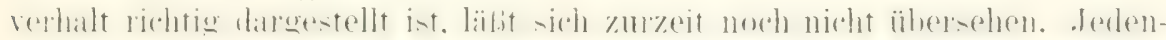
falls sind für manche Verhältnisse noch genauere 1)arstellungen und Bestätigungen ron anderel Seite abzuwarten. Denn die Frage des Zn-

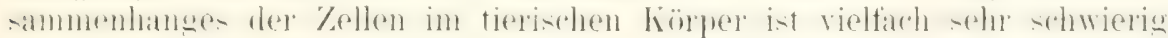
zul entscheiden; sie ist indessen eine so wichtige. dals nur gewünscht werden kann. es möchten sich die besonders auf sie gerichteten Detail-

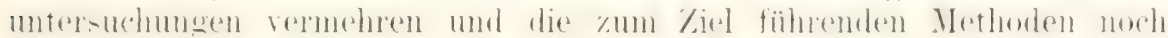
vervollkommmet werlen.

\section{Die physiologische Bedeutung.}

Reizleitung und Stofftransport durch Protoplasmaverbindungen.

Die physiologische Bedeutung der Plasmaverbindungen zwischen den Zellen kann eine doppelte sein. Eimmal haben wir in ihnen Bahnen zu erblicken. auf denen lieize von einer Zelle a uf die andere übertragen werden. Zweitens können sie auch zum Transport von Stoften dienen.

Im Vergleich zur Nervenleitung wird wahrscheinlich die Übertragung durch P'rotoplasmafäden eine viel weniger rasche und intensive, aber dafür vielleicht eine mehr kontinuierliche mol durch ihre Daner eine wirlsamere sein. Wenn man die Leistungen eines l'elephons berïcksichtigt, und überlegt. wie durch einen einfachen Metalldraht auf grobe Entfernungen hin Sätze und komplizierte Melodien mitgeteilt werden können, damn wird man auch die Möglichkeit nicht in Abrede stellen liönnen. dabs durch einen feinen Falen des viel höher organisierten Protoplasmas liomplizierte Zustände eines Plasmakörpers sich anderen mitteilen liömen.

Mit Hiilfe des Versuchs wird es möglich sein, hie und da in das Wesen der Reizübertragung durch Protoplasmabricken tiefere Einblicke 
zu gewinnen, wie durch das folgende, von PFEFFER ausgeführte Experiment. Schon im ersten Hauptteil (Seite 255) wurde mitgeteilt, dab das Protoplasma einer P'tlanzenzelle nur unter dem Einflul des Kerns be-

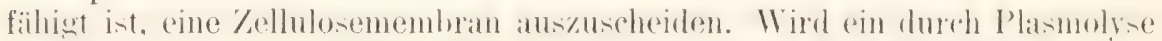

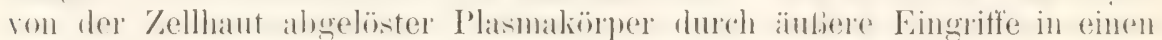
kernhaltigen und einen kernfreien 'Teil zerlegt, so umgibt sich nur der erstere hei vollstandiger 'Tremmung mit einer neuen Membran. I) a gegen scheidet auch der kernfreie 'Teil Zellulose ab. wenn er auch nur durch einen allerfeinsten Protoplasmafaden mit dem kernhaltigen Stück zusammenhängt.

Es läbt sich der Versuch noch in anderer Weise modifizieren. P'FEFEer hat Zellen eines Moosprotonema ete. derart pränariert, dali eine völlig isolierte. kernfreie Protoplasmamasse der einen Zelle durch feine, die Zellwand durchsetzende Färlen mit dem liernführenden Inhait der Nachbarzelle in Verbindung hieb. In diesem Falle bildete sich um das kernfrein Stück eine Membran aus. Sie trat aber nicht auf, wenn in der Nachbarzelle die trennende Querwand ebenfalls nur mit isoliertem, kernfreiem Protoplasma in Verbindung stand. Damit ist erwiesen, daß der zur Hauthildung erforderliche Reiz auch durch die feinen, die Scheidewand zweier Zellen durchdringenden Verbindumg-ärlen äbermittelt werilen kann.

Es steht nichts im Wege, Ähnliches auch für die Übermittelung anderer funktioneller Zustände anzunehmen. Aufgabe hierauf gerichteter beobachtungen und Experimente wird es sein, das zurzeit noch sehr spårliche Tatsachenmaterial zu vervollständigen.

AuBer der Reizleitung haben die Protoplasmaverbindungen zwischen benachbarten Zellen in vielen Fillen der Stoffwanlerung zu dienen. Bei den PHanzen können wahrscheinlioh durch sie kleinste Stärkekïrnchen und Fettröpfchen etc. direkt von Zelle zu Zelle transportiert werden. wie Klebs, Russow. Pfurtscheller und andere Botaniker annehmen. Auch das Protoplasma selbst könnte auf diesem Wege von einer in die andere Zelle ïberwandern. Hieraus wïrde sich erklären. daß im Herbst bein Absterben der Blïtter die Zellen mit Ausnahme der Schliebzellen ihren Inhalt verlieren (Kinexitz, Meyer). BArfurtu gibt an. den Transport feiner Körnchen aus einer Zelle in die andere auf der Bahn protoplasmatischer Verbindungsfäden direkt an den lehenden Zellen des Zwiehelhäutchens beobachtet zu haben.

In der tierischen Literatur finden sich nur einzelne zerstreute Bemerkungen über das vorliegende Thema. PLATo hat den Nachweis zu führen gesucht, dal.; die interstitiellen Zellen des Hodens vom Kater uml ron anderen süugetieren Fett in sich auf-peichern und es zu gewiser Zeit durch Röhrchen in der 'Tunica propria der Samenkanälchen an die Fußplatten der Sertolischen Zellen abgeben, von welchen es dann weiter als Nährmaterial den Samenzellen ühermittelt wird. Die Zellhrïcken, welche

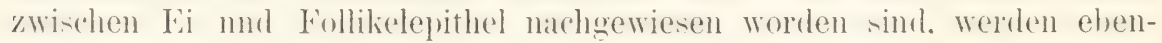
falls von vielen Forschern für Ernährungswege gehalten.

\section{Verbindungen der Zellen durch Yervenfibrillen.}

Bei den Tieren ist auber der Protoplasmaverbindung und wahrscheinlich auf Grundlage derselben noch eine zweite höhere Form des Zusammenhangs zwishen den Elementarteilen in der Nervenverbindung entstanden. Inuch sie wirl eine direkte. ummittellare Beziehung zwischen 


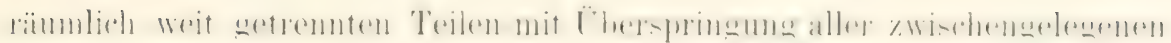
(iewebe hergestellt. Erregungszustänle eimes Körperteils können so auf grobe Distanzen in kürzester Zeit auf einen anderen weit entfernten Teil

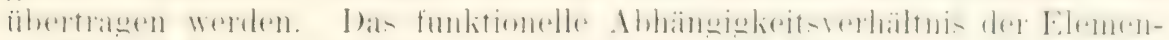

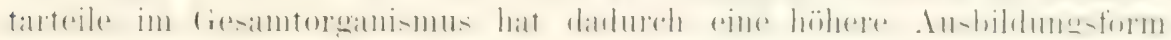
angenommen. Wie grol, dasselbe ist, läbt sich schon daraus ersehen.

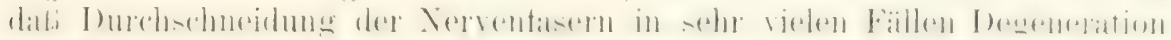

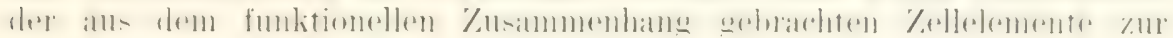
Folge' hat.

\section{Verkehr der Zellen dureh die im Oranismus rirkulierenden sifte.}

Ein stofflicher Verkehr und eine dardurch berlingte, wechselseitige Abhängigkeit der Elementarteile vonemander wird durch die Saftströme

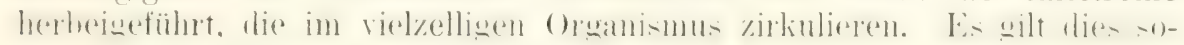
wohl für die Pthanzen. wie fïr die Tiere.

Bei den Pflanzen bewegen sich in Wasser gelöste Stoffe, die von den Wurzeln aus dem Boden aufgesaugt werden, nach den oberirdischen Teilen, um dort bei der Blatt- und Blütenbildung verbraucht zu werden. Und umgekehrt werten von den oberirdischen Teilen durch den Assimi-

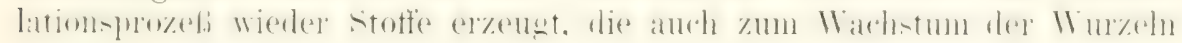
dienen, welche ja selbst nicht imstande sind, aus den dem Boden entzogenen Stoffen organische Substanz zu erzengen. So mub im Pflanzen-

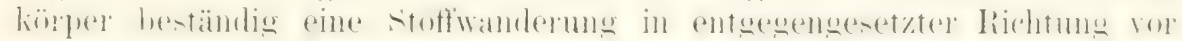
sich gehen. Infolgedessen müssen oberirdische und unterirdische Teile

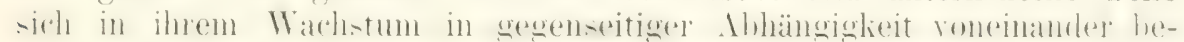
finden. Blätter und Blüten können nur in dem Maße erzeugt werden, als das Wurzelwerk imstande ist, die dazu nötigen Stofte, Wasser und Salze, zu liefern, und umgekehrt.

Viel komplizierter liegen die Beziehungen in tierischen Organismus. Verdaunngssäfte werden in den Darmkanal ergossen, wo sie die aufgenommenen Speisen chemisch rerändern und resorbierbar machen; die so

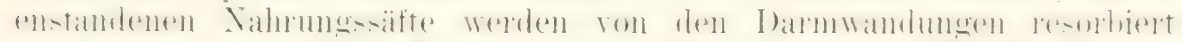
mond in den Lymph- und Blutstrom iubergeführt. Lymphe und Blut zirkulieren in allen 'Teilen des Körpers, Stoffe aus den Geweben aufnehnem und wieder an sie abgebend. Ihre Zusammensetzung mub sich daher beständig ändern, da die einzelnen Organe: Speicheldrüsen, Leber. Niere. Geschlechtshlïsen, Muskeln. Gehim. Knochen, einen sehr verschiedenartigen Stoffwechsel gemäh ihrer verschiedenen Vatur haben und hier diese, dort jene Stoffe aufnehmen und abgeben. Die normale Blutbeschaffenheit hängt daher von sehr zahlreichen Organen ab. Störung eines Teiles, wie zum lieispiel der Leber, des Pankreas, der Niere etc. ruft eine andere Blutmischung hervor und beeinflubt dadurch wieder den Stoffwechsel in den verschiedensten anderen Orwanen.

Durch Einbringung von Armeimitteln in den Körper. entweler in den Darmkanal oder direkt in das Blut orler in den Lymphstrom, kamn man anf dieses odler jenes Organ, auf dieses oder jenes (iewele, je nachdem es besondere Affinitäten zu den eingeführten chemischen Stofien besitzt, unmittelbar eine Wirkung ausüben. Narkotika rufen Erscheinungen am Nervensystem hervor, Pilokarpin an den verschiedensten Drüsen,

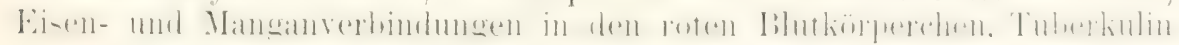
in den Geweben, wo sich Tuberkelbazillen angesiedelt haben. 
Eine noch ungleich gröhere Bedeutung für die Wechselbezichungen der Elementarteile zueinander läßt DARWr die Säfte in seiner Theorio der Pangenesis spielen. Um die Erscheinungen der Vererbung zu erklären, läbt er von den Zellen sich kleinste organisierte Teilchen die

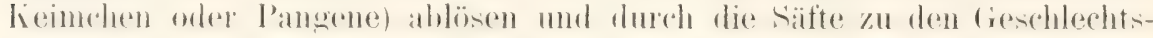
driisen gefïhnt und in ihmen anfgerpeichert werden. Der Kemohentransport ist indessen eine höchst unwahrscheinliche Hypothese, zu deren Gunsten sich nichts Tatsübhliches vorbringen läbt. Eine alloemene P'hrsologie hat daher mit ihr nicht zu rechnen. Näheres darüber findet sich in den letzten Kapiteln, welche üloer die Geschichte einzelner Vererbungstheorien handeln.

\title{
Literatur zu Kapitel XVI.
}

\author{
I'fla $\mathrm{nzen}$
}

1) Coulter, Continuity of protoplasm. Bot. Gaz. NIV. 1880.

2) Gardiner, On the continuity of the protoplasm through the aedls of aregetable cells. Arbeiten des botan. Instit. in 11 üraburg, Bd. III. 1884-

3) Derselbe, The continuity of the protoplasm in plant tissue. Nature, 13d. XXX1. 1885.

4) Hick, Protoplasmic continuty in the fucaccen, Jonrn. of Bot., Bd. XXIII.

5) Hilhouse, Einige Beobachtnongen ïber den interzelhularen Znisammenhang zon Protoplasten. Bot. Zentralblatt, Bid. 1883 Seite 80

(i) Kienitz Gerloff, Die Protoplasmaverbindungen awischen benachbarten Gcredebelementen in der Pflanse. Bot. Zeitung $189 \mathrm{~g}$.

7) Klebs, Über die neuen forschungen betreffs der Protoplasmazerbindungen benachbarter Zellen. Bot. Zeitung $188+\mathrm{V}$. 20 Seite 443.

S) Klein, Morphologische und biologische Studien über die Gattung Volvox. Jahrb. für wiss. Botanik, Ba. XX. 1880.

9) Kuhla, Fr., Die Plasmanerbindungen bei Tiscum album. Liot. Zeitung. Jahro. 58 . 1000 .

10) Meyer, Arthur, Die Plasmarerbindmeen und die Membranen won Tolvox slobator anerens und tertius mit Rücksicht anf die tierischen Zellen. Bot. Zeitnng, ISg6.

11) Derselbe, Methoden zum Aachateis ron Plasmarerbindungen. Ber. d. Deutsch. Bot. Gesellsch. 1807. Seite 160.

12) Moore, Studies in zegetable biolosy. Observations on the continuty of protoplasm. Joum. of the Linman Soc. XXY, pag. 505-62I. 1885.

13) Overton, Beitrag sur Kenntnis der Gattung Folvox. Bot. Zentralbl. 1889.

14) Pfeffer, W., Uber den Einfluß des \%illkerns anf die Bildung der Zellhaut. Berichte der mathem.-phisiol. Iilusse der Königl. Sä̈hs. Gesellsch. der II issensch. an Leipzig. 1800.

15) Strasburger, E., Uber Plasmaverbindungen thanzlicher Zellen. Jahrb. f. wiss. Bot., Bd. XXYTl, InOI

16) Tangl, Zur Lelure z'on der Fontinuität des Protoplismas im Pflansenreich. Sitz.-Ber. d. math.-phy's. Klasse d. Wiener Akad., Bad. IC', Abt. I.

1i) Wortmann, Über die Beziehungen der Reizberegungen wachsender Organe zu den normalen Trachstumserscheinungen. Bot. Zeitung 1880.

Tirr.

1) Barfurth, Uber Zellbrïcken olatter Mhuskclfasern. Archiz für mikroskop. Anatomie. Bd. IXXTTII. I8OT.

2) Derselbe, Zellïcken und Zellbrïcken in Uterusepithel nach der Geburt. Ferhandl. d. anat. Gesellsch. Berlin 1800 , Seite 23.

3) Bizzozero, Über den Bone geschichteter Pforsterepithelien. Moleschotts Untersuchungen, lit. $\mathrm{N} \%$. $1 \mathrm{~N}-2$.

4) Bohemann, Interzellularbrïcken und Saftrinune der glatten Muskulatur. Anatom. Anzeiger, Bd. A. I807.

5) Bonnet, Shhußleisten z'on Epithelien. Deutsche mediz. Wochenschrift 1805 .

(i) Carlier, On interceltular bridges in colnmnar epithelizm. La cellute t. II, Fasc. 2. 1806. 
7) Flemming, Zellsubstanz, hirn- und Zelltiluns. Letipsis isi\$2.

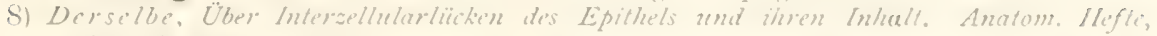
Bat. IT lleft I. ISO 5 .

9) Garten, S., Die Interselhularbricken der Epithelien und itre Funktion. Archiz fuir Anat. u. Phisiol., physiol. Abt.. Iteft 5 it. 0 , Serite for. ISO5.

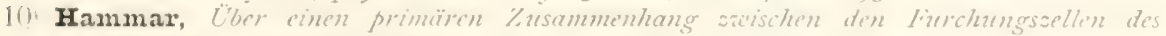

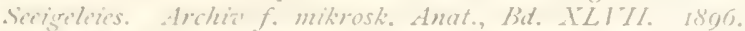

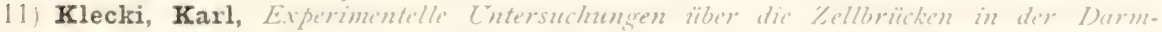
muskulatur der habbtiere. Dissert. Dorpat 7801 . (Ausfihr/iche Literaturangaben.)

12) Kolossow, Über die Struktur des Pleuroperitoneat- und Gefïßepithels. Archiz fü. mikrosk. Anat., lid. NLII. 1893.

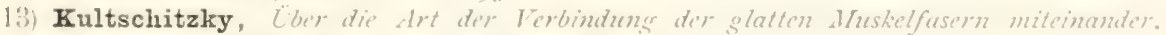
Biolog. Zentralbl., Kid. ITI, Seite' 572 IS88.

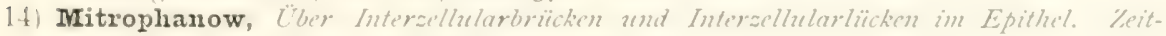
schrift fo wiss. Zool. Bd. MTIZT seite 302.

$15)$ Nicolas, A., Internat. Honatsschr. f. Anat. u. Phrsiol., Bit. I'III.

16) Nizel et Cornil, De l'undothelium de la chambre anterricure de l'anl, particulièrenent de celui der la cornée. Archize's de biologie to $\mathrm{X}$.

17) Paladino, I ponti intercellulari tra l' uoze oz'nrice e le cellule follicolerit. Anetom. Anveiger, Bid. 1; , Seite 25t. 1890.

1Si Plato, Julius, Die interstitiellen Zellen des Hodens und ihre physiologische bidentung. Archia f. mikenst. Anat., Jid. HLVIII. 1806.

19) Ranvier, De l'endothélium du péritome et des modifuations qu'il subit duns l'm-

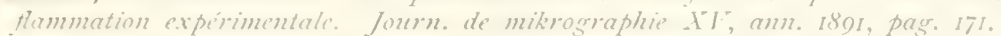

3(1) Retzius. Die Tnterzellularbräken des Eierstockeies und der Follikelsellen. Ferhandl. der matom. Gesellsch. ISSOO.

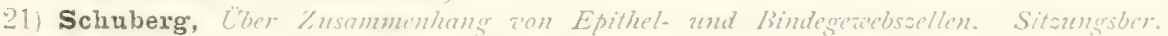
1. II "ïnburger phusiol-mediz. Gesellsch. Isqr.

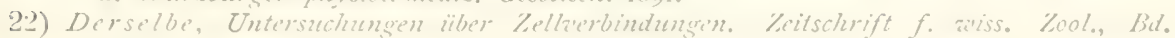
L.I.III 1003. 


\section{SIEBZEHN'TES KAPITEL.}

\section{İber die Ursachen, durch welche Zellenaggregate in diewebe und Organe gesondert werden.}

Nachdem wir in den vorausgegangenen Kapiteln gesehen haben, daß Pflanzen und Tiere gleichsim staaten von vielen zn einer höheren Inclividualität vereinten, artgleichen Zellen sind, gehen wir näher auf die Frage ein: Welche Ersachen hewirken, dab die ans dem Fi durch Teilumm entstandenen. zuer'st gleichartigen Zellen sich sichritt für šchritt. wie nach einem festgesetzten Plan, in die rerschiedenen firwebe und orame wihrend der Embryonalentwicklung umwandeln?

Hiermit werfen wir eine der schwierigsten Fragen auf, welche das immerste Tesen des Entwicklungsurozeses hetreffen und schon vor tahrhunderten die Naturforscher in zwei sich befehdende Lager, in die Anhänger der Präformation und der Epigenese. gespalten haben. Anch in meren Tagen sind üher diesen Geonstand vielfache mol lehhafte Erörtermuen angestellt worlen und hahen zu ähnlichen. allerings durch die Fortichritte der Wissenschaft morlifizierten (iegensiitzen geführt. Wieler stehen Theorien. die sich mehr in der (iedanlienrichtung der älteren Fvolutionstheorie hewegen mol daher auch als Neoevolutionismus bezelohnet werlen kömnen. solchen gegenüher. welche mehr eprgenetische frumblumzipien enthalten und sie in einer der Neuzeit angepaßten Form durchzuführen suchen. Als Vertreter der ersteren Richtung sind besonders WeIsuaxi und liogx zu nemmen. Theorien der letzteren drt dagegen sind von Spexcer, Nägel, von mir, von DrIEsch und anderen entwickelt worden.

Meine Anschaumgen habe ich in der ersten Autlage rles rorliegenden Buches zusammengefakt und als

\section{die Theorie der Biogenesis}

bezeichnet. - Nach der Biogenesistheorie, welche den Inhalt der nächstfolgenden Kapitel bildet, treten die durch ihre Abstammung artgleichen

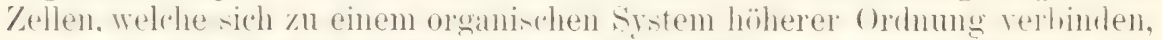

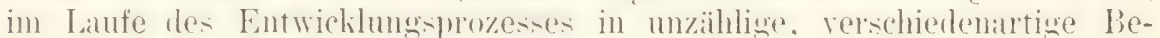
ziehumgen ein. durch welehe sie zu hesomleren Aufgalen determiniert mul infolgedessen in die einzelnen Gewebe und Organe differenziert werden. Da, wie im ersten 'Teil schon ausführlicher nachgewiesen wurde, und wie von einem anderen Standpunkt aus noch im Kapitel XXVI ete. gezeigt werden wird, der Zellenorganismus eine im allerhöchsten Grade reizbare

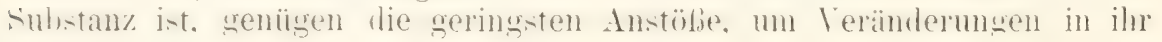
hervorzurufen. 
Die Beziehungen, in welche in Laufe der Entwicklung die Zellen eintreten. lassen sich in zwei Gruppen sondern. Die eine (rmpue biliten die verschiedenerlei Beziehungen zur Aubenwelt mit ilren zahlreichen Krïften. Wir wollen sie mit Herbert SPENCER kurzweg als die äulieren Faktoren des organischen Entwicklungsprozesses benennen. Die weite nicht mincler wichtige, ja für den tierischen Organismus noch riel

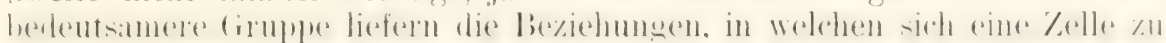
allen ïbrigen Zellen rles Aggregates befindet. Letztere sind für die ein-

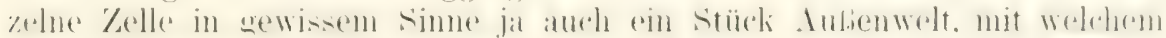

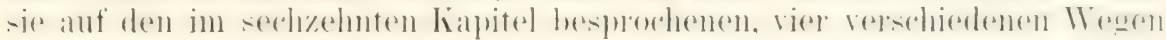
in ununterbrochenem Verkehr steht. Tom Standpunkt der Zelle aus läht sich die Aubenwelt gewissemaben in zwei Kreise zerlegen, in einen immeren Kreis, welcher ihren Verkehr mit den übrigen Zellen des über-

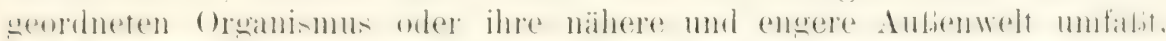

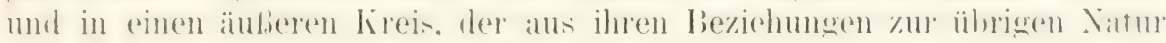
orler zu ihrer entfernteren Außenwelt besteht.

Wenn wir unseren Standpunkt dagegen wechsehn und vom Orga-

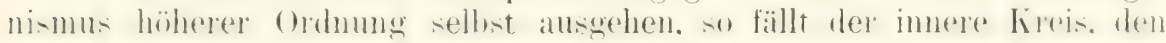
wir eben für die Zelle als ihre nähere Außenwelt unterschieden haben. in den Organismus selbst, gewissermaßen mit in seine Innenwelt hinein. Was füu die Zelle äufere Ursachen. sind für den iubergeordneten Orga-

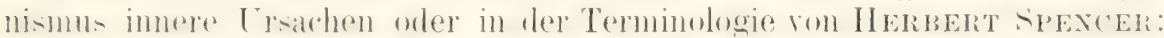
innere Falitoren des organischen Entwicklungsprozesses.

Es ist klar, daß bei den immeren Faktoren damn wierter zwei wichtige

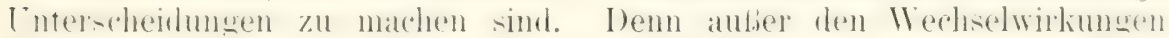
der 'Zellen aufeinander sind als innere Faktoren anch noch die Eigen- rhatten oder die Anlagen der Zellen selhst zu nennen, jene Eigensohatten.

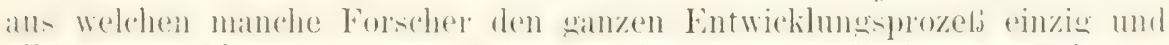
allein zu erklären versucht haben. Ich nenme sie die inneren Faktoren im engeren Sinne; sie sind die einzigen sogar, wenn wir uns wieder auf den Standpunkt der Zelle stellen, oder wemn wir unsere Untersuchung mit dem ungeteilten Ei oler dem Anfang der Enwirlinng hesinnen. wo die Beziehungen der Zellen zu einander, oder unsere zweite Kategorie innerer Ursachen im weiteren Simne, ja von selbst wegfallen.

Im folgenden wollen wir an diesen drei Unterscheidungen festhalten

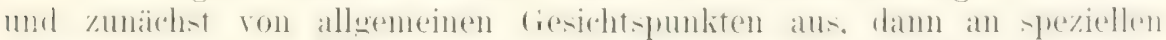
Fällen, gestïtzt auf Tatsachen mnd Experimente, untersuchen, wie dic

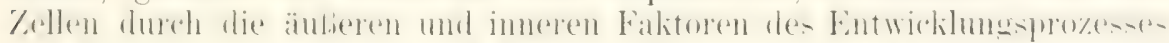

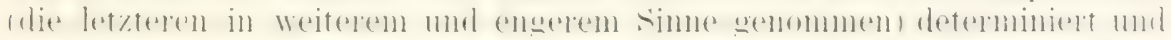

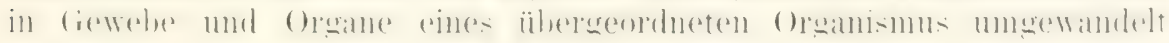
werlen.

I. Erstes Gesetz. Die Wichtigkeit konstanter Verhältnisse für die Ausbildung besonderer Funktionen und Strukturen an den Zellen. (Spezifische Energie.)

Bei dem Verkehr der Zelle mit ihrer entfernteren und näheren Andienwelt sind zwei Unterscheidungen zu machen; entweder befindet sic sich in beständig wechsehnden, verschiedenartigen oder in honstanten.

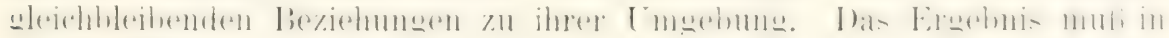
beirlen Fällen ein verschiedenes sein. Im ersteren Falle erhält die Zelle nach keiner Richtung eine besonders differenzierte Or.manisation, da sie. um unter den wechselnden Bedingungen zu bestehen, balk in dieser. bald 
in jener Weise mit Gegenwirkungen antworten mul. Das Protoplasma ist der Urtypus einer derartig organisierten, in einem beständigen labilen Gleichgewicht seiner 'leile befindlichen. sich zersetzenden und wieder erzengenden, im beständigen Wechsel sich erhaltenden Substanz.

Wemn sich dagegen die Zelle unter gleich bleibenden Bedingungen hefindet und von einer das Leben selbst nicht vernichtenden, aber häutic mul heständig wiederliehrenden leizursache getroffen wirl. so ist damit

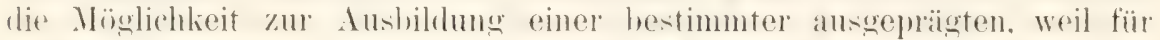
konstant wewordene Verhälnisse einseitig eingerichtefen Oromisation gegeben.

Auf den gleichen Reiz antwortet die Zelle durch gleichmäbig sich wiederholende Reizwirkungen. Sie ist daher immer in einer bestimmten Richtung tätig orler in Funktion. Ton den zahlreichen Funktionen, in welche sich die Lebenstatigkit einer Zelle zorlegen läbt. wird eine, welche die Reaktion gegen die beständig wirkende äuBere Ursache dlarstellt, vorzugsweise geübt und ausgebildet. So hat jetzt die Zelle durch ihre besondere Art, sich mit der AuBenwelt in Verkehr zu setzen, eine II a utfunlition erhalten, welche für sie ein Lnterscheidungsmerkmal gegenüber den Zellen geworden ist, welche sich unter anderen Verhältnissen befinden und daher anders reagieren.

Nun kann keine Zelle tätig oder in Funktion sein, ohne hierbei irgendwelche Veränderungen in ihrer stoftlichen Zusammensetzung zu erfahren, die, wie wir fruher gesehen haben, eine auBerortentlich komplizierte ist. so diali zahlreiche chemische Prozesse gleichzeitlog neheneinander im Laboratorium der Zelle ablaufen können. Die Veränderungen in ihr müssen in einer bestimmten Richtung erfolgen, wenn die Funktion der Zelle eine bestimmte ist: und sie werden rom Beobachter erkamnt werden müssen. wenn die bei den chemischen Prozessen gebildeten spezifischen Produkte sich in dem Protoplasmakörper mit mseren mikroskopischen Hilfsmitteln sichtbar machen lassen. In diesem Falle findet die in einseitiger Richtung vor sich gehende Funktion der Zelle einen wahrnehmbaren Ausdruck auch in der besonderen Art ihrel Organisation oder, wie man gewöhnlich sagt, in einer Struktur. welche für die bestimmte Art ihrer Funktion charakteristisch ist. So hat die Ausbildung des Vermögens der Zelle. sich in eimer stets gleichen Richtung energisch zusammenzuzixhen. ihren sichtharen Aushruck gefunden in der cogentümliehen strulitur der liontraktilen Muskelsubstanz, ihr Vermögen, Reize fortzuleiten. in der Differenzierung der Nerrentibillen. ihre Reaktion gexen schäligende Reize der Aufenwelt in der Absonderung einer Hüllschicht, die ans einer chenisch weniger leicht verïnderlichen Substanz besteht.

Wenn zuweilen eine Zelle in ausgeprägter Weise funktioniert, ohne in ihrer Organisation besondere Eigentümlichkeiten aufzuweisen, so ist hieraus weniger zu schlieben. daß solche fehlen, als daß sie außerhalb der Grenze unseres Wahrnehmungsvermögens liegen. Funktion und Struktur sind ebenso wie Kraft und Stoff. Seele und Leib, zwei zusammengehörige und sich ergänzende Begriffe. Der eine kann olme den anderen nicht gedacht werden. Denn eine bestimmte Funktion setzt allemal a ch eine bestimmte Struktur oder eine entsprechend organisierte materielle Grundlage voraus, sowie eine bestimmte Struktur auch nur in einer ihr gemäßen Weise fungieren kann. Somit müssen sich zwischen ursprünglich gleichartigen \%ellen eines Iogreates gleicheitig mit den funktionellen auch struliturelle (resp. stoftliche) Verschiedenheiten ausbilden. 
Dieses Verhälnnis verdient besonders hetont zu werden. (la vielfarh unklare und unrichtige Auffassungen hieriber geäubert werien. Denn es ist ebenso falsch. zu sagen, wie man zuweilen liest, dab die Funktion eine bestimmte Struktur erzenge orler die Ursache einer solchen sei. wie es falsch ist. dab erst die Struktur sich bilde und dam die Funktion nachfolge ${ }^{1}$. Daher ist wegen der ihm anhattenden Unklarheit auch der Ausdruck..Prinzip der funktionellen Selbstgestaltung des Zweckmäbigen: zu verwerfen. Denn da nichts aus sich selbst entstehen liann.

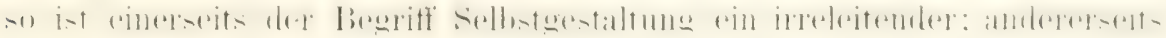
aber ist es aus dem oben angegebenen (irunde ebensowenig möglich, von einer Selhstgestaltung durch Funktion $\%$ reden: rielmehr ist das Verhältnis so, dab, eine bestimmte Struktur mit einer ihr gemäben Funktion an einer reizbaren Substanz entsteht. wenn bestimmte, gleich bleihende Ursachen in häufiger Wiederkehr auf sie einwirken.

Übertlüssig ist daher auch die jetzt so häufig beliebte Verkoppelung der Worte ,Funktion und Struktü" in den Ausdrücken .f un kt ionelle Struktur". und ., funktionelle Giestalt”. Denn will man damit nur ausdriteken, dab die Besonderheit einer Struktur oder Gestalt sich auch in ihrer Funlition und umgehehrt ausspricht, so sagt man, im cirmele genommen, etwas Selbstrerständliches: cinen Fehler aber wïrole man begehen, wenn etwa mit dem Ausdruck angedeutet werden sollte, das es Strukturen von zweifacher Art gebe, Strukturen und (iestalten .m it th $^{6}$ und „ohne Funktion". was nicht der Fall ist. Demn die Funktion jedes Jinges hängt mit seiner Struktur und seiner Gestalt untrembar zusammen. Man kam in der Mechanik keinen heil als eine Kugel und keine Kungel als einen Keil verwenden: wenn daher ein Stück Holz als lieil orler als kiugel dienen soll, so mub man ihm selhstverständlicherweise die der beabsichtigten (rebrauchsweise zweckentsprechende Form geben.

In diesen Bemerkungen liegt kein Wirlerspruch zu der Tatsache, (lab eine Struktur nicht zu funktionieren braucht oder überhaupt der Möglichkeit zu funktionieren vorübergehend oder dauend beraubt sein kann. zum Beispiel. wem ein Muskel und Nerv ruht, oder wenn er durch Zerstörung seines Zusammenhange mit den zu ihm gehörigen Teilen a uher Funktion gesetzt ist. Denn auch in diesem Falle behält der Muskel orler Nerr. solange seine Strulitur noch bestehen bleibt, eine für Liontraktion mol für Reizleitung eingerichtete und keine andere Struktur. Erst in dem Mabe. als sie dureh Inaktivitätsatrophie zugrumde geht, hört auch die Möglichkeit auf, als Muskel- mu Nervenfaser zu funktionieren.

bei der Erörterung des Verhältnisses, in welchem Struktur und Funktion zu einander stehen, ist wohl der geeignetste Ort, auch anf den in der Physiologie häutiger gebrauchten Ausdruck der sperifischen Energie näher einzugehen. Bekanntich hat ihn zuerst JoHswes Mǘler für das Verhalten der Simesnerven eingeführt und damit die eigentiunliche $\mathrm{Art}$ bezeichnet, wie ein Simesnerv reagiert, wenn er in verschierlener Weise gereizt wird.

Ein Sehnery antwortet immer nur mit Lichtemptindung. mag die Netzhaut in normaler Weise ron Lichtstrahlen getroften oder mag der Stumpf des Sehnerven nach Entfernung des Augapfels auf elektrischem. chemischem oder mechanischem Wege direht gereizt werlen. Der Hörnery vermittelt nur Gehörsemptindungen, auch dann, wenn er dureh entzïndliche Prozesse im Labyrinth in Mitleidenschaft gezogen wird.

1) Zu*atz Seite 425 
Es läbt sich dieses Verhalten der Sinnesnerven daraus erklären, dab sie zwischen eigenartig konstruierte, periphere und zentrale Endapparate, zwischen das Simnesorgan und das im nervösen Zentralorgan gelegene "Erfolgsorgan" eingeschaltet sint. Da das mit der Netzhaut verknüpfte Zentralorgan immer nur Lichtreize zugefüht erlält und auf sie mit einer Gegenwirkmg antwortet, die von uns als Licht empfunden wird, hat es anch eine spezitische Organisation in der oben ausgefühten Weise ge-

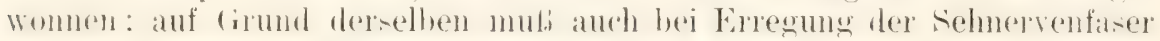
durh anderseartete Reize wieder die Emptindung von Licht wachererufen werden, wie die Muskelfaser auf jeden Reiz vermöge ihrer Struktur nur mit einer Zusammenziehung und nicht anders antwoten kann. Sprezitische Energie ist daher ebenfalls ein Anzeichen für spezifische Organisation auch von solchen 'Teilen, an denen wir sie zu erkennen nicht in der Lage sind.

Einem gleichen Ideengang folgend, hat SucHs dem Ausdruck ..spezifische Energie." in der Pthanzenphysiologie eine allgemeine Fassung gegeben, indem el reizbare Pflanzenorgane. wie die Sinnesorgane der Tiere, mit slezifischen Energieen ausgestattet sein lïht. Sicus versteht darmer ,im Crunde nichts anderes als den durch die Struktur der Organe vermittelten Verkehr derselben mit der Aubenwelt".

Der Ausdruck "spezifische Energie“ besagt daher so viel als besondere Funktion auf Grund besonderer Struktur. In diesem Sinne sind alle Organe und Gewebe vermöge der ihnen eigentümlichen Organisation und Struktur mit ihren besonderen, nur ihnen eigenen Energien ausgestattet, mit welchen sie im Organismus wirken und durch welche sie mit der Aubenwelt in Verkehr treten.

\section{Zweites Gesetz. Die Wichtigkeit der Wechselwirkung mit anderen Zellen fur die Ausbildung besonderer Funktion und Struktur in einer Zelle. (Gesetz der physiologischen Arbeitsteilung.)}

Uniser oben aufgestelltes erstes Gesetz, daß eine Zelle, um eine besondere Funktion (spezifische Energie) und Struktur zu erwerben. unter

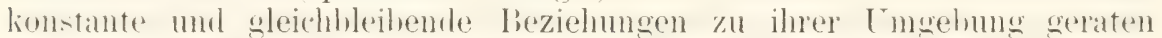

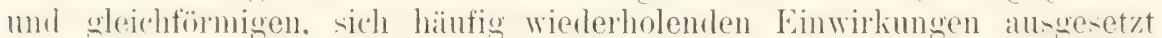
sein muß; bedarf 'noch eines wichtigen Zusatzes. Es läßt sich nämlich zeigen, dab äubere Einwirkungen in einem Aggregat von Zellen viel intensivere und verschiedenartigere Veränderungen hervorrufen, als wenn sie nur eine vereinzelte. für sich lebende Zelle treffen. Die letztere kann sich nicht in dem Maße, wie es in einem Zellenaggregat möglich ist, in einer Richtung einseitig entwickeln; denn sie mus gleichzeitig zahlreiche verschiedene Funktionen, soweit sie für die Erhaltung ihres Lebens notwendig sind, auszuïben imstande sein und muß sich demmach

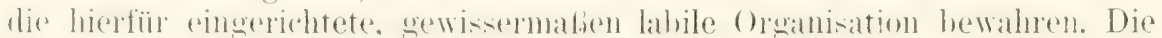
Beziehungen, in welche sie ïberhaupt zur Augenwelt treten kann, sind hierdurch eingeschränkt. Denn sie kann nur solche Veränderungen eingehen und nur solche Strukturen ausbilden, welche mit dem Bestand ihrer ïhrigen Funlitionen mol ihrer damit zusammenhängenden Oramisation verträglich sind.

Um ein Beispiel anzufïhren, so darf eine einzelne Pflanzenzelle ihren

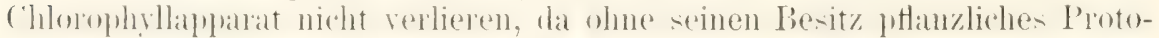
plasma nicht die zum Leben, zum Wachsen und zur Fortptlanzung nötigen 
Stoffe bilden kann: sie mul, daher unter Einflüssen der Außenwelt. die

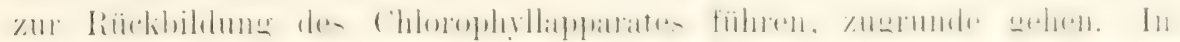
vielzelligen Pflanzen dagegen sehen wir die Zellen in Imneren der Zweige und in den Wurzeln das Chlorophyll ohne Schaden verliesen.

Oder nehmen wir Beispiele rom tierischen Gebiet. Eine einzellevende Zelle wirl niemals wie die Oberhautzelle ihren ganzen Könjer in Hornsubstanz ofler wie eine Muskelfaser in kontraktile Substanz umwan-

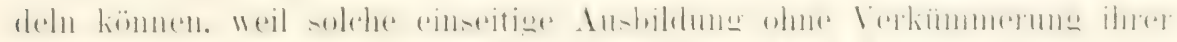

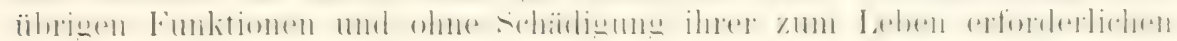
Gesantorganisation nicht möglich ist. Sie mub sich daher bei allen fiegenwirkungen gegen die Einflüsse der Aubenwelt und bei allen Veränderungen. die sie erfährt, doch stets in einem Gleichgewicht aller dem Leben dienenden Funktionen erhalten. Hierin liegt der einfache

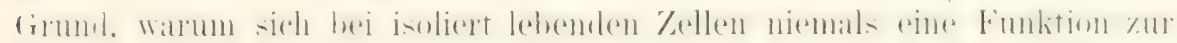

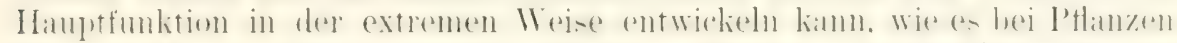
und 'Tieren in vielen Geweben (Muskel-. Nerven-, Drisenzellen ete.) ge-

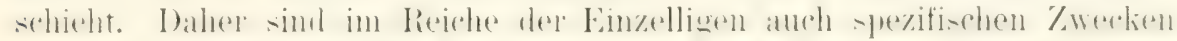
diemende. datakteristische strulituren. wie Muselfihrillen. Verventihrillen. Stïtzsubstanzen, höchstens in schwachen Anfängen vorhanden.

Wodurch gewinnt nun aber die eimzelne Zelle durch den Verband

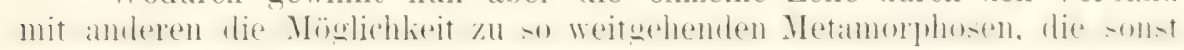
ïberhaupt nicht eintreten können?

Die Beantwortung dieser Frage führt uns auf das

.Gesetz der physiologischen Arbeitsteilung."

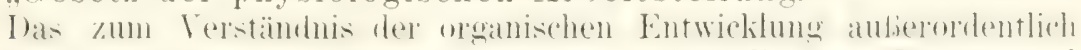
wichtige Gesetz ist von MrLne EDwards aufgestellt, yon Brovx und

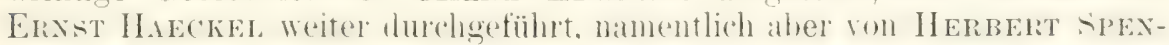

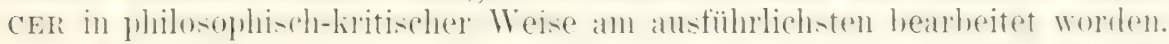

Milse EDwards hat zuerst darauf aufmerksam gemacht, (lab bei der Entricklung der ()romismen. hei der sonderung des kïrpers in orgrane und fewehe sich andoge P'rozese vollziehen wie hei der Entwirli-

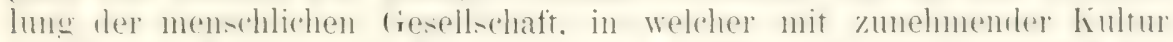

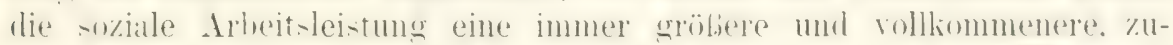

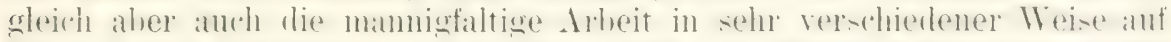

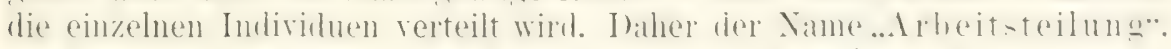

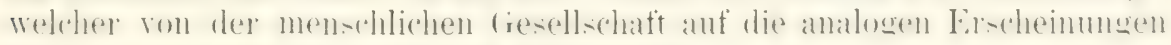
im Organismenreich ïbertragen worden ist.

\section{a) Die Arbeitsteilung in der menschlichen Gesellschaft als Vergleichsobjekt.}

Da die Arbeitsteilung in der menschlichen Gesellschaft zur Erläuterung des Prozesses. mit welchem wir es hier zu tun haben, besonders geeignet ist, wollen wir zuerst ih Wesen kur\% auseinander setzen.

Als isoliertes Wesen nach Art eines Robinson mub ier Mensch in seinem Verkehr mit der Natur durch Ausübung der verschiedensten 'Täi-

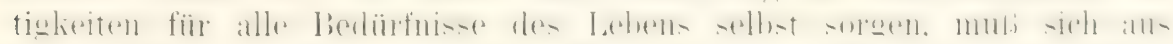
eigener Kraft in dieser oder jener Weise Nahrung. Kleidung und Schutz verschaften. Er gleicht einer einzeln lebenden Zelle, die auch, um erhal-

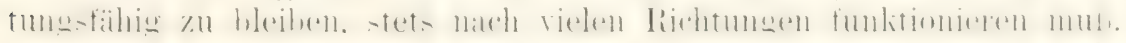

Aus diesem niederen, tierïhnlichen Zustand hat sich der Menseh zu höheren Stufen der Kultur erst als (ilied einer menschlichen (iemeinschaft erheben können: durch den Verloand mit anderen wachsen ihm 
gewissermaben neue Fähigkeiten zu, werden seine Anlagen zu viel

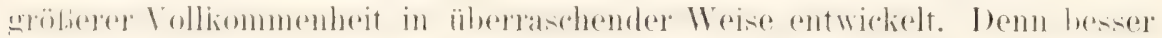
als es der einzelne vermag, kamn eine soziale Gemeinschaft die Natur zu ihrem Vorteil ausnutzen. Anf Grund der in ihr sich ausbildenden (regenseitigkeit wird jetzt der einzelne in die Lage versetzt, seine Arbeitskraft in einer bestimmten Richtung, wie es zuvor nicht möglich war', zu konzentrieren und durch die häufige Ausübung derselben 'Tätigkeit eine gröbere Fertigkeit in ihr zu erlangen; er kann so ohne gröbere Mühe in einer Richtung mehr und vollkommenere Arbeit leisten. von dem fiir ihn daraus erwachsenten Überschuß an andere abgeben und von ihnen dafür Gegenwerte in anderer, von ihm selbst nicht verrichteter Arbeit entgegen nehmen.

Je mehr die Arbeitsteilung in verschierlenen Richtungen Platz greift und je mehr sich ein innigeres, auf sie basiertes Gegenseitigkeitsverhältnis dere eimzelnen muteremanter entwickelt. mo so mehr wird die Lebens-

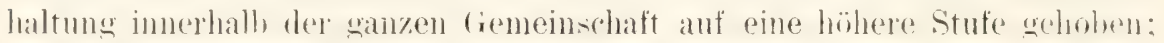
ein $u$ mo so höherer Grad von Kultur wird erreicht.

Zur Entwicklung einer größeren Arbeitsteilung ist indessen noch erforderich, daß die menschliche Gemeinschaft nach dem von uns oben aufgestellten ersten Gesetz (S. 411) zu der umgebenden Natur in festere und gleichbleibende Beziehungen tritt. Denn erst in dieser Weise kann die Aufenwelt anf die einzelnen Glieder der Gemeinschaft die verschiedtenen differenzierenden Wirkungen ausüben, wie dies früher schon für die Zelle nachgewiesen wurle.

Bei einem Nomaden- und Jägervolk, welches seinen Wohmplatz häufig wechselt und sich darlurch in immer wechselnden Beziehungen zur umgebenden Natur befindet, ist keine Gelegenheit zu einer tiefer greifenden Arbeitsteilung gegeben. Eine solche bildet sich dagegen Schritt für Schritt aus, sowie ein Volksstamm sebhaft geworden ist und anfängt, die vel'schiedenartigen Gelegenheiten, welche ihm die umgebende Natur mit ihren reichen Schätzen darbietet, zum Nahrungserwerb und zur Lebenserhaltung auszunutzen. Je nach dem Orte seiner Ansiedelung beginnt der eine den Boden zu kultivieren. um von ihm mehr Frïchte zu beziehen, der andere treibt Tierzucht, ein Dritter, an Flub-oder Seeufer angesiedelt, übt Fischfang, ein Vierter die Jagd. Bald tritt der Stand der Händler hinzu. um die Früchte der Kulturarbeit zwischen den einzelnen, über ein größeres Landgebiet zerstreuten Genossen eines Stammes auszutauschen. Mit der Entwicklung des Hambels hilden sich allmählich auch Handelsplätze mol Märkte, Handelswege und Mittel des Transportes aus. Der Kahn des Fischers wird zum Schiff, das den Handel auch auf größere Entfernungen vermittelt und fremdartige, durch Umtausch erworbene Produkte von weither dem Markte zuführt.

Durch Anpassung an die verschiedenen Erwerbsgelegenheiten, die ein Land darbietet. hat sich die menschliche Gesellschaft schon auf frïhen Stufen der Kultur in Ackerbaner, Viehzüchter. in Fischer. Händler, Seefahrer etc. in Land- und Stadtbewohner gegliedert. Mit der 'Teilung der Arbeit ist die größere Ausnutzung der Schätze der umgebenden Natur ermöglicht, durch den Austausch der Arbeitsprodukte ein Glied der Gesellschaft rom anderen abhängig, zugleich aber auch die Lebenshaltung, rlie Art. sich zu emähren. zu kleirlen und zu wohnen. auf eine höhere Stufe gehoben worden. Ferner hat sich an Stelle der Gleichartigkeit einer Tomadenbevölkerung eine verschierlenartige Struktur in der Gesellschaft

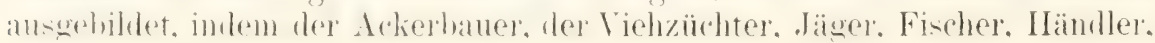




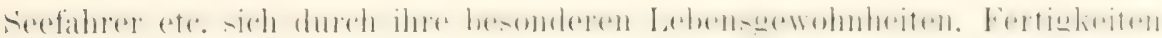
und Charaktereigentümlichlieiten unterscheiden.

In manchen Fällen scheint der Prozeb. der aus einem Aggregat

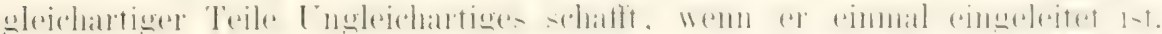

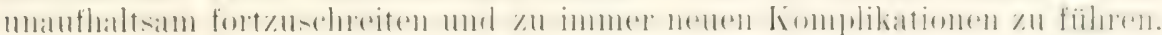
Wie jeder weib, hat in Iaufe der liulturentwicklung die Arbeitsteilung

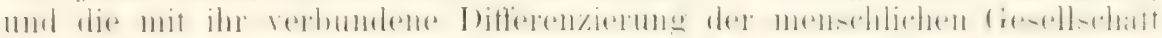
in den Kulturstaaten eine sanz wunderbare Ausdehnumg und Höhe. wenn anch noch lange nicht ihren Abschlub erreicht. Immer nene Seläitze lernt der Mensch der Natur abgewinnen, und jede derartige neue beziehung. die zur Aubenwelt geknüpft wird, ist ein Mittel zu nener Arbeitsteilung und Differenzierung und zu weiteren Kulturfortschritten.

Wenn in einer (iegend ein ergiebiges Kohlenlager oder Eisenerze

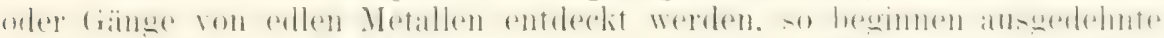
Schichten der Bevölkerung, wie in Schlesien mol Westfalen, sich dem

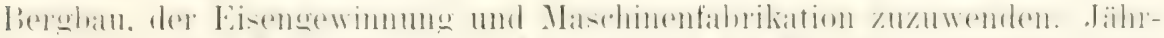

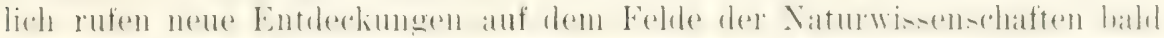

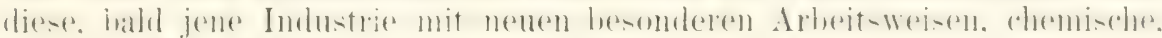
elektrotechnische Fabriken etc. ins Leben.

\section{b) Die Arbeitsteilung im /ellenagregat.}

Wir sind jetzt in der Lage, die Frage, die wir am Eingang dieser Betrachtung aufwarfen, zu beantworten: Warum die einzelne Zelle erst durch den Verband mit anderen die Möglichlieit zu Metamorphosen gewinnt. die an ihr nicht eintreten können. solange sie ein isoliertes Lebewesen bleibt. Die Erklärung bietet uns auch hier das Gesetz der Arbeitsteilung. welches in einer Gemeinschaft von Zellen sich in ähnlicher Weise geltend macht wie in einer menschlichen Gemeinschaft und ähnliche Erscheinungen wie in dieser hervorruft.

Anch die 'Lel!en treten gewissermaßen in einen 'Tauschverkehr' mitcinander: sie können in einseitiger Weise besondere Verrichtungen aus-

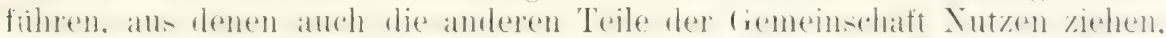

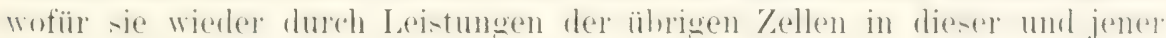
Weise gleichsam entschädigt werden. Denn vermittels der anatomisch-

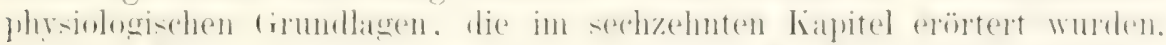

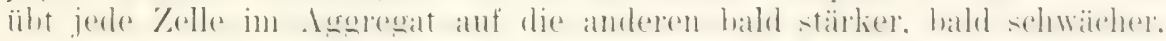
bald in dieser, bald in jener Weise je nach Lage und Entfernung Wirlimgen aus.

As 'Teile einer höheren Lebenseinheit kiönnen sich die Zellen in ihren Funktionen ergänzen, indem die eine Zelle eine Funktion mit übernimmt, welche bei einer anderen verkimmert ist. Infolge dieser Wechselbeziehungen kömnen sich jetzt anch differenzierende Wirkungen der Lmgebming an einzelnen Zellen und Zellengruppen geltend machen. die nicht möglich wären. wenn die Zelle zur Erhaltung ihres Lebens in der rielseitigen Weise wie ein isoliertes Lebewesen funktionieren mülite. Auch die Lelle wird erst als Glied einer Gemeinschaft in die Lage versetzt. unter den Einflüssen der Aubenwelt sich in einer Hauptrichtung einseitig zu entwickeln, eine Hauptfunktion oft bis zum Extrem nebst einer iln entsprechenden spezifischen Struktur auszubilden, unter teilweiser Verliummerung anderer zum Leben erforderticher Funktionen, für deren Ausfall dann Ersatz dureh andere Zellen geschatfen wird. 
Für diese wichtige Wahrheit bietet uns die Pflanzenzelle mit ihrem

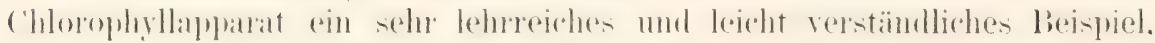
das schon oben (S. 41t) kurz erwähnt wurde und jetzt noch weiter ausgeführt werden soll. Für die Ernährung einer Ptlanze ist es unbedingt notwendig, dab sie Chlorophyll besitzt, und zwar in einer Lage, in welcher es vom Licht getroffen werlen kann. Demn nur unter diesen Berlingungen kamn die Pflanzenzelle die Kohlensäure der Luft zersetzen uud zum Aufbau von Kohlenhydraten verwenden. Eine einzellige Pflanze darf daher, wenn wir von einigen Gruppen von Schmarotzern absehen, ihren Chlorophyllapparat nicht replieren und hamn mur unter bedingungen existieren. unter denen er funktionieren kann, wozu der Einfluß des Lichtes gehört. In einer Zellengemeinschaft dagegen kimn ein Teil der Zellen ohne Scharlen das Chlorophyll verlieren. wenn nur ein anderer 'Teil es behält und für die Einährung der ersteren durch fertigrebildete lohlenhydrate sorgt. Die von Chlorophyll frei gewordenen Zellen können daher auch unter liedingungen lehen, wo das Licht fehlt. und wo die einzehne Ptlanzenzelle absterben muf. Bei den meisten höheren Pflanzen ist denm auch als Folge äuberer Einwirkugen eine Somblemg in chlorophyllhaltige und chlorophyllfreie Zellen erfolgt, indem ein Teil von ihnen in Lagen gekommen ist, wo er nicht mehr vom Sonnenlicht getroffen werden kann. Auf diese Weise lassen sich als das Resultat einer durch äuBere Einwirkungen hervorgerufenen Arbeitsteilumg zwei tief eingreifende und wichtige Sonderungsprozesse verstehen, die hei den meisten Pthanzen während ihrer Entwicklung eintreten. Der eine Prozeb ist die Sonderung in oberirdische, grime und unterirlische, chlorophyllfreie Organe. Wurzeln haben in den Erdboden eindringen und unter Verlust des Chlorophylls im D)unkeln existieren kömnen. weil sie mit den Nahrungsstoffen, die sie selbst z.u bikden auberstande sind, von den oherirdischen, grimen Zellen versorgt werden. Aber auch diese werden wegen ihrer räumlichen Trennung vom Borlen, un gerleihen zu kömnen, wierler in anderer Beziehung auf die Wurzelzellen angewiesen. von welchen sie Wasser und salze zugeführt erhalten.

Der zweite Gegensatz hat sich an oberirdischen Pflanzenorganen. überall da, wo sie eine beträchtlichere Dicke erreichen, aus gleichen Ursachen wie oben ausgebildet. Nur an der Oberfläche sind die Zellen, soweit als der Idichtstrahl mit einer gewissen Stärie noch in die Tiefe wirken kamn. grün gehliehen. im Innern des Stammes und diclierer Äste dagegen haben sie wieder ihr Chlorophyll verloren und müssen daher von den ersteren mit ernährt werden. Selbst an den Blättern. welche doch dem Assimilationsprozeh in allererster Linie dienen, tritt der durch das Licht direkt veranlabte histologische Gegensat\% zwischen Iuberem und Innerem auf, wenn sie eine erheblichere Dicke erreichen, wie bei den Serlumarten und den Kakteen. Nur bis zu einer gewissen Tiefe sind die Zellen des Blattes grïn. werden damn immer chlorophyllämer und schliefilich gamz. farblos wie in den Wurzeln, da in das Innere des Blattes das Licht nur sehr stark abgeschwächt eindringt.

Noch in vielen anderen Beziehungen gestattet der Prozeb der Arbeitsteilung und der mit ihr zusammenhängenten I)ifferenziermug Parallelen zwischon der (tranisation der menschliehen fiesellschaft mul der Zellengemeinschaften zu ziehen. Wie in den an meisten vorweshittenen hulturstaten die Albeitsteilung schlielich eine unendlich mannigfaltige und kaum noch zu übersehende geworden ist und trotzdem noch weiterer Komplikationem fähig ist. so hat sie anch im liörper der höheren Tiere eine ganz erstaunliche Verschiedenartigkeit von Funktionen hervorgerufen. 


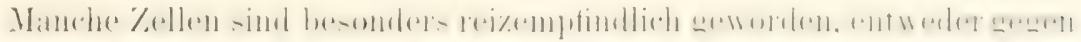
Licht, oder gegen Schall, oder gegen mechanische lierïhrung, oder gegen Wärme, oder gegen chemische Stotfe in gasförnigem und in flüssigem Zustande. Andere zeichnen sich durch das Vermögen aus, ihre Form durch

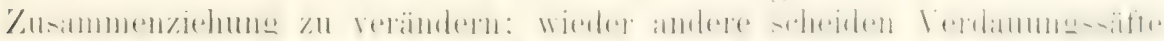
entweder dieser oder jener Art ab. Säfte zur Verdaumg von liohlenhydraten, von Eiweibliöpern odler von Eett, andere dienen zum Schutz. andere zur Stiitze, wieder andere zum 'Transport der Nahrungssäfte, andere zur Fortptlanzung etc.

Ferner haben die einzelnen Zellen und Zellengruppen nach unserem

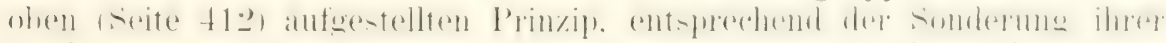
Fumlitionen, auch entsprechende Strulifuren erhalten, durch welche sie die besondere Arbeit verrichten. und welche wir daher als ihre besonderen

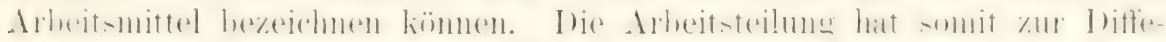
renzierung in verschiellene Arten von Simnes- und Nervenzellen. in Muskelzellen, in Drüsenzellen, welche wieder Speichel-, Schleim-, Leber-, Pankreas-, Talg-, Milch-, Nierenzellen ete. sein können, in Zellen der zahl-

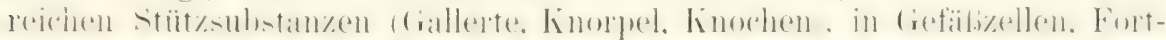

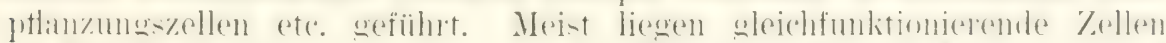

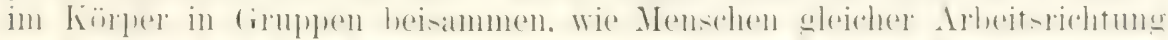

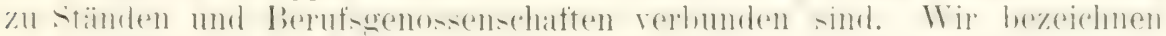
damn solche als ein Gewebe (Partes similares). In diesem Simne sprechen wir ron einem Muskel-. Nerven-, Binde-, Epithelgewebe etc.

Auch der Mensch bildet sich gleich der Zelle bei dem Prozeß der

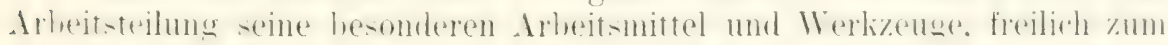
Teil in einer prinzipiell anderen Weise. Während die Zelle in und aus

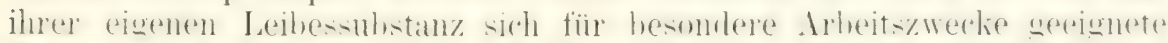

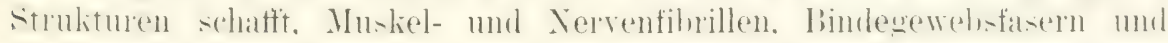
die chemisch verschiedenen Arten der Stützsubstanzen etc. erwirbt zwar anch der Mensch sich hesmilere. für eine Arheitslestung erforderliche

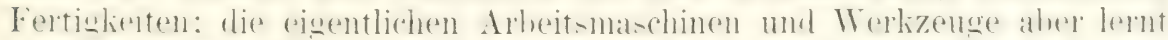
el der äuberen Natur abgewinnen, indem er sie sich aus Eisen und Glas

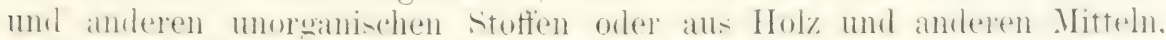
welche ihm anch die oreanische Satur liefert. liünstich herstellt. Tele-

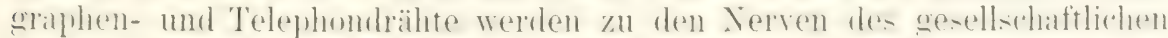

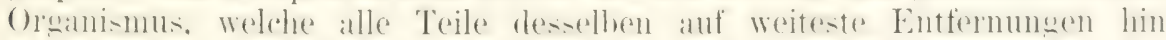

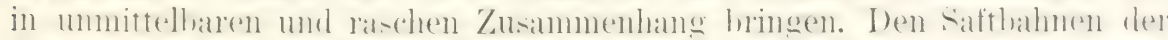

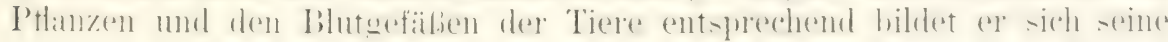
besonderen Transportwege für den Nahrungs- und Güteraustausch aus, schiffbare Kanäle, Fahrwege, Dampf- und elektrische Bahmen. Zahllos sind die Maschinen, Werlizeuge und Instrumente, welche zur Ausführung

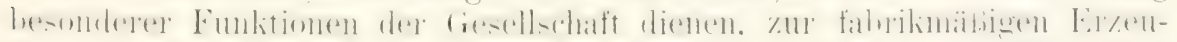

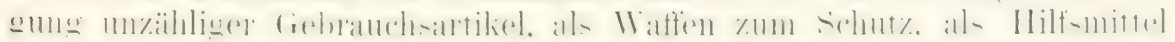
systematischer wissenschaftlicher Durchforschung der Natur.

3. Drittes Gesetz. Entsprechend dem Grad ihrer Differenzierung wird die einzelne Zelle $z u$ einem unselbständigen und abhängigen Teil einer ubbergeordneten Lebenseinheit. (Gesetz der physiologischen Integration.)

Bei der Besprechung des Gesetzes der phrsiologischen Arbeitsteilung hahen wir zum Schlul, noch anf ein sehr wichtiges Verhälnis eimzugehen. welches Herbert SPExcer als rlie physiologische Integration he- 
zeichnet. In demselben Maße nämlich, als in einer Lebensgemeinschaft ein Teil eine besondere Leistung übernimmt und dementsprechend differenziert wird, tritt er in immer festere Abhängigkeit zu den anderen 'Teilen oder zum Ganzen; er wird ihm subordiniert oder integriert: das heibt: er wird als wesentlicher 'Teil in ein höheres cranzes, in einen Organismus höherer Ordnung eingefügt, wordurch er in demselben Maße seine Selbständigkeit und unabhängige Existenzfähigkeit verliert.

Der Prozef der Arbeitsteilung, der zur Sonderung der Funktionen fülnt, findet so seine naturgemäße und notwendige Ergänzung in dem entgegengesetzten und ebenso wichtigen Proze B der Integration; durch welche wieder die differenzierten und gesonderten Teile zu einer untrennbaren höheren und volkommeneren Lebenseinheit zusammengefalit warlen.

Auch in rlieser Beziehung bietet sich uns eine lehrreiche Parallele zwischen den Erscheinungen der menschlichen Gesellschaft und eines Zellenstaates dar. In wie hohem Maße ist jeder einzelne von uns in seiner Lebenshaltung von dem Mitwirken unzähliger Personen und von der gedeihlichen Entwicklung des ganzen staatengebildes ahhängig. in reiner Ernährung, seiner persönlichen Sicherheit, in seiner Ausbildung, seiner Berufstätigkeit? Wie werden ihm Störungen, die irgendwo im sozialen

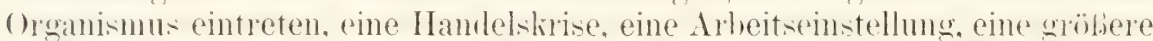
Verliehrshemmung, soziale und politische streitfälle. in irgend einel lieviehung fühlhar". . Wähend auf den frïhesten stufe gesellschaftlicher Entwicklung," hemerkt Herbert spexcer. ...ich jede kleine firuphe der lievölkerung. ja oft jede einzelne Familie ihre eigenen Lehensherlürnisse verschaffte, existiert jetzt für jedes Lebensbedürfnis und für jeden Luxusgegenstand ein verwhelter Aplatat von (irob- und Kleinhändlern. welcher durch seine verzweigten Kanäle die fiegenstände in das bereich aller hringt. Während jeder einzelne bürorer ein deschäft treiht. Welches keine-wess unmittelbar auf die Befriedigmo seiner personlichen Bedürfnisse abzielt. werden doch diese persünlichen Berlürfnisse hefriedigt durch eine allgemeine Tätigkeit, welche ron allen Seiten her die erforderlichen Dinge für ihn und seine Mithürser herheischatft - cine Tätigkeit, welche ihre eigentimlichen ()hliegenheiten nicht auch nur für wenige 'Tage außer acht lassen könnte, ohne sich selbst und die Tätigkeit der meisten anderen Venshen in Frage zu stellem."

So ist bei genanerer Prüfung im Kulturstaat der einzelne trotz seiner scheinbaren Freiheit und eines eingebildeten Gefühls der Unabhängigkeit in Wirklichkeit zı einem sehr abhängigen Glied eines übergeordneten, sozialen Organismus geworden.

In derselben Weise bildet sich im Zellenstaat, dem Grad der pliysiologischen Arbeitsteilung entsprechend, ein geringerer oder höherer crad von Integration aus. Bei niederen Pflanzen und Tieren, z. B. bei Moosen nnd Hydroidpolypen, bei welchen die Zellen in geringerem Maße in Gewebe und Organe gesondert sind, ist die Abhängigkeit der einzelnen Teile eine entsprechend geringere. Fs kömnen daher diese ()rganismen in stiucke zerlegt werden, von denen jerles auch selbständig weiter zu leben und aus sich das Ganze zu regenerieren vermag.

Je mehr aber, wie bei den höheren Tieren, eine unendlich komplizierte Arbeitsteilung, eine Sonderung in viele, sich gegenseitig ergänzende und bedingende Gewebe und Organe eingetreten ist. um so mehr wird jeder Teil dem Ganzen untergeordnet und verliert die Möglichkeit, sich selbst zu erhalten, sowie er rom Ganzen abgetrennt wird. In diesem Fall ist die vellstänligkeit der Zellen als Elementarorganismen so aufgehohen. dab sie nur noch als untergeordnete und in Abhängigkeit vom Ganzen funktio- 
nierende Teile erscheinen. In ihrer Determination sind sie zu einseitig wirkenden Werkzengen geworden, die dem höheren Organismus nur in einer durch ihre Struktur begrenzten Weise dienen und auf äubere und innere Reize jelesmal nur mit ihrer spezitischen Energie antworten. Eine Knochen- und Knorpelzelle kann nu als Stütze dem Ganzen dienen: eine Drïsenzelle reagiert auf die verschiedensten Reize, die sie treffen. durch Absonderung eines Sekretes. welches durch ihre besondere stoffliche Orannisation bestimnt wird, ebenso die Muskelzelle durch Kontraktion, die Tervenzelle durch Übertragung von Reizen.

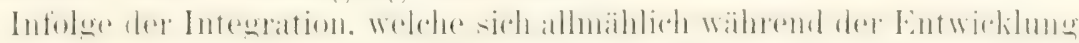
immer fester ausbildet. wird die Tätigkeit der Zellen durch Gesetze. die

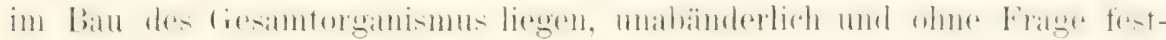
gelegt. Den! was geht im Organismus vor, wenn \%. B. ein Reiz die Netzhaut trifft und momentan eine energische Bewegung veranlabt? Es

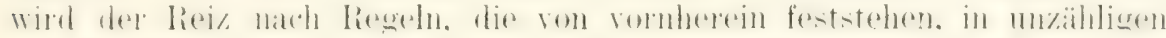
Nervenfilorillen zum Zentralorgan und von diesem weiter zu Tausenden ron Muskelfaser'n fortgeflanzt. die sich sofort auf den Reiz verkïrzen und ihrerseits wieder ein Bündel von Sehnenfasern in Spannung versetzen. durch welche dann der Zug wieder auf die Knochensubstanz äbertragen

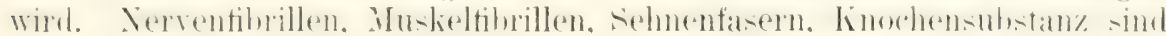

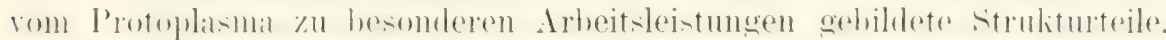
In ihnen spielt sich der durch den Reiz der Retina veranlabte Prozef ab. Dagegen sind, wenn wir yon den Ganglienzellengruppen absehen, die Hundertansende von Zellen, die als Kerne der Scmwavsschen Scheide

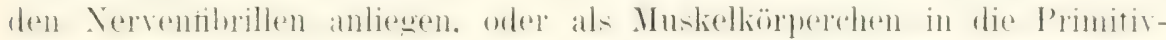

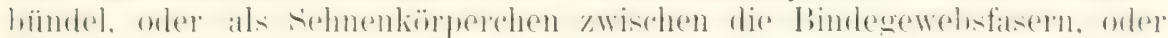

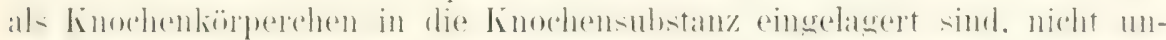
mittelbar in irgend einer Weise beteiligt. Offenbar hat hier die einzelne Zelle auf den durch den Reiz hervorgerufenen Enderfoly gar keinen Einfluf. denn dieser hängt lediglich ab von der bereits vorhandenen und zur

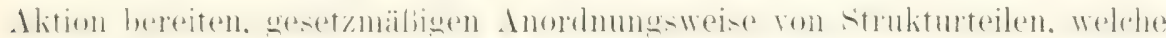
in der Entwicklung des ganzen Organismus begründet ist, und welche auch in ihrem leistungstähigen Zustand vom Ganzen aus erhalten wird.

Natürlich ist hiermit nicht gesagt, dab die Kerne der Schwaxxschen Scheirle, die Muskel-, Sehnen- und Knochenkörperchen fïr die zu ihnen

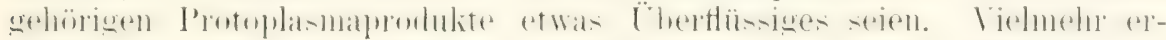
halten sie durch die nutritiven Prozesse, die sich in ihmen abspielen. die

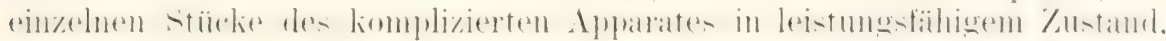

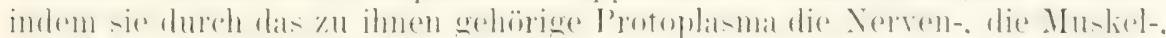
die Sehmenfibrillen und Knochensubstanz ernähren und. wo es erforderlich ist, auch bei veränderten Verhältnissen in entsprechender Weise gewissermafien umbanen.

Der vorstehende Gedankengang läbt sich in anderel Weise anch so ausdrüicken: Der durch den Reiz der Retina hervorgerufene Enderfolg ist

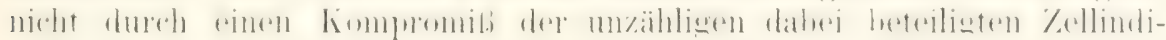
viduen zustande gekommen. sondern erklät sich aus allgemeinen Gesetzen. die auf der ganzen Eimrichtung des Organismus heruhen. dessen integrierte Teile die aufbanenden Zellen geworden sind. Somit treten in dem höehst

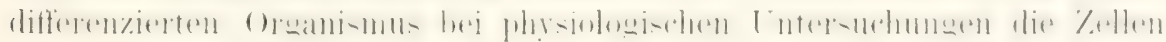
den Eigenschaften des Ganzen gegenïber mehr in den Ilinterorum. wähend man bei morphologischen Untersuchungen mehr geneigt ist. sie als die Elementarorganismen, dureh deren Zusammenorinumg der zusammengesetztere Organismus erst zustande geliommen ist, in den Mittelpunkit jeder letrachtung zu stellen. 
In wetcher Weise die Zellen durch die Vergesellschaftung mit andern ihresgleichen von den Bedingungen und Gesetzen abhängig werden, die sich im Zellenstaat allmählich ausgebildet haben, sei noch an einigen

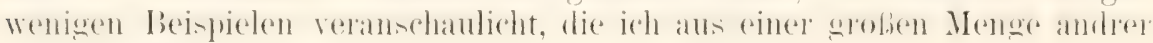
herausgreife.

Im tierischen Körper beziehen Milliarden von Zellen die zur Lrhaltung des Lebens erforderlichen Nahrungsstoffe nicht mehr direkt von der Außenwelt, sondern durch Vermittelung einer zentralen Ernährungsanstalt, die allmbihlich nach dem P'rinzip der Arbeitsteilung mol I)ifferenzierung im Zellenstaat entstanden ist. Im Magen und Darmkanal werden die von andien bezogenen. im Mund zerkleinerten Nähnaterialien in liomplizierter Weise chemisch verarbeitet. Durch die Sekrete verschiedener I) rïsen werden liohlenhrdate. Fette und Eiwcibkïrper in areignete Iösungen übergeführt und für die Darmwandungen aufsaugbar gemacht. Eine konzentrierte Nährflüssigkeit, zusammengesetzt aus allen zur Erhaltung der Zellen erforderlichen Materialien, wird so von einer Zentralstelle aus geschatfen. Iierdurch wird auch ten abseits von ihr gelegenen. mit andern Funktionen betranten Zellen die Befriedigung ihres Nahrungsbedürfnisses so sehr erleichtert und vereinfacht. dab sie nur noch den zum ummittelharen (iehrauch fertig gestellten Nahrumgsaft von der Zentralstelle aus zu beziehen brauchen. Auch hierfür sind im Zellenstaat nach dem Gesetz der Arbeitsteilung hesondere Vorkehrungen entwickelt worden. Lm rom Darmlianal aus den Nahrungssaft an jede Verhauchsstelle sofort und in raschester Weise zu schaffen. sind hesondere Kanäle von grälierem und kleinerem Kaliher, die Blut- und Lrmphofäbe entstanden. Sie nehmen durch den Prozef der Aufsaugung von den Wandungen des Darmkanals den Nahrungssaft auf, um ihn auf tausend und abertausend Wegen den einzelnen Provinzen und Organen des Körpers zuzuführen. Hier wird er schlieblich wieler in feinsten Rührohen his in die ummittelharste Tähe fast jeder einzelnen Zelle herangehracht. Zur Forthewegung der Xährfliisidekeit, des Blutes, in den groben Gefäßen und feinsten Haarröhrchen, ist auch noch bei der Arbeitsteilung ein zentrales Pumpwerk, das Herz, geschaffen worden. Mit liäftig arbeitenden Muskelzellen. mit Klapren und Ventilen ausgestattet, macht es erst eine gleichmäßige Zirkulation des Blutes in bestimmter Richtung möglich. So sind alle Zellen in dem sie mmströmenten Nahrungsaft gewisermalien gebalet umb können in jedem Moment ihren Bedarf aus ihm hestreiten. Da der Saft, je nach seiner 'bubereitung, für jede Art yon Organismus seine ganz besondere Mischung hat, ist jetzt jede Zelle, wenn ich mich so ausdrüicken darf, in ein für jeden Organismus spezifisches Milieu geraten, sie ist ihrer ganzen Natur nach so auf dasselbe angewiesen, daf sie überhaupt nur in ihm existieren kann.

Nehmen wir noch ein zweites Beispiel: Zur Unterhaltung der chemischen Prozesse in der Zelle und damit ihres Lebens überhaupt ist Sanerstoft ein unbedingtes Erfordernis. Niedere einzellige Organismen nehmen den Sauerstoff an ihrer ganzen Körperobertäche direkt aus der Luft oder aus dem Wasser auf und geben die Schlacken des Lebensprozesses, die bei der Verbrenmung des Sanerstoffes entstehen, unter ihnen besonders die Kohlensäure, auch direkt wieder an die Ungebung ab. Bei Zellstaaten aber von Millionen und Milliarden von Elementarindividuen ist ein solcher direkter Bezug von der Quelle und ebenso eine direkte Abscheidung (ler Zerfallsprodukte nach auBen eine Unmöglichkeit geworden. Denn die meisten Zellen sind ja wegen ihrer Lage in der Tiefe des Kör-

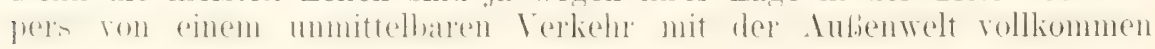


abgeschlossen. Sie sind daher, wie es auch bei der Ernähung der Fall

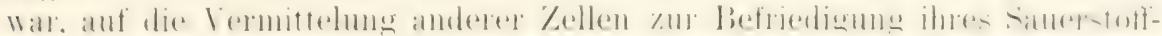

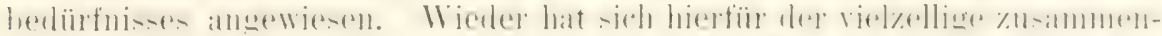

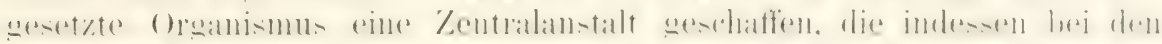

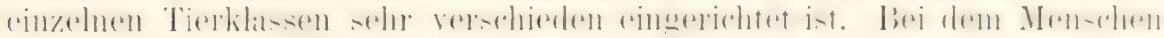
und den höheren Wirbeltieren ist es die Lumge, die vermöge ihres eigentïmlichen Baues große, dem Bediirnisse des ganzen Körpers entsprechende Mengen von Sauerstoff durch den Atmungsprozeb aus der Luft

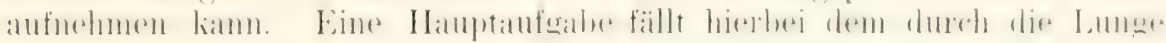
zirkulierenden Bhut zu, und zwar den roten Blutkörperchen. Diese sind

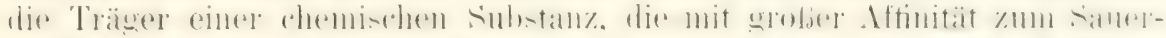
stoff ausgerïstet ist. des Hämoglobins. Vermittelst des roten Blutfarl)-

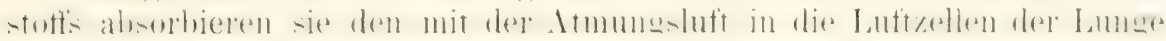
geratenen Sauerstoff und tragen ihn mit der Blutwelle zu allen Organen. allen Geweben und Zellen des Körpers und versetzen sie so in die Lage.

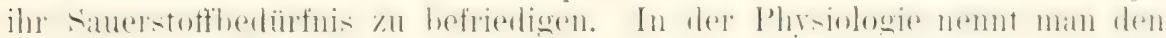
letzteren Vorgang im Gegensatz zur Lungenatmung die innere Atmung. Also anch in diesem Beispiel sind die emzelnen Kellen im Zellenstaat. gerarle wie es auch bei der Ernährung der Fall war, von besonderen Einrichtungen des höheren Organismus abhängig geworden. Für den nor-

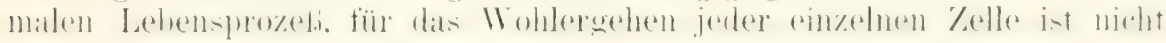
nur die normale Arbeit einer gesunden Lunge, sondern auch die richtige

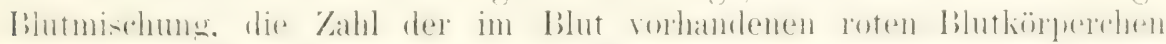
und ihre richtige Ausrïstung mit Hämoglobin eine notwendige Vorbedingung geworden. Und ähnlich geht es in der sozialen Lebensgemeinschaft der Zellen noch in sehr vielen andern Beziehungen zu. Überall

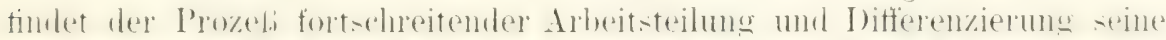

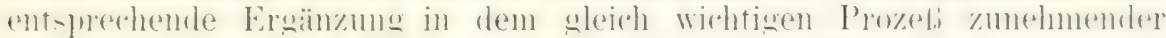

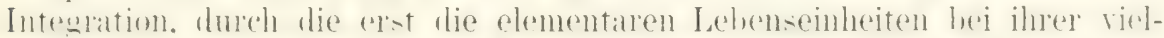

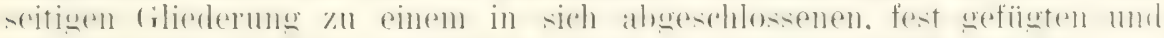

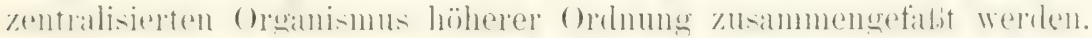

In vollkommenster Weise wird dies schlieblich herbeigeführt durch ein Organsystem, durch das die zahlreichen Einzelbetriebe verknïpft. untereinander und von höheren Zentralstellen abhängig gemacht und

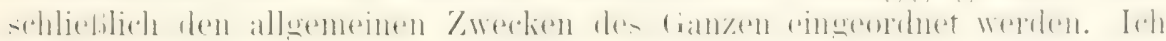
meine das Nervensystem. Zahlreiche, mit Reizleitung begabte Fäden

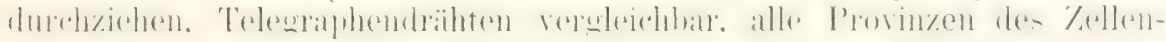
staates bis in die kleinsten Bezirke hin. Was hier mol dort im Körper vor sich geht, die verschiedenartigsten Empfindungen von Zuständen im Reizleben der Zellen. werden durch sie als Botschaften nach Zentralstationen, den Ganglienzellen, übermittelt, durch sie zum Bewubtsein des Ganzen gebracht. Und ungekehrt werden durch andre Fiden. durch die motorischen Nerven, von den Zentralstellen Willensimunlse zu diesen und jenen Organen fortgeleitet. Muskeln und Drüsen, Herz und Blutgefïlìe werden hierduch zu geordneten. zweckmäbigen Leistungen veranlabt. Zeit und Mas, der Arbeit wird in vielen Fällen nicht mehr von den ansführenden Zellen, Geweben und Organen selbst bestimmt, sondern von Zentralstellen aus, die ihrerseits wieller im Dienste dies Ganzen stehen.

Über die doppelte Stellung der Zelle als Elementarorganismus und als determinierter und integrierter 'leil eines ïberocorilneten, höheren Orwanismus.

Von den beiden Betrachtungsweisen, welche wir als die morphologische und als die physologische unterscheiden wollen. ist jede 
in inrer Art einseitig, weil die eine zu ausschließlich das Ganze, die andere den 'T'eil betont; eine jede von ihnen ist daher wissenschaftlich unberechtigt, wem sie für sich ausschliefliche Gültigkeit beansprucht. Dies führt uns zur Schlichtung einer Streitfrage, welche sich betreff's der Wertung der Zelle durch die Literatur hindurchzieht.

In unseren Augen bedarf daß zellulare Prinzip, durch welches die Zelle als Lebenseinheit, Lebenszentrum, Elementarorganismus oft in unberechtigter Weise über Gebühr hervorgehoben wirl, yon allgemeineren

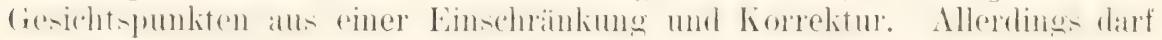
man dabei nicht wieder in den entgegengesetzten Fehler, in ein Verkennen der allgemeinen biologischen Wiehtigheit der Zellenhegrift-s. verfallen. Dies scheint mir von Sachs. de Bary. Whituan. Rauber u. a. geschehen zu sein in mehreren interessanten Erörterungen, denen ich, von dem einen Prunte ahgesehen, somst in vielfacher Hinsicht hriptlichten kann.

Die genamnten Forscher wenden sich gegen die Tragweite und Allgemeinguiltigkeit der Zellentheorie. Auf ihre Bemerkumgen sei hier noch näher eingegangen. damit die Berlentung der Zelle als einer selh-

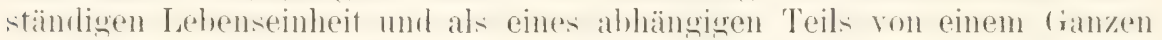
odler von einer übergeordneten, höheren Lebenseinheit nach allen Richtungen kiar gestellt werde.

Der berühmte Pflanzenphysiologe SAcHs bezeichnet es als eine gänzlich verfehlte Auffassungsweise, ,daß die gesamte Gestaltung und Volumzunahme einer Pflanze ans dem Leben ihrer einzehnen Zellen erklärt werden könne". "Ebenso wie das Wachstum der ganzen PHanze und eines ganzen Organs derselben, sei auch das ihrer einzelnen Zellen das Resultat allgemeiner Gestaltungsgesetze, welche die organische Materie ganz ebenso wie die unorganische beherrschen." "Die Zellenbildung ist" für SAcHs ,.eine im organischen Leben zwar sehr allgemeine Erscheinung. aber doch nur von sekundärer Bedeutung, jedenfalls blof eine der zahlroichen Ïudierungen des fiestaltungstriehes. der aller Materie, im höchsten Grade aber der organischen Substanz imme wohnt."

Den gleichen Ideengang hat DE liARY in den kurzen, prägnanten Satz zusammengefaßt: „Die Pflanze bildet Zellen, nicht die Zelle bildet die Pflanze."

In ähnlicher Weise hat sich in einer interessanten Rerle auf dem Zoologenkongress, der hei tielegenheit der Weltaustellung in ('hicago

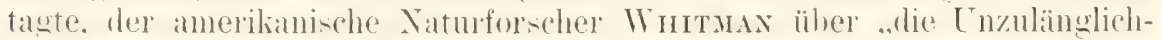
keit der Zellentheorie für die Entwicklungstheorie" ausgesprochen. An bei-pielen sucht ar darzutun, dab die Zellenbildung heinen hestimmenten Einflub (directive influence) auf die Gestaltungsprozesse ausübt. „So spiele sich beim Ei die Zellteilung von Anfang bis zu Ende ab, ohne in irgend einem wesentlichen Punkt, möge sie in regelmäbiger oder in

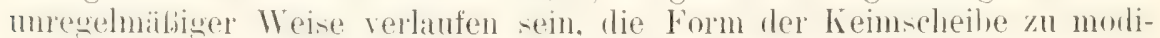
fizieren. I)as (iehemunis der Organisation, des Wachstums. der Entwicklung beruhe nicht in der Zellhildung. sondern in nod elenentareren Elementen der lebenden Substanz (Idiosomes). In ihnen habe jedes Wachstum (Assimilation, Reproduktion und Regeneration) seinen Sitz. Sie setzen jede lebende Substanz zusammen, seien die Träger der Erblichkeit und die wahren Bildner der ()ranismen. Ihre Alion sei nicht durch Zellgrenzen beschränkt."

Was diese Elemente sind und wie sie die Form der Organismen und ihre Differenzierung bestimmen, nennt WhitwaN das Problem der Probleme, welches uns allein mehr Licht bringen kann. 
..Das Wesen der Organisation". hier stellt sich Writuax ganz anf den Standpunlit von Sicris, .,kam nicht mehr in der Zahl der Zellkerne. als in der Zahl der Zellen liegen. I)ie Struktur, welche wir in der Zellemmosaik erblicken, ist etwas zur Organisation noch Hinzugefügtes. nicht sellost der Grund der Organisation. Vergleichende Entwicklungsgeschichte belehrt uns auf' Schritt mol 'Tritt, daf der Organismus die Zellenbildum beherrscht, indem er für den gleichen Zweck eine, einige oder viele Zellen gebraucht, das Zellenmaterial zusammenhäuft und seine Bewegungen leitet und seine Organe formt, als ob die \%ellen nicht existierten oler als ob sie nur sozusagen in völliger Subordination unter seinen Millen existierten."

Almliche Anschaumgen hat sehon vor Wintams in etwas anderer Weise RAUBER in seinen ,nenen Grundlegungen zur Kenntnis der Zelle* entwickelt. Den Zelltheoretikern, welche bei ihren Untersuchungen die Zelle in den Vordergrund stellen und aus ilurer Vereinigung den zusammengesetzten Organismus erklären wollen. hält er die These entgegen: .Das (ianze bestimme die Teile, und nicht umgekehrt. Denn der fertige Organismus sei nichts anderes als das in gesetzmähiger Weise gewachsene und zerlegte Ei. Die bestimmung der Art des Wachstums sei im Ei enthalten, ebenso die bestimmung seiner Zerlegung. Das Ei sei also das Ganze im jugendlichsten Zustand."

Auch Rauber nennt, wie Sachs. .olen werdenden Organismus einen nach bestimmten Richtungen im Wachstum sich ausclehmenden. nach verschiedenen Ausdehnungen des Raumes sich zerklïftenden, in gesetzmäbiger Weise chemisch und histologisch sich gliedernden Protoplasmakiörpei.".

Einseitig erfabt, ist weder der extrem zellulare Standpunkt, noch die in den Ausspribchen von SACHS, WhItax und RAUBER vertretene Auffassung ganz zutreffend und das Verhältnis erschöpfend. Denn so verkehrt es ist. wenn man über der Beschäftigung mit den Zellen die Bedeutung des (ianzen, ron welchem doch der Bestand und die Wirkungsweise der einzelnen Zellen abhängig ist, tibersehen wollte, so wäre es nicht minder verfehlt. wenn man die Wirkungsweise des Ganzen erkiären wollte, ohne dabei auf die Zusammensetzung aus Teilen in gebührender Weise Rücksicht zu nehmen. Das Ganze und die Teile gehören eben zusammen; . sie sind," wie Kuxo Fischer vom allgemein philosophischen

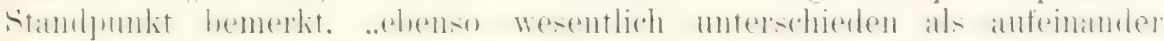

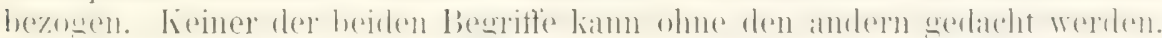
Das Ganze ist nur Ganzes in Rücksicht auf die Teile, in deren Verbindung es besteht. Die Teile sind nur Teile in Riücksicht auf ein (ranzes. zu dem sie sich als Teile verhalten. So fordert jerler der beiden Begrifte den andern als notwendige Berlingung."

Nach meiner Meinung sind daher die Schlagworte: .,die Pflanze bildet Zellen" oder ..die Zelle bildet die PHanze" keine sich ausschliehenden

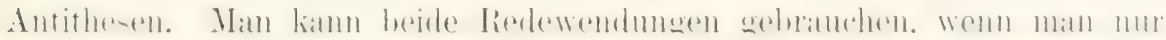
das Verhältnis. in welchem die Zelle als der' 'Teil und die Pflanze als das Ganze zu emander stehen, in der richtigen Weise erfakt. Denn hierauf kommt es für das Verständnis der ptlanzlichen und der tierischen Organisation allein an.

\section{Zusatz zu Sieite 413.}

Das sechzehnte Kapitel seiner Prinzipien der Biologie beginnt HeriberT Spexcer mit der Aufwerfung der Frage: "Ist die Struktur die Ursache der 
Enuktion oder die Funktion die Ursache der Struktur? - Das ist eine Frage, über welche viel hin und her gestritten worden ist."

SPENCER ,hält es nicht für leicht, die Frage gewöhnlich beide (Struktur und Funktion) so innig miteinander verbunden finden, daß keines ohme das andere mörlich zu sein scheint; und allgemein scheinen sie auch gleichzeitig zuzunehmen und abzunehmen".

Nach meiner Meinumg ist die anfgeworfene Frage einfach dahin zu beantworten, dab weder die eine, noch die andere der beiden gestellten Alternativen das Richtige trifft. Denn weder ist die Struktur die Ursache der Funktion, noch die Funktion die Ursache der Struktur. Vielmehr sind Struktur und F'unktion zusanmengehörige und sich ergänzende Begriffe, wie Stoff und Kraft, von denen auch der eine ohne den andern nicht gedacht und der eine nicht die Ursache des andern sein kaun. Wie jeder Ver:inderung des Stoffes notwendigerweise stets auch eine Veränderung seiner Kraft entspricht, so muß jeder Veränderung in einer Struktur auch eine Teränderung in der Funktion parallel gehen. Wie eine gegebene Stoffeinheit mit ihrer Kraft, so kann sich eine bestimmte Struktur mit der ihr entsprechenden Funktion nur durch Einwirkungen von außen, durch äußere Ursachen, verändern. Ganz richtig bemerkt auch $H$. Spencer an anderer Stelle (S. 182), ,es miisse notwendig ein vollständiger Parallelismus zwischen der Eutwicklung der Struktur und der Entwicklung der Funktion bestehen. Wenn die Struktur von dem Einfachen und Allgemeinen zum Komplizierten und Besonderen fortschreitet, so müsse für die Funktion dasselbe gelten."

Dieselben Einwürfe sind zu erheben, wenn JuL. WoLfF, „die Funktion als das einzig und allein formbildende Element" bezeichnet.

\section{Iiteratur zu Kapitel XVII.}

Erster Abschnitt.

1) Haacke, Lehrbuch der Entaicklunosmechanik. 1807.

2) Herbst, Kuxt, Über die Bedeutung der Reisphysiologie für die kausale Anffassung z'on Torgängen in der tierischen Ontogenese. Biol. Zentralbl., Bid. AlV u. IT. I89t. 1805. Wit einem ansfïhrlichen Literaturveraeichnis.

3) Hermann, Handbuch der Physiologie, Bit. II, I, S. 8-IO, II, 2, S. 207.

4) Johannes, Müller, Handbuch der Physiologie des Menschen, Bd. Il. C'oblenz 1870.

5) Roux, Wilhelm, Der Écampf der Teile in Organismus. Ein Bcitrag sur Vera'ollständigung der mechanischen Zneckmäßigkcitslchre. Leipzis 1881 .

6) Sachs, Julius, Vorlesungen über Pflansenphy'siologic. Vorlesung 34. I882.

7) Spencer, Herbert, Die Prinzipien der Biologie, Bd. I u. II, S. I66-I82. I876.

$$
\text { Yweiter Abschnit. }
$$

1) Bronn, Morphologische Stutien über die Gestaltungsesetse der Ninturkörper iübrhanpt und der oremischen insbesondere, S. I6I-409. I858.

2) Haeckel, Generelle Horphologie, Bit. II, S. 240. 1866.

3) Milne Edwards, Legons sur la physiologie et l'anatomie comparie etc., 1. I. I857.

4) Derselbe, Introduction ì ler soologic generale. Paris 1851 .

$$
\text { D) ritter dhschnitt. }
$$

1) De Bary, Botrnische Zeitung 1879, S. 222.

2) Hextwig, Oskar, Die Tragacite de' Zellentheorie. Die Aula, Wochenbl. f. a. akcal. Helt, I. Johts. 1805, Heft 2 und 3.

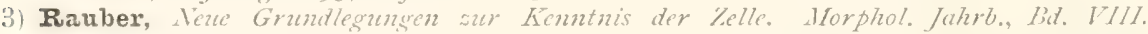
1883.

4) Whitman, The inadernacy of the cell theory of developpenent. Hoods Holl. Bioleg. Lectures 1803 . 


\section{ACHTZEINTES KAPI'TEL.}

Verschiedene Beurteilung der Veränderungen, welche in den Zellen durch die Arbeitsteilung hervorgerufen werlen.

\section{Die Lehne von der Spezifizität der Zellen. ihren Metamorphosen und ihren verschiedenen Zustinden.}

Wie im 17. Kapitel kurz auseinandergesetzt wurde, gewinnen die

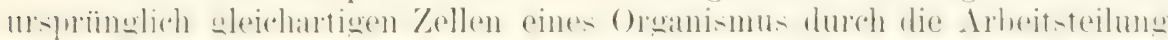

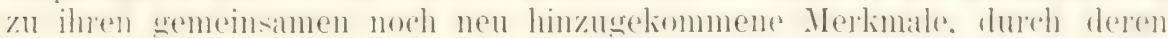
Besitz sie sich voneinander unterscheiden. In die Bedeutung dieser Unterschiede müssen wir jetzt noch tiefer einzudringen versuchen, dem in bezug hierauf herrschen unter den Histologen zurzeit noch zwei sehr

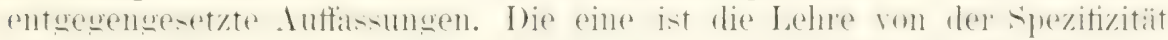
der Gewebszellen, die andere die Lehre von der Artgleichheit der verschieden differenzierten Zellen eines Organismus.

\section{a) Die Lehre von der Spezifizitiit der Gewebszellen.}

Was das Dowma von del Spezifizität der Gewebsellen zu bedeuten hat. darüber haben sich Bard, Pfitzyer. Hansendaxy, Nussbaum in klarer Weise und: wie ich fast glaube, im Sinne der Mehrzahl der Histologen ausgesprochen.

Der Begriff' (ler Spezies, wie er sich durch Untersuchmmg des PHanzenund 'Tierreiches ausgebildet hat, oder der naturhistorischen Art. wie sie Nïgeri genannt hat, wird auf das Verhälnis der Zellen im Organismus ibertragen. Wie sich das Tierreich ans verschiertenen Spezies von Tieren. so setzt sich der Organismus aus verschiedenen Spezies von Zellen zusammen. Wie eine jerte 'lierart nu ihresgleichen zeugt, so soll auch eine spezitische Zelle orler eine Zellenspezies nur wieder eine Zelle ejusdem

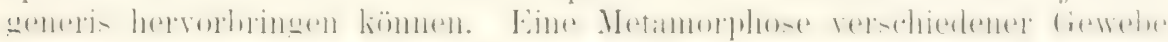
inemander oder eine Metaplasie wird daher in Abrede zu stellen orler in ihrer allgemeinen Bedeutung wenigstens abzuschwächen versucht.

So hat BARD in einer besonderen. unser 'Thema behandelnden Schrift den Satz aufoestellt: „Omnis cellula e cellula ejusilem generis." Der Zusat\% ,ejusdem generis" soll hier sagen, daf es in einem Organismus generisch verschiedene Zellen, (1. h. verschiedene Spezies von Zellen giht.

PFITZNER bezeichnet es in einer kïrzlich ersehienenen Schrift als

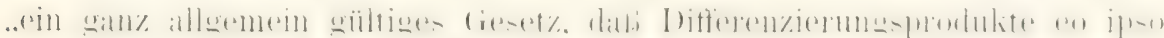
auch Spezitizität erlangen". Das Wort ..Spezifizitï" aber definiert er gleich noch genauer in rier Weise: "Wemn Wolf und Fuchs auch einen gemein- 
Samen Stammvater haben, so erzengt doch seit der Trennung der Wolf nur Wölte, niemals Füchse. Muskelzelle und Nervenzelle sind Teilungsabkömmlinge einer und derselben Zelle, aber seit sie sich differenziert haben. sind sie spezifische Zellen, gehen nicht mehr ineinander ïber:

Über die Spezifizitit der Gewebe handelt in eingehender Weise anch Haxsemann, wobei er auf Verschiedenheiten der Mitosen groben Wert legt und die Hypothese IVErmunns von der erbungleichen Teilung. welche später noch besprochen werden wird. zu demonstrieren sucht:

.Wenn sich das Schleimgewebe des Fötus in Fettgewebe verwandelt, das Schleimgewebe des Glaskörper's aber nicht, so ist das schon allein ein Zeichen, dab man es mit zwei verschiedenen Arten von Schleimge-

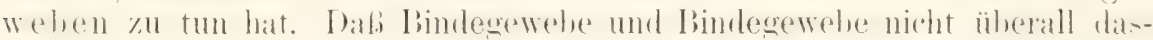
selbe ist, geht eigentlich schon aus der gewöhnlichen Betrachtungsweise hervor, wem man z. B. das Bindegewebe der Cutis mit dem des Ovariums vergleicht, und die Mitosen zeigen auch hier erhebliche Unterschiede. Ja. ich bin geneigt anzunehmen, dab das Bindegewebe jedes Organs ein spezifisches ist, und zwar besonder's auf Grund der Formen der Mitosen."

Nach unserer Meinung liegt hier eine Lehre vor, welche fundamentale Vorgänge der organischen Entwicklung in einem ganz falschen Lichte erscheinen läßt und um so gefährlicher ist, weil sie gewöhnlich als etwas Selbstverständliches, als ein Dogma angesehen wird. Zu ihrer richtigen Beurteilung und um eine V'erständigung zı ermöglichen, mub man sich darüber klar werden, in welchem Sinne man den Begrift ,Art oder Spezies" gebrauchen will, ob bloß in formaler Hinsicht als Unterscheidungs-

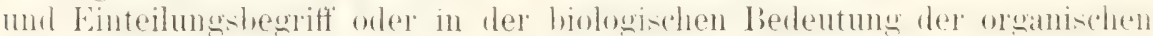
Spezies. Man kann eine Summe von Dingen in sehr verschiedener ,.Art" untereinander vergleichen und einteilen, entweder nach diesem oder jenem besonders in die Augen springenden Nerkmale, also in einer mehr äuberlichen Weise oder nach tieferen allgemeinen Gesichtsjunkten, welche das ganze Wesen der einzelnen Gegenstände zu erfassen suchen. So exhält man Systeme mit ganz verschiedener Artgruppierung. Salze lassen sich nach ihrer Farbe in weiße, rote, grine, blane etc., oder nach ihrer Kristallform, orler nach ihrer tiefer liegenden chemischen Konstitution einteilen. Ebenso kann man die Zellen in verschiedener Weise zu Systemen vereinigen.

Unser histologisches System ist ein rein künstliches, wenn auch ein wissenschaftlich durchaus berechtigtes und notwendiges. Es ist ein kïnstliches. weil nur einzelne Merkmale als Kriterien der Fintheilung verwendet werden. Nach dem äulierlichen Merkmal der liontraktilität werden div Muskelfasern eines sïugetieres, eines Mollusks, einer Meduse ete. unter der hegriftlichen Einheit des Muskelgewehes zusammentefalit, und ehenso alle anderen (iewehsformen. Nim liegt aher doch wohl kilar auf der Itand. daß durch das einzelne Merkmal der Kontraktilität das Wesen der Muskelzelle nicht erschöpft ist. Eine jerle ist ja T'eil eines Organismus und wird in dieser Hinsicht Eigenschaften besitzen, durch welche sie sich von der Muskelzelle eines anderen Organismus unterscheidet. I ch bezeichne sie im Gegensatz zu den histologischen Merkmalen der Gewebe als ihre Arteigenschaften, weil sie das Wesen der Zellen einer Organismenart ausmachen.

Während die histologischen Merkmale uns in den Differenzierungsprodukten der Gewebe etc. erkennbar zutage treten. entziehen sich die Arteigenschaften der Zellen unserer Beobachtung, weil wir zur- 
zeit in die feineren, auf dem mizellaren Gebiet liegenden Organisationsverhältnisse der Zellen mit unseren der\%eitigen Ililfsmitteln der Forschung

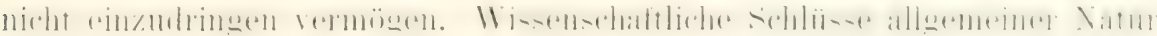
sind es, die uns mit Notwendigkeit zwingen, auserhall, unseres Simnesbereichs gelegene Organisationen anzunchmen.

Am besten läbt sich woh! der P'mkt. anf den es hier ankommt. an dem Beispiel der (ieschlechtszellen klar machen. Wo eine Difterenzierung in zwei Geschlechter im Organismenreich eingetreten ist. treffen wir in ter Regel zwei Arten von Zellen, die sich nach Gröbe, Inhalt und form in auftalliger Weise voneinander unterscheiden: die Fier und die Samenfälen. Im histologisehen Systene stellen wir die Eier der verschiedenen 'Tier- und Pthanzenarten in einer fruppe und ehenso die Samenfälen in einer anderen (iruppe zusammen: wir erhalten durch diese Zu-

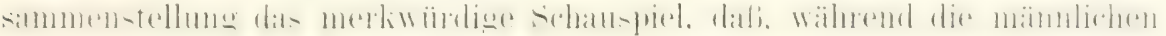
und weiblichen (ieschlechtszellen ein und derselben Organismenart in allen ihren änferen Merkmalen im höchsten Grade verschieden sind. die Eier ron Organismen, die in Srstem sehr entfernt ronemander stehen, zum Beispiel von manchen Wirbeltieren und Wirbellosen, ja selbst von Pflanzen und Tieren, zum V'erwechseln ähnlich sind. und ebenso ihre Samenfäden. Die Eier lamn man damn weiter nach der Beschaffenheit des Dotters in die bekannten Unterarten einteilen, ebenso die Samenfïlen nach weiteren Strulitureigentümlichkeiten.

Das so erhaltene System ist ein in mancher Hinsicht zweckmäliges. weil es emen raschen Überblick über manche Verhälnisse grestattet, aber ein durchaus kïnstliches, wie das ganze histologische System. Denn die Einteilung beruht anf äuBerlichen und nebensächlichen Merkmalen der

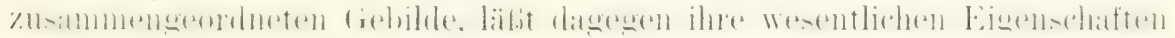
ganz unbericksichtigt. Was diese sind, ergibt sich aus der Erwägung. (lab Ei und Samenfaden die Anlagen für einen nenen Organismus bilden.

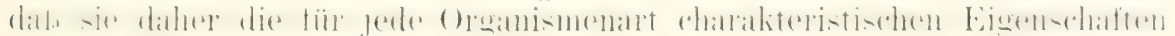
der Anlage nach enthaIten müssen. Durch solche Erwägungen gewamnen wir den Begriff des Idioplasmas (siehe ersten Teil, Seite 354) oder (ler Anlagesubstanz. welche das eigentliche W'esen der (ieschlechtszelle ausmacht. In der Organisation ihres Idioplasmas müssen Eier und Samenfiiden ein und derselben Organismenart im wesentlichen gleich sein, dagegen müssen sich die (ieschlechtszellen verschiedener Tierarten, z. B. einer Säugetier- und einer Vogelart. in der Beschaffenheit ihrer Idioplas-

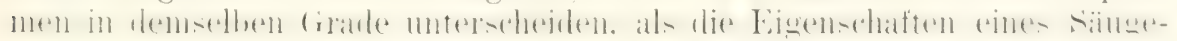
tieres ron denen eines Vogels verschieden sind.

Die so erschlossene Organisation des Idioplasmas ist mit unseren Simnen nicht wahrnehmbar. Wären wir in der Lage, für sie eine Formel.

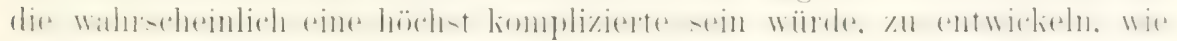
es die Chemiker für ihre unendlich riel einfacher aufgebauten Stotte rermögen, so wären wir in der Lage, auf Grund der Konstitutionsformeln des Idioplasmas die Geschlechtszellen der Organismen in ein System zu bringen, welches nicht. wie das histologische, aut nehensächliche, sondern auf die wesentlichen Eigenschaften gegriundet ist. In einem solchen System würden männliche und weibliche Geschlechtszellen emer Organismenart wahrscheinlich nur unbedeutende Varianten derselben Konstitutionsformel darbieten. wïhrend die Formeln für die (ie-

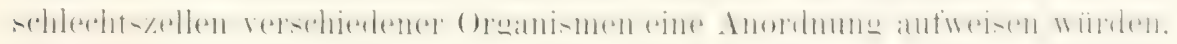
die etwa der Gruppierung der 'Tier- und Pflanzenspezies im natürlichen System entspräche. 
Mit ilen verschiedenen Gewebsarten verhält es sich genau ebenso wie mit den Ei- und Samenzellen. Die histologischen Unterschiede immerhalb der Zellen sind erst sekundären Ursprungs; sie beruhen anf Verschiedenhoiten dex für hesondere \%werke anseschiedenen bildumesprodukte des Protoplasmas, der formed matter von Beale; ihre Artgleichheit dagegen beruht - was das viel Wichtigere ist - auf der Organisation der die

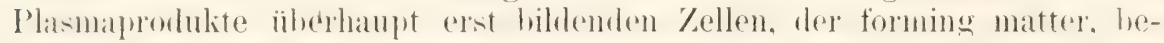
sonders aber auf der Konstitution des von den Geschlechtszellen üherliommenen Idioplasmas, welches fïr jerle Orwanismenart ein besmoleses ist. In den histologischen Unterschierlen eines Organismus erblicke ich daher nur verschiedene Zustände von Zellen, die in der Konstitution ilres Irlioplasmas ühereinstimmen und als Abkömmlinge einer gemeinsamen Mutterzelle der Art oder Spezies nach gleich sind.

Untersuchen wir noch genauer die einzelnen Gründe, welche sich zugunsten der Lehre von der Artgleich heit der verschieden differenzierten Zellen einer Organismenspezies anführen lassen. Denselben Unterschied, den wir oben bei den Gewebszellen gemacht haben zwischen einer beständigen Organisation, auf welcher das Wesen der Spezies beruht und einer im Vergleich zu ihr mehr nebensächlichen Organi-

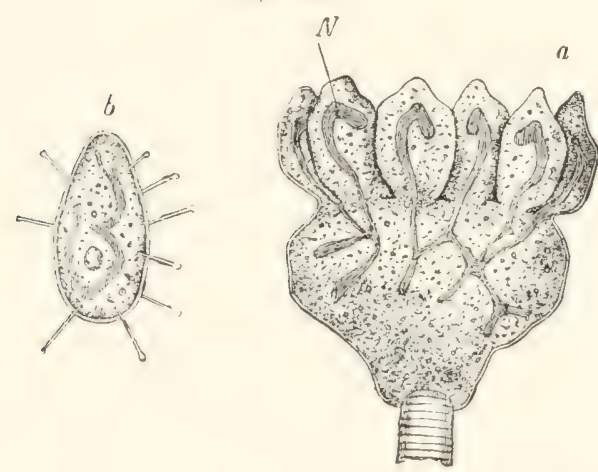

Fig. : 3 in.

Fig. 302. Podophrya gemmipara mit vielen Knospen. a Knospen, die sich ablösen und zum Sclowirmer b werden. $N$ Kern. Nach R. Hertwig, Zoologie.

Fig, 303. Gregarinenentwicklung: Nach R. Hertwia, Zoologie. I Clepsidrina blattarum in Konjugation. ck Ektosark. en Entosark, cu Cuticula. pm Protomerit. dm Deutomerit. $n$ Kern. II $A-C$ Cysten in Umwandlung zu P'seudonavizellen. pr Pseudonavizellen. rk Restkörper. III $A$ Eine I'seudonavizelle stärker vergrößert. $B$ Dieselbe geteilt in die sichelförmigen lieime sk.

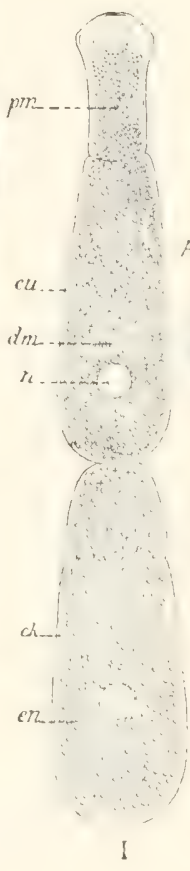
Fici. : : $; 13$.

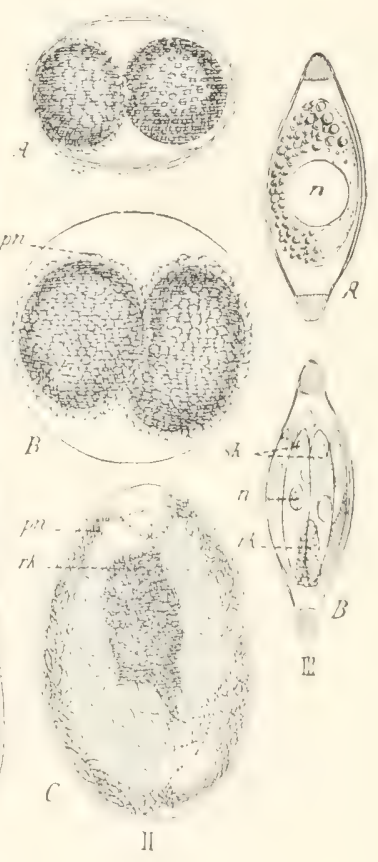

sation, welche durch Arbeitsteilung entstanden ist, beobachten wir vielfältig auch sonst bei Lebewesen. sowohl bei einzelligen Organismen als auch bei polymorphen 'Tierstöcken. Wir kömnen feststellen, daß im Leben der Art ein und dasselbe Individuum uns häufig unter sehr verschiedenen Formzuständen entgegentritt, über deren Zusammengehörigkeit unter einen gemeinsamen Artbegriff kein Zweifel aufkommen kann.

Zwei Beispiele mögen zur Veranschaulichung dienen. 
Podophrya gemmipara (Fig. :302) eine Acinete. sitzt im ansgebildeten Zustand mit einem langen Stiel an anderen Körjern fest und

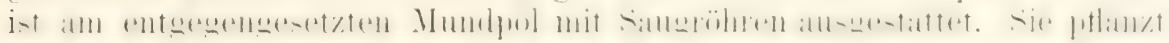
sich durch Bildung mehrerer kleiner knospen fort, die auf ihrer OberHäche nach drt freischwimmender, hypotricher Infusorien bewimpert sind.

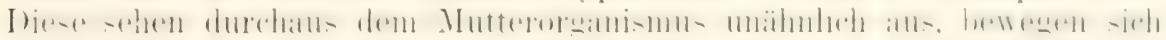
eine Zeitlang als Schwärmer im Wasser fort. setzen sich später ircrendwo fest und entwickeln num einen Stiel. Tentakeln und Saugröhren, wodureh sie erst allmählich wieder die Form des Muttertieres gewinnen.

Die Grearinen (Fig. 303) sind grobe, in zwei Stïcke, Protomerit

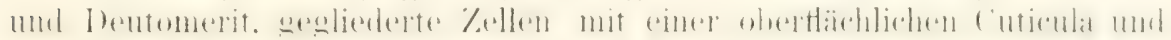
einer Lage Muskeltibrillen unter ihr. Sie encystieren sich nach vorausgegangener Konjugation und zerfallen dann unter 'leilung des Kerns in

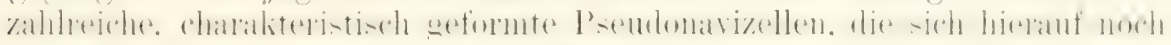
in die sichelförmigen lieime teilen. Aus den auBerordentlich kleinen Liemzellen entwickeln sich allmählich wieder die so ganz ander's gestalteten Gregarinenzellen.

So lassen sich noch viele derartige Metamorphosen von einzelligen Organismen anführen, wobei die Arteigenschatten ron einem auf den andern Zustand einfach übertragen werlen. Derartige Verhälnisse bei

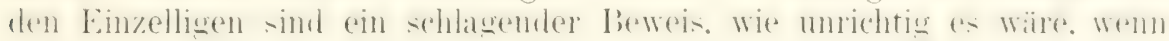
wir aus dem Umstand, daß eine Zelle eine besondere Differenzierung erfahren und datür gewir-ermalien ein nene- Kleit erhalten hat, also all- dem

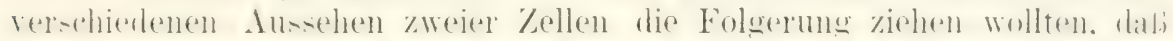

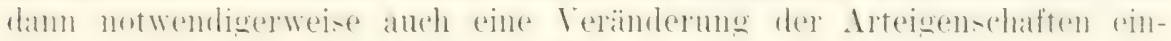
getreten sein müsse. Denn wenn überhaupt die Arteigenschaften an eine Substanz gebunden sind. die als Erbmasse ron dem Mutter- auf den Tochterorganismus übertragen wird, so müssen die infusorienartigen

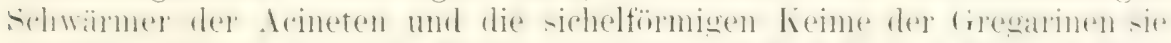

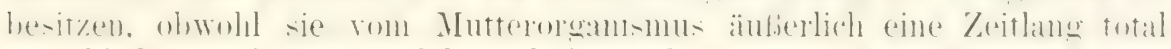
verschieden sind; sie wandeln sich ja wieder in eine Acinete oder (rregarine oder in die form 1 m. von der sie selbst als lieime abstammen.

Nicht minder lehrreich für die Beurteilung der uns beschäftigrenden

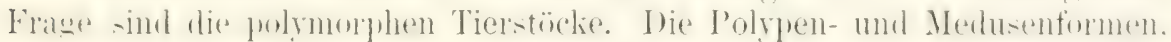

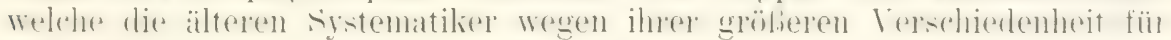
mehrere Tierarten gehalten hatten, sind nur, woran jetzt kein Tierkum-

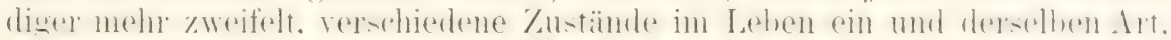

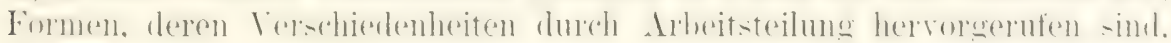
Formen. die sich zum Teil ineinander umwandeln kömuen und von denen

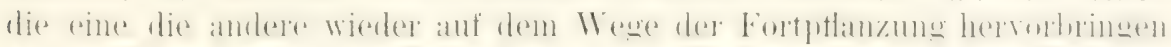

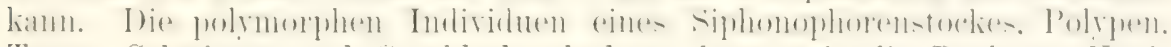
'Taster. Schwimm- und Geschlechtsglocken, ebenso wie die Drohnen. Königimnen. Arbeiter eines Bienenstockes oder die rerschiedenen Individnen der T'ermiten (Fig. 304), sind wie die verschiedenen (iewebe eines Organismus einander der Art nach gleich, aber in sekundären Charakteren.

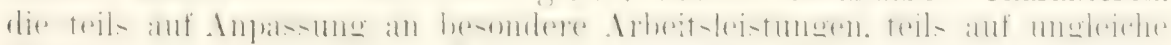

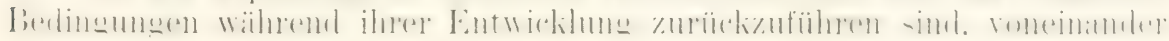
oft erheblich verschierlen.

Bei den versehiedenen Individuen einer Siphonophoren-, Bienen-. Termitenkolonie haben wir ebenso wie bei den Geweben eine der Art eigen-

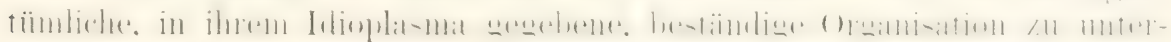
scheiden und eine sekundäre Organisation. Welche anf Ampassung an besondere Arbeitswecke beruht. 
Es ist wichtig, diese Unterscheidung sich in ihrer ganzen 'Tragweite klar zu machen. wem man vom Wesen des Organismus sich eine richtige

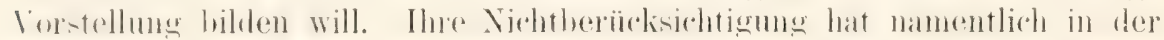
Medizin zu manchen Verirrungen Anlaß, gegeben. Weil die für bestimmte Arbeitszwecke gebildeten Produkte der Gewebe bei verwandten Tieren

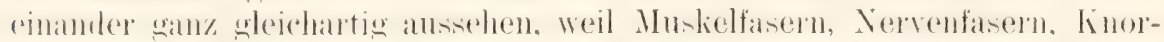
pel, Knochen, Blut rom Mensch, vom Hund und Kaninchen unter Umstünden für uns histologisch nicht zu unterscheiden sind, hat man den auf einen grofen Irrtum beruhenden Fehischlub gemacht, dab sich gleiche Gewebe bei zwei Organismen auch durcheinander ersetzen lassen miibten.
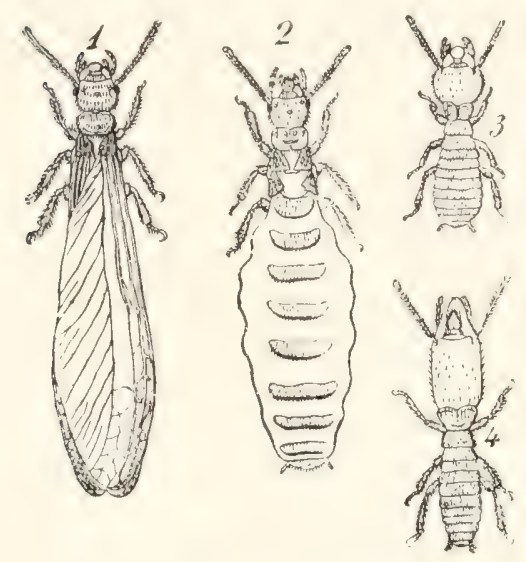

Fig. 304. Termes lucifugus. Nach Leunis-Ludwig. I Geflïgeltes Geschlechtstier. 2 Weibchen nach Verlust der Flügel mit liesten derselben. ; Arbeiter. + Soldat.

Entstehung in einem bestimmten orwanismus und aus seinem hestänligen Verkehr mit allen übrigen 'Teilen des Organismus erklären. Daher vertragen sich zwei fremde Blutarten nicht miteinander und zersetzen sich gegenseitig. Anstatt als Heilmittel, wirkt fremdes Blut vielmelir als ein in die Arlern gebrachtes Gift.

Chirurgen haben Gewebsteile und Organstiicke von einer 'T'ierart auf eine andere zu transplantieren versucht, in der Meinung, daß Kinochen zum Stützen, Haut zur Bedeckung von Oberflächen diene. Sie haben auch hierhei erfahren, dabzwischen gleich funktionierenden feweben zweier Tierarten doch anch Verschiedenheiten hestehen, welche den Frfolu ainer Überpflanzung verhindern, weil sich „Fremdartiges“ oder Artungleiches nicht miteinander verbinden läbt.

So haben Fragen, welche auf den ersten Blick rein theoretischer Natur zu sein scheinen, doch auch schon ihre praktischen Konsequenzen in der Medizin gezeitigt.

Indem ich mit aller Entschiedenheit die Lehre von ,der Spezifizität (ler Zellen" bestreite, trete ich nicht in Wirlerspruch zu den Erfahrungen, welche pathologische Anatomen und Histologen übel die Vorgänge bei der Regeneration der Gewebe gesammelt haben. (Vergleiche hierzu auch meine Pemerkung in Zeit- und Streitfragen, Heft I, S. 142.) 
Um Mibverstandnissen gleich von vornherein vorzubengen, sei dies mit allem Nichdruck hier noch hervorgehoben. Daraus, dab alle Zellen eines Organismus der Art nach gleich sind und Erbmasse enthalten, folgt noch lange nicht, dab num auch an allen Orten und bei allen Tieren aus jeder Zelle alles mögliche werden müsse. Wenn daher jemand uns rorhalten wollte. daf noch niemand die Umwandlung einer Ganglienzelle in eine Muskelfaser orler einer Bindegewebszelle in eine Epithelzelle beol)achtet hat etc. so ist dies lein Einwand, der unsere Theorie berïhrt. da sie dergleichen Behauptungen nicht aufstellt. Demn es hängt ja das, wozu eine Zelle wird, unter allen Cimstänlen von verwickelten Bedingungen ab. welche nicht in jedem Moment im Handumdrehen herzustellen sind.

Hier kommen in Betracht nicht allein die Lagebeziehungen der

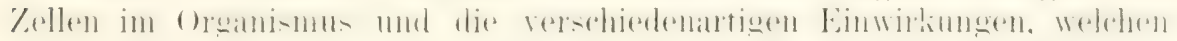
sie infolgedessen ausgesetzt sind, sondern auch die zahlreichen Zustände.

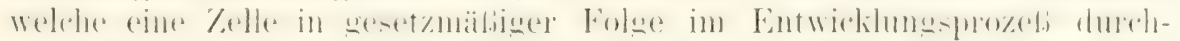
gemacht hat und dureh welche ihre Stellung im Organismus bestimmt und ihr das besondere Gepräge aufgedruickt worden ist.

Es befindet sich jede Zelle auch unter Nachwirkungen vorausgegangener Zustände, was an späterer Stelle noch, näher atisgefuhrt werden wird. Hieraus erklärt es sich, dab, wie die ron uns

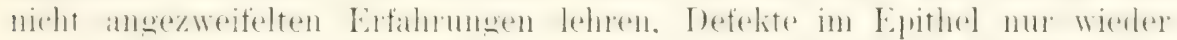
rom Epithel aus ersetzt werden, und dali im allgemeinen Bindegewebe

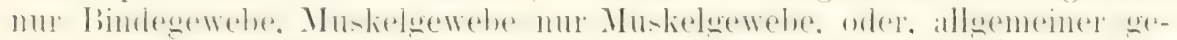

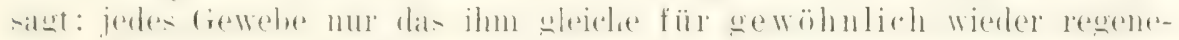
riert. Unter allen Umständen ist dieser $\mathrm{Weg}^{\mathrm{T}}$ der nächstliegende und einfachste.

Was von uns bestritten wirl. ist der Schlub. welchen viele Forscher aus solchen Erfahrungen ziehen, dab die Zellen der einzelnen Gewebe

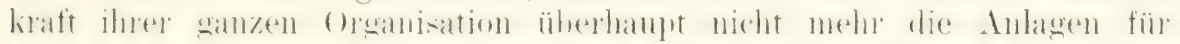

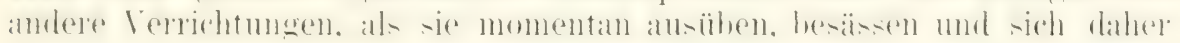
äberhaupt zu nichts anderem. als was sie schon sind, entwickeln kömnen.

Im Gegensatz hierzu behaupten wir, dab aus dem Nichteintreten einer Entwickhung man nicht ohne weiteres auf das Fehlen einer ent-

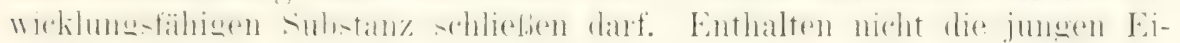
und Samenzellen im Eierstock und Hoden eines neugeborenen Säucetieres Keimsubstanz: Trotzdem hat noch niemand aus den Keimen eines solchen

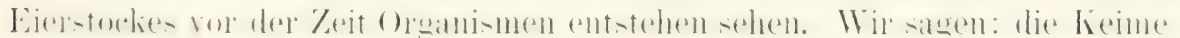
sind unreif: das heibt nach unserer 'Theorie: die Bedingungen, unter denen sie sich zu entwickeh vermögen. sind noch nicht erfüllt. So müssen auch für ein Gewebe mancherlei Bedingungen erfüllt sein, ehe es sich in eine andere Form umwandeln kann.

Wenn jemand vol zehn Jahren hätte behaupten wollen, daf die

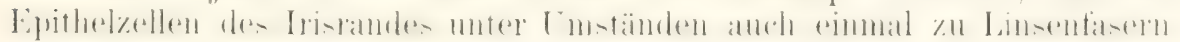
auswachsen kömnten, er wiurde nirgends Glauben gefunden haben. Jetzt liegen die Tatsachen vor, welche wir noch in einem späteren Kapital beschreiben werilen.

Der Lehre von der Spezifizitiat der Zellen wird es ihnlich ergehen wie vor Zeiten dem in der Chemie herrschenden Dogma. daß es für den Chemiker ummöglich sei, organische Verbindungen. welche im lebenten Körper entstehen, in der Retorte künstlich herzustellen. Das Dogma erhielt seinen ersten Stoh, als WönLer die kïnstliche Srnthese des Harnstoffes entdeclite; es ist damn bald durch die ganze weitere Entwicklumg der organischen Chemie zu Grabe getragen worden.

O. Hertwig, Allemeine I3iologie. 2. Aufl. 
So ist auch jetzt das Dogma von der Spezifizität der Zelle fim Prinzip durch die Entreckmo der Linsentegeneration vom Irisepithel aus nachhaltig erschïttert worken, und es brauchen in Zukunft nur noch mehrere derartige fiewelsmetamorphosen auf experimentellem Wege. Was wohl nicht ausbleiben wird. hervorgerufen zu werden, um anch die letzten Zweitler zu bekehren.

Anmerkung. Es ist von historischem Interesse, hervorzuheben, daf schon zu einer Zeit, wo die Zellentheorie eben in ihren ersten Anfängen stand, Johannes MüLler in sehr klarer Weise ähnliche Gedanken ausgesprochen hat, wie sie im Kapitel XVIII entwickelt worden sind. Der sehr bemerkenswerte Passus in seinem Lehrbuch der Physiologie heißt:

„Wann blobe Stücke einer Planaria, einer Hydra, und bei letzterer sehr kleine Stücke, die Kraft zur Bildung eines Individums enthalten, so ruht diese Kraft offenbar in einer Masse von Teilchen, welche, solange sie mit dem Stamme verbunden waren, speziellen Funktionen des granzen 'Tieres dienten und seinen Willenseinflub erfuhren. In diesen Stücken werden Muskelfasern, Nervenfasern etc. sein. Eine klare Vorstellung dieser Tatsache führt zu dem Schluß, daß ein Haufen tierischer Gewebe von verschiedenen physiologischen Eigenschaften von einer Kraft beseelt sein kann, welche von den spezifischen Eigenschaften der einzelnen Gewebe ganz verschieden ist. Die Eigenschaften der Gewebe in einem abgeschnittenen Stiick Hydra z. B. sind Zusammenziehungskraft der Muskelfasern, Wirkung der Nervenfasern auf die Muskelfasern etc. Diese Eigenschaften hängen von der Struktur und dem Zustande der Materie in diesen Teilchen ab. Jene Grundkraft hingegen ist identisch mit der, welche den ganzen Polypen erzeugt hat, wovon das Stück abgeschnitten wurde.

Johannes MüLler wirft bei dieser Gelegenheit auch die von uns erörterte Frage anf: "Wie kommt es denn, daß gewiße Zellen der organischen Körper, den andern und der ersten Keimzelle gleich, doch nichts erzengen können als ihresgleichen, d. h. Zellen, aber keineswegs der Keim zu einem ganzen Organismus werden können? Wie die Hornzellen zwar neben sich durch Aneignung der Materie neue Hornzellen, die Knorpelzellen neue Knorpelzellen in sich bilden, aber keine Embryonen oder Knospen werden können?"

JoHaxnes MÜLLER antwortet auch auf diese Frage: "Es kann davon abhängen, daß diese Zellen, wenngleich die Kraft zur Bildung des Ganzen enthaltend, doch durch eine spezielle Metamorphose ihrer Substanz in Horn und dergleichen eine solche Hemmung erfahren haben, daf sie sowohl bald ihre Keimkraft am Stammorganismus verlieren und, tot geworden, sich abschuppen, als auch, rom Stamm des Ganzen getrennt, nicht wieder Ganzes werden können."

Hier ist wohl auch der geeignete Platz, noch etwas tiefer in manche Figentïnlichkeiten der durch Arheitsteilung erworhenen Organisation der Zellen einzudringen, Im Gegensatz zur ererbten Organisation bezeichnete ich sie schon früher als eine mehr unbeständige und vergängliche.

WTas ist die Ursache ihrer größeren Neigung zur Veränderung? Sie ist offenbar darin zu suchen, dab die auf Arbeitsteilung beruhende Organisation nur unter ganz bestimmten Bedingungen und zur Erfüllung einer besonderen einseitigen Leistung entstanden ist und zwecklos wird, wem die Berlingungen sich änder'n und ihre Leistungen nicht mehr vom (resamtorganismus in Anspruch genommen werden. Solange die Protoplasmaprodukte, in welchen sich uns die einseitige Differenzierung der Zelle 


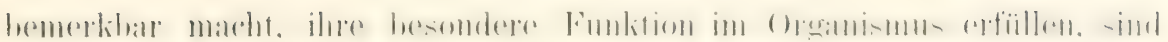
sie gewöhnlich der Schauplatz eines sich besonders rasch vollziehenden Stoff- und Kraftwechsels, je nach der Intensitiat ihrer limktion. Muskel-

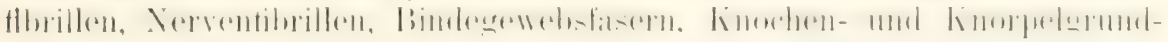
substanzen, Drïsenzellen ete. haben, ein jedes (iebilde in seiner Art, be-

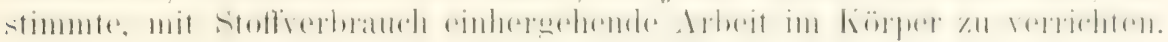
Da nun der Lebensprozels, wie schon fräher auscinandergesetzt wrurle. auf einer beständigen '/erstörung und Neubildung orenanischer Substanz beruht, so müssen anch die Protoplasmaprodulite sich bei ihrer Tätigheit. allmählich verbranchen und mïssen, um sich in ihrem Bestand zu erhalten. durch nen eintretende 'Teilchen ersetzt werden, welche die formative 'Tätigkeit „ler zu ihnen gehörigen '/ellen bildet. Um erhalten zu bleiben. müssen sie immer wieder neu erganzt werden. Dazu ist aber erforderlich, dab

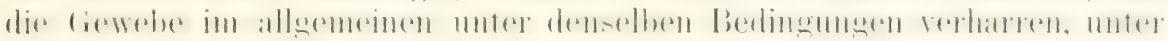
welehen sie entstanden sind und funktionieren.

Nun ist aber, wie wir gleich anfangs hervorhoben, die Entstehung der Protoplasmaprodukte inmer an besondere, zuweilen wahrscheinlich sehr komplizierte Bedingungen gebunden. Es geht mit den im Iabora-

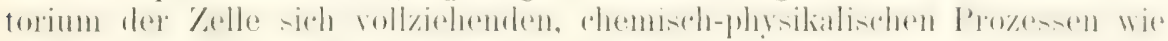
bei der kïnstlichen Darstellung von hoch komplizierten oromischen Verbindungen. Auf direktem Wege, durch einfache Mischung der in der

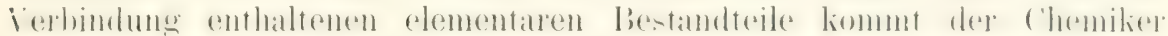
niemals zum 'Ziele; er muß, um ein Kohlenhydrat ron einer besonderen Strukturformel darzustellen, erst die Bedingungen ausfindig machen, unter welchen sich die einfacheren Teile zu dem limplizierten Ganzen

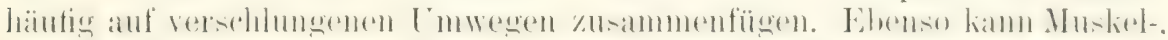
Nerven-, Knorpelsubstanz usf. in der Zelle allein entstehen, wenn der ganze Komplex der auf Bildung von Muskel-, Nerven- und Knorpelsulbstanz hinwirkenden Ursachen gegeben ist. Nicht nul müssen von ihmen

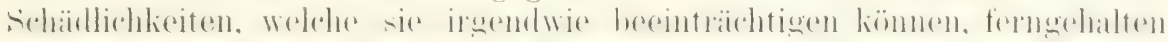

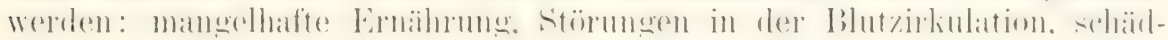
liche mechanische und thermische Einflüsse, giftige chemische Verbindumgen, welche in den Blut- und Säftestrom durch irgendwelche Um-

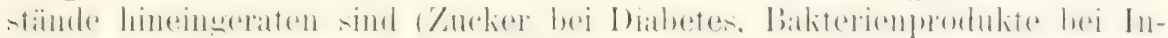
fektionskrankheiten, (iifte dureh Aufnahme in den I)armkanal), sondern die (iewebe müssen, was weniger selbstrerständlich erscheint, die T'errichtungen, für welche sie im Organismus vorhanden sind, auch wirklich ansüben. Sie müssen, wenn anch nicht immer, doch zeitweise in der ihnen angemessenen Weise in Tätigkeit treten; denn das ist nit ein Zeichen dafür, daß sie sich unter den Bedingungen, unter denen sie entstanden sind, im allgemeinen noch befinden. Gin Nery mub Reize leiten. das Auge Licht emptinden, ein Muskel sich zusammenziehen; Kunochen. Sehnen und Bänder miissen '/ug und Druck aushalten, Blutgefube durch

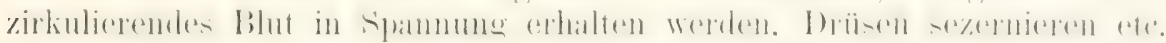
Ein spezifisches Gewebe kamn nieht dauernd in einem Zustand der Untätigkeit oder Leistungsunfühigkeit verharen, ohne dab es in der lie-

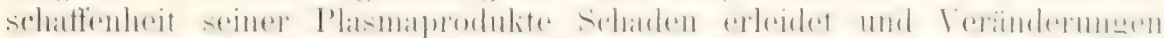

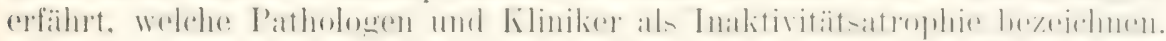

Beweisende beispiele hierfï finden sich in grober Zahl. Ein Musliel.

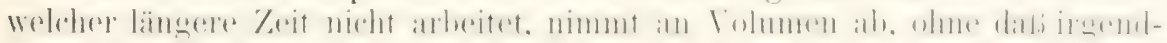

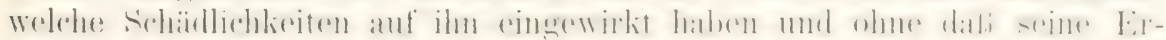
nährung durch den biutstrom eine beeinträchtigung erfalıren hat. Chi-

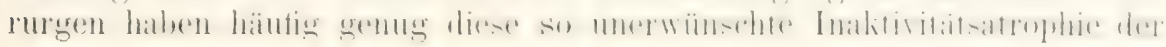


Muskeln zu beobachten Gelegenheit gehabt, wenn sie eine Gliedmaße

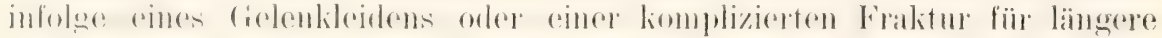
Zeit durch einen Gipsverband mbeweglich gemacht und die Muskulatur zur Untätigkeit genötigt haben.

Die Schorgane von Tieren, die beständig in unterirdischen IIöhlen wohnen, sind vollständig verkümmert, sodals sie auf Lichteindrücke überhaupt nicht mehr reagieren.

Lin Blutgefüß, das infolge einer Veränderung der Zirkulation aus dem Bhutkreislauf ausgeschaltet wird, verödlet und verliert in kurzer Zeit voll-tändig die einem IBhutgefäl.j zukommende Struktur; die Schichtmmg seiner Wand in 'Tunica intima, media und adventitia, die charakteristische Verteilung von elastischer Substanz und von Muskelfasern. Es wird ein Bindlegewebsstrang, wie uns die Vorgänge, die sich nach der Geburt eines

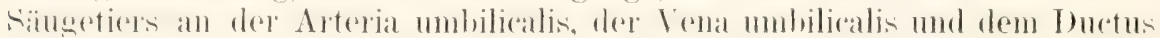
Botalli abspielen, zur Genïge lehren.

Ein Knochenvorsprung, von welchem die einen Zug auf ihn ausïhende Muskelsehme abgetrennt wirl, verkleinert sich. - Der Rand des Acetabulums verändert sich allmählich, wenn bei einer (H)arshenkelluxation der Femurkopf wieder in die alte Lage zurïckversetzt wiril. - Die Zahnalveolen schwinden, wenn die in ihnen befestigten Zahnwurzeln durch Ausziehen oder durch Resorption entfernt sind.

Ein Magen, dem fortgesetzt nur ein Minimum von Speisen zur Ver'-

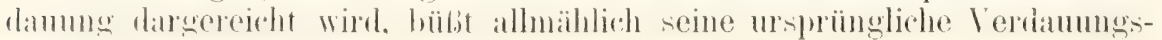
kiraft ein.

Der Abschnitt des Darmes unter einer ergiebigen Kotfistel, einem sogenamnten Anus praeternaturalis, atrophiert zu einer dïnnen Haut (COHNHEIM).

So zerstört sich gewissermaßen jerle Struktur im Organismus allmählich von selbst, wenn sie nicht mehr den Bedingungen entspricht, unter welchen sie entstanden war und deren sie daher auch zu ihrer Erhaltung berlarf. Es ist dies eine einfache Konsequenz der ganzen Auffassung, die wir rom Lebensprozel gewomnen haben; es ist eine Konsequenz des Satzes, dab die Beständigkeit der organischen Substanz nur auf ihrer fortdanernden Nenerzengung beruht. Kein Strukturteil des Körpers ist an sich etwas Dauerhaftes, sondern wird es nur insoweit, als er bei dem Zerstörmosprozeh, dem el in seinen einzelnen 'T'eilen ausgesetzt ist, in demselben Iabe wieder nen ersetzt wird. Damit dies aber möglich ist, müssen anch alle Bedingmugen erfüllt sein, an welche die Entstehung einer bestimmten Struktur gekniupt ist. Muskelsubstanz entsteht und erhält sich nur an Orten, wo etwas zu bewegen ist, Knochensubstanz, wo etwas zu stützen und Zug und Druek auszuhalten ist, Nervensubstanz, wo Reize zu empfangen und fortzuleiten sind.

Han hat die komplizierten Erscheinungen, welche zum T'eil schon die älteren Naturforscher und Ärzte gekannt und zu erklären versucht haben, in unserer Zeit verständlich zu machen gesucht durch den Satz: es sei zur Erhaltung organischer Gebilde ein funktioneller Reiz, das heilst, ein Reiz, welcher in dem gereizten 'Teil die ihm eigentümliche Funktion hervortuft, erforderlich. Roux hat hiermit die Hypothese ver-

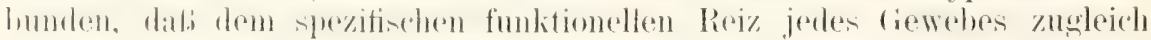
cine trophische, die Ermährung anregende Wirkung zukomme. Der funkfionelle Reiz soll neben der spezifischen Funktion zugleich auch ,direkt oder indirekt" die Assimilation anregen, welche ohne seine Einwirkung nicht gehörig von statten gehen kamn; er soll somit zugleich trophisch, die Lrnährumg hebend wirken." 
Den Sätzen liegt ebenso wie der alten Isehre ron der Wirkung des Gebrauches und Nichtgebrauches der 'Teile oder von der Wirkung der' Übung etwas Richtiges zugrunde. Aber beide Formeln sind zu eng und einseitig gefabt und dringen nicht bis zum Grund der Sache vor. Denn

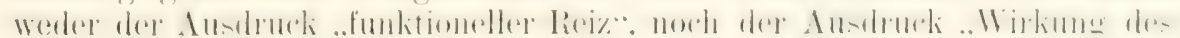

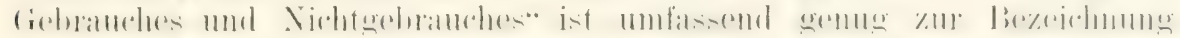
der meist verwickelten liedingungen, welche in der oben angegehenen Weise zur Entstehung und zum Bestand einer or wanischen Strulitur erforderlich sind.

Ein Beispiel wird dies am besten zeigen. Eines der am raschesten funktionierenden Organe, auf welches man sich am häufigsten bei den

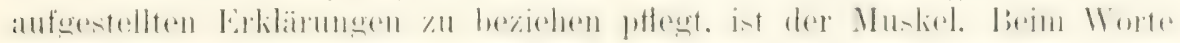
.funktioneller Reiz" denkt man hier gewöhnlich an den Impuls, weleher dem Muskel durch seinen Nerven erteilt wirl. Durchschneidung, überhaupt Degeneration des Nerven, ruft ja Verändermugen in der Strulitur der Muskelfasern und schlieblich ihre Atrophie hervor, weil ihnen rom Nerven aus kein .funktioneller Reiz" mehr erteilt wird. Hierauf palst der

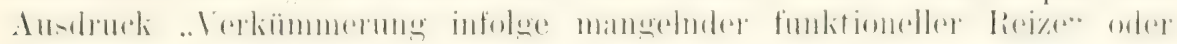
Verkimmerung infolge Nichtgebrauchs ganz gut, und soweit scheint alles mit der Erlikirumg in Ordmung zu sein.

Nun gibt es aber auch Fälle, in denen der Sachverhalt doch ein etwas komplizierterer ist. Ein Muskel kann atrophieren, auch wenn er noch mit seinem leitungsfähigen Nerven verbunden ist. So nehmen bei

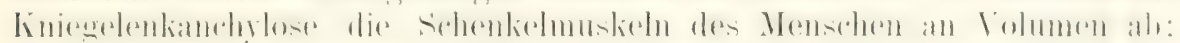
sie können zwar noch vom Nerven aus gereizt werlen, aber sie kömen keine entsprechende Arbeit mehr verrichten, weil die Knochen, welche sie gregeneinander bewegen sollen, absolut unbeweglich geworden sind.

In einem anderen, gewissermaben entgegengesetzten Falle verkimmern die Muskeh, wenn man sie von ihren Ursprungs- und Insertionspunkten abgetrennt hat, so dab sie bei ihren Verliurzungen lieine Widerstinde mehr zu überwinden haben, eine Erscheinung, welche man an Amputationsstümpten zu beobachten (ielegenheit hat.

Es kommt, wie die zwei angefühten Beispiele lehren, nicht nur darauf an, dab der Muskel vom Nervensystem "funktionelle Reize" zugefülut erhät und sich zusammenzicht, sondern yor allen Dingen, wie er sich zusammenzieht. Das hängt aber wesentlich ron den Bedingungen ab, unter denen er sich befindet, besonders von der Art und Gröbe der zu ïberwältigenden Widerstinde, von der Spammung seiner Fasem ete. Fin Muskel. $u m$ in semem Bestand erhalten zu werden. mub die ihm adiauate Arbeit verrichten. Ändern sich daher die bedingungen, unter denen ein Muskel entstanden ist und zuvor gearbeitet hat, so werden sich nach einiger 'Leit anch entsprechende Rï̈ckirlitngen in Veränderungen semer Strulitur bemerkbar machen.

Von Wichtigkeit für die Danertahigkeit von Struktmen ist anch der Unfang der Zerstörungs- mol Neubildungsprozesse, welche in einem (iewebe hei seiner funktion stattfinden. Strukturen werden sich um so leichter und rascher verändern können, je mehr sie einer Zerstörung bei der Funktion ausgesetzt smol. Denn dann werden sich die infolge ver-

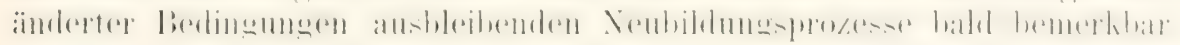
machen. In dieser bezichung bestehen offenbar erhebliche Unterschierle zwischen den eimzehen Organen und Geweben. Am raschesten verindern sich in ihrer Struktur wohl Muskelfasern. Driisenzellen und Simeszellen. in welchen der Stoffumsatz bei ihrer Funktion am gröbten ist. Bestän- 


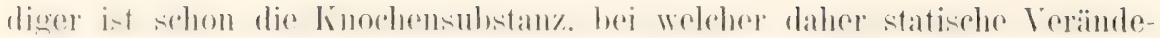
rungen der Struktur sich nur nach längeren 'Leiträmmen und unter konstant einwirkenden Zug- mul Druckkiäten ausbilden werden. Noch passiver als die Knochen sind vermutlich die Sehnen, Fascien und Bänder, so dab sie, wenn sie eimmal gebildet sind, in ihrer Form sich längere Zeit erhalten, auch wenn die Bedingungen ihrer Gebranchsweise andere geworden sind.

Auberordentlich gering sind endlich oftenbar die Zerstörungs- und

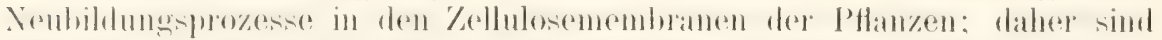

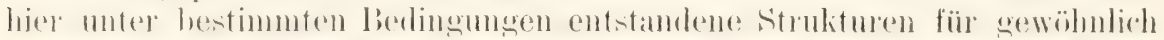

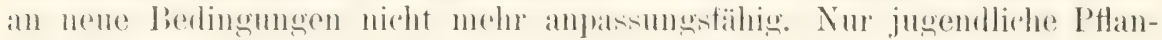
zenteile sind, wie wir später (Seite 463) sehen werden, geotropisch und heliotropisch etc. und veraindern, wenn sie in andere Lagen gebracht werden, ihre Wachstumsrichtung (Fig. 309); schon fest verholzte Pflanzenteile dagegen reagieren nicht mehr. Auch an veränderten Zug und Druck kömmen sich die mechanischen Gewebe der Pflanzen nicht mehr anpassen, wie es im tierischen Körper die Knochen tm (siehe Seite 479). Die in die Dicke

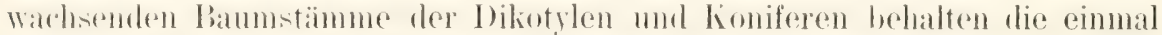
ergengte Holzmasie, sind daher ..fast kompalite, also mechanisch irrationell gebaute Säulen“ (JuLIus WoLFF).

SCIIWENDENER bemerkt hierzu: „Denken wir uns irgend ein jugendliches ()rgan, dessen Zellwände oder vewobstamellen dem fraglichen liurvensystem augenblicklich genau entsprechen, so leuchtet ein, das jede nachträgliche Streckung notwendig ane Verzerrumg descellon herbeiführen mul, sofern nicht sleichzeitig für rine fortwährende liesorption rinzelner (iewrebelemente und für Neubildung anderer an gänstiger stelle Sorge getragen ist. Ein solcher Vorgang findet in Gebälke der Knochen tatsächlich statt und ist von JuLIUs WoLFF noch neuerdings eingehend dargelegt worden." "In regetabilischen diewehen dagegen liommen hödhstens

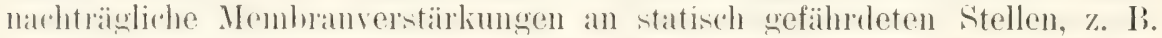
Bilınng von Holzparenchym in den Lürden eines gesprengten Bastringes u. dgl., vor; aber eine fortwährende Umgestaltung und Neubildung von Geweben nach Mabgabe der jeweiligen Zug- und Druckspannungen ist nirgends beobachtet. Wäre sie möglich, so würde es z. B. für die Dikotylen mit Dickenwachstum rationell sein, die inneren Jahresringe des stammes durch einen in zentrifugaler Richtung fortschreitenden Lösmosprozeß in Glykose zu verwandeln und diese zum Aufbau neuer Jahresringe zu verwerten. Ebenso würde im Verlauf der äußeren Dimensionsänlerumen noch manche andere Transformation der immeren Architektur erwünscht sein, wenn sie nur ausführbar wäle. Allein die Pflanze steht hier vor uniberwindlichen Schranken, welche die strenge Einhaltung vorgezeichneter Kurvensysteme von vornherein ausschließen."

Bei den 'Tieren sind Kliniker und pathologische Anatomen auf die Veränderlichkeit der Gewebe schon früh aufmerksam geworden, weil sie sich ja besonders mit den Störungen der normalen Lebensprozesse und Strukturen zu beschäftigen haben. Vor allen Dingen hat VIrchow zur libirmug der sich hier darbietenden Erscheinungen durch seine \%ellularpathologie viel heigetragen. Fir hat zuerst die einzehnen Zustände, welche im Leben der Gewebe eintreten und sich einander ablösen können, scharf unterschierlen und sie mit Namen belegt, welche sich seitdem in der bathologischen Anatomie eingebiirgert haben. Anber dem normalen Zustand der Organe und Gewebe unterscheidet Virchow 1. einen Zustand der Hypertrophie, 2. der einfachen Atrophie, 3. der Metamorphose oder 


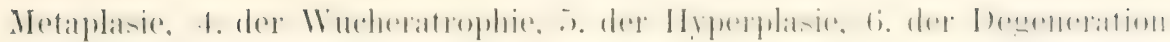
und Nekrose.

Wir wollen auch im folgenden an dieser Einteilung in ganzen festhalten, dabei aber der besseren Übersicht halber die an der \%elle zu unterscheidenden 'Lustände in zwei drmppen einteilen, erstens in eine Gruppe, in welcher sich der veranderte '/ustand der Gewehe nur in der Beschaffenheit der Protoplasmaprodulite äubert, zweitens in eine (irupje, in welcher sich an den Veränderungen der Protoplasmaprodukte anch die

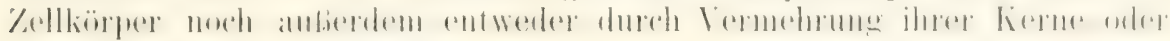
durch Degeneration beteiligen.

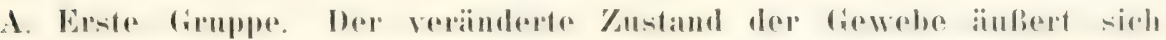 nur in der Beschaffenheit der Protoplasmaprodukte.}

\section{Die Hypertrophie der Gewebe.}

Es ist eine allgemeine Eigenschaft der lebenden Sulostanz, unter günstigen Berlingungen nicht nur die im Lebensprozed verbranchte Substanz zu ersetzen, sondern zugleich noch einen Mehrwert zu liefern. Die

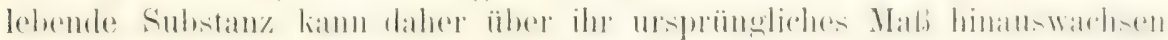
und immer mehr fremden Stoff in ihren Jebensprozeß hineinzielien.

Eine Überkompensation des Verbrauches kommt auch in der Hypertrophie eines Gewebes, in der Vermehrung der für bestimmte Verrichtumg gebildeten Substanz zum Ausdruck. Hierfür verschiedene Beispriele:

Zellen, deren ganzer Stoflwechsel im tierischen Körper darauf eingerichtet ist, aus dem allgemeinen Säftestrom Fette an sich zu ziehen und in ihrem Protoplasma aufzuspeichern, hypertrophieren, wenn im Körper der Verbranch von Fett für Arbeitszwecke sinlit, während die Zufuhr die gleiche bleibt. Die Fettzellen kommen so in die Lage, mehr Fett aufzumehmen, als sie wieder an die Orte des Verbrauches abgeben kïnnen.

Die Epithelzellen der gewmdenen Harnkanälchen haben vermöge ihrer spezifischen stofflichen Zusanmensetzung die Fähigkeit, aus dem Blute harnfähige Substanzen an sich zu ziehen, und nachdem sie ihr Protoplasma durchsetzt haben, wieder mach anben abzugeben. Wenn infolge der Exstirpation einer Niere der von ihr auszuscheidende Anteil an harmfähiger Substanz in Blut zurückbleibt, so wird der andern Niere ein Über-

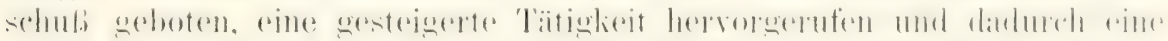

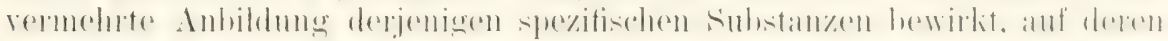
Anwesenheit die Figentimlichkeit der Nierenzellen beruht, harnfähiges Material an sich zu ziehen. Die Nierenzellen vergröbern sich, wie durch Messungen festgestellt ist, die ganze Niere bypertrophiert.

Am ausgeprägtesten tritt uns die Überkompensation beim Stoffumsat\%

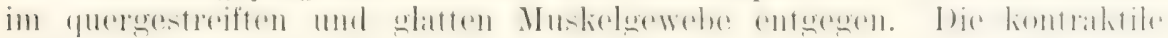
Substanz vermehrt sich unter allen Berlingungen, durch welche sie in höherem Maße in Anspruch genommen wird. Mehr kontralitile Teilchen. als sich abnutzen, fügen sich damn den alten an; der ()uerschnitt des

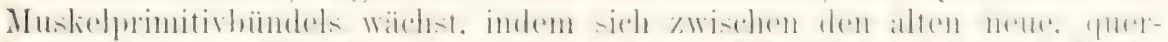

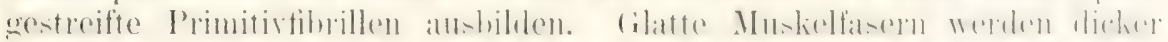

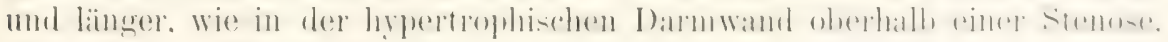
oder in der Wand der Harmblase bei Prostatahypertrophie, oder in der

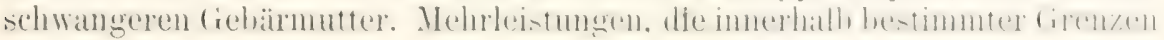


an das arbeitende Organ gestellt werden, fördern sein Wachstum und rufen allmählich eine größere Leistungsfähgkeit hervor, bis ein nenes

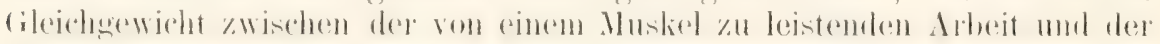
Masse der zur Arbeit beanspruchten Substanz hergestellt ist.

Die Muskeln eines Armes, welche tagüber beständig, aber nur zu leichter Arbeit in Bewegung gesetzt werden, verhalten sich ganz anders in der Ausbildung kontraktiler Substanz als die Muskeln eines Turners, welcher schwere Hanteln nur stundenweise hebt, oder eines Schmiedes, welcher beim Amboh den schweren Eisenlammer schwingt. Nicht die Kontraktion allein, sondern vor allen Dingen die Größe des hierbei zu

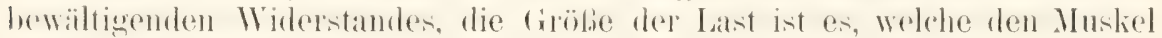
stärkt. Muskelsubstanz findet die zu ihrer Entstehung, sowie die zu ihrer Weiterbildung erforderlichen Bedingungen nur an Stellen, wo Muskelarbeit, und in dem Maße, in welchem solche zu verrichten ist. Daher palit sich ïberall das Muskelsystem rom sellost immerhalh gewisser Grenzen den jhm im Organismus gestellten Bedingungen an und wird in seiner ungleich starken Aubildung in den verschiedenen Ahschnitten des fiefädsystems, des Darmkanals, der 'Teile des Skeletts von selbst reguliert.

Es geht hier in der Ökonomie der Lebewesen wie in der menschlichen (iesellschaft, in welcher verstähte Vachfrage nach einem Gehrauchsgegenstand rom selbst and die Bedingungen für rine stäliere Erzengmng desselben schafit und so mit der Zeit auch ein vergrößertes Angebot hervoriuft.

Den hier begrïndeten Ideengang bat PFLÜGer in seiner Schrift: "Die teleologische Mechanik der lebenden Natur" in einer melır teleologischen Fassumg in dem Satz ansgedriickt: "Die Ursache des Bediurnisses ist zugleich auch die Ursache der Befriedigung des Bedürfnisses." Und er fügt an späterer Stelle hinzu: „Dies fuiht uns leicht zur Erkenntnis, daf, wenn eine Zelle durch starke Arbeit Stoff und Kraft verbraucht hat, abermals der Verlust die Ursache des Wiedergewinnes sein mul. Diejenigen Stellen, wo aus dem Gebäude der lebendigen Organisation Bausteine ausgetreten sind, werden mit starken Anziehungen begabt sein, welche sie zur Wiedereinführung neuen Nährmaterials befähigen. Es ist aber eine Tatsache, dał bei gröferem Verluste infolge verstäkter Arbeit solche Bedingungen entstehen, denen zufolge immer etwas mehr wieder gewonnen wird, als verloren ging. Denn der anhaltend stärkere Gebrauch des Organs läBt dasselbe an Masse und Kraft zunehmen. Deshalb werden Muskeln durch gröbere Arbeit umfangreicher und berlentenderer Anstrengung fähig. Das Beduirnis nach größerer Arbeitskraft hat diese zur notwendigen Folge."

\section{Die Atrophie der Gewebe.}

Wie schon oben erwähnt, zerstört sich jerle Struktur im Organismus allmählich von selbst, wenn sie nicht mehr den Bedingungen entspricht, unter welchen sie entstanden ist und deren sie daher auch zu ihrer Erhaltung bedarf. Die Atrophie bildet die Kehrseite der Hypertrophie.

Wenn die Neubildung von Fett und Drüsensekret, von Muskel- und

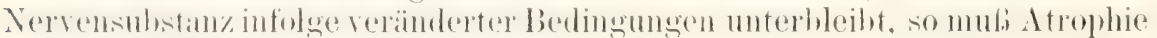
der betreffenden Gewebe eintreten, weil sich jetzt in ihnen allein der

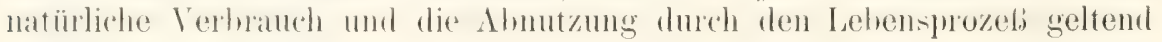
macht.

Nach langem Hungern oder bei sehr starkem Stoffverbrauch nimmt die Fetrelle an Tonfang ab, weil ihr Material von den Arbeitsorganen 
des Körpers in Anspruch genommen und nach den Orten des stïlieren Verbrauchs geschafft wird; der in der 'zelle eingeschlossene l'ettronfen wird kleiner und heiner und zerfällt schliefilich in einzelne 'lröpffchen. die ebenfalls schwinden kömen. Nu das P'rotophasma mit dem Kern bleibt als Rest der Zelle zurïck, welche so von einer einfachen lindegewebszelle nicht mehr zu unterscheiden ist.

Eine Drüse, die nicht mehr oder nur spärlich sezerniert, nimmt an Volumen ab: ilme Zellen verkleinern sich. Im leichtesten kamn man diesen Zustand durch Durchschneidung des Drïsennerven hervor-

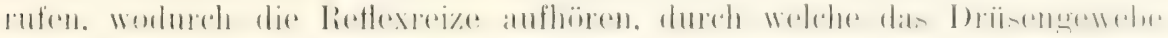
normalerweise zur Sekretion angeregt wird. So verkleinert sich zum Bei-

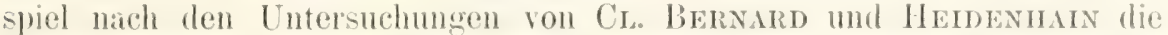
Unterkieferdrüse des Hundes sehr erheblich, wenn der zu ihr führende Nervenast durchschniten worlen ist; , sie gewimnt im frischen /ustande ein wachsgelbliches Aussehen und zeigt bei der mikroskopischen Untersuchung ein unverkembar veründertes Verhalten. Twischen zahleeichen Acinis, deren Zellen den Ban der Zellen untätiger Drüsen besitzen, liegen zerstreut andere von der charakteristischen Form der Acini tätiger Drüsen.

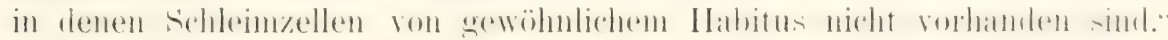
(HEIDENHAIN.)

Wie bei der Hypertrophie, so treten auch bei der Atrophie die Erscheinmgen um so rascher und prägnanter zutage, je mehr es sich um (xewebe handelt, deren Arbeitsleistung an hochorganisierte I'rotoplasma-

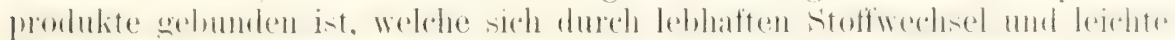
Zerstörbarkeit auszeichnen.

Obenan stehen in dieser Beziehung das Muskel- und das Nervengewebe.

Die Muskelprimitivbündel nehmen durch Schwund ron kontraktiler Substanz sowohl in der Längen- als in der Dickendimension unter den

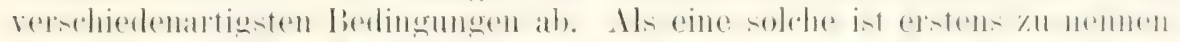

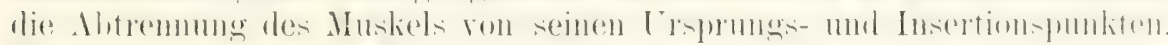

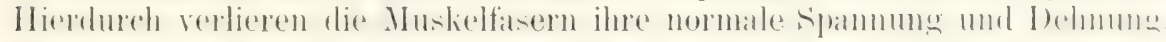
Wenn sie sich zusammenziehen, sind die bei der kontraktion zu be-

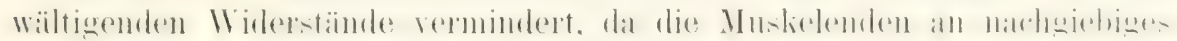
und dehnbares Bindegewebe angreifen, Der Muskel hat daher, auch wenn er innerviert wird, weniger Arbeit als früher zu leisten. line zweite Ursache der Atrophie ist verminderter oder anz anfgehobener Gebrauch der Muskeln. Muskelgruppen, die infolge starker Arbeit bein 'T'umen oder in einem Berufe hypertrophisch geworden sind, verkleinern sich wieder, wenn sie infolge veränderter Lebensweise wähend längerer Zeit verhailtnismäBig untätig geblieben sind. Mangelhafte Bewegung der Extrenitäten

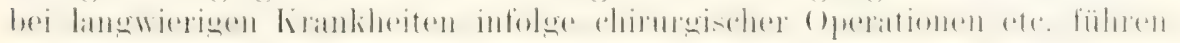
zur atrophischen Prozessen geringeren Grades.

Am häufigsten wird endlich die Anberfunktionssetzung der Muskeln

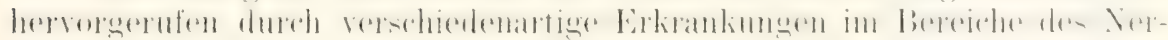
vensystems, welche Degenerationen motorischer Nervenfasern zur lolge haben: essentielle Kinderlähmung, progressive spinale Muslielatrophie, Lähmung nach Apoplexien. Sie läbt sich experimentell an leichtesten

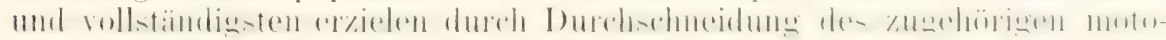
rischen Nerven.

Höhere Grade von Atrophie der Muskelfasern bleiben nicht auf eine einfache Mbnahme der kontraktilen Substanz beschrinkit. sondern

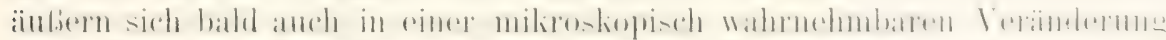

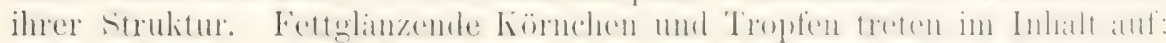


die Querstreifung wird dalurch undentlicher und schwindet schlieblich

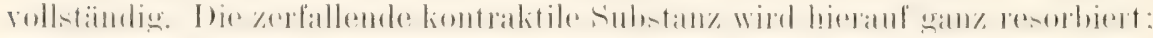
von einem Muskelprimitivbündel bleibt nichts als das Protoplasma mit den Kernen zuriek. Während das keiner funktion mehr dienende P'roto-

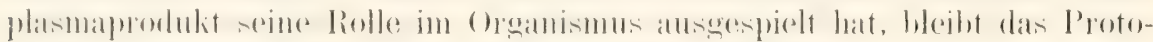
plasma mit den liernen, die forming matter, erhalten.

(ileich der Muskeltibrille zerfällt atuch nach kurzer Zeit die auber Dienst gesetzte Nervenfibrille. Wie fur jene zu ihrer Erhaltung die Lontraktion, so ist für diese eine zeitweise Erregung durch Nervenreize erforlerlich.

Da ferner die Aufgabe der Nervenfasem darin besteht, verschiedene

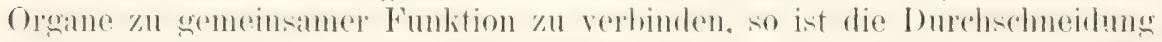
der Nervenfiscren ein vorzügliches Mittel. nivht nur um physiologiseh den Ausfall von Funktionen, sondern auch histologisch die Atrophien von strulituren zu studieren. welche den auswefallenen Funktionen dienen. Mit der motorischen Nervenfaser degeneriert die zugehörige motorische Endflatte und das Muskelprimitivbiundel: wïrde man noch genaner und weiter den Prozel. verfolgen, so wïrle man gewil, noeh damit in Kusammenhang stchende Veränderungen an den schmen eines atrophischen Muskels mol an dem zum Insertions- oder Ursprungspunkt dieneuden Knochengewehe wahrnehmen können.

Degeneration sekretorischer Fasern hewirkt Veränderumgen am Drüsengewebe, Durchschneidung eines Sinnesnerven hebt die Funktion der mit ihm zusammenhängenden nerö̈sen Endaplarate auf und ruft infolge der mangelnden Lieizfortleitung degenerative Pozesse anch an den heizaufnehmenden Apparaten hervor.

Wie S. MEYer durch Durchschneidung des Nervus glossopharyngeus vom Kaninchen feststelle, hegimnen schon : 0 Stunden nach der (Operation Verånderungen an den Geschmacksknospen der Papilla foliata nachweisbar zu werden. Es bildet sich eine Wucherung von Zellen am Fuf der Knospen aus. durch welehe ihre Ahgrenzung gegen das Epithel mehr und mehr verwischt wird. Die Zellen der Knospen verlieren ihre charakteristische form und wandeln sich in indifferente Elemente des Plattenepithels um. Am 12. Tage sind alle Geschmacksknospen spurlos verschwunden; an ihre Stelle ist ein gewöhnliches Plattenepithel getreten.

In ähnlicher Weise berichtet Colasantr von Degeneration der Riechschlemhant noch I) urchehneilung des Nervus olfactorius. Was indessen von NEUBERGER etc. in Abrede gestellt wird.

Die Atrophie von Sinnesapparaten nach Nervendurchschneidung ist ron besonderem theoretischen Interesse, weil sie eintritt, trotzdem die äuferen „funktionellen Reize“ niemals aufhören, auf sie einzuwirken. Die Geschmacksknospen werden von denselben Flüssigkeiten wie zuvor umspült; was gestört ist, ist allein die Reizfortleitung in der degenerierten Nervenfaser. Auch diese Art der AuBerfunktionssetzung ist daher schon imstante, in den \%ellen die eigentiunlichen Strukturen zu zerstiren, durch welche sie sich als funktionierende Simmeszellen auszeichnen und sie dadurch wierler in indifferente Elemente umzuwandeln.

\section{Funktionswechsel. Metamorphose und Metaplasie der Gewebe.}

Je nach den Berlingungen, dureh welche die Prozesse des Zerfalls und der Neubildung bei dem Stoffiwechsel in den Geweben reguliert werden, lieben sich an ihnen drei verschiedene Zustände unterscheiden, die 


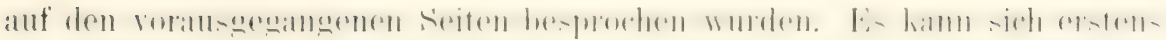
ein (iewebe in seinem normalen Bestand erhalten. wenn in dem dureh die Verhältnisse regulierten Stoffwechselprozel, sich Zerstörung und Nenbildung die Wage halten. Kweitens kamn die Kerstörmug, drittens die Neubildung überwiegen und im einen Fall zur Atrophie, im anderen Fall zur Hypertrophie führen.

Nun ist aber auch noch en vierter '/ustand möglich: I)ie formative 'ätigkeit der 'belle kann durch verïnderte Lebensbedingungen in gan\% andere Bahmen gelenkt werden und an Stelle des zerstörten ein ander's

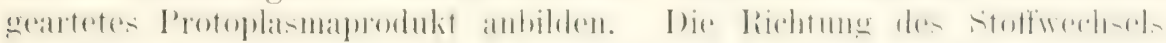
der Zelle verindert sich. Wie manche Organe, erleiden auch die fiewebe einen Funktionswechsel und damit anch selbstverstandlicherweise eine verinderte Struktur. Daher unterscheiden wir im Eigenleben der

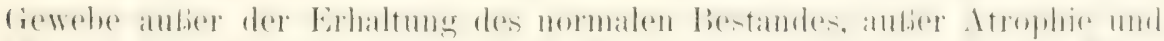

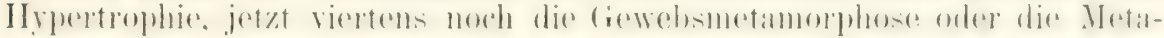
plasie. Je nachdem diese infolge von liedingungen erfolgt, die für den

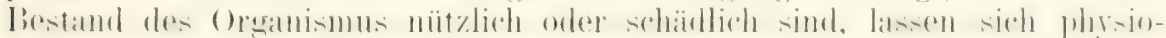
logische und pathologische Gewebsmetamorphosen muterscheiden.

a) Die physiologischen Gewebsmetamorphosen.

Während der Entwicklung eines Organismus aus dem Li bieten sich uns, namentlich in der Gruppe der Stützgewebe, verschiedenartige inter-

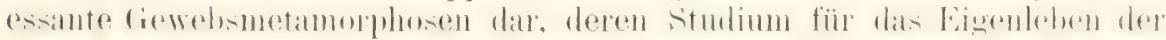

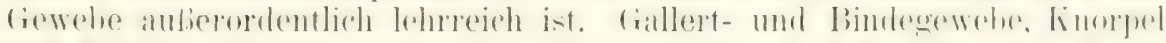

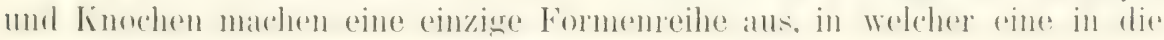
andere Form sich umwandeln kann.

Das Gallertgewebe ist die einfachste und ursprünglichste, zugleich

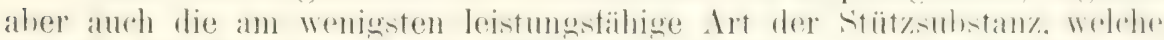
sich in der Entwicklumg allor Wirheltiore zwinchen den liomblittern zuerst ausbildet. Es wird normalerweise teils in faseriges Bindegewebe,

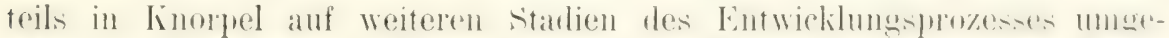
wandelt. Im ersteren Fall produzieren die ciallortzellen, welols in ihrem

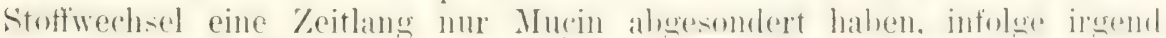
eines Anreizes liollagen. das sich an der (Oherflärhe ihres Protoplansmakörpers in feinen, zu einem Bündel vereinten Fibrillen ablagert. So entsteht das fötale Bindegewebe, welches aus einem Gemisch urspriang-

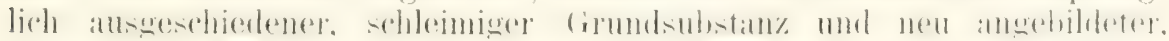

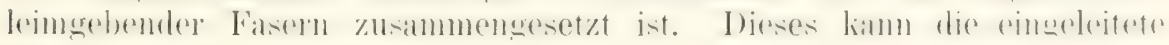
Metamorphose noch weiter fortsetzen; wir erhalten das reife lBindege-

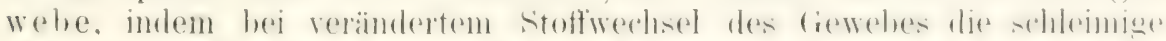

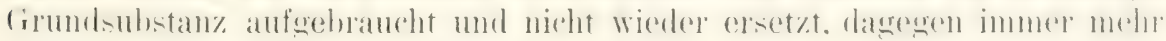
Kollagen in der Form von Fasern gebildet wird.

Das faserige Bindegewebe selbst ist ein wahrer Proteus durch

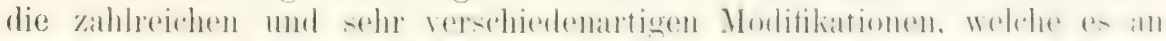

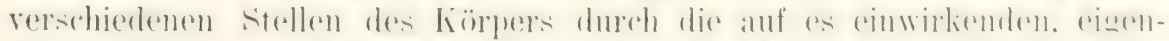

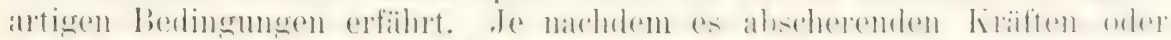

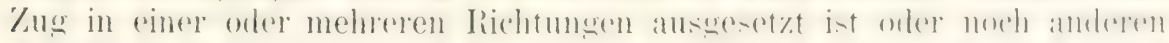
Aufgaben zu dienen hat, gestaltet es sich hier zu lockerem und inter-

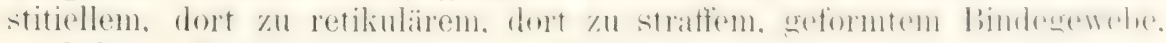
zu Sehnen, Fascien, Aponeurosen, Bändern um.

Noch in andern Richtungen kömnen die chemischen Prozesse in den

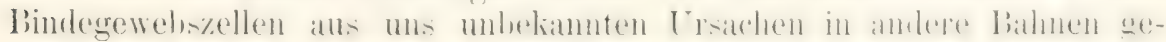
lenkt werden und zu neuen Arten formativer 'Tätigkeit führen. 
Flastin entsteht beim Stoffwechsel der Zelle und scheidet sich in einer für diese Substanz wieder charakteristischen Weise in feinen Fäser-

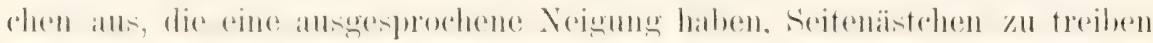
und sich dadurch untereinander zu Netzen zu vereinigen. Je nach der

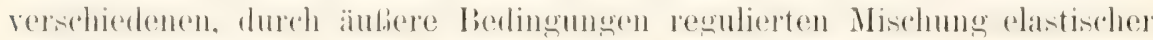
und lomgehender Fasern gehen wieder mannigfache nene fiewebsmetamorphosen hervor:

An manchen Orten im Körper gewimnen ferner die Bindegewebszellen stärkere Affinitäten. durch welche sie aus dem Sïftestrom entweder Kallisalze odler Fette an sich ziehen. Indem die Kalksalze mit dem Kollagen chemisch fest verbunden werden, wandelt sich faseriges Bindegewebe in Knochensubstanz um. Am unmittelbarsten läbt sich diese Metamorphose an den verknöchernden Sehmen der Vögel verfolgen. Die "Häutchenzellen" der Sehnenfasern nehmen eine den veränderten Bedingungen entspreshende nene form an. Wie die sternförmigen Gallertzellen mit der Entstehunor der Bindegewehsfasern sich in IIäuthenzellen umgewandelt haben, so wandeln sich jetzt wieler die Iäutchenzellen mit der Entstehung der Knochengrundsubstanz in die ihr angepabten zackigen Knochenkörperchen um.

Indem an manchen Orten Bindegewebszellen Fett aus dem Säftestrom an sich ziehen und in ihren Protoplasma in größerem Mabstab) abscheiden, wandelt sich lockeres Bindegewebe in Fettgewebe um, und dieses kann sich unter Umständen wieder zu Bindegewebe rïckbilden, wenn das Fett durch Atrophie aus den Zellen schwindet.

Zu den schon aufgezählten, zahlreichen Metamorphosen gesellt sich noch weiter der Faserknorpel hinzu. Er entsteht, wenn Zellen, die ursprünglich leimgebende Fasern ausgeschieden haben und als Bindegewebkïnerchen zwischen ihnen erhalten geblieben sind, ihre formative Tätigkeit ändernd. Chondrin auf ihrer Obertläche anbilden und, sich mit einer Knorpelkatsel umgehend. nummehr als Knorpelkörperehen erscheinen. wie in der Achillessehne des Frosches.

Eine zweite Reihe von Metamorphosen führt vom Gallertgewebe dureh das Kinorpel-zum Kuochengewehe hindurch. Indem in die schleimige Grundsubstanz das konsistentere Chondrin abgelagert wird, entsteht als Mischprodukt der Vorknorpel, der wieder verschiedenartiger Umwandlungen fähig ist (Hyalinknorpel, elastischer Knorpel, Knochen).

Unter den Begriff der Metaplasie lassen sich endlich auch die oft tief greifenden Umwandlungen einreihen, welche die Knochen sowohl während ihrer Entwicklung, als auch später bei jeder Veränderumg der statischen Verhältnisse erleiden, wie es nach den noch genauer zu besprechenden Untersuchungen von Roux und von Jubus WoLfF der Fall ist. Wenn sich die struktur der spongiosa infolge einer reränlerten Richtung del Zug- und Druckkurven umbildet, so mïssen ältere Konochenbälkchen, soweit sie nicht mehr mechanisch in Anspruch genommen sind, entweder verdünnt oder selbst ganz aufgelöst, und ihr Raum muf durch rotes Kinochenmark ausgefüllt werden, während sich neue Bälkchen in anderen Richtungen anlegen oder alte in entsprechender Weise verstärit werden.

Neben den Bindesubstanzen, welche allerdings die zahlreichsten und

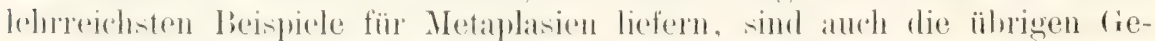
webe als Zengen in der uns beschiftigenden Frage heranzuzichen.

Platte Epithelzellen kömen durch veränderte Bedingungen veranladit werden, sich in lubische oder zylindrische Elemente umzuwandeln, wie umgeliehrt Zylinderzellen sich atch alplatten kïmnen. In dem später 


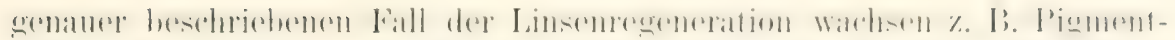
zellen des Irisrandes, welche vom Epithel des sekundären Angenbechers, also von der Wand des ersten embryonalen IIrmbläschens abstammen,

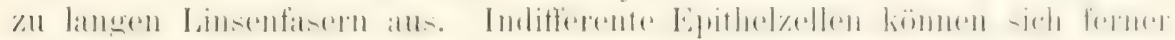
in diese oder jene Art von Sinneszellen differenzieren, wie die Erschei-

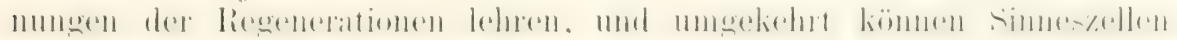
wieder ihren spezifischen Charakter verlierend, \%. B. beim Abtremen von

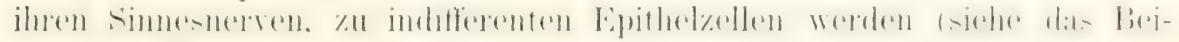
spiel der Degeneration der Geschmacksknospen, Seite 442).

Selbst den Charakter eines Bindegewebes können Eiphelzellen

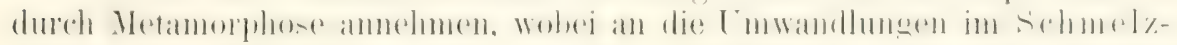
organ der Säugetiere erinnert sei. Ursprünglich polygonale Epithel-

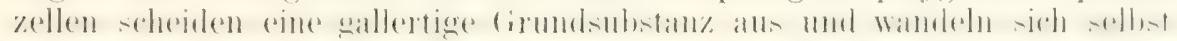

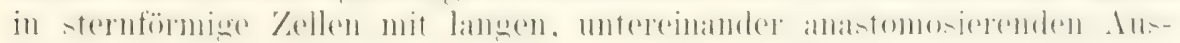
lïufern um. So entsteht die Schmelzpulpa. welche sich in nichts von einem Gallertgewebe unterscheilen läßt.

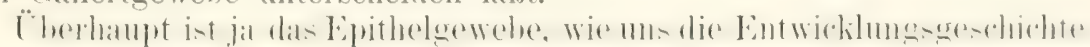

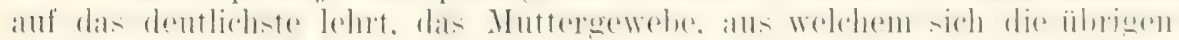
Gewebsformen direkt oder indirekt herleiten. Aus den primären liem-

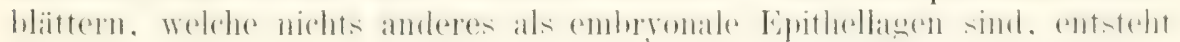
das Gallertgewebe, wie sich besonders klar bei Ctenophoren und Echinodermenlarven verfolgen läbt; aus ihnen leitet sich das Muslielgewebe her, nicht minder das Nervengewebe. In dieser Hinsicht bilden die Cölenteraten einen lochinteressanten Tierstamm, indem bei ihnen zum T'eil Nuskel- und Ganglienzellen noch in der äuberen und inneren Epithelschicht des Körper's, in dem Ektoderm und Entoderm, gelagert sind und

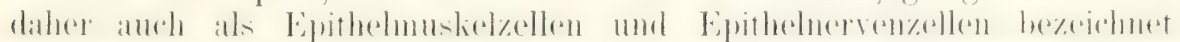
worden sind. Auch läßt sich hier in so schöner und lehrreicher Weise verfolgen, wie die Epithelmuskelzellen sich aus dem Verbande mit dem

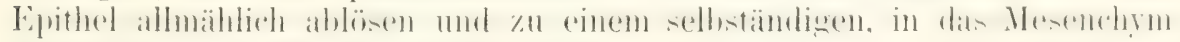
eingeschlossenen Muskelgewebe werden.

\section{b) Die pathologische Gewebsmetamorphose.}

Metaplasien spielen auch bei krankhaften Prozessen im Körper eine grobe Rolle. Alle Lehrbïcher der allgemeinen Pathologie beschätigen sich daher sehr eingehend mit ihnen. Nach starken Aderlässen verliert das gelbe Knochenmark seinen Fettgehalt und gewinnt das Aussehen vom Schleimgewebe.

„Bei Arthritis fungosa (Fig. 305) verflissigt sich die Grund-

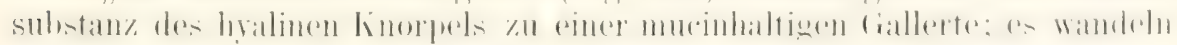
sich die dadurch frei werdenden knorpelzellen in sternförmige, untereinander anatomosierende Kellen $\mathbf{m}$. so dab ein Giewebe entsteht. das

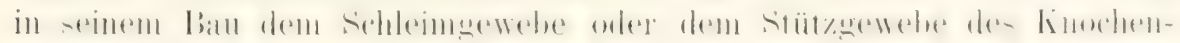
marks entspricht".

liei intensiven Ernährungstörungen werlen manche Organe und fiewebe von der amyloiden Entartung befallen; es entsteht eine eigen-

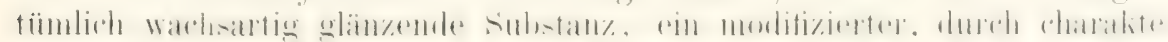

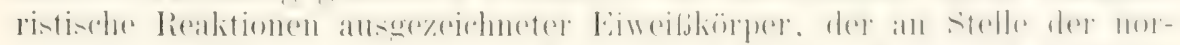

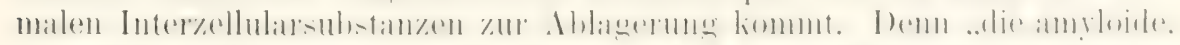

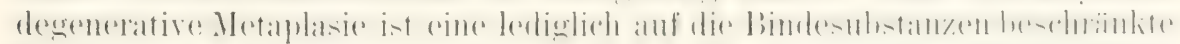

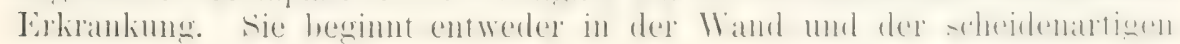




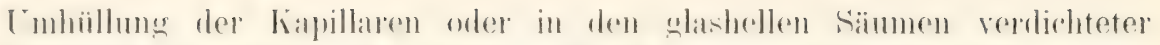
Bindesubstanz, womit das Stroma sich gegen die eingeschlossenen, spezifischen Parenchymteile abgrenzt; und nicht die Muskelfasern selbst sind

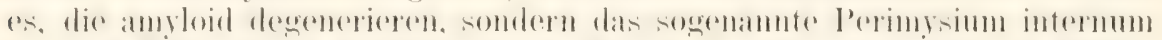

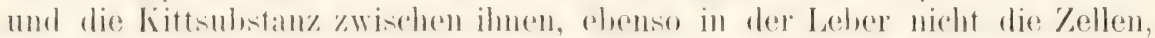
sonder'n das Stroma, und in der Milz mol den Lymphdriisen nicht die Pulpa und Lymplizellen, sondern die Gerỉstbällichen."

Bei der ADDisonschen Krankheit fïllen sich die Zellen des Rete Malpighii mit l'igment, so dabs die Haut eine eigentiimliche bronzefärbung (Bronzeskin) gewinnt.

Selo läutig sind abmorme Kallablagerungen in den Arterienwänden älerer Indiviluen mol in vielen linorpeh. Rippenknorpel zeigen im Mlter die hekannte faserige ouler ashestartige \%erklïfung der Interzellularsubstanz.

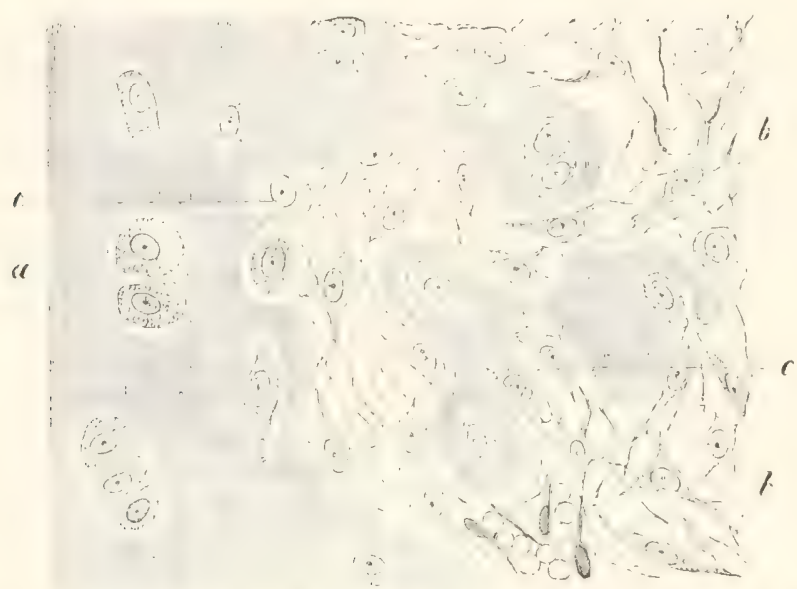

Fiin. 31, Metaplasie des Knorpels in retikuliertes Gewebe bei Arthritis fungosa. Vergr. 400 fach. Nach Zieglar, a Iyaliner Knorpel, b Aus verzweigten Zellen bestehendes Gewebe. c Durch Auflösung der Knorpelgrundsubstanz frei gewordene Knorpelzellen in Schleimgewebszellen übergehend.

In ähnlicher Weise treten bei pathologischen Prozessen noch vielfach

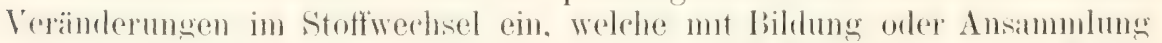
abnomer Stoffe und mit ihrer Abscheidung im Protoplasma der Zellen oder in der Zwischensubstanz verbunden sind. Hier werden allerdings meist die Gewebe in schädlicher Richtung verändert, so daf alle diese Metaplasien den Charakter der Degeneration an sich tragen.

\section{Zweite (iruppe. Der verinderte Zustand der fiewebe auBert sich auker in der Beschaffenheit der P'rotoplasmaprodukte auch in der Beschaffenheit von Protoplasma und Kern.}

Bei Untersuchung der Frage, an welchen Stellen des Körpers im ausgebildeten Zustand Kernteilungsfiguren rorkommen, fällt es auf, daf solche in Zellen, die mit einer spezifischen Funktion betraut sind, solange sie normal fungieren, fast stets vermißt werden. Nach den umfassonden, mit den zuverläsigen Mitteln der molernen Fürhungsmethoden allsgefühten L'ntersuchungen von bizzozero finden in den sezernierenden 


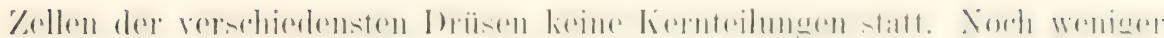
ist dies bei Ganglienzellen der Fall. Ehenso werlen die Eizellen, wenn sie in das Stadium treten, in welehem sie Reservestoffe aufruspeichem begimnen, absolut unfähig zur 'T'eilmog. Sie wachsen oft zu einer gewaltigen Gröbe heran, vermehren sich aber nicht mehr. Auch nimmt der liern als liembläschen eine lieschaffenheit an, welche ihn ehenfalls als wenio geeignet zur 'Teilung erscheinen lüist.

Dab im Leben aler Eizelle Zeiten sehr lehhafter Vermehrungr und Zeiten von 'Teilungsunfähigkeit abwechseln, läbt sich in eklatanter Weise besonders bei Untersuchung der Eiröhren von Nematoden feststellen. In

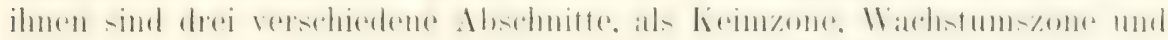
Reifezone. zu unterscheiden. In der Keimzone findet man die Ureier in

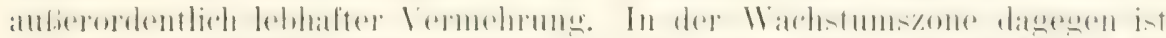

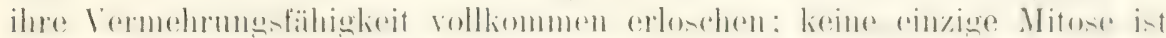

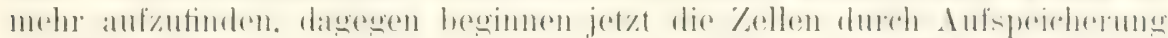
von Dottermaterial zu wachsen. Erst mit Abschlub des Wachstums liehrt die Fïhigkeit zur hernsegmentierung in der Reifezone wieder, indem das

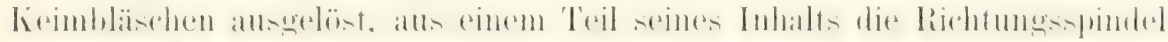
und darauf der erste Richtungskörper gebildet wird.

Angesichts derartigor Beobachtungen läßt sich die lirage aufwerfen:

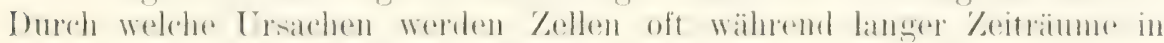
einen Zustand der 'Teilungsunfähigkeit versetzt:?

Die Antwort scheint mir nahe zu liegen, wenn wir beachten, dab

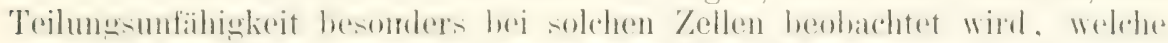

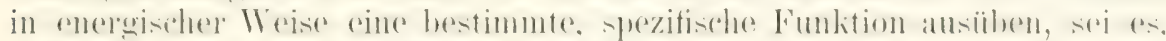

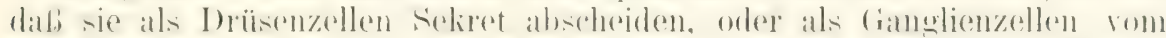
Norvenstrom errent werdens obler als Eizellen Nahrungsmaterial fïl die Zukunft aufspeichern etc. Wie mir scheint, wird hier alles in die \%elle

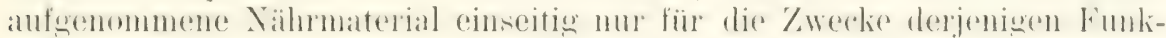
tion verwandt, auf welcher die Eigenart der betreffenden Zelle beruht,

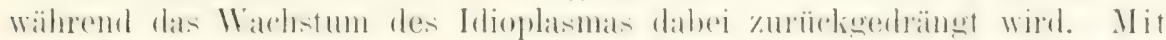
der Arbeitsteilung ist daher besonders fü die Zellen, welche eine intensive Arbeit leisten, dabei einem leichteren Kerfall ausgesetzte Plasmaprodukte bilden und einen spezifischen Stoffwechsel unterhalten, eine Abnahme ihrer Vermehrungsfähigkeit verbunden; die mehr indifferent gebliebenen Zellen des Köpers dagegen bewahren inre Teilfähigeit mehr oder minder.

Nach dem Mitgeteilten stehen offenbar formative und reproduktive Prozesse in einergewissen Abhängigkeit voneinander.

Auch bei den oben als Atrophie und Hypertrophie beschriebenen

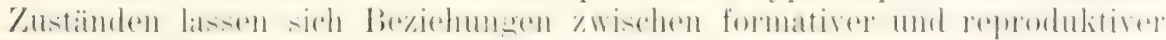
'Tätigkeit feststellen. In leichteren Graden der Atrophie und der Hypertrophie, welche man dann als einfache bezeichnet, bleiben die V'erände-

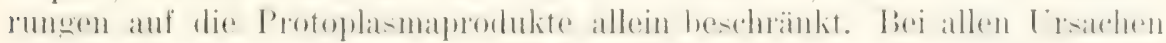
indessen. welche in intensiverer Weise in den normalen Verlanf des Stoftwechsels der Zelle eingreifen, bei nutritiver Reizung der Zelle, wie sich VIrenow ausdritickt, werden außer den Plasmaprodukten auch die bildenden Substanzen der Zelle selbst, Protoplasma und líern, in Mit-

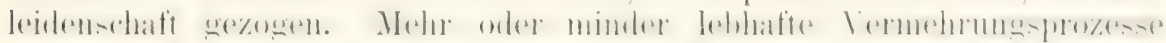

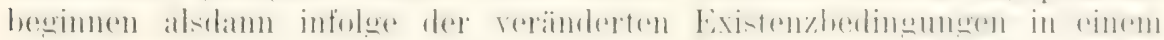
Gewebe aufzutreten, sowohl bei höheren Graden von Atrophic als von 
Hypertrophie. Im ersteren Fall redet man von einer Wucheratrophie, im andern Fall yon einer Hyperplasie (VneHow).

\section{Wucheratrophie.}

Atrophie, verbunden mit Vermehrung der lierne, beobachtete FLEmma beim Fettgewebe. Bei langsam eintretendem, aber iuber längere Zeit sich

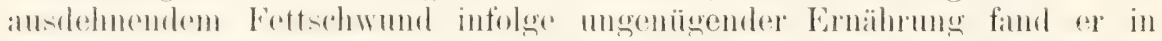
vielen Fettläppehen den gröbten 'Teil der Zellen, deren Fettgehalt stark herabgesetzt war, mit zwei, drei oder vier Kernen versehen, welche in der den fettropten einshliebenten Trotoplasmahüle verteilt waren. bei starker Nahrungsentziohung und akuten Krankheitsattarken tritt nach den Untersuchungen von FLEmming - bei Tieren schon nach wenigen Tagen - eine hochgradige Wucherung der Kerne zugleich mit dem Schwund und Zerfall des Fettropfens auf; $u$ m die einzehen Kerne sammelt sich das gleichfalls vermehrte Protoplasma an und grenzt sich ab, so daß es anssieht, als ob innerhalb der mit Serum und Fettkïgelchen erfüllten Membran der fettzolle sich eingedrumerene Lymphkörperehen hefänden.

In ähnlicher Weise treten Kernwucherumgen in der degenerierenden Muskel- und Nervenfaser auf, dort sind es die lierne der Muskelkörjerchen,

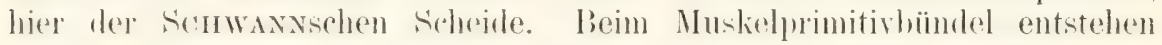
so auf vorgeschrittenen Stadien der Degeneration innerhalb des unveränderten Sarkolemmschlanches lipmhaltige Protoplasmamassen, welche mehr obler minder voneinander isoliert sind: wenn die kontraktile Muskelsubstanz die ()uerstreifung verloren hat und in einzelne Sohollen zerfallen ist. nehmen sie letztere zum Teil in sich auf und beschleunigen ihren weiteren Zerfall und ihre Resorption. In ähnlicher Weise treten Zellen, die durch Wucherung der Kerne der Schwansschen Scheide und des sie einhüllenden I'rotoplasmas motstanden sind, in den mit den Zerfallsprodukten des Arhsenzylinders mol der Mychincheide erfüllten Nemilemmschlïmehen auf und vermitteln ihre Resorption.

Ebenso wurden Kernwucherumgen bei der Atrophie der Geschmacksknospen beobachtet.

Hieraus läbt sich der allgemeine Schlus ziehen: Während bei höheren Graden der Atrophie die spezifischen Strukturen, auf denen die Eigenart der einzelnen Gewebe beruht, zugrunde gehen, bleiben die Zellen selbst nicht nur als solche erhalten, sondern ihre Kerne werden sogar durch den Zerfallsprozeb der Protoplasmaprodukte und durch den veränderten Stoffwechselprozeb noch zu Wachstum und zu wiederholter Teilung an geregt.

\section{Hyperplasie.}

Wie bei der Atrophie ist auch bei der Hypertrophie die Veränderung an den Plasmaprodukten in gewissen Fällen mit einer Vermehrung der Kierne verbunden. Man bezeichnet sie dann als eine Hyperplasie. Sie scheint besonders in den Fällen zustande zu kommen, in denen die Inanspluchuhme der hypertrophierenden Organe, wie einzelner Drüsen und Muskeln, eine übermälig große ist.

Bei Exstirpation der einen Niere oder eines großen 'T'eils der Leber,

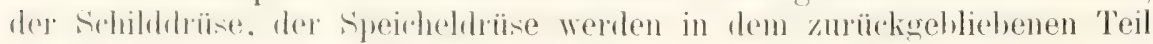

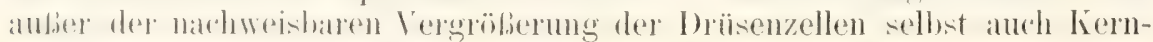




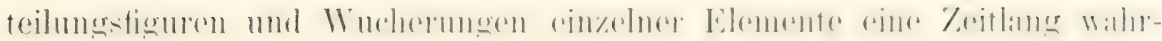
genommen.

Bei bäufig und stark in Anspruch genommenen Muskeln treten in

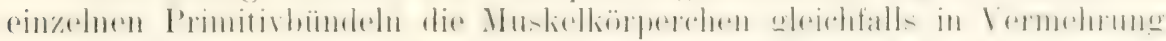
ein. So entstehen vergröberte, besonters kermeiche Fasern. welche wahrscheinlich zu einer Vermehrung der Fasern auf dem Wegre der Lüngsspaltung führen, zu einer Ilyperplasie des Muskelgewebes.

Die Vermehrung der Zellen ist hier durch andere Reize als bei den Prozessen der Atrophie herbeigeführt und bleibt im Verhältnis zu ihnen auch auf einen viel geringeren Grad beschränlit.

\section{Degeneration und Tod der Zelle (Nekrose).}

Auch wenn ein vielzelliger Organismus selhst noch in voller Lebenstätigkeit steht und ron der Zeit weit entfernt ist. wo er dem Untergang ver-

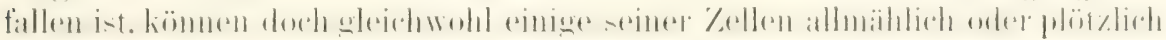

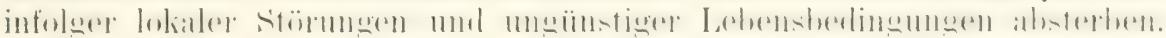
Die eingetretene Degeneration kann man gewöhnlich an einigen charakteristischen Veränderungen sowohl des Protoplasmas als des lierns erkemen.

Das Protoplasma der Zellen wird trüber. Es treten in ihm lileinere und gröbere Körnchen auf, die wie Fett glänzen nud sich anch wie dieses durch Osminmsïme sehwämen.

firs. :306. Chromatolyse von Zellkermen. Al Samenzelle mit entartetem liern ans dem Hoden von salamandra maculata. Nach lismunxor.

b' /wischenkörperchen (corps réxiduel) ans dem Hoden oder Eierstock von Ascaris megalocephala. Nach Hertwig.

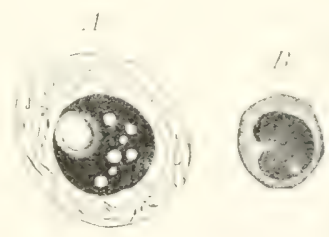

Auf experimentellem Wege haben mein Bruder und ich solche Verïnderungen häufig an Eizellen, die befruchtet waren und sich furchten. dadurch hervorgerufen, dal, wir sie kürzere Zeit der Linwirliung dümner Lösungen von Chloralhydrat, Morphim, Chinin etc. aussetzten. Wenn der Grad der Einwirkung so war, dal, sich die Eier, wenn auch in etwas verlangsamter und gestörter Weise, noch weiter entwickeh komnten, so wurde mach 12 oder 20 Stumden doch immer ein verändertes Aussehen des Dotters durch Auftreten fettglinzender Könchen beobachtet. Die Körnchen nahmen noch einige \%eit an Gröbe zu, vielleicht indem sie untereinander verschmolzen. Öfter's wude auch bemerkt, dafo, wenn die Körnchen in gröberer Menge vorhanden waren. sie vom iibrigen Protoplasma ausgestoben wurden.

Der Prozels der Degeneration hat nach einiger Zeit auch eine veränderte Struktur des Kierus zur Folse. Namentlich das Nuclein erführt eigentümliche Veränderungen, welchen FLEmming den Nanen der Chromatolyse gegeben hat.

Geeignete Organe zu ilner Untersuchung sind namentlich die männlichen und weiblichen Geschlechtsdrisen. Neben Elementen, die hier in lebhafter Neubildung und raschem Wachstmm hegriften sind, findet man

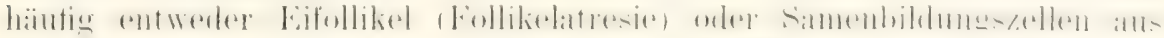
mbekamten Ursachen in Degeneration begriften, wie Fremung und Hermany bei Sïugetieren und Amphibien, ich an den Ei- und Samenröhren von Ascaris nachgewiesen haben. An den liernen geht das Geriist 


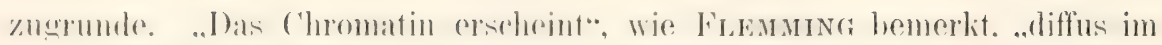
kern verteilt und verleckt jede Struktur dessellon; dieser tingierbare lilumpen (Fig. :306) ist mehr oder weniger von Vakuolen durchsetzt, unter denen eine besonders groß und an die Peripherie gelagert zu sein pflegt. Andere solcher Kerne finden sich, an denen eine solche randstandige Vakuole stark vergrößert ist, kleinere daneben nicht vorhanden sind, wobei oft einzelne kleine chromatische Brocken am freien Rande der Vakuole liogen. In noch andoren ist der chromatinklumpen verkleinert mul besomblers stark färbbar; wieder andere zeigen gar nichts mehr von der Vakuole, nur einen groben chromatischen Klumpen und viele, sehr kleine solcher im Zellenleib verstrent. Die Zelle ist in solchem Falle verkleinert. Endlich timlet man anch violfach lileine '/elllïrper. die nur verstrente chromatisehe Körnchen und gar keinen gröberen Kermest enthalten."

Derartig verkümmerte Zellen mit ganz desorganisierten Kernen sind in Fig. 306 abgebildet. $A$ ist eine Samenzelle aus einem Hodentollikel von Salamandra, $B$ eine Keimzelle von Ascaris, wie sie sowohl im Hoden als im Eierstock vorgefunden wird und in der Literatur unter dem Namen corps résiduel orler Zwischenkörperchen bekannt ist.

Wasielewsik hat durch Injektion von 'Terpentin in den IIoden von Säugetieren die Kerne von Keimzellen in einen entsprechenden Zustand der chromatolytichen Degeneration anf experimentellem Wege versetzen können.

\section{Literatur zu Kapitel XVIII.}

(Außer den schon in vorausgegangenen Kiapiteln zitierten Schriften.)

1) Arnold, Über Teilungsabröinge an den Wanderallen, ihe progressize und regressize Wetamorphose. Archin f. mikrosk. Anat., Bit. XYX. 1887.

2) Bard, La spécificité cellulaire et l'histogénèse chez l'embryon. Archives de physiologie, tome VII, sér. 3, p. 406 . Perris 1886.

3) Colnnheim, Vorleszingen über alloemeine Pathologie, Bd. I t. II. 2. Aufl. 1882.

4) Eberth, Die Sarkolyse. Nach semcinsam mit Herrn Dr. Noetzel etc. Festschrift der Fakultät z. 200jähr. Jubelfeier der Universität Halle. Berlin 1894. Hirschwald.

5) Flemming, Über die Bildung zon Richtungsfiguren in Sängetierciern bein Untergang Graafscher Follikel. Archiv f. Anat. u. Physiol., anat. Abt. 1885.

6) Derselbe, Nene Beiträge zur Kenntuis der Zelle. Arch.f. mikrosk. Anat., Bal. XXIX. 1897.

7) Derselbe, Beiträge sur Anatomie und Physiologie des Bindegenabes. Arch. f. mikrosk. Anat., Bd. XII. IS76.

S) Hansemann, Studien iüber die Spezifizitüt, den Altruismus und die Anaplasie der Zellen. 1803.

9) Hexmann, Uber regressive Metamorphosen des Zellenkernes. Anatom. Anz., Bd. III. 1888 .

10) Hertwig, Oskar ". Hertwig, Richard, Uber den Befruchtungs- und Teilungsvorgans des tierischen Eies unter dem Einfuß änßerer Agention. Jena I887.

11) Hertwig, Oskar, Veroleich der Ei- und Scmenbildung bei Nematoden. Eine Grundlage fïr sellulüre Streitfragen. Archiv f. mikrosk. Anat., Bd. XXXIT, S. 86-. 100. 1890 .

13) Derselbe, Zeit-und Streitfragen der Biologie. Heft I. Präformation oder Epigenese. Jenci 1894.

1.1) v. Kupffer, Über Energiden and paraplastische Bildungen. Rektoratsrede. Miinchen İ०ó.

15) Lukjanow, Grundä̈ge einer allgemeinen Pathologie der Zellen. ISgI.

16) Meyer, Semi, Durchschneidungsversuche am Nerans glossopharyngens. Archiv $f$. mikrosk. Anat., Bal. TLVIII. 1807. 


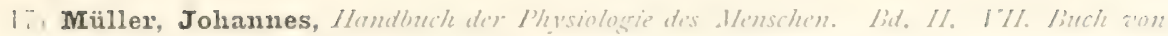

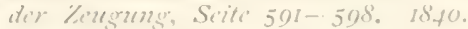

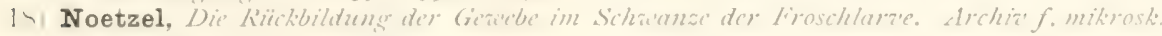
inct.. lidt. ILI. Iso5.

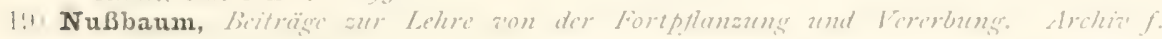
mikrosk. Anat., bit. L.WT. 1803 .

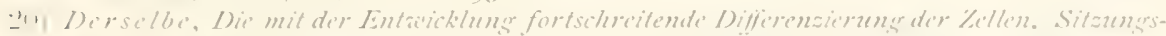

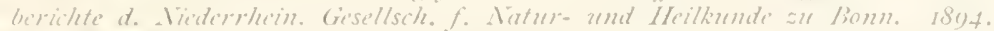

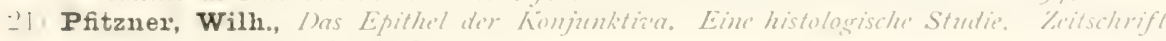

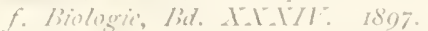

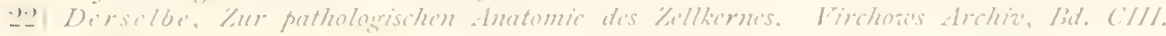
lisiso.

…) Pflüger, Tiliologische Mechanit, Lonn.

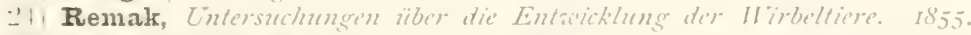

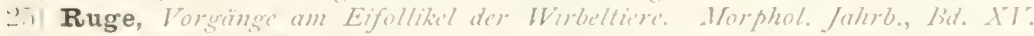

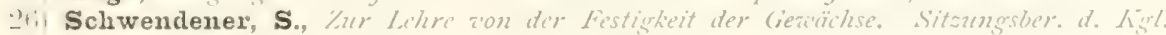
prenk. Akad. d. Il issensch, an lierlin. 1884 .

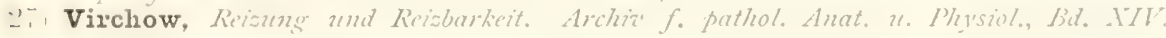
1858 .

$\because \rightarrow$ Derselbe, Virchow's Archiz', Bet. W111. 1855.

․:1 Derselbe, Die Kellularpathologie. 3. Autl. IS6z.

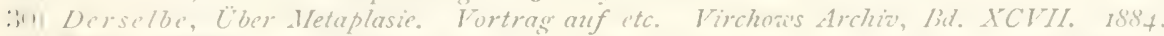

:il) Wasielewski, Due Kémzone in den Genitulschlänchen t'on Ascaris megalocephala. Arch. f. mikrosk. Lnat., IrA. HLI. 1893.

:-) Ziegler, Lehrbuch der allsemeinen und speziellen pathologischen Anatomie. Jena. 


\section{NEUNZEHNTES KAPITEL.}

\section{Besprechumg der Keimplasmatheorie von Weasuaxs.}

Um die Sonderung der embryonalen Zellen in die verschiedenen Gewebe $z u$ erklären, hat WEISMANN einen diametral entgegengesetzten Weg zu dem hier hetretenen in seiner liemplamatheorie eingerdilagen. Während nach der Theorie der Biogenesis alle Zellen eines Organismus 'Träger der Arteigenshatten sind. das gleiche Idioplasma besitzen mud nur

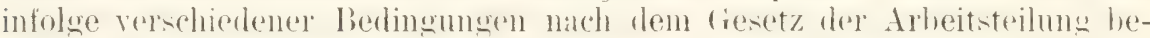

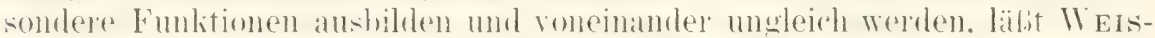
Maxs das Idioplasma selbst im Laufe des Entwicklungsprozesses in seine einzelnen Anlagen zerlegt werden und dadurch, daf diese sich in ungleicher Weise auf die Abkömmlinge der Eizelle verteilen, die Differenzierung in Organe und Gewebe zustande kommen.

Weisuand hat seine Hypothese bis in das kleinste Detail auszuarbeiten versucht. Nach ihm ist das Keimplasma des Eies aus außer-

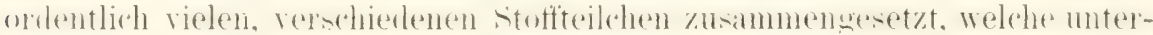
einandel zu einer komplizierten Architektur verbunden sind. Alle Zellen odler Zellengruppen, welche selbständig rom lieim aus veränderlich sind,

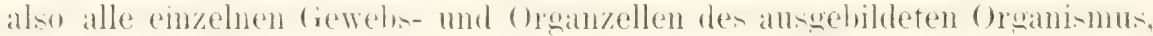
sind im Keimplasma durch kleine, besondere Einheiten, die Determinanten. vertreten. deren Zahl sich auf viele Hundertausende belaufen kann. Sie sind die Träger der Zelleneigenschaften. Da diese in

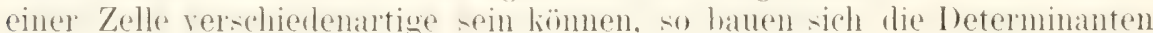
jeder einzelnen Zelle selbst wieder aus noch kleineren Einheiten. den Biophoren, auf, durch welche je eine einzelne Eigenschaft der Zelle repräsentiert wird.

Aus der Annahme, dab durch je eine Determinante je eine im hörper rämmlich genau hestimmte. sellstïndig rom Keim aus reränderliche Zelle oder Zellengruppe im Keimplasma vertreten sein muß, zieht WEIsmANN die weitere Folgerung, daf die Determinanten auch im Keimplasma fest lokalisiert und in sehr komplizierter Weise zu einem Verbande vereint sein müssen. Er nennt die so entstehende, gewissermaben eine besondere Architektur anfweisende höhere Einheit ein Id. Es ist der Inhererift aller zum . Iufhan eines Individumm der Art nötigen Determinanten. Es würde genügen, wenn die Erbmasse nu ein einziges enthielte; indessen nimmt WeIsMann aus verschiedenen Gründen, auf welche einzugehen uns hier zu weit führen würde, im Keimplasma eine Vielheit von Iden an, welche. von näheren orler entfernteren Vorfahren abstammend, als Erbstücke die Eigentïmlichkeiten ihres Baues überliefern und eventuell bei einer Gelegenheit zur Wirksamkeit kommen (Erklärung des Atarismus). 


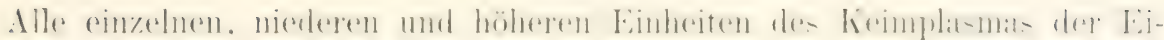
zelle haben die Eigenschaft, durch Stoffaufnalıme zu wachsen und sich durch Teilung zu vermehren.

Biophoren, Determinanten, Iden, Architektur des Keimplasmas sind Annahmen, gemacht zu dem Zwecke, um mit ihnen die Frage nach den

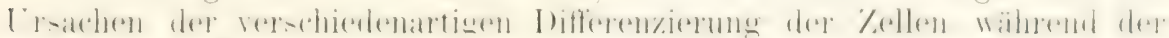
embryonalen Entwicklung zu beantworten. Hiermit kommen wir zu dem uns besonders interessierenden Kardinalpunkt der WEIsMAxschen Hyothesen.

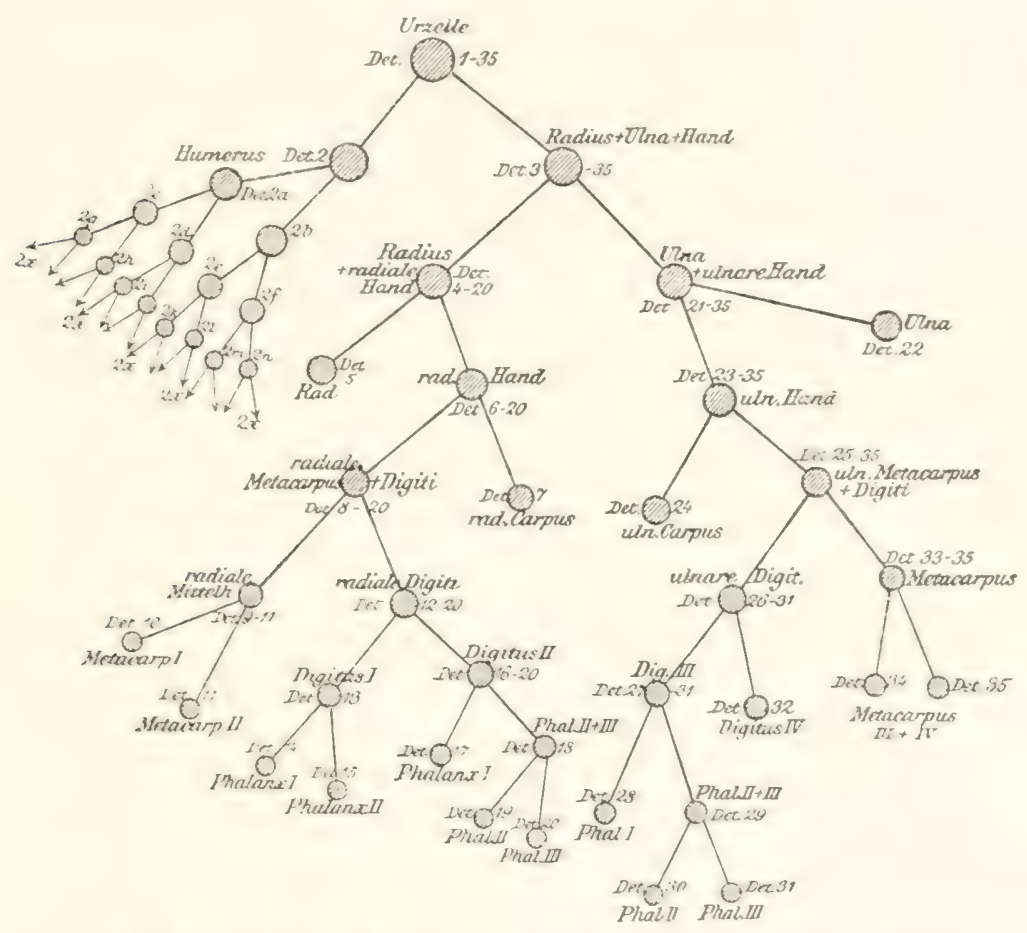

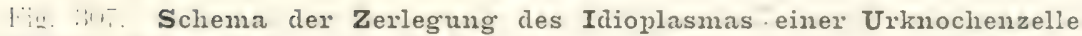
dex vorderen Extremität. Sach WrisuAx. Die hieiso in Fig. :30- belenten je eine Stammzelle des hetreffenden Lnochenstückes, von denen jede der linfachleit halber ak durch eine Determinante bestimmt gedacht wirl. Also die Lrzelle der ganzen Kinochenachse wïrle durch die Determinante $I$ bestimmt, erhielte aber danehen noch in ihren Iden die Determinanten 2-35. Bei der ersten Zellteilung trennen sieh diese in die Stammzellen des Olverarms (Humerus) und des Vorderarms samt Hand. Erstere enthält die Determinanten 2, und von ihr ist hier die weitere Teilmug in /sellen angedented mit den Deterninanten $2 a-2 x$. Letztere enthält die ïbrigen Determinanten $3-35$. die sich nun bei jeder weiteren Zellteilung in immer kleinere firuppen spalten, his zuletzt jede \%elle nur noeh je eine Determinante enthïlt. Das schema rilot nur musefiln die Knochenstücke der vorderen Extremitit wieder. Die einzehen Handwnzelknochen sind weggelassen.

Die Beantwortung gibt Wessuxy in der Weise. dab er die Determinanten, die er im Keimplasma des Eies zu einem kunstrollen IVerk durch seine Ammalmen zusammengefügt lat, infolge des Entwickhumgsprozesses durch einen im Ei ebenfalls vorausbestimmten und geregelten. aber seiner Natur nach mbehannten mul rätselhaften Mechanismus allmählich wieder auseinander gelegt und auf die einzelnen Zellen, die durch sie in ilrem Charaliter bestimmt werlen sollen, anf die Determinaten. 
verteilt werlen läbt. Die Entwicklung gestaltet sich auf diese Weise zu einem Prozeh der Selbstlifferenzierung des Eies.

Das Keimplasma-Id spaltet sich, wenn (ler Entwicklungsprozeb begimnt, bei jeder oder doch sehr vielen, ,Zell- und Kernteilungen in immer kleinere (iruppen von Determinanten, so dah an Stelle einer Million verschiedener Determinanten, die etwa das Keimplasma-Id zusammensetzen

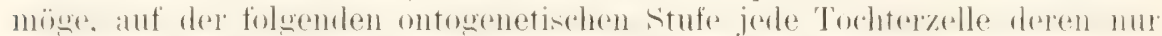
noch eine halbe Million, jede der darauf folgenden Stufen nur eine viertel Million usw. enthält. Zuletzt bleibt in jeder Zelle nur noch eine Art

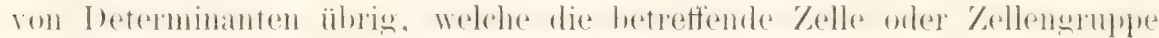
zu bestimmen hat." Auf jeder einzelnen Stufe der Entwicklung hat in jerler Zelle ,jerles Id seine feste ererbte Architektur, einen verwickelten, aber

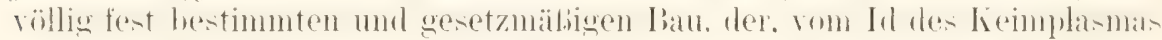

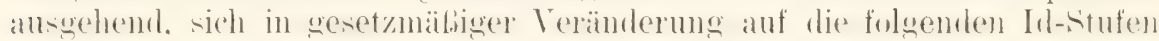
iiberträgt. In der Architelitur des Keimplasma-Ids sind alle Strukturen der folgenden Idstufen potentia enthalten, in ihr liegt der Grund der regelrechten Verteilung der Determinanten, d. h. der Grund für den gesamten Aufbau des Körpers von semer Grundform an zu der Anlage und zu den Beziehungen der Teile; in ihr liegt der Grund, warum z. B. die Determinante für einen kleinen Fleck auf dem Flügel eines Shmettrings genau an die richtige Stelle gelangt und an keine andere".

Zur Teranschaulichung seines Gedlankenganges hat WEIsunds das beifolgende Schema, Fig. 307, über die Entwicklung des Skeletts der vorderen Extremität entworfen. Zum V'erständnis desselhen wird auf die beigefügte, ausführliche Figurenerklärung verwiesen.

Als das Mittel, dessen sich die Natur bei dem wunderbar verwickelten Zerlegungsprozeh des liemplasmas berlient, bezeichnet WEIsMann die Zell- und Kernteilung. Er unterscheidet nämlich nach einer nicht näher begründeten Anmahme, welche aber doch schlieblich der wichtigste Grundstein seines Systems ist, zwei Arten von Kernteilung, die sich zwar an ihrem äußerlichen Verlauf durch Beobachtung nicht erkennen lasien. die aber nach ihrer Wirkung ermolrershieden ausfallen. Dir eine Art wird als erbaleiche oder integrelle Teilung. die andere als erbungleiche oder differentielle bezeichnet.

Die erbgleiche Teilung beruht auf einer Terdoppelung der Determinanten durch Wachstum und auf ihrer ganz gleichmäßigen Verteilung auf die Ithälften und weiterhin auf die Tochterchromosomen: sie tritt bei Embryonalzellen und später bei Gewebezellen ein, welche Tochterzellen genau der gleichen Art hervorbringen.

Die erbungleiche Teilung dagegen wird durch ungleiche Gruppierung der Determinanten während ihres Wachstums eingeleitet: infolgedessen spalten sich die Iden derartig, dab hierbei die in ihnen eingeschlossenen Determinanten in ganz verschiedenen Kombinationen auf die Tochter-Iden übertragen werden. Diese Art der Halbierung des Keimplasmas spielt bei der Umwandlung des Eies in den fertigen Organismus die Hauptrolle. Nur durch ihre richtige Funktionierung ist es möglich, dab die im Keim-

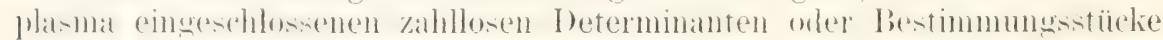
so entwickelt werden, laß sie, zur rechten Zeit an den richtigen Ort gebracht, in die Vererbungstïcke (Determinaten) des fertigen Körpers übergehen können.

Bei Beurteilung der nur kurz und der Hauptsache nach referierten Hypothesen von WEIsmans will ich auf die vielen Schwierigkeiten, die sich im einzelnen darbieten, nicht näher eingehen, sondern mich nur auf 
einige Hauptumkte beschränken, von denen mir alles übrige abyubängen scheint.

Ein solcher, an erster Stelle zu besprechender Hauptpunkt ist die Frage, ob ibberhapt nach unseren Kenntnissen rom \%ellenleben ...les. Prozelo der Auseinanderlegung des lieimplasmas", welchen WEermANx selbst einen ..Wumberbar verwiclielten" nennt, vermittelst der liern- und Zellteilung möglich ist. Ich glaube es in Nbrede stellen zu müssen und die Ummöglichkeit durch Argumente beweisen zu kïmmen, welche zugleich eine der hauptsächlichsten (ilundlagen meiner eigenen Theorie abgelien.

Wozu dient überhaupt in I,eben der Zelle ihre T'eilung. bei welcher die Kermsegmentierung die führende Rolle spielt? Doch zu ihrer Vermehrung. zu ihrer Fortptlanzung, und diese ist das Mittel, dessen sich die Natur zur Erhaltung eines Organismus als Art berlient. Der als ein-

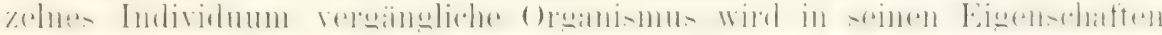
auf dem Wege der Erzengung vervielfältigt und als Art erhalten.

Von Ptlanzen und Tieren wissen wir auf Grund unzähliger Erfahrungen, daf jerles Individuum einer Art nur das V'ermögen besitzt. wierler nene Individuen derselben Art hervorzubringen. Die 'Theorie der heterogenen Zeugung. Wo sie anfgestellt wurde, ist als ein grober Irrtum bald beseitigt worlen. So gilt denn als ein allgemeiner (irundsatz in der Biologie der Ausspruch ,Gleiches erzengt nur (ileiches" oder besser ... Art erzeugt stets seine Art". Bei allen einzelligen Lebewesen ist erbgleiche

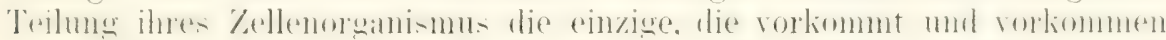
kann. Anf ihr beruht die Konstanz der Art. Wenn es möglich wäre.

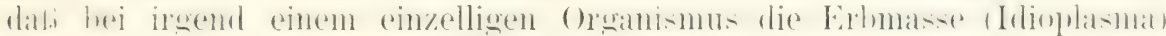
sureh Teilung in zwei moleide lomponenten zerlent und anf die Torhterzellen ungleich ïbertragen werden könnte, dann hätten wir den Fall viner heterogenen \% aus einer Art. Wie indessen alle Beobachtungen lehren, werlen auch bei

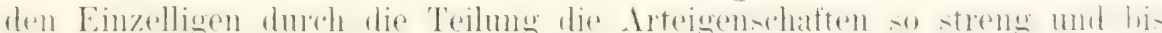
in- kleinste ïherliefert, dab.) einzellige P'ilze. Algen. Infusurien aluh nuch

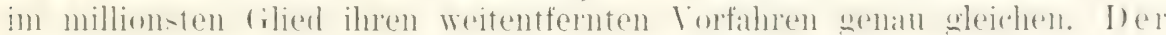
T'eilungsprozed als solcher erscheint daher auch bei den einzelligen Organismen nie und nirgends als Mittel, um neue Arten ins lieben zu lufen.

Aus den angefïhrten Grïnden scheint es mir nicht statthaft zu sein. daf die Zellenteilung bei der Entwicklung des Eies als Xittel für ganz

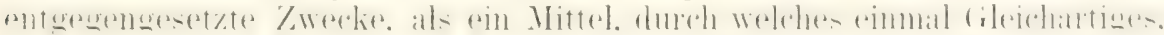
das andere Mal Ungleichartiges entstehen soll, gebraucht wirl; auch hier hann jede Zellteilung ihrer Natur nach einzig und allein eine .erbgleiche* sein: deshalb müssen alle aus dem Ei dureh Fortuflanzung entstehenden 'mellen Träger der vollen Erbmasse und der Art nach weich sein.

In seinen Vorträgen übex Deszendenztheoric erkennt MEISMAxy die Berechtigung des obigen Einwandes nicht an. Er meint. dal, wenn die 'l'eihung nur erbgleich wäre. so könnte es lieine Entwicklung der ersten Organismen zu höheren gegeben, so mübte jedes Lebewesen immer nu genaue Lopien semer selbst als Nachkommen geliefert haben.

Weisumxio ühersieht, dab.es noch einen andern Weg als den der

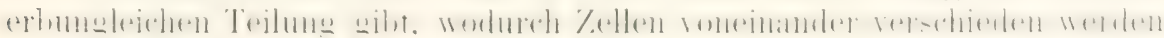
kömnen, nümlich den. Weg, daß sie sich durch neue Faktoren, die auf sie einwirken. in ihrer Beschaftenheit (auch in ihrem Iolioplasma) verändern. 
Wenn aber so verinderte Zellen sich teilen, so tun sie es nur durch erl, gleiche T'eilung, iibertragen also ihre newerworbenen Eigenschaften anf beide Tochterzellen gleichmäßig.

Somit steht die Lehre von der erbgleichen 'T'eilung in keinem Wirlerspruch zu der Annahme einer allmählich erfolgenden Umwandlung der Or'ganismen.

Ebenso wenig stichhaltig ist der Versuch Wersmanns, die Existenz. einer erbungleichen Teilung an dem Beispiel der ,weiblichen und männlichen Eier*. der Rotalorien, Blattläuse und Phylloxera zu beweisen. Mir erscheint durchaus nicht als etwas Selbstrerständliches der von ihm gezogene Schluß: Wenn die kleinen Eier, aus welchen die Männchen hervorgehen, und die groben Eier. aus welchen die Weibchen kommen, alle aus einer ersten Urogenitalzelle hervorgegangen sind, so mu bei einer der die Vermehrung dieser ersten Zelle bewirkenden Teilungen eine

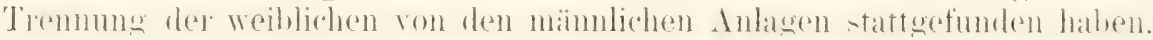
d. h. eine erbungleiche Teilung, für die kein äußerer, auch kein intrazellulärer Einfluß verantwortlich gemacht werden kann.

Nach meiner Ansicht ist das volle Idioplasma in den großen Eiern ebensogut wie in den kleinen enthalten, wie ja auch Samenfaden und Ei einer Tierart als Träger der Arteigenschaften einander gleichwertig sind.

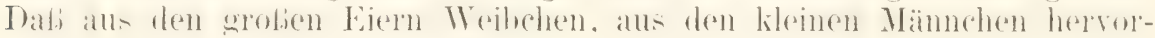
gehen, könnte, wie ich ïbrigens nur vermutungsweise ausspreche, seinen Grund im ungleichen Gehalt an Dotter und daher in ungleichen Wachstumsvorgängen in Eierstock haben, die sich unserer Beurteilung im einzelnen entziehen. Üher die Ursachen, durch welche das Geschlecht des Eies bestimmt wird, wissen wir ja überhaupt noch so gut wie nichts

Zweitens lassen sich mit Weisuanss Hypothese einer Zerlegung des Idioplasma- durch erbmoleiche Teilung die Erscheinmenen der Reprodulition. der Kein- mol Kinospenhildme. ohme Anmahme besonderer Hiltshypothesen. gar nicht in Einklang bringen.

Bei vielen niederen Tieren unf Pflanzen haben kleine Stückchen Lörpersubstanz, die man den verschiedensten Regionen entnehmen kann. das Vermögen. wieder den ganzen Organismus aus sich zu reproduzieren. Bei der Annahme einer erbungleichen T'eilung der aus dem Ei hervorgehenden Zellen ist dies nicht begreiflich, wohl aber, wenn jedle Zelle, wie das Ei, infolge erbgleicher 'Teilung die Anlage zum Ganzen enthält und daher nu der hesonderen liedingungen herlarf. 7il werden.

In einer dritten Richtung lehren wieder die Ergebnisse der Propfung. der Transplantation und Transfusion, daß alle Zellen und Gewebe eines ()ranismus anber ihren sichtharen. histologischen Figenschaften anch noch latente. weniger offen zutage liegende Eigenshaften hesitzen. welde sich als der Art eigentümlich nachweisen lassen und daher auf die gleichmäBige Verbreitung des Idioplasmas durch den ganzen Organismus hindeuten.

Viertens endlich fallen gegen die Weismanssche Hypothese schwer ins Gewicht alle Experimente, durch welche der Entwicklungsprozeß in seinen einzelnen Stalien abgeandert werten kann. Demn es läbt sich auf diesem Wege beweisen, daß die einzelnen, durch Teilung entstehenden Zollen liemestress dureh einen vorans bestimmten Plan, der in der komplizierten Architektur des Idioplasmas gegeben und durch die Art seiner Ansinamblergung vollzogen wirl. unahweislich nur für eine bestimmte liolle von vornherein prïlestiniert sind. Ich meine die schon anf seite ¿t4 


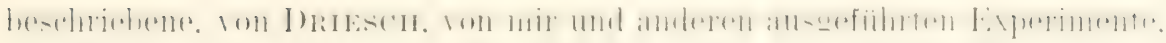
durch welche der Verlauf des Furchungsprozesses durch liompression

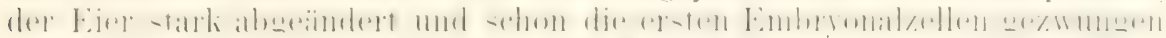
werden. sich zu anderen Stücken des Embryos aus\%ubilden, als es heim normalen Entwicklungsverlanf der Fall gewesen sein wïrle.

Em dem Leser recht anschaulich zu machen, wie in diesen Experimenten die sich vermehrenden lierne auf ganz andere Bezirke der Lisubstan\%, als es der Norm entspricht, verteilt werden, sollen die drei

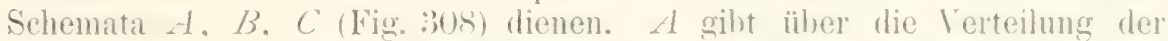
hemsubstanz bei normal gefurehten Eiern Aufschlub, B bei Eiern, die zwischen parallelen. horizontal gelagerten Platten geprefst sind. und $C$ bei Eiern, iie eine Pressung zwischen vertikal gestellten Glasplatten erfahren
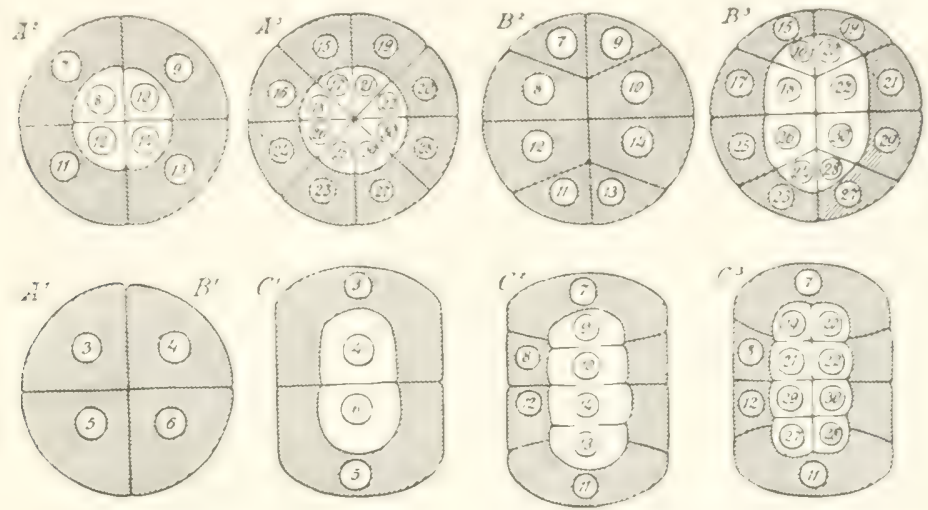

Irig. :30s. Schemata ron Froscheiern, welche zeicen, wie das hermmaterial hei

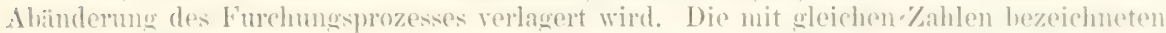
Kerne sind in den einzelnen schemata immer gleicher Herkunft. Mle Eier sind rom

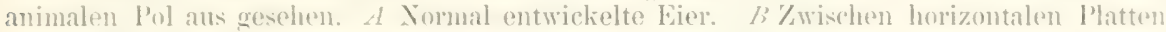
geprelite Eier. C \%wishen vertikalen Platten geprelite Eier.

haben. Die Schemata zeigen uns die Lage der Furchungszellen und ihrer lierne bei betrachtung des Eies vom animalen Pol aus. Anf den Stadien. wo durch die T'eilumg zwei übereinander gelegene Zellschichten gebildet worklen sind, ist die tiefer gelegene von der anderen durch Schraftierung kenntlich gemacht worden. In den drei Schemata haben die Kerne Zahlen erhalten. damit der Leser sofort weib, in welcher Reihenfolge sie von den Kernen der beiden ersten Furchungszellen abstammen. Es wird dies durch folgende zwei Stammbäume ausgedrielit:

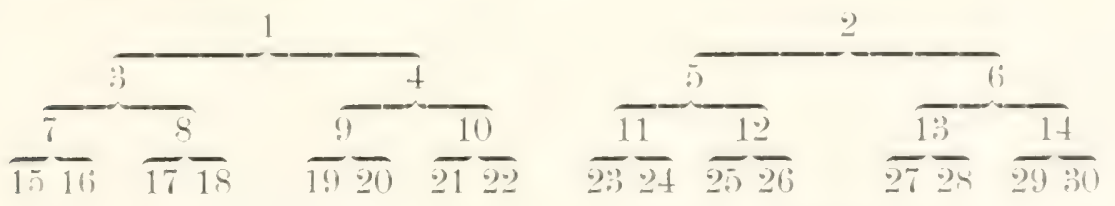

In den drei Schemata sind also die gleich bezifferten lieme sowohl

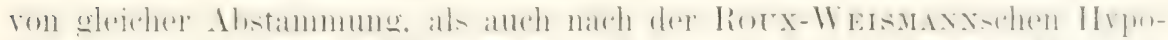

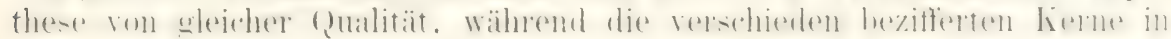
ihren Eigenschaften voneinander abweichen.

Sehen wir nun, wie die Kerne bei den drei verschiedenen, zum 'I'eil

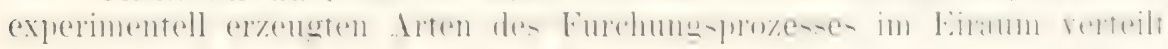
werlen, 
Im ersten 'Teilungszyklus gleichen sich die Kerne in allen Fïllen: beim zweiten Zyklus tritt der erste Unterschied auf: bei $A^{1}$ und $B^{1}$ liegen die keme :3 und 5 nach links. + mol ; nach rechts von der zweiten T'eilungsebene, welche nach einer Hypothese von Roux der Medianchene des späteren Embryos entsprechen würde; bei $C^{1}$ dagegen sind sie in zwei Schichten äberemander gelagert, $t$ und 6 dorsal, 3 und 5 ventral.

Im dritten Zyklus ist in keinem Falle mehr eine Ubereinstimmung in der Lage der Kerne vorhanden.

In Schema $A^{2}$ und $B^{2}$ sind zwar die Kerne noch in gleicher Weise mach links und rechts von der Medianebene verteilt, aber dort liegen sie in doppelter Schicht über-, hier in einfacher Schicht hintereinander. Die Kerne s, 10, 12, 14, welche in $A^{2}$ der oberen Lage angehören, hehmen in $\mathrm{B}^{2}$ die Mitte der einschichtigen Scheibe ein und haben die in $A^{2}$ ventral gelegenen kerne 7 und 9. 11 und 1:3 nach entgegengesetzten Enden nach den Kanten der Scheibe auseinander gedrängt.

In Schema $C^{2}$ endlich ist auch auf dem dritten Teilstadium noch keine Medianebene entstanden; es liegen die Kerne 9, 10, 14, 13, die in A' und b'2 der rechten Körperseite amsehören. in der dorsalen Zellschicht. und die Kerne 7, 8, 12, 11 ventralwärts. Im vierten Teilungszylilus ist das Kernmaterial, wie eine Vergleichung der Figuren $A^{3}-C^{3}$ lehrt, im Eiraum noch mehr durcheinander gewürfelt.

Während im normal geformten und gelagerten Ei die Vervielfiiltigmg und Verteilung der Kernsuhstanz in nahezu ilentischer. typischer Treise erfolgt, genügt schon die blobe Abänlerung der Kungelform zum Zylinder oder zur Scheibe, um eine vollständige Andersverteilung hervorzurufen, wenn wir die Kerne auf Grund ihres Stammbaumes miteinander vergleichen. Je nach dieser oder jener Art des Furchungsverlaufes werden sie bald mit diesem, bald mit jenem Raumteil der Dottersubstanz in Verbindung gebracht.

Wenn wirklich die Kerne durch den Furchungsprozeb mit rerschiedenen (oualititen amsestattet wïrlen. wodurch die sie hergenden Dotterstïcke von vornherein zu einem bestimmten stïcke des Fmbryos zu werden gezwumgen wïren, was für absomerliche Mibbildungen mübten dam ans den Eiern mit dem in verschiedenster Weise ..lurcheinander gewïrfelten" Kermmaterial entstehen? -

T'm diese und die zahlreichen anderen ohenerwïhnten schwierigheiten zu umgehen, welche sich mit (ler Zerlegung des Keimplasmas in Determinantengrupen und mit der Annahme der erbmoleichen Teilung nicht erlibiren lassen, haben Wessuxx mol Roux mehrele Zusatzhypothesen, die ich nicht unerwähnt lassen will, aufgestellt.

Da dlas Kieimplasma aus sehr zahlreichen Iden besteht, ron denen

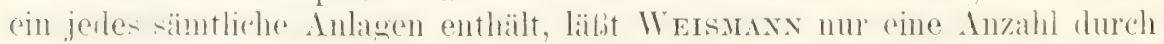
erbungleiche Teilung in die Determinanten zerlegt werlen, welche den Verlauf der Embryogenese und den endlichen Charakter der Zellen bestimmen, einen anderen Teil dagegen unzerlegt bleiben, indem er seine Determinanten fest zusammenhält und sie bei den Zellteilungen nicht in ungleichen Gruppen auf die Tochterzellen verteilt werden läist. Den ersten Teil der Irle bezeichnet er als aktives, zerlegbares Kieimplasma,

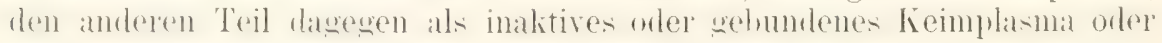
als Nebenkeimplasma. Die aktiven Iden dienen zur Erklärung der embryonalen Vorgänge, welche von ihnen geleitet werden, das Nebenkeimpla-ma dagesen bleiht für dic suateren Fortptlanzmosellen. sowie für die Bildung ron Krnospen reserviert; es wird vom befruchteten Ei aus in ge- 
bundenem Zustand neben anderem aktiv werdenden lieimplasma durch mehr oder minder lange Zellfolgen hindurch bei der Zellteilung weitergegeben bis zu den Orten schlieflich, wo die (ieschlechtsorgane oder wo Knospen entstehen. In ähnlicher Weise werden auch die Prozesse der Regeneration aus dem Vorhandensein von ,inalitivem Vebenidioplasma* zu erklïren versucht.

Alle diese /usatzhypothesen laufen im wesentlichen darauf hinaus. den 'I'eil der Anlagen. welcher durch erbungleiche Teilung aus den Zellen herausbefördert wurde, jetzt wieder in sie hineinschlïpfen zu lassen. Aufier den schon oben (Seite to 4 ) beschriebenen zwei Arten der Kernteilung wird daher jetzt sogar noch eine dritte Art angenommen. Das líemplasma kann sich gleichzeitig sowohl erbgleich als auch erbungleich teilen, wodurch es fïr alle Fälle der Erklärung anscheinend brauchbar wird. Ls läßt sich so gewissermaben in eine alitive und in eine Reservearmee sondern. Die

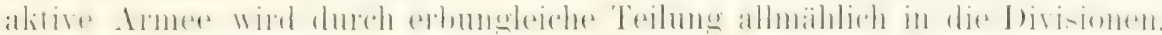
Brigaden, Regimenter, Bataillone etc. der den einzelnen Zellgruppen zufallenden Determinanten zerlegt und führt auf diese Weise nach einem

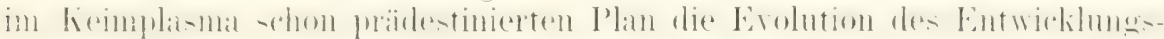
prozesses aus. Die passive Reservearmee dagegen wird durch erbgleiche

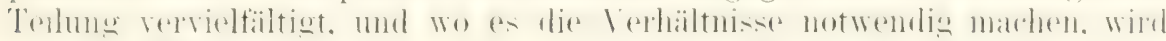

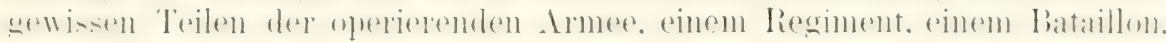
einer Kompagnie orler einem einzelnen $\mathrm{Zug}$, je eine ganze Reservearmee mit auf (len Weg gegeben.

Für gewöhnlich soll diese Beigabe in einem gebundenen oder inaktiven Zustand verharren, so daß sie auf den Verlaut des normalen Ent-

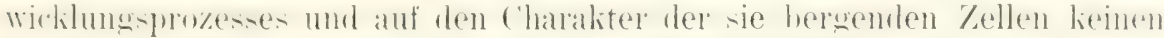
Einfluh hat: für besondere Fälle aber ist sie in Wirksamkeit zu treten

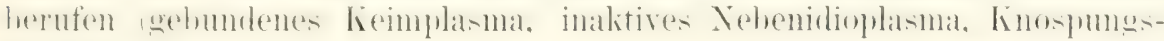
inlinglatollar.

Trotz dieser willkürlichen Hilfsannahmen bleibt es, wie mir durch die

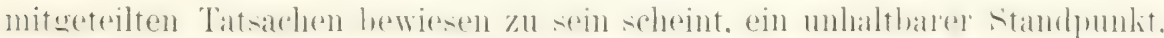
wenn. Weisuaxy nur einem Teil der Zellen, je nachdem er es gerade

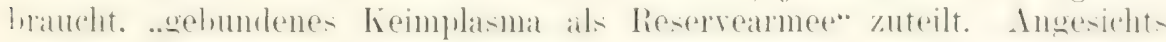
der von Driesch und mir angestellten Experimente, die lehren, wie die ersten Kerngenerationen gleich einem Haufen von Kugeln im Eiram

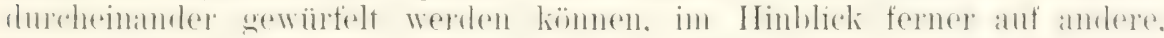
erst später mitzuteilende Resultate, nach welchen aus der Hälfte, einem Viertel orler Achtel eines Eies ein anzer Embryo werlen kam. bleibt für

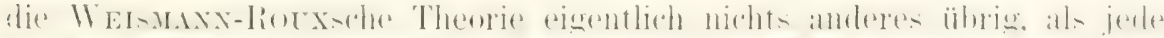

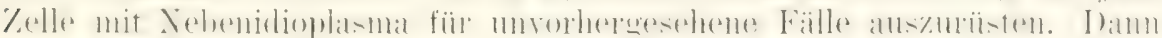
stehen wir aber auf dem von mir rertretenen Standpunkt, dab jede Zelle

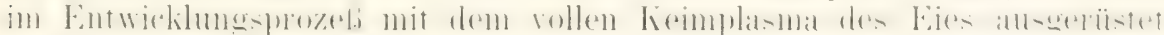
wird, mit dem Unterschied allerdings, daß WEIsMaxy es in eine aktive und

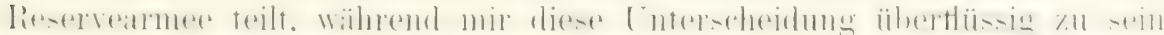
scheint, weil sich damit doch nichts erklären läßt. Denm bei jeder Störung des Entwicklungprozesses mula ja der im roraus bestimmte Operationsplan der alitiven Armee nicht mehr verwertbar sein. Wie soll sich der komplizierte, in der festen Architelitur des Keimplasmas begründete Entwicklungsmechanismus den wechselnden Verhältnissen ampassen? Welche Verwirtung mulj entstehen, wenn durch ämbere Eingrifte bald in dieser. bakl in jener Weise die Abteilungen der aktiven Armee in Unorlnung gebracht werden und wenn dam den zerstrenten 'Trummern derselhen die Reservearmeen mit ihrem Torrat latenter Anlagen zu Hilfe kommen sollen: 
Wer gebietet den durch den prïstabilierten Plan zur Aktivitä bestimmten Determinanten, jetzt nicht mehr zu determinieren an Stellen, wo es nicht mehr paßt, und wer reaktiviert die Anlagen der Reservearmee, die im Entwicklungsplan gebunden bleiben sollen, an Stellen, wo ihre Hilfe notwendig geworten ist:

Iir scheint, dab die Determinantenlehre bei jeder Änderung der im

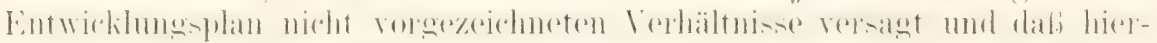
durch, wie durch die nachgewiesene Unmöglichkeit einer erbungleichen T'eilung die Kímplasmatheorie das Wesen des organischen Entwicklungsprozesses nicht erkiären kann. Schon in philosophischer Hinsicht beruht sie auf falschen (irundannahmen. Denn die Entwicklung des Eies ist weder eine Selhstdifferenzierung, noch verläuft sie auf Grund von Selbstletermination der Zellen.

Der Entwicklungsprozeh, um verstanden zu werden, mus vielmehr erfaßt werden als ein kleines Stïckchen des Naturverlaufs, das will heifen:

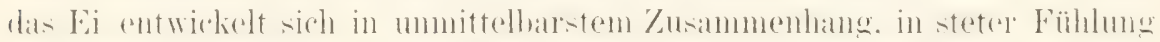
mit dem Naturganzen unter Benutzung der es umgebenden Aufenwelt. Stoff' und Kraft treten beständig in dasselbe ein und aus. Das Ei ist daher kein mechanisches Kunstwerk, dessen Mechanismus nur in Gang gesetzt zu werden braucht, um damn ruhig in der ihm vorgeschriebenen Weise abzulaufen, sondern ein Organismus, dessen Leben auf jeder Stufe der Entwicklung und zu jeder Zeit auf seinem beständigen Verkehr mit der AuBenwelt beruht.

In entgegengesetzter Richtung als die Keimplasmatheorie, welche durch einen in das Ei hineinkonstruierten, in der Architektur und der gesetzmäBigen Zerlegung des Keimplasmas gegebenen Mechanismus die Entwicklung mechanisch als Evolution und Präformation erklären will, sucht die von mir aufgestellte Theorie der Biogenesis das Entwicklungsproblem zull lösen.

Durch sie wird, wie schon im Namen ausgedrückt ist, das Ei als ein mit allen Eigenschaften des Lebens ausgerïsteter Organismus erfabt. als eine Zelle, die sich in zahlreiche artgleiche Zellen weiter vermehrt. Die Entwicklung ist ein Naturprozeb, der auf dem Zusammenwirken der durch Vermehrung der Eizelle entstehenden artgleichen Lebewesen beruht und sich unter dem beständigen Eintub der Aubenwelt und in beständiger Fühlung mit ihr vollzieht. I) ieser Vorgang ist ein durchaus epoenetioher.

Anf der anderen Seite ïherbrïclit indessen die Theorie der birgenesis in gewisser Hinsicht die tiefe Kluft, welche früher zwischen der alter Präformationstheorie und der Theorie der Epigenese von Caspar Friedrich WolfF bestand dadurch. daß sie zum Ausgangspunkt und zur Grundlage der Entwicklung ein kleines Lebewesen mit einer schon anderorilentlich lomplizielt heschatfenen Anlagesubstanz annimmt. Denn der Organismus der Eizelle vereinigt auch in unsern Augen in sich die Hauptbedingungen, durch welche der spezifische oder ,artgemäße“ Verlauf und das Endergebnis des Prozesses in erster Linie bestimm t wird. 


\section{Literatur zu Kapitel XIX.}

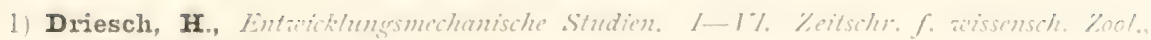
Lid. LIII, LI: ISOl.

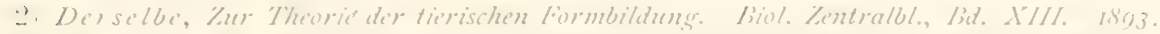

$\therefore$ Derselbe, Die Terlagemung de' Blastomeren des Eihinideneies. Anatom. Anzeiger. Jid. ITI1. Iso3.

1. Hertwig, Oskax, lescleich der Ei- und Samenbildung bei Nematodiz. Fine Gimmt-

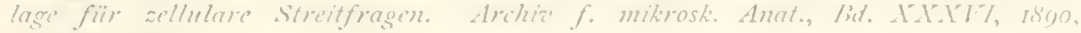
Sitit $86-100$.

$\therefore$ Derselbe, Zeit- und Survitfragen der Jbiologie, Heft I. Präformation oder. Epigenese? Grandä̈ge einer Entricklangstherie der Organismen. Jena 1897.

A. Dersclbe, Lber den lliet der ersten Furchungsallen fïr die Organbildung des Embrro. Experimentelle Studien am Froscli- und Tritonei. Archiz $f$. mikrosk. Aluat, Bat. II,II. I803.

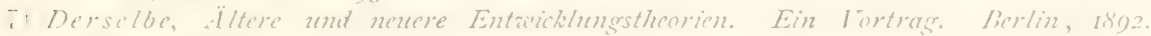
Mirschicald.

Nägeli, 1Fechanisch-physiologische Theorie der Abstammungslehre. 1884.

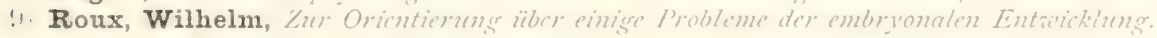

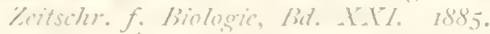

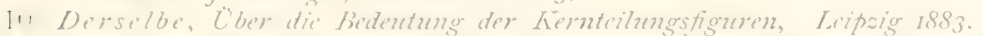

11 Derselbe, ¿ber die kïnstliche Herorbringung halber Embryonen durch Zerstönns

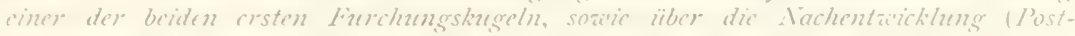

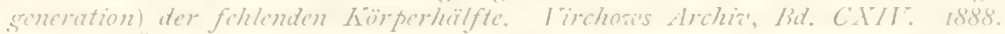

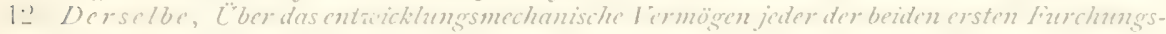
zellen des Eies. Jerhandl. d. anat. Gesellsch. d. O. Iers. in Il ien Ison.

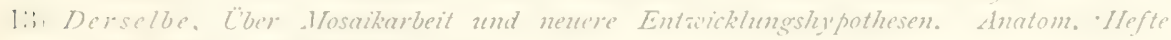
a'on . Merkel and Bomet. Iso3.

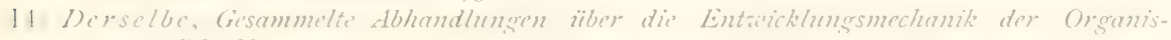
men, B'd, II. I805.

1:. Weismann, Das Keimplasma. Eime Theorie der Tererbuns. Jena 1802.

11i. Derselbe, Die Allnacht der Vaturä̈chung. Eine Eraidermo an Ilerbert Spencer. 1.303

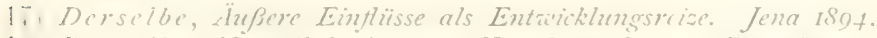

In. Derselbe, Vize Gedanken zur Tererbungsfrage. Jenc 1805.

1!) Derselbe, Über Germinalselektion. Extrait du compte rendu des simnes du troisinue congris international de zoologie. Leiden 1806 .

2.1 Derselbe, Iorträge ziber Dessendenstherie, Jid. I 21. II. Jena 1002. 


\section{ZWANZIGSTES KAPITEL.}

\section{Die 'Theorie der Biogenesis.}

\section{Die ïußeren Faktoren der organischen Entwicklung.}

In den vorausgegangenen Kapiteln wurden in mehr theoretischer Weise die allgemeinen Grundsätze aufgestellt, von denen aus sich die I)ifferenzierung gleichartiger Zellen in vershiedene dewehe mul (rowne begreifen läßt. Ihre Tragweite im einzelnen zu prüfen und zu erläutern,

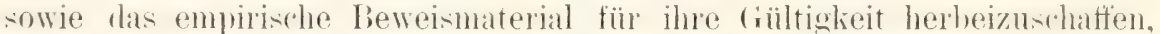
wird die Aufgabe der folgenden Kapitel sein. Sie handeln teils von den :uberen. teils von den imneren Faktoren. durch welche Zellenaggregate zu Sonderungsprozessen veranlaßt werden. Die Beispiele sind sowohl dem Pflanzen- wie dem Tierreich entnommen und aus der schon ziemlich umfangreichen, aber sehr zerstreuten Literatur so ausgewählt, dab sie uns ein moefähes Bild gehen ron der ungeheuren Mamnigfaltigkeit aller Falitoren. welche fïr die Unformung der Zellen und für die Bildung von Gereben und Organen in Betracht kommen.

Obwohl die inneren Faktoren für den Ablauf der Entwicklung und ihr Ergebnis weitaus die wichtigsten sind, so wollen wir sie doch erst an zweiter stelle besprechen, da ihr Vorstindnis arobere Schwierigheiten bereitet. Wir beginnen daher mit den äußeren Faktoren.

Infolge seines beständigen Verkehrs mit der AuBenwelt, auf welchem der Lehensprozeb heruht, mul, sich der ()ronismus unzihligen Bedingungen anpassen. Schwerkraft und mechanische Kräfte, wie Zug und Druck. Licht und Wärme und alle die zahllosen chemischen Kräte. welche in den stoffen der Luft, des Wassers und der Erde wirksam sind, üben ihren Einflud anf ihn aus und beherrschen seine Gestaltbildung.

Nur in seltenen Fällen läbt sich die Wirksamkeit eines einzelnen Faktors rein für sich erkennen. Meist handelt es sich um komplizierte Faktoren, unter deren Einfluf sich der Organismus befindet.

Endlich sind neben den Einwirkungen der unbelebten Natur atich noch solche zu erwähnen, welche dadurch entstehen, daf zwei Organismen mit ihren etwas verschiedenen Lebensprozessen in Beziehung zu einander treten. Hierher gehören die Verbindungen zweier oder mehrerer Organismen durch Pfropfung, die Erscheinungen der Bastardbefruchtung, die Wrehselwirkmgen zwishen Embryo mol Muteroromismus. die Telegonie und endlich das Zusammenleben artverschiedener Zellen teils in normal phrsologischen symbiosen. teils in pathologischen oromisationen wio in den krankhaften Geschwiilsten. 
Wir werden die hier angeführten verschiedenartigen Einwirkungen fler Anbenwelt im einzelnen der Reihe nach genauer besprechen und mit der Schwerkraft begimmen.

\section{Die Schwerkraft.}

Die Gravitation ist die allgemeinste Naturkiaft. unter deren Einflul. sich jeder liörper fortwihrend befindet und weleher sich lieiner entziehen kann. Unorganische wie organische Körper sind jederzeit bestrebt, sich ihrer Schwere nach im Raume zu orientieren, und wo die Orientieruns unterbleibt, hängt es jedesmal von besonderen bedingungen ab, welche ihren Eintritt ummöglich gemacht haben. So kann man durch Stïtzen

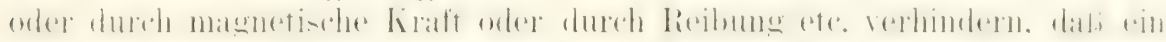
Körper die seiner Schwere entsprechende Lage im Raume eimnimmt. Aber .atufheben" lamn niemand die Wirkung der Schwerkraft, welche, allgegenwärtig. nur in ihrer momentanen Äufermog gehindert werden kamn.

Im Bau der Pflanzen und 'Tiere läbt sich der Einfluf der Gravitation

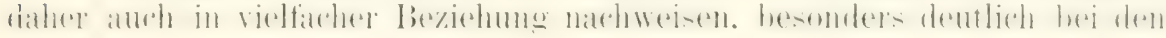
ersteren.

liig. : $3(1) 9$

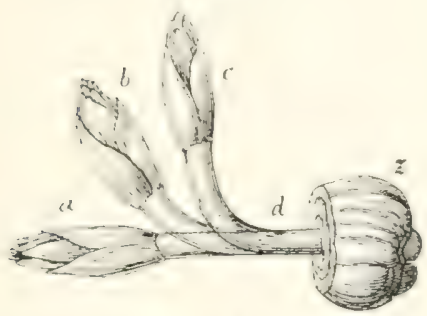

Fing. 310.

[.i!. : ; I. Austreibender Blütensproß der Kaiserkrone (Fritillaria imperialis). Nach SAcHs. Der' obere 'Teil der Ziebel $Z$ ist ringsum wegreschnitten, um den unteren Teil des Schaftes d freizulegen. Dann wurle die l'flanze horizontal geleut, und nach etwa 20 Stunden erhob sich der anfangs gerade Sprob a durch $b$ in die Lace $c$.

Fïg. 310. Selema für die geotropische Auf- mol Abwärtskrümmung. Nach S.Acis. s s sprob, w a $z^{\prime}$ Wmzel.

Wie SAcris auf (imund ausgedehnter Untersuchumgen bemerkt, .he-

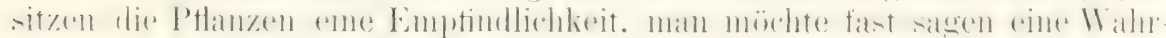
nehmung davon. unter welchem Winkel ihre Organe von der Vertikalen ihres Standortes geschnitten werden. Sie sind empfindlich für die Richtung. unter welcher die Gravitation anf jedes ihrer Organe cinwirkt. und zwar unabhängig von dem Gewicht und etwaigen Druck. Sie besitzen für die Schwere eine Empfindung, wie wir für das Licht und für die Wràrme: wälrend uns eine ummittelbare Wahrnehmung (ler Gravitation völlig abgeht: denn wir selbst nehmen diese nur durch die Wirkungen des Gewichtes und des Druckes wahr:"

Man kann sich ron dieser Eigenschaft der Ptlanzen durch ein sehr

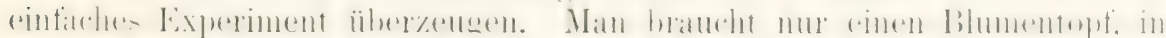

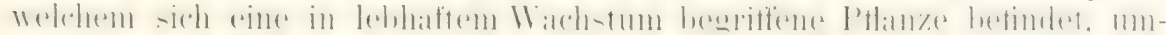
zulegen, so dab jetzt ihr Stamm aus der vertikalen in eine horizontale Lage gebracht ist (Fig. 309) u. :30). Nach kurzer Zeit bemerlit man. wie

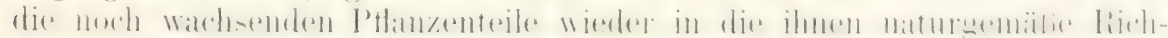

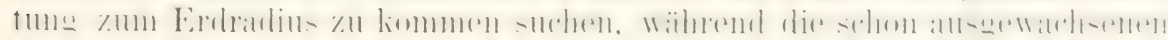

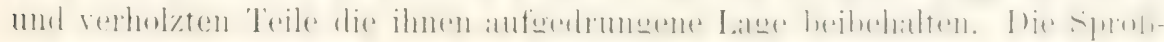


achse $(a)$ beginnt, wie die nebenstehende Figur zeigt, nach einiger Zeit sich nach oben ( $b$ und $c$ ) zu lirummen und in der Krïmmung solange fortzufahren, bis ihre Wachstumsrichtung wieder mit der Vertikalen zu-

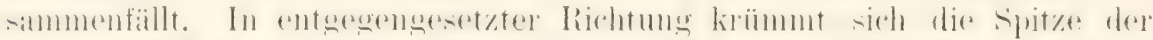

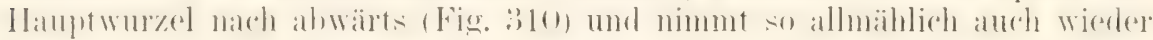
ihre ursprüngliche Lage und Wachstmmsrichtung ein. Man nennt die Reaktion der Pthanze, vermöge deren sie die Lage ilner Teile immer in

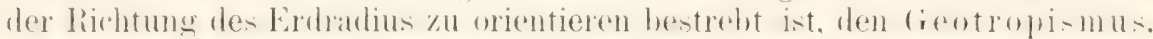
In den geotropischen Erscheinumgen erblickt SAcHs ..Reizwirkngen, da-

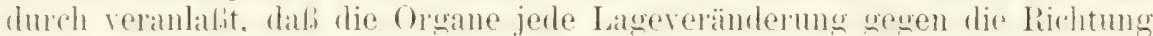

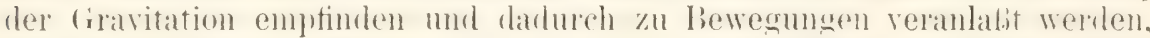
welche erst dann aufhören. wenn sie ihre urspoungliche Richtung wiedor erlangt haben". In dem senkrechten Wuchs eines Kornhalms oder eines Bammschaftes wie der Tanne gibt sich die richtende Wirkung der Gravitation zu erkennen: darlurch gewinnen die Pflanzen eine statische Gleich-

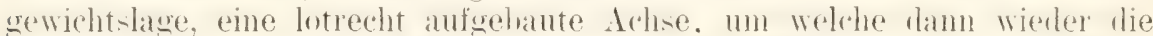
horizontal oder schüge aus ihr hervolwalsenden seitensprose angeordnet sind.

Neuerdings haben auch gleichzeitig zwei Forscher, NĚuEc und HABER-

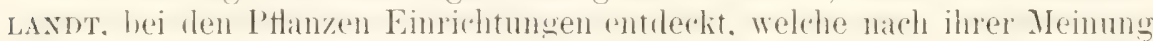
der Schwerkraftswirkung dienen. Es sind die Statocysten, Zellen, welche eine Anzahl beweglicher Stärkekörner, die passiv dem Zug der Schwere folgen. als Statolithen einschließen. Sie finclen sich stets in den geotropisch reizbaren Organen in den Wurzelspitzen und in den Stengeln und Blattstielen, wo sie einen einschichtigen Hohlzylinder, flie sogenannte Stärliescheide, bilden.

Die Wirkungsweise der Statocysten denkt sich HABERLANDT in der Weise, daf ihre ..wandständigen Plasmahäute für den Druck der auf ihnen lagernden Stärkekörner in verschiedenen Graden empfindlich sind und daf diese Empfindlichkeit so abgestimmt ist. dab in der geotropischen Gleichgewichtslage der Druck der' Stärkekörner auf die physikalisch unteren

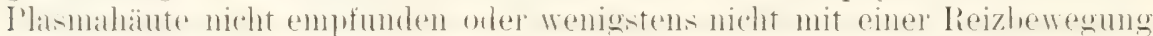

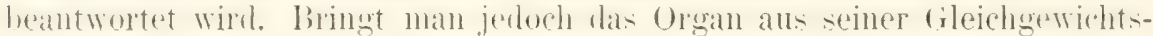
lage heraus, wird z. B. ein aufrechter Stengel, eine abwärts wachsende Wurzel horizontal gelegt, so sinken die stärkekörner anf die nummehr nardo unten gekehrten Plasmahäute hinüber, und der darlurch ausgeübte nene und ungewohnte heiz löst eme geotropisohe hrömmume ans, die dar ()rwan in die Gleichgewichtslage zurückführt.

Die Zellen mit den sensiblen Plasmahäuten und den umlagerungsfähigen Stärkekörnern sind demnach die Sinneszellen für den Schwerliraftreiz."

A uch in der inneren Struktur der Pflanzen hat der beständige Einfluß der Schwerkraft bis zu einem gewissen Grade einen polaren Gegensatz hervorgerufen, auf welchen VöcHTING aufmerksam gemacht hat.

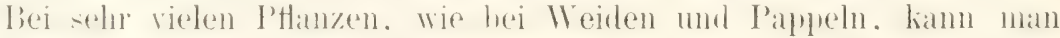
jeden beliebigen Zweig durch Querschnitte in viele einzelne Teilstücke zer-

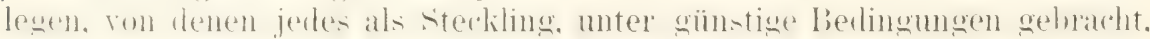
wieder zu einer vollständigen Pflanze auszuwachsen imstande ist. Das Gelingen derartiger Experimente ist aber an die Bedingung geknüpft. dah jeder Steckling in richtiger Weise zur' Schwerkraft orientiert ist. An jedem

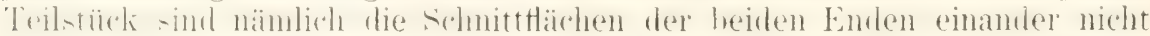
gleichwertig, sondern zeigen gewissermaßen denselben polaren Gegensatz zu einander ausgeprägt, welchen man an der ganzen Ptlanze zwischen dem 
zenitwärts mol erolwärts wachsenden Ende, zwischen Sprolispitze und Wurzelspitze findet. Vöchtixg bezeichnet daher auch die del Spitze zu-

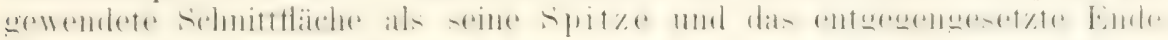
als seine Basis. Ein Zweig, den man in viele Stücke quer durchschneidet. verhält sich ähnlich wie ein Magnet. den man in Stïcke bricht, von denen jedes ebenfalls einen Tordpol und einen Sïdpol unterscheiden läit.

Der polare Gegensatz an einem beliebig herausgeschnittenen Stiuck eines Zweiges gibt sich bei der weiteren Entwicklung darin zu erkennen, daf an seiner basis, mag sie erdwäts oder zenitwärts gerichtet sein, die Kinospen sich zu Wurzeln umbilden, währent an der Spitze sich die Angen zil 'Trieben entwickeln.

Das Experiment stellt man in der Weise an, daß3 man entweder die

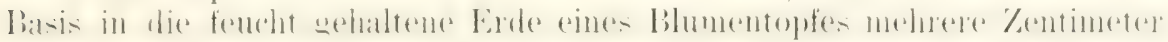
tief einsenkt und mit eines darïber gestülpten Glasglocke bedeckt oder

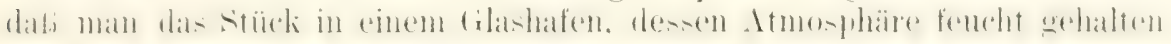
wird, mit seiner Basis nach abwärts gekehrt, aufhängt.

Wäre das Teilstück seiner Länge nach gleichartig organisiert, so claß die beiden Schnittenden sich nicht voneinandel unterschieden. so mübten an der Spitze des Stückes, wenn sie nach abwärts gekehnt wïrde, unter

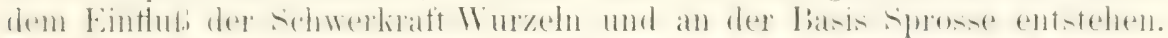

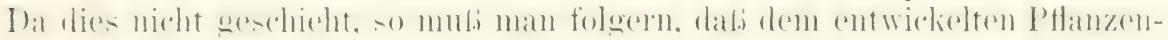
teile durch den beständigen Einfluf der Schwerkraft eine polare Organisation aufgeprägt worden ist, die sich dann darin kundgibt, daß auch an den verkehrt orientierten Enden Wurzehn statt Sprosse an der Basis und Sprosse anstatt Wurzeln an der Spitze zum Vorschein kommen.

Allerdings macht sich in weiteren Verlaufe der Entwicklung cin

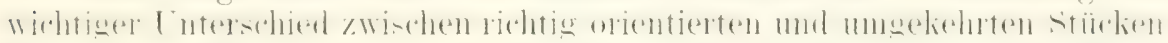
bemerkbar. Erstere gedeihen, treiben an der Basis ein immer kräftiger werdendes Wurzelwerk und an der Spitze Laubsprosse. Die umgekehrten Stiicke dagegen gehen nach kïrzerer oder längerer Zeit zugrunde.

.Ein Schwarzwerden und Eintrocknen der Rinde an der Basis zeigt,"

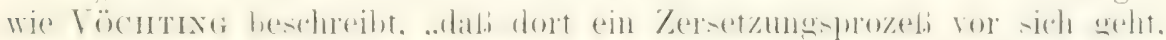

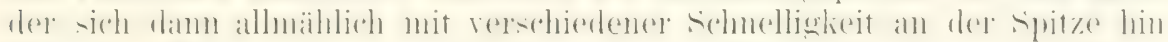
fortsetzt. Während die jungen Triebe in der Nähe der Spitze noch frisch und grün sind, wird das Laub der weiter nach der Basis hin befindlichen schon gelb und fällt ab, ein Vorgang, dem dann bald das Eintrocknen der

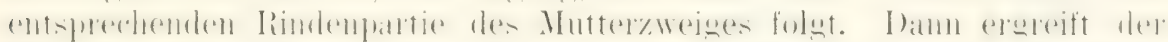
Zersetzungsprozeh auch die apikalen Partieen dicht über und in der Lide. und es bleiben endlich nur noch solche Spitzen lebendig, deren Kunospen in der Erde aus-, dam über dieselbe gewachsen waren und num grüne Laubblätter gebildet hatten. - Beim schlieblichen Untersuchen der Zweige stellt sich heraus, daf in fast allen Fällen in der Erde Augen entwickelt. aber vor Erreichung der Obertläche zugrunde gegangen waren. In den Fälen, in welchen sie ïber die Obertliche gelangt waren, hatten sie in der Erde ihre eigenen Wurzehn gebildet und stellten num normal aufrecht stehende Pthanzen dar. - Wem an den Spitzen in der Erole Wurzeln erzeugt waren. so standen sie regehmäBig an Zahl, Stärke und Liange weit hinter denen zurïck, welche die Basen der aufrecht gesetzten Zweige gebildet hatten. - Von allen diesen Erscheinumgen war an den normal aufrecht gesetzten Zweigen nichts zu sehen. Sie hatten an ihren basen kräftige

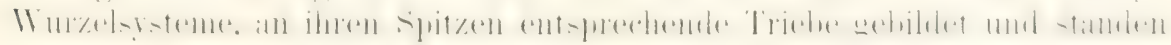
iippig und gesund zu der Zeit, als die verkehrt gesteckten längst zugrumde gegangen waren."

O. Hertwier. Aluemeine Binlocic. 2. Aufl. 
Es liegt die Frage nahe, ob eine ähnliche, durch den Einftub der Schwerkiaft bewirkte Polarität der 'Teile auch bei 'Tieren beobachtet werden kann. Nach den spärlichen, in dieser Richtung angesteliten Versuchen läBt sich ein allgemeines Ergebnis noch nicht formulieren.

Bei 'l'ubularia zeigen Stiicke eines Zweiges nach später zu besprechenden Expermenten von LOEB wenigstens keine dentlich ausgesprochene Polaritä. Basis und spitze verhalten sich gleichartig, da an jedem Ende, je nachdem es nach abwäts oder nach oben gerichtet ist, Haftwureln oder ein köpfchen regeneriert wir.

Auch WETzEL ist durch seine neuesten Versuche zu dem. Ergebnis gelangt, daß sler Körper von Hydra keine Polarität, wie sie Vöchtrivg für die Ptlanzen annimmt, besitzt. Denn als

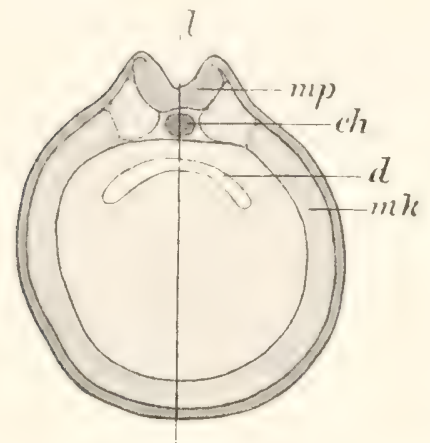

Fig. 311. Querschnitt durch ein normal symmetrisch entwickeltes Froschei, hei welchem sich die Medullarwülste $(m p)$ in gleichem Abstand ron der Gleichgewichts- nud Srmmetricebene (l) anlegen. ch Chorda. d Darm. mo Mittleres Keimblatt. er an zwei Hydren die basalen Enden wegschnitt. sie mit den Schnitttlächen zusammenpfropfte und später bei einem Individuum auch den Kouf entfernte. so entwickelte letzteres jetzt an der Schnittliache einen FuB. der durch seine hohen Sekretzellen als solcher deutlich gekennzeichnet war.

Daß auch bei Tieren die Schwerkraft auf ilıre Organbildung während der Entwicklung einen Eintluß ausübt, läßt sich durch genaues Studium des Froscheies nachweisen. Da es zu den polar differenzierten Eiern gehört. nimmt es bald nach der Befruchtung im Wasser eine feste Ruhelage nach der ungleichen Schwere der vegetativen und der animalen Hälfte der Kugel ein. Hierbei scheinen schon frühzeitig die Dottersubstanzen zu beiden Seiten einer Symmetrieebene angeordnet zu sein, die, weil sie sich zur Schwere lotrecht einstellt. auch als Gleichgewichtsebene bezeichnet werden kam. Zu ihn werlen anf den einzelnen Entwiclumg-stalien die sich anlegenden Organe normalerweise symmetrisch orientiert (Fig. 311); der Urmund legt sich als Halbrinne so an. dab er von ihr in der Mitte halbiert wird: die Verwachsung der Urmundränder erfolgt wieder ron vorn nach hinten in der durch sie bezeichneten Richtung; in gleichen Abstand von ihr und von der Urmundnaht erheben sich die Medullarwülste (Fig. $311 \mathrm{mp}$ ) und verschmelzen wieder in der mit der Symmetrieebene zusammenfallenden Naht des Rückenmarkes. Wenn man durch die verschiedenen Stadien des unter dem Einfluf, der Gravitation sich normal entwickelnden Frosch-

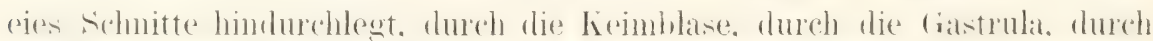
Embryonen mit Rückenwülsten etc., so findet man immer die Dottermasse,

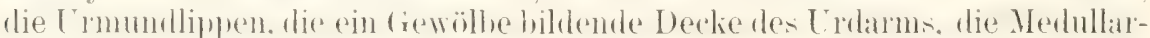
platte etc. zur Gleichgewichtsebene des Eies so genan orientiert, daß vollliommen symmetrische Bilder entstehen.

Die symmetrische Entwicklung des Eies wird sofort gestört, wenn man durch ändere Eingriffe dem richtenden Einfluld der sohwerkitt entgegenwirkt. Dies geschieht, wenn man das befruchtete Froschei zwischen zwei horizontal oder vertikal gestellten, parallelen Glasplatten durch Kompression zu einer dicken Scheibe etwas abplattet (Fig. 312). Dem rich-

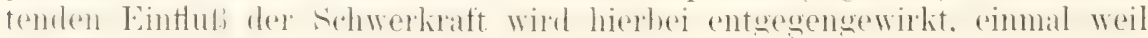


die Scheibe nicht mehr so frei mach allen Richtungen wie die Kugel ro-

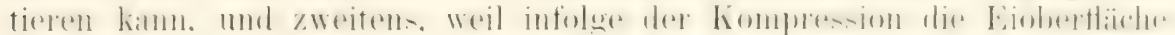
auch die Reibung an der Eihaut zu überwinden hat. So kann das Ei

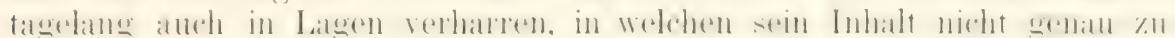
einer Symmetrie- und (ileichgewichtsebene orientiert ist. Da in dieser

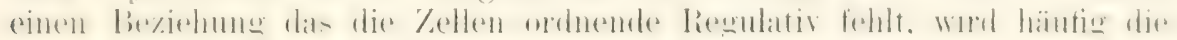
Gestalt des Embryos eine mehr oller minder asymmetrische.

Anstatt besonderer Beschreibung genïgt es, auf die Durchschnitte durch vier Froscheier hinzuweisen (Fig. 312 ), die auf vier verschiedenen

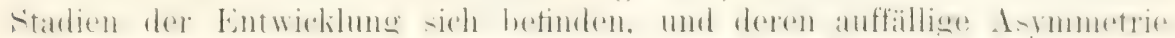

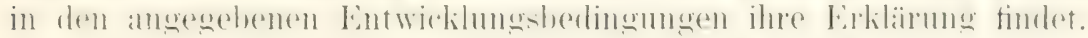

Am meisten wird dem richtenden Einfluh der Gravitation entgegen-

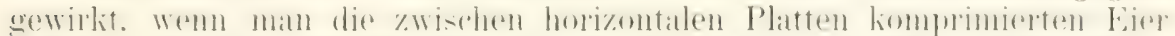

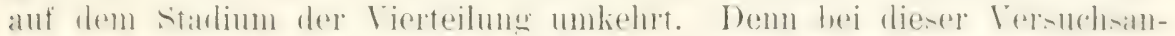

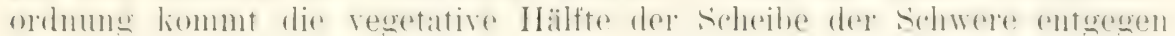
nach oben zu liegen und läßt sich in dieser Lage ein bis zwei 'Tage erhalten. da die Umdrehung infolge der Teilung des Eies in vier Stiicke,
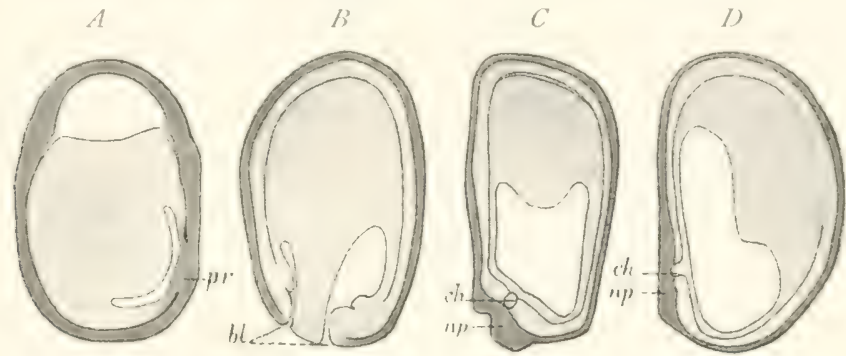

Fig. 312. Durchschnitt durch Froscheier, die bald nach der Befuchtung zwischen zwei rertikal gestellten Glasplatten geprebt und zu verschiedenen /seiten in Chromsäure gehärtet wurden. A Ei auf dem Gastrulastadium. B' u. C Querschnitt durch ein Ei, an welchen die Medullarwiilste anfzutreten beginnen. B ()uerschnitt durch den Blastoporus. C Q Querschnitt in einiger Entfermung von demselben durch Medullarplatte? und Chorda. D (Nuerschnitt durch ein asymmetrisches Froschei mit Iedullarplatte und Chorda. pi. Ermmonaht. ol Urmund. ch Chorda. np Nervenplatte.

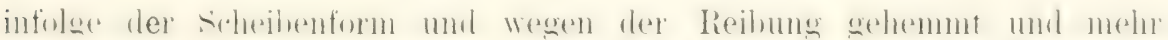

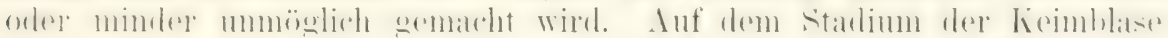
schieben sich allmählich die Dotterzellen mehr nach einem Rande der Scheibe hin und nehmen eine seitenständige Lagre ein. Die clurch die

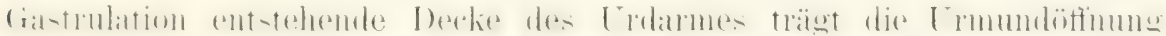
und später die Urmundnaht nicht in der Mitte des Gewölbes, sondern in noch höherem Grade als bei den vorher beschriebenen astmmetrischen Embryonen zur Seite geschoben. Die Urmundnaht erfolgt anstatt in einer 'gerarlen in einer' mehr oder minder stark gezackten Linie.

Die Resultate der yon mir angestellten Experimente konnte ich daher in die beiden Sätze zusammenfassen: . Wenn die Froscheier gezwungen werden. sich in Kwangslage zu entwickeln. sei es, dab sie ihrer Schwere entgegen im Raun umgekehrt orientiert sind, sei es, daf durch hompression zwischen (ilasplatten erzengte Reibungswiderstinde die Orientierung nach der Schwere behindern, so entstehen asymmetrische Embryonen mit ungleich entwickelten Körperhälften. Wie bei den P'tlanzen, ïht

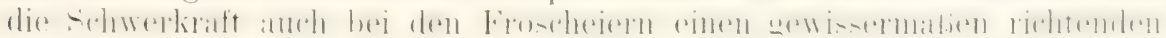
Einflub auf die Zellen und auf ihre Anordnung zu beiden Seiten einer Symmetrie- und Gleichgewichtsebene aus. 
Man kann daher mit SACus sagen: „Alles, was im Pflanzen- und l"ierreich mit den liegriften Bauch- und Rïrkenseite, rechte und linke Flanlie etc. irgendwie zusammenhängt, trägt den Stempel der Schwerkraft ins Organische ïbersetzt an sich."

\section{Die Zentrifugalkraft.}

In ähnlicher Weise wie die Schwere wirkt die Zentrifugalkraft. Für Experimente bietet letztere sogar den Vorteil dar. dali man es in seiner Hand hat, die Kraft heliebig zu varieren. Entweder kann man dem Zentrifugalapparat, auf den man den zu untersuchenden fiegenstand bringt. eine verschieden starke T'mdrehungsgeschwindigkeit geben, oder man kann den Radius des Kreises, in dessen Peripherie der (iegenstand rotiert. helielig verlängern odeì verkürzen. Wie durch die Gravitation wird auch durch die Zentrifugalliraft eine Sonderung der Substanzen von ungleicher sichwere hervorgerufen. indem die schwersten sich am weitesten rom Lmdrehungsmittelpunlit entfernen, die leichteren sich poximalwäts anordnen. Wenn

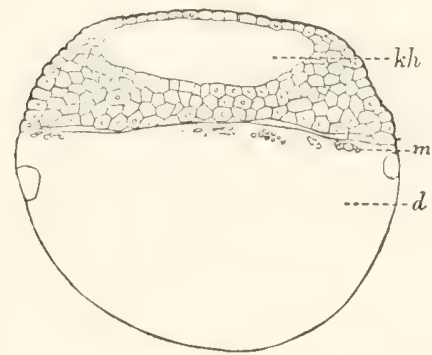

Fig. 313. Froschei, durch den Einflufi der Zentrifugalliraft

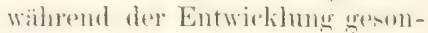
dert in eine Keimscheibe und eine unentwickelt gebliebene Dottermasse mit einem Dottersyncytium. die Zentrifugalkraft die Wirkung der Gravitation der Erde übertrifft, so muß sie natürlich auch einen stärker sondernden EinfluB auf organische Teile und auf Organismen ausiiben. die aus Substanzen von verschiedener Schwere zusammengesetzt sind.

Von diesem Gesichtspunkt ausgehend, ist es mir gelungen, die ersten Entwicklungsprozesse des Froscheies, dessen Dotterplättchen, Protoplasma und Zellkerne von verschiedener Schwere sind, von Grund aus umzuändern. Bei genügender Stärke der Zentrifugalkraft wirl im hefruchteten Ei der vegensatz zwischen animaler mol regetativer Eihälfte noch vergrößert. Der Furchungsprozeß bleibt mehr und mehr auf die animale Hälfte beschränkt, weil die Kerne als die leichtesten Teile in der Nähe des der Tmorehungachse zugekehrten animalen Poles gewiscemalien festgehalten werden. Man kann auf diesem Wege schlieblich das holoblastische Froschei mehr oder minder in einen meroblastischen 'Typus überfïhren (Fig. 313). Wem nach 24 Stunden der Furchungs-

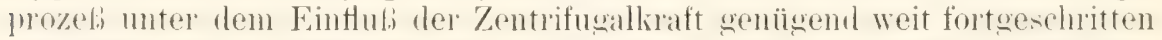
ist. findet man das Froschei wie das Ei eines logels ans einer kleinzelligen, die Iblastulahöhle einschlielienden heimshenbe und einer ungeteilt gebljehenen. gröberen Masse von Nahrumgshotter zusammengesetzt. Deide sind ziemlich scharf mit einer ebenen Fläche gegeneinander abgegrenzt. Die Übereinstimmung geht sogar so weit, daß sich in der subgerminalen Schicht des Dotters reremzelte Kerne eingelagert finden. Darlureh int eine

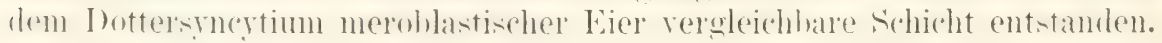

Auf Grumd derartiger Experimente kann man wohl die Behauptung aufstellen und rechtfertigen, rlaß, wem eine der unsrigen entsprechende Lebewelt auf einem vielmals mößeren Planeten, als die Erde ist, existierte, sie unter dem Eintlub einer stärkeren Gravitation in ihrer Organisation vielfarh ahgeänderte Zü̈ge aufweisen müble. So würden vielleicht die Eier mancher 'Tierklassen, wie der Amphibien oder der Accipenseriden, die sich 


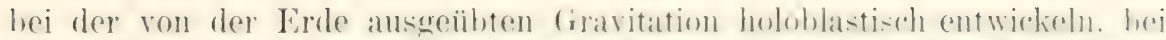

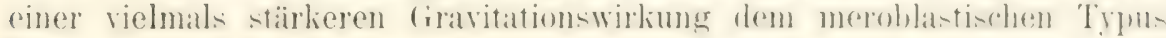
folgen.

\section{Mechanische Einwirkungen von Zug, Druck und Spannung.}

Auf manche Gestaltungsprozesse bei PHanzen und 'Tieren, auf die

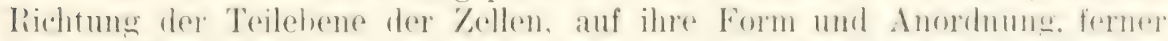

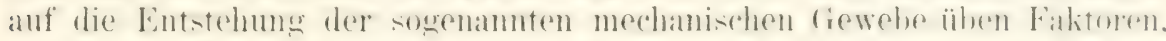
wie Druck. Zug usw., einen sehr wichtigen Einflub aus, wenn sie in kon-

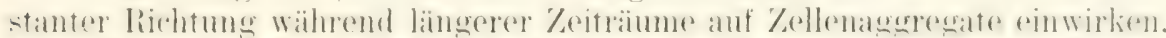

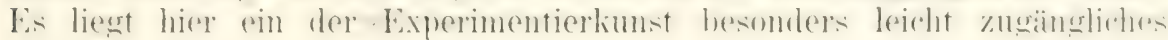
(iebiet ror.

a) Einwirkung auf sich teilende Zellen.

Es ist nicht schwer, durch Druck und Zug die Form von Eiern zu

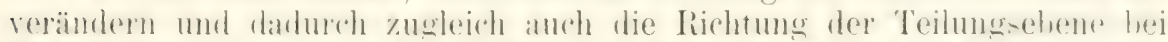

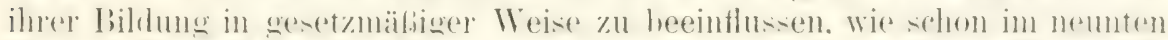

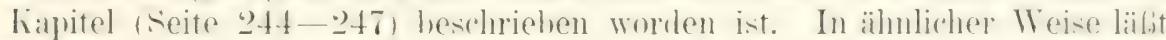

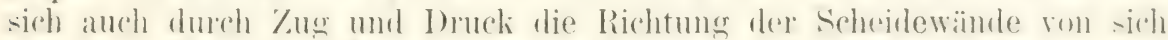

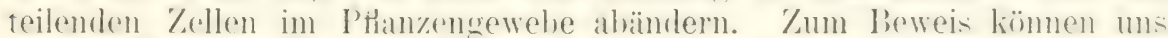
die interesinten. an der Kartoffel angestellten Experimente ron kix dienen.

Wenn man an einer Kartoffelknolle eine Schnittfläche anbringt. so wirl an inr nach zwei Tagen Wundperiderm gebildet. Hierbei kommen die sibendewände der sich teilenden Zellen mit wenigen Ansnahmen der

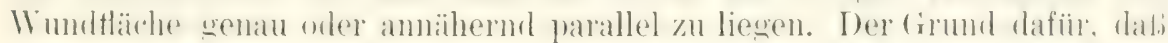
diese Richtung bevorzugt wird, ist wohl darin zu suchen, dab die sich zur

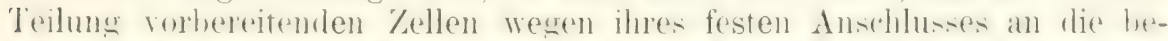

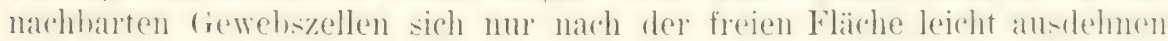
und verlängern können.

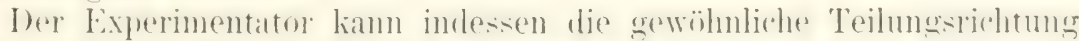
der Zellen durch Druck oder Zug verändern. Um dies zu erreichen. hat

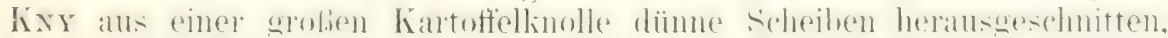

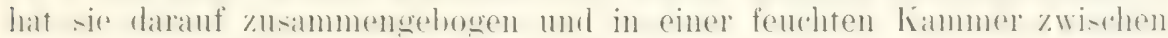
zwei parallele Glasplatten gebracht, yon welchen er die obere in zweck-

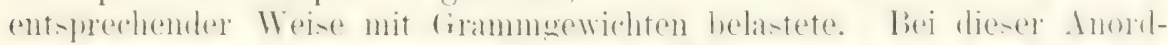

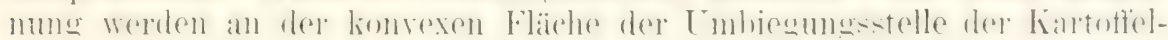
scheibe die Zellen in einer Richtung parallel zur Oberfläche gerlehnt, dagegen an der konkaven Fläche von ihren Seiten her noch mehr zusammengeprelit als unter gewöhnlichen Verhältnissen.

.Der Erfolg des Versuchs". berichtet KNx, ,war der erwartete. An der konkaren Seite waren die Teilungswände, welche die Bildung des

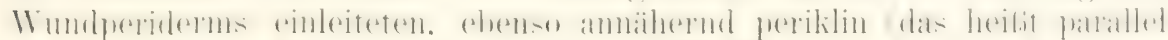
zur Oberfläche) gerichtet wie an ehenen Wundtächen. An der lionvexen

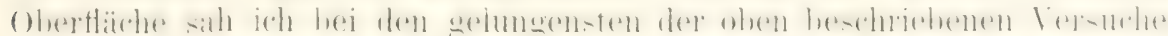

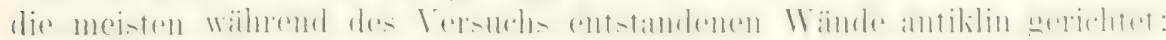
neben diesen traten aber in gröberer oder geringerer Zahl auch perikline und solche von mittlerer Stellung auf. In allen Versuchen, wofern bei

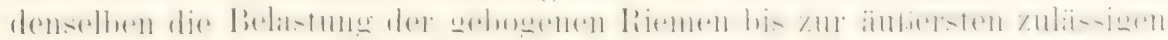
Grenze getrieben war, sprang der Unterschied in der vorherrschenden Richtung der 'Teilungswände an der konvexen und an der konkiven 11 undfläche so deutlich in die Augen, dafo eine ursächliche Beziehung zu Zug und Druck unverkembar war:" 
Man kann den Versuch auch in der Weise anstellen, daß man aus

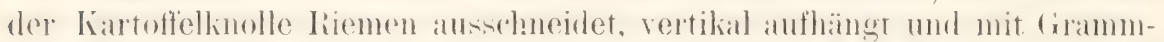
gewichten stark behatet. Auch hierbei zeigt soh nach eingen Tagen, dab. die rahl der nen webildeten antiklinen Wände die der periklinen erhehlich übertrifft. In einem Versuch von KNy war das Verhältnis beider etwa wie $3: 1$.

Die angeführten Versuche werfen Licht auf die in der Natur zu be-

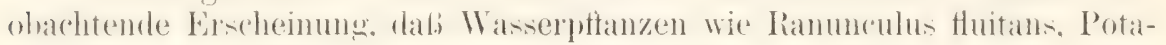
mogeton und andere in schnellfließendem Wasser stärker in die Länge wachsen als im ruhigen Wasser. Wahrscheinlich wird auch hier durch den mechanischen Zus eine stähere streckung der Zellen in der Lichtumg

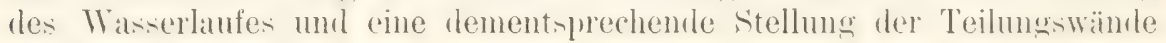
begïnstigt werden.

\section{b) Die Bedeutung ron Druck und Zug für die Entstehung} mechanischer Gewebe.

Wie aus mehreren wleich mitzuteilenden Erscheinungen hervorgehen wird, wirken Zug und Druck als Reiz, welcher die Sildumg von zuw- nund druckfesten substanzen im Protoplasma und ihre dblagerung an den am meisten in Anspruch genommenen Stellen hefirrlert. PHanzen und Tiere bieten uns in ihren Eimrichtungen eine aulierorlentlich interessante Parallele dar.

Bei den Pflanzen werden die Gewebe, welche sich vor anderen Zellaggregaten durch ihre Zug- mon Biegungsestigheit hesonder's auszeichnen, nach dem Vorschlag von ScHWENDENER als die mechanischen zusammengefaßt. Sie setzen sich aus verschiedenen drten meist langgestreckter und sehr dickwandiger Zellen zusammen. welche man je mach Form und Lage als Bast-, Libriform-, Holzzellen, als Tracheiden, Collenchymsewehe ete. bezeichnet. Dal. mechanische Einwirkmoen an gedehnten PHanzenteilen eine Zumahme dieser (rehilde. eine T'ermehrmo in der Zahl der Elemente. eine Verdidime ihrer Wandumen verur-arlien, dafür hat Hegler unter PFEFfers Ideitung den experimentellen Vachweis geführt.

Wachsende Pflanzenteile wurden durch Grammgewichte bis an die (irenze ihrer Leistungstähigheit belastet unt ron Tag zu Tag die belastung erhöht, weil in ent-prechendem Mabe die Zunfertigheit infolge entretenter Reaktion von seiten der Pflanzengewebe eine Zunahme erfuhr.

..Das Hypokotyl der Kembinges ron Helianthus ammuss, welehes hei 160 Gramm zerrib, konnte bei Belastung mit 150 Gramm nach zwei 'Tagen bereits 250 Gramm tragen, und nach dem Einfluß dieser Belastung konnte das spannende Gewicht nach einem weiteren Tage auf 300 Gramm und nach einigen Tagen auf 400 Gramm gesteigert werden. Keimlinge ron Phaseolus, welche bei 180 Gramm zerrissen waren, erfuhren durch allmabliche steigerung des fiewichts in siehen Tagen ein Tragrermögen von

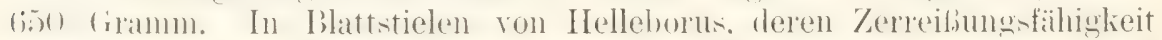

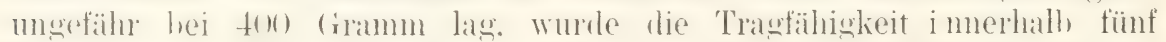

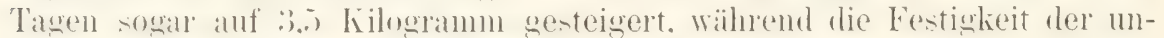
hehandelten (Mjelite sich in dieser Zeit nicht merlich anderte. bei Helleborus bilden sich Bastfasern aus, die sonst fehlen."

Im übrigen lehrt auch die Natur selbst, daß mit Zunahme der Be-

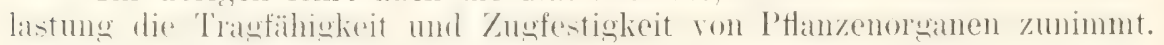
Frïchte, die allmählich zu beträchtlicher Größe heranwachsen und ein er-

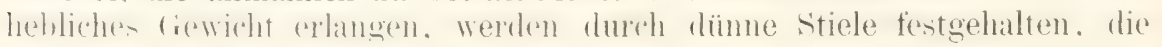




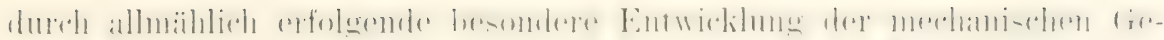
webe mit einer der zu tragenden Last proportionalen 'Tragfäluigkeit ausgestattet werden.

In dieser Weise denten, wie schon Spexcer vor :3() Jahren hervor-

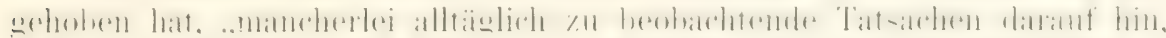

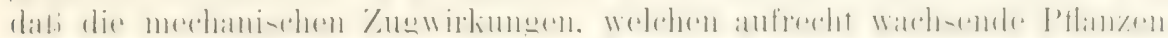
ausgesetzt sind, an sich schon eine Zunahme in der Ahlagerung fester Substanzen verursachen. wodurch solche PHanzen in den Stand gesetzt werlen. den genannten Wirkungen Widerstand zu leisten*".

Eine Parallele zu den Versuchen von HEGLER, welche gelehrt haben,

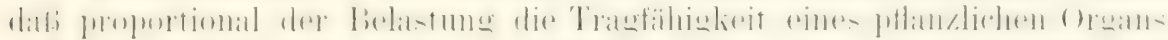
in kurzer Zeit erheblich zunimmt. liefern auf tierischem (xebiet die schon 1 s64 ausgeführten Experimente von SEDILLot. Der französische Physiologe entfernte bei jungen Humden von den beiden Unterschenkelknochen teilweise die Tibia, indem er das ganze Mittelstiick resezierte. Die ganze Last des hörpers. welche sich sonst anf Thihia und Fibula verteilte, wirkte jetzt allein auf letztere ein. Die Folge derartiger Operationen war. dab nach lïngerer Zeit die Fibula, welche normalerweise fïnf- bis sechsmal schwächer als die 'Tibia ist, diese an Gröhe und Dicke erreicht hat, ja endlich selbst noch iibertrift't.

Wemn die Entwicklung mechanischer Gewebe eine Reaktion anf mechanische Reize, anf Zug und Druck ist, so läßt sich auch erwarten, daf die

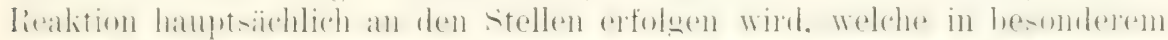

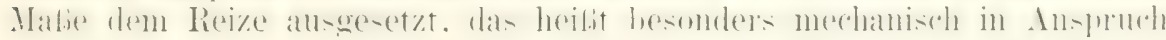
genommen werden. Daher müssen die in dieser Weise erzeugten Strukturen als durchaus zweckentsprechende erscheinen, insofern sie nun auch den an sie gesteliten mechanischen Bedingungen entsprechen. Sie sind uns überaus lehreiche Beispiele, die zeigen, wie direkt durch Anpassung

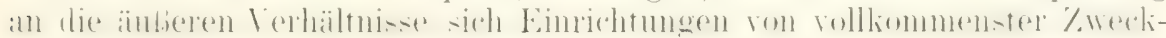
mäßigkeit haben entwickeln kömnen.

Wie für die pttanzlichen, gilt dies in demselben Maße auch für die tierischen Skelettbildungen. Beide sind im großen und ganzen den cie-

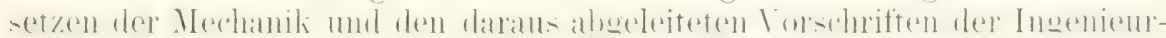

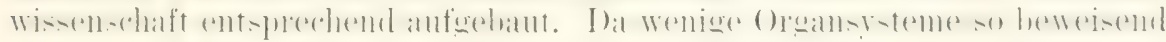
wie die mechanischen für den direkten Einfluf äulerer Verhältnisse anf die Gestaltbildung sind, emptiehlt es sich, etwas austühllicher bei ilnen zu verweilen und als Einleitung einen kleinen Exkurs auf das ciebiet der Mechanik vorauszuschicken.

Un sich zunächst über die Veränderungen klar zu werden. welche

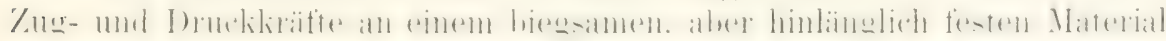
hervolrufen, denke man sich einen ursprünglich geraden, dicken Stab ron

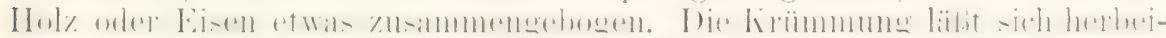
führen entweder dadurch, dab man den Stab aufrichtet. an seinem unteren Ende in der Erde gut befestigt und am oberen Ende einen seitlichen Zug mit entsprechender liraft ansfïhnt, oder dadurch. dab man (len Stab) horizontal mit seinen Enden auf zwei feste Unterlagen legt und auf die nicht unterstützte Mitte ein schweres (iewicht einwirken lïbt. In ersteren Falle wird der Stab durch den anf sein freistehendes Ende seitlich ausceülıten Zug und im zweiten Falle durch einen auf seine nicht unterstïtzte Mitte ausgeübten Druck infolge starker Belastung geliummt.

In beiden Fällen haben die Teilchen in der Mitte des so gehogenen Stabes einen verschiedenen Widerstand gegen die biegende liraft zu leisten. An der jetzt lonkav gewordenen Fläche des Stabes werden die Teilchen 
stark zusimmengeprebt. an der entwegengesetzten, konvexen Fläche werlen sie digegen anseinandergezogen oder gedehnt. Es liegt auf der Itand, dab der Dehmung resp. der Zusammenpressung an meisten die oberflächlichsten Schichten der zwei gegenïber liegenden Flïchen des Balliens unterworfen sind. Denn nach der Achse des Stabes zu müssen sich die entgegengeverten Wirkungen der Pressung und der I)ehnung allmählich ausgleichen und shlieblich gegenseitig aufheben. An der konkaven Seite werden die Teilchen, je weiter von der Oberfläche entfernt, um so weniger zusammengedrürkt und an der konvexen Wläche in entsprechender Weise, je mehr nach imnen, um so weniger gedelınt werden. In der Achse selbst aber werlen die Teilchen weder gedehnt noch geprebt, sie bleiben gegen I)ruck und Zug vollständig indifferent und heiben daher die , neutrale sichicht".

Da die Biegumgsestigkeit eines Stabes auf dem Widerstand beruht. welchen seine oberflächlichen, allein mechanisch in Anspruch genommenen Sichichten den einwirkenten Kräften entgegensetzen, kann man ohne Schaden die neutrale Schicht aus ihm herausnehmen oder durch eine mechanisch minderwertige Substanz ersetzen.

,Zerrung und Pressung sind aber nicht die einzigen Wirkungen" eines fiewichts, "welches den Balken belastet. An einem auf Biegungsfestigkeit beanspruchten Körper hahen die T'eilchen eines jeden (querschnittes das Streben, sich gegen die Teilchen des benachbarten ( $u$ uerschnittes, und die Teilchen jedes Längschnittes das Streben, sich gegen die des henachbarten Längsschnittes zı verschieben. Die Kraft, mit der dies geschieht, nennt man die Schub-oder Scherkraft, und es wird demnach in jedem Schnitte noch eine spamnung, die Schubspannung, hervorgerufen, welche der V'erschiehung zweier benachbarter Schnitte gegeneinander Widerstand leistet" (J. WoLFF).

Die scherende Kraft wird in der neutralen Achse am größten. Am besten überzengt man sich davon, wenn man einen Balken in seiner Mitte der Länge nach entsprechend der neutralen Schicht durchsägt (Fig. :34). Bei einer durch Belastung hervorgerufenen Verbiegung des Balkens wird sich dann die eine gegen die andere IIälfte verschieben orler ahscheren. Un dies zu vermeiden, müssen daher Druck- und Zugseite untereinander fest verbunden sein.

Die hier kurz auseinanderosetzten mechanischen Prinzipien bringt man in der Ingenienwistenschaft hei ler Konstruktion eiserner Träger in Anwendung. Um Material zu ersparen und gleichzeitig den Träger möglichst leicht zu machen, verwendet man keine eisernen Vollhalken, sondern läbt die .neutrale Schicht” ausfallen. Je nachlem der Träger nur einseitig orler allseitig hiegungstest sein soll. hat el verschiedene Formen erhalten.

Zum erstgenannten Zweck hat man den sogenannten T'-Träger konstruiert, welcher auf dem (suershnitt die Form eines römischen Doppel-T hat (T). Zwei in einem grölieren Lhstand voneinander hefindliche parallele Eisentulatten werlen ihrer Länge nach in ihrer Mitte dnrch eine dritte. vertikal gestellte Platte untereinander in feste Verbindmo gesetzt. Dio eino der parallelen Eisenplatten, welche der Pressung Willerstand zu leisten hat, heift die Druckgurtung, die entgegengesetzte die Zuggurtung, weil sie anf der aedehnten scite liegt. Die Verbindungsplatte ersetzt die

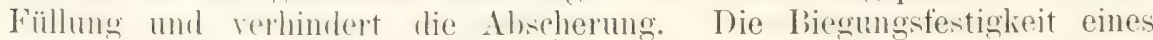
solchen T-Trägers wächst nit der cröbe des Alstandes der beiden diurtungen voneinander.

sioll der Trïger nach allen Richtungen den gleichen Grad von Biegungsfestigkeit besitzen, so gibt man ilm die Form eines hohlen Zylinders. 
Here int jerle stelle des Zylinders, je nach ter Richtung. in weleher die

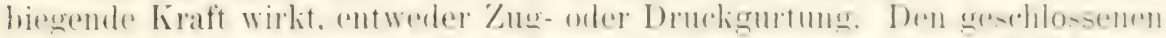

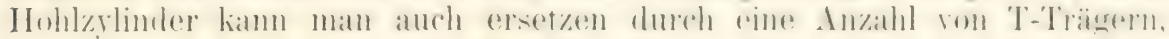
die man so anordnet, wie es lig. 315 zeigt. Wenn man in dieser Figur

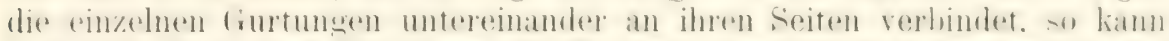

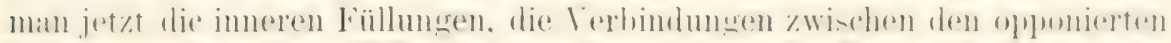
Platten der einzelnen T-Träger, weolasen, ohne die Festigkeit der ganzen Anordnung zu verringern und erhält dadurch die hohle Säule.

b-a Xach denselhen Regreln sind gewöhnlich anch die mechanischen die-

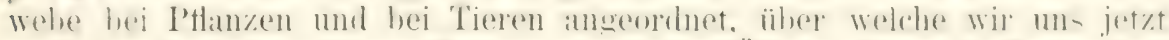

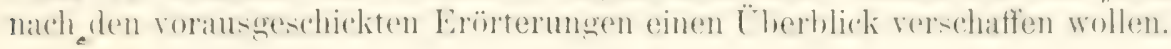

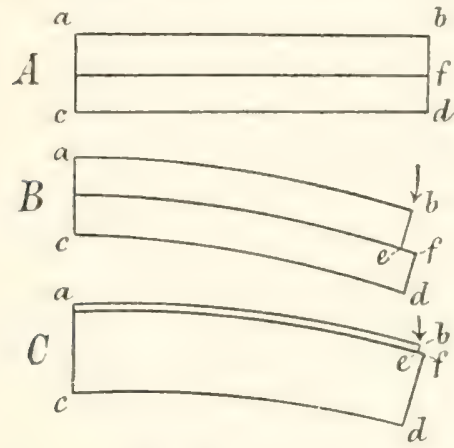

Fig. 314.

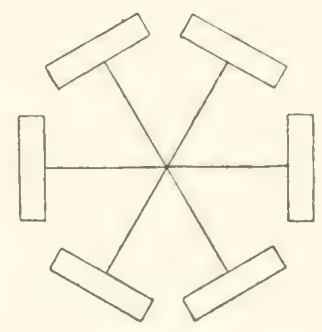

Fig. 315.

Fig. 314. Schema zur Erläuterung der Abscherung. Nach J. WoLfF

$A$ Ein gerader Balken $a b c d$, der hei $a c$ befestigt ist, ist genau in der neutralen Faserschicht $f$ durchgesägt. $B$ Derselhe Balken infolge einer starken Belastung bei $b(\downarrow)$ eingekrümmt, wobei sich die ohere gegen die untere Balkenhälfte infolge Alsscherung um $e f$ verschoben hat. $C$ In einen entsprechenden Balken eine obere dünne Schicht durch einen Längsschnitt abgesïgt und bei $b$ belastet. Die Verschiebung $e f$ ist viel geringer ausgefallen.

HiL. :15. Querschnitt durch eine mehrseitig biegungsfeste Konstruktion.

a) Die mechanischen Einrichtungen bei Pflanzen.

In die hei P'thnzen bestehenden verschierlenartigen Einrichtungen gewährt un- das bahnbrechende Werk rom scuwexpexen einen Einhlieli.

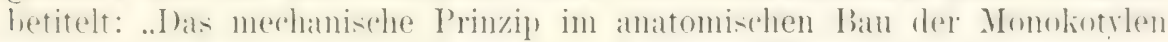
mit vergleichenden Ausblicken auf die ïbrigen Ptlanzenklassen.".

Viele PHanzen besitzen einen über die Erdoberfläche senlirecht in

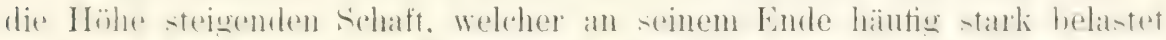

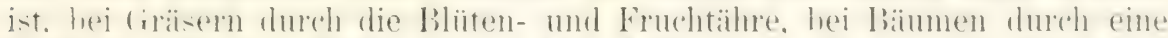

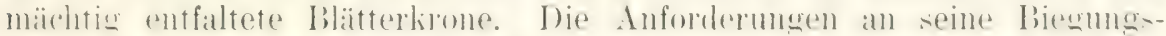

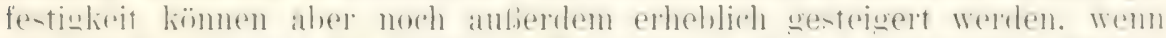

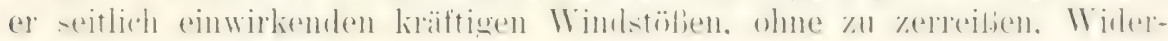
stand zul leisten hat.

Die Festigkeit des Schaftes beruht auf Strängen der obenerwähnten

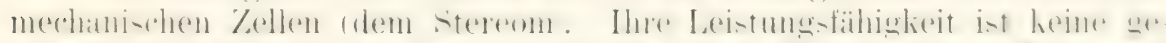

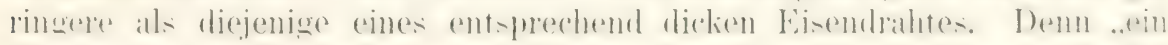
Farlen frischer Bastzellen von 1 fumm Querschnitt vermagg je nach der

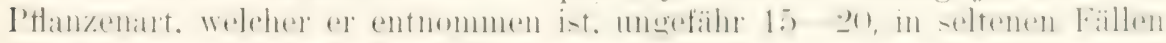
25 Kïlo zu tragen, ohme daß er nach Entfermung der Gewichte eine

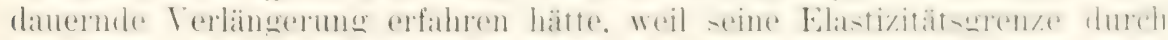
die Belastung nicht ïberschritten wurde". 
Die Stereomstränge sind nun mit sehr seltenen Ausnahmen im Schaft so angeordnet, daß sie möglichst dicht an der Obertläche liegen und zu-

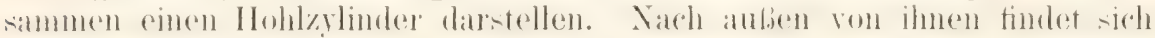
noch die Epidermis und je nach der Pflanzenart, 1 m die es sich handelt,

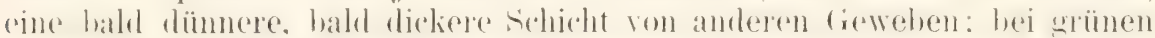
Stengeh zum Beispiel ein Assimilationsgewebe, welches wegen seines Chlorophylls ja ebenfalls auf die Oberfläche angewiesen ist und so gewissermalien mit den mechanischen Geweben um den Raum konkurriert.

Im eimzelnen finden sich mannigfache Variationen in der Anordnung der Stereomstränge, wie uns die Querschnittsbilder durch den Schaft von drei Pflanzen lehren.

Bei Arum maculatum (Fig. 316) bilden den Skelettyylinder 24 parpher gelegene stereomstringe. deren quershnitte. mus sie lismolich

Fï. 316.

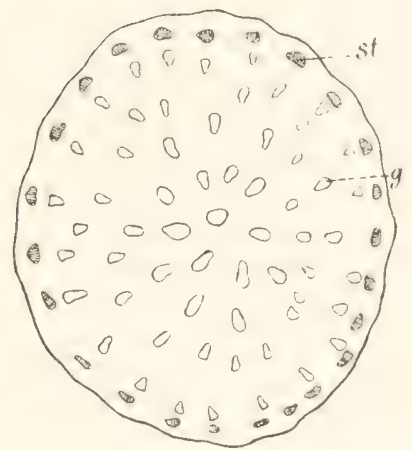

Fig. 317

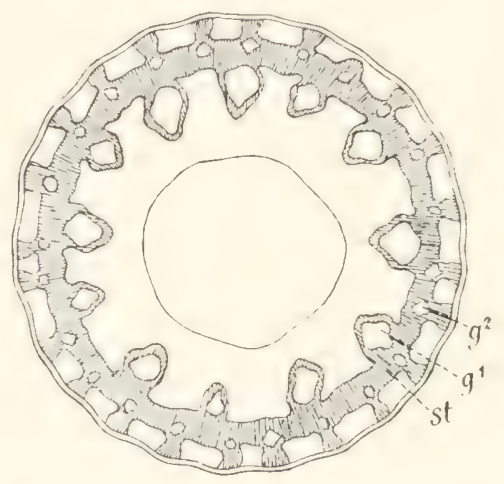

lïg. : 16 . Querschnitt durch den Blütenschaft von Arum maculatum mit 24 peripherischen Stereomsträngen, deren Querschnitte schraffiert sind. Die ïlnigen, ïber den ganzen Querschnitt zerstreuten, hell gelasseneu, umschriebenen kleinen Partien sind (querschnitte der die Nahrung leitenden Strange. Nach Potoxí Fig. S.

19ig. 317. Quexschnitt durch den hohlen Stengel von Molinia coerulea. In dem schraffierten, gerip)ten Skelett-Hohlzylinder sind die Mestombïndel eingebettet. Die sich an die Innenfläiche des Zylinders anlehnenden grölieren Bündel sind ron Stereom ungehen, welches mit dem Zylinder in Terbindung steht. Zu äußerst die Epidermis. Nach l'otoxí Fig. 10.

zu machen, schraffiert sind: sie sind voneinander getrennt durch breite

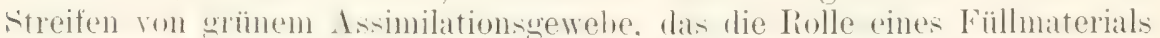
spielt und sich auch noch unter der Rinde in dünner Schicht ausbreitet.

Der Querschnitt durch den Stengel einer Graminee, Molinia coerulea (Fig. 317), zeigt uns die Stereomstränge zu einem geschlossenen

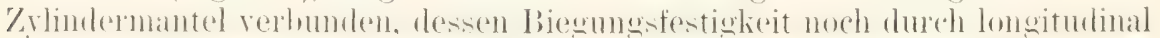
verlaufende, von seiner AuBen- und Innenfläche vorspringende Stereomrippen erhöht ist. Die Zwischenräume zwischen den äuferen Rippen und der Epidermis werden wieder durch Assimilationsgewebe ansgefüllt. während in die nach innen vorspringenden Rippen die Mestombündel, das Nahrung leitende Gewebe, eingebettet sind.

Ein ebenfalls geschlossener, aber innen und aufen glatt begrenzter Zylindermantel von Stereom ist drittens anf dem Querschnitt durch den Bliitenschaft von Antherieus Liliago (Fig. 318) zu sehen. Nach außen 


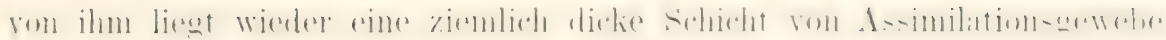
und die Epidermis.

Der Raum im Innern des Skelettzylinders kamn bei den Ptlanzen eine sehr verschiedenartige Füllung zeigen. welche aber in allen Fällen mechanisch ohne Bedeutumg ist. Bei Arum maculatum und Anthericus

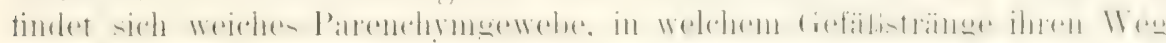
nehmen. deren (juerschnitte in den Figuren von dem Stereomgewebe durch Fortfall der Schraffierung zu unterscheiden sind. An stälier verholzten Stengeln wird die in skelettzylinder eingeschlossene und leicht aus ihm

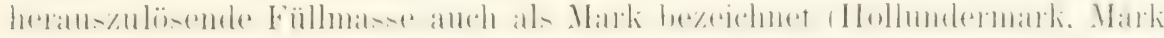
der Somnenblume). Bei den meisten (xrïsern und vielen andern I'flanzen sind die Schäfte im Innern ganz hohl und lufthaltig, wie die zu Trägern beim Haushau verwandten eisernen IIohlzylinder.

As konstruktives Material dient das mechanische Gewebe bei den Pflanzen noch zu anderen Zwecken als zur Herstellung biegungsfester Organe und läbt damn auch in diesen Fälen wieder eine dem Zweck entsprechende Anordnung erkemen. Auf manche Pflanzenteile wirken nur Zugkräte in ihrer Längrichtung ein, wie besonders anf die meisten unterirdischen Teile. Die Hauptwurzeln eines vom Winde heftion

Kig. 31s. Querschnitt durch den Blütenschaft von Anthericus Liliago. 'Wwischen der schraffierten Shelettpartie und der Epidermis befindet sich ein Ring ron Assimilationswewebe. Üher dem zentralen Teil des Querschnitts finden sich Mestombündel zerstreut. von denen sich einige an die Inmenflïche des Skelettzylinders anlegen. Nach PoToxí Fig. 11.

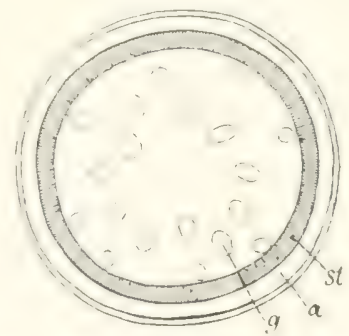

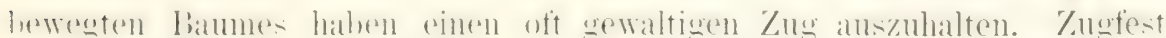

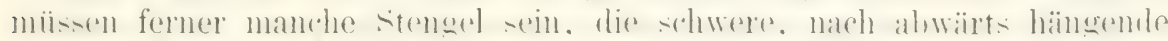

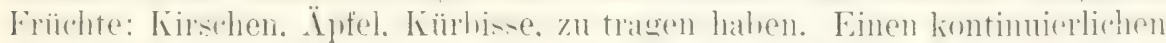

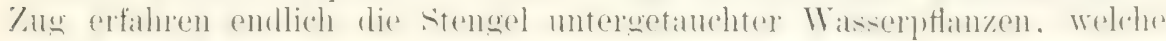
mit ihren Blättern im strömenden Wasser Hottieren. wie Ranunculus Huviatilis.

Die Zugfestigkeit einer Konstruktion hängt ron der Masse des ver-

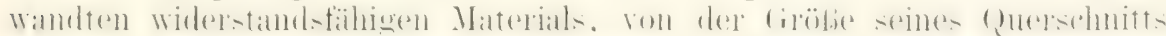
ab: und es ist am zweckmäbigsten. wenn das Material auf einen einzigen

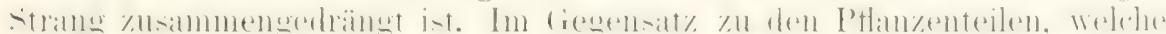

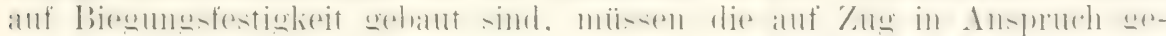
nommenen Organe die mechanischen (iewebe mehr oder minder zu einem Strang vereinigt haben, welcher die Vitte der Wurzel oder des Stengels einnimmt. Das ist in der Tat bei den oben autgeführten Organen auch mehr oder minder der Fall.

$\beta$ ) Die mechanischen Einrichtungen bei Tieren.

Wie bei den Pthanzen das Stereom, ist bei den Wirbeltieren das Knochengewebe in vielen biallen oftenbar nach den Vorschiften der Ingenieurwissenschaften zur Bildung biegungstester Stiitzen mit dem Aufwand der geringsten Menge zweckilienlichen Materials ausgenutzt worlen. Dic

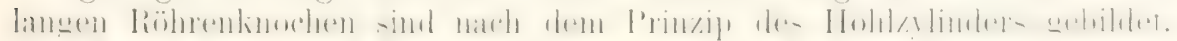

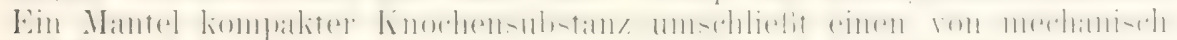

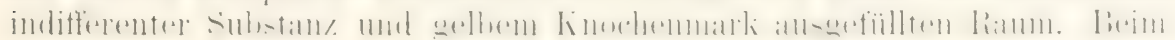


Stulium der Entwicklung der Röhrenknochen kamn man verfolgen, wie in demselhon Mabe, als sich an der Obertlïche der erst knorveligen, später spongiösen Skelettanlage eine Scheide kompakter Knochensubstan\% entwickelt, die merhanisch ïberflüssig werdenden zentralen Teile allnählich resorhiert und in Fettgewehe umgewandelt werlen. Oder die Röhrenknochen werden, wie bei den Vögehn, pmemuatisch, indem Ausstiilpungen der Lungentlügel in sie hineinwachsen.

Eine noch wunderbarere, nach mechanischen Prinzipien durchgeführte Architektur, deren Abhängrgkeit fon Zug und Druck sich nawheisen läbt.

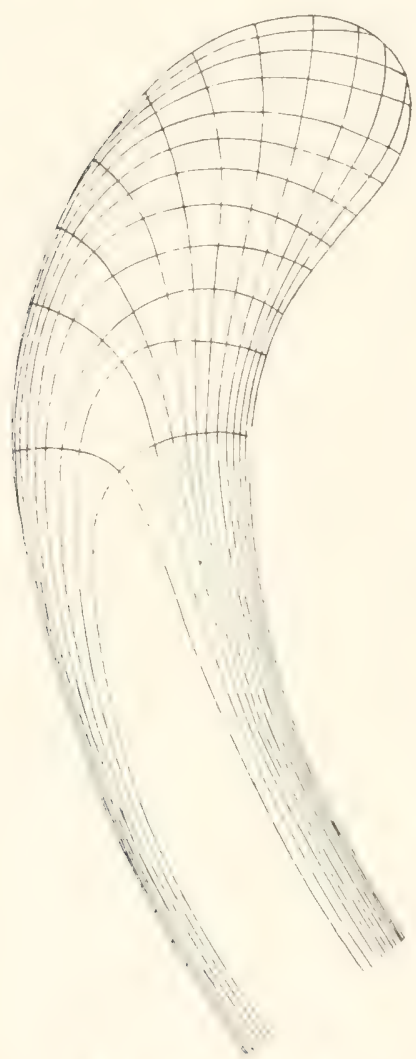

Fie. :319. Gebogener Krahn. mit Zug und Druckkurven. Nach einer lionstrulition von CULMANN ans H. V. MFYer. findet sich in der spongiösen Knochensubstanz, an den Enden der Röhrenknochen. in den Wirbelkörpern, in den Hand- und Fußwurzelknochen. Den Einblick in das Wesen derselben verdankt die Wissenschaft dem glücklichen Umstande, daß Hermans von Meyer, als er sich mit der feineren Struktur (ler Knochenspongiosa beschäftigte, den Begründer der graphischen Statik, Culmans, als Berater zur Seite hatte.

Besonders lehreich ist das obere Ende des Femur geworden, welches man seiner Form und Aufgabe nach einem Krahn vergleichen kann. Wie Juluus WoLfF in seiner Geschichte der Knochenarchitektur erzählt. ,bemerkte Culmaxs bei Betrachtung der Meyerschen Präparate, daß die Spongiosabålkchen an vielen Stellen des menschlichen Körpers in denselben Linien aufgebaut sind, welche er für solche Körper zu zeichnen gelehrt hatte, die ähnliche Formen haben wie die betreffenden Knochen und ähnlichen Kräfteeinwirkungen ausgesetzt sind, wie diese“. ,,Er zeichnete nun einen Knochen (Fig. 319), dem er die Umrisse des oberen Endes eines menschlichen Oberschenkels gab, und bei dem er eine den Verhältnissen beim Menschen entsprechende statische Inanspruchnahme annahm. In diesen Krahn lieb er unter seiner Aufsicht die sogenannten Zug- und Drucklinien von seinen Schiilern hineinzeichnen. Es zeigte sich, daf diese Linien in der Tat ganz und gar identisch waren mit denjenigen, welche die Natur am oberen Ende des Oherschenkels durch die Richtungen, die sie hier den Kinochenbälkchen gegeben, in Wirklichkeit ausgeführt hat."

Was versteht man in der Mechanik unter Zug- und Drucklinien oder Kurven? Sie zeigen uns die Richtungen an, in welchen ein belasteter lïrper an meisten durch Zus und Druck in Anspruch genommen wird und daher am widerstandsliriftigsten gehaut sein mul. Tugleich sind in der Richtung der Kurven auch die scherenden Kräfte beseitigt. Ein Körver. welcher, dem Verlauf der Zug- und Druckkurven entsprechend, aus Stäben und Bändern einer mechanisch brauchbaren Substanz zusammengesetzt wird, kamn eine ebensolche Belastumg aushalten wie ein solider Körper 
aus der gleichen Substanz. Es wird also durch die lionstruktion derselbe Zweck, aber in vorteilhafterer Weise. Weil mit einem Minimum von Material, erreicht.

Von diesen Gesichtspunkten ausgehend, wollen wir jetzt die Architektur des oberen Femurendes untersuchen. Ein in frontalur lidelumen

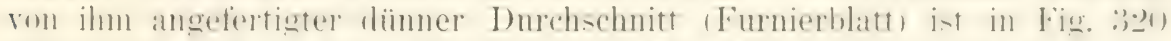

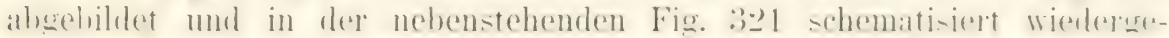

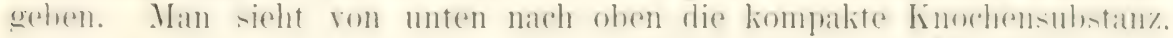

Fig. 320.

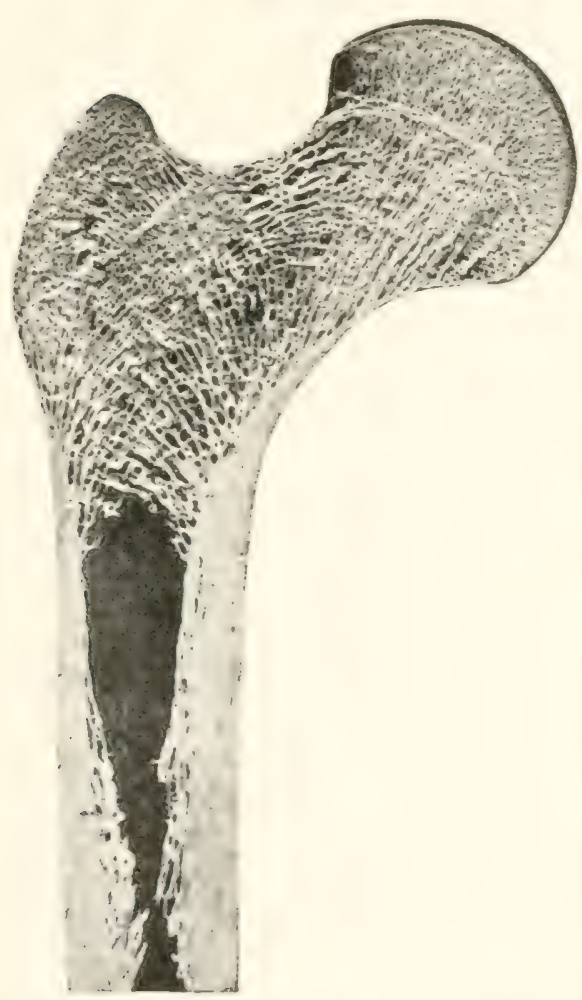
welche unten die Markhöhle umgibt, allmählich dümner werden und schließlich zugespitzt aufhören. In demselben MaBe aber, als dies geschieht, lösen sich von (ler Subst. compacta in kleinen Abständen voneinander feine Knochenbliitter ab.

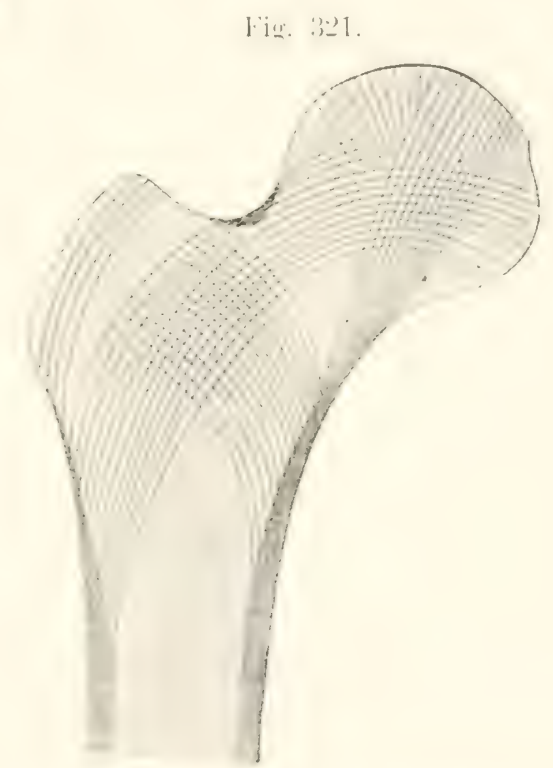

1.i., $;$. Schnitt (Furnierblatt) durch das obere Ende des Femur eines noch nicht ausgewachsenen (15 jährigen) männlichen Individuums. I'hnt.grapluische thbildung nach J. WOLFF.

1.... endes. Tach II. V. MErer (1867).

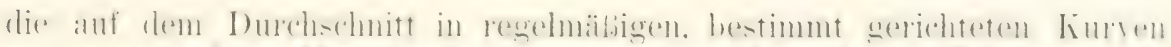

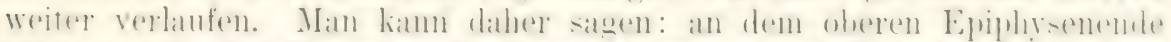

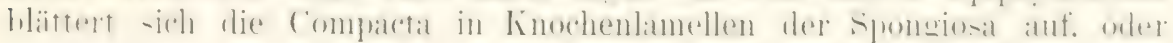
man kann auch umgekehrt, wie H. von MEYER und Julius WoufF be-

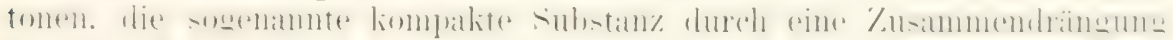
der Bällichen der Spongiosa gebildet sein lassen.

Auf dem Frontaldurehschnitt sind zwei Blättchenziige zu unterscheiden, ein von der großen 'Trochanterseite ausgehender und ein an der

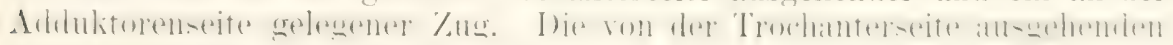
Kurven enden auf der Adduktorenseite und umgekehrt. Wie WoLfF aus- 
sinandergesetzt hat, stehen erstens die Enden der Bälkchen beider Züge

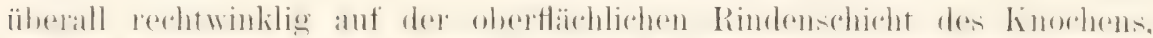

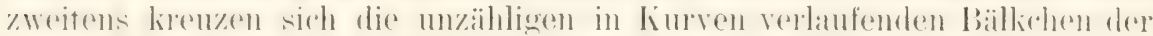
beiden Seiten, wo sie in ihrem Verlaufe einander schneiden, unter rechtem Winkel. Die zwischen ihnen gelegenen, von rotem Knochenmark ausgefuillten Räume sind daher mehr odier minder quadratisch.

Mit den Augen des Ingenieurs betrachtet, stellen die von der Adduktorenseite ausgehenden Züge „Druckbälkchen oder Druckplättchen dar, d. i. Bälkchen, in denen die scherenden Kräfte aufgehoben sind und

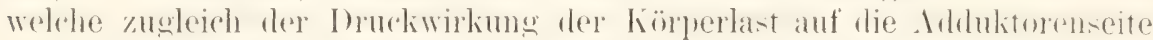
den erforderlichen Widerstand entgegensetzen. Es wird ausschließlich in den Richtungen dieser Bälkchen das obere Ende des Oberschenkels ge-

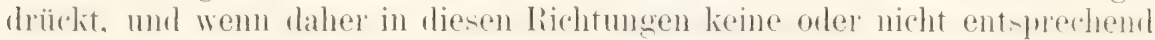
starke Bälkchen vorhanden wären. so mübte der Druck zu einem Zer-

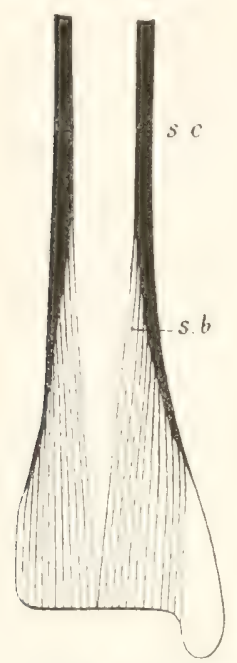

Fi(x. :i2.). Fron-

taler Durchschnitt durch das untere Ende der Tibia. Schema mach H. T. MEYER. drïcken des Knochens führen".

Die Bälkchen der Trochanterseite dagegen sind Zugbälkchen, in denen ebenfalls lieine scherenden liräfte störend wirken und welche zugleich dem durch die Körperlast bedingten, auf die Trochanterseite wirkenden Zug den erforderlichen Widerstand leisten und demnach ein Auseinanderreißen des Knochens zu verhindern bestimmt sind.

Wie in der Konstrulition des Krahns (Fig. 319) die Zug- und Drucklinien, so ,drängen sich am Femur (Fig. 320) die Bälkchen der Spongiosa gegen das Mittelstïck des Knochens hin zul kompaktem (iefüge zusammen. welches am festesten und dicksten sein muf gegen das Wittelstiick des Knochens hin", weil hier die größte Biegungsfestigkeit vorhanden sein muß.

In den meisten Fällen ist die Architektur der Spongiosa für einfachere statische V'erhältnisse als am obern Femurende eingerichtet; sie ist gewöhnlich nur einem Druck durch Belastung: in einer Richtung unterworfen. Als dehreichstes und einfachstes liei-prel hierfür führt $H$. NeYer das untere Ende der T'ibia an (Fig. 322).

Auch hier beginnt wieder nach rlem (ielenkende zu die kompakte Knochensubstanz sich erheblich zu verdïmmen, wobei sie sich allmählich in ein

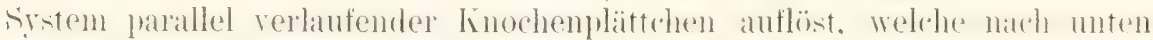
ein wenig auseinander weichen und auf der dümnen, kompakten Rindensubstanz der Gelenkfläche in ihrer ganzen Ausdehnung senkrecht enden. Verbunden werden sie untereinander durch Plättchen. die sie in senkrechter Richtung rechtwinklig schneiden. Aus diese Weise wird ein Ausweichen orlel Ausbiegen eines Plättchens bei gesteigertem In'uck unmöglich gemacht. Durch die Zerlegung der kompakten Knochensubstanz in Lamellen, welche sich wie Strebepfeiler von der unteren Gelenkttäche erheben und den spongiösen Bau des unteren Gelenkendes bedingen. wird der durch das Mittelstïck der Tibia von oben her fortgesetzte Druck gleich-

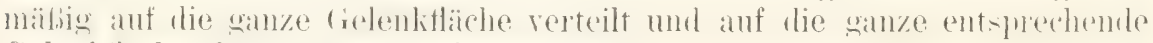
Gelenkftäche des Astragalus fortgeptlanzt.

Noch mehr als die Architektur normaler Knochen ist für die Lehre, (lal.) die Gestaltungsprozesse der Organismen durch äubere Faktoren beeinflust werden, von Berleutung der Nachweis, dab die Architelitur eines 
Knochens etwas Veränderliches ist und, wie WoLfF und Roux zu zeigen versucht haben, während des Lebens .'Transformationen* erfairen kann.

Wemn bei Brïchen oder infolge anderer krankhafter Störungen die

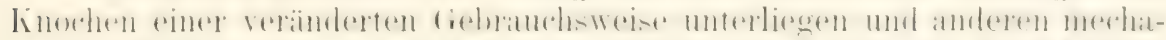

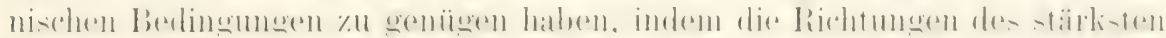

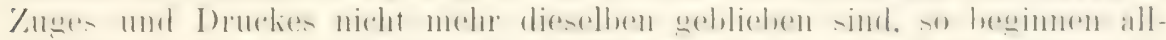

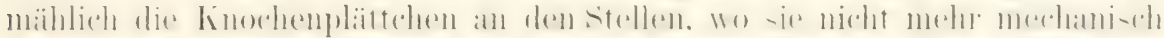

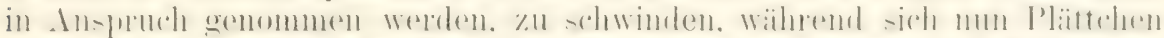

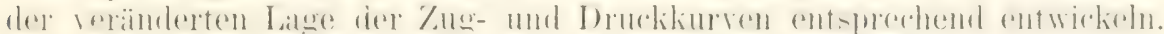

..An vielen Frakturenpräparaten", bemerkt JUL. WoLFF, ,hatte ich beobachten kömnen, dab in der 'Tat jedesmal, wenn die Fraktur' mit einer'

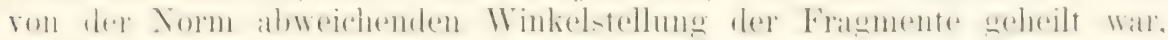
eine nene Architektur des Knochens sich gebildet hatte, die den nenen

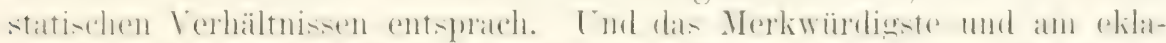

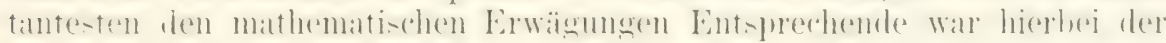
Umstand. dab die Architeliturumwandlungen sich bis in sehr weit von

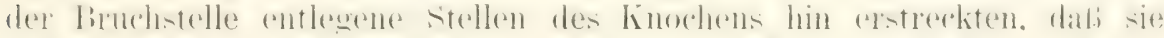

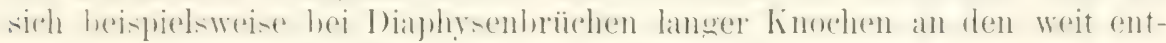
fernten (ielenkenden dieser Knochen bemerklich machten."

..Ebenso hatte ihm das Studium rachitisch verbogener Knochen gezeigt, dab sowohl in der neutralen Faserschicht, als in der senkrecht zu ihr stehemden knochenschicht eine wanz nene, den nenen merhanischen Verhältnissen genau entsprechende Architektur entsteht."

Zu demselben Ergebnis wurde Roux durch das Studium einer Kiniegelenksankylose geführt.

\section{Literatur zu Kapitel XX.}

1) v. Bardeleben, Karl, Beiträge zur Anatomie der Wirbelsäule. Jenc 1874 .

2) Born, Über Druckersuche an Froscheiern. Anatom. Anzeiger 1803.

3) Derselbe, Veue Kompressionsaersuche an Froscheiem. Gahresber. d. schles. Gesellsch. f. vaterl. Lizultur. 1804 .

4) Derselbe, Über den Einfluß der Schiere auf das Froschei. Archia f. mikrosk. Anat. bit. XXIV. 1885.

5) Driesch, H., Entwicklungsmechanische Studien II: Zeitschr. f. wiss. Zool., Ird. L.I 1803.

(6) Derselbe, Zur Ferlagerung der Blastomeren des Echinidencies. Anat. Anz., Bat. ITII. 1803.

7) Haberlandt. Die Simesorgane der Pflanzen. Leipzic 1004.

S) Derselbe, Über atie Perzeption des geotrophischen Reizes. Berichte d. Dentsch. bot. Gesellsch., Lid. XlTll. 1900.

9) Derselbe, Zur Statolithentheorie des Gootropismus. Jahrb. f. aissensch. Lot., bit. X.XYIII. I003.

10) Heglex, Uber den Einfhuß ron Zugkräften anf die Festigheit und die Ansbildung mechanischer Gearbe in Pfansen. Sitzungsber. d. sächs. Gesellsch. d. II issensch. $1801, S, 638$.

11) Heider, Uber die Bedeutuns der Furchung gepreßter Eier. Archio f. Entuickl.-alich., bit. V. 1807.

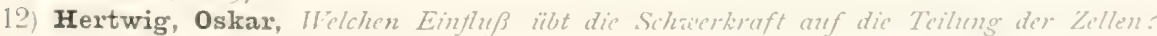
1884 . Jenu, Fischers Verlas.

13) Derselbe, ¿̈ber den Vert der ersten Furchungszellen für die Organbildung dis Embryos. Experimentelle Studien am Frosch- und Tritonei, Archiz f. mikrosk. Anat., Bat. VILII. 1803.

14) Derselbe, Uber cinige am befruchteten Froschei durch Zentrifuselkeraft herrorgerufene Mechanomorphosen. Sitzungsber. der Königl. prenß. Alad. dè Missensch. in Berlin. math.-phy's. Klersse. 1897. 
15) Kny, L., Über den Einfluß von Zug und Druck auf die Richtung der Scheiderëünde in sich teilenden Pfanzenzellen. Berichte d. deutschen bot. Gesellsch., Bal. XIT. I806.

16) Keller, Biologische Studien. Biolog. Zentralbl., Bd. XVII, VY. 3. 1897.

17) Meyer, Hermann, Die Statik und Mechanik des menschlichen Knochengerïstes. 1873.

18) Derselbe, Die Architcktur der Spongiosa. Zehnter Beitrag aur Wechank des menschlichen Lnochengeriütes. Archiv f. Anat. und Physiol., Jahrg. 1807.

19) Morgan, Experimental studies on Echinoderm Eggrs. Ancrt. Anzeiger, Bd. IX. 1897.

20) Nèmec, B., Über die Art der Wahmehmung des Schacrkraftrezaes bei den Pflanzen. Ber. a. deztsch, bot. Gesellsch.,Bd. XVIII. 1000.

21) Derselbe, Über die Wahrnehmeng des Schierkraftreizes bei den Iflanzen. Jahrb. f. wissensch, Bot., Bd. XXXVI. Igor.

22) Pfiüger, Über die Einawirkung der Schuerkraft und anderer Bedingungen auf die Richtung der Zcllteilung. 3 Abhandl. Archiz fïr die ges. Physiol., Bd. XXXIV. 1884.

23) Potonié, Henry, Das Skelett der Pflansen. Sammlung gemeinuerständlicher, apissenschaftlicher Vorträge, Serie XVT. 1882.

24) Roux, Wilhelm, Gesammelte Abhandhngen ïber Entaickhungsmechanik der Organismen, Bal. I. Finnktionelle Anpassung. Leipsig 1895.

25) Derselbe, Beschreibung and Erläuterung einer knöchernen Kiniegelenksankylose. 1885.

26) Derselbe, Über die Entreicklung des Froscheies bei Aufhebung der richtenden II irkung der schwere.

27) Derselbe, Über die Bestimmung der Hauptrichtungen des Froschembryos im Ei und über die erste Teihung des Froscheies. Breslauer är ztliche Zcitschrift 1885.

28) Sachs, Jul., Vorlesungen ïber Pflanzenphysiologie. 1882.

29) Derselbe, Wechanomorphose and Phylogenie. Flora, Bit. LXYVIII. I894.

30) Schultze, Oskar, Über die unbedingte Abhängigkeit nomaler tierischer Gestaltung von der Wirkung der Schacekraft. Verhandl. der anat. Gesellsch., S. Versammlung.

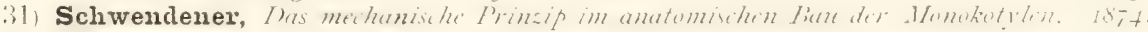

32) Sedillot, De l'influence des fonctions sur la structure et la forme des organes. Comptes rendus de l'académie des sciences de Paris, T. 59, pag. 539. 1867.

33) Spencer, Herbert, Die Prinzipien der Biologie, Bd. II, S. 27t-283, S. 205-22t etc, 1877.

34) Vöchting, Über die Teilbarkeit und die Wirkung innerer und üußerer Iräfte anf Organbildung in Pflanzcnteilen. Pflügers Archiv, Bd. IV. 1877.

35) Derselbe, Uber Organbilanng im Pflanzenreich. Heft I 24. 2. Bonn 1878 11. 1884.

36) Wetzel, G., Transplantationszersuche mit Hydra. Archiv f. mikrosk. Anat. I898.

37) Wilson, On cleavage and mosaik work. Archiv für Entroicklangsmechanik, Bd. III. 1896.

3S) Wolff, Julius, Das Gesetz der Transformation bei Knnochen. 1892.

39) Derselbe, Über die innere Architektur der Knochen. Virchous Archiz', Bd. L. 1870.

$40)$ Ziegler, H. E., Über Fiurchung unter Pressung. Verhandl. d. mat. Gesellsch. I897.

41) Derselbe, Untersuchungen z̈ber dic Zellteihung. Verhandi d. deatsch. zool. Gesellsch. 1895. 


\title{
EINUNDZWANZTGSTES KAPITEL.
}

\section{Die äukeren Faktoren der organischen Entwicklung.}

\author{
(Fortsetzung.)
}

\section{Das Licht.}

Schon bei Besprechung der Irritabilität des Protoplasmas haben wir das Licht (Kap. VII. Seite 149 ) als eine wichtige Reizquelle kennen gelernt. Anch viele formative Prozesce vielzelliger Oromismen stehen unter

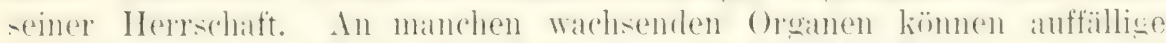

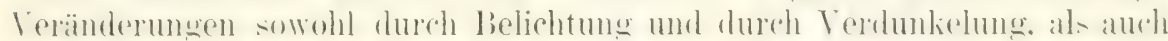

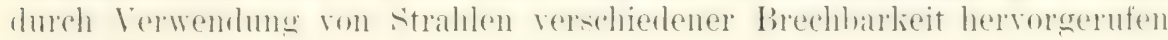
werden.

Zu Experimenten auf diesem (iebiete sind Pflanzen viel geeignetere ()hjelite als tierische ()ranismen: sie reagieren viel leichter und intensiver als diese. sie lehren uns an zahlreichen verschierlenartigen Beispielen anf das unzwoidentigste, dabi man durch experimentelle Eingrifte den ort. an

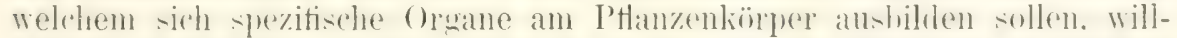

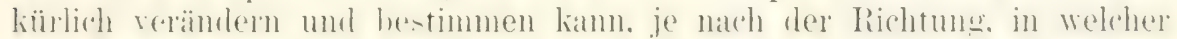
man Lichtstrahlen einfallen läßt.

Als eines der lehrreichsten Beispiele sind die Prothallien der Farnkräuter zu nennen, wie aus den Experimenten von LEITGEB hel-

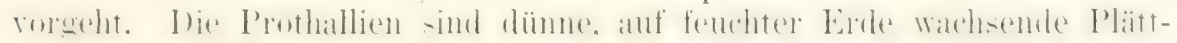
chen grüner Zellen, welche an ihrer der Erde zugekehrten Unterseite

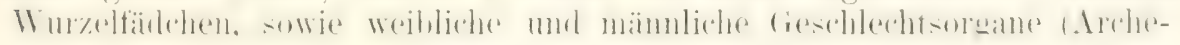
gonien und Antheridien) normalerweise entwickeln. An ihnen gelingt es.

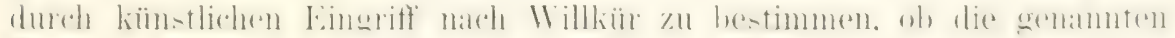

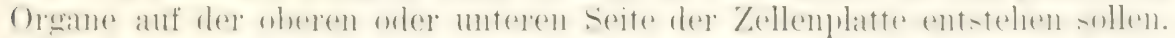

Man verschaftit sich, wie es zuerst LeitgeB getan hat, das zum Ex-

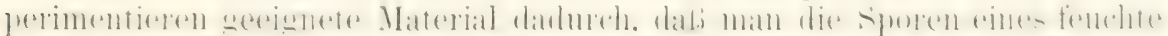

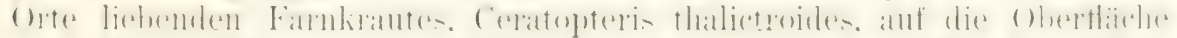
einer Nährstoftlösung aussät. Man hat es dann in seiner Hand, die Prothallien, welche sich aus den Sporen als schwimmende P'latten entwickeln. entweder von ihrer oberen oder unteren Seite zu beleuchten. Bei Be-

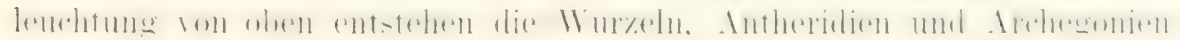
wie unter normalen Verhälnissen an der unteren. beschatteten Fläche. Bei Einfall des Lichtes von unten dagegen äudert sich das Verhältnis:

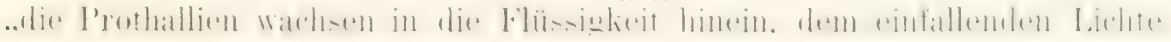


entgegen, krimmen sich aber, sobald sie die eigentliche Fläche zu entwickeln beginnen, so daß die eine Seite der letzteren senkrecht zum einfallenden Lichte gentellt wirl." lieide Flächen verhalten sich jetzt in bezus

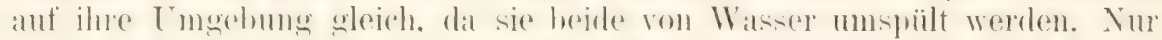

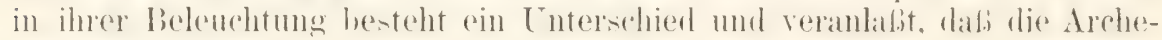
gonien und die Wurzelfasern sich num an der oberen oder der Schattenseite entwickelı.

In ähnlicher Weise läßt sich auch bei einigen Phanerogamen der

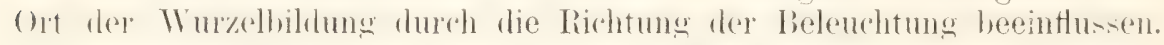
Als geeignetes Versuchsobjekt ist von Vöchtivg eine kleine Kaktee. Lepismium radicans, und von SAcHs der Epheu empfohlen worden. Lepismium hesteht ans hreiten. plattgedrückten Stengeh mit tlügelartig ror-yningenden Kanten. die mit kleinen. shuppenartigen Blättehen berleckt sind. Die Stengel kriechen auf der Erde hin orler erheben sich ein wenig iiber sie; in der Mitte ihrer unteren Seite erzengen sie in Längsreihen

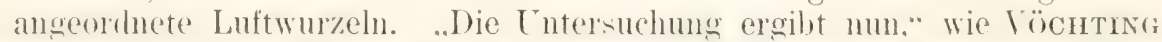
mitteilt. ..labi die Wurzeh stets auf derjenimen seite des stengels gebildet

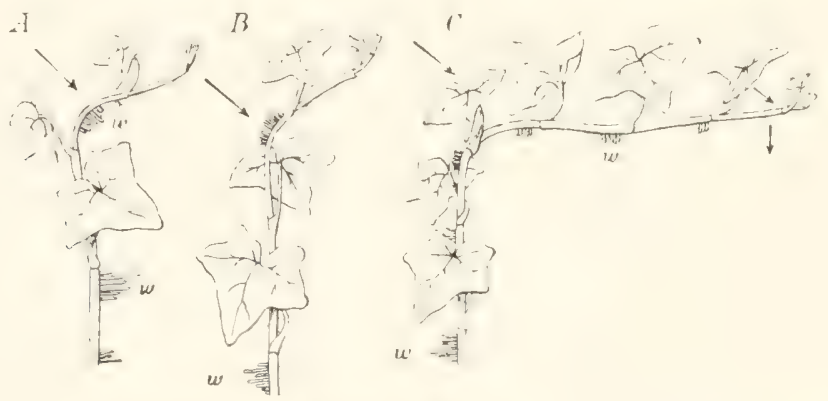

Fig. 323. EpheusproB (Hedera Helix). A Seit mehreren Tagen von der Rïckenseite, $B$ ebenso von der Bauchseite her beleuchtet; $C$ ein späterer, aus $B$ hervorgegangener Zustand. Tach SAcHs Fig. 339.

werden, welche am schwächsten beleuchtet ist: nie auf derjenigen, welche vom direkt einfallenden Licht getroffen wird. Bindet man die Zweige vertikal und stellt sie so, daß die eine Seite vom Licht getroffen wird, so entstehen die Wureln auf der Schattenseite. Sind hier nun mehrere Wurzeln getrildet. mol man kehrt die Ptlanze um, so rlab die frïhere Schattenseite nummehr zur beleuchteten wird. so werden die nenen Wurzeln wieder auf cler Schattenseite erzengt. Befestigt man Zweige so, daß sie horizontal vom Topfe abstehen und auf keiner Seite von einem beschattenden Gegenstand berïhrt werden — was durch geeignete Manipulation leicht zu erreichen ist - und läßt das Licht von oben einfallen. so entstehen die Wurzeln auf der Unterseite. Bringt man num den Topf so an, daß die Zweige ihre horizontale Stellumg behalten, jedoch von unten beleuchtet werden. so bilden sich die neu entstehenden Wureln auf der Oberseite."

Ein genau entsprechendes Verhalten hat SACHS beim Epheu

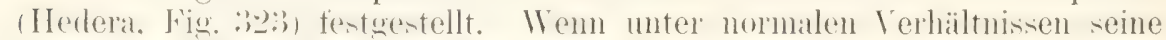
/weige anf einer Lnterlage hinklettern. entwickeln sich Inaftwoeln nur an der ihr zugekehrten Fläche, welche man als die untere bezeichnet und welche zugleich die beschattete ist. Das ist auch der Fall, wenn ein einzelner Zweig frei soluwehent in horizontaler Richtung gezogen wird, no dal. seine untere Fläche nach abwïrts gekehrt ist. Dagegen wird die Wurzel- 
bildung hier unterdrïclit. sowie man lingere Keit das Licht auf' sie ein-

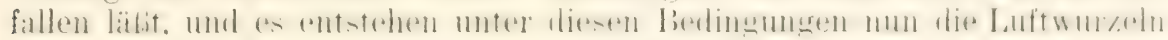
anf der ursprünglichen Rücken- orler Lichtseite.

Nicht minder beweisend für den Einfluf. des Lichtes sind die von Vöchtsxg an Weidenzweigen ausgefüluten Experimente. Unter der

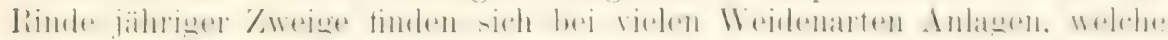
unter geeigneten bedingungen zu Wureln auswachsen. Dies geschieht aber nur auf der vom Licht abgewandten Seite; um zu erzielen, dal, an einem Zweig ringsum die Anlagen $7 u$ Wurzeln auswachsen. mul man den

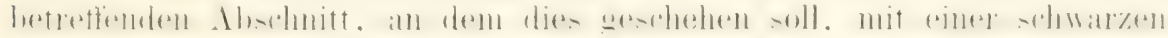
Hiilse umgeben und dadurch vor der direkten Einwirkung des Lichtes schïitzen.

Auch alle mit der Fortpflanzung der (iewächse zusammenhängenden Prozesse sind vom Licht oft auberordentlich abhängig. Besonders die umfassenden Untersuchungen von KLEBS haben uns auf

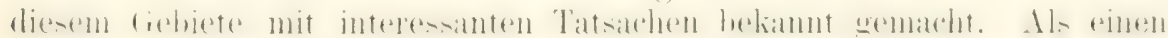
lehreichen Fall wähle ich unter anderm die Entwicklung ron Funaria lygrometrica, einem kleinen, weitrerbreiteten Laubmoos.

Sporen, die auf eine Nährlösung ausgesät werden, entwickeln zuerst, wie bei allen Lebermoosen, eine Art Torkeim. das Protonema, welches

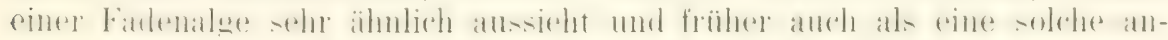
gesehen wurde. An ihm entstehen erst nach einigen Wochen durch un-

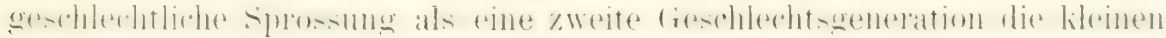
Moosptlinzchen. Für ihre Entstehung ist aber eine nicht zu schwache Belichtung unbedingt notwendig. Denn wenn man eine drei bis vier Wochen alte Kultur von kräftig gewachsenem Protonema ,halblunkel, z. B. in Hintergrunde eines sonst hellen Zimmers aufstellt, so treten an

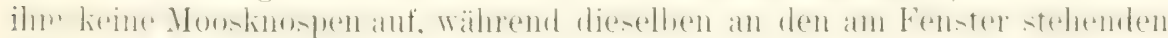
Liulturen sich reichlich zeigen ${ }^{\circ}$.

KLEBS hat Kulturen von Protonema zwei Jahre lang im Halbdunkel fortgezïchtet. Die Protonemafäden assimilierten und wuchsen in dieser

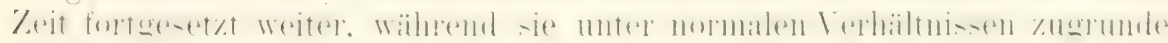

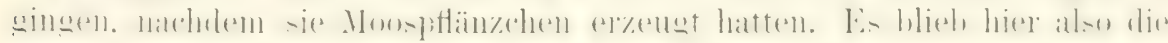
sonst vergïngliche ongendform über die Zeit erlıalten, weil sie durch mangelnde Intensität des Lichts verhindert war, die höher organisierte Geschlechtsform zu bilden.

Öhnliches ist auch bei einer Sïßwasserfloridee, Batrachospermum. experimentell testgestellt worlen.

Ganz anderer Art als in den bisher angefïhrten Fällen sind wieder die Veränderungen. welche Gegenwart oder Mangel des Lichts bei manchen Phanerogamen in der Struktur einzelner Organe verursacht. Nach den Untersuchmgen von STAHL, GeNEAU DE LAMARLIÈre, Keller etc. zeigen die Blätter von Schattenpthanzen eine etwas abweichende Struktur von den Blätern von Pflanzen, die in Licht anfwachsen. Und dieselhen Unterschiede kann man anch beobachten. wenn Individuen ein und derselhen Pftanzenart an schattigen oder somigen Orten gezogen werden.

Die Blätter von stark beleuchteten Pthanzen (Sonnenptlanzen) haben ein Parenchym. zusammengesetzt aus zwei verschiedenen \%ellenformen (Fig. :30t-326). Die eine Form, das Palissadenparenchym (p). bildet an der nach oben gekehrten Fläche des Blattes eine besondere Schicht von gestreckten, zylindrisch geformten \%ellen. die mit ihrer Lïngsachse senkrecht zur Blattobertläche angeordnet sind. In den P'alissadenzellen

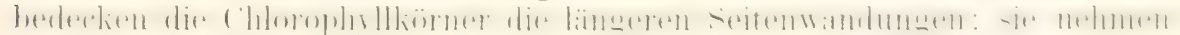


also eine Profilstellung ein (s. I. Teil S. 153). Die zweite Gewebsform ist das Schwammparenchym (sch), zusammengesetzt aus mehr polygonalon oder parallel zor Blattobertliable efwas abgeplatteten Zellen. Sie

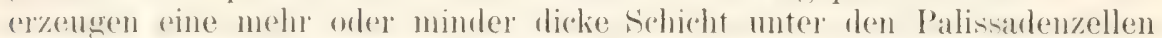
an der unteren filähe des blattes. Die ('hlorophyllkörner nehmen die der Blattolerfläche parallelen \%ellwände ein und befinden sich daher in

Fig. 3:-1.

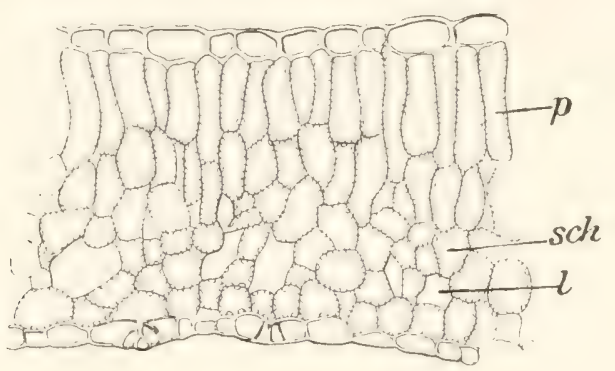

Fies. 3i:

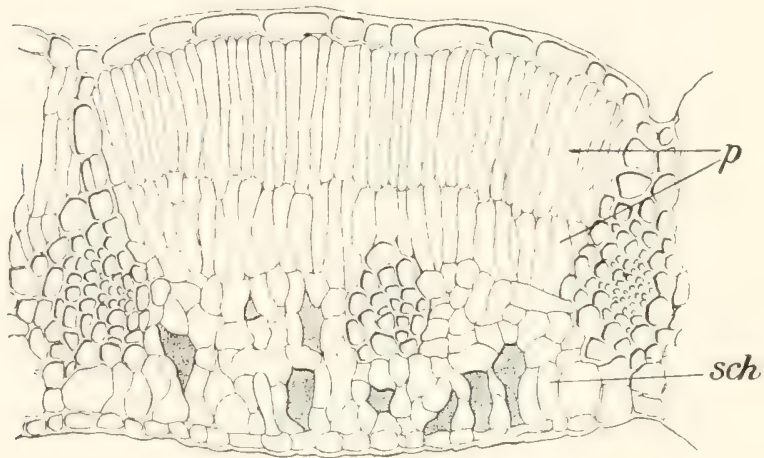

Fig. 326 .

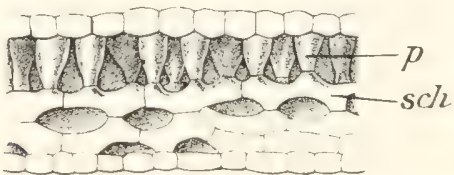

Fir. 3. 4. Querschnitt durch ein Buchenblatt aus halbschattiger Lage.

Fig. 325. Querschnitt durch ein Sonnenblatt der Buche.

Standort.

Fig. 326. Querschnitt durch ein Buchenblatt von sehr schattigem

Fig. 324-326. Nach E. STAHL. p P'alissadenparenchym; sch Schwammparenchym; l Interzellularlïcken.

En-fare- orler Flächemstellung. I)ie ('hlorophylliörner in den Palis-adenzellen werden von den Lichtstrahlen am stärksten getroffen; die Körner in den Schwammzellen nur von dem abgeschwächten Licht, welches noch von den darüber gelegenen Zellshichten durchgelasen wird. .. Die Palissadenzellen sind die für starke Lichtintensitäten, dieflachen Schwammzellen die für geringe Intensitäten angemessenere Zellenform." 


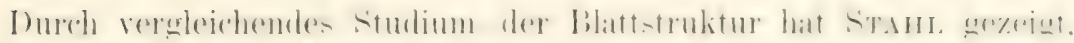

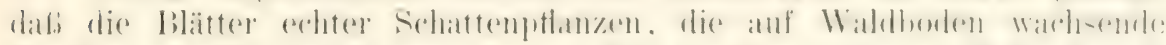

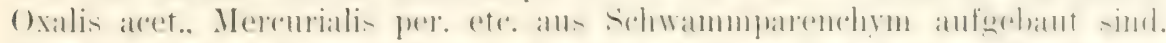

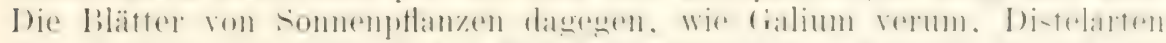

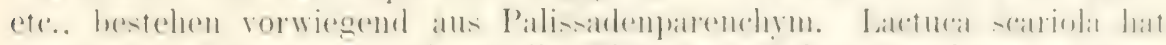

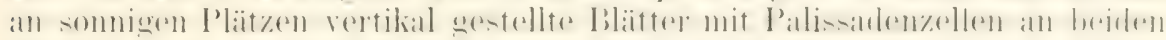
Flächen. An schattigen Orten wachsende Exemplare zeigen die Blatter horizontal ausgebreitet, in welchem Falle fast alles grïne Parenchym in Hache Schwammzellen umgewandelt ist.

IV as für erhebliche Unterschiede in der Blattstruktur durch starke.

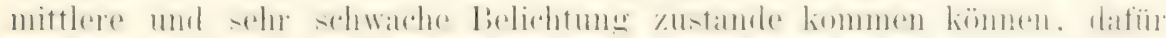
liefert eines der lehrreichsten Beispiele nach den Untersuchungen von

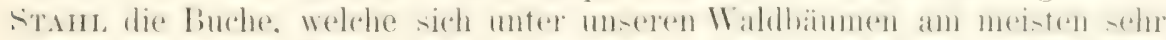

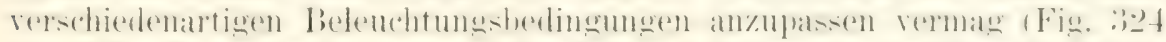
bis : sowohl dureh ihre areringere firobe als alleh dureh ilne zalleres strulitur.

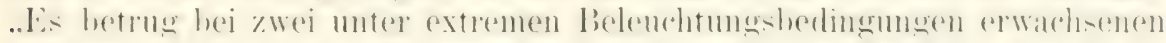

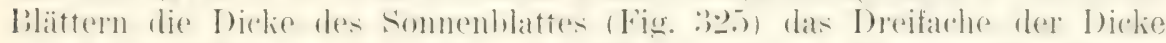

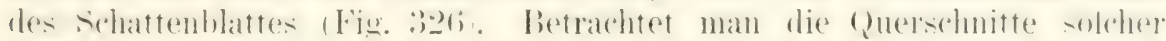

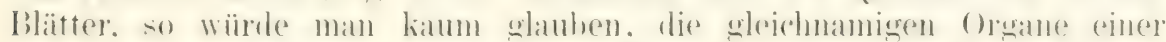
und derselben Pflanzenart vol sich zu haben."

.Im Somnenblatt ist beinahe sämtliches Assimilationsparenchym als

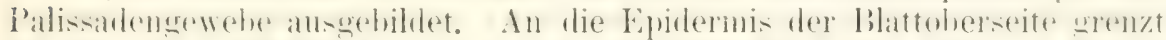

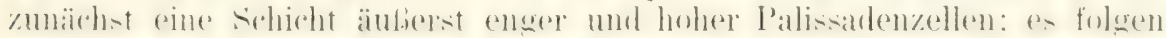
weiter nach immen noch ein oder zwei Lagen ähnlicher Zellen. Nur wenige

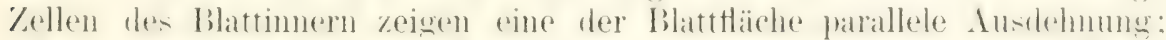

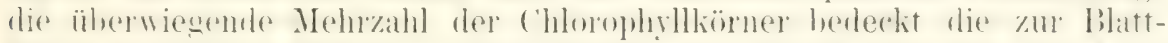

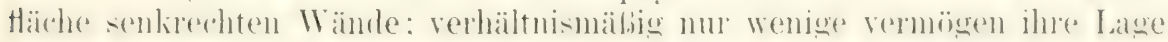
zu verändern — Flächenstellung mit Profilstellung umzutauschen."

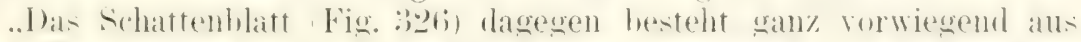
flarhen sternzellen (sih). Die Zellen der ohersen \%ellochichten allein zeigen eme sich an die der Palissalenzellen amnahernde Form: sir sind zu Trichterzellen (p) ansgebililet. I) be betrachtumg der heden blattpuer-

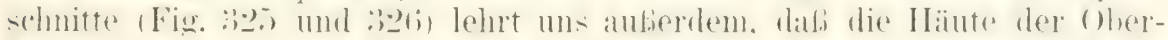

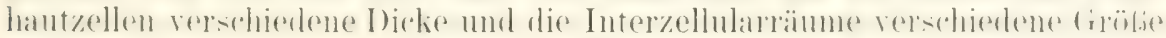
erreichen.:

Zwischen den beiden Extremen (Fig. 325 und 3206) kommen je nach

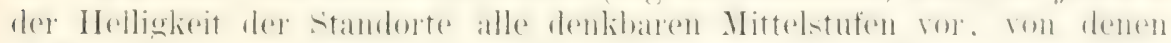
in Fig. 32t eine dargestellt ist. Hier liegen unter der Epidermis an der

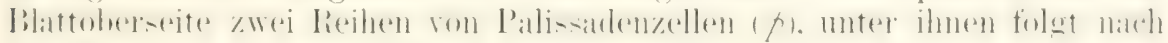
der Blattunterseite zu Schwammgewebe (sch).

Entsprechende Ergebnisse gewann G. DE LAגarLì̃e hei seinen

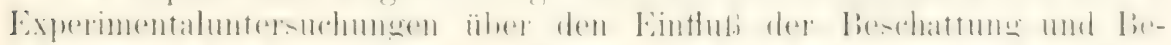

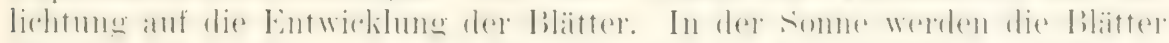
dicker und gewimnen eine andere Struktur. Was sich in höchstem Grade bei 'Taxus baccata zeigte. Die Verdickung der Sommenblatter betrug hier' unter Umständen 50 bis $100 \%$ der Dicke der Schattenbliitter. Sie war vor allen Dingen durch eine Vermehrung des Palissadengewebes hervor-

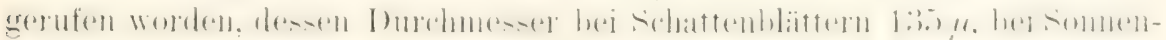
blättern 215 $\mu$ beträgt. Unter dem Einflußs starlier Belichtung ist in vielen Fillen entweder eine zweite Palissadenzellschicht oder ein dichteres zellgewebe entstanden, welche beide den Schattenptlanzen fehlen. 
Ähnliche Veränderungen der Struktur durch das Licht lassen sich ans dem Pflanzenreich noch in großer Anzahl zusammenstellen.

Daß im T'ierreich das Licht auf die Entwicklung einzelner Organe hemmend oder fordernd einwirkt obler sogar strukturen verändert. ist hier schwieriger zu beobachten. Trotzdem fehlt es auch im Tierreich an bewoisenten Ibispielen nicht. T̈her oinge herichtet LoEs in seinen Expe-

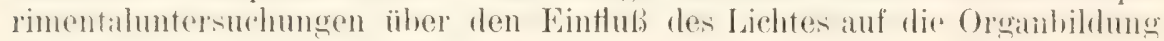
bei Tieren:

Das Polypenstöckchen Eudendrium racemosum läßt sich in einen seewaseraquarium gut kultivieren, verliept aher in den ersten 'lagen ,wahrscheinlich infolge der mit dem Sammeln des Materials verbmolenen Insulte" alle Polypenköpfchen, die bald daranf von dem Stamm aus durch nene ersetzt werden. Dei diesem Regenerationsprozels spielt das Licht mit eine wesentliche liolle, wie sich leicht nachweisen läbt. wenn man einen Teil der Stöckchen, welche die Polypen verloren haben, im Licht, einen anderen Teil im Dunkeln. aher sonst unter genau gleichen berlingungen kultiviert. Bei den belichteten líulturen entwickeln sich im Laufe von fünf Tagen zahlreiche nene Polypen, während im I)nnkeln kein einziger in dieser Zeit gebildet wird. Selbst nach drei Wochen war noch keine Neubildung eingetreten; sie kann aber sofort noch hervorgerufen werlen. wenn man die im Dunkeh gehaltenen Tiere jetzt gleichfalls ins. Licht bringt. In der kurzen Zeit von fünf Tagen werden damn alle Stänmmchen mit neu erzeugten Polypen berleckt.

Aus anderen Versuchen geht hervor, dab durch Beleuchtung oder Mangel an Licht die Färbung der Körperoberfläche in hohem Maße verändert werden kann. Flemming hat dies für Salamanderlarven. LoEB für Fundulusembryonen festgestellt.

Wenn man jüngere Salamanderlarven im Halbdunkel hält, so nehmen sie durch stärkere Pigmententwicklung eine dunklere Farbe an. Werten sie dagegen in weilden Porzellanschalen im Lichte gezüchtet unter smst gleichen Verhältniscen (Zimmertemperatur, Fütterung mit Tubifex rivulorum etc.), so werden sie hell und gebleicht. Die Bleichung, welche sich nach FischeL auch im Dunkeln durch Erhöhung der Wassertemperatur auf $20^{\circ} \mathrm{C}$ hervorrufen läßst, beruht auf einer Abnahme der Menge des Pigments. Nach den Angaben von Fischel, die Flemming bestätigt. .,ist an den gebleichten Larven erstens das im Epithel enthaltene Pigment bedentend an Menge vermindert; zweitens sind die verästelten Pigmentzellen des Epithels nur selten mit Fortsätzen versehen. meist rund oder eiförmig zusammengezogen; drittens endlich sind die großen, verästelten Pigmentzellen in der Cutis fast säntlich auf runde Formen kontrahiert".

Ebenso wie bei den Salamanderlarven fällt die Pigmentierung von Fundulusembryonen verschieden aus, je nachdem man sie sich im Dunkeln oder im Licht entwickeln läbt. Im Lichte entstehen. besonders in der

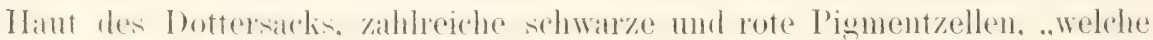
auf die Blutgefäbe kriechen und sie wie eine Scheide umhüllen“. So gewinnen allmählich die Embryonen mit ihrem Dottersack ein ganz dunkles Aussehen. Bei der im Dunkeln gehaltenen Zucht dagegen bilden sich zwar in lïrper des Embryos die P'igmentzellen, so im I'iomentepithel der letina, in normaler Weise aus: der Dottersack aber wird völlig hell und durchsichtig; denn es entstehen hier nur sehr wenige Pigmentzellen, die auch auf die Blutgefälie kriechen, aber anstatt wie bei den belichteten Embryonen eine fast lückenlose Scheide zu bilden, nur hie und da ver- 


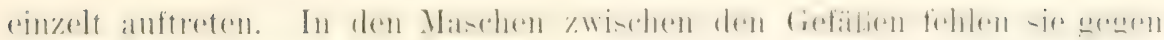
das Ende der Entwicklung ïberhaupt.

Danernder, vollständiger Lichtmangel ist der Pigmentlildung ungünstig. Ein Höhlentier, wie Proteus anguineus, der IBewohmer der Adelsberger Grotte, ist daher vollkommen farblos. Er wird aber durch Pigmentbildung wieder etwas dunkler, wenn er im Aquarium bei Lichtzutritt geziichtet wirl (EMER).

Auf die organischen Prozesse, und dadurch auch auf die (iestaltbildung, üben die stälker brechbaren, die ultravioletten mol die blanen Strahlen des Spektrums einen andegenden Einfluk aus. Während die schwächer brechbaren. roten strahlen in ihrer Wirkung dem völligen Mangel des Lichtes gleichkommen. Es gilt dies wieder sowohl von Pflanzen wie yon Tieren.

SAcris züchtete jahrelang Pthanzen von Tropaeolum maius in hall)geschlossenen Kästen, deren eine Seite, von welcher allein Licht einfallen konnte, mit einer glänzenden Kuvette geschlossen war. In der Hälfte der Kiasten wurde die Kuvette mit remem Wasser. in der anderen Hälfte mit einer Lösung von schwefelsaurem Chinin gefüllt, durch welches die ultra-

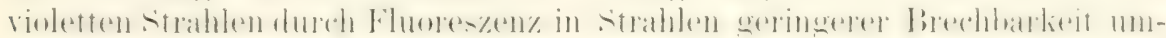
gewandelt werden. Es zeigte sich bei den Versuchen, dab in den Fällen, wo das Licht durch die Chininlösung ging. die Blütenbildung unteldrückt wurle: demn von 26 Pflanzen eines Versuches bildete nur eine einzige eine verkümmerte Blüte. während bei normaler Beleuchtung ron 20 PHanzen 5); Bliiten entwickelt wurden.

Ein analoges Ergebnis erhielt LoEB bei entsprechenclen Versuchen mit dem schon obenerwähnten Eudentrium racemosum. Er belichtete die Stöckchen durch Strahlen. welche entweder durch rote odler durch blaue (jasscheiben durchgehen mukten. Wieder zeigte es sich ausuahms-

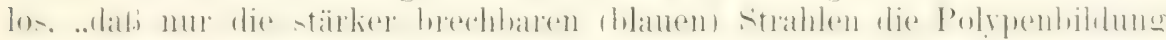
begïnstigen, während die weniger brechbaren (roten) Strahlen wie tie

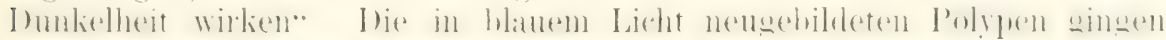

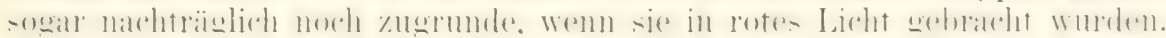

\section{Die Temperatur.}

Die organischen (iestaltungsprozesse werden durch 'Temperaturunterschierle in noch höherem Maße als durch das Licht beeinflulist. so vor allen

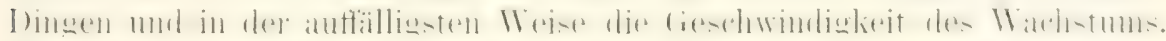

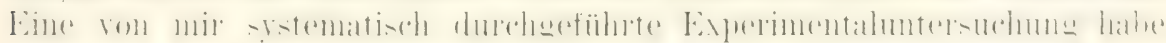
ich schon hierïber im siebenten Kapitel (Seite 14s) mitgeteilt.

Aber nicht nur die 'Zeitrlaner des Entwicklungsprozesses, auch seine Form kann in dieser und jener Weise durch die Wirkung der 'Temperatur verändert werden. So ist für manche Pthanzen- und 'Tielarten durch Ex-

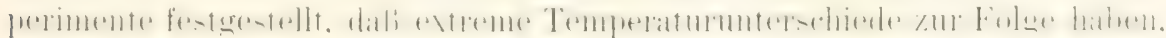
dab sich aus einer Anlage entwerler nur die männliche oder nur die weil)liche Form entwickelt. Melonen und fiurken. welche an demselhen stamme männliche und weibliche Blüten erzengen. entwickehn bei hoher 'Temperatur nur die mïnnliche. im Schatten und bei fenchtigheit dagegen nur die weibliche Form.

Sehr zu Abänderungen geneigt infolge von 'T'emperaturdifferenzen sind die aut verschiedenatiogen Pigmenten beruhenden Fir. bungen im tierischen Körper. Iier liegt ein für experimentelle Lntersuchungen sehr geeignetes und lohnendes Gebiet vor. Vershiedene Unter- 
suchungen, welche von Fisches und Flemming, von Dorfueister, Weisuan, Standersis und Fischer ansgefüht wurden. haben sehon manche interessanten Ergebnisse zutage gefördert.

Von Frsches und Flemming wurden Larven von Salamandra maculata in zwei (rruppen getrennt; die eine von ihnen wurde in fließendem Wasser von 5-70'Temperatur, die andere in stehendem Wasser bei einer 'Temperatur von $15-18^{\circ}$ geziichtet. Bei ersteren nahm die Haut ein immer dunkleres, schwämliches dusehen an: die Wämelarven dagegen wurden zusehends heller. „Der früher schwarze Grundton der Farbe wird zuniehst ein goldhrauner: an ganzen, früher gleichmäbig schwarzen Rumpte treten helle Flecke hervor; am dritten 'Tage wird der Grundton mehr gelblich, besonders am Kopfe. In diesem Stadium verharren die Larven meist längere Zeit; es kann dieses Stadium auch wochenlang andauem: gewöhnlich jedoch sind die Larven nach längstens zwei Wochen ganz hell."

Wenn die während längerer Zeit in kaltem oder in warmem Wasser gezüldhteten Larven nachträglich noch in Wasser ron höherer oder niederer Temperatur gebracht werden, so tritt jetzt zwar auch noch eine entsprechende Cmfïrhung, aber viel langsamer mol in viel geringerem firale ein. FrscheL schlielit hierans, dalis hei Salananderlarven in .jungen Stadien eine weit lehbaftere Reaktion des Pigments auf äubere Reize hin stattindet, dab fermer die durch Wärme orler Kälte hervorgerufene verschiedene Pigmentierung lieinen hob dem momentanen Reize der vershiedenen Temperaturen ent-urechenden vorüherwehenden Zustand darstellt. sondern dab.j sie sich allmählich stahilisiert und daher um so schwerer veründerlich ist. je länger sie hestanden hat". Wärme mol hälte vermögen also die Färbung danermol 7.u beeinflussen.

Die interessantesten Versuchsobjekte für das Studium der T'emperatureintlïsic liefern unstreitig die schmetterlinge mit ihren prachtrollen. charaliteristischen Färbungen. Fs giht unter ihnen eine gröbere Anzahl von Arten, welche unter zwei oder drei verschieden gefäbten und wezeichneten Formen vorkommen. I) eine von ihmen entwickelt sich aus Puppen. die ïberwintert haben, die andere aus Puppen, welche ihre ganze Entwicklumg ans dem Ei, sowie anch die Rampen- und Puppenmetamorphose in den Frühiahrs- und sommermonaten durchmachen. Die erste oder die Winterform hat daher ihre Flugzeit im Frühjahr, die letztere oder die Sommerform im Sommer und Herbst. Beide Formen sind bei einzelnen Arten so vershieden romeinander, dals sie als hesondere Spezies heschriehen worlen sind. his die Kultur der einen Form aus den Eiern der anderen gedang.

Die Erscheinung, dab eine Art in zwei Formen auftritt, die mit der Jahreszeit varieren, hat man als Saisondimorphismus bezeichnet. Man kennt einen solchen von Vanessa, von Papilio Ajax, Autocharis, Lycaena, von verschiedenen Pierisarten etc. Ihre Winterformen werden als Vanessa Levana, Papilio Ajax Telamonides, Autocharis Belia, Autocharis Belemia, Lratena Polysurehom. Pieris Bryoniae heschriehen: die zu ihnen gehörenden Sommerformen sind Vanessa prorsa. Papilio Ajax Marcellus, Autocharis Ausonia, Autocharis glanca, Lycaena Amyntas, Pieris Napi.

Durch künstliche Veränderung der Temperatur gelang es nun, wie DORFMEISTER, WEISMANn. STANDFuss und Fischer durch ausgedehnte Experimente nahgewiesen hahen, ans der Puppe, welche die Sommerform liefern sollte, die Winterform oder wenigstens Zwischenformen zwischen ihnen, welche allerdings in der Natur gewöhnlich nicht gefunden werden, künstlich zu züchten. 
Weismand hat Puppen von Vanessa prorsa viel Wochen lang bee einer Temperatur von $0-1^{0} \mathrm{R}$ aufgehoben. Als sie dann in Zimmer-

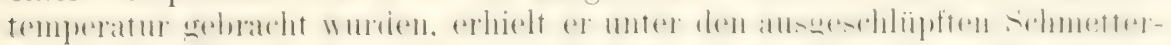
lingen eine kleine Anzahl von Exemplaren, welche in ihrer Fïrbung so umgewandelt worden waren, dab man sie für die echte $V$. levana hätte

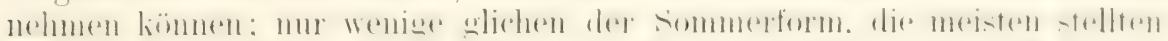

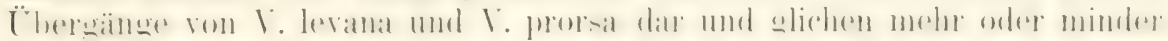

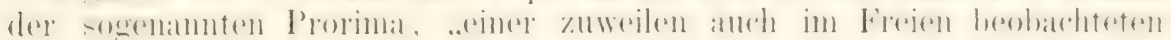
Zwischenform. welche mehr oder weniger noch die Zeichmung ron P'rorsa besitzt. aber bereits mit vielem Gelb der Levana vermischt:. Bei Pieris

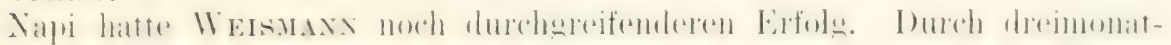
liche Alkïhlume komnte er alle Exemplare der sommorform in die Minter-

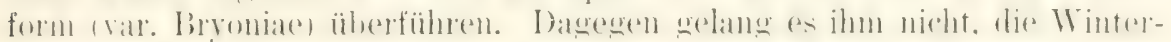
generation von Vanessa zur Annahme der Sommerform zu zwingen.

Noch umfassender, weil mit 'lausenden von Puppen ausgeführt, sind

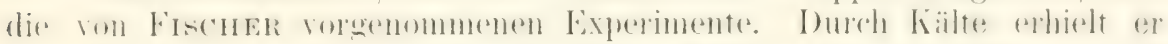
von Vanessa antiopa L. die Varietät artemis. Ton Vanessa io die

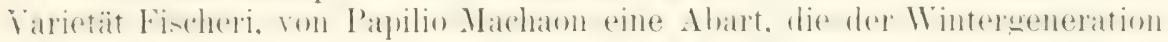
entsprach. Ebenso liefen sich durch höhere 'Temperaturen von :34 bis $36^{\circ} \mathrm{C}$ Veränderungen in der Zeichnung und Färbung hervorrufen; so lieferte V'anessa urticae eine Abart, die der in Sizilien vorkommenden var. ichmusa gleicht; Vanessa antiopa ergab die Varietät epione etc.

Entsprechende Umwandlungen hat STANDFuss noch an zahlreichen

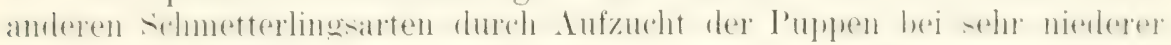
resp. hoher 'Temperatur hervorgerufen. So konnte er Araschnia levana in

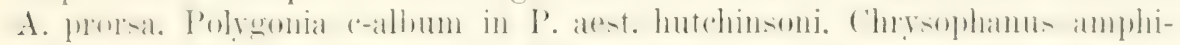
damas in Chr. obscura, Callimorpha dominula in Chr. rar. bithynica um-

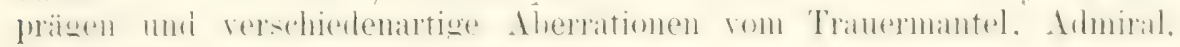
dem groben und kleinen Fuchs erhalten.

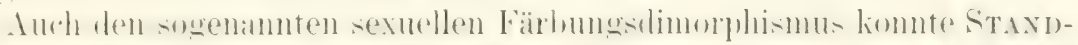

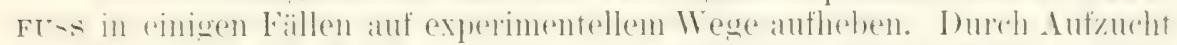
der Puphen in der Wirme erhielten die weibliehen Zitronenfalter. Welche

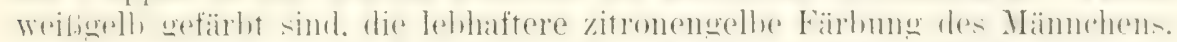
,Yon unserem schönen Bergfalter, dem Apollo, welcher ebenfalls in den

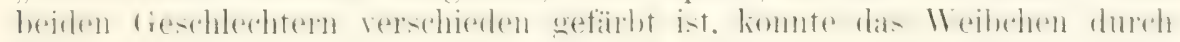
Wärme in das Gewand des Männchens, das Männchen durch Kälte in das Gewand des Weibchens gekleidet werden (STandfuss 1905, Seite 11).

Auf Grumd derartiger Experimente liegt der Schlub nahe, dab die

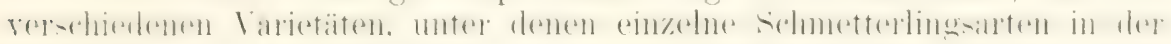
nördlichen. in der semäbigten und in der heifien Zone auftreten, direlit durch die Einwirkung des Klimas auch in der freien Natur entstanden sind. Ermer. Welcher dieser Ansicht ist, führt zu ihren (iumsten noch folgende erläuternde Beispiele auf.

.,Der bei uns so gemeine Bläuling, Polyommatus Phlaeas, welcher von Lappland bis Sizilien vorkommt, hat in Lappland nur eine Generation im Jahr. in Deutschland zwei. Aher erst in Süddentschland sind diese beiden Generationen verschieden - in Nordileutschland sind sie sich noch gleich."

..Ein anderer Bläuling, Lycaena Agestis, hat eine doppelte Jahreszeitenabartung: der Schmetterling liommt in dreierlei Crestalt ror. A und B) wechseln in Dentschland miteinander ab als Winter- und Sommerform. B und C dagegen folgen in Italien als Winter- und Sommerform anfeinander. Die Form B kommt also beiden Kimaten zu. aher in Deutschland tritt sie als Sommer-. in Italien in Winterform auf. Dic deutsche 
I'interform I alier fohlt in Italien vollständig die italienische Sommerform dagegen (var. Allous) kommt in Deutschland nicht vor. Damit ist also

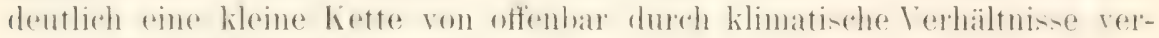
anlaßten Umbildungen gegeben."

\section{Chemische Reize.}

Auf den Ablauf der zahllosen chemischen Prozesse. die für die Lebens-

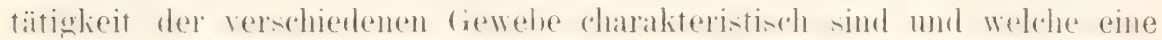

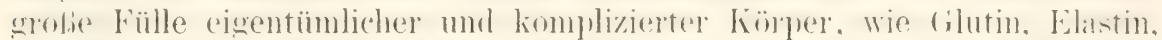

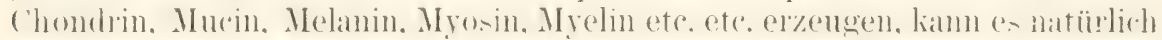

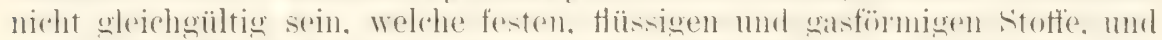
in welcher Menge sie in das rhemische Laboratorimn des ()roanismus ein-

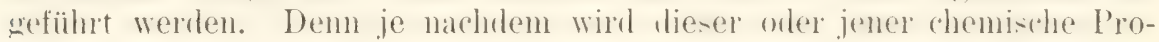
zeb im Organismus eine Abänderung erfahren können. Und hierdurch kömnen wieder Wachstmms- und diestaltmugrmozesie in Mitledienschaft gezogen werden. Daher bilden demn rhemische Körper in festem. Hüs-igem

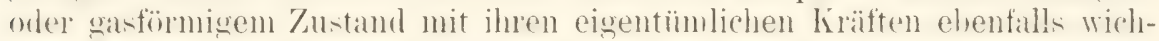
tige. auberordentlich mannigfaltige Reize. welehe gleich den mechani-chen, thermishen ete. die Gestalthildmm und Fntwicklmosweise hei Ptlanzen wie bei Tieren direkt beeinflussen.

\section{a) Beeinflussung bei Pflanzen.}

Es ist bekannt. wie die im Boden enthaltenen Nährstoffe das Wachstum vieler Pflanzen morlifizieren. wie manche Arten auf einem fetten orler zu stark gedüngten Borden ins Lraut schieben, aber dabei nicht zur Libutenmul Fruchthildung gelangen. ...lle blumenzüchter sind". wie Donzws ausführt, ,einstimmig der Ansicht, daß gewisse Varietäten durch sehr unbedeutende Differenzen in der Natur der künstlichen Erde. in welcher sie gezogen werden, dureh den natiorlichen Boden des Distrikt affiziert werlen."

Ohne geringe Spuren vou Eisensalzen z. B. ist eine normale Entwicklmo dhlorophyllhaltiger Pthanzen nicht möglich. Wird ein lieinemdes I'tänzchen in einer eisenfreien Nährstoffläsmng gezüchtet, so mateht sich schon in wenigen Tagen die von GRIEs nachgewiesene Erscheinung del Chlorose bemerkbar. Die zur Entfaltung gelangenden Blätter bleiben weiß, weil in ihren Zellen keine Chlorophyllkörner gebildet werden. Da

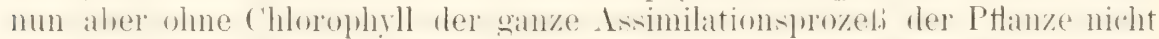

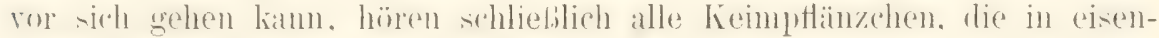
freier Nährstofflösung gezüchtet werlen, auch wenn in ihr sonst alle zum Wachstum nötigen Stoffe reichlich vorhanden sind, überhaupt ganz zu wachsen auf und müssen so nach einiger Zeit zugrunde gehen. Es ge-

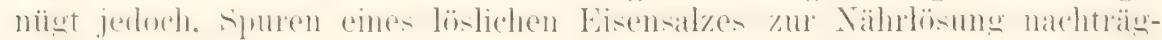

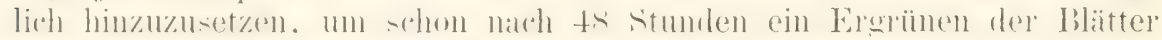
und damit auch die Möglichkeit weiterer Entwicklung hervorzurufen. Ebenso ergrint auch bald das chlorotische Blatt, wenn man seine Ober-

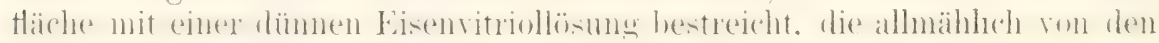
Zellen aufgenommen wird.

Durch Beimengung bestimmter Substanzen zur Nährtlüssigkeit kann

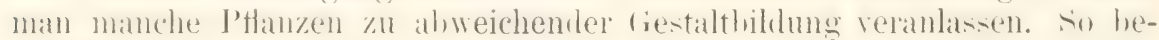

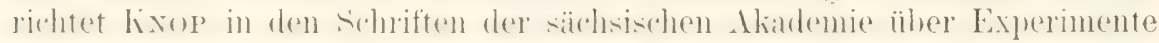
an Maispflanzen, die in einer Nährtlüssigkeit gezüchtet wurlen, welche

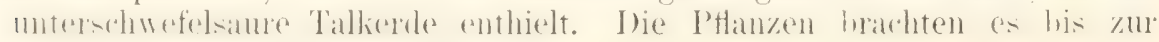




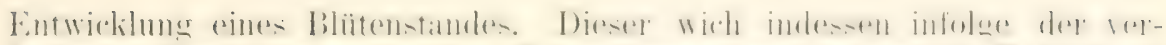

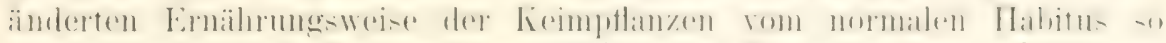
erheblich ab, daf Kxor sich $\%$ folgender liemerkung veranlabt sah:

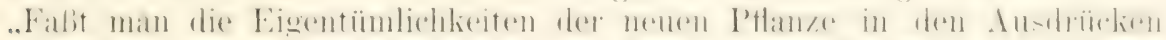

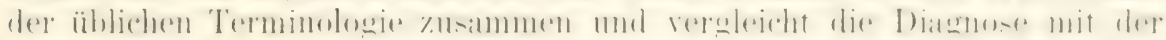
der Gattung Zea, so findet man die Abweichung so stark, dab man sie dieser Gattung nicht mehr einreihen kamn."

Nach Lesage macht die Nähe des Heeres und die Benetzung mit

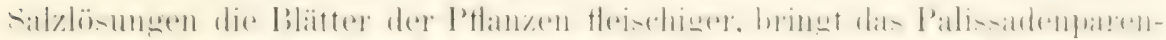

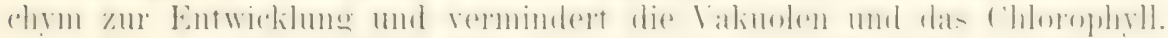

..Die normal erst im zweiten Jahre blühencle Runkelribe geht auf

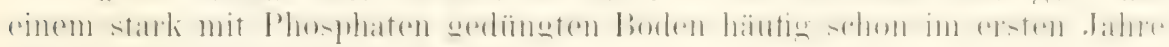
zur bilitenbildung ïber.” (SACHS).

\section{b) Beeintlussung bei T'ieren.}

Zahlreiche und mannigfaltige Beispiele liefern uns auch die Tiere.

Bekamut sind die mit Phosphor und Arsen angestellten, interessanten Experimente von WAGNer, Gies und Kassowitz. Kileinste. täglich verabreichte Gaben ron Phosphor $(0,0015 \mathrm{~g})$ oder von Arsen

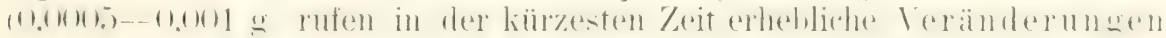
im Knochenbildungsprozesse hervor, welche sich ïberall da zeigen, wo Knochensubstanz neu gebildet wird. sowohl an den Epiphysen als an Periost. Fs wird die normale Einschmelzung des verlialliten Kinorpels und der jüngsten Krnochenteile eingeschränkt. An den Epiphysen wirl

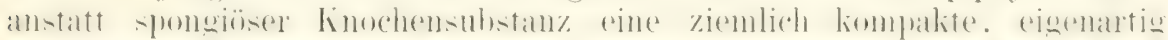

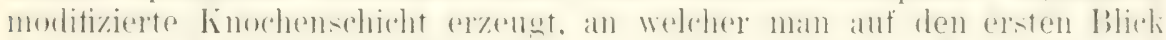

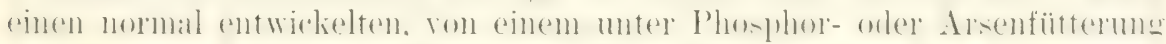

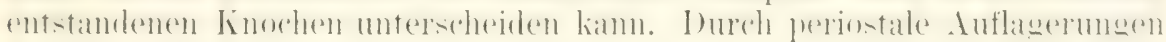
wird die Diaphyse dicker, zumal da auch die von seiten des Markramms

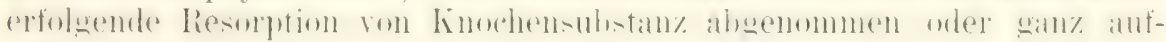
gehört hat. Ja es kann sogar durch längere Zeit fortgesetzte Fütterung

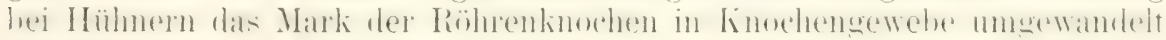
werden.

Durch Entziehung des zur Skelettbildung erforderlichen Kalks kann man ebenfalls formative Prozesse abändern. Solche Versuche haben Pouchet und Chabry mit Erfolg an Seeigeleiern ausgeführt. welche

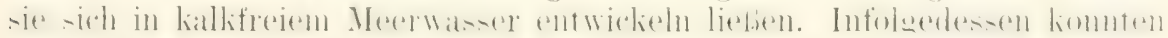
beim Ubergang der Gastrula in die Pluteusform die lialknadeln. welche sich zum Skelett der Arme verbinden, wegen mangelnden Bammaterials

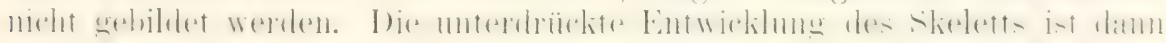
wieder die Ursache geworden, dab auch das weiche (iewebe der Arme

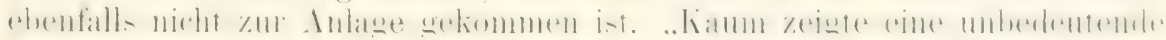
Verdickung des Ektoderms - bemerken die französischen Forscher eine schwache 'Tendenz des äuberen Blattes an. fül die drme noch einige Zellen mehr zu erzeugen."

In dasselbe Gebiet der Verinderung tierischer Formbildung durch stoffliche Einwirkungen rechne ich eine Reihe bemerkenswerter Erscheinumgen, welche uns hie und da auf dem Gebiet der Biologie der Tiere entgegentreten und welche teils in nenerer Zeit durch Scmaxikewitsch und lioch. dureh Grassi und ExERY beobachtet, teils aus der älteren Literatur durch DARWIX zusammengestellt worklen sind. 
Scmmankwisch hat Artemia salina mehrere Generationen hindurch gezüchtet, indem er allmïhlieh den salzgehalt des Wassers erhöhte. Er limnte auf diese IVeise bei den gegen Salzgehalt ungemein emptindlichen Tieren leränderungen an den sichwanzhorsten mol schwanzlappen hervorufen, bis schieblich eine Form entstand, welche der Artemia Mïhlhausenii genau entsprach. Ebenso konnte er durch Verdünnung des salzwassers die Artemia salina in einer anderen Richtung verändern und allmählich in die Form Branchipus umwandeln.

Einen ähnlichen Fall von der Entwicklung verånderten Salzgehaltes auf die Schalenbildung von Muscheln berichtet Costa. Junge, von den Kïsten von England genommene Austern, wenn sie in das Mittelländische Meep versetzt werden. verämlern alshald ihre Wachstumsweise und bilden vorragente, diverwierende strahlen. wie sie den Schalen der eigentlichen Mittelmeeraustern eigentümlich sind.

Dankbare Objekte für Fiitterungsexperimente sind die Raupen der Schmetterlinge. Es ist eine bekannte, besonders durch Experimente von dem Lepidopterologen Kón festogestellte Tatsache, ..lab wenn man die Raupe unseres deutschen Bären (Chelonia caja) schon vom Ei aus bis zur Verwandlung mit Blättern von Lactuca sativa odler Atropa belladomna füttert. alshann von den daraus hervorgegangenen schmetterlingen lieiner den ursprïnglichen melı gleicht. In der Regel eryielt man an mit Salat gefïtterten Raupen Exemplare, bei welchen die weilie cirmulfarbe

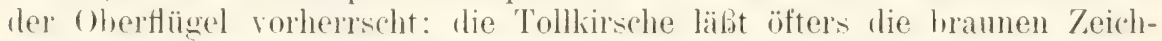
nungen auf den Ohertlügeh zusammentliefien und das Weife verschwinden. ehenso vereinigen sich die blanen Zeichmungen auf den T'nterthïgehn und verdrangen die orangegelhe (irumblarbe". In ännlicher Weise lionnte liocu bei anderen Arten. wie dem Wegerichspinner (Chelonia plantaginis) und den Föhrenspinner (fastropacha pini) reränderungen in der Färbung erzielen.

Zieht man außer diesen Experimenten noch die Tatsache in Betracht,

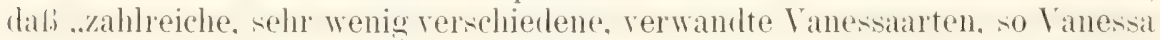
polychloros, xanthomelas, alhum und urticate ihre Eier an verschiedene FutterpHanzen ablegen". so ist die Ansicht vou Emmer nicht unbegründet: „es seien viele neue Schmetterlingsarten wohl dardurch entstanden. dab Rampen sich zu irgend einer \%eit einem Futterwechel anzubepuemen gezwngen waren".

Auch für die Ǩlasse der Vögel liegt eine Anzahl ähnlicher Erfahrungen vor, welche DARWIN gesammelt hat.

„Die Fütterung mit Hanfsamen wird die Ursache, daß Gimpel und gewisse andere Vögel schwarz werden. Nach den Angaben von WaLLAce füttrn die Eingehorenen des dmazonenstromgehietes den gemeinen grünen Papagei (Chrysotis festiva) mit dem Fett grober welsartiger Fische, und die so behandelten Vögel werden wundervoll mit rothen und gelben Federn

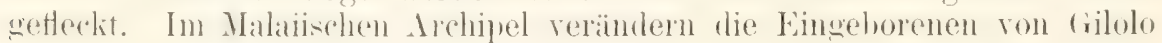
in einer analogen Weise die Farben eines anderen Papageis, nämlich des Lorius garulus, und produzieren hierdurch den Lori rajah oder Königslori. Werden diese Papageien auf den malaiischen Inseln und in Südamerika fon den Eingeborenen mit ihrem natürlichen vegetabilischen Futter, wie Reis und Pisang gefüttert, so behalten sie ihre gewöhnlichen Farben.

Mr. Wallace hat auch einen noch eigentümlicheren Fall angeführt: .Die Indianer von Südamerika besitzen eine merlswürdige Kunst, durch welche sie die Farben der Fedtern vieler Vögel verändern. Sie rupfen diejenigen von den Teilen, die sie zu färben wïnschen, aus und impfen 


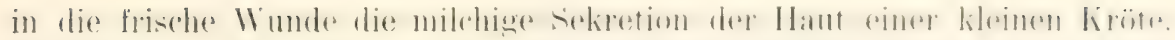
Die Federn wachsen nun mit einer brillanten, gelben Farbe. und werden sie ausgerupft, so sollen sie von derselben Farbe wieler wachsen, ohne irgend einen frischen Eingriff."

Nahrungseinflüsse werden um so leichter tiefere Verinderungen hervorzurufen imstande sein, auf je früheren Stadien der Ei-Entwicklung sie einen Organismus treffen. Als Belege hierfür seien die Bienen Termiten und Ameisen angefüht. Wie LuEry, Grassi, Herbert Spexcer ete. glauben ammehmen zu müssen, wird der bei diesen tierstaaten beobachtete Polymorphismus der Individuen (Fig. :207) direkt durch die äuferen Einflüsse hervorgerufen, welchen die Eier in bezug auf Wohnung und Nahrung wähend ihrer Entwicklung a usgesetzt werden.

Nach den zahlreichen Beobachtungen und Experimenten der Bienenzüchter sind die befruchteten Eier der Bienenkönigin fähig, sowohl Arbeiterinen als wieder Königinnen zu werden. Es hängt dies lediglich diavon ab, in welche Kellen des Bienenkorbes die Eier gebracht und in welcher Weise sie ernährt werden. In besoniers großen Zellen (Weichselwiegen) und bei reichlicher Ernährung werden sie zu Köönigimnen, bei knapper liost in engeren Zellen zu Arbeiterimmen. Es können sogar nachträglich Larven von Arbeiterinnen durch reichlicheres Futter, wenn es noch zeitig genug geboten wird, in Königinnen umgewandelt werden.

Auch für die 'Ter'miten (Fig. 327) ist dem italienischen Zoologen (iRAssi der Nachweis gelungen. dah sie es in ihrer Macht haben, die Zahlenverhältnisse der Arbeiter und Soldaten zu regulieren und letztere je nach Be-
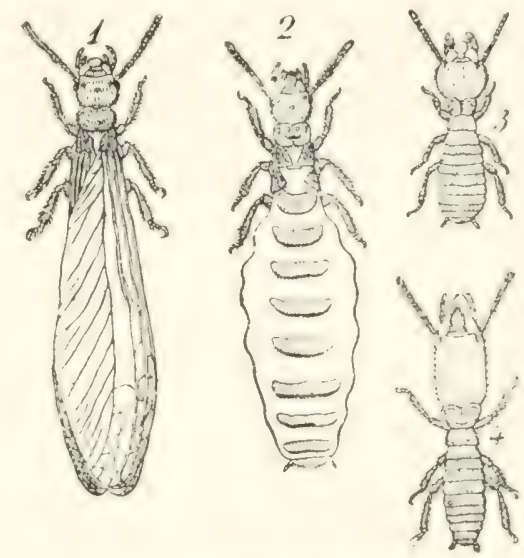

Fig. 32- Termes lucifugus. I (ieflügeltss Geschlechtstier: 2 Weilochen nach Verlust der Flügel mit Resten derselhen: 3 Arheiter: + Soldat. Aus LetrisL.TIWI(i.

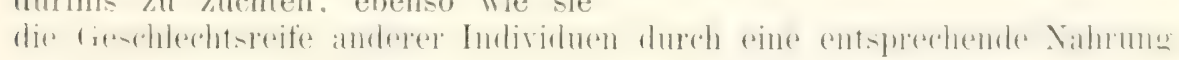
zur Erzeugung yon Ersatzgeschlechtstieren beschleunigeñ können.

In ähnlicher Weise erliärt EuERY die Arbeiterbildung bei den

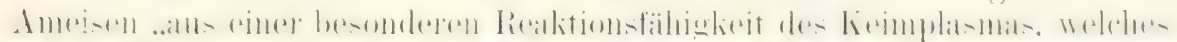

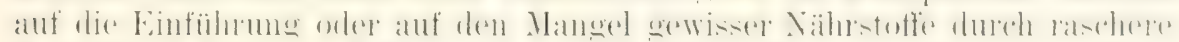

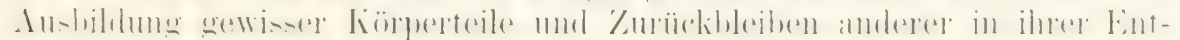
wicklumo antwortet. Arbeiternahrung muld die Kiefer- und (iehirnentwick-

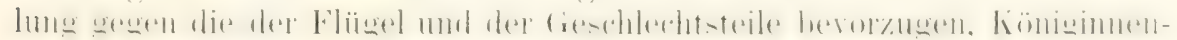
nahrung umgekehrt." \%wischen der Verkümmerung der Geschlechtsdrüsen und der stärkeren Ausbildung des lopfes findet eine Korrelation statt. gerade so wie bei den Wirbeltieren zwischen der Entwicklung der Ge-

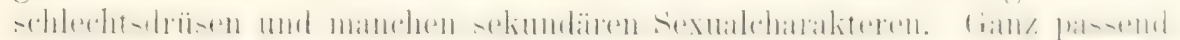
hat daher FuERY die V'erschiedenheit der Individuen bei 'Termiten. Bienen und Ameisen als Nahrungspolymorphismus bezeichnet.

Jach unserer Erliairung läbt sich auch recht sut die durch sorofältige Beobachter (CI. DARWIN. EmerY ete.) festgestellte l'atsache verstehen. dab bei manchen Arten der Ameisen die verschiedenen extremen 


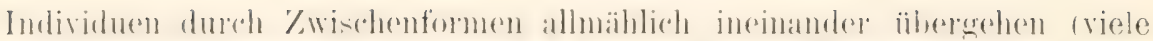
Myrmiciden, die meisten Camponotiden, Azteca). Übergänge finden sich

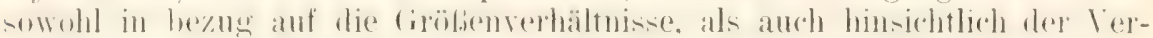
kïmmerung der Geschlechtsorgane und auch hinsichtlich der sehr verschiedenen Struktur ihrer Kiefer etc. Sie erklären sich, wie SPENCER mit Recht hervorhebt, dadurch, daß die Entziehung der Nahrung bei allen Eiern nicht zur selben Zeit während ihrer Entwicklung stattgefunden hat.

Wie in den angeführten Beispielen normale Formwandlungen, so lassen sich endlich auch ganz charakteristische Monstrositaten erzielen, wenn bestimmte chemische Substanzen oft in ganz minimalen Quantitäten auf Eier, namentlich in den Anfangsstaten ihrer Entwicklung, einwirken.

Der Zoologe Herbst hat durch Zusatz ge-

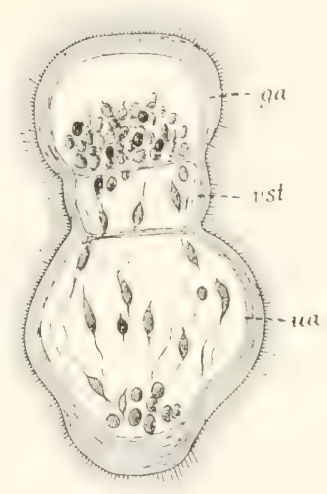

Fig. :328. Larve von Echinus mikrotuberculatus, welche in Meerwasser, dem etwas Lithiumchlorid zugesetzt war, gezüchtet ist. ga Teil der Aukenwand der Gastrula (Entoderm); vst Verbindungsstïck; $u a$ nach auken hervorgestiilpter Urdarmabschnitt (Entoderm). ringer Mengen von Lithimmsalz zum Meerwasser aus den befruchteten Eiern eines Seeigels, des Sphaerechinus granularis, eigentümlich gestaltete Lithiumlarven. wie er sie nennt, erhalten (Fig. 328). Die Eigentümlichleit ihrer Entwicklung besteht darin, dab der Bezirk der Keimblase, welcher zum Darm wird (ua), sich infolge der Einwirkung des Lithiumsalzes nicht in die Blastulahöhle einstïlpt, sondern gerarlezu in entgegengesetzter Richtung nach auben als Fortsatz hervorwächst. Werden die Larven zu geeigneter Zeit in reines Meerwasser zurückgebracht, so bleibt der Darm nach aufen hervorgestiilpt, der iubrige Körperteil aber beginnt die für die Pluteusform charakteristischen Veränderungen zu erleiden und die Arme, den Wimperring, Mesenchym und Kalknadeln zu entwickeln. Um die Reaktion zu erzielen, mul. das Salz auf die Eier während der ersten Entwicklungsstadien einwirken; Eier, welche auf späteren Furchungsstarlien orler als junge Blastulae noch in der Eihülle in die Lithiummischung gebracht werden, erleiden nicht mehr die oben beschriebene Veränderumg.

Aus Frosch- und Axolotleiern erhielt ich Embryonen mit teilweiser Anencephalie und Hemikranie, wenn sie sich in Kochsalzlösungen voll 0,6\% (resp. 0,7\%) entwickelten (Fig. 329, 330, 3:31). Die zur Anlage der nervösen Substanz dienenden Teile des äuberen Keimblattes werden durch den chemischen Eingritt geschädigt. Die Tervenplatte, anstatt sich rechtzeitig zum Rohr zu schließen, bleibt Hach ausuebreitet, ein Zustand. der meist anf den Bereich des dritten bis fünften Himbläschens beschränkt ist. Die nicht zum Verschlub gelangten Partien

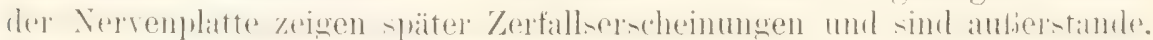
Nervensubstanz zu entwickeln.

Näheres über die Amphibienlarven mit Anencephalie und Rückenmarksspalte ist aus (len Fig. 329-331 und der ihnen beigefügten Erklärung zu ersehen.

Iranche Misbildungen bei Sängetieren und beim Menschen werden sich wohl in ähnlicher Weise als Chemomorphosen erklären lassen, entstanden durch abnorme Stoffwechselprozesse von seiten der Wandungen der Gebärmutter. 


\section{Reize zusammengesetzter Art.}

In den seltensten Fällen sind die äuberen Ursachen, die auf einen

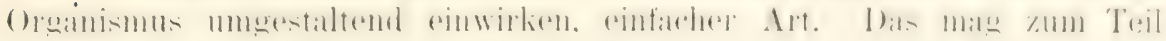
schon bei einigen Beispielen der lall sein, welche auf den vorausgegangenen Seiten besprochen worden sind, wie bei den Schattenblättern, bei Hydatina usw. Meist kommen gleichzeitig viele Faktoren zusammen, so dab man ihre einzelnen Konten nicht voneinander trennen und nur

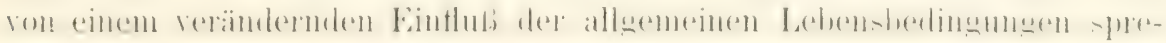
chen kann.

In ilirem allgemeinen Habitus und in vielen Zügen ihrer Organisation sind die IIasser- ron den Landpflanzen unterschieden, was sich aus

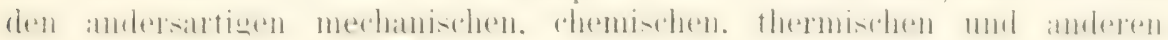

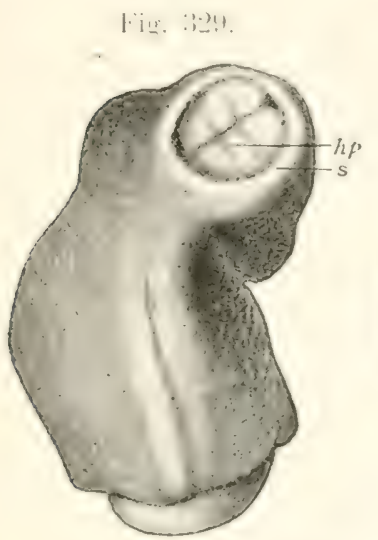

Fing. 330 .

lïis. $: 3: 31$.
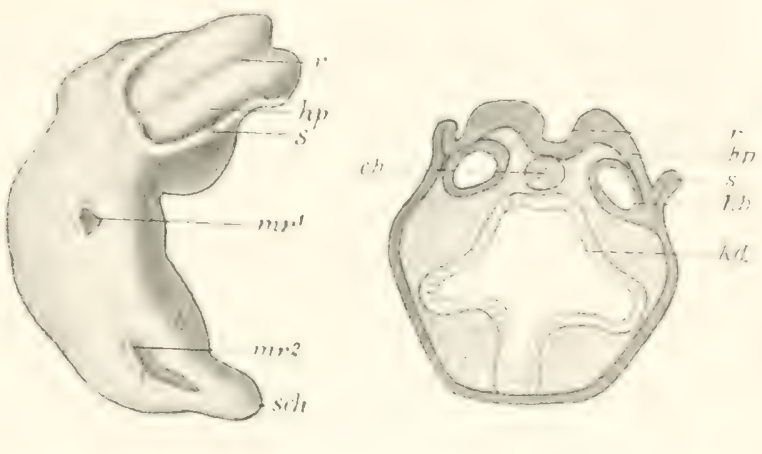

[iig. :39. Embryo von Rana fusca. Aus einem Li, das nach dor Befruchturng an 10. Mäm in einer 0,6 prozentigen Kochsalzlösung bis zmm 14. März gezürhtet wurde, rom liücken asesehen. Die dritte bis fünfte Inimblasenanlage haben sich nicht zum Rohr geschlossen, hp Hirmplatte, mmeben ron einem Samm der Epidermis s.

Fig. 330. Embryo von Axolotl, mit Anencephalie und Spalten im IMedullarrohr. Ats einem Ei, das rom 26. November bis 4. Dezember in einer 6prozentigen Kochsalzlösung gezïchtet wurde. hp Ilimplatte; r. Rinne zwischen beiden Ilälften

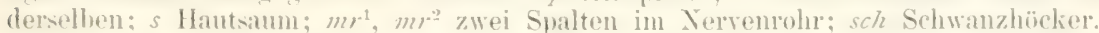

Fi... Querschnitt durch die unentwickelt gebliebene Hirmanlage des in Fig. 330 abgebildeten Embryos in der Gegend der Ohrbläschen. $\therefore$ Hirnplatte: r mediano linme derselhen; ch Chorda; s Samm der buidermis an der (irenzo? der offen crehliehenen Himplatte; hb Hörhlïschen; kd Loptidarmhöhle.

Bedingungen des ungebenden Mediums, hier des Wasser's, dort der Luft. erklärt. So sind bei Wasserptlanzen die mechanischen (rewebe gar nicht oder nur in viel geringerem Mafe als bei Landpflanzen entwickelt. weil Zweige und libäter mit dem Wasser nahezu das gleiche spezitische Gewicht haben und flottierend aufrecht erhalten werden. Da Wasseraufnahme und Wasserabgabe bei ihnen in anderer Weise als bei Landptlanzen erfolgen. fehlen die saftleitenden Gefäße oder sind wenig entwickelt: die Blätter sind zarter. mit diuner Cuticula. Ihr Bau wird statt dorsiventral mehr zu einem isolateralen.

Nun gibt es anch eine Anzahl von Pflamzenarten Mentha aruatica, Glechoma hederacea, Scrophularia), welche, in Sümpfen orler am Rand von Bächen und Flïssen wachsend, gelegentlich auch lüngere Zeit ganz in Wasser eingetaucht lehen können: anch können sie kïnstlich unter Wasser 
gezïchtet werlen. Die unter Wasser entstandenen Teile dieser gewissermaben akzidentellen Hydrophyten zeigen sleichtalls morphologisehe Ahïmlermgen mehr oder minder ausgeprägter Art: sie nähern sich der Struktur echter Hydrophyten und lassen sich als Zeugnisse für den umgestaltenden Einflub des Wasserlebens verwerten.

Ämliche durch Verschiedenheit der äuBeren Faktoren hervorgerufene (iegensätze wie zwischen Land- und Wasserpflanzen treten uns zwischen

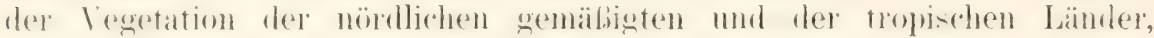
zwischen der Vegetation der Alpen und der Ebene oder eines Kulturlandes und der Wüste entgegen. Alpine Pflanzen zum Beispiel, die an der Grenze des ewigen Schnees nur wenige Sommermonate nicht vom sirhnee hedeclit sind und unter ganz hesonderen Verhälnisien der Sonnenstahlung und Temperatur vegetieren, zeigen \%wergwehs, haben aher ein mächtig entwickeltes Wurzelwerk, intensiv gefärbte Blüten etc. In die Ebene verptlanzt, verändern sie ihren Habitus, nehmen aber die alpine Form wieder an, wenn sie oder ihre Nachkommen aus der Ebene an den ur-prünglichen standort zurürligebracht werlen. wie die alpinen Arten ron Hieracium, mit denen Xäresi experimentierte. Daher kann dievelbe Pflanzenspezies, je nach den Standorten, an denen sie geziichtet wird, in verschiedenen Standortsmodifikationen auftreten.

Zu zahlreichen Variationen neigen besonders die der Kultur unterwortenen diewädse, weil sie den verschiedenartigsten. oft einseitigen und „unnatürlichen" Entwicklungsbedingungen unterworfen werlen.

In gleicher Weise wie auf die Ptlanzen übt auch auf die Tiere das Iand- und Wasserlehen, die amphibische Lebensweise, die Domestiliation, das Klima usw. einen umändernden Einfluß aus. Dasselbe gilt vom danernden Aufenthalt in unterirdischen Räumen. so dab die Vertreter der Ilöhlenfanna ans den vershielensten Tierstämmen gewisse gemeinsme Zïge anfweisen.

Die obertlächlichen Grenzschichten des Körpers nehmen sofort bei sehr vielen Tieren ein besonderes Aussehen an, je nachdem sie mit der Luft, mit Wasser oder mit Körpersäften in Berührung sind. Die rom Wasser umspölte Oberhaut rieler Fische (Fig. 3930) ist physiologisch wie aine Srhleimhant heshaften, mit Becherzellen wie das Epithel des Darmkanals ausgestattet und zur massenhaften dbonderung von Schlem hefähigt: bei den landhewohmenden Wirheltieren dagegen steht der Epitheliblierzuw der Inat zmm Epithel des I)armkanals in ausge-prochenem ciegensatz. Durch den Einflul, der atmosphärischen Luft, die dem weichen Protoplasma sein Wasser rasch entziehen würde, sind die oberflächlichsten Zellen in Hornsubstanz umgewandelt und bilden zusammen eine ziemlich undurchlässige Schicht, das Stratum corneum, welches sich als schützende Decke über' den eigentlichen lebenstätigen 'Teil der Oberhaut, das Rete Malpighii, herïherlegt. Die inneren Epithelschichten des kïrpers entbehren einer solchen zum Schutz gegen die Luft berechneten Decke, weil

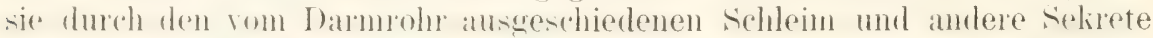
fencht und sohlüufrig rhalten werden. Daher sehen wir anch an den stellen. wo die inneren Höhlen an der Oberfläche des Körpers ausmünden, sich mit dem Wechece der bedingungen eine entsprechende Cmwandlung der Schleimhaut in eine Oberhaut vollziehen: es bildet sich auf eine kurze Strecke ein Übergangsepithel aus, wie am Rand der Lippen und NasenHiïgel oder am After.

Auch der experimentelle Beweis ist hier für die Richtigkeit der geachernen Frlibrung zu erhringen. Wie atu der allgemeinen Pathologie genug- 


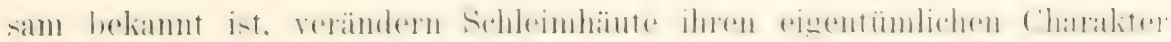

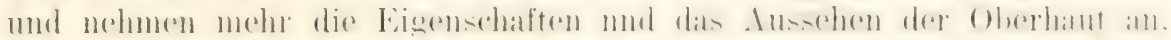
wemn sie, aus ihrer normalen Lage gebracht (wie hei Vorfall der Gebair-

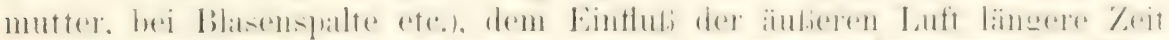

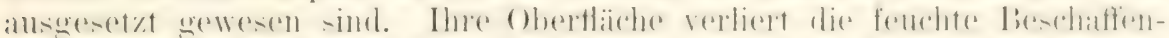

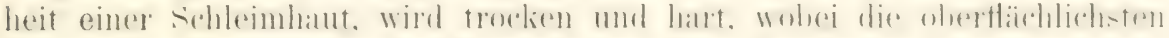
Zellei die charakteristische Hormmetamoryhose erleiden.

Festsitzende Pflanzen und Tiere stehen mit ihren beiden Körperenden

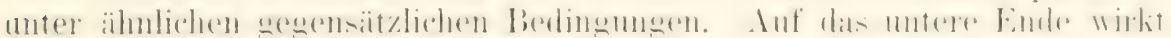

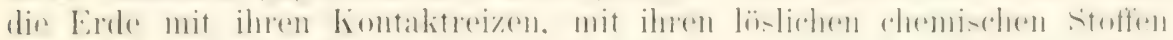
und in gröberer Tiefe durch den Abschluf, des Lichtes; das nach oben gekehrte Ende dagegen ist, abgesehen von anderen Falitoren, vor allen Dingen dem vollen Einflub des Lichtes ausgesetzt. Die Folge davon ist

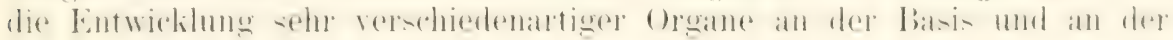

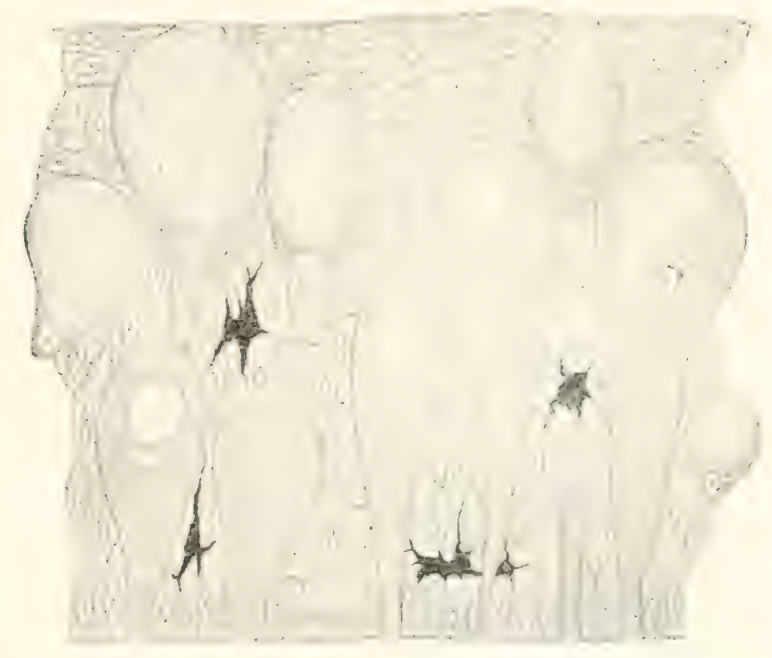

liu. :i:). Senkrechter Durchschnitt durch die Epidermis der Bauchhaut eines erwachsenen Aales. Nach Eir. Schulze Taf. VII, Fin. 4.

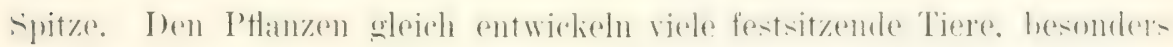
aus dem Stamm der Cölenteraten, an ihrer Basis ebenfalls eine Art von Wurzelwerk zum Festhalten. Stolonen oder Ausläufer. die auf dem Boden hinkriechen oder sich auch ein wenig in denselhen einsenken. Durch Experimente gelingt es sogar bei niederen Pflanzen und 'Tieren, durch Un-

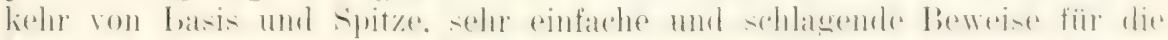

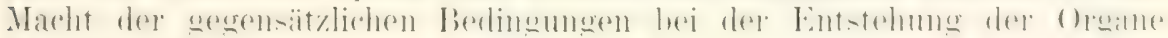
beizubringen.

Erwähnenswert sind hier die interessanten Erobebnisse, welche der

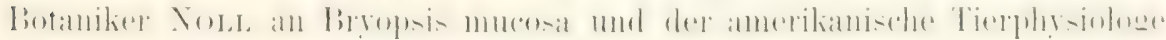
LoEB an Tubularia mesembryanthemum gewomnen haben.

Bryopsis (Fig. $339 l$ ) ist ein in Wasser lebender Cöloblast wie

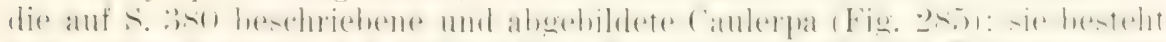

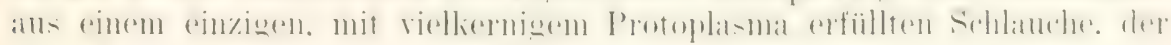
aber änerlich wie ein zelliges Pflänzchen in einen vertikalen Stamm mit einem Gipfelsprob (s). in Blätter, die am oberen Ende in zwei Reihen 
regelmïbig rerteilt sind und in ein den Borlen durchziehendes, verzweigtes Wurzelwerk $(w)$ gegliedert ist.

Sm den Eintluli der äuleren Faktoren zu prüfen, hat NoLL einfach

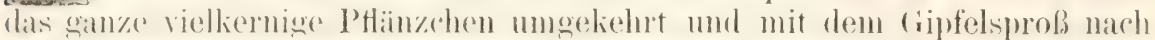
unten in die Erde des Aquariums eingegraben (Fig. $33: 3 / 1$ ). Die Folge davon war, daß jetzt aus (lem Gipfelsproß $(s)$, an welchem sonst, wemn er nach oben gekehrt ist, seitlich junge Blattanlagen entstehen, sicl verzweigende Wurzelfälen (a') heworsprossen und den Sandlörnchen (lî́ des

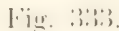

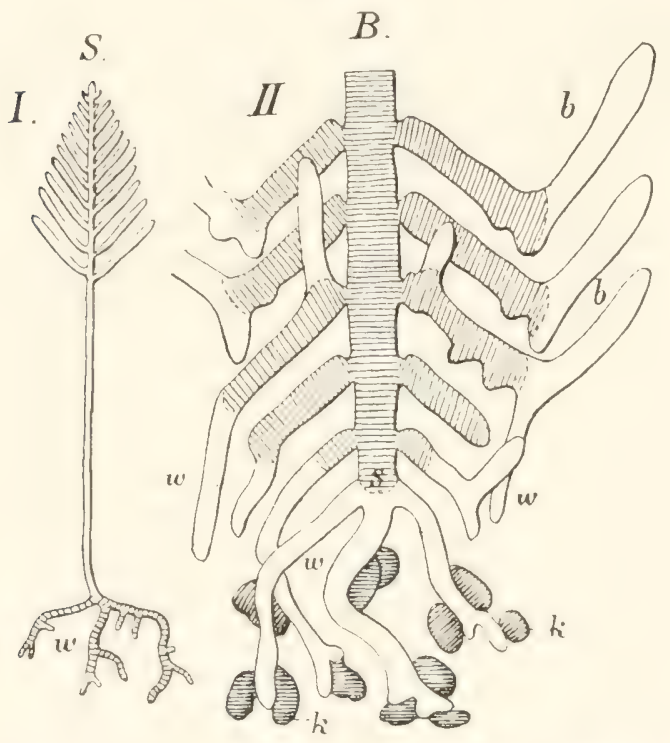

Fï. :3:1.

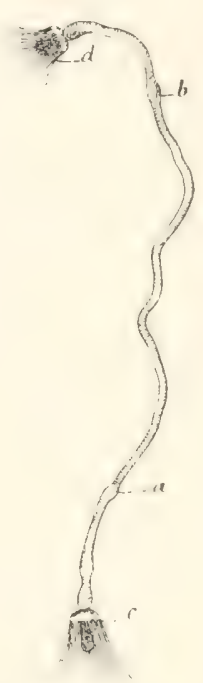

Fig. 333. I. Aufrecht gewachsenes Pflänzchen von Bryopsis mucosa. (Hialh whiltish.) II. Spitze einer umgekehrten Bryopsis mucosa, deren Spitze sich in eine Wurzel umgewandelt hat. Der schraffierte Teil stellt die Gröfe der ursprünglich umgekehrten l'flanze dar, die nicht schraffierten Teile den Zuwachs in umgekehrter Lage. $w^{\prime}$ Wurzelschläuche; $k$ Sandkörnchen, mit denen die Wurzeln verwachsen sind; $b$ Blattfiedern; s Stammspitze. Nach F. Nout.

Fin. 334. Heteromorphose bei Tubularia mesembryanthemum. Biorales Tier. Das aus der Mitte pines Stammes herans geschnittene Stïck $a b$ bildete an jedem Schnittende einen Polypen ( $d$ und $c$ ). Nach der Polypenbildung erfuhr der Stamm $a b$ den Zumachs $b$ a und $a c$. Die neugebildeten Stücke sind durchsichtiger als das alte.

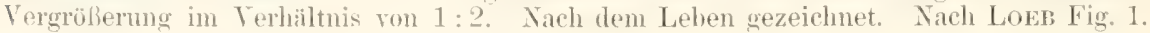

Liodens fest anhaften. Desgleichen sind auch Lmwandlungen an den Lhattschläuchen hervorgerufen worden; ihre, anstatt wie normal nach oben, jetzt mach unten und dem Borlen zugekehrten Enden, die sich mit ihrem von vielen licuen durehsetzen P'rotophasma wie Vegetationspunkte rerhalten. treiben einerseits Wurzelfäden $\left(w^{\prime}\right)$ nach abwärts, andererseits Sprosse, die, sich nach oben richtend, eine Grundlage für neue Stämmchen mit Blattfiedern abgeben.

Der kleine, auf dem Boden festgewachsene Hydroidpolyp, Tubularia

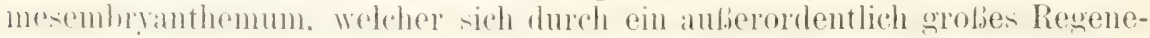
rationsermögen anszeichnet und darlureh zu Versuchen sehr qeeignet ist. besteht aus einem Stamm, dessen eines Ende in der Erde mit Ausläufern wie: mit Wurzalfälen hefestigt ist, während das andere sich in Zweige teilt. 
deren jeler mit cinem Polypenlïppechen endet. Wem man letzteres abschmeidet. so wird von der Wundfläche in wenigen Tagen ein neues gebiliket.

LoEm hat num einen gröferen 'Tuhulariazweig, den er semes liöptchens beraubt hate, zugleich auch noch von dem Stamme alugetremt. Er hat anf diese Weise ein zweigartiges Stück T'ubulariasulostanz mit zwei IVundenden erhalten. von denen wir das am Stamme abgetrennte Ende als Basis, das des líoptes beraubte Ende als Spitze bezeichnen wollen. Je nach den Bedingungen, in welche er die beiden Enden des Zweiges versetzte, lionnte er jetzt im roraus bestimmen, welche Organe der Zweig

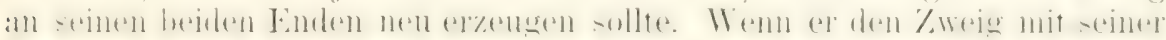
Basis in den Sand eines Seewasseraquariums eine Strecke weit eingrub), so daf. das andere Ende, die Spitze, vertikal nach oben gerichtet war, so

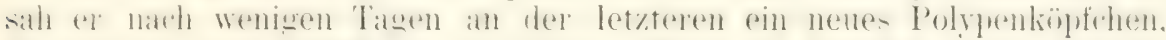
an er-teres abes Hatffirlen ent-tehen. Wrin er dagegen einen anderen

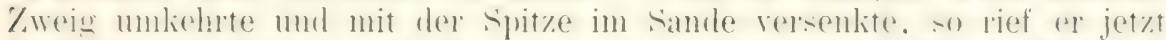

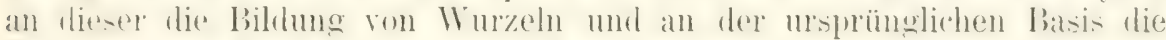
Bildung eimes Hydroidpolypenköpfehens hervor.

Jerartige Eroehnise lehren auf das mowedelentigste, dab es ledig-

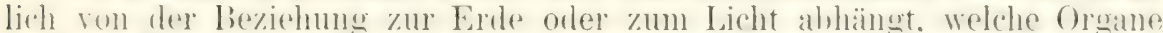
an dem Ende eines Tubulariaweiges entstehen sollen. Die rershierlene

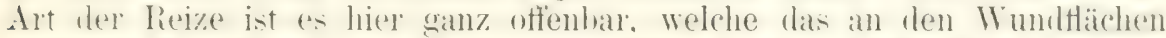
gelegene Zellmaterial zu dieser obler jener Art von organhildung veranlinbt: unl weil der lieizerfols der Reizwirkung entspricht, er-cheint uns zugleich der ganze Vorgang als ein zweckmäßiger.

Man kann schließlich das Experiment noch in einer dritten Weise varieren, derart. dial. man das Bruchstüch frei und horizontal im Waser

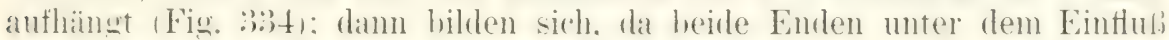
des Lichtes stehen, an beiden auch Polypen aus.

\section{Organische Reize. die in Einwirkungen zweier Organismen aufeinander bestehen.}

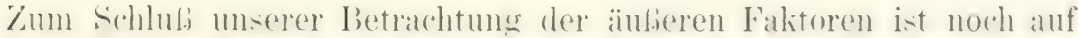
eine mamigfaltige (implye von lieizuratehen einzugehen, welche or wanischer

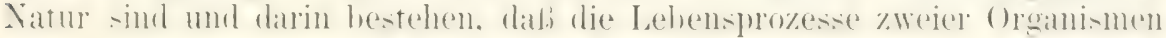

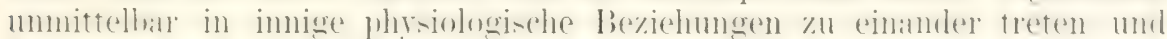
Wachstum und form bestimmen. Ich meine die Verhältnisse. die durch

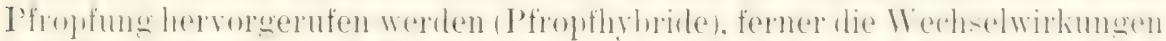

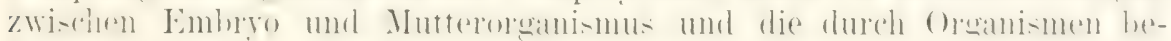
dingten Gallen und Geschwiilste.

\section{a) Pfropfung, Transplantation und Pfropfhybride.}

Am lehrreichsten und überzengendsten sind die Fïlle, in denen der Experimentator willkürlich die Art des Wachstums und der Gestaltung

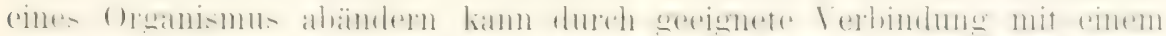

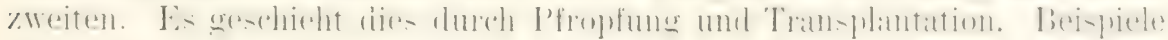
in grober Zahl liefert uns die Gïrtnerkmst.

Wenn man zwei verschiedene Pflanzenindividuen durch Pfroptung zu einer neuen Individualität verbindet, so wird das Pfropfreis in seiner

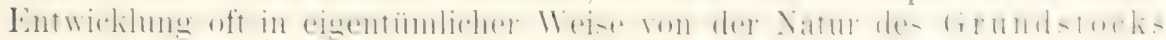
abhängig gemacht. Um zum Beispiel das Wachstum eines Baumes zu 
beschränken und ihn zu einem Zwergwuchs zu zwingen, hat man nur das Pfropfreis auf eine Unterlage einer verwandten, aber nur einen Strauch bildenden Art zu transplantieren. Ein Birnreis, welches der Gärtner auf die durch strauchartigen Wuchs ausgezeichnete Quitte als Unterlage aufpfropft, wirl infolgerlessen in seinem vegetativen Wachstum sehr stark gehemmt; es bilden sich nur kurze und schwächliche Laubsprosse. Alle die kleinen Zwergsorten von Birnen, die zu Spalieren und kleinen Pyra-

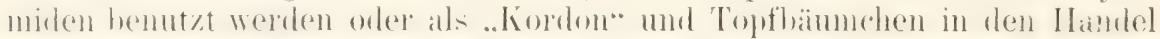
kommen, wïrden nicht rorhanden sein, wenn der Gärtner nicht eine Lnterlage wie die Quitte besäße (Vöchting). Durch die Beschränkung des vegetativen Warhstums wird gleichzeitig noch eine gesteigerte und frühzeitig eintretende Fruchtharkeit erzielt. Ännliches lehren andere kultivierte Obstsorten (Äpfel, Aprikosen usw.).

Durch die Verbindung mit einem etwas anders gearteten Organismus kamn ferner auch die Widerstandsfähigkeit des Reises gegen äuliere Einflüsse oder sogar seine Lebensdauer verändert werden. Auch hierfür zwei Beispiele.

Der Pistazienbaum (Pistazia vera), der, in Frankreich kultiviert, bei einer Temperatur von mehr als $-7.5^{\circ}$ erfriert, erträgt eine Kälte von $-12,5^{\circ}$, wenn er auf $\mathrm{P}$. terebinthus gepfropft wirl. Ferner erreicht er, ..als sämling gezogen, ein Alter ron höchstens 150 .Jahen; auf P. tere-

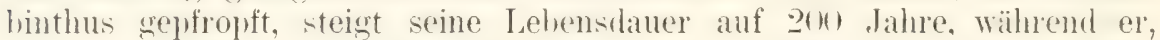
mit $P$. lentiscus als Grundstock verbunden, ungefähr 40 Jahre alt wird" (Vöchting).

Noch beweisender sind die von Vöchtivg an der Runkelrübe annestellten Experimente, weil sie schon im Laufe eines Jahres das Ergebnis liefern. Das lieis einer Rumkelrühe, dessen Kinospen noch undifferenziert sind, grestaltet sich $z u$ einem regetativen surobsstem. wenn man es mit einer jungen, noch wachsenden Wurzel verlindet: es hildet dagegen einen Blïtenstand. wemn es im Frühjahr einer alten Rühe anfgesetzt wirl". In der jungen Rübe fehlen offenbar noch gewisse, in der alten Rübe als Roservematerial ahgelagerte stoffe. welche zur Erzeugung eines Blïtenstander notwendig sind und das Reis zu einem entsprechenden Wadhstum bestimmen.

Die Summe der zahlreichen Erfahrungen, welche in der Obstbaumzucht üher die gegenseitigen lieeinflussungen von Impthing und lirundstock für verschiedene Apfelsorten gewommen worlen sind, hat LINDEx in einige wenige inhaltsreiche Sätze zusammengefald:

..Auf den sehr zwergartigen Johannesapfel (Paradies-) geimpft, bleihen dic von Natur baumartigen Sorten sehr nieslrig und fruktifizieren häutig schon in dem auf die Impfung folgenden .Jahr: anf dem splittaptel erreichen sie schon hetrïchtlichere Dimen-ionen und müssen zu mittelhohen Formen erzogen werden: die Fruchtharkeit tritt nach wenigen Jahren ein. Auf Sämlingen der ellon Sorten orler anf anderen hammartigen suezies entwicliehn sich die Impfreiser der aufgepropften, edlen. von Natur bammartigen Sorten zu kräftigen Bäumen; die Fruchtbarkeit tritt erst nach einer längeren Reihe von Jahren ein. - Die anf Johannesäpfel geptroptten Sorten hringen ihr Lehen selten ïher 15-20 .Jahre, die auf sylittäptel etwas höher, während die auf Sämlinge der hammartigen, edlen Sorten ge-

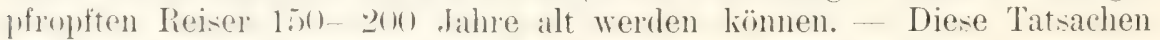
henutzt der Ohstzüchter narh Willkür für seine Zwecke."

IVie manche Forscher annehmen, andere aber stark bezweifeln. lï̈nnen die Beeintussungen, die zwischen Imptling und Grundstock stattfinden, 


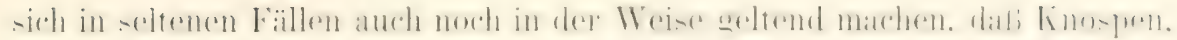
die sich an einem von beiden bilden, in ihren Spezieseigenschaften rerändert werden und Mittelformen lieferm, welehen D)ARWIN den Tamen

\section{Pfropthybride}

gegeben hat. Allerdings ist das Kapitel der Pfropfhybride oder der durch Pfropfung hervorgerufenen Knospenvariation noch ein. dunkles, da viele der in der Literatur berichteten Fälle nicht als einwandfrei gelten können oder sich in anderer Weise erklären lassen.

Als Beispiel führe ich die Übertragung der Panachüre an. Bei

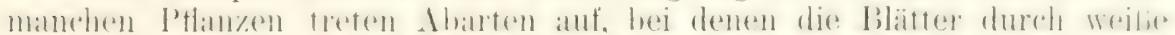

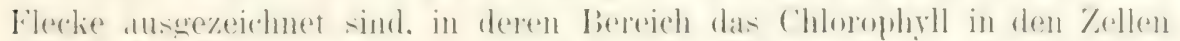

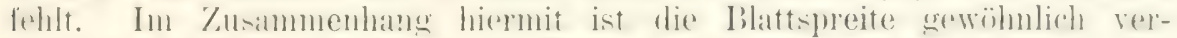

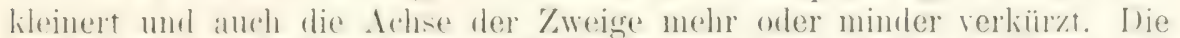

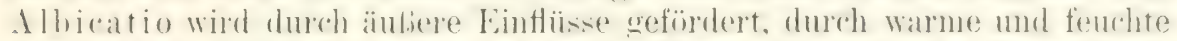

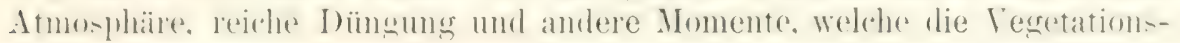
tätigkeit anregen.

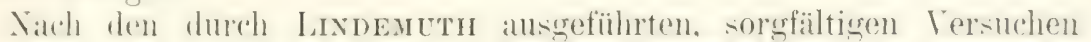
gelingt die Chertrasumg der I'anachüre dureh Pfreptumg mit sicherheit und Leichtigkeit bei Abutilon Thompsonii. Wenn man einen pana-

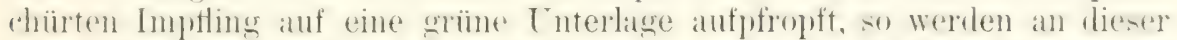
die Kinosien, welche sich unterhalh und in einiger Entfernumg von der Impfstelle später entwickeln, in ihrer Natur verändert, indem sie auch fanachürte libitter erhalten. Eine Vorbedingung für das lielingen de- Experimenter besteht nur darin, dali der Imptling entweder hei seiner lereinigung hunte bläter hesitzen obler nach derselben aus hinospen hunte Blätter hervorgebracht haben muß.

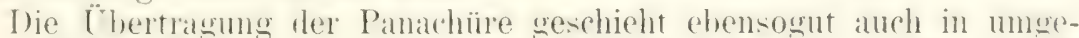
lohrter Richtung von einer panachürten Cnterlage auf einen grimen Imptling. Sie ist abhängig von der Säftebewegung. Man kann daher von rinem hereits bunthlattrig gewordenen Zweig die Panachüre durch zweck-

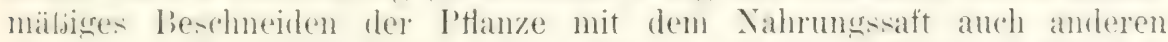
Zweigen und schlieblich der ganzen Pthanze mitteilen. Dagegen läbt sioh sine panathärbläterige Lnterlage von Abutilon nicht heeinflus-en duroh einen grönhläterigen Imptling. in der Weise. dal. sie nur Knospen mit rein grimen libittern hervorluärhte. und ehensowenig wirkt in dirsem simne din grimer Imptling auf eine panachürblätterige Unterlage ein.

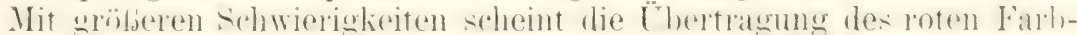

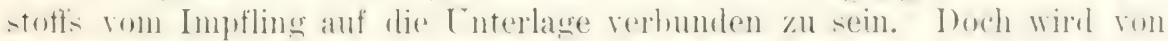

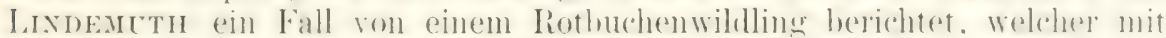

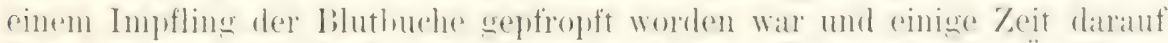

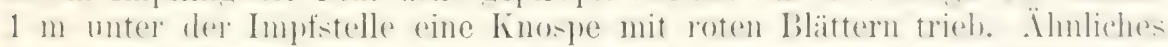

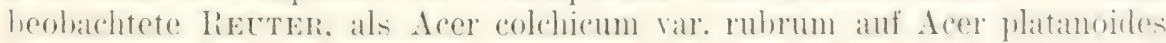
gepfropft wurde.

Auch bei verschieden gefürbten Kartoffelsorten gelingt es, durch

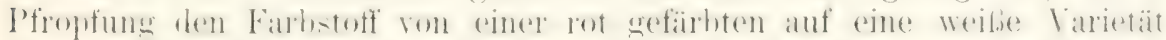

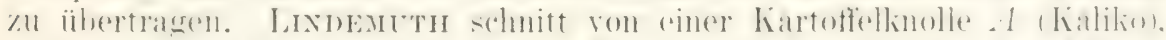

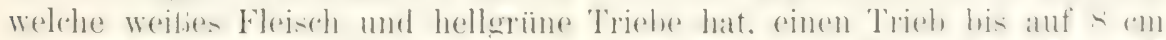

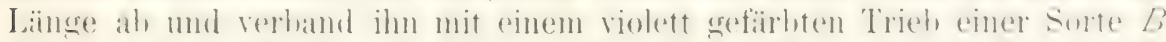

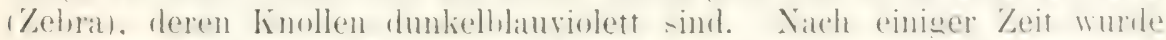

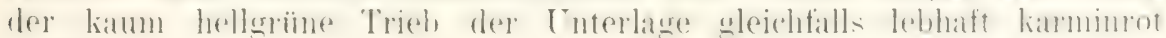
gefärbt. 
Noch merlwingliger ist der berïhmte Fall von Cytisus Adami, der in seinen Eigenschaften eine Mischung von C. laburnum und C. purpureus darstellt und über ganz Europa in vielen Exemplaren verbreitet ist, welche alle von einer gemeinsamen Mutterptlanze aus Stecklingen gezogen sind. „Fs gewährt einen überraschenden Anblick," so schreibt DARWIN, ,auf demselben Baume schmutzigrote, hellgelbe und purpurne Blüten untereinander gemischt zu sehen, welehe auf Zweigen stehen, welehe sehr von-

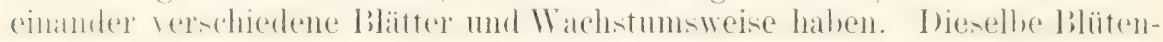
ïhre trägt zuweilen zwei Sorten von Blüten; und ich habe eine einzeine Blüte gesehen, die genau in zwei Hälften geteilt war; eine Hälfte war hellgell, und die andere purpurn, so dab die eine Hälfte des Hauptkronen-

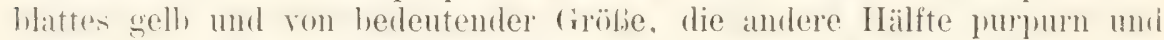
lileiner war. Bei einer anderen Blüte war die ganze liorolle hellgelh, aher genau die Hälfte des Kelches war purpurn etc.".

Cher die Entstehung des (ioldregen-Bastards gehen die Meinungen auscinander. Nach dem liericht des dï̈rners ADAM, welchen DARWLy fï̈: richtig hält, handelt es sich um einen Pfropfbastard. ADAm hatte ein Stück Rinde des Cytisus purpureus auf den Stamm des Cyt. laburnum geimpft und nach einiger Zeit aus einer an der Impfstelle entstandenen Knospe einen Zweig erhalten, welcher die oben beschriebenen, merkwürdigen Mischcharaktere zeigte. Darwix bemerkt hierzu: "Nehmen wir den liericht ADAus als richtig an, so müssen wir auch die auberordentliche Tatsache zucrehen, dab zwei distinkte Spezies sich durch ihr Zellgewebe verhinden und später eine Pflanze erzeugen können, welche Blätter und sterile Blüten trägt, die intermediär im Charakter zwischen dem Pfropfreis und dem Stamme sind, und gleichfalls Kinospen, welche einem Rückschlag gern unterliegen, kurz, eine PHanze, welche in jerler wichtigen Hinsicht einem Ibastard gleicht, der auf die gewöhnliche Weise durch Samenproduktion entstanden ist."

Die feineren Vorgänge, die bei der Pfropfung stattgefunden haben müisen, damit eine linospe mit gemischten Charakteren zustande kommen konnte, entziehen sich zurzeit unserer Kenntnis, wie denn das ganze Gebiet der Pfropfhybride noch als ein recht unklares bezeichnet werden muB.

b) Wechselwirkungen zwischen Embryo und Mutterorganismus.

Bei Tieren, deren Embryonalentwicklung sich eine Zeitlang im Innern des weiblichen Fortphanzungsapparats rollzieht, sehen wir mehr oder minder intensive Wechselwirkungen zwischen mütterlichen und kindlichen Orwanen eintreten. Sie sind um so erheblicher, je länger die Tragzeit dauert und

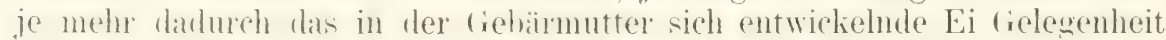
erhält, sich mit der Uterinschlemnhaut zu verbinden. Nicht nur wird wïhenu einer schwangershaft der stoffumsatz im weihlichen Körper ganz enorm gesteigert, sondern es werden auch teils in den direkt vom Reiz hetroffenen ()rounen. teils anch an weit ahgelegenen Stellen eigentümliche

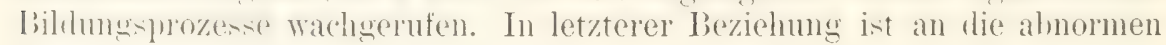
Pigmentablagerungen in der Haut zu erinnern, welche mit unter den Sichwangerschaftsmorkmalen aufgeführt werden: an die Pigmentierung der Linea alba, der Umgebung des Warzenhofes, der Chloasmata uterina, an die Entwicklung der Brüste. an das corpus luteum verum usw. Lnter dem Reiz, der vom Ei auf seine Umgebung direkt ausgeübt wird, verändert

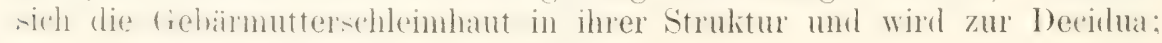


die Muskinlatur vermehrt sich betriehtlich, die Arteriae uterinae verorobliern sich. Eigentïnliche, zur Placenta materna führende Verändermenen entstehen an rler Stelle. wo das Chorion in Zotten auswächst, die sich in rlie Decillua einsenken.

Wir haben es in allen diesen V'orgängen mit direkt durch organische Reize bewirliten Anpassungserscheinungen zu tum. Denn durchaus analoge Veränderumen stellen sich ein. wemn das Li anstatt an normaler Stelle in der fiehamutterhöhle schon in dem Eileiter sich festsetzt orler. wenn es durch irgend einen Umstand in der Bauchhöhle zurickgehalten, zu einer

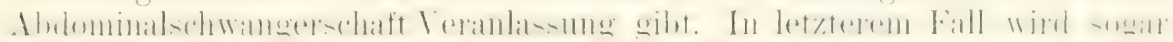
das in seiner Struktur yon der Schlemhaut der (iebärmutter so grundverschiedene Bauchfell zu einer Art Placenta materna umgewandelt.

Wie das Ei auf den mütterlichen Organismus, so wirkt andererseits anch wieder die Gebärmutterschleimhant auf das sich entwickelnde Ei als

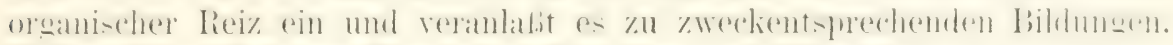

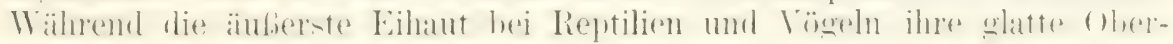
Häche nie verliert und als Serosa bezeichnet wird, paft sie sich bei den siangetieren der ihr dicht anliegenden Decidua an, vereribliert durch \%ottenbildung ihre Oberfläche und wird zum Chorion.

Anch bei vielen Pflanzen lommen analoge Werbelwirkmaen zwishen Nutterpthanze und dem Fi vor. wenn es reme ersten Entwicklung-starlien. wie hei den Phanerogamen, im Fruchtlonoten durchläuft. Fs findet damn zwischen dem sich entwickelnden Embryo und den umgelusulen miiterlichen fiewehen eine lehhafte Wachstumskorelation statt. ähulich wie hei der Placentabilılung trächtiger Sängetiere. Während Bhäten, lèi weldhen die Befruchtung unterhlieben ist. nicht weiter wachsen. welk werden und abfallen, ruft der durch rlie Iefruchtumg im Ei angeregte Entwicklungsurozeli zugleich auch ein oft ganz energisches Wachstum des Fruchtinotens. eine eigentïmliche Lmbiliung seiner Zellen, mit einem Wort die Entstehung der verschiedensten Formen von Frïchten hervor.

Ja zuweilen dehnen sich die durch Befruchtung hervorwerufenen Veränderungen noch über den Fruchtknoten hinaus auf die angrenzenden Pflanzenorgane aus und ziehen sie ebenfalls in die Frucht-

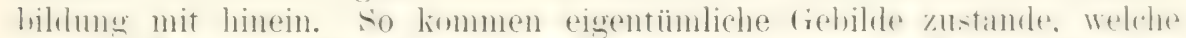

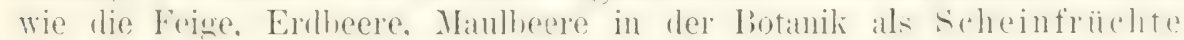
bezeichnet werden.

c) Organismen als Ursachen von Gallen und krankhaften (ieschwïlsten.

In dlas Kapitel der organischen Einwirkungen gehören endlich auch

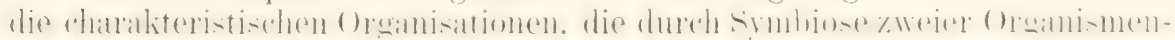
arten oder durch parasitäre Vereinigumg oder durch anderweite Einwirkungen eines Organismus auf einen anderen zustande kommen.

Fül die Entstehung besonderer Lebewesen mit ganz spezitischen Art-

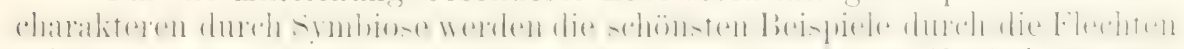

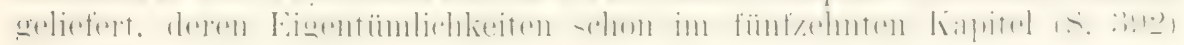
eingehender besprochen wurden.

Es genügt daher, auf das dort bereits Gesagte zu verweisen. Dagegen sei hier noch etwas näher aut die Bildungen eingegangen. die sich am Körper von Pthanzen und Tieren als etwas ihn Fremdartiges unter dem Einthu anderer Organismen entwickeln liönnen. wie die crallen vieler Ptlanzenarten oder die krankhaften Geschwïlste vieler 'Tiere. 
Manche Insekten, wie die Gallwespen, stechen junge Pflanzenblätter an und legen ihre kleinen Eier in das Gewebe ab. Unter den abnormen

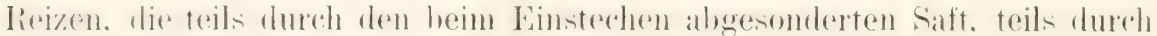
die Entwicklung der Eier zu Larven ausgeübt werden, treten lebhafte

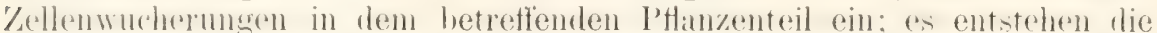
allheliannten fiallen, ()rane, die eine wanz charakteristische. komplizierte Struktur, besondere Zellenformen, Gefäße etc. und ebenso eine ganz bestimmte äußere Form erhalten. „Es ist, als ob die Galle", wie SAcHs sich ausdrückt, „ein Organismus sui generis wäre." Und diese Organe fallen wieder sehr verschiedenartig aus, je nach dem spezifischen Reiz, der sie hervorgerufen hat, und je nach der spezifischen substanz, welche auf den spezitischen lieiz dureh (iallenbildung reagient hat. Daher entstehen auf derselben P'Hanze durch verschiedene Insekten ganz verschiedlene Gallen. und nicht minder lassen sich die Gallen verschiedener Pflanzen voneinander systematisch auf das strengste unterscheiden.

Auber den fiallen kömmen als pathologische Organisationen im P'Hanzenreich noch mancherlei (iebilde aufgefïhrt werten: so die durch c'hermes riridis an den Rottamen erzeugten tannenzapfenähnlichen Wucherungen. ferner die monströsen Blütenentwicklungen, sogenannte Vergrünumgen von Arabisarten, die man auch kiunstlich dadurch hervorrufen kann, dab man Biattlänse bestimmter suezis auf die noch jungen Infloreszenzen setzt etc. (SACHS, S. 652).

Den Gallen vergleichbar sind bei 'Tieren die krankhaften Geschwälste, welche durch fremde Mikroorganismen hei ihrer Ansiedelung im tierischen Gewebe erzeugt werden. Auch diese Geschwülste erhalten je nach der Art des angesiedelten Mikroorganismus und des befallenen Tieres ihr hesmoleres (iepräge, durch welches sie als eigenatige, spezifische Geschwulstindividuen zu unterscheiden sind.

Tuberkelbazillen erzeugen im Gewebe des Menschen den Miliartuberkel, der einen charakteristischen Bau und eine ihm eigentümliche Entwiklungsgeschichte hesitzt. Siarkosporidien rufen in der speiseröhre des Rindes Geschwülste mit einem fächerförmigen Bau hervor. Myxosporidien sind die Lrsache ron Muskelgeschwälsten, die im Fleisch mancher Fische anftreten.

Ob Sarkome und Karzinome des Menschen ebenfalls derartige Organisationen sind, die durch uns noch umbekannte organische Reize hervorgerufen werden, ist noch nicht bewiesen, aber nicht unmöglich.

\section{Literatur zu Kapitel XXI.}

Abschnitt: Licht.

1) Fischel, Über Becinfussung und Entreicklung des Piomentes. Archiz f. mikroskop. Anat., Bir. XLTIT.

2) Flemming, Über den Emfluß des Lichtes auf die Pigmentienmg der Salamanderlarie'. Archar f. mikroskon. Anat., Bd. XLITII. S. 360 w. S. 600.

3) Goebel, K., Über die Einzerkung des Lichtes auf die Gestaltung der Käkteen und anderer Pflansen. Flora, Bid. LXXY. I895.

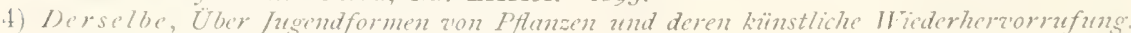
Sitamersber. d. math.-physit. Klasse d. Kol. bayer. Akad. d. Wrissensch., Bd. XXT\%, Heft 3. 1806

5) Keller, Biolovische Studien. Biol. Zentralbl., Bd. XTII., Nr. 3. 1897.

(i) Derselbe, Fortschritte me dem Gebiete der Pfansenpluysiologie. Biol. Kentralbl., Bd. XIII. I803. 


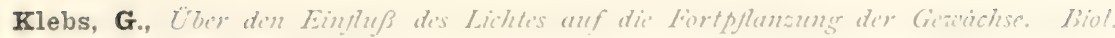
Yintralbl., bit. W/11. 1803.

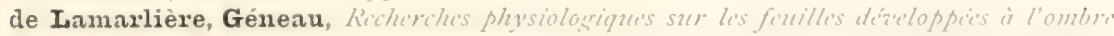

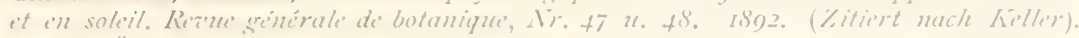

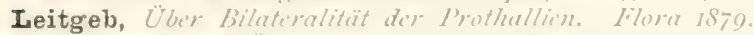

1. Loeb, Jacques, Über den Einthe des Lichtes anef die Organbildung bei Jiem,

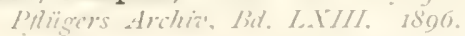

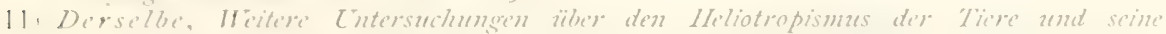

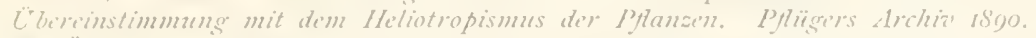

1.- Pick, Über den Einfluß des Lichtes auf die Gestalt und Orientumng der Kellen dex Assimilationssentebes, Bot. Zentrabl., Bad. LA. 1882.

1:i, Sachs, Torlesmingen äber. Pflanzenpleviologie, Lixp. XXXT, S. 620-655. 1882.

11) Stahl, E., Ube' den Einfuß der Lichtintensitiot auf Struktur wnd Anordnung ders

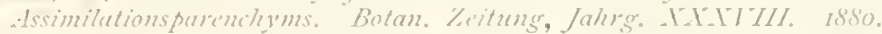

1.it Derselbe, Lber den Einthe des somigen oder" schattigen Standortes anf die Ausbildung der Lanbbläter. Fenaische Zeitschrift f. Watura'ssensch., Ba. XYT. 1883.

Iti vöchting, ¿ber die Beatentung des Lichtes für die Gestaltung bluttförmiger haktecn.

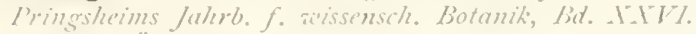

17. Derselbe, Ubir den Einflup des Lichtes anf dir Gestaltumg und Anlage der IBhaten. Elende, Bit. XXl: Lierlin 18903 .

\section{Alschnitt: 'T'emperatur.}

Dareste, Recherches expirimuntales sur la production artificicle des monstruosités, $\therefore$ Aut?. Paris ISOI.

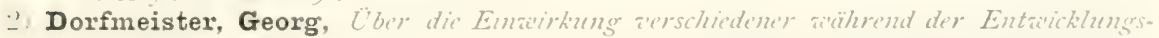

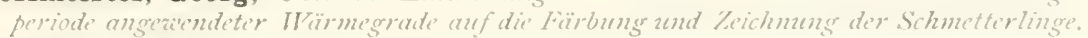
Mitteil. d. naturat. Tereins f. Steiermark. 1864 .

:A Derselbe, Uber den Einflup der Timperatur bei der Eraenguns der Silumetterlingsínrietäten alitteil. a. naturai. léreins f. Steiermark 1879 und Fricaländer u. Solun. $18 s_{0} 0$.

1) Eimex, Due Entstehune der Arten auf Grund ion Verrben cratorbener Eigensehaften nach den Gesetzen organischen Machsens. Jena 1888.

Fischer, E., Transmulation der Schmettelinge infolge von Temperaturinderungen. Experimentelle Tntersuchungen über die Phylogenese der Vanessen. Berlin I805.

(i) Derselbe, Experimentille Lntersuchungen äber die liverbung erriorbener Eigenschaften. Allgemeine Zeitschrift f. Entomologie, Bat. IT. 1901.

Dersilbe, Weitere Untersuchunsen zuber die Vererbung cravorber Eigenschaften. Ebinat, Bit. III. 1902.

Dersilbe, Lepidopterologische Experimentalforschunsen (I-III). Allgemeine Zieitschrift $f$. Entomologic.

!Hertwig, Oskar, Über den Einfuß der Temperatur anf die Entwicklung ron Rana fusca und Runa isculenta. Archio f, mikrosk. Anat., Bit. LI. ISos.

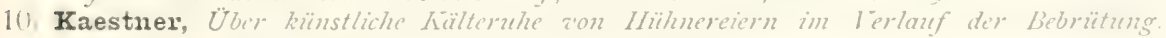
Arihit f. Anat. und Phisiol., anat. Abt. 1895.

11 Maupas, Sur le déterminisme de la serualité cher l'hudutina senta. Comptes rendus de's séances de l'académile de's scrince's. Paris 1801 .

1.) Merrifield, The colouring of Chrysophanus Phlaias as affected by temperature. The' Entomologist. Deamber IS92 i. 1803.

1:; NuBbaum, Die Entstehung des Geschlechte's bei Mydatina senta. Archie f. mikrosk. Anat, But. NLILI. $189 \div$ \%.

14. Pfeffer, Iflanzenplysinlogie. Einfluß der Timperatur, I. Aull., Iit. II, S. I22. $198 \%$

1.. Sachs, Julius, Phrsiolorische Untersuchungen ïber die Abhängigkeit der Keimmens zon der liemperatur. Jahrb. f. wissensch. Botanik, Lid. II. 1800.

lit Standfuß, M., Zur Frage der Gestaltung und leverbung anf Gromet 28 jührivery Experimente. Fortras in der Käricher naturf. Gesellsch.. Ziulich 1005.

1. Derselbe, Ilandbuch der paläarktischen Grepschmetterlinge, 2. Anth. Jena ISe0.

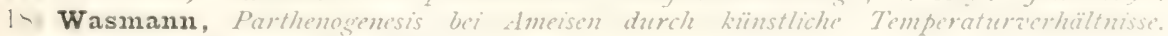
Bivlos. Zentralbl., Did. HT. 1807 .

1:1. Weismann, Aug., Studien zur Descendenatheorie. Über den Saisondimorphismzus der Schmetterlinge. Lerpaig 1875 .

Ahschitte: Chemische lieize und lieize zusammengesetzter Art.

1. Bateson, On some rariations of Cardium cdule apparently connected to the comitions of life. Philosoph. Transections isoo. 
2) Born, Experimentelle Untersuchungen lïber die Entstehung der Geschlechtsunterschiede.

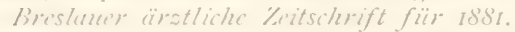

3) Costa, Bullet. de la soc. d'acclimat., tom. WI/I. pas. 351. Yiticrt nach Darwin.

4) Darwin, Ch., Das Inrieren der Yiere und Pflanien im Zustande der Domestikation. fit. II, Liap. 23, S. 310. 1873.

5) Emexy, Die Entstchung und Ansbildung des Arbeiterstandes bei den Aneison. Biolog. Kintiulbl., Bit. H/Y. 1807.

(i) Gies, Experimentelle Untersuchungen äber dcn Eimfluß des Arsens anf den Orgunismus. Archia f. experim. Path. "T. Therapie, Jid. VIII. 1878.

i) Gurwitsch, Uber die formatiz'e Whrkung des reränderten chemischen Jedinems anf die embryonale Entaicklung. Wersuche am Frosch-und kiötonci. Archiz f. Entaicklungsmechanik d. Organismen, Bid. III. 1896.

S) Hexbst, Experimentelle Untorsuchungen ïber den Einfluß acr veränderten chemischen Zusammensetzung des umgebenden Mediums anf die Entwicklung der Tiere. Ilitieil. ants ater Zool. Station zu Veapel, Bd. XI.

9) Derselbe, Über die sur Entwicklung der Seeigellarven notwendigen anorganischen Stoffe, ihre Rolle und ithe Vertritbarkeit. Archiá $f$. Entaicklungsmechanik, fid. $V$. 1897.

10) Hertwig, Oskar, Beitrüge aur experimentellen Horphologie und Entraicklungsseschichte. Die Entwicklung des Froscheies unter dem Einflüs schä̈cherer und stärkerer Lochsalilösmng. Archio f. mikrosk. Anat., Bd. XLII. 1895.

11) Derselbe, Experimentelle Eraeugung tierischer Hißbilanngen. Festschrift fïr Farl Gegenbaur. Leipaig 1896.

12) Kassowitz, Die Phosphorbehandhung der Rachitis. Zeitschrift für klinische Medizin, Bd. VII. I887.

13) Keller, Robert, Über aie Anpassungsfähigkeit phaneroganischer Landpflansen an das Leben im II asser. Biol. Lentralbl., Bd. XIYll. 1897.

14) Knop, w., Über cine merkwïrdige Ungestaltung der Infloreszenz der Maispflanze bei künstlicher Ernährung. Berichte über d. Verhandl. d. Kg gl. sächs. Gesellsch. d. Wissensch. zu Leipzig, math.phys, Klasse, Bd. XXX. 1878 .

15) Koch, Gabriel, Die indo-australische Lepidopterenfaund, 2. Auft. Berlin 1873.

16) Lesage, Influence du bord de la mer sur structure des feuilles. Thèse de Paris 1890.

17) Loeb, Untersuchungen aur physiologischen Morphologie der Tiere. II. Organbildung and Hachstum. Wiurzburg 1892.

18) Morgan, The orientation of the frog's egg. Quarterly Joumal of microscop. science, Vol. XXXV, Nr. 5. 1894.

19) Noll, Über den Einfluß der Lage anf die morphologische Ausbildung einiger Siphoneen. Arbeiten d. bot. Inst. in Hüraburg, Bd. III. I888.

20) NnBbaum, Die Entstehung des Geschlechtes bei Hydatina senta. Archiz f. mikrosk. Anat., Bid. XLLX. 1897 .

21) Ponchet und Chabry, L'eau de mer artificielle comme agent tératogénique. Journ. de l'Anat. et de lo Physiol. de Robin et Pouchet, p. 298-307. 1889.

22) Sachs, Phy'siologische Votizen, VIII. Mechanomorphosen u. Phylogenie. Flore I89t.

23) Schmankewitsch, Über das Verhältnis der Artemia salina zur Artemia Mühlhansenia und dem Genus Branchipus. Zeitschr. f. wissensch. Zool., Bd. XXV, Suppl.-Bd.

24) Schulze, Eilhard Fr., Epithel und Drïsenzollen. Archio f. mikrosk. Anat., Bd. III. 1867.

25) Spencer, A rejoinder to Professor Weismann. Contemporary revieve. 1893.

26) Wallace, A. R., Travels on the Amazon and the Rio Negro, p. 29f. Zitiert nach Dartoin.

27) Wegner, Der Einfluß des Phosphors auf den Organismus. Virchou's Arch., Bit. LV. 1872.

2S) Ziegler und Obolonsky, Experimentelle Untersuchungen über die Wirkung des Arseniks und des Phosphors anf Leber und Vieren. Beitr. z. pathol. Anat. q'an Ziegler, fid. II. ISS8.

Ahschnit: Organische Reize.

1) Darwin, Charles, Das Variteren der Tïre und Pfanaen im Zustonde der Domestikation, Bd. I, Kap. II, S. AI7; Bd. II, S. 322-326.

2) Focke, Die Pflanzcmmisithlinge, S. 510. Berlin 1881 .

3) Hildebrand, Einige Experimente und Bcobachtungen i) n̈ber den Einfuß der Conterlage anf das Pfropfreis und 2) z̈ber den direkten Einfluß des fremden Pollens auf dic Beschaffenheit der durch ihn ersengten Frucht. Bot. Zeitg. I868, S. 321.

1) Lindemuth, Uber vegetertice Bustarderiengung durch Impfung. Landairtschaft. Jahrbiacher, Bd. Fll. 1878 .

5. Sachs, Jul., Vorlesungen ïber Pflanzenphysiologie, S. 652. ISS2. 


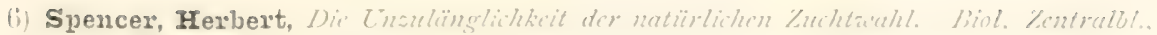

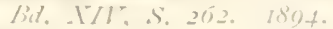

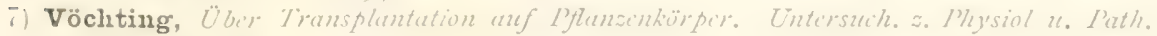
Tïbine? Is 2 2.

8) de Vries, Hugo, Intrazellulare Panginesis. Jina. Iss'o.

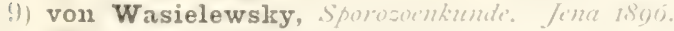

1(1) Weismanm, Dis Keimplismu. Kap. I2. Kairifelhafle Vererbungserschuinungen. Jent $\left.1 s^{\circ}\right) 2$.

Es sei ferner noch anf folerende schriften allgemeineren Inhalts üher die Wirksimkeit indierer laktoren der lintwicklung verwiesen.

1) Darwin, Dit Entstehung der Atten.

2) Derselbe, Ders Varieren der Tiere und Pfanzen.

3) Driesch, Inalutische Theoric der orgernischen Entwicklung. Leipzig 1804.

4) Haeckel, ciencrelle llorphologie der Organismen. 1860.

5) Herbst, ïber die bedentung der keisphysiologie für die kausale Auffassuns von Vorecinsen ind der tirrieschen Ontogenese. Biol. Zentralbl., Bat. IIV; 1807. Bid. Xl: 1805. Daselbst auch ansführliches Literaturzerzcichnis, anch ron einzelnen hicr nicht anf gefülurten Schriften.

(i) Iamarck, Zoologische Philosophie. L̈bersetat z'on 4. Lang. IS76.

7) Roux, Gesammelte Abrandlungen, Bi. I. Fanktionelle Anpassung.

S) Sschs, Vorlesungen über Pflansenphysiologie. 1882 .

()) Derselbe, Stoff und Form der Pfiknzenorgane. Mechanomorphosen und Phylogenic. Filora, Ba. L.T.VIII. $189+$.

10) Spencer, Herb., Prinzipicn der Biologie, Bid. I u. II, I876, 1877. 


\section{ZWEIUNDZWANZIGSTES KAPITEL.}

\section{Die Theorie der Biogenesis.}

\section{Die inneren Faktoren der organischen Entwicklnng.}

Wie der Organismus in einer Beziehung von unzähligen äuGeren Falitoren abhängig ist. welche erhaltend oler vernichtend, heschleunigend oler hemmend, fördernd oder schädigend in den Lebensprozef eingreifen. die \%ellen, die fiewelse und organe modifizierend und umgestaltend. so hängt in anderer beziehung sein liestand im ganzen, ferner die Funktion und (iestaltume jedes einzelnen T'eiles von nicht minder zahlreichen in neren Faktoren ab.

Wie schon im neunzehnten Kapitel auseinandergesetzt wurde, zerfallen die imneren Faktoren der Entwicklung in zwei Gruppen. Die eine (irupue bilien die Eigenschatten und Anlagen der (ieschlechtszellen und ihrer 1 hä̈mmlinge selhst (die inneren Haktoren im engsten sinne), in der zweiten fruple digegen fasien wir die zahllosen und verschiedenartigsten WTechselwirkungen zusammen, welche die Zellen, Gewebe und Organe eines Organismus gemäb ihrer Beziehungen aufeinander ausüben.

Hit der zweiten Gruppe, den inneren Faktoren im weiteren Sinne, wollen wir uns jetzt zunächst beschäftigen. Sie sind besonder's für das Verständnis der tierischen Formbildung von der allergrößten Bedentung. Denn bei den Tieren ist die physiologische Arbeitsteilung und die als Ergänung zu ihr sich ausbildende Integration (siehe S. 414 u. 419) in ungleich größerem Maße durchgeführt als bei den Pflanzen. Während bei diesen die Wirksamkeit der äuberen Faktoren klarer hervortritt. sind die Tiere für das Studium der inneren Faktoren die geeignetsten Objekte.

Die Wechselwirkungen (Korrelationen) zwischen den Zellen eines Organismus und ihren Derivaten bilden sich mit dem Beginn des Entwidilungsumesses aus, ändern sich von stufe zu stufe und lomplizieren sich in demselben Malie, als die Entwicklung fortschreitet. Ihre Besprechung geschieht daher am besten in zwei Abschnitten. Der erste wird von den Kiorrelationen des sich entwickelnden, der zweite Alschnitt ron den Korrelationen des ausgebildeten Organismus handeln.

\section{A. Die Korrelationen der Zellen während der Anfangsstadien des Entwicklungsprozesses.}

Im Gegensatz zur Mosaiktheorie von Roux und der Keimplasmatheorie von WEIsmann stellt die Theorie der Biogenesis den Crundsatz auf. dafo vom ersten Beginn der Entwicklung an die durch 
Teilung des Eies sich bildenden Zellen bestindig in engster I'eziehung zu einander stehen und dab dadurch die Gestaltung des Entwicklungsprozesses sehr wesentlich mit bestimmt wird. Die Zellen determinieren sich zu ihrel späteren Ligenart nicht selhst, sondern werden nach (iesetzen. die sich aus dem Zusammenwirken aller Zellen auf den jeweiligen Entwicklungsstufen des (iesamtorganismus ergeben, determiniert. Allerdings sind die Wirkungen, welche yon einer Zelle auf die Nachbarzellen oder umgelehrt rom Ganzen auf die einzelnen Kellen ausgeübt werden. fïr uns nicht unmittelbar wahrnehmbar: dafo aber solehe stattfinden miissen.

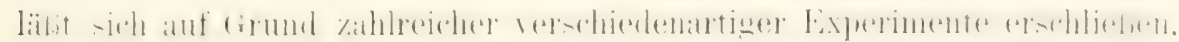
durch welche in den letzten , Jahren unsere Einsicht in das Wesen des

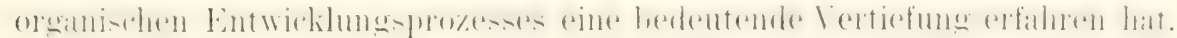

Dab schon die beiden ersten Teilhälften, in welche das Ei durch den Furchungsprozeß zerlegt wird, in Korrelation zu einander treten, aufeinander einwirken und sich in ihrer Entwicklung bedingen, läbt sich in einfacher Weise feststellen. wenn man ihre beziehungen zu einander entweder ganz aufhebt oder wenigstens in eingreifender Art stört und ver-

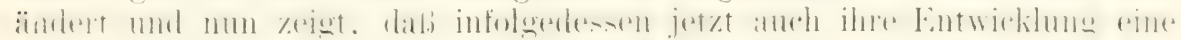
andere als unter den normalen Verhältnissen wird.

Fiv. 335), Normale und Teilgastrulae vou Amplioxus. Nith Wricox. 1 Aus dem ganzen Ei, I3 aus einex einzigen, kïnsilich isolierten Zelle des zweigeteilten, $C$ des viergeteilten, $D$ des achtgeteilten Eies gezïchtete (iastrula.

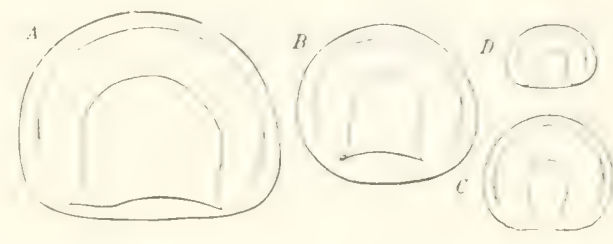

Driesch hat zuerst eine Reihe derartiger höchst wichtiger Experi-

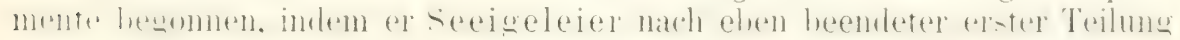
schïttelte. In vielen Fällen gelang es ihm hierdurch, die Eihülle zu sprengen, die beiden Teilstücke zu isolieren und sie dadurch zu zwingen. sich getremnt roneinander weiter zu entwickeln. Und siehe da! aus jeder Teilhälfte entstand jetzt nicht ein monströses Stïck eines Embryos. sondern der Teil war durch die Trennung selbst wieder zu einem Ganzen geworden: er rundete sich mehr ab, furchte sich weiter, wandelte sich damn in eine geschlossene Keimblase um: aus dieser entstand eine Darmlarve (Gastrula) und schlieflich ein Plutens. DRIEsch hatte somit ans

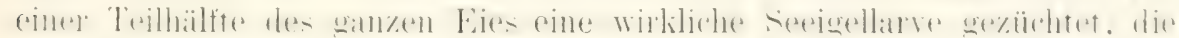
ron den gewöhnlichen Larven nu! durch eine geringere Gröbe untelschieden ist, da sie ja nu aus der Hälfte des Materials hervorgegangen war.

Die von Driescin geübte Methode versuchte damn der amerikanische Forscher Wilsox mit glänzendem Erfolg beim Amplioxus, einem Tiere. das für uns in dieser Frage besonderen Wert besitzt. weil es schon hoch

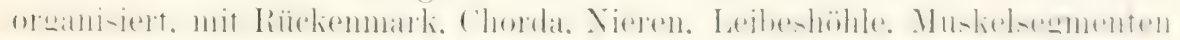
etc. ausgerüstet ist und seinem ganzen liau nach zum Stamme der Wirheltiere hinzugerechnet werden muß. Durch Schütteln trennte er hei einzelnen Eiern, die sich anf dem Stadium der Zweiteilung befanden. die einzelnen Furchungszellen voneinander und züchtete sie isoliert weiter. Auch bei seinen Tersuchen (Fig. :335) entwickelten sich aus den Teilstücken normale Keimblasen. aus diesen wieder Gastrulae. die nur die

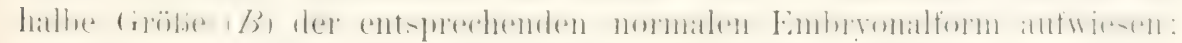
es lieben sich sogar ältere Embryonen mit Chorda, Nerrenrohr und ['rsegmenten heranziichten. 
Ähnliche Experimente sind seitdem mit gleichem Erfolg noch bei anderen 'T'ieren ausceführt worden, hei Cölenteraten (ZoJA), bei Aszidien (Fig. 390 11. 3937 , Cmabry, Driesch, Crampton), bei Amphibien (Hertwig, Herlitzika, Morgan, Spearand) ete.

Die bei Ascidiella aspersa gewomnenen Ergebnisse veranschaulichen die Fig. $3: 36$ und $3: 37$. In Fig. 33961 ist die durch Anstich zerstörte Hälfte $(G)$ des Zweiteilungsstadiums geromnen, wälurend die unverletzt geblichene Hälfte $D$ weiter lebt, sich nach einiger Zeit teilt (Fig. $330, B$ ) mud sich bald in eine normale typische Gastrula $(C)$ umwandelt. Die Gastrula läbt sich sogar noch zu einer Larve (Fig. 337) weiter züchten, welche Chorda, Nervenrohr, Otolith, Papillen zum Anheften, Anlage des Atriums entwickelt zeigt.

Besondere Erwähmung verdienen auch die Experimente von HERI.TzkA wegen des hei ihmen angewanden, eigenartigen Verfahrens. Welohes ich zuerst versucht hatte, aber wegen der Schwierigkeit der Ausführung ohne Erreichung des beabsichtigten Erfolges aufgeben mußte.

Fig. 336.

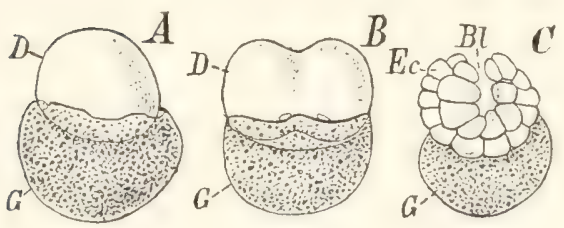

Fig. $33 \bar{r}$.

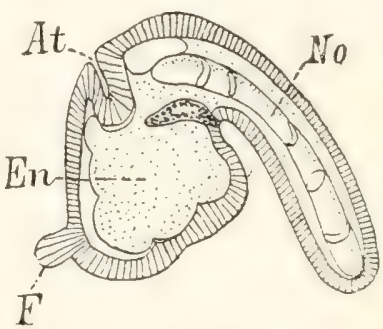

Fị. 336 . Ei von Ascidiella aspersa, bei welchem eine Teilhälfte durch Anstich mit einer Glasnadel zerstört ist. Narh CHAnRY. A liald nach Z wrstuing der einen Teilhälfte gezeichnet. $\boldsymbol{B}$ Die crhaltene Eihälfte im Stadium der Zweiteilung vom oberen P'ol gesehen, wie es die Richtungskörperchen lehren. $C$ Die überlebende Eihälfte auf dem Gastrulastadium. Bl Blastoporus; $E_{c}$ Ektoderm; $G$ zerstörte, $D$ üherlebende Eihälfte.

Hig. 337. Larve von Ascidiella aspersa, von halber Größe, entwickelt aus einem halben Ei, da auf dem Stadium der Vierteilung zwei Viertelzellen durch Anstich zerstört wurden. Die Larve zeigt den Schwanz mit entwickelter Chorda und den Beginn der Einstïlpung eines Atriums. Nach CHABry. At Atrium; En Entoderm; $F$ l'apille zum Anheften; No Chorda.

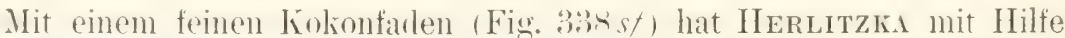
eines zu dem Zwecke von ihm erfundenen Instrumentes das zweigeteilte Tritonei in der Teilungsebene durchgeschnürt und in einer Reihe von Fällen die heilen ersten Furhungsingehn vollständig ronemander i-oliert. Eine jerle entwiolelte sich innerhalh der gemeinsamen tiallerthïlle des Eies zu einem ganzen Embryo von halber Größe.

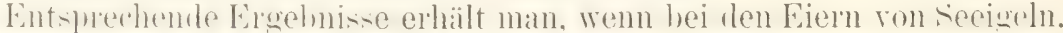
('i)lenteraten mul hesonders som Imphioxus nach dem zweiten Teilstalium die vier, oder nach dem dritten Teilstadium die acht Furchungskugen voneinander durch Sehütteln getrennt und isoliert fortgezüchtet werden. Es gelingt nicht selten, aus den Bruchteilen, die nur $1 / 4$ oder $1 /$ des $^{2}$

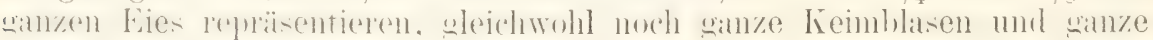
Gastrulae zu gewinnen, die allerdings dann nur $1 / 4$ oder $1 / \mathrm{s}$ so grob als das normale Entwicklungsprodukt sind (Fig. $335 C$ und $D$ ).

Alle diese Versuche lehren in unzweidentiger Weise, daf ron den zwei, vier oder acht ersten Teilstücken eines Eies ein jedes sich in seinem 
Entwicklungsvermögen sehr verschieden verhält, je nachdem es sich mit den anderen Zellen in normaler Weise zu einem (sanzen verhunden in Korrelation oder getrennt rom Ganzen für sich allein entwickelt. In ersteren Falle wird es in seiner Entwicklung vom famzen aus. dessen Teil es ist, durch die Korrelation zu anderen 'Teilen in seinen Sehicksalen bestimmt und trägt nur zur bildung eines halben (1esp). vierten und achten) 'Teiles des embryonalen Körpers bei, im anderen lall erzengt es aus sich allein das vanze, weil es von Haus aus die Anlage dazu in sich trägt mul weil es nach Abtremung yon den anderen ihm artgleichen Teilen selbst wieder ein Ganzes geworden ist. I'on den ersten Furchungszellen ist also eine jede ihrem imneren Wesen nach gewissermaßen 'Teil und Ganzes zugleich und kann je nach den Umständen bald in dieser, bald in

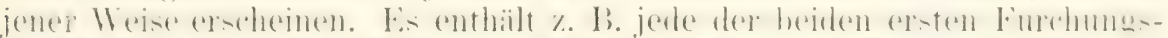

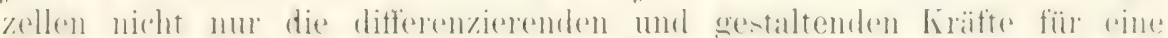

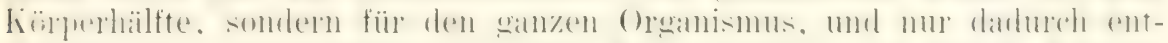

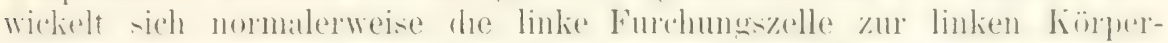
hïlfte. dal.i sie zu einer rechten Furchumgszelle in beziehumg gexotzt int.

Fig. 338. Ein Ei von Triton cristatus, bei welchen auf dem $/ /$ weiteilungsstadium die zwei Zellen durch Umschnürung mit einem Seidenfaden getrennt wurden und sich infolgedessen zu zwei selbstädigen Embryonen entwickelten. Kurze Zeit vor dem Ausschliupfen der zwei aus einem Ei entstaudenen Embryonen. Nach HFrLitzkA.

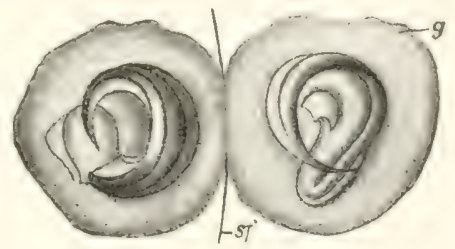

In einem Widerspruch mit unserer 'These sollen nach der Ansicht einiger Forscher Ergebnisse stehen, die am Ei von Ctenophoren gewomnen wurlen: sif rerdienen daher auch noch herïcksichtigt zu werien.

Nach Experimenten, welche zuerst von CHUN, dam von Driesch mal Morgax mol nenerdings wieder von Fischel angestellt worlen sind. kann man das große. sehr dotterreiche Ei von Beroë ovata, nach der \%wei-. Vier- obler Achteilung odler auf einem noch späteren stadium in dieser oder jener Weise in zwei oder vier Stücke zerlegen, welche sich unabhängig voneinander zu Larven weiter züchten lassen.

Fischel, der letzte Untersucher des Ctenophoreneies, hat in der

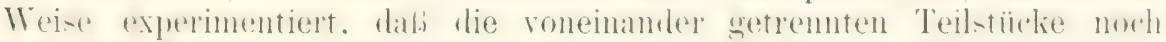

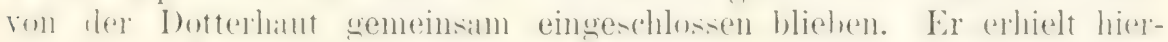
durch den Vorteil. die von einem Ei abstammenden Iarven mitemander vergleichen zu können. So sind in Fig. 339 in der Dotterhaut vier kleine

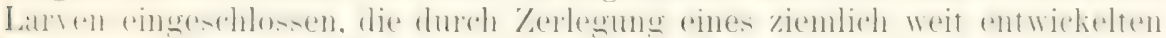
Eies, in welchem die Makromeren von den Mikromeren schon umwachsen waren. gezüchtet worden sind.

Wie in dem vorliegenden Beispiel, zeigen num überhaupt die durch Teilung eines Beroëeies entwickelten Larven das Eigentümliche. dal. am Anfang die Anzahl ihrer Riplen stets unter der Normalzahl ,acht' bleibt, welche für die Ctenophoren typisch ist. Erst alle aus

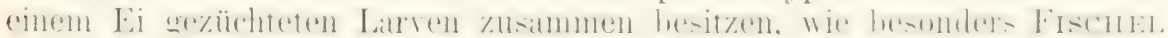
betont, acht Rippen von Flimmerplättchen und ergänzen sich in dieser Beziehung. So hat ron den vier Larven unserer Figur eine drei, zwei zwei und die kleinste nur eine Rippe entwiclielt, was in Summa erst die

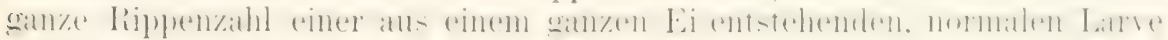
ergibt. 
Man hat aus solchen Befunden die unserer 'These entgegengesetzte Ansicht zu stützen gesucht, daß jedes Teilstïck des Ctenophoreneies infolge des Furchungsprozesses fuir eine besondere Aufgabe im weiteren

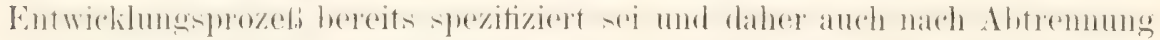
vom Ganzen zunächst nicht mehr aus sich das Ganze, sondern nur einen bestimmten 'Teil erzengen könne. Indessen lassen sich die scheinbar abweichenden, eigenartigen Verhältnisse sehr wohl mit unserer oben aufgestellten These verembaren. Drei Punkte sind hierbei zu berücksichtigen.

Erstens zeigt das sehr große, dotterreiche Ei von Beroë einen besonders geateten liau, indem grolie Deutoplasmaliugeh, von feinen plasmatischen Scheidewïnden getrennt, die zentrale Iamptmasse bilden, welche nur an der (Bhertläche von einer dickeren I'lasmarmole eingeschlonsen ist. Bei der 'Trenumg des zwei- oder vier- oder mehrgeteilten Eies erhält man daher Teilstïcke, bei welchen die ganze Tremnumstläche anberortentlich arm an Protoplasma ist und dadurch in einem Gegensatz zur konvexen, ursuringlichen (Oberfläche steht. Da auberdem das Dentoplasma auch noch fast das gleiche spezifische Gewicht wie das Meerwasser hat - denn

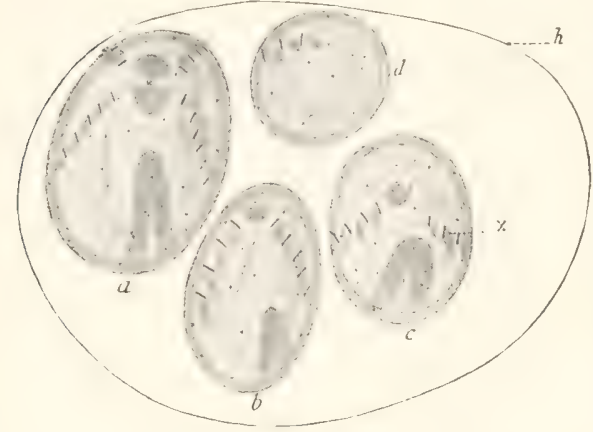

Hig. 339. Vier Larven $a b c d$, die ans einem Ei von Beroë ovata durch Zerlegung desselben in vier Stïcke gezüchtet sind. Nach Fisches. h Eihülle; $x$ Flimmerplättehen. die Eier schwimmen im Wasser zeigt das Teilstiick längere Zeit gar kein Bestreben, sich abzurunden, wie auch Fischel besonders hervorhebt. Von der ursprünglichen konvexen Oberfläche her wirl allmählich das freiliegende Deutoplasma überwachsen und mit einer wahrscheinlich erst sehr dünnen Hautschicht überzogen. Auf der mangelhaften Ausbildung der letzteren und damit in letzter Instanz auf dem plasmatischen Bau des unbefruchteten Eies (vergleiche hierüber auch das in einem späteren Kapitel Gesagte) wird es wohl beruhen. daß nur auf der Obertläche des Teilstiuckes, welche der' ursprünglichen Obertläche des ganzen Eies entspricht, zunärchst Ripren und daher nur in reduzierter Zahl entwickelt werlen.

Zweitens haben DrIEsch und Morgan durch ihre sinmeich varirerten Exprerimente gezeight, daß man genan dieselhen Defekte in der Anzahl der Flimmerrippen erhält, wenn man an befruchteten Eiern von Beroü vor der Teilung gröbere Stücke des Eilïrpers wegschneidet und so den sich entwickelnden, mit dem Kern versehenen Teil auf einer größeren Strecke seines Hautplasmas beraubt. Schon durch diese Prozedur vor der Teilung ist die Bildungsmöglichkeit von Rippen in der Gegend des freiliegenden Deutoplasmas zunächst vernichtet worden. Mit Recht heben daher Driesch und Morgan hervor, dal. .die Defelite in der Ripuenzahl an Larven lediglich auf protoplasmatischer Basis beruhen und in keinem Fall geeignet sind, die Lehre ron yualitativer liernteilung zu stützen”. Denn , dlie defekten Larven, welche ic aus isolierten Blastomeren aufzogen, waren denen aufierordentlich ähnlich oder sogar gleich gestaltet, welche sich aus ungefurchten Eiern, denen Plasma genommen, aber das volle Kernmaterial belassen ward, entwickelten". 
Drittens endlich bilden die aus Teilstücken des Eies grezichteten Larven mehr Organe als sie - die Richtigkeit der Spezifikation angenommen - bilden diurften. Denn jede erhailt einen ganzen, in sich ab-

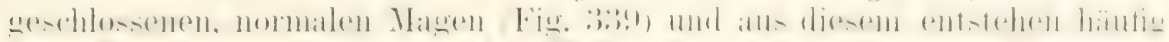

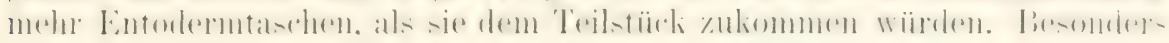
aber ist hierbei im Ange \%u behalten, dab die Magenanlage in ganz anderer Weise orientiert ist. als es bei einem aus dem ganzen Ei hervorgegangenen Magen der Fall ist. Die Magenanlage des 'Teilstuickes ent-

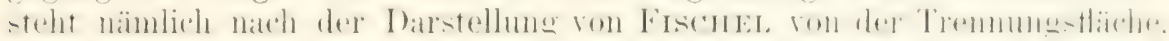
zuweilen sogar von ihrer Mitte aus und wächst von hier mit ihrem Grund

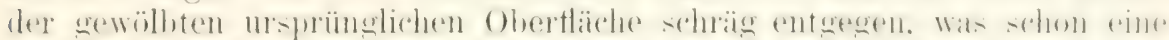

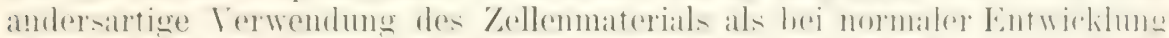

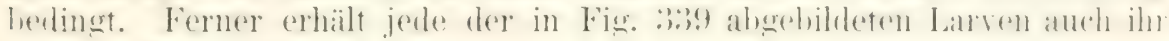
eigenes Zentralnervensystem.

Somit läßt sich das scheinbar abweichende Verhalten des Ctenoplioreneies, zumal wenn man die Bemerkungen über die Organisation des

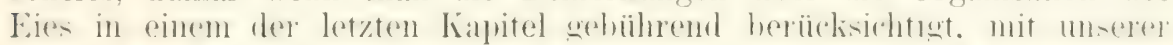
Theorie in Einklang bringen.

Man kann übrigens den mitgeteilten Versuchen der Zerlegung zwei-

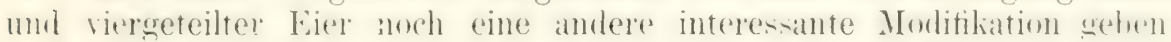
und dadurch erreichen, daß sich aus der zweigeteilten Eizelle weder ein einfacher Embryo, noch ihrer zwei, sondern ein verschieden uestaltetes Mittelding zwischen heiden, eine Dopledmibhildung. entwickelt. Zu den Zwerke mul. man rersuchen. die hejden Teilhälten durch Schütteh oder andere Eingriffe nur teilweise voneinander zu trennen: man muf nur die normale Korrelation der beiden Zellen, ihre

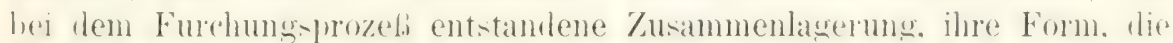
Verteilung ihrer rerschienlenen substanzen. wo solche schärfer gesondert sind. stören und etwas abändern.

Auf diesem Wege lassen sich aus einem Ei an geeigneten Versuchsoljekten, besonders an Eiern von Amphioxus und Rana fusca, Mißbildungen erhalten, hei welchen der vordere Teil des hiorpers in groulderer

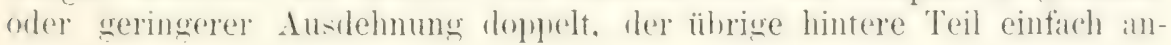
gelegt ist.

Durch Schütteln der Eier von Amphioxus rief Wilsox in vielen

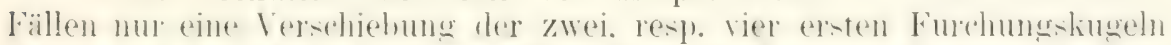
hervor und ergielte on wewi-sermalien, als einen lomponilis zwishen oiner doppelten und einer einfachen Entwicklung, Zwillinge von sehr verschiedener Form.

Aus der Abhandlung von Wruson habe ich in Fig 340 vier Bei-

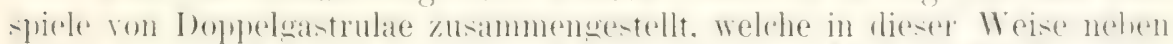

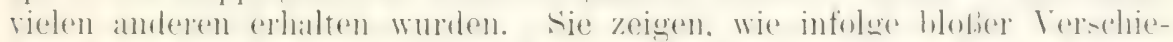
humg der levilen ersten Teilhälften ameinamber ans jeder für siols eine Gastrula entstanden ist. die mit der andern bald mehr. bald minder weit musmmenlä̈ngt. Dabei sind in jerlem der vier answewïhlten fäle die

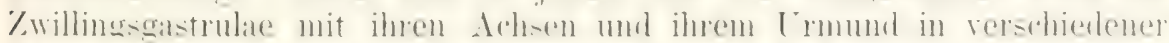

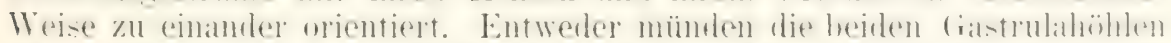

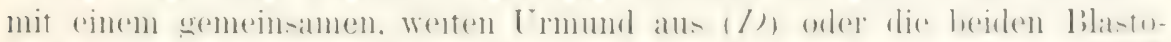

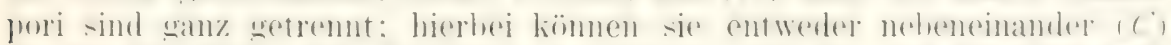

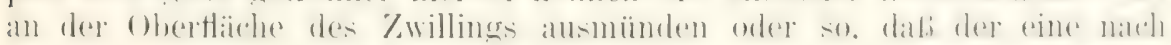
vorn, der andere nach hinten $(A)$, oder der eine nach links, der andere

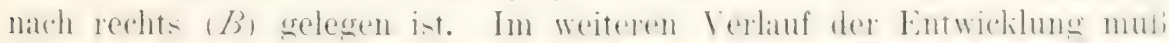

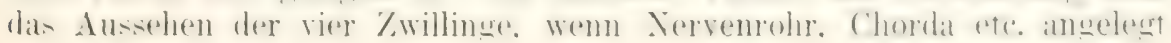


werden, sehr verschieden ausfallen, wie sich aus der ungleichen Stellung der Achsen der Gastrulae zu einander von selbst ergibt.

Auch einige ailtere derartige Doppelmibbildungen mit Chorda und

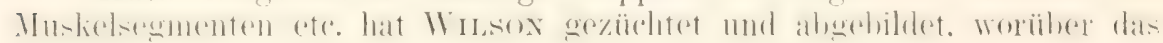
Nihere aus seiner Abhandlung zu ersehen ist.

Durch einen eigenartigen Kunstgriff hat ferner Oskar Schultze Verdoppelungen von Froscheiern erreicht, die sonst sehr wenig zu derartigen Mißbildungen neigen. Er hat Froscheier zwischen horizontalen

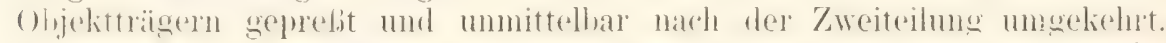
In jorler Teilhälfte machte sich hierauf das be-trehen geltent. die amimale. pigmentierte Hailfte durch Imkehrmug wieder mehr nach ohen zu hringen. Infolgedessen wird allmählich die normale Iage der beiden Furchungslablıkngeln zu einander melı gelockert und verändert. The animalen

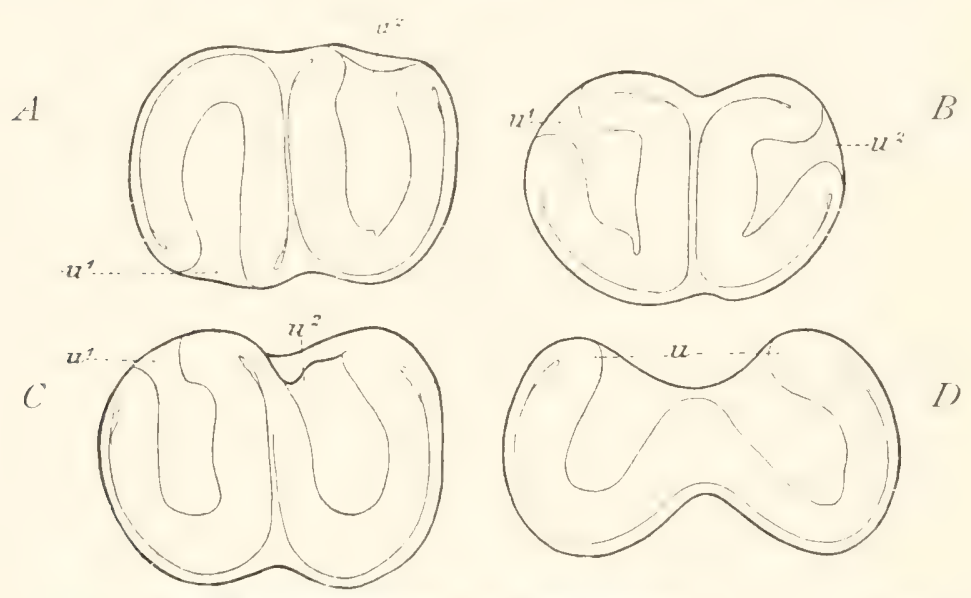

Fig. 340. vier Doppelgastrulae von Amphioxus ( $A$ B $\quad C \quad D$ ), entstanden dureh Schïtteh des Eies auf dem Stadium der Zweiteilung, sieben Stunden nach der Befruchtung. Nach WILsox, $u t^{1} \imath^{2}$ Nach rerschiedenen Richtungen orientierter Urmund der zwei aus je einer Eihälfte entstandenen Gastrulae; z gemeinsamer Urmund zweier Gastrulae.

Alschnitte stellen nicht mehr zusammen eine einfache animale Scheibe dar, sondern sind gleichsam in zwei getrennte Teile zerlegt. indem sich ein Streifen von vegetativer Dottermasse zwishen sie trennend hineinschieht. I)ie so hervorgerufene Störung in der normalen Korrelation der beiden Zellen wird dann im weiteren Verlauf wieder die Ursache, daß hei fortgesetzter Furchung zwei getrennte Furchumghöhlen (Fig. $3+1 k$ k) entstehen. dal. aus dem einfarchen Ei also eine Dopprellieimblase wird. dab. sich an dieser zwei (iastrulaeinstälpmugen bililen. D)a jede der aus dem natürlichen /nsammenhang gehrachten Iälften sich teilweise für sich selbstämlig entwickelt, liefert das ursprünglich einfache. aber durch hompression mol Tmlieh in verinderte berlingungen gehlachte Froschei anstatt eines einfachen Embryos Zwillinge, die teilweise untereinander zusammenhängen und einzelne Körperteile gemeinsam haben.

Von den für die Theorie der Biogenesis ebenfalls sehr lehrreichen

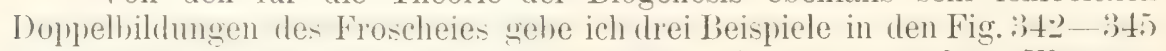

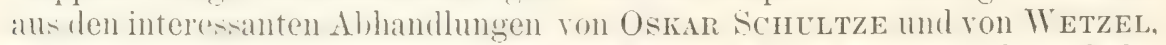
welcher die Lmkehrversuche mit dem gleichen Erfolg wielerholt und die mißgebildeten Eier auf Schnittserien weiter untersucht hat. 
Fig. 342 $A$ u. $B$ stellt eine aus einem normalen Ei kïnstlich er-

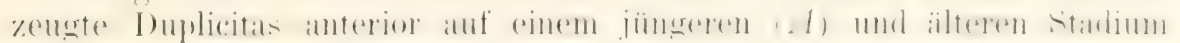
$(B)$ dar, beide vom Rücken aus gesehen. Auf dem jüngeren Stadium sind die Medullarwïlste entwickelt, welche, von der Norm abweichend. eine in

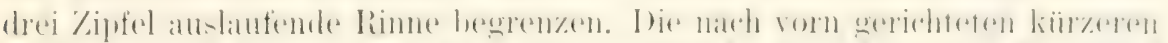

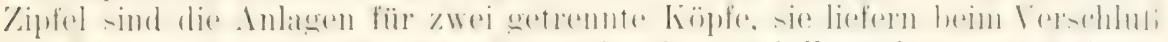

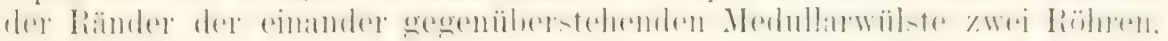
aus denen sich die einzelnen Blasen für zwei (iehirne differenzieren. Der

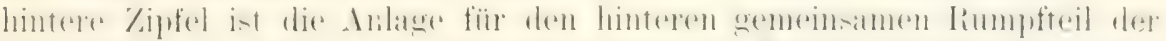

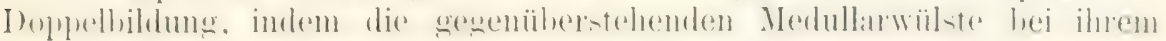
VerschluB ein einfaches Rückenmarksrohr liefern.

Im Laufe der weiteren Entwicklung ist aus dem Stadium $A$ der

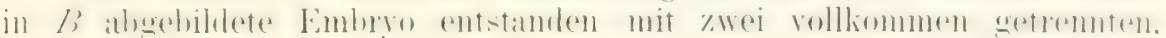

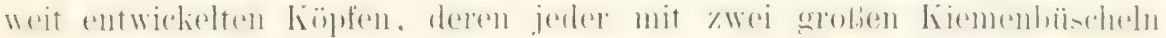
ausuestattet ist. Die Verdoppelung erstreckit sich auch noch auf den

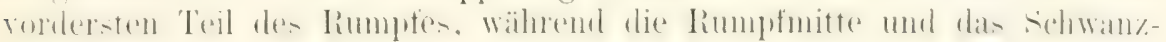

Fig. 341.

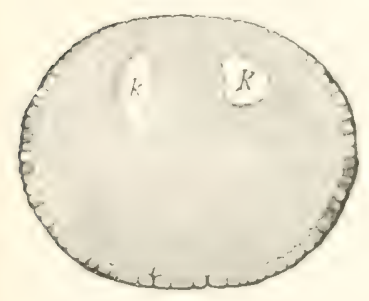

Fir. 341. Schnitt durch ein komprimiertes und nach Beginn der ersten Furche gedrehtes Ei von Rana fusca auf dem Blastulastadium nach Auflebung der Kompression. $k$ límhöhle. Nach WetzeL.

Fin. $342 A$ und $B$. Zwei zwischen horizontalen Platten gepreßte Eier von Rana fusca, welche anf dem Stadiun der ersten f'urche so gedreht wurden, dals das helle Feld genau nach oben gerichtet war. Nach Oscir Schultze. A Medullarrinne mit vorderer 'Teilung als Anlage einer Duplieitas anterior; $B$ dasselhe Ei zu einem typischen Dicephahus geworden.

ende einfach sind. Ventralwärts besitzt die Duplicitas anterior einen gemeinsamen Dottersack.

Noch weiter ist die Sonderung der beiden Anlagen in Fig. 3̈4:3 gediehen. Aus jeder Hälfte des zweigeteilten Eies ist eine von hohen

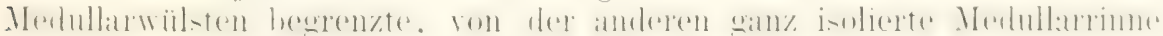
entstanden, und zwar so, (lab ilue liopfenden nach entgegengesetzten Enden in ähnlicher Weise wie bei der Doppelgastrula des Amphioxus (Fig. : 40 A) orientiert sind. Aus den Anlagen kann man mit großer Sicherheit hinsichtlich des weiteren Verlaufes wohl voraussagen, (lab) zwei mit

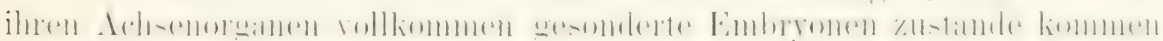
werden, die nur ventralwäts einem gemeinsamen Dottersack aufsitzen.

In dem dritten Beispiel endlich (Fig. $34+$ ) sind aus den beiden ersten

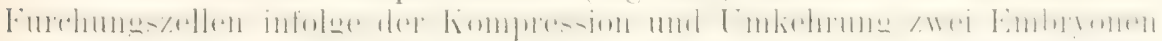
hervorgegangen, die mit ihren Längsachsen parallel und dicht neheneinander liegen, wie die Doppelgastrulae von Amphioxus (Fis. :30) ("). Sie betinden sich auf dem Stadium der Medullarime mit weit vorspringenden Rüickenwïlsten. Nur die liopfenden. welche in derselben Richtung orientiert sind. 
weichen nach vorn, wie in der Fig. $342 \mathrm{~A}$, ein wenig auseinander und sind vollständig gesondert.

Auf einer Quersehnittserie (Fig. 345 A u. B) durch den abgebildeten

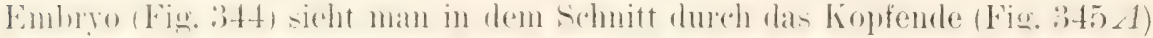

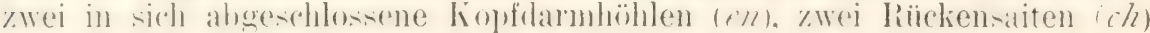

Fig. 3443.

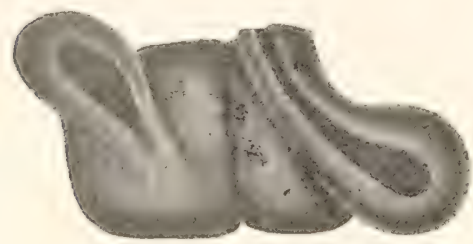

Fig. 343. Ei von Rana fusca, nach derselben Methode, wie in Fig. 342 behandelt. Nach Oscar Schultze. Auf jeder der beiden Eihälften haben sich Medullarwïlste entwickelt, deren Kopfteile jedoch entgegengesetzt gelagert sind.|

Fig. 344. Ei von Rana fusca, mach derselben Nethode, wie in Fig. 342 und 343 behandelt. Nach

Wetzei. Aus jeder Eihälfte ist ein Embryo mit Medullarwïlsten entstanden. Beide Embryonen zeigen Rückenmark und Chorda getrennt, sind dagegen in der Bauchgegend verschmolzen. $h$ Getrennte Kopfenden; $m$ Medullarwülste; $c$ Linie, in der die median gelegenen Medullarwülste zusammentreffen.

und zwei Himanlagen, zwischen welche eine tiefe, von Ektoderm auscrekleidete Rinne einschneidet. Die eine Ilimanlage ist hereits zum Rohr geschlosien, die andere noch als Rimne geöfthet. In der Mitte der Dopyelhildung (Fig. : :5t) B) sind heide Anlagen näher zusammengerïckt. Während ventralwärts die in den Kopfanlagen getremten Damböhlen zu einem Ilohlrann verschmolzen sind, haben sich die liächenorgane noch ganz.

$A$

$B$
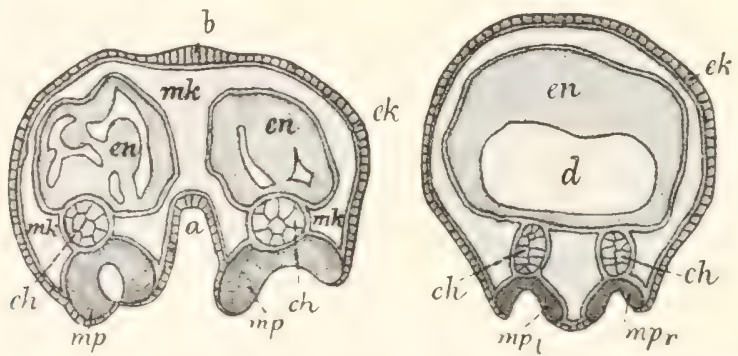

Fig. $345 A$ und $B$. Zwei Durchschnitte durch die in Fig. 344 abgebildete Doppelmißbildung. Nach Wetzer.

gesondert erhalten: doch liegen die beiden Medullarrimnen so dicht zusammen, daf die einander zugekehrten Medullarwülste sich mit ihren Rändern fast berẗhren.

Ähnliche Doppelmißbildungen, wie sie infolge künstlicher Eingriffe

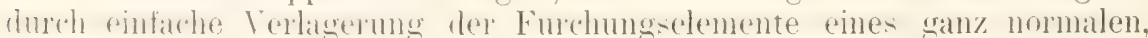
einfachen Eies willkürlich erzengt werden können. kommen in der Natur 


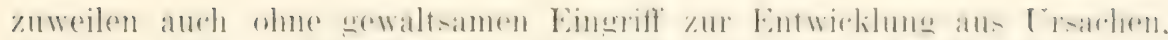

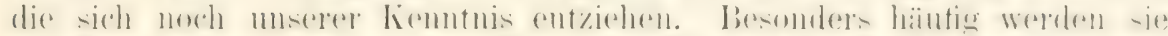

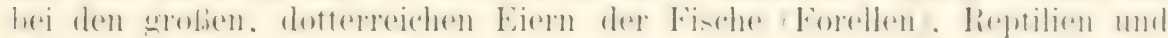
Vögel beobachtet.

An einem sonst anscheinend normalen li entstehen anstatt einer zwei Gastrulaeinstülpungen an zwei getrennten Stellen der Keim-

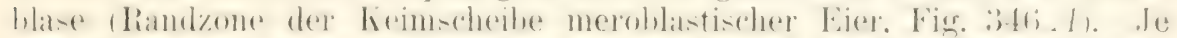

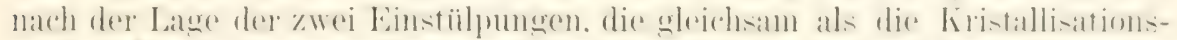

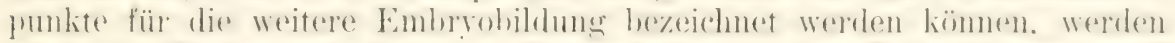

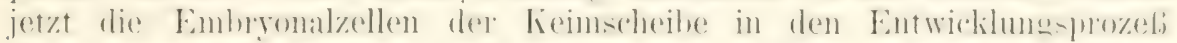

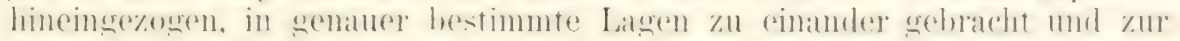

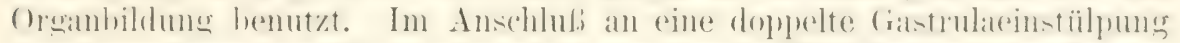
chtotehen dam zum beisped anstatt zweier ver ()hrblïshen, vier dugen-

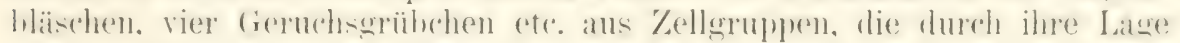
zu den Orten der ersten Einstülpung bestimmt werden.

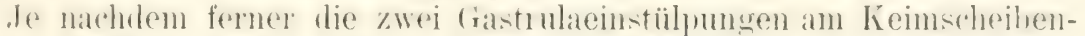
rand in gröberer Nible orler in srölierer Entfernumg vomeinander anfuretreten sind, fallen die vorleren verdofyelten Rumpfteile kïr\%er oder lïnger
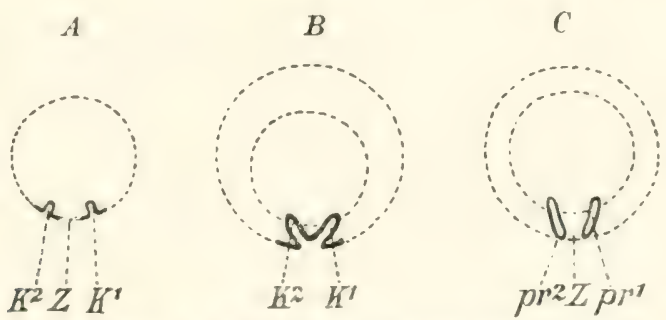

Fig. :ili. . I und $I$ Z Zwei Schemata zur Erläuterung der Entstehung einer Doppelmißbildung des Lachses aus zwei Gastrulaeinstülpungen. $K^{-1} h^{2}$ [ircht: und linke Kopfanlage einer Doppelbildung. Z Zwischenstïck. C Schematische Darstellung der Keimscheibe eines Hühnchens mit zwei Primitivrinmen.

ans. wovon damn wieder die Länge des sich einfarh anlesenden. hinteren Körperendes abhängt ( $F i g . ~ 346 B C$ ).

Wie leicht ersichtlich int. bilden die Doppelmibliblumesen. deren Ent-tehung dureh die experimentell erzeneten Formen unserem Verstandnis

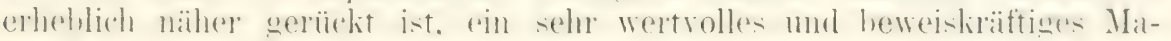
terial für die Lehre, daB die Embryonalzellen nicht von vornherein für

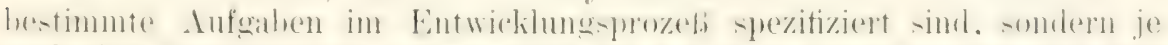
narb den berlingmugen. unter welehe se anf dem mormalen orler anf dem

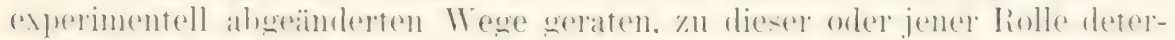
miniert und zum Aufbau dieses oder jenes Organes und ciewebes verwandt werden. Denn je nachdem durch künstliche Eingriffe die beiden

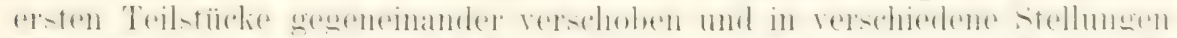

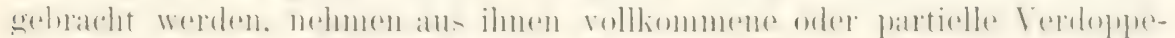

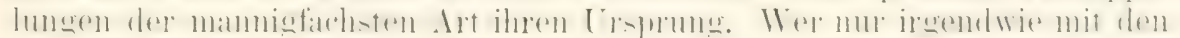
Grundprozessen bekannt ist, durch welche sich die Entwicklung eines

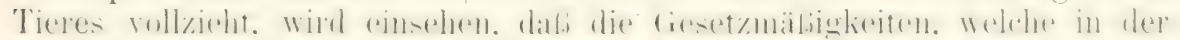

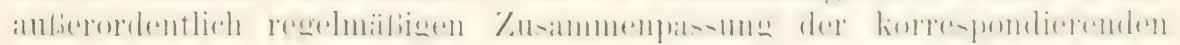
Organe der linken und der rechten Körperhälfte auch bei den Doppel-

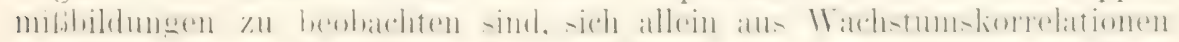
begreifen lassen, das heißt aus den Beziehungen, in welche die rorhan- 
denen, bestimmt gelagerten Embryonalyellen durch den Entwicklungsprozelo selbst erst gebracht werden. Alle l'räformationshypothesen rersagen hier ihn'en I)ienst oder müssen mit Zusatzhypothesen derart heladen werden. daß sie auch dadurch in ihr Gegenteil verwandelt werden.

Im übrigen ergibt schon, von allen Experimenten abgesehen, eine einfache Therlegung dab anch hei Anmahme erbgleicher Toilung jedesmal die nergehildeten \%ellen ihre Beziehumgen zum Ganzen und mithin zum zukünftigen Endprodukt des Entwicklungsprozesses, wenn wir ihren Anteil

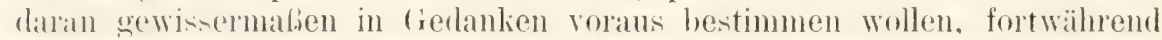
verändern, ohne daß wir mit Weismans und Roux zu dem Zweck eine Zerlegung des Keimplasmas in differente Determinantengruppen anzunehmen halien. Denn auf der ersten Stufe der Furchung macht jerle Zelle die Hälfte des Ganzen, auf der zweiten Stufe nur ein Viertel, dann nur ein Achtel. ein Sechzehntel und so weiter aus und nimmt demmach selbstrerständlicherweise auf jeder Stufe in anderen Bruchwerten an der Ausbildung des entwickelten ()rganismus teil. Dabei verändert sich auch die Form der Zellen, indem sie Halbkugeln, (Quadranten, Oktanten etc. werden. nach allgemeinen Gesetzen, die sich aus dem Verhältnis der Teile zur Natur des Ganzen ergeben.

Und so ändern sich einfach infolge erbgleicher T'eilung noch viele andere Beziehungen der Zellen zu einander mil zur Aubenwelt. Erstens ruft die liernsubstanz - um noch einge hesonders deutlich zutage tretende Verhältnise herauszugreifen - eine immer gröber werlente Mannigfaltigkeit schon allein dadurch hervor, dab sie sich durch eine Reihe der rerwickeltesten chemischen Prozesse Schritt für schritt Stoff aus dem im Ei aufgespeicherten Reservematerial und sauerstoff aus der umgebenten Atmosphäre aneignet. Denn die Massenzmahme der Kerusubstanz hat nach allgememen fiesetzen des organischen Wachstums ihre fortlaufente Vermehrum in 2., 4, ^. 16 gleichartige Stücke etc. zur Folge. Die Vermehrunn ist aber gleichzeitig wieller die Ursache für eine sich stetig ändernde räumliche Verteilung der Substanz. Die 2, 4, 8, 16 etc. durch Teilung entstandenen Kerne weichen ebenfalls wierler nach diesetzen in entgegengesetzten Richtungen anseinander und gewinnen in lestimmten Abstänlen voneinander nene Stellungen in Firamim. Waren anfangs alle Stoffteilehen des Eies um den befruchteten Kern herum als einziges Kraftzentrum angeordnet, so gruppieren sie sich jetzt um so viele individuelle Zentren herum, als neugebildete Kerne rorhanden sind, und sondern sich um dieselben zu Zellen ab. Ohne Frage hat das Ei als vielzelliger Organismus im Vergleich zum Ausgangsstadium seine (pualität Shohritt für Sehritt verandlert, schon allein durch den Prozeß der erbgleichen Teilung.

In einer zweiten Beziehung geschieht dies auch dadurch, daß die

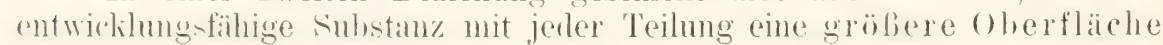
gewimnt, durch welche sie mit der Umgebung in Verkehr tritt. Die so-

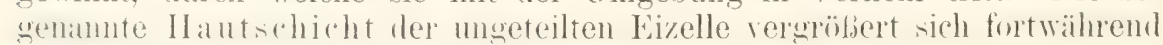
erheblich mit der Zwei-. der Vierteilung und so fort.

I)ritten- treten infolge der Zerlegumg sualten in der antwicklungs-

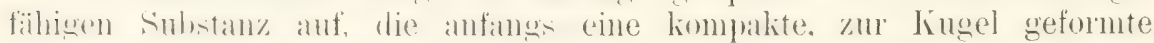
Hasse darstellte. Die Spalten Hießen allmählich nach innen zu einem größeren Hohlraum zusammen, der sich durch Absonderung von Flüssigkeit zur Keimblasenhöhle ausweitet.

Um alle diese Vorgänge zи verstehen, bedarf es nicht der Annahme besonderer im Keimplasma gelegener Determinanten, die durch erbungleiche Teilung in verschiedener' Weise auf die Zellen verteilt werden. 


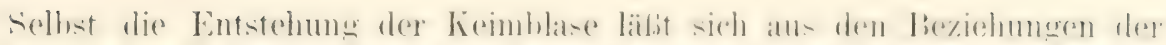

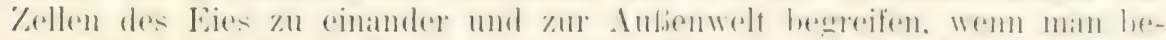

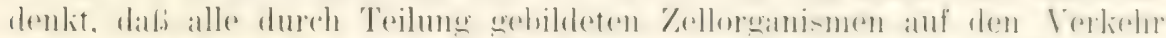

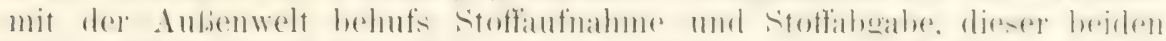

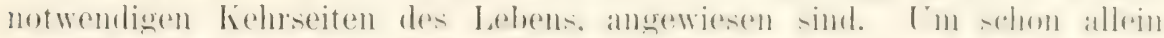

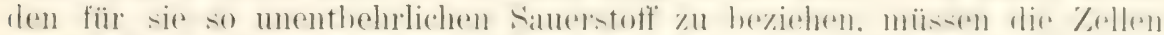

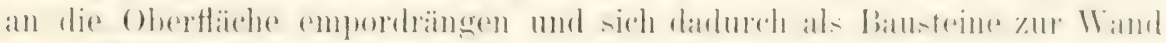
einer Hohlkugel verbinden.

BERGMAN und LEuCKart haben bereits yor langer Zeit das allge-

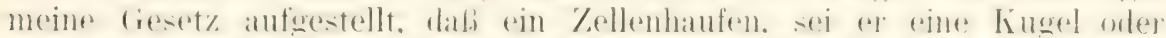

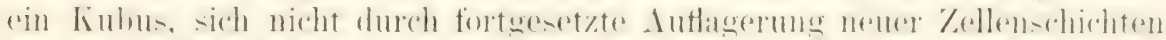

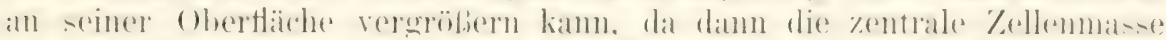

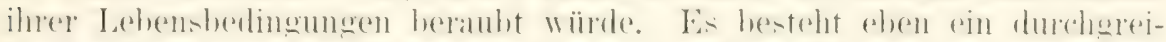
fender fumbamentaler Entersehied zwischen dem Wachstmm eine- () reatnismus und eines Kristallindividums.

Ein Kristall kann in seiner Mutterlauge wachsen, indem er auf seiner

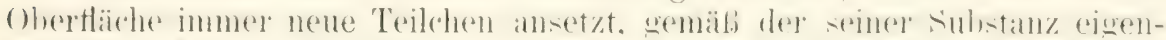
timliehen Art, zu kristallisieren. Ine eimmal anstiristallisierten Teilehen

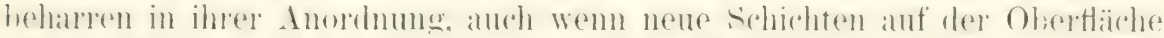

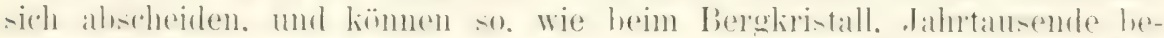
stehen hleihen. wemn sie nicht durch veränderte äuldere Eingritfe in ihrem Beharrungsvermögen gestört werden.

Die, ein Lebewesen aufbanende Substanz aber kamn in dieser Weise nicht wachsen. Sie nimmt Stoffe von außen anf, um sie, nicht wie der Kristall, an ihrer Oberfläche abzusetzen, sondern ihrem Innern (durch

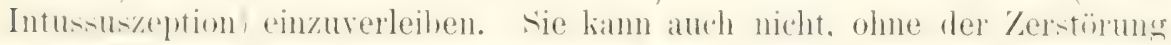
zu verfallen, in dem eimmal angenommenen Zustand beharren: denn sie mul Stoff unsetzen, worin ja der Lebensprozeß zu einem wesentlichen Teil mit besteht, und ist hierbei auf die stete Wechselwirkung mit der

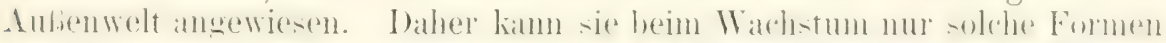

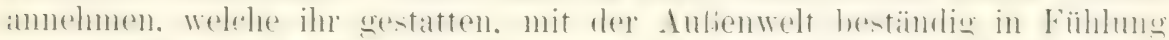

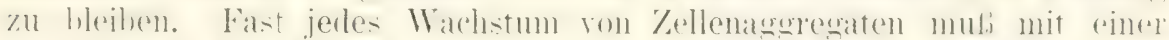

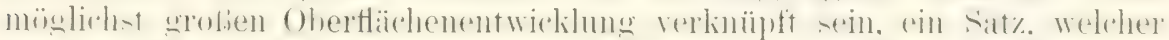

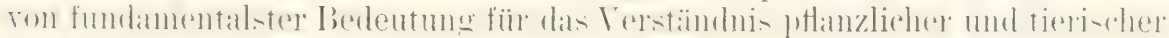
Gestaltbildung ist.

Wie bei der Entwicklung der Keimblase, tritt uns die Berleutung

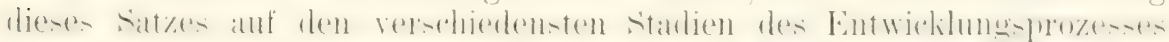

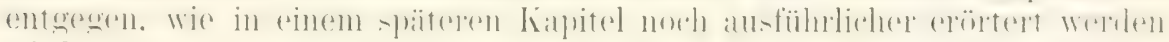
wirl. Die jeweilige Form erscheint so in mancher Hinsicht als eine Funktion des Wachstums der organischen Substanz: ihr Bestand ist an bestimmte Bedingungen gebunden, die, wenn sie infolge fortschreitenden Wachstums sich verändern. bei der reaktionsfähigen Substanz zu einer zweckentsprechenden Verïnderung der Form führen. (Siehe Kap. XXV.)

D)atïr, daß auch auf späteren Stadien der Entwicklung die schon zu

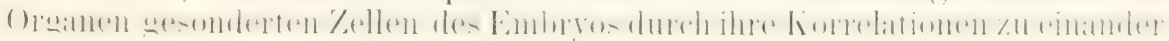
die Gestaltungsprozesse beeinflussen, bietet ein lehrreiches Beispiel die Art und Weise, wie bei den Wirbeltieren dem Atemberturfnis des Embryos

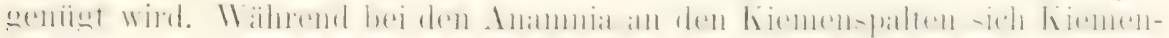
blättchen als Atmungsorgane entwickeln, wird bei den Ammioten, weil ihre

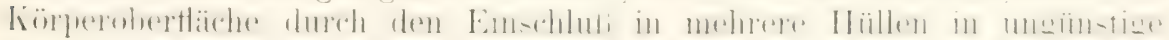
Lage zu der Samerstoff(puelle gebracht ist. das Atmungsbedürnis dureh

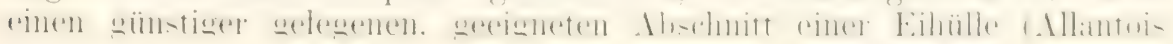




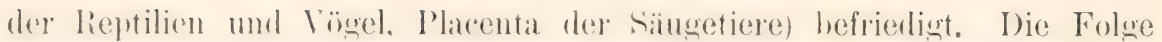
ditrom ist. dab hei allen Immioten. obwohl kiement palten noch nach wie

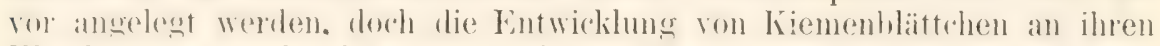

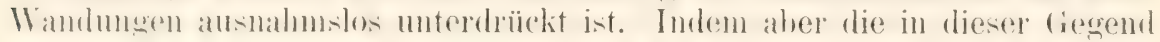
urspriunglieh lokialisierte Atmungsfunktion auf einen anderen Teil des orwa-

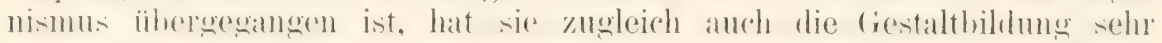
wesentlich beeinflubt, teils durch den Ausfall der-nutzlos gewordenen Kiemen. teils durch die anderen Prozesce. welche wieder mit diesem Eroignis kansal verknüpft sind, durch den nachfolgenten Verschluliden liemenspalten, die I'mwandlung im Skelett und Muskelapnarat, in den fefialien. Nerren, Drüsen der Halsgegend.

So zieht Verånderung eines Teiles auf vielen verschierlenen Wegen zahlreiche Veränlerungen an anderen 'Teilen bald in einer für uns erkennbaren, bald noch verborgenen Weise auf jeder Stufe des Entwicklungsprozesices nach sich. Fin Falitor verändert viele andere Faktoren durch seine Beziehungen zu ihmen. so daß schlieflich eine kleine Ursache fast im ganzen ()rganismus Wandlumgen gröberen und geringeren (irades hervorbringen kann.

Die Ergebnisse unserer Betrachtungen lassen sich mithin in den Satz zusammenfassen:

Durch die sich stetig verändernden Beziehungen, welche die sich vermehrenten Zellen der entwicklungstähigen substanz nach allgemeinen (iesetzen untereinander eingehen. mol durch die gleichfalls einer steten Veränderung unterliegenden bezichungen dieser inneren zu den äuberen Faktoren werlen auf jeder stufe des Entwicklungsprozesses neue fiestaltungen in einer sich immer melı limplizierenden Mamnigfaltigleit hervorgerufen.

\section{Literatur zu Kapitel XXII.}

1) Chabry, I., Embryologie normale et tératologique des ascidies. Thèses présentées à la faculté des sciences de Paris. 1887.

2) Chun, C., Die Ctenophoren des Golfes ron Neapel. Fanma and Flore des Golfes von Neapel, B3. I. 1880 .

3) Derselbe, Die Dissogenie, eine nene Form der geschlechtlichen Zeugung. Festschrift fïr Leukart. 1802.

4) Crampton, Experimental studies on gasteropod development. Archic f. Entreickl.Mech., Bit. IIT. I806.

5) Derselbe, The Ascidian half-embryo. Anmals of the New Fork Acad. of sciences, Tol. X. 1897 .

(i) Driesch, Entrizklungsnechanische Studien I. Der Wfert der beiden ersten Furchungsacllen in der Echinodermenentwicklung. Experimentelle Eracugung won Teil- und Doppelbildungen. Zeitschr. f. zeriss. Zool., Bd. LIII. 1892.

7) Derselbe, Entielickmngsmechanische Studien III. Die Terminderung des Furchungs. materials und ihre Folgen. Ebenda, Bd. LIT. I993.

s) Dorselbe, Fon der Entwicklung einselner Assidienblastomeren. Archiz' f. Entarickl.Mech., Bid. I. 1895.

9) Derselbe und Morgan, T. H., Zur Analysis der crsten Entuicklungsstadien des Citenophorencies. Archiv für Entrickl.-Mech., Bd. II. 1895.

10) Fischel, Alfred, Experimentelle Untersuchungen am Ctenophorenei. I. Ion der Ent-

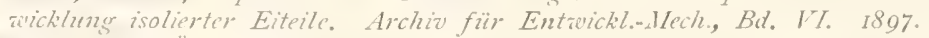

11) Heider, Karl, Über die Bedentuns der Furchung gepreßter Eier. Archir f. Entzinckl.Jech., Bd. V. 1807.

12) Herlitzka, Amadeo, Contributo allo studio della capacita evolutiva dei due primi blastomeri nell' noz'o di tritone. Archizl f. Entreickl.-1/ech., Bd. II. 1805.

1:i) Derselbe. Sullo striluppo di embrioni completi da blastomeri isolati di unza di tritone. (.Molge cristata.) Archia f. Entuickl.-Mech. der Organismen, Bd. IV. 1897. 
14) Derselbe, Ricerche sulla differnziazione cellulare nello sribuppo embranale. Archit. f. Entrickl.-1Yectlo, Jid. IY. I\$97.

15) Hertwig, Urmund und Spince bifidn. Archio f. merosk. Anat., Bd. XVITX. 1802

16) Derselbe, Uber den Wirt der ersten Furchungsaellen für die Organbildung des Embryos. Arithir f. mikrosk. Anat., Bd. XLII. 1803.

17) Dirselbe, Altere und newere Entwicklungstheorin. Ein Iortrag. Berlin 1802.

1S) Loeb, Jacques, Beiträgo zur Entwicklungsmechanik der ans cimem Ei entstehendin

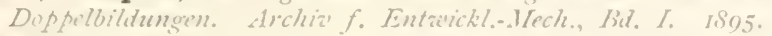

19) Morgan, The formation of one Embryo from tro Blastulue. Studies of the "partimlw Larrede of Spluarechinus. Archio fiir Entwickl.-ilech., lid. II. 1895.

20) Derselbe, Experimental studies of the Blastula and gastruler stases of Echinus. Ebendu.

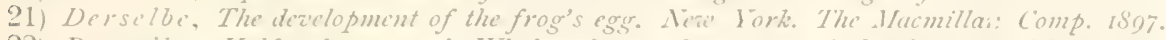

22) Derselbe, Ifalf-embrues and IIhole-embiryes from one of the first taid blastomeres of the frog's eger. Anat. Anzeiger., B'a. X. 1805.

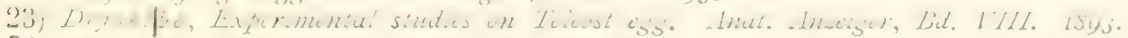

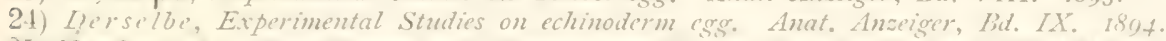

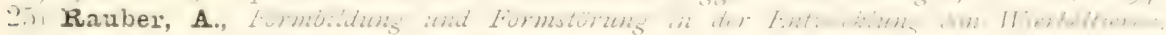
Morphol. Jahrbuch, Bit. T. I\$79, Bd. II. 1880.

26) Roux, Uber die künstliche Iheriorbringung halber Embryonen durch Zerstörung cinc" der bezden ersten Furchungskugeln, sowie züber dir Vichentaicklung (Postgeneration) der fehlenden Körperhälfte. Iirchou's Arihiz', Jid. CXII: 1888.

27) Derselue, rber das entricklungsmechanische Fermögen jeder der benden ersten Furchungrszellen des Eies. Terhandl. a. anat. Cesellsch. a. G. Ters. in II ien. ISoz.

28) Derselbe, Über Mosaikarbeit und neucre Entaicklungshypothesen. Anat. Hefte a'on lerkel und Bonnet. 1893.

29) Derselbe, Über die aerschiedene Entwicklung isolierter erster Blastomeren. Archiz f. Entreklel.-1Yech., lid. I. 1894.

30) Schultze, Oskar, Uber die Bedeutung der Scharerknaft für the organische Gestaltzeng.

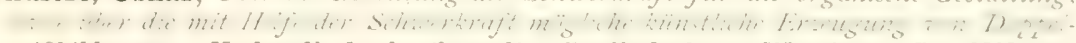
mipbildngen. Terhandl. d. physik-mediz. Gesellschaft zul Mürburg, Bd. XXI"III. $11.2 \quad \therefore$ i 1 .

31) Derselbe, Die künstliche Eraengung ion Doppelbildungen bei Froschlaren mit Ililfe abnormer Gravitationsairkung. Archiz f. Entwickl-Mech., Bit. I. I894.

32) Spemann, Entrieklungsphysiologische Studien an Tritonet. Archiz f. Entrickl.Mech., Bit. Ill. Ig0I und Bid. XV. 1902.

33) Wetzel, Beitrag zum studinm der kiüstlichen Doppelmißbilumugen r'on Raner fusca, Inczug.-Diss. $\quad$ I896.

31) Derselbe, ¿̇ber die Bedeutung der zirkulären Furche in der Entaicklung der Schultzéschen Doppelbildungen a'on liana fusca. Archio f. mikrosk. Anat., Bd. XLIT. I895.

35) Wilson, Amphionus and the mosaic theory of deaclopment. Journal of morphology. Fol. VIII, Ni. 3. $189,3$.

36) Derselbe, On cleaz'age and mosaic-azork. Archiz f. Entwickl.-lech., Bu. III. I896.

37) Zoja, Raffaello, Sullo stiluppo dei blastomeri isolati delle wora di alcune meduse e di altri organismi. Archio f. Entwickl.-1Fech., Bd. I u. II. 1895. 


\title{
DREIUNDZWANZIGSTES KAPITEL.
}

\section{Die imneren Faktoren der organischen Entwicklung.}

\author{
(Fortsetzung.)
}

\section{B. Die Korrelationen der Organe und Gewebe auf späteren Stadien der Entwicklung und im ausgebildeten Organismus.}

Wenn schon bei Beginn des Furchungsprozesses die beiden ersten Teilhälften des Eies. wie die Experimente gelehrt haben, je nach ihrer gegenseitigen Iage und Beziehung verschiedenerlei Wirkungen aufeinander ansühen, welche für die weitere fiestaltung des Entwicklungsprozesses ausschlaggehend sint, aber in ihren Folgen in voraus sehr schwierid zu heurteilen sind. un wie viel mehr muf diese Schwierigkeit zunehmen. wenn ss sich darum handelt, die zahlreichen liorrelationen zu hegreifen. welche anf späteren Stadien der Fntwicklung und im ansgebildeten Organismus zwischen den Milliarden von Zellen stattfinden, welche in seln kunstroller Weise in zahlleichen Schichten angeordnet und in grölieren und hileineren Gruppen zu Organen und Geweben gesondert sind!

Um in das unendlich verwickelte Getriebe einen einigermaßen orientierenten Finhlick zu gewinnen. sei folgender Weg eingeschlagen. Zunächst soll an einigen hesonders instruktiven Beispielen aus dem Pflanzen- und 'Tierreich gezeigt werden, wie die zahlreichen verschiedenen Teile eines ()romismus in Ahhänglieit voneinamler stehen nnd zu ihrer Erhaltung aufeinander angewiesen sind. Alsdamn wollen wir versuchen, unser Thema in systematischer Weise zu zergliedern, indem wir die im Kiörper stattfindenden Korrelationen in Gruppen einteilen in ähnlicher Weise, wie es mit den äuberen, auf den Organismus einwirkenden Faktoren geschah.

Beispiele leicht walnuehmbarer, ausgebreiteter Korrelationen bei Pflanzen und bei Tieren.

Bei den Pflanzen läbt sich eine tief eingreifende Korrelation zwischen ihren wherirlisehen und ihren unterirdischen Teilen leidht nathweisen. .. Wis stehen", wie Vöchting bemerkt, ,an einem unter normalen Bedingungen und ungestört wachsenden Baume alle Oroane untereinander in einem bestimmten Verhältnis. Einer gewissen Anzahl von IBättern entspricht eine bestimmte Summe von Zweigen und Ästen. Diese entspringen einem ctamm rom proportionaler Dicke. und dieser ruht endlich auf einer Hanpt-

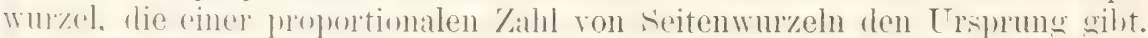
Zwivhen allen diesen Teilen herrscht unter normalen Verhälnissen ein 


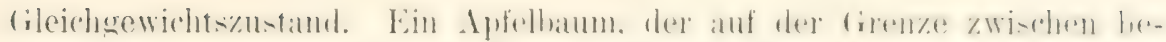
arbeitetem Gartenboden und Rasen steht. wächst anf der dem ersteren

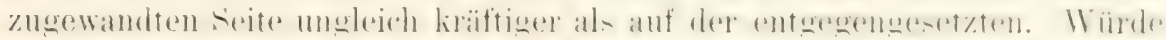
man einem Apfelbaum, der drei Hauptwurzeln und drei ihnen entspre-

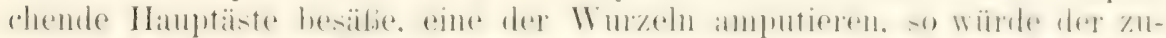

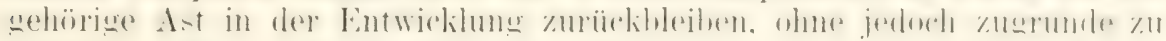
gehen." ,Dieses Gleichgewichtsverhïlnis ist verschieden, je nach der spezifischen Natur des Bammes; es ist ein anderes bei der Eiche, ein anderes bei der Buche: es ist verschieden bei differenten Varietïten derselben Art ete."

Durch das Experiment kam man die hier berührte Korrelation zwischen den ober- und unterirdischen 'Teilen einer PHanze leicht iiber

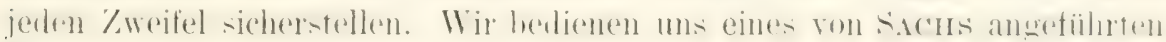
Bisispiels:

Läßt man eine 'Tabakptlanze, einen Rizinus oder' eine Sonnenrose sich im freien Lande auf gutem Borlen oder in einem Blumentopf ent-

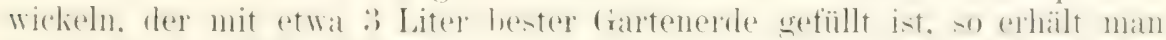

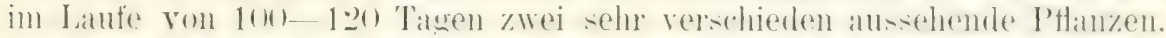

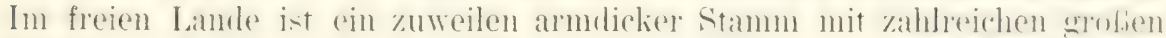
[B]ïtern und einem ïprgen Wumelwerk entstanden: im lilumentopfe da-

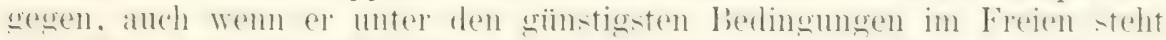
umd öfters mit guten Xählösumgen begosen wirl. hat side mur ein stamm

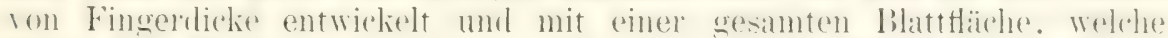
latum den fïnften orler sechsten Teil der anderen I'flanze hetrïgt: dort ist also eine arobe mol lirätige, hier eine kleine und schwärhliche PHanze trotz guter Emährung entstanden.

Der wesentliche Grund fül den Unterschied in der Entwicklung ist einzig und allein in dem Umstand zu suchen, dab in dem beschränkten

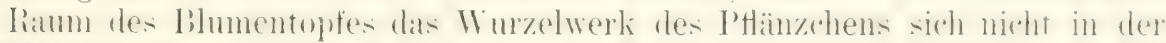

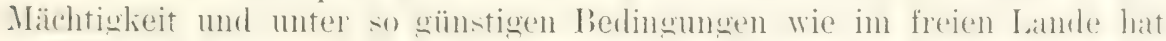

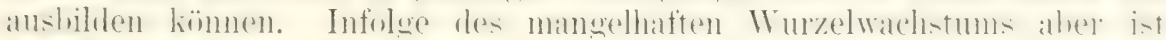

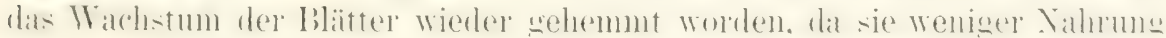
aus dem Boden (Wasser und Salze) zugeführt erhalten. Die kleineren Blätter aber assimilieren num anch ihrerseits weniger, was wierler auf die Holzbildung im Stamm zuriickwirkt. So treten uns in dem noch relativ

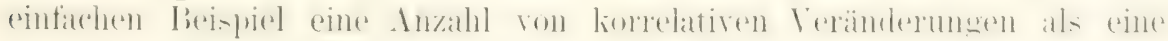
zusammenhängende Kette von Ursachen und Wirkungen entgegen.

Ämliche Korrelationen des Wachstums kamn man bei den PHanzen leicht in der verschiedensten Weise durch äußere Eingriffe hervorrufen. Wie bekannt, wachsen die Fichten an ihrem oberen Ende in vertikaler Richtung vermittelst des Gipfeltriebes in die Länge und erzengen unter ilm sich in horizontaler Richtung ausbreitende Seitensporosse, welche zu vier bis fünf in einem Quirl zusammengeordnet sind. Wenn num del Gipfeltrieb einer Fichte ahgeschnitten oder durch irgend einen anderen Umstand zerstört wird, so mïßte man erwarten, daf das Lüngenwachstum mit der Entfernung des ihm dienenden Organes aufhören würde. Anstatt

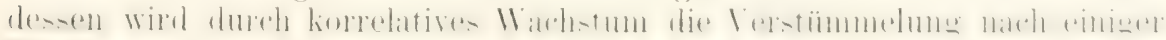

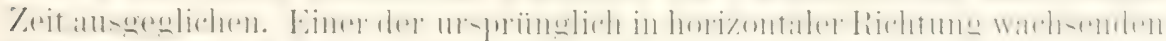

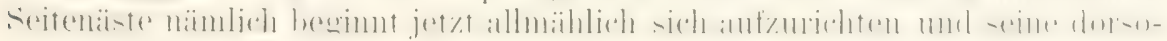
rentrale Beschaffenheit zu verlieren; er wir( orthotrop), tritt schlieblich ganz in die Stelle des Gipfelsprosses ein, wächst wie dieser in rertikaler Richtung weiter und erzengt wie dieser jetzt Quirle ron sich horizontal aushreitenden Seitensprossen. 
Das korrelative Wachstum, das zwischen den verschiedenen Organen einel Pflanze besteht, gibt dem Gärtner Gelegenheit zu mannigfachen zoredinaligen Fingritfon, dureh welche er vele Ptlanzen wie eine plastisehe Masse seinen Zwecken entsprechend formt. Da unentwickelte Ḱnospen

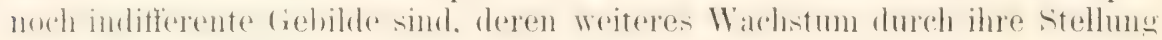
an der ganzen Pflanze durch Korrelation bestimmt wird, liann er sie durch

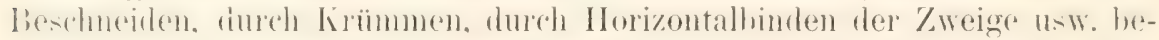
stimmen, daß sie entweder zu einem längeren oder kürzeren Laub- oder zu einem Blïtenzweig auswachsen. „Um z. B. bei Prunus spinosa einen Langsprof an Stelle eines Dorns entstehen zu lassen, braucht man nur

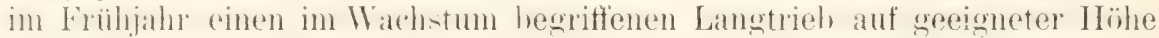
zu durchschmeiden. Aus der oder den unter dem Schnitt gelegenen Kunpen entwickehn sich nun Langsposse, welche dem müterlichen 'Tüger uldehen mol desen ununterhochenes Wachstum fortsetzen. Während sie sich an der unverletzten Achse zu Dornen umgebildet haben würden. Wir verwandeln somit die Anlage eines Dornes in die eines langen Laubsprosses* (Vöchting).

In allen derartigen Fällen korrelativen Wachstums scheint es, um uns eines Ausspruches von Nägeli zu bedienen, als ob das Idioplasma genau wüfte, was in den übrigen Teilen der Pflanze vorgeht und was es tum mul., um die Integrität und die Idehensfähgheit des Individumms wieder herzustellen.

Bei den viel weiter und höher differenzierten Tieren herrscht eine noch viol arobere Harmonie und gegenseitige Abhängigkeit zwischen einzelnen Organen und Geweben, so daß Veränderung in dem einen Teil allmählich auch eine Masse weiterer Veränderungen in vielen anderen Teilen unfehlbar zur Folge hat. Auch hierfür zwei Beispiele.

Zur Fortbewegung in der Luft sind viel stärkere motorische Kräfte erforderlich als zur Fortbewegung auf dem Lande oder in dem Wasser. liei den Vögeh sind daher die zum Flügelschlag hauptsächlich gehrauchten Muskehn, nämlich die srofien M. pectorales, zu so gewaltigen Massen wie sonst bei keinem anderen Wirbeltier entwickelt. Besonders mächtig aber sind sie bei den besten Fliegern, unter denen die kleinen, pteilschnell dureh die Luft schiefenden liolihris in erster Reihe stehen. I) (nn fiegensatz zu ihmen bilden die Laufvägel. von denen die Straube ihre vorteren Extremitäten üherhaupt nicht mehr zum Flug benutzen kïmnen und daher auch nur schwach entwickelte Brustmuskeln besitzen.

In allen Fällen nun, in denen durch Anpassung an das Fliegen die Iirustmuskulatur stark ausgebildet ist. hat sie an einer groben Reihe anderer () pansteme antsprechende liorrelative Abänderungen nach sich gezogen. Zu aroben Muskehassen gehört ein entsprechend grobes Trsprungsgebiet am skelett. Infolgerlessen sehen wir bei allen Flugrögehn das Brustbein, damit es den zahlreicher gewordenen Fasern des Musc. pectoralis eine genügende Ursprungstläche darbietet, mit einer großen Crista sterni an-_erïstet: diese gewinnt wieler dlie gröbten Dimensionen bei den besten Flierpen mit den stirksten M. peetorales. So ist hei den kleinen liolibris (Fig. : 47 ) der Inustheinkamm von einer ganz überraschenden Höhe, indem er noch $11 \mathrm{~m}$ ein beträchtliches den sterno-vertebralen Durchmesser des Brustkorbes übertrifft. Im Gegensatz dazu fehlt eine Crista sterni ganz bei den Straußen mit ihrer verkiummerten Brustmuskulatur.

Zu der offenkundigen Korrelation zwischen Muskel- und Knochensystem gesellen sich noch zahlreiche andere. Da jede Muskelfaser von siner Nervenfaser innerviert wird, erfahren die Nervi pectorales hei den 


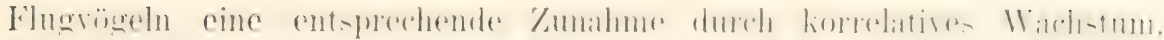
Wahrscheinlich sind hiermit wieder Veranderungen an den Ursprungsstellen der Nerven im Rückemmark verknüpft, da die motorischen Nerven-

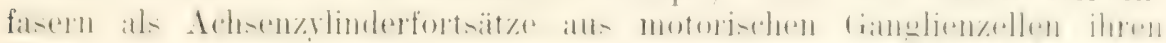

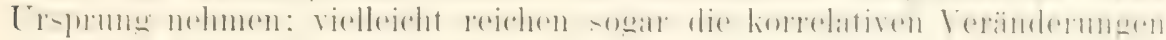
bis in die Himrinde hinein. wo die Prramidenbahmen ihre zentralen Ursprünge haben.

Wie das Nervensystem wird auch das BlutgefäBsystem verändert. indem das Kaliber der die brustmuskeln ernährenden

Arteriae thoracicae in entsprechender Weise zunimmt. Mit ter Vergrößerung des Durchmessers mub sich die Gefäbwand verdicken und sich in ihren Schichten der stärkeren Beanspruchung gemäß histologisch verändern: sie mun eine dickere Intima. melı elastisches Gewehe und zahlreichere glatte Muskelzellen erhalten. Und wenn wir das korrelative Wachstum noch mehr in seinen Einzelheiten velfolgen wollen, so müssen wil weiter himzufügen, daß mit der new entstandenen und vergrößerten Crista sterni, dem stårker

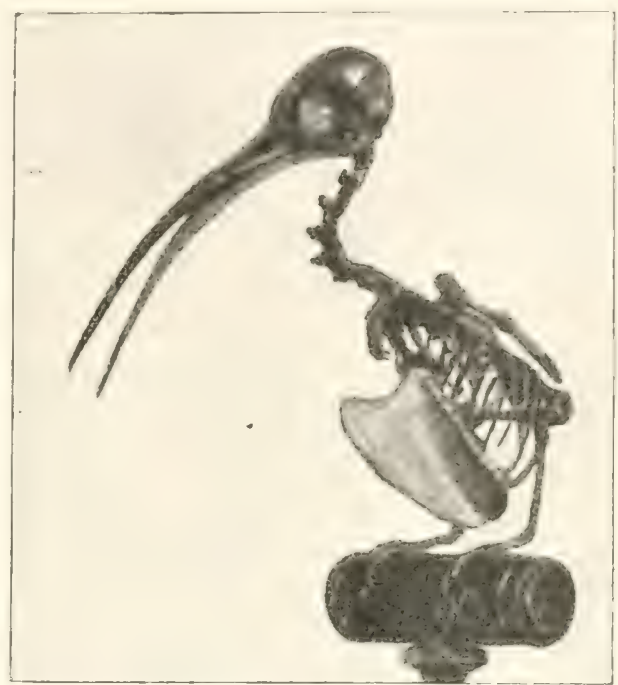

Fig. 347. Skelett eines Kolibri (Lampormis). Die Crista stemi ühertrifft an IJöhe um ein Erhebliches den Sterno-rertehraldurchmesser des Brustliorlies. gewordenen Nery usw. ebenfalls

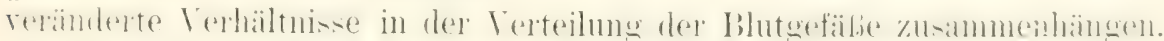

Korrelative Veränderungen geht fermer auch das mit allen genamnten

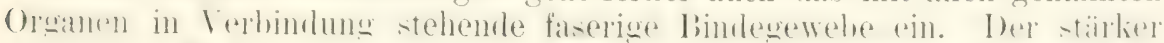

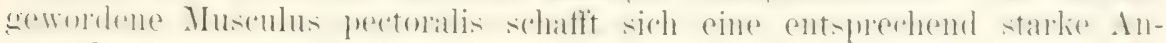
satzsehne am Oberarmknochen, welcher selbst infolgedessen mit einer ansehnlicheren 'Tuberositas an der Ansatzstelle ausgestattet wirl. Das interstitielle Bindegewebe zwischen den Muskelfasem nimmt \%u. Der dicliere Tervenstamm erhält ein entsprechendes Perineurium.

In dieser Weise hat die durch Ampassung an den Flug herrorge-

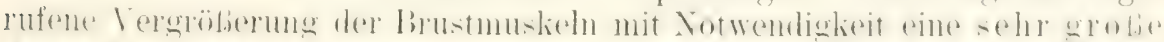

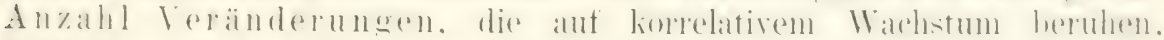
Veränderungen an Organen und vielen Geweben zu ihrer Folge gehabt. wobei wir noch ron zahllosen anderen Prozessen in Körper (an Lunge. Herz etc. etc.) ganz absehen.

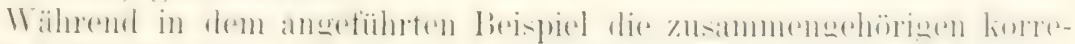

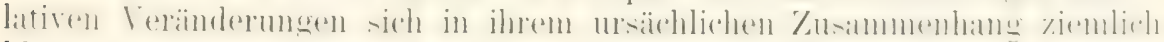
klar überschauen lassen. fehlt uns in anderen Fillen. aus denen wir das zweite Beispiel herausgreifen, zurzeit noch die tiefere Einsicht.

Mehr oder minder unverständlich ist uns der Zusammenhang zwischen der Entwicklung der Geschlechtsdrüsen und der sogenannten sekundären Sexualcharaktere, die bei manchen Tieren.

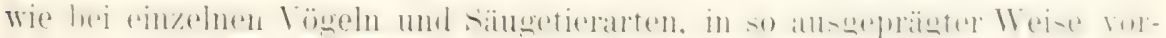

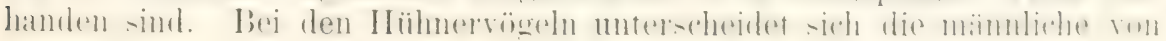


der weiblichen Form durch den liesitz oigentümlieher bhtreicher Hautlappen an kopf, durch die eigenatige Befiederung, namentlich des IIalses: bej den sehweinearten sind die Eckzähne des Männchens zu den mä̈htigen Ilanern (ntwiclielt: heim Menschen treten Lnterschiede in der Behanmug. in der Form des Kehlkoptes und in der von ihr abhängigen tieferen oder höheren Stimmlage ein.

Daß die Ausbildung der sekundären Sexualcharaktere in Korrelation

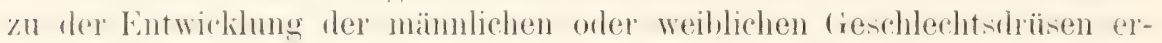
folgt, läßt sich experimentell beweisen; denn sie läßt sich ganz oder teilweise unterdrücken, wenn man den männlichen Tieren, z. B. dem Hahn bald nach seinem Anskiechen aus dem Ei orler dem newgeborenen Fiber die Hoden kastriert. Ferner ist von (ler Henne bekannt, daß sie in vorgechrittenem Alter; wenn die Elentwicklung im ()varium aufhört, be i der Mauserung in der neu sich lidenden Befiederung dem Iahne ähnlicher wird: man hat taher den bei alten Hemen gelegentlich auftretenden Znstand als Itahnenfedrigkeit bezeichnet. Auch menschliche Eunuchen erfahren infolge der Kastration mangelnde Iusbildumg der sekundiuren Siexualcharalitere. zeichnen sich durch verändertes Wachstum des Kehlkolfer: hohe Stimme und mangelhaften Bartwuchs aus.

Wenn auf der einen Seite der Zusammenhang zwischen der Entwieklumg der Geschlechtshlïsen mul der sekundïren sexualcharaktere nicht in Ahrede gestellt werlen kann. so fehlt uns auf ler anderen Seite roch das tiefere Verständnis dafür. Wird die Korrelation zwischen den Organen, welche funktionell direht nichts miteinander zu tum haben, durch das Nervensistem vermittelt, oder sind es vielleicht besondere Suhstanzen, welche rom IIorlen oder rom Fierstock ahgesondert werden, in den Blutstrom eraten und so die weit abgelegenon Körperteile zu korrelativem Wachstum reranlassen? $\mathrm{Zu}$ einem Entscheid der aufgeworfenen Alternative fehlt es noch an jeder experimentellen Unterlage.

\section{Einteilung der Korrelationen in einzelne Gruppen.}

Zum richtigen Verständnis der Korrelationen mub man in Betracht ziehen, dab innerhalb eines Organismus, wie anf Seite 411 auseinandergesetzt wurde, sich jeder Teil zum anderen als Außenwelt verhält. Daher sind tür die beurteilung ihrer gegenseitigen Rezichungen dieselben liesichtspunkte mabgehend wie für die Bezixhmeren zwishen ()romismus und Aubenwelt. Wie letztere auf den ()ronismus mit unzähligen, mamniofaltigen licizen einwirkt, die wir als mechanische, chemische, themische. elektrische etc. unterschieden haben, so ist im Organismus ein Teil als eine Reizquelle für andere Teile in genau der gleichen Weise anzusehen.

Hierbei sind es nicht bloß die Nerven, welche Reize übertragen. Reize können viehnehr noch auf manchen anderen IVegen übermittelt werden. Zellen, welche besondere Stoffe in die Säfte des Körpers abscheiden, liefer'n ebenso viele chemische Reize, welche an den verschiedensten, oft rom Entstehungsort weit abgelegenen Stellen ihre Wirlimngen anf andere reizemptangliche Zellen ausiben kömnen. Denn durch

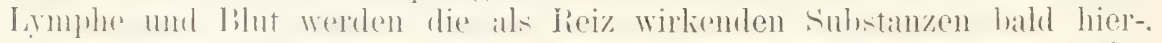
bald dorthin fortgeleitet. Ebenso wird beim Lebensprozeb der Zellen Wärme produziert, die ebenfalls, indem sie zunächst die Bluttemperatur bestimmt, an eimzehnen Stellen des Körpers als Reiz zu besonderen Wirkungen führen kann. An mechanischen Reizen zwischen den Geweben

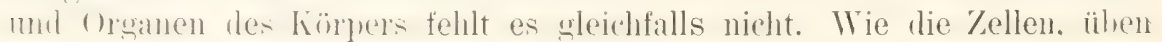


die wachsenden Gewebe und Organe einen Druck aufeinander aus umb hestimmen sich dadurch in ihrer äuBeren Form. Muskeln wirken durch

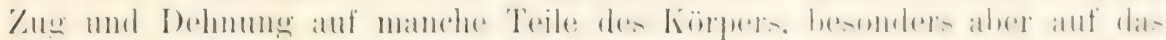
faserige Bindegewebe ein, das sie dementsprechend formen. Die Wan-

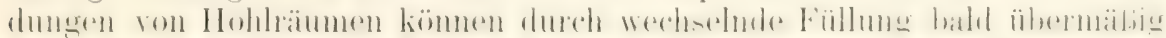

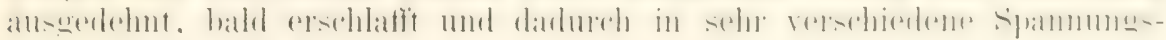
zustände versetzt werden.

Je nach den in Frage kommenden Reizen können wir daher auch die Korrelationen des Körpers in (iruppen einteilen, in Korrelationen,

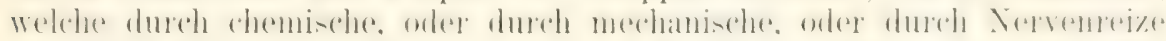
vermittelt werden. Dazu kommen noch Wachstumsprozesse, lie in einer

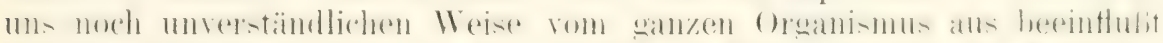

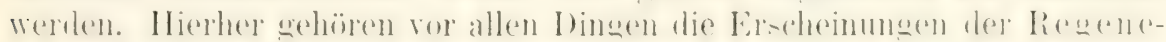
ration und der Heteromorphose.

\section{Chemische Korrelationen.}

a) Chem isch-physikalischer Prozeb der. Sauerstoffaufuahme und Kohlensäuleabgabe.

Die Zellen des Körpers produzieren bei ihrer 'Tätigkeit Kiohlensäure

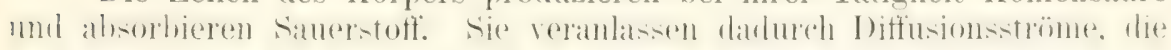
an verschiedenen Orten stattfinden, einmal zwischen den Zellen und den

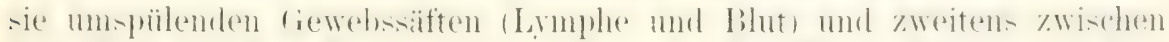

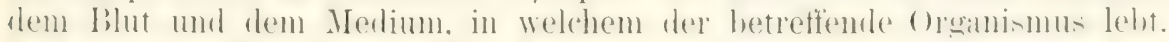
Durch die Diffusionsströme wird ein Ausgleich in der Gasspannung an

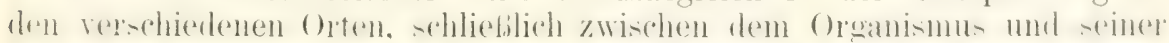

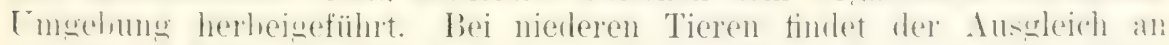

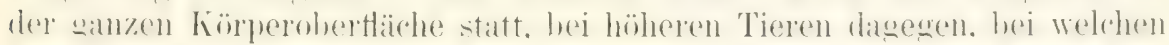

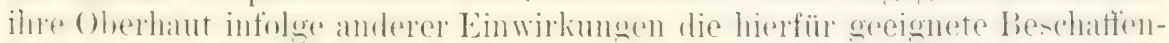

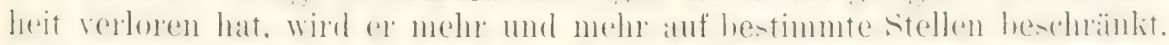
die je nach ihrem Ban als Kiemen, Lumgen, Tracheen bezeichnet werden.

Nun muß, wie eine einfache Überlegung lehrt, ein jerler Organismus ein bestimmtes Atembedürfnis besitzen. dessen Größe ron der Zahl der

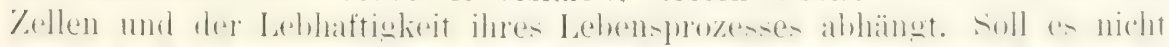

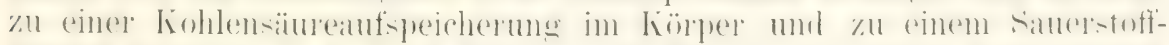

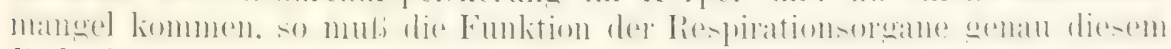
liedürfnisse angepaßt sein. Für jerlen Organismus muß daher die respirierende Obertläche entweder der Kiemen, oder der Lungen, oder der

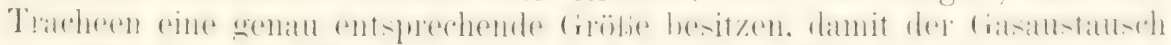
in entsprechender Weise stattfinden kamn. Die Atmungsorgane müssen daher so lange wachsen und inre Oberfläche vergröbern. sei es durch Zottenbildung, wie bei den Kiemen und der Placenta, oder durch Alveolenbildung. wie bei den Lungen, bis der notwendige Ausgleich eingetreten ist.

Wodurch wird dieses Wachstum des einzelnen Teiles in liorrelation

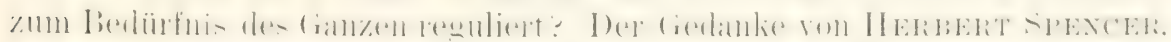
(laf) es der Diffusionsstrom des Samerstoffes und der Kohlensäure orler die Höhe der Gasspannung ist, welche auf die zur Atmung dienenden Körperstellen als Wachstumsleiz wirkt. scheint mir den Weg zu einer naturgemähen Erklïrung anzuzeigen. Die respirierende Oberfläche wächst so lange, bis die Gasspannung zwischen dem Körper und dem ungebenden Merlium auf einen bestimmten Grenzwert herabgesetzt ist.

In dieser Weise erklïren sich wohl die Beobachtungen. die Scurenbers an Proteus anguineus angestellt hat. einem Amphibium. welches sowohl 
durch Kiemen als durch Lungen atmet. ScHrembers hat beim Proteus

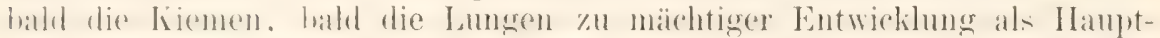

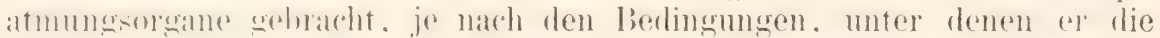
Tiere züchtete. Wurden die Tiere gezwungen, in tieferem Wasser zu lehen. - o entwickelten sich die Kiemen bis zum Dreifachen ihrer gewöhnlichen Größe, während die Lungen zum 'T'eil atrophierten. Bei einem Aufenthalt in serditerem Was-er dagegen wurden die Lungen gröber und wetabliredeher. weil jetzt die Tiere hiutiger an die Ohertläche kamen und Luff dinatmeten. Da durch die Lumgen dem Atemberlürnis nuter dienen

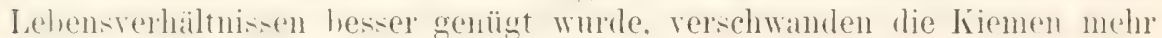
oder weniger vollständig.

Was für den chemisch-physikalischen Prozeß der Atmung, das gilt in gleicher Weise für andere derartige Prozesse, die sich in unserem Liorper alspielen. Ein wertrolles beohachtungsmaterial hierüber hahen mis die pathologischen Anatomen und Klinilier durch Exstirpationen ron einer Niere, oder eines 'Teiles der Leber, oder der Schilddrüse, oder des Pankreas, oder durch starke Aderlïs̄se geliefert.

\section{b) Harnbildung. Niere.}

Entfernung einer Niere hat regelmäBig eine Arbeitshypertrophie der anderen Niere zur Folge. Letztere hat zuweilen nach längerer Zeit so sehr an Größe zugenommen, daß sie das Gewicht von zwei Nieren hesitz. An der Vergröferung ist weniger die Marksubstanz als hanptsädhlich die Rinde heteilint: , olie gewumbenen Kanälchen werden hreiter. die Epithelien unfünglicher, anch die (iefäbknänel hypertrophieren”. Man findet eine Zeitlang rom vierten Tage nach der Exstirpation bis in die vierte Woche zahlreichere Kernteilungsfiguren in den Tubuli contorti.

Die das Wachstum verursachenden Momente sind ähnlicher Art wie hei den Kiemen mul den Lumwen. Bald nach Entfermung der einen Niere tritt an die andere eine erheblich gesteigerte Aufgabe heran, die Entfernung der doppelten Menge der im Blut sich ansammelnden ,harnfïhigen sulstanzen". Ihre Menge hat ja gegen früher keine Verrmgerung erfahren, da sie von den Lebensprozessen in allen Organen und Geweben des Körpers abhängt. Die eine Niere wird daher jetzt viel stärker in Anspruch genommen.

Unter auBergewöhnlichen Umständen kann fast jedes Organ des Körpers mehr leisten, als seine normale Leistung beträgt; es besitzt, wie man sich aurdrüclit, noch eine äher seine sewöhnliche Arbeit hinausgehende Reservekraft, die nun noch ausgenutzt wird. So kommt es, lali schon 24 stumlen nach einer Nierenexstirpation täglich die gleiche Ilarmmenge mit demselhen (iehalt an festen Sulstanzen ausceschieden wird wie vorher. Durch die Glomeruli muß daher eine größere Menge Harnwasser und durch die Epithelien der Tubuli contorti die doppelte Quantitait von Harnstoff usw. hindurchgehen.

In den so veränderten chemisch-physikalischen Verhältnissen haben wir anch hier wieder die Reize zu suchen. Welche die Nierenhypertrophie veranlassen. „Es liegt hier", wie schon ZiEgLER hervorgehoben hat, „ein Fall vor, in welchem eine Zellulation direkt durch die Anwesenheit chemischer Substanzen, welche die Zellen zu erhöhter Tätigkeit anregen, bewirkt wird." Das korrelative Nierenwachstum wird so lange andauem, bis wieder ein Ausgleich eingetreten 
ist, d. h. his die Harn sezernierende Oberfläche wieder der vom fiesant-

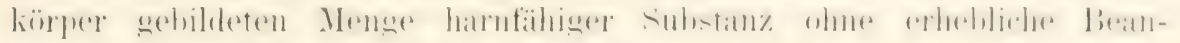
spruchung der Reservekraft angepabt ist.

\section{c) Die Leber'.}

Nicht minder instrulitiv sind die von PONFICK und voN PODWrssozkr

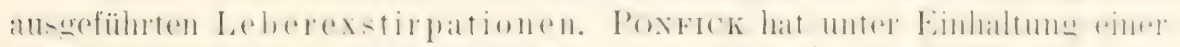

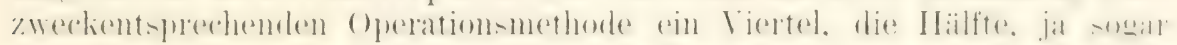
drei Viertel von der Leber zahlreicher Kaninchen weggenommen, ohne

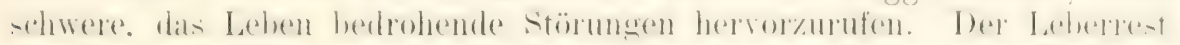
scheidet nach der Operation Galle weiter ab, was sich an der Fïrbung

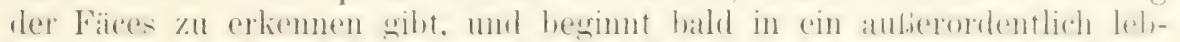
haftes Wachstum einzutreten. Schom nath wenigen Tagen sinel die zurürli-

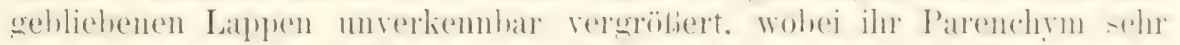
weich wird: nach 11 Wochen war in einem Fall ein voller Wiederersatz. des entfernten Ieberteiles eingetreten. Man hamm sogal die Mucherung--

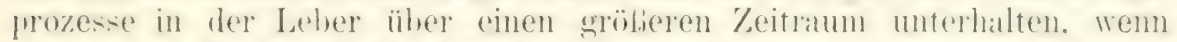
man einige \%eit nach der arsten noch eine zweite mul hach diesere noch eine dritte Exstirpation vornimmt. Daher bemerkt Ponfick:

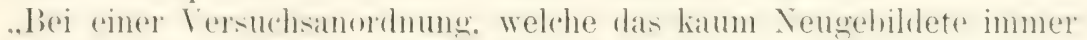
wieder auszuroten tradetet, hetatiogt sich der Wachstumstrieh mit solcher

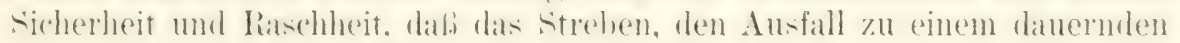
zu gestalten, fort und fort wieder vereitelt wird. Immer von neuem ist er fähig, den zugefügten Verlust wett zu machen."

In eimzelnen Experimenten hat sich der Torso auf mehr als das

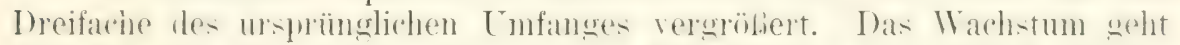
teil- ron den Leberzellen. teils ron den Evithelzellen der tiallendapillaren alls. Welche strïnge hilden und sich weiterhin in Salken ron Leberzellen umwandeln. Während man in dem normalen Zustande niemals Kernteiluns-figuren in den Leberzellen tindet. treten soldhe he-onder's an zweiten

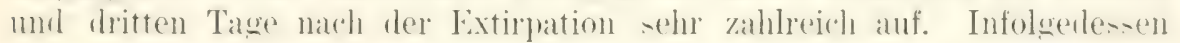
vergrößern sich auch die Leberacini über ihr normales Maß hinaus.

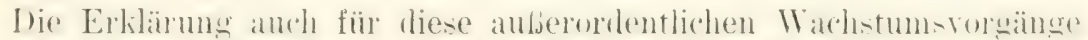
wird in derselhen Itichtung wie für die Lange mul die Niere zu suchen sein. Auch der Leher werden durch das von Darm und Milz kommende Ifortarlerhlut hestimmte chemische stoffe zugeführt. Welche in ihr zu rils-

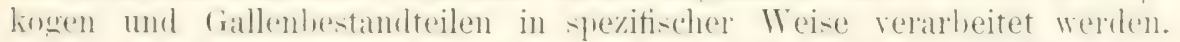
Daher wird nach der Extirpation eines Teiles der Leber der Rest eine

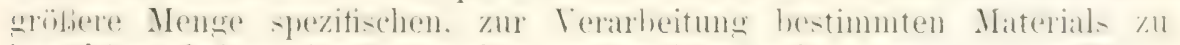
hewätigen hahen. die Lebermellen werden hierdurch zu gesteigerter Tätiskeit und zur Vermehrung so lange gereizt werden, bis wieder ein Ausgleich herbeigeführt ist.

\section{(1) Die Schildrüise.}

Die Untersuchungen des letzten Jahrzehnts haben uns als ein wichtiges Stoffwechselorgan die Schilddrïse kennen gelehrt. Das aus Fol-

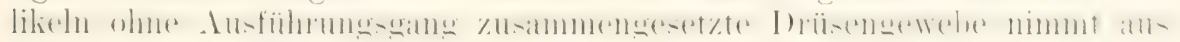
dem es so reichlich durchströmenden Blut einzelne Bestandteile auf, die es verändert und im Innern der Drïsenbläschen abscheidet. Durch die wichtige Entleckung BaUmaxs wissen wir jetzt, dah in den Follikel-

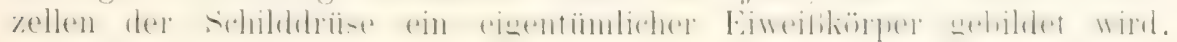
welcher sich durch einen sehr hohen fichalt an Jod anszeichnet und daher 
auch fon ihm den Namen Thyreojodin erhalten hat. Durch Fütterung:versuche isf ferner von ihm nathewiesen worden, dab der Jobgehalt der

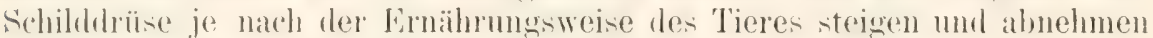

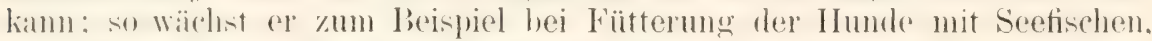

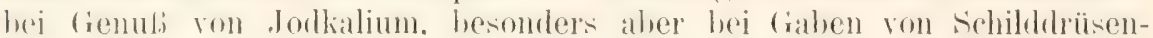
extrakt oder Thyreojodin. Die Schilddrüse ist also ein Organ, welches die Eigenschatt hat. kleinste im Bilut zirkulierente Mengen ron .Jod an sich zn ziehen, an einen Eiweißkörper zu binden und in dieser Form in sich aufzuspeichern.

Indessen ist mit der Absonderung eines Stoffes aus dem Blut und soiner Aufseicherung in den Follikeh die Wirksmbeit der Sohildnrïse noch nicht erschöpft. Die in der schilddriase nemgebildeten mol anferespeicherten Stoffe. wie unter anderem das Thyreojodin, geraten selhst wieder in den stoffirechsel hinein. wahrseheinlich durch Vermittelung des Lymphstromes. Dem wie Kixg nachwies mol Horsley (S. :37!) mol andere bestätigten, genügt schon ein leichter Druck auf die Drüsenlappen, den Inhalt der Drïsenfollikel in die peripheren Lymphbahnen zu treihen. Demnach bildet die Schilddrüse ein Beispiel für ein ()rgan mit innerer siekretion im Sinne von BROWN-SEQUARD.

Durch die Veränderung der chemischen Beschaffenheit des Blutes kamn nun aber die Schildhüse, wie jedes stoffwechselorgan. korrelative Prozesse im ganzen Körper hervorrufen, was auf Grund von zahlreichen Experimenten und von Krankengeschichten Wahrshemlich ist. Ein bestimmteres Trteil kimn zurzeit noch nicht abgegehen werlen, da gegen die Deutung und Tragweite vieler Experimente. am entschiedensten vom II. Muxk. Einwände erhoben werden. welche alle Berïckisichtigung verdienen.

Das fast ausschließlich angewandte Verfahren, $u m$ in die Funktion der Schilddrüse einen Einhlick zu gewinnen, ist die operative Entfernung der Schildruice orler die Thrreoillektomie. In simnreicher Weise ist dieselhe von Erselsbers noch mit einer 'Transplantation der Schilddrüse in die Bauchwand kombiniert worlen. Ihr Erfolg fällt, wie es von den meisten Experimentatoren dargestellt wirl. verschieden aus. je nacholem esich un eine totale oler eine partielle Entfernumg des organs handelt und je nadhlem man die Operation im jugendlichen oder vorgeribchteren Alter ausgeführt hat.

Unter totaler Exstirpation versteht man jetzt die Entfernung der gesamten Ilanptschildhrïse und aller sogenamnten Nehenschildhrïsen (cilandular parathreoileae. SAxpströnsche, (isersche Dä̈sen). Letztere liegen bei manchen Säugetieren (IImulen) der IIauptroüse mmittelbar dicht an. so dal, sie für sewöhnlich absichtlich orler unahsichtlich mit ihr zugleich entfernt werden; bei anderen dagegen liegen sie am Hals von ihr getrennt und mehr oder minder weit entfernt (Kaninchen), so daß der Operateur auf ihre Entfernung besonders achten mub. Die totale Exstirpation in diesem Sinne ist, wenn sie bei jungen Tieren ausgeführt wird, stets eine absolut tödliche Operation, welche in wenigen Tagen das Ende herbeifiiht. Es erfolgt nuter shweren störungen im Bereich des Nervenststens. unter allgemeinen Krämpfen und Konvulsionen (Tetanus).

Jie unvollständige Entfernung der schilddrüre dagegen führt. menn sie im jugendlichen Alter vorenommen wird. zu einer eigentïn-

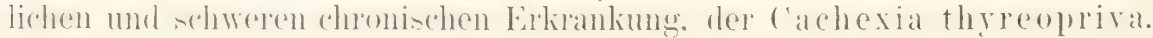
Unvollstündig nennen wir die Operation, wenn irgend ein Rest ron Schilddrüsensubstanz, entweder ein Stückchen von der Hauptdrüse oder alle 


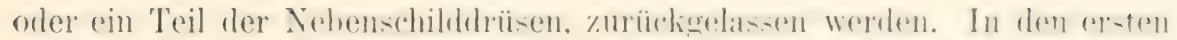

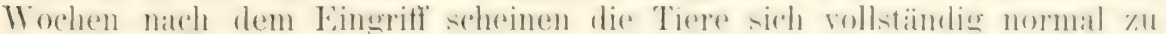

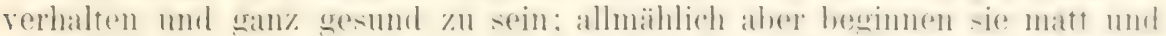

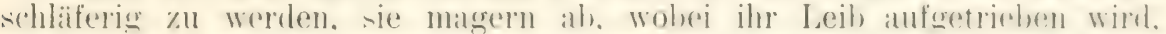
sie bleiben im Wachstum geren andere gloichatterige fiere orhehlich zu-

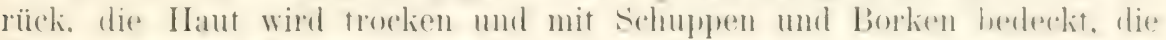
Haare beginnen teilweise auszufallen.

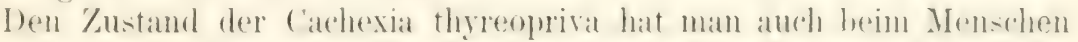
eintreten sehen infolse von hroptextirpationen. zumal wenn sie vor der Pubertiat ansegeülrt wurlen. Vorher intelligente Kranke verloren ilne geistige Jegsamkeit in hohem (ilade, hliehen im Wahtotmm zurürk. ihre Wärmeregulation war gestört (hïltegrefühl), die IIaut wurle hart, rauh uml

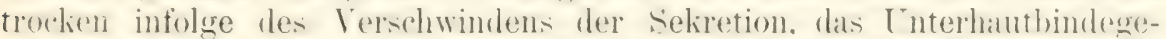
weine wurde dicker und elastisch. Was nit eigenartigen Veränderungen im Binderewehe zusammenhängt, die man unter dem Samen des II yxödems zusammengefaßt hat.

Der bei Tieren und Menschen heobachtete Stillstand im Wachstum des liöpers heruht hauptsïhlich auf Störungen in der linorhenentwirklung. Wie die mikroskopischen Intersuchungen bei jungen himinchen selehrt haben. tritt eine spezifische Degeneration der das Wachstum vermittehden Epiphysenknorpel ein. bestehend in Herabsetmong der normalen Zellwucherung. in quellung und Zerklüftung der Cirmonsulstanz. verhunden mit hlasiger Aufreibung der hinorpelhöhlen und schrumpfung. ja sogar teilweisem Interwang der Zellen (chondrodystrophlia thyreopriva. HoFMEISTER).

Iner bei der (achexia thyreopriva heobachtete simptomenkmulex zeist vielfache Beziehungen zu dem Kretinismus und zur .fïtalen Ihluachitis" und bietet hierlurch eine stiitze für die Theorie. welche auch jene beilen Erkrankungen von Stïrungen oder V'ernichtung der Funkition der Schilddrỉse schon während des intrauterinen Lebens herleitet.

Auf die durch Exstirpation der Schildlüise hervorgerufenen Zustände wurle an dieser Stelle näher eingegangen. weil nach dem ['rteil vieler Forscher sowohl in der zum Tode führenden 'Tetanie. als auch in der Cachexia thyreopriva, in der lieeinträchtigung der Iirnfunktionen, in dem Myxïlem, in den gestörten Verknöcherungsporessen etr. Wahrscheinlich die Folgen eines arstörten chemismus oler stoffwerhsels zu erblicken sinu.

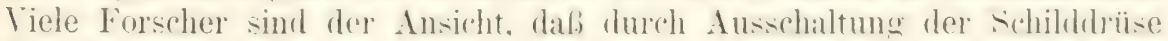
das blut eine verinderte vhemische Zusammensetzung erhält. entweder weil wichtige chemische hörper nicht gehildet oder weil schädliche. in bilut zirlinlierende stoffe nicht ausesechieden und umerewandelt werilen. oder weil beides zugleich stattfindet.

Wie Spuren abnormer Substanzen in dem die Zellen umspülenden

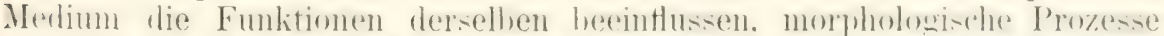
strïren. liemmen und andere an ihrer stelle herrorrufen, hathen un- schon die im Kapitel XXI angeführten Beispiele gelehrt.

Dab es sich um chemische Reize handelt, läßt sich in dem Fall der

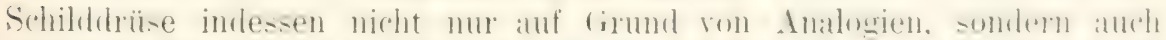

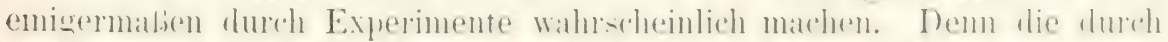

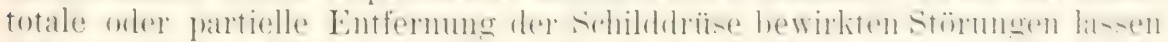

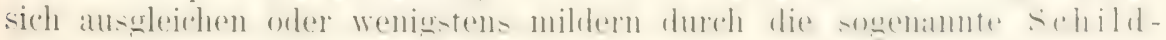
driisentherapie. Der Terlust der Schilddrüse läßt sich teilweise da-

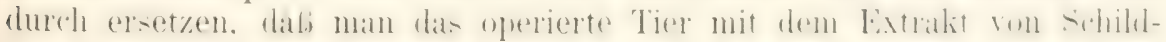
drüsen füttert oder ihm ein geeignetes Präparat subkutan zeitweise 


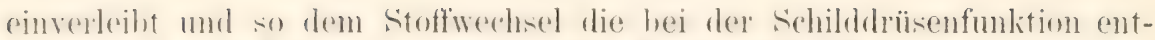
stehenden, dem Körper unenthehrlichen substanzen künstlich zufiihnt.

Noch wirksamer aber als der Schilddrüsenextrakt hat sich die medi-

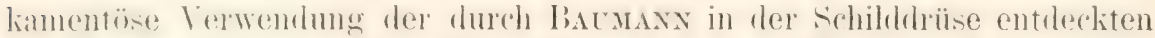
-provitishen substanz, des Thyrojorlins, erwiesen. Sach den übereinstim-

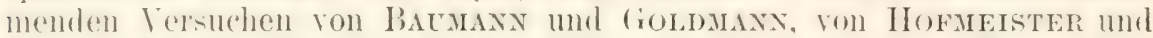
HILIEERANDT treten nach totaler 'Thyeoilektomie tetanische Erscheinung(n - o lange nicht ein, als den schilddrüsenlosen Hunden oder Kaninchen

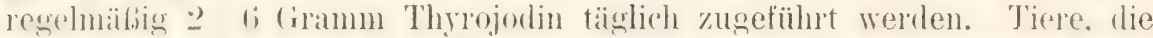
sonst einige Tage nach der Operation unfehlbar an Tetamus gestorben sein wïrden, hahen sich auf diese Weise worhen- und monatelang an Lehen erhalten lassen. Dagegen traten bei den Versuchstieren Kramufanfälle labl ein. nachlem entweder mit rler Verabreichung des Thyrojodins ausgesetzt orler die Dosierung in erheblicher Weise verringert worden war. Wem bei schilddrüsenlosen Tieren die tetanischen Krämpfe auftreten. so lassen sie sich mildern und anch ganz unterdrücken durch sofortige Verabreichung srölierer Mengen von Thyrojorlin, welche an besten sublintan erfolgt.

Durch Gaben von Schilddrüsensubstanz oder Thyrojodin (Substitutionstherapie) kann man auch in günstiger Weise den Kropf, das Myxödem und die Cachexia thyreopriva beeinflussen.

Bei der Substitutionstherapie wird, um eine dauernde Wirkung zu erzielen. unverhältnismäbig viel schilddrüsensubstanz oder Thyrojodin verbraucht. Man erklärt dies in cler Weise, daß unter normalen Verhältnisicen das in der Schilddrüse gebildete Thyrojodin von ihr zurückgehalten und nur langsam im Stoffwechsel aufgebraucht wird, während hei schilddrüsenlosen 'Tieren das durch den Darm aufgenommene orler sulkutan eingeführte 'Thyrojodin nicht lange im Organismus bleiht, sondern hald als solches onler in Form einer anderen organischen Verbindung in Harn ausgeschieden wird (BAUMANN).

Zu einigen Bemerkungen gibt noch die partielle Thy reoidektomie Teranlassung. Nicht nur erfahren wir aus den Versuchen, dab eine äulierst geringe Menge von Schilddrüsen- und Nebenschildhüsengevehe genügt, um den tödlichen Ausgang der ()peration zu verhüten; noch mehr interessieren uns in diesem Kapitel einige korrelative Wachstumsprozesse, die atch hier in ähnlicher Weise wie bei einseitiger Entfermung der Niere oder teilweiser Entfernung der Leber beobachtet werden.

Nach Beresowsky tritt bei Hunden nach Abtragung des gröberen 'Teils der Sohildurise eine kompensatorische Hypertrophie des Restst ï ckes ein. Man heohachtet einige Tage nach der Operation Kernteilungstiguren im schildulïsenserwehe und Neubildung ron Follikeln. Doch hleiht hier in Verglesh zur Niere und Leber die Iypertrophie eine selır geringfügige.

AuBerdem findet eine kompensatorische Hypertrophie noch an zwei anderen Stellen statt. Eimmal verenöbern sich in reringem Mabe die Nebenschilddrüsen (Gley, Verstraeten und Vanderlinden). Zweiten- heobachtet man nach Wromblne der Hauptschildhüse eine charakteristische Umwandlung des Hirnanhanges, der Hypophysis (Bogowitsch, Stieda, Hofmeister, Gley). Ihr Volumen nimmt oft in be-

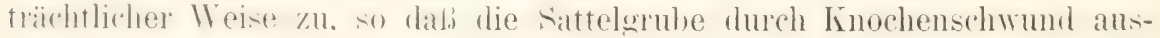
geweitet wird. Es kamn sogar die Drüse bei besonders hohen Graden der Hypertrophie über den Rand der Grube nach außen hervortreten. Ihre 7ellen zodgen sich vergribliert: in ihrem Protoplasma sind Valimolen 
entstanden. Hofmeister zieht hieraus den Schlub, daß die IIypophysis eine ähnliche Funktion wie die Schilddruise ausübt. und

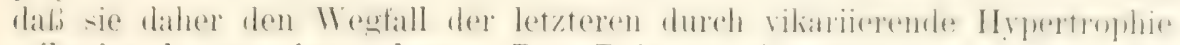
teilweise kompensieren kann. Der Reiz zur Hypertrophie wird in der

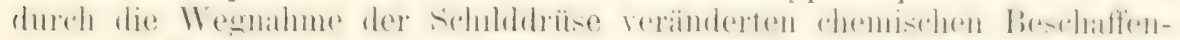
heit des Blutes in ïhnlicher Weise zu suchen sein, wie für die Nieren-

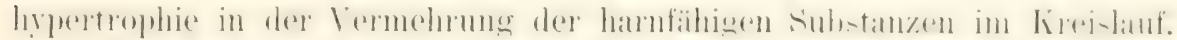

Wieviel ron den hier mitgeteilten Beobachtungen und Deutungen

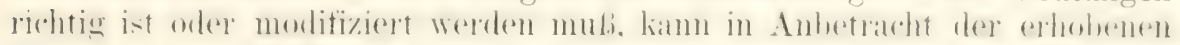
Einwïnde ron H. MuNk nur durch weitere und umfassendere Untersuchungen entschieden werden.

\section{e) Blutbildung.}

In das Kipritel der ahemischen Korrelationen sind endlich aurde die?

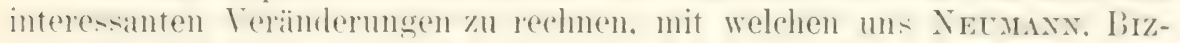
zozero und viele andere hei ihren srumblegenden L'ntersuchungen ijher die Blutbildung bekannt gemacht haben.

Wer prïfen will, in welcher Weise und an welchen Stellen des Körpers ein Ersat\% für die roten Blutkörperchen stattfindet, welches im Krei-lauf ihre Polle auscespielt haben und zerfallen. hommt an leichtesten zum Ziel. wem er auf experimentellem Wege den Prozeli der Bluterneuerung zo einem hesonders lehhaften zu machen imstande ist. Man kimm dies durch zwei Methoden erreichen, durch welche die Beschatfonheit des lihtes verändert und namentlich das normale Mengenverhältnis der roten lihthïrperchen stark verindert wird. Die eine Methode brsteht in starken Aderlässen, welche man mehrmals in Pausen von 2--3 Tagen an den Versuchstieren vornimmt. Bei der zweiten Methorle injiziert man

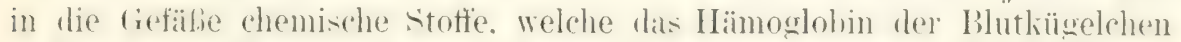
autiősen (wie Toluydendiamin, Jodeyan, Azetylphenylhydrazin).

In beiden Fällen wird die Qualität des Blutes in erheblicher Weise verändert: die gefornten bestandteile werden -tark vermindert. auch das IBlutplasma erhält eine andere Znsammensetzung. inden nach delerliissen

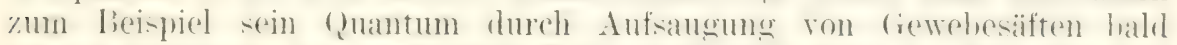
wierler zunimmt. I) ie reränderte Blutgualitait aher wirlit als Reiz für eine

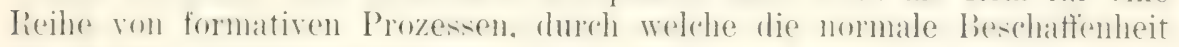
des Blutes allmählich wiederhergestellt wird.

Für den Mikroskopiker am leichtesten nachweisbar sind die Vorgänge, welche zu einer raschen Vermehrung der roten Blutkör-

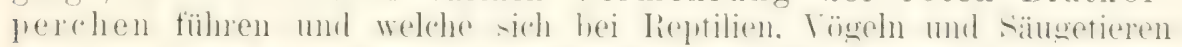
besonders im Knochenmark nach der Entdeckung ron Neumany und bizzozERo abspielen.

Nach wiederholten, ausgiebigen Arlerlässen, desgleichen nach An-

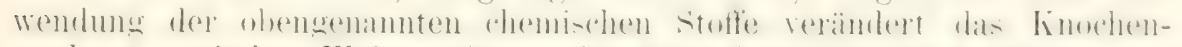

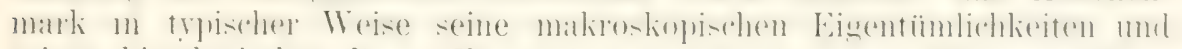

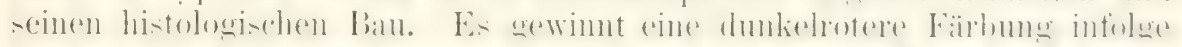

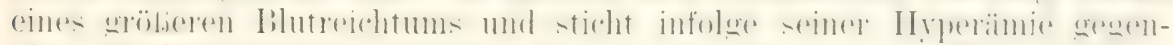

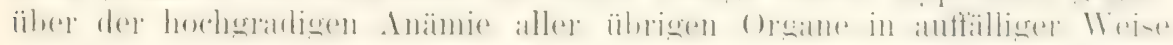
ab. (Bei Vögeln nimmt es nach starken Arlerlïssen häufig eine graue Farbe an.) Es wird weicher und sulziger. Denn die Venenliapillaren haben sich stark erweitert, während das Zwischengewebe reduziert wirch. Die Fettzellen in letzterem werden kleiner und atrophieren. Besonders aber wandelt sich das GefüBnetz im Mark zu einem Bildungsherd für zahlreiche, neue, rote Blutkörperchen mu; daher es von Brzzozero als 
,ein wahres endovaskuläres Organ der Blutregeneration" bezeichnet wird.

Man findet nämlish in den erweiterten Venenkapillaren auffaliend viele Jugendzustande roter Blutlörperehen, die Erythroblasten (BrzzOzERo) oder Hämatoblasten. Es sind dies Blutkörperchen, die an rioulie hinter den normalen etwas zurückstehen und einen kugelrunden liern hesitzen. worlureh sie sich besonders bei siügetieren sofort unterscheiden lassen. In ihrem Stroma ist ferner nur sehr wenig Iämoglobin (nuthalten, so dals sie sich nur durch geringe (ielbärbung von Lenkoryten unterscheilen. Die Erythroblasten zeichnen sich wie die embryonalen Bhutkörperchen durch die Fähigkeit aus, sich durch Teilung zu vermehren. Namenthich 10-15) Stunden nach dem letzten Aderlab findet man in sehr vielen von ihnen Kernteilungsfiguren und Teilungsstadien.

Erythohlasten kommen zwar zu allen Zeiten im roten Knochenmark vor; ihre Zahl ist aber eine viel geringere. Wie zahlreiche Forscher, Bizzozero, Neumann, Kolin, Denys, Eliasberg, Freiberg, Foa usw., in überemstimmender Weise angeben, wird durch Aderlässe und durch die anderen obenerwähnten Eingriffe ihre Zahl und ihre Vermehrung ungemein westeigert. In riegensatz dlazu tritt eine starke Abnahme bei humgernden oder sehr abgemagerten oder kranken Tieren ein, so dab Erythroblasten im Knochemmark kaum oder ïberhaupt gar nicht mehr nachzuweisen sind.

Abgesehen vom Kinochenmark ist eine Neubildung roter Blutkörperchen infolge der obenerwähnten Eingrifte anch noch in der Milz von einzelnen Forschern beobachtet worden. Brzzozero findet in ihr viele Teilungsfiguren von Erythroblasten bei den geschwänzten Amphibien, deren Knochenmark keine Bedeutung für die Blutregeneration in Gegensatz zum Frosch hesitzen soll. Nach Eurasberg treten bei den Säugetieren (Hund) liernhaltige Bhutkörperchen und Teilungsstadien von ihnen auber im Kinochenmark auch noch in der Milz auf, und zwar hauptsächlich in den intravaskulären Pulpasträngen.

Das allgemeine Ergehnis der mitgeteilten Experimente kömnen wir in den einen Satz zusammenfassen: Durch Korrelationen unbekannter Art wirkt die veränderte Beschaffenheit des Blutes als Reiz auf die blutbildenden Organe ein und regt sie zu vermehrter Tätigkeit an, bis der normale Zustand und dadurch das gestörte Gleichgewicht im Körper wiederhergestellt ist.

\section{Mechanische Korrelationen (Mechanomorphosen).}

Wie Zug und Druck, von außen auf die Organismen einwirkend, in ihnen Reaktionen hervorrufen. welche zur Entstehung der im XX. Kapitel hesprochenen mechanischen (iewebe und Organe führen, so kommt es auch in Innern des Körpers selhst zwischen den einzelnen Organen zu mechanishen Weohelwirkumgen, als deren Folge sich bestimmte Einrichtungen ausbilden.

Je nachdem sich hierbei die einzelnen Organe mehr aktiv oder passiv verhalten, lasen sich anch die mechanischen forrelationen in zwei fruppen einteilen, in dir. Mechanomorphosen aktiv beweglicher und in die Hechanomorphosen passiv bewegter Organe und Gewebe. 
a) Mechanomorphosen aktiv beweglicher Organe und Gewebe.

Aktiv ist die Formveränderung der Organe, wenn sie kontraktile

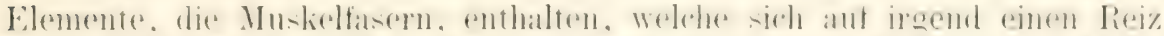
in einer Richtumg stark verkïrzen mol in der anderen Iichtumg an Dicke

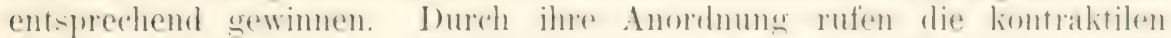

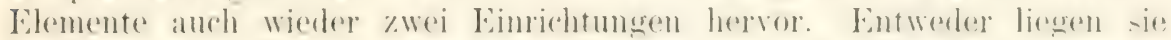

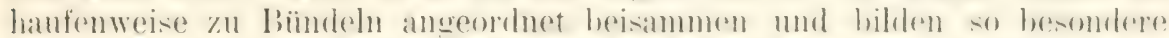

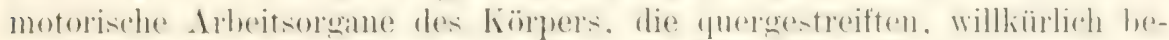
werglichen Muskeln. oder sie sind in die Wand ron Hohlorwanem. von

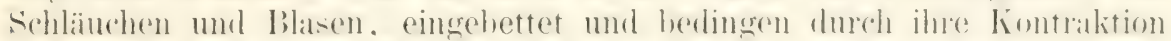
oder Erschlaffung eine Volumenveränderung. eine Verengermug orler Erweiterung der betreftenden Hohlräume.

Fis ist nun eine den Naturforshern und Ir\%ten allhelamnte Tat-ache. dalia alle muskulösen Orwane der mechanischen Arheit, welehe sie im Körjer zul verrichten hahen. anf das enenaneste angepalit sind. Die Nackenmuskeln dines säugetieres. desen kopf dureh mächtige fieweih- und Hörnerbildungen stark belastot ist, sind dementsprechend viel kräfiger auscebildet als heim Menschen, hei welchem sich die Narkemmukeln unter wanz anderen Berlingungen betinden. Inf die Korrelation, die bei den Flugvägeh zwischen der enormen Entwicklung der brustmuskulatur und dem Gehrauch der vorderen Extremität als Flugwerkzenge besteht. wurde schon an anderer stelle die Aufmerksamkeit gelenkt. Therall hei den Tieren sehen wir, das nach den zu hewegenden Teilen des körpers sich die (iröfe und die Form der zu ihnen gehörenden Muskeln ron selhst regulieren darlurch, dab die Zahl und Stärke der kontraktilen Elemente. entsprechend der Gröbe der zu bewältigenden Widerstände, zu- orler ahnimmt.

(ienau wie Muskeln des Skeletts rerhalten sich auch die muskulösen Iohlorgane. Die Ausbildung des Muskelgewebes in den einzelnen Ahschnitten des Ciefälosystems, des Darmkanals usw. erfolgt ebenfalls in harmonischer Beziehung zu der mechanischen Arheit, welche in den einzelnen Abschnitten zu leisten ist. Das Muskelgewebe ist daher auch in auswedehntem Mabe Teränderungen fähig, wemn sich die mechanischen Bedingungen ändern, unter denen seme Arbeit vor sich geht: es wird häftiger entwickelt. wie durch zahlreiche Experimente und hrankengreschichten in eklatanter Weje über allen Zweifel sichergestellt ist. an allen Stellen. wo Hohlorgane ihren Inhalt nur unter Hindernisien entleeren kïnnen: so leim Magen. wom der Pylorus rerengt ist: am Darm oherhalh pathologischer Strikturen: hei der Blase infolge von P'rostatahypertrophie und anderen die Hamentleerung erschwerenden /ustanden: heim Ilerzen. wem es hesondere strombindernisse zul hewältigen hat, welcho entweder durch Kilapuenfehler oler durch Erkrankungen der Arterienwandungen hervorgerufen sind.

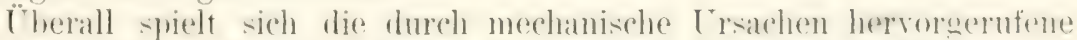
liorrelation ofwa in folgender Weise ah. In allen muskulizien Hohloreanen zichen sich ihre Muskelelemente zusammen. wenn sirh in ihren Hohlräumen

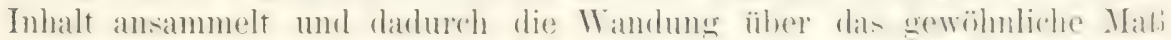
linaus gespannt und gereizt wird. Lei Vorhandensein von Hendernison

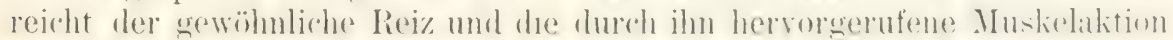
zur Entleerung nicht aus. Es kommt daher zu stärkerer Anhäufung

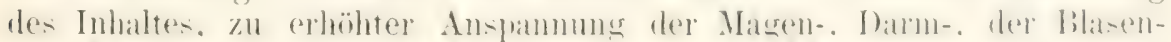

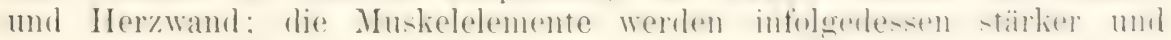


hïufiger gereizt. his sie dureh erhöhte Arbeitsleistung unter Benutzung ihrer lieservelisaft das Hindernis iiberwinden und den vermehrten Inhalt enteren. Die weitere Folge der stäkeren Inanspruchahme ist damn die eintretende Hypertrophie der Muscularis.

Nach diesem Prinzip) kann sich die Wandung des Gefäßsystems den verschiedenen Anfuahen, welche es in seinen einzelnen Abshnitten mnd hei aclegentlich auftretenden Störungen zu ilner Beseitigung zu erfüllen hat, in besonders feiner Weise anpassen. Fin modelliert gewissermalien der IBlutstron die Wreite seiner Kanäle und die wechsehrle Dicke seiner Wandungen in den verschiedenen Abshnitten seines Iantes selbst. Ilierlee lommen einige histomerhanische Prinzipien zur (ieltung, welche T'mond in seiner Histomechanik des Gefälsystems in die Sütze zusammengrefalit hat: .. Ftrombeschleunigung führt zu einer Erweiterung, dagegen Sitromverlangsamung zu einer Verengerung der ciefälichtung." .Das Dichenwarhstum der (refäband ist abhängig von der Wandspannung. diese von dem Blutdruck und dem Gefäßdurchmesser."

Das Anpassungsvermögen der Gefäßwand an die ihr gestellten Aufgaben offenbart sich am lehreichsten unter pathologischen Verhälnissen. Trenn infolge irgend eines Klappenfehlers oder eines an anderer Stelle gelegenen Ilindernisses die linke oder die rechte Herzkammer stärker mit lilut gefïllt und dadurch über die Norm ausgeweitet (dilatiert) wird. so wïchst der endokardiale blutdruck. Dieser ruft wieder eine Vermehrung der sistolischen Energie des Herzmushels hervor und als weitere Folge eine Arbeitshypertrophie. durch welche unter Umständen die in diefälssrstem vorhanden gewesene Störung vollständig lompensiert werden kann.

Erhebliche Veränderungen in der Gefäßbahn, die sich in verhältnismäbig kurer Zeit ahspielen, werden durch Unterbindung eines grölieren Gefabes hervorwerufen. Aus unscheinharen liollateralästchen, die, oberhall, der Ligatur gelegen, in das anämisch geworlene fiebiet führen, entwicheln sich ziemlich rasch Gefäbe von stärkerem Kaliber, mit dickeren Wandungen und mit einem ihrer Dicke entsprechenden histologischen Iau. Auch hier ist wieder für alle diese verwickelten Prozesse die Ursache in den veränderten mechanischen Verhälnissen der Iblutzirlunation gemäli den oben aufgestellten Gesetzen zu suchen, vor allen Dingen in der erhehlich rermehrten Geschwindigkeit. mit welcher der Bhutstrom oberhalh der Lnterbindungsstelle das Kollateraluefïl) nach dem anamischen vebiete durchströmt.

\section{b) Mechanomorphosen passir bewegter Organe und Gewebe.}

Von den aktiven sind die passiven Formveränderungen zu tremen, welche an den nicht kontraktilen Organen und Geweben durch Muskeltätigleit usw. notwendigerwerse herrorgerufen werden. Die Nachbarteile. welche sich an den beiden Enden von Muskelbündeln ansetzen, erfahren bei jerler Verkürzung derselben einen entsprechend starken Zug. Desgleichen drängt der Muskel, indem er der Verkürzung entsprechend anschwillt, die ihn seitlich einhïllendlen Teile zur Seite und übt so einen Druck auf sie aus und setzt sie in Spannung. Wemn Gliedmaßen oder

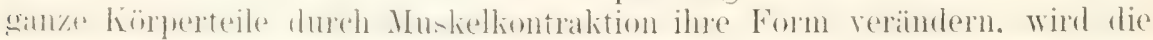
sie einhüllende Haut rerschoben und bald in dieser, bald in jener Richtung stärkel gespannt. Wenn Knochenstücke durch Muskelkontraktion gegeneinander verschoben werden, erleiden alle Gewebe, welche den Zusammenhalt zwischen den Knochen vermitteln, Dehnungen und Zugwir- 


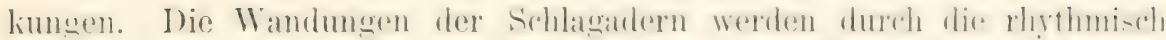

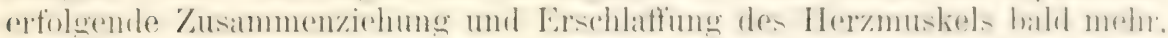

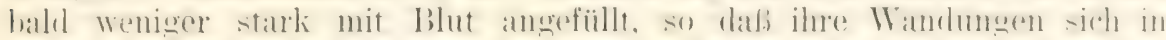

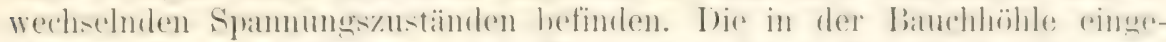

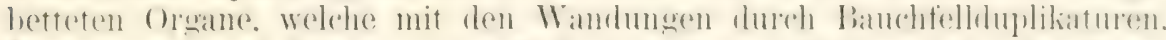

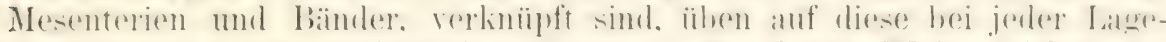
veründerung einen wechselnden Zug aus. In dieser Weise wirken bei allen höheren ()ranismen zahlreiche ()rane hei ihree Tätigkeit in menhat nischer Weise aufeinander ein und sind die Ursachen von mechanischen

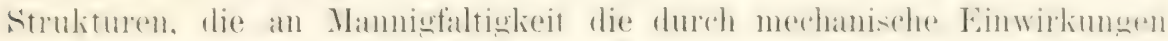
der AuBenwelt bedingten weit ïbertreffen.

Das Gewebe, welches am meisten der Einwirkmo der Muskelaktion unterliegt, ist das faserige Bindegewebe, weil es zunächst die bewe-

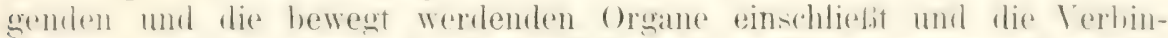
dumgen zwischen ihnen dureh Ausfïllung der Zwischemräme lerstellt. $\mathrm{Es}$ ist unter allen mechanischen Geweben für die mannigfaltigste Verwendung und Anpassung an verschiedene Aufgaben

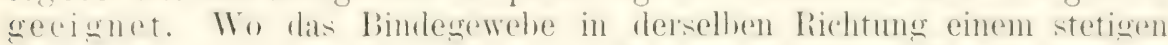
Zug ausgesetzt ist, sehen wir seine Fasern sich in der Zugrichtung pa-

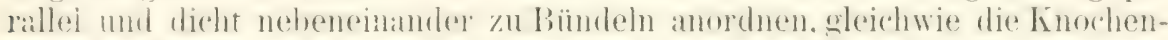

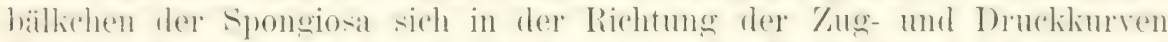
bilden. Sis entstehen in der Verlängerung der Muskelenden die sielnnen und Aponeurosen, um die motorische Kraft der Muskelelemente, wie Zustemen einer Arbeitsmashine. anf die zu hewegenden Knochen zu üher-

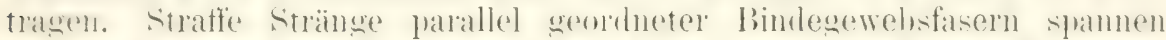
side nath denselhen P'rinzipien als bänder zwischen Reihen hinterein-

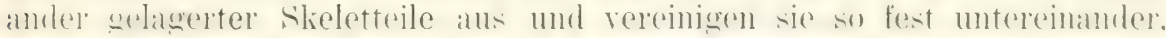

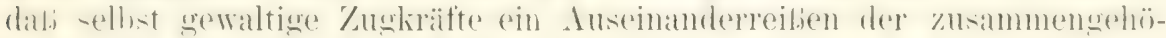
rigen Organe nicht zuwege bringen.

Ito das Bindlegewebe zur Umhïllung von Muskelmassen dient und

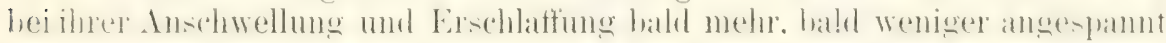
wird, ordnen sich seine Fasern quer zur Verlaufsrichtung der Muskelfasern an und bitden straffe Hänte, die Fascien. Wo es in verschiedenen Richtungen, wie in der Haut, einem wechsehden Zug unterworfen

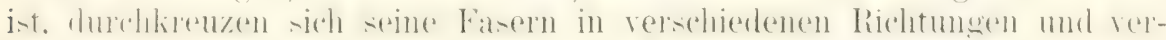
laufen teils in der Längsrichtung des Körpers, teils quer zu ihr, teils senkrecht zur Körperobertläche.

In wie wunderbarer Weise das faserige Bindegewebe in der Schwanz-

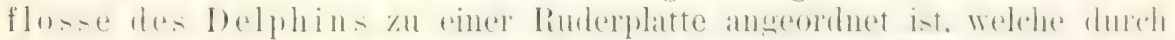

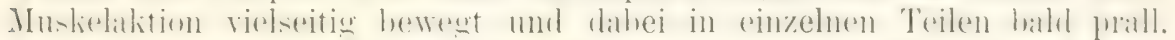

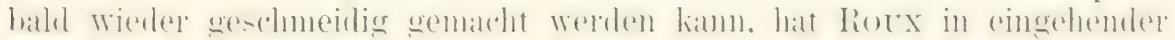
Weise anseinandergesetzt.

Auberdem dient aber an manchen Orten das faserige Bindegewebe

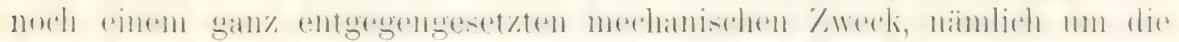
Abscherung sich verküzender Organe gegen ihre Umgebung zu er-

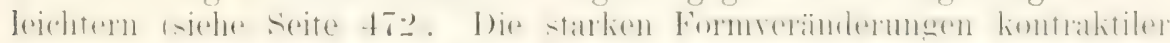
Organe mübten die umgebenden 'leile mitmachen, wenn sie fest unter-

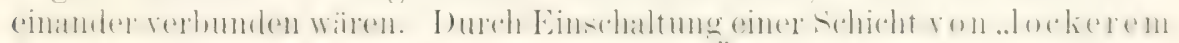

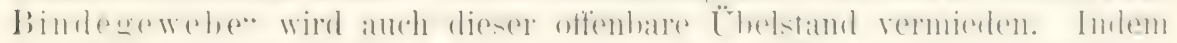

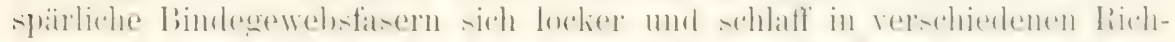

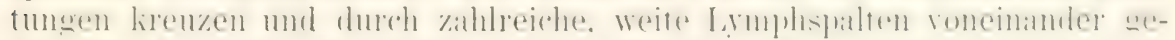

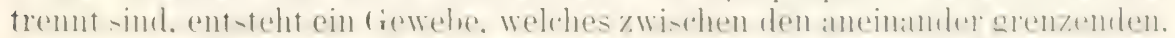

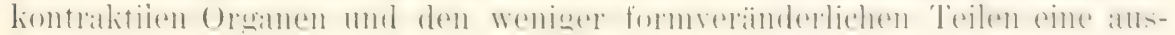




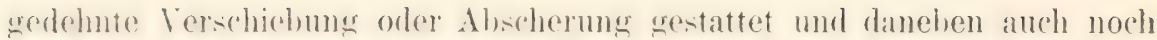
grledehreitig der Ansammlume und Forthewegung der Lymphe dient. So ist die Muskelhaut des I arms einerseits gegen die 'Tunica murosa andererseits ungen die Tumica serosa dureh die lockeren lindegewebsschichten der Submucosa und der Subserosa abgegrenzt; ebenso die Haut wewen die ron ih hedeckten Muskelmassen dureh das I'nterhantbindegrowe be: die versohiedenen Muskelindividuen gegenemander duch lockeres interstiticlles Bindegewebe: die obertläche der kontraktilen blutgefäße gegen ihre Umgebung durch die lockere I'unica adventitia.

Merhanische Anpassmgen finden ferner auch noch statt zwischen dem slielett und den es begrenzenden und mit ihm in lieziehung stehenden ()romen. Wo Sehnen und Aponeurosen sich an die Knochen ansetzen und die Zugkiaft der Muskehn auf sie ïbertragen, entstehen Tuhercula, Spinae, Cristae ete. Unter dem Druck der wachsenden Hirnteile bilden sich die Impresciones digitatae an der Immentläche der Schädelkapsel.

Wie sehr die Konfiguration des Skelettes ron der Muskelaktion beeintluft wird, lälit sich auf experimentellem Wege üherzeugend nachweisen, am schönsten, wem man bei jungen, noch sehr unentwickelten Tieren durch Nervendurchschneidung eine Lähmung und dadurch bedingte A trophie von einzelnen Muskelgruppen kïnstlich hervorruft. Nach einiger Zeit zeigt sich auch der Kinochenapparat. welcher zu den gelähmten Muskeln in Beziehung steht, teilweise mangelhaft entwickelt.

Als HrRTHLE einem jungen Kaninchen bald nach der Geburt den Bewegungsnerv der Gesichtsmuskeln auf der einen Seite durchschnitt. waren nach Jahresfrist, abgesehen von der Muskelatrophie, auch die Kopfknochen der einen Seite in auffallender Weise in ihrem Wachstum zurückgehlieben. Es fehlte ihnen infolge der Nuskellähmung, wie Hyrthle erklärend bemerkt, ,der Zug und Druck, welcher die lebenden Teile des Kinochens zur Tätigkeit anregt und so das normale Wachstum des Knochens reranlasst".

\section{Literatur zu Kapitel XXIII.}

1. Korrelationen von Drüsen. Chemomorphosen.

1) Baumann, Über den Jodgehalt der Schilddrïsen von Menschen und Tieren. Zeitschr. f. physiol. Chemie, Bd. XXII, S. I.

2) Derselbe, Über das Thyrojodin. Münch. med. Wochenschr., Nr. 14. 1896.

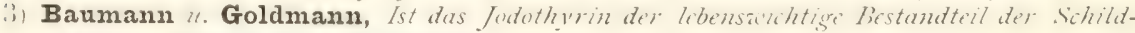
drïse? Niünch. med. Wochenschr., Nr, 47. 1896.

4) Beresowsky, Über die kompensatorische Hypertrophie der Schildariüse. Zieglers Beiträge, Ba. YII. 1893.

5) Breisacher, Untersuchungen ïber die Glandula thyreoidea. Archiv f. Anat, w. Phy'siol., physiol. Abt. I8go.

6) Brown-Séquard, Compt. rend. de la Société de biol. I89I. *

7) Capobianco, La tiroidectomia nei mummiferi. La Riforma medica, p. 254. 1895.

8) Eckard, Über die kompensatorische Hypertrophie und das physiologische IVachstum der Niere. Virchowes Archiz, Bd. CXIV. $1888-$

9) v. Eiselsberg, Über Tetanie im Anschlie an Kropfoperationen. Thener klin. Hochenschr., Nr. 5. 1802 .

10) Ewald: I) Versuche ïber die Funktion der Thyreoidea des Hundes. 2) Wcitere Versuche über die Funktion der Thyreoided. Berliner klin. Wochenschr., Ni. II. I887, N. 15. 1889 .

11) Ewald u. Rokwell, Archiv f. d. gesamte Physiol., Bd. XLVII, S. 160. I8go.

12) Gley: I) Contributions à l'etude des effets de la thyroidectomie chez le chien. p. 8I, $135,664.2)$ Recherches sur la fonction de la glande thyroide. Archives de physiol, $5^{e}$ série IV. 1802. 
13) Gley, Recherches sur le roble des glandules thyroüles chez le chich. Arch. d. physiol., 5e serie $V, p .760,1893$.

1.1) Derselbe, Bemerkungen ïber die Funktion der Schildariëse und ihrer Nebendrïsen. Pflïgers strchizi, Bd. L.IVI.

15) Golgi, Sur l'hypertrophic compensante ates reins, Arch. ital. d. biol., t. I1. I882.

16) Haasler, Über kompensatorische Lungenhupertrophie. Ref. Zentralbl. f. allgem. Path. 21. pathol. Hnat., S. 800. 1801 .

Ii) Hildebrandt, H., Zur pharmakologischen héntnis des Thyrojodins, Berliner klin. Hockenschr., Ar. 37.1800 .

18) Hofmeister, Zur Frage nach den Folgezustänten der Schilddrüsencrstirpation. Deutsche mediz. Wochenschr, Nr. 22. 1806.

19) Derselbe, Experimentelle Untersuchungen über die Folgen aes Schilddrïsenzerlustes. Beiträge zur kilin. Chimurgie, Bd. N1. IS94.

20) Horsley, Viktor, Die Funktion der Schilddrïse. Eine historisch-kritische Studic. Intcrmat. Beiträge zur wissenschaftl. ILedizin, Bd. I, S. 367. Berlin I80I.

21) Kocher, Archio f. klin. Chirurgie, S. 254.1883.

22) Leichtenstern, Dentsche mediz. Wochenschr., Vr. 49--5I. I803.

23) Martinotti, Uber Hyperplasie und Regeneration der drïsigen Elenente in Beztehung auf ihre Funktionsfäligkeit. Zentralbl. f. allgemeine Pathol. u. pathol. Anat., Bd. I, S. 633.1890 .

24) v. Mering, J. u. Minkowski, Diabetes mellitus nach Pankreasexstirpation. Archiv f. experim. Pathol., Bid. XXVT. 1890.

25) Minkowski, Weitere Alutteilungen über den Diabetes mellitus nach Exstirpation des Pankreas. Berliner klin. Wochenschr., S. 90. 1892.

26) Mnnh, Hermann, Zur Lehre von der Schilddrïse. Virchoues Archia, Bd. CL. I897.

27) Nothnagel, Die Anpassung des Organismus bei pathologischen Veränterungen. Tor=trag zum internat. med. Liongreß 21 Rom. Wiener med. Blätter, 1894.

28) Petrone, Du processus régénerateur sur le poumon, sur la foie et sur le rein. Arch. ital. de biol.g t. $V$. 1884 .

29) Podwyssozki, Regeneration. Fortschritte der Medizin. 1887.

30) Derselbe, Experimentelle Untersuchungen iuber die Regeneration der Driisengewebe. Lieglers Beiträge, Bd. I u. II.

31) Derselbe, Die kompensatorische Hypertrophie der Speicheldrïsen. Dissert. Bonn 1888.

32) Ponfick, Experimentelle Beiträge aur Pathologic der Leber. Virchous Archiu, Bal. CIVIII u. CXIX. $1889-1890$.

33) de Quervain, Fr., Über die Veründerungen des Zentralnervensystems bei experimenteller Cachexa thyreopriva der Tiere. Inaug.-Diss. Berlin 1893. Archiv f. pathol. Anat. und Physiol., Bd. CXXXIII. 1893.

34) Ribbert, Uber kompensatorische Hypertrophie der Vieren. Virchowes Arch., Bd.LXXXVIII.

35) Derselbe, Über die Regeneration des Schilddrïsengenvebes. Virchou's Arch., Bd. CXVII.

36) Derselbe, Über die Regeneration der Schilddrïse. Virchows Arch., S. 151.1889.

3i) Derselbe, Die kompensatorische Hypertrophe der Geschlechtsariësen. Arch. f. Entui..Meih., Bd. I. 1895.

38) Derselbe, Beiträge zur kompensatorischen Hypertrophie und zur Regeneration. Areh. f. Entwickl.-Nech., Bd. I. 1805.

39) Rogowitsch: I) Sur les effets de l'ablation du corps thyroide che les animanx. Archives de Physiol., p. 719. 1888. 2) Die Veränderungen der Hypophyse nach Entfermug der Schilddrüse. Beiträge zar pathol. Anat. u. allgen. Pathol. v. Ziegler, $B d . I V, S .753$.

40) Stieda, Beiträge zur pathol. Anat. und allgem. Pathol. 189o,

41) Tizzoni, Über die Wirkungen der Exstrpation der Lebennieren anf Fianinchen. Zieglers Beiträge, Bat. IT. I889.

42) Vassale et. Generali, Sur les effets de l'exstirpation des glandes parathyyéoide's. Arch. ital. de Biologie, T. XXY, p. 450. 1806. Ebenda, T. XXVI, p. 6I. I806.

43) Vassale, Zentralbl. f. mediz. Wissensch, S. 14. 1891.

14) Verstraeten $u$. Vanderlinden, V., Etude sur les fonctions du corps thy'roide, Mémoire's de l'Alcad. roy. de míd. de Belgique, XIII. 1894.

15) Weigext, Hemicephalie und Aplasie der Nebenneren. Virchons Archiv, Bd. C.

16) Ziegler, E., Über die Ursachen der pathologischen Geriebsneubildungen. Festschrift f. Virchoi, Bd. II. I89T.

\section{Blutbildung.}

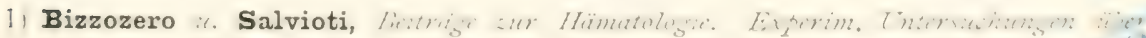
die lienale Hëmatopoësis. Wheschots Unters., Bd. MII, S. 595. ISS7 u. Zentrallas) f. d. med. Wissensch., Bd. XVII, S. 273. 1879. 
$\because$ Bizzozero, Neue Untersuchungen zïber den Bau des Finochenmarkes bei Vögeln. Archiv f. mikrosk. Anat., Bd. XXYV. 1800 .

:i) Derselbe, Archives italiennes de Biologie, T: I. 1882.

1) Derselbe et Dr. Tome, De l'origine des corpuscules sanguins rouges dans les differentes classes des vertebrés. Arch. italiennes de Biologie, I. IV. I883. In deatscher Übersetzung:

i) Dieselben, Über die Entstehung der roten Blutkörperchen bei den verschiedenen II irbeltierklassen. Virchoze's Archiz, Bd. XCV. 1884.

(i) Dénys, La structure de la moille des os et la genise du sang chez les oiseanx. La cellule, Tome $1 \mathrm{~V}$. 1886 .

-) Eliasberg, Experimentelle Untersuchungen über die Blutbildung in der Mils der. Sängetiere. Dissert. Dorpat 1893.

-) Foà, Nene Untersuchungen z̈ber die Bildung der Elemente des Blutes. Fiestschrift $f$. Firchow, Bd. I, S. 481 . 1891 .

(1) Freiberg, Experimentelle Untersuchungen ïber die Regeneration der Blutkörperchen im Inochenmark. Dissert, Dorpat 1802.

11) Korn, H., Über die Beteiligung der Wils und des Kinochenmarkes an der Bildung roter Blutkörperchen bei Vügeh. Virchows Archiv, Bd. LXXXIT. I88T.

11) Neumann, Archio fïr Heilkznde, Bd. X. 1860.

1:) Derselbe, Über die Entwicklung roter Blutkörperchen im nengebildeten Kunochenmark. Virchores Archiv, Bd. CXIX. I89o.

1:i) Derselbe, Hämatologische Studien. Virchozers Archiv, Bd. CXLIII. I896.

11) Rindfleisch, Über Knochenmark und Blutbildung. Archiv $f$. mikroskop. Anatomie, Bd. NVII. IS8O.

3. Nechanomorphosen.

1) Bardeleben, Muskel und Fascie. Jenaische Zeitschr. f. Naturzerissensch., Bd. Xl.

-) Busachi, Thomas, Über die Neubildung von glattem Muskelgerebe. (Hypertrophie und IIvperplasie, Regeneration, Neoplasie.) Zieglers Beiträge zur pathol. Anat. u. zur alloemeinen Pathologie, Bd. IV. 1889.

i) Hermann, Handbuch der Physiologie, Bd. II, S. 202. I870.

1) Hürthle, Über den Einfuß der Bewegungsnerven unf das II achstum der Muskeln and Kinochen. Jahresber. d. schles. Gesellsch. f. uaterl. Kultur, Bd. LXXI. 1893.

i) Nothnagel, Über Anpassungen und Ausgleichnngen bei pathologischen Störungen. Zeitschr. f. klin. Med., Bid. XT. IS88 u. Bd. X' u. XI. 1886.

(i) Roux, Gesammelte Abhandlungen. Bd. I. Funktionelle Anpassung. 1895. Besonders Beiträge zur Morphologie der funktionellen Anpassung: I) Struktur eines hoch differenzerten, bindegezebigen Organs (Schwanzflosse des Delphins). 1893. 2) Über dic Selbstregulation der morphologischen Länge der. Skelettmuskeln des Menschen. 1883.

-) Derselbe, Über die Budeutung der Ablenkung des Arterienstammes bei der Astabgabe. 1870.

a) Derselbe, Über die Versueigungen der Blutgefüße des Menschen. 1878.

9) Derselbe, Dir züchtende Kampf der Teile oder die Teilanslese in Organismus. Zugleich eine Theorie der funktionellen Anpassung. I88I.

111 Stahel, Hans, Über Arterienspindeln und z̈̈er die Besichung der IFanddicke der Arterie zum Blutdruck. Archio f. Anat. 21. Phwsiol, anat. Abt. 1886.

11. Strasser, Zur Kenntuis der funktionellen Anpassung der quergestreiften Ifuskeln. Stuttgart ${ }_{1} 88_{3}$.

1.) Thüler, Iouis, Studien Ḧber die Funktion des fibröscn Gerebes. Inaugural.-Diss. Zïrich 1884.

1:i) Thoma, R. Untersuchungen über die Histogenese und Histomechanite des Gefäßsy'stems. Sizttoart 1803 . 


\section{VIERUNDZWANZIGSTES KAPITEL.}

\section{I) inneren Faktoren der organischen Entwicklung.}

(Fortsetzung.)

\section{Die Erscheinungen der Regeneration.}

Iit dem Worte Regeneration wird das Vermögen bezeichnet, in Ver-

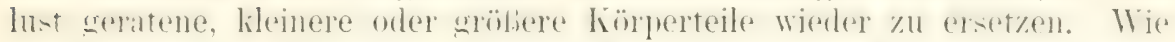
bei den meisten Pflanzen, ist es in hohem Grade auch bei den niederen Tieren, bei Cölenteraten. bei Würmern und Echinodermen. entwickelt.

Ein durch 'T'REnBLExs, Untersuchungen bekannt gewordenes, klassisches Beispiel ist Hydra viridis. Je nachdem bei einem Individuum vom shlandhfömigen hönger das vordere orler das hintere Ende durch eiren shonitt aldgetrennt ist. bildet sich in wenigen Tagen wierler ein voll-

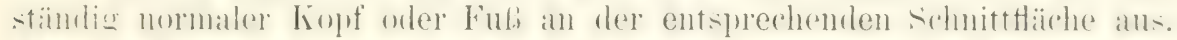

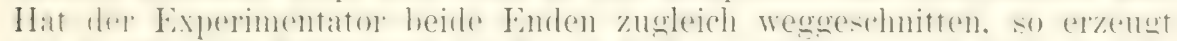

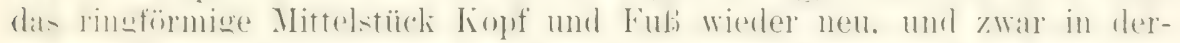

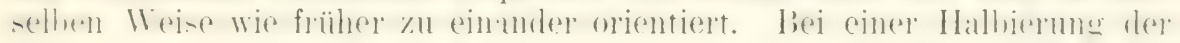
Hyclra ihrer Länge nach vervollständigt sich jede Hälfte wiedler zum ganzen 'Tier.

Mit steigender Höhe der Organisation nimmt im allgemeinen das Regenerationsvermögen ab; doch gibt es selbst unter den Wirbeltieren

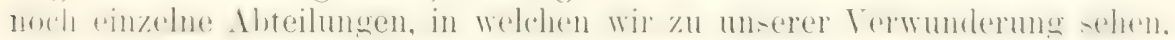
daß junge 'Tiere, wie Triton- oder Salamanderlarven, in Verlust geratene vordere oder hintere Extremitäten, den Schwanz, das Auge usw. nach einiger' Zeit wieder ersetzen.

Todurch wird das bei der Regeneration verwandte Zellemmaterial. so lautet die schwierige Frage, bestimmt, genau die dem Organismus

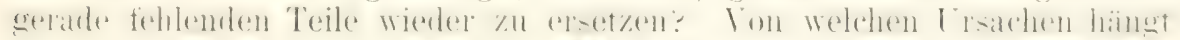

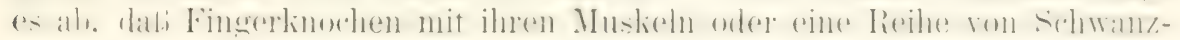
wirbeln oder ein Auge wieder entstehen? Zum Leben kömmen diese Teile zur Sot entbehrt werden, wie es ja die Tiere lehren, bei welchen das

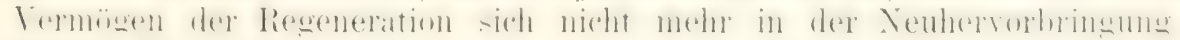
solcher' 'Teile betätigt.

In allen Fällen, mag es sich wn die Regeneration eines einfachen

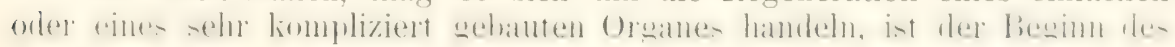
Prozesses genau derselbe; es entsteht zuerst ein kleiner Höcker inclifte-

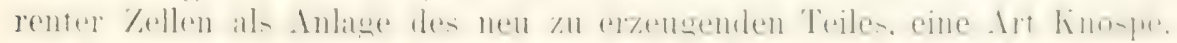
ein lieingewebe. Ein solches entwickelt sich, wenn das lïppehen eines 


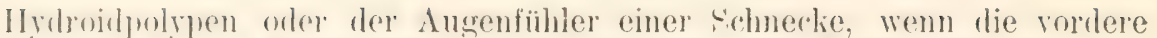

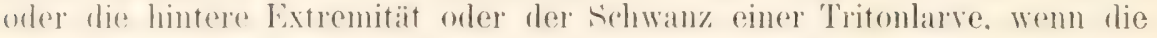
Schere eines Krebses durch einen Messerschnitt entfernt worden ist.

In den angefïhrten Beispielen enthält das Keimgewebe von den abgetrennten ()ranteilen selhst lieinen Iest, aus welehem sie durch einfaches Warhstum wiedor hervorgehen kïnnten. Die Knospe für den Angenfühler der sidnerce enthïlt lieine Spur yon Rotina- und l'igmentzellen. ehenso die Knospen für die Extremitait keine Spur vom Material der Inandwurzelund Fingerknochen mit den zu ihnen gehörigen Muskeh und Sehnen: sie ist also eine vollständige Neubildung: sie bringt, wemn wir den Prozel, weiter verfolwen. die liomplizierten Strukturen des zu regenerierenden Kïrperteiles auf ähnlichem Wege hervor, auf welchem sie während der Ontogenese entstanden sind. D ie Knospe besteht daher ans einer plastischen Sulsstanz, welche in ihrem Vermögen am meisten der Suhstanz der Eizelle wleicht und wie diese mit den spezifischen Eigentümlichlieiten der Tierart, von welcher sie abstammt, ausgerüstet ist.

In einem Punkte aber unterscheiden sich Eizelle und Knospe voneinamder: die erstere bringt einen vollstimdigen, neuen Organismus aus sich hervor, die letztere nur einen bald grölieren, bald kleineren, bald diesen, bald jenen Teil des fanzen. Worlurch wird dieser Untersehied im plastischen Vermögen zwischen beiden hervorgerufen! Nach meiner Meinung dadurch, dab die Eizelle sich rom mütterlichen Organismus ablïst oder, wo dies nicht gleich geschieht, sich auber näherer Beziehung zu ihm entwickelt, die Knospe dagegen, in engster Beziehung zum ranzen bleibend, nicht bloß durch die in ihr selbst gelegenen hräfte, sondern auch auberdem noch durch ihre Beziehungen zum Ganzen in ihrer Gestaltung bestimmt wird.

Wir nehmen hier zur Erklärung dieselben Vorgänge an, deren Wirksamkeit wir in früheren Kapiteln in einfacheren Fällen schon nachgewiesen haben. Wie die Knospe einer Pflanze ein indifferentes rebilde ist, das sich zu einer Wurzel oder einem Laubsproß, zu einem Dorn oder einem Blïtenstand, zı einem orthotropen Endsprob oder einem plagiotropen Seitensproß entwickeln kann, je nach den Ursachen, die während der Entwicklung auf sie einwirken, und je nach den Beziehmngen, in denen die Knospe zu den Nachbarorganen und zum ganzen Pflanzenindividuum steht, in derselben Weise wird auch das Keimgewebe bei der Regeneration von ()rganen niederer und höherer Tiere in seinem plastischen Vermögen eingeschrïnt und in hestimmte Bahnen gelenkt durch die Beziehungen, in welchen es sich zum (iesamtoroanismus befindet. Es entwickelt sich verschieden, je nachdem es sich in der Mitte orler am Ende eines Ober-oder Interschenkelstumptes oder in der Mitte einer Zehe einer Tritonlarve befindet; durch die (jrtlichlieit und durch die Beziehungen, die sich hieraus zum franzen ergeben, wirl es bestimmt, bald einen crößeren. bahl einen kleineren Abschnitt der Extremität zu regenerieren.

Was Nügeli von den Wachstumsprozessen der Pflanzen sagt, das gilt anch für die tierischen Regenerationsprozesse. .Es ist, als ol das Idioplasma genan wäbte, was in den übrigen Teilen der Ptlanze vorgeht und was es tun mul, um die Integrität und die Lehensfähigkeit des Individuums wiederherzustellen."

Nach der hier entwickelten Auffassung fallen die mit dem Reiz des ficheimnisvollen hesonders ansgestatteten Erscheinungen der Regeneration chenfalls unter den liegriff der Korrelation in seiner allgemeinsten Fassung und mußten daher an dieser Stelle mit besprochen werden. 


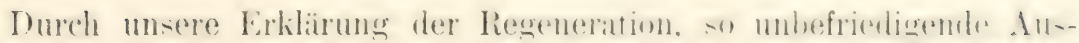

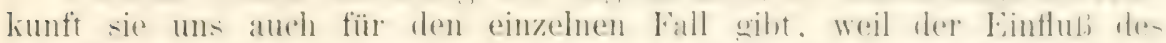
Ganzen anf die Teile sich einer genanen Analy-e und Jiliemmoi- entrieht. sind wir anf denselben alleremeinen Standpunkt gefïhnt worden, den anderes

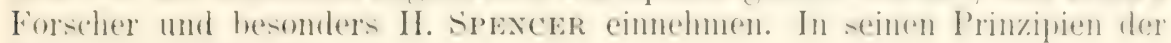
Biologie bemerkt Spencer:

„Die Fähigkeit eines Organismus, sich selbst wieder zu ergänzen,

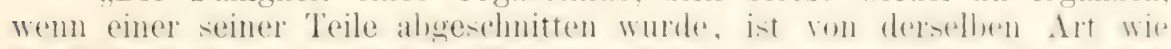
die Fähigkeit eines verletzten hristalls. sirh solhst zul eroinzen. In heilen Fälen wirl die neu asimilierte Materie so algesetzt. dab die ur-yrünglichen Lmrisse wienterhergestellt werden. Cunl wenn wir hinsiohtlich ile

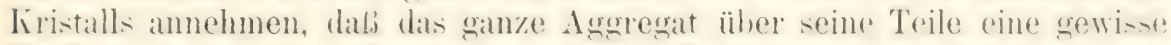
Kraft ausible, welche die neu integrierten Molekïle zwinge, eine he-simmte Form anzunehmen, so müssen wir hei dem (trganismus wohl eine analoge liraft vorausetzen. I)ies ist übrigens nicht eine blobe Iypothese. es ist vielmehr nichts anderes, als ein verallgeneinerter Aushruck der 'Tatsarhen. Wenn an derselben stelle. wo das Bein einer Eidechse soeben amputiert wurde. ongleich wieder die Anlage eines neuen hervorsprobt, die, indem sie gewise Entwicklungsphasen durchlüuft. Welche denen des ursprünglichen lieines gleichen, endlich eine gleiche strulitur und festalt ammimmt. :0 ist es nicht mehr als der einfache Ausdruck dessen, was wir gesehen hahen. wenn wir hehaupten. dal.j der Organismus als franzes eino nolohe liraft ïher das neu sich hildende filied ausïht, dal.i es zur Wiederholung seines Vorgängers wird. Wenn ein Bein wieder herrorsprolit. Wo vorher ein Bein war, und ein Schwanz, wo vorher ein Schwanz sich befand, so läßt sich das nur so auffassen, daß die Gesamtkräfte des Körpers die libungspozesse kontrollieren. Welche in jerlem einzelnen 'Teile stattfinden."

Über die Spencersche Ansicht urteilt WeIsuans, daß ,die von ihm angenommene Kraft der spiritus rector oder Nisus formativus frïherer Zexten sei und keine Spur einer mechanischen Erklärma enthielte". Wir

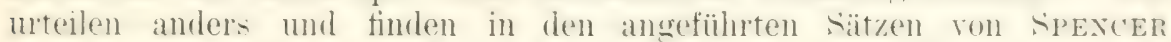
nur in anderer Weise die Ansicht ausgedrücht. die wir auch hegen. dali die bei der Regeneration sich abspielenden Prozese als Wachstmmskorrelationen zu erklären sind. Wenn diese in einzelnen einer kausalen Analy-e auch sehr grolje sichwierigkeiten entgegensetzen. so verhalten sie sich jrinzipiell einer mechanischen Erklämog gegenüber nicht ander's aläherhaut hologische Prozesse. wie wir an ilen verschiedensten orten uns nachzuweisen bemüht haben. Die Erkiärung der Lehensurozenso führt ïherall schlielifich auf dieselhen schwierigkeiten. und os ist im firmule grenommen nur vine ans (iewöhnung entsprungene Einhilitums. Wenn wil glauben, andere Lebensprozesse besser zu verstehen.

\section{Die Erscheinungen der Heteromorphose.}

Der Regeneration in mancher Hinsicht nahe verwandt, in anderer

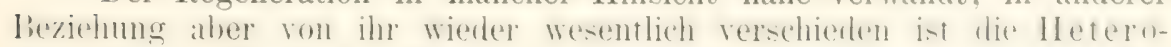
morphose. Nach der Definition von LOEB, welchel zuerst den Be-

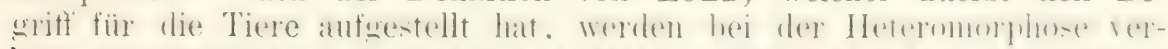

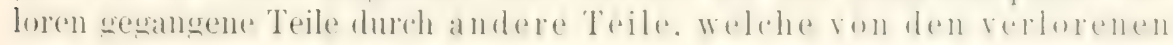
nach Form und Funktion verschieden sind. ersetzt. oder es werden infolge äuberer Eingriffe neue Organe an lïrperstellen gebildet, wo sie unter normalen Bedingungen nicht hingehören 
und nicht gebildet werden können. Während also bei der Regeneration eine Frzelgung rom Gileichartigem stattindet, handelt es sich hei der Heteromorphose um die Erzeugung von Ungleichartigem.

ITas die Zellen eines sich hildenden Keimgewehes plïtlich hestimmt, zu diesem oder jenem ()rgan, welches in der hetreffenden Kö̈rerwegend vorher niemals vorhanden war, auszuwachsen, liegt ebensowenig wie der Vorgang hei der Regeneration deutlich zutage: wir kömnen nur sagen, dalj

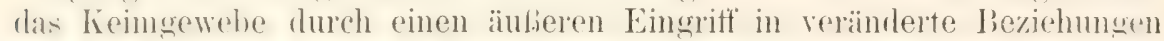
zur den Nachbarteilen und zum (iesamtorganismus gehracht und infolge-

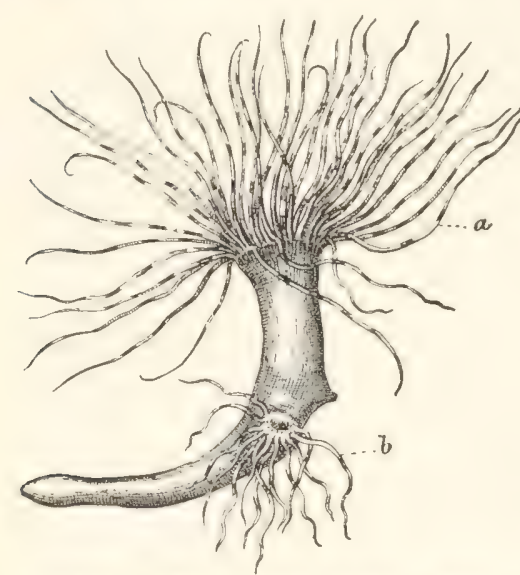

Fig. 348. Cerianthus membranaceus, lwi welchem sich infolge eimes Finschnittes fine zweite Mundoffinungr angelegt lat. Nach LOEB. a Tentakeln in der Ungebung der natiurlichen Mundscheibe, $b$ solche an der künstlich gebildeten Öffnung. dessen zu verändertem Wachstum gereizt wird. Aus diesem Grunde besprechen wir auch die Heteromorphose neben der Regeneration in dem die Korrelationen behandelnden Kapitel.

Um uns in die höchst eigenartigen, aus dem Bereich des Normalen heraustretenden und dadurch besonders auffällig werdenden Wachstumskorrelationen einen Einblick zu verschaffen, diene eine Analyse von vier Beispielen.

Loeb hat bei einer Seerose, Cerianthus membranaceus, unterhalb des Mundes die Körperwand durch einen Schnitt geöffinet und das Zuwachsen der Öffnung kïnstlich verhindert. Infolge des Eingriftes wuchsen an dem nach abwïrts geliehrten Rand der Schnittöffinung äubere und innere Tentakeln in gröberer Zahl hervor (Fig. :348); auch eine Mundscheibe legte sich an. LoEB hatte demnach auf künstlichem Wege ein Tier mit zwei Mundenden oder zwei Köpfen rrzeut: auch homnte er in derselhen Weise Tiere mit drei mol mehr iibereinander gelegenen Köpfen herstellen.

Im Prinzip ähnlich ist das zweite Beispiel, welches eine solitäre Aszidie, Cione intestinalis, betrifft, also ein Tier, das sich schon durch einen höheren Grad von Organisation auszeichnet

Bei der Cione (Fig. 349A und $B$ ) ist sowohl der Rand ihrer Mundïthnung wie ihrer Kloake nit zahlreichen, einfach gebauten Augenflecken (Ocellen) versehen. Als nun LoEB in einiger Entfernung entweder von der Mundöftinung. (Fig. 349 A) oder von der Auswurfsröhre nene sichnittöftnungen (a) anlegte, bildeten sich an den Schnittrïndern nach einiger Zoit ocellen aus: lamm wuchs die kiunstlich erzengte Mundöffnumg (Fig. 349 B) nach außen zu einer Röhre $(a)$ hervor, die meist

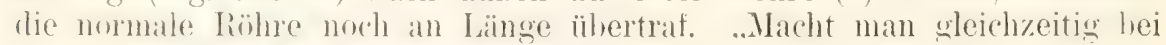
demselhen Tiere an vershielenen stellen Eimschnitte, so können weichzeitig mehrere neue Röhren entstehen."

Die beiden Experimente haben das Gemeinsame, daß durch den Einsohnitt die \%ellon in der T'mgehung der Öftume. welche his zur Verheilung der Schnittränder am Zuwachsen verhindert wird, in eine Summe von Bedingungen versetzt sind, wie sie sich in ähnlicher Weise an den Mundrïndern vorfinden. Ektorlerm und Entorlerm gehen hier wie dort ummittelhar ineinander ïher. Flüssigkeit und teste Körper kïmen ebenfalls durch 


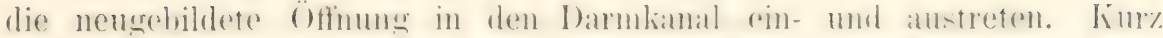
und gut, unter ähnlichen Bedingungen wird die ylastische Substanz an den Rändern der künstlich hergestellten Öffnung zu gleichen Bildungen angeregt, wie sie an der normal entwickelten Mundöffnung für die betreffende Tierart charakteristisch sind. Bei Cerianthus entstehen 'Tentakelkrinze und ein Nervenring, bei Cione zahlreiche dugenflecke.

Da die Schnittläche, in welcher bei Cerianthus Tentakeln, bei Cione

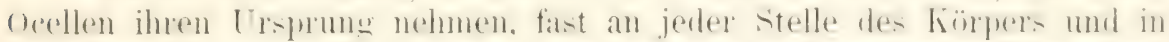
den versohiedensten liblitungen angelegt werden kimm, -o muli man mit

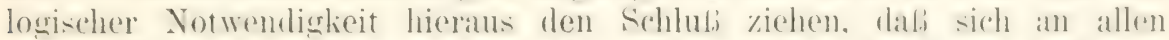
diesen stellen des Kïruers plastisches Material findet. Wolches so limmplizierte Oreane, wie Tentalieln. Nerveming. Ocellens, in der für die betreffende Tierart typischen Weise anch am umrechten ort hervoryubingen

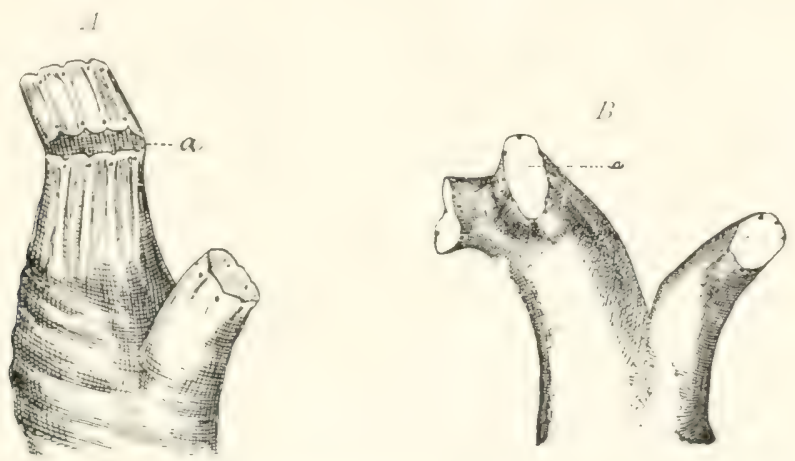

Fig. $3 \pm 9$ A und $B$. Cione intestinalis. Nach LoEB. A Die orale Röhre wurde. nahe der IIundöffnung hei a eingeschnitten; an der künstich erzeugten Öffnung bildeten. sich Ocellen. B Das in $A$ dargestellte Tier einige Wochen später; aus der Schnittstelle ist eine neue Röhre $(a)$ hervorgewachsen. Natïrliche Größe.

imstande ist. In Körper eines Cerianthus, einer Cione etc. verhält sich jeder kleinste Teil in semen Bildungsvermögen. das mter nomalen lor-

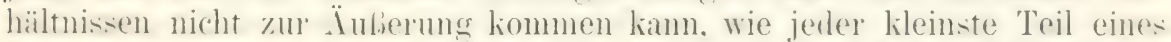
Weilenzweiges. an weldem an jeder künstlich er\%eugten ()uerschnitt-Häche Knosjen entstehen mul zu Wurzeln orler Laubsurosen auswathsen

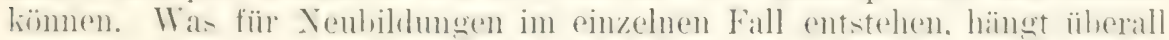
ron der besomberen Art der plastischen substanz (Iolioplasmal mul rom

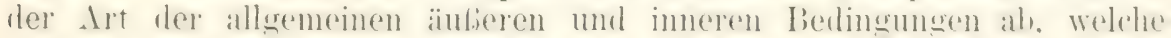
auf sie als Bildungsreize einwirken.

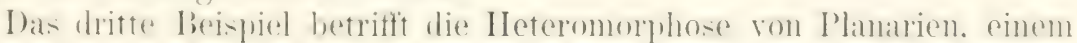

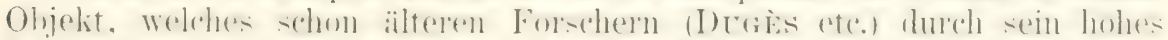

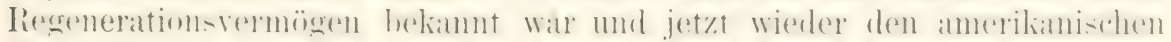
Physiologen Vax DUYxe, Morgax u. a. zu Experimenten gedient hat.

VAx DUYxe hat am lebenden 'Tiere bald in dieser, bald in jener'

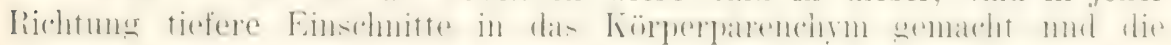
Wundränder. welche vom Schnittwinkel aus leicht und rasch wierler zu-

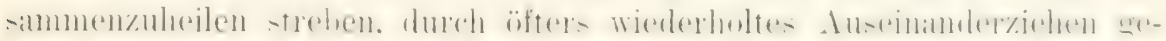

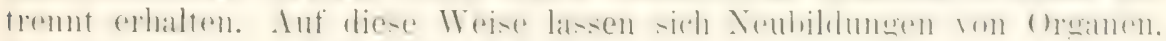
Verdopyelungen ron Kopf- und Schwanzenden erzeugen.

An dem in der T'extfigur :350 dargestellten 'lier ist infolue eines

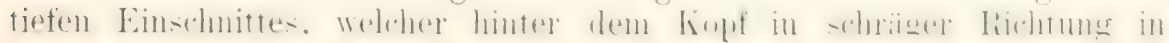


den Rumpf vorgenommen wurde, eine regelrechte Duplicitas anterior cutstanden. Es hat nämlich der eine Lappen des Schnittes einen vollstïndigen lopf (b) neu erzeugt, eine eigene Mundöffinung, zwei neue Augentlecke etc. An allen operierten Tieren ist das neugehildete Gewebe duch seinen geringen P'igmentgehalt leicht kenntlich: es ist in der Text-

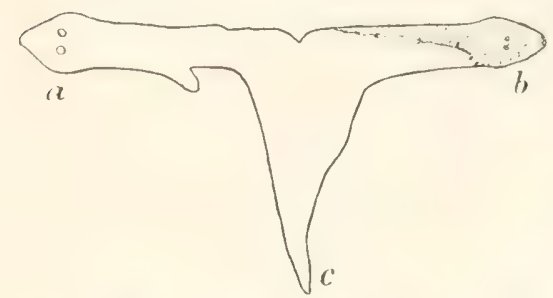

Figr. :3). Eine künstlich erzeugte Planarie mit zwei Köpfen. Nach J. YAX DCYNE. Italiener Colucci, ron WolfF und yon ERIK MÜLLER festgestellt worden ist, regeneriert sich die Linse ron jungen Tritonlarven wenige Wochen, nach(lem sie durch eine Art Staroperation vollständig, doch olme weitere Beschädigung des Auges entfernt worden ist. Die neu sich bildende Linse stammt hierbei, was ich durch eigene Kenntnisnahme der Präparate als

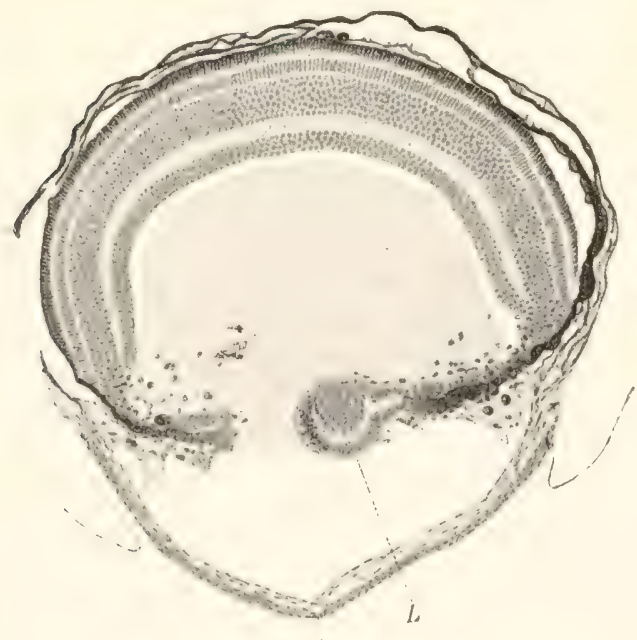

Fig. :3.j. Meridionalschnitt durch ein Auge einer Tritonlarve, 13 Tage nach der Operation (Entfernung der Linse). Nach ErIK MülLER. $L$ Linsenblase; $C$ geheilte Cornealwunde. vollkommen sicher bestätigen kann, weder von einem etwa zurückgebliebenen Rest der alten Linse ab, welche meist in toto durch die Schnittöffnung nach außen entleert wird, noch stammt sie von dem Hornhautepithel ab, an welches man, gestützt auf die Abstammung der Linse bei (ler normalen Entwicklung, zunächst denken wird. Vielmehr führt die nene Anlage ihren Ursprung auf das Epithel des Irisrandes (Fig. 351-354), das heißt auf den Rand des sekundären

Augenbechers zurück; sie entwickelt sich also dureh eine ganz offenbare $\mathrm{He}$ teromorphose aus einem Zellenmaterial, das von (ler Wand des primären Vorderhirnbläschens herriult und das in der ganzen Reihe der Wirbeltiere zu der Linsenanlage niemals in irgendwelcher Beziehung gestanden hat.

Noch merkwïrdiger aher wird die Heteromorphose dadurch, dab die Inwandlumg eines Teils des Randes des Augenhechers in eine Linse sich in sehr :ihnlicher Weise vollzieht, wie die normale Entwicklung der Linse 
aus dem äußeren Leimblatt (Fig. 351-3:35). Äuberes und inneres lilatt

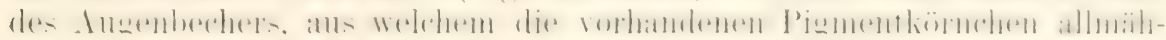
lich sanz schwinden, weichen an einer kleinen Stelle des oberen Randes auseinander: es bildet sich so aus ihnen ein klemes Linsensäckchen (Fig. 352). An seiner hinteren Wand wachsen die Zellen zu langen Linsenfasern aus, während aus den Zellen der vorderen Wand das Linsenepithel cutsteht. (Fig. 35):3).

Fin. 352.

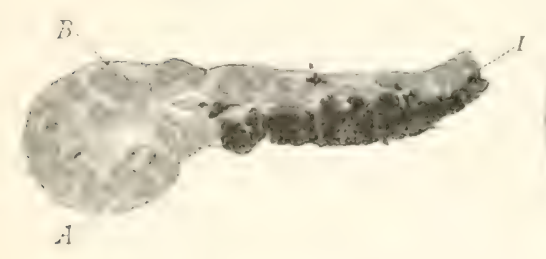

lï. : :i,

\section{Bs}

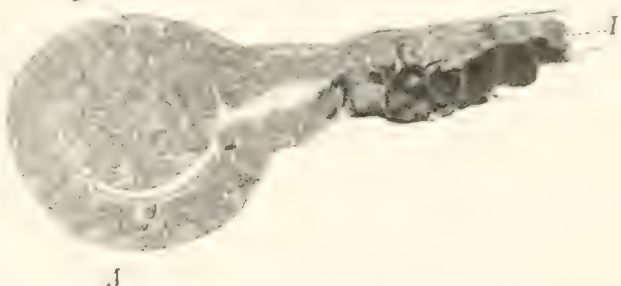

.1

Fiı. 3 . Irisrand einer Tritonlarve, welcher die Linse entfernt ist. . I Rande hat sich ein neues Linsensïckchen gebildet. 12 T'age nach der Operation. Nach ERIK MÜLLER.

Fịg. 353. Irisrand eines ebenso operierten Tieres. 13) Tage nach der Operation. Fom hinteren Rand des Linsensäckchens bildet sich Linsensubstanz. Nach ErIK MIÜLler. I Durchschnitt durch die Iris; $A$ vordere, $B$ hintere Wand des Linsensïckchens.

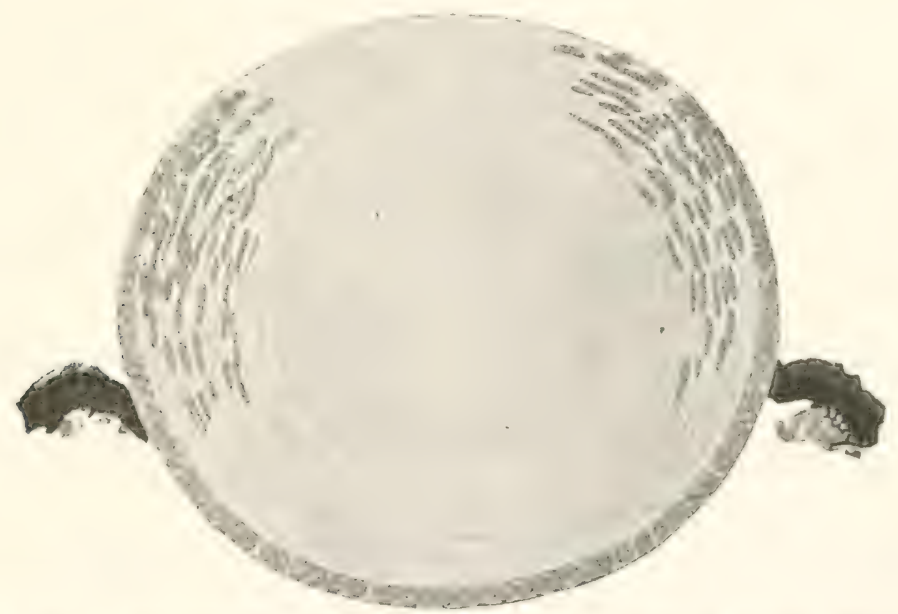

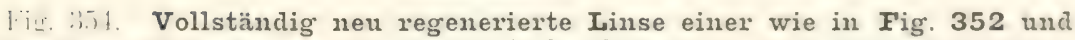
353 operierten Tritonlarve. 40 Tage nach der Operation. Nach EnK MǗt.tir.

Im Laufe der weiteren Difterenzierung löst sich die Linsenanlage rom Irisrand ganz ab und wird regelrecht in die Nitte der Pupille aufgenommen (Fig. $35 \bar{t}$ ).

Auch in unserem vierten beispiel verhält sich das Zellenmaterial des Irisrandes wie ein indifferentes Keimgewebe. welches unter den verin-

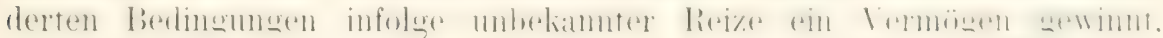
welches wir den Zellen dieser Gegend im ganzen Stamm der Wirbeltiere gewöhnlich nicht innewohnen sehen. 
Überblicken wir noch eimmal die in diesem Kapitel beschriebenen und die sonst noch in der Literatur bekannt gewordenen Eirscheinungen der Regeneration und der Heteromorphose, so kam ich mein allgemeines Urteil über sie in Übereinstimmung mit den Grundgedanken, die in die-

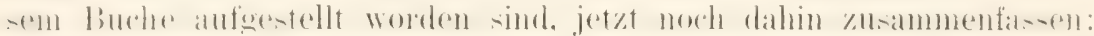

Die aus Zellen zusammengesetzte organische Substanz besitzt wie der Kristall das allgemeine Vermögen, verloren gegangene Teile entweder wieder in der ursprünglichen Weise neu zu erzeugen (einfache Regeneration) oder sie unter veränderten Bedingungen durch andere, diesen entsprechende Organe zu ersetzen (Heteromorphose). Das allen Teilen eines

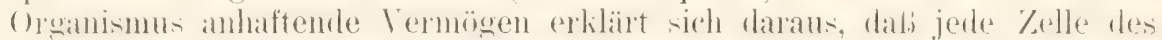
liorpers als Mitgift der Artzelle, won weleher sie abstammt. Itionlasma abler Anlagesubstanz enthält. Welde Träger der allowemen Artejgenschaften ist.

Für gewöhnlich ist in der organischen Substanz das Vermögen zur Regeneration nur latent vorhanden; es berlarf in jedem Fall zu ihrer Ver-

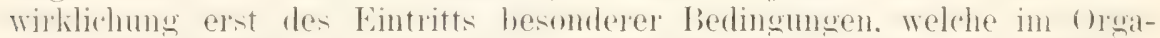
ni-meneivh offenhar ball einfacher Art. hald sehr liompliziert mu rhwieriger herzustellen sind. Unter diesen ist eine der wichtigsten die Verstïmmelung des Organismus; sie gibt für gewöhnlich den ersten Anstoß mul scheint in vielen Fïllen allein schon hinzmeichen. dats sich dat regenerationsvermögen betätigen kiann: in anderen Fällen indescen wirken wohl dem durch die Verstïmmelung gesetzten Reiz andere Bedingungen

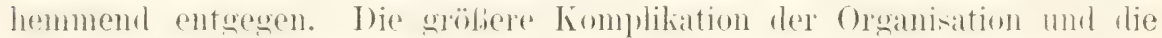
mit ihr gewöhnlich einhergehende. stälier durehgeführte Integration der

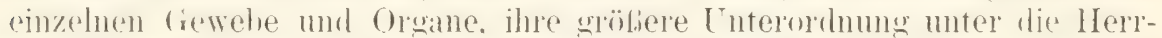

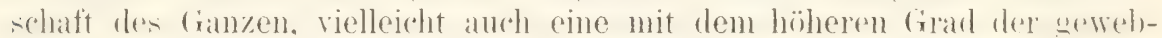
lichen Differenzierung verbundene Abnahme in der Zeugungskraft der Elementarteile, scheinen solche Hindernisse abzugeben.

Hieraus würde es sich erklären, daf das Regenerationsvermögen bei den Pflanzen und den am niedrigsten organisierten Tieren am gröbten ist. lagegen mit steigender Organisation in allgemeinen abzumehmen hewimnt und shlieblich shembar fast ganz schwindet, wie bei den bägeh mul šangeteren. Ich sage shembar schwimlet. Demn nach meiner Ansicht ist anch hier an den verletzten stellen Anlagesnbstanz. wie in anderen Fiallen, wo Regeneration stattfindet, vorhanden; nur kam sie nirht in Wirkamkeit treten. weil in aregehenen Fall nicht allo hierzu erforderlichen Berlingungen erfïllt sind.

Wie von einer einzigen Berlingung das Ausbleiben oder der Eint!itt eines organischen Prozesies abhängen kamn. haben uns manche lieispielo in den vorausgexangenen Kapiteln gelehrt. Ein Polypenstörchen von Eudendrium racemosum - worauf noch eimmal hingewiesen sei regeneriert in Licht in wenigen Tagen die ahgeschnittenen Polypenkïptchen. wihrend sie. in Inulieh gehalten ofler nur durh rote strahlen belenchtet. auch nach vielen Wochen kein einziges wieder zu erzeugen vermag, aber, ins volle Licht gebracht, das Versäumte rasch nachlıolt (Seite 486).

Ton dem eben begrïndeten Standpunkt aus kamn ich nicht die von

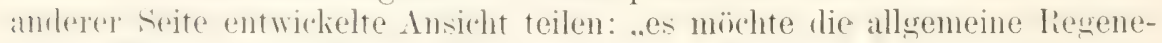
rationsfähokeit simtloher Troile eine durch Selektion herbeigefiihrte Errmongenshaft nieslerer und einfarherer Tierformen sein, die im Lanfe der P'hylowenese und der -teigenden Kompliziertheit des liaues zwar allmählich mehr und mehr von ihrer ursprünglichen Höhe herabsank, die aber auf jerler stufe ihrer Rö̈cklildung in hezug auf hestimmte, biologisch wichtige 


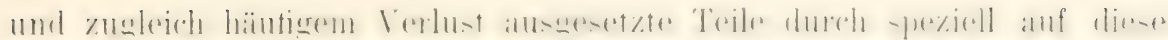

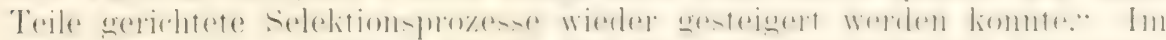

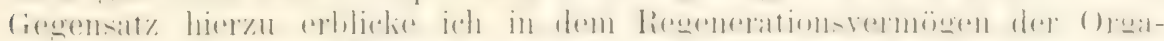

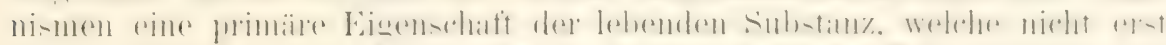

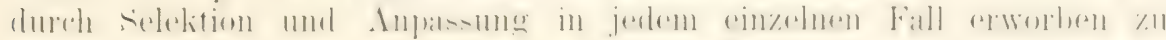
werden brauchte.

\section{Literatur zu Kapitel XXIV.}

Barfurth, Regeneration. Ergebnisse der Anat. u. Entricklungsgesch., Bd. I. I80r, lit. II- I .

$\because$ Derselbe, Zur kegeneration der Getecbe. llit 3 Tafeln. Archid f. mikrosk. Anat. Bist. I.T.IVII, S. 392. 189r.

: Derselbe, Die experiment. Kegeneration überschüssiger Gliedmapenteile bei Amphibien. Archiz f. Entreithl.-1Yech., B.t. I. 1805.

t) Blumenbach, Specimen phisiol. comparat. inter animantia calidi ct frigidi sanguinis. Commentationes soc, res scient. Gottinsensis, Vol. VIII. 1780.

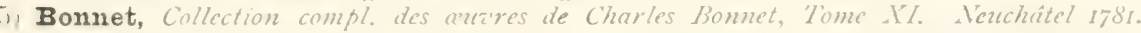

¿i) Colucci, Sulla rigenerazione parziale dell' occhio nei Tritoni. Mem. Acad. Bologna. T. I I80I. Zoolow. Jahresbericht f. I89I, S. 17 t.

Driesch, H., Studien über ders Régulationsvermögen der Organismen. drchio f. Enta'.-Alech., Bid. V. 1897.

Dugès, Richerches sur l'organisation et les muzurs des Planaries. Annal. d. scienc.

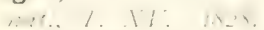

van Duyme, J., Uber Ileteromorphose bei Planarien. Archio f. d. sesamte Physiol. Bit. L.TII. ISO0.

1ii) Flemming, Studien ïber Kegeneration der Geacbe. Archiv fïr mikroskop. Anat. B.t. H.YT. 1885.

11. Fraisse, Die Kescheration ion Geneben und Organen bei den llirbeltieren, besonders Amphibien and Reptilien. Fiassel 1885.

l: Kochs, W., Versuche äber Regeneration aon Organen bei Amphibien. Archiz für mikreskiop. Amate, Bid. ILLA. 1897 .

$\because$ Korschelt, Über das Regenerationszernügen der Rewenaïrmer. Sitzungsberichte dir Gesellschaft etc. zat Marburer 1897.

11) Morgan, T. H., Regeneration in Allobophora foetide. Archit f. Entuickl-slechanik der Or.s. Bd. IT. 1807.

:ii Derselbe, Some problems of reseneration. Biol. Lect. IVoods Hall. Boston 1899.

iti. Derselbe, The control of hetcromorphosis in Planaria maculata. Archiz f. Entac.-

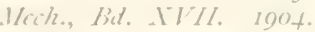

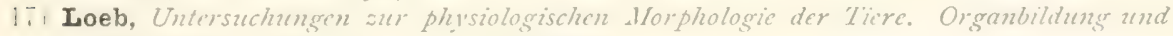
Ilachstum. Ileft I u. 2. ISOT u. I892.

It Derselbe, Bemerkungen über Regeneration. Arch. f. Entaickl-alsech., Bd. II. 1890.

I!) Müller, Evik, Über die Reseneration der Augenlinse nain Exstirpation derselben be'i Triton. Archiz f. mikrosk, Anat., Bd. XLVII. 1890.

$\because 1$, Randolph, Harriet, Obserations and experiments on regeneration in plancrians. Archiz, f. Entreickl.-Alech., Bd. V. 1807.

21) Röthig, Uber Linseneseneration. Doktortissertation. Berlin ISoS.

-.- Samuel, Die histogenetische Energic unat Symmetrie des Gerebenachstums. Virchon's Archio, Bit. CI. 1885.

: $:$ Spallanzani, Physit. u, mathemat. -16h. Leipzig 1706.

¿t. Spencer, H., Dic Prinzipien der Biologic. Ubersetat ron Vetter. Bd. I, S. I9t. 1876.

.-. Ströbe, Experimentelle Untersuchunen ïber Degeneration und Regencration peripherer

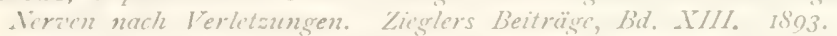

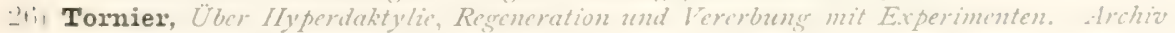
f. Entrickl.-1lech., B'. III. 1806.

.-. Viexing, Experimentelle Untersuchung diber die Regeneration des Selaningentebes. Wirchores Archio, Bd. CXYT, S. 252.

$\because$ Weismann, Das Kémplasma. Eime Theorie der Vererbung, S, I24. Jena ISO2.

:14, Wolff, Gustav, Entricklungsphysiologische Studien I. Dic Regeneration dar Lrodelentlinse. Archiz f. Entritikl.-11ech. d. Organismen. Bid. I. 1805. 


\section{FÜNFUNDZWANZIGSTES KAPITEL.}

\section{I)ie im Organismus der Zelle enthaltenen Faktoren des Entwicklungsprozesses.}

Bei unserer Analyse der zahlreichen Faktoren der organischen Entwicklumg hahen wir jetzt noch auf das shwierigste Thema einzugehen, auf die Intersuchung der in der Zelle selhst enthaltenen Falitoren, welche ja schlielilich bei allem, was im Organismus geschieht, die Hauptrolle spielen und dem Entwicklungsprozel, allein das ler Art remälie repräge aufdrïcken. Bei unserer auf Seite +11 gegehenen Einteilung unterschieden wir sie als die inneren Faktoren im engeren Sinne. Jeder Versuch, in sie tiefer einzudringen, stellt uns vor eine Fülle von Rätseln, welche dem tiefer denkenden Forscher der wunderbare Organismus der Zelle darbietet. Auf jeder Stufe des Entwickhungsprozesses erscheinen uns die Zellen als die in geheimnisvoller Weise wirkenden Bammeister, wenn unter dem Einthuf von Schwerkraft oder von Zug, von Licht oder Wärme, von diesem oder jenem rhemischen Agens sich irgend ein fiehilde gestaltet: wenn Knochenbälkchen in der Richtung von Zug- und Druckliurven entstehen, wenn an der Pflanze Blätter sich bilden. damit das Sonnenlicht auf den Chlorophyllaphatat einwirken kamn, oter Speichehdrüsen beim Tier für die Verdauung der Stärke.

Überall aber, wo das Wirken der Zelle in Frage kommt - und das geschieht bei jorlem Problem in rer biologie, wenn man es genügent weit verfolgt - beginnt das Gebiet, welches sich schlieflich einer exakten naturwisenshaftlichen Analyse entzieht. Denn eimmal wisen wir so gut wie nichts von der Natur und Anordnung der kleinen Lebenseinheiten, welche den Dikiroliosmus der Zelte zusammensetzen und zu deren Annahme mo his jetzt nur eine logisch hegrindete mol berechtinte natmisisenschaftliche Hypothese hinführt. Wir befinden uns der Organisation der Zelle gegeniiber genat in der Iage wie ein Mechaniker, dem anfgegehen wird. aus einer nach auben hervortretenden Wirkmng ein auberordentlich komplizirert zusammenesetztes mechanishes limstwerk, hei welchem alle nur (2rdenkbaren Mittel physibalischer und chemischer Technik in Verwendung gekommen sind, mechanisch zu erklären, ohne daß er in die unzähligen struliturteile anen Finblick nehmen liamn. Weil sie in ein festrerschlossenes. undurchsichtiges Gehäuse eingeschlossen sind.

Ebenso entziehen sich die Kräfte, die im Zellenorganisnus diese oder jene Lethensersheinumg hervorruten. anf dem derzeitigen Entwicklungssarlimm der Vatmwistenshaften gewöhnlich einer physikalischen und einer chemischen Erkenntnis. 
Niemand vermag durch physikalisch-chemische Analysen zu beantworten, warum an diesem oder jenem Ort unter Zug und Druck gewisse

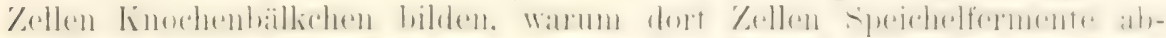

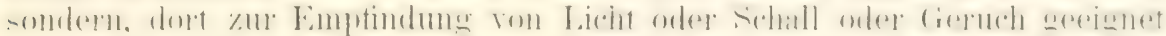
geworden sind, oder gar sich zu einem Auge, einem Hör- oder Riechlabrrinth zusammengeordnet haben. Kwar kömuen wir ïberall bei den

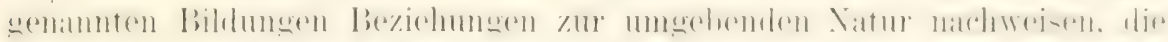

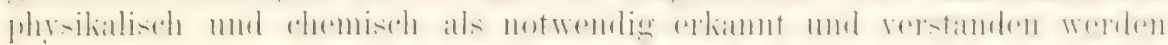

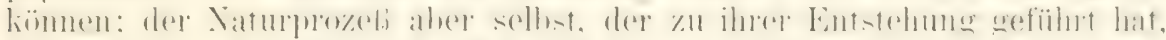

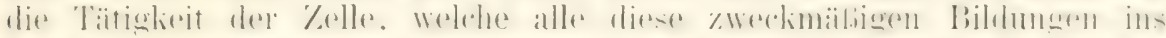

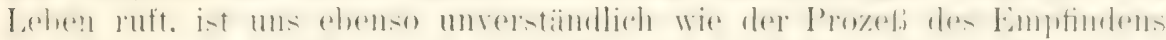
und Denkens, der sich in minserem Simnes- und Nervenapparat abspielt.

Es zeugt daher von einem Verkennen der Sachlage, wenn jemand

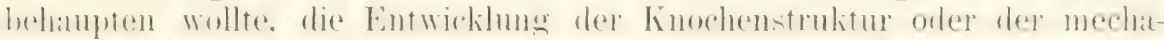

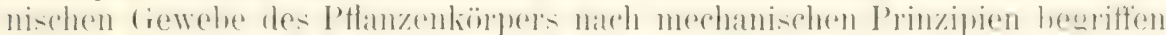
zu haben. In Wahrheit hat er nur nachgewiesen, daß der Ḱnochen usw. nach mechanischen Prinzipien gohant ist, was ja ler Fall sein muli, wem er mechanischen Zwecken dienen soll. Lr hat somit für den Knochen

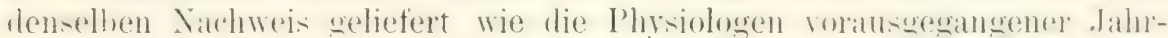

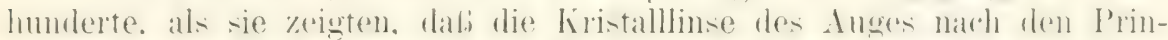

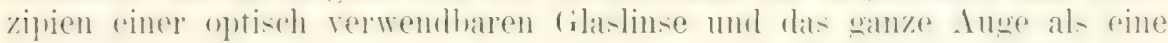
Camera obscura eingerichtet sei, oder dab die Membrana tympani des

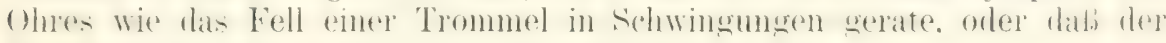
Kehlkopf wie eine membranöse Zungenpfeife wirke.

Die Entwicklung des Auges, des Ohres, des Kehlliopfes sowohl wie

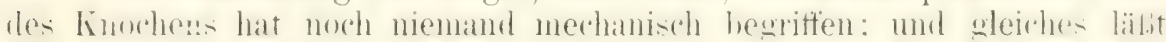

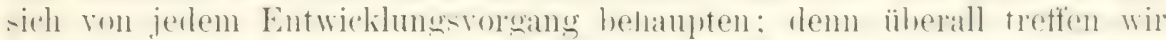
auf den einer merhanischen Frkemntnis sioh absolut entziehenden Falitor. wolcher abey von allen der wichtigste ist. auf die Tätgheit de- Zellenorganismus.

Wem ich jetzt trotzdem auf die im Organismus der Zellen ent-

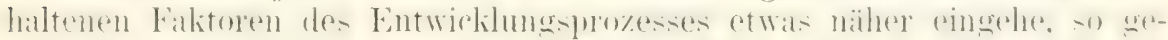

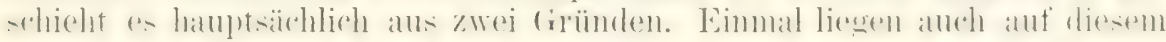
Gehiete noch eine Reihe interessanter 'Tatsachen vor. die in den letzten Jahrzehnten beobachtet worden sind, und zweitens haben wir hier noch

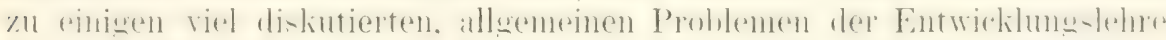
Stellumg zu nehmen, vor allen Dingen zu dem Problem der Vererhung.

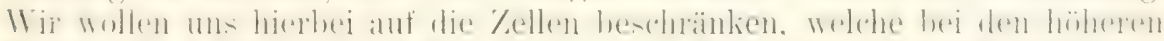

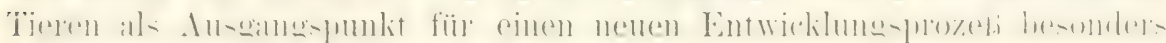
differenziert sind, auf Ei und Samenfaden.

Beide haben, wie schon im ersten Buch besprochen wurde (S. :55̄o).

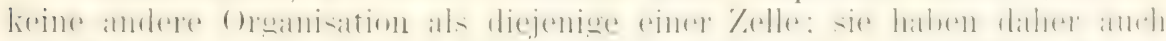
auf den bau des aus ihrer Vereinigung entstehenden (ieschöpfes keinen anderen Bezug. als dal sie Zelleneigenschaften besitzen, welche für eine

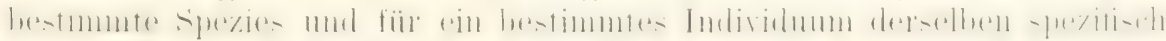
sind. Ferner wurle schon im ersten Buch das Axiom anfegestellt, dabi die beiden Geschlechtszellen zu den Eigenschaften des neu entstehenden Geschöpfes gleich viel beitragen, dab im Samenfarlen die Charalitere der Spezies und die Besonderheiten des Individums als Zelleneigenschaften ebensogut enthalten sind als im Li.

Nun sind aber Ei und Samenfaden in ihrer (irölie. in der (Quantität und Qualitait ihres Stoffes, sowie ïberhaupt in vielen Eigenschaften sehr rerschieden voneinander. Daraus folgt, dal wir an ilmen 1. für beide 
gemeinsame und daher wesentliche und 2. für Ei und Samenfaden besomblere und daher mohr unterweordnete onler unwesentliche Zelleneigenschaften als imnere Faktoren des Entwicklungspozesses zu unterscheiden haben.

\section{Die in den Finerialeigenschaften von Ei- und samenzelle gegebenen besonderen und mehr untergeordneten Faktoren des Entwicklungs- prozesses.}

Ei und Samenfaden sind nicht bloß 'Träger der Erbmasse, sonciem zuslejch auch für hesondere Aufuaben des befruchtungs- mol Entwicklungsprozesses in versehichener Richtung extrem differenzierte Elementarteile. wie gleichfalls fruher (siehe Kap. XI, S. 299-313) erörtert und begründet worden ist. Die Eizelle ist gleichsam ein Nahrungsreservoir geworden, mehr oder minder reichlich gefüllt mit Stoffen, die den Zweck laben. den sich bildenden Embryo für längere Zeit zum Teil unahbängig von änderer Nahrungszufuhr zu machen. I)er Samenfarlen dagegen. vollständig entblößt von derartigen Stoffen, ist die allerkleinste Zelle des Körpers geworden; mit einer Geifel ausgerüstet und zur Fortbewegung fähig, ist er lediglich für den Zweck der Befruchtung differenziert.

()he Frage üht die gewaltige Ansammlumg rom Dottematerial in der Eizelle auf den Ablauf des Entwicklungsprozesses. namentlich in seinen fröhenten Stadien, einen sehr tioforeifenden Einfluls aus und dient für viele Eisentümlichlieiten desselhen zur Frliburms. Darlureh sind viele Forscher veranlaßt worden, in dem $\mathrm{Ei}$ etwas mehr als eine einfache Zelle zu sehen und es noch mit einer besonderen, gewissermaßen über die Zelle hinausgehenden, höheren Organisation auszustatten. Fin solches streben macht sich auch in dem interessanten und ideenreichen Aufsatz von Whitarax geltend, z. B. in den Sätzen: „Im Ei ist schon vor aller Zellenbildung eine hestimmte Organisation vorhanden" oder ..die Oromisation des Eies wird durch alle Wandlumen des Entwicklungsprozeses hindurch als eine ungeteilte Individualität übertragen".

Je mehr in diesen und ähnlichen Äußerungen ein richtiger Kern enthalten ist, den wir sogleich herauszulösen versuchen wollen, um so mehr ist ilnen gegenüber zn betonen, dal. durch die heträrchtiche Stoffansammlumg der ('haraliter des Eies als einer einfachen Zelle nicht im geringsten geändert wirl und dab anch die durch sie hervorgerufenen

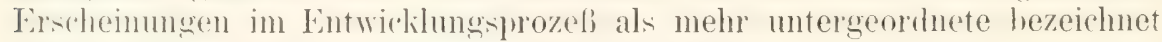
werden können, weil sie sekundärer Art sind.

Massenzunahme einer Zelle bedingt an sich noch keine höhere Stufe der Organisation. Das mit unbewaffnetem Auge kaum sichtbare kleine Ei des Säugetieres hat als Anlagesubstanz denselben Wert wie das gewaltige Straußenei. Trotz seines kolossalen Wachstums bleibt letzteres doch nur eine Zelle. und wemn es in dieser Art auch noch weiter fortwüchse, bis es an Tolumen dem Tiere gleichkäme. zu dem es werden soll, es wäre damit seinem Ziel, den Körper eines Straußes zu bilden, auch nicht um eines Haares Breite näher gerückt. Das Wachstum des Eies durch Substanzaufnahme ersetzt nicht, was nur durch den Entwicklungs-

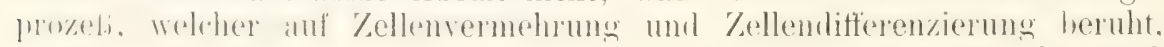
geleistet werken hamn. Die Individualität des Eies als Zelle muf sich in viele Zellenindividualitäten umwandeln, wenn das Ziel der Entwicklung erreicht werden soll. 
Somit bleibt jetzt zu prüfen, in welcher Weise und inwieweit die Ansammlung ron Dotter in den Eizellen als ein besonderer Faktor den Ablauf des Entwicklungsprozesses beeintlubt.

Hier ist hervorzuheben. dab das sich ansammelnde Dottermaterial

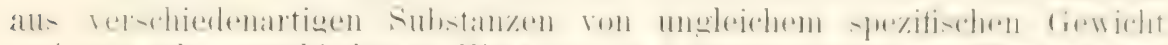

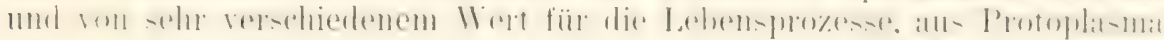
und aus Deutoplasma usw.. zusammengesetzt ist. - Protoplasma und

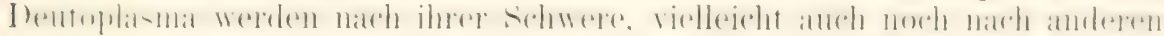

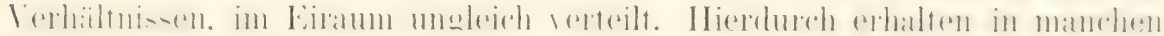
Tierliassen die Eier eine Organisation, welche man als polare Differenzierung usw. bezeichnet hat. In ihrer einen Hältte hat sich mehr das schwerere Deutoplasma, in der anderen das leichtere Protoplasma angesammelt. Da infolgedessen ihr Schwerpunkt exzentrisch zu liegen kommt. müssen die Eier, sofern nicht andere Momente der Schwerkraft entgegenwirken, eine feste Ruhelage im Raum einzunehmen suchen.

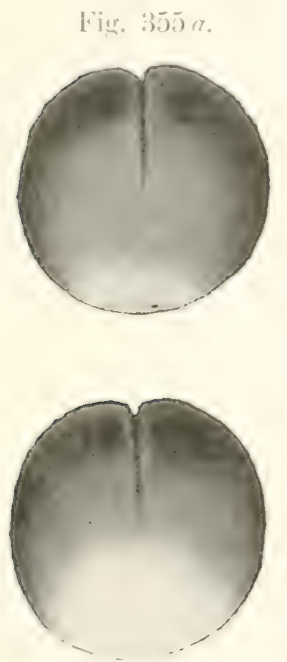

Fier. 3550 .
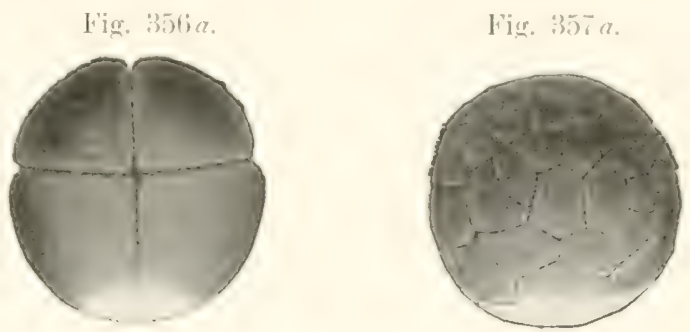

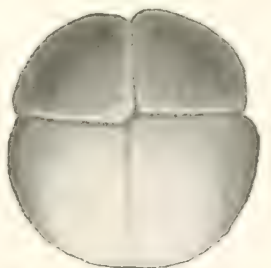

Fig. 35068

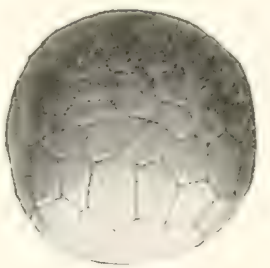

Fig. 3576

Fig. 355-357. Drei Furchungsstadien von Rana fusca, jedes Fi einmal von rorn (a) und von linten (b) gesehen, mm zu zeigen, daß das lichtere fiekd auf allen drei Entwicklumgsstadien auf der hinteren Seite des Embryos mehr liam eimnimmt, als auf der vorteren. Nach $O$. SchrotzE.

Aulier der polaren Difterenzierung scheint sich bei manchen Eizellen zugleich noch eine bilateral-symmetrische Organisation

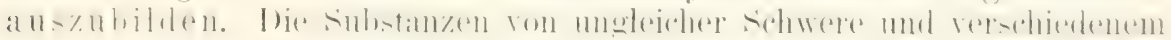
physiologischen Wert sind dam zu beiden Seiten einer Symmetrieebene gleichmäbig verteilt. Da die Symmetricebene sich stets der Schwere nach senkrecht einstellen wird, kommt ihr auch noch die Bedeutung einer Gleichnewichtsebene zu.

Eine bilaterale symmetrische Organisation ist bei den Eiern der Amphibien dentlich zn erkemen (Newport. Pplüger. Roux. Osrar Sciultze). Namentlich auffällig ist sie bei Rana esculenta. Bald nach der Befruchtung stellt sich das Ei so ein, dal. bei Betrachtune von oben an einem Rand der unpigmentierte Dotter in Form eines Halbmondes zu sehen ist. Eime den Halhmond unter rechtem Winkel und lotrecht schnei-

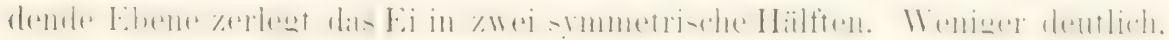


aber doch erkennbar ist die bilaterale Symmetrie auch am Ei von Rana fusca (Fig. $355 a$ ). Es grenzen sich nämlich nach den Beobachtungen von

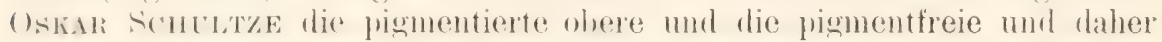

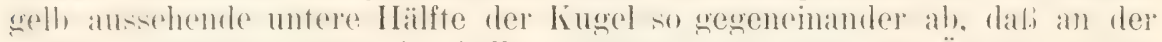
suäteren hinteren seite das helle Dotterfeld his über den Äruator höher

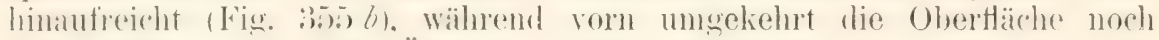
eine Strecke unter dem Äquator schwarz pigmentiert ist. Von vorn ge-

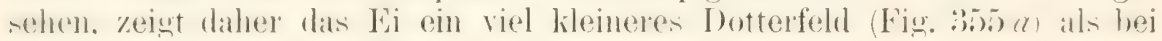
Betrachtung von hinten (Fig. 355 b).

Wie Eier mit bilateraler Symmetrie, gibt es vielleicht auch Eier, in welchen Protoplasma und Deutoplasma nach einem radiären T'y us verteilt sincl oder in welchen ein solcher sich nach den ersten Furchungen ausbildet. Wahrscheinlich gehören die Eier der Ctenophoren hierher.

Bei der Ansammlung von Dotter gewinnen außerdem die Eier je nach den 'Tierarten eine kugelige, oder eine oroile, ofler eine tommentörmige oder eine zylindrische Gestalt.

Durch die in der Form des Eies und in der Differenzierung seines Inhaltes gegebenen Vorhälnisse wirl ein sehr eingreifenter, gewissermaljen richtenter Einthuli, auf eine wanze Reihe ron Entwicklungsinrozesien. am meisten aber anf die ersten Stadien, ansgeäht: er ist schon von HaEcKeL in seiner (iastraeatheorie hei der Erklärung der verschienlenen Formen der Keimblase und Ciastrula in ausuezeichneter Weise verwertet. seitrlem ron vielen Forschern als Trsache für diese oder jene Frscheinung erkamnt, aber in seiner sehr verschiedenartigen und großen Tragweite doch nur zum Teil genügend gewürdigt worden.

Erstens bestimmen Form und Differenzierung der Eizelle die mit einem hohen Grade von Gesetzmäbjigkeit anftretemlen Richtung(n ihrer ersten T'eilebenen, Es kommen hierbei die im ersten Buch (S. 228) ausemandergesetzten, schon im Jahre 1 sit von mir formulierten Regeln zur Geltung.

Bei manchen Eiern bildet sich durch die ersten Furchungslinien ein sehr regehmäliges Zellemmosaik aus, an welchem man eine linke unt rechte Hälfte, ein vorderes und hinteres Ende in einer Weise, die der Orientierung des später erkembar werdenden embryonalen Körpers ent-pricht, unterscheiden kann. Auch hierfür einige Beisjiele:

Beim Froschei fällt unter normalen Verhältnissen die erste Teilebene (Fig. 355) in der Regel mit der oben unterschiedenen Symmetrieebene mehr oder minder zusammen, desgleichen die spätere Medianebene des Embryos. Hierdurch wurde Roux veranlast, der ersten Teilung die Auf-

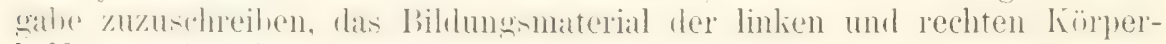
hälfte voneinander zu sondern.

Ein sehr schönes bilateral symmetrisches Zellenmosaik liefern die ersten Furchungsstadien des Eies ron Clavellina, einer Aszidie, und des

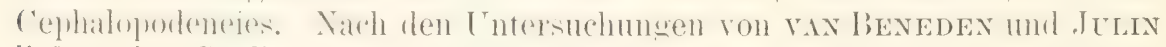
liefert das Stadium von 16 Zellen das nebenstehende Bild (Fig. 358), in welchem die Linie a p die Symmetrieebene des Eies darstellt, mit welcher sowohl die erste Teilebene als auch die spätere Medianebene des Embryos zusammenfällt. Gleichzeitig kann man nach der verschiedenen Größe der Zellen das spätere Kopfende $(a)$ und das Schwanzende $(p)$ bestimmen.

Auch in den Figuren 359 und 360 , welche rom Cephalopodenei das Achtzellenstadium und ein Stadium von 22 Zellen nach WATASÉ darstellen, ist die bilaterale Symmetrie sehr deutlich ausgeprägt. Die erste

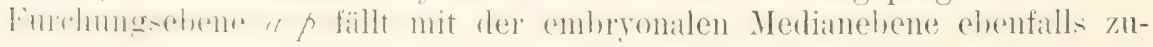


sammen. Kopf- $(a)$ und Schwanzende $(p)$ wird an der sehr verschiedenen Größe der Zellen imterscheidbar.

Zweitens üben die Form und die Differenzierung der Eizelle einen

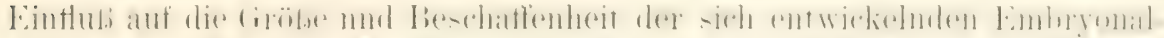

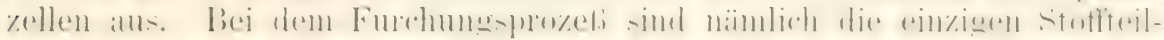

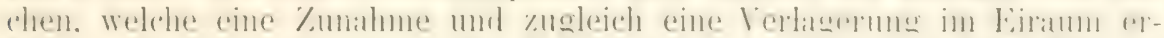

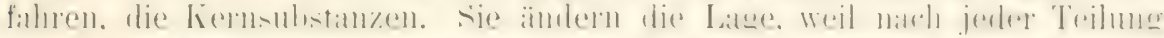

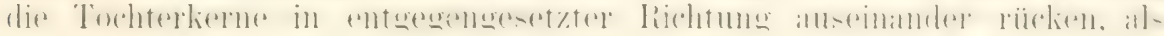

Fïg. :35s.

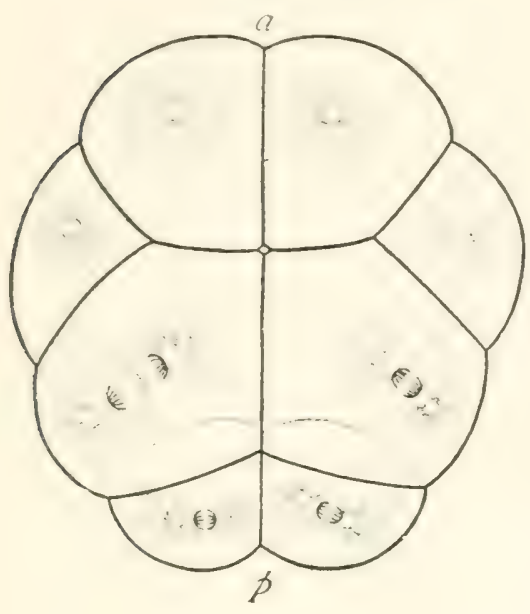

Fig. 35S. Bilaterales Stadium vou 16 Zellen vom Ei von Clavellina. Mach vax Bexperex und Jutix. a Vorderes, p hinteres Ende.

Fig. 359 und 360). Zwei bilateral symmetrische Furchungsstadien vom Cephalopodenei. Nach WATASÉ. a Vorderes, phinteres Ende; $r$ rechte. $/$ linke seite.
Fing. 3599.

a

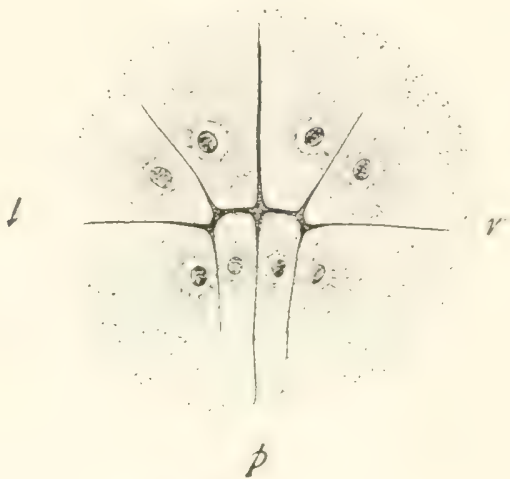

Fing. :itis.

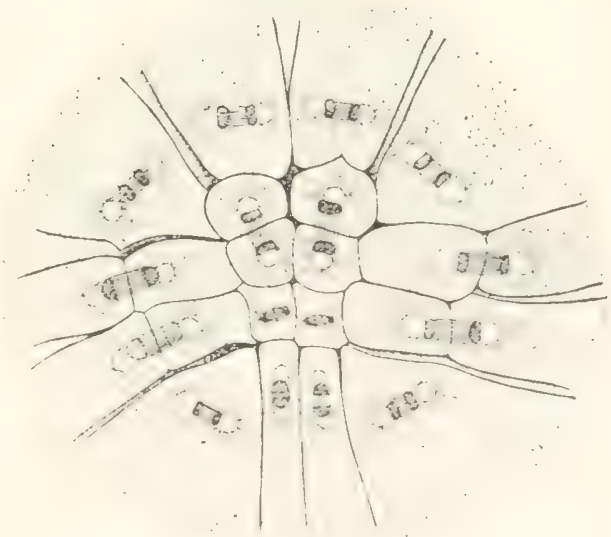

ob sie sich wie die gleichnamigen Pole zweier Magnete gegenseitig abstieben. Hiervon abgesehen, wird durch die Zerlegung der groben Eizelle in immer kleiner werdende 'Tochterzellen die von vornherein gegebene räumliche Verteilung der Stoffteile yon verschiedener Schwere und ron verschiedenem Wert im ganzen wenig geändert. Daher sind hei polur differenzierten Eiern die nach unten gelagerten Zellen auch auf späteren Entwicklungsstadien reicher an Deutoplasma, die nach oben gelegenen dagegen reicher an Protoplasma. 
Ferner laingt mit der Verschiedenheit ihres Inlıalts stets auch ein Unterschied in ihrer Gröbe zusammen. Denn wie ich gleichfalls schon im Jahre $188+$ nachgewiesen habe, bewegt sich der Kern stets nach dem

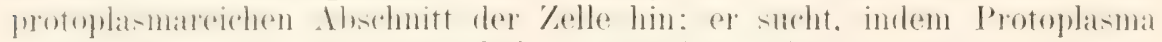
und Kern ja in den mannigfachsten Wechselwirkungen stehen. wie ich

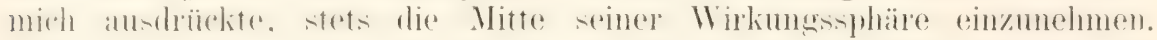
Daher rïckt nach der befruchtung der Kern im polar differenzierten Ei nach dem animalen Pole hin und kommt exzentrisch zu liegen; infolgedersen werden beim Amphibienei dureh die dritte Teilumg \%ellen von ungleicher Gröfe, vier kleine animale und vier große vegetative (Fig. 356),

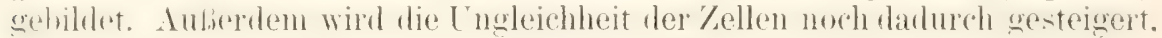

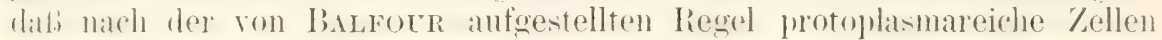

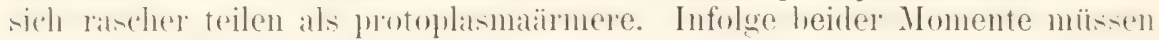
sich im Ei verschierlene Bezirke ungleich großer und mit verschiedener benchwindigkeit sich vermehrender Zellen anshilden, bezirke. welche schon vor der 'Teilung gewisermaben der Anlage nach in der heschriebenen ()ranisation der Fizelle angerlentet sind. Xur werlen die Engleichheiten. die anfangs zum Teil kaum wahrnehmbar sind, im Laufe der Entwicklung immer schärfer ausgeprägt.

Drittens beeinflussen Form und Differenzierung der Eizelle den Ort, an welchen innerhalh ihrer Inttermasse spätere Entwicklungsuromerse ihren Ausgang nehmen, und die Richtung, in welcher sie sich vollziehen. so wird am meroblastichen Ei der Fische. Feptilien und Vögel der emhryomale Entwicklumgrnozess auf eine kleine stelle les gewaltigen Eies. anf die lieimscheibe. heshö̈nkt: von ihrem Rand geht die Gastrulaeinstülpung aus. Ebenso vollzieht sich die Urmundbildung am Ei der Amphibien stots an der Clbergangsitelle der anmalen in die vorgetative Hailfte der Keimblase innerhalb der sogenamnten Randzone etc.

Ja, es lassen sich sogar, wie es scheint, noch genautere Lokalisationen ronelmmen, indem der bereich. wo die kleinsten und am raschesten sich teilenten Embnyonalzellen liegen, zum ()rt der (iastrulaeinstülpung wirl. Ist dieser aber eimmal gegeben, so ist iuber die Lage und Richtung, in wellher sich eine lieihe anderer ()randifferenzierungen vollziehen muls. entschieden, so ïber den Ort, an welchem sich die vordere Hirnplatte und das vordere Chordaende anlegen müssen; es ist gewissermaBen ein fester hristallisationsmittelpunkt für die tierische Formbild ung gegeben. Von beilen Enden der Urmundrinne aus setzt sich der Finstiilpungsurozel. hontimuierlich fort und zieht einen Zellenbezirk nach dem andern in die von einer kleinen Stelle aus eingeleitete Substanzbeweoung mit allen ihren weiteren Folgen mit hinein.

Als Beispiele für derartige Lokalisationen erwähne ich das Hühnerund das Froschei.

An der Keimscheibe des Hïhnereies zeigen schon während des

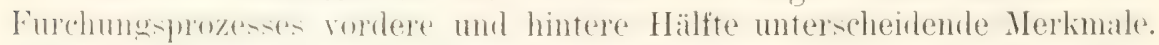
Denn vorn verläuft die Furchung an der Keimscheibe etwas langsamer als hinten. Dort findet man größere, hier kleinere und zahlreichere Embryonalzellen (OEllacher, KöLliker, Düval). Am kleinzelligen Rand entsteht später die Sichelrinme, auf dem vor ihr gelegenen Feld die Medullarplatte.

In ähnlicher Weise gibt OsKar Schultze für das Froschei an. daß anf dem Morula-tadium sich zwri gerenublerliegende Bezirke in der Randzone finden, die er als vorderen und hinteren unterscheidet (Fig. 357). Der

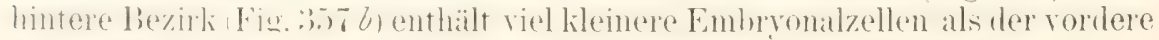




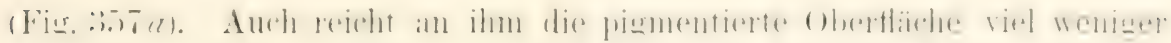
weit nach abwärts als ror'n und läßt daher ein gröberes, helleres Dotterfeld erkennen, in welchem sich später der Urmund anlegt. Im Bereich

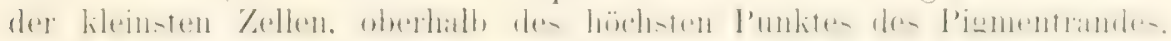
ist nach Schultze das jetzt schon erkennbare Material für das Zentralnervensystem (Himplatte) auf einen verhälnismäßig kleinen liaum zusammengedrängt.

Wenn man, durch äubere Momente geleitet, die Stelle erkennen kann. an weicher am Ei des Hühnchens oder des Frosches ror Begim der

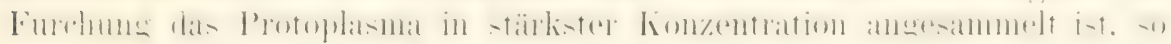
kamn man auch amnähernd voraussagen, in welcher Gegend sich später die erste Lrmundeinstiilpung zeigen wird. Denn an dieser Stelle werlen beim

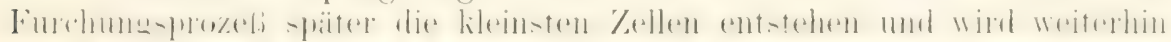

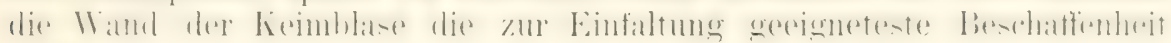
annehmen.

Daher ist auch die Möglichkeit gegeben, dab man am Froschei dureh äubere Eingriffe den Ort der Urmundbildung beeinflussen kann. Wemn man ein Froschei zwischen zwei horizontalen Glasplatten ein wenig lomprimiert und diese dann schräg geneigt aufstellt, so kommt die Übergangs-

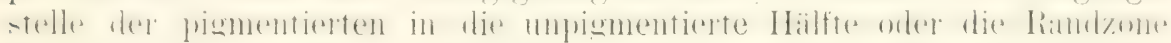
an einer Stelle höher als an der anderen zu liegen, und zwar entsprechend dem nach oben gekehrten Rand der Glasplatten. Infolgerlessen sehen wir hier den Urmund sich an der höchsten Stelle des hellen Feldes bilden. Dasselbe wird durch einfache Zwangslage der Eier in der von PFLC̈gER ausgeführten Weise erreicht, wie zuerst von Rovx nachgewiesen worden ist. Der nach oben gekehrte Teil der Randzone ist eben protoplasmareicher" und wird sich daher rascher und in kleinere Zellen abfurchen als ihr tiefer gelegener und daher dotterreicherer 'Teil.

Wie den Ort, so nannte ich auch die Richtung, in welcher sich die

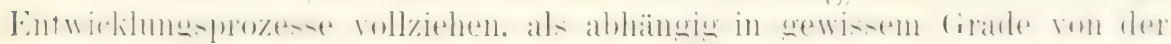

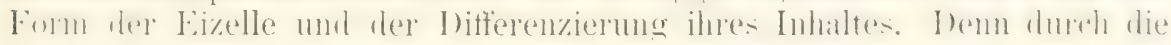
Zerlegung des Eikörpers in immer zahlreichere Zellen wirl am Anfang der Entwicklung werler die Form des Eies, noch die ursprïnglich gege-

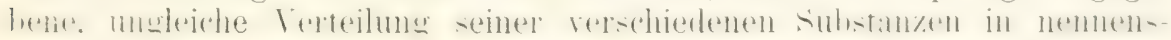
werter ITeise verändert, wie schon früher auseinandergesetzt wurde. Daher müssen das ungefurchte Ei und die aus ihm hervorgehende Keimblase in beiden Beziehungen Übereinstimmungen anfweisen. Die in der sich entwickelnden Stoffmasse enthaltenen Richtungen und Unterschiede gehen einfach von dem einen auf das nächste Stadium iiber. Ein ovales Ei liefert eine ovale Keimblase: ein kugeliges. polar differenziertes und eventuell bilateral symmetrisches Li gelut in eine lieimblase mit denselben Eigenschaften iuber. Ungefurchtes Ei und Keimblase mïssen daher annihernd auch dieselbe symmetrie- und Gleichgewichtsebene besitzen, da es fïl dieses Verhältnis gleichgültig ist, ob die durch ihre Schwere unterschiedenen Substanzen den Raum einer einzigen, grofien Zelle erfüllen oder auf den Inhalt vieler.denselben Raum einnehmender \%ellen verteilt sind.

I) Form der liemblase und die ihr vom Ei ïberkommene. ungleiche Massenverteilung ihrer. Substanzen mub naturgemäb auch wieder auf rlie

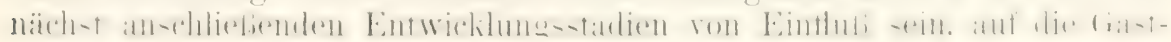
rula und auf die aus dieser sich entwickehnde Embryonalform, an welcher die ersten charakteristischen Organe des Wirheltierembryos, Chorda und 
Vervemrohr, zum Lorschein kommen. Es kamm daher nicht wunder nehmen. wenn auch diese sich in einem gewissen Grarle gemäß der ersten Organisation der Eizelle im Eiraum annähernd orientiert zeigen und wenn die

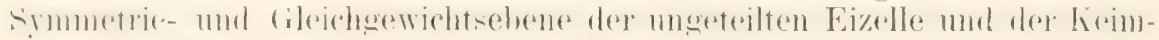
blase annähernd auch zur Svmmetrieebene der Gastrula mol des Embryos mit den sichtbar werlenden Rückenwülsten wird.

Am deutlichsten treten solche Beziehungen an Eiern hervor, bei denen eine Achse an Länge ïberwiegt. Bei den langgestreckten Inseliteneiern fällt die Längsrichtung des Embryos stets mit der langen Eiachse zusammen, ebenso an ovalen Ei von Ascaris nigrovenosa und am ovalen Ei der Tritonarten. Da letzteres zugleich polar differenziert ist und die Läns sachse nicht mit der Vertikalachse zusammmenfällt. so besitzt es schon von Anfang an alle drei Inauptachsen, welche im wanzen auch mit den drei Achen des Embryos in ihrer Lage später übereinstimmmen. Cuter diesen IBedingungen entwickelt sich hei Triton die Längsachse der drastrula und weiterhin des Embryos in der Richtung der längsten Achse des Eies.

Mit einem Wort: Mit der anfangs gegebenen Massenverteilung der unentwickelten Substanz stimmt auch die Massenverteilung der weiter entwickelten Substanz überein. Ein solches Zusammenfallen wird a priori als das natürlichste und einfachste erscheinen. Denn sollte der spätere Iängsturchmesier des Fmbryos in die Richtung des anfangs kïrzesten Firlurchmessers zu liegen kommen, so mübte wïhrend ler Entwicklung die ganze Fisulstanz uncelagert werlen, was jerlenfalls ein wenig zweckentsprechender Vorgang sein würde.

Bei manchen Tierarten kam man auf diese Weise vor der ersten Teihng. wie von verschiedenen Forschern heobachtet worden ist, dem Ei ansehen, wie später der Embryo in ihm orientiert sein wird; man richtet sich hierbei nach der Form des Eies, nach kleinen, äuBerlich sichtbaren Tonterschieden in der substanzverteihng. in der Pigmentierung und nach anderen derartigen Merkmalen.

In diesem Sinne bezeichnete ich in einer Abhandlung, in der ich auf die ohen hesprochenen beriehungen aufmerkam vemacht hahe. das eben befruchtete Ei gewissermaßen als eine Form, welcher sich der werdende Embryo, besonders auf den Anfangsstadien der Entwicklung, in vielfacher Beziehung anpassen mub; orler an einer anderen Stelle: Die in der Form des Eies und in der Differenzierung seines Inhaltes gegebenen Verhältnisse üben auf eine ganze Reihe von

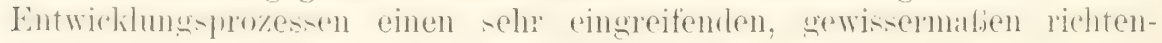
den Einflul, aus.

Die Anwesenheit von reichlichem Dottermaterial im Ei verändert am meisten die ersten Stadien des Entwicklungsprozesses, kann aber auch noch die Gestaltung des Embryos in sehr späten Embryonalperioden beeinflussen. Denn man bedenke nur, daß hiermit die bruchsackartige Ausstülpung des Darmkanals und der Bauchwand, der sogenannte Dottersack, bei vielen Fischen und allen Ammioten zusammenhängt; daß der Dottersack wieder das eigentimliche Gefäfsystem der Vasa omplialomesenterica

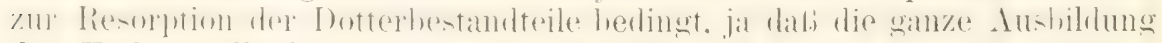
(ler Embryonalhïllen (Amnion, seröse Hülle, Allantois) mit dem Dottergehalt des Eies in einem gewissen ursächlichen Zusammenlang steht.

In diesem Sinne verstanden und genauer interpretiert, haben die frïher zitierten Ausspriiche von Whrtman und RaUbER, sowie die Theorie 


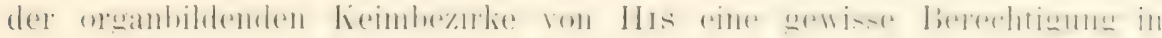
sich. Allerdings mul, man den richtigen liern von präformistischen Vorstellungen, die sich leicht an ihn anhängen, reinigen. In bezug hierauf hebe ich noch einmal. um von vornherein keine Mifverstindnisse aufkommen zu lassen, besonders hervor. was ich schon in einem anderen Buch auseinandergesetzt habe:

Die Ungleichheiten, die man an der unbefruchteten Eizelle in der

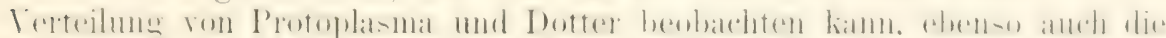

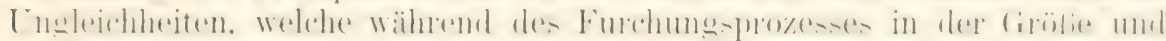

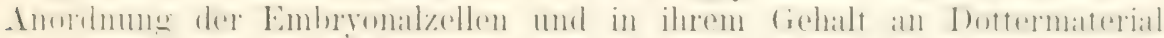

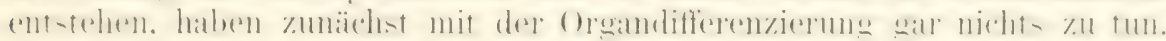
Wie beim unbefruchteten, so spricht auch beim befruchteten und abgefurchten Ei nichts dafür, daß die Zellen der verschiedenen, am Ei unter-

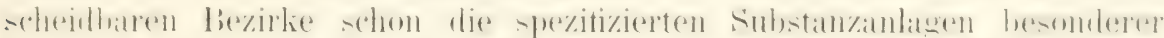
Organe repüäsentieren; vielmelr müssen wir behaupten, daß erst dem weiteren Gang der Entwicklung vorbehalten ist, darüber zu entscheiden. was aus den einzelnen Zellen werden wird.

Eine jede Störung, die wir vor oder nach dem Eintritt des Furchungsprozesses setzen, sei es. daß wir einen 'Teil der Substanz dem Ei ganz

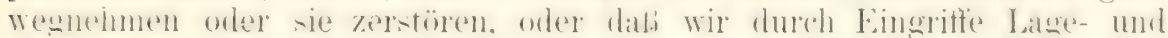

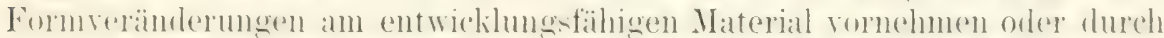

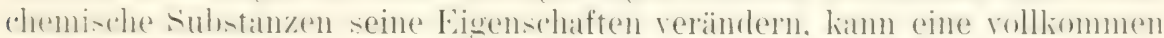

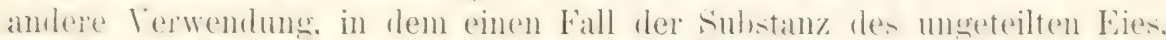
in dem anderen Fall der schon gebildeten Embrvonalzellen bei der Entwirklung des embryonalen hörpers hervorufen: ja. es kamn sogar dasselbe Material durch besontere ['mstimble veranlabt werden, anstatt in einen finfathen Emhryo sich in zwei oler sogar drei Embryonen umzuwandeln.

Daraus, daß im gewöhnlichen Lauf der Dinge ein Stadium der Entwirlibng dis nächotfolgende und so fort nach einer fexten Norm und in schembar strenger Totwendighert ans sich entstehen läbt. dürfen wir nioht schlieben, es müsse nun jedesmal so sein, und es könne überhaupt nicht anders herohen.

IV er solche Gedankengänge hegt, rerkennt, wie ich schon mehrfach

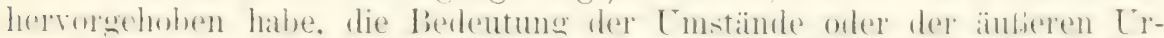

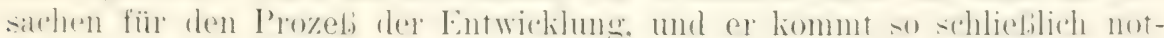

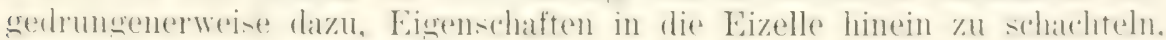
welche ihr ganz fremd sind.

Man darf über die Art der Kausalitït, die zwischen den einzelnen

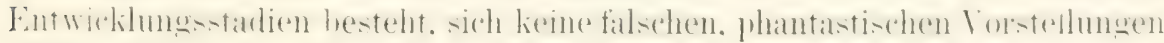

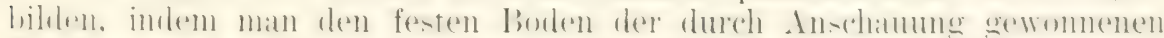

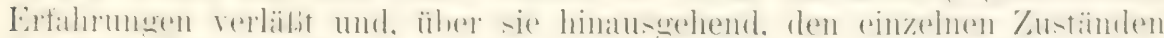

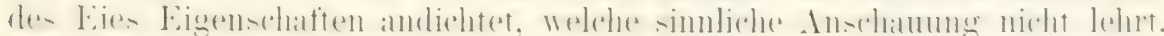

Wenn z. B. die ungleiche Verteilung von Protoplasma und Dotter-

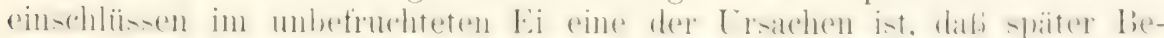

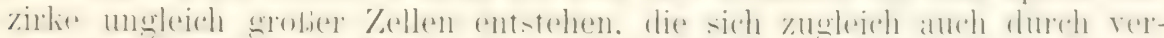

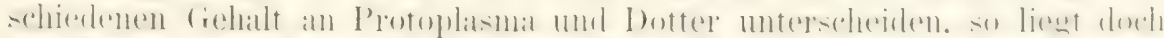

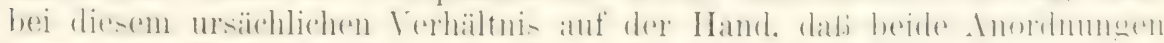

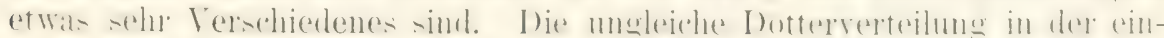
fachen Eizelle ist in jeder Hinsicht ein ganz anderes Verhïlnis als die

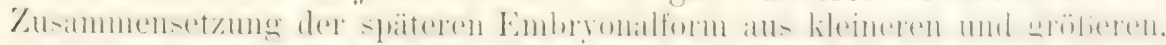
substantiell etwas voneinander verschierlenen Zellen. Daher kann man auch gewiß nicht sagen. daß die kleineren und grögeren Zellen in Ei

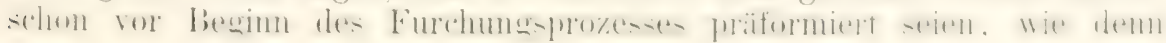


zum Beispiel yon Kernsubstanz in den später von Zellen eingenommenen Substanzbezirken keine Spur anzutreffen ist. Nur Ursachen für ihr späteres Zustandekommen oder allgemeine Anlagen dafïr sind in der ganzen Organisation der Eizelle, einmal in der Eigenschaft ihrer Vermehrbarkeit durch 'Teilung, zweitens in der allgemeinen Disposition ihrer Dottersubstanzen gegeben.

Schon das Wort ,Anlage", wenn man es richtig versteht, besagt ja, dab ïber das, was werden kann, erst noch entschieden werden mub durch andere Momente und Umstände. Ein solches Moment ist hier die Eigenschaft der Zelle, sich zu teilen, wobei der Kern die fülnende Rolle spielt.

Aber auch wenn dieses eine Moment in richtiger Weise eintritt, so hamn inmer now aus der Anlage efwas V'erchiedenes hervorgehen, je nach den weiteren Umständen, die noch in dieser oder jener Weise hinzutreten lïnnen. Es kamn der Furchmestrozel. eines hestimmt organisierten Fies die mamniofaltigsten. einander sehr unähnlichen Variationen darbieten. je nachdem wir die im Ei gegebene Anlage (Disposition der verschiedenen Substanzen) äuberen Eingriffen auscetzen. Das Kermmaterial kamn rabureh im Eiraum in der verschiedenartigsten Weise verteilt werden; die Zellen lïmnen andere Formen- und fröbenverhätnisse annehmen (vergl. hieribler S. 244 und 457 ).

Trotzdem sind alle diese durch äuBere Momente künstlich erzeugten Verschedenheiten riemlich sleichgültig für den Fortwang mol das l'roblukt der Entwicklung und lehren, wie ich schon hervorhob, dab die Organisation des Fies, welche anf der Einlagerung von Deutoplasma herult. doch schliefilich nur ein untergeordnetes Noment von seliundärer und vergänglicher Art im Entwicklungsproze? ist.

Das Wesentliche in den ersten Entwicklungsstadien ist nur die Zerlegung des Eies in Zellen. Mag die Zerlegung in dieser oder jener Weise vor sich gehen, in jedem Fall entsteht doch immer eine zusammengehörge Marse von Embryonalzellen. welche die Inlage für das nächstfolgende Stadium abgeben.

Zu dem gleichen Ergebnis führt uns auch die vergleichende Embryologie der ersten Entwicklungsstadien bei einigem Nachlenken.

Eier von Tieren, die verschiedenen Stämmen angehören. können einen

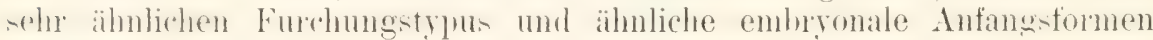
darbieten, während Eier aus nahe verwandten Abteilungen ein und desselben Stammes sich in sehr verschiedener Weise furchen und in der Beschaffenheif ihrer lieinhlase und rastrula andierordentlieh differieren (Fische. Amphibien, Vögel, Säugetiere).

Die Einlagerung von Dottermaterial in das Ei drückt daher den

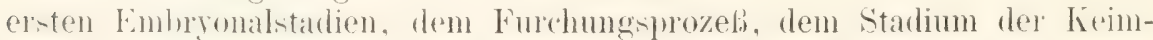
blase, Gastrula usw. usw., ein ganz charakteristisches Gepräge auf, aber auf das Wesen der Tierart selbst und daher auch auf die Entstehung einer besonderen Tierspezies hat es keinen Einfluß.

Denken wir uns aus dem Ei der Amphibien, Reptilien und Vögel den Nahrumsolofter wan\% entfernt, dagegen die mu klein sewordenen Zellen in eine ihnen zusagende Nährlösung eingebettet, so würden sie sich zu grenau denselben Tierformen, wie es vorher der Fall war, entwickeln müssen.

Aus diesem Grunde lassen sich die im Dottermaterial enthaltenen Anlagen der Eizelle im Hinblick auf die Endform, die erreicht werden -rill. als untergeondnete Falitoren des Entwicklungsprozesses bezeichnen: 
somit kommen wir auch auf diesem Wege zu demselben Resultate. zu welchem uns schon der Vergleich des Eies und der Samenzelle gefïhrt hatte, daf der Samenfaden, obgleich er des Dottermateriales vollstärlig entbehrt, doch ebensogut Träger der Arteigenschaften ist als das oft viel tausentmal gröbere Ei.

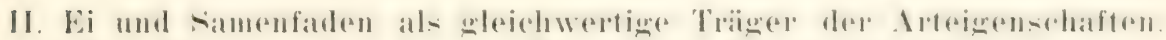 Das Idioplasma als innerer Faktor des Entwicklungsprozesses.}

Aus Grimden, die schon im ersten Hauptteil (S.954-36:3) auseinandergesetzt worden sind, wurde einerseits von NigebI der legriff des Inio-

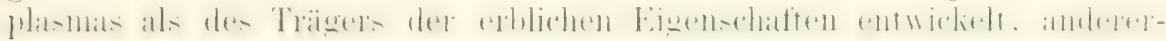
seits von mir nachzuweisen versucht, dafo das Irlioplasma in der Kernsubstanz von Ei- und Samenzelle enthalten ist.

Fiur die Berechtigung solcher begrifflichen Unterscheidungen spricht aufer den im rorausgegangenen Abschnitt angestellten Betrachtungen anch eine Analyse der Prozesse, die sich von der Befruchtung an im Ei vollziehen.

Mit dem Begimn des Entwicklumgsprozesses wird das Ei der Schau-

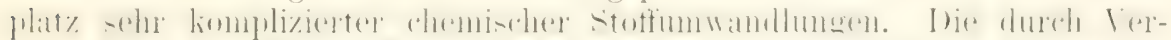

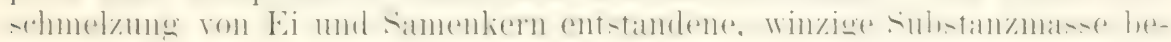

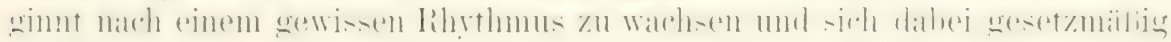
im Eiraum zu verteilen. Während das Ei nach seiner Entleerung aus dem Eierstock als Ganzes nicht mehr wächst, beginnt mit den Eintritt der Entwicklung die kleine Substanzmasse, in welcher wir das Idioplasma NïgELs erblicken, auf Kosten der angesammelten Nährmaterialien zu wachsen.

Die chemische Zusammensetzung des Eies wird dadurch auf das grimdlichste umgeändert. Un sich eine Vorstellung davon zu machen,

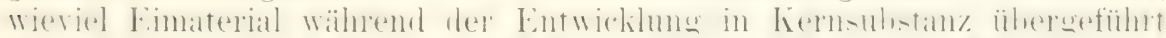

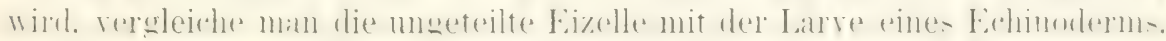

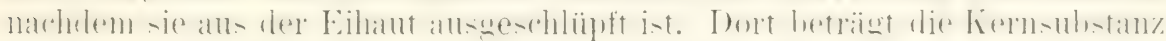
kaum einen tausendsten 'Teil des Eies und bei dottereicheren Eiern sogar'

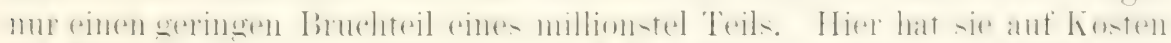

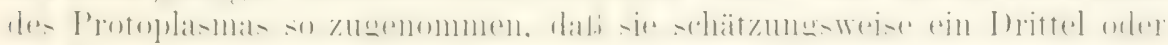
ein Viertel der Gesamtmasse der urspurünglichen Eisubstanz ausmacht.

Diese chemische Seite des Entwicklungsprozesses ist aller beachtung wert. Dem wie ich schon in meiner 1894 erschienenen

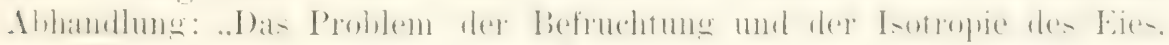
eine Theorie der Vererbung.6 mit Nachdruck hervorgehoben habe, ist am

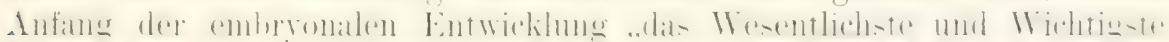

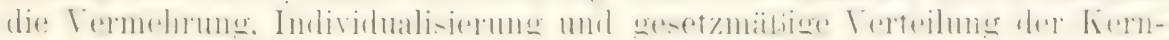
substanz".

In chemischer Hinsicht lassen sich in der Entwicklung des Eies drei

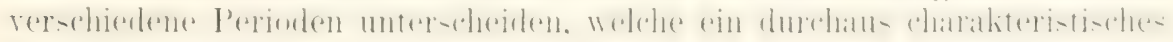
(iepräge tragen.

\section{a) Erste Periode in der Eientwicklung.}

Die erste Periode gehört der Vorentwicklung des Eies im Ovarimm an. Die während ihrer Dauer sich abspielenden chemischen Prozesse bestehen in einer Aufnahme und Ausbildung von Nïnmaterialien, durch

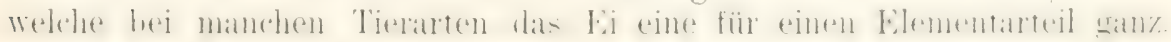




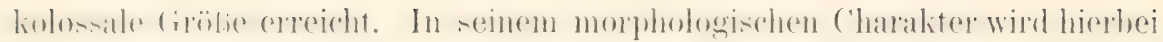
das Ei nicht verändert, es bleibt - mag es auch die gewaltigsten Dimensionen annehmen - eine einfache Zelle.

\section{b) Zweite Periode in der Eientwicklung.}

Erst mit der Reife und Befruchtung des Eies beginnt die zweite

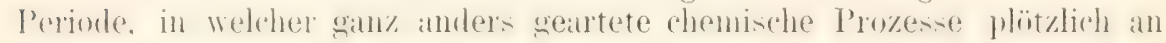
Stelle der früheren in den Vordergrund treten und alle Veränderungen beherrschen.

Eine ursprünglich kleine Stoffmasse, die durch Verschmelzung von Ei- und samenliern gebildete liernsubstanz. heht jetzt plötzlich an, auf losten des ïhrigen vorher angesammelten Stotfgemenges periorlisch zu wachsen: hierhei wird die (pualität der Eisubstanz, gleichzeitig aher auch ihre Organisation durch den Furchungsprozeb, durch die Anlage der Keimblätter. durch die ersten Organanlagen schritt für Schritt reränlert. Die zweite Periode in rler Eientwicklung kamn daher auch als die Periode des Wachstums der Kernsubstanz, gleichzeitio aber auch al- organisatorische bezeichnet werden, da die chemischen Prozesse mit Zellen- und Organbildung einhergehen.

Durch das Wachstum der Eizelle durch Stoffaufnahme (Nahrungs(lotter) ror der Befruchtung ist die zweite oder die organisatorische Periode mit ihrem Wachstum der Kernsubstanz so vorhereitet worden, dab nach der befruchtung sofort die ihr eigentünlichen chemischen Prozesse in leschleunigtem Tempo ahlaufen kïmnen, weil es an dem geeigneten Material für Kern- und Zellenbildung nicht fehlt.

Wenn wir diesen Gesichtspunkt im Auge behalten, damn scheint mir (ler Schluß nicht so weit abzuliegen, daß diejenige Substanz, die wir in der zweiten Entwiclilungsperiode allein wachsen sehen, auch für die anderen Vorwänge, die mit ihrem Wachstum zusammenhängen, in erstel Linie verantwortlich zu machen ist, also für die Zerlegung des Dottermaterials in Zellen. Was wohl zurzeit ron niemand mehr hestritten werden wird, dam aber auch für die Anordnumg der Kellen und ihre Sonderung in die einzelnen Schichten und Organe. wohei die im XX. his XXIV. Kapitel hesprochenen änfieren und immeren Fahtoren des Entwicklungsprozesies oder die Berlingungen in ihrer Art mitwirken.

So führt uns auch der eben durchgeführte Gedankengang wieder znr Hypothese, daß in der Kernsubstanz das Idioplasma oder der als Träger der erheblichen Eigensdaften wirkamste Teil der Zelle zu suchen ist.

Als Einwand gegen unsere Auffassung hat man unter anderem geltend gemacht, daß sich der Kern rom Protoplasma nicht trennen lasse und daf er getrennt von ihm zugrunde gehe, oder man hat dagegen anweführt. dab Kern und Protoplasma einen heständigen Stoffaustausch miteinander unterhalten.

Das sei alles zugegeben, wie ich denn selbst stets hervorgehoben und Beweise dafür zu erbringen versucht habe, daß der Kern einen Einflub durch seinen Stoffwechsel auf dlas Protoplasma ausubt und ebenso

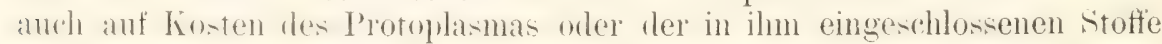
sich ernährt und wächst. Nur kann ich nicht, wie VERWorN ${ }^{1}$ ), hieraus

1) In seiner allgemeinen Physiologie (S. 526) bemerkt VERwors: „Mit dem Gedanken einer einzelnen Vererbungssubstanz, die irgendwo in der Zelle lokalisiert sein und bei der Fortpflanzung übertragen werden soll, wird sich die physiologische Denkweise kaum jemals befreunden können. Eine Substanz, welche die Eigenschaften 
als etwas Selbstverstïndliches den Schluf, richen, daf dam jede berechtigung fehle, einen einzigen Zellenbestandteil als Vererbungsträger zu bezeichnen, und da lin dann das Protoplasma der Zelle genauron dem gleichen Wert für die Vererbung wie der liern sein müsse.

Wenn in einem zentralisierten Organismus anch alle Teile zusammen gehören und voneinander gretrennt nicht zu bestehen vermögen, so kann doch jeder 'Teil in Organismus eine besondere Rolle spielen, welche aufzusuchen die Aufgabe der Wissenschaft ist.

bei den höheren Organismen verlegen wir, worïber in früheren Zeiten ja auch sehr heftig gestritten worden ist. den Prozel.; des Denkens hauptsächlich in das fiehirn hinein und lassen uns in dieser Ansicht nicht dadurch stören, daß zwischen Hirn und dem übrigen Kï̈rver ehenfalls fortwïhrend ein Stofi- und Kraftwechsel stattfindet, durch welchen auch

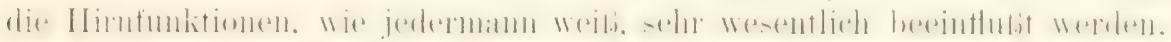
Den Drïsen legen wir die Funktion, Verdaumgssekrete zu bereiten, bei. obwohl doch der Bluthreislauf und das Nervensystem bei dem Vorgang auch heteiligt sind. Oder bleiben wir bei der Zelle stehen, so legen wir

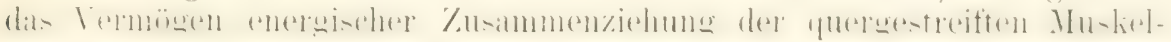
substanz bei, obwohl sie von dem Protoplasma, ferner wohl auch von dem

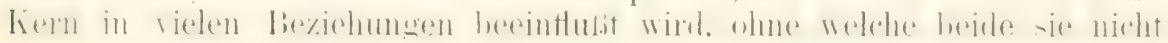
bestehen kamn, durch deren Termittelung sie ernährt und immer wieder neugebilitet wirl.

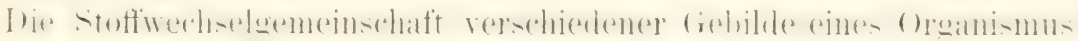
kann daher wohl nicht als Grund gegen eine Theorie angeführt werden. flurch welche dem Protoplasma und der Kernsubstanz eine verschieden

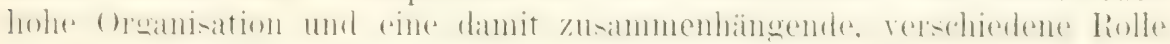
als Triger erblicher Eigenschaften zugewiesen wirl.

Auch wird damit selbstverständlicherweise gar nicht geleugnet, daß

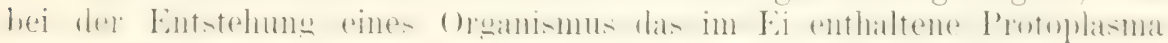

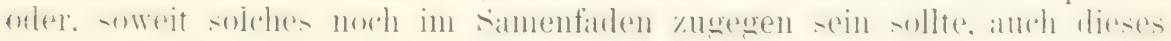
seine Eigenschaften direkt vererbt. Das scheint uns selbstverständlich. ist auch auf Seite 363 . 364 ausdrücklich erwähnt worlen. Es beweist aher nichts gegen die durch viele Gründe unterstützte Theorie. daß für die

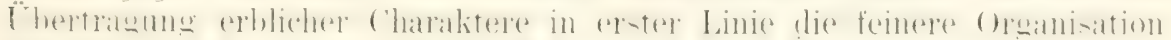

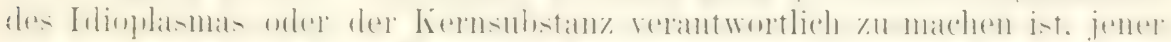

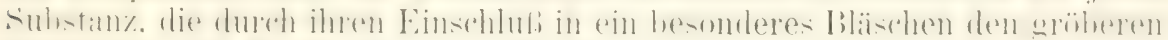

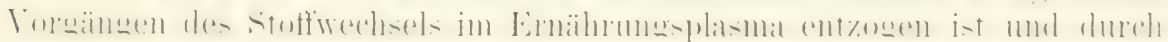

einer Zelle auf ihre Vachkommen übertragen soll, muB ror allen Dingen lebensfihis sein, d. h. mul einen Stoffwechsel haben, und dieser ist nicht möglich olne ihren $Z_{4} 1-$ sammenliang mit den anderen, zum Stoffweelsel einer \%elle nötigen Substanzen, d. h. ohne die Integritit aller wesentlichen Zellhestandteile. Dann fehlt aher jele berechtigung, einen einzigen Zollbestandteil als Vererbungstriger zu hezeichnen" usw.

Tach den im IIaupttext (S. 562,563 ) gevehenen Erlänterungen kamn ich nicht glauben. daf zu der Vererbungsrage die Physiologen eine wesentlich andere stellung als die Morphologen eimelnmen sollten. Denn die Idioplasmatheorie von Xicien, sowie die

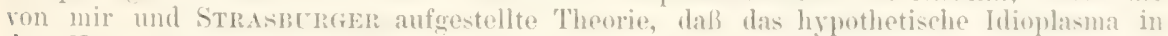
den Kernsubstanzen der \%ellen enthalten sei, ist ans physiologischen Erwägungen (2ntsprungen, welche an Tatsachen der allgemeinen Inatomie angeknïpft worden sind: sie sind also ihrem Wesen nach physiologische Thenrien. Der ron VErWorx als (iegenargment aufirestellte, ,physiologische (iesichtspunkt" des nicht tremularen. Stoffwerhsels

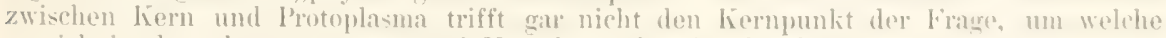
es sich in den obengenannten zwei Vererhungstherien handelt.

Der von YErWORx aufgestelite Satz: . Was den Charakter oiner julen Zelle he-

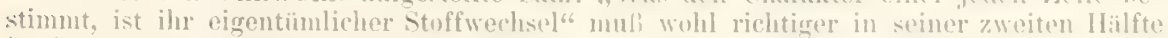
in die 11 orte geindert werden: , ist die ilı eigentiimliche Organisation". 


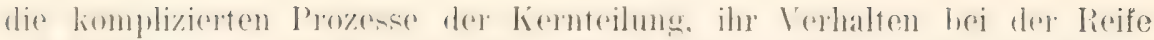

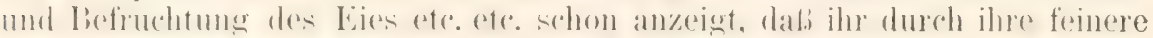
Organisation eine besondere Rolle im Zellenleben zufällt.

\section{c) Die dritte Periode in der Eientwicklung.}

Yon der zweiten Periode, welche durch die Vermehrung der liernsubstanz, ihre gesetzmäßige Verteilung im Eiraum und die hiervon beherrshaten organisatorischen Prozesse in der Anordnumg der Zellen geliemmeichnet wirl, ist die dritte Periode ebenfalls wieder durch die Satur der ehemischen Prozesse, welehe in ihr die (Oherhand gewimnen. seln wesentlich rerschieden. Es werten nämlich jetzt aus dem Fimaterial von den in verschiedene Organe gesonderten Zellen die sehr verschiedenartigen chemischen Produkte gebildet, auf deren Anwesenheit die spezifischen Leistungen der einzelnen Organe und Gewebe heruhen: Mucin, Chondrin. (ilutin, Ossein. Elastin etc.. vezifische I) rüsensekrete, die Substanz der Muskel- und Nervenfibrillen etc.

Indem jetzt mit der (iewebebildung die Plasmaprodulite immer mehr anwachen, treten ihmen gegenïher Protoplasma und liemsubstanz selhst in den Intergrund, gleichzeitig aber gewinnt der Orwanismus den hörhsten (iral seiner Jeistungsfihligheit, welche an die verschiedenen Arten der Protoplasmaprolukte gehmolen ist. Diese kömmen daher als die Arbeitsmittel des Organismus bezeichnet werden.

Die an dritter Stelle unterschiedenen chemischen Prozesse sind daher der Periode der histolosischen Differenzierung und der funktionellen Tätigkeit des Organismus eigentümlich.

\section{Literatur zu Kapitel XXV.}

1) Driesch, Analytische Theorie der organischen Entroicklung. Seite 13. Leipzeg 1894.

2) Hertwig, Oskar, Das Problem der Befruchtung und der Isotropie des Eies. Eine Theorie der Vererbung. Jena 1884.

3) Derselbe, Über den Wert der ersten Furchungszellen für die Organbildung des Embryo. Archiv f. mikrosk. Anat., Bd. XLII. 1893.

4) Derselbe, Die Tragaecite der Zellentheorie. Die Aula, Wochenschr. f. d. akadem. Welt, Jahrg. I. 1895 .

5) Derselbe, Leit- und Streitfragen der Biologie. Heft 2. Mechanik and Biologie. Seite $170-196$. Jena 1807.

6) Verworn, Allgemeine Physiologie. Seite 526. Jena 1895. 


\title{
Hypothesen über die Eigenschaften des Idioplasmas als des Trägers der Arteigenschaften.
}

\author{
Das Problem der V'ererbung:
}

\begin{abstract}
Iotto: .Jede organische Form ist das Resultat einer Geschichte, welche so alt ist wie die organische W'elt überhaupt." J. SAcHs.
\end{abstract}

Aus unserer Untersuchung der äuBeren und der inneren Faktoren

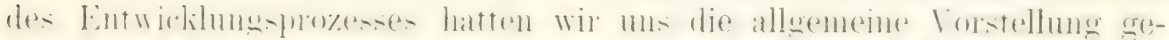

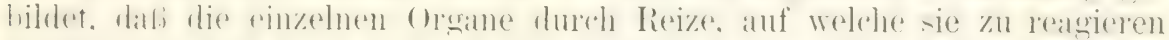

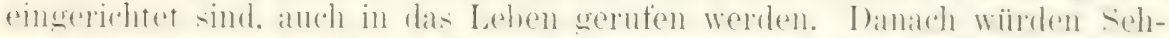

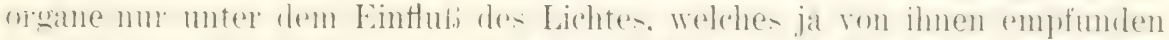

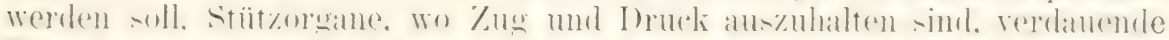

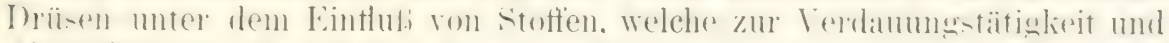

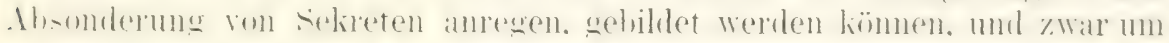
so mehr, je stärker und häufiger die adäquaten Reize einwirken.

Diesen Vorstellungen entspricht num aber nicht der Vorgang in der Ontogrenie. Denn in der Entwirlilung eines oranismus werden meistens

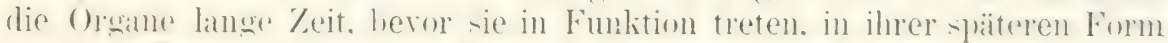

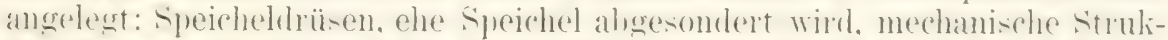

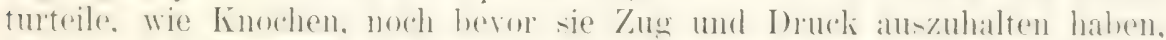

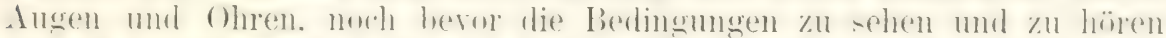
fiir sie vorhanden sind. wie hei dem in der liebarmutter eingeschlon-enen

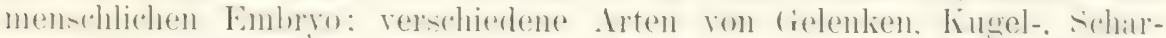
nier-, Drehgelenke etc., noch ehe die Gliedmaßen in der ihnen später eigentümlichen Weise bewegt werden.

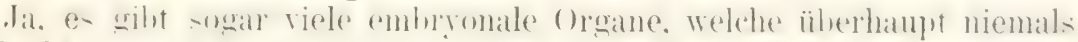
die Funktion. Welehe sie phylogenetiseh eimmal erfüllt hatrem. auszü̈hen

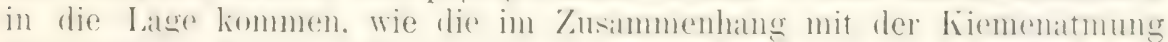
(ntstandenen Kiemensualten. an welehen hei den Ammioten noch nicht einmal

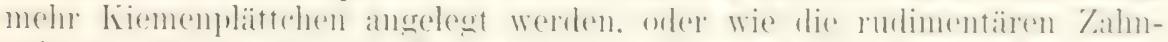

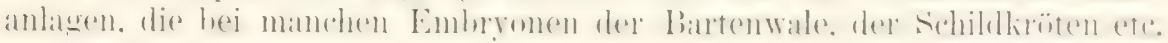
an den Kieferrändern entstehen. aber nicht zum Durchloruch kommen.

Dasselbe kamn man noch von manchen anderen Organsystemen und Geweben sagen. Überall ruft, zumal bei den höheren Wirbeltieren, ein

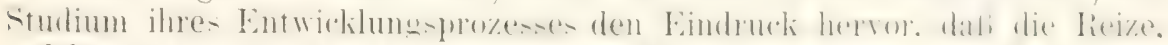

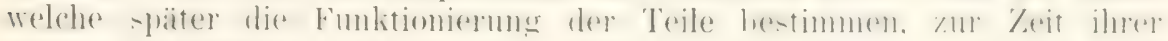
ersten Entstehung noch gar nicht wirksam sein kömnen, und daß somit 


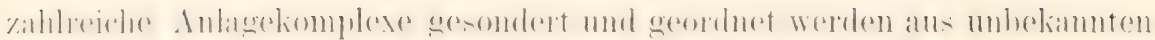
Ursachen, aber gewissermafien im voraus berechnet für Reize, die später eintreten und das vorgebildete Werkzeng zur Funktion anregen sollen.

Luf diese und ähnliche 'Tatsachen der Entwicklungsgeschichte pHegt sich WEISMANx gern zu stützen, indem er in ihnen lieweise gegen eine allgemeinere (iiltigkeit des LAmarckschen Prinzips erblickt, dal. Organe durch Anpassung an äubere Verhältnisse oder durch Gebranch und Nichtgebrauch ihre spezifische Struktur erhalten.

Als besonders beweiskräftig werden von ihm die Skeletteile der

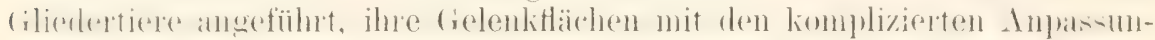

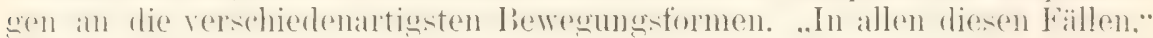
bemerkt WEISMANN, „tritt erst das fertige, harte und unveränderbare ('hitinstïnk in Tätigkeit, seine Anpassung an die Funktion muld also vorher erfolgt sein, unabhängig von dieser Funktion. Diese Gelenke und sonstigen T'eile haben sich demnach in genauester Weise für die Funktion arebilılet. ohme dab doch diese einen direkten Anteil an ilner IBildumg gehabt haben kann.

WeIsuANn hält es für unmöglich, die Gestaltveränderungen im Bau der Cielenke als direkte mechanische und hinterher vererhte Folse der veränderten liewegungsweise anfzufasen und sucht das Lanarchische Prinzip slurch seine Hypothese der Germinalselektion zu ersetzen. Für ihn ist ,nicht die somatische Abänderung durch die Funktion das Primäre, sondern die Keinesändermg. der die somatishe nur soheinhar vorhergeht".

In der Erklärung dieser und ähnlicher Verhältnisse stimmen wir mit Weismans darin überein, daß sie nicht ummittelbar auf Anpassung an

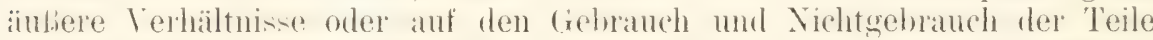
zurïrkzuführen sinul. Auch gehen wir ihm darin recht, dab die Erlibärung in Eigenschaften des Idioplasmas zu suchen ist. So erhalten wir bei weiterer Erörterung dieser Frage noch (ielegenheit, in die inneren Faktoren im engeren Sime, in die Arteigenschaften des Zellenorganismus,

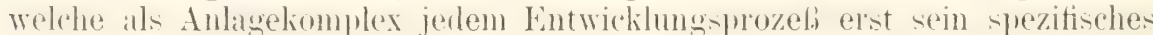
uml individuelles fepräge verleihen, tiefer als in den früheren Kapiteln einzudringen.

Dagegen weichen wir voll WeIsmans vollkommen in der Beantwortung der Frage ab, wie das Idioplasma seine so auBerordentlich komplizierten Eigenschaften, durch welche es der Ontogenie bis ins einzelne gewissermaßen seine Direktive gibt, erworben hat. WEIsmans sucht das Riitsel durch seme Iypothese der tremminal-elektion zu lönen. Wir suchen die Erklärung in dem Problem der Vererbung.

Wie das an Eingange dieses Krapitels stehende, den Schriften von SicHs entlehnte Notto richtig hervorhebt, ,ist jede organische Form das Resultat einer Geschichte, welche so alt ist, wie die organische Welt überhaupt". Also hat auch das Idioplasma seine Geschichte, und seine gegenwärtige Konfiguration ist nur aus seiner historischen Entwicklung zu verstehen, durch welche es allmählich zu dem veränderten, komplizierten (iebilde geworden ist. welches es nach unserer Annahme gegenwärtig bei den höheren Organismen darstellen mub. Ferner dürfen wir bei unseren Betrachtungen nicht übersehen - denn einiges Nachdenken und das

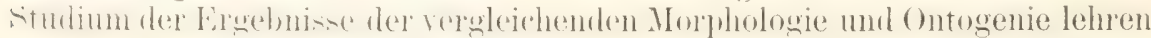
es - daf wir es in jeder eimzelnen Ontogenie nicht mit dem ursprünglichen phrognetishen, sombern mit einem ahgeänderten. abgekïrzten Futwicklungsprozeß der Organe zu tum haben. Denn es entspricht gewiß nicht dem Hergang in der Phylogenese, daß ein sich neu anlegendes Organ in 
seiner Form und Struktur gleich fertig auftritt und damn erst zu funktionieren beginnt. Struktur und Funktion müssen sich vielmehr in phylo-

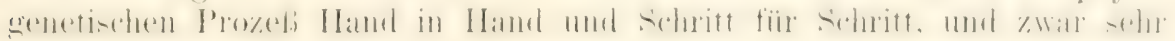
langsam ausgebildet haben.

Aus einer Epithellamelle wird sich ein besonderes Organ, z. 13. eine Muslielzellengruppe oder eine Drüse, nur dann absondern, wenn in ihr

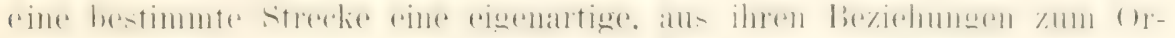
ganismus und zur Aubenwelt berlingte Funktion und Struktur gewinnt, dadurch von ihrer Umgebung verschieden wird und eine besondere, von ihrer Funktion abhängige Wachstumsenergie erhält.

Somit bleibt uns jetzt noch der Zusammenhang näher zu untersuchen, in welchem die Hypothese vom Idioplasma und das Vererbungsproblem zu einander stehen.

Um in das Problem der Vererbung einen klaren Finblick zu gewimnen, mub man im Begriff Vererbung zwei verschiedene V'orstellungs-

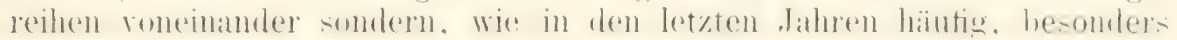
aber von WEIsuAx, auseinander gesetzt worden ist. Man muls unterscheiden zwischen einer Vererbung ererbter und einer Vererbung neuerworbener Eigenschatten.

\section{Vererbung ererbter Eigenschaften. Die Kontinuitit der Generationen.}

Die Eltern vererben auf ihre Kinder die Eigenschaften, welche sie selhst ron ihren Vorfahren ererht hahen; sie wehen einfach heim \%engunsfmozelo die Erhmase weiter. in der Berchaffenheit. in welcher sie ihnen einst von ihren eigenen Erzeugern ïberliefert wurde.

Die Chereinstimmung der dureh Zeumung auseinamber hervorohenden und sich in der \%eitfolge ahlïsenden Individuen erklït sich in einfarher

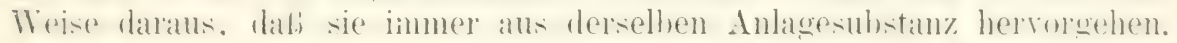
die von Individuum zu Individuum. von Generation zu Generation als

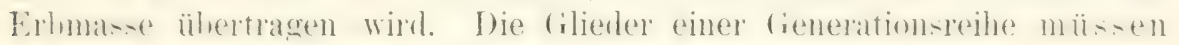
sich gleichen nach dem Grundsatz: Gleiches erzeugt Gleiches.

..Betrachtet man eine Reihe von Generationen in diesen Lichte." bemerlit Nïgerr. ,so hat die Vererbung nur noch eine figürliche Be-

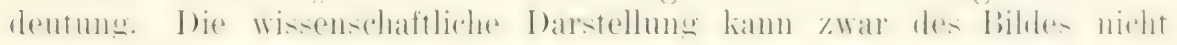
wohl entbehren, ohne die bisherige Anschauung wesentlich zu ändern,

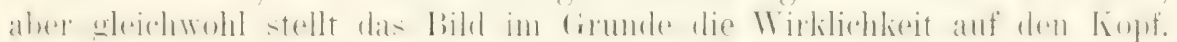
Dem statt daß die Eltern einen Teil ihrer Eigenschaften auf die Kinder vererben, ist es vielmehr das nämliche Idioplasma, welches zuerst den

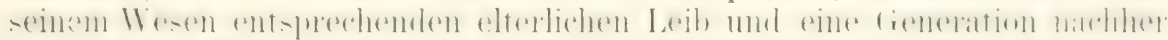

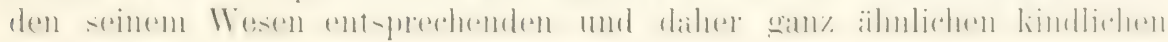
Leil) bilklet."

.Der ganze Stammbamm ist im Grunde cin einziges, aus Idioplasma bestehendes, kontinuierliches Individuum. welehes wächst, sich rermehrt und dabei verändert, und welches mit jeder Generation ein nenes hleid anzieht, d. l. einen nenen individuellen Leil, bildet."

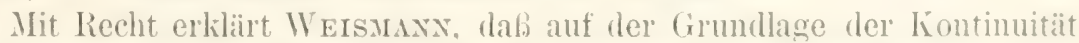
des Protoplasmas der Keimzellen die 'Tatsache der Vererbung bis zu einem gewissen Punkt, nämlich im Prinzip), hegreiflich werde; ,dem jetzt führe man sie wirklich auf Wachstum zuriick, man betrachte jetzt mit gutem Grund die Fortpflanzung als ein Wachstum über das Mab des Individuums hinaus". Es ist dies ein prägnanter Ausdruck, welchen wohl HAECKEL zuerst in seiner generellen Morphologie gebrancht hat. 
Die Lehre, daß die Entwicklung der Organismenarten und die Vererhme anf lomtmotat heruht. ist ein be-tambeil fast aller Entwelihngstheorien. Die verschiedenen Formen der Präformation sowohl, als der Epigenesis, die Pangenesishypothese von Darwin ebenso wie GaLtons

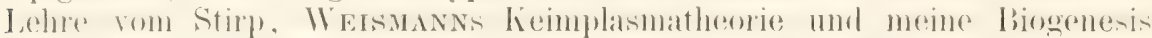

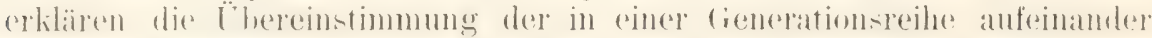
folgenden Formen aus einer zwisehen ihnen bestehenden Kontinuität.

Daß Entwicklung auf Kontinuität beruht, ist mehr wie Hypothese: es ist ein allgemeiner Erfahrungssatz; denn alle Erfahrung lehrt, dab ein Organismus nur aus einem Organismus derselben Art wieder entstehen kann, und sie hat schon früh ihren wissenschaftlichen Ausdruck gefunden in den bekannten Sätzen: „Omne vivum e vivo." „Omne vivum ex ovo."

Nicht die Kontinuität des Lebens an sich, welche eine Erfahrungstatsache ist, sondern die Art und Weise, in welcher zwischen den einzelnen Gliedern einer Generationsreihe die Kontinuität, auf welcher ihre Artgleichheit beruht, hergestellt wird, ist das große Problem, welches in den einzelnen Theorien eine verschiedene Beantwortung gefunden hat.

Die alten Evolutionisten stellten sich die Kontinuität in der Weise vor, daß jedes organische Individuum zugleich auch der Träger ist aller nachfolgenten (ilieder der Generationseihe, welche gewisermaben on miniature in ihm eingeschachtelt sind. Sie gleichen sich, weil sie am Schöpfungstag alle gleichzeitig als Reprïsentanten emer ()romismenart so geschaffen sind, dal.j sie im Entwicklungsprozel, im Laufe der Zeiten allmählich auseinander gewickelt werden können.

Eine Kontinuität nimmt auch in seiner Theorie der Epigenesis C. F. WolfF, sowie sein Nachfolger Blumenbach an, nur stellen sie sich die Kontinuität in einer ganz anderen Weise yor als die Evolutionisten. Denn sie lassen die Verbindung yon Organismus zu Organismus durch eine unorganisierte Substanz vermittelt werden, welche von dem ausgebihleten Oramismus abgachieden wirl mol mit einer formbildenden Kraft (nisus formativus) begabt ist, vermöge deren sie sich allmählich organisiert und die elterliche Form reproduziert.

Für denjenigen, der sich im vorigen Jahrhundert aus allgemeinen (irïnlen nicht auf den Standpunkt der Evolutionisten stellen lionnte, scheint mir die Lehre WoLfFs der naturgemäße Ausdruck für das Wissen seiner Zeit zu sein. Denn in einem Jahrhundert. in welchem man von feineren Organisationsverhältnissen der Pflanzen und 'Tiere und von chemischer Konstitution eines Stoffes so gut wie keine Almung hatte, lag es wohl am niidh-ten. schom dem unorwaniserten stoff Figenschaften zuzuschreiben, welche, wie wir jetzt wissen, nur dem bereits schon hoch organisierten Stoff zukommen.

Um ein gerechtes Urteil zu fällen, dürfen wir nicht vergessen, daß unsere Vorstellung einer feineren Organisation der den liörper bildenden Stofte sehr jungen Datums ist. Nach WoufFs Ansicht war eine Leber, eine Niere oder irgend ein Pflanzenorgan nach Wegnahme der Gefäße weiter nichts als, ein Klumpen Materie, die zwar die Eigenschaften der tierischen und ptlanzlichen Substanz haben kann, in der aber noch so wenig Organisation oder Struktur anzutreffen ist als in einem Kilumpen Wachs".

Grundverschieden hiervon ist wieder die Vorstellung, welche sich DARWrin in seiner Theorie der Pangenesis von der Art der Kontinuität 
zwischen den Gliedern der Generationsreihe zurecht gelegt hat. Er sucht flen Zusammenhang dadurch zu wahen, dab er alle einzelnen Organe

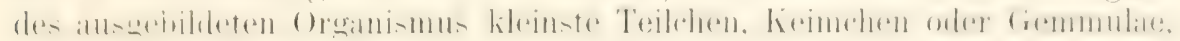
abgeben läbt, die sich an einzelnen Stellen, besonders aber in ren fie-

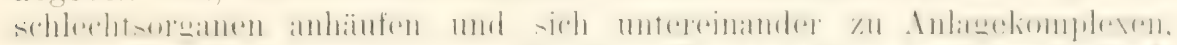

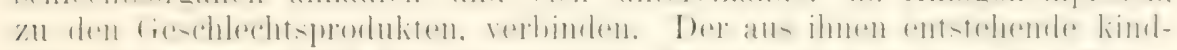

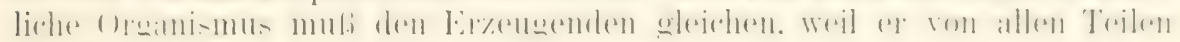
der letzteren die Anlagen enthält.

Die Pangenesis von DARWIN ist ebenso wie die alten P'räformations-

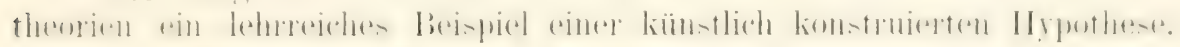
Formell lassen sich durch ihre Ammahme alle Tatsachen der Vererbungs erklären: aber die Erklärung ist nicht mehr als eine bloke Scheinerklärung. ebenso wie die Lehre von den eingewickelten Keimen; denn die Annahme, auf welcher die Pangenesis beruht, wie die Abgabe und

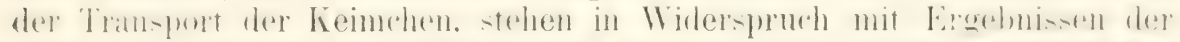

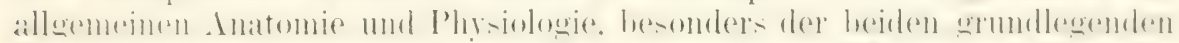

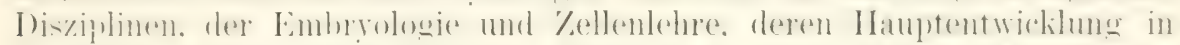

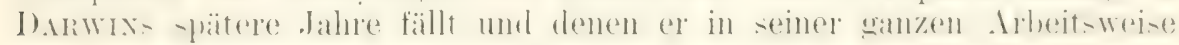
und Gedankenrichtung nicht recht nahe getreten ist.

Bei der Aufstellung einer Entwicklungs- und Vererbungsthenlid hat aber shlielich die allgemeine Anatomie und Physiologie das entscheidende Wort. Sie hat uns in dem reichen Schatz

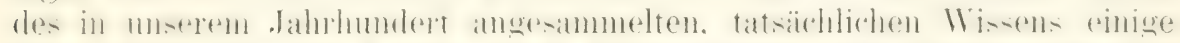

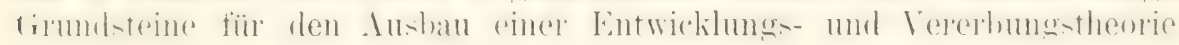
durch die Lehre von der Zelle geboten.

Die Kontinuität in der Entwicklung wird weder durch eingeschach-

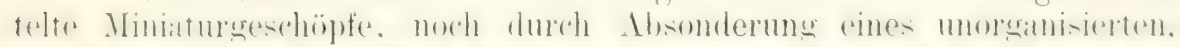

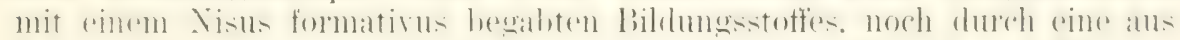

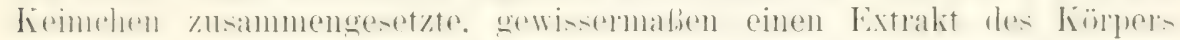
darstellende Substanz bewirkt. sondern durch die Zelle. cinen lebenden

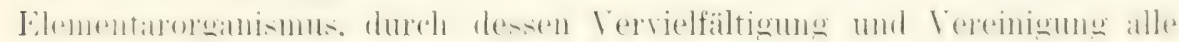
ptlanzlichen und tierischen Giestalten hervorgehen.

Die Kontinuität der organischen Entwicklung und des organischen Lehens heruht also auf dem Grundsatz: Ommis cellula e cellula. Durch

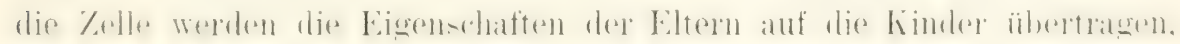
sie ist der 'Träger der Eigenschaften, durch welche sich eine Organismenart ron der anderen mterseheidet. Daher erklärte ich in meinen Zeit-

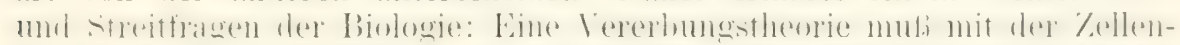

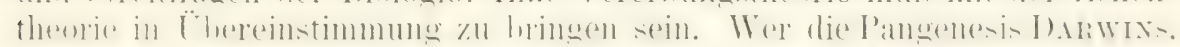
GALToxs Lehre rom Stirp. die Idioplasmatheorie Nïgeris, die Lieim-

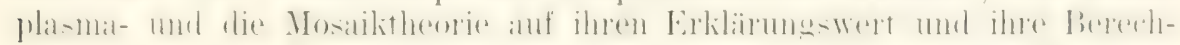
tigung prüfen will, wird sich daher stets vor die Frage gestellt sehen: Wie lassen sich diese Lehren mit unserer Auftassung von der Organisation und der Funktion iler Zelle vereinen? 


\section{SIEBENUNDZWANZIGSTES KAPITHL.}

\section{Das Problem der Vererbung.}

(Fortsetzung.)

\section{Die Vererbung neuerworbener Eigenschaften.}

Während ,die Vererbung ererbter Eigenschaften" als eine nicht wegzudiskutierende Tatsache von den Naturforschem zugegeben, aber in verschiedener Weise zu erklären versucht wird, gehen hinsichtlich des zweiten Problems, mit welchem wir uns jetzt heschäftigen wollen, ihre Ansichten in diametral entregengesetzten Richtungen auseinander. Sind doch in der Neuzeit nicht wenige Stimmen laut weworden. welche das Problem üherhaupt ganz aus der Welt schaffen wollen, indem sip schon die Möglichkeit einer Vererhbarkeit nenerworhener Eigenschaften sauben in Abrede stellen zul müssen.

Den prononciertesten Standjunkt hat auch in dieser Beziehmng WeIsmaxy eingenommen. welcher sich das Verdienst erworben hat. die Diskussion iiber das Vererhungsproblen wieder in lehhaften Flub gehracht zu haben. Dabei hat el viele Fragen schärfer formuliert und auch manches alte Vorurteil heseitigt. Die Vererbung erworbener Eigenschaften sucht (r als eine ummönliche Ammahme darzustellen, weil er sich keinen Mechanismus denken kann, durch welchen sich Zustände anderer Kö̈rperteile und Veränderungen den Keimzellen derart mitteilen sollten. daß die substanz des leimes . korrespondierend verändert würde”: andicrdem aber sieht er sich auch noch ., lurch eine Reihe grolier (irupen von Tatsachen verhindert, eine derartige Vererbung als wirklich vorkommend anzunehmen“".

Indem Wersuaxy der Anpassung der Organismen an äußere Ver-

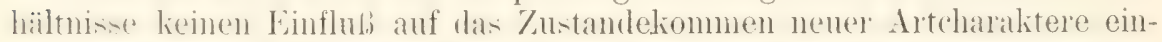
räumt, weil die wihrend des individuellen Lehens erworbenen Eigentümlichlesten seiner Meinums narh nicht auf den Keim ïhertraghar sind, mub er notwendigerweise zu der Ammahme geführt werden, daß neue Artcharaktere direkt vom Keim aus bewirkt werden. Auf diesen Standpunkt ist in der Tat auch WEISnavy immer mehr gefïht worden, bis er ihn

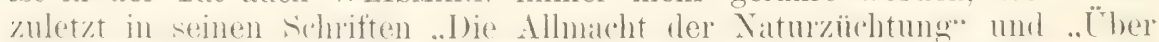
(iemminal-olektion"* in aller homsequenz durchgefiilnt hat. In ihnen sucht er alle Veränderumgen in der Organismenwelt durch zufällige Keimesvariation und durch Naturziichtung zu erklären.

Wersmanns Ansichten haben anf vielen Seiten Beifall gefunden, und as uhit nicht wenige. Welche die Thertrabarkeit erworhener Charalitere als eine wissenschaftlich unhalthar gewordene Lehre betrachten. 
.Für denjenigen, der sich die Gröbe des Rätsels der angeblichen

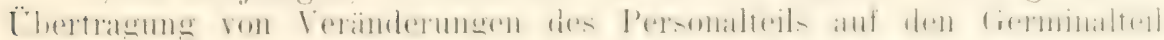
vorgestellt lat," bemerkt Roux, ,ist die von WeIsusxy sorgfiiltig begrimdete und neben ilm auch von anderen angehahnte Theorie von der Kontinuität des Keimplasmas die Erlösung von einem auf unserem Er-

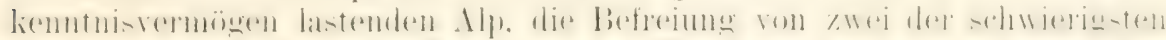

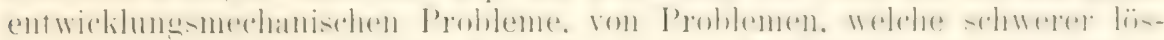
bar erscheinen als das der Entstehung des Zweckmäbigen ohne zwecktätiges Wirken."

Auch in dieser Hinsicht ist unser Standpunkt ein entgegengesetzter. Wie Darwix und Spencer. Virchow, Haeckel, Hering, Nägeli u. a.

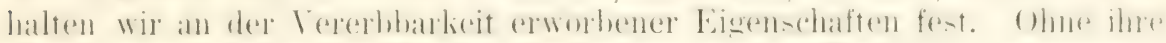

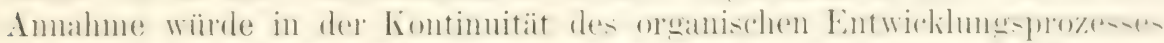

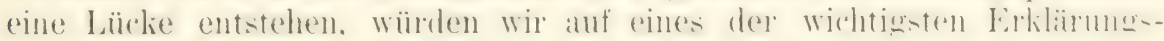
prinzipien für die Entwicklung der Organismenwelt verzichten.

Hiermit wollen wir natiurlich keineswegs alles gutheiben, was in der

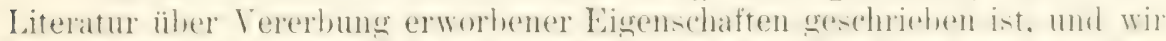

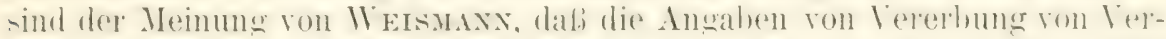
stïmmelungen, von zufalligen lerdetzungen. ron dieser und jener lirankilest

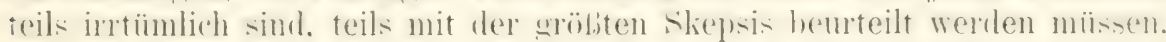

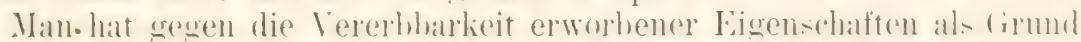

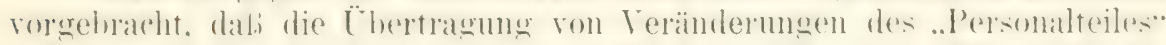
anf den .. ierminalteil" mechanish nicht vorstellbar sei. Wir gelen zu.

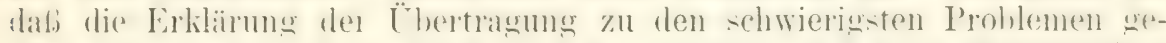
hört. müssen aber dahei gleichzeitior hervorhehen, dabi diese sohwieriohoit nicht minder für den umseliehrten I'rozer hesteht, für die Entfiltung der in der Erbmasce der Zelle gexehenen mosichtharen Anlagen zu den sichtharen Eigenschaften des Persmalteiles. I)enn kann sich etwa jembmil .mechanisch" vorstellen. wie es das Iolioplasma oder der Kexm anfänot. dalf sich aus ihm ein duge oder ein Ilim mit seinen millionenfarh verschlumgenen Vervenbahnen. für einem elst später zu erfüllenden Zwerli auf das beste im voraus angepaßt, bildet?

Wir sind im einen wie im anderen Fall noch weit davon entfernt. in die imere Werkstatt der Natur hineinzusehen und miissen uns hier

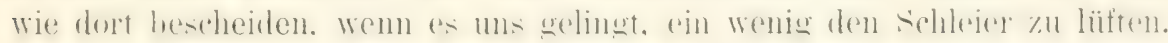

Es kann im folgenden nicht meine Aufgabe sein, das schwierige

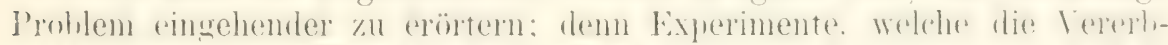

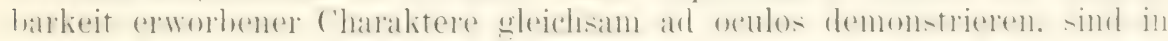
der Literatur noch sehr spärlich zu finden. Da aber das 'Thema in letzter Zeit wieder vielfach verhandelt worden ist und mit allen Fragen der Theorie der Biogenesis so innig verwebt ist, kann ich es auch nicht ganz. mit Stillschweigen übergehen, sondern muß wenigstens in aller Kïrze

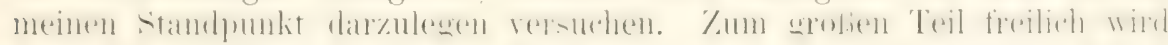
es mehr ein Hervorheben von dem sein. was schon von anderen Seiten darüber in treftender Weise gesagt worden ist.

Analysieren wir zuerst im allgemeinen den Vorgang, wie er sich bei der Übertragung erworbener Eigenschaften vollziehen muls.

Zunächst müssen äubere Ursachen in einem Organismus eine V'eränderung bewirken. Die Verinderung mub von Dauer sein, sie darf nicht, wie es bei Veränderungen im Organismus so häutig der Fall ist. beim Aufhören der Ursache wieder in den früheren '/ustand zuriekfallen.

Sie mub ferner an derienigen Substanz in der Zelle eingetreten sein. welche wir als ihre Erbmasse (Idioplasma) bezeichnet 
haben. Damn erst hat die Zelle durch äußere Ursachen eine neue Anlage erworben, welche sie hefähigt, gegen früher in veränderter Weise zu wirken, so oft die Anlage im Lebensprozeb der Zelle als innere Ursache in Lraft tritt. Da die neuerworbene Anlage von Daner ist, mub sie bei jeder Vermehrung durch Teilung auf die '́ochterzellen mit ïbertragen werilen.

An diesem Vorgang haftet, wenn wir ihn in seine einfachsten Ele-

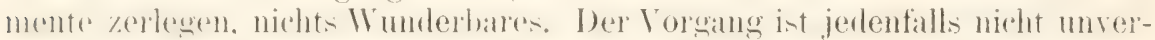
standlicher als jeder andere als Lrathe und Wirkmesich im Bereich des Organischen abspielende Prozeß. Einige Beispiele sollen den Vorgang nicht nur noch begreiflicher machen, sondern auch zeigen, daß er tatsäblich existient. Wir wollen dabei rom Einfacheren zum homplizierteren fortschreiten.

Wie im ersten Teil beschrieben wurde (S. 151), zeichnen sich Algens.hw irmer durch ihre Lichtempfindlichkeit (Phototaxis) aus: zugleich wurle angeführt. dabs durch äuliere I'rsachen. wie durch andauernde starke lielichtmog oder durch andanernde tohe Temperatur. sich ihre Lichtempfindlichkeit verändern läßt (S. 152). Es müssen daher wohl materielle Verinderungen in den Algenschwirmern eingetreten sein. welche der brums ihrer jetzt veränderten Reaktion gegen den Lichtstrahl sind. Wenn sich nun solche Algenschwärmer in dem veränderten Zustand teilen würden, so würde gewiß sich niemand wundern, wenn auch ihre Nachkommen eine andere Lichtstimmung zeigen würden.

Ein anderes Beispiel geben uns die Bakterien. Wie durch PAsteur und andere experimentell festgestellt ist. kömnen virulente bakterienarten. wie der Milzhrandhazillus, die Mikroorwanismen der Hühnercholera etc. ihre giftigen ligenschaften verlieren, wenn sie unter aulierwewöhnlichen Ierlingungen. in hesonderen Nährlösmoen oder hei hoher Temperatur, gezüdhtet werden. Die so durch äuliere Eingrifte nenerworhenen Eigenschaften haften in manchen Fällen den Bakterien so fest an. daB sie dieselben nicht nur für ihre eigene Lebensdauer bewahren, sondern anch auf ihre Xahlommen ibhertracen. Fs mïscen also auch hier wieder materielle Veränderungen in ihmen eingetreten sein, die erblich sind, so dabs man von einer neuen, künstlich erzengten ,physiologischen Varietät“ des Nilzhamdhazillus ote. sprechen kam. Die Varetät hehäl auch ihre Eigenschaft in vielen fienerationen boi. wemn die abmormen /achthedingungen schon längst aufgehört haben, z. B. wenn sie sich in einem für Milzbrand sonst empfänglichen Versuchstier entwickelt; sie kann dann sogar dieses gegen die virulente Varietät immun machen.

In seinem Handbuch der Ptlanzenphysiologie hat PFEFfer eine snähre \%ahl entsprechenter Fälle zusammengestellt. ron denen ich noch einige kurz referiere: Aus farbstoffbildenden Bakterien lassen sich unter hesombern kultuberlingungen farblose Rasien züchten, in denen der nenerworbene Charakter, auch wenn sie sich unter normalen Verhältnissen wieder befinden, für längere Zeit erblich fixiert ist. Eine solche erhielt \%. B. Schottelius durch Kultur des Micrococens prodigiosus bei $41^{\circ} \mathrm{C}$. Ciledehzeitin war bei ihr auch die Produktion ron Trimethylamin unterdrückt. Ebenso zïchteten Charrin und Phisalix den Bacillus pyocyaneus und LAURent den roten Kieler Bazillus in farblose Rassen um (Pfeffer 1897. S. 498.)

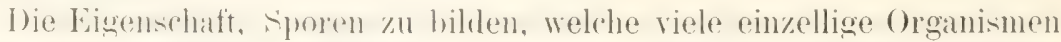

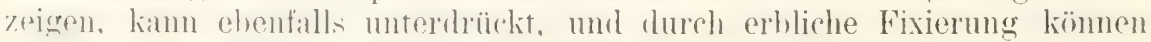
sporenlose (asporogene) Rassen gezüchtet werden. Roux gewann eine 
solche durch Zusatz von etwas Karbolsäure zu einer Kultur von bacillus anthracis. PHisalx durch Lrwirmung auf to ${ }^{\circ} \mathrm{C}$. „Die fixierte asporogene

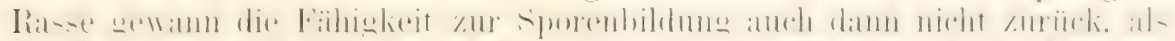

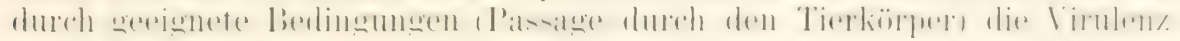
restauriert wurde, die in den genamnten Experimenten zugleich mit der Fähigkeit zur Sporenbildung unterdriickt worden war."

Durch Verwendung höherer 'T'emperaturen, bei welchen Wachstum noch stattindet, aber die Sporenbildung sofort unterbleibt, verwandelte HAxsex rerschiedene Arten ron Sacharomyces ebenfalls in asporogene

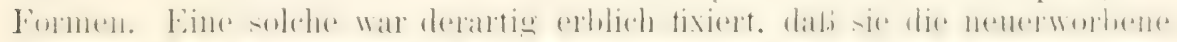

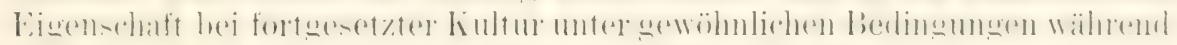
8 Jahren konstant beibehielt, (PFEFEer 1!04, S. 242).

Wie in diesen Fällen, deren Zahl sich noch leicht vermehren ließe.

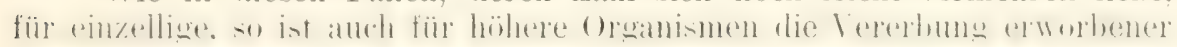
Eigenschaften - allerdings von einfacherer Art - experimentell nachgewiesen, sowohl für Ptlanzen, wie tür Tiere.

Recht beweisend sind die Experimente, welche ScHüBELER über die

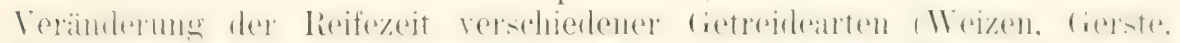

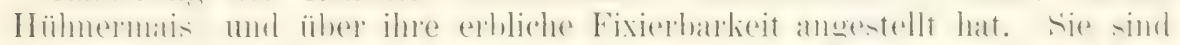
auch ron SExox in seiner Schrift über die ..Mneme* als Beispiele von Ver-

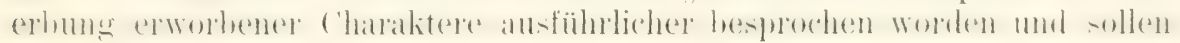
mir zu dem gleichen Zwecke dienen, wobei ich mich in der Darstellung an SEmox halte.

Schübeler hat Samen von Triticum vulgare aristatum, der in Deutschland von der Aussaat bis zur Reife 100 Tage braucht, frisch aus Eldena bezogen und in Christiania, wo die Licht- und Temperaturwirkung

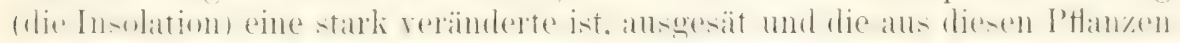
erhaltenen Samen ebenso wieder im folgenden Jahre usw. Im ersten Jahre

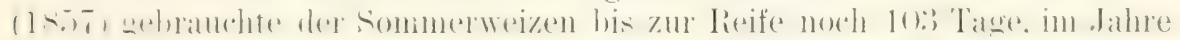
1858 9: Tage. im Jahre 1859 nur noch 75 Tage, also vier Wochen weniger als bei der ersten Kultur. Es hat sich also bei diesem Experiment infolge der veränderten Insolation ..die Zeit zwischen Aussaat und Reife von Generation zu Generation mehr und mehr verkürzt, bis endlich ein Stadium erreicht ist, auf dem sie wieder annähernd konstant wirl*:

Ihnliche Ergebnisse erzielte ScHüBELER mit dem Hühnermais und der (ierste.

Durch weitere Experimente lieb sich dann auch noch weiter fest-

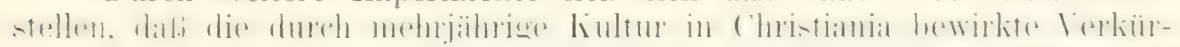

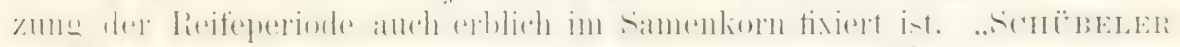

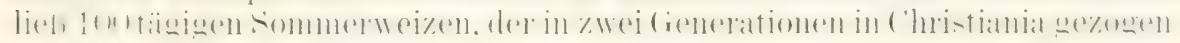
worden war. in der dritten Generation sowohl in Christiania, als auch in Deutschlaud (Breslau) kultivieren. In ersterem Ort bratuchte der Samen 75). in letzterem 80 Tage zur Reife. also etwa drei Wochen weniger als

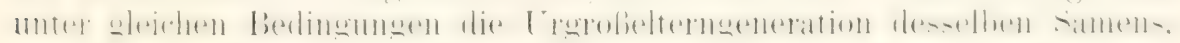
die nicht durch den komplexen Insolationsreiz der höheren Breite (engraphisch) beeintlußt war. Dazu brauchte diese Urenkelgeneration in Breslau fünf Tage mehr zur Reife als in Christiania. was leicht verständlich jst. da ja während der in Frage stehenden Vegetationsperiode in Breslau die Lin-

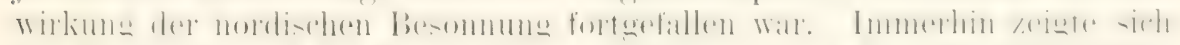

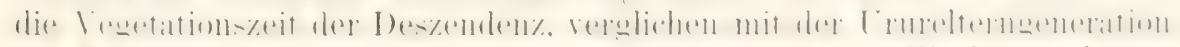

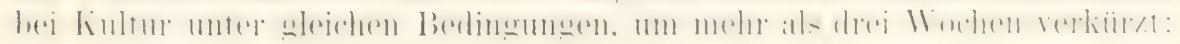
ein unzweidentiger Fall von Vererbung." 
Bei sorgfailtigem Durchgehen der botanischen Literatur werden sich

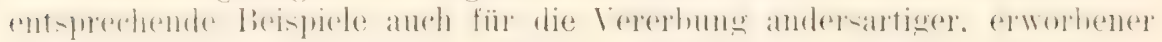
Eigenschaften gewiß noch in größerer Anzahl zusammenstellen lassen.

Auch für das Tierreich liegen beweiskräftige, experimentelle Untersnchumgen vor, von denen ich einige anführe:

T'izzoni hat durch eine Reihe von Züchtungsversuchen nachgewiesen, daß tetanusfeste Mäuse oder hundswutfeste Kaninchen ihre gegen den Tetam-erreger, resp. das Humbwutgift erworhene Immunitä anch auf ihre Nachkommen als Erbe mit iibertragen. BEHRING hat ähnliches für Diphteritis gefunden. liesonders interessant sind aber die Experimente von EHRLicH tiber die Wirkung von Rizin und Abrin bei Mäusen.

Rizin und Abrin wirken schon in kleinsten Dosen bei Mäusen als starkes Gift. Mit der Nahrung aufgenommen; rufen sie im Darm eine starke Entzïndung und dadurch den Tou hervor. Indessen können dureh ihre allmähliche steigerung die Nüuse gegen die Giftwirkmg so meniftullich werlen, dab sie jetzt selbst gröbere Gaben. welche bei anderen Mäusen lasch den Toul herheiführen, anstandslos rertragen. Sie sind rizinmler ahrintest geworden, sie hahen gegen die riftwirkung des Rizins und Abrins einen gewissen Grad von Immunität erworben.

Die Rizinfestigkeit - und das interessiert uns hier besonders - ist eine nenerworhene Eigenschaft nicht nur ron den Wandungen des Damliamals, mit welchem das Rizin direlit in berührung gelommen ist. sondern rom ganzen hörper. Auf zwei rerschielenen Wegen läbt sich dies leicht feststellen.

Der eine Weg ist die sublutane Einverleibung des Mittels. Während sonst schon 1/200000 Lösung bei der Maus sicher tödlich wirkt, werden jetzt $1 / 1000$ bis $1 / 500$, in seltenen Fällen sogar $1 / 250$ vertragen.

Der zweite Weg ist die Behandlung der Conjunctiva des Auges mit

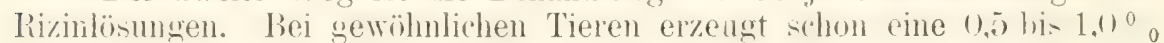
Lïsung eine intensive Entzïndung der ('onjunctiva, welche sich schlielitich zu riner Panophthahmitis steigern und den Yutergang des ganzen Auges zur Folge haben kamn. Iiei Mäusen dagegen, welche wïhrend längerer Zeit mit kleinen Dosen von Rizin gefüttert worden sind, reagiert die

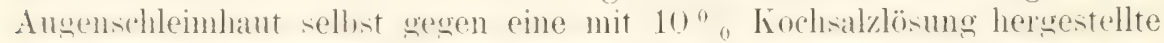
Rizinpaste nicht mehr. D)uch die Verfütterung kleiner Rizindosen ist. wie

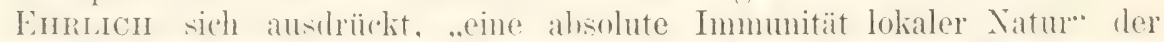
rmst on selur emptindlichen (injunctiva des Auges hervorgerufen worden.

Ein Mittel also, welches zumächst nur auf die. Darmwand einwirkte, hat, wie im ganzen Körper, so auch am Auge Veränderungen im Zustand der fiewehe mul Zellen hervorgerufen. Ihre lizinfentigkeit ist nach meiner Ansicht in der Weise zu erklären, daß von den Darmwandungen aus der giftige Eiweißkörper resorbiert wird und in klemen Dosen durch die Körpersiafte iiberall hin verteilt wird. So erfahren schließhich alle Zellen des Körpers die Einwirkung des Rizins in refracta dosi, passen sich durch Gegenwirkung dem Gifte an und werden ,rizinfest".

EHRLICH hat im Verfolg seiner Experimente auch die wichtige und sich sofort aufdrängende Frage geprüf, ob die gegen Rizin erworbene

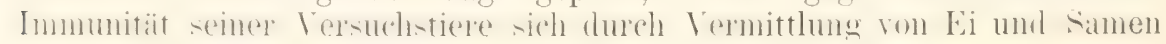
auf ihre Nachkommen vererben läbt.

Samenfäden und Eier zeigten hierbei ein verschiedenes Verhalten. Denn als Männchen von hoher Rizin- resp. Abrinfestigkeit mit einem normalen Woibehen wepart wurlen, lief sich an der Nachliommenschatt lieine Spur von Immunität gegen das Gift nachweisen. Das Idioplasma der 
Samenfäden ist also nicht fähig, die vom Vater erworbene Giftestigkeit anf die Nachkommenschatt zu übertragen.

Ganz anders war der Erfolg, als Weibchen, die gegen Mrin resp. Rizin gefestigt waren, mit normalen Männchen gepaart wurden. Die Nachkommenschaft erwies sich selhst $6-8$ Worhen nach der fiehurt noch ausnahmslos als rizinfest.

Das zwischen Ei und Samen zutage tretende, verschiedene V'crhalten möchte ich mir in der Weise erklären. dal. das in den Säften kreisende Gift bei der kurzen Dauer der Versuche nur auf das Ernährumgsplasma der Zellen eingewirkt hat. Das Idioplasma dagegen als die stabilere und ïberhaupt den direkten Eingriften der Aubenwelt weniger ausgesetzte Substanz ist noch unverändert geblieben. Es können daher wohl die proto-

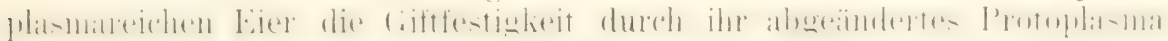
den aus ihmen hervorgehenden Embryonalzellen ïbertragen, nicht aber

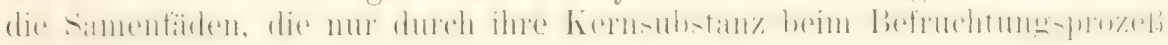
wirken.

Überhaupt ist bei der Beurteilung der von EHRLICH angestellten Experimente im Auge zu behalten. daß die von ilım erzielte Rizinfestigkeit nur von kurzer Dauer ist: sie ist noch lieine absolute geworden, (l. h.

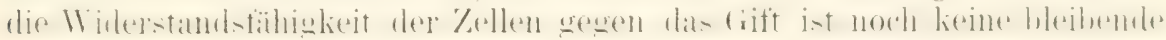
Anlage ihres Idioplasmas geworden. Um dies zu erreichen, mübte wohl der canze Stoffwechsel der Zellen in einer über längere Zeiträume sich

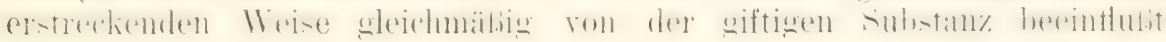
werilen.

Ein sehr interessantes Material für die experimentelle Bearbeitung der Vererbungsfrage bieten uns die Schmetterlinge dar. Wie schon im

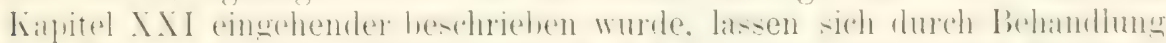

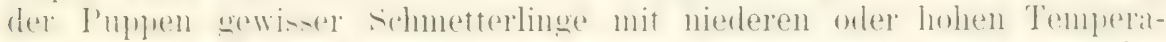

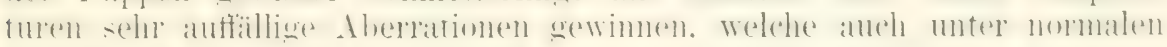
Verhältnissen in anderen Kilimaten als natürliche Varietïten beobachtet

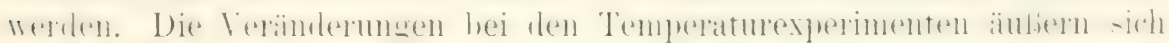

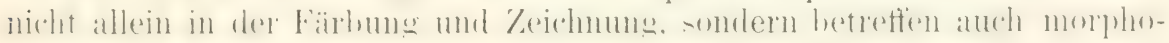
logische Merkmale. wie die Form und Gröbe der Flïgel und die Gestalt der Schuppen.

Die verdienten. durch ihre ausgedehnten Experimente wohlbekannten Lepidopterologen Staxdfuss und Fischer haben sich num die Aufgabe gestellt, auf experimentellem Wege die Frage zu lösen, ob die durch Tem-

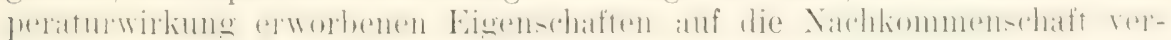
erbt werden kömmen. Beide sind zu dem positiven Lrgebnis gekommen. dab dies der Fall ist.

STAxDFuss hat im Jahre 1897 10) Pärchen ron stark aberrativen

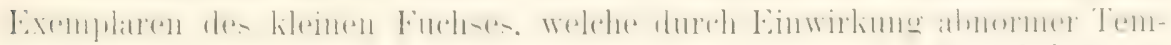
peratur auf die Puppen gewommen worden waren, in den (rewächshäusern der Züricher Samenkontrollstation zur Nachzucht benutzt. Davon lieferten.

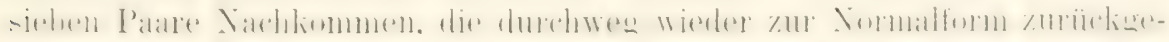
kehrt waren. Ein achtes Paar indessen. von welchem das Weibchen unter den Versuchstieren am meisten anomal gebildet war, lieferte unter 4:) Nachkommen vier Individuen. welche von der Normalform im Sinne des elterlichen 'Typus abwichen, und zwar eines vollkommen. die drei anderen weniger weit. STaxpfuss hält dieses Ergebnis, trotzdem es sich bei ihm

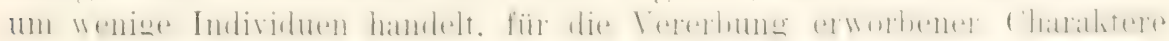
für beweisend, indem er bemerkt: ..Indes dürften schon die gewommenen Tatsachen für die Schätzung des Einflusses, welchen die Falitoren der 
Aubenwelt auf die Umgestaltung der lebenden Organismen ausibben, ron

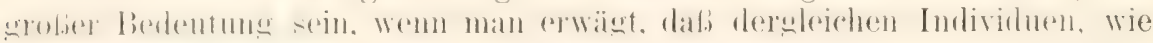
die hier aus der Brut anomaler Eltern erhaltenen, selbst unter ungezählten 'T'ausenden von 'Tieren aus normaler' Abstammung. die unter ganz denselhen Verhältnissen heranwachsen, niemals auftreten."

Noch mehr aber als diese Erwägung spricht dafür, dab wir es in diesen Fällen mit einer Vererbung erworbener Eigenschaften zu tum haben, eine Untersuchungsreihe von F. FisCHER, welcher unabhängig von STAxDFuss

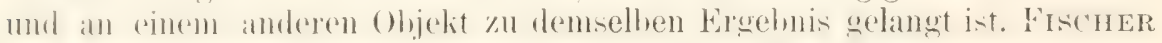
benutzte zu seinen Experimenten den deutschen I3är, Aretia caja.

Aus seinen Puppen wurden durch eine Kältewirkung von - $8{ }^{\circ} \mathrm{C}$ stark aberrativ veränderte Schmetterlinge gezogen. Von diesen wurde

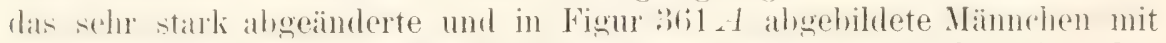
einem weniger abweichenden Weibchen zur Paarung gebracht. Aus den

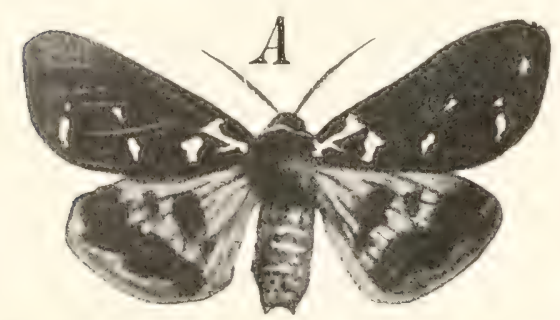

Eiern des Paares wurden unter normalen Verhältnissen Raupen und Puppen gezuichtet, deren Zahl sich auf 173 belief. Unter den ausschlüı̨fenden Faltern befanden sich 17 aberrative Exemplare, die in der Tat ganz im Simne der Eltern verändert waren und von denen zwei sogar dem elterlichen Männchen sehr nahe kamen. wie Figur $361 B$ lehrt.

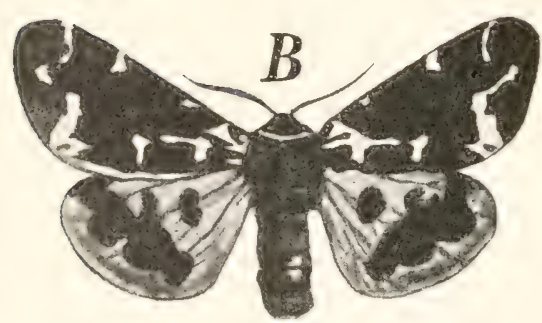

Fig. 361. A Kälteaberration von dem ,deutschen Bär" Arctia caja. $B$ Der am stirksten aherrierende unter dron Nachlimmmen desselben. Sach F. Fischer. Aus Weisuaxis. aher dieser unbegreitliche lorgang trotz alledem doch stattindet, das hat das Experiment direkt hewiesen! I'nd damit ist unzweifelhaft eine selur wichtige Aufklärung gegeben ïber die Umwandlung ler Arten infolge Einwirkung äußerer Faktoren."

Die Gegner der Vererbbarkeit erworbener Eigenschaften suchen auch die beweisliraft lex angefühten und ahnlichen Fälle in Zweifel zu ziehen und zu entliäften. So macht Weismans den Finwurf, dab bei den S'chmetterlingsexperimenten die 'T'mperatur nicht nur die Flügelanlagen der elterlichen I'uppen. somdern auch das Keimplasma in den fieschlechtszellen getroffen und rerändert hahe. Anf diese Weise komme der schein siner Tererlung erworbener (haraktere zustande; in Wahlieit sei es nicht die somatische Abänderung selbst, welche sich vererbt, sondern die ihr liorrespondierende. von demselhen äüberen Eintlub hervorgerufene Abänderung der entsurechenden I)eterminanten im Kieimplasma der Keimzellen, der Determinanten der folgenden Generation. 
Der Einwurf ron Weisuaxs mag zunächst diesem und jenem als

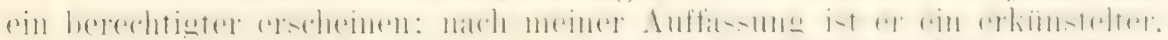

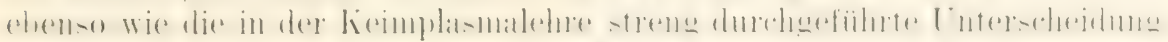
zwischen einem Personalteil und einem Germinalteil. Nach dem. was man gewöhnlich unter dem Wort ..vererben" versteht, ist ein besitz, den jemand erworben hat, ein Erbe. wem er auf seine Deszendenz übergeht. Davon. wie der Besit\% erworben worken ist. wird es nienand abhängig machen. ol) er das Erbe nur als ein scheinbares oder als ein tatsächliches bezeichen soll. Und so scheint mir denn auch in dem angefiihrten Bei-

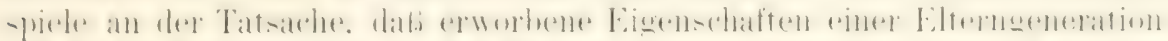

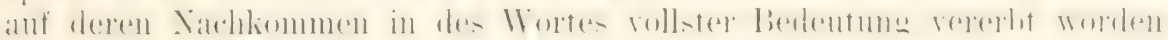
sind, gar kein Zweifel aufliommen zu lönmen.

Im ïbrigen stimme ich in der Deutung des Vorganges volliommen mit Wersmaxy überein und bin, ebenso wie auch Standfuss. Fischer u. a.,

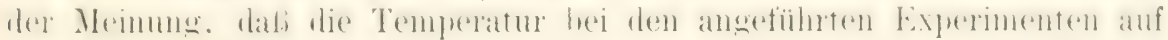
den ganzen Organismus und nicht allein auf die abändernden Flügelanlagen eingewirkt hat. Daher haben anch die Geschlechtsorgane und

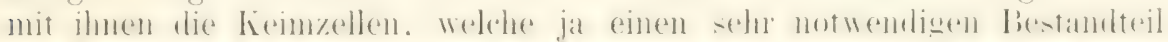

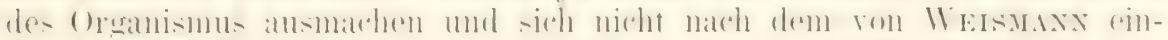

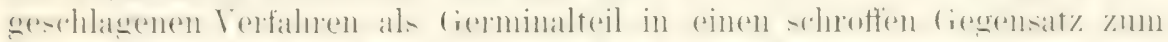

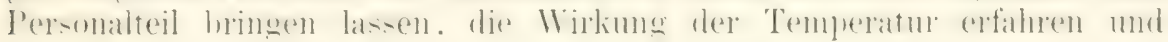
sind in ihrem Idioplasma ebenso wie das Idioplasma im ganzen Körper verändert worden. Ebenso verhält es sich in allen anderen oben ange-

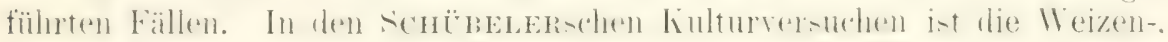
Gerste- oder Maisptlanze als Ganzes, also ist auch das Idioplasma für die nïchste (ieneration affiziert worden.

In den Rizinversuchen, können wir sagen, ist durch das in den Körper

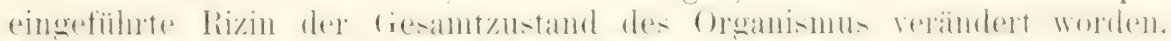

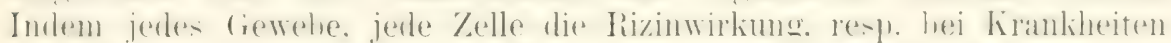

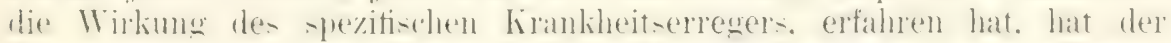

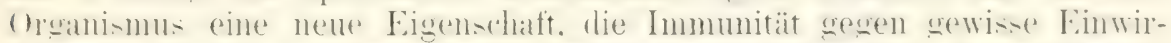

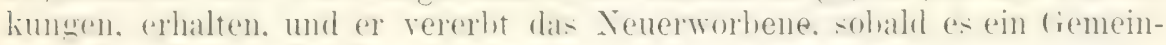
sut aller Zellen. die fieshlechtszellen nicht auscenommen. weworden ist.

Würde eine PHanze oder ein niedriger stehendes Tier in derselben Heise cine nene Eigenschaft als comeingut aller seiner \%ellen erworlen hahen. so würde die Vererhung. wie durch die fieschledhtsprodulite. st

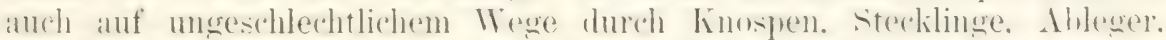

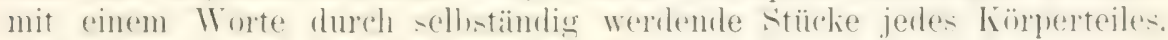
erfolgen können.

Auf diesen Wege, der nichts Wunderbareres enthält, als überhaupt

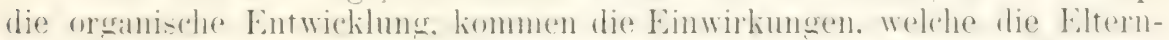

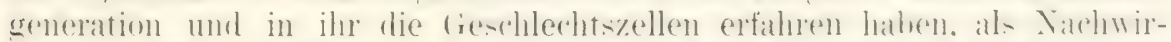

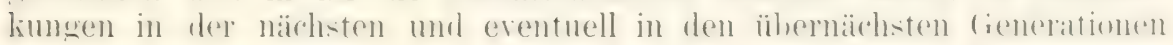
wieder zium Vorschein.

Ebenso wie gegen äubere. verhält sich die Zelle auch gegen innere Faktoren. Genau so wie die Zelle das Rizin empfindet und eine mate-

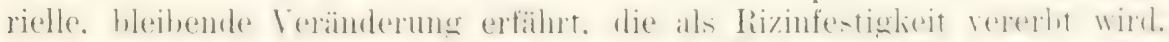

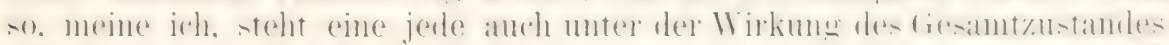

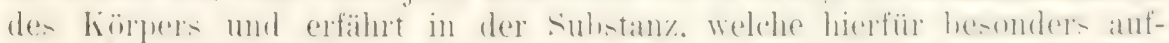

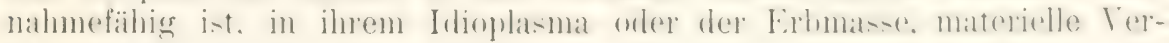
änderungen, welche der Ursache als Wirkung entsprechen, wie in den Körperzellen so auch in den Geschlechtsprodukten.

0. Hertwig, Allgemeine Biologie. 2. Aufl. 
In dem Organismus als einer physiologischen Lebenseinheit müssen sich die Wirkungen aller einzelnen Organe, aller Gewebe und Zellen schlieliblich zu einer komplizierten Gesantwirkung vereinigen. welche den ('esamtzustand des Orwanismus bedingt, der von jedem einzelnen 'Teil emp)funden wird und, soweit es zu einer dauernden Veränderung im Idioplasma kommt, zu einer neuerworbenen Eigenschaft wird.

In besonderen Abschnitten (S. 399) haben wir fröher die Mittel und Wege besprochen, auf denen Einwirkungen aller Teile des Körpers aufeinander erfolgen können, die Säfte, in welche alle Zellen ihre Stoffe abgeben und aus welchen sie Stoffe aufnehmen, die Protoplasmabrücken, die \%elle mit Zelle verbinden, und die zahllosen Nervenbahnen. Wir haben in anderen Abschnitten gesehen, wie durch solche Mittel und Wege die Organe in allseitiger Fühlung (Korrelation) untereinamer stehen mol sich anch Einwirkungen der Außenwelt mitteilen.

Gleichwohl müssen wir sagen. (lak wir in Wirklichkeit von allen den komplizierten Prozessen, von dem ganzen Kraftwechsel oder der Dynamik eimes vielzelligen Organismus so gut wie nichts wissen.

Auf unorganischem Gebiete sind wir in unserem Jahrhundert mit den wunlerbarsten Kraftiihertragungen und Fnergiemmandlungen bekannt geworlen. Ton einem Weltteil zum anderen können wir vermittelst eines

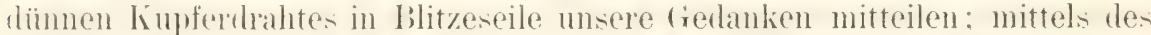
Tolephons kamn das in Berlin gesprochene Wort in München gehört werlen: sogar durch das bloße Medium der Luft ist bei geeigneter Vorrichtung eine Telegraphie ohne Draht auf Entfernung ron Stunden möglich. Auf riner chemisch hergerichteten dilasplatte hinterlasien die kompliziertesten Gegenstände - und, wie lange wird es dauern, selbst in ihren verschiedenen Farbennuancen - naturgetreu ihre Spuren als Bild. Von einer simmeich präparierten Wachsplatte bälst sich das Lied einer Sängerin belichig oft und noch nach Jahren durch den Phonowraphen reproduzieren.

Wemn wir so sehen. wie durch relativ einfache Stotfe der unorwanischen Natur. durch einen Kinferdiaht, eine chemisch priparierte cilasplatte, eine Wachstafel, die kompliziertesten Zustände - ein Konzertstück, ein Lied tinctr Sängerin, ane Landschaft, eine menschliche Figur mit ihrem fiesichts-

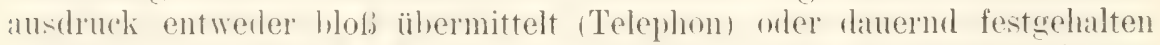
und in letzterem Fall dureh aeeignete Vorkehrungen beliebig oft reporduziert werden kömnen (I'homograph, photographische Platte), so diurfen wir wohl ähnliche Vermögen, nur noch höher und feiner ausgebildet, auch bei der am hörhsten orgunisierten substamz der Natur. dem lehemdigen Organismus der Zelle, voraussetzen.

Unsere Ansicht läßt sich demnach in die These zusammenfassen: Veränderungen, die im Gesamtzustand eines Organismus durch Abänderung dieser oder jener Funktion während des individuellen Lebens eintreten, rufen, wenn sie ron Dauer sind, auch ju den einzelnen \%ellen des ()randsmus Veränderungen hervor. hesonders in joner sulstanz. welehe wil als die Trägerin der Arteigenschaften bezeichnet haben. Zustände des zusammengesetzten Organismus werden so in Arteigenschaften der Zelle, in ein anderes materielles System, umgesetzt. Die Erbmasse des Organismus wird um ein neues Glied, eine neue Anlage bereichert. Welche bei der Entwicklung der nächsten Generation sich wieder manifestiert. indem das neuentstehende Individum jetzt schon, ,vom Keim aus" oder aus inneren Ursachen die von 
den Fltern im individuellen Leben. im Verkehr mit der Aubenwelt. erworbenen Eigenschaften mehr oder minder reproduziert. In ähnlicher Weise haben sich schon andere Forscher, die das Ver-

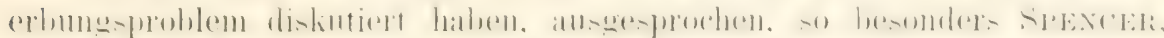
dessen Schlubfolgerungen ich mit seinen eigenen Worten wiedergebe:

..Es ist nicht a priori einleuchtend, dah auch Abänderungen der Strulitur, welche durch dbänderungen der funktionen erzeugt wurden. anf die Jachliommenschaft übertragen werlen müssen. Es ergibt sich nicht ron selbst, dab Veränderung in der form eines 'l'eils, verursacht

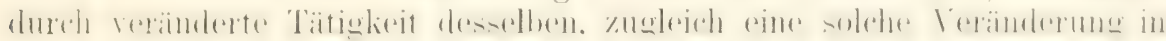

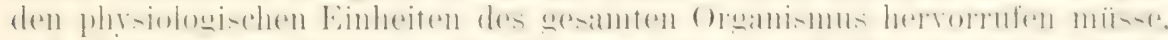

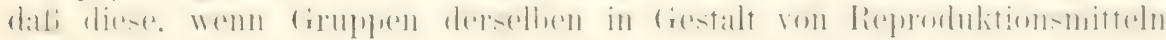
abgeworfen werden, sich zu cinem Organismus entfalten, bei dem dieser

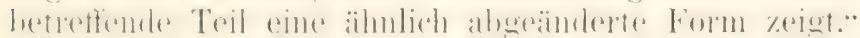

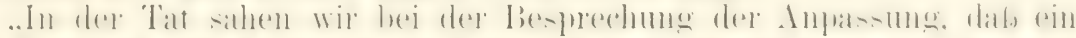

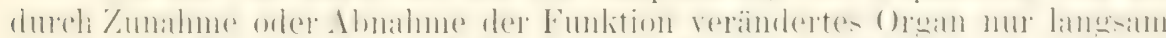

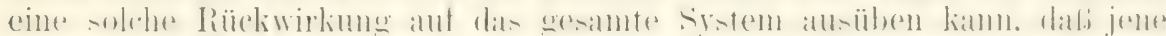

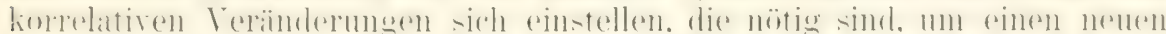

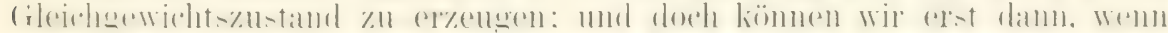

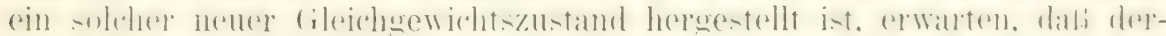

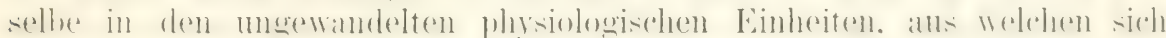
der Organismus aufluaut, vollständig seinen Ausdruck finde; - nur dann

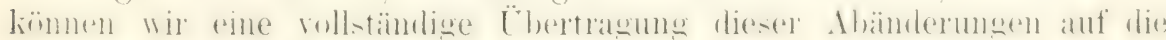
Nachkommen mit Sicherheit voraussetzen."

..Nichtsdestoweniger ergibt es sich als Dedulition - oder wenigstens als allgemeine Folgerung — aus ersten Prinzipien, daß Veränderungen

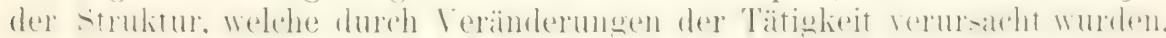
ebenfalls. wenn auch nur sehr verwischt, von einer Generation auf die andere übertragen werden müssen. - Denn wenn ein Organismus $A$

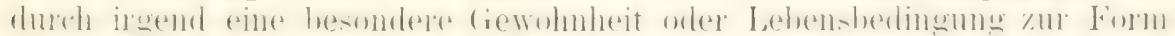

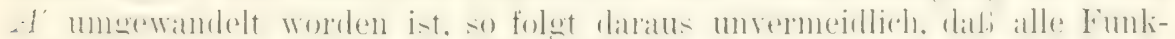
tionen von $A$ ' mit Einschluß der Zeugungsfunktion in gewissem Grarle von den Funktionen von $A$ verschieden sein müssen."

.. Wem ein Organismus nichts anderes ist als eine liombination

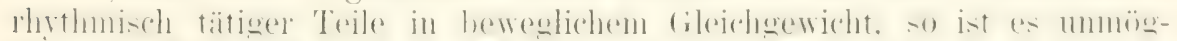

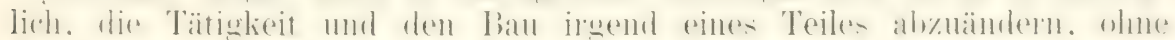

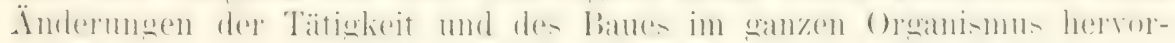

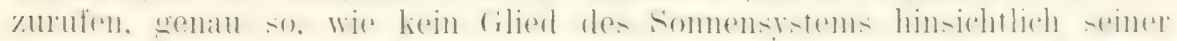

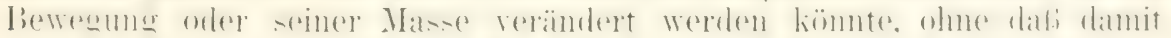
eine durch das ganze Sonnensystem hindurch sich erstreckende neue Anordnung verursacht wïrle. Und wemn der Organismus $A$ bei seinem Übergang zu $A^{\prime}$ in allen seinen Funktionen verändert worden sein muß. dann kann auch die Nachkommenschaft von $A^{\prime}$ nicht dieselbe sein. die sie sein wïrde, hätte ihr Erzenger die Form $A$ beibehalten. Es hieße das Fortbestehen der hiraft in Abrede stellen, wenn man behaupten wollte, (laf. $A$ sich in $A^{\prime}$ verwandeh und doch noch eine Nachkommenschaft erzeugen könne, welche genau derjenigen gleich wäre, die er ohne diese Veränderung erhalten haben wïrde. Daß aber die Veränderung in der

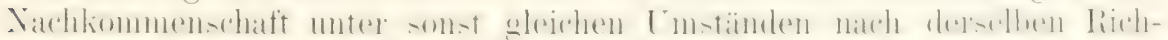

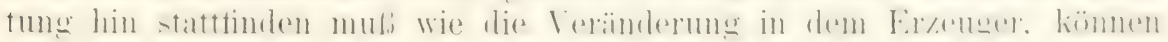
wir im allgemeinen schon aus der Tatsache erschliefen. dab die in das

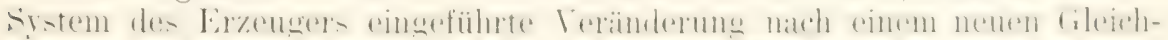

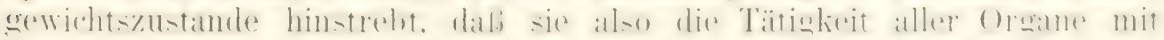


Einsthluli der \%ongungsorgane in thereinstimmung mit diesen nenen Tätigkeiten bringen mul."

.Oder um die Frage auf ihre letzte und einfachste Form zurïckzufïhren. lïmen wir agen. dali ebenso wie die physologischen Einheiten jhrerseit- infolge ilner speziellen polaren hräte sich zu einem orominnus

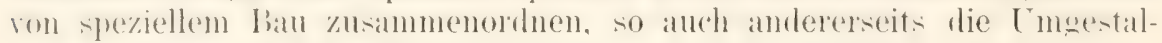
tung. welche der Bau dieses Organismus, durch reränderte Funktion erfahren hat. irgend eine entrprechende Lmgestaltung im lian und in den Polaritätan somer Einheiten erzeugen wirl. Die Einheiten und ihre Aguremate müssen aufeinander einwirken mol zuräckwirken. Die ron jester Einheit auf das Ageregat und ron dem Iggregat auf jede Einheit alusweïhten liräfte müssen stets einem (ileichgewichtsustande zustreben. Wenn keine Störung eintritt, so werden die Einheiten das Aggregat in einer Form herstellen, welche ein (ileichgewicht zwischen ihren vorher schon hestehenden Polaritäten ermöglicht. Wird ungekehrt das Aggregat durch einwirkende Kräfte veranlabt, eine nene Form anzunehmen. so müssen seine Lirifte danach strehen, die Einheiten im Finklange mit dieser nenen Form mmzugestalten. Und wenn wir sagen. dab die physologi-chen Einheiten in irgendwelchem Grade so umgestaltet sind, daß ihre polaren Kräfte mit den Kräften des umgewandelten Aggregats ins dileichgewicht gehracht sind. so ist damit zugleich gesagt, dabi diese Eimheiten. Wenn sie in fiestalt ron Reprodulitionszentren sich ahsondern. das Ibestrehen zeigen werden, sich zu einem Aggregate aufzubauen, welches in derselben Richtung umgeändert ist."

Mit den Eigenschaften, welche H. SPExcer seinen hpyothetisch anacnommenen phrsiologishen Einheiten heilegt. ist nach der Theorie der biogenesis die substanz alusgestattet. Welche Träger der Arteigenschaften (Idioplasma) ist und als Erbmasse in jeder Zelle des vielzelligen Organismus eingeschlossen ist.

H. SPENCERS physiologischen Einheiten entsprechen somit unsere Artzellen, insofern sie Träger der Erbmasse sind.

Nach der Theorie der Biogenesis haben wir der Zelle das V'ermögen zuweschriehen. Yustänle des übergeordneten Orwanismus. dessen anatomische Flementareinheit sie ist. durch materielle Veränderungen ilnes folioplanmas festzuhalten, also in ihr materielles System, wenn man den Vergleich gestatten will, geviscrmaben ein Bild des ans anderen Bestandteilen. Zellen und Zchluroduliten, aufgehatuten materiellen systems des Körper- aufzunehmen und letzteres beim Entwicklungsprozeb dam wieder aus inneren Ursachen zu reproduzieren.

Ein derartiges Vermögen bietet in mancher Hinsicht eine Analogie zu dem Vermögen der Hirnsubstanz, Zustände der Außenwelt, die ihr durle die simnesoroane in Bildern. Klängen und anderen Emptindungen zugetragen worlen. in das ihr eigene materielle system aufzumehmen und

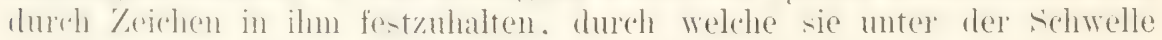
des Bewubtseins kürzere oder längere Zeit in uns fortbestehen, bis sie gelegentlich entweder durch äuberen Anstoß oder aus inneren Ursachen wieder reproduziert werden, als Erimnerungsbilder auftauchen und komplizierten psychophysischen Prozessen mit als Material dienen.

Damit betreten wir ein Gebiet, auf welchem wir uns an den äulersten Grenzen rler Naturwissenschaft bewegen, zugleich aber auch ein Gebiet, allt welchem wir den verwandten Anschammoen so allsegeichneter I'hrsiologen wie Fechner und Hering begegnen. 
Beide Forscher haben die Analogie. welche sich zwischen dem Ver-

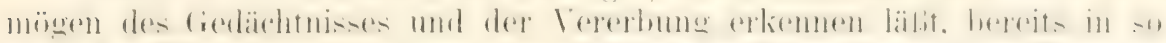

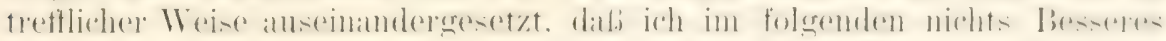
tun kann, als mich mehr oder minder ihrer eigenen Worte zu bedienen.

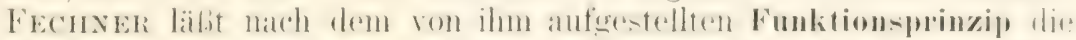

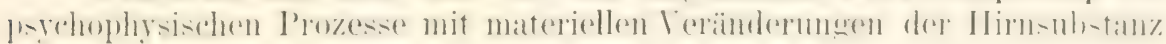
einhergelien. In den näheren Erläuterungen hierzu bemerkit er:

.Was bei der Ansicht, daß die Erinnerungsbilder so gut psycho-

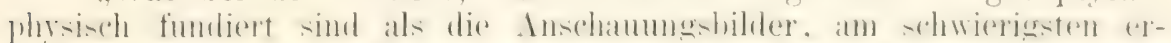

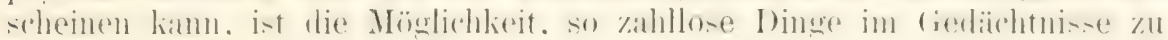
behalten und in Erimnerung zu produzieren. Aber sie ist nicht wunder-

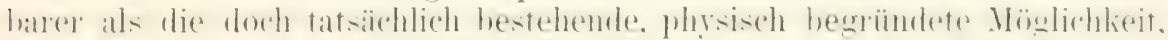

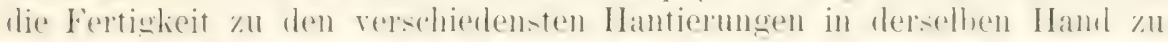

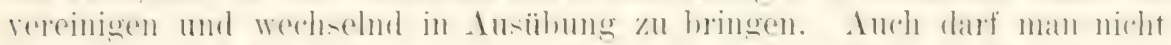

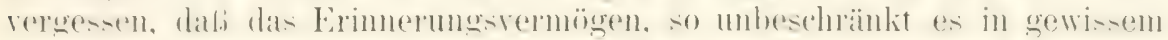
Simne ist, so beschrinkt von anderer Seite ist. Es unterliegt Gesetzen

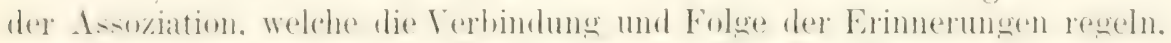
umb elensen wie rerwandte Fertigkeiten der Hand sich unter-tützen und disparate stören kömnen, ist es mit den Erinnerungen der Fall."

.,Sich den psychophysischen Mechanismus oder die organische Ein-

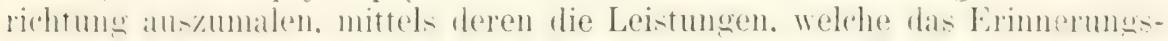

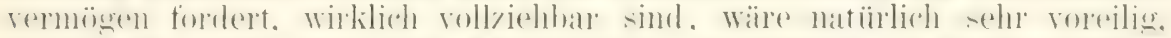
shange wir noch kamm eine Almumg äber das Prinzip der Vervonwirkmog iiberhaupt und mithin über die Weise, wie es dabei zu verrechmen wäre, haben. So viel läbt sich nur ganz im allgemeinen sagen, daf der Mechanismus ein, wenn nicht im Prinzip, aber in den aufgewandten Mitteln ungeheuer komplizierter und nicht fester. sondern veränderlicher, entwicklungsfähiger sein müsse. Diesen Bedingungen sehen wir entsprochen, und viel mehr ist für jetzt nicht zu verlangen. Doch lïbt sich noch einiges erläuternd zufïgen."6

..Die Nachklänge unserer Anschaumgen in den Nachbildern haben

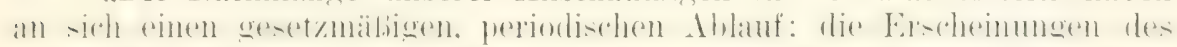

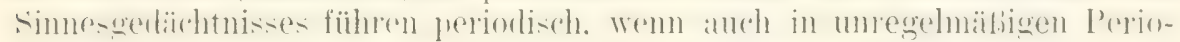
den. selbst nach längerer Zeit noch Gestalten und bewegungen ganz mwillkïrlich in die Erscheinung zurück und würden es unstreitig viel mehr tun, wemn nicht teils neue Eindrücke. teils die Zusammensetzung mit den alten den deutlichen Hervortritt einzelner periodischer Erscheinungen in diesem wogenden Meere blok auf die Folgen sehr intensiver. oft wiederholter Eindricke beschränkte. Fis besteht aber doch hiernach

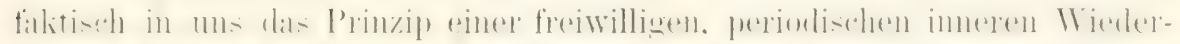

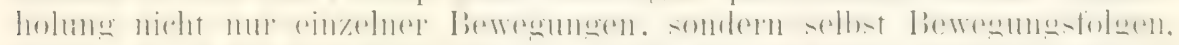

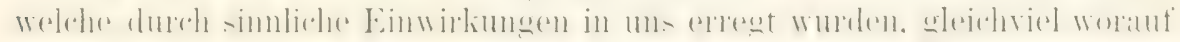
es beruhe. will man anders nicht schon die simnlichen Phänomene von der physischen Unterlage loslösen; und so ist kein Hindernis, zu glauben. daß dies Prinzip auch als eine der psychophysischen Grundlagen unseres Erinnerungsvermögens eine grobe Rolle spiele. AnBerdem läbt sich voraussetzen, dab das Prinzip der ungestörten Existenz und Superposition

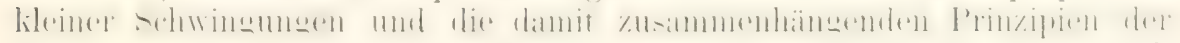
Interferenz und ungestörten Durchkreuzung ron Wellen bei den sich lirenzenden. sich miteinander zusammensetzenden. sich zeitweise ins Linbewustsein herabdrïckenden und wieder daraus hervortretenden Erinnerungen nicht außer spiel sein werden." 
.. Wenn wir sehen, wie alle physikalischen Ifilf-mitel aufgehoten sind,

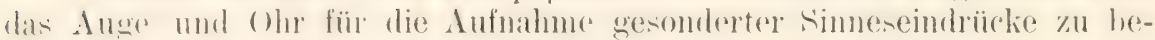
fähigen, so kann man es zwar bequemer finden, die Aufbewahrung und Wiederholum derselhen als ein der seele ohne alle äuberen Hilfsmittel zulommentes lermögen anzusehen, aber es auch hiergegen mur konseyuent finden, wenn man dieselbe an eine noch tiefer gehende Verwendung der physilialischen l'rinzipien und IIilfsmitel geknüpft glauht. womit man nicht sow ohl das Geistige herabsetzt, als die Natur heraufhebt" etc.

"Wenn die Erinnerungsbilder, Phantasiebilder und das Denken bewhitenden sichemata alle noch prychophysisch fundiert sind, so ist es anch das Denken selbst. indem jeder andere stoff und fimg des Ienkens ein anderes Material und eine andere Verknüpfungsweise rer Schrmata roraussetzt, ohne die ïherhaupt kein Denken stattinden kam. wie eine andere Melodie und, Harmonie nicht ohne andere 'Töne und eine andere Verbindungsweise der Töne sein kann. Nun gewährt ein Klavier in seiner verhïlnismäbig zeringen Zahl festliegemler Tasten doch die Möglichlieit. die allerverschieriensten Melodien und Iarmonien anszuführen, und so viclerlei und so hohe fiedanken der Mensch fasien mag. „2.) Iuchstaben reichen hin, sie auszudrïcken; es kommt beide Male nur auf die Verbindung und die Folge an. in der die Ruchstahen oder Tasten durchlaufen werden. Das Gehirn in seinen zahllosen, in verschiedenel Weise tätigen Fibern aber enthält in dieser Ilinsicht unvergleichlich reichere Mittel;

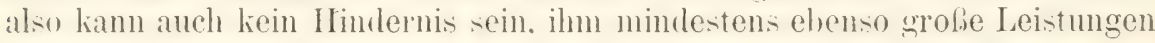
innerlich zuzutrauen, als wir äußerlich mittelst derselben ausführen.‘

Dieselbe Vorstellung, die hier FEcHNER vom psychophysischen Substrat des Gedächtnisses. haben NäGELI und ich von der Beschaffenheit des Idioplasmas entwickelt; hier wie dort wird eine organische Einrichtung angenommen mit einem Mechanismus, der ungehener kompliziert und nicht fest. somlern veränderlich und entwicklungsfähigist. Wie ron Fechner. so wirl von Näresi und mir an die Art mul Weise erimnert, wie durch die beschränkte Anzahl von Tasten eines Klaviers oder durch die 25 Buchstahen des Alphabets allein durch verschiedenartige Zusammenordnung und Aufeinanderfolge die verschiedenartigsten Harmonieen mol Gedanlienfolgen zum Ausdruck gebracht werden können.

Soch mehr aber werden verwande fielankenreihen angeschlagen in dem Vortrag von Hering: "Über das Gerlächtnis als eine allgemeine Funktion der organisierten Materie."

Wie Fechner betrachtet Herrng „die Phänomene des Bewußstseins als Funlitionen der materiellen Vuänderungen der organischen Substanz und umgekehrt." Wenn wir daher an uns beobachten, wie eine Vorstellung the andere auslist. wio an die Emptindmog die Vorstellung, an diese der Wille anknüpt, wie Gefïhle und Gedanken sich ineinander weben. so wirl der Physiologe (ntsprechende Reihen materieller Prozesse anzunehmen haben. welche einander aushösen, sich miteinander verknüpfen und in ihrer materiellen Weise das anze Getriehe des bewuliten Lebens mach dem ciesetre des funlitionellen Zusammenhanges zwischen Materie und Bewubtsein begleiten. Herswg bezeichnet daher, als ein firundrermögen der organisierten Materie ihr (iedächtnis oder ihr Reprorluktionsirermögen."

„Ganze Gruppen von Eindrücken, welche unser Gehirn durch die simnerorgane enpfangen hat, kïnnen in ihm lange Zeit gleichsam ruhend

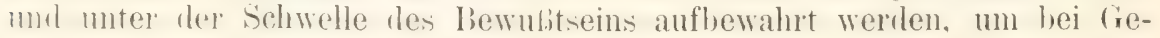
lowenheit. nach Raum und \%eit richtig georhet. mit solcher Lebendigkeit 


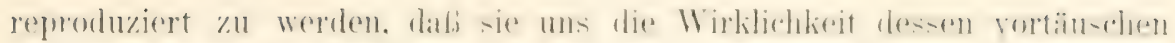
kömnen, was schon längst nicht mehr gegenwärtigs ist."

..Dies zeigt uns in schlagender Weise, daf, wenn auch die bewuBte

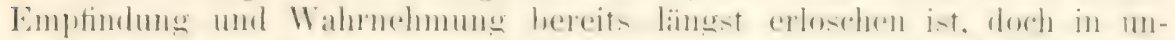

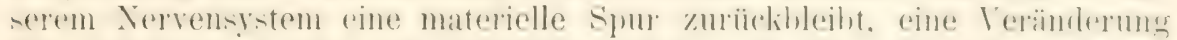
des molekularen oder atomistischen liefïges, dureh welehe die Sirvent-

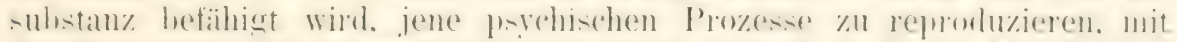

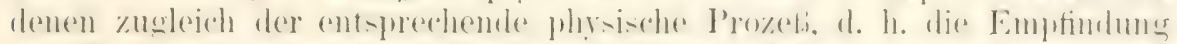
und Wahmehmung, gesetzt ist." „Es dauert fort eine besondere Stim-

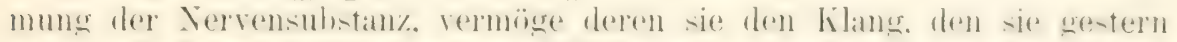
sab, anch heute wioder artönen lälit. Wenn sio nur richtigr angeschlatron wirl."

..so reihen sich fortwährend zahllose lieprodulitionem orwanisher

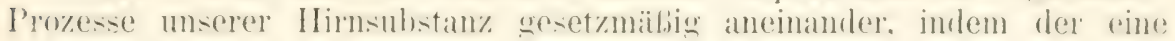
als Reiz den anderen auslöst."

.Die Nervensubstanz bewahrt treu die Erinnerung der oft geübten Verrichtungen: alle zur IJerstelhng der richtigen Wahrnehmung nötigen

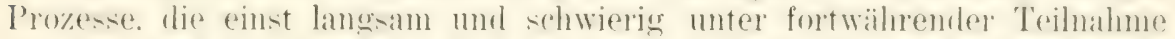

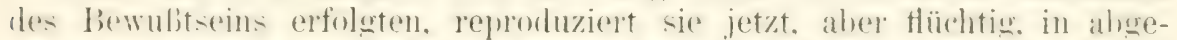

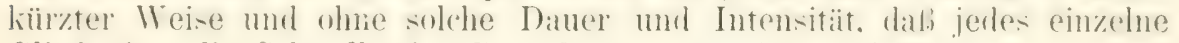
Glied über die Schwelle des Bewußtseins geriickt würde."

Ein ähnliches Vemögen des Ciedïrhtnises und der lieprodulition

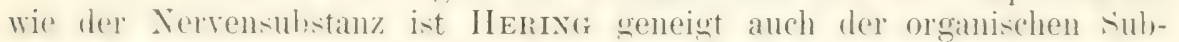

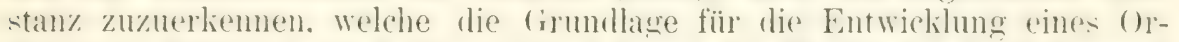
sanismu- hildet: ja er findet sogar. dals uns die Macht des fiedächtnisses ler ormanisierten Materie auf diesen (iebiete am sewaltigrten entrerentrete. Er entwickelt seinen Gedanken in folgender Weise:

.Wir sind auf Grund zahlreicher Tatsachen zu der Annahme berechtigt. dab anch solehe Eigensehaften eines Organismus sich auf seine Natehlommen ïhertragen kïmnen, welche er selhst nicht erepht. somdern erst muter den hesonderen Verhältuissen. unter denen er lehte. sich angeeignet hat. und dad, infolgedesien jerles orwanische Wesen dem lieime, der sich von ihm tremt. ein klemes Erhe mitgiht. Weldhes im individuellen Leben des müterlichen Oromismus erworben und hinzugelegt wurde zum grolien Erbgute des ganzen Geschlechts."

.Wenn man bedenkt, daß es sich hierbei um Forterbung von el-

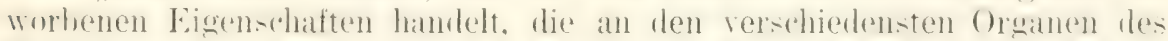

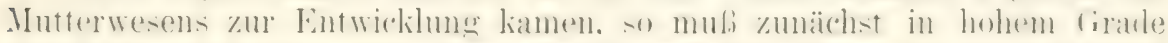

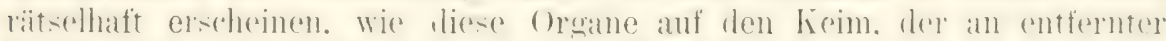

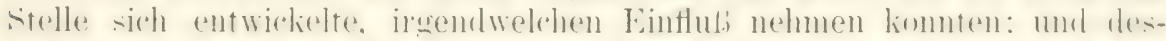

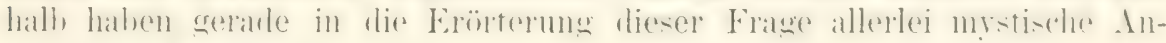
sichten sich eingedrängt."

Um den Vorgang dem physiologischen Verständnis näher zu rïcken.

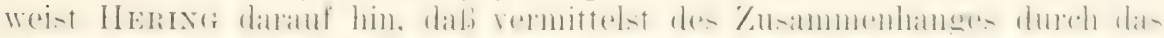

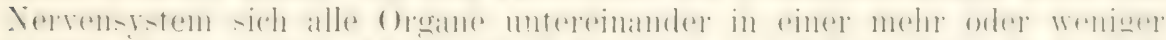

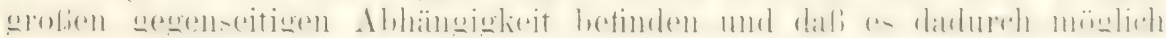
sei. ..lab die Schicksale des einen wiederluallen in den andern und von der irgendwo stattindenden Erregung eine wenn auch noch so dlumpte Kunde bis zu den entferntesten Teilen dringt. Zu dem durch dis Nerven-

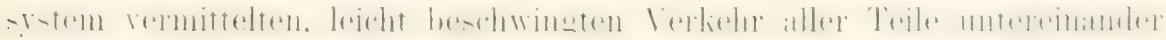
geselle sich damn noch der schwerfäligere, welcher durch den Kreislauf der Säfte hergestellt werile." 
HERING findet so deutlich genug den Weg angedentet, auf welchem

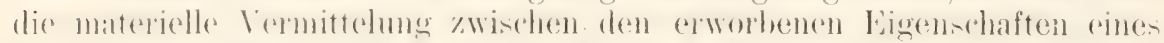

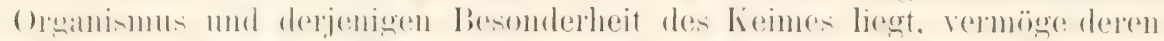
er jene mütterlichen Eigenschaften auch seinerseits wieder zur Lutwicklumg zu bringen vermag.

„Wie eine unendlich kleine Verschiebung eines Punktes oder Punkt-

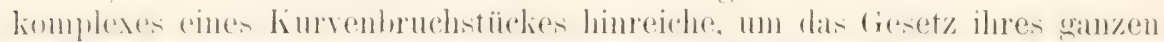

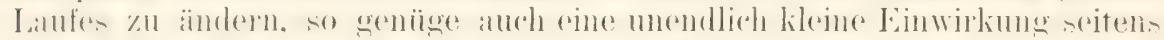
des mütterlichen Organismus auf das molekulare Gefüge des Keimes, um betimmenel für seine gante liüntige Entwicklung zu werden."

„Was aber ist". fügt Hering hinzu, ,dieses Wierlererscheinen von Figensehaften des Mutteroranismus an dem sich entfaltenden Tordeterorganismus anderes als eine Reproduktion solcher Prozesse seitens der organisierten Materie, an welchen dieselbe schon eimmal, wenn auch nur als Keim im Keimstocke, teilnahm und deren sie jetzt, wo Zeit und Gelegen-

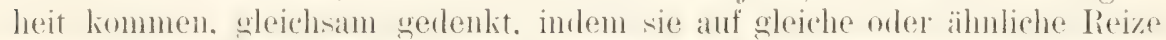
in ähnliner Weine reagiert. wie früher jener ()rganismus, dessen Treil sir einst war und dessen Geschicke damals auch sie bewegten."

„Wemm dem Mutterorganismus durch lange ciewöhmmg oder tatusendfache Übung etwas so zur andern Natur geworden ist, das auch die in ihm ruhende Keimzelle davon in einer, wenn auch noch so abgeschwächten Weise durchdrungen wird - und letztere beginnt ein neues Dasein, dehnt sich aus und erweitert sich zu einem neuen Wesen, dessen einzelne 'Teile doch immer nur sie selbst sind und Fleisch von ihrem Fleische, und sie reproduziert dann das, was sie schon eimmal als Teil eines großen Ganzen mit erlebte - so ist das zwar ebenso wunderbar, als wemn den Greis plötzlich die Erimerung an die früheste Kindheit ïherkommt, aher es ist nicht wunderbarer als dieses. Und ob es noch dieselbe organische Substanz ist, die ein einst Erlebtes reproduziert, oder ob es nur ein Abkömmling, ein Teil ihrer selbst ist, der unterdes wuchs und grob ward, dies ist offenbar nur ein Unterschied des Grades und nicht des Wesens."

Während die Eigenschaft, Zustände des Körpers zu empfinden und gleichsam im Gedächtnis damernd zu bewahren, von Hering nur für die Keimzelle angenommen wird, kommt sie nach unserer Theorie der Biogenesis überhaupt der Substanz zu, welche Träger der Arteigenschaften ist mol sich mehr orler minder in jeder Zelle des Körpers vorfindet.

In diesem Punkte stimmen wir mit Herbert Spencer ïberein.

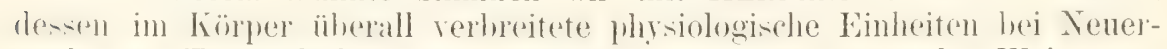
werb von Eigenschaften sich ebenfalls in übereinstimmender Weise verändern.

Inshesondere aber harmonieren unsere Anschaungen mit denjenigen von NÄGELI. Dieser hervorragende Denker nimmt an, daß die zum Ilioplasma organisierten EiweiBkörper ein Bild ihrer eigenen lokalen Veränderung nach anderen Stellen im Organismus führen und dort eine mit dem Bilde übereinstimmende Veränderung bewirken.

,Jede Veränderung, die das Idioplasma an irgend einer Stelle erfährt, wird überall wahrgenommen und in entsprechender Weise verwertet. Wir müssen sogar annehmen. daß schon der Reiz, der lokal einwirkt, sofort

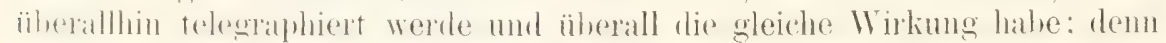

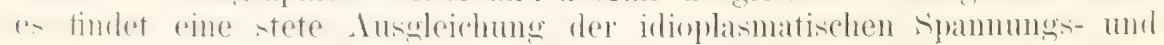
Bewegungszustände statt. Diese fortwährende und allseitige Fühlung,

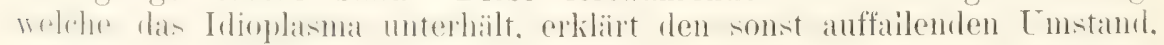
daß dasselbe trotz der so ungleichartigen Ernährungs- und Reizeinflüsse. 
denen es in den verschiedenen 'Teilen eines Organismus ausgesetzt ist.

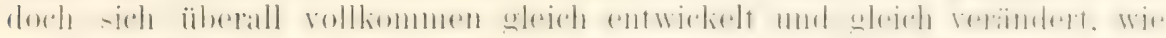
wir namentlich aus dem Umstande ersehen, dab die Zellen der Wurzel. des Stammes und des Blattes ganz dieselben Individuen hervorbringen" (1. $1 ., 5 ., 1)$.

„Das Idioplasma in einem beliebigen T'eil des Organismus erhält Kuncle von dem, was in den iibrigen Teilen vorgeht. Dies ist damn möglich, wemn seine Verinderungen und Stimmungen auf materiellem orler dymamischem Wege iuberallhin mitgeteilt werden:

Und an dritter Stelle heibt es: ..Die von auben kommenden Reize treften den Organismus gewöhnlich an einer bestimmten Stelle; sie be-

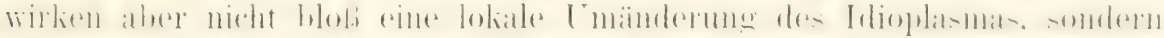

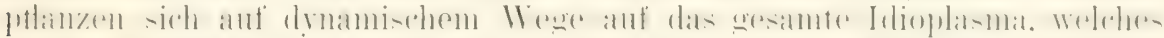

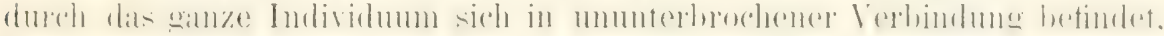
fort und verändern es ibberall in der nämlichen Weise, so dab die irgend-

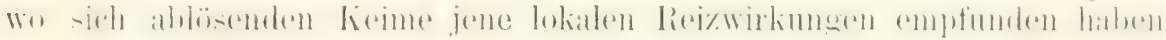
und vererben."

\section{Weitere Folgerungen.}

Durch die im rweiten Abschnitt entwickelte Ammahme, dab neu erworbene Eigenschaften des Individuums auch durch materielle Veränderungen von der Erbmasse der Zelle festgehalten und so zu einem hleibenden Besitz werden. der auf spätere Generationen mit vererbt wird, läßt sich die im ersten Abschnitt erörterte Lehre von der Vererbung ererbter Eigenschaften noch von einer anderen Seite her belenchten. Überhanpt

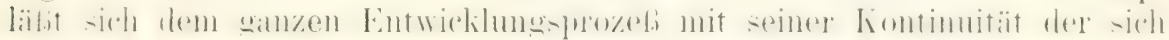
ablösenden Generationen noch ein tieferes Verständnis abgewinnen.

Es ist kilar, dah, wenn die nenerworbenen Eigenschaften eines Individums als Bestandteil in die Erbmasse seiner Zellen eingehen und als ein dauernder Besitz späteren Generationen überliefert werden können. auch die von ihm ererbten Eigenschaften sich als ein Besitz betrachten lassen. der erst allmählich von früheren Generationen der Art im Iaufe des groben Entwicklungsprozesses der Natur in Anpassung an äufere Ursachen erworben worken ist.

Die Erbmasse - so können wir, dem angeregten Ideengang folgend, weiter schliefen - ist von kleinen Anfängen aus Schritt für Schritt um nene Glieder bercichert worden, hat ihr materielles Gefüge ron (ieneration zu fieneration verindert, immer neue Eindrïcke in sich aufnehmend. dem Gehirn vergleichbar. das immer nene Reihen von Gerlïchtnisbildern und daraus abgeleiteten Vorstellungen in seiner Substanz festhält.

Ion solchem Standpunkt aus erscheint uns erst in ihrer wahren Bedeutung die besonder's ron der DARwisschen Schule ausgebildete, grofartige Auffassung, (lab die ganze Formenreihe, welche z. B. ein Säugetier vom einfachen Ei- bis zum kompliziertesten Endzustand in gesetz-

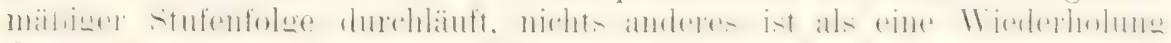
des Entwicklungsprozesses, welchen die Art im Laufe vieler Erdperioden durcheemacht hat von dem Stadium der einfachen Zelle an allmählich

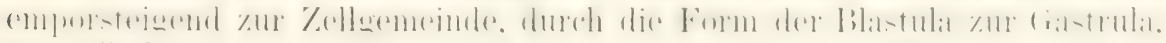
rom Fischstadium sich erhehend zum landbewohnenden Wirbeltier ete.

Im Besitz des Erbes zahlloser Generationen entfaltet die Eizelle die ererbten Anlagen, indem sie aus imnern Ursachen und dlabei in beständigem Verkehr mit der Aubenwelt in ähn- 
licher Weise wieder wächst, in welcher sich die Art in steter Wechselwirkung mit der AuBenwelt - also angepaßt an sie entwickelt liat.

So erscheint denn die Ontogenie eines Individumms, wie es nach

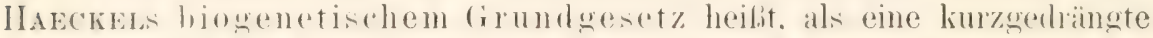
Rekaphitulation der P'hylogenie. oler die individuelle Entwicklungr-geschichte wierlerholt nur die Stammesgeschichte.

.. Die Entfaltumg der Anlagen des Idioplasmas". bemerkt Nïres. das

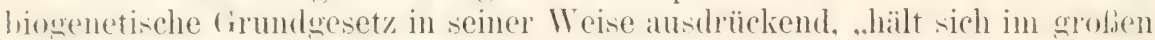
und ganzen an die phylogenetische Ordnums. Indem der ontogenetisch sich entwiclielnde Organismus nacheinamder die Stadien durchläuft. welche sein phylogenetischer Stamm durchlauten lat, kommen die idioplasmatischen Anlagen in derjenigen Folge zur Verwirklichung. in der sie entstanden sind."

Nach der Ausdrucksweise von Hering ,steht so schließlich jedes organische Wesen der (iegenwart vor uns als ein Produlit des mubrwubten (iedächtnisses der organisierten Materie, welche immer wachsend und immer sich teilend, immer neuen Stoff assinilierend und anderen der organi-chen Welt zurïckgebend. immer Neues in ihr verlächtnis aufnehment. um es wieder und wieder zu reproduzieren, reicher und immer reicher sich gestaltete, je länger sie lebte".

..Die ganze individuelle Entwicklungsgeschichte eines höher or nanisierten Tieres bildet aus diesem Gesichtspunlit eine fortlaufende Kette von Erinnerungen an die Entwicklungsgeschichte jener groben Wesenreihe deren Endglied dieses 'Tier bildet: mul wie eine verwickelte Wahmehmung durch eine flüchtige und sozusagen ohertlächliche Reproduktion lange und mülssam eingeühter Hirmprozesse zustande kommt, so durchläuft der sich entwickelnde Keim schnell und nur andeutungsweise eine Reihe von Phasen, die von der Wesenreihe, deren Abschluf, er bildet. wïhrend eines unabsehbar langen Lebens nur Schritt für Schritt zur Entwicklung und Fixierung im Gedächtnis der organisierten Materie gelangten."

Am Schluß dieses Abschnittes mub ich noch einmal zur Verhütung von Mibverständnissen, welche sich auf diesen schwierigen (iebieten leicht ainstellen, ausclrücklich hervorhehen, dab ich, dem von HERIvg angeschlagenen (iedankengang folgend, hervorhehen wollte. wie zwischen den wumlerbaren Eigenschaften der Erhmasse und den nicht minder wumlerlaren Eigenschaften der Hirnsubstanz eine Analogie. eine gewisse Übereinstimmung, besteht.

Dal, diese Analogie keine Irlentität ist, haucht für den Finsichtigen kaum bemerkt zu werden; denn wie die materiellen Grundlagen der Hirnsubstanz und der Erbmasse verschiedene sind, so wohl auch die in beiden ablaufenden Prozesse; daher ich im allgemeinen auch nicht (mulfehlen kann. das für die Hirmphänomene gebrauchte Irort .. re-

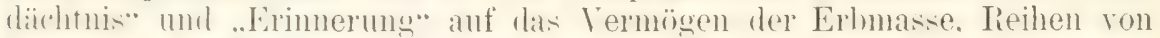
Zu-tänlen festzuhalten und wieder zn remoduzieren, einfach zu ühertragen.

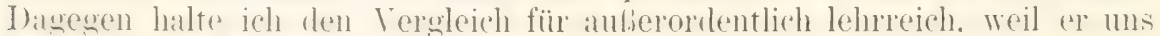
hinweist auf Eigenschaften (ler organisierten Substanz, von welchen uns

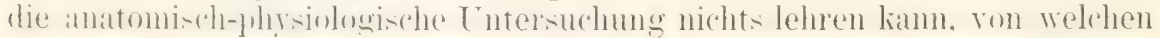

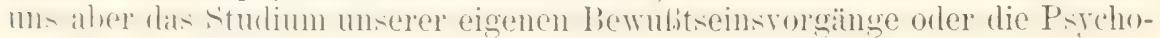
logie Krunde gibt $\left.{ }^{1}\right)$.

1) Den yon Herixg in einem Vortrag entwickelten Gedanken, daß Erinnerungsrermögen und Erblichkeit eine Reihe von Ubereinstimmungen aufweisen, habe ich mit Tïcksicht auf seine wissenschaftliche Bedeutung und in roller Würdigung derselben zum 


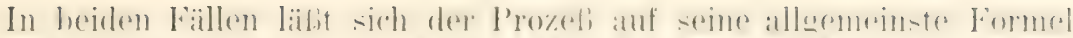

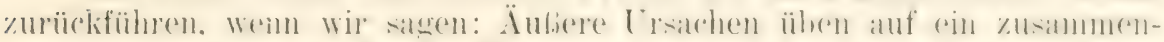

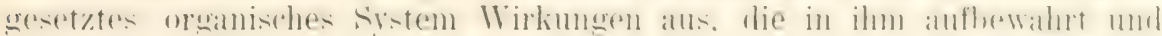

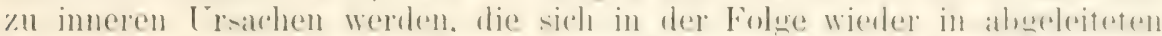

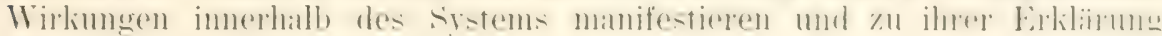
herangezogen werden müssen.

ersten Male als Bestandteil in ein Lehrbuch (1898) anfurenommen, in eingehender Weise erörtert und so wieder die Aufmerksamkeit weiterer hreise auf ihn hingelenkt. Seitden hat RichArD SFmox den Vergleich weiter ausgeführt in seinem 1901 erschienenen IBuch "Die Ineme als erhaltendes Prinzip im Wechsel des organischen Geschehens". Er geht auch hier von dem l'rinzip aus, das ich im Anschluß an Nïgen zuerst konsequent durchgeführt habe, daß die Erhmasse und ihre Finigkeit der Reproduktion, die er Aneme nennt, in jeder '/elle enthalten ist.

In seinem Buch stellt R. SEMox es mit Unrecht so dar, als ob ich mich ablehnend gegen den Herixgschen Gedanken verhalten hahe, obwohl eher das Gegenteil der Fall ist. In einem Referat hat Forer, diese irrige Darstellung wiederholt. Lu ihr ist

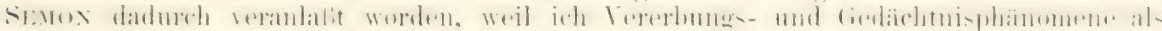
analog, aber nicht als identisch bezeichne, da zwischen beiden trotz wichtiger Über-

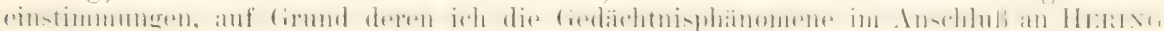
zur Erklärung der Erblichkeit herheiziehe, anch vielerlei Unterschiede bestehen.

Mir scheint, als ob SwMox sich meinem Standpunkt in einer Anmerkung auf Seite 20 selhst sehr nähert. Demn er sicht sich, aus zahlreichen Gründen bestimmt, von den guten deutschen Worten Gedïchtnis und Erinnerungsbild keinen Gebranch zu machen. Zu den hauptsächlichsten dieser Grïnde grehört in erster Linie der, daß ich fïr meine /,wecke die vorhandenen deutschen Worte in einem viel weiteren Sinne fassen müßte, als sie gewöhnlich gebrancht werden, und dadurch zahllosen Mißverständnissen und zwecklosen Polemiken Tür und Tor öffnen wïrle. Fs wire auch sachlich ein Fehler, den weiteren Begriff mit einer Bezeichmung zu belegen, die für gewöhnlich

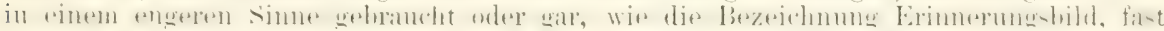

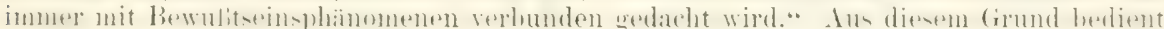
sich SEmox in seinem Buch des Wortes . Mn eme". Dasselle bezeichnet num zwar im Griechischen auch nichts anderes als unser Wort Gedachtnis. Aber in dieser Bedentung gebraucht es SErox nicht, sondern hat ihm einen andern Sim untergeschoben; er versteht unter Ineme die Summe der Engramme, die ein Organismus ererbt oder während

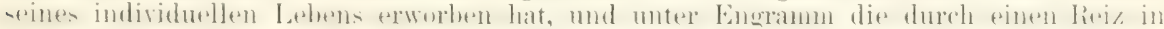

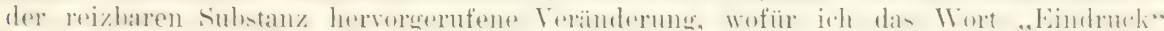

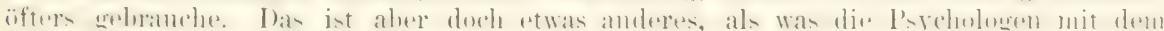
Wort Gedichtnis hezeichnen.

Nach meiner Ansicht fallen die Erscheinungen der ,Ineme“, also der Erblichkeit, und die Erscheinungen des Gedächtnisses unter den allgemeinen Begriff der Reproduktion und zeigen hierbei in ihrem Wesen eine gewisse Identitü, was ich weder je bestritten habe noch bestreite. Zwei Begriffe, die unter einen allgemeinen Begriff subsummiert werden können, müssen ja eine Reihe ron identischen Merkmalen darbieten, sonst könnten sie nicht unter einen solchen untergeordnet werden, aber sie müssen ebensogut auch voneinander verschieden sein: denn wie könnten sie sonst als zwei Sonderbegriffe unter dem Hauptheoriff unterschieden werden?

Wie Gediichtnis- und Vererbungsphänomene unter eine allgemeine Formel gebracht werden künnen, habe ich selbst auf S. $252 \mathrm{im}$ II. Buch der ersten Auflage (Seite 5S- der zweiten Auflage) genauer ausceführt.

Auch meine von SEyox und Forec heanstandete Bemerkung: ,wie die materiellen Grundlagen der IIrnsubstanz und der Erbmasse verschiedene sind, so wohl auch die in beiden ablaufenden l'rozesse"s, muß ich nach wie vor als zutreffend aufrecht erhalten. Demn von Gedichtnis sprechen wir nur bei Organismen mit einem schon hoch entwickelten Nervensystem und nehmen zugleich an, daß es an die Entwicklung des Großhirns gebunden sei. Daf I'flanzen oder einzellige Infusorien ein Gediachtnis hahen, wirl kaum jemand zu behampten wagen. Das Vermögen der Erblichkeit kommt aber allen Organismen und jeder \%elle zu.

Die Verschiedenheit der materiellen Grumdlagen besteht also darin, daf die l'hänomene der Erhlichkeit schon die einzelne Zelle zeint, daß die I'hänonene des (rediichtnisses daregen erst durch einen besonderen Verband vieler Zellen, durch die Entwicklung eines hochkomplizierten Vervensystems und besonders der froblirmrinde zustande kommen. Wie will da jemand noch an einer Verschiedenheit des Substrates, an welchem Gedichtnis und Erblichkeit ablaufen, zweifeln? Meine Behauptume heruht doch gant und gar auf den tatsächlichen Verhältnissen. 
Wenn ein Erinnerungsbild an Ereignisse, die längst abgelaufen sind mond daher nicht meln ummittelbar auf uns wirken kömnen. trotzriem aus inmeren Ursachen von der Himsubstanz reproduziert wird, so offenbart sich uns darin die Macht des Gerlächtnisses odter des Erinnerungsvermögens der organisierten Substanz.

Wenn embryonale Prozesse, abgelöst rom unmittelbaren Eingreifen ïuferer Ursachen, als Folge innerer Ursachen, die auf der eigentümlichen. im Laufe der Stammesgeschichte langsam erworbenen Organisation der Erbmasse beruhen, in zweckmäBiger Weise Organe schaffen, die, wie Ange mol Ohr, für äußere, erst später eintretende Einwirkungen im voraus berechmet sind, so offenbart sich uns darin das Wesen der Vererbung, jener

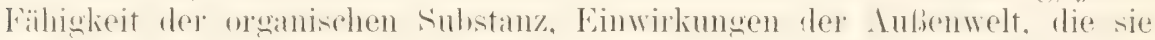
eimmal erfuhr, als einen Bestandteil in ihr System mit aufzunehmen und in eine Anlage umzuwandeln, bereit, sich bei Gelegenheit zu entfalten, gleichwie das im Gedächtnis der Hirnsubstanz aufbewahrte Erimnerungsbild wieder lebendig werlen kann.

Wir haben jetzt eine allgemeine Formel gewonnen. mit welcher sich das am Eingang des Abschnittes aufgeworfene Problem beantworten läßt. wie es zu erklären sei, daß in der Entwicklung eines Organismus die Organe in ihrer späteren Form meist angelegt werden, lange Zeit ehe sie

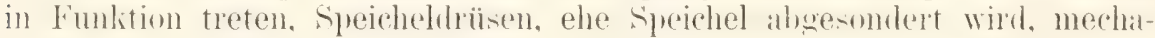
nische Strukturteile, wie Knochen, noch bevor sie Zug und Druck auszuhalten haben, Augen und Ohren. noch bevor die Bedingungen zu sehen und zu hören fïr sie vorhanden sind etc.

Es liegt hier klar auf der Hand, daß die Entwicklung der genannten Teile sich weder mit dem Satze vom Gebrauch und Nichtgebrauch der T'eile, noch in irgend einer anderen Weise durch unmittelbare Bewirkung dui'ch äußere Ursachen erklären läßt, sondern es müssen hier zur Erklärung innere Ursachen herangezogen werden, in welchen sich die Macht der Vererbung oder die Entfaltung von Anlagen der Erbmasse offenbart; das heißt, wir müssen sagen: während der Entwickhng nehmen die emhryonalen Teile diese und jene für hesondere fiebanchsweisen berechneten Formen an, weil letztere im Lanfe der Stammesgeschichte von den rorausgegangenen Generationsreihen allmählich erworben und durch einen heihemden Findruck in dem materiellen syotem der Frbmaxie festgehalten worden sind.

Zurzeit sind wohl alle Versuche als aussichtslos zu betrachten, einen Mechanismus oder eine Struktur der organisierten Substanz sich auszuklügeln, vermöge deren die Erscheinungen des Simnengedächtnisses und die Erscheinungen der Vererbung erworbener Charaktere durch die Zelle sich mechanisch erklären lassen.

Beim Gehin sind wir zwar in den feineren Bau schon tief eingedrungen; zahlreiche Ganglienzellen und noch zahlreichere, feinste Nervenfibrillen sind nadgewiesen mol in ihren gegenseitigen Verhindungen studiert worden. Gleichwohl bleibt es nach wie ror ein Rätsel, wie die organisierte Substanz Eindriicke der AuBenwelt in Zeichen festzuhalten und aus ihmen wieder nach langer Zeit früher Erfahrenes zu reproduzieren vermag; namentlich aber ist uns der Mechanismus absolut unvorstellbar, vermittelst dessen Reihen von Eindrücken in der Zeitfolge wieder gesetzmäßig verbunden werden kömmen, wie im Gedächtnis eines Klavierspielers sich in

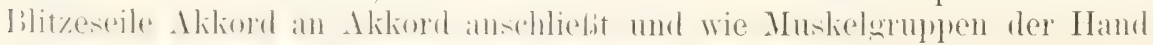
zu den komplizierten Bewegungen veranlaßt werden. 
Von der Lrbmasse ist uns die feinere Organisation, da sie ganz dem Molekulargebiet angehört, absolut unbekamnt. NïgELI und WEISMANx haben zwar den Versuch gemacht, sich eine Organisation auszudenken. Un zu beurteilen, was durch solche Versuche erreicht werden kann. möge man erwägen, was vor 100 . Jahren wohl ein Forscher zu Wege gebracht haben würde, der sich rorgenommen hätte, auf spekulativem Wege die Zellen- und Gewebelehre zu erfinden und die Wirkungsweise der Organe aus ilurer elementaren 'Zusammensetzung zu begreifen!

Wir haben es daher vorgezogen. uns in dieser Frage nur sehr vorsichtig auszudriicken und nur die Vermutung auszusprechen, dab die Sub)stanz. welche so verwickelte Erscheinmon hervorzurufen imstande ist.

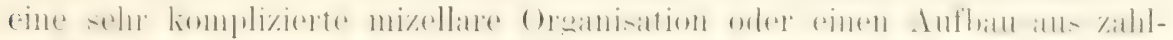

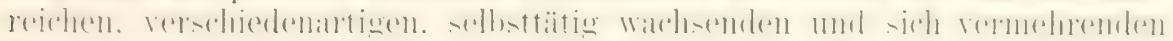

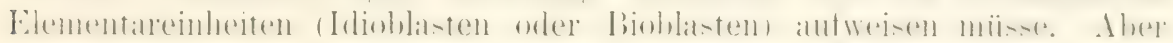
es ist gar nicht ausgeschlossen, dah das Verfahren. mit dem die Natur ihre Wirliungen hervorbringt, ein riel einfacheres oder wenigstens ein anders geartetes ist, als wir uns vorstellen.

Weniger schwierig ist es vielleicht zu verstehen, dalo die in der Erbmasse vorhandenen Anlagen sich zeitlich in einer gewissen Reihenfolge entfalten müssen. Denn hier bietet uns der Entwicklumgsprozef selbst einen Anhalt dar, indem er lehrt, dab sich die Anlagen in demselben Maße entfalten, als die Anlagesubstanz durch Vermehrung der Zellen wïchst.

Durch fortschreitende Vermehrung der Zellen werden durch ihr Zu-

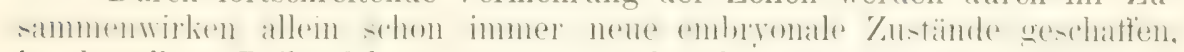
in derselhen Reihenfolge, wie sie in der Stammesgeschichte entstanden sincl. Die einzelnen Tellen werden zu einander und zu ilh rer äuberen Umgebung in neue Bedingungen gebracht, durch welche die in ihnen latenten Anlagen geweckt werden. Die jeweilig ron einer Zelle zu verrichtende Funktion wird in erster Linie, wie Vöcutrus sich ausdrückt, durch den morphologischen Ort bestimmt, den sie an der

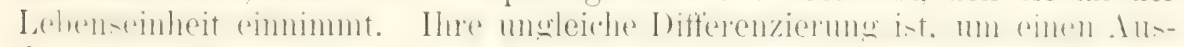
druck von Driescri zu gebrauchen, ,eine Funktion des Ortes:. In den

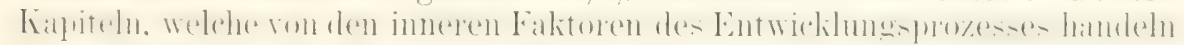
(Kiap. XXII-XXIV), wurde auf diesen Umstand schon ausclrïcklich hingewiesen.

In demselben Sinne bemerkt NüGELI: .. Nit dem wichtigen Umstande.

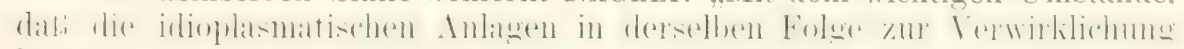

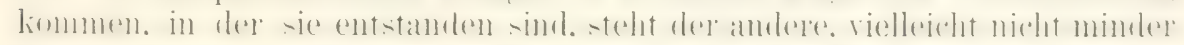

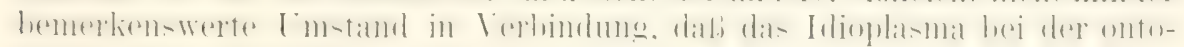

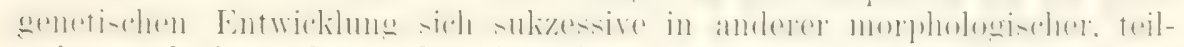
weise auch in anderer physiologischer Umgebung befindet. und zwar jeweilen in derjenigen Umgebung, welche mit jener analog ist. in del die Anlage, die sich zunächst entfalten soll, entstanden ist. Es ist aber selbst-

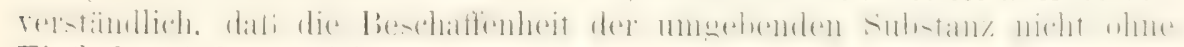
Einfluf auf die Entfaltung der idioplasmatischen Anlagen sein kamm.: 


\section{Literatur zu Kapitel XXVI und XXVII.}

1) Daxwin, Das Varieren der Tiere und Pflanzen, Bd. II. Vererbung, Irop. 12-I5. Provisorische Hypothese der Pansenesis, Kap. 27. 1873.

$\therefore$ Detmer, Zum Problem der Vererbung. Pflügers Archiv, Bd. XLI. 1887.

3) Ehrlich, Experimentelle Untersuchungen iüber Immunität. I. Über Rizin. II. Über Abrin. Deutsche mediz. Wochenschr., XVII. Jahrg., S. 976 14. 1218. 1891.

4) Derselbe, Über Immunität durch Vererbung and Säugung. Zeitschr. f, Hygiene u. Infektionskrankh, Bd. XII, S. 183-205. 1892.

5) Eimex, Die Entstehung der Arten auf Grund von Vererben erworbener Eigenschaften nach den Gesetzen organischen Wachsens. Jena 1888.

(i) Emery, C., Gedanken zur Deszendenz-und Vererbungstheorie. Biologisches Zentralbl., bi. Xll1. 1893.

7) Fechner, Elemente der Psychophysik, 2. Aufl., S. 464, 536. 1889.

b) Derselbe, Die Tagesansicht gegeniüber der Nachtansicht, S. 118-120. Leipzig 1879.

(1) Fischer, E., Experimentelle Untersuchungen iuber die Vererbung eraerbener Eigenschaften. Alloemeine Zeitschr. f. Entomologie, Bd. VI. Igor.

11) Derselbe, Weitere Untersuchungen ïber die Vererbung eraborbener Eigenschaften. Ebenda, Bd. VII. 1902.

11) Fränkel, Karl, Grundriß der Bakterienkunde, 2. Aufl, S. 15I-160. Berlin 1887.

12) Galton, A theory of heredity. The contemporary reviea, Vol. XXVII. I876.

13) Derselbe, Hereditary Genizes, an inquiry into its laves and consequences. Londan 1869.

14) Haeckel, Generelle Norphologie. 1866.

1i) Hensen, Viktor, Über das Gedächtnis. Rektoratsrede. Kiel 1877.

1(i) Derselbe, Die Grundlage der Vererbung nach dem gegentürtigen IVissenskreis. Landwirtsch. Jahrb., Bd. XIV. 1885.

17) Hering, Über das Gedächtnis als eine allgemeine Funktion der organisierteu Materie. Vortrag in der Wiener Akademie 1870. Almanach a. Kaiserl. Akad. d. Wissensch., 20. Johrg. IIjen 1870 .

1i) Hertwig, O., Das Problem der Befruchtung und der Isotropie des Eies, eine Theoric der Vererbung. Jena 1884.

19) Derselbe, Vergleich der Ei- und Samenbildung bei Nematoden. Archiv f. mikrosk. Anat., Bd. XXXVI. 1890.

211) Derselbe, Zeit- und Streitfragen der Biologie. Heft I. Präformation oder Epigenese. Jena 1897.

21) Keller, Vererbungslehre und Tierzucht. Berlin 1895.

2.) Minot Sedgwick, Über die Vererbung und Verjüngung. Biol. Zentralbl., Bd. XV. 1895.

2:') Nägeli, Mechanisch-physiologische Theorie der Abstammungslehre. I88.4.

2) NuBbaum, M., Zur Differenzierning des Geschlechts in Tierreich. Archiv f. mikrAnat., Bd. XVIII. I880.

2.) Derselbe, Beiträge aur Lehre von der Fortpflaniung und Vererbung. Archiv f. mikr. Anat., Bd. XLI.

26) Orth, J., Über die Entstehung und Vererbung individueller Eigenuschaften. Festschrift fïr Albert von Kölliker. Leipzig, 1887.

27) Osborn, Alte und nene Problene der Phylogenese. Merkel-Bonnets Ergebnisse. I894.

24) Pfeffer, w., Pflanzenphysiologie, Bd. I. 1897. Bd. II. 1907.

':1) Roux, Entwicklnngsmechanik. Herkel-Bonnets Ergebnisse der Anat. u. Entreickl., Bd. II. 1893 .

30) Semon, Richard, Die Mneme als erhaltendes Prinzip im IVechsel des organischen Geschehens. Leipzig 1904.

:i1) Spencer, Herbert, Prinzipien der Biologie. Bd. I, S. 258, 276-278. I876.

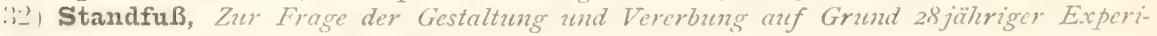
mente, Vortrag. Zïrich 1905.

:i.) Tizzoni u. Cattaneo, Über die erbliche Überlieferung der Immunität gegen Tetanus. Dentsche mediz. Wochenschr., Nr. I8. I802.

:1) Virchow, Dessendens und Pathologie. Virchones Archiv, Bd. CIII. 1887.

(ii) Derselbe, Rossenbildung und Erblichkeit. Bastian-Festschr. I896.

:ii) Weismann, Über die Vererbuns. Jena 1883 .

:-. Derselbe, Die Kontinuität des Leimplasmas als Grundlage ciner Theorie der Vererbung. Jena 1885.

:is Derselbe, Zur Frage nach der Vererbung erworbener Eigenschaften. Biol. Zentralbl., Bit. VI. 1880.

:in, Derselbe, Die Bedeutung der sexuellen Fortpfanzung für die Selektionstheorie. Jena I886. 
40) Derselbe, Amphimixis oder: Die Termischung der Individuen. Jena Jison.

$\$ 1$ Derselbe, Die Allmacht der Naturä̈lutung. Eine Erwiderung an llevert Spencer. lena 1893.

42) Derselbe, lene Gedanken an lierbungsfrage. Jena 1805.

43) Derselbe, Über Germinalseliktion. Extrait du compte remdu des siances du treisieme (ansmers international de zoologie. Le'yde'n $1895,1896$.

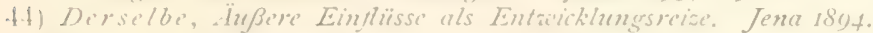

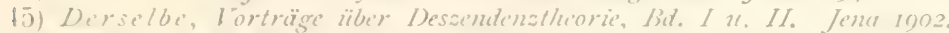

46) Whitman, C. O., Evolution nut Epigenesis.. Jieston 1895.

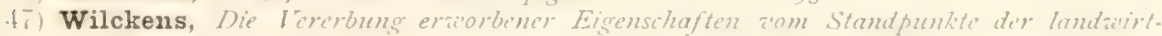
schaftichen Tierzucht in bezug unf Ileismanns Theorie der Vererbuns. Biolog. Zintralbl., lid. WIIl. ISO3.

(4) Yves Delage, La structure du protoplasma et le's théries sur l'hividite et le's grmuls problemes de la binlogie ginerale. T'aris 1895 .

49) Ziegler, Ermst, Sïmen erworbene pathologische Eigenschaften aererbt werden, und wie entstehen erbliche Krankheiten and Mißbildungen? Beiträgè aur pathol. Anatomie 2. Physiologie, Bit. I. 1880.

51) Ziegler, Heinrich, Die Tererbungslelue in dir Biologie. Jena 1005. 


\section{ACHTUNDZWANZIGSTES KAPITEL.}

\section{Ergainzende Betrachtungen.}

\section{Die Biogenesistheorie und das biogenetische firundgesetz.}

In allen unseren Betrachtungen haben wir gleichsam als eine Mabeinheit für die T'ntersuchumg der Organismenwelt die Zelle hingestellt. Sie steht in Mittelpunlt der Theorie der Biogenesis. Auf ihrer Eigenschatt. sich durch Teilung zu rermehren, heruht allein die Kontinuität der Entwicklung. Eingeschohen als Fortptanzungszelle zwischen die aufeinander folgenden Cienerationen sich entwickelnder. funktionierender und wienlel ahsterhenter, vielzelliger Individuen. erhält sie allein den Lehensprozed der „naturhistorischen Art" mit ihren spezifischen Eigenschaften.

Durch dergleichen Erwägungen wurden wir zu dem Begriff der Artzelle geführt, das heift einer Zelle, in deren feinerer (mizellarer) Orannisation die werentlichen Eigenschaften der Art als Bestimmungstüclie. ubbersetzt in das System von Zelleneigenschaften, enthalten sind. Aus so vielen Spezies sich das Pflanzen- und das Tierreich zusammensetzt, ebensoviele Artzellen sind in ihm zu unterscheiden. Sie sind die Repräsentanten der Siezies. deren wesentliche Charaktere in ihnen auf die einfachste Formel gebracht sind.

Aus philosophischen Grïnden, die hier nicht weiter zu erörtern sind, nehmen wir die IIymothese an, dab.) die jetzt lebenden Pthanzen- und Tierspezies die bald mehr. bald minder homplizierten Endprodukte eine- mandlich langen historischen Entwicklungrurozesses sind, in weldhem sich die organische Lebenssubtanz — ich will mich hier eines sehr alloemeinen Ausdrucks bedienen - beginnend mit Zuständen sehr einfacher Organisation, von Stufe zu Stufe allmählich erhoben hat.

Da nun die komplizierteren, vielzelligen Vertreter der Art, die Individuen höherer Ordnung (das Soma WEIsuanss), ihrer Anlage nach schon durch die Organisation der Artzellen bestimmt werden, so müssen die letzteren in der Erdgeschichte ebenfalls eine korrespondierende Entwicklung von einfacheren zu immer komplizierteren Zuständen ihrer feineren Organisation durchlaufen haben. Wie sich ein kleines, gut angelegtes Kapital durch Zinsen vermeliren und ins ungemessene vergrößern kamn, so wächst auch die in der Artzelle eingeschlossene Erbmasse, mit kleinen Anfängen begimmend, indem von Generation zu Generation Eigenschaften, welche im

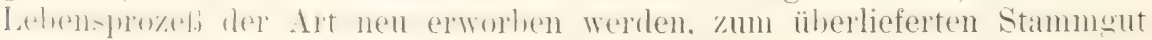
himzugeschlagen werden. 
In diesem Simne spricht auch NïGELI ,von einer Geschichte des

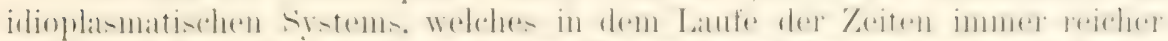

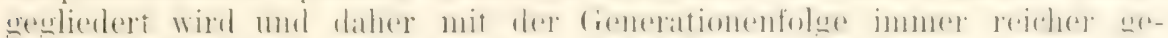

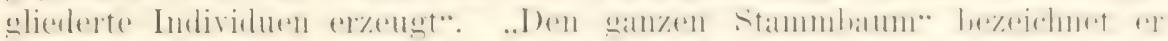

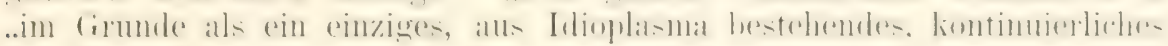
Individum, welches wïchst, sich vermehrt und dabei verïnlert, und welches mit jeder Generation ein neues Kleid anzieht, d. h. einen nenen individuellen Leib) bildet. Es gestaltet sich dieses Kleid, entsprechend semer eigenen Veränderung, periodisch etwas anders und stets mannig-

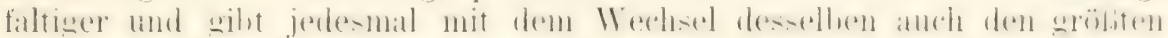
Teil seiner eigenen Substanz preis."

Unsere Lehre, daßs die Artzelle ebenso wie der aus ihr sich entwickelnde. vielzellige Repräsentant der Art im allgemeinen eine fort-

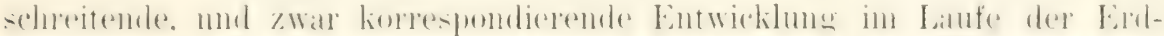

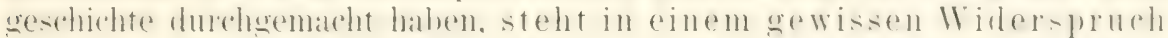
zu dem „biogenetischen Grundgesetz“. Nach der von HaEckex

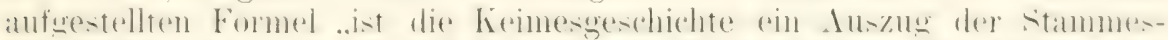

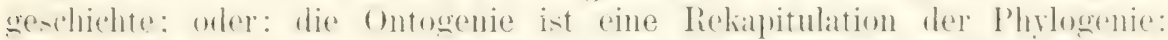

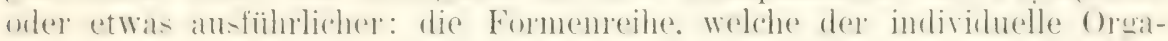
nismus während seiner Entwicklung von der Eizelle an bis zu seinem

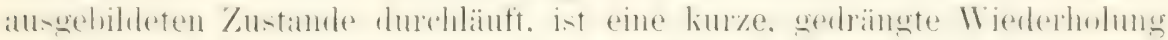
der langen Formenreihe. welche die tierischen Vorfahren desselben Organismus oder die Stammformen semer Art von den ältesten Zeiten der

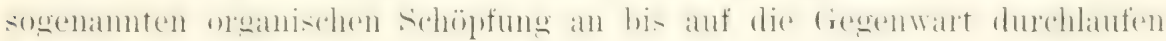
haben."

HAECkEL läßt den Parallelismus zwischen beiden Entwicklungsreihen allerdings , dadurch etwas verwischt sein, (lab) meistens in der

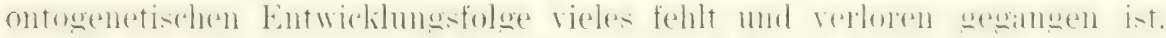

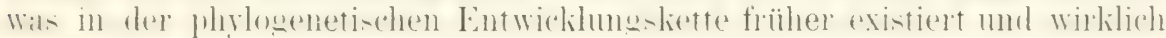
gelebt hat".

.Wenn der Parallelismus beider Reihen"*, bemerkt er ..vollständig wäre, und wenn dieses große Grundgesetz von dem Kausalnexus der Ontogenese und Phylogenie im eigentlichen Sime des Wortes volle und unbedingte (ieltung hätte, so würden wir blob mit Hilfe des Mikro-

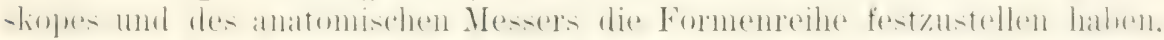
welche das befruchtete Fi des Menschen bis zu seiner vollkommenen

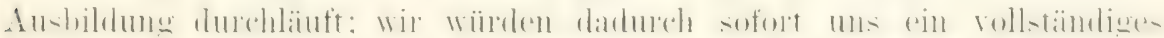

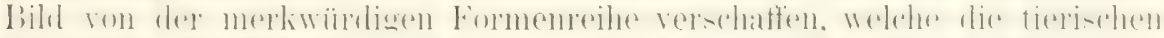

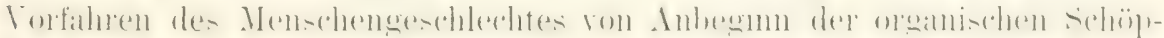
fung an bis zum ersten Auftreten des Menschen durchlaufen haben. Jene

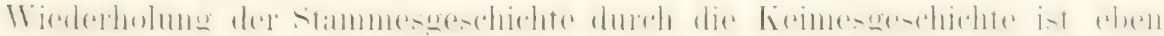
nur in seltenen Faillen ganz vollsändig und entspricht nur selten der ganzen Buchstabenreihe des Aphabets. In den allermeisten raillen ist viehmehr dieser Auszug sehr unvollständig, vielfach durch Ursachen, die wir später kemmen lernen werden, verändert, gestört oder gefälscht. Wir sind daher meistens nicht imstande, alle verschiedenen Formzustände. welche die Vorfahren jedes Organismus durchlaufen haben, umnittelbar durch die Ontogenie im einzelnen festzustellen; vielmehr stofien wir gewöhnlich auf mannigfache Lïclien."

Die Theorie der Biogenesis macht an der von HAECKEL gegebenen Fassung des biogenetischen Grundgesetzes einige dbänderungen und erläuternde Zusätze notwendig. Wir müssen den Aushluck: ., Wielerholung von Formen ausgestorbener Vorfahren" fallen lassen und dafiir setzen: 


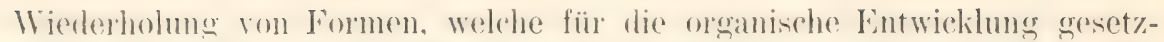
mïlige sind und rom Einfachen zum Komplizierteren fortsehreiten. Wir miissen den siohwerpmbt darauf legen, dal.s in den embryonalen Formen whenso wio in den ausgebildeten Tierformen allgemeine besetze der Entwicklung der oreanisierten Lebenswustan\% zum Ausdruck kommen.

Nehmen wir, um unsern Gedlankengang klarer zu machen, die Eizelle. Indem jety die Entwioklung aines jeden ()ranismus mit ihr beginnt, wird keineswess der alte L'mustand rekapituliert aus der Zeit. wo vielleicht nur einzellige Amöben auf unserem P'laneten existierten. Denn nach unserer Theorie ist die Fizelle zum berispiel eines jetzt lehenlen Süugetieres kem einfacher und indifferentes. hestimmungsloses Gehilde, als welches sie nach dem hiogenetischen (irundgeset\% betrachtet werden mübte: vielmehr erblicken wir in ihr das anderordentlich komplizierte Fudprodukt eines sehr langen historischen Entwicklungsprozesses. Welchen die organisierte Substanz seit jener hypothetischen Epoche der Einzelligen durchgemacht hat.

Wenn schon die Eier eines Säugetieres von denen eines Reptils und eines Amphibiums sehr wesentlich vershieden sind. weil sie ihrer sanzen Organisation nach nur die Anlagen für ein Säugetier, wie diese für ein lieptil oder an Amphibimn, reprïsentieren, um wie viel mehr müssen sie verschierlen sein ron jenen hypothetischen einzelligen Amöhen, die noch keinen andern Erwerb aufzuweisen hatten, als nur wieder Amöben ihrer Art zu erzeugen!

Allgemein ansgedrückt, beginnt der Fntwicklungsprozel, hei der Entstehung eines vielzelligen ()ranismus nicht da. wo er vor Trzeiten eimmal begomnen hat, somdern er ist die unmittelhare Fortsetzung des höchsten I'unktes, his zu welchem die orwanische Entwicklumg his jetzt geführt hat.

Mit der Zelle nimmt die Ontogenese für gewöhnlich wieder ihren Anfang, weil sie die elementare Grundform ist, an welche das organische Leben beim ZeugungsprozeB gebunden ist und weil sie für sich schon die Eigenschaften ihrer Art „(ler Anlage nach" repräsentiert und, losgelïst von der höheren Individualitätsstufe, die aus der Vereingung von Zellen hervorgegangen ist, wieder imstande ist, das Ganze zu reproduzieren.

Die Eizelle ron jetzt und ihre einzelligen Vorfahren in der Stammesgeschichte, die Amöben, sind nur, insofern sie unter den gemeinsamen Begriff der Zelle fallen, miteinander vergleichbar, im ührigen aber in ihrem eigentlichen Wesen auberordentlich versohieden roneinamder. Denn dis Idioplasma jener Amöhen — so müssen wir schliegen muf noch von einer relativ sehr einfachen mizellaren Organisation sein. da es nur wielle Amöben hervorzubringen die Anlage hat; die Eizelle rines Siugetieres daweren ist rine hoch komplizierte Anlagesubstanz, wie früher zu begründen versucht wurde.

Man mub in der Artentwicklung zwei verschiedene Reihen von Vorgängen auseinander halten:

1. Die Entwicklung der Artzelle, welche sich in einer steten, fortschreitenden Richtung von einer einfachen zu einer komplizierteren Organisation fortbewegt:

2. die sich periodisch wiederholende Entwicklung des vielzelligen Individum a dus dem einzelligen Repräisentanten der Art oder die einzelne Ontogenie, die im allgemeinen nach denselben liegeln wio in den vorausgegangenen Ontogenieen erfolgt, aber jellsmal ein wenigmodifiziert. entsprechend dem Betrag. um welchen sich die Artzelle selbst in der Erdgeschichte verändert hat. 


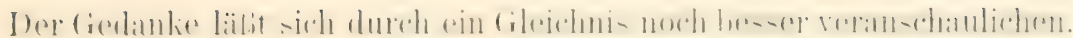

Die Zelle nimmt im Verhältnis zu dem aus ihrer Vereinigung ent-

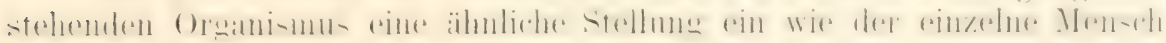
zum statlichen Organismus. Wie die Zelle, so kann auch ein einzelnes,

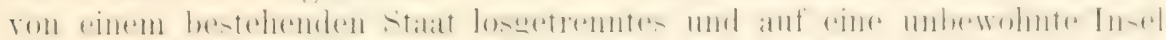

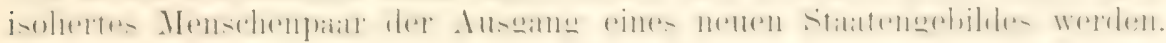
Dieses wirl bei (ileichheit der äulieren Falitoren doch sehr versehieden

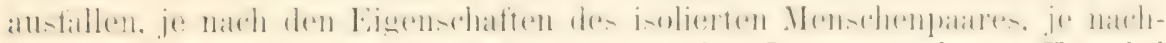
dem es der schwarzen, der roten oder weißen Rasse angehört. Es wirl aber auch verschieden ausfallen, wenn die Isolierung an Gliertern ein und

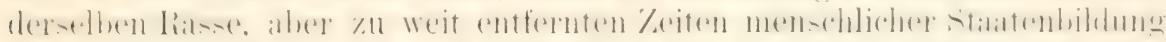
vorgenommen wurde. Ein Vorfahre aus einer zweitausendjührigen Ver-

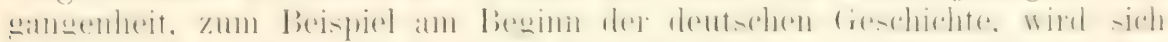
auf der unbewohnten Insel in anderer Weise einzurichten beginnen, als ein jetzt lebender Vertreter derselben Rasse, der eimen groben 'Teil der

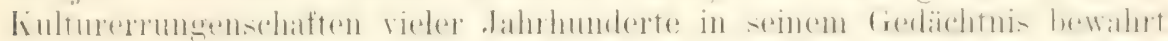
und sie zum 'Teil wieder seiner Deszendenz überliefert. In beiden Fällen

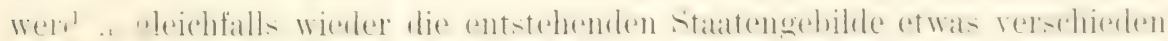
ar stajen mïssen. weil thre Ausgangspunkte verschieden waren, weil die

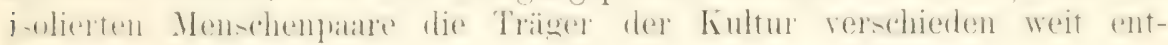
vickelter Gemeinschaften waren, von welchen sie abgelöst wurden.

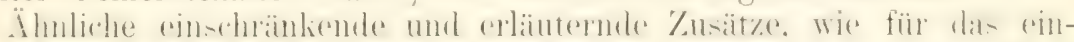

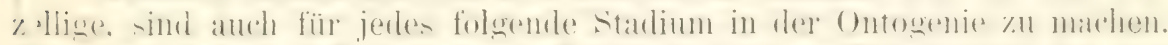

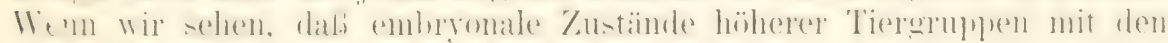
ausge!ildeten Formen verwandter, aber im System tiefer stehender Tier-

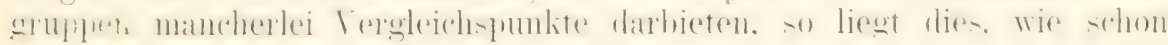
C. E. Y. b:ER richtig hervorgehoben hat, daran, ,dal die am wenigsten

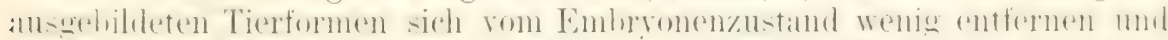

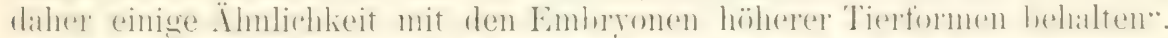

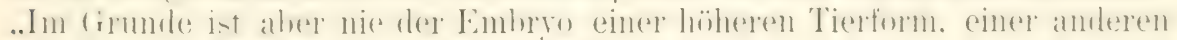
'Tierfor'm gleich:" (BAER, 1828, p. 22t).

Wemn ein Systematiker einen einfachen Hydroidpolypen und die nur

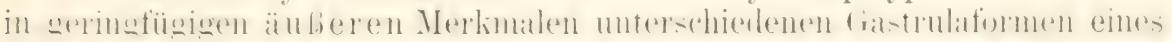

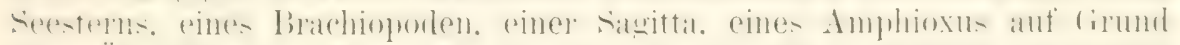

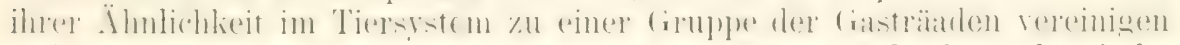
wollte. so wïrde er handeln wie ein Chemilier. der verschieclene chemische

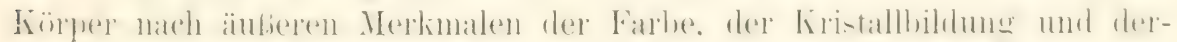

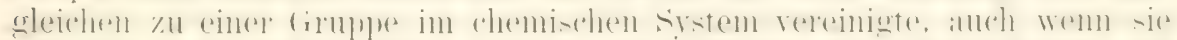

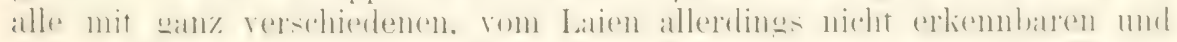
auch nicht nachzuweisenden Molekularstrulituren versehen sind. Wie in

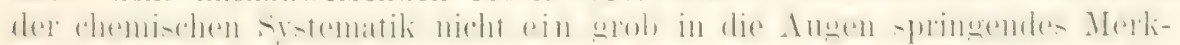

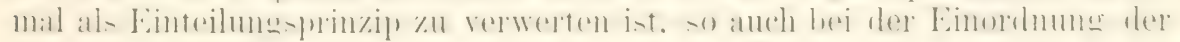
äuferlich einander ähnliohen Gastrulaformen. Dem die Gastrulae eines

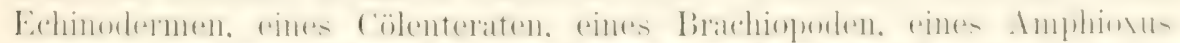

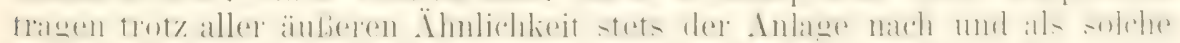
für uns nicht erkennbar die Nerkmale ihres Typus und ihrer Kilasse an sich, nur noch im unentwickelten Zustand: alle Gastrulastadien sind also in Wahrheit ehenso weit vonemander unterschieden. wie die nach allen

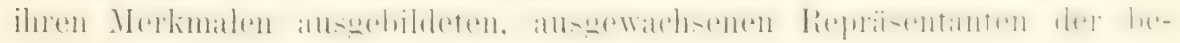
treftenden Art.

Dab gewisse Formzustände in der Entwicklung der verschiedenen Tierarten mit so grober Konstanz und in prinzipiell iibereinstimmender Weise wiederkehren, liegt hauptsächlich 
daran. dab sic unter allen Verlältnissen die notwendigen Vorbedingungen liefern, unter denen sich allein die folgende höhere Stufe der Ontogenese herrorbilden kann.

Der einzellige Organismus kanm sich seiner ganzen Natur nach in einen vielzelligen Organismus nur auf dem Wege der Zellenteilung umwandeh. Daher mula bei allen Lebewesen die Ontogenese mit einem Furcliungsprozeb beginnen.

Aus einem Zellenhaufen kann sich ein Organismus mit bestimmt

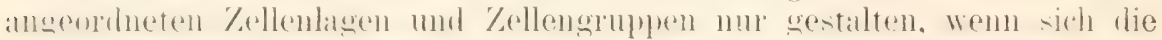
Zellen bei ihrer Vermehrung in feste Verbände zu ordnen beginnen und

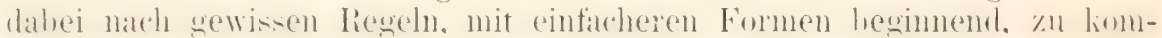
plizierteren fortschreiten. So setzt die Gastrula als Vorbedingung das einfachere Kleinblasenstadium voraus. So müssen sich die Embryonalzellen erst in Keimblätter anordnen, welche für weitere in ihrem Bereich

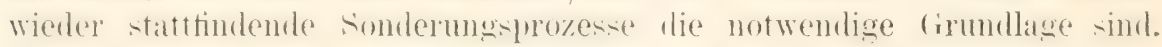
Die Anlage zu einem Auge kamn sich bei den Wirbeltieren erst bilden,

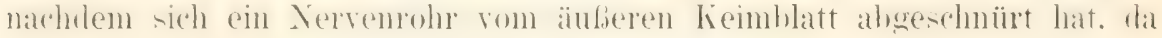
in ihm das Bildungsmaterial für die Augenblasen mit enthalten ist.

So führt uns die Vergleichung der ontogenetischen Stadien der verschiedenen Tiere teils untereinander, teils mit den ausgebildeten Formen niederer Tiergrupen zur Erkenntnis allgemeiner Gesetze, von welchen der Entwicklungsprozef der organischen Materie beherrscht wird. Bestimmte Formen werclen trotz aller beständig einwirkenden, umändernden Faktoren im Entwick-

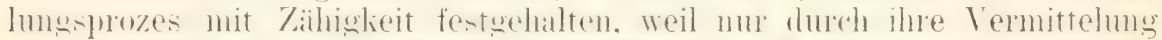

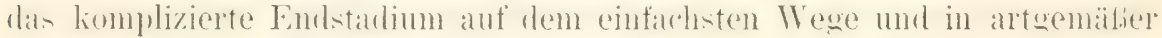
ITeise erreicht werlen kann.

Endlich muf zux richtigen Beurteilung ontogenetischer Gestaltungen stets auch beachtet werden, dab, äufere und innere Faktoren auf jerle

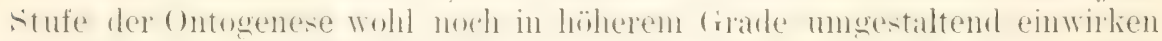

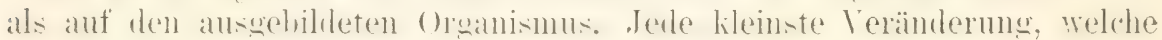
auf cliese Weise am Beginn der Ontogenese neu bewirkt worden ist, kam der Anstol, sem für immer angenfälligere Formwandlumgen auf späteren Stufen.

So sehen wir, wie die Masse des Deutoplasmas und seine Verteilung

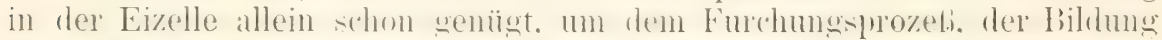

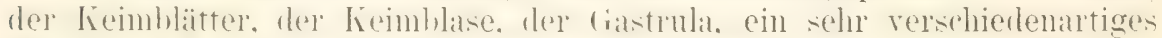

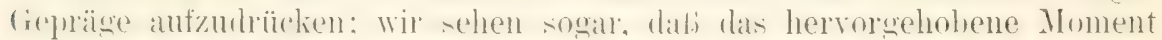

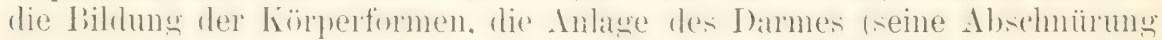
vom Dottersack, die Anlage des Herzens aus zwei Hälften bei den meroblastischen Eiern etc. etc. bis in weit vorgeruickte Starlien der Ontogenese auf das nachhaltigste beherrscht. Ferner kann der Embryo durch Anpassung an besondere Bedingungen des embryonalen Lebens, welche vorübergehender Natur sind, Organe ron ebenfalls vergänglicher Natur ge-

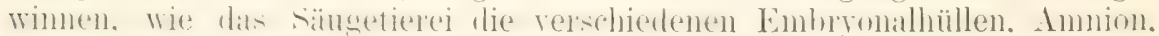
('horion und I'ladental dureh Anpa-sumg an die liedingmen, welche der längere Aufenthalt in der Gebärmutter mit sich bringt.

In dieser und anderer Weise kömnen in die Ontogenese ganz neue Gestaltungen gewissermaßen eingeschoben werden (Caenogenese ron IIAE(ket), fietaltungen. Welche in der Vorfahrenliette als ausgeloblete \%unamble nicht existient hahen mul ihrer Satur nath nicht hahen exi-tieren können. 
Überhaupt ist bei der Vergleichung ontogenetischer Stadien mit vor-

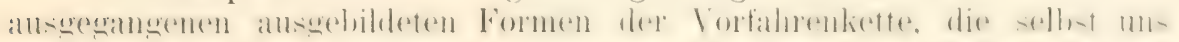

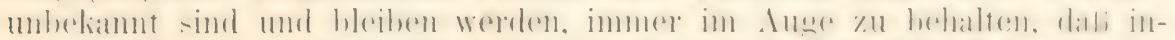

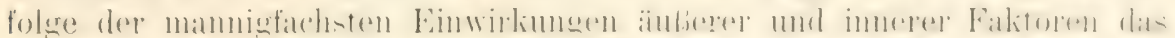

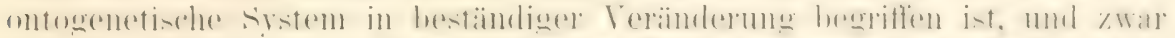

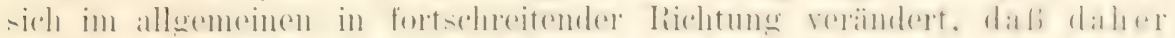
in Wirklichkeit ein späterer Zustand niemals mehreinem vorausgegangenen entsprechen kann.

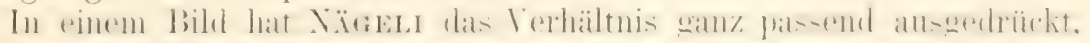

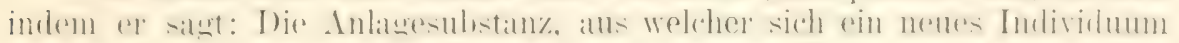

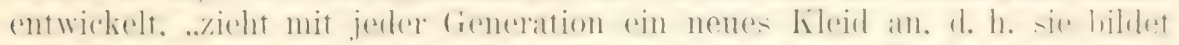

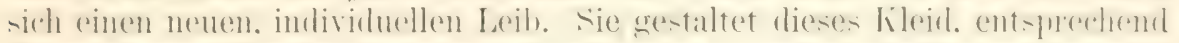

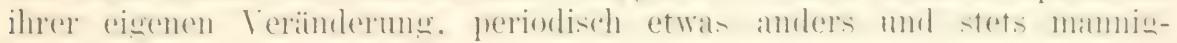
faltiger aus."

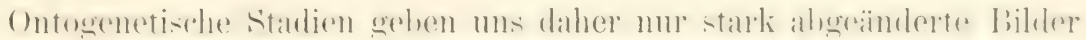
von Stadien, wie sie in der Vorzeit eimmal als ausgebildete Leberesen

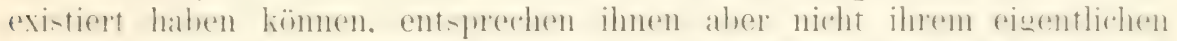

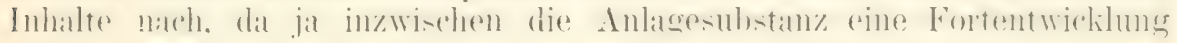
erfahren hat.

\section{Zusatz 1 .}

Den Widerspruch, welchen man zwischen der Theorie der Biogenesis und dem biogenetischen Grundgesetz konstruieren kann und welchen wir durch unsere Erläuterungen zu demselben wohl beseitigt haben, hat WEIsMANN auch der Idioplasmatheorie von NïGELI vorgeworfen. ,Geradezu als ein Widerspruch mit sich selbst", bemerkt er, ,erscheint die NïgeLIsche Annahme, wenu man bedenkt, dak el das «biogenetische Grundgesetz" anerkennt, in den Stadien der Ontogenese somit eine abgekïrzte Wiederholumgr der phyletischen Entwicklungsstadien sieht und nun doch die einen aus einem andern Prinzip erklärt als die anderen. Die Stadien der Phylogrenese beruhen nach NïGELI auf wirklicher, qualitativer Verschiedenheit des Idioplasmas; das Keimplasma also z. B. eines Wumes ist qualitativ rerschieden von dem des Amphioxus, oder des Frosches, oder des Süugetieres. Wem aber derartige phyletische Stadien in der Ontogenese einer einzigen Art zusammengedrüngt vorkommen, sollen sie nur anf verschiedenen "Spannungs- und Bewegungszustanden » ein und desselben Idioplasmas beruhen! Ich gestehe, mir scheint es ein zwingender Schluf, daf, wenn ïberhaupt das Idioplasma im Laufe del phyletischen Entwicklung seine spezifische Beschaffenheit allmählich ündert, diese Veränderungen auch in der Ontogenese durchlaufen werden müssen, soweit dieselbe phyletische Stadien wiederholt.

IIan fragt sich unwillkïlich, wie ein so scharfsinniger Deuker wie NïGel dazu kommt, einen solchen Widerspruch nicht zu sehen."

Ich glaube nachgeriesen zu haben, daß weder von NïgELIs, noch von meiner Seite ein WViderspruch vorliegt, sofern man nur das biogenetische Grundgesetz von dem richtigen Gesichtspunkt aus betrachtet.

\section{Das Prinzip der Progression in der Entwicklung.}

Von mehreren Naturforschern, vor allen Dingen auch von NÄGEL.

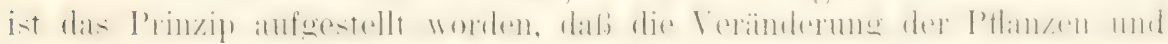
Tiere lieine beliebige odler ricitungslose sei.

"Sowie die Entwicklungsbewegung einmal im (zange ist," bemerlit Nïgeli, ,so kamn sie nicht stille stehen, und sie muß in ihrer Richtung 
heharren. In habe dies frïher das Vervolliommmungsprinzip genannt, nuter dem Vollkmmeneren die zusammengesetztere ()ranisation rerstehend. Minder IV eit-ichtige hahen darin Mrstik finden wollen. Es ist aher mechanischer Natur und stellt das Beharrungsgesetz im Gebiet der organtichen Entwicklung dar. Vervollkommmung in meinem Simne ist also niehts anderes als der Fortschritt zum komplizierteren bau und zu gräborer T'rilme der Arbeit und wïrle, da man im allgemenen geneigt ist, dem Worte mehr Bedeutung zu gewähren als dem ihm zugrunde liegenden liegritt, vielleicht hesser durch das unverfügliche Wort Progression»ersetzt. ${ }^{6}$

Von darwinistischer Seite ist NïGELIS ,Vervollkommmungsprinzip" orlel das „Prinzip der Progression", welches C. E. v. BAER mit einem weniger geeigneten Namen auch ..Zielstrebigkeit" genannt hat. vielfich angexriffen und als eine teleologische und nicht naturwissenschaftliche duffassungsweise getaclelt worden.

Ich kann dem Tadel nicht beipflichten, möchte aber, indem ich das "P'rinzip der Progres,ion" ammehme, ihm eine etwas andere Fassmg gehen. als es durch NäGELI erhalten hat.

Wie ich bei meiner Darstellnng öfters hervorgehoben habe, muß bei der kausalen Erkbärung des Entwicklumgsprozesses der volle cirumd für jerle Erscheinung stets in dem Zusimmenwirken innerer mol äberer Faktoren gefunden werden. In diesem Simme bemerkte ich:

„Der Entwicklungsprozeß, um verstanden zu werden, muß erfaßt werden als ein kleines Stückchen des Naturverdaufs, das will heiben: Das Fi entwickelt sich in ummittelharstem Zusammenhang, in steter Fühlung mit dem Naturganzen, unter Benutzung der as umgehenden Aulienwelt. Stoff und Kraft treten beständig in dasselbe aus und ein."

Daher halte ich es für richtiger, das Prinzip der Progession auf den Trelauf des Naturprozesses, dessen orumisiertes Substrat eine hestimmte Organismenart ist. anzuwenten. Bei dieser Fassung hängt die bestimmte Richtung des Verlaufes von dem Zusammenwirken innerer und äuberer Lrsachen ab; doch wird auch hierbei, was NäGELI besonders im Auge hat, die Eigenart des Prozesses in überwiegendem Maße von der organisierten sulstanz selhst, als dem liomplizierteren, mithin von inneren Irrsachen bestimmt.

Das Verhältnis ist in jeder Beziehung ein ähmliches, wie bei einer irgendwie komplizierter gebauten Maschine, hei welcher zwar die Triebliatte von anden geliefert werlen, die Figenart ihrer Leistung aber von inneren Ursachen, nämlich von ihrer Konstruktion, abhängt.

Das wunderbarste Beispiel eines mit Progression einhergehenden Entwicklungsprozesses ist jede Ontogenese aus dem Ei. Denn jedes Stadium ist fïr das nächstfolgende die Anlage, welche unaufhaltsam zu ihrer Verwirklichung drängt, sowie auch die äuleren Bedingungen. Luft. Wïme. Nalnumg. gewiscrmaljen die Letrielsmittel des Prozesses. gegeben sind. Selbst kleine Störungen können den Prozeß in seiner Progression nicht aufhalten. dia -io durch vielerlei Mittel ïherwunden und ausgeglichen werden, so daß der Gang der Entwicklung doch immer wieder in die durch die Anlage vorgezeichnete Bahn zurürlgeführt wird mol seinem

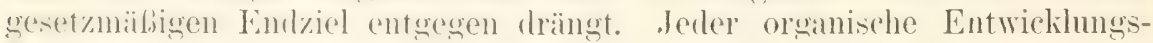
prozeß zeigt uns, wenn wir in sein Wesen tiefer einzudringen versuchen, ein außerordentlich großes „Beharrungsvermögen“.

sollte nirht in dermelhen Weise. wie der vielzellige organismus durch Fingenese ans den Fi, aluch die naturhistorische drt, wenn wir uns auf 
den lionlen der I)

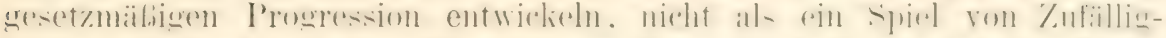

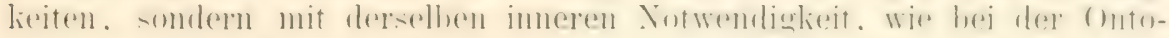
genese aus der Blastula die Gastrula hervorgehen mul?

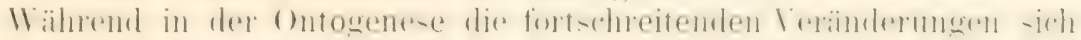
sehr rasch vollziehen, ist die Progression in der Phylogenese an sehr

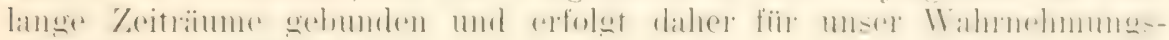
rermögen unmerklich.

Befunde der Paläontologie sprechen, wie ron Osionx hesonders hervorgehoben wird, zugunsten der NïGELschen Theorie.

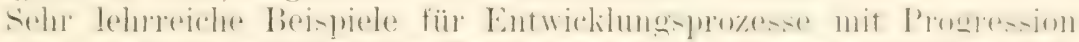

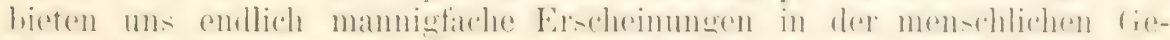
sellschaft.

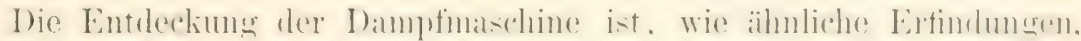

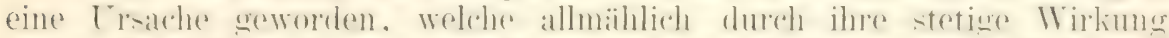

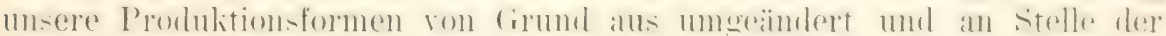

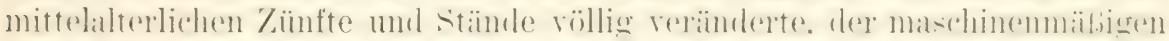

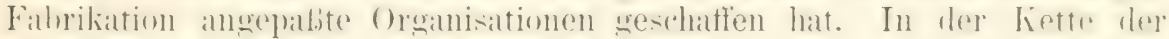

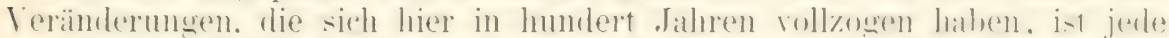

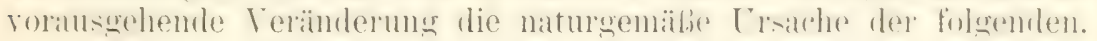

Ebenso ruft jede neue wichtige Erfindung auf dem Gebiete des Verliehrswesens mol der Teehnili nene Differenzierungen. nene limmpliziertere (iestaltungen in der menschlichen fiesellschaft herror. Prozesse. Welche sich langsim. aber stetig. nach einem Endziel gerichtet, mit Xaturnotwendigkeit vollziehen.

Die menschliche diesellschaft lirgt daher in ihrer jetzigen struktur

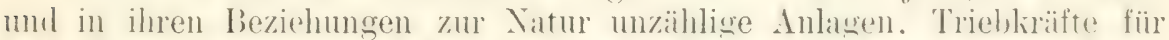
zukïnftige (iestaltumgen in sich. Wie der fendale Stat ans semem scholij in steter Progresion den molernen stat erzengt hat, so trä̈st die-er wieler die Bedingungen in sich. aus denen sich ju allmählichen 11 andel. nicht als ein Produlit von Zufülligheiten. somlern narlo tiesetzen sozialer Entwirklung, die näbhste Stufe staatlicher Organisation gestalten wirk.

\section{Literatur zu Kapitel XXVIII.}

1) v. Baer, Karl Emst, Über Entrickinugsgeschichte der Tiere. Biobachumo unt Reflexion. 1828 .

2) Haeckel, Inthropogenie oder Entricklnugsgeschichte des llenschen, t. Anh. ISOT.

3) Hertwig, Richard, Lehrbuch der Znologic, t. Auft., S. f4- 75.1897.

4) Mehnert, Bionechanik erschlossen ans dem Prinzip dor Organogenese. Jina I\$88.

5) Nägeli, Alechanisch-physiologische Theorie der Abstammungslehre. 1884.

6) Osborn, Alte und newe Probleme der Phylogenese. Herkel and Bonnets Er-sebnisse, Bd. III. I804.

7) Weismann, Die Kontinuität des Keimplasmas als Grundlage ciner Theorie dir Ter. erbung. Jena 1885 . 


\section{NEUNUNDZWANZIGSTES KAPITEL.}

\section{Erklärung der Unterschiede pflanzlicher und tierischer Form durch die Theorie der Biogenesis.}

IBei der Erlkïrung der Form, welche der einzelne Organismus während der Entwicklung allmählich annimmt. kommen drei Grupen ron Falitoren in Betracht:

1. rlie mit zahlreichen spezitischen Figenschaften ausgestattete organisierte Substanz der Keimzelle:

2. die nicht minder zahlreichen Faktoren der Außenwelt, unter deren Einwirkung die Entwicklung der so andierordentlich reizemptindlichen Substanz vor sich geht;

3. die Korrelationen, welche sich zwischen den einzelnen Teilen des wachsenden Zellenaggregates auf jeder Stufe der Entwicklung in immer wöforer Zahl uml Jamnigfaltigkeit notwendigerweise anshilden. Pei konsequenter Prüfung der (lrei Gruppen von Faktoren wird uns sellost der grolie (iegensatz eingermalien begreitlich, der zwischen pttanzlicher und tierischer Form besteht. Er läßt sich zu einem großen Teil wenigstens auf einige wenige Grundursachen, welche die ganze Gestaltbillumg hei der Entwicklung his in ihr Imnerstes beeinflusen. zurärliführen. nämlich anf die Verschiedenheit des ptanzhichen und tierischen stoffwechsels und der pflanzlichen und tierischen Nahrungsaufnahme.

\section{Die Formbildung bei den Pflanzen.}

Die Pflanzenzelle erzeugt vermittelst des ihr eigentümlichen Chlorophyllaplanates orsanische Sub-tanz ans Kohlensäme, die sie aus der Luft hezieht, sowie ans Wasser und leicht diffundierenden Salzlösmugen, die sie

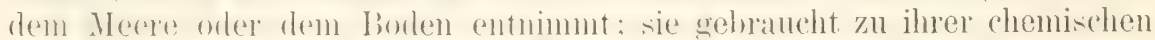

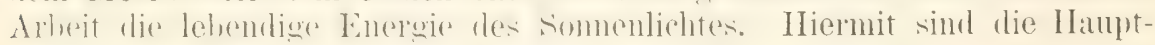

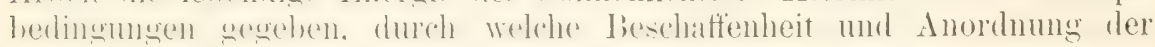
Elementarteile in einer vielzelligen PHanze bestimmt werden.

Die Pflanzenzellen können sich infolgedessen zum Schutze des weichen Protoplasmakörper's mit einer dicken und festen Membran umhüllen, weil sie für den Durchtritt ron Gasen und leicht diffundierenden Salzen kein

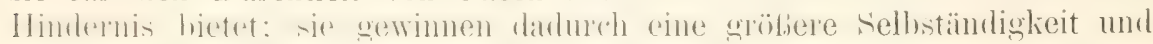
Abgeschlossenheit gegeneinander und werden fü eine große Anzahl von Differenzierungen ungeeignet, wie für Bildung von Muskel- und Nervenfihrillen: dawexen kïmmen tierische Zellen solche erzengen, weil sie wegen

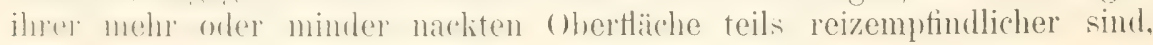




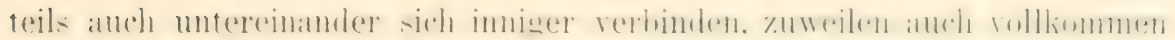
verschmelzen können.

Der Natur ihres Stoffwechsels entsprechend müssen sich ferner PHanzenzellen bei ihrer Vermehrung zu umfangreicheren Aggregaten so anordnen. daß sie mit den umgebenden Medien, aus denen sie Stoff' und Kraft beziehen, mit Erde und Wasser, mit Luft und Licht, in möglichst

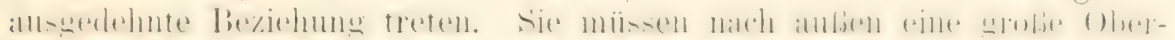
Häche entwickehn. Dies geschieht, inden sie sich zu Füilen, die sich vielfach verzweigen, oder in der Fliche zu blattartigen Organen anorinen.

Lim aus dem Boden Wasser und Salze aufzusaugen, verbinden sich

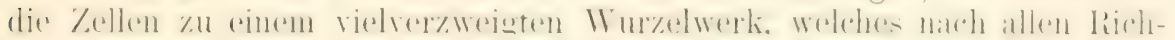
tungen hin die Erde mit feinen Fädchen durchsetzt.

Um Kohlensäure der Luft zu entziehen und die Einwirkung der

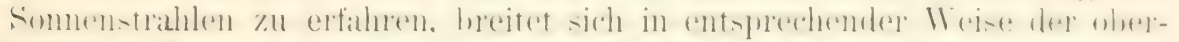

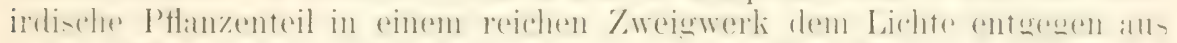

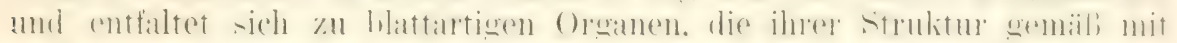
dem Assimilationsprozel betraut sind. Es wird daher die ganze Formbildung der Pflanzen auf Grund der oben hervorgehobenen wirkamen Faktoren eine nach außen gerichtete und äuberlich sichthare.

Einen entsprechenden Gedankengang finden wir schon von JuLrus

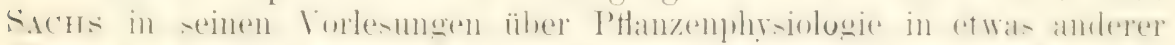
II

.Zwischen den Eigenschaften des Chlorophylls und der gesamten

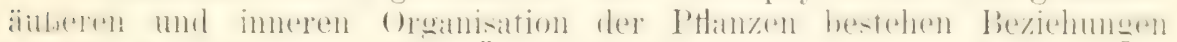
in der Art, daß man ohne Übertreibung behaupten kann, die gesamten

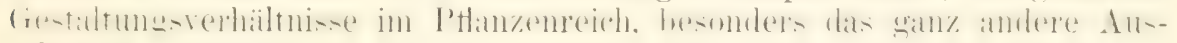
sehen der PHanzen im Vergleich zu dem der Tiere. beruhe auf den Eigenschaften und den Wirkungen des Chlorophylls."

..Die Erfahrung lehrt. daß schon eine sehr dïnne Schicht von chloro-

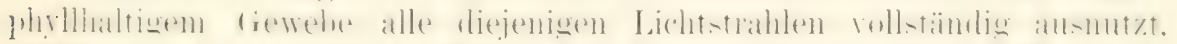

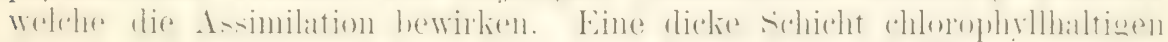
Gewebes hat daher gar keinen Zweck, ja sie wäre eine Stoffiverschwendung

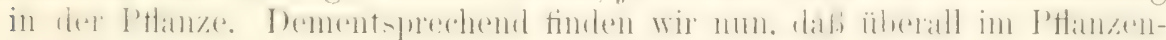
reich nur sehr düme Schichten von grünem Assimilationsgewebe zur V'errendung liommen, Schichten von ein oder einigen zehnteln Millimeter Dicke. Dagegen ist es für eine kräftige, ausgiebige Assimilation oder Er-

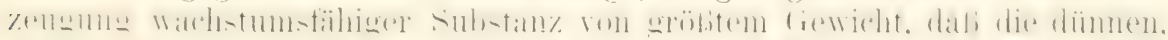

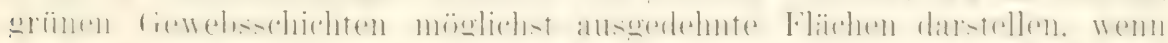

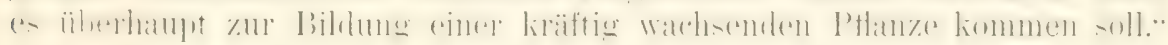

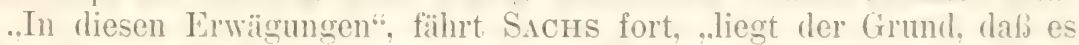

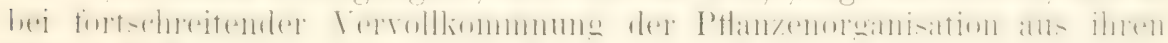
ersten Anfïngen vor allem darauf ankommen mufte. Organe herzustellen.

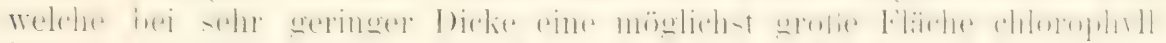
haltigen Gewebes besitzen. Bei niederen Algen wird dies dadurch erreicht. dab sie die Form haardünner, langer Fäden oder aber schr dümmer, Hacher Lamellen, anmehmen, so daß in beiden Fällen das Körpervolumen im Verhältnis zu seiner Fläche ein sehr geringes bleibt."

..Allein viel volliommener wird der genannte Zweck erreicht. wenn sich die Sprosse in Blätter und Achsenteile difterenzieren. Was schon läufig genug bei Algen, ganz allgemein bei den Laubmoosen und Crefülptlanzen einzutreten pflegt. Dadurch wird es dem Sprolisstem möglich. eine große 'Zahl chlorophyllhaltiger, dünnel Iamellen in zweckmäliger 


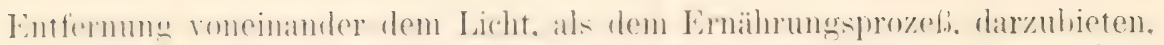

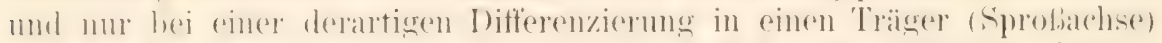
und ans ihm hervortotende. chlorophyllhaltuge Lamellen (Blätter) schwingt

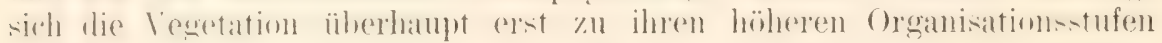
und ganz besonders auch zu mächtigen, das trockene Land bewolmenden Formen empor, wie sie uns in den groben Farnen, Palmen, Koniferen, Laubhölzern und dikotylen Stauden bekannt sind. Wie sonst könnte das Problem gelöst werden, eine kaum $0,2-0.3 \mathrm{~mm}$ dicke Schicht von

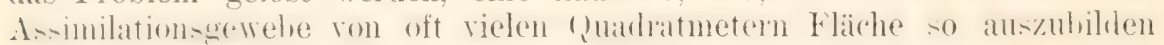

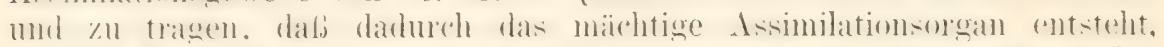
wie wil on in der tancendhlätterigen lammlirone einer liuche oder Eirhe. in den wenigen, aber großen Blättern einer Banane oder Palme vorfinden."

„Die Pflanzenwelt, soweit sie durch grïnes Gewebe sich selbständig emährt, wird ganz und gar in ihrer (xesamtform von dem Prinzip beherrscht, an relativ dünnen Trägern oder Sproßachsen möglichst zahlreiche. möglichst diume und grobe. ariune Flïchenorwane (Blïtter) zu entwirkeln. Der daraus entspringende. im allgemeinen so überaus graziöre Wuchs der dhlorophyllhaltigen P'tlanzen wird also eben durch ihren chlorophyllgehalt hervorwerufen. weil die Tätigkeit des Asimilationsparenehyms nur in diesem Fall zu voller Geltung kommt. Den Gegensatz bieten uns sofort die nicht chlorophyllhaltigen P'tlamzen. die Fruchthörper der I'ilze und die phanerogamen šchmarotzer und Humushewohner. Gerarle der Mangel des chlorophylls ist es. der hier die Flächenaushreitung in Form von wrolien libuttern ïberhaunt überthüs-ig macht: die rorwiegend als surndisachen entwickelten Pthanzenkörper erscheinen daher nackt, feist, plump und ungraziös."

Während die ganze Formbildung der chlorophylführenden Pflanzen infolge ihres eigenartigen Stoffwechsels eine nach außen gerichtete und äuBerlich sichtbare wird, fehlt ihnen im Gegensatz zur tierischen Organisation eine nach innen gerichtete Differenzierung in Organe und Gewebe entweder ganz oder bleibt eine relativ beschränkte. Wo sie aber auftritt, läßt sie ganz deutlich wieder den direliten Einfludi ändierer Faktoren und die Bedeutung der Wachstumskorrelation für die Erklärung der Ptlanzenformen erkennen.

Wegen ier Verschiedenheit des umgrehenden Merliums erhalten die meer- mil die landhewohnenden Pflanzen, einerseits die Algen. andererseits die Phamerowmen. sehr deutlich ansgeprägte Gegensätze in ihrer inneren ()ranisation, mol zwar besonders in der Aushildung zweier (rewebe, eines mechanischen und eines die Zirkulation vermittelnden.

Bei den Algen, deren Körper nahezu das gleiche Gewicht wie das Was-er hat. liommt es nicht zur Au-bildmo hesonderer mechan ischer (iewele da die surose mol biatter sidh flottierend und schwehend im IV a-.-er erhalten unl ihnen die Zellulosememhranen der einzelnen Zellen eine genügende Festinlieit unter ihren Lehenshedingungen geben. Bei den P'hanerogamen dagegen mulich in demsellon Mabe als sie eine heträhtlichere diöbe areichen und sich üher die Erde erhehen. indem sie ihre as-imilicremben Chlorophylltächen dem Lichte und der Luft entgegentragen. ein stïtzendes fiewelie entwiclieln. mäichtiger in den Hauptästen, schwächer in den Blättern. doch immerhin so, daß die dünne Chloroblyllnatte durch ihre Vervatur wie durch feine speichen flach ausgehreitet erhalten wird. 
Derselbe Gegensatz zeigt sich in der Ausbildung eines der Zirkulation dienenden (rewebes.

Bei den Phanerogamen treten ober- und unterirdische 'l'eile in

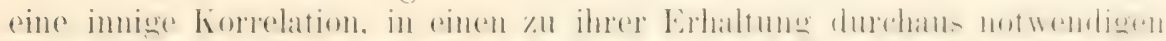

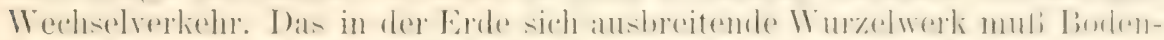

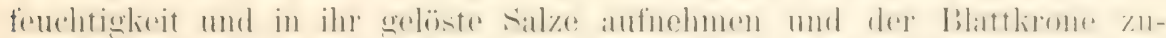
fühluen. wo Wasser in der trockenen Luft verdunstet wird und die Salze

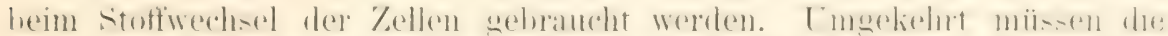
von den Blättern assimilierten Stoffe aus den früher erörterten Gründen

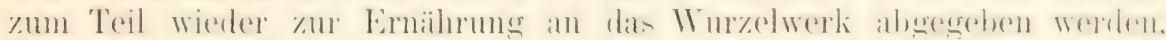

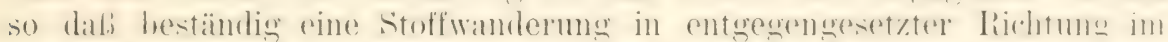
Pflanzenkörper vor sich geht. Um den Säftestrom zu vermitteln, ent-

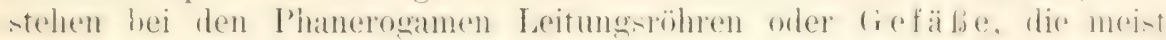
mit den mechanischen Geweben zu Strängen vereinigt sind (Fig. :316 bis $: 318$.

Bei den meerbewohnenden Algen dagegen unterbleibt eine derartige Differenzierung. da es an der Vorbedingung hierzu, an einem

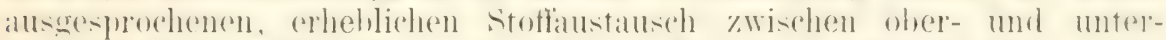

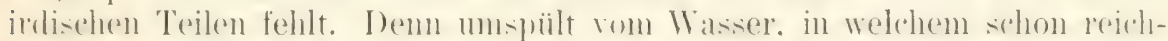

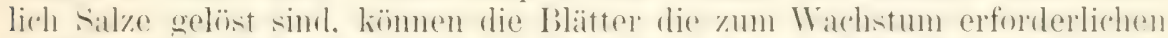
stotfo gleich direlit anfnehmen. Fnol da anch die Wasselahgahe dureh Verdunstung wegfïlt, ferner ein kräftiger befestigmesaplarat in der Errde ehenfalls nicht erforderlich ist. da stäkerer Zux an den im Wiscer

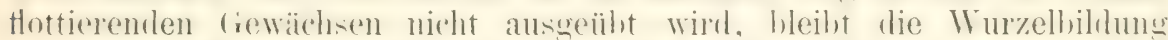
überhaupt auf ein sehr geringes Mal. heschä̈nlt mol dient mur zum Anheften an die Unterlage.

Danach liblst sich anch hei den I'flanzen die innere I)ifferenzieruner in mechanische und saftleitende (iewelıe, wo sie anftritt. auf ein ron äulieren Faktoren beeinfußtes, korrelatives Wachstum zurïickfülıren.

\section{Die Formbildung bei den Tieren.}

Den absoluten Gegensatz zur pflanzlichen bildet die tierische Organisation, wie auch in der Art der Ernähung ein grober Gegensatz besteht.

Die tierische Zelle nimmt bereits fertige organische Substanz auf; sie bleibt daher entweder nackt, so daß feste Köruer direkt in ihr Protoplatima eintreten lïmnen. oder umgiht sich nur mit dümmen. von öffinumgen durchsetzten Membranen. durch welche die schwer ditfundierenden folloblsubstanzen in gelöstem 7ustande hindurehgehen lïmurn.

Infolge der Mangels einer starren Lmhüllume wird anch die mealat-

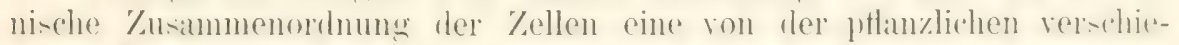
dene. Die weichen Zellenleiher lexen sich in ter Fläehe diehter zusimmen.

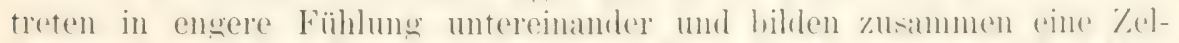

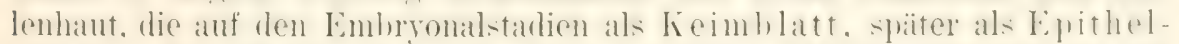

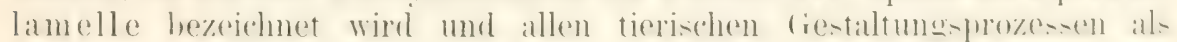
Ausgangspunkt und Grundlage dient.

In unmittelbarstem Zusammenhang mit der Art der Er-

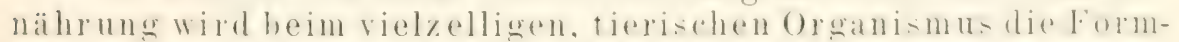
bildung eine nach inmen gerichtete.

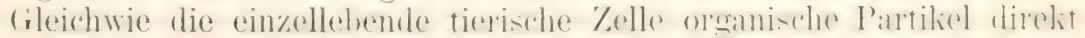

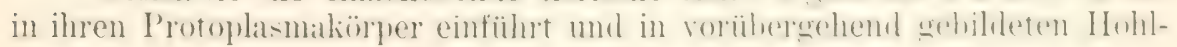




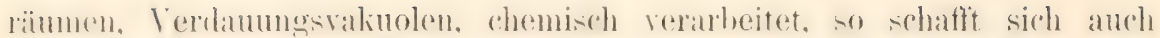
der vielzelliwe tiorische ()reanismus, nadelem seine Zellen am Anfang der Entwicklung zo einem Keimblatt zusammentetreten sind mol gewöhnlich

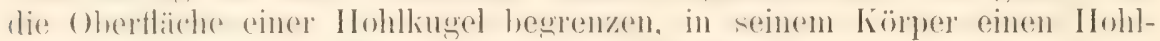

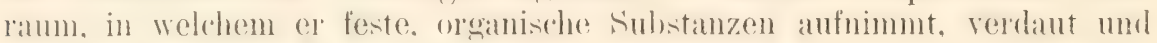
von ihm aus in gelöstem Zustand an die einzelnen Zellen verteilt. Die Keimblase (Fig. :362) stiilpt sich an einer Stelle ihrer Oberfläche nach immen ein und wandelt sich in einen Becher um (Fig. 363), dessen nach anlien kommzierenter IBimenramm. der sogenannte Tridarm, zur Nahrungsaufnahme und zur Verdaumg dient.

Der tierische Körper wird dadurch vom umgebenden Medium meñ unabängig; die Ernährung, welche für dien Bestand des ()ruanismus die crmolbedingung ist, erfolgt in absolutem fegensatz zur Pflanze durch einen Darmraum von innen heraus. Die Gastrula ist die allen Tierstämmen gemeinsame, charakteristische Grundform.
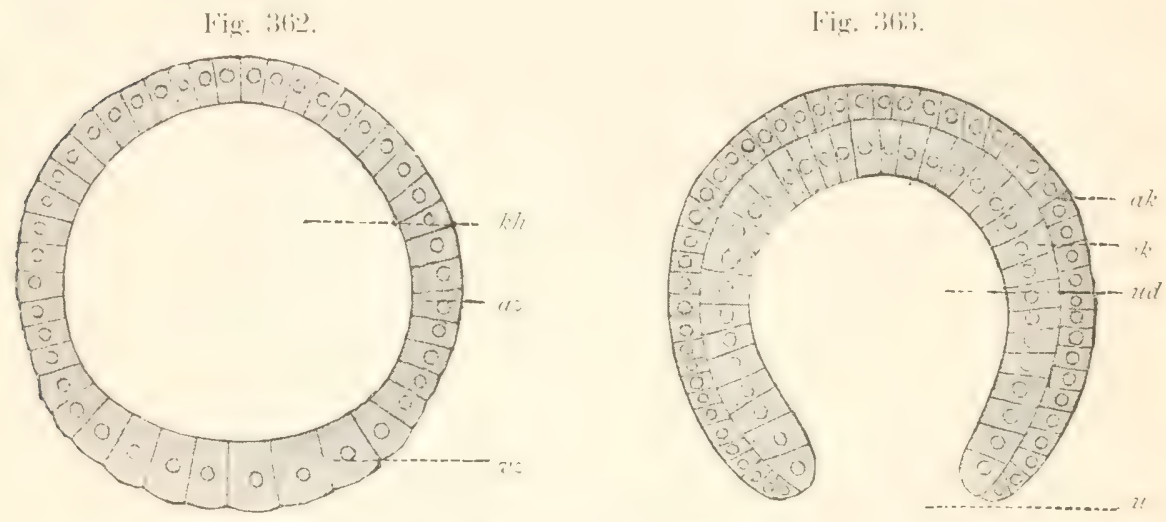

Iig. 362. Keimblase des Amphioxus lanceolatus. Nach HATschek. $k / 2$ Keimblasenhöhle; az animale, vz vegetative Zellen.

Fin. 363. Gastrula des Amphioxus lanceolatus. Nach HAtscheK. $a k$ Äuleres, it inneres Keimblatt; „ Urmund; ut. Urdarm.

Nach demselben Prinzip schreitet die weitere, höhere Ausbildung der tierischen Form von den einfachen Anfängen aus in der Weise weiter

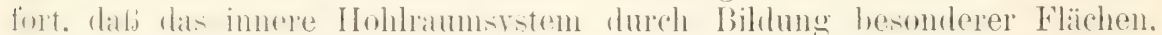
die zur Abscheidung von Sekreten dienen, ferner durch Abtrennung der Leibeshöhlen, die sich noch weiter zerlegen können etc., ein immer komplizierteres wirl.

Während bei der Pflanze eine Oberflächenentwicklung nach außen, finclet eine solche bein Tiere, gemäß der gegebenen Berlingungen, im Innern des Kiörpers statt. Die Differenzierung der Pflanze zeigt sich in

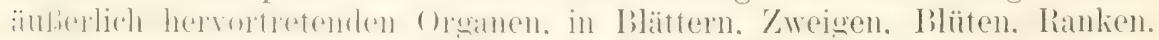
Die Differenzierung beim Tier erfolgt im Innern des Körpers verborgen, indem die inneren Flächen der Ausgangspunkt für die verschiedensten Organbildungen, für zahlreiche Drüsen, mehrere seröse Höhlen und für

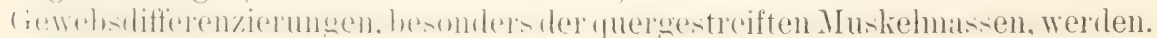

Durch komplizierte Aus- und Einstülpungen der primären Keimblätter beim Wachstum des Embryos wird auf einem kleinen Raum eine

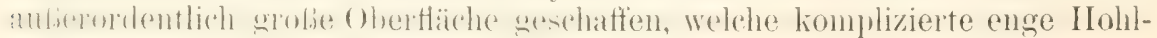




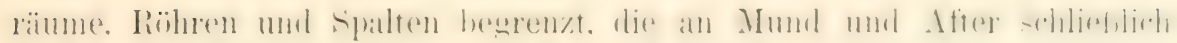
nach aufen fïhren und so den Verkehr mit der Aubenwelt unterhalten. Mit der Bildung innerer Oberfäthen wird gewissermalien ein Teil der AuBenwelt in den tierischen liörper selbst mit a ufgenommen, Nahrung in (len Darmkanal, Luft in die Lungen oder Tracheen, Wasser in Kiemen bei den wasserbewohnenden 'Tieren.

Obwohl die Tiere nach ihrem bau in den einzelnen Stämmen er-

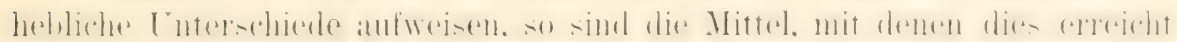
wirl, doch nur sehr einfacher Art. Immer wieder stolien wir beim Stu-

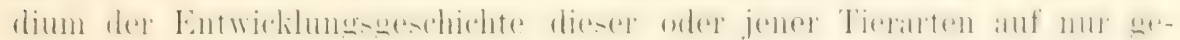
ringfügige Variationen einiger weniger allgemeiner Formbildungsgesetze.

Da eine Bekanntschaft mit ihnen für ein tieferes Verständnis der

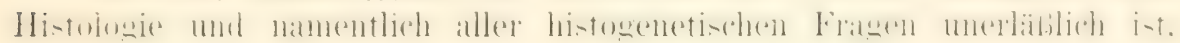
scheint es geboten, noch etwas genauer einzugehen auf:

\section{die Gesetze der tierischen Formbildung.}

Wrie oben hervorgehohen, läßt sich nach der grumdlegenden Gasträatheorie ron Lowalevsisy, HaEckel und LAxKester als die gemeinsame Grundform aller Tiere die Gastrula bezeichnen (Fig. 363). Ihr durch Einstïlpumg entstandener Hohlraum oder der Urdarm wirl von zwei Epithellamellen begrenzt, dem eingestïlpten und dem nicht einge-

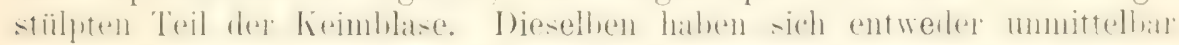

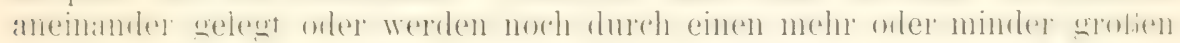
Zwischenramm, einen Rest von der Keimblasenhöhle orler dem Blastocöl

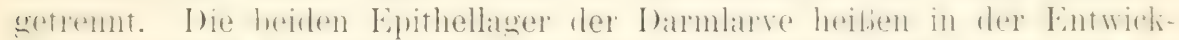

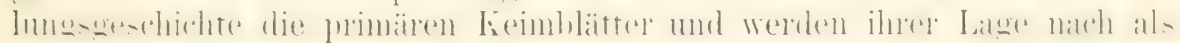
äuberes $(a k)$ und inneres ( $i k$ ) unterschieden (Ektoblast oder Hautsinnesblatt. Entoblast oder Darmoliusenblatt). Sie sind auferordentlich bedeu-

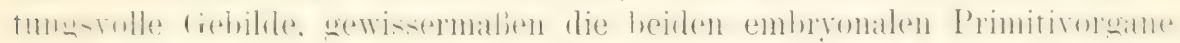
des tierischen Körpers. Denn eine der Hauptaufgaben der Embryologie besteht darin. nachzuweisen, von welchem der beiden Blätter und in welcher Weise die einzelnen Organe und Gerebe aus ihmen ihren Ursprung nehmen.

Veränderungen an den beiden primären Keimblättern kömnen durch drei in ihrem Wesen verschiedene Prozesse hervorgeruten werden: 1. durch

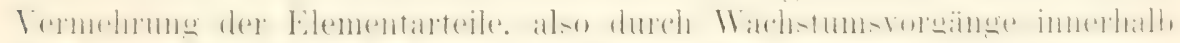

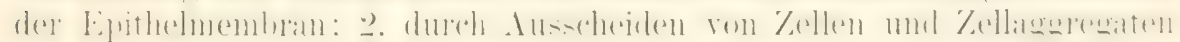
aus dem epithelialen Verband, und :3. durch verschiedenartige Differenzierung der einzelnen Zellen infolge ron Arbeitsteilumg.

\section{Ungleiches Wachstum einer Epithelmembran.}

Fassen wir zunächst den Prozed des Wachstums einer Lipithehmembran näher in das Auge. Wenn ilue einzelnen Elementarteile sich gleichmälig durch 'Teilung vermehren, so wird entwerler eine Verdickung der Membran oder eine Grölenzunahme in der Fläche orler beides die Folge davon sein. Das erstere tritt ein. wenn die 'Teilungsebenen der Zellen der Oberfliche der Membran gleich gerichtet sind, das zweite. Wenn sie vertilial zu iln stehen, das dritte. wenn die 'Teilungen in immer abwechselnder Richtung erfolgen. Bei der Gröbenzunahme in der Fläche werten die ur-

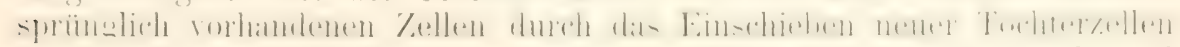
gleichmäßig und allnählich auseinander gerlrängt, da sie ja weich und 
dehnbar und nur durch eine weiche Kittsubstanz verbunden sind. Nehmen wir num an. daß ein solches Wachstum bei der Keimblase oder in der

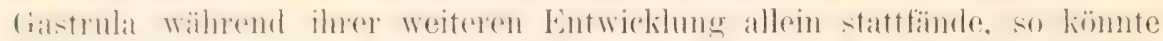

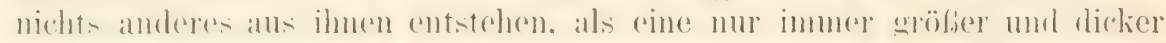
werdente Hohllkugel von Zellen oder eine sich vergrößernde Gastrula.

Neue Formen können nur durch ungleichartiges Wachstum in das Leben gerufen werden. Wenn in der Mitte einer Epithelmemhan eine Zollengrupe allein sich zu wiolderholten Malen in limzer Zeit durch vertikale Ebenen teilt, so wird sie plötzlich eine viel größere ()hertläche für sich in Anspruch nehmen mür-sen und wird infolgerlesen

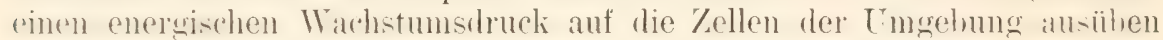
und sie auseinander zu drängen versuchen. In diesem Fall aber wird ein Ansemanderweichen der henahbarten \%ellen. wie heim langsamen und gleichmähig verteilten, interstitiellen Wachstum, nicht möglich sein: dem

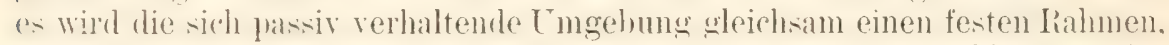
wie sich His ausgedrückt hat, um den sich rlehnenden Teil bilden, der infolge heshlennigten Wachstums ane gröbere (oherthärhe für sich hean-ynucht.

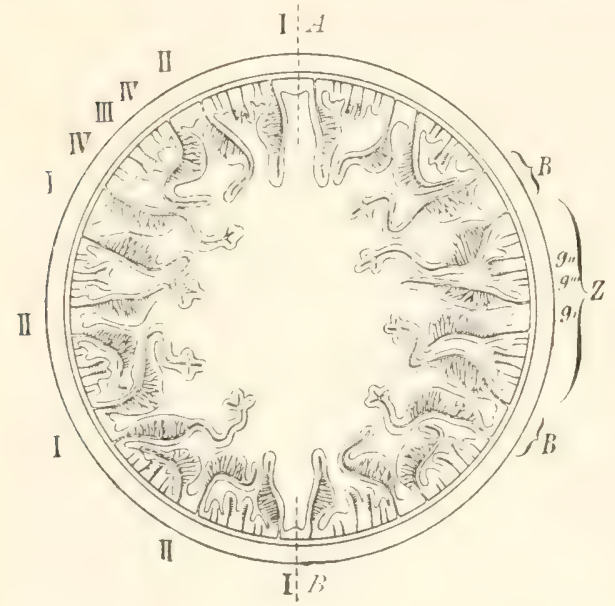

Fir. 364. Querschnitt einer Aktinie (Adamsea diaphana) unterhalb des Schlundrohres. A B Richtungsfächer, zugleich Enden der Sagittalachse, welche die eine Symmetricebene des Körpers bezeichnen, wihrend die zweite dazu senkrecht steht. I-IV Cyklen der Septenpaare I.-IV. Ordnung; $B$ Binnenfach I. Ordnung; $Z$ Zwischenfach I. Ordnung, in welchem new angelegt sind Septenpare und Bimnenfächer II., III., IV. Ordnung ( $\left.g^{\prime}, g^{\prime \prime}, g^{\prime \prime \prime}\right)$.

Die in Wucherung hegriffene Strecke der Epithelmembran mul. sich mithin in anderer Weise Platz schaffen und ihre Ohertläche dadurch vergröberm. dalj sie aus dem Niveau des passiven Teils nach der einen oder der anderen Richtung heramstritt und einen Fortsatz oder eine Falte hervorruft. Letztere werden sich noch weiter vergröliern und über das ursprüngliche Niveau erheben, wenn die lebhafteren Zellteilungen in ihnen andauern.

Auf solche Weice ist aus der ursprünglich gleichartigen Epithehmemhran surch ungleicher Wachstum ein neuer, für sich unterscheidharer Teil orler ein besonderes Organ entstanden.

An den Epithelmembranen, die zur Begrenzung eines Körpers dienen, wie bei der Keimblase und bei der Gastrula, kann man zwei ver-rhiedene Flichen unterscheilen, eine an die ungehenden Medien angrenzende orler ihre freie Fläche und eine von ihnen abgewandte odler die basale. Bei der Keimblase ist die letztere nach der Keimblasenhöhle I Blastoröl). hei der (iastrula entweder nach dem Zwischenram gerichtet. der die beiden Keimblätter noch trennt oder, wenn ein solcher ganz geschwunden ist, nach der basalen Fläche des angrenzenden Blattes. 
Es liegt nun auf der Hand, dal die Falten und Fortsätze sich in einer doppelden Weise bilden kömnen. Entweder erheben sie sich über die freie Fläche der Membran und entwickeln sich in die den Körper begrenzenden Medien hinein, oder sie treten an der basaltiäche hervor in

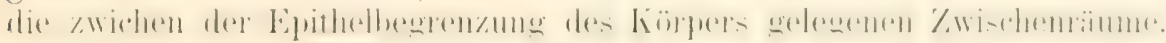

Im ersten Fall spricht man von einer Ausstülung. im zweiten Fall vou einer Einstülpung oder Einfaltung (Invagination)

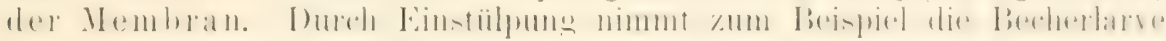
aus der Kiemblase ihren Ursprumg.

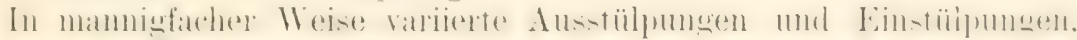

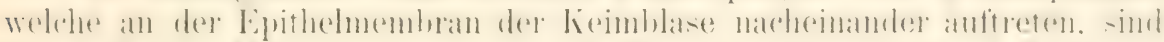

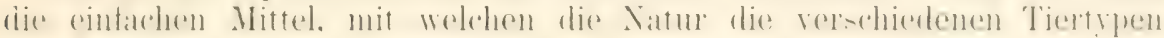

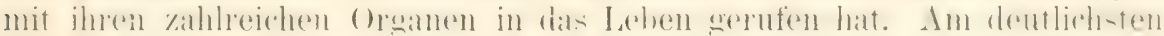

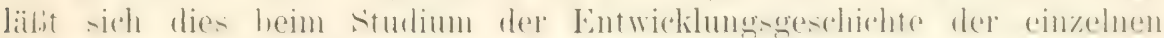

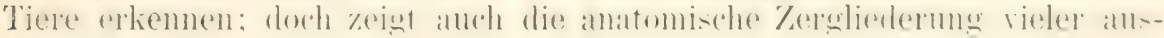
gebildeter 'Tiere, namentlich der Cölenteraten und W ürmer, daß ilır Körper schlieflich nichts anderes ist als ein System ineinander

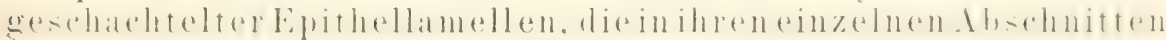
eine ungleiche histologische Differenzierung erfahren haben.

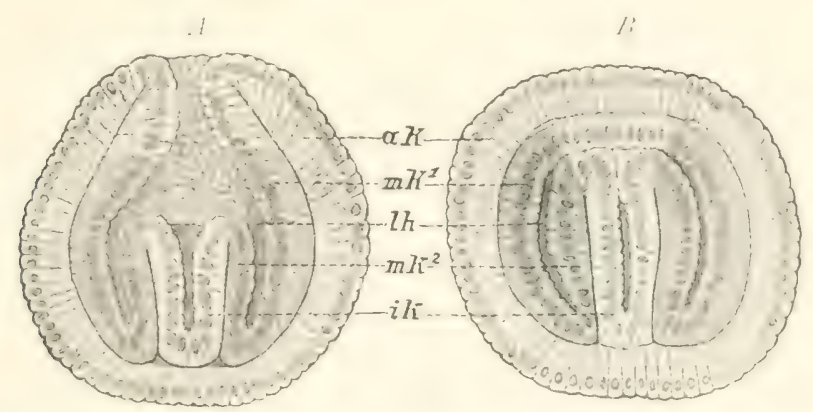

Fig. 365 A 1 . b. Bildung des mittleren Keimblattes und des Cöloms von Sagitta. Nach HErTwg. A Vom Grumde der Gastrula erhehen sich zwei Falten, welche den Urdarm in den bleihenden Darm und die Cölondivertikel ahteilen. B Die Sonderung durch Vordringen der Falten fast beendet. $a K^{-}$Auberes, m $K^{-}$mittleres, i inneres Keimblatt; $m K^{-1}$ Hautfaserhlatt; $m K^{-2}$ Darmfaserblatt: $1 / 2$ Leibeshöhle.

Un von diesen wichtigen Vorgängen eine klarere Vorstellung zu ge-

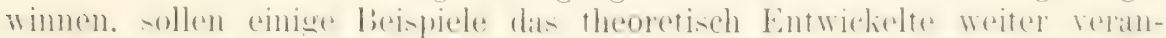

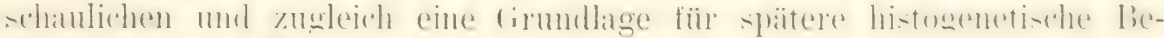
trachtumgen schaften.

Der Körper der Cölenteraten läbt sich im allgemeinen auf zwei

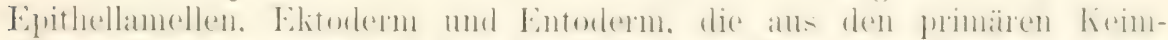

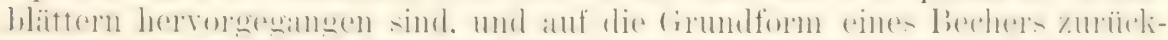

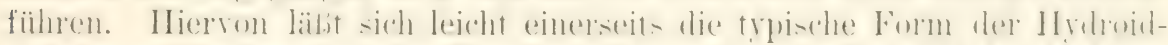

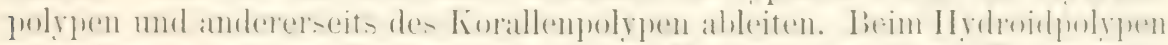

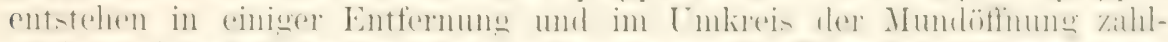

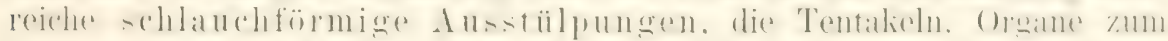
Einfangen der Nahrung. Für Aktinien und Anthozoen (Fig. 36t) ist

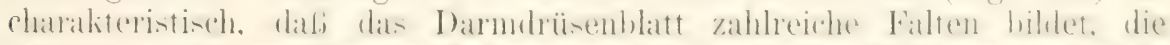

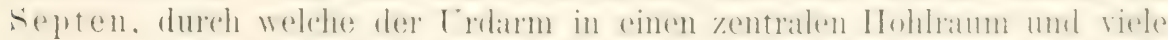

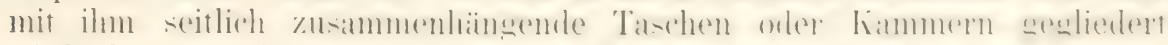
wird, deren Zahl sich zuweilen auf mehr als 1000 belaufen kann. 
Eine große Anzahl ron Tierklassen, Abteilungen der Würmer. die

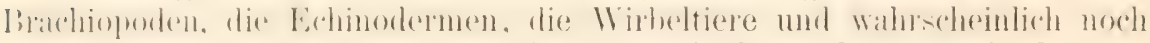
andere, lassen sich auf eine Grundform zurückführen, die man als Cölomlarve bezeichnen kamn (Fig. $355 A, B$ und Fig. 366 u. 367 ). Sie ist aus der Becherlarve in der Weise entstanden, daß durch Faltungen des

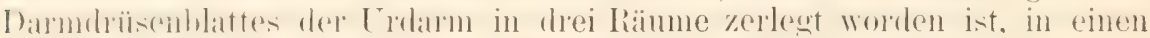

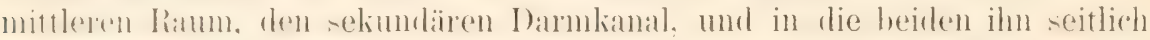
umgebenden Leibessäcke (Fig. 365 A, B, . l/ und Fig. 366, 367 /h). Bei allen Tiren. bei denen dies geschicht. wirl gleich in den Anfangsiatlien der Entwicklung die Zahl der beiden primitiven Epithelblätter um ein drittes vermehrt, das von ihnen als mittleres Keimblatt (Mesoblast) zı unterscheiden ist und sich zwischen sie tremnend hineinschiebt. Auf Grund dessen kann man die Tiere in zwei- und dreiblätterige Formen einteilen, von denen die ersteren im allgemeinen einfacher, die letzteren komplizierter gebaut sind.
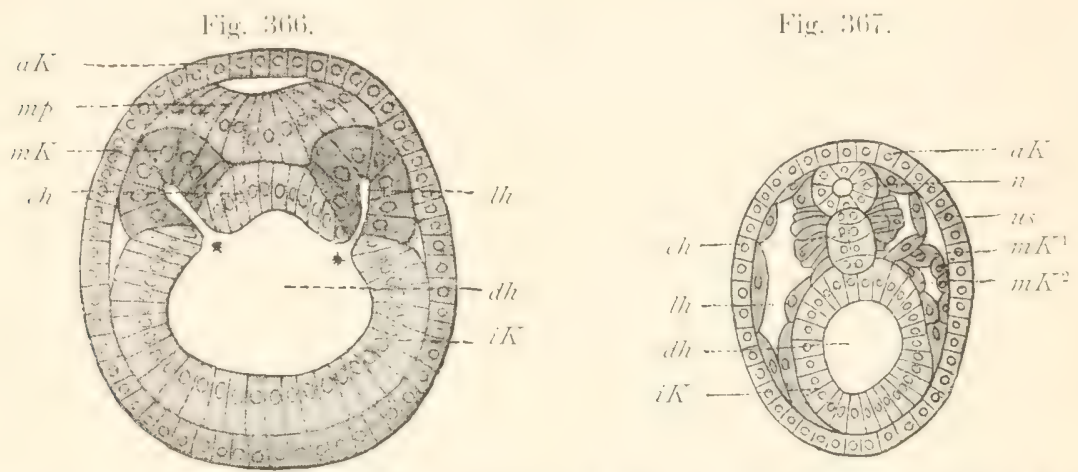

Fig. 360. Querschnitt durch einen Amphioxusembryo, an welchem die Epithellamelle des Urdarms sich sondert in das Epithel des bleibenden Darms

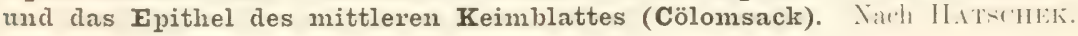

Fig. 367. Querschnitt durch einen älteren Amphioxusembryo, an dem sich bleibender Darm und mittleres Keimblatt ganz voneinander getrennt haben. Nach HatwcheK. $a I^{-}$Iußeres, $i K^{-}$inneres, $m K^{-}$mittleres Keimblatt; mp Medullarplatte; ch Chorda; dh Darmhöhle; $7 /$ Leibeshöhle; $n$ Nervenrolrr; zs Ursegment.

Die drei Keimblätter dienen zur Begrenzung von drei verschiedenen ()herflächen. Das äulere liemblatt hegrenzt die IIautoherfläche des hörpers. das sekmuläe innere Keimblatt den dureh Finstülpung entstandenen, repdauenden Hohlram und das mittlere Keimblatt die durch weitere Einfaltungen vom Urdarm nachträglich abgesonderten Leibeshöhlen.

Wie die Grumdformen der tierischen Organisation (Becher- und (a)lomlarve) durch Lns- und Einstülpungen einer primären Epithehmembran entstanden sind, so lassen sich weiter auch fast alle einzelnen Or@ane durch den gleichen Prozeß von den grundlegenden zwei resp. drei Lieimhlïtern ahleiten: die rahlechen I) riisen, viele simmesorgane, das Zentralnervensystem etc.

Bei der Entstehung von Drüsen (Fig. 368) wuchert ein kleiner umschriebener Bezirk der Epithelmembran des äußeren, inneren oder mittleren Keimblatts und stuilpt sich als ein Hohlzylinder in das unterliegende Gewebe hinein; hierbei geht er entwerler in die tubulöse orler in die alveoläre Drüsenform über. Besitzt der Drïsenschlauch.

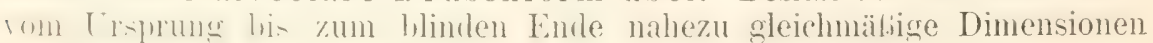


(Fig. 368, r), so erhalten wir die einfache tubulöse odler röhrenfürmige

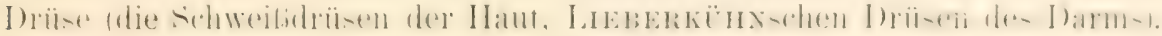
Ton ihr unterscheidet sich die alveoläre I)rïsenform dadurch. daf. der ein-

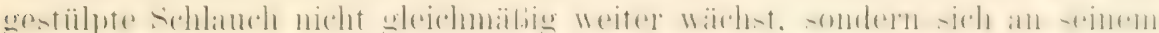

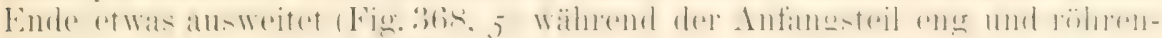
förmig bleibt und als Ausführungsgang dient.

Aus dem einfachen Drüsenschlauch bilden sich zusammengesetztere Formen. wem an ihm sich derselbe Prozeb. welchem er seine Ent-

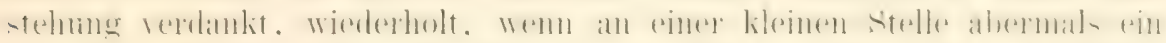
lehlafteres Wachstum stattindet und eine Partie sich wieler als Seiten-

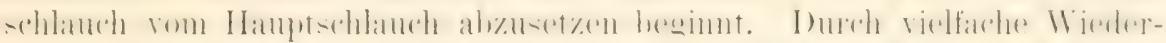

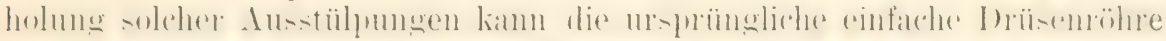
die Gestalt eines vielvel\%weigten Bames (Fig. 368, 2 u. 6) gewimnen. an

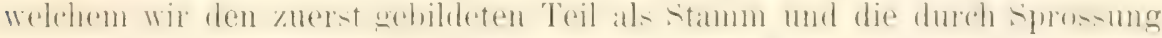
an ihm hervorgewachsenen Teile je nach ihrem Alter und der dem Alter

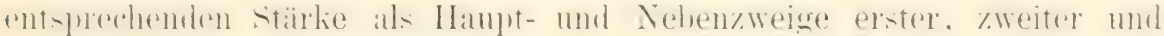
dritter Ordnung unterscheiden.

Fig. 368. Schema der Drüsenbildung Xach IIERTwI*. I Einfache tubulöse Drïse: 2 verzweigte tuhulöse Drüse: 3 verzweigte tubulöse Drïse mit netzförmiger Verbindung; +11.5 einfache alveolïre Driise: $a$ Ausfiihrführgang, at Drüsenbläschen; $\sigma$ verzweigte alveoläre Drüse.

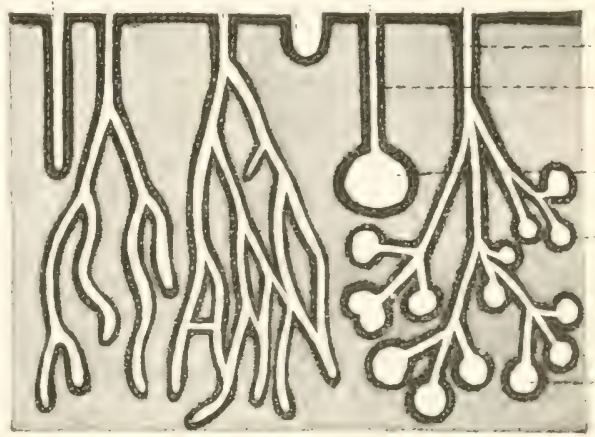

Wieder andere Formen nimmt der sich einstïlpende 'Teil einer ur-

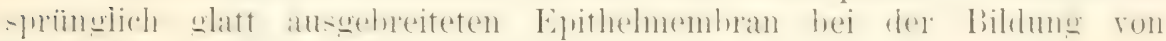
Simnesorganen und vom Zentralnervensrstem an.

liem Gehörorgan \%. B. (Fig. 369 ) entwickelt sich der die Nervenendigung tragende Teil oder das häutige Labyrinth aus einer kleinen

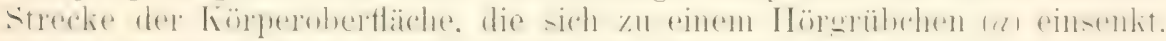
Seine Rändler wachsen hierauf einander entgegen, so daß er sich mehr und mehr in ein Säckchen (b) umbilltet: und dieses liefert schließlich

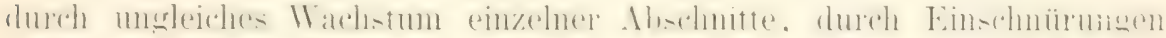

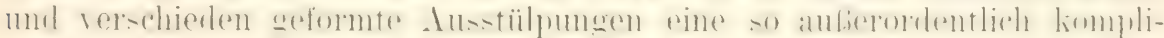
zierte Gestalt, daß es den Namen des häutigen ..Labyrinths" mit Fug und Recht erhalten hat.

Gehirn mul Rückenmark entwickeln sich aus einem verdickten

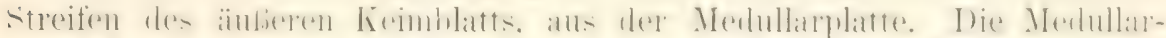

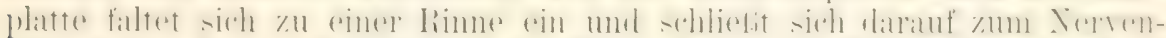

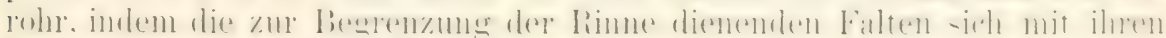
Rändern zusammenlegen und verwachsen.

Neben der Einstülpung spielt bei der Formgebung des tierischen Körpers die zweite Art der Faltenbildung, die auf einem Ausstïl.

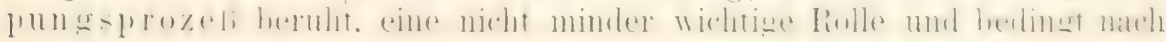


anlien hervortrefende l'ortsitze der Körperobertläche, welche ehenfalls verschiedene Formen annehmen können (Fig. 370).

Durch Wucherung eines kleinen, kreisförmigen Bezirks einer Zellmembran entstehen yalfenfömige bihebungen. wie anf der hungenschleimhaut die Papillen $(c)$ oder im Dünndarm die feinen Zotten $(a)$, welche, sher dicht ancinamler gelagert, eine samtartige beschattenheit der oherthitehe der I armschleimhant verleihen. Wie die tubulösen Drüsenschläuche sich reichlich verästeln können. so entwickeln sich hie und da auch aus den einfachen Zotten Zottenbüschel (b), indem lokale Wucherungen dat Hervorsursien ron Seitenästen zweiter, dritter und vierter ordnung veranlasion. Beispiele liefern die änberen Kiemenbüschel verschierlener Fisch- und Amphibienlarven, welche in der Halsgegend frei in das Wasser hineinragen. orler die durch noch reichere Verzweigung an-gezeichneten Chorionzotten der Säugetiere.

Wemn die Wucherung in der Epithelmembran längs einer Linie erfolwt. bilden sich mit dem freien Ramb nach aufen werichtete Kïmme oder Falten, wie am Dünndarm die KERKRINGschen Falten oder an den Kiemenbögen der Fische die Kiemenblättchen.

Fig. 369.

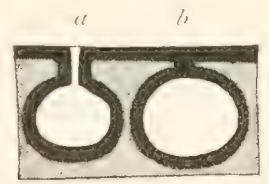

Fig. 369. Schema der Bildung des Hörbläschens. a Hörgriblochen; 8 Hörbläschen, das durch Aloschnürung entstanden ist und mit dem äußeren Keimblatt noch durch einen soliden Epithelstiel zusammenhängt.

Fig. 370. Schema der Papillen- und Zottenbildung. a Einfache l'apille; $b$ verästelte Papille oder Zottenbüschel; $c$ einfache Papille, deren Bindegewebsgrundstock in drei Spitzen auslïuft.
Fig. 370 .

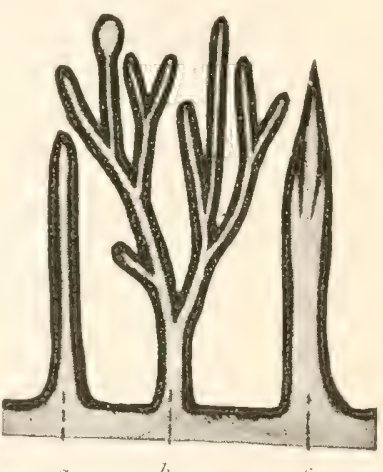

\section{Ausscheiden von Zellen und Zellaggregaten aus dem epithelialen Verband.}

Ein zweiter wichtiger Prozeß, welcher in hohem Grade dazu beiträgt, die tierische Organisation immer komplizierter zu gestalten, ist das Ausscheiden von Zellen und Zellaggregaten aus dem epithelialen Verband. Die ausgeschiedenen T'eile kommen in die Zwischenräume zu liegen, welche bei den Faltungspro\%x+m zwischen den basilen Flächen der drei Keimblätter übrighleiben mul Reste iler ursurünglinen Keimblasenhöhle (des Blastocöls) sind.

Durch Anssoheiden einzelner Zellen hommt eine Gewebsform zustande. welche zum Epithel in einem scharf ausgesprochenen, histologischen (iewensat\% steht und als Mesenchymgewehe von Richard Hertwig und mir hezeichnet worlen ist. Bei niederen Tieren wird von den heimblättern in den zwischen ihnen gelegenen Ram zuerst eine gallertige (irundsubstanz ausgeschieden (Fig. $371 \mathrm{~A}$, sc). In sie wandern dann aus dem Eivithel einzelne Zellen ein, indem sie amöhoide Fortsätze ausstreclien (Fig. 371 B, ms). 
Je nach den einzehnen Tierklassen scheinen die Mesenchymkeime entweler vom äuberen orler vom inneren oder vom mittleren lieimblat abzustammen. Bei den Wirbeltieren ist das letztere der Fall. Die (rallerte wähst durch Vermehrung der in sie eingewanderten Ele. mente von einer bestimmten Zeit an gan\% unabhängig vom Epithel für sich weiter. dringt in alle Lücken hinein, welche bei den Ein- und Ausstiilpungen der licimbläter hervorgerufen werten, und gibt so ein ver-

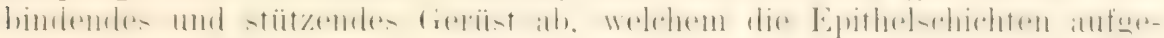
lagert sind. Dabei wird das Mesenchymgewebe in der Tierreihe der Sitz

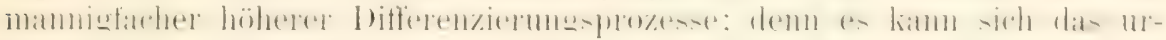
sprimgliche Gallertgewebe in faseriges Bindegewebe, in linorpel- und Knochengewebe ete. umwandeh.

Aber auch größere Zellkomplexe können während der Entwicklung

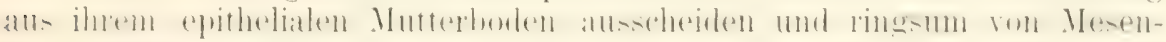
chymgewebe eingeschlossen werten. Es ist dies bei allen denjenigen Organen der Fall, welche sich zwar durch Einstülpung aus dem Epithel

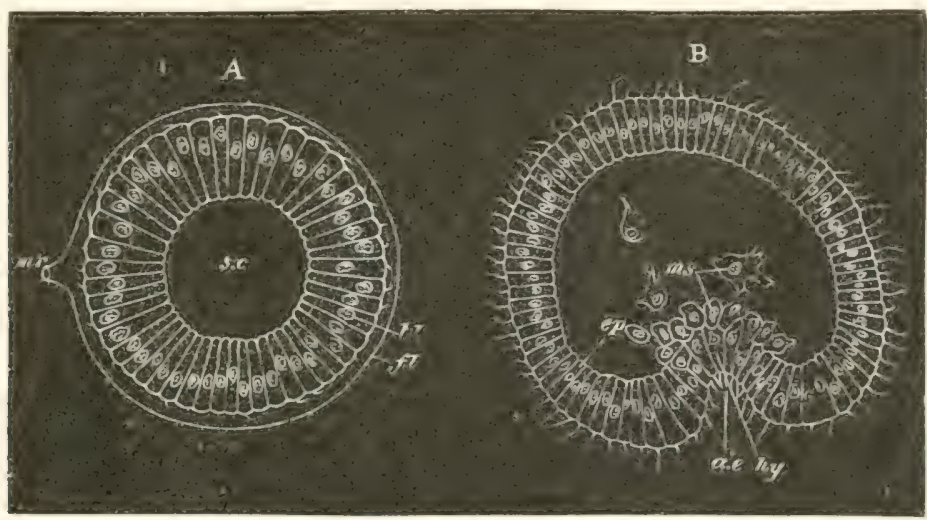

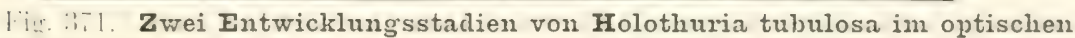
Querschuitt. Nach SEIExKA. I Kimblase am Ende der l'urchung. B (iastrulastadium. mr Mikropyle; $t$ Chorion: s.c Furchungshöhle, in welche fribzeitig fallerte als Gallertkern alugeshieden wird; b/ lieimblatt ( $B$ Blastoderm); (p änlieres, hy inneres Leimblatt: ms rom inneren heimblatt abstammende, amöboide \%ellen: a.e Griarm.

entwickeln. in ihrer Funktion aber nicht auf einen bleibenden /usammenhang mit der freien Epithelobertläche angewiesen sind, wie es zum Beispiel bei den absondernden Driisen notwendig ist.

So löst sich meist das IIörbläschen von seinem Mutterboden ab und nimmt, ringsum von Mesenchymgewebe umschlossen, eine geschütztere

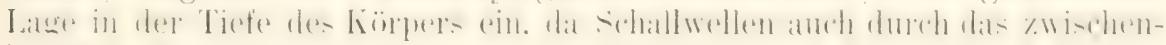

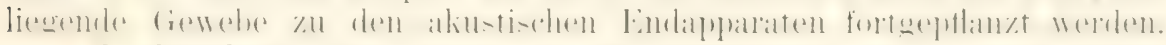

In derselhen Weise trennt sich das Nervenrohr vom äuberen Keim-

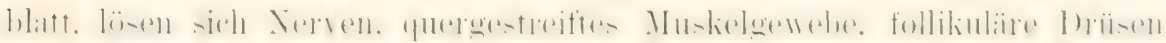
und manche andere Organe von ilnen Ursprungsbezirlien in den grundlegenden Epithelmembranen ab und umgeben sich allseitig mit Mesenchymgewebe.

Bei den höheren 'lieren füllen sich daher die Wwischenräume zwischen den Epithellamellen. welche einerseits die Oberfläche des Körpers begrenzen, andererseits die groben Itohlräume in seinem Inneren. die Darm- und die Leibeshöhle. auskleiden. mit den verschiedenartigsten Differenzierungsprodukten 
an. mit Geweben und Organen, dievon dieser oder jener Epithelschicht (von dem äuberen, inneren oder mittleren Keimblatt) entweder durch zelluläe Auswanderung oder dureh Abschnürung eingefalteter Epithelbezirke entstanden sind.

\section{Verschiedenartige Differenzierung der Zellen infolge von Arbeits- teilung.}

In Liufe der embryonalen Entwicklumw sondern sich aus dem Zellenmaterial. welches der Teilumsprozel. geliefert hat. anf den oluen ange-

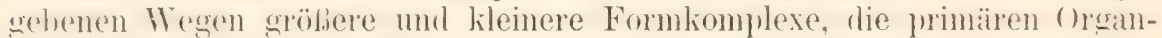
anlagen. Sie hesitzen anfangs noch heinen ausgespochenen histologischen ('harakter. erwerben ihm aber allmählich anf späteren Starlien des Entwicklungsprozesses.

Hierbei tritt uns bei tieferem Nachdenken ein neues Problem entgeven. welches sich aus den in den voransgegangenen Kapiteln entwickelten Prinzipien nicht erklären läßt. Wir vermissen nämlich in weitaus den meisten Fällen den zureichenden (irumd für die Arbeitsteilung. welche im embronalen Lehen zwischen den einzelnen Zellkomplexen vor sich geht.

Aus minserer Untersuchung der äußeren und der inneren Faktoren des Entwicklungspozesses hatten wir uns die allgemeine Vorstellung gebililet. dab die einzelnen Orome durch Reize, auf welche sie zu reagieren eingerichtet siml. anch in das Leben gerufen werden. Danach wïrden sehorgane um unter dem Einflub des Lichtes, welches ja von ihnen empifunden werilen soll. Stützolgane. wo Zug und Druck auszuhalten sind, verdauende I) riisen unter dem Einthul von Stoffen. Welche zur Verdaumg-tätigkeit und Absonderung von Sekieten anregen, gebildet werden könmen und zwar um so mehr. je stälier und häutiger dle alüyuaten Reize einwirken.

Diesen Vorstellungen entspricht num aber nicht der Vorgang in der ()ntosenese. Denn hei dem in der fiebä口mutter eingeschlosienen säugetierembryo bildet sich ein Auge aus, während alle Lichtreize und somit alle äulieren Berlingungen zum Sehen fehlen. Sipeichel- umb Magendrüien entstehen, lange hevor Lohlenhydrate mol Eiweibkörper in den Dammkanal aufgenommen werden und dir Drü-en zur zweckent-prechenden Funlition reizen.

Dasselbe kann man noch von manchen anderen Organsystemen und Geweben sagen. Überall ruft, zumal bei den höheren Wirbeltieren, ein Stulium ihres Entwidkmasmoze-ses den Findruck hervor, dab die Reize. welche später die Funktionierung der Teile bestimmen, zur Zeit ihrer ersten Entstehung noch gar nicht wirksam sein können und daß somit

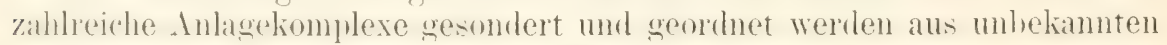
Ursachen, aber gewissermaßen im Voraus berechnet für Reize, die später eintreten und das vorgebildete Werkzeug zur Funktion anregen sollen.

Vergleichendes Studium niederer und höherer Tiere lehrt, daß hier in dor Embryonalentwicklung nicht der nrsuringliche. phylogenetische. son-

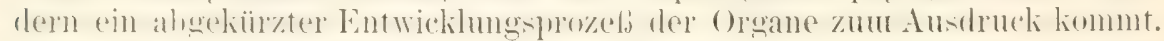
I) Organ erst in seiner Form und Struktur fertig angelegt wird und damn

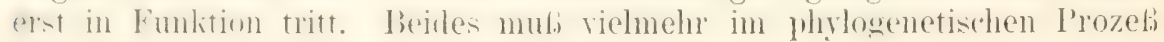
Hand in Hand gehen.

Aus einer Epithellamelle wird sich ein besonderes Organ, z. B. eine Muskelzellengruppe oder eine Drüse, nur dann absondern, wenn in ihr aine herimmte strecke aine eigenartige. aus ihren Beziehungen zum Or- 
danismus und zur Anlienwelt berlingte fouktion mol strulitur gewinnt.

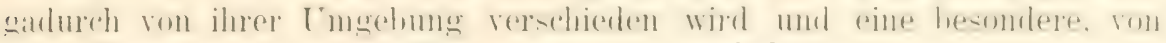
ilner Funktion abhängige Wachstumsenergie erhält.

Den Weg zu zeigen, auf welchem sich das neu auftauchende Problem

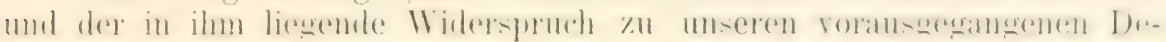
duktionen erklären läßt, wird Aufgabe der folgenden Kapitel sein.

\section{Literatux zu Kapitel XXIX.}

1) Haeckel, Die Gasträatheoric, die phylogenetische Klassifikation des Ticmrichs clc. Jenaische Zeitschrift, Bat. VIII. 1874.

2) Hertwig, Oskar und Richard, Der Orgunismus der Medusen und scine Stellung zur feimblätcrtheorie. Jend 1878 .

3) Dieselben, Studien zur Blättertheorie. Heft I. Die Aktinien. Ileft II. Die Chactognathen. Heft III. Die Colometheoric. 18\%0-1881.

4) Hertwig, Oskar, Lehrbuch der Entuicklungsgeschichte des Menschen und der IIrbelticre, 7. Auft., hap. IV. 1902.

5) Derselbe, Zeit- und Streitfragen der Biologie. Heft I. Präformation oder Epigenese.

1894. S. 97: Gedanken zu einer Entwicklungstheorie der Organismen.

6) His, Untersuchungen ïber die erste Anlage des Wirbeltierleibes. 1808.

7) Derselbe, Unsere Körperform und das physiologische Problem ihrer Entstehung. 1871.

S) Pander, Beiträge zur Entaicklung des Hühnchens im Ei. Whiraburg I8I7.

3) Ray-Lankester, On the primitize cell-layers of the cmbrye as the bersis of genealogial classification of anmals etc. Amnals and Llag. nat. Hist., Vol. XI. 1873.

10) Sachs, Julius, Vorlesumgen Über Fflansenpluysiologie. Lcipaig I882. 


\section{DREISSIGSTES KAPITEL.}

\section{Ilistorische Bemerkungen ïber die Stellung der Biogenesistheorie zu anderen Entwicklungstheorien.}

Die Biogenesistheorie geht rom lioulen den allwemeinen Kansalgesetzen aus. Sie nimmt daher auch, abgesehen von den zahlreichen Tatsachen, welche sich zu einem empirischen beweismaterial zusmmenstellen lasion. den frumbatz an, dab, ehenso wie die unorganischen Körper dureh äubere Faktoren fortwährend verändert werden. auch die Organismen sich dem umgestaltenden Einflub der Außenwelt nicht entziehen können.

Die erste Grundlage der Biogenesistheorie ist daher der Lamarckismus oder, wie sich NägELI ausdrückt, die ..Theorie der bestimmten und direkten Bewirkung".

Nach dem Kausalgesetz müssen ferner auch die Teile innerhalb eines O)romismus sich gegenseitig bestimmen und rinen umändermblen Eintlub

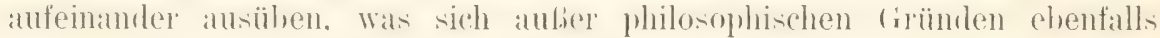
wieder durch ein reichliches Beobachtungsmaterial erhärten läbt. Es ist daher konsequent. anzmnehmen, dal. Veränlerungen, welche der ()rganismus als danzes unter dem Einflub der Anlenwelt erfährt. auch indirekt Veränlerungen in den das tranze anflatuenden Teilen, zu denen selbstrerständlicherweise die Keimzellen gehören, nach dem Kausalgeset\% hervorrufen.

Fine \%weitr (irmullage der Biogenesistheorie ist mithin die Lehre von der Vererbung orler der Chertrabarkeit erworbener Figenschaften durch die Keimzellen auf die Nachkommen.

Die Entwicklung der Organismenwelt besteht daher aus kontinuierlichen, bestimmt gerichteten Prozescen, welche sich ats den Finwirkmugen

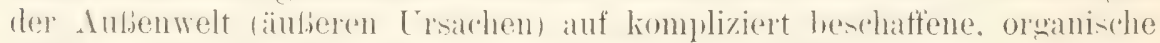
Sulstrate (imnere Tratchen, Anlagen) ergehen. Folglich nimmt die biogenesistheorie die Lehre rom der Komtinnität des Entwicklungsprozesses und (las Prinzip der Progression, das heibt: einer in bestimmter Richtung stetig fortscheitenden Lintwicklung. an. Hierhei kamn die fortacheitende

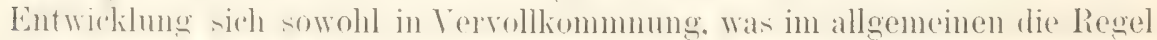

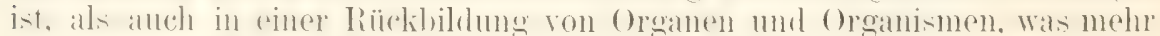
die Ausnahme darstellt, in dem einzelnen Falle äubern.

Auf diesen drei Grundlagen, in V'erbindung mit den Vorstellungen, zu welchen uns die allgemeine Anatomie und Physiologie der Zelle in neuerer Zeit geführt hat, ist die Theorie der Biogenesis entstanden, teils

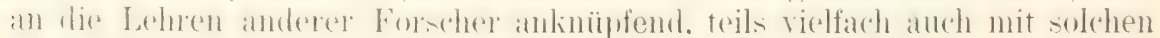
in Widerspruch tretend und eigene Bahnen einschlagend.

Ein kurzer historischer Exkurs mag auch hierüber noch zu weiterer Orientierung dienen; doch mul ihm gleich vorausgeschickt werden, daß 


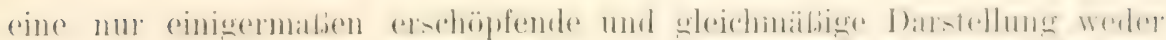

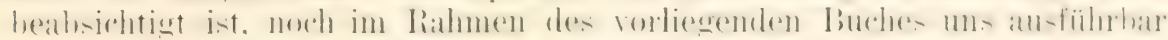

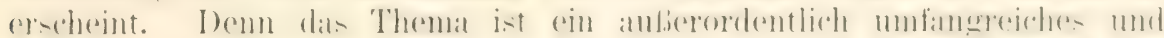
zugleich ein sehr verwickeltes, da die von verschiedenen Forschern auf-

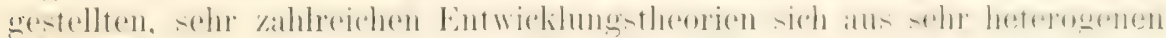

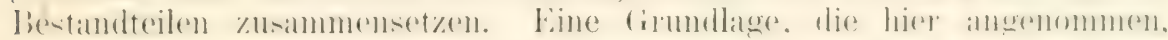
wird dort verworfen. Vor allen Dingen aber verbinden die einzelnen

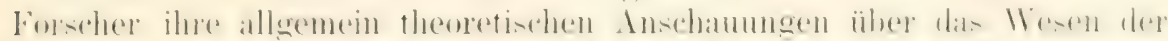

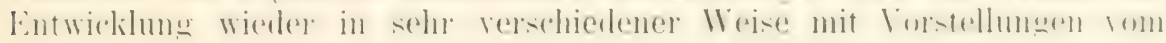
feineren Bau der Organismen und besonders der Zelle.

Es ist daher sehr schwierig, einige leitende Gesichtspunkte bei der

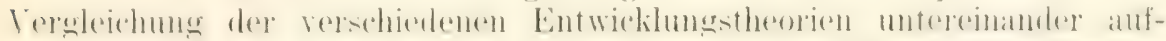

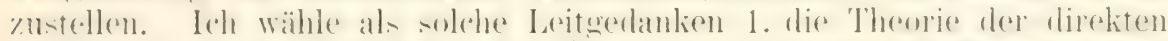

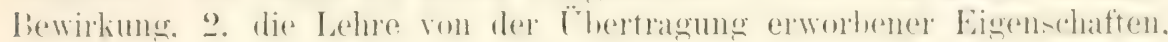
3. die Lehre von der Kontinuität im Lntwicklungsprozeß.

\section{Die Theorie der direkten Bewirkung. Der Lamarckismus.}

Es ist das große Terdienst von Lamarck, 1809 in seiner Philosophie zoologrigue in voller Klarheit den cirmol-at\% aufge-tellt mol mit lieweisen

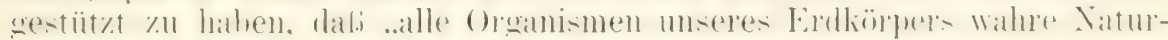
erzeugnisse sind, welche die Natur ununterbrochen seit langer Zeit hervorgebracht hat" (S. 30). Die Natur hat mit den unvolliommensten

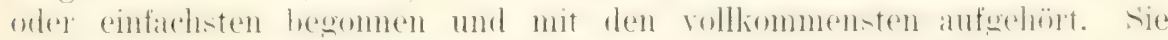
hat unter den veränderlichen Einthüssen der äuBeren Verhälnisse ..ihre Organisation stufenweise verwickelt" (S. 138).

Fiir die Tiere besonders nimmt Lamarck an. dab bei einer wemn

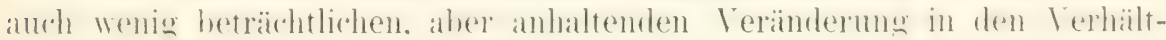
nissen. in welchen sie sich befinden, ihre Gewohnheiten und Berlüfnisse

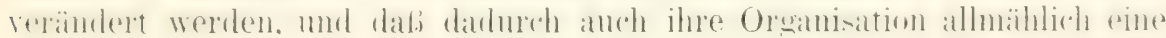
andere wirl. Das von LAmarck aufgestellte Gesetz lantet in seinen eigenen Worten:

..Bei jedem Tiere, welches das Ziel seiner Entwicklung noch nicht

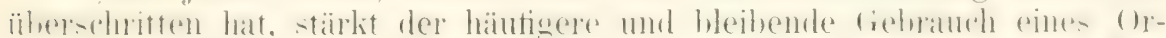

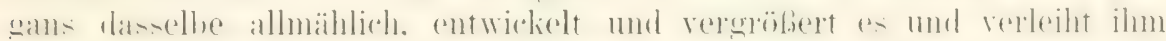
eine Kraft. die zu der Dauer dieses Gebrauchs im Verhälnis steht;

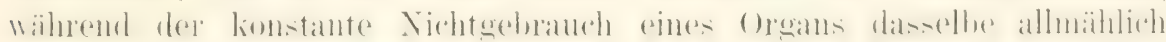

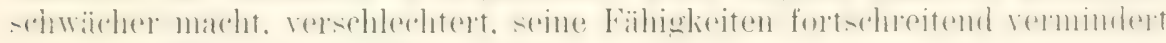
und es endlich verschwinden läbt."

Ähnliche Anschaumgen, wie sie Lavarch in seiner Philosophie zoo-

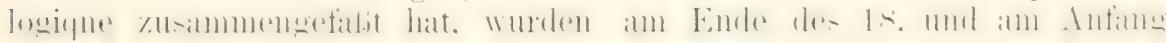

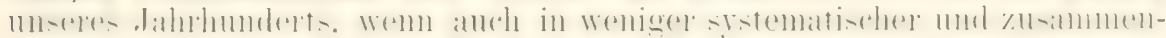
hängender Weise, von G. ST. HrLatre in Frankreich, von Lrasuus Darwis, dem Grobvater seines berühmten Enkels, in England, von 'TREvIRAxus und GOETHE in Deutschland geinfert. Es ist ein merkinturliges

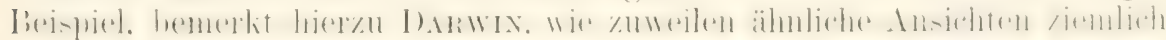
zu gleicher Zeit mehrfach und unahhängig voneinander auftauchen.

Als damn Charles DARwix 185̆!) durch sein epochemachendes lbuch: .Über die Entstehmm der Arten" dlie Deszendenztheorie zu allgemeinel'

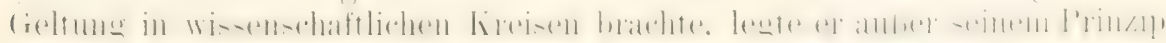
rom Kampf ums Dasein und ron del natülichen Zuchtwahl auch ein grofies Gewicht auf den LAmarckschen Faktor. Er äubert sich ïber ihn besonders in dem fünten Kapitel, in welchem er üher die Wirkungen ver- 


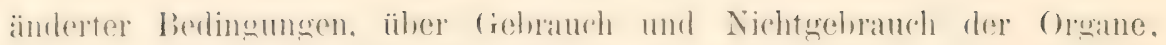
übel korrelative Abänderung handelt. In bezug auf letztere hebt er

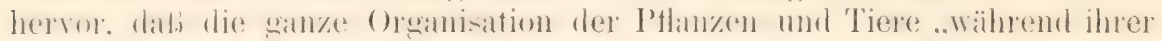

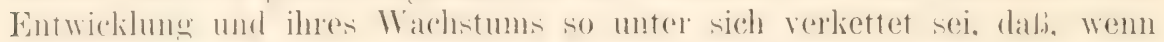
in irgend einem Teil geringe Abänderungen erfolgen und von der natürlichen Zuchtwahl gehäuft werden, auch andere 'Teile geändert werden".

Noch mehr aber als in seinem Buch über die Entstehung ler Arten hat DARWIN den LAMARckschen Faktor in seinem großen, später erschienenen Sammelwerk gewürdigt: .Das Variieren der Tiere und Pflanzen im Zustande der Domestikation."

Gleichzeitig mit CharLes DARwin hat sich in England HerberT spexcer mit der Entwicklungstheorie der Oramismen von unfatsenden philonphischen diesichtspunliten ans beschäftiot und in sritematischer Weise die fiesetze der orsanischen Formbildumg und die lierlentung äuberer und innerer Falitoren klarzustellen gesurht. Er legt dabei dis grialite Gewicht auf das Prinzip der bestimmten und direkten Bewirkung, zu deren Gunsten el zahheiche belege anführt, und eörtert am emgehendsterì das

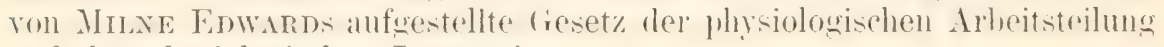
und der physiologischen Integration.

Spencers Ansichten sind teils in den zwei Bänden der Prinzipien der Biologie, teils in dem kurzen, auch in deutscher Übersetzung im Kómos erschiencuen Aufsatz .Die Fakitoren der oromischen Entwicklumg.". teils in mehreren libineren streitschriften nitelergelegt, in welchen er die neneren Theorien von WEssuaxs bekïmptt hat. Am entshierlensten ist sein Standpunkt pointiert in dem gegen Weismans gerichteten Essay ,Die Unzulänglichkeit der natürlichen Zuchtwahl".

In Deutschland hat HAECKEL, welcher am erfolgreichsten für die Verbreitung der Destendenzlehre und des Darwinismus gewirkt hat. von vornherein auch die wrolie Tragweite des Lumarcrschen Faktors stets anerkannt. Als ,oberstes Grundgesetz der Anpassumg“ stellt er in seiner

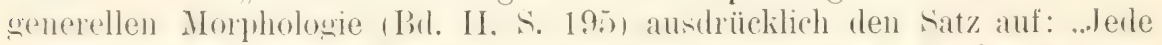
Anpas-mugerscheinumg (Abänderung) der Organismen ist durch die materielie Wachselwirlung zwishen der Materie des organismus und der Daterie, welche denselhen als Aubenwelt nmeibt, hedingt, und der crad der Alündrerung al. h. der (irad der morphologischen und physiologischen Ungleichheit zwischen dem abgeänderten Organismus und seinen Eltern) steht in geradem Verhältnis zu der Zeitdauer und zu der Intensität der materiellen Worhatwirkmo zwischen dem ()ranismus und den verimblerten Existenzbedingungen der Außenwelt."

HAECKEL unterscheidet zugleich eine ,indirekte und eine direkte

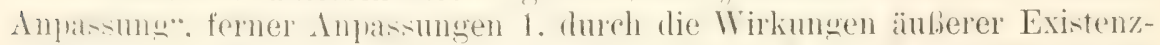

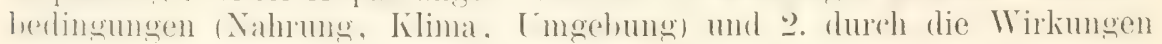

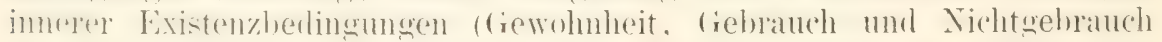

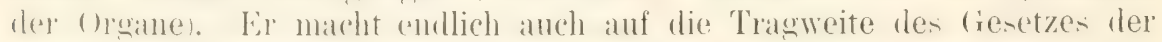
korrelativen Anpassung aufmerksam, welches er in die Worte faßt: „Alle Abänderungen, welches in einzelnen Teilen des Organismus durch kumulative oder sonstige Anpassung entstehen, wirken auf den ganzen Organismus und oft besonders noch auf einzelne bestimmte Teile desselben zurück und bewirken hier Abänderungen. welche nicht unmittelbar durch jene Anpassung bedingt sind."

Am konsequentesten unter allen Forschern in Deutschland - in England steht ihm Herbert SPENCER an nächsten - hat wohl NägeLI in -inen sidniften. zumal in seiner mechanisch-physiologischen Theorie 


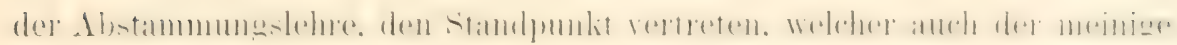
ist und welchen ich in diesem Buch im Zusammenhang zu entwicheln versucht habe, daß „elie Eigenschaften der Organismen die notwendigen Folgen von bestimmten Ursachen seien'. In (iegensatz zum D $\Lambda \mathrm{R}$ Wroschen Prinzip, (las ron beliebigen. richtungslosen leranderungen ausgeht und sie allein dureh Selektion zur Er\%eugung zweckmäbiger und der Umgebung angepabter Naturprodukte gerichtet und geoldnet werden läbt, bezeichet NïGELI seine Auffassung von der Entwicklung der Organismen als , die T'heorie der bestimmten und direkten bewirkung" (l. c. S. 28t).

Ämliche Ideen vertritt Ener in seinem Buch: Die Entstehung der Arten auf Grund von Vererben erworbener Eigenschaften nach den Gesetzen organischen Wachsens.

Auber den angeführten. mehr theoretischen Sehriften, welchen sich noch manche andere anreihen, ist der Lamarckismus in unserem , Jahrhundert durch Sammlung von Tatsachen und Beweisen geförlert und

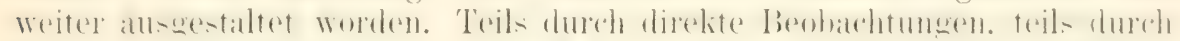

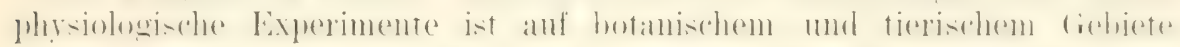
gezeigt Worken, wie die Ausbildungr. und die besondere Gestaltung von Organen und Geweben durch äubere Faktoren, wie Schwerkraft, Druck und Zug, Wäme. Licht, chemische Stofte etc., in bestimmter Weise beeintlufit wird.

Auf botanischem Gebiete erimere ich an ScHwexpexer. dessen

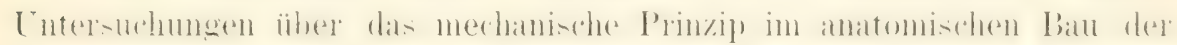
Monokotylen hier als mustergültige zu nennen sinr, an SAcHs und seine Schule, an die Arbeiten von Pfeffer, Goebel, Stanl, Iöchtixg. KLEBS, KELLER und vielen andern. Die verschiedenen Umgestaltungen. die sich an den Organismen durch die angeführten Faktoren bewirken

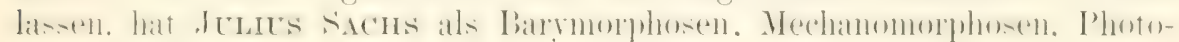
morphosen. Chemomorphosen zu klassifizieren gesucht.

Ähnlichen Bestrebungen begegnen wir auf tierischem Gebiete bei

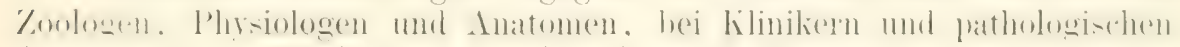
Anatomen. Im Vordergrunde stehen hier die Untersuchungen über den

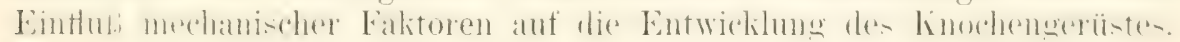
Man denke an die Arbeit von SEDrLlot 1864, sowie an die Entrleckung

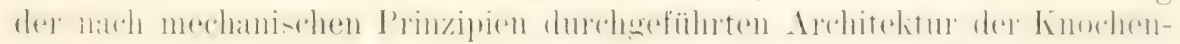
spongiosa durch HERMANx y. MEYER und an die sich anschliefende Literatur. von welcher Julius WoLfF die beste Zusammenfassung in seinem Gesetz der Transformation der kinochen gegeben hat.

Eine andere Reihe von Untersuchungen betriftt die Einwirkung von Licht. 'Temperatu und chemischen Agentien. Es sei nur kur\% auf die

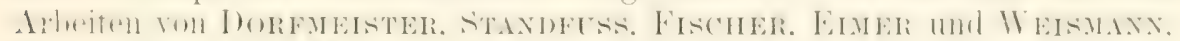
Merrtfield, von Maupas, Nussbaum und Born. yon Batesox, Costa. Gies. Herbst, Hertwig. Kissowitz, Wagner, von Loeb. Schalanewitseh. Pouchet mil Chabri verwiesen.

Besonders zahlreiche Ergebnisse aber hat die experimentelle For-

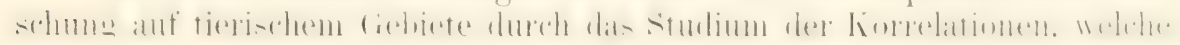
zwischen den einzelnen Organen stattinden, zutage gefördert.

Pathologisch-anatomische und klinische Archive bilden hier eine reiche Fundstätte der verschiedenartigsten 'Tatsachen.

In einer Reihe von Arbeiten hat Roux das Studimm der funktionellen

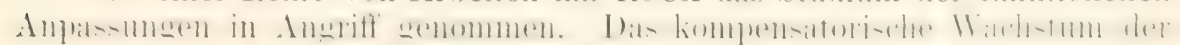

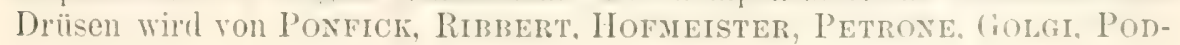


Wyssozkr, ZIEgier, Rogowitscu u. a., die Blutbildung von Neuman, Bizzozero, FOA. KORN, Denys u. a., die Wachstumskorrelationen von

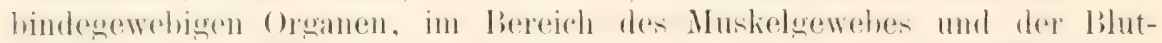

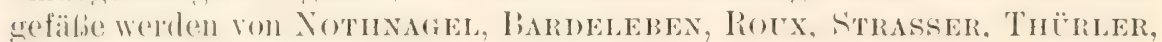
THOMA и. a. untersucht.

Einen jüngsten Sproß endlich auf diesem Gebiete bildet die Unter-

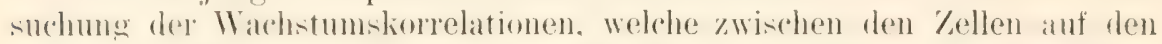
fröhesten Stadien des Entwicklungspromesses stattinden. I)uroh Intersuchungen zahlreicher jüngerer Forscher. Wolche durch eine lebhaft weführte Polenik angeregt wurlen. sind hier: in wenigen dahren einige grmullegende Tatsachen festgestellt worden (C'HABRy, ('Hun, ('RAMptox. Driesch,

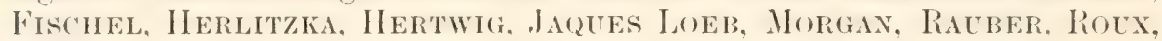
Oskar Schultze, Wetzel, Wilson, Zoja).

So ist im Laufe der letzten 50 Jahre in der Literatur ein reiches Tatsachenmaterial über den Finthb änberer und innerer Falitoren auf die (iestaltbildung bei Pthanzen und bei Tieren angehäuft worden. Von ihm habe ich in diesem Buche eine Zusammenstellung zu geben versucht, welche freilich noch eine sehr unvollständige ist mol sich bei einer systematisch vorgenommenen Durchsicht der Literatur noch um viele lieinjuele leicht würde vermehren lassen.

Während das Lamarcksche Prinzip der bestimmten und direkten Bewirkung yon DARwin, HAEckel u. A. angenommen, besonders aber von Herbert Spencer und Nägeli in seiner ganzen Tragweite für die Erklärung ter organischen Entwicklung erkannt worden ist. während ferner das Tatsachenmaterial. das - sich zu seinen Gunsten verwerten läl.t. von Tag zu Tag wächst, hat es auch nicht an Stimmen gefehlt, welche sich gegen seine Bedeutung ausgesprochen haben.

Als entschiedenster und bedeutendster Gegner des Lamarckismus ist in Laufe der letzten zwanzig Jahre WEISuAN bei verschiedenen Gelegenheiten und in zahlreichen sichriften anfuetreten: er ist dahei in eine heftige und interessante literarische Fehde über die Ursachen der organischen Entwicklung mit Herbert spexcer geraten. In seinen streitschriften: 1. Die Allmacht der Naturzüchtung, 2. Neue Gedanken zur

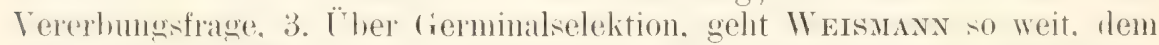
IAdurckschen Prinzip jede Bedeutumg für die Veränderung der Organismenwelt ahzuspechen. Als einziges natioliches Erklämugsprinzip erkennt er nur den I)ARWixschen Faktor, die Selektion oder die Auslese de- Existenzfähigen, mit einem Wort, , die Allmacht der Naturzïchtung" an. "Naturzüchtung bewirkt nach WEISMANN allein alle Artanpassungen."

Wodurch WEIsMans in seine prinzipielle Gegnerschaft gegen den Lamarckismus geführt worden ist, wird erst verständlich, wenn wir uns dem

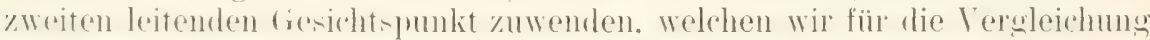
dex vershiedenen Entwicklungsheorien anfgestellt hahen. Was jetzt geschehen soll.

\section{I) Lehere von der Übertragung erworbener kigenschaften auf den Keim. (Die Vererbungstheorie.)}

Eine notwendige Ergänzung zum Lamarckschen Prinzip bildet die Lehre von der Übertragung erworbener Eigenschaften auf den Keim. Dies spricht sich schon darin ans, dab LAMARcK in seiner zoologischen Philosophie sofort an die Formulierung seines ersten Grundgesetzes (s. S. 281) cin zweites Gesetz angeschlossen hat, welches heiBt: 
,Alles. was die Tiere durch den Einflul, der Verhältnisse, denen sie

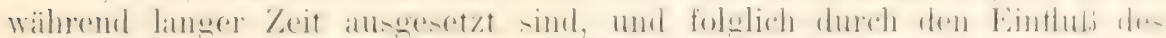

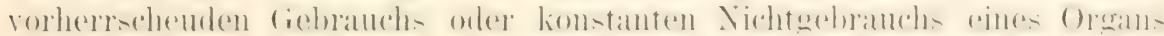

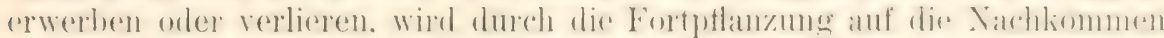
vererbt, vorausgesetzt, dab die erworbenen Veränderungen beiden Ge-

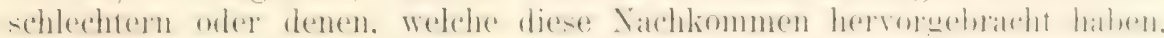
gemein seien".

Zu seinen zwei Gesetzen fügt LAmarCK gleich noch die Worte hin211: ..Es sind dies zwei bleibende Wahrheiten, welche nur von denen

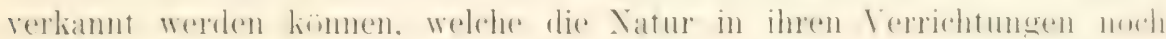
nie beobachtet und rerfolgt haben."

Beide Gesetze gehören allerdings untrennbar zusammen. Nit dem

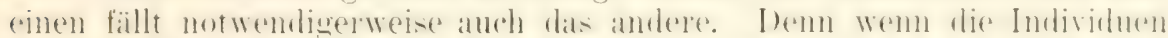

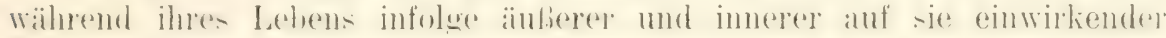
Faktoren neue Eigenschaften zwar erwerben, der Erwerb aber nicht zu-

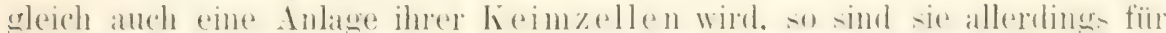

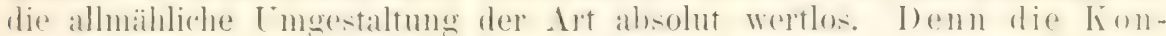
timuitä der Entwicklung ist ja an diesem einen Punkte unterbrochen.

Wir sehen daher, dab alle Forscher, welche das LAmarcksche Prinzip) angenommen haben. anch in dieser oder jener Form an der Lehre von der Vererbung erworbener Charaktere festhalten; so vor allen Dingen

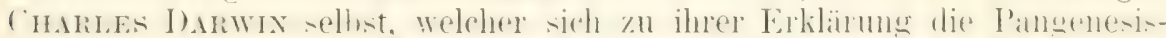
theorie ausgedacht hat, Herbert SPExcer, HAECKEL, N̈̈GELI.

HAECKEL hat in der generellen Morphologie der Lehre folgende For-

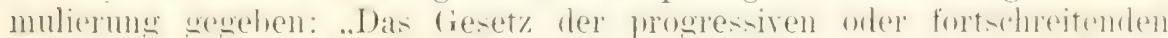

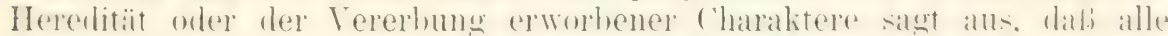
Deszendenten von ihren Eltern nicht blof die alten. von diesen ererbten. sondern auch die neuen, von diesen erst während ihrer Lebenszeit er-

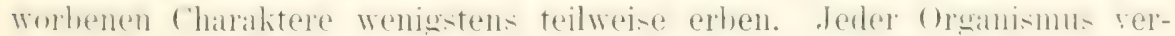

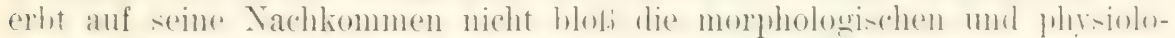

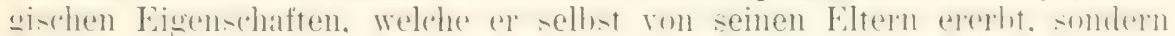

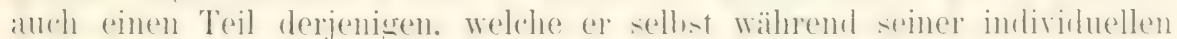
Existenz durch Anpassung erworben hat: (l. c. S. 178).

Indessen birgt die Frage nach der Vererbung erworbener Charaktere. wenn man tiefer in den Gegenstand einzudringen sucht und nach den

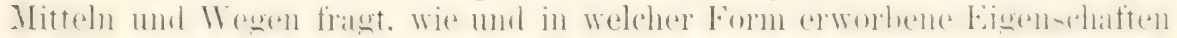
auf den Keim ïbertragen werden, ihre Schwierigkeiten.

Zwar haben DARwix, SPExcer. Herixg und Nïgel sich Vererbungs-

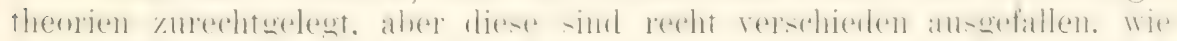
die Pangenesistheorie von DARWIx, die (iedächtnistheorie von HERIXG und die Idioplasmatheorie ron NïGELI.

In seiner Übersicht über .,Alte und neue Probleme der Phylogenese"

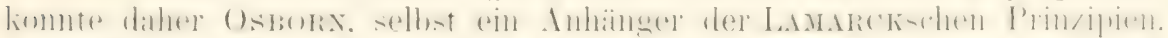

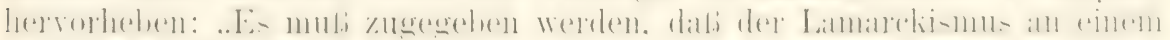

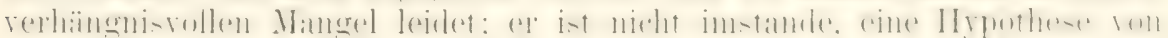
heuristischem Wert über die Natur der Vererbung aufzustellen. ganz im Gegensatz zum Neu-Darwinismus nit seiner einfachen und urachtrollen .Stamm- (stirp-) oder , Kontinuitätshypothese". Wer an eine Úbertragung von erworbenen Variationen glaubt, wird offen zugeben missen, (lat. wir

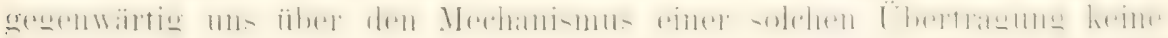
Yorstellung zu machen imstande sind. Damit schlielien wir jedoch nicht die Möglichlieit aus. daß ein solcher Mechanismus vorhanden ist. und es 
wäre unlogisch, wenn wir ihn ableugnen wollten, weil wir ihn nicht kennen. Andererseits ist es erstens sehr wahseheinlich, dab wir noch nicht alle in der lebenden Materie tätigen Kiäfte kennen; es kann sehr wohl eine bis jetzt noch völlig unbekannte kraft vorhanden sein, und zweitens sind wir gezwungen, einen Mechanismus der genamnten Art anzunehmen, wenn sich die Übertragung erworbener Variationen induktiv nachweisen läßt."

Die Geschichte lehrt, daß gegen die V'ererbbarkeit erworbener Charaktere sich zu allen Zeiten einzelne Forscher ausgesprochen haben, bald aus diesen. bald aus jenen Gründen. Von keiner Seite aber ist es mit solcher Energie

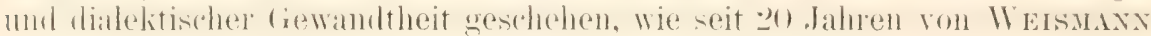
in seinen populär gehaltenen und polemisch gefärbten Schriften zur Entwicklungstheorie. Dadurch ist WEISAIANN zum Vertreter einer besonderen Richtung geworden, die man als Neu-Darwin ismus bezeichnet hat.

Indem WEIsManN die Vererbbarkeit funktioneller Abänderungen oder erworbener Charaktere auf das entschiedenste in Abrede stellt, wird er konsequenterweise auch zum Gegner des Lauarckschen Prinzips, welches in der Desrendenztheorie von Darwin, Haeckel, Spencer, Nägeli ete. eine so bedeutende Rolle spielt. Um die dadurch entstandene Lücke in der Deszendenztheorie auszufüllen, muB er das von DARWIN aufgestellte Prinzip) weit über die von seinem Urheber gezogenen Grenzen selbst ausdehmen. Daher führt auch eine seiner Schriften den prägnanten Titel: .Die Allmacht der Naturzïchtung*.

An Stelle der Entwicklung aus bestimmten Ursachen, an Stelle der

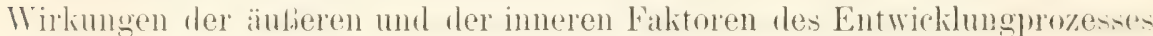
tritt in WeIsmanss Theorien als Ersatz die zufällige und richtungslose Variabilität der Keimzelle und Naturzüchtung auf allen Stufen der Entwicklung.

Anstatt den Versuch zu machen, den Ursachen und Wirkungen, überhaupt den Gesetzen in der Entwicklung der Organismenwelt nachzuforschen, werben unhestimmte, vichlentige und ..in metaphorischem simne" gehrauchte Auslrüclie, wie Kampt ums Dasein, Auslese, natürliche Zuchtwahl, als „erste Erklärungsprinzipien“ auf alle organischen Naturprozesse ausgerlehnt. Der Kampf ums Dasein, welchen DARWIN pflanzliche und tierische Individuen untereinander und mit der Natur führen läßt, wird anch auf die im XIV. Kapitel unterschiedenen Arten der Indiridualitätsstufen übertragen. Wir erhalten den Kampf der T'eile im Organismus, welchen Titel Roux einer seiner Schriften gegeben hat. Und nicht nur

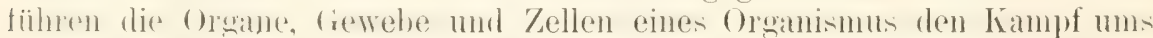
J)asein mitcinamler, aus welchen sich alles nach mechanischen Prinzipien auf das beste erklären soll, dasselbe Schauspiel wiederholt 'sich zwischen den kleinsten Teilchen der Zelle noch eimmal; vom Keimplasma wird uns ebenfalls ein Kampf (ler Keimesanlagen mit Bevorzugung des Besseren ron WEISMANy geschildert.

An die Personalauslese von Darwin und WALLACE schliegt sich die Histonalauslese von Wilherm Roux. an diese die Germinalanslese orler die Intraselelition, in welcher Weisunans die letzte Konsequenz der Anwendung des MalThusschen Prinzips auf die lebende Natur erblickt ${ }^{1}$ ).

1) Daß man durch Redewendungen, wie Lampt der 'Teile im Organismus, Intraselektion, Histonalauslese, Germinalanslese, in dem Verständnis organischer Naturprozesse um keinen. Schritt rorwärts kommt, scheint mir offen zutage zu liegen. Man erfäht hierdurch von dem. was sich im Organismus abspielt, nicht mehr, als der Chemiker von dem Zustandekommen einer chemischen Verbindung erfahren wiole, wenn er sich mit der Formel eines, ,hampfes der Moleküle im Reagenzglas", als einem chenischen Erklirungsprinzip, zufrieden geben wollte. 
Mit der Preisgabe der V'ererbbarkeit erworbener Charaktere durchbricht WeIsuaxy die Rontinuität des Entwicklungsprozesses. Welche in den Beziehungen des sich entwickehnden Körpers. der allein den Einwirkungen der Anfenwelt direlit unterworten ist, zu den in ihm eingeschlos-

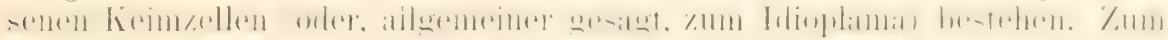

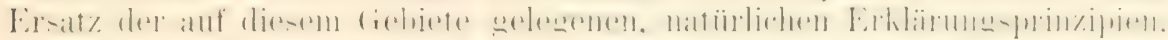
die auf dem Kausalgesetz fuben. bietet el die Hypothese einer Geminalselektion. ohne uns aher des näheren zu verraten, in welcher Weise Ursachen auf die líeimzelle so einwirken kömnen, dab aus dem Kampte der Anlagen im Keim vielzellige, an alle möglichen Einwirkungen der Aubenwelt angepaßte liörper hervorgehen kömnen, und ohne uns einen Weg

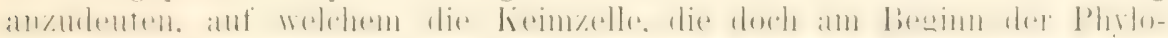
genese an Anlagen sehr arm war, überhaupt ihre zahllosen Anlagen zu der höheren Organisation des aus ihr entstehenden, vielzelligen Körpers hat gewinnen kömnen.

Um die Schwierigkeit zu umgehen, die Erblichkeit zu erklären, hat

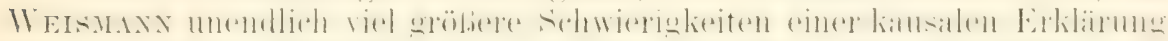

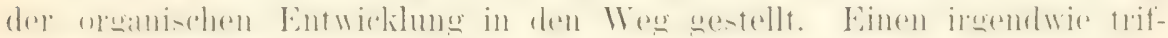
tigen lieweis aber gegen die Vererbbarkeit hat er in keiner seiner Sehriften geführt. Teils wendet er sich gegen spezielle Fïlle, wie besonder's die Vererbung von zufäligen Verletzungen (Narben, Zirkumzision etc.), auf welche wohl niemand ein grobes Gewicht legen wird, teils hat er sich

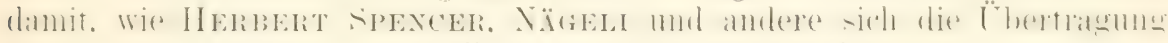
erworbener Charaktere vorstellen, gar nicht auseinandergesetzt.

Dab die erworbenen. sichtbaren Strukturen als solche vererbt werlen. z. B. die Bälkchen der Spongiosastruktur (siehe Weisuraxx: ÄuBere Einfliisse etc.. S. 10), hat niemand behamptet, welcher sich tiefer mit dem Vererbungsproblem beschäftigt hat. Im Gegenteil wird ron den Anhängern der Idioplasmatheorie und so auch von mir betont, dab die für Ver-

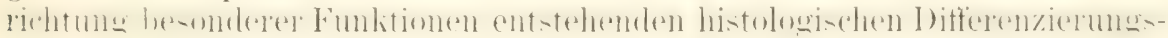
produkte (die formed matter) stets von den Zellen als der bildenden Sub)-

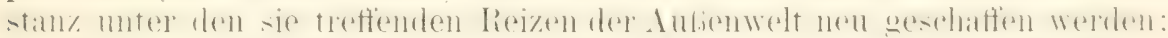
was daher vererht wird. ist nicht die Struktur als solche. sondern die Reizbarkeit der Zelle, unter bestimmten Bedingungen in gleicher Weise zu reagieren. Die Anlagesubstanz oder das Idioplasma ist es, welches sich unter den äuberen und imneren Faktoren des Entwicklungsprozesses ver-

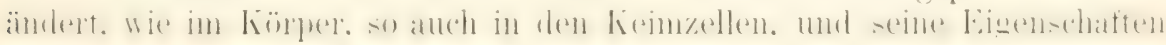
vererl)t.

Dem negierenden Standpunkt von WEISuAxy hat man auch Beifall aus dem Grumde gespendet, dah man sich über den Mechanismus der

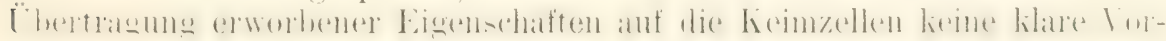
stellung hat machen können. Darauf ist nur zu antworten, daßs es mit der mechanischen Erhlärung vieler anderer Lebensprozesse auch nicht besser steht. (Man vergleiche meine Schrift: Mechanik und Biologie und S. 571 (lieses Buches.)

Die Schwierigkeit, einen Mechanismus auszudenken, kamn also auch kein Argument zu Cngunsten einer Vererbbarkeit erworbener Charaktere bilden. Alles in allem liann es uns nicht als ein Vorzug irgend einer Entwicklungstheorie erscheinen, wemn sie ohne den Falitor (ler Vererbung auszulommen versucht. Viehmehr erscheint uns in deratigen Versuchen eine Durchbrechung sowohl des Kausalgesetzes und des mechanischen

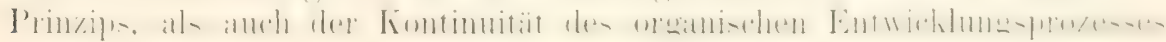
rorzuliegen. 


\section{EINUNDDREISSIGSTES KAPITEL:}

\section{Historische Bemerkungen über die Stellung der Biogenesistherorie zu anderen Entwicklungstheorien.}

(Fortsetzung.)

\section{Die Kontinuität im Entwicklungsprozeß.}

Mannigfach verschiedene Theorien sind über die Art und Weise, wie in Entwicklungsprozeli die Kontinutiat gewaht wird, anfgestellt worden.

Wir sprechen zuerst von den Tatsachen, welche durch ausgedehnte Beobachtungen festgestellt umb als sichere frumblagen vom jerler Theorie zu berücksichtigen sind, alsdann von den einzelnen Theorien selbst.

\section{A. Die durch Beobachtung festgestellten Tatsachen.}

Dank der Zellentheorie und der durch sie angeregten Untersuchungen wissen wir jetzt, dals die Kontinuität in der Entwicklung durch die Eisenschaft der Zelle, sich durch Teilung zu vermehren und neue Zellen ihrer Art hervorzubringen, gewahrt wird. Auf botanischem Gebiet verdanken wir diese Erkenntnis besonders den vorzüglichen Untersuchungen von MoHL und NäGELI, in der tierischen Histologie den Bemühungen zahlreicher Forscher. Inter denen in elster Reihe Köldner, Reichent. Rearak und VIRchow zu nennen sind (s. S. 169-171). VIRchow hat zuletzt die grundlegenden Ergebnisse über die Zellengenese in der bekannten Formel zum Ausdruck gebracht: "Omnis cellula e cellula".

Durch eine zweite Reihe von Entrleckungen ist die für das Zellenlehen nicht minder wohtige, zweite Tatsache festgestellt worden, wab) mit

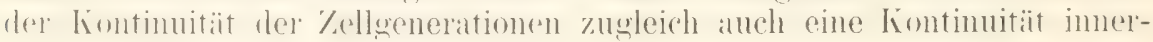
halb der Kerngenerationen einhergeht.

1875 suchte ich für die Eizelle den Beweis zu erbringen, daf sie in keinem Voment ihrer Entwiklumg ein kernloses stadium durehlänf, wie fast allgemein angenommen wurle, dab vielmehr rom Keimbläschen direkt der Eikern abstammt, daß hierauf rom befruchteten Eikern sich wieder die Kerne aller Embryonalzellen herleiten vermittelst eines 'Teil-

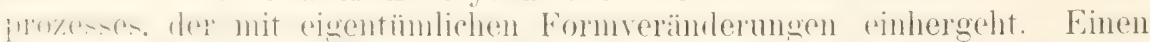

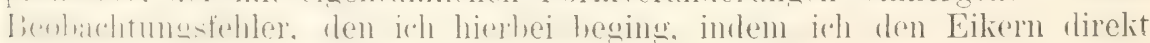




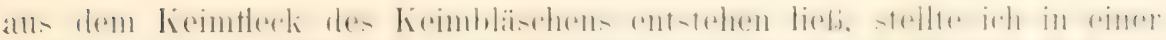

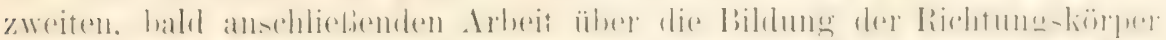
richtig und erbrachte den Nachweis, das bei dem Reifeprozel, der Lier

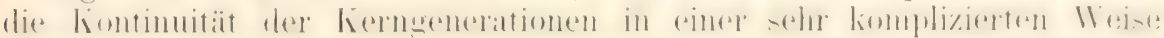
gewahrt wird.

Im Anschlub an diese Untersuchumgen betonte Ricmard HerTwig in einem kleinen Aufsatz, dab unsere Auffassung rom Kern einen ähnlichen Wandel wie unsere Auffassung von der Zelle erfahren müsse, dab. ehenso wie bei der Zelle auch beim Kern die Bläschennatur etwas Neben-

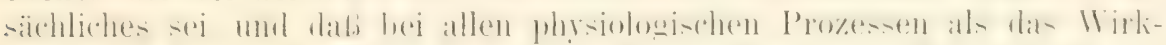

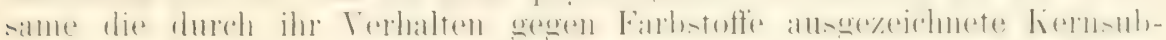
stanz. das Nuclein oder Chromatin. ehenso wie in der Zelle das P'rotoplasma, angesehen werden müsse.

Glänzende und ausgedehnte Untersuchungen von STRASBURGER, von FoL mol Frammang, denen sich noch viele bedentende Arbeiten anderer Forscher angereiht haben, stellten die liaryokinese im Pflanzen- und 'lierreich in ihrer weiten, fast könnte man sagen, wenn man von den ein-

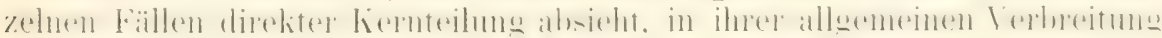
fest; zugleich wiesen Richard HerTwig, SCHuitz und andere nach, dab auch Protisten. welche man vorher für kernlose Protoplasmagebilde gehalten hatte, ebenfalls mit Kernen, die sich durch 'Teilung rermehren. versehen sind.

Das in kurzer Zeit durch zahlreiche Forscher gesammelte, imponierende Tatsachenmaterial fafte FLemang im Anschluf an die Virchowsche Formel in die Formel .Omnis nucleus e nucleo* zusammen.

Eine dritte, für die Kontinuität des Entwicklungsprozesses wichtige

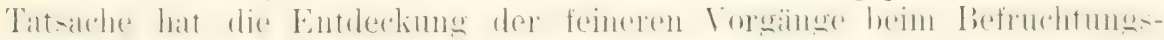
prozeß geliefert. Am Echinodermenei gelang es mir 1875 testzustellen, dal.) ein Samenfaden in den Dotter eindringt, dab sein Kopf, welcher aus

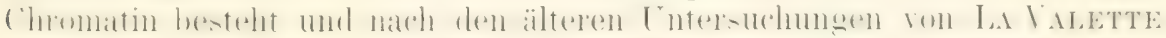

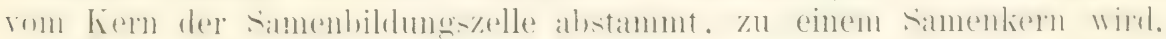
thaf Ei- und Samenkern einander entgegen wandern und durch ihre Vereinigung den mit neuen Kräften ausgestatteten Keimkern liefern. von welchem die weiteren Entwicklungsvorgünge beherrscht werden. Damit war eine materielle Grundlage für die Tatsache gewomnen, dab' das neue

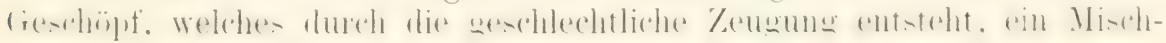
produkt aus den Eigenschaften seiner beiden Erzeuger darstellt.

Durch zahlreiche Untersuchungen wurde die GesetzmäBigkeit dieser Vorgänge für das Ptlanzenreich (STRAsburger, GurgNard), fül das Tierreich (Fol, Fleming, SElexkA, VAx BENEDEN, Boveri und andere),

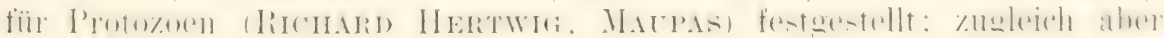
wurle unsere Erkenntnis des Prozesses auch noch weiter vertieft 1. durch die von E. VAN BENEDEx festgestellte Tatsache, dab Ei- und Samenkem

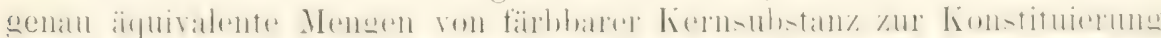

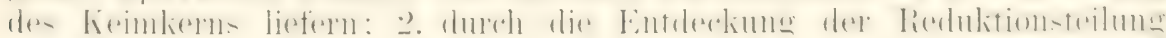
(vax Benedex. Boveri, Weismaxy, O. Hertwig, voir Rath, Rǘchert. HAECKER, BRAUER u. a.).

Eine vierte Reihe grundlegender 'T'atsachen endlich ergaben die Experimente von Driesch, WILsox, Morgax und anderen. Welehe lehrten: 1. dab die durch die ersten Teilungen gelieferten Embryonalyellen nach ilner Isoliermng wienler Ganzgebilde liefern:

2. daß sich die gegenseitige Lage der Kerne in der Eizelle erheblich verändern lälit, olme Störungen im Entwicklungsgang hervorzurufen. 


\section{B. Hypothesen uber die Kontinuität im Entwicklungsprozeß.}

Es wiirle uns zu weit führen, auf die zahlreichen verschiedenen Ansichten einzugehen, die in dieser Sache geäubert worden sind; wir müssen

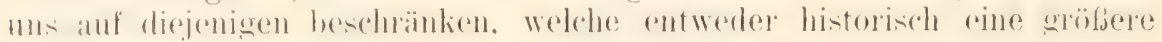

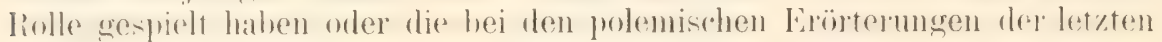
15. Jahre besonders in den Vordergrund getreten sind.

Je nachdem die Hypothesen ohne Rücksicht auf die eben mitgeteilten formblagen der empirischen Forschung oder in Anknippung an d i eselben ausgearbeitet worden sind, kömnen wir sie in zwei Gruppen teilen.

Zur ersten Gruppe gehören die Hypothesen von DARwin und GALTON, von Herbert SPENCER, von NïGELI.

\section{Erste Gruppe.}

\section{Die provisorische Hypothese der Pangenesis von DARWIN.}

In seinem großen Werk über das Variieren der Tiere und Ptlanzen hat DARWIN anch zahlreiche Erscheimungen der Vererhung zusammengestellt und den Versuch gemacht. sie ron einem gemeinsamen Prinzip aus zu erklären. Er nimmt an, daß im Körper der Ptlanzen und Tiere die einzelnen Zellen sich nicht nur auf dem Wege der Teilung rermehren, sondern andierdem zu allen Zeiten und während aller Entwiclilungszustände des ()ranismus noch unsichthar kleine Kärnchen orler Atome von sich ahstoben. welche in die Körpersifte welangen und mit dem Blut durch den ganzen Körper frei zirkulieren. Sie werden als die Zellkeimchen oder lïrzer die .Keinchen” (gemmulae) bezeichnet. Sie haben tie Figenschaft, wenn sie mit gehöriger Nahrung versorgt werden, sich durch Teilung zu vervielfïltigen. sowie auch suäter wieder zu Zellen zu werden. wleich denen. ron welchen sie herrühren. Sie haben ferner in ihrem schlummernden Zustand eine gexenseitige Verwandtschaft zu einander und werlen dadurch veranlabt. sich entweder zu Kónospen orler zu den Sexualelementen zu vereinigen.

Genau genommen wird daher ein Tochterorganismus nicht von einer Eizelle oder einer Knospe, sondern von allen Zellen der elterlichen Organismen gebildet, welche ihre Keimchen an die Sexualelemente abgegeben haben.

Die Entwicklung des Tochterorganismus aus dem Ei läßt DARwin in der Weise vor sich gehen, daß jedes Keimchen seine Zelle, von der es herstammt, wieder hervorbringt, und daß die Keimchen der verschiedenen \%ellen in derselhen Reihenfolge vermöge ihrer gegenseitigen lerwandtschaft zu einander in Tätigkeit geraten, in welcher die ihnen entsprechenden Zellen in der Ontogenese ihrer Erzeuger sich folgten.

Indes brauchen — so lautet noch eine andere Anmahme von DARwis - die ron den Fltern dem Kind überlieferten Keimchen nicht alle in diesem selbst wieder zu Zellen entwickelt zu werden, sondern sie können oft viele Generationen hindurch in einem schlummernden Zustand als latente Anlagen vererbt und erst viel später entwickelt werden. Durch solehe Annalnme sollen die Erscheinumgen des Atavismus mud des Riülischlags auf entferntere Vorfahren erklärt werden.

Wie DE Vries mit Recht hervorgehoben hat, setzt sich die Pan-

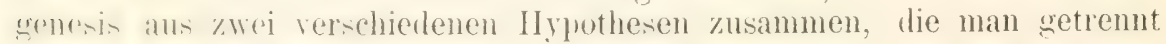
beurteilen muß: 
1. aus (ler Hypothese, dali in jeder lieimzelle die einzelnen erl)-

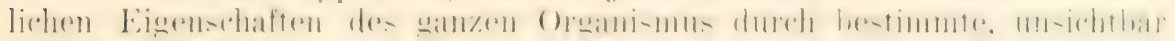
kleinste Stofteinheiten, die Keimchen, vertreten sind, welche sich durch Teilung vermeliren;

2. aus der Hypothese, daf yon allen Zellen des Körpers fortwïh-

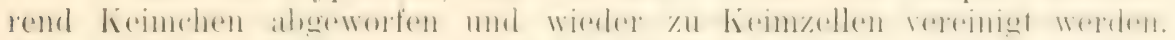
Man kann die zweite ron der ersten Annahme als "Transporthypothese" unterscheiden.

Wie von verschiedenen Seiten mit Recht schon hervorgehohen worden

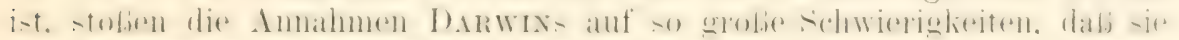

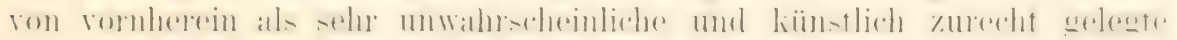
bezeichnet werlen müssen.

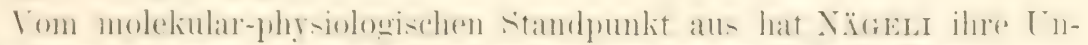

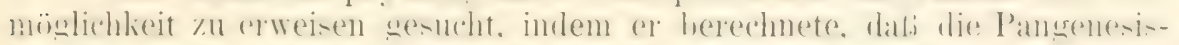

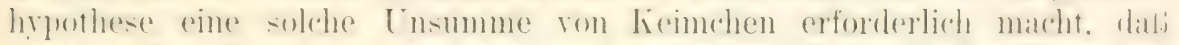

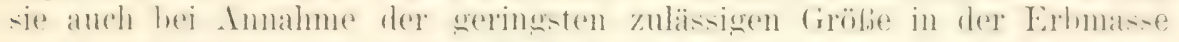
cines Samenfadens gar keinen Platz finden würden.

Mit nicht minderen Schwierigkeiten ist die Annahme einer Zirku-

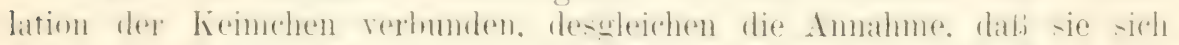

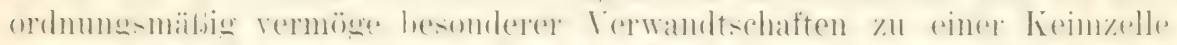

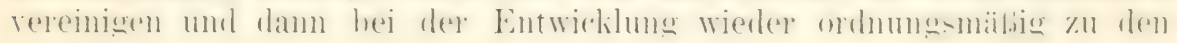
Geweben und Organen umbilden sollen.

\section{GALTONS Theorie vom Stirp.}

Bald nach dem Erschemen yon DARwins provisorischer Hypothese

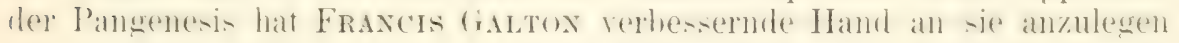
versucht. In einem 1875 erschienenen kurzen Aufsatz: .A theory of here-

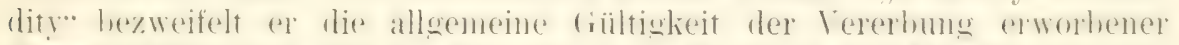

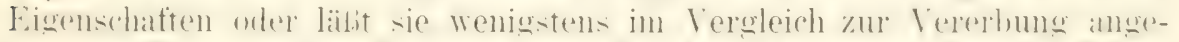

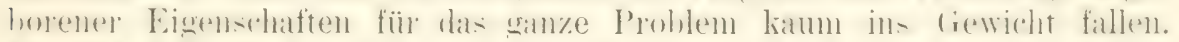

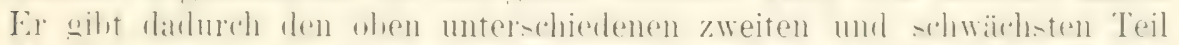

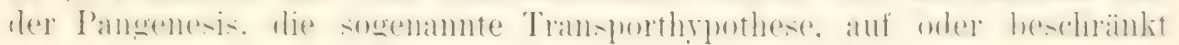
sie wenigstens auf ein Mindestmak.

Anstatt einer allgemein stattfindenden Abgabe und Zirkulation ron

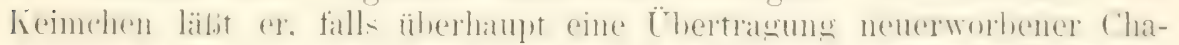
balitere stattinder. nur selten eimmal rom der hörperzelle sich ein lieinchen ablösen, das in die Blutbahn gerät und so Gelegenheit erhält, sich mit den Geschlechtszellen zu vereinigen.

Zur Erklärung der Vererbung behält GALTOx nur den ersten 'l'eil der Pangenesis. die Amnahme zahlloser Kemehen, bei. die in den Ge-

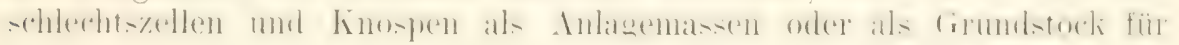
das neue Individum, als ..Stirp ${ }^{66}$, eingeschlossen sind. Zum Ersatz der

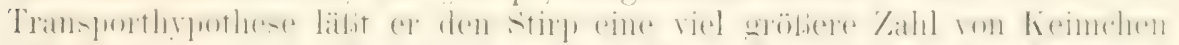

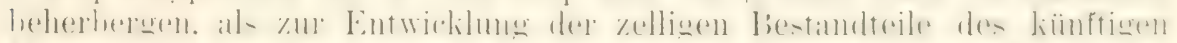

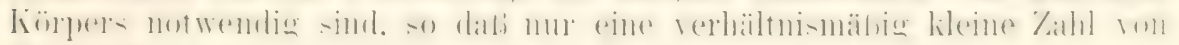
ilmen während einer Ontogenese zur Entwicklung gelangt.

Er nimmt also im Stirp zwei Gruppen von Keimchen an: Die eine

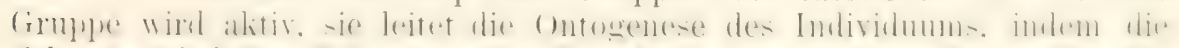

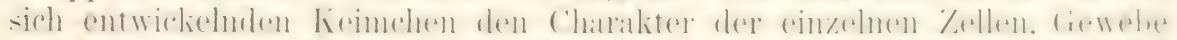

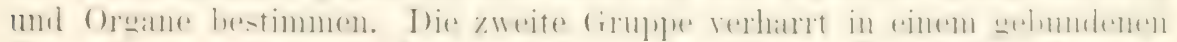

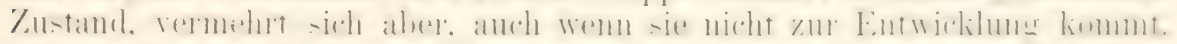

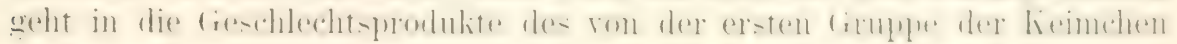


(rebildeten Individumms ïlore nnd stellt so den stirp der folgenden (ieneration dar.

Bei der geschlechtlichen Fortpflanzung findet nach GaLTon eine Vereinigung von zwei Stirps statt, von der Ei- und von der Samenzelle. Da num aber im Laufe der Generationen der Stirp sein Volumen nicht verändert. muß er allmählich auf die Hälfte der Keimchen reduziert werden. Zu dem Zweck nimmt GaLTon zwischen den Keimchen, welche durch die Befiuchtung zusammengefüht werden, ,a sharp struggle for

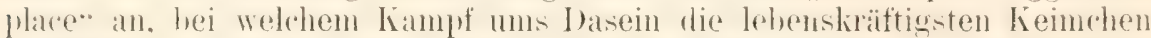
den sieg davontragen und später allein als Erbschaftsträger zur Creltung kommen.

Galtons Lehre vom ,Stiry" hat sehr große Ähnlichkeit mit Wersmaxs liomplasmatheorie, in welcher die in ihn enthatenen frundzäge in Totail weiter ausgeabeitet sind. (regen beide lasen sich die sleichen Einwändle erheben, so daß ihre weitere Besprechung auf später verschoben werden kann.

\section{HERhert Spexckis Hypothese von den physiologischen Einheiten.}

Um die Erscheinungen der Fortpflanzung and der Regeneration aus

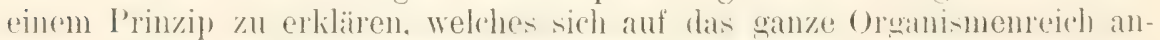
wenden läßt. macht HerberT Spencer die Annahme, daß PHanzen und Tiere sich ans kleinsten Teilchen zusammensetzen, welche die Fähigkeit haben, aus sich wieder das Ganze oder verloren gegangene T'eile desselben zu erzengen.

[Auf die verwandte Ansicht von JoH. MÜLLer braucht hier nicht näher eingegangen zu werlen, da der Passus, welcher sie enthält, schon an einer früheren Stelle (S. 4:3) aus seinem Lehrbuch der Physiologie wörtlich wiedergegeben worden ist.]

Herbert Spencer hat seine Hypothese in seinen Prinzipien der Biologie, allerdings auch nur in kurzen und allgemeinen Umrissen, entwickelt. Er vergleicht die Fühigkeit eines Organimus, sich selbst wieder zu ergänzen, wenn einer seiner Teile abgeschnitten wurde, der Fähigkeit -eines verletzten Kristalls, sich selbst zu ergänzen.

.In beiden Fällen wird die neu assimilierte Materie so abgesetzt, daß die ursprünglichen Umrisse wieder hergestellt werden. Und wemn wir hinsichtlich des Kristalls annehmen, dah das ganze Aggregat über soine Teile eine aewisse Kraft ansïhe, welche lie nen integrierten Molekïle zwinge, eine bestimmte Form anzunehmen, so muissen wir bei dem Organismus wohl eine analoge Kraft voraussetzen." Wie den Kristall aus Molekülen, die nur in einem bestimmten System zu kristallisieren die Fähigkeit haben, so lälit II. SPEACER jerle Organismenspezies aus klemen Einleiten anforelatut werden, denen ein hxonderer Bamplan zulomment. nach welehem sie sich sellst anzuorinen und die Gestalt des Organismus zul erzengen streben, welchem sie angehören.

„Es scheint zunächst schwierig," bemerkt H. SPEncer zu seiner Annahme, ,sich vorzustellen, daß sich dies so verhalten kömne; allein wir sehen, daß es so ist. Gruppen von Einheiten, die wir aus einem ()ranismu herannehnen. hesitzen in der Tat das Vermögen, das ganze von neuem aufzubauen: und wir sind somit genötigt, anzuerkennen, dab allen Treilen des Oromi-mus das strehen innewohnt, die spezifische Form anzunelimen.6" 
H. Spexcer nennt die jeder Organismenart zugrunde liegenden kleinsten 'feilchen "lie physiologischen Einheiten" und ihr Vermögen, sich in emer speziellen Form anzuordnen, ihre ,organische Polaritä" oder die Polarität der organischen Einheiten. Er lälit sie jhrem

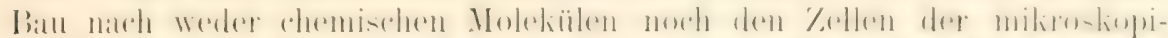

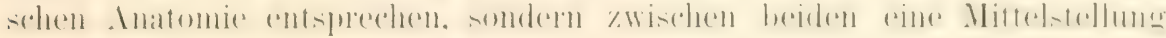
eimmeltmen.

.Es scheint nichts anderes übrig zu bleiben," bemerkt SPExcer,

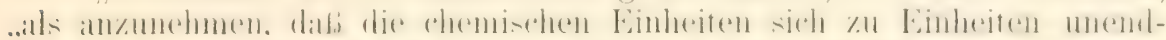

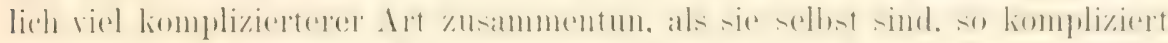
sie auch sein mögen, und dalj in jedem Organismus die durch eine solehe

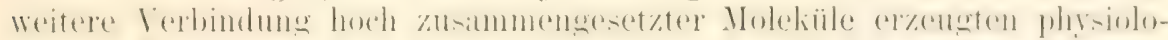

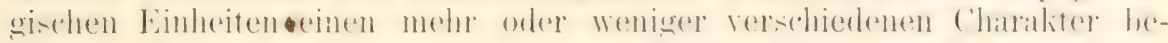
sitzen. Wir müssen schliefen, dab in jedem ralle irgend eine kleine Verschiedenheit in der Zusammensetzung dieser Einheiten zu einer ent-

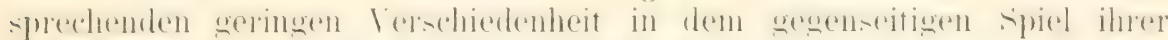

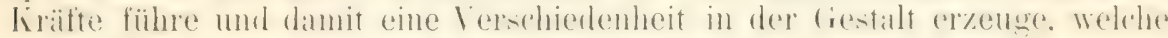
das aus ihnen gebildete Aggregat annimmt."

\section{Die Idioplasmatheorie von NïGELI.}

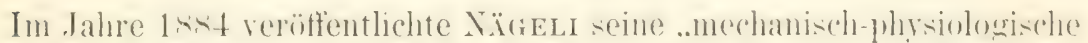

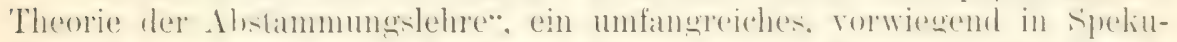

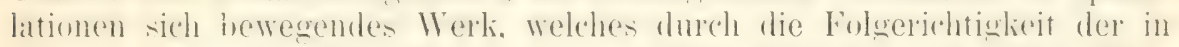
ihm vorgetragenen doengänge einen groben Einflub nach viclen Richtungen ausgeübt hat.

NüGELI geht von dem Axiom ans, daß die mütterliche und die

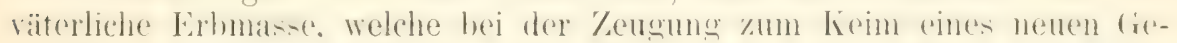
schöpfes vereint werden, ungefähr gleich grob sind, obgleich der Vater

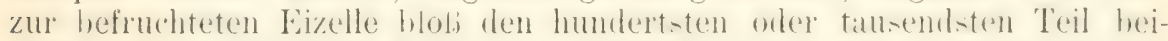
getragen hat. Er zieht hieraus den Schlub, daß in den Geschlechtsprodukten und in allen aur dem befruchteten Li abstammenten \%ollen zwei verschiedene Arten von Substanzen enthalten sein müssen, welche er

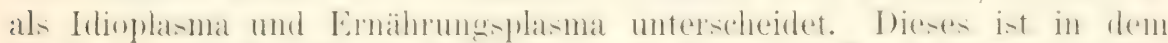

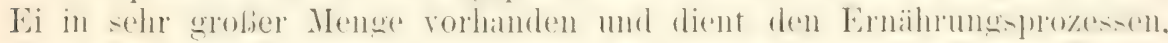

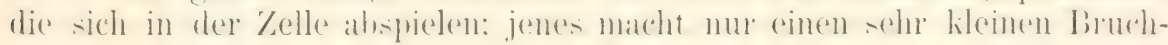
teil des Eies aus und ist der' 'Träger der erblichen Eigenschaften, da

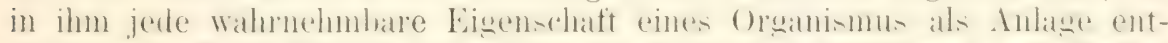

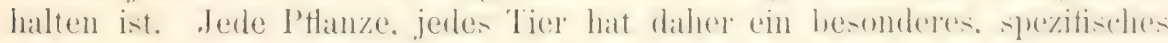
Idioplasma.

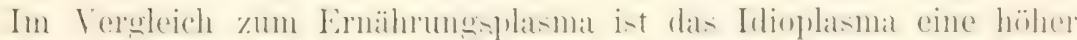

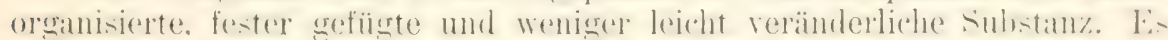

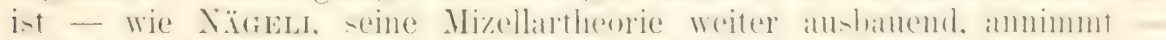

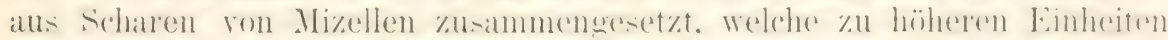

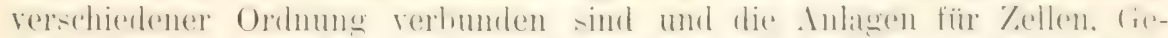

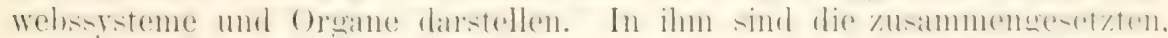

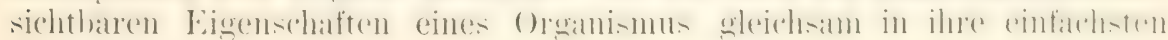
Elemente zerlegt etc.

NïGELI läßt ferner die Mizellen zu Strängen verbunden sein, die

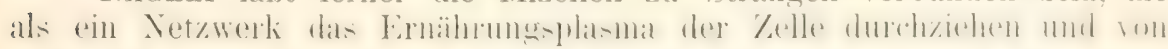
hier sich liontinuierlich auf andere Zellen fortsetzen, so dab der ganze

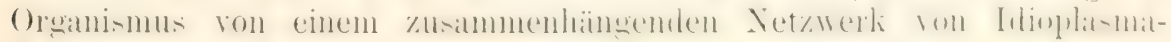
fälen durchsetzt ist. 
I) a jerler Faden alle Anlagen enthält, die das betreffende Individuum als Keimzelle geerbt hat, so ist jede Zelle des Organismus idioplasmatisch befähigt, zum Keim für ein neues Individuum zu weldon. ()h diese befähigung sich verwirklichen kam, lälit Yägeur von (ler Beschaftenheit des Ernährungsplasmas abhängen.

Dat Idioplatma verursacht in den Zellen chemische und physikalische Vö̈nderungen dadurch, dab in seinen Strängen infolge irgendwelcher Anstible hestimmte Mizellgrupen in 'Tätigkeit treten, und beeinflubt dadurch den Verlauf der Ontogenese.

Lis kamn endlich selbst in der Konfiguration seiner Mizellen, allerdings nur langsam und im Verlauf grölerer Zeiträume, unter dem Einfub änlerer Reizwirlungen Veränderungen erfahren. Alle ,von der Aubenwelt auf den Organismus ausgeühten Reize werden anf das Idioplasma fortureptianzt. Da der Organismus bei jedem Wechsel der Ontogenese zugrumble seht und nur das Idioplasma auslauert, so bewirken die äuferen Einflisse einzig in dem letzteren bleibende Veränderungen, welche erst, narchlem sie zu fertigen und entfaltungsfähigen Anlagen sich entwickelt halben. an dem Organismus sichthare Lmbildungen hervorbringen" (S. 535).

..Die von auben kommenden Reize treften den Orwanismus gewöhnlich an einel hestimmten Stelle; sie bewirken aber nicht bloß eine lokale Umänderung des Idioplasmas, sondern pflanzen sich auf dynamischem Wege auf das gesamte Idloplasma, welches durch das ganze Individum in ununterbrochener Verbindung sich befindet, fort und verändern es überall in der nämlichen Weise, so dab die irgendwo sich ablösenden Kíme jene lokalen lieizwirkungen empfunden haben und vererben" (S. j:st).

Auf diesem Wege nimmt also NäGeli ebenso wie Herbert Spencer eine Übertragung neuerworbener Charaktere an.

So etwa lauten die Hauptgedanken der Itlioplasmatheorie, an welche ihr Trheber noch nach vielen Richtungen hin lehrreiche und geistreiche Erörterungen angelnüpft hat. Eine gewisse Übereinstimmung derselben mit der Theorie der physologischen Eimheiten in den allgemeinsten Fragen liblt sich nicht verliemen, obschon die Ausführmg in einzelnen ihr ein ganz anderes Aussehen verleiht.

Beide Theorien haben ihre starke und ihre schwache Seite in derselben Richtung.

Ihre Stårke liegt bei beiden in der streng logischen und auf guter (xpundlage durchgeführten Spelulation. Bei der einen wie bei der andern scheinen mir ihre arundlegenden sätze und die daraus abgeleiteten Folgerungen nicht leicht zu wirlerlegen. In spekulativer Hinsicht glaube ich sie daher als die Fundamente bezeichnen zu müssen, auf welchen in Zukmuft jede Entwicklungs- und Vererbungstheorie wird weiter bauen miissen.

Die schwache Seite besteht sowohl bei SpEncers Lehre von den physologischen Einheiten. wie hei Nïgerss Lehre vom Idioplasma darin, daß sie reine Spekulationen sind, daf sie in der vorliegenden rorm keine Verbindung mit der empirischen Forschung gestatten und sie daher auch nicht beeinflussen können. Damit fehlt ihmen aber fiir ihre eigene weitere Entwicklumg der feste Grund und linklen. Welcher in den Erscheinungen der realen Wirklichkeit für alle Naturwissenschaft gegeben ist.

\%ur \%eit, als II ER BERT SPEACER seine Iypothese der physiologischen finheriten anfetelte. Wall die allgemeine Anatomie und Physiologie noch

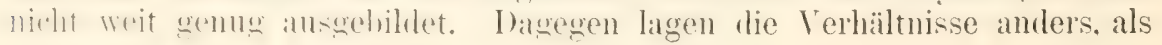




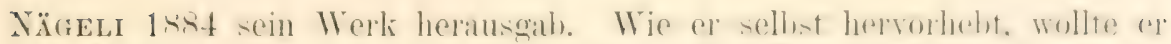

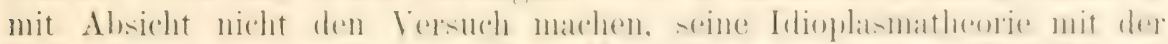

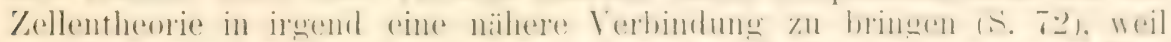

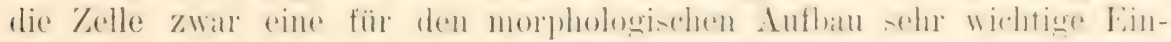
heit, aber nicht etwa allgemein die Einheit schlechthin sei.

„Unter Einheit", bemerkte er, „müsse man, physikalisch aufgefaßt, ein System von materiellen 'leilen verstehen. Es gebe demmach in der

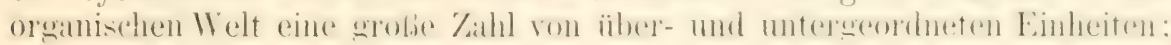
die Pflanzen- und Tierindividuen - die Organe, Gewebsteile - Zell-

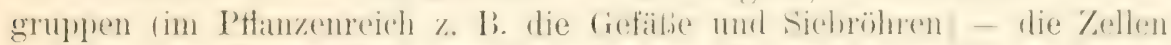
- Teile von Zellen I'tlanzenzellmembranen. I'latmaliörper. I'lat-maliristal-

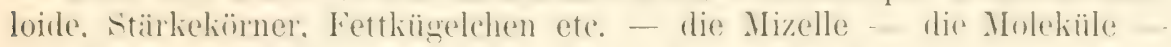
die Atome. Bald trete die eine, bald die andere Einheit in morpholo-

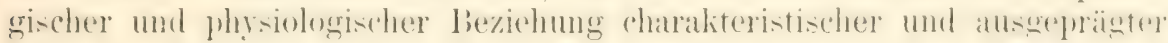
hervor. Somit sei kein Grund, warum bei einer allgemeinen Theorie eine besondere Stufe der Gestaltung begünstigt sein solle."

Wenn num auch mit NägELI anzuerkennen und nicht aus dem Auge zu verlieren ist, daf es in rler organischen Welt mehrere einander über-

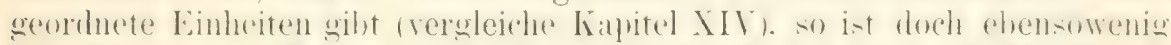

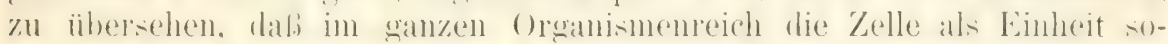

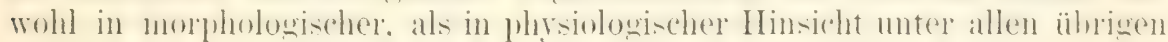

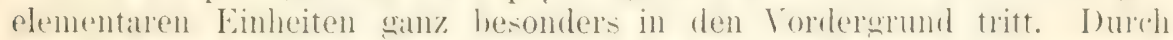

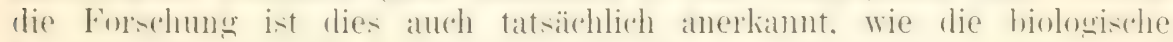
Literatur der letzten 40 Jahre lehrt. Insbesondere aber ist die Einheit der \%elle bei der Vererhung-lehre nicht \%u mongehen, weil ja nachgewiesenermalien die Einheiten, vermittelst weleher sich die Arten durch Fort. pHanzung erhaten. Sinoren. Ei- und samenfaden rom I'thanzen wie rom Tieren den Formenwert von Zellen haben.

Hier stehe ich ganz im Gegensatz zu NïGELI, mit dessen Grund-

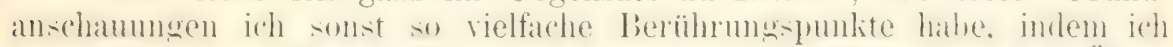

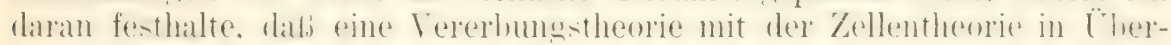

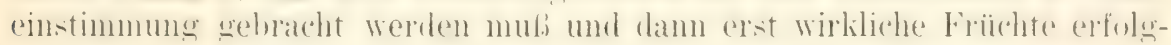
reicher Naturerkenntnis liefern wird.

Das rein Spekulative, was NïGELI als einen Vorzug, betrachte ich

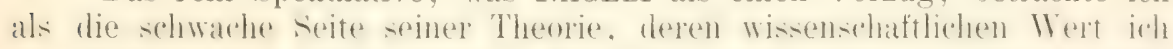
in übrigen sehr hoch schätze. Ich kann daher zwar in diesem einen

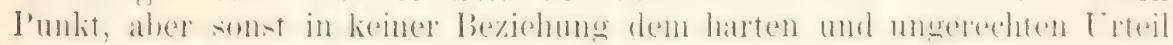
von JUL. SACHS beistimmen, wenn er sagt (S. 1202):

„Die Darwinschen Kemchen, die von den Zellen abgegeben werden. und Nägelis, Idioplamab, das in Form unsichtbar feiner Fäden den

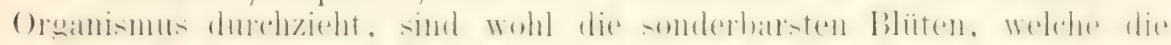

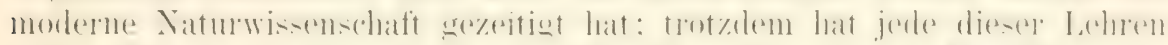

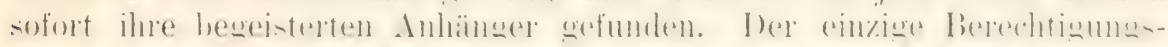

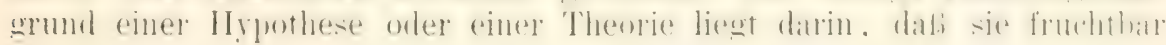
ist, daß aus ihr neue Gedanken, neue Forschungswege gefunden werden: was läßt sich aber aus diesen I'hantasiegebilden ableiten ?:

\section{Zweite Gruppe.}

Die zweite Gruppe ron Theorien, deren Charakteristik uns noch be-

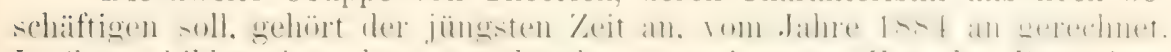

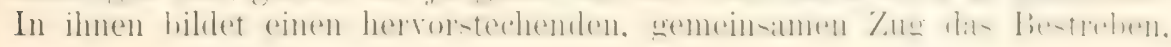


die theorotischen spekulationen mit den dureh die empirische Forschung

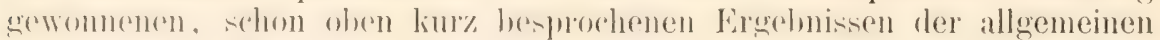
Anatomie und Biologie in Verbindung zu setzen und in ihnen eine feste (irumblage für theoretische Verallgemeinerungen zu fimlen.

Besonders in Deutschland, auf das ich hier meine historische Skizze herchäinke, sind viele Forscher in dor angedenteten Richtung mit Eifer tïtig, von Botanikern namentlich Strasburger und Hugo DE Vries, von Anatomen und Zoologen Oskar Hertwig, Roux. Weismann und DRIESCH.

Die Darstellung, wie sich die leitenden Gedanken entwickelt haben, ist mit einigen Schwierigkeiten verknüpft. Denn fast jerler Forscher ist mit riner Anzalhl oft in kuzen \%wischenräumen sich folgender Schriften anf dem Plan erschienen. Die Fäden durchkreuzen und verweben sich. Yon der einen Seite aufgestellte Ansichten werden von der anderen aufgegriffen, modifiziert und um- und weitergebildet.

Zwei mit unverkennbarer Lebhaftigkeit geführte literarische Fehden spielen dazwischen: eimmal eine mit mehrfacher Replik und regenreplik verhmolene Polemik zwischen Wersmans und Herbert Spencer, und zweitens bine nicht minder heftige P'olemik, an welcher sich auf der einen Seite Weismann und Roux, auf der anderen Seite Hertwig und Driesch beteiligten.

Bei dieser Sachlage empfiehlt es sich, erst eine orientierende Übersicht üher die Zeitfolge zu geben, in welcher sich die einzelnen Schriften der an der Bewegung beteiligten Forscher gefolgt sind, verbunden mit ciner kurzen Charakteristik der einzelnen verschiedenen Theorien; zum Schlul.' werde ich dann noch eine Zusammenstellung ihrer hauptsächlichsten Differenzpunkte geben.

Im Jahre 1884 veröffentlichten gleichzeitig und unabhängig voncinanler (Iskar Hertwig und Fo. Strasburger zwei Schriften über Befruchtung und Vererbung: 1. Das P'roblem der Befruchtung und der Isotropie des Eies, eine Theorie der Vererbung; 2. Neue Untersuchungen ïher den liefruchtungsprozel bei den Phanerogamen als cirundlage für cine Theorie der Zeugung. Anknüpfend an ihre früheren Untersuchungen des Befruchtungsmozesses und an das liurz vorher erschienene Werk ron NÄGELI, kamen beide zu dem Ergebnis, daß die Kerne, welche bei der Defruchtung allein eine Rolle spielen, die Träger der erblichen Eigenschaften sind, daher das Idioplasma von NÄGELI beherbergen. Beide lasisen die in den Zelliernen eingeschlossene Erbmasse durch den Prozeb „ler Zohlteilung im Kï̈rper gleichmäbig verhreitet werden und nähern sich dabureh abenfalls den N̈̈GELIschen Anschaumgen.

Als lieweise für die von mir vertretene Auffassung führte ich an: 1. den Verlauf des Befruchtungsprozesses, ¿2. die Äquivalenz der von den heilen Ermerern bei der Befruchtung zusammentretenden Kernstoffe, :. die an lieiner Stelle unterbrochene Kontinuität der Kerngenerationen, 4. die limplizierten Erscheinmgen der Karyokinese, welche auf eine gleichmälige Verteilung der Kernsubstanzen hinauslanfen, 5. die Isotropie des I'rotoplasmas. An diese fünf lieweisgründe lieben sich späterhin noch (ainige andere anreihen. (Man vergleiche hierüher S. 355.)

In seiner ein Jahr später (1885) erschienenen Schrift: „Die Kontimuitat des Keimplasmas als (xrundlage einer Theorie der Vererhung", trat Wemsane der Ansicht hei, dafo die Kemsubstanz das Idioplasma sei, baute aber im übrigen in der zuerst von GALTON eingeschlagenen Richtmen weiter. Fr muterchied in Idioplasma einen die Ontogenese leitenden, 


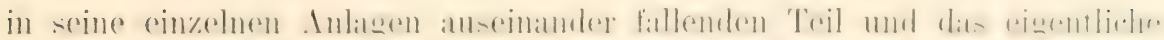

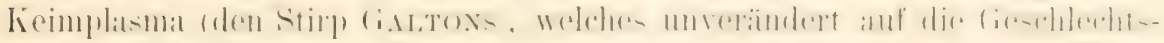
produkte der folgenden (ieneration iblortragen wird und auf diese Weise

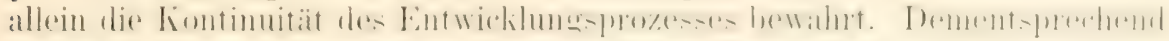

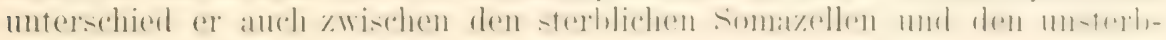
lichen Kieimzellen.

Durch die Weisuansehe Kontinutätslehre war die Nïgrusche

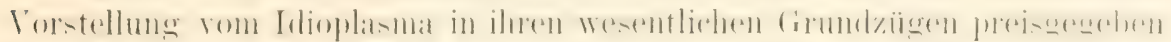
und der Gegensatz der Ansichten, welcher bei den nachfolgenden polemischen Erörterungen eine so große Rolle gespielt hat, festgestellt.

In der WeIsuaxwschen Richtung bewegten sich auch mehrere von

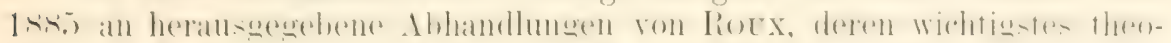

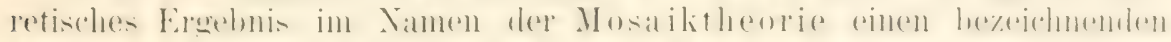

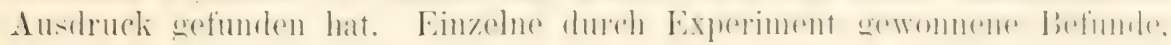
welche Roux beschrieb, waren sehr geeignet, WEISmaxy noch mehr in ien von ihm eingeschlagenen Bahnen festzuhalten.

Einen nenen Gedanken in das Vererbungsproblem brachte del holländische Botaniker Hugo DE VRIEs durch seine interessante Schrift:

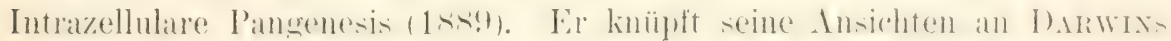

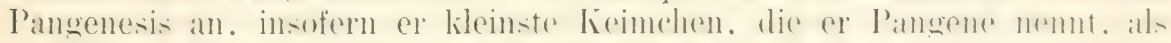

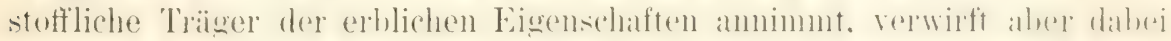
vollständig die Transporthypothese. Im Anschluß an die von STRASBURGER und mir aufgestellte Theorie läßt er allein in den Kernen, und zwar gleichmäbig in allen Zellen eines Organismus, alle erblichen Anlagen der Art vertreten sein.

Um zu erklären, wie Anlagen aktiv werden und den Charakter einer

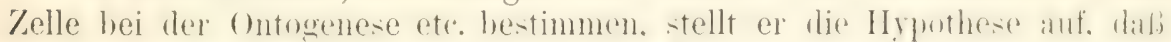
von den zahlreichen I'angenen, de in den hernen meist in einem inalitiven Zustand als Erbmasse vereinigt sind, einige aktiv werden und dabei in

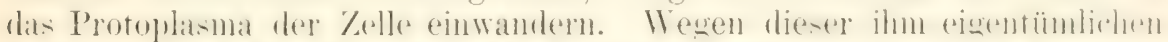

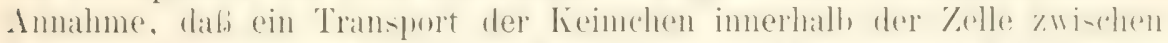

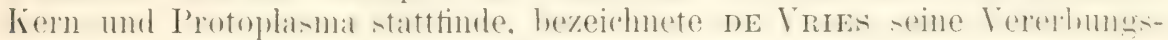
theorie als intrazellulare Pangenesis.

Vielleicht kann der yon DE VRIES neu ausgesprochene Gerlanlie für die Erlibrune mancher Voreänge in der Zelle noch fruchthat werden, wie ich bereits auf S. 36:3, 36t hervorgehoben habe.

In den Jahren 1890 und 1892 erschienen meine zwei Abhandlungen: 1. Vergleich der Ei- und Samenbildung bei Nematoden, eine Grundlage ffir zelluläre Streitfragen, und 2. Urmund und spina bifida.

In ersterer stellte ich liurz meinen abweichenden Standpunkt von der Lehre Weisuaxss fest, in letzterer, sowie in einem Vortrag (1892):

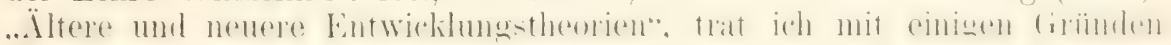
der Mosaiktheorie von Roux entgegen.

Gegen Weismaxy hob ich hervor: „Als ich den liern wegen seines

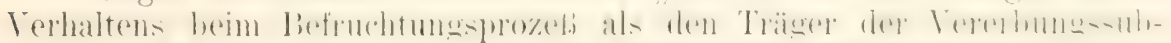

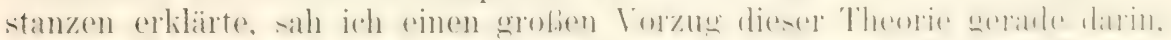

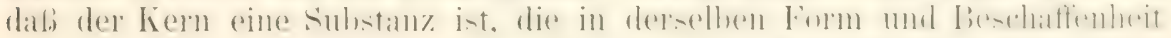
in jeder Zelle wiederkehrt, eine Substanz, die den gröberen Vorgïngen

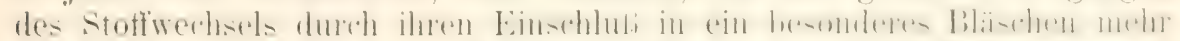

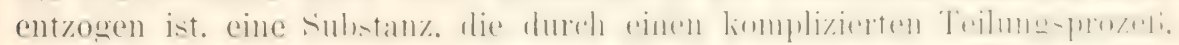
wie es scheint, in gleicher Menge ron der Mutterzelle auf die Tochterzellen

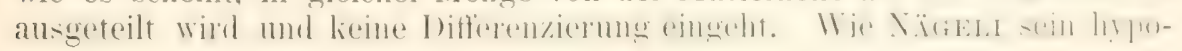


thetisches Idioplasma durch den ganzen Körper als fierïstwerk verbreitet sein läßrt, so enthält nach meiner 'lheorie auch jede Zelle des Körpers als Abkömmling des Eies Erbmasse in ihrem Kern, während die spezifischen Leistungen an die Entwicklung der Plasmaprodukte gebunden sind. Durch den besitz dieser Erbmasse trägt jede Zelle die Möglichkeit in sich, unter geeigneten Bedingungen aus sich das Ganze zu reproduzieren. Daraus lailit sich eine Fülle ron Erscheimumgen der Zeugung und Regeneration erklären."

.WEismann hat diesen Vorzug beseitigt, indem er die von STrasBurger und mir mahhängig mol in etwas verschiedener Wrese hesgundete Vererhungstheorie kurze Zeit nach ihrer Veröfentlichung anf seine lieinflasmatheorie iibertragen hat, die ron ganz anderen (iesichtspunkten aus entstanden ist."

Der Mosaiktheorie von Roux und seiner These: „Die Entwicklung der Froschasstrula und des zunächst daraus herrorgehenden Embryos ist ron der zweiten Furchung an eine Mosaikarbeit, und zwar aus mindestens vier verschierlenen, sich selbständig entwickelnden Stürcken" stellte ich die Antithese gegenüber: .Die Teile emes ()ronismus entwiclieln sich in Beziehung zu einander, orler die Entwicklung eines Teiles ist abhängig von der Entwicklung des (ranzen. Die Entwicklung eines Oruanismus ist also keine Mosaikarbeit."

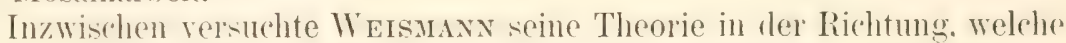
schon in der s'chrift über die Kontinutät des Kemplasmas dentlich vorgezeichnet ist, bis in feinere Details noch weiter auszubanen, wobei er gleichzeitig anch Bestanlteile der von DE YRIEs entwickelten Lehre von den I'angenen mit aufnahm. So entstand das umfascende, 18, 2 erschienene Buch über das Keimplasma, eine Theorie der Tererhung. auf welches sich wohl der früher zitierte Ausspruch von OsBons bezieht, daB der NeuDarwinismus mit seiner einfachen und prachtrollen ... Stamm-" oder ..Kontinuitätshypothese" einen Vorsprung vor dem Lamarckismus voraus habe.

WEIsmann macht hier die Annahme, daß das im Keim enthaltene Liemplasma eine verwickelte Architektur, eine Zusammensetzung aus Idanten. Illen. Thetrminanten mul Biophoren hesitzt. Ein Teil des Keimplasmas wird als Stirp) für die nächstfolgende (ieneration reserviert, von dem anderen Teil ans wird die Ontogenese des Individume, des vergänglichen Somas, geleitet dadurch, daß er nach einem Plan, der in der Anordnung seiner Elemente voraus bestimmt ist, in seine tausende und hunderttausende Finzelanlagen zerlegt wirl, welche den Charakter der Zellgrupren und Zellen der einzelnen Vererbungsstücke bestimmen.

WEISudnN stellt sich somit auf denselben Standpunkt wie Roux in seiner M os a ktheorie. Er gerät mit seinen Annahmen einer festen präformierten Arditelitur des Keimplasmas, durch welche der Verlauf der ()ntogenese bis ins kleinste Detail im voraus genan geregelt ist, ganz in die Cienankenriohtung der alten Evolutionisten, wnd so erklärt el demn gleich im Vorwort: "Ich kam zuletzt zu der Einsicht, daß es eine epigenetische Entwicklung überhaupt nicht geben kann. In ersten liaphitel dieses liuches wird man emen förmlichen lieweis für die Wirklichkeit der Evolution finden, und zwar einen so einfachen und naheliegenden. dab ich heute laum hegreife. wie ich so lange an ihm vorübergehen konnte."

Betreffs weiterer Einzelheiten kann auf die schon im XIX. Kapitel gegebene Analyse der Keimplasmatheorie verwiesen werden. 
Das Hypothesengebäude von WEIsMaxw, in bestechender irorm ror-

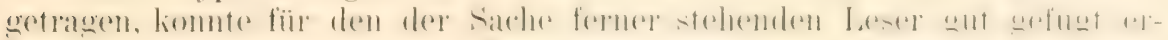
scheinen; gibt man ein paar Voraussetzungen zu, so scheint ein Schluf, sich aus dem andern mit Notwendigkeit zu ergeben. Die Sachlage ist dieselbe, wie bei der Pangenesis, mit welcher sich alle von DARWIN zu-

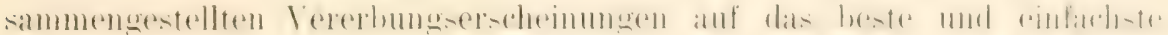

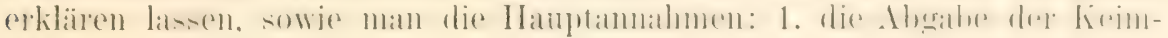
chen. 2. ihren 'lransport, 3). ihre Zusammenordnung nach inneren Verwandtschaften, als zulässig anerkennt.

Weisunves Grundannahmen bieten aber sowohl von allgemeinen

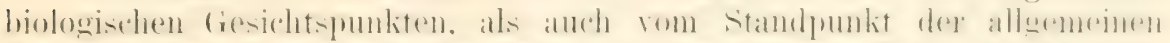

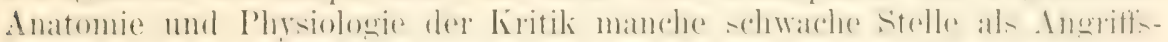
punkt dar. Zugleich fügte es der Gang der empirischen Forschung, daf

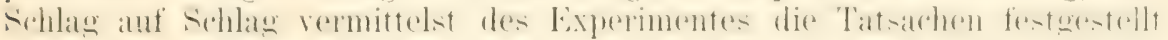

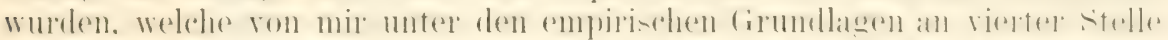

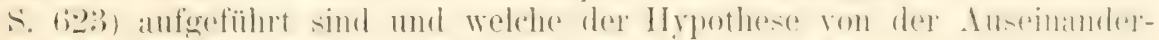

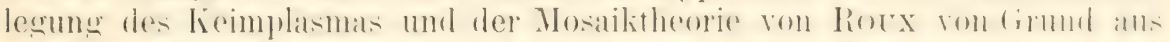

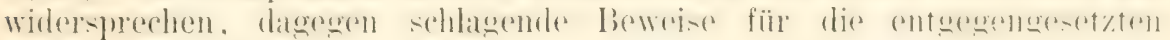
Theorien yon SPENCER und Nïget. von mil und DrIesch sind.

Daher nahm ich jetzt noch eimmal Gelegenheit, der evolutionistischen Keimplasmatheorie von WEISMAN und der Mosaiktheorie von Roux

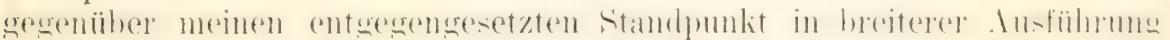
zu entwickeln im ersten Heft meiner. 1894 herausgegebenen Zeit- und Streitfragen der Biologie. Indem ich als T'itel die Frage „Präformation

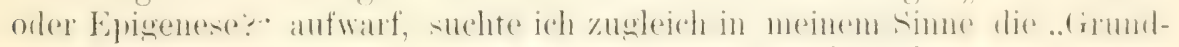
ziige einer Entwicklungstheorie der Organismen“ aufzustellen.

Die Ideengänge sind im wesentlichen dieselben, wie sie in diesem

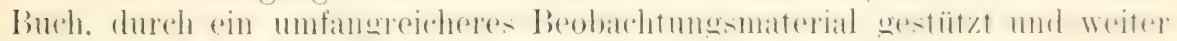

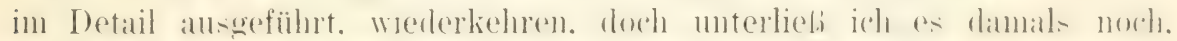
anf die Frage nach dor Vererhbarkeit erworbener ('hatralitere einzugedum. welche hier in dem Kapitel XXVII erörtert ist.

Auf das erste Heft ließ ich 1897 noch ein zweites folgen unter dem Titel „Mechanili und Biologie". um mich mit den von Roux vertietenen Ansichten auseinanderzusetzen.

Gleichzeitig mit meiner Streitschrift: "Prïformation oder Epigenese" liat Driesch, dem wir eine Anzahl grundlegender Entrleckungen ver-

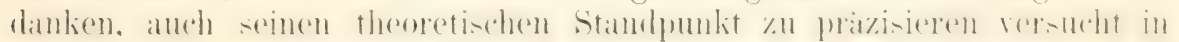
seiner Schrift ,Analytische Theorie der organischen Entwicklung"." Sein

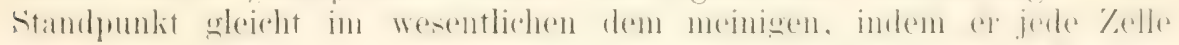
mit dem vollen Idioplasma ausgestattet sein läßt. Die Ursache für ihre

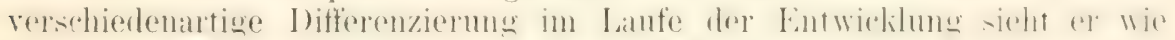
ich in den Bedingungen, in welche die Zellen geraten; er fabt daher die

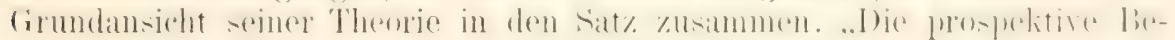
dentung jeder Blastomere ist eine Funktion ihrer Lage im ganzen."

Die Roux-WEIsuaxsche Theorie erklärt Driescix ehenfalls für unfruchtbar und nennt sie wegen ihrer unsicheren Fundamente und zahl-

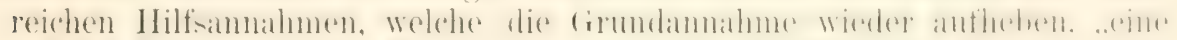

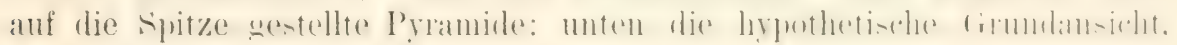
darauf Hilfsannahme auf Hilfsamnahme."

Seine Ansichten als Ganzes charakterisiert er als: 'T'heoric der epigenetischen Evolution.

Seitdem hat WEIsurax noch mehrfach das Wort zum Lamarelismus

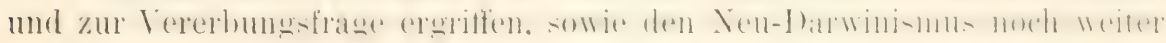


fortzubilden versucht in den Schriften: 1. Allmacht der Naturziichtung

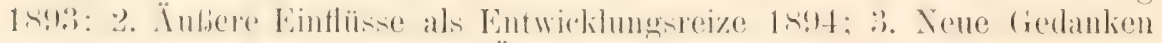
zur Vererbungsfrage 1895 ; 4. Über Germinalselektion 1896 etc.

Wenn wir am Ende unseres historischen Überblicks die besprochenen 'Theorien noch cinmal unteremanter auf ihre Ähnlichkeit und Verschiedenheit vergleichen, so können wir sie je nach der Stellung, welche ihre Autoren zu einigen Hauptgesichtsumliten eimehmen, in drei Grupen einteilen.

Zur ersten Gruppe gehört allein DARwins provisorische Hypothese der Pangenesis. Sie nimmt in vieler Hinsicht eine Sonderstellung ein wegen der Annahme einer Abgabe und eines Transports der Keimchen mol bäbt sich dadurch an die ..Extrakttheorien" älterer Naturforscher anreihen. Dagegen ist die Hypothese kleinster Stoffeinheiten, welche einzelne Eigenschaften des zusammengesetzten Organismus repräsentieren, ein Bestandteil vieler anderer Theorien geworlen; besonders liehren Dinwiss Keimchen wieder in den Pangenen von DE VBIEs und den Biophoren WEISMANNS.

Eine zweite natürliche Gruppe bilden die älteren Theorien von Јон. Müller, Herbert Spencer und Nägeli und die auf den neueren Errungenschaften der allgemeinen Anatomie und Physiologie basierten Theorien: die Biogenesis von mir, die Theorien von STrasburger und Driesch, die intrazellulare Pangenesis von DE Trues. Sie hahen alle das Gemeinsame. dlab sie die Suhstanz, welche Träger der erblichen Eigenschaften ist, welche die "Anlage des Ganzen" oder, wie JoH. HüLlER sich ausclruickit, „die Kraft zur Bildung des Ganzen“6 enthält, in allen einzelnen Teilen des Körper's, in allen einzelnen Zellen gegenwärtig sein lassen. Die .physiologischen Einheiten" von SPExcer sind gleichsam Stüclichen des durch den ganzen Körper als Netz verbreiteten Idioplasmas von N̈̈GELI, welches nach der Lehre von mir, Strasburger, de Vries und Driesch in den Kernen der Zellen enthalten ist.

Nit der Tellentheorie habe ich wohl am meisten die Lehre in feste Verbindung gehracht durch die Ausarbeitung der Begriffe der Artzelle, dor spezifischen Eneroie. des Verhältuisses von Lemsubstanz (Idioplasma oder Frhmasise), ron P'rotoplasma und ron Protoplasmaprodulit zu einander. Der Begriff der Artzelle entspricht, wie ich schon früher bemerkt habe (S. 580), dem Begriff der physiologischen Einheit von Spencer.

Die Forscher der zweiten Gruppe stehen auf dem Boden des Lamareki-mus mol nehmen damit anch eine Vererhbarkeit erworbener Eigenschaften an. indem das. Idioplasma allmählich durch äuliere Crsachen in soincr Kontiguration sellost verändert wird. Eine Sonderstellung in bezug

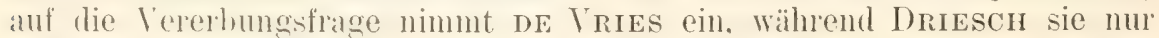
nebenbei berïhrt hat.

Zu einer dritten Gruppe rechne ich Galton, Jäger, Nussbaum, Weismann, Roux. Ihre Theorien stehen in einem ausgesprochenen Gesensat\% zu der Lehre ron den physiologischen Einheiten, rom Idioplasma und ron der Artzelle. Sie suchen den Entwicklungsprozeß zu erklären und leichzeitis die liontinutiat der Generationen zu wahren dadurch, dab sie die Erbmasse der Keimzelle in zwei Teile sondern, in einen die Konfinnitiit allein moterhaltenden Stammteil (Stirp) für die nächste (ieneration und in einen zweiten Teil, durch welchen die Ontogenese geleitet wird. 
Die Leitung soll, was indessen nur yon WEIsmaxy in allen Kionsequenzen klar durchgefiihrt. aber in liouxs Lehre der qualitativen Kernteilumg mul Galtons Abgabe der Keimchen angedeutet ist, durch eine unendlich verwickelte und in der Architelitur in vorans geordnete Zerlegung des liem-

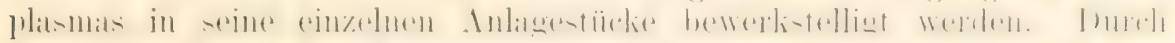
diesen das Wesen der Entwicklung ausmachenden Prozeb, welcher in rerinderter Form an die Vorstellungen der alten Evolutionisten wieder an-

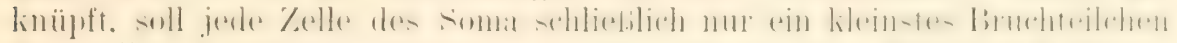
der vollen Erbmasse erhalten. Hierbei werden von Wrisusx Berlingungen, die durch den Entwicklungsprozeb erst neu geschatfen werden, als Determinanten, d. h. als imere Ursachen in das Keimplasma von Anfang an hinein verlegt. So wird eine große liluft zwischen lieimzellen und den ährigen ...

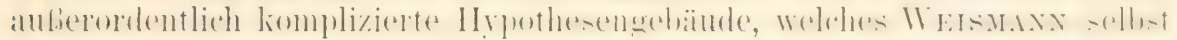
eine Architektur des Keimplasmas genannt hat, sich scheinbar der ganze

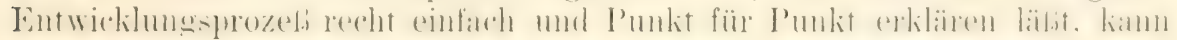
nicht wunder nehmen. da WEIsumx das, was erklärt werden soll. zuror

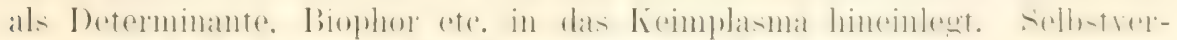

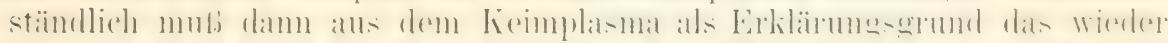

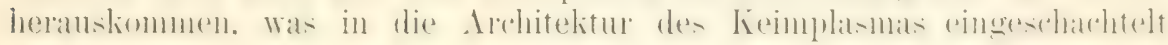
worden ist.

Hierdurch, sowie auferdem durch die Stellung zum Lamarckismus und zur Vererbungsfrage tritt namentlich WEIsuANx zu den Grumdprinziepien der in der zweiten Gruppe zusammengestellten Theorien in den schärfsten Gegensatz.

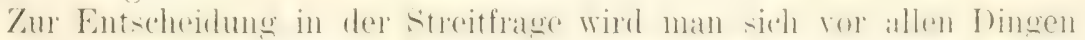

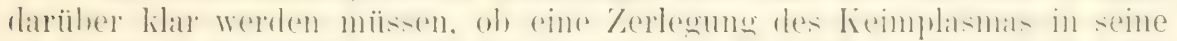

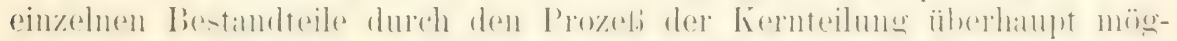

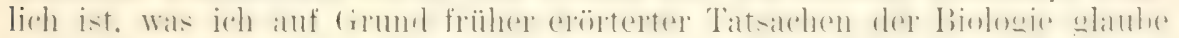
bestimmt verneinen zu müssen. Ist erst in diesem Punkt eine Einigung

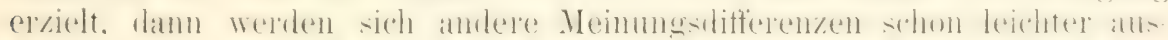
gleichen.

Ich schließe mit einer kurzen

\section{Zusammenfassune der Hauptereschtspunkte der Theorie der biogenceis.}

Die Zelle mit ihren Eigenschaften ist das elementare Lebewesen.

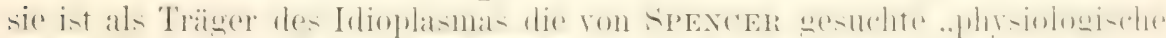

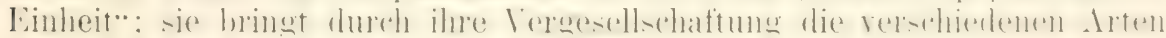
der Pflanzen und 'Tiere hervor.

Da alle Organismen während ihrer Entwicklung eimmal den einzelligen Zustand durchlaufen, so sind in diesem alle konstanten oder wesentlichen Merkmale, durch welche sich Art ron Art unterscheidet, in ilurer einfachsten Form enthalten oder gewissermafen auf ihren einfachsten

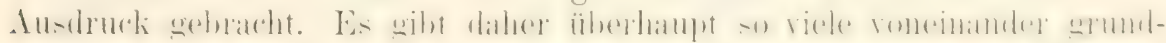
verschiedene Arten von Zellen. als es verschiedene Arten von JHanzen und Tieren gibt.

Worin die wesentlichen Merkmale bestehen, durch welche sich die Zellen als Reprïsentanten der verschiedenen Arten voneinander unterscheiden, ist unserer direkten Wahnehmung verborgen; nur aus logischen Gründen müssen wir anmehmen, 1. dab die Zellen eine feinere, unser Lr-

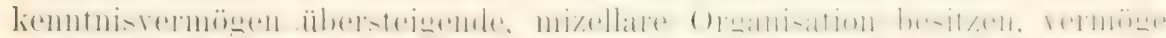

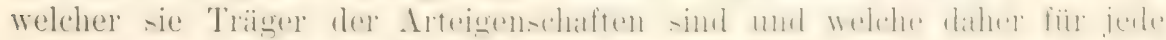


()rominmenart eine rershiedene sein mul: "2. dal die hochorwanisierte Substanz, welche die .Art" der Zelle bestimmt und von Nägeri als Idio-

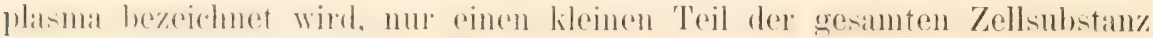
ansmacht und nach unserer 'Theorie im Zellenkern eingeschlossen ist.

Die Übereinstimmung zwischen den verschiedenen Individuen einer

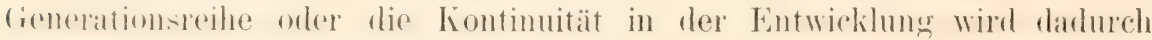
gewahrt, daß ein jedes Individuum immer von einer Zelle mit denselben Arteigenschaften hervorgeht. Daher kamm man die Substanz, welche Träger der Arteigensibaften ist mol im Lehensurozef, dureh das Mittelglied der Zelle von einem Individum auf das nächste überliefert wird, auch als die Frbmasse bezeichnen.

Hiermit kommen wil' zum zweiten 'Teil der Biogenesis, zur Frage, wie aus der Zelle und ihren unsichtbaren Arteigenschaften die zusammengesetzte (Orwanismenart oder die Individualität höherer Ordnung mit ihren sichtbaren Arteigenschaften hervorgeht.

Die Theorie der Biogenesis antwortet hierauf: durch die Vermehrung der Artzelle und den damit Inam in IIand gehenden Prozels sozialer Vereinigung, Arbeitsteilung und Integration.

Fine physologische (immoleigenshaft eines jeden Lehewesens ist das Vermögen, seine Irt zu erhalten. Die Zelle, welche einem ühergeordneten

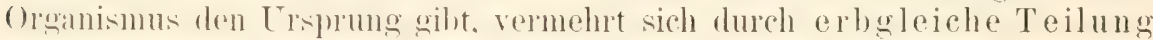
in unzählige Generationen von Zellen, welche alle Träger der Arteigenschatten oder der Erbmasse sind. Das so sich vermehrende, aus artgleich ormanisicrten Einheiten zusammengesetzte Agoregat nimmt bei seinem Wachstmm bestmmte Formen an. Welche auf jeder Stufe les Wachstums der Ausdruck sind: 1. des Einflusses zahlloser äußerer Faktoren, noch mehr aber 2. der unendlich komplizierten Wirkungen, welche die immer zahbreicher werlenden elementaren I.ebenseinheiten aufeinander ausühen.

Die einzehıen Zellen, obschon der Art nach gleich als Abkömmlinge einer wemein-amen Mutterzelle, geraten infolge des Wachstumsprozesses unter ungleiche Bedingungen räumlich und zeitlich.

Einmal nehmen sie im Aggregat verschiedene Stellungen zu einander ein, durch welche ihre Beziehungen zu einander, zum Ganzen und zur Außenwelt bestimmt werden, sie erhalten gewissermaßen ein ihre Wirkungsweise beeinflussendes Raumzeichen; sie werden räumlich determiniert. Die einen werden zum Beispiel um den animalen, die amderen $u n$ den vegetativen Pol des Eies gruppiert: die einen kommen ins änlere, die anderen ins immere liemblatt zu liegen, die einen erhalten eine Iage in der Tomebung des T'mundes (Nervenplatte. Chorda), die anderen in Erölierer Entfermm von dissem für die Organhildung wichtigen Orte; somit geraten hei ihrem Zusammenwirken die artgleichen Zellen in verschiedene Zustände gemäl ihrer verschiedenen Position, welche sich auf jeder Stufe des Wachstums ändert.

Die Zellen werden aber außerdem noch dadurch, daß sie der Zeit nach unter rämuliche Budingungen geraten, welohe für die einzelnen Gruppen verschieden sind, determiniert: sie erhalten eine verschiedene Geschichte. Die Zellen unterscheiden sich auf späteren Stadien des Entwicklungsprozeses untereinander nud ron frïheren Zellengenerationen auch dadureh. dial. sie ein stück .hesonderer Entwicklungseschichte" hinter sich hahen, nämlich dic frïher durchlaufenen Zustände des Irachstumsprozesses, welche hei den einzelnen (imuluen in vershiedener Weise eingetreten sind. Zallen des änberen Kómblattes haben andere Einwirkmgen als Abkömmlinge des immeren keimblattes erfahren. Indem in ihnen die früher durch- 


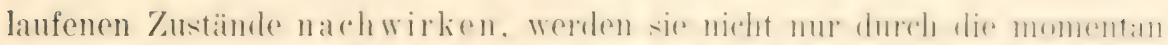

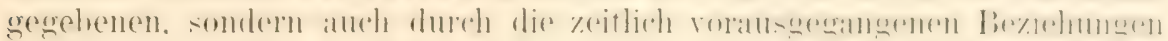
determiniert. Inbezug hierauf sei an die schon fröher (S. 5) 82) hervor-

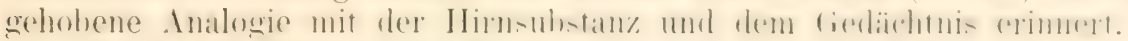

Nach der Theorie der Biogenesis wird also die Erbmasse auf un-

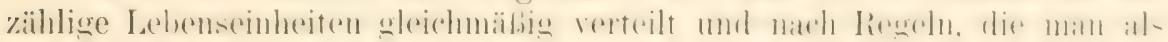
das Gesetz ihrer Entwicklung bezeichnen kann, unter zahlreiche ver-

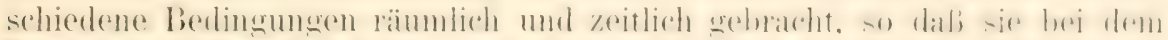

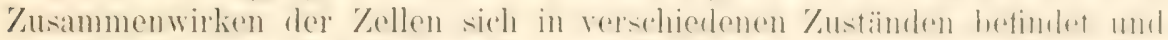
vermöge dessen auf änlere und insere Reize in der ihrem jeweiligen \%nstand entsprechenden Weise reagiert.

In diesem Prozeb werden die Anlagen, welche die Erbmasse einer Art-

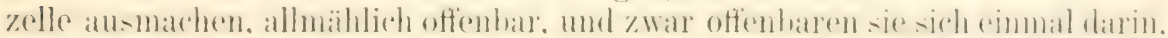

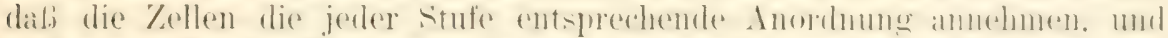

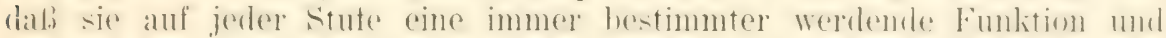

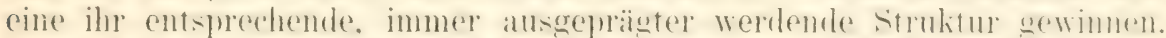

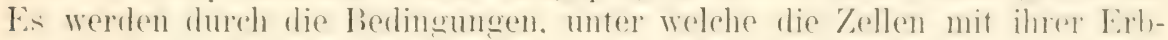
masie in der \%eitfolge und in ihrer rämmlichen Verteilume seratent sind.

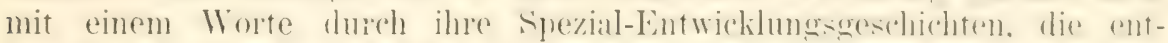

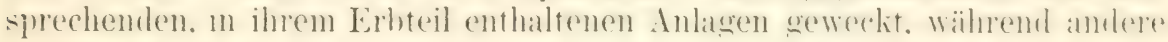

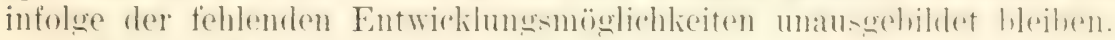

Innerhalb der Generationsreihe der Personen oder zwischen den ein-

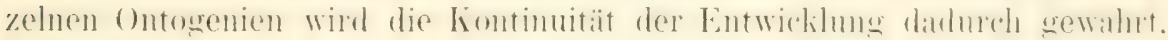
daß aus dem Aggregat der Artzellen einzelne sich ablösen und wieder den Ausgangspunkt für neue Entwicklungsprozesse abgeben.

Bei niederen Pflanzen und 'lieren können alle Zellen des Aggregates diesem Zwerke dienen. hei höheren Organismen dagegen wird die Wahrung

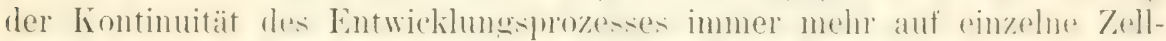

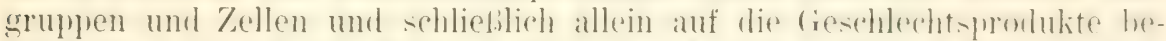
schränlit und anch hei diesen sogall nur anf eine hestimnte l'erionle ihres

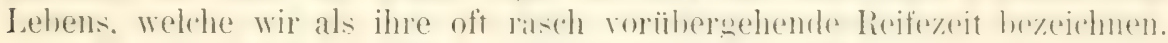

Die Erscheinung erklärt sich daraus, daß im Aggregat die meisten

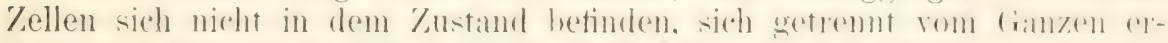

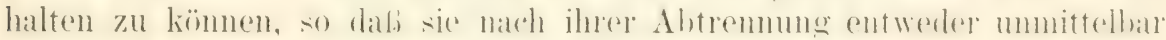

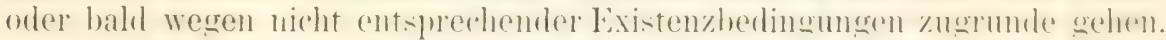

Und so sehen wir gerade an dem Fall der Geschlechtsreife in sehr

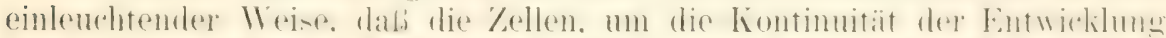

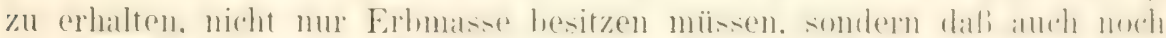

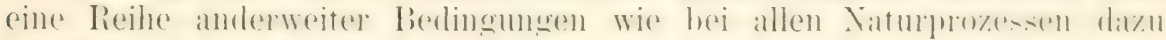
unbedingt notwendig ist.

\section{Literatur zu Kapitel $\mathbf{X X X}$ und $\mathbf{X X X I}$.}

1) van Beneden, E., Recherches sur la maturation de l'auf, la ficondation ct la dirision cellulaire. 1883 .

2) Darwin, Charles, Über die Entstehung der Arten durch natürliche Zuchtiohl. Erste Auflage. 1859 .

3) Derselbe. Das Fariueren der Tiere und Phanzen. Bd. II, Fererbuns, Lap. I2-15. Provisorische Hypothese der Pangenesis, Liap. 27. I868.

1) Driesch, Entwicklungsmechanische Studien, Zeitschr. f. wiss. Zool., Bi. LIII. Dir Wert der beiden crsten Furchungszellen in der Echinodermenentaickluns. Experim. Erieugung i'on Teil- und Doppelbildungen. 1892. 
i) Driesch, Analytische Theorie der organischen Entreicklung. Leipzig 1894.

(i) Flemming, W., Zellsubstanz, Kern- und Zellteilung. Leipzig 1882.

¿) Fol, Recherches sur la fécondertion etc. 1879.

is Galton, A theory of heredity. The contemporary review, Hol. XXVII. I876.

!) Haeckel, Emst, Generelle Worphologie. 1866.

111, Derselbe, Anthropogenie oder Entricklungrggeschichte des Mensehen, 4. Anfl. I801,

(l) Derselbe, Zur Phylogenie der australischen Fauma. Syst. Einleitg. zu Semons Zool. Forsch. in Australien. Jena 1893.

I') Hertwig, Oskar, Beiträge zur Kenntnis der Bildung, Befruchtung und Teilung des tierischen Eies. Morpholog. Jahrb., Ba. I. I875. Fortzsetzung ebenda, Bd. II. 1877. Bd. IV. 1878.

1:3) Derselbe, Das Problem der Befruchtung und der Isotropie des Eies, eine Theorie der Vererbung. Jena 1884 .

14) Derselbe, Versleich der Ei- und Samenbildung bei Nenatoden. Archiv f. mikroskop. Anat., Bd. XXXVI. 1800 .

15) Derselbe, Urmund und spina bifida. Archiv f. mikrosk. Anat., Bd. XXXIX, S. 476 bis 482.1802 .

16) Derselbe, Altere und newere Entwicklungstheorien. Ein Vortrag. Berlin 1892. Hirschaeald.

17) Derselbe, Zeit-und Streitfragen der Biologie. Heft I. Präformation oder Epigenese. Jene $180+$.

18) Derselbe, Zeit- und Streitfragen der Biologie. Heft II. Mechanik und Biologie. Jena 1897

19) Hertwig, Richard, Bemerkungen zur Organisation und systematischen Stellung der Foraminiferen. Jenaische Zeitschr., Bd. IV. 1876.

20) Derselbe, Beiträge zur einheitlichen Auffassung der verschiedenen Kernformen. Morph. Jahrb., Bd. II. I876.

21) His, W., Die Theorien der geschlechtlichen Zeugung. Archiv f. Anthropologie, Bd. IV 11. I. 1871 u. 1872 .

2.) Keller, C., Vererbungslehre und Tierzacht. Berlin 1895.

23) Kölliker, Bedeutung der Zellkerne fïr die Vorgänge der Vererbung. Zeitschr. $f$. zoissensch. Zool., Bd. XLII. 1885.

24) Derselbe, Das Karyoplasma und die Vererbung. Ebenda, Bd. XLIV. I886.

2.) Lamarck, Jean, Zoologische Philosophic. 180g. Dentsche Übersetzung von Arnold Lang. 1876.

?(i) Müllex, Johannes, Handbuch der Physiologie des Menschen., II. Band. 1840. Buch VII: Von der Zeugung, S. 59T.

2)- Nägeli, Mechanisch-physiologische Theorie der Abstammungslehre. 1884.

'4, NuBbaum, MI, ZurDifferencienung des Geschlechts im Tierreich. Archiv f. mikrosk. Anat., Bd. XVIII. 1880.

$29)$ Derselbe, Beiträge zur Lelwe von der Fortpflanzung und Vererbung. Archiv $f$. mikrosk. Anat., Bd. XLI. 1893.

311) Ortmann, Arnold, Über Keimaraiation. Biol. Zentralbl., Bd. XIIII. I898.

:31) Osborn, Alte und nene Probleme der Phylogenese. Merkel und Bonnets Ergebnisse, Bd. III. Wiesbaden 1894. Daselbst findet sich auch eine ausführliche Zusammenstellung der Literatur von 118 Nummern (besonders vollständig für englische und amerikanische Literatur.)

(3) Rohde, Fr., Uber den gegenwiötigen Stand der Frage nach der Entstehung und Vererbung individueller Eigenschaften und Krankheiten. Jena 1895. (Daselbst auch Literaturverzeichnis.)

:3i) Roux, w., Der Eimpf der Teile im Organismus. Leipzig I881.

:H) Derselbe, Über die Bedeutung der Kérnteilungsfigureu. ${ }_{18} 88$.

3.) Derselbe, Über die künstliche Hervorbringung halber Enbryonen durch die Zerstörung einer der beiden ersten Furchungskugeln. Virchowes Archiv, Bd. CXIV. I888.

(i) Derselbe, Über das entwicklungsmechanische Vermögen jeder der beiden ersten Furchungssellen des Eies. Verhandungen d, anatomischen Gesellsch. d. 6. Versamml. in Wien. 1802.

3i) Derselbe, Über Mosaikarbeit und newere Entwickhungshypothesen. Anatom. Hefte von llerkel and Bonnet. 1893.

ihs Sachs, Julius, Abhandhengen über Pfanzenphysiologie, Bd. II, S. I202. I893.

3!4, Spencer, Herbert, Prinzipien der Biologie, Bd. I, S. 258, 276-278.

(11) Derselbe, Die Faktoren der organischen Entwicklung. Kosmos 1886.

11) Strasburger, Ed., Über Zellbildung und Zellteilung, 2. Auft. 1876.

1.' Derselbe, Über Befruchtung und Zellteilung. Jena 1878 .

4:i) Ders:lbe, Neue Untersuchungen über den Befruchtungsvorgang bei den Phanerogamen als Grundlage einer Theorie der Zeugung. 1884. 
11) Thomson, The history and Theorie of heredity. Proced. of hoy. Soc. of Fdinburgh, Vol. NTI, S. 91. 1888-1889.

4.i) Verworn, Max, Allgemeine Physiologie. Jenc 1895.

lii) de Vries, Hugo, Intrazellulare I'angenesis. Jena 18890.

4.) Wallace, A. R., Der Darainismus. Deutsch ron Branns. ISor. Eingliache Ausgabe. 1889 .

14i Weismann, Über dic Vererbung. Jend 1883.

19) Derselbe, Die Kontimulät de's Keimplasmas als Gmundage einer Theorie der liererbung. Jena 1885.

(1) Derselbe, Zar. Frage nach der Vererbung eraerbener Eigenschaften. Biolog. Kentralblatt 1T. 1886.

51) Derselbe, Die Bedeutung einer seruellen Fortpflanzung für die Selektionstherie. Jena 1880.

52) Derselbe, Amphimixis oder: Die Vermischung der Individuen. Jence $189 \pi$.

53) Derselbe, Das Keimplasma. Eine Theorie der Verevbung. Jena 1802.

54) Derselbe, Die Allmacht der Vaturzüchtung. Eine Eraiderung an Herbert Spencer. Jena isg3.

55) Derselbe, Iußere Einflïse als Entricklungsreize. Jena 1 \$9.7.

56) Derselbe, Neue Gedanken zur Vererbungsfrage. Jena 1895.

57) Derselbe, Über Germinalselektion. Extrait du compte-rendu des siances du troisieme congrès international de zoologie. Leyden 1895, 1806.

58) Whitman, C. O., Evolution and Epigenesis. Boston 1805.

59) Wolf, Kasp. Friedr, Theoria generationis. 1750.

60) Yves Delage, La structure du Protoplasma et les théories sur l'hérédilé et les granuts problèmes de la biologie générale. l'aris 1895. 


\section{Register.}

Abortiveier 279.

Abrin. Versuche Ehrlichs 574.

Abscherung 472. 537.

Abutilon Thompsonii 501.

Acetabularia 334.

Achromatische Kernfigur 172.

Actinosphärium 379.

Kernteilung 188.

Addisonsche Krankheit 446 .

Aderlaß Einfluß auf Blutbildung 533.

Äpfelsäure als Lockmittel für Samenfäden der Farne 164.

Äquationsteilung 277.

Äquivalenz der männlichen und weiblichen Erbmasse 35.5 .

der Kernsubstanz bei der Befruchtung 300 .

Aethalium septicum 17. 150. 159. 162. 163.

Affinität, sexuelle 319. 329. Beeinflussung derselben durch Eingriffe 339.

Ahmenplasmatheorie-35\%.

Aktinien 607.

- Symbiose mit Algenzellen 394.

Albicatio 501.

Algen 4. 7. 308.

Zellkolonien 375. Symbiose 392.394.

Allolobophora (transplantiert) 388 .

Alveolarsehicht 22.

Ameisen 493.

Amitose 209.

Amöbe. Bewegung derselben 109.

$$
\text { - Reizung 155. 159. }
$$

Amphiaster 181.

Amphimixis 281.

Amphioxuseier auf Teilstadien durch Schütteln zerlegt 5() 9 .

Amphipyrenin 33 .

Amyloplasten 85.87.

Analyse der Eiterkörperchen 18.

Anästhetika 160.

Wirkung auf Mimosa, auf Eier und Samenfaden 160. 161.

Anencephalie von Frosch- und Axolotembryonen 194.
Anilinfarben. Aufnahme in die lebende Zelle 66. Animalkulisten 352.

Anlage eines Organismus 349. 363. 560.

- Entfaltung der Anlagen 363. 585. La. tente 624.

Anthericus. Mechanisches Gewebe 174.

Antheridien. Ablenkung 330.

Antikline Teilebene 231 .

Antimeren 372.

Apfelbaum. Verhalten beim Pfropfen $386^{\circ}$

Aphiden 322.

Apogamie 321. 329.

A poneurose 537.

Apposition 88. 142.

Arabis. Vergrüung 50 t.

Arbeitshypertrophie 528. 535.

Arbeitsteilung 415.617. 636.

- Gesetz der physiologischen 414.

- in der menschlichen Gesellschaft 415. im Zellenaggregat 417 .

zwischen chlorophyllhaltigen und chlorophyllfreien Pflanzenzellen 418. zwischen ober- und unterirdischen Pflanzenteilen 418 .

zwischen den verschiedenen Geweben 419 .

Architektur des Keimplasmas 452.

Archoplasma 178. der Knochenspongiosa 476.

Arctia caja. Experimenteller Beweis für Vererbung 576.

Aroideen. Erwärmung der Blütenkoiben 62. Arsen. Einfluß auf Knochenwachstum 491. Arteigenschaften der Zelle und Gewebe 389. 390. 428. 636 .

Artgleichheit der Zelle und Gewebe 385. 430. Artemia salina u. Mühlhausenii 492.

Arthritis fungosa 145 .

Artzelle. Begriff derselben 374. 375. 429. 592. 634.

Beweise tür die Ansicht, daß alle Zellen eines Organismus Träger der Arteigenschaften sind 430 .

Arum maculatum. Mechanisches Gewebe 474. Ascaris megalocephala. Kernteilung 178. 
Asearis megalocephala. Reduktionstcilung der Samenzellen 274.

Reduktionsteilung der Eizellen 278. Corps résiduels 220 .

Befruchtung 271.

Aschenanalysen von Fucusarten $66^{\circ}$.

Ascidie. Heteromorphose 544 .

symmetrische T'eilung des Eies 554 .

Ascidiella aspersa 510.

Asparagin. Reizmittel für Bacterium termo und Spirillum $166^{\circ}$.

Asplenium. Apogamie desselben 329.

Assimilation 63 .

Asymmetrie der Embryonen 467.

Atavismus 624.

Atmung 519. 527.

der Zelle 61.

intramolekulare 63.

Attraktionssphäre 172. 178.

Atrophic 410.

Ausstülpung von Epithelmembranen 607 bis 610.

Auster. Veränderung der Schale $\$ 92$.

Autonomie des Chromatins 289.

Bakterien als Rengenz auf Sauerstoff 16:2.166. anaïrobe lil

- Abschwächung derselben 572.

- Physiologische Varjetit 572.

Bakterienfalle 166 .

Basidiobolus ranarum. Einfluß der Er. nährungauf Bildung der Geschlechtszellen 321.

Basis bei abgetrennten Pflanzenteilen 465.

Bastardbefruchtung 386.

Bastarde 339

Rastardendosperm 294 .

Batrachospermum 483.

Becherzelle 83.

Befruchtungsbedïrftigkeit 318 .

Befruchtungsprozel3 265. $31 \mathrm{~s}$.

Befruchtung 265.

Befruchtung des Echinodermeneies 269. von Ascaris meg. 271. von Phanerogamen (Lilium Nartagon) 292.

der Infusorien 294. 330 .

der Vortizellen 299.

der Noctilucen 304.

der Desmidiazeen 304.

der Zygnemazeen 306.

von Spirogyra 307.

von Monjeotia 306 .

von Botrydium 308 .

von Phaeosporeen 309.

der Algen 30 .

isogame, oogame 309.

der Cutleriaceen $309-310$.

der Fucazeen 310.

vegetative bei Pflanzen 204.

der Volvocineen 310.

von kernlosen Plasmastïcken

(Merogonic) 32\%.

Beroë-Ei zerlegt und zu Teilbildungen gezüchtet 511.

Bewegungserscheinungen des l'rotoplasmas s. Protoplasmabewegung.

o. Hertwig, Allgomeino Biologie. '丷. Aufl.
Bewerungserscheinungen von Ölgemischen $11+-116$.

Bewegungserscheinumgen der Geifel und Flimmerzellen $11 \%$.

der kontraktilen Vakuolen 126.

infolge von Zug 128 .

bei Erwärmung 144.

bei Lichtreiz 149 .

Bienen 321. 493.

Bildungstrieb 352 .

Bindegewebe. Umgestaltung durch Zug, Spanmung, Abscherung 537. 538 . Metamorphose 143.

Bindegewebsfibrillen 94.

Bimmenbläischen von Thalassicolla 213.

Bioblasten 24. 52. 54. 354. 357. 361. 589.

Biogenesis, Theorie der 370 . 410. 592.

Biogenetisches Grundgeset\% 586. 592-597.

Biologische Reaktionen 391.

Biophoren im Keimplasma 452.

Blattgrün 86 .

Blutbildung 533. Literatur 539.

Blutbuche (Pfropfhybrid) 501.

Botrydium 151. 309 .

Branchipus $49 \%$.

Brechungslinie bei der Zellteilung 231. 235. Bryopsis 497.

Buche. Einwirkung des Lichts auf die Blattbildung 485.

- Pfropfung. Pfropfhybrid 501.

Cachexia thyreopriva 530.

Caenogenese 596.

Carica papaya $7 \%$.

Caulerpa crassifolia 350 .

Causae externae u. internae, 132 Causa efficiens 140 .

Centrosoma 45. 90, 172. 178. 189. 195. 271.

Cephalopodenei-Teilung 554 .

Ceratopteris. Lichtwirkung auf Prothallien 481.

Cerianthus. Heteromorphose 54.

Charazeen. Rotation 112.

Kern 211.

Parthenogenese 322.

Chelonia caja u. plantaginis 492.

Chemie des Stoffumsatzes $7 \%$.

Chemische Rcize 161. 490. Literatur 505. bei der Kernteilung 216.

Korrelationen $52: \overline{7}$.

Chemomorphosen 490. 527. Literatur 538. Chemotaxis 162. 164 .

Chemotropismus 162. 164.

von Athalium 162.

- Bakterien und Infusorien 167.

- der Samenfäden 16.t.

Chermes viridis 504 . der Lymphkörperchen 166.

Chitimhaut 105 .

Chloral. Wirliung auf Eier und Samenfäden 160.

Auf Kernteilung 216.

Chloroform 160. 161.

Chlorophyll 86.

Bedeutung für ptlanzliche Formbildung 601. 
Chlorophyllfunktion 64. 75.

gehemmt durch Chloroform 64. 75.

Chlorophyllkorn 85.

Chlorophyllwanderung bei Lichtreiz 153.

Chloroplast $8 \overline{5}$.

Chloruse bei Pflanzen 490.

Chromatin 30. 36. 356 .

Chromatindiminution 199.

Chromatische Kernfigur 173.

Chromatolyse 449.

Chromatophoren 150.

Chromoplasten 85.

Chromoromen 171. Zahlengesetz "02.

Chromosomenindividualitït 205 .

(Whoococeacee 376.

Cione intestinalis. Heteromorphose 544 .

Clavellina. T'eilung 554.

Closterium 305. 360.

Coelenteraten 384. 607.

Coeloblast 379. 380. Vergleich mit vielzelliger Pflanze 497.

Coelomlarve 608.

Corps résiduels von Ascaris 220. 450.

Crista sterni. Entwicklung bei Flugvögeln 524.

Ctenophorenei. Zerlegt und zu Teilbildungen gezuichtet 511.

Cuticula. Cuticulargebilde 105.

Cutleriazeen. Befruchtung 309. 320. Sexuelle Affinität 320.330 .

Cytisus Adami 502.

Cytoblast 169.

Cytoblastem 6. 169.

Daphnoiden. Parthenogenese 322.

Damereier 322.

Danerstoffe der Zelle 26.

Degeneration 449 .

Degeneration des Kerns 220. 295. 319. 320.

Desmidiazeen 304.

Determinanten im Keimplasma 452.

Deutoplasma 26.

Rolle derselben 454 .

Diapedesis 166.

Diastase 77.

Differenzierung 414. 416-420. 612. des Eies 552-558.

Doppelmißbildungen 513 .

von Amphioxus 513.

vom Frosch 514.

von Fischen, Reptilien,

Dotterhaut 2609.

Vügeln 517 .

Dotterkerne 88.

Dottermaterial. Einfluß auf den Verlauf der Ontogenese 552. 596.

Dotterplättchen 83.

Dottersyncytium 468.

Drosera 77.

Druck. Einfluß auf Gestaltung 469. 470.

Druckbälkehen 478.

Druckgurtung 472.

1) rucklinien 476 .

Drüsenentwicklung 608 .

Duplicitas anterior 515 . 14chinodermen. Eiteilung 180.

Eehinodermeneier komprimiert 244.

Efen (Lichtwirkung) 182.

lii. Eigenschaften desselben im Entwicklungsprozel 55.); Bau desselben 5.53; polare Differenzicrung 553; bilateral-symmetrischer Bau 5.53; als Träger der Arteigenschaften 561; Unterscheidung von drei Perioden in seiner Entwicklung nach Verschiedenheit der chemischen P'rozesse 561- 564 .

Einschachtelungstheorie $35 \%$.

Einstülpung 607-610.

Eiweißbildung 74 .

Eiweißkörper peptonisiert 77.

Eiwcißkristalle 76.84.

Eiweißmolekiil 17. 5.

Ektocarpus 3:1.

Elektrische Reize 154.

Elementarorganismus 8. 52. 374. 375. 423.

Elementarteil. Elementareinheit 3. 24. 5') bis 55.364 .

Embryo. Einfluß auf den Mutterorganismus 502 ; bei Pflanzen 503; bei Tieren 502. 503.

Embryosack der Phanerogamen 243.

Empfangnisfleck (bei Algen) 310.

Empfängnishügel des Eies 269. 331.

Energie, potentielle und kinetische 59.

Entwicklungstheorien 350, 353.

Epigenese 350 .

Epistylis. Befruchtung 299.

Epithelmembran, Wachstum derselben 605 . Erbmasse 353. 585.

Äquivalenz derselben 355.

_. Verteilung derselben auf die Zellen 356.

Verhütung der Summierung 358.

Teilbarkeit derselben 359. 361 .

Mischbarkeit 361 .

feinere Organisation derselben 589.

Ernährung. Einfluß auf Pflanzen 490; Tiere $491-494$.

Ersatztheorie 302.

Erythroblasten 534 .

Eudendrium racemosum 486.

Eudorina. Befruchtung 266. 311.

Euglena viridis (Lichtreiz) 150.

Evolutionstheorien 350. 632 .

Iaktoren des organischen Eutwicklungsprozesses 411. $462-504$. 616 ; äußere und innere (Korrelationen) 411; imnere, in der Zelle gelegene 508 . 550 .

Faltenkranz des Froscheies 185.

Farbkörmer der Pflanzenzelle S6.

Farbstoffe. Aufnahme in die lebende Zelle 66.

Faszien 537.

Femur. Architektur des Femurkopfes 476 .

Fermente 76. 77.

Fermentwirkung 77.

Fett 77.83.

Fettgewebe 439. 440. 448.

Fibrille 100.

Filartheorie von Flemming 23.

lilagellaten 376.

Flechten. Symbiose 392. 503.

Fleischfressende I'flanzen $7 \%$. 
Fibrille 100

Flimmern. Flimmerbewegung 117. Entstehung der Flimmern $11 \%$.

Fötale Rachitis 5:31.

Follikelatresie 449 .

Formative 'lätigkeit der Zelle 59-107. 73. 79.

Formbildung bei den P'flanzen 600. - bei den Tieren 603.

Fortpflanzung der Zelle 169.

Fragmentierung des Kerns 209.

Fritillaria imperialis. Kernteilung im Embryosack 185. der Pollenzellen 186 .

Froscheier komprimiert 457. 466. durch Zentrifugalkraft in meroblastischen Typus umgewandelt 468.

Fucteen. - Befruchtung 310.

Funaria hygrometrica (Lichtwirkung) 483.

Fundulusembryonen $486^{\circ}$.

Funktion 412. Thr Verhältnis zur Strulktur 412. 426. Wichtigkeit konstanter Verhältnisse für Ausbildung besonderer Funktionen 411. 413

Funktionelle Selbstgestaltung. Kritik des Ausdrucks 413.

Gestalt und Struktur 413.

Reize 436.

Funktionsprinzip von Fechner 581 .

Funktionswechsel 443 .

Furchungskern 271.

Furchungsprozeß des Eies $235-238$.

Gallen 503.

Gallwespe 504.

Galtons Theorie vom Stirp 625.

Galvanotropismus 156 .

Gametangien 308.

Gameten 308. 320.

Gaskammer 159.

Gastriatheorie 605.

Gastrophaga. Veränderung durch Fütterung 192.

Gastrula 595. (604.

Gedächtnis 5SO; Vergleich mit dem Vererbungsvermögen \% 90.583.

als Funktion der organischen Materie 5\$2.

Gefriße der Pflanzen 4.

Gefäßsystem 535. $536^{\circ}$

GieiBeln 117

Gemmulae (Darwins) 5) 1. 624

Generationswechsel 267.

Geotropismus 464 .

Germinalselektion 5666.620 .

Geriisttheorie des Protoplasmas 21.

Geschichte der \%ellentheoric 4.

der Protoplasmatheoric 7.

Geschlechtsdifferenzen 302. 303.

Geschlechtsdimorphismus derVortizellen 299.

Geschlechtskern der Infusorien 294.

Geschlechtslosigkeit 319.

Geschlechtsreife 319-321.

Geschlechtssporen $30 \mathrm{~s}$.
Geschmacksknospen nach Durchschneidung des Nervus glossopharyngeus $44^{2}$.

Gieschwiulste. Pathologische 396. 503.

Gesetz der physiologischen Arbeitsteilung 414 .

Gesetz der konstanten Verhailtnisse 411.

der physiologischen Integration $\$ 19$.

Getreidearten. Veränderung der Reifezeit 573.

Gewebe. Arteigenschaften und histologische

Eigenschaften derselben 428.

Wesentliche und nebensäichliche (29).

Gleichgewichtsebene des Eies 416. 5.57.

Glitschbewegung 112.

Glykogen 83.

Granula 24.

Granulatheorie von Altmann 24.

Gravitation 463.

Gregarinen. Entwicklungszyklus derselben 131 .

Gromia oviformis. Bewegung 111.

Grund formen dergeschlechtlichen Zeugung 304.

Grundstock beim Pfropfen 499.

Guaninkristalle 83.

Iämatoblasten 534.

Hämoglobinurie bei Transfusion disharmonischen Blutes 389.

Hämolysine 392.

Hahnenfedrigkeit 526 .

Halbkern $30^{\circ}$.

Harnbildung 5\%8.

Harnfähige Substanzen 528.

Hauptkern der Infusorien 297.

Hauptspindel der Infusorien 297.

Hautplasma 14.

Hautsehicht der Zelle 67.

des Eies von Rana 15.

ihre Rolle bei der Osmose 68 .

Heder helix (Lichtwirkung) 482.

Hektocotylus 372.

Helianthus. Reaktion des belasteten Keimlings 470 .

Heliotropismus 157

Helleborus. Reaktion bei Belastung 470 .

Hermaphroditismus des Kerns 302.

Herz 534 .

Heteromorphose 5 $43-549$. I iteratur 5 549 . Hirnanhane 532.

Histologisches System, ein künstliches 428.

Hornhaut. Interzellularbrücken 403.

Hyaloplasma 14.

Hydra. Transplantationen zwischen fusca $u$. viridis 387 .

Polarität 466 .

Regeneration 541 .

Hydrocharis 112.

Hydrodiktyon, Experimente 320.

Hydrophyten $\$ 96$.

Hydrotropismus 163 .

Hyperplasie 44 S.

Hypertrophie 458. 439.

der Ilypophysis 532

des Muskelgewebes 139 .

der Niere 469 .

Hypophyse. Hypertrophie nach Exstirpation der Schilddrüse 532 .

I

Idioplasma $353-355,429,561.571 .(127$. 
Idioplasma als innerer Faktor des Entwicklungsprozesses 561 .

Idioplasmatheorie 621. 627 .

Immmuitait 574.

Inaktivitiitsatrophie 435.

Individualitätsbegriff $371-373$.

Individualitätsstufen im Organismenreich 371.

Indiciduum, morphologisches und physiologisches 371 . genealogisches (Huxley) 373. erster Ordnung, die Artzelle 374.

zweiter Ordnung, Zellkolonien 375.

Personen 378.

Infektionsgeschwiilste 396.

Infusorien 376 .

- Befruchtungsbedürftigkeit 319.

-.. Befruchtung 294.

Galvanotropismus derselben 156.

Kernteilung 187.

Inkrustation der Zellhaut 102 .

Innere Sekretion 530.

Inotagmen 99.

Integration 419. 636 .

Interfilarmasse 23.

Interzellularbriicken bei Volvox 400 .

bei Pflanzen 402 .

bei Tieren 403 .

Methode ihrer Darstellung bei Pflanzen 402.

zwischen Bindegewebszellen 403; Epithelzellen 403; Endothelzellen 401; Eizelle 404; Furchungszellen 405 .

Interzellularsubstanz 105.

Intramolekulare Atmung 63.

Intramolekulare $W$ ärme 59.

Intraselektion 620 .

Intrazellulare Pangenesis 364.

Intrazellulare Verdauung 71.

Intussuszeption 102.

Invagination 607 .

Invertin 77.

Inzucht 337.

Irritabilität der Zelle 131.

Isogam 309.

Isotropie des Protoplasmas 62.

Kaktusarten. Verhalten beim Pfropfen 386. Kältestarre, Kältetod 14 כ.

Kampf der Teile im Organismns 620.

Kartoffel (Pfropfhybride) 501.

Karyokinese 171. 208.

Karyolyse 191.

Kanisalitätsgesetz in seiner Anwendung auf den Organismus 132.

Verschiedene Formen der Kausalitât 133 .

Keimblase 604.

Keimbläschen, Keimfleck 38. 39.

Keimblatt 603. 605).

Keimesvariation 570 .

Keimflecke von Mollusken 41.
Keimflecke von Asteracanthion 43.

Keimkern 271.

Keimplasma 452; Zusammensetzung und Architektur desselben 452; Zerlegung desselben 454 . inaktives 45 ?

Keimplasmatheorie von Weismann 452.509. 626.

Kern s. 'Lellkern.

Kerndegeneration 220 .

Kernfärbung 32.

Kerngerüist 35. 36.

Kernlose Elementarorganismen 44.

Kermmembran 33.

Kernplasmarelation 257.

Kernsaft 33.

Kernsegmente 171. Spaltung derselben $17^{\circ}$. Zahl bei der Reduktionsteilung 277. 278.

bei der Befruchtung 27:3. 274. 281.

Kernsegmentierung 171. 201. Bedeutung derselben 208.

Kernspindel 172. Entstehung 192. Bau derselben 192. Herkunft 193.

Kernstruktur 34.

Kernsubstanz 29.

als Träger der Arteigenschaften 561.630 .

ihr Wachstum während der Eientwicklung 562 .

- Einwand von Verworn 562.563.

71. Beeinflussung derselben durch Eingriffe 214.

- pathologische 218.

- mehrpolige 216.

- erbgleiche (integrelle) 454.

- $\quad$ erbungleiche (differentielle) 454.

- $\quad$ Einwände gegen letztere 45̄.

Wahrung der Kontinuität 622 .

Kernzerschnürung 209.

Klimpchentheorie von Arnold und Purkinje 8.

Kniegelenksankylose 437. 479.

Knochenarchitektur $476-479$.

Knochenentwicklung gestört bei Cachexia thyreopriva 531.

Knochenfraktur 479

Knochenmark 533.

Knochenspongiosa $476-478$.

Knospenvariation 501 .

Knospung der Zelle 239.

Körnchenströmung 110. 111.

Körnerplasma 14.

Körperzellen, somatische 266.

Kohlenhydrate 74 .

Kohlensä̈ureaufnahme 63.

Kolloide Stoffe 50 .

Kolibri 524.

Kompression von Echinodermeneiern 244 bis 246.

von Froscheiern 457. 466 .

Konjugaten. Befruchtung 304.

Konjugationsepidemie der Infusorien 295.

Konstanter Strom. Einwirkung auf Rhizopoden 155. 
Kontinuität der Generationen in der Entwicklung 567

in Entwicklungsproze 3622.

Kopfknorpel der Cephalopoden (Interzellularbriicken) 403.

Rorrelationen $50 \mathrm{~s}$.

zwischen Embryonalzellen 508. auf späteren Stadien der Entwicklung und beim Erwachse. nen in.

bei Pflanzen 522. 6092. 603.

zwischen oberirdischen u. unterirdischen Teilen 523.

Gipfeltuieb bei der Fichte 523.

bei Tieren. Knlibri 524.

Einteilung 526.

chemische 527 .

mechanische 534.

Krahn. Kontruktion desselben 476 .

Kreislauf des Lebens 74.

Kretinismus 531 .

Kreuzung bei Azetabularia 334.

bei Infusorien 335

bei Pflanzen 336 .

bei Ascidien 335 .

bei Echinodermen 338.

bei Amphibien 338.

Nutzen derselben 345 .

Kristall. Vergleich mit Organismus 519.

Regeneration 543.

Kristalloide Stoffe 50 .

Kropfexstirpation 530 .

Lamarcksches Prinzip. Lamarckismus 566. 614.615 .

Latente Eigenschaften 349.

Lebenseirenschaften der Zelle 58 .

Lebenseinheit, pflanzliche und tierische 3. 371 . 372.

Lebenskraft 131 .

LebensprozeB 59.

Leber 529.

Lepismium radicans 482.

Leukocyten. Chemotropismus derselben $166^{\circ}$. Aufnahme fester Körper 71. 72.

Leukoplast 85.

Leukophrys patula 265. 319.

Licht. Einfluß auf organische Prozesse 481 bis $48 \overline{\text {. }}$.

von verschiedener Brechbarkeit 487. Literatur 50 - 1 .

Lichtbilder auf Pflanzenblätern 153. 154.

Lichtempfindlichkeit der A Igensch wärmer 572.

Lichtreize 149.

Lichtstimnung 15) 1 .

Lichtwirkung bei Athalium, Pelomyxa, Chromatophoren 150. Pigmentzellen 150. Euglena, Schwärmsporen $1 \overline{1} 1$.

Linin des Kerns 33.

Linsenregeneration 5.16 .

Literaturibersichten 9. 55. 107. 129. 143. 167. 220, 247. 263. 313. 346. 365. 384. 397. 408. 426. 450, 461, 479. 504. 520. 538. 549. 564. 590, 599.613. (537.

Lithiumlarven der Seeigeleier 494.

Lochkerne 28, 211.
Lumbrieus, transplantiert 388.

Lymphkörperchen. Bewegung dersciben iog,

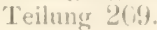
Zentralkörperchen 47. Iochkerne "211.

Lycaena. Saisondimorphismus 488.

Maispflanzen (unterschwefelsaure Talkerde) 490 .

Makrogamelen 299.

Makronucleus der Infusorien 2!.4.

Maschinenwesen, verglichen mit dem Organismus $1.41-143$.

Mechanische Einwirkungen 169.

Mechanische Gewebe $\$ 70$. bei Pflanzen $473.60^{\circ}$. bei Tieren 475

Mechanische Reize 158.

Mechanomorphosen 534. Literatur 5111.

Mehrbefruchtung 161. 218.

Membran der Zelle 7.

Merogonie 325 ,

Merocyten 219. 243.

Mesenchymgewebe 610 .

Mesenchymkeim 611 .

Mesoblast 608.

Mesocarpus (Lichtwirkung) 153).

Mestombündel 474.

Metameren 372 .

Metamorphose der Gewcbe 442.

Metaplasie 442.

Mikrogameten 299.

Mikrogomia socialis 376 .

Mikronucleus der Infusorien 29.1.

Mikroorganismen. Kerne derselben 4.4. 45. ihre Zerstörung durch Phagocyten $7:$.

ihre Stoffwechselprodulite 167.

Tikrosomen 14. 22

Milz 534.

Mimosa pudica 160.

Mitochondrien 91.

Mitom 23.

Mitose 171. pluripolare 218.

Mittelstück des Samenfadens 269.

Mizelle (Mizellartheorie) 50, 51, (52:-

Mizellarlösung 51.

Ineme (Semon) 597.

Molekularstruktur 49.

Molinja. Mechanisches Gewebe 47.t.

Ioneren 44.

Vonstrositäten, durch Ernährung crzengt 494.

Mosaiktheoric von Roux 508. 6331. (6333.

Muskelfibrillen 84. 96.

Muskelgewebe 440, 441.

Ireoderma aceti 74 .

Wrofibrille 96.

Myxödem 531.

Myxomyzeten 379.352. Bewegung 110.

Myxosporidien 504.

Nachwirkung 433 .

Nährlüsung, liünstiche 74.320 . 
Nahrungspolymorphismus der Ameisen, Termiten und Bienen 193.

Narkose (Protoplasma, Mimose, Eier, Samenfiden) 160. 161.

Naturzïchtung 570.

Nebenkeimplasma 459.

Nebenkern 91; der Infusorien 187. 297.

Nebenspindel der Infusorien 297.

Nekrose 449.

Nematoden. Kerne in der befruchteten Eizelle 225. 229.

Nervendurehschneidung. Einfluß auf die Entwicklung des Skeletts 538.

- $\quad$ - D Düsensekretion 441 .

Nervenfibrillen 84 Muskulatur 441 .

Nesselkapsel 84. 93.

Neu-Darwinismus 620. 632.

Neurofibrille 96

Niere 528; Nierenhypertrophie, Nierenexstirpation 528.

Nisus formativus 352. 568 .

Noctilucen. Befruchtung 304.

Nostochacee 376 .

Nuclein 26. 30. Reaktionen 30.

Nucleolen 32. 38. 39. 43.

Schicksal bei Kernteilung $19 \overline{7}$.

Nucleocentrosoma 190 .

Nutritive Reizung 447 .

Ontogenese 593. 594.

Onychodromus grandis 266. 319.

Oogam 309

Oogonium 310. 322

Oogenese 278.

Opuntia Labour. Vereinigung mit Rhipsalis 386.

Oscillariazee 376 .

Osmose 67.

Ovisten 352 .

Palissadenparenchym 483.

Panachure 501.

Pandorina 266. Befruchtung 311.

Pangene 631.

Pangenesis 54. 408. 624. 631. 634; intrazellulare 364 .

Paramaecien. Sauerstoff 163. Befruchtung 296.

Paramitom 23.

Paraplasma 26.

Parasit 396

Parthenogenese, parthenogenetisch 321.

Pelomyxa 150. experimentelle $326-329$.

Pepsin 77

Perikline Teilebene 231.

Peronosporeen, sexuelle Affinität 330 .

Personalauslese 620

Pflanzenanatomie 4 .

Pfropfhybride $499-504$.

Pfropfung bei Pflanzen 385. 499.

bei Tieren 387.

Siehe Transplantation.

- Hauptergebnis der Versuche 500.

Phaeosporeen. Befruchtung 309.

Phagoerten 71.
Phagocytose 71 .

Phaseolus. Reaktion des belasteten Keimlings 470 .

Phosphor. Einflußauf Knochenwachstum 491.

Phototaxis der Algenschwärmer 52\%.

Phylloxera. Einfluß der Ernährung auf dic Zeugung 321 .

Phylogenese 593. 59.4.

Physiologische Einheiten von Spencer 54. 580.628.

Phytogenesis 5.

Pigmentkörnchen 83.

Pistazia (Pfropfung) 500.

Planaria. Heteromorphose 54.5.

Plasmaprorlukt 26. 79.

Plasmodium 110, 379. Lichtreiz 150)

Plasmolyse 68. 255.

Plasome 53.

Plastide 73.

Plastin 17. Reaktionen 17

Podophrya gemmipara. Entwicklungszyklus derselben $43 \mathrm{I}$.

Knospung 240.

Polare Differenzierung des Eies 553 .

$$
\text { - _ der Zelle } 227 .
$$

Polarer Gegensatz zwischen Basis und Spitze bei Pflanzen 464.

Polfeld des Kerns 174.

Pollenkorn, Pollenschlauch 292. 293.

Polymorphe Tierstöcke 431

Polyommatus. Saisondimorphismus 489.

Polyspermie 218.

Polzellen 239. 278. parthenogenetischer Eier 323--325.

Präformation 460 .

Präformationstheorie 350 .

Präzipitine 392.

Primordialschlauch 80 .

Progression in der Entwicklung 597.

Pronuclei 302.

Proportionales Kernwachstum 201. 257.

Proteinsubstanz 17.

Proteus anguineus 487. Atmung 527.

Prothallium. Lichteinfluß 481 .

Protonema 483.

Protoplasma. Erste Anwendung des Namens 7.

Untersuchung des Protoplasmakörpers 13.

Wassergehalt 17

Alkaleszenz 17.

Einschlüsse 17. 26.

chemische Zusamnensetzung 17.18.

Protoplasmabegriff 12,13

Protoplasmabewegung 108-116.

- der Lymphkörperchen 109.

- _ _ der Amöben 109.

- der Myxomyceten 110. bei Gromia 111.

- derPflanzenzellen 112.

-- Erklärungsversuche 114.

Protoplasmastruktur 19.

Protoplasmatheorie. Geschichte derselben 7. 
Pseudopodien 70. 109. 158.

Psychophysische I'rozesse 51.

Pteris cretica, Apogamie derselben 3:9.

Ptyalin 77.

Prrenin. Reaktionen, Fïrbbarkeit 32.

(2uitte. Verhalten beim Pfropfen 386.500.

IRadiolarien. Skelett St. Vielkembildung 213. Symbiose mit Algenzellen 394.

Reduktion der Kernsegmente 277 . bei Infusorien 297.

Reduktionsteilung 27. 28:. 359. - $\quad$ - bei Cosmarium 306 .

Rereneration 35̄. $5+1$. Literatur 549.

Reifeprozeß von Ei- und samenzelle 274.

Reis 35.). 499.

Reiz und Reizwirkung 133-138 verschiedene Arten derselben 144 bis 167 .

Disproportionalität zwischen Reizursache und Reizwirkung 134.

Reizbarkeit 131.

Reize des Protoplasmas 144.

thermische 145 .

elektrische 154

- chemische 159.

mechanische liss.

durch Belichtung 149.

zusammengesetzter Art 495 .

Reizleitung $13 \vec{\imath}$.

durch Protoplasmaverbindungen 405.

durch Nerven 406.

Experiment von Pfeffer 406.

Reizursache 133. 137.

Reizwirkung 133. 136.

Reservekraft 528. 536 .

Reservestoffe 26.76 .

Rheotropismus der Myxomyceten 110.

Rhipsalis. Vereinigung mit Opuntia 386.

Rhizopoden. Bewegung 111.

Richtungskörper 239.

Ricin. Versuche Ehrlichs 57t.

Ricinfestigkeit 574.575.

Riesenzellen 210. Vielpolige Kernfiguren 219.

Rohrzucker. Reizmittel für Samenfäden der Laubmoose 160 .

Rotation 112.

Rotatorien 322.

Runkelriibe. Bliitenbildung 491.

Transplantation 500 .

Saccharomyees, mit Chloroformwasser behandelt 161 .

Saisondimorphismus 488.

Salamanderlarven 486. 488.

Regeneration 541.

Salamandra maculata. Kernteilung 173.

Samenfaden 552. 561 .

als Träger der Arteigenschaften D61.

Bau desselben 34 .

von Ascaris 35́.

Bewegung desselben 120.
Samenfaden, Narkose dessciben 160. der Echinodermen 269.

Samenkern 218. 270. 325. sich in kernlosen Ëistücken teilend 325.

Samenspindel 218.

Sarkode 8.

Sarkosporidien 504.

Saucrstoff. Wirkung auf dic Zelle fil. - Wirkung auf Ẍthalium 16\%.

- Wirkung auf Bakterien und Infusorien $162.16: 3$.

Schattenpflanzen 18 \%.

Schäume. Struktur derselben 2)1.

Scherkraft 472.

Scheinfüßchen 109 .

schilddriise 52 ?.

Schilddriisenextrakt 531.

Schilddriisentherapie 531 .

Schleimhäute. Verïnderung durch die Luft 197.

Schleimzelle 83 .

Schmetterlinge (Saisondimorphismus) 488.

Einfluß des Futters auf Färbung 492.

Einfluß der Temperatur 488.

Experimente zum Vererbungsproblem 575.

Schubkraft und Schubspannung 472.

Schwammparenchym 484.

Schwanzflosse des Delphins 537.

Schwärmspore, ungeschlechtliche, geschlechtliche 308 .

Auskriechen derselben 7 .

Lichtwirkung 151 .

Schwerkraft, Einfluß auf Differenzierung der Zelle $2:-7$

Einwirkung auf Pflanzen 463. - $\quad$ Tiere 466 .

Seeigeleier. Durch Schütteln zerlegt 509.

Seeigellarven, bei Kalkentziehung gezüchtet 191.

Sehne $5: 37$.

Selbstbefruchtung 334. 336. 341.

Selbstdifferenzierung. Einwände gegen den Begtiff 139. 460.

Sexualcharakter $300-304$.

Sexulcharaktere, sekundire 525.

Sexulle Affinität 330. 385.

Siebröhren. Interzellularbrücken derselben 402.

Siphonophoren 384.

Skelett der Zelle 84.

Sommereier 322.

Spannkraft 75.

Spermatogenese 27.

Spezies, organische 373.

Begriff derselben 427.

Spezifische Energie $411 . \$ 13.6: 34$.

der Zelle 1:30.

Spezifischer Charakter der Zellen 4:S.

Spezifizität der Zellen 427 . 434.

Spindel s. Kernspindel.

Spindelagregate 21S-220.

Spindelfaserm. Merkunft derselben 192.

Spindelrestkörper 91.

Spirogyra. Befruchtung 307.

Spitze bei abgetrennten Pflanzenteilen 465. 
Sporangien 308.

Sporen 266 .

Standortsmodifikationen $\$ 496$.

Stärke in der Pflanze gebildet 63. 86.

Stärkebildner 85. 87.

Stiirkekorn 86.

Stapliylokokkus 167.

Stationärer Kern der Infusorien 298.

Statocysten 464 .

Stereom. Stereomrippen 474.

Stoffmetamorphose 59.

Stofftransport durch Protoplasmafäden 405.

Stoffivanderung 76 .

Stoffwechsel der Zelle 59-107.

Stoffwechselprodukte des Protoplasmas 17. - _ der Mikroorganismen als Reizmittel für Leukocyten 167.

Strahlenfiguren im Protoplasma 172, 181. - - im Ei der Echinodermen 181.

Struktur. Verhältnis zur Funktion 412. 426.

Wichtigkeit konstanter Verhältnisse für Ausbildung besonderer Strukturen 411 .

Erworbene Struktur 190. 211.

Stylonichia 266. 319 .

Suberin 102.

Subitaneier 322.

Substitutionstherapie 532.

Symbiose 392. 503.

Flechten, Radiolarien, Aktinien 392 bis 395 .

Symmetrieebene des Eies 466. 557.

Synapsis 291.

Syncytium 378. 379.

Teilbildungen von Seeigeleiern 509.

- Amphioxus 509.

-- Ascidiella 510.

- $\quad$ - $\quad$ - $\quad$ - $\quad$ Triton 510.

Teilebenen der Zelle. Lage derselben zu einander $225-234$.

Beeinflussung der Lage durch åußere Eingriffe 244.

Teilung der Zelle s. Zellteilung.

der Zentralkörperchen. Centrosomen 48

der Kerne s. Kernsegmentierung,

Kernzerschniirung, Vielkernbildung.

der Chlorophyllkörner 85.

-. der Trophoblasten 84.

- der Bioblasten 53 .

- der Plasome 53.

Telolecithal 242.

Temperatur $487-490$.

Einfluß auf Geschlechtsbestimmung bei Melonen, Gurken 487.

- Färbung 489. 489. Literatur 505.

Temperatur. Einwirkung auf die Zelle 144. Optimum. Maximum 144. 146.

Termiten 493.

Tetanus 574.

nach Schilddrüsenexstirpation 530 .

'Tetraster 218.

Theorie der Biogenesis 460. 462. 635 .
'Theorie der Pangenesis 408. 624.

- Evolution und Präformation 460.

- - Epigenese 568.

- _ organbildenden Keimbezirke 559.

'Thermische Reize 144.

direlten Bewirkung 614.615.

Thyreoidektomic 530. 532.

Thyrojodin 530. 532.

Tierstock 383.

'oxine 396.

'Tradescantia 6. 113. 145. 155. 211.

Träger, eisemer 472. T-Träger 472.

Transformationen am Knochen 479.

Transfusion 389. 432. Beweis für die Art. eigenschaften der Zellen 456.

Transplantation bei Pflanzen 385.

harmonische u. disharmonische 386 . bei Tieren 387.

bei Hydra, Rana, Regenwürmern 387.388.

artgleicbe (homoplastische), artungleiche (beteroplastische) 388.

von Periost 388.

- Schwanzspitzen (Bert) 388.

- Hauptergebnis der Versuche 389.

- Beweis für die Arteigenschaften der Zelle 456.

- Beeinflussung von Pfropfreis und Grundstock 499.

Transporthypothese Darwins 625.

Transversale Teilebene 231.

Trianea bogotensis 112.

Triaster 218.

Tritonei, zerlegt und zu Teilbildungen gezüchtet 510 .

Tritonlarven. Regeneration 542 der Linse 546 .

Tropäolum 487.

Trophoplast 84. 86.

Tuberkelbazillen 397. 504.

Tuberkulinwirkung 167.

Tubularia 466. 498.

Tüpfel. Interzellularbrücken 102.

Turgor (Turgeszenz) der Pflanzenzelle 69.

Überfruchtung 218 .

Überreife der Zeugungsprodukte 320.

Ulothrix 309.

Umkehrversuche beim Froschei, der Schwere entgegen 467. 514.

Unterlage beim Pfropfen $3 \$ 5$.

Urformen der Zeugung 304.

Ursachen des Entwicklungsprozesses, äußerc und innere 132

-- auslösende 137. 138.

… Bedeutung der vielen Ursachen 138.

Urzengung 260.

Vakuolen 79. 80. 82. kontraktile 82 .

Vallisneria 112.

Vanessa. Saisondimorphismus 489.

Veränderung durch Fütterung 492.

Vaucheria. Wundheilung 250.

Vegetationskegel. Konstruktion des Zellennetzes in demselben 231.

Ansammlung des Protoplasmas 248. 
Vegetationspunkte von Caulerpa 380. Ansammlung des Protoplasma 248. 252.

Vegetative Affinitit 385. 390.

Vegetative Vermehrung 266.

Verbindung der Zellen durch Protoplasmafäden $4(0)$.

Verbindungsfäden des Kerns 177.

Verbrauchsstoffe der Zelle 26 .

Vereinigung von Organismen 385. artgleiche 385.

symbiontische 392.

parasitische 395.

harmonische und disharmonische durch Pfropfung 386.

Vererbung 564. $61 \mathrm{~S}$. ererbter Eigenschaften $56 \overline{\text {. }}$

- erworbener Eigenschaften

- erworbener Eigenschaften

Vergriinung bei Arabisarten 504.

Verholzung der Zellhaut 102.

Verkehr der Ze!len im Organismus 398-408.

Verkorkung der Ze!lhaut 102.

Verwandtschaft, systematische beim Pfropfen 356.

Vielkernbildung 213.

Vielzellbildung 242.

Vierergruppe der Chromosomen 275. 283.

Vitalismus 131.

Vögel. Veränderung des Gefieders durch Fütterung 492.

Volrocineen 310 .

Volvox 375. Interzellularbrücken zwischen den einzelnen Zeilen 401.

Volvox globator 312.

Vorentwicklung des Eies 561 .

Vortizellen 299. 331.

Waben theorie des Protoplasmas ron Bütschli 21.

Wachstmu 605. Wachstumskorrelation 543.

Wahlvermögen der Zelle für chemische Stoffe 65.

Wanderkern der Infusorien 298.

Wärmebildung beim Lebensprozeß 62 .

Wärmetod. Wärmestarre 146.

Wassernetz. Experimente 320.

Wintereier 322.

Wucheratrophie 448 .

Xanthophyll 63.

Zahlengesetz der Chromosomen 202.

Zea mais. Einfluß voln unterschwefelsaurer Talkerde 490.

Zellbegriff 423.629 .

Zelle 4. Definition von Schleiden und Schwann 6.

Definition von M. Schultze 8.

Definition von Brücke 8.
Zelle als Elementarorganismus und als determinierter und integrierter Teil eines höheren Organismus 423.

morphologische und physiologische Betrachtungsweise derselben 423.

Modifikationen und Zustinde 138.

Zellentheorie. Geschichte derselben 4 .

\%ellfusionen 378.

Kellhaut 100. Wachstum derselben 102 .

Zelliger Verband 375.

Kellkern. Entdeckung desselben 5. 11. 26.

Zur Geschichte desseltien 26.

Definition desselben 28.

Form, Größe, Zahl 28.

Gesetze, welche die Lage desselben in der Zelle bestimmen $225-229$.

Konstante Lage in Pflanzenzellen250.

in tierischen Zellen 253.

im Ei von Dytiscus 254.

in sezernierenden Zellen von Nepa 254.

Einflul\} auf die Lebenstätigkeit der Zelle 250.254.

von Bakterien, Oscillarien 45.

als Träger der erblichen Anlagen 354 .

Kellkolonien 375.

Zellplatte 186.

Zeliteilung 169. 225. 234.

äquale 235 .

inäquale 236.

partielle 240.

Beeinflussung durch äußere Eingriffe 244 .

Yellterritorium 106.

Zellularpathologie 3.

Zellulose. Bildung 78. 100.

Reaktion 100.

Zentralkörperchen der Zelle 4\%.

- der Lymphkörperchen 47.

der Pigmentzelle 47.

bei Überfruchtung 218 .

im befruchteten $\mathrm{Ei}$ der

Echinodermen 270.

im Ei von Ascaris 273 .

Zentralspindel 193. der Radiolaren 213.

Zentrifugalkraft 468 .

Zentrolecithal 342 .

Zentrosom s. Centrosom.

Zeugungskreis 26. 322. 373.

Zeugungstheorien 353.

Zirkulation des Protoplasmas 112.

Zug. Einfluß auf organische Prozesse 469. 470.

Zugfestigkeit 475 .

Zuggurtung $4 \% 2$.

Zuglinien 476 .

Zustïnde der Zelle 438.

Zwangslage der Froscheier 467 .

Zwischenkörperchen des Kerns 91. 18-.

Zygnemazeen. Befruchtung 306.

Zygote 305. 307. 

Lehrbud) der vergleidhenden mikroskopischen Hnatomie der (Uirbeltiere. Von Dr. med. Albert Oppel, praktischer Arzt in Stuttgart, a. o. tiere. Professor.

Erster Teil: Der Magen. Von Prof. 1)r. A. Oppel. Mit 275 Abbildungen im Text und 5 lithographischen 'Tafeln. 1896. P'reis: 14 Mark. - ZWeiter Teil: Schlund und Darm. Von Prof. Dr. A. Oppel. Mit t43 Ablsildungen im 'Text und 4 lithographischen 'Tafeln. 1597. P'reis: 20 Mark. - Iritter Teil: Mundhöhle, Bauchspeicheldrise und Leber. V'm Pm. Ir. A. Oppel. Mit 279 A bubildungen im 'lext und 10) lithographisehen Tafeln. 1900. J'yein: $31 ;$ Mark. Vierter leil: Ausfïhrapparat und Anhangdrüsen der männlichen Geschlechtsorgane. Y'on l)r. limblf Dis-ollhorst. Prof. der Universität Halle a. S. Mit 4:35 Ahbilimenen im 'Text und 7 lithograph. Tafeln. 1904. Preis: 20 Mark. Fïnfter Teil: Die Parietalorgane. Von Dr. F. K. Studnička, Brïn. Mit. 134t Abbildungen im 'lext und I lithographischen Tafel. 1905. Preis: 8 Mark. Sechster '́eil: Atmungsapparat. Yon Prof. Dr. A. Oppel. Mit 364 'Textabbildungen und t lithogr." Tafeln. Preis: 24 Mark.

Lebrbuch der vergleichenden Fistologie der Ciere. Vun 1). Karl Cat Privatdozent an der Uniresitä Wien. Mit 691 Abbildungen. 1902. Preis: 24 Mark.

Uleber die gegenwärtige Lage des Biologischen Unterrichts an böheren Sdulen. Verlandiungen der vereinigten Abteilungen fïr Zoo-

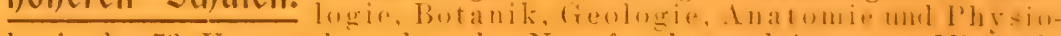
logic der 73 . Versammlung dentscher Naturforscher und Aerzte am Mittwoch, den 25. September 1901 im großen Hörsaal des Naturhistorisehen Nuseums in Hamburg. Preis: 1 Nark.

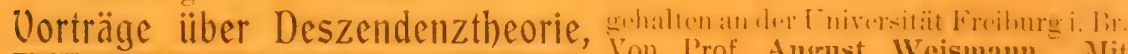
3 farbigen Tafeln und 131 Textfiguren. "Zw eite verbesserte Auflage. Preis: lorosch. 10 Mark, geb. 12 Mark.

Frankfurter Zeitung Nr. 287 v. 16. Oktober 1902 sagt üher die crste Auflage: Wenn ein Naturforscher von der Bedeutung WV eismanns, der während eines langen Lebens über die tiefsten Probleme der Biologie geforscht, gedacht und geschrieben hat, ein umfangreiches. Werk über die Abstammungslehre erscheinen läßt, so sollte dies nicht nur die Fachgelehrten angehen, sondern es sollte ein Ereignis für die ganze gebildete iVele sein.

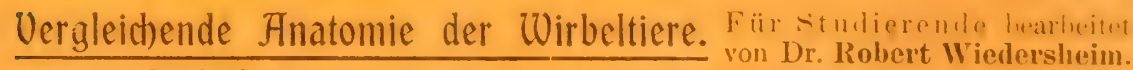
o. ̈̈. P'rof. der Anatomic und vergleichenden Anatomie, Direktor des anatomischen Instituts der Universitit Freiburg i. Br. Sechste, vielfach umgearbeitete und stark vermehrte Auflage des "Grundriss der ver. gleichenden Anatomie der Wirbeltiere". Mit 1 lithogr. Tafel und 416 Textablildungen in 814 Einzeldarstellungen. (Erscheint in Kürze.)

Die Vererbungslebre in der Biologie. Yim 1r. Heimich Eemet Zingler 9 Figuren im lext und 2 Tafeln. Preis: 2 Mark.

Eebrbuch der vergleid)enden Entwidkelungsgeschichte der niederen

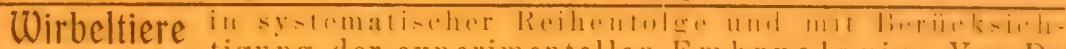
Wirbeltere tigng der experimentellen Embryologic. Von Dr. Heinrich Ernst Ziegler, Prof, an der Liniversität Jena. Mit $3-6$ Abhiliungen im Text und einer farbigen 'Tafel. Preis: 10 Mark, geb. 11 Mark.

Nature, Nr. 1723, vom 6. Norember 1902:

. In his concluding words, the author expresses the mood of the whole book when he says that embryology is luminous only in the light of the evolution-itea.

Roux' Archiv fiir Entwickelungsmechanik, Bcl. XVI, Heft 1, 1903:

Der Verfasser gibt in knapper, klarer Darstellung cinen Ueberblick der Hauntthatsachen der Entwickelungsgeschichte der Anamnia und einen IHinweis auf die ersten Entwickelungsvorgänge der Reptilien und Vëgel. 
Das biomed)anisd)e (neo-vitalistische Denken) in der Medizin und Biologie. Von Professor 1)r. II. Benedilit, Wien. 1902. Preis: I Mark

Corbuch der veraleidenden Hnatomie. Von B. Haller, a. o. Prof. der IIt 878 Abbildungen in Text. 1904. Preis: 20 Mark.

Zcllen-Studien. Von Dr. Theodor Boveri, Professor an der Universitat Wiurz-

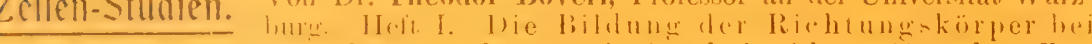
Ascaris megalocephala und Ascaris lumbricoides. (Aus dem Zoologischen Institut zu München.) 1857. Mit 4 lithographischen Tafeln. Preis: 4 Mark 50 l'f. - Heft II. Die Befruchtung und Teilung des Eies Fon tscaris mogalocephala. (Aus dem \%oologischen Institut zu München.) 1888. Mit 5) lithographischen Tafehn. Preis: 7 Mark 50 Pf. - Heft III. Ueber das Verhalten der chromatiscluen Kernsubstanz bei der Bildung der Richtungskörper und bei der Befruchtung. 1890. Mit 3 lithographischen Tafeln. Preis: 4 Mark. Heft IV. Ueber die Natur der Centrosomen. 1901. Mit 8 lithographischen Tafeln und 3 Textfiguren. Preis: 15 Mark. - Soeben erschien: Heft V. Ueber die Abbängigkeit der Kerngrösse und Zellenzahl der Seeigel-Larven ron der Chromosomenzahl der Ausgaugszellen. Preis: $t$ Mark.

Das Problem der Befrudbtung. You lr. Theodor Boveri. Prof. an der dungen. Preis: 1 Mark 80 P'f.

Ergeonisse iiber die Konstitution der d)romatischen Substanz des Zellkerns. Vou 1)r. Theodor Boveri, Prof. an der Universität Würzburg. Ueber die Biologie in Jena während des 19. Jahrbunderts. Vortray in der sitzung der medizinisch-naturwissenschaftlichen Gesellschaft am 10. Juni 1904. Von 1)r. Erust Haeckel, Prof. an der Universität Jena. Preis: 50 Pf.

Praxis und Cheorie der Zellen- und Befrudhtungslebre. Yon Dr. ValenProfessor in Freiburg i. Br. Mit 137 Abbildungen in 'Text. 1899. Preis: brosch. 7 Mark, geb. \& Mark.

Uleber das Senicksal der elterlichen und großelterlichen Kermanteile.

Norphologische Beiträge zum Ausbau der Vererbungslehre. Von Dr. Valentin Haicker, Professor an der Technischen Hochschnle in Stuttgart. Mit 4 Tafeln und 16 Textfiguren. 1902. Preis: 4 Mark.

Ceitfaden für das Zoologische Praktikum. Y'on 1)r. Willy Küikenthal, o, ö. Prof. der Zoologie und vergleichenden Anatomie an der Universität Breslau. Dritte umgearbeitete A uflage. 1905). Preis: brosch. 6 Mark, geb. 7 Mark.

Celorbud der vergleidenden Anatomie der wirbellosen Ciere. Yon Ir.

Lang; o. P'rofessor der Zoologie und vercleichenden Anatomie an der Universität und am eidmenössischen l'olytechnikum in Zürich. Zweite umgearbeitete Anflage. Erste lieferung. Mollusca. Bearbeitet von Dr. Karl Hescheler, Assistent und Privatdozent an der Universitüt Zürich. Mit 410 Abbildungen. 1900. P'reis: 12 Mark. Zweite Lieferung. Protozoa. Vollständig neu hearbeitet ron Arnold Lang. Mit 259 Abbildungen. 1901. Preis: 10 Jark. 


